\title{
LAURENCE DANGUY
}

\section{LE NEBELSPALTER ZURICHOIS (1875-1921)}

Au cœur de l'Europe des revues et des arts

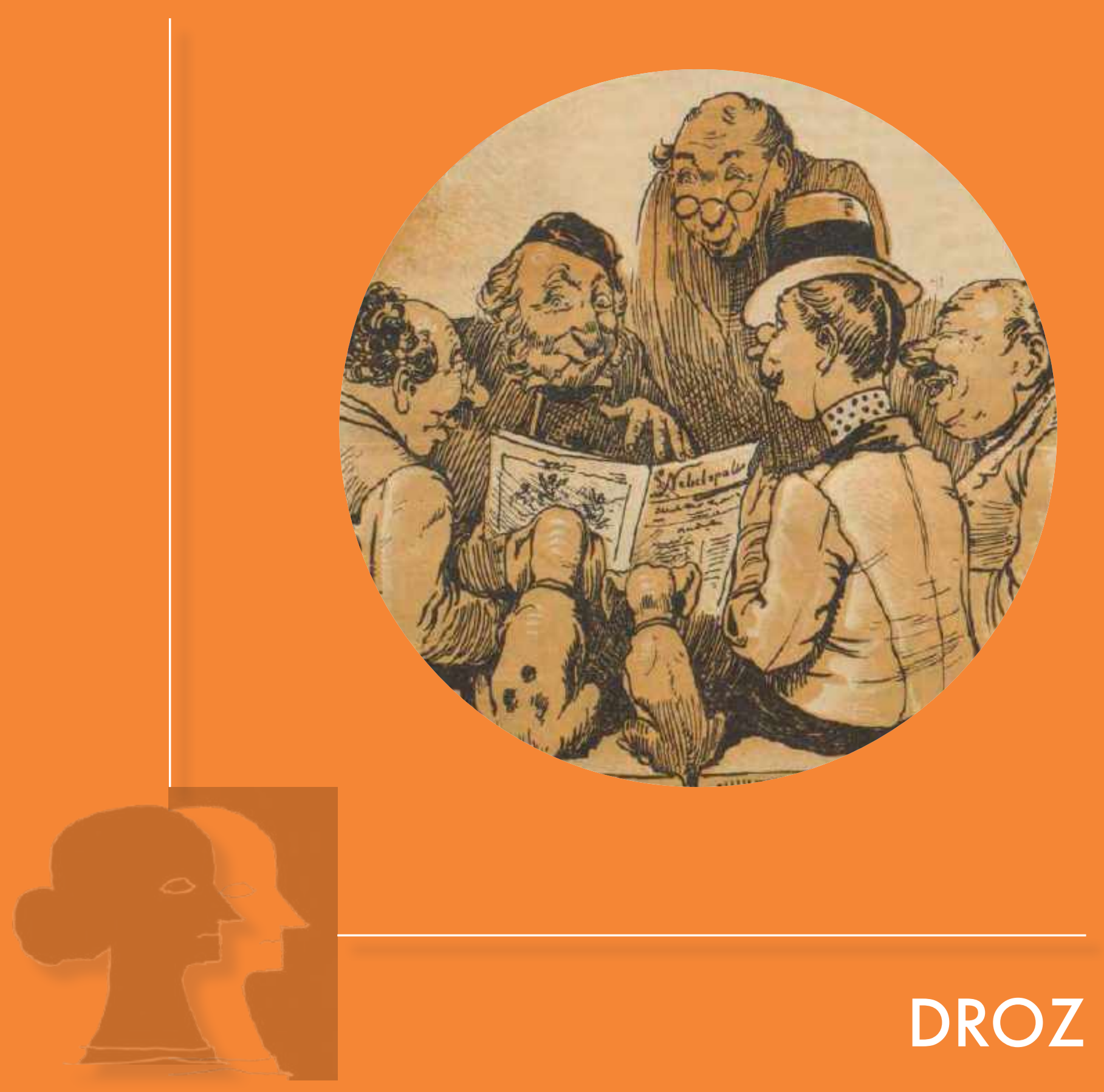




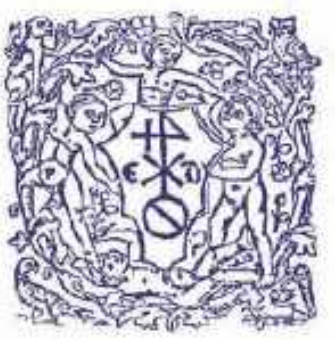

\section{LIBRAIRIE DROZ}

Tous droits réservés par la Librairie Droz SA en vertu des règles de propriété intellectuelle applicables. Sans autorisation écrite de l'éditeur ou d'un organisme de gestion des droits d'auteur dûment habilité et sauf dans les cas prévus par la loi, l'œuvre ne peut être, en entier ou en partie, reproduite sous quelque forme que ce soit, ni adaptée, représentée, transférée ou cédée à des tiers.

Ce travail est sous licence Creative Commons Attribution - pas d'utilisation commerciale - pas de modification 2.5 Suisse License. Pour obtenir une copie de la licence visitez http://creativecommons.org/licenses/by-nc-nd/2.5/ ch/ ou envoyez une lettre à Creative Commons, PO Box 1866, Mountain View, CA 94042, USA.

Pour toutes informations supplémentaires, merci de contacter l'éditeur : droits@droz.org
All rights reserved by Librairie Droz SA as proscribed by applicable intellectual property laws. Works may not, fully or in part, be reproduced in any form, nor adapted, represented, transferred or ceded to third parties without the written authorization of the publisher or a duly empowered organization of authors' rights management and except in instances provided for by law.

This work is licensed under the Creative Commons Attribution - No commercial use - No modification 2.5 Suisse License. To view a copy of this license, visit http://creativecommons.org/licenses/by-nc$\mathrm{nd} / 2.5 / \mathrm{ch} /$ or send a letter to Creative Commons, PO Box 1866, Mountain View, CA 94042, USA.

For any additional information, please contact the publisher : rights@droz.org 
Presse et caricature

1 


\section{Collection dirigée par Philippe Kaenel}

avec la Librairie Droz 


\section{LAURENCE DANGUY}

\section{LE NEBELSPALTER ZURICHOIS (1875-1921)}

AU CCEUR DE L'EUROPE DES REVUES ET DES ARTS

Avant-propos de Philippe Kaenel

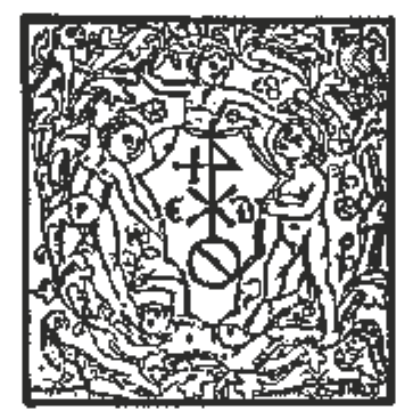

DROZ 
Publié avec le soutien du Fonds national suisse de la recherche scientifique

\section{FN TNF}

FONDS NATIONAL SUISSE

DE LA RECHERCHE SCIENTIFIQUE

www.droz.org

ISBN : 978-2-600-05912-1

ISBN PDF : 978-2-600-15912-8

ISBN EPUB : 978-2-600-35912-2

ISSN : 2624-5868

ISSN PDF : 2624-764X

(C) 2018 by Librairie Droz S.A., 11, rue Massot, Genève.

All rights reserved. No part of this book may be reproduced, translated, stored or transmitted in any form or by any means, electronic, mechanical, photo copying or otherwise without written permission from the publisher. 


\section{REMERCIEMENTS}

La recherche dont est issu le présent ouvrage a pu être conduite grâce à un subside accordé par le Fonds national suisse de la recherche scientifique en faveur d'un projet hébergé au Centre des sciences historiques de la culture de l'Université de Lausanne. J'aimerais exprimer ici toute ma reconnaissance à ces institutions. Ce travail a, par ailleurs, bénéficié de l'aide et de l'apport de tant de personnes que je dois remercier collectivement ceux que j'aurais omis de mentionner. À son origine, se trouve un intérêt ancien de Philippe Kaenel pour le Nebelspalter, la revue satirique dominant le paysage éditorial suisse. Toute ma gratitude va naturellement à Philippe Kaenel, qui a su me transmettre sa curiosité et avec lequel j'ai élaboré les différentes étapes de cette étude. Mon approche s'est, par ailleurs, nourrie de nombreux échanges lors de colloques et dans le cadre de séminaires à l'Université de Lausanne et à l'École des hautes études en sciences sociales. J'ai ainsi une dette de pensée vis-à-vis de nombreux chercheurs, et notamment : Joëlle Beurier, Laurent Bihl, Laurence Brogniez, Clément Dessy, Cyrille Devès, Alexandre Elsig, Gianni Haver, Ursula Koch, Françoise
Lucbert, Julien Schuh, Evanghelia Stead, Vanja Strukelj, Bertrand Tillier, Myriam Tsikounas, Hélène Védrine et Francesca Zanella. Pour l'accès toujours bienveillant aux collections, il me faut remercier les équipes des Alte Drucke und Rara et des Graphische Sammlung de la Zentral Bibliothek de Zurich, ainsi que celles de la Bibliothèque nationale suisse ; je tiens en particulier à remercier Urs Leu, Christian Scheidegger, Sandra Weidmann, Hans-Dieter Amstutz, Yasmine Keles et Liliane Regamey. Je suis également redevable à Marco Ratschiller, Regula Schmid et Mirjam Bernegger de la transmission d'informations inédites et de l'accès aux archives de la famille Boscovits. Ma reconnaissance va enfin envers mon premier lecteur, André Danguy, ainsi qu'à l'endroit de mon éditeur, Max Engammare et de ma relectrice, Melinda Tacchi. Je souhaite pour finir exprimer ma gratitude à la Société Académique Vaudoise, à la Fondation pour l'Université de Lausanne et au Fonds national suisse de la recherche scientifique, qui ont généreusement accordé un subside pour l'édition et l'impression de ce livre. 


\section{AVANT-PROPOS}

\section{LA PRESSE SATIRIQUE EN SUISSE}

Le Nebelspalter est le doyen des périodiques illustrés sur le plan mondial. Fondé en I 875 à Zurich, il se développe dans un paysage éditorial particulièrement dynamique.

En effet, jusqu'à la Première Guerre mondiale, la Suisse est le pays qui possède le plus grand nombre de périodiques illustrés satiriques par habitant. Selon Josef Leopold Brandstetter, qui répertorie systématiquement les périodiques publiés en Suisse de I 800 à I 896, environ 3,3\% de l'ensemble (soit ro8 titres) relèvent des "Blätter für Humor und Satire ${ }^{1}$. Au XIX ${ }^{e}$ siècle et durant le premier $\mathrm{xx}^{\mathrm{e}}$ siècle, l'histoire de la caricature en Suisse est, en outre, étroitement liée à celle de la censure, de son abolition progressive, puis de son retour durant les deux guerres mondiales ${ }^{2}$. Les conditions sont cependant différentes d'un canton à l'autre et les plus conservateurs, mais aussi les plus exposés aux frontières, sont ceux de Bâle et de Genève³.

Dans l'histoire suisse, la période dite de la Régénération (I $830-$ I 848) est particulièrement intéressante car elle met aux prises les libertés acquises avec les pressions censoriales et leurs mesures répressives. L'histoire de la presse satirique est ponctuée d'affaires, de procès très révélateurs de la société helvétique, de sa conception $\mathrm{du}$ droit, des sensibilités politiques et linguistiques et de la place attribuée à la caricature. La géographie de la caricature suisse au XIX ${ }^{\mathrm{e}}$ siècle apparaît ainsi changeante. Les nouveaux centres naissent de la coïncidence entre un environnement politique spécifique, la vitalité de l'édition et l'initiative de personnalités qui dynamisent le champ éditorial. Tandis que Genève, Berne et la région zurichoise occupent le premier plan jusque vers I 820, l'essor du libéralisme et l'influence du modèle parisien font du canton de Vaud le nouveau relais de la culture visuelle satirique vers I 830 , alors que Genève bénéficie du rayonnement de la figure de Rodolphe Töpffer (I 799-I 846) ${ }^{4}$. La scission du canton de Bâle en I 833 stimule temporairement l'activité des caricaturistes avant que les cantons de Berne et de Soleure ne prennent le relais grâce à des dessinateurs engagés et de premier plan, comme le Soleurois

Josef Leopold Brandstetter, Bibliographie des revues, gazettes et almanachs suisses, [partiellement avec localisation des titres], Berne 1896 (fascicule I b de la Bibliographie nationale suisse / Bibliographie der schweizerischen Landeskunde, Berne, s.l., 1896).

Sur la caricature en Suisse et l'imagerie politique: Georg Kreis, Helvetia im Wandel der Zeiten. Die Geschichte einer nationalen Represäntationsfigur, Zurich, Neue Zürcher Zeitung, 1991; Philippe Kaenel, " Pour une histoire de la caricature en Suisse ", Nos monuments d'art et d'histoire, 4 (1991), p. 403-442; Philippe Kaenel (éd.), 1848: le carrefour suisse. Le pouvoir des images, Lausanne; Zurich; Lugano, Payot - Chronos Verlag - Dadò, 1998; en particulier Philippe Kaenel, "Régénération, révolution, constitution. L'imagerie politique suisse », p. $43-84$ de l'édition française.

Werner Gysin, Zensur und Pressfreiheit in Basel während der Mediation und Restauration, Bâle, Helbing und Lichtenhahn, p. 39.

Philippe Kaenel, « Cent cinquante ans de presse satirique illustrée », dans Le Livre à Lausanne. Cinq siècles d'édition et d'imprimerie 1493-1993, éd Silvio Corsini, Lausanne, Payot, 1993, p. 191-200.
Martin Disteli (I 802-I 844), et des journaux illustrés de diffusion suprarégionale, comme le Postheiri. Le canton de Zurich, après une courte flambée satirique conservatrice allumée par le crayon de Johann Jakob Ulrich dans les années I 840 se met ensuite en retrait, et seule une conjonction de facteurs permet, quelque trente ans plus tard, la naissance du Nebelspalter. Pendant ce temps les périodiques satiriques prolifèrent en Suisse romande, notamment à Genève et à Lausanne.

Retour, à présent, sur quelques épisodes saillants de cette histoire. En I 828, le canton de Vaud libéralise la presse, suivi l'année suivante par les cantons de Glaris, de Zurich, de Lucerne et d'Argovie. En I 830 et I 83 I, Berne, Zurich, Neuchâtel, SaintGall, Bâle et Soleure suivent le mouvement, ce qui conduit Alexis de Tocqueville (I805-I859) à écrire en I 836 : "Les Suisses abusent de la liberté de la presse comme d'une liberté récente; les journaux sont plus révolutionnaires et beaucoup moins pratiques que les journaux anglais ${ }^{5}$. Le libéralisme qui caractérise la Régénération fait de la Suisse un cas à part. En I 830 comme en I 848, les mouvements révolutionnaires conduisent à des réformes constitutionnelles, qui précèdent la Révolution de Juillet, et qui se maintiennent au moment où le reflux réactionnaire frappe les pays voisins ${ }^{6}$. Certaines de ces réformes concernent la liberté de la presse, «La presse française est l'un des leviers du mouvement radical en Suisse ", note un auteur de la Revue des deux mondes en I 847 ; " et cela suffirait, à mon avis, pour prouver qu'on a aujourd'hui devant soi un des plus sérieux, des plus dangereux efforts que la propagande européenne ait jamais fait ${ }^{7}$.

Dans les années I 830 et I 840, divers types de censure subsistent néanmoins sous la forme de taxes (droit de timbre, cautionnement), de barrières douanières cantonales mais aussi de procès intentés au nom des bonnes mœurs et de l'ordre public. L'éditeur bernois Friedrich Jenni (I809-1 849) et son journal Der Gukkasten (I 843-I 849) en fait plusieurs fois l'expérience. Le 28 juin I 845 , le journal fait ainsi état de dix-huit procès intentés à son encontre. Jenni passe quelque temps en prison et se voit même banni de son canton bernois ${ }^{8}$. La réception dans les années I 840 du calendrier

Alexis de Tocqueville, CEuvres complètes, vol. 8, p. 455, cité dans Karl Weber, Die Schweizerische Presse im Jahr 1848, Bâle, Frobenius, 1927, p. 36.

Voir notamment le catalogue de l'exposition européenne Les Révolutions de 1848: l'Europe des images, Paris, Assemblée nationale, Turin, Museo Nazionale del Risorgimento Italiano, Prangins, Musée national suisse, Nuremberg Germanisches Nationalmuseum, 1998 (textes de Philippe Kaenel, Ségolène Le Men, Rosanna Maggio Serra, Nicole Moulonguet, Rainer Schoch et al.).

Saint-René Taillandier, « Des affaires de la Suisse. Le Sonderbund et le radicalisme en Suisse - Les hommes et les partis ", Revue des deux mondes, 19, 1847, p. 702. Sur l'histoire sociale et politique de la Suisse au XIX siècle: Jean-Claude Favez, Georges Andrey et Eugène Badou (éd.), Nouvelle histoire de la Suisse et des Suisses, Lausanne, Payot, 1983, et Georg Kreis, Der Weg zur Gegenwart. Die Schweiz im neunzehnten Jahrhundert, Bâle, Boston, Stuttgart, Birkhaüser, 1986. Hans Gustav Keller, Die politischen Verlagsanstalten und Druckereien in der Schweiz. Ihre Bedeutung für die Vorgeschichte der deutschen Revolution von 
édité par le dessinateur républicain Martin Disteli (I 802-I 844) est également éclairante. Il tire son Schweizerischer Bilderkalender ( I 839-I 844) à près de vingt-mille et même trente-mille exemplaires. Confisqué à Lucerne où l'artiste est puni d'une amende - sans qu'il se soit déplacé pour son « procès "-, violemment rejeté par l'évêque de Bâle, interdit à Zoug, l'almanach est même brûlé en public dans divers lieux catholiques conservateurs ${ }^{9}$. L'homologue bâlois de Disteli, Hieronymus Hess (I799-I850), qui a donné un dessin inspiré par l'œuvre du célèbre illustrateur français J.-J. Grandville ( I 803-I 847) dans le calendrier de I 840, ne réussit pas à échapper à la cour correctionnelle de sa ville ${ }^{10}$.

Bien avant la naissance du Nebelspalter, la presse satirique illustrée est déjà bien installée dans le paysage éditorial européen, après avoir fait ses débuts dans la foulée des épisodes révolutionnaires européens de la première moitié du XIX ${ }^{\mathrm{e}}$, sans grand éclat autour de 1830 et avec bien plus de succès après I 848 , sous l'impulsion de la lithographie ${ }^{11}$. Comme ailleurs, celle-ci devient en Suisse l'instrument de prédilection de la lutte politique, particulièrement dans les mains des journalistes de gauche, radicaux, socialistes et sympathisants républicains. Elle favorise la naissance de journaux autographiés, certains adoptant néanmoins la typographie et la xylographie, d'un rendu supérieur mais qui alourdissent les coûts de production. Les gravures sur bois au format plus réduit pour mieux s'intégrer à la typographie restent donc le privilège de publications annuelles, comme le Schweizerischer Bilderkalender de Disteli de I 839 à I 845 , ainsi que de quelques périodiques, comme le Postheiri, imprimé à Soleure, depuis I 845 . Le changement qui s'opère dans les années I 840 est à la fois d'ordre quantitatif et qualitatif. D'un côté, l'essor des techniques d'impression, la libéralisation de l'édition favorisée par l'absence de toute censure préventive, l'extension du public lettré ou mal-lisant stimulé par l'illustration expliquent l'apparition d'imprimés populaires, diffusés par les libraires, les kiosques, les services postaux, qui vont donner le coup de grâce au colportage personnifié par le messager boiteux. D'autre part, l'amélioration du réseau routier, les nouvelles performances des postes, l'invention du télégraphe accélèrent la communication des informations. De manière plus générale, les nouvelles étrangères prennent alors, selon les villes suisses, trois ou quatre jours pour arriver de Paris, quatre à cinq de Londres, trois de Francfort, quatre ou cinq de Vienne, neuf à onze de Rome ou onze de Varsovie ${ }^{12}$.

Un tournant se produit après I 848 . La Constitution fédérale de I 848 affirme, dans son article 45, qui devient l'article 55 dans celle de I 874, que « la liberté de la presse est garantie. Toutefois les lois cantonales statuent les peines nécessaires à la répression des abus ». Une certaine marge d'autonomie est alors concédée

1848, Berne et Leipzig, Université de Berne, 1935, p. 79-93.

Gottfried Wälchli, Martin Disteli 1802-1844. Zeit - Leben - Werk, Zurich, Amstutz, Herdeg, 1943, p. 53 sq.

L'épisode est raconté par Jules Coulin, Der Anti-Philister. Maler Distelis Kalender, Bâle, Rhein-Verlag, 1920 ainsi que par Heinrich Kuhn, Hieronymus Hess. Ein Basler Karikaturist des 19. Jahrhunderts, Bâle, Buchverlag Basler Zeitung, 1980. Hess répondit à son inculpation par un nouveau dessin dans lequel il se représente face à des juges animalisés.

Seules les Fliegende Blätter, apparues en 1844, connaissent un destin florissant, tant en terme d'influence que de pérennité, puisqu'elles survivent plus d'un siècle. Rapidement, leur ambition se limite toutefois à distraire; William A. Coupe, German political satires from the Reformation to the second world war (15001848), New-York, Kraus international publications, 1987, tome 1, p XII-XV. Pour une approche différentielle, cf. Christophe Charle, Le siècle de la presse (1830-1939), Paris, Seuil, 2004 ; Jean-Claude Gardes et Ursula E. Koch, « Histoire de la presse satirique allemande ", Ridiculosa, Hors-série La presse satirique dans le monde (2013), p.13-43.

Selon Karl Weber, Die Schweizerische Presse im Jahr 1848, op. cit., p. 134. aux cantons. Par ailleurs, différents types de censure plus ou moins « douce » persistent, avec des contrôles de police ou de la poste, la pratique du cautionnement ou le droit de timbre, qui défavorisent la petite presse, notamment satirique. Celle-ci ne manque évidemment pas de s'en plaindre ${ }^{13}$.

De I 848 à I 874 , on ne dispose guère d'informations sur la diffusion des illustrés satiriques et leur tirage, qui doit très rarement dépasser le millier d'exemplaires. Sous la Régénération, le tirage moyen des périodiques non illustrés est inférieur à ce chiffre $^{14}$. Le cas du Bilderkalender de Disteli (un almanach, rappelons-le), imprimé en moyenne à vingt-mille exemplaires, demeure une exception particulièrement redoutable aux yeux des conservateurs. Mais qu'il s'agisse de cet almanach ou d'autres périodiques, le nombre de lecteurs est toujours supérieur au chiffre du tirage, car les journaux sont lus en famille, en société, en public, et passent de main en main. À la rareté des lecteurs et d'une audience suprarégionale ou nationale, s'ajoutent les difficultés rencontrées par les concepteurs, écrivains et artistes, dont les carrières débutantes dépendent en partie de la nouvelle presse illustrée. Les impératifs économiques déterminent fortement la marge de manœuvre.

Lutte idéologique et lutte économique vont de pair dans un marché éditorial très restreint, au sein duquel l'illustration sert à appâter le lecteur. De ce point de vue, le succès rencontré par le Postheiri. Illustrierte Blätter für Gegenwart, Öffentlichkeit und Gefühl ( I 845-I 875), périodique satirique soleurois de tendance libérale, est tout à fait remarquable. Son sous-titre (feuilles illustrées pour l'actualité, l'espace public et le sentiment) résume à lui seul les nouvelles orientations de la presse politique suisse, à la recherche de la plus grande actualité et du public le plus large. Au fil des ans, le journal va devenir une lecture incontournable de la classe politique. Der Postheiri est entièrement anonyme. Les rédacteurs et dessinateurs se cachent tous sous l'identité fictive d'Heinrich van der Post, alias Henri de la Poste ou Enrico della Posta. Celui-ci apparaît en frontispice du prospectus de I 845 , tendant la main vers la devise inscrite en italique: "Honni soit qui mal y pense ». Avec ses moustaches et sa barbe, il est le portrait même de Disteli ${ }^{15}$. À la différence du Postheiri, les vignettes du journal Der Gukkasten. Zeitschrift für Witz, Laune und Satyre, édité par l'officine Jenni à Berne, et qui se dit « radical de A à Z » (radikal von $A$ bis $Z)^{16}$ sont souvent signées dans les premières années par le dessinateur et coéditeur, Heinrich von Arx. De I 840 à I 842, le périodique est autographié, avant de se convertir à la typographie, tout en maintenant les lithographies en pleine page. Ces dessins, croqués de manière assez sommaire, sont imprimés sans grand ménagement sur du papier de qualité très moyenne. On y trouve des caricatures animales qui renvoient implicitement au modèle réinventé par l'un des dessinateurs phares des journaux parisiens La Caricature et le Charivari, J.-J. Grandville (I 803-I 847) ${ }^{17}$. Sur la vignette de titre xylographique, un personnage sort d'une tombe

\footnotetext{
Ainsi le Charivari vaudois (Lausanne) face au fisc dans son numéro de novembre 1839.

Karl Weber, Die Schweizerische Presse im Jahr 1848, op. cit., p. 52.

Cette ressemblance est relevée par le journal qui parle de « personnalité stylisée à la Disteli » (distelischstylisirte Persönlichkeit); Postheiri, 1853/31-32.

Derneue Gukkasten, 22 juin 1850, «Invitation à s'abonner au Neuer Gukkasten » (Einladung zum Abonnement auf den Neuen Gukkasten). Un «Gukkasten » est une boîte d'optique. Les numéros 1 et 6 du journal mettent en scène de telles boîtes, très populaires dans ces années, munies d'ouvertures à travers lesquelles on pouvait regarder des images contre rémunération.

Philippe Kaenel, « 1830-1848: la réception de l'œuvre de Daumier et Grandville en Suisse ", Sociétés et Représentations, 10 (2000), éd. Christian-Marc Bosséno, Frank Georgi et Marielle Silhouette, p. 145-161.
} 
et brandit le fouet de la satire contre les deux aristocrates qui le pensaient enterré.

La grande diversité idéologique des périodiques illustrés suisses après I 848 renvoie aux différences linguistiques et culturelles de la Confédération. Mais, dans l'éventail politique, la presse de "gauche " - c'est-à-dire de tendance socialiste ou radicale domine largement. Quelques débats cruciaux forment l'espace public helvétique. Il s'agit des affaires religieuses, de la question des réfugiés politiques et, plus généralement, de la neutralité, à savoir l'attitude à adopter face aux puissants voisins, français et autrichiens principalement. Ces débats font évidemment le bonheur d'une presse satirique dont les titres sont parfois très volatiles. Les journaux se multiplient, disparaissent, puis renaissent sous d'autres noms, des centres éditoriaux se constituent, les caricaturistes voyagent de feuilles en feuilles ${ }^{18}$. Ces journaux se distinguent également par leur format, de l'in-I $6^{\circ}$ à l'in-folio. Les chiffres de tirages, rarement mentionnés, devraient être pris en considération pour évaluer leur impact, tout comme devrait l'être leur longévité, très variable. Celle-ci va du spécimen annonçant un journal qui ne paraîtra finalement pas jusqu'au Nebelspalter dont la publication court depuis I 875 , en passant par des périodiques de longue durée, tel le Carillon de Saint-Gervais (I 8 54-I 899), Guguss' au Grand Théâtre (Genève, I 894-1936), Le Papillon (Genève, I889-I9I 8); ou encore de durée moyenne, comme c'est le cas de Der Gukkasten (Berne, I843-I849), Jocko ou le Révélateur (Berne, I 849-I 854), La Guêpe (Lausanne, I 85 I-I 853 ), le Neue Postillon (Zurich, I 895-I9I4) ${ }^{19}$ ou encore la Wochenzeitung (Zurich, I 844-I 846). Les raisons de cette longévité variable sont diverses: les feuilles satiriques tendent à surgir comme des réponses à des situations politiques locales bien précises et ont parfois de la peine à se reconvertir lorsque ces conditions changent; les journaux sont souvent édités à l'initiative d'individus disposant de peu de fonds propres, soumis à la tyrannie des abonnements et des coûts de production. Le cas exceptionnel du Nebelspalter s'explique certes par le talent de son équipe éditoriale mais aussi par la disparition du Postheiri, en I 875, dont il reprend le lectorat et le créneau.

Le Nebelspalter a traversé les guerres mondiales, les révolutions matérielles de la presse européenne et il a surmonté les concurrences diverses, réussissant sa mue numérique après un passage à vide dans les années I990, qui a failli mettre fin à l'entreprise, sous la pression du nouvel environnement médiatique. En I998, le tirage tombait ainsi à mille exemplaires. Depuis il publie dix numéros par an et compte environ vingt mille abonnés. Sa mise en ligne (www.e-periodica.ch) permet aujourd'hui de mesurer l'évolution de la caricature depuis près de cent cinquante ans.

L'ouvrage de Laurence Danguy s'inscrit dans la continuité des travaux qu'elle a conduits sur la presse satirique à la suite de sa thèse L'ange de la jeunesse. La revue Jugend et le Jugendstil à Munich, publiée à la Maison des Sciences de l'Homme, dans la collection «Philia », en 2009. Elle montre ici les liens qui unissent le journal suisse non seulement à la célèbre revue munichoise, mais encore le paysage graphique et satirique international autour de I900. Elle en renouvelle notre connaissance en se fondant notamment sur les archives inédites de l'éditeur Jean Nötzli, un homme de réseaux, qui correspond par exemple avec l'un des deux principaux spécialistes de la caricature en Europe, le Parisien d'origine genevoise, John Grand-Carteret ${ }^{20}$. C'est avec érudition et finesse qu'elle guide le lecteur d'aujourd'hui sur le chemin d'une histoire vivante, au cour de l'Europe des revues et des arts ${ }^{21}$.

Philippe KaEneL
Philippe Kaenel, « Pour une histoire de la caricature en Suisse », op. cit.

Marianne Berchthold, Der "Neue Postillon », eine illustrierte satirische Arbeiterzeitschrift von 1895-1914, mémoire de licence, Berne, mars 1984.

\footnotetext{
Philippe Kaenel, « Faire revivre l'histoire par l'imagerie vivante: John GrandCarteret, Eduard Fuchs et les cultures visuelles transnationales autour de 1900 », Quelle place pour les images en histoire? sous la direction de Christian Delporte, Laurent Gervereau et Denis Maréchal, Paris, Nouveau Monde, 2008, p. 305-332 (traduction allemande: «Faire revivre l'histoire par l'imagerie vivante: John GrandCarteret, Eduard Fuchs und die europäische visuelle Kultur um 1900 », Mit Klios Augen. Bilder als historische Quellen, hrsg. v. Kornelia Imesch Oechslin, Alfred Messerli, Julia Burckhardt \& Mario Lüscher, Oberhausen, Athena, 2013, p. 85-108). La première version des lignes qui précèdent a été publiée dans: Philippe Kaenel, "Pour une histoire de la caricature en Suisse », op. cit. La question de la caricature en Suisse est reprise et développée de manière plus générale dans Philippe Kaenel, La caricature en Suisse, Lausanne, Presses polytechniques et universitaires romandes, collection Le Savoir suisse, 2018 (à paraître).
} 


\section{INTRODUCTION}

Zurich, I 875 : une nouvelle revue illustrée voit le jour: Der Nebelspalter, littéralement " (celui) qui fend le brouillard". Publiée de façon interrompue depuis sa création, il s'agit désormais de la plus ancienne revue satirique au monde. Le succès n'allait pourtant pas de soi. Même si le périodique profite d'une tradition caricaturale et d'une opportunité éditoriale, les conditions de sa genèse étaient loin d'être idéales. Dans les années i 870, Zurich est en effet une ville en plein essor, ouverte sur le plan intellectuel et académique, mais politiquement et culturellement conservatrice, particulièrement frileuse en matière $d$ 'art. Le moment charnière dans l'histoire des revues européennes ${ }^{1}$, mais surtout la géographie culturelle, politique et linguistique de la Suisse complique par ailleurs la situation, limitant de facto le lectorat. Malgré cela, Jean Nötzli et J.F. Boscovits (senior) réussissent leur pari éditorial, basé sur une alliance qui aura longtemps été cachée. Une fois Nötzli disparu, en I900, Boscovits senior prend les commandes, favorisant son fils, Fritz Boscovits (junior), et permettant l'émergence d'une "dynastie Boscovits " - d'où l'ajout derrière le nom de Boscovits des qualificatifs senior et junior. Les autres dessinateurs, d'un nombre finalement assez restreint, auront à composer avec cette domination, dont on ne peut tout à fait dire si elle aura été globalement profitable à la deuxième période zurichoise de la revue, entre I900 et I92I.

La constance tout à fait exceptionnelle du Nebelspalter zurichois s'exprime d'abord dans sa dimension matérielle et sa périodicité hebdomadaire, avec une parution le samedi. Un certain nombre de changements s'observent néanmoins, qui concernent la tendance politique, cependant toujours à dominante libérale, la stratégie commerciale, la place respective du texte et de l'image, le langage visuel et plus généralement la conception de la page, surdéterminée par le cadre au trait, son maintien et ses oscillations. Cela dit, durant les deux premières décennies, ce cadre au trait est bien accroché, un peu à l'image de l'équipe Nötzli/Boscovits qui domine et contrôle cette époque. Le spectre thématique, sa qualité et ses variations, sont autant redevables aux choix de la rédaction qu'aux affaires du monde. À l'arrière-plan se trouve un public, indispensable à la vie de la revue, qu'il importe d'attirer, d'élargir et de retenir, en usant de différents leviers. Le Nebelspalter est marqué par une série de césures rédactionnelles, coïncidant assez souvent, mais pas toujours, avec des changements de personnes. Cinq cycles de vie, eux-mêmes parsemés d'événements, peuvent ainsi être identifiés : I 875-I886; I 887-I899; I900-I906; I907-I9I2; I9I3-I92I.

Dominique Kalifa, Philippe Régnier, Marie-Ėve Thérenty, Alain Vaillant, « Les scansions internes à l'histoire de la presse », dans La Civilisation du journal. Histoire culturelle et littéraire de la presse française au XIx siècle, éd. Dominique Kalifa, Philippe Régnier, Marie-Ėve Thérenty et Alain Vaillant, Paris, Nouveau Monde, 2011, p. 249-294.
Dans bien des domaines, la première décennie du Nebelspalter se place sous le signe de la stabilité, preuve que la conception a été soigneusement pensée par le binôme Nötzli/Boscovits. La maquette, le langage visuel et rhétorique ne font, de fait, que s'enrichir. La ligne politique, tout du long libérale, est marquée par un anticléricalisme suisse. Des changements, les plus remarquables sont sans doute l'inclusion de l'adjectif « satirique » (satyrisch) dans le sous-titre, en I876, et l'insertion, en I880, d'une doublepage. L'année I 887 marque un premier tournant avec l'apparition de la couleur. L'arrivée de quatorze dessinateurs entre I 887 et I900, le choix d'une nouvelle technique de reproduction en I 889 , l'introduction en I 897 de couvertures imagées, une forte ouverture internationale ainsi qu'un positionnement nettement plus artistique constituent les autres traits saillants de cette deuxième période. Cela, alors que la rédaction, la maquette et la politique commerciale sont globalement stables. Si le sous-titre reste le même, c'est à présent le titre qui flanche, ou du moins son article, l'arrivée du Jugendstil ouvrant la voie à des allégories féminines, peu compatibles avec le genre masculin. On parlera, d'ailleurs, ici de Nebelspalter - sans article - histoire de ne pas compliquer les choses, et de donner toute sa place au personnage allégorisant la revue ${ }^{2}$.

La mort soudaine de Jean Nötzli, le 2 I avril I900, met fin à cette période de stabilité éditoriale exceptionnelle, non seulement dans l'histoire de la revue mais plus largement au sein des revues illustrées européennes. Elle ouvre sur une période de flottement et de frilosité. Elle voit aussi la montée en puissance des Boscovits, père et fils. Le graphisme évolue vers le Heimatstil, une acculturation conservatrice de l'esthétique Jugendstil. L'époque est en fait paradoxale: d'un côté, le cadre au trait, symptôme manifeste d'une volonté de contenir, est sérieusement menacé; de l'autre, on observe différents signes de replis, commercial, visuel, identitaire et idéologique. L'année 1907 imprime un nouveau tournant avec l'arrivée d'Alfred Beetschen, associé pour la deuxième fois aux affaires éditoriales. Il ne s'agit cependant plus d'ouvrir mais de recadrer une formule éditoriale pour ainsi dire enkystée, sur le plan visuel comme sur celui des idées. L'heure est à un retour au texte, et ce n'est pas pour rien que l'on renonce à des couvertures Jugendstil, privilégiant l'image. Comme souvent, les informations sur le public sont maigres, le corpus laissant transparaitre un lectorat mixte, plutôt progressiste et relativement jeune. En I9 I3, débute le dernier cycle de vie du Nebelspalter zurichois. L'arrivée à la tête de la rédaction de Rudolf Huber et Fritz Ebersold, fin I9I 2, débouche, début I9I3, sur une nouvelle refonte du périodique. Titre, maquette, tendance, positionnement et langage visuel sont modifiés. Les deux changements éditoriaux qui suivent, le départ

Le Nebelspalter en italiques désignera la revue, tandis que le Nebelspalter en caractères romains vaudra pour sa personnification. 
de Ebersold début I9I3, laissant Huber seul aux commandes, puis la prise en main par Jean Frey, en I9I9, ne modifient plus guère les choses, si ce n'est dans le sens d'un appauvrissement et d'un durcissement.

Le regard que porte le Nebelspalter sur le monde entre I 875 et I92 I est une histoire autocentrée, s'ouvrant à partir de 1887 jusqu'au déclenchement de la Première Guerre mondiale. Ce regard vaut autant pour ce qu'il expose que pour ce qu'il ne montre pas, ou de manière biaisée. Le monde du Nebelspalter est une image iconographique ou/et mentale - façonnée par un rédacteur et/ou un dessinateur, et ( $\mathrm{r}-$ ) ajustée par la rédaction - le « $\mathrm{r}$ » se justifiant selon le moment où celle-ci intervient dans le processus de création. Métaphoriquement, cet univers est formé de cercles concentriques, qui ne sont pas tous visibles à l'origine mais apparaissent au fil du temps. Les plus proches du centre, les cercles zurichois et suisse, sont les premiers à se montrer, mais pour être vus, encore ont-ils besoin de la lumière des autres et surtout de leurs (grands) voisins, la France et l'Allemagne: la Suisse du Nebelspalter a besoin de leur présence pour être explicitée. Les cercles de pays plus lointains apparaissent progressivement. Il est plusieurs manières de voir l'histoire et de la regarder: le Nebelspalter, lui, regarde par la lorgnette de ses intérêts, restituant son regard avec des mots et des images. Et ces dernières, auxquelles on donne ici la priorité, auront probablement efficacement édifié les esprits.

Durant la Première Guerre mondiale, plus de la moitié des contributions concerne directement la guerre et, parmi le reste, une bonne partie traite de ses conséquences. Le traitement de la guerre est chose compliquée et ce sont une série de questions qui se posent à la rédaction et aux dessinateurs. Comment rendre compte d'une guerre à laquelle on ne participe pas? Quel point de vue adopter qui ne mette en danger la cohésion de la nation et la neutralité ? Quelle part réserver aux affaires intérieures? Comment transmettre un discours malgré la censure? Comment montrer la guerre? Est-il possible d'en rire et, si oui, comment? Comment, enfin, prendre sa place dans la guerre des images qui se joue en Europe? Ces défis vont générer des pages à la teneur et à l'iconographie inédites, traçant un chapitre à part dans l'histoire du Nebelspalter. L'après-guerre est la chronique désenchantée d'une douleur et d'un ressentiment, dont on ne sait s'ils valent pour un monde blessé, pour la Suisse ou pour une revue montrant les stigmates d'un déclin inéluctable.

Confronté à la matérialité de la revue, on en oublierait qu'il s'agit d'une création collective, sous-tendue par une organisation sociale ayant besoin de prendre ses marques et trouver sa légitimité. Pour border son espace symbolique, le Nebelspalter se trouve face à trois tâches: assurer une cohésion en créant un esprit de groupe, se singulariser dans l'univers de la presse hautement concurrentiel et se positionner vis-à-vis du monde artistique; le tout dans un contexte suisse ne pouvant faire l'économie de la dimension européenne. Au-delà des discours, des modèles vont être mobilisés, passant par l'image, parfois très subtilement. Cela dit, il ne faut pas perdre de vue que l'opération est menée dans un contexte favorable aux images et à leurs créateurs, et que des événements influent sur la ligne éditoriale, comme par exemple l'organisation d'une activité muséale à Zurich dans la seconde moitié des années I 890. Les premières positions artistiques du Nebelspalter dans les années I 880 , du reste assez tardives, s'inscrivent dans le contexte tout à fait singulier en Europe d'une quasi-absence d'institutionnalisation de l'art. Le constat témoigne d'une difficile intégration du critère artistique dans l'identité nationale, contrastant avec la situation des voisins français, allemand et italien. Le moment est donc celui de revendications très fortes de la part des acteurs du champ de l'art, l'importance des enjeux symboliques et financiers ouvrant sur des luttes sans merci.

La nature hybride du Nebelspalter, mélange de verbe et d'image ainsi que sa situation sociétale à la croisée des champs de l'art, de la littérature populaire et de la presse, font qu'il aura plusieurs types de modèles. La maquette d'autres périodiques, les images de revues, les œuvres artistiques ainsi que des structures de discours vont être soumises à un processus d'appropriation. Cela illustre la réalité d'une Suisse s'imprégnant des créations européennes, fournissant également son tribut à l'activité bouillonnante des revues illustrées. Qui dit modèles, dit aussi réseaux, puisque les modèles empruntent des canaux de circulation. Les images de revues, en particulier, voyagent via des réseaux internationaux aux ramifications multiples, dont la cartographie est délicate à établir. Derrière ces canaux de circulation, se trouvent des hommes, et la part des passions n'est pas moins grande que celle de l'art c'est une litote. Ce qui se joue dans les réseaux relève, en fait, moins de l'aspect créatif de l'activité artistique que de l'aspect social, économique, symbolique et politique. Ce sont de véritables affaires fleurant le scandale qui ont pu être reconstituées grâce aux archives. Celles-ci engagent invariablement l'éditeur du Nebelspalter autour duquel s'organise un Network extrêmement complexe. Elles ont en commun d'avoir un dénouement inattendu et une fin incertaine. Enfin, comme toujours avec les réseaux, il y est question d'argent, d'honneur, de pouvoir et de manipulation.

Car le Nebelspalter zurichois, cet objet de papier, de pixels maintenant sous sa forme numérisée ${ }^{3}$, renferme, raconte et met incessamment en scène des histoires d'hommes, de passions, intimement liées à la Suisse et connectées à l'Europe. À cet égard comme à d'autres, il constitue un témoignage unique pour l'histoire des périodiques européens entre deux siècles ${ }^{4}$.

La revue a été numérisée durant le projet de recherche par la Bibliothèque nationale suisse qui l'a mise en accès libre pour les années 1875 à 1974 ; http://www.e-periodica.ch/digbib/vollist?var=true\&UID=neb-001.

Michel Melot « L'image et les périodiques en Europe entre deux siècles (18801920) ॥, dans L'Europe des revues (1880-1920), éd. Evanghelia Stead et Hélène Védrine, Paris, Presses universitaires de Paris-Sorbonne, 2009, p. 13-19. 


\title{
PREMIÈRE PARTIE
}

\author{
IDENTITÉ ET CHRONIQUE \\ D'UNE REVUE SATIRIQUE ZURICHOISE
}




\section{GENÈSE ET FIGURES}

Que le Nebelspalter soit à présent la plus ancienne revue satirique n'était guère imaginable au moment de sa création. Rien n'était gagné d'avance dans cette aventure éditoriale entamée en I 875 , ponctuée de crises et de remaniements. Certes, la revue bénéficie d'une tradition caricaturale et d'une opportunité éditoriale mais l'environnement est plutôt hostile. Dans les années I 870, Zurich est une ville en pleine croissance économique, intellectuellement ouverte mais conservatrice dans les domaines politique et culturel, notamment concernant l'art. La scène nationale se présente tout aussi mal, le plurilinguisme étant très défavorable aux revues satiriques. C'est donc un coup de maître que réussissent Jean Nötzli et Johann Friedrich Boscovits (senior), dont l'association n'est revendiquée que très tardivement ${ }^{1}$. La date de 1900 marque pourtant un tournant dans l'histoire du Nebelspalter: Jean Nötzli meurt subitement, laissant la rédaction sans chef. Boscovits senior se saisit de l'opportunité. Le dessinateur vieillissant en fait son profit mais surtout celui de son fils, Fritz Boscovits junior, installant une dynastie Boscovits qui va modifier les rapports de force chez les dessinateurs. Ceux-ci, peu nombreux, auront dès lors à composer avec cette domination, dont il n'est pas certain qu'elle ait été bénéfique à la seconde période zurichoise de la revue, entre I900 et I92I. Quoi qu'il en soit, beaucoup d'entre eux auront participé, avec ou contre les rédacteurs, c'est selon, à l'entreprise de légitimation du périodique vis-à-vis des champs de l'art et de la presse.

\subsection{Décryptage de la fondation et de la vie éditoriale : focus sur Boscovits senior}

En l'absence d'archives unitaires, la reconstruction de la genèse du Nebelspalter est une entreprise ardue, à moins d'admettre la paternité exclusive de Jean Nötzli, difficile à accepter une fois le corpus connu ${ }^{2}$. La carence archivistique est en partie compensée par la succession Nötzli, versée à la Zentral Bibliothek de Zurich

Ce type d'association entre un éditeur et un dessinateur n'est alors pas le scénario le plus courant; Fabrice Errre et Bertrand Tillier, « Du journal à l'illustré satirique », dans La Civilisation du journal. Histoire culturelle et littéraire de la presse française au XIX $x^{e}$ siècle, éd. Dominique Kalifa, Philippe Régnier, Marie-Ėve Thérenty et Alain Vaillant, Paris, Nouveau Monde, 2011, p. 417-435.

Ce chapitre reprend et actualise une communication intitulée « Johann Friedrich Boscovits, figure centrale du Nebelspalter des années zurichoises », tenue lors du colloque L'Artiste en revues à l'Université libre de Bruxelles, le 28 octobre 2013. L'article est à paraître sous le même titre dans un volume édité par Laurence Brogniez, Clément Dessy et Clara Sadoun-Édouard aux Presses universitaires de Rennes. fin $2012^{3}$ ainsi que par les enseignements encore plus récents des archives familiales Boscovits ${ }^{4}$. Le fonds Nötzli est d'un exceptionnel intérêt concernant la personnalité de l'éditeur Jean Nötzli (I 844I900) ainsi que les transactions commerciales et éditoriales autour de la revue ${ }^{5}$. Peu d'informations étaient auparavant disponibles et toutes livrées par Peter Métraux. Selon celui-ci, Nötzli est né à Höri près de Bülach (canton de Zurich) en I 844, et boite depuis son plus jeune âge, en raison d'une fracture mal soignée. Il gagne d'abord sa vie en tant que secrétaire, entre autres, auprès de Gottfried Keller, qui l'aurait encouragé à éditer un journal satirique d'orientation progressiste. Quoique n'adhérant à aucun parti, Nötzli s'essaie brièvement à une carrière politique au conseil municipal de Zurich mais y renonce faute de parvenir à imposer ses idées progressistes auprès de la bourgeoisie conservatrice. Nötzli livre également des contributions satiriques à différentes revues, telles que le Postheiri et les Fliegende Blätter, et travaille comme rédacteur des pages littéraires du Zürcher Presse ainsi que comme correspondant du Grenzpost et du Landboten. Il décide ensuite de fonder sa propre entreprise ${ }^{6}$.

Si l'on s'en remet aux sources accessibles au public ainsi qu'à la littérature secondaire, le cas de Johann Friedrich Boscovits (I 845I9 8 ), alias Boscovits senior, représente un défi. On ne trouve ainsi pas trace de l'homme avant son arrivée à Zurich et les rares informations dont on dispose à son sujet sont contradictoires ou sujettes à caution. Le nom de Boscovits n'apparaît, en outre, que dans une unique lettre du fonds Nötzli - il est vrai incomplet datée de l'été I 890, sans qu'il soit, du reste, clair qu'il s'agisse du père ou du fils ${ }^{7}$. Parmi les sources dispersées dans les différentes archives, cantonales et fédérales ${ }^{8}$, seule une minorité concerne Boscovits senior. De même, les cinq entrées fournies par différents ouvrages biobibliographiques ${ }^{9}$ sont pour la plupart elliptiques, voire incorrectes. Seuls deux documents apportent, en fait,

Cf. « 6.1. La leçon des archives Nötzli : un éditeur et ses réseaux ».

Les archives des descendants Boscovits ont pu être consultées courant 2014 grâce à l'intermédiaire de la conservatrice du musée de Zollikon ainsi que l'aide précieuse de la famille Schmid-Schönenberger

Cf. « 6. Des affaires de réseaux autour de l'éditeur Jean Nötzli ».

Peter Métraux tient ses informations de l'une des filles de Jean Nötzli, Martha am Rhyn-Nötzli, ainsi que d'une biographie publiée par la Zürcher Wochen-Chronik à l'occasion de la mort de Nötzli (ํ17, 28 avril 1900); Peter Métraux, Die Karikatur als publistische Ausdruckform untersucht am Kampf des « Nebelspalters » gegen den Nationalsozialismus 1933-1945, Berlin, 1966, p. 25, 164; ces informations sont, cependant, en partie contredites par d'autres sources.

Cote 1.33 de la succession Nötzli, lettre à Rigi-Klosterli, datée du 20 août 1890 : la lettre est signée Boscovits mais l'initiale n'en est pas claire.

Base Helvetica de la Bibliothèque nationale suisse; Zentral Bibliothek (bibliothèque universitaire de Zurich); Archives du canton de Zurich; Archives de la ville de Zurich.

Boscovits senior est présent dans différents ouvrages biobibliographiques suisses, allemands et français: Schweizerisches Künstler-Lexikon de Carl Brun (1905); Dictionnaire sur l'art en Suisse de l'Institut suisse pour l'étude de l'art (2011); Allgemeines Künstler-Lexikon - Die Bildenden Künsler aller Zeiten und Völker de KG Saur (1996); Dictionnaire biographique de l'art suisse, conjointement édité par l'Institut suisse pour l'étude de l'art et les éditions de la Neue Zürcher 
quelques informations précises: une notice biobibliographique du Schweizerisches Künstler-Lexikon (Dictionnaire suisse des artistes) datant de 1905 ainsi qu'une notice nécrologique, datée du 25 novembre I9I 8 , parue dans le quotidien zurichois de référence, Neue Zürcher Zeitung (NZZ). Tout habitué de ce type de sources sait néanmoins que la teneur en repose pour l'essentiel sur les déclarations (antérieures) de l'intéressé ou de ses ayants-droits, et qu'il convient d'être circonspect.

Selon la notice biobibliographique du Schweizerisches KünstlerLexikon, Friedrich Boscovits senior, peintre (Maler) et illustrateur (Illustrator), né le 6 janvier I 845 à Budapest, a étudié sous l'autorité de différents maîtres, entre I 863 et I866, aux Académies de Vienne, puis de Brera, à Milan, et enfin de Munich sous la direction du professeur Alexander (Sandor) Wagner; ceci avant de s'installer à Zurich où il exerce une activité artistique, tout en étant l'illustrateur attitré de la revue humoristique illustrée Der Nebelspalter depuis sa fondation, en $1875^{10}$. De ce texte, où se trouve retracé un parcours de formation entre les différentes académies de Vienne, Milan et Munich, alors typique pour les artistes originaires d'Europe de l'Est ${ }^{11}$ mais plus encore pour les Suisses ${ }^{12}$, on notera qu'il n'est pas question d'un rôle dans la fondation du journal, pas plus que n'est précisée la nature de l'activité artistique. La notice se clôt par l'indication d'une direction des dessins de costumes pour le défilé de la grande fête populaire zurichoise des Sechselaüten célébrant la fin de l'hiver, signe d'une bonne intégration dans le tissu culturel zurichois.

Le texte est à rapprocher de la notice relative au fils, publiée sur la même page ${ }^{13}$. Celle-ci livre en filigrane l'une des raisons de l'actuelle mauvaise fortune critique de Boscovits père. Boscovits junior (I87I-I965) y est dit peintre (Maler) et non illustrateur, et il n'est pas même fait mention de son activité dans le Nebelspalter, pourtant intense à cette époque ${ }^{14}$. Le fils, plus stratège que le père, aura mieux compris les règles de la consécration historiographique, en mettant en valeur son activité artistique et en taisant ses liens avec la presse illustrée; ceci lui vaudra une fortune historiographique croissante, inversement proportionnelle à celle de son père. Il sera tout de même rattrapé sur le tard par son activité de dessinateur ${ }^{15}$.

Le bref article de la NZZ, publié à l'occasion de la mort de Boscovits senior, et dont la teneur laisse apparaître qu'il a été rédigé par l'un de ses familiers, met, quant à lui, en avant plusieurs points: un parcours entre Budapest et Zurich; une formation académique et une activité d'illustrateur du Nebelspalter depuis sa fondation, au milieu des années I 870; un rôle dans l'organisation de la fête des Sechselaüten; un tempérament affable; un engagement en faveur de la presse, ce dernier point sans nul doute fatal à une reconnaissance par l'historiographie de l'art, alors que plusieurs sources de la succession Nötzli documentent cette réticence des

Zeitung (1998); Dictionnaire critique et documentaire des peintres, sculpteurs, dessinateurs et graveurs de Bénézit E. et révisé par Jacques Busse (1999).

H. Appenzeller, « Boscovits, Friedrich, sen. », dans Schweizerisches KünstlerLexikon, tome 1, éd. Carl Brun, Frauenfeld, Huber, 1905, p. 180.

Cela est surtout vrai de Munich; Susanne Gourdon, La « Jugend » de Georg Hirth: la Belle Époque munichoise entre Paris et Saint-Pétersbourg, Strasbourg, Centres d'Études germaniques, 1997, p. 68-69.

Hans A. Lüthy, «L'art en Suisse 1890-1945 », dans L'art en Suisse 1890-1980, éd. Hans A. Lüthy et Hans-Jörg Heusser, Lausanne, Payot, 1983, p. 9-10.

H. Appenzeller, « Boscovits, Fritz, jun. », dans Schweizerisches Künstler-Lexikon, op. cit., p. 180.

Boscovits junior fait ses débuts dans le Nebelspalter en 1889. À l'exception des années 1893 et 1896, il est actif durant toute la période zurichoise; cf. «1.7. Liste et période d'activité des dessinateurs ».

Cf. « 1.3. La domination Boscovits ». artistes à s'afficher dans les terres supposées mal fréquentées $\mathrm{du}$ dessin de presse ${ }^{16}$. Voici la situation qu'a permis de retracer un premier travail archivistique, très loin de rendre justice à l'importance d'une figure majeure du paysage de la presse suisse et, plus généralement, des revues illustrées européennes.

Cet état des lieux est partiellement corrigé par les archives de la famille Boscovits, qui, à vrai dire, le précisent plus qu'elles ne le réorientent. Tout d'abord, le volume des notices nécrologiques plus de quatre-vingt - parues dans la presse suisse germanophone et francophone, et réunies par l'Argus suisse de la presse, probablement à la demande de la famille, donne un indice de l'importance de Boscovits senior dans l'univers culturel de l'époque. L'une d'elles, provenant de la Zürcher Wochen-Chronik, est particulièrement nourrie. Elle déroule une vita relatant une cofondation du Nebelspalter en 1874 avec Jean Nötzli ${ }^{17}$. Les archives gardent, par ailleurs, trace de sa formation viennoise entre I 863 et I 865 mais pas de celles milanaise et munichoise. Deux contrats signés avec le photographe Ganz, établi à Zurich, comportent des informations précieuses, en particulier le premier d'entre eux : l'engagement pour quatre ans de Fritz Boskowitz ${ }^{18}$ le 2 janvier I 869 en tant que peintre (Maler), retoucheur d'images positives et négatives (Retoucheur für negative und positive Bilder) et aide pour les dispositions et arrangements lors de prises photographiques (Mithilfe bei Stellungen und Arrangements bei photographischen Aufnahmen), selon des modalités de rémunération mensuelle fixées selon les années à I 60, 200, 220 et 250 francs. Ce contrat sera renouvelé en I 874. Antérieur à l'installation de Boscovits senior à Zurich et même à son mariage à Munich, le contrat originel est signé du nom germanisé de "Fritz Boscovits » ${ }^{19}$, contredisant celui reporté par l'employeur. Une pochette en cuir présente dans la succession est, par ailleurs, gravée au nom de «F. Boskovicz Zürich ».

Des documents des autorités policières et paroissiales de la ville de Munich, très difficilement lisibles, concernent l'union contractée en I 870 avec Mathilde Adam. Celle-ci appartient à une famille d'artistes munichoise en vue, avec laquelle les Boscovits continueront d'entretenir des liens. Une série de pièces rend compte, en outre, des démarches entreprises pour obtenir la citoyenneté zurichoise et, par là même, la nationalité suisse. Celle-ci est accordée par le conseil municipal zurichois le 2I juin I 887 aux quatre membres de la famille contre la coquette somme de 500 francs $^{20}$. Il a fallu fournir une déclaration de revenus et de patrimoine, respectivement annoncés à hauteur de 2000 francs et de 4000 francs, ainsi qu'un extrait du livret de famille (Familienschein) laissant, entre autres, apparaître la germanisation (non datée) du nom de Boskovicz en Boscovits ${ }^{21}$. La succession conserve, en outre, une carte de presse tamponnée pour les années I9I 3 à I9I 6, où Boscovits senior est désigné comme rédacteur (Redakteur). De la correspondance avec la famille hongroise, l'on sait que celle-ci n'était pas de langue maternelle allemande, un certain Belà déplorant dans un courrier adressé à Boscovits

\footnotetext{
Cf. « 6.4. Passions d'artistes: Richard Kissling, Evert van Muyden, Henri van Muyden et Jean Nötzli »; cf. en particulier les lettres de Henri van Muyden. La coupure de presse, sans date, est la seule de cette ampleur. L'orthographe est conforme à l'original.

Fritz est un diminutif de Friedrich, à l'occasion employé pour le père, rarement, cependant, lorsque le fils devient actif.

Somme à laquelle il faut ajouter d'autres taxes pour un montant de 61,40 francs. II est impossible de savoir si la raison en est une volonté de simplification ou d'éloignement d'un patronyme très répandu dans les communautés juives d'Europe de l'Est.
} 
junior en I9I9 que " la belle langue allemande [lui] soit à demi étrangère ${ }^{22}$.

Ce sont, en fait, six pages copieusement raturées, écrites par le fils, Fritz Boscovits junior, qui éclairent bien des points. Elles constituent très probablement le brouillon d'une lettre en réponse à l'auteur du premier ouvrage scientifique sur le Nebelspalter, Peter Métraux ${ }^{23}$. Consignées au début des années I960, et donc passées au filtre de la mémoire familiale, leur fiabilité est relative, ce que souligne d'ailleurs leur auteur. On y apprend notamment que Boscovits senior était le fils d'un médecin de Budapest; que selon les souvenirs du fils, celui-ci n'aurait étudié qu'à Vienne, en particulier la peinture d'histoire, et non à Milan et Munich; que c'est au travers de la famille de sa femme qu'il aurait été engagé l'année de son mariage ( I 870) chez le photographe Ganz, établi à Zurich; que le peintre n'avait jamais œuvré comme caricaturiste avant d'être embauché comme dessinateur par Jean Nötzli mais s'était, par contre, distingué en dessinant les costumes des Sechselaüten; que les deux amis, Nötzli et Boscovits, auraient trouvé le nom de Nebelspalter lors d'une promenade nocturne, par temps de brouillard, alors qu'ils étaient à la recherche d'un nom pour le journal projeté par Nözli; que Boscovits père aurait racheté les éditions du Nebelspalter à la veuve de Jean Nötzli après le décès de celui-ci, avant de s'en dessaisir quelques années plus tard au profit de l'imprimeur Jean Frey; que l'artiste, après le changement de propriétaire de l'atelier Ganz, se serait entièrement dédié au Nebelspalter comme éditeur (Verleger), rédacteur (Redakteur) et dessinateur (Zeichner); qu'il aurait, pour finir, intégré la gilde zum Widder (Zunft zum Widder) de la fête des Sechselaüten en I $887^{24}$, l'année de sa naturalisation.

Le Nebelspalter, considéré non comme un corpus de documents à exploiter mais comme une source unitaire vis-à-vis de laquelle la distance critique est également de mise, livre une version un peu différente de l'histoire. Le périodique témoigne de cette propension des revues illustrées à se mettre en scène, sur un mode particulièrement aigu, et l'on peut y lire un "roman Boscovits ", tout d'abord écrit par le père, puis par le fils. Si le rôle de Boscovits senior dans la fondation de la revue et sa fonction de rédacteur n'apparaissent que très tard dans l'historiographie comme dans les documents officiels - après un quart de siècle -, plusieurs documents du Nebelspalter laissent filtrer plus tôt une co-fondation. Cette attitude de retrait de Boscovits senior peut sans beaucoup de risque être rattachée à sa nationalité hongroise au moment de la fondation du journal. Jean Nötzli ayant officiellement assumé la responsabilité éditoriale et rédactionnelle, seul son nom apparaît dans le bandeau de couverture, ne laissant rien voir du rôle de Boscovits senior jusqu'en I900.

Boscovits senior, lui-même, se prête à cet affichage pour la couverture célébrant les vingt-cinq ans du journal en I 899, un an avant la mort de Jean Nötzli. Le bébé Nebelspalter y est, en effet, confié aux bons soins d'un Nötzli, désigné comme rédacteur

(Leider ist mir die schöne deutsche Sprache halbfremd).

On retrouve en effet une bonne partie de ces éléments dans la thèse de Peter Métraux: Peter Métraux, Die Karikatur als publistische Ausdruckform untersucht am Kampf des "Nebelspalters » gegen den Nationalsozialismus 1933-1945, op. cit.

${ }^{24}$ II s'agit d'une gilde très ancienne, fondée en 1336; les Seechseläuten consiste, entre autres, en un défilé de gildes représentant tout à la fois une corporation et un quartier.
(J. Nötzli Redakteur) sur le papier dépassant de sa poche ${ }^{25}$ (cf. fig. I cahier couleur).

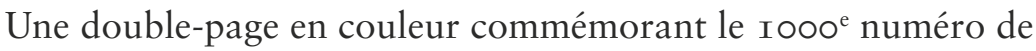
la revue en I 894, cinq ans auparavant, restituait cependant un fonctionnement en binôme entre Nötzli et Boscovits. Boscovits, auteur du dessin, s'y met en scène à côté de Nötzli ainsi qu'avec tous les concepteurs et personnages du Nebelspalter ${ }^{26}$.

C'est à travers un encart publié lors du décès de Jean Nötzli, en I 900 , que le rôle de Boscovits senior dans la fondation du Nebelspalter apparaît au grand jour. Il y est relaté que Jean Nötzli a fondé 26 ans auparavant le Nebelspalter avec l'artiste "Mr F. Boscovits ", le même Boscovits étant qualifié quelques lignes plus loin de cofondateur (Mibegründer) ${ }^{27}$. On apprend par un bandeau de couverture du numéro suivant que Boscovits senior assure l'intérim de la rédaction ${ }^{28}$, avant que la succession Nötzli, qui reste propriétaire des éditions, ne confie quelques mois plus tard la partie artistique à Boscovits senior et la partie littéraire à Edwin Hauser ${ }^{29}$. Deux ans plus tard, en I902, une nouvelle mention du bandeau de couverture rapporte que Boscovits senior a acquis les éditions du Nebelspalter, jusque-là dans les mains des héritiers de Jean Nötzli ${ }^{30}$. La responsabilité éditoriale reste toutefois partagée entre Boscovits senior et Edwin Hauser.

En I903, une indication sur la couverture ${ }^{31}$ informe d'une nouvelle étape décisive: Boscovits senior règne désormais sur le Nebelspalter, cumulant les fonctions d'éditeur, de rédacteur en chef et de dessinateur vedette, soit la situation décrite par Boscovits junior à Peter Métraux. En I907, on apprend par le même biais l'arrivée d'Alfred Beetschen comme responsable rédactionnel de la partie littéraire, alors que la revue connaît à nouveau une refonte importante. La cohabitation avec Alfred Beetschen dure jusqu'en I9 I $2^{32}$, année d'une nouvelle révision, et de la maquette, et de la tendance ${ }^{33}$. Cette année-là, Boscovits senior cesse également ses fonctions éditoriales, devenues trop pesantes selon les notes de son fils, s'en expliquant lui-même dans un encart intitulé "Adieu " $(Z u m \text { Abschied })^{34}$. Il cède alors la rédaction et les éditions à deux collaborateurs au long court, Rudolf Huber et Fritz Ebersold ${ }^{35}$, qui exposent longuement leur démarche dans une page intérieure du numéro suivant, Huber assumant, de surcroît, les fonctions d'éditeur ${ }^{36}$. À l'occasion de son départ, Boscovits senior se portraiture en compagnie de son successeur à la tête du Nebelspalter avec ses attributs d'éditeur, de rédacteur et de dessinateur, la plume et la pique, lançant à son

Nebelspalter 1899/52, couverture de Boscovits senior

Nebelspalter 1894/9, double-page de Boscovits senior intitulée «À l'occasion du numéro 1000 du Nebelspalter » (Nebelspalter bei Nro. 1000); cf. sur cette image «1.5. Ambitions voilées et assumées: de la délimitation avec les champs de l'art et de la presse ».

Nebelspalter 1900/17, encart nécrologique.

Nebelspalter 1900/18, bandeau de couverture.

Nebelspalter 1900/37, bandeau de couverture.

Nebelspalter 1902/36, bandeau de couverture.

Nebelspalter $1903 / 40$, bandeau de couverture.

Jusqu'au numéro 43 de l'année 1912.

Cf. « 2.5. 1907-1912 Remous, hésitations et révisions 》.

Nebelspalter 1912/48, encart intitulé «Adieu » (Zum Abschied).

Sur Fritz Ebersold: Karin Marti-Weissenbach, « Ebersold, Fritz », Dictionnaire historique de la Suisse (28/02/2006); http://www.hls-dhs-dss.ch/textes/f/F11762. php.

Nebelspalter 1912/49, textes intitulés « nouvelle direction » (Neue Fuhre) ainsi que "Aux anciens et aux nouveaux amis du Nebelspalter» (An die alten und neuen Freunde des "Nebelspatler »). Sur Rudolf Huber, cf. André Salathé, "Huber Rudolf », Dictionnaire historique de la Suisse (15/01/2008); http://www.hls-dhsdss.ch/textes/d/D6388.php; sur Fritz Ebersold, cf. Karin Marti-Weissenbach, "Ebersold, Fritz », Dictionnaire historique de la Suisse (07/11/2005); http://www. hls-dhs-dss.ch/textes/d/D11762.php. 
Zum Hbíchied.

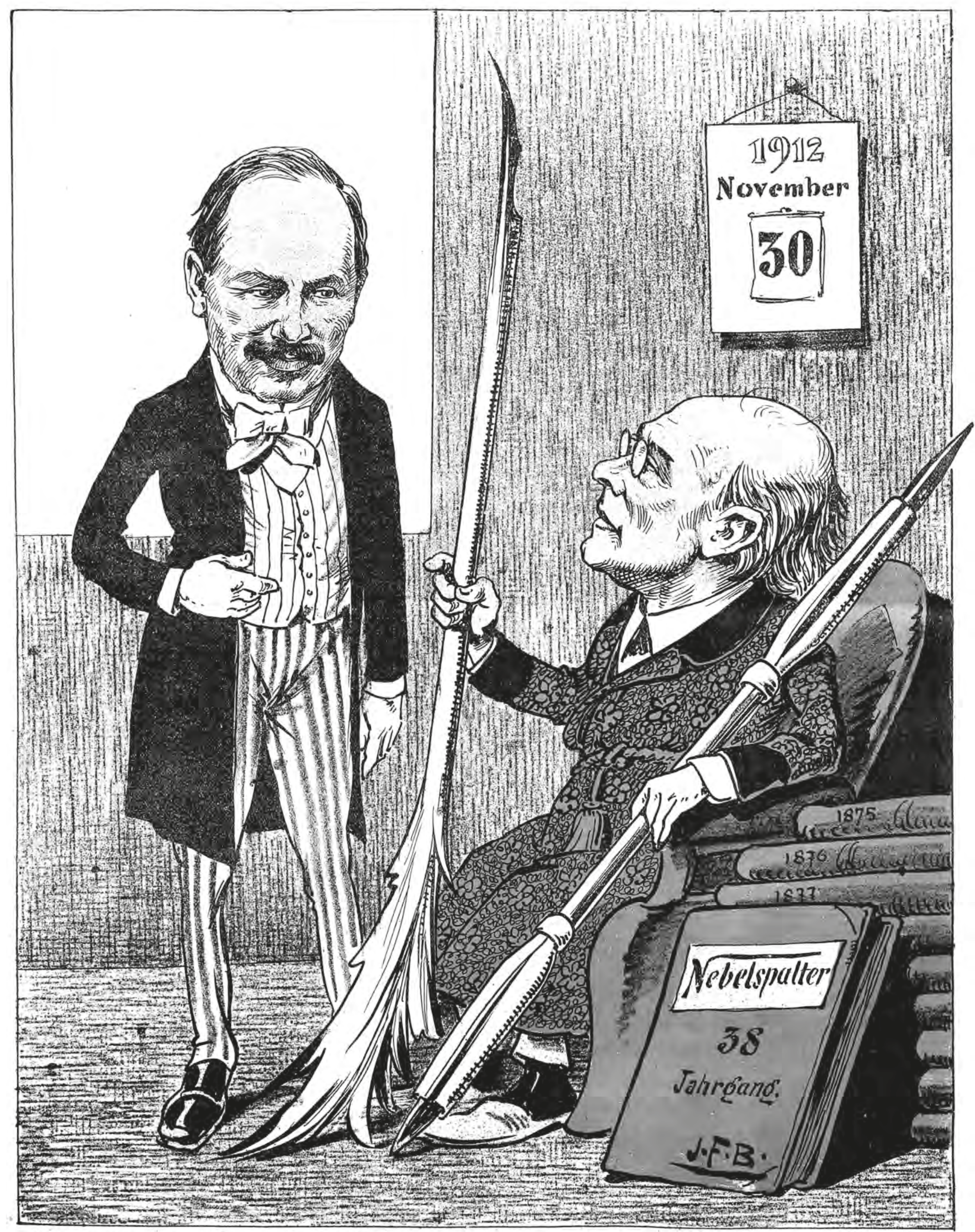

Freund, hier hast Du meinen Speer, meinem Arm wird er zu fchwer . .

Fig. 2. Nebelspalter 1912/48, dessin pleine page en couleur de Boscovits senior intitulé « Adieu » (Abschied). 
interlocuteur l'injonction suivante: "Ami, voici ma lance, elle devient trop lourde à mon bras » 37 (cf. fig. 2).

À la fin de l'année suivante, en I9I3, la revue est l'objet d'un nouvel avatar. Une mention discrète sur le bas de l'avant-dernière page ${ }^{38}$ indique que l'imprimeur Jean Frey en assume désormais la direction et que la responsabilité éditoriale est confiée à Paul Altheer ${ }^{39}$. Boscovits senior continue d'œuvrer comme dessinateur jusqu'à sa mort, survenue en I9I 8 . Il succombe à ses blessures le 23 novembre I9I 8 après avoir été renversé par un taxi, ce dont fait état un encart du numéro 47 , daté du 30 novembre I9I 8, et qui est confirmé par les souvenirs du fils ainsi que par de nombreux encarts de presse. L'ère Boscovits père se clôt avec un portrait réalisé par le fils. Publié en dernière page, il s'intitule «À la mémoire de J.F. Boscovits » (J.F. Boscovits zum Andenken) et comporte la légende suivante:

Une vie entière, il a tenu le crayon / il luttait en riant, sans blesser / S'il en est un que l'on doive remercier / Alors, c'est bien ce brave / qui s'est donné sans compter / jusqu'à ce qu'il rencontre la froide main de la mort ${ }^{40}$.

En I9I9, Jean Frey prend la direction entière de la revue, d'abord personnellement puis sous la forme d'une société anonyme ${ }^{41}$.

\subsection{La domination Boscovits}

Durant toutes ces années, tout de même quarante-quatre ans, Boscovits senior est donc le dessinateur vedette du Nebelspalter, pour ainsi dire sa griffe. C'est évidemment lui qui a créé le personnage du Nebelspalter auquel il finit par s'identifier, comme en témoigne son autoportrait de $19 \mathrm{I} 2^{42}$. Seule une étude de signature, d'un «B » logé dans le coin inférieur du bandeau, permet cependant d'attester cette paternité. Car Boscovits senior ne signe quasiment jamais ses dessins en I 875 , première année de parution, ou alors très discrètement; il ne signe, du reste, guère davantage les années suivantes, témoignant, ce faisant, d'une réticence de bien des artistes à lier leur nom au genre déprécié de la caricature, redoutant peut-être aussi la censure. Il signe ainsi parcimonieusement les dix premières années, jusqu'en I 884 , usant de plusieurs signatures plus ou moins explicites selon le

(Freund, hier hast Du meinen Speer, meinem Arm wird er zu schwer.); Nebelspalter 1912/48, dessin de Boscovits senior intitulé « Adieu » (Abschied).

Nebelspalter $1913 / 45$.

9. On corrige ici les erreurs sur les rôles attribués par Julia Schramm au père et au fils dans un récent article sur la presse satirique suisse ainsi que par Bruno Knobel dans un ouvrage plus ancien, ayant servi de référence aux différents mémoires universitaires sur le Nebelspalter; Bruno Knobel, Die Schweiz im Nebelspalter. Karikaturen 1875 bis 1974, Rorschach, Nebelspalter-Verlag, 1974, p. 6-8; Julia Schramm, « Schweizerische Satire-Journale im Überblick. Von den Anfängen der Bildsatire bis zur Gegenwart », Ridiculosa - La presse satirique dans le monde, hors-série (2013), p. 249-251. Sur Paul Altheer, cf. Karin Marti-Weissenbach, "Altheer, Paul », Dictionnaire historique de la Suisse (05/05/2001); http://www. hls-dhs-dss.ch/textes/d/D11468.php.

40 (Ein Leben lang hat er den Stift geführt: / er kämpfe lächelnd, ohne zu verwunden /Wenn Einem unser heiber Dank gebührt, / dann diesem Wackern, der sich stets gerührt, / bis ihn des Todes kalte Hand gefunden.); Nebelspalter 1918/47, dessin de Boscovits junior intitulé «À la mémoire de J. F. Boscovits » (J. F. Boscovits zum Andenken).

À partir du premier numéro de 1919, on trouve sur le bas de l'avant-dernière page la mention «Rédaction, impression et édition, Jean Frey, Zurich, Dianastraße Nro. 5/7. - Telephone Selnau 10.13 » (Redaktion, Druck und Verlag: Jean Frey, Zürich, Dianastraße Nro. 5/7. - Telephon Selnau 10.13); à partir du numéro 6, est rajoutée la mention « Société anonyme » (Aktiengesellschaft) devant Jean Frey. Sur Jean Frey; Ueli Müller, « Frey, Jean », Dictionnaire historique de la Suisse (22/05/2007); http://www.hls-dhs-dss.ch/textes/f/F30937.php.

Nebelspalter 1912/48, dessin de Boscovits senior intitulé « Adieu » (Abschied). type de dessin, une signature complète pour les compositions spécialement valorisées, le chiffre «FB » ou le monogramme pour les caricatures secondaires, s'abstenant de signer les dessins d'un sujet sensible, tels ceux engageant les autorités fédérales ou relevant de thématiques financières. Jusqu'en I 887 , Boscovits senior est quasiment le seul dessinateur de la revue, si l'on excepte les contributions des lithographes C. Knüsli et Emil Graf, très sporadiques pour le premier d'entre eux ainsi que celles d'un improbable « $\mathrm{AN}$ » (pour anonym ?). Dans ces années où prime le texte et avant que n'apparaisse la couleur, le dessinateur aura installé un univers et un langage graphique personnel, riches d'une galerie de personnages déformés et animalisés, et d'objets animés. Un univers tourné vers une tradition française consacrée par la figure de Honoré Daumier, dont on retrouve des citations régulières, mais vers une culture humaniste, lisible à travers des références visuelles, sans doute acquises au cours de sa formation de peintre d'histoire, ainsi que de légendes qu'il écrivait très probablement lui-même ${ }^{43}$.

Au cours de la première décennie, le langage plastique de Boscovits senior évolue, s'adaptant à l'évolution générale des revues illustrées européennes. En I 887, année du passage à la couleur, Boscovits senior demeure le plus important des dessinateurs malgré l'arrivée de nouveaux artistes, Evert van Muyden en I 887, Heinrich Jenny en I 888, Henri van Muyden et Boscovits junior en I 889, Emil Dill en I 890 et Willy Lehmann-Schramm en I 893 , qui tous participent à la typicité du graphisme. Certains dessinateurs contestent cependant la primauté à Boscovits senior, soit qu'ils aient une présence institutionnelle supérieure, comme Heinrich Jenny, professeur de dessin à Soleure, œuvrant dans différentes revues satiriques suisses et se distinguant avec des tableaux de la guerre de I 866 et des portraits du Kaiser ${ }^{44}$; soit qu'ils portent mieux que le dessinateur vieillissant de nouvelles ambitions graphiques, tel Willy Lehmann-Schramm durant les années Jugendstil. À partir de I 893, ce dernier va ainsi progressivement disputer à Boscovits senior la signature des compositions les plus valorisées, couvertures, double-pages et feuillets engageant l'identité suisse. Il ne lui ravira toutefois pas le quasi-monopole des dessins mettant en scène sa créature, le personnage du Nebelspalter.

Après I900, Boscovits senior profite, selon toute évidence, de sa position éditoriale non tant pour récupérer ses privilèges mais pour favoriser son fils aux dépens de Willy Lehmann-Schramm, un développement permettant de démontrer, s'il en est besoin, qu'une direction éditoriale et des liens familiaux sont loin d'être sans influence sur le graphisme d'une revue. Boscovits junior signera dès lors la majorité des couvertures. Ceci, à l'exception notable de la couverture du numéro en hommage à Jean Nötzli, où Boscovits senior reprend le bandeau originel de $1875^{45}$. Le dessinateur amorce dès cette époque le virage Heimatstil au cours duquel les motifs et thèmes populaires liés au terroir prennent la primauté, et où l'on réactive certaines formules graphiques anciennes; soit nettement avant le restant des dessinateurs, pour lesquels cette tendance ne s'affirme qu'autour de 1907. De fait, nombre de dessins de Boscovits senior dénotent dès I900 une tendance archaïsante, sa marque de fabrique jusqu'au terme de son

\footnotetext{
Les archives familiales ne contiennent malheureusement pas d'originaux des caricatures de Boscovits senior, permettant de confirmer cette hypothèse.

4 Thomas Gürber, "Jenny, Heinrich », Dictionnaire historique de la Suisse; http://www.hls-dhs-dss.ch/textes/f/F35035.php.

Nebelspalter 1900/17, couverture de Boscovits senior.
} 
activité, quand bien même le propos auquel ceux-ci sont associés est acide.

Le cas Boscovits, c'est aussi aborder la problématique des ententes et des rivalités entre les acteurs d'un périodique, comme entre les artistes d'une même famille. Ceci, d'autant que Boscovits junior va prendre de l'épaisseur, en tant qu'artiste et sur le plan institutionnel. Formé à l'École des arts appliqués de Zurich (Kunstgewerbe Zürich) d'avril I 887 à mars I $889^{46}$, il fréquente entre octobre I 890 et I $896^{47}$ les classes de Lüdwig von Löfftz, Franz von Defregger et Paul Höcker ${ }^{48}$ à l'Académie royale bavaroise des beaux-arts de Munich (Königliche Akademie der bildenden Künste in München). C'est probablement dans l'entourage de Paul Höcker, le plus moderniste des professeurs de l'académie munichoise, attirant les étudiants les plus audacieux ${ }^{49}$, que Boscovits junior s'est essayé au Jugendstil, avec lequel il s'impose dans le Nebelspalter au cours des années I 89050. De Munich, l'artiste envoie, de temps à autre, des dessins pour la revue, où son père l'a introduit en I 889 , touchant pour son premier dessin un cachet de 200 francs $^{51}$. Lors de son séjour d'étude à Florence et Fiesole en I 896, Boscovits junior fait la connaissance de Carlo Böcklin et du père de celui-ci, Arnold Böcklin ${ }^{52}$, pour ainsi dire le pape de l'art pour les artistes germaniques de cette génération. Une photo des archives familiales les montre ensemble ${ }^{53}$. À côté de son activité dans le Nebelspalter, Boscovits junior exécute des commandes de peintures murales et exerce en tant que graphiste, réalisant des affiches, des cartons d'invitations, des ex-libris, des menus, des cartes postales et des lithographies. Il fournit également son tribut à la propagande de guerre sous la forme de cartes postales et de dessin pour un emprunt de guerre ${ }^{54}$.

Boscovits junior intègre tôt les cercles officiels, contrairement à ce que pourraient laisser penser certaines de ses compositions souvent acerbes et dont on peut estimer qu'elles relèvent surtout d'une posture de satiriste ${ }^{55}$. Il est ainsi membre de la Zürcher Künstlervereinigung dès sa fondation en $1897^{56}$, en intègre la direction à partir de $1902^{57}$, pour la présider de 1905 à $1908^{58}$. Très lié à l'artiste Sigismund Righini ( I 870-I937), connu pour son influence dans les milieux artistiques, il siège, en outre, dans différentes commissions ${ }^{59}$, celles-là même dont la partialité avait été auparavant dénoncée dans le Nebelspalter ${ }^{60}$. En I 898 ,

${ }_{46}$ Certificat en date du 30 novembre 1898; Archives de la famille Boscovits.

Thomas Kain et Regula Schmid (éd.), Fritz Boscovits (1871-1965) - Olgemälde, Uetikon am See, FAP, 2015, p. 223

${ }_{48}$ Thomas Kain et Regula Schmid (éd.), Fritz Boscovits (1871-1965) - Olgemälde, Uetikon am See, op. cit., p. 222-223. II reçoit, en outre, pour la classe de Paul Höcker un certificat daté du 24 février 1893; Archives de la famille Boscovits.

49 Certificat de l'Académie royale bavaroise des Beaux-Arts en date du 24 février 1893; Archives de la famille Boscovits. Paul Höcker était réputé comme le plus moderniste des professeurs de l'académie; cf. également Laurence Danguy, "L'interdit biographique des artistes allemands de la « mauvaise génération » Le cas de die Scholle d'après les dictionnaires encyclopédiques allemands ", dans La biographie d'artistes, éd. Dominique Poulot, Paris, éditions du CTHS, 2012, p. 37-49.

Cf. « 2.3.5. Langage visuel - Jugendstil, Belle Époque et caricature ».

Thomas Kain et Regula Schmid (éd.), Fritz Boscovits (1871-1965) - Olgemälde, Uetikon am See, op. cit., p. 223.

Ibid., p. 224.

Cliché non daté; Archives de la famille Boscovits.

Cette diversité des médiums est documentée dans les archives familiales; Archives de la famille Boscovits.

Cf. « 4. DISCOURS SUR L'ART ».

Thomas Kain et Regula Schmid (éd.), Fritz Boscovits (1871-1965) - Olgemälde, Uetikon am See, op. cit., p. 225.

Ibid., p. 228.

Ibid., p. 229.

Ceci est attesté par plusieurs sources, telle une invitation à siéger au Kunstlerhaus pour la commission de l'exposition le 9 novembre 1909, de la part de la Zürcher Kunstgesellschaft; Archives de la famille Boscovits.

Cf. « 4.1. La question de l'art Suisse ». il intègre la Zürcher Kunstgesellschaft ${ }^{61}$; en I904, la GSMBA (Gesellschaft Schweizerischer Maler, Bildhauer und Architekten / Société des artistes, sculpteurs et architectes suisses) ${ }^{62}$. Boscovits junior participe à plusieurs reprises aux expositions de la Zürcher Kunstgesellschaft, de la Künstlervereinigung de Zurich et de la GSMBA. Entre I 897 et I9I4, il signe cinq fois le programme festif des Sechselaüten, des commandes qu'il a très probablement obtenues par l'entremise de son père ${ }^{63}$. Il ne connaît cependant de son vivant qu'une unique rétrospective, organisée par la galerie Neupert à Zurich en I9I $6^{64}$.

Son activisme porte ses fruits. Dès I905, les notices biobibliographiques deviennent honorables, aboutissant, par un effet de repoussoir, à l'absence, historiquement inadéquate, du père dans le Dictionnaire historique de la Suisse ${ }^{65}$ ainsi qu'à la très laconique notice du Dictionnaire sur l'art en Suisse, édité et mise en ligne par l'Institut suisse pour l'étude de l'art en I998: « artiste, illustrateur et dessinateur du Nebelspalter, père de Fritz Boscovits " ${ }^{66}$. Car Boscovits junior ne fait pas exception à la « règle sociologique " des dessinateurs de son époque, c'est au grand art qu'il rêve de lier son nom ${ }^{67}$. Son œuvre peint, composé de portraits, de natures mortes, de scènes de genre et de paysages, notamment du lac de Zurich, bénéficie à présent d'une fortune critique modeste, surtout redevable à son activité graphique. L'auteur de la notice bibliographique la plus récente, publiée dans le Dictionnaire sur l'art en Suisse, conclut son appréciation dans ses termes: «Le talent artistique s'exprime surtout dans les domaines de la gravure et de la caricature ${ }^{68}$. Une monographie, très récemment éditée par la petite-fille de l'artiste, tente de réhabiliter l'œuvre, essentiellement peint ${ }^{69}$.

Que Boscovits senior ait été la figure centrale du Nebelspalter pendant la période zurichoise ne fait rien à l'affaire. Boscovits junior est à présent dans la mémoire collective « le Boscovits " du Nebelspalter. À la mort du père, il ôte le « $\mathrm{j}$ » (pour junior) de sa signature $(\mathrm{FBj})$, signe ensuite « $\mathrm{B}$ » et enfin " Bosco ». Alors, commence une nouvelle ère Boscovits qui n'est bientôt plus zurichoise mais se joue, à partir de I922, à Rorschach, et que l'on pourrait intituler «Ou comment Boscovits est devenu Bosco » ${ }^{70}$. Quoi qu'il en soit, « $\mathrm{FBj}$ » aura été le dessinateur caméléon par excellence du périodique. Ses dessins les plus réussis relèvent de l'esthétique Jugendstil, encore qu'il excelle dans le genre un peu canaille qu'il développe dans les années I905-I9I0.

Thomas Kain et Regula Schmid (éd.), Fritz Boscovits (1871-1965) - Olgemälde, Uetikon am See, op. cit., p. 226.

Ibid., p. 228.

Ibid., p. 224-233.

Ibid., p. 234.

Le fils y est, lui, représenté; Tapan Bhattacharya, « Boscovits, Fritz », Dictionnaire historique de la Suisse; http://www.hls-dhs-dss.ch/index.php.

(Maler, Ilustrator und Zeichner für den Nebelspalter. Vater von Fritz Boscovits); Anonyme, « Boscovits, Friedrich Johann », Sikart (14/09/2011); http://www.sikart. ch/KuenstlerInnen. aspx?id=4024088.

Laurence Danguy, « Le dessinateur jugendstil », dans Face à Face - Les acteurs des périodiques illustrés (1890-1940), éd. Philippe Kaenel, Gollion, infolio, 2010, p. 87-114.

${ }_{68}$ (Das künstlerische Talent kommt vor allem in der Druckgraphiken und Karikaturen zum Ausdruck); Doris Zollikofer, « Boscovits, Fritz », Sikart, 1998 (14/09/2011); Sikart, 1998; http://www.sikart.ch/KuenstlerInnen.aspx?id=4024088.

69 Thomas Kain et Regula Schmid (éd.), Fritz Boscovits (1871-1965) - Olgemälde, Uetikon am See, FAP, 2015.

Fritz Boscovits est actuellement presque uniquement connu sous ce diminutif. 


\subsection{La configuration artistique et sociétale des dessinateurs}

Hormis la revue munichoise Simplicissimus et son dessinateur vedette Theodor Th. Heine, aucun périodique pérenne de l'aire franco-germanique ne présente une configuration semblablement resserrée et dominée par un dessinateur, comme c'est le cas avec Boscovits père (senior), puis par une "dynastie ", lorsqu'est associé le fils (junior). De même alors que Jugend aura compté près de 300 dessinateurs par semestre ${ }^{71}$, l'équipe artistique du Nebelspalter n'aura jamais excédé une trentaine de dessinateurs ${ }^{72}$. Les pics numériques correspondent à des repositionnements de la revue, au moment de l'arrivée de la couleur, en I 887 et les années qui suivent; assez progressivement dans les années I 890 , alors que la revue entend participer à la compétition européenne; après le départ de collaborateurs piliers, tel Lehmann-Schramm en I908, où l'on observe une internationalisation des arrivées; pendant et après la guerre, où l'instabilité et les défaillances sont importantes.

Les dessinateurs se répartissent en quatre cercles ${ }^{73}$ : les Boscovits, père et fils, qui façonnent le graphisme de la période zurichoise occupent le premier; le deuxième comprend les dessinateurs piliers, fournissant régulièrement des contributions pendant une période assez longue et qui ont une influence décisive sur l'évolution de la maquette; le troisième cercle est composé par des dessinateurs importants, sans être omniprésents; les dessinateurs occasionnels, nombreux à partir des années I 890 et plus encore après 1907 , forment un quatrième et dernier cercle. Ces derniers, ne signant souvent leurs dessins que d'un monogramme, voire pas du tout, sont difficilement identifiables. Les auteurs des trois premiers cercles influent sur le graphisme, puisqu'il existe dans le Nebelspalter une perméabilité tout à fait insolite entre les dessinateurs. Celle-ci est fortement alimentée par les Boscovits, absorbant les apports de leurs collègues, plus encore que les modèles exogènes. Ceci quand bien même les archives Boscovits documentent une collection de revues tout à fait respectable, comprenant de nombreux volumes des Fliegende Blätter, six volumes du Simplicissimus ( I 906 à I 9 I 2), onze volumes de Jugend (à partir de I 896), plusieurs numéros de Ulk (dont l'un daté du I ${ }^{\text {er }}$ juillet I 875) et des Meggendorfer Blätter, ainsi que des revues non satiriques et divers ouvrages sur la caricature ${ }^{74}$.

Cette configuration sociétale du Nebelspalter ne permet guère de fidéliser les dessinateurs, hormis les Boscovits, d'autant que les conditions offertes sont mauvaises. On sait par la succession Nötzli, qu'Henri van Muyden ne réussit jamais à se faire payer un dessin plus de 20 francs en I 89 I et I $892^{75}$, ce qui selon ses dires est inférieur à ce que paie la concurrence, et qu'il ne parvient pas davantage à obtenir, malgré son insistance, de contrat prévoyant au minimum un préavis de six mois avant le terme éventuel de sa

Laurence Danguy, L'ange de la jeunesse - La revue Jugend et le Jugendstil à Munich, Paris, Maison des sciences de l'homme, Philia, 2009, p. 57.

Cf. « 2.5.5. Victoire du Heimatstil et confinement de l'image à l'illustration satirique $»$.

Ces catégories sont reprises par un système d'astérisques dans la liste des dessinateurs; cf. «1.7. Liste et période d'activité des dessinateurs ». Cf. la liste fournie par Regula Schmid sur la base des archives familiales.

II s'agit d'abord de 17 dessins devant être réglés pour un montant de $340 \mathrm{Frs}$, puis de 12 dessins pour un montant de $240 \mathrm{Frs}$; cote 1.14 de la succession Nötzli, lettres de Henri van Muyden datées du 21 novembre 1891 et du 2 octobre 1892. collaboration ${ }^{76}$. Boscovits junior touche, pour sa part, 30 francs par dessin en $1907^{77}$. Cette situation a une autre conséquence, une espèce de "conflit de presse ", puisqu'une partie non négligeable des collaborateurs, Willy Lehmann-Schramm, Adolf Sulzberger, Hermann Hintermeister, Paul Thesing, Walter Lilie et Arthur Treichler, collaborent à une autre revue satirique zurichoise, Der Neue Postillon, d'une tendance fort différente. Paraissant entre I 895 et I9I $4^{78}$, Der Neue Postillon est en effet rattaché au mouvement socialiste. Cette confluence de courants de pensée opposés éclaire en partie l'impression d'une tendance fluctuante du Nebelspalter durant cette décennie. Elle génère, de plus, une sorte de polyphonie entre les dessinateurs libéraux de la première génération et d'autres radicalement progressistes, tendant à faire apparaître les premiers comme conservateurs. Il est certes courant que des dessinateurs collaborent à plusieurs organes, et cela est même nécessaire à leur survie économique et leur visibilité, tous le font, y compris Boscovits junior ${ }^{79}$ et Heinrich Jenny ${ }^{80}$, mais ce type de situation d'une double activité permanente avec des orientations très divergentes n'est pas si fréquent. Les frères van Muyden collaborent, pour leur part à la revue genevoise Le Papillon (I 889I9I 8) ainsi qu'à la très éphémère revue Sapajou, fondée autour de l'exposition nationale de $1896^{81}$. Paul Thesing fournit, entre autres, deux numéros de l'Assiette au beurre ${ }^{82}$.

Il faut, en outre, prendre garde au fait que les dessinateurs piliers ne sont pas nécessairement ceux bénéficiant de la fortune bibliographique la plus importante, ce qu'illustre plus que tout autre Willy Lehmann-Schramm, certes présent dans divers dictionnaires et bases de données mais dont il est impossible de retrouver la date du décès. Pour une raison inconnue, LehmannSchramm disparaît de la scène artistique. À l'inverse, certains dessinateurs ayant brièvement œuvré bénéficient d'une notoriété, un temps importante, tel le peintre militaire Wilhelm Stückelberger (I867-I926) grâce à la large diffusion de ses lithographies ${ }^{83} \mathrm{ou}$, dans une moindre mesure, l'Allemand, Walter Lilie ${ }^{84}$.

Six dessinateurs de la période zurichoise peuvent être identifiés comme des dessinateurs piliers. Ce sont par ordre d'arrivée dans la revue: Evert van Muyden, Heinrich Jenny, Henri van Muyden, Emil Dill, Willy Lehmann-Schramm, Paul Thesing et Arthur

Cote 1.14 de la succession Nötzli, lettres en date du 25 décembre 1888, du 16 avril 1890 , du 16 novembre 1890 ainsi que lettre non datée clôturant l'échange. Thomas Kain et Regula Schmid (éd.), Fritz Boscovits (1871-1965) - Olgemälde, Uetikon am See, op. cit., p. 230.

Thomas Gürber, « Neue Postillon, Der », Dictionnaire historique de la Suisse (og/11/2010), Bern (http://www.hls-dhs-dss.ch/textes/d/D10983.php).

Les archives familiales contiennent un dossier des dessins parus dans d'autres revues. Le dessinateur s'est représenté sur la couverture, au-dessus de la mention "Illustrations de Bosco en provenance de diverses revues " (Illustrationen aus div. Zeitschriften von Bosco); Archives de la famille Boscovits. Entre 1928 et 1947 - donc après la période zurichoise -, Fritz Boscovits collabore à la Schweizer Illustrierte Zeitung, à la Schweizerische Radio-Zeitung, la Schweizer FamilienZeitung, la Zürcher illustrierte et la Schweizer Wochen Zeitung, le tout représentant 2700 dessins; Thomas Kain et Regula Schmid (éd.), Fritz Boscovits (1871-1965) - Olgemälde, Uetikon am See, op. cit., p. 238.

Celui-ci collabore également au Charivari (français), à la revue Die Gartenlaube (allemande) et au Postheriori (suisse); Andreas Beyer, Bénédicte Savoy et Wolf Tegehoff (éd.), Allgemeines Künstler-Lexikon, volume 77, Berlin, De Gruyter, 2012, p. 513-514

Philippe Kaenel, « Du Chat noir au Sapajou. Les échanges artistiques et satiriques entre Paris et la Suisse autour de 1900 », dans L'Europe des revues (1880-1920), éd. Evanghelia Stead et Hélène Védrine, Paris, Presses universitaires de ParisSorbonne, 2009, p. 225-247; Carl Brun (éd.), Schweizerisches Künstler Lexikon, Frauenfeld, Huber \& co, t. 2, 1908, p. 464 (seul Henri y est mentionné comme dessinateur).

Le numéro 441 du 11 septembre 1909 et le numéro 561 du 13 janvier 1912

SIK-ISEA, Biographisches Lexikon der Schweizer Kunst, t. 2, Zurich, NZZ, 1998 p. 1019

Cf. notamment Carl Brun (éd.), Schweizerisches Künstler Lexikon, Frauenfeld, Huber \& co, t. 4, 1917, p. 288. 
Treichler. Leur biographie est souvent mal connue ${ }^{85}$. Aucun ne s'est vraiment fait une place dans l'histoire de l'art, ce qui renseigne davantage sur la situation de la caricature que sur la qualité de leurs contributions. Les plus connus de ces dessinateurs sont à présent Henri Van Muyden, Emil Dill et Paul Thesing. Des frères van Muyden, on retiendra surtout l'imbroglio autour de leur identité ${ }^{86}$. Il faut enfin remarquer que, parmi ces dessinateurs piliers, deux sont Allemands, Willy Lehmann-Schramm et Paul Thessing, deux autres Suisses romands, les frères Muyden, ce qui illustre l'ouverture et l'amplitude culturelle du Nebelspalter zurichois. D'autres dessinateurs, moins actifs, marquent la revue. Par ordre d'arrivée, ce sont: Emil Graf, Otto Maehly, Josef Kälin Küpfer, A. Staehle, Emil Huber, Wilfried Schweizer, Hermann Hintermeister, T.S. Salis, Walter Lilie, Karl Czerpien, H. Henrik, S. Mohr, Alfred Hirschler et M. Raquette. L'usage de l'initiale pour un prénom qu'il a été impossible de retrouver révèle le peu - voire l'absence - d'informations sur ces artistes ${ }^{87}$.

\subsection{Ambitions voilées et assumées : de la délimitation avec les champs de l'art et de la presse}

Lors de la naissance du Nebelspalter, la presse satirique illustrée est déjà bien installée mais les assises restent à consolider. Pour border son espace symbolique, le Nebelspalter se trouve face à trois tâches: assurer une cohésion en créant un esprit de groupe, se singulariser dans l'univers de la presse hautement concurrentiel et se positionner vis-à-vis du monde artistique; le tout dans un contexte suisse ne pouvant faire l'économie de la dimension européenne. Pour ce faire, au-delà des discours, prises de positions et créations iconographiques, des modèles vont être mobilisés, passant par l'image, parfois très subtilement ${ }^{88}$.

Durant les deux premières décennies, une série de dessins présentent une rédaction fonctionnant tel un atelier organisé autour de deux maîtres, Jean Nötzli et Boscovits senior, et d'une série d'apprentis, tous unis dans leur travail. Ces images reprennent le modèle de l'artisan d'art, un système ancien d'organisation sociale au statut valorisé. La plus ancienne de ces compositions est un dessin de 1876 (donc de Boscovits senior) montrant dans

\footnotetext{
Pour les frères van Muyden, on se reportera au chapitre « 6.4 Passions d'artistes: Richard Kissling, Evert van Muyden, Henri van Muyden et Jean Nötzli »; pour Heinrich Jenny, de préférence à: Andreas Beyer, Bénédicte Savoy et Wolf Tegehoff (éd.), Allgemeines Künstler-Lexikon, volume 77, Berlin, De Gruyter, 2012, p. 513-514; pour Emil Dill, de préférence à: Sephan E. Hauser, « Dill » Emil, Sikart, 1988; http://www.sikart.ch/KuenstlerInnen.aspx?id=4023022; toujours sur Emil Dill et en complément; Tapan Bhattacharya, Dictionnaire historique de la Suisse (23/04/2004); http://www.hls-dhs-dss.ch/textes/d/D22270.php.; sur Willy Lehmann-Schramm, de préférence à: Carl Brun (éd.), Schweizerisches Künstler Lexikon, Frauenfeld, Huber \& co, t. 2, 1908, p. 242 ; sur Paul Thesing, cf. de préférence un site web présentant une biographie et recensant la littérature; http://paul-thesing.de/werk/index.php; sur Arthur Treichler: cf. de préférence Hans Vollmer (éd.), Allgemeines Lexikon der bildenden Künstler von der Antike bis zur Gegenwart, vol. 33, 1939, p. 370.

Cf. « 6.4. Passions d'artistes: Richard Kissling, Evert van Muyden, Henri van Muyden et Jean Nötzli ».

Sur ces dessinateurs, cf. «1.7. Liste et période d'activité des dessinateurs ».

${ }_{88}$ Sur cette question, voir plus largement; Guillaume Pinson, «Travail et sociabilité », dans La Civilisation du journal. Histoire culturelle et littéraire de la presse française au XIX siècle, éd. Dominique Kalifa, Philippe Régnier, Marie-Ėve Thérenty et Alain Vaillant, Paris, Nouveau Monde, 2011, p. 653-666; Christian Delporte, "Le dessinateur de presse, de l'artiste au journaliste », Vingtième Siècle, revue d'histoire, 35, 1992, p. 29-41.
}

sa partie supérieure - une banderole reproduisant le titre de la couverture -, Nözli, Boscovits et un rédacteur aux yeux bandés, en compagnie d'ouvriers travaillant à la presse ${ }^{89}$. Dans la partie inférieure, des feuilles volantes sont jetées telles des cartes à jouer: ce sont des caricatures chargeant les cibles de la revue. Le groupe s'identifie néanmoins à un autre corps de métier. Une composition de I 894 commémorant les 20 ans du Nebelspalter montre l'équipe en pompiers (cf. fig. 3 cahier couleur). Boscovits senior, auteur du dessin, s’y portraiture à côté de Nötzli, entouré des concepteurs et des personnages du Nebelspalter. Rédacteurs et dessinateurs, coiffés d'un casque à leur nom, remplissent de papiers la machine à éteindre l'incendie. C'est Boscovits qui tient la lance à eau. Il est au tir de l'humour (Humor), du bon mot (Witz) et de la satire (Satyre), d'une machine estampillée "Nebelspalter I 874 ", soit l'année précédant la naissance du périodique. Ses munitions détruisent l'orgueil (Ehrgeiz), le mensonge (Lüge), la sottise (Dummbeit), l'indolence (Indolenz) et la corruption (Corruption). Dans un second cercle, sont déclinés les personnages du bandeau de la couverture ainsi que ceux accompagnant sous forme d'icones les chroniques du Nebelspalter. Ceux-ci, qui ne fabriquent pas le Nebelspalter mais en sont des créations, ne sont pas costumés en pompiers. Boscovits interpelle Nötzli :

(Boscovits) : Ne voudrions-nous pas arrêter? (Nötzli) : Quoi? Aussi longtemps que les feux brûlent et que notre équipe est gaillarde, nous restons au jet! (Tous) : Nous restons au jet! $9^{90}$

Parallèlement, d'autres modèles sont utilisées pour se positionner vis-à-vis du monde artistique, et notamment les très nombreuses figures de l'artiste, apparaissant à l'aube des années Jugendstil pour ne plus quitter la revue. La série s'ouvre en I 890 avec un peintre de passage en Suisse, effrayé par les réclames en tout genre qui l'entourent ${ }^{91}$. Mais c'est le plus souvent en pauvre hère accablé par la pauvreté et l'incompréhension de ses contemporains, et même parfois soumis à leur cupidité, qu'est représenté l'artiste. L'iconographie de cet artiste bohème ne connaît guère de variations et, à vrai dire, le chapeau est l'élément qui change le plus. La légende est fréquemment piquante. L. Marrug voit l'un de ces amateurs en contemplation devant une peinture s'exprimer ainsi:

Certes, l'image est excellemment composée, les couleurs remarquablement harmonieuses, elle est décorative et saisissante, la technique ne laisse pas non plus à désirer. Mais - je me pose la question - le peintre est-il une personnalité ?92

Certaines légendes sont plus grinçantes encore:

Peintre: Quoi, vous me proposez à peine le quart du prix pour cette image? Non, je ne peux pas m’en défaire dans ces conditions, Dieu soit loué, je ne suis pas en train de mourir de faim! Amateur d'art: bah, je peux encore attendre jusque-là... ${ }^{93}$

Nebelspalter 1876/1, dessin pleine page non signé intitulé « 1876, Santé! » (1876 Prosit).

(Boscovits: "Wollen wir nicht aufhören?" / Nötzli: "Was, so lange diese Feuer brennen und unsere ganze Mannschaft so munter ist! Wir bleiben bei der Spritze! » / Alle: " Wir bleiben bei der Spritze!) » : Nebelspalter 1894/9, doublepage en couleur de Boscovits senior intitulée « À l'occasion du numéro 1000 du Nebelspalter » (Nebelspalter bei Nro. 1000).

Nebelspalter 1890/27, dessin pleine page en noir et blanc de Emil Dill intitulé « Hé, les autorités, venez-moi enfin en aide » (He, ihr Behörden, endlich zu Hilfe!). (Gewiss, das Bild ist vorzüglich komponiert, die Farben sind wunderbar harmonisch, es ist dekorativ und ergreifend, auch die Technik lässt nichts zu wünschen übrig. Aber - so frage ich mich - ist der Künstler eine Persönlichkeit ?); Nebelspalter 1913/28, dessin en couleur de L. Marrug, intitulé « Le mot clé » (Das Schlagwort).

(Maler: Was, Sie bieten mir für dieses Bild kaum den vierten Teil des Preises? Nein, dafür kann ich es nicht geben, ich bin gottlob noch nicht am Verhungern! Kunstfreund: Na, dann kann ich ja bis dahin noch warten ...); Nebelspalter 1912/11, dessin en couleur non signé intitulé « L'amateur d'art » (Der Kunstfreund). 
De rares compositions, toutes du principal représentant de l'époque Jugendstil, Willy Lehmann-Schramm, tempèrent cette image en présentant un artiste hédoniste entouré de femmes ${ }^{94}$. Mais, si les artistes du Künstlerhaus profitent de la compagnie des élégantes, ils doivent aussi subir celle beaucoup moins attrayante des critiques, visiteurs provinciaux et autres marchands cupides, et l'artiste reste finalement maudit ${ }^{95}$. La figure du critique d'art, assez rare ${ }^{96}$ ainsi que celle du mécène ${ }^{97}$, tout aussi rare, servent à conforter l'idée d'un artiste incompris et soumis aux caprices du marché, ne parvenant pas à trouver son autonomie financière ou ne le voulant pas. La légende des "Méchants critiques" (Die Bösen Kritiker) de Willy Lehmann-Schramm est de cette veine:

Mécène artistique: Quoi, vous ne parvenez pas à vendre votre dernière image? Elle était pourtant magnifique! Artiste: Certes, mais depuis que la critique s'en est mêlée, elle est devenue invendable ${ }^{98}$.

C'est sans doute également dans le sens d'une délimitation artistique que doivent se comprendre tant l'omniprésence de Arnold Böcklin que celle de Ferdinand Hodler. Le premier, est une référence majeure, quasi-tutélaire des peintres germaniques de la génération des années I 890 ; le second représente une cible ambiguë du journal, notamment critiquée pour son emprise institutionnelle ${ }^{99}$. Il est fort possible que les critiques incessantes $\mathrm{du}$ fonctionnement des subventions publiques, du Kunstlerhaus, puis du Kunsthaus, où peu d'artistes du Nebelspalter parviennent à trouver leur place - Boscovits junior et Willy Lehmann-Schramm ${ }^{100}$ - soient, au moins en partie, à comprendre dans ce sens.

Deux autres modèles accompagnent cette quête de légitimité : le rédacteur et le dessinateur. Leur fonction est d'installer la revue dans l'univers de la presse illustrée. Trois combinaisons iconographiques coexistent : celle unissant dessinateur et rédacteur, celle centrée sur le rédacteur et celle consacrée au dessinateur. On ne relève que trois occurrences combinant rédacteur et dessinateur, toutes de l'époque Nötzli, avant I900, et organisées autour du couple Boscovits/Nötzli ${ }^{101}$. Ces images portent le message crypté d'une direction éditoriale partagée entre Nötzli et Boscovits, ne pouvant

Nebelspalter 1896/23, dessin pleine page en noir et blanc de Willy LehmannSchramm intitulé "Pictural » (Malerisches); Nebelspalter 1897/14, dessin pleine page en noir et blanc de Willy Lehmann-Schramm intitulé « Images du Künstlerhaus » (Bildervon Künstlerhaus); Nebelspalter 1898/5, dessin pleine page en noir et blanc de Willy Lehmann-Schramm intitulé "Les méchants critiques " (Die bösen Kritiker).

s Nebelspalter 1897/14, dessin pleine page en noir et blanc de Willy LehmannSchramm, intitulé « Images du Künstlerhaus » (Bilder von Künstlerhaus).

${ }^{6}$ On en retrouve quatre occurrences, dont deux ne concernant pas les arts plastiques mais la musique (Nebelspalter 1916/2, dessin de T.S. Salis intitulé "Critique d'art » [Kunstkritik]) et l'art dramatique (Nebelspalter 1894/4, dessin de Willy Lehmann-Schramm intitulé « La grosse grenouille coasse » [Der grosse Frosch quakt!])

On n'en trouve que deux occurrences, une première fois en 1898 (Nebelspalter $1898 / 5$, dessin pleine page de Willy Lehmann-Schramm intitulé « Les méchants critiques » [Die bösen Kritiker]) et en 1915 (Nebelspalter 1915/43, dessin pleine page de Karl Czerpien intitulé « Misère d'artistes » [Künstler-Elend]).

${ }_{98}$ (Kunstmäcen: "Was, Sie können Ihr letztes Bild nicht verkaufen? Aber es war doch ganz wundervoll. " Künstler: "freilich, aber seitdem die Kritik darüber gegangen, ist es unverkäuflich! »); Nebelspalter 1898/5 dessin pleine page de Willy Lehmann-Schramm intitulé «Les méchants critiques » (Die bösen Kritiker).

99 Cf. « 4.4. Le couple Arnold Böcklin et Ferdinand Hodler » et « 5.3 Le statut très particulier de Arnold Böcklin et Ferdinand Hodler. »

100 Ainsi que l'enseigne une étude des encarts du Kunstlerhaus, des registres d'expositions et des notices biobibliographiques.

o1 Nebelspalter 1876/1, dessin pleine page non signé intitulé «À l'année 1876! » (1876 Prosit); Nebelspalter 1884/1, dessin pleine page de Boscovits senior intitulé «À la nouvelle année. Le Nebelspalter et sa famille » (Prosit Neujahr Nebelspalter \& Familie).; Nebelspalter 1894/4, double-page en couleur de Boscovits (senior intitulée «À l'occasion du numéro 1000 du Nebelspalter » (Nebelspalter bei Nro. 1000). s'afficher au grand jour ${ }^{102}$. Elles n'ont pas vraiment vocation à situer le Nebelspalter dans le champ des revues illustrées. Les modèles isolés du rédacteur et du dessinateur sont beaucoup plus nombreux. La très nette supériorité des représentations du rédacteur sur celles du dessinateur, dix contre trois, indique une délimitation qui s'exerce en premier lieu vis-à-vis de la presse écrite. Si le rédacteur apparaît dès I 877 , il faut attendre I 893, le moment où l'image prend en importance, pour voir véritablement émerger la figure du dessinateur ${ }^{103}$, néanmoins déjà présente dans un dessin de I $880^{104}$.

Invariablement montré comme peinant à la tâche, le rédacteur s'aligne sur un idéaltype: seul devant son labeur, il doit traiter d'une pluralité de thèmes et affronter l'adversité, souvent aidé d'une bouteille de vin. Le schéma le plus fréquent est celui du rédacteur désespéré, titre du reste de deux compositions (Redaktor in Verzweiflung) ${ }^{105}$. À l'origine de ce désespoir, la peur de ne pouvoir faire face à la tâche :

Mon Dieu, envoie un fléau, ce que tu veux, envoie poisse et souffre sauve-moi seulement de cette submersion ${ }^{106}$.

Le rédacteur de Boscovits senior implore les cieux devant une montagne de papiers, les bras levés, la plume dans une main. Ce rédacteur est, en outre, très régulièrement montré comme un esprit libre et anticonformiste. Une composition antithétique de Willy Lehmann-Schramm de I90 I s'intitule « La rédaction d'un journal humoristique ». Elle présente dans sa partie supérieure légendée "Telle que certain voudrait volontiers la voir » (Wie sie Mancher gerne sehen möchte), un rédacteur obéissant aux desiderata d'un ecclésiastique; dans la partie inférieure légendée « Telle qu'elle doit être » (Wie sie sein soll), un rédacteur maniant avec entrain une plume, d'où s'échappent satire, esprit et bon mot (Satyre, Geist, Witz) ${ }^{107}$.

En plus de n'apparaître que tardivement, le dessinateur se montre avec parcimonie et exclusivement dans le champ de la satire, renseignant assez finement sur l'espace destiné aux dessinateurs du Nebelspalter dans le champ artistique. En I 893, Boscovits senior est dessiné un carton à dessin sous le bras, prêt à « sévir "; en I 894, un " barbouilleur caricaturiste " (karikaturistischer Kleck) œuvre, comme le rédacteur, entre labeur et ivresse; en I908, un dessinateur maladroit tente enfin de s'affranchir de sa condition ${ }^{108}$.

\footnotetext{
102 Cf. « 1.2. Décryptage de la fondation et de la vie éditoriale: focus sur Boscovits senior ».

${ }_{103}$ Nebelspalter 1877/19, dessin pleine page en noir et blanc de Boscovits senior intitulé « Le rédacteur en proie à mille détresses " (Der Redaktor im Tausend Nöthen); Nebelspalter 1893/51, double-page en couleur, non signée, intitulée «Instantané de la politique suisse » (Die Schweizerische Politik zur Stunde).

${ }^{\circ 4}$ Nebelspalter 1880/14, dessin pleine page en noir et blanc non signé intitulé « En provenance de la galerie des peintures » (Aus der Gemäldegallerie); dans cette image primitive, deux spectateurs s'émerveillent devant un dessin encadré à la manière d'une toile, en provenance, selon le titre, de la galerie des peintures. On y voit le président de la République française, Jules Grévy, chassant les Jésuites de l'école.

105 Nebelspalter 1881/42, couverture anonyme intitulée « Le rédacteur au désespoir) (Der Redaktor in Verzweiflung); Nebelspalter 1892/30, dessin pleine page en noir et blanc de Boscovits senior intitulé « Le rédacteur au désespoir) (Der Redaktor in Verzweiflung).

(Himmel, schick'eine Plage, wie du willst, schick'Pech und Schwebel - nur errette mich endlich aus dieser Überschwemmung!); Nebelspalter 1892/30 dessin pleine page en noir et blanc de Boscovits senior intitulé « Le rédacteur au désespoir » (Der Redaktor in Verzweiflung).

Nebelspalter 1901/41, dessin pleine page de Willy Lehmann-Schramm intitulé « La rédaction d'un journal humoristique » (Die Redaktion-Stube eines Witzblattes).

${ }_{108}$ Nebelspalter 1893/51, double-page en couleur non signée, intitulée «Instantané de la politique suisse » (Die Schweizerische Politik zur Stunde); Nebelspalter 1894/3, dessin en noir et blanc de Hans Wirz intitulé « Trois moments de la vie du barbouilleur caricaturiste » (Drei Momente aus dem Leben des Karikaturristen Klecks); Nebelspalter 1908/30, dessin en couleur de Boscovits junior intitulé « Mal dessiné » (Verzeichnet).
} 


\section{"Verzeichnet."}

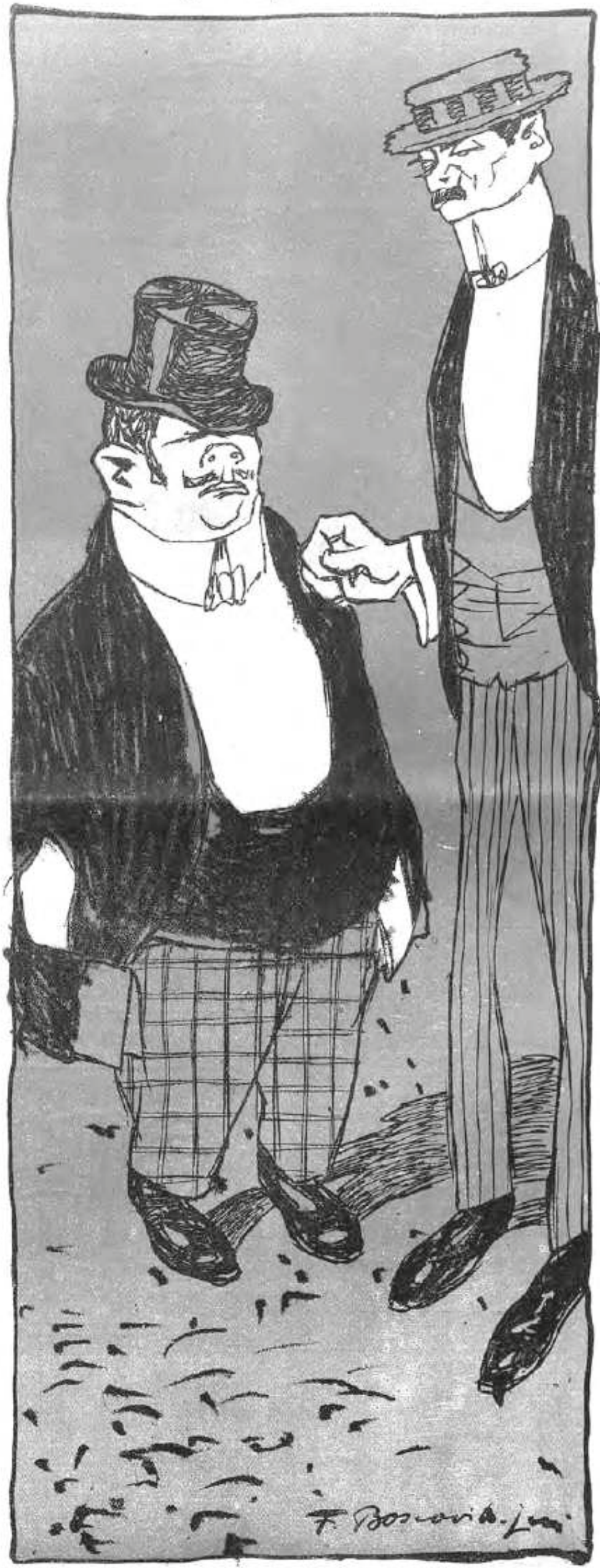

"Donnerwetter haben Sie aber kurze Beine." -

- Da kann ich nichts dafür, der Zeichner hat lie eben zu kurz gezeichnet.

Fig. 4. Nebelspalter 1908/30, dessin en couleur de Boscovits junior intitulé «Mal dessiné » (Verzeichnet).
Alors que, fait extrêmement rare, Hans Wirz utilise, en I 894, le terme de " caricaturiste ", le dessin de Boscovits junior de I 908 met en abyme la figure du dessinateur. "Mal dessiné » (Verzeichnet) montre deux personnages côte-à-côte en conversation, l'un replet et courtaud, l'autre dégingandé (cf. fig. 4):

Pardieu, comme vous avez de courtes jambes!; - Je n'y peux rien, le dessinateur les a dessinées trop courtes ${ }^{109}$.

Ce type de représentation correspond à un topos de l'iconographie Jugendstil qui se développe dans la seconde moitié des années I 890. Le dessinateur s'y exerce à une (auto-)ironie, dont le rôle est de dénier les contraintes du médium. Si les limites physiques de la revue peuvent être outrepassées, alors celles esthétiques et sociétales peuvent l'être également. Autrement dit, le dessinateur est un artiste complet ${ }^{110}$.

D'autres éléments plus discrets modèlent l'identité artistique du Nebelspalter, telle la présence des artistes parmi les hommages " aux grands hommes ». Il faut attendre quatre années, et plus d'une trentaine de ces hommages, pour voir honorer un artiste en la personne de Georg Ludwig Vogel (I788-I879), présenté dans la légende comme "peintre d'histoire suisse" (schweiz. Hinstorienmalerei), décédé à Zurich, le 20 août I 879, selon l'encart nécrologique publié dans le même numéro ${ }^{111}$. À l'exception d'un hommage au peintre autrichien Hans Mackart (I 840-I 884) 112 $^{112}$ les artistes ne s'installent dans cette catégorie très codée qu'en I 890 . Entre I 890 et I 908, onze artistes sont célébrés. Le premier est Frank Buchser (I 828-I890), artiste suisse, politiquement très engagé et ami de Jean Nötzli avec lequel il échange une correspondance nourrie ${ }^{113}$; le dernier est le peintre et dessinateur allemand Wilhelm Busch (I832-I908). Si l'on excepte ce dernier, les hommages concernent des artistes suisses, fréquemment zurichois et/ou proches de la rédaction, comme Franck Buchser et Heinrich Jenny, collaborateur regretté dont on souligne qu'il est l'un des derniers élèves de Disteli ${ }^{114}$.

Trois de ces hommages s'écartent du schéma iconographique habituel et sont commémoratifs, et non nécrologiques, comme cela est de règle. Ils concernent Rudolf Koller ( I 828-1905), peintre zurichois, dominant la scène culturelle ${ }^{115}$ que l'on fête à l'occasion d'une rétrospective ${ }^{116}$; Martin Disteli ( I 802-I 844), le plus connu des caricaturistes suisses, engagé aux côtés des libéraux ${ }^{117}$ et qui réalise une synthèse entre les traditions germanique et française ${ }^{118}$ ainsi que Giovanni Segantini (I 858 -1 899) ${ }^{119}$, artiste apatride, rattaché au symbolisme international et célèbre pour ses paysages

(«Donnerwetter haben Sie aber kurze Beine. » - - Da kann ich nichts dafür, der Zeichner hat sie eben zu kurz gezeichnet.); Nebelspalter 1908/30, dessin de Boscovits junior intitulé « Mal dessiné » (Verzeichnet).

Laurence Danguy, «Le dessinateur jugendstil », op. cit., p. 87-114.

Nebelspalter 1879/35, encart nécrologique et dessin pleine page en noir et blanc de Boscovits senior intitulé « Georg Ludwig Vogel, peintre d'histoire suisse » (Georg Ludwig Vogel, schweiz. Historienmaler).

Nebelspalter 1884/41, dessin pleine page de Boscovits senior intitulé « Une surprise » (Eine Ueberraschung)

Cf. « 4.1. La question de l'art Suisse ».

Nebelspalter 1891/34, dessin de Boscovits senior intitulé « Vincenzo Vela » et texte de Jean Nötzli.

Sigmund Widmer, Zürich. Eine Kulturgeschichte, tome 10 Soziale Umgestaltung, Zurich, Artemis Verlag, 1983, p. 80.

"Koller, Rudolf », Dictionnaire sur l'art en Suisse; http://www.sikart.ch/ kuenstlerinnen.aspx?id=4000080; l'exposition est au reste annoncée dans un encart du Nebelspalter (1898/22).

" Disteli, Martin », Dictionnaire sur l'art en Suisse; http://www.sikart.ch/ Kuenstlerlnnen .aspx?id= 4022886 .

Philippe Kaenel, « 1830-1848: la réception de l'œuvre de Daumier et Grandville en Suisse », op. cit., p. 152-153.

Nebelspalter 1898/21, dessin pleine page de Willy Lehmann-Schramm, sans titre; Nebelspalter 1902/21, couverture de Boscovits senior intitulée « Martin Disteli »; 
des Alpes de l'Engadine ${ }^{120}$. Ces trois artistes délimitent un panthéon interne au Nebelspalter et déclinent sa carte d'identité: suisse, zurichois, libéral, artistique et à la pointe de la caricature. La fin de ces hommages aux artistes, en I908, correspond à un tournant identitaire. Aux côtés des hommes politiques et des militaires (la part fixe des hommages), les écrivains forment désormais la part culturelle. Ce changement coïncide avec l'arrivée à la rédaction en 1907 de Alfred Beetschen, porteur de nouvelles ambitions littéraires. Il signe la bataille perdue par les arts dans la concurrence avec les lettres.

Un dernier élément concourt à orienter la perception artistique de la revue, la signature. Si la manière de signer les dessins, ou d'ailleurs de ne pas les signer, varie au fil du temps, la pratique est néanmoins toujours systématisée ${ }^{121}$. La correspondance entre Jean Nötzli et Henri van Muyden, conservée dans la succession Nötzli, permet de jeter un éclairage précieux sur cette question rarement documentée ${ }^{122}$. Henri van Muyden revient plusieurs fois sur l'usage de la signature, d'abord au début de sa collaboration, à la fin $\mathrm{I} 889$, puis à la fin de l'année $\mathrm{I} 892^{123}$. Il débute ainsi sa première lettre:

Cher monsieur / Je vous envoie par le même courrier 2 dessins, qui vous plairont j'espère et que j'ai signés de mes initiales, je pense que nous n'y verrez pas d'inconvénient puisque d'ailleurs vous aviez l'intention de m'annoncer dans votre journal, où vous pouvez alors expliquer l'initiale HvM.

pour rajouter en post-scriptum du même courrier:

PS. Réflexion faite, j'ai signé mes deux dessins, mais pour la suite, je préférerai, en ce qui concerne les dessins politiques signer de mes initiales HvM. Quant aux dessins autres, je signerai mon nom en entier. Je ne pense pas, que vous y voyez de l'inconvénient ${ }^{124}$.

Ces deux mentions contradictoires, présentes dans la même lettre, témoignent de l'ambivalence d'un artiste qui ne se résigne guère à gagner sa vie avec des caricatures, qu'il juge indignes de son talent, comme le confirme un cri du cœur, lancé un an plus tard:

Mais rappelez-vous, cher monsieur, que je ne suis caricaturiste que d'occasion et non de profession ${ }^{125}$.

Fin I 892, Henri van Muyden, qui est issu d'une famille genevoise bien établie, évoque un autre aspect de la signature, liée cette fois à sa position sociale:

J'ai lu votre dernier mot dans la Briefkasten, et en effet peut-être aurais-je mieux fait dans le cas susdit de dissimuler ma signature. Je voudrais par exemple faire quelque chose pour l'affaire du Mt Blanc, que j'y serai empêché et par mon nom et par des raisons de relations ${ }^{126}$.

On peut sans peine imaginer que ces préoccupations identitaires et sociales aient été partagées par d'autres dessinateurs ${ }^{127}$.

Nebelspalter 1907/37, couverture de Boscovits junior intitulée « La tombe de Segantini » (Segantinis Grab).

"Segantini, Giovanni Battista Emmanuele Maria », Dictionnaire sur l'art en Suisse; http://www.sikart.ch/kuenstlerinnen.aspx?id=4000079.

Cf. 2. CYCLES DE VIE D'UN ORGANE BOURGEOIS À L'IDENTITÉ COMPLEXE.

Cf. « 6.1. La leçon des archives Nötzli : un éditeur et ses réseaux ».

${ }_{23}$ Sa collaboration au Nebelspalter s'achève en 1897; une incertitude demeure sur une deuxième phase de collaboration entre 1909 et 1912; pour le reste de la correspondance avec Nötzli, cf. « 6.4. Passions d'artistes: Richard Kissling, Evert van Muyden, Henri van Muyden et Jean Nötzli ».

124 Cote 1.14 de la succession Nötzli, lettre du 10 octobre 1889

125 Cote 1.14 de la succession Nötzli, lettre du $1^{\text {er juin } 1890 .}$

${ }_{126}$ Cote 1.14 de la succession Nötzli, lettre du $1^{\text {er }}$ octobre 1892

${ }_{127}$ L'habitus de ces dessinateurs diverge de celui défini par Bertrand Tillier pour les dessinateurs des revues françaises qui voient dans la revue un tremplin artistique

\subsection{Liste et période d'activité des éditeurs et rédacteurs en chef}

La liste des éditeurs et rédacteurs en chef du Nebelspalter a été constituée d'après le corpus, en fonction des indications du bandeau de la première page et de différents encarts. Les données ont été ensuite enrichies par des sources secondaires, notamment le Dictionnaire de l'histoire de la Suisse (DHS). Cette liste, donnée par ordre chronologique, corrige les erreurs de la littérature sur le Nebelspalter, puisque aucun ouvrage ne donne d'informations tout à fait exactes. Il faut enfin prendre garde à une chronologie éditoriale et rédactionnelle parfois sinueuse, tous les éditeurs ayant assuré à un moment ou un autre des responsabilités rédactionnelles, partagées on non avec un second rédacteur, tandis que la rédaction est, selon les époques, unique ou scindée entre une rédaction littéraire et une rédaction artistique.

\section{Éditeurs}

Période d'activité

NöTZLI Jean (I 844-I900)

I $875 /$ I à I900/I 4

Succession Nötzli

I900/2 I à I 902/35

Boscovits Johann Friedrich (I 845-I9I 8 ) = senior $\quad$ I 902/36 à I9 I $2 / 48$ (direction qui continue d'être partagée)

EBERSOLd Fritz (I 85 I-I 923 )

I 9 I $2 / 49$ à I 9 I $3 / 2$

Frey Jean (I86I-I95I)

I9I3/3 à I92 I/ 53

Rédacteurs en chef

NöTZLI Jean (I 844-I 900) rédaction entière

Période d'activité

I 875/I à I $895 / 37$

BeEtschen Alfred (I 864-I924) rédaction partagée NöTzLI Jean (I 844-I900) rédaction partagée

I $895 / 40$ à I $897 /$ I 4 I $895 / 40$ à I $897 /$ I 4

NöTZLI Jean (I 844-I 900) rédaction entière

Boscovits J. F. (I845-I918) intérim

Boscovits J. F. (I 845-I9I 8) rédaction artistique Hauser Edwin (I 854 -19I3) rédaction littéraire

I 897/I 5 à I900/I 7 I900/I 8 à I900/36 $1900 / 37$ à $1903 / 39$ $1900 / 37$ à $1903 / 39$

Boscovits J. F. (I845-I9I8) rédaction entière I903/40 à I907/I3

Boscovits J. F. (I845-I9I8) rédaction partagée I 907/I 4 à I 9I 2/43 BEETSCHEN Alfred (I 864-I 1924) rédaction partagée I 907/I 4 à I 9 I $2 / 43$

Boscovits J. F. (I845-I9I8) rédaction entière

I9I $2 / 44$ à I9I $2 / 48$

Huber Rudolf (I867-I928) rédaction partagée EBERSOLd Fritz (I 85 I-I923) rédaction partagée

I $912 / 49$ à $1913 / 7$ I $912 / 49$ à I $913 / 7$

HubER Rudolf (I 867-I928) rédaction entière

Altheer Paul (i 887-1959) rédaction entière

I9I $3 / 8$ à I $913 / 44$

Frey Jean (I 86I-I95I) rédaction entière

I9I $3 / 45$ à I9I $8 / 5$ I

I9I9/I à I $921 / 53$

et non un gagne-pain par défaut; Bertrand Tillier, "La revue satirique, obje hybride », dans La Belle Époque des revues 1880-1914, éd. Jacqueline PluetDespatin, Michel Leymarie et Jean-Yves Mollier, Paris, Imec, 2002, p. 230-231. 


\subsection{Liste et période d'activité des dessinateurs}

Les dates de naissance et de mort (cette dernière parfois inconnue) ainsi que le prénom sont donnés quand ils ont pu être retrouvés, ce qui suppose une entrée au minimum dans l'un des dictionnaires biobibliographiques consultés: le Schweizerisches KünstlerLexikon édité par Carl Brun; le Dictionnaire sur l'art en Suisse édité par l'Institut suisse pour l'étude de l'art; le Allgemeines Künstler-Lexikon-Die Bildenden Künsler aller Zeiten und Völker édité par KG Saur; le Dictionnaire biographique de l'art suisse, conjointement édité par l'Institut suisse pour l'étude de l'art et les éditions de la Neue Zürcher Zeitung; le Dictionnaire critique et documentaire des peintres, sculpteurs, dessinateurs et graveurs de Emmanuel Bénézit et révisé par Jacques Busse, le Dictionnaire de l'histoire de la Suisse (DHS), publié online; le Allgemeines Lexikon der bildenden Künstler von der Antike bis zur Gegenwart, dit Thieme und Becker; le Allgemeines Lexikon der bildenden Künstler des XX. Jahrhunderts édité par Hans Vollmer.

Concernant les pseudonymes ou monogrammes, l'identité du dessinateur est indiquée lorsqu'elle a pu être retrouvée; dans ce cas, la période d'activité n'est pas mentionnée et il convient de se référer au nom.

Le nombre d'astérisques, de un à trois, indique l'importance du dessinateur.

\section{Nom}

Période d'activité

Auer Hans (I847-I906)

Bachmann Paul (I 896-I971)

Beurmann Emil (I 862-I950)

Billet B.

BindSCHEDLER H.

***Boscovits Johann Friedrich (I845-1918) = senior

***Boscovits Fritz (I87I-1965) = junior

BüNZLIN

${ }^{*}$ CZerpien Karl (i 878-i947)

Dacho F.

De воск

Dier Erhard Amadeus (I 893-I969)

**Dill Emil (I86I-I938)

Diveky (von) Josef (I887-I95 I)

DUPRÉ L.

Eschbach J.

Felix Hans ou Jacob

Frans $\mathrm{H}$.

FÜRST R.M.

Goppelsroeder Ernst (Goppel) (I 894-I949)

*Graf Emil (I 845-I924)

I917, 19

I 893

I9I 8

I9I 8

I 875 -I 8

I 889-92, 97-2 I

I9I 5

I913-19

I9IO

I9I 4

I919-20

I 890-93, 95, 08-09

I 920

1909

I9I 5

I9I3-I 4

I9I 6

I9I 6

I9I 3

I 879,8 I $-83,87$

\section{Nom}

Période d'activité

*Henrik H.

*Hintermeister Hermann (I 87 I-I946)

*Hirschler Alfred

*Huber Emil Albert (I 883-I943)

**Jenny Heinrich (I 824-I 89I)

*KäLIn Küpfer Josef (I 870-1965)

KaUders Walter

KLING M.

KNÜSLI C.

Kranich

LAUTERburg Emil (I 86I-1907)

**Lehmann-Schramm Willy ( I 866-?)

Liermann Frieda (I 877-I958)

* Lilie Walter (I 876-I 924)

MaAsen Paul

*Maehly Otto (i 869-1953)

MARrug L.

MAY (de) (I 876-1942)

Messmer Charles (I893-I95 I)

Mayer ou Meyer

* Mohr S.

Moos Karl Franz

Morgenthaler Ernst (I 887-I962)

**(VAN) Muyden Evert (I 853 -I 922 )

**(VAN) MuYden Henri (I 860-I936)

Obser H.

Peyer W.

Piguet Raoul

Ramp James

RANSTEgG T A

*Raquette M.

Rickli Herbert
Ropaz

Röpe F.

RÜEGG Ernst (I 889-I 944)

* Salis T.S.

SARToris Spyridon Demetrius

Schalcher Traugott (I 886-i 944 )

Schlegel Karl Martin (I 892-1960)

Schmid Fritz (Frederic) (I 898-I 979)

*SChweizer Wilfried (I 884-I974)

Selig Hans ou Jakob

*Staehle A.

Straus Victor

STRÜBIN J.

StÜCKelberger Wilhelm (I867-I926)

SulzBERgER Adolf

**Thesing Paul (I 882-I954)

** Treichler Arthur (I89I-?)

WANGER Franz (I 880-I945)

WiRz Hans
I9I6-I9

I9 I 8-20

I909, I3-I 5 I 888-I 89I

I 900, 08-09

I9I9

I 921

I 875

I9I 6

I 890

I 893-08

I9I 7-I9

I9I3-I 5

I9I 6

I 892-94, O6-I I

I9I 3-I 4

I 896

I9I 6

I9I 5

I 9I 7-I 8, 20

I9I 5-I 7

I9I 3-I 4

I 887-I 889

I 889-I 897, O9-I 2

I9I 5

I9I 6

I9I 7

I9 I 6-I 7

I9I 4-I 5

I9I9-2 I

I 9 I 2 -I 3

I9I9

I9I9

I 9 I 2-I 3

I9I 3-I 8

I9I 2

I9IO

I9 I 5-I 7

I 920

I 9 I 2-I 4

I9I 3-I 4

I9O2-03

I9 I 8-2 I

I 899

I 894

I 893-94

I 909-I 4, 20

I 9 I 4-2 I

I 913

I 893-94
I 9 I 2-I 4, I 6-I 7 
Monogramme ou pseudonyme

A

$\mathrm{AB}$

$\mathrm{AH}=\mathrm{A}$. HIRSCHLER

AL

AM

AN

AR (ou RE)

$\mathrm{AS}=\mathrm{A}$. STAEHLE

AS (bis)

ASP

AV

$\mathrm{B}=$ Boscovits junior ou senior

$\mathrm{BL}$

CA (ou CA)

$\mathrm{CH}$

CK

CM (ou MC ou WC)

$\mathrm{CO}$

EA

ED (ou Edj ou Edg ou End) = Dill

EG

ER

EDLZ

EHL

$\mathrm{FB}=$ J.F. Boscovits (senior)

$\mathrm{FBj}=$ Fritz Boscovits (junior)

FL

GE

GINO

GK

GL (ou GLj)

GM

GN

${ }^{*} \mathrm{G}$ v St $=$ Gustav von Strathmann ?

GR

GW (ou WG?)

$\mathrm{H}=$ HENRIK

Hgut

$\mathrm{HH}$

$\mathrm{HJ}=$ Heinrich JENNY

$\mathrm{HO}$

HR

HW

JE

JJL

JKK = J. KäLIN KÜPfer JOCUS

Klaus

KM

$\mathrm{L}$

LC

LK

LM
Période d'activité Monogramme ou pseudonyme

$$
\begin{aligned}
\text { I909-Io } & \text { LO } \\
\text { I9I2 } & \text { LR } \\
& M
\end{aligned}
$$$$
\text { I904, I909-I I } \quad \text { M et Mo = Maehly }
$$$$
\text { I92 I Max S (ou Max) }
$$$$
\text { I } 876 \quad \mathrm{ME}
$$

I909, I9I I ML

MMM (arrondis)

1909 MR

I $893 \quad$ MR bis

I908, I0 MZ

$$
\mathrm{nEH}
$$

$1903 \quad \mathrm{nEB}$

I907-08 $\mathrm{nFO}$

I9I $2 \mathrm{nTH}$

I9IO NB

I909, I9I2 NCK

I9I I Nemo V

I909-10 NG (ou Nfg)

NK

I910 NP

I9IO $\mathrm{O}$

I902 OG

$1908 \mathrm{OH}($ ou $\mathrm{HO})$

OHL

OI

I9I9 OM (ou M ou OMT) = O. MAELHLY

$1902 \mathrm{ON}$

I92 I OV

I9IO OW

I905-07, I0, I2 OY

I909, I2 OZ

i9i I Pastarella (ou PA) = Evert van Muyden $=$ Henri van Muyden

I907-I2 PE

I908- PG

I908 Piou piou

RP

I92 I RS

I92I Samy

Sch $=$ SCHLEGEL

I909 Sch M

I92 I *Sch-S (ou SS)

I9IO, I2 $\mathrm{SHM}=\mathrm{S}$. MoHR

I896* $*$ STOCK $_{\text {TOC }}$

I9IO THS $=$ P. THEsSING ?

I9IO TOC

I 9 I 0 TS $=$ P. THESSING ?

I908 $\mathrm{TZ}=$ TREICHLER

$1909 \quad \mathrm{VM}$

I9IO $\mathrm{VS}=$ STRAUSS

I905, 08, I0-I 2 WC (ou MC ou CM)

I908, I0, I2 ZO
Période d'activité

I9I I

I908

I9I9, 2 I

I9I 4-I 5

I 909

I 908

I 907

I908

I9I I

I9I I

I9I I

I9IO

I9I I

I9IO

I9I 2

I9I I

I919

I907-08, I9I I

I9IO

I9IO

I 908

I9I 3

I909, I9I I-I 2

I9I 2

I9I 2

I9I I

I903

I9I 2

I9I 2

I9I I

1908

I9IO

I9IO

I 908

I 908

I9I 2

I9IO

I909-I 2

I 9 I I-I 2

I 908

I 9 I I

I9I I

I910

I909, I 9I I-I 2

I909 


\section{CYCLES DE VIE D'UN ORGANE BOURGEOIS À L'IDENTITÉ COMPLEXE}

La dimension matérielle du Nebelspalter zurichois reflète sa stabilité. Son format est immuable et la qualité ordinaire du papier ne change pas davantage, sauf pour se dégrader durant les années de guerre. De même, sa périodicité hebdomadaire avec une parution le samedi reste identique. Des changements interviennent néanmoins, qui concernent la ligne idéologique, la place respective du texte et de l'image, la maquette, la couverture, le langage visuel, les rubriques, la politique commerciale, la typographie et plus généralement la conception de la page, surdéterminée par le cadre au trait, son maintien, ses oscillations, sa suppression et enfin son revival. Pendant les deux premières décennies, ce cadre au trait est cependant bien accroché, de la même façon que l'équipe Nötzli/ Boscovits, qui a la main mise sur cette époque. Les thèmes, leur qualité et leurs variations résultent autant des choix de la rédaction que du cours du monde. Derrière tout ceci, se trouve un public, qu'il importe d'attirer, d'élargir et de retenir par tous les moyens, afin d'assurer la pérennité de l'entreprise. Le Nebelspalter est ainsi marqué par une série de césures, souvent liées à des changements rédactionnels, quoique pas uniquement. Cinq cycles de vie, parsemés d'événements, peuvent ainsi être identifiés : I 875 -1886; I 887-I899; I900-I906; I907-I9I2; I9I3-I92I.

\subsection{5 , un premier numéro fixant les choses: maquette, tendance, identité visuelle et commerciale}

\footnotetext{
Dès son premier numéro, le Nebelspalter se distingue dans le monde des revues par son grand format de $34 \mathrm{~cm} \times 24,5 \mathrm{~cm}$, accordant une forte présence aux figures comme aux espaces vierges. Son papier est, par contre, d'une qualité ordinaire. Le premier numéro comprend quatre pages: une couverture, partagée entre un texte et un bandeau imagé, deux pages de textes et une dernière page, entièrement occupée par une caricature. La typographie est serrée, l'écriture en gothiques et chaque page soigneusement encadrée d'un cadre au trait. Ce cadre au trait est double, avec à l'extérieur, un trait épais et à l'intérieur, un trait plus fin. Il confère à la page une impression de profondeur, comparable à celle des encadrements de tableaux (cf. fig. 5).
}

Sur la couverture, au-dessus du cadre, se lit, réparti de part et d'autre: "Zurich, ${ }^{\text {er }}$ janvier I $875 . \mathrm{N}^{\circ}$ I » (Zürich I 875. $N^{\circ}$ I. I. Januar). Une banderole est tendue sur le cadre portant le titre «Der Nebelspalter ", doté de deux lettrines. La scène du Nebelspalter est installée, le décor consiste en un paysage indistinct, très embrumé. Le Nebelspalter ${ }^{1}$, Chronos et un petit bouffon font face à une farandole de personnages en fuite.

Der Nebelspalter est, en fait, l'iconisation d'un jeu de mot, « Nebelspalter» désignant, d'une part, dans la langue parlée, un tricorne, qu'aime volontiers à porter le bourgeois du XIX ${ }^{\mathrm{e}}$ siècle, tandis que, d'autre part, la décomposition des deux substantifs accolés, "Nebel ", brouillard et "Spalter ", dérivé du verbe «spalten "- fendre, diviser, trancher, dédoubler -, suggère que l'on taille dans le brouillard afin de débusquer la vérité, selon une métaphore usuelle. La métaphore est néanmoins détournée, puisque ce n'est pas un tricorne qui est donné à voir mais un bicorne, pourvu d'une connotation plus moderniste. Dans cette composition originelle, signée d'une discrète initiale « B » pour J.F. Boscovits ${ }^{2}$ (Boscovits senior), les attributs sont aussi importants que les personnages. Vêtu d'un costume d'Arlequin, le Nebelspalter tient de ses deux mains une énorme plume, l'instrument de la satire et de son pendant visuel, la caricature; il arbore à la taille un encrier prêt à servir ${ }^{3}$. Derrière lui, est assis Chronos, une faux dans une main, un bouclier gravé de l'inscription «En avant» (Vorwärts), dans l'autre. Plus en retrait, le bouffon actionne des cisailles pour tailler dans le brouillard. Les autres personnages sont autant de cibles de la revue: le jésuite, reconnaissable à son vêtement sombre et son chapeau noir aux bords retournés, l'élégante, un peu ridicule avec son ombrelle, le gardien de l'ordre ainsi que divers personnages en costume, porteurs des pancartes " action" (Actie), " liquidation" (Ausverkauf), "privilèges" (Privilegien), « cours" (Cours), " pétrole» $(\text { Petroleum })^{4}$.

Sous ce bandeau historié se trouvent deux zones de texte. La première décline le sous-titre et l'identité éditoriale de la revue: "Périodique illustré humoristique et politique (Illustriertes humoristisches-politisches Wochenblatt), publié et édité par Jean Nötzli, avec pour adresse Hofgasse $n^{\circ}$ 2, une ruelle de la vieille ville, aujourd'hui débaptisée. La seconde bande de texte égrène les données commerciales du périodique pour lequel est annoncée une

Nebelspalter 1875/1, couverture. On distingue le titre du Nebelspalter, en italiques, et sa personnification, en lettres romaines (Nebelspalter).

Cf. « 1. 3. La domination Boscovits».

Cf. « 5.1. Le Nebelspalter, la caricature et les revues illustrées européennes ». Les mots ont parfois une orthographe qui n'est plus usitée. 
Zürich 1875.

$N: 1$. 1. Januar.

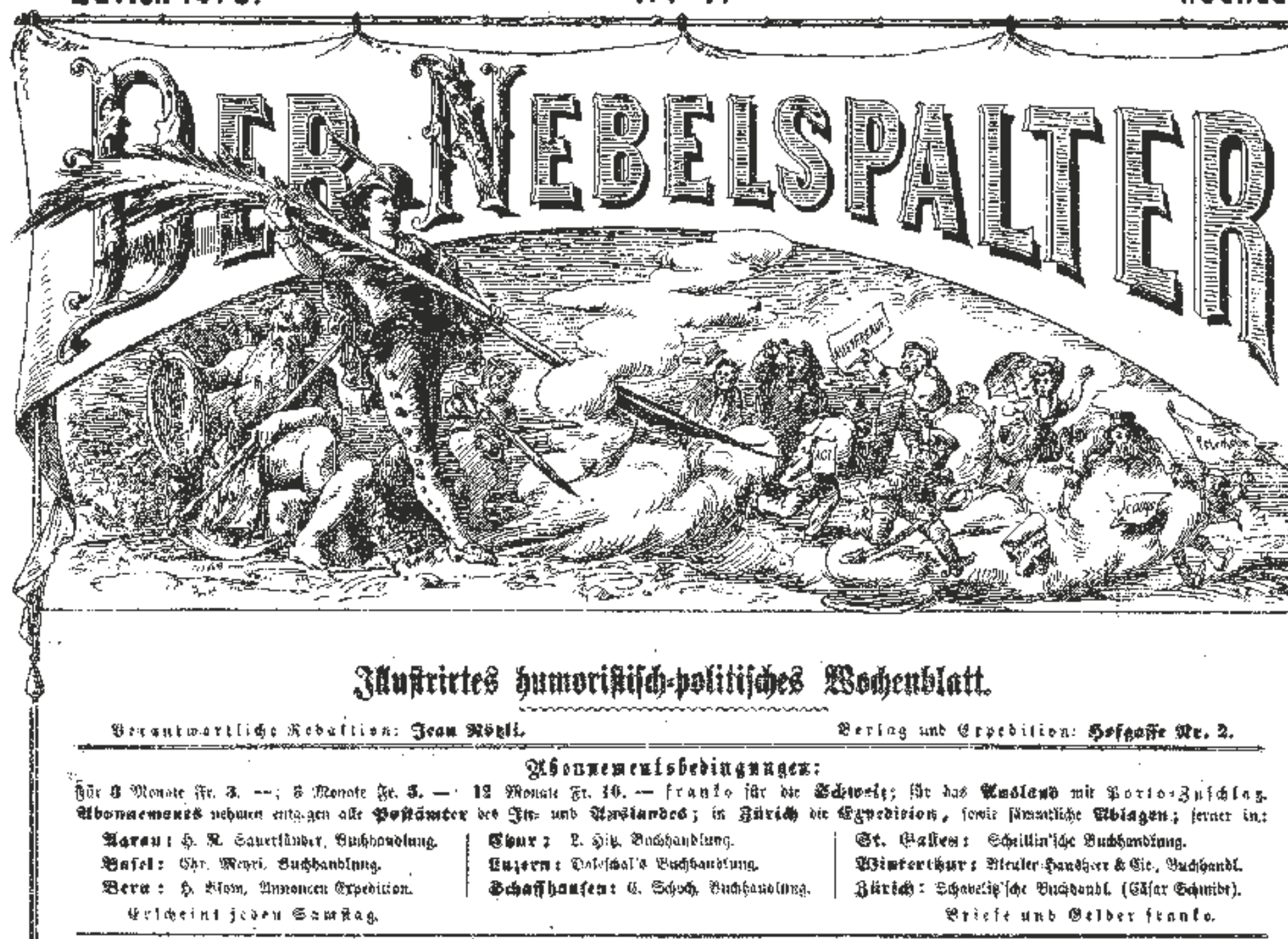

\section{Gethorfaner Miener!}

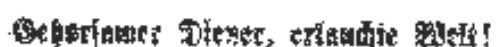

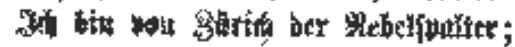

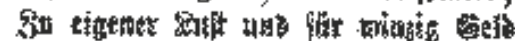

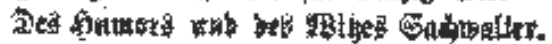

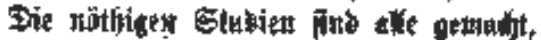

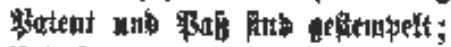

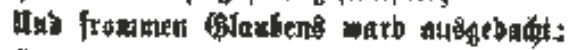

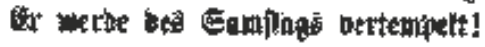

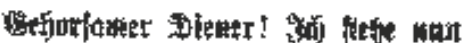

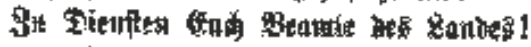

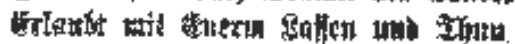

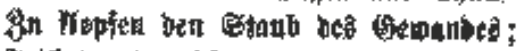

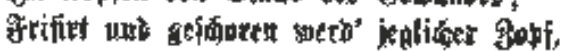

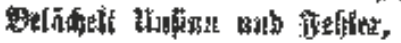

Tit for

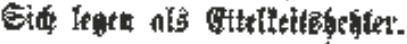

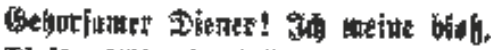

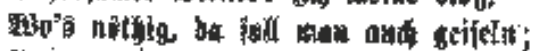

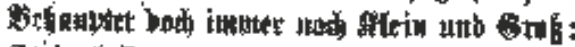

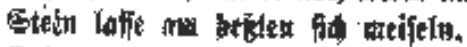

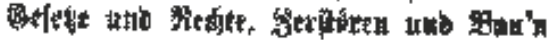

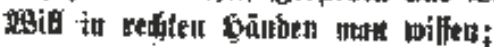

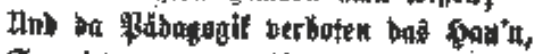

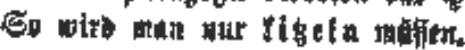

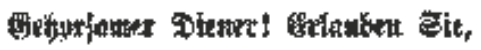

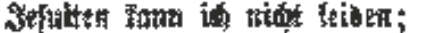

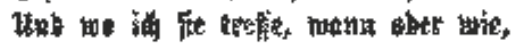

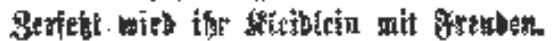

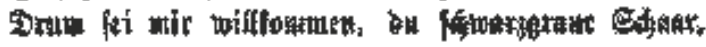

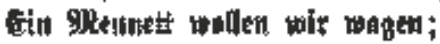

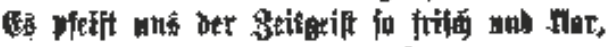

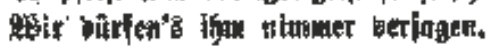

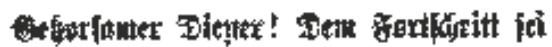

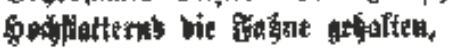

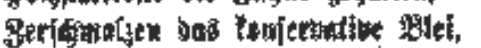

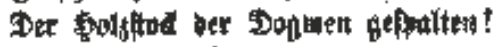

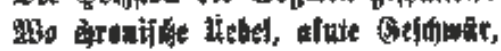

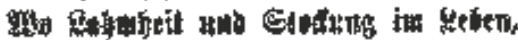

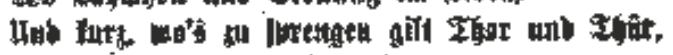

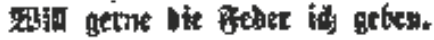

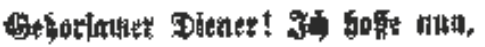

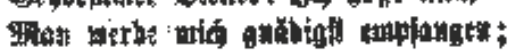

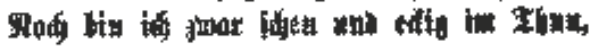

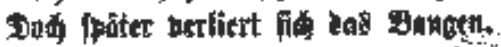

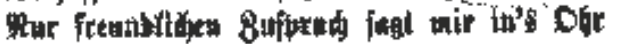

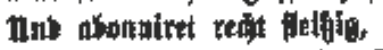

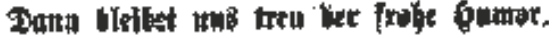

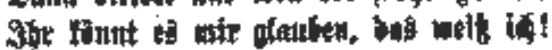




\section{Pronit Mamma!}

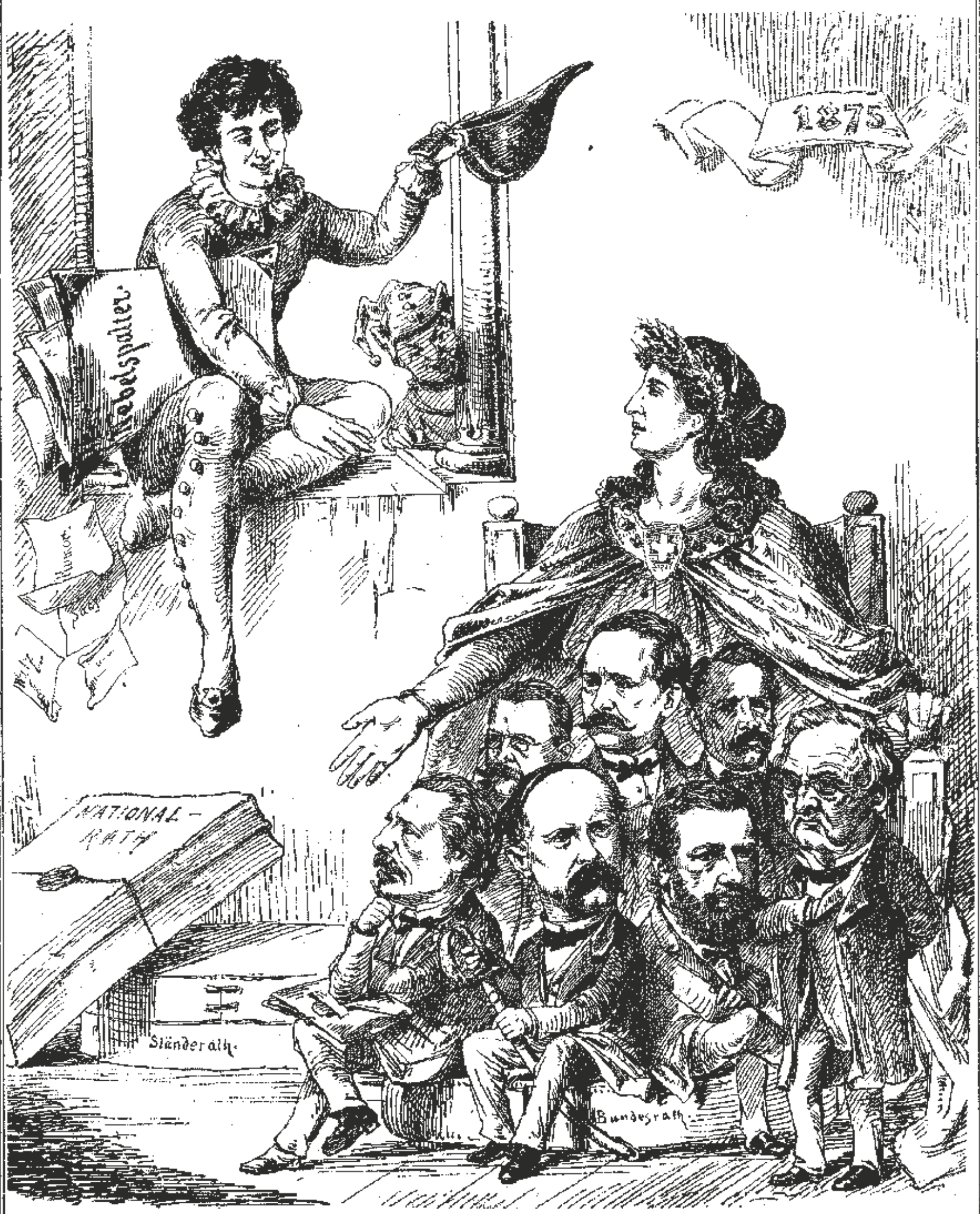

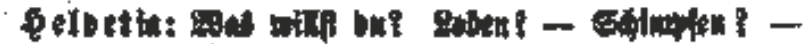

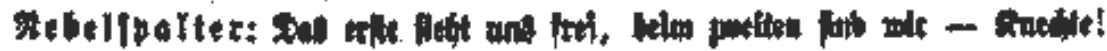

Typo dithogr. C.Knüsli, Zürish

Fig. 6. Nebelspalter 1875/1, dessin en noir et blanc non signé intitulé « Santé Maman! » (Prosit Mamma!). 
parution hebdomadaire, le samedi5. L'abonnement est proposé sous trois formes: trois mois pour $3 \mathrm{Fr}$., six mois pour $5 \mathrm{Fr}$., douze mois pour io Fr., et il faut compter un supplément de port pour l'étranger. Il peut être contracté auprès de tous les bureaux de poste suisses et étrangers, ainsi que, pour Zurich, auprès du service d'expédition. Pour le reste de la Suisse, Aarau, Bâle, Coire, Lucerne, Schaffhouse, Saint-Gall et Winterthour, on s'adressera aux libraires; pour Berne, à un expéditeur. Aucune indication de prix au numéro ou concernant des insertions publicitaires n'est alors présente, pas plus que de mention de l'imprimeur.

L'éditorial, signé "Der Nebelspalter ", comme de nombreux textes des premiers numéros, a valeur programmatique. Le Nebelspalter zurichois, avocat de l'humour et du mot d'esprit, prend à parti un " docile serviteur » (Gehorsamer Diener) et «le monde illustre » (erlauchte Welt), et se met au service du pays, afin d'en dénoncer les maux chroniques ou aigus, en premier lieu la « chape conservatrice " (konservative Blei) et les "jésuites » (Jesuiten) $^{6}$. La caricature de la dernière page est une réponse à la couverture (cf. fig. 6).

Intitulée "Santé maman! (Prosit Mama!), le personnage du Nebelspalter s'y présente à Helvetia, personnification de la Suisse en Vierge de Miséricorde qui protège de son manteau les sept conseillers fédéraux ${ }^{7}$. Négligemment assis sur le rebord d'une fenêtre qu'il a de toute évidence impudemment Franchie, le Nebelspalter se pose en mauvais galopin. Des feuilles marquées « satire » (Satyre), « mot d'esprit » (Witz) et « humour» (Humor) s'échappent du journal à son nom, coincé sur l'une de ses jambes. Elles échoient sur les livres du Conseil national (Nationalrath) et du Conseil des états (Ständerath), les deux instances du parlement suisse. Le Nebelspalter lève son chapeau pour engager un dialogue avec Helvetia :

Helvetia: Que veux-tu? Louer? Lancer des invectives? - Nebelspalter: Pour le premier, cela reste ouvert, pour le second, nous en sommes - les serviteurs $!^{8}$

Le Nebelspalter déclare ainsi son intention de surveiller et commenter avec insolence la vie politique suisse. Ce qu'il va faire avec assiduité, selon une tendance fortement teintée de libéralisme, tel qu'on l'entendait au XIX ${ }^{e}$ siècle, c'est-à-dire avant tout une opposition aux conservatismes de toutes sortes et une liberté d'entreprendre. Il va ouvrir à différentes échelles, locale, cantonale, supra-cantonale ou nationale, une discussion sans relâche, soit en haut-allemand, soit en dialecte, sur les questions et l'identité suisses. Les thématiques centrales des premiers numéros vont porter sur les questions religieuses (le Kulturkampf), politiques, constitutionnelles, financières, primant sur les questions sociales, telles que les lois sur les alcools ou sur le mariage, tandis que certains thèmes essentiels dans la géographie politique de la Suisse, comme la question du Gothard ou le transport ferroviaire, vont s'inscrire dans la durée. Deux autres thématiques seront

Le Nebelspalter se distingue alors partiellement de ses congénères françaises en se disant " périodique » (Wochenblatt), sans toutefois prétendre au statut de revue (Wochenschrift). Comme celles-ci, il ne revendique par contre (pas encore) son identité satirique; Bertrand Tillier, "La revue satirique, objet hybride », dans La Belle Époque des revues 1880-1914, éd. Jacqueline Pluet-Despatin, Michel Leymarie et Jean-Yves Mollier, Paris, Imec, 2002, p. 223-233.

Nebelspalter $1875 / 1$, couverture.

Georg Kreis, Helvetia im Wandel der Zeiten. Die Geschichte einer nationalen Repräsentationsfigur, Zurich, Verlag Neue Zürcher Zeitung, 1991, p. 156

(Helvetia: Was willst du? Loben? Schimpfen? - Nebelspalter: Das erste steht uns Frei, beim zweiten sind wir-Knechte ); Nebelspalter 1875/1, dessin en noir et blanc non signé intitulé « Santé Maman! » (Prosit Mamma!). particulièrement prégnantes: celles des «grands hommes », une sorte de panthéon de la Confédération, et les questions militaires.

Le cœur du lectorat, les abonnés qui assurent la pérennité du journal, apparaît en filigrane dans la personnification du Nebelspalter : ce sont des bourgeois avertis, ayant fait leurs humanités, à même de comprendre les nombreuses citations et références humanistes, textuelles comme visuelles, émaillant le périodique. Ces citadins - tout le propos du Nebelspalter est construit dans ce sens - sont d'abord zurichois, même si la multiplication des points de vente indique qu'un lectorat plus large est visé.

\subsection{5-1886 : les années noir et blanc de l'ère Nötzli ou quand la Suisse prime sur le monde}

Preuve que la conception a été soigneusement pensée par le binôme Nötzli/Boscovits, la première décennie du Nebelspalter est marquée par une stabilité générale. La maquette, le langage visuel et rhétorique ne font, de fait, que s'enrichir, avec un épaississement des numéros, un développement des formules rhétoriques et des motifs iconographiques, l'accroissement des hommages aux grands hommes et l'insertion, en I 880, d'une double-page. Le libéralisme et un anticléricalisme suisse marque alors la ligne politique. Il est bien sûr quelques changements, le sous-titre d'abord, qui inclut la dimension satirique en I876, mais surtout la politique commerciale, toujours plus agressive, avec, en I 879 , le début de la vente de produits dérivés et l'apparition, en I 884 , d'une véritable rhétorique guerrière. Prix, abonnements et circuits de distribution sont, par ailleurs, sans cesse révisés.

\subsubsection{Identité, maquette et technique - On affine}

Deux changements interviennent lors de la deuxième année de parution, en I 876: l'adjonction, en début d'année, de l'adjectif "satirique " dans le sous-titre, le Nebelspalter devenant désormais un " hebdomadaire illustré humoristique et satirique » (Illustrirtes humoristisch-satyrisches Wochenblatt) ${ }^{9}$, et l'apparition d'un numéro plus cossu de huit pages, en fin d'année, à l'occasion de Noël. À l'origine composée de quatre feuillets en noir et blanc - deux feuilles recto verso -, la revue compte régulièrement six feuillets à partir de I 878 , dont deux pages de publicité. Jusqu'en I 886 , le nombre de pages varie entre quatre et dix, malgré l'annonce, à la fin I 883 , de doubles numéros hebdomadaires ${ }^{10}$, qui auraient dû correspondre à huit pages.

Plusieurs innovations surviennent en I 880 : la refonte du bandeau de la couverture et l'apparition de doubles-pages. Le bandeau est épuré: le Nebelspalter se trouve désormais seul à dissiper le brouillard. Chronos, le bouffon et les autres personnages

Nebelspalter 1876/1, couverture; avec cette énonciation d'une identité satirique, le Nebelspalter affirme plus nettement son identité que ne le font ses congénères françaises, se disant " artistique », " littéraire » ou " politique »; Bertrand Tillier, "La revue satirique, objet hybride », op. cit., p. 223-224. II est, sous cet aspect, également plus audacieux que ses congénères allemands, les Fliegende Blätter, par exemple, ou le bien plus tardif Simplicissimus (1896-1944) ou encore les périodiques suisses, tel le Postheriori.

Nebelspalter 1883/51, couverture. 
sont effacés et remplacés par des oiseaux (de mauvais augure) et des batraciens. Des éléments iconographiques sont modifiés ou ajoutés : le Nebelspalter adopte un jeu de jambes inversé; il porte désormais un journal marqué «En avant» (Vorwärts) en bandoulière, d'où s'échappent une feuille titrée "Nebelspalter» et une autre invitant à l'abonnement " 3 Fr. par semestre » (Pro Quartal Fr. 3); l'encrier à sa taille est redoublé, plus grand, à gauche de l'image; l'effet architectonique a été supprimé; le titre sur la banderole est remplacé par une inscription dans l'image; «Der Nebelspalter » est imprimé en lettres noires, sans lettrines; l'article surplombe maintenant le jeune homme, pour ceux auxquels l'allégorisation aurait échappé. Le bandeau est désormais signé « FB » dans le coin gauche, en vis-à-vis du nom du lithographe, C. Knüsli ${ }^{11}$ (cf. fig. 7).

La double-page - à l'exception de l'année r 88 I - s'installe quant à elle jusqu'en I9 I 5 , avec une dernière occurrence en I920. Le Nebelspalter s'aligne ainsi sur le modèle français des revues de qualité ${ }^{12}$. La double-page est un lieu particulier, graphiquement très conservateur mais idéologiquement très investi, mettant fréquemment en scène la personnification de la revue.

En I 884, le nom de l'imprimeur - en l'occurrence J. Herzog apparaît; l'année suivante, en I 885 , c'est le tour du lithographe. Ce n'est donc que très tardivement qu'est mise en avant la fabrication du périodique, très probablement d'après le procédé de la zincographie, et non à proprement parler de la lithographie, qui confère à la page des reliefs que ne montre pas le Nebelspalter. La zincographie est dérivée de la lithographie, technique d'impression à plat sur une plaque de calcaire, ici remplacée par une plaque de zinc. Le principe consiste dans le report du trait sur une plaque de métal, puis la protection de celle-ci par une substance grasse, avant l'étalement au pinceau d'un acide. Le trait se trouve donc en relief sur la plaque. Le procédé n'a pas la finesse de la pointe sèche et fait intervenir un ou plusieurs intermédiaires aux côtés de l'artiste. Il est d'un prix beaucoup plus abordable que ne l'est la lithographie ${ }^{13}$.

En I 885 , après une décennie d'existence, la physionomie des pages intérieures a bien changé : les pages à quatre compartiments imagés sont devenues la règle et le dessin pleine page, l'exception.

\subsubsection{Distribution, politique commerciale et lectorat - Essor}

La stratégie commerciale de cette première décennie est basée sur l'accessibilité du journal et un argumentaire commercial, rythmé par les encarts. Le prix et l'abonnement en sont les éléments centraux et l'objet de nombreux tâtonnements. Au cours de la première année, la revue n'est disponible que via un abonnement de trois, six ou douze mois, respectivement au prix de 3 Fr., 5 Fr. et ıo Fr. L'abonnement peut être contracté de diverses façons, recensées sur la couverture du premier numéro. Les encarts invitant à s'abonner fleurissent: il est primordial d'obtenir des abonnés. En I 876, la liste des dépositaires est supprimée et un prix au numéro, fixé à 25 cts., apparaît. Les modalités de l'abonnement

Nebelspalter 1880/2, couverture.

Laurent Bihl, La Grande Mascarade parisienne. Production, diffusion et réception des images satiriques dans la presse périodique illustrée parisienne entre 1881 et 1914, Université de Paris I, Thèse de doctorat en histoire, p. 251-252 (thèse à paraître aux éditions Nouveau monde).

Ibid., p. 211-212. sont également revues: la périodicité trimestrielle est supprimée et seuls les abonnements de six et douze mois sont maintenus. Un abonnement pour l'étranger est également proposé pour le reste de l'Europe, l'Égypte et les États-Unis, aux prix de 7 Fr. et I 3,50 Fr.; pour l'Amérique du Sud, l'Asie et l'Australie, aux prix de I $2 \mathrm{Fr}$. et $22 \mathrm{Fr}^{14}$.

L'abonnement de trois mois est rétabli deux ans plus tard, en I 878, alors que l'abonnement de six mois est supprimé ${ }^{15}$. Il restera au prix de 3 Fr. jusqu'en I907. La politique commerciale s'organise, la rhétorique et les gestes destinés aux abonnés se multiplient: un abonnement permettant de se prémunir de la perte d'humour face à la menace de guerre est inventé ${ }^{16}$; puis, un abonnement pour la saison ${ }^{17}$; « un grand tableau de l'Assemblée fédérale, I98 portraits groupés réalisés par nos excellents artistes " (ein grosses Tableau der Bundesversammlung, I 98 Porträts, sämtliche durch unsern trefflichen Künstler ausgeführt) est offert à tout abonné en fin d'année ${ }^{18}$. L'année suivante, en I 879, l'éventail de trois, six, et douze mois est rétabli, avec une augmentation de l'abonnement semestriel de 5 Fr. à 5,50 Fr. Les destinations et le prix pour l'étranger sont en partie modifiés et concernent désormais, non plus l'Amérique du Sud, l'Asie et l'Australie, mais l'Asie du SudOuest et l'Amérique du Sud, pour un prix minoré de 9 Fr. et I 6 Fr. ${ }^{19}$

L'innovation est, cependant, la vente en I 879 de deux produits dérivés, le calendrier du Nebelspalter, vanté, extraits à l'appui, sur les deux tiers d'une page ${ }^{20}$, et le tableau de l'Assemblée fédérale, envoyé contre I, Io Fr. ${ }^{21}$ Cette pratique commerciale s'installe ${ }^{22}$ : le calendrier de l'année en cours coûte I Fr.; tout comme, en I 882 , une composition célébrant l'ouverture du tunnel ferroviaire du Gothard ${ }^{23}$.

Les argumentaires s'affinent: en I 88 I, le feuilleton de M. Reymond, humoriste connu pour ses publications, nous dit-on, doit appâter le lecteur, sur le modèle de la presse germanique ${ }^{24}$. En I 882, on passe au mode participatif en incitant le lecteur au prosélytisme:

Dans l'intérêt de leur cause, les amis du progrès décisif dans les choses cantonales et fédérales sont priés de s'occuper de la diffusion du Nebelspalter ${ }^{25}$.

L'année suivante, en I 883 , un abonnement spécial est vendu pour la durée de l'exposition nationale, du $\mathrm{I}^{\mathrm{er}}$ mai au I ${ }^{\mathrm{er}}$ octobre, pour un montant de 5 Fr. En I 884, alors que la mention des

Nebelspalter1876/1, bandeau de la couverture.

Nebelspalter 1878/21, bandeau de la couverture.

Nebelspalter $1878 / 14$, encart.

Nebelspalter 1878/21, encart; l'abonnement est proposé soit de mai à octobre pour $5 \mathrm{Fr}$., soit de juin à octobre pour $4 \mathrm{Fr}$.

Nebelspalter $1878 / 51$, encart.

Nebelspalter 1879/28, bandeau de couverture.

Nebelspalter 1879/48, encart intitulé "Échantillons illustrés du calendrier du Nebelspalter » (Illustrationsproben aus dem « Nebelspalter-Kalender »).

Nebelspalter 1879/30, encart.

À ce sujet, cf. Benoît Lenoble, "Les produits dérivés ", dans La civilisation du journal. Histoire culturelle et littéraire de la presse Française au XIX siècle, éd. Dominique Kalifa, Philippe Régnier, Marie-Ėve Thérenty et Alain Vaillant, Paris, Nouveau Monde, 2011, p. 605-613.

Nebelspalter $1882 / 20$, encart.

Nebelspalter $1881 / 1$, encart. Sur le rôle du feuilleton dans la fidélisation du public germanique; Jörg Requate, "Aspects de la société médiatique allemande du XIX ${ }^{e}$ siècle ", dans Presses, nations et mondialisation au XIX siècle, op. cit., p. 52 ; plus généralement, sur le rôle changeant du feuilleton dans la presse : Lise Dumasy-Quéffélec, "Rubriques et fonctions du feuilleton au XIXe siècle », dans La civilisation du journal. Histoire culturelle et littéraire de la presse Française au $x I x^{e}$ siècle, op. cit., p. 925-936.

(Freunde des entschiedenen Fortschrittes in kantonalen und eidgenössischen Dingen werden im Interesse der Sache ersucht, für mögliche Verbreitung des "Nebelspalter » besorgt sein zu wollen); Nebelspalter 1882/25, encart. 
Zürich 1880.

VI.Jahrgang N: 2.

10. Januar.

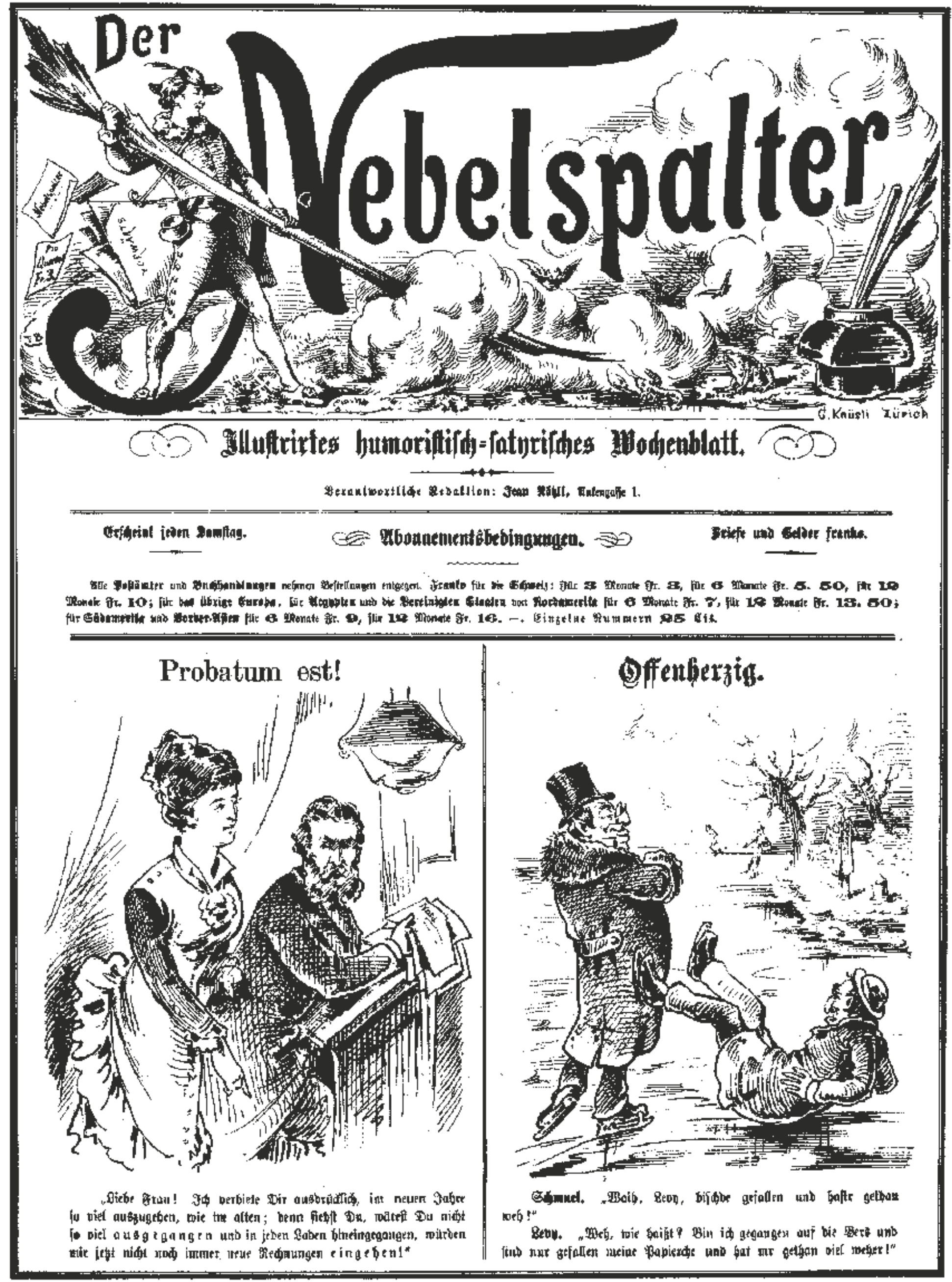

Fig. 7. Nebelspalter $1880 / 2$, couverture.

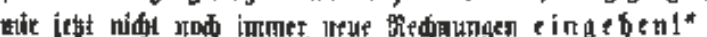

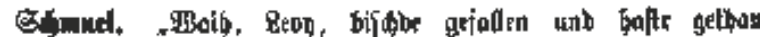

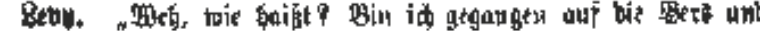


distributeurs revient, un point de vente à Milan apparaît, en charge de la distribution pour l'Italie entière ${ }^{26}$. Le prix des insertions publicitaires baisse à $25 \mathrm{cts}$. par ligne pour la Suisse et $30 \mathrm{cts}$. pour l'étranger, signe d'une politique commerciale plus agressive, également présente dans la teneur des textes autopromotionnels, tel le « bilan au 30 juin I 884 " (Bilanzpro 30 . Juni I 884), dressant une comptabilité humoristique en faveur du Nebelspalter ${ }^{27}$. À la fin de l'année I 884 , le Nebelspalter débute une politique de communication de type guerrier:

Invitation à l'abonnement. Avec la nouvelle année, le Nebelspalter entre dans sa onzième année de parution. Dans une époque difficile et trouble, il a réussi, devant le public, avec son humour, ses bons mots et ses riches illustrations à se constituer un lectorat si large qu'il avance fort et vigoureux sur le champ de bataille, en dépit d'ennemis particulièrement acharnés ces derniers temps. Son programme est resté le même. Le drapeau du progrès est brandi, et sous lui, il combat en politique tout ce qui n'est pas libre, qui n'est pas vrai, tout ce qui est rouillé, corrompu, mauvais; l'égotisme, l'égoïsme, la soumission et l'abus de pouvoir. Il s'engage pour la promotion et le soutien du commerce, de l'artisanat et de l'agriculture; pour une solution progressive, compréhensible et pacifique de la question sociale; il se met, en fait, au service de la cause patriotique. Ni sous la coupe de la gauche ni sous celle de la droite, il reste toujours fidèle à l'intérêt de la cause, et sous cette devise, afin d'accroître encore le nombre de ses amis, de les faire encore se rapprocher, le Nebelspalter paraitra en I 885 de nouveau sous la forme d'un doublenuméro, en étant non seulement le journal le meilleur marché mais aussi le plus riche de sa catégorie. Nos plus grands quotidiens ont loué sans réserve les performances du Nebelspalter; il cherchera à mériter encore davantage cette reconnaissance, l'année prochaine. Le Nebelspalter est avec ses portraits d'un intérêt particulier pour les Suisses de l'étranger ${ }^{28}$.

Maints textes de ce genre, à la rhétorique patriotique et guerrière, s'appuyant sur l'image d'ennemis déterminés et à l'affût, seront publiés au cours des décennies suivantes. Ils ressortissent à un topos de la presse satirique européenne ${ }^{29}$. Ce discours agressif fait partie d'une stratégie plus affirmée vis-à-vis des annonceurs. Alors que le marketing est absent les deux premières années, puis présent via des encarts entre I 877 et I 883 , il intègre le bandeau de la couverture en I 884 , avec un prix inchangé de 25 cts. la ligne pour la Suisse et l'apparition d'un prix de $30 \mathrm{cts}$. la ligne pour l'étranger. Deux ans plus tard, en I 886, l'argument du prix est renforcé: la ligne passe à 20 cts. pour la Suisse et 25 cts. pour l'étranger.

\footnotetext{
Nebelspalter 1884/34, bandeau de la couverture.

Nebelspalter $1884 / 27$, texte de la couverture.

(Abonnements-Einladung. Der « Nebelspalter » beginnt mit Neujahr seinen elften Jahrgang. In schwerer und trüber Zeit mit seinem Humor, seinem Witz, seinen reichen Illustrationen vor das Publikum tretend, hat er sich trotz der, insbesondere in neuester Zeit, wieder rastlos arbeitenden Feinde einen so grossen Leserkreis geschaffen, das er stark und kräftig in's Feld zieht. Sei Programm ist dasselbe geblieben. Hoch voran weht ihm die Fahne des Fortschritts und unter ihr kämpft er in der Politik gegen alles Unfreie, Unwahre, gegen alles Verrostete, Korrumpirte, Schlechte; gegen Selbstsucht, Eigennutz, Kriecherei und Amtsmissbrauch; Er steht eine für Hebung und Unterstützung von Handel, Gewerbe und Landwirthschaft, für eine allmälige, aber Friedliche verständige Lösung der sozialen Frage; überhaupt für die Pflege alles Vaterländischen. Unbeiirt, weder von Links noch Rechst, bleibt er stets dem Interesse der Sache treu und um unter diesem Zeichen die Zahl seiner Freunde weiter zu mehren, noch enger an sich zu schliessen, wird der « Nebelspalter » 1885 wieder in Doppelnummern erschienen und so nicht nur das billigste sondern auch das grösste und reichhaltigste Blatt seiner Art sein. Unsere grössten Tagesblätter haben den Leistungen des "Nebelspalter » rückhaltlosen Beifall gezollt und er wird sich auch das kommende Jahr diese ehrenden Anerkennungen noch in höhere Maasse zu erwerben suchen. Für die Schweizer im Auslande ist der " Nebelspalter » mit seinen Portraits von besonderem Interesse.); Nebelspalter $1884 / 51$, texte de la couverture.

29 Laurence Danguy, L'ange de la jeunesse - La revue Jugend et le Jugendstil à Munich, Paris, Maison des sciences de l'homme, 2009, p. 90-94.
}

Le système de numéros spéciaux n'est alors qu'embryonnaire. Deux numéros thématiques, consacrés au tunnel ferroviaire du Saint-Gothard en I 882 et à l'exposition nationale suisse de I 883 , ne sont pas présentés comme des numéros spéciaux ${ }^{30}$.

Le contenu du Nebelspalter renseigne sur son lectorat réel et sur celui souhaité par la rédaction. Les encarts se situent à la croisée de ces deux catégories. À la fin de l'année I 876 , un encart, qui sera présent jusqu'en $\mathrm{I} 882^{31}$, montre une foule massée devant un mur couvert d'affiches, dont la plus voyante est tenue par un colleur d'affiches (cf. fig. 8).

Il s'y détache l'inscription "Supplément illustré des annonces du Nebelspalter "(Illustrirte Annoncen-Beilage zum Nebelspalter) ainsi que le personnage du Nebelspalter, enroulé dans la majuscule du titre. Le poseur d'affiches harangue une foule formée d'hommes et de femmes d'âge et d'origine sociale différents, et d'un garçonnet qui n'est pas sans rappeler le personnage de Gavroche. Dans le coin droit, au bout d'une diagonale partant du poseur d'affiches, un homme en retrait est occupé à lire un exemplaire du Nebelspalter Frappé du numéro « 53 ». Ce détail sera réactualisé à chaque publication de l'encart, sept années durant ( 38 pour le $n^{\circ} 38$, par exemple). Quant à l'homme au haut-de-forme noir, au nez chaussé de lunettes et à la barbe en broussailles, il correspond au type du juif. "Même le juif lit le Nebelspalter ", tel est le message, qui sera repris régulièrement. Cet encart installe la politique commerciale du Nebelspalter en même temps qu'il surdétermine le public. Car, le Nebelspalter peinera à dépasser le cercle des bourgeois lettrés auquel il s'adresse. Quant à chiffrer précisément ce lectorat, c'est chose impossible. Pas plus le périodique que les archives ne livrent d'informations sur le tirage ou le nombre d'abonnés. À regarder le peu d'aménagements de la tendance politique ou de la maquette durant la première décennie, une évolution de l'image qui ne fait que suivre celle des revues illustrées européennes et, somme toute, une continuité dans la publication, il est manifeste que le public a été, dès l'origine, bien ciblé. L'organisation rapide d'une distribution à l'étranger ainsi que le virage communicationnel de I 884 montrent une volonté d'élargissement géographique de ce public, probablement avérée, puisque cette politique commerciale s'installe. Un autre indice est fourni par les encarts publicitaires. Les deux revues munichoises Simplicissimus et Jugend, toutes deux positionnées contre le régime wilhelminien, choisissent en I 896 et I 997 le Nebelspalter pour faire leur publicité, confirmant un lectorat ouvert vers l'étranger et une certaine dissidence politique ${ }^{32}$.

\subsubsection{Déclinaisons thématiques d'une tendance stable}

Durant la première décennie, la revue est fidèle à ses déclarations initiales et à sa ligne libérale-patriote. Celle-ci est teintée d'un anticléricalisme virulent et constant ainsi que d'un antisémitisme moins présent mais parfois très agressif. En I 877, les juifs sont ainsi tenus pour responsables de la crise de l'industrie et Boscovits senior introduit le type du juif capitaliste qui ne quittera plus la revue 33 (cf. fig. 9).

\footnotetext{
Respectivement Nebelspalter 1882/20 et Nebelspalter 1883/17.

Nebelspalter 1876/53, encart.

En 1896 et 1897 pour Simplicissimus, en 1897 pour Jugend, les deux revues commençant leur parution en 1896.

Nebelspalter 1877/11, dessin signé Boscovits senior intitulé « L'origine de la crise » (Die Ursache der Krisis).
} 
ZURICH, 1876.

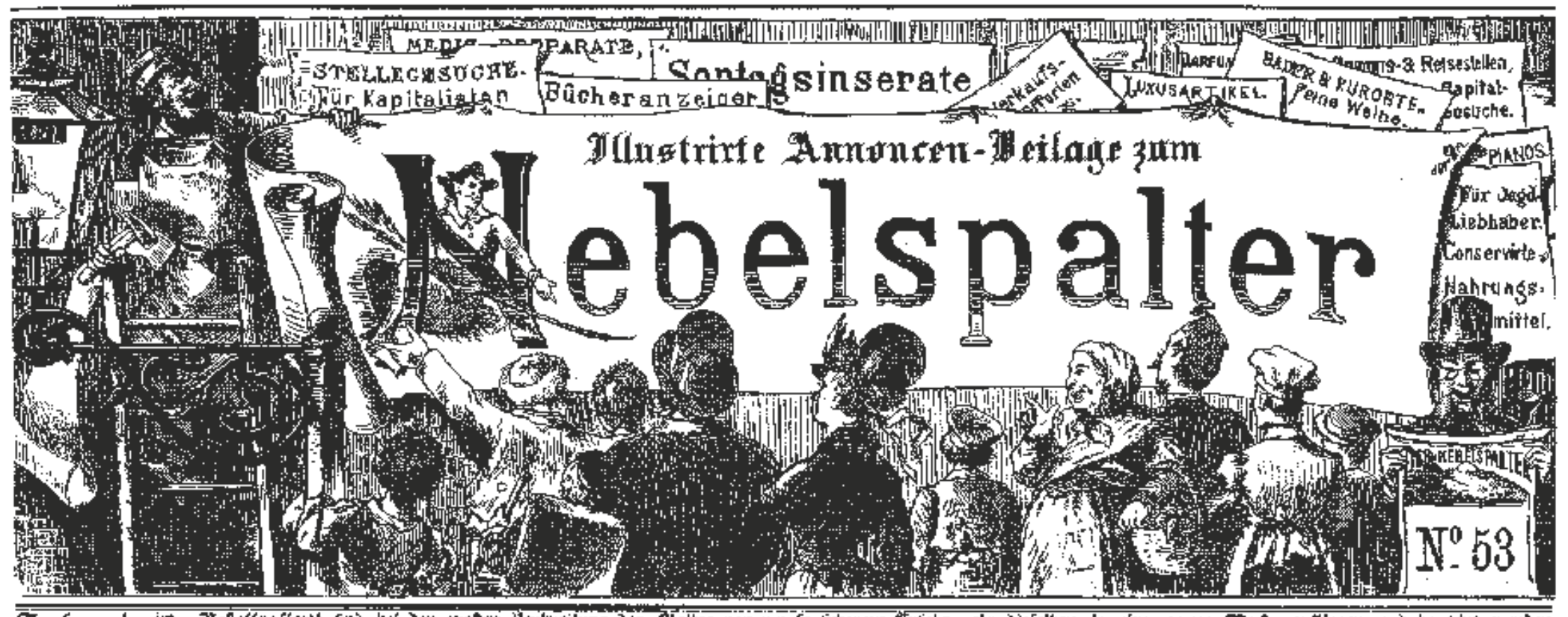

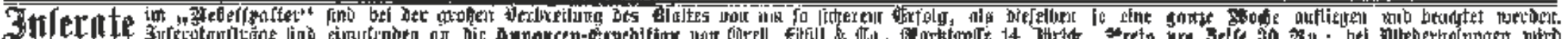

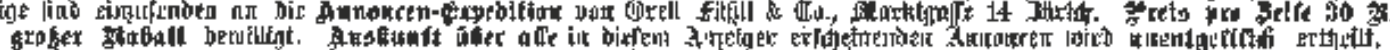

Fig. 8. Nebelspalter 1876/53, encart.

Ceci dit, l'antisémitisme est - et restera - contrasté, voire l'objet d'un double discours. Présent dans le traitement des affaires intérieures, il n'est pas toléré pour l'étranger. Les antisémites allemands sont, ainsi, l'objet d'une dénonciation sans équivoque en I 88 I, où l'on convoque jusqu'au modèle du Laocoon pour leur stigmatisation ${ }^{34}$. Même s'il est des exceptions, l'écart est tel entre les affaires intérieures et extérieures qu'il est permis de se demander si cette dose d'antisémitisme « de proximité » n'est pas attendue par le lectorat, et ne s'aligne pas sur un horizon d'attente, réel ou supposé ${ }^{35}$. Cette hypothèse est confortée par les images humoristiques sur les juifs, notamment les démêlés entre Schumel et Levy, deux figures récurrentes de la palette satirique du Nebelspalter, parlant en dialecte (zurichois) dans des dessins humoristiques censés transmettre un certain humour juif ${ }^{36}$.

Lors de cette première période, la priorité est d'abord accordée aux affaires suisses. À partir de la fin des années I 880 , l'international représente cependant la moitié des compositions ${ }^{37}$. La question primordiale est la libération des forces du peuple face aux forces religieuses, en premier lieu les catholiques mais également les protestants, représentés jusqu'à la minorité piétiste. Le Nebelspalter prend une part très active dans le Kulturkampf, le conflit qui oppose l'État au clergé et aux institutions catholiques. Les références à ce Kulturkampf, moins connu que son homologue prussien, sont légion ${ }^{38}$. Une caricature de 1875 dépeint Philipp Anton von Segesser, chef de l'opposition catholique dans le

Nebelspalter 1881/2, dessin pleine page non signé intitulé « Laocoon » (Laokoon). Sur la notion d'horizon d'attente, devenue classique au-delà des études littéraires: Hans Robert Jauss, Pour une esthétique de la réception, Paris, Gallimard, 1978. Voir, par exemple: Nebelspalter 1880/2, dessin de couverture non signé intitulé "Franc" (Offenherzig). Sur les stéréotypes et l'iconographie du juif à cette époque, voir en première intention: Marie-Anne Matard-Bonucci, Antisémythes. L'image des juifs entre culture et politique (1848-1939), Paris, Nouveau Monde, 2005.

Cf. « 3.2.1. Le face-à-face (helvétique) du Nebelspalter avec Helvetia ».

Franz Xaver Bischof, "Kulturkampf », Dictionnaire historique de la Suisse (03/03/2009); http://www.hls-dhs-dss.ch/textes/f/F17244.php?topdf=1; sur la présence et le traitement du Kulturkampf dans le Nebelspalter: Marija Borer-Cifric, Der « Nebelspalter » als kulturhistorische und politische Quelle des Kulturkampfes der Jahre 1875-1890, 1999 (mémoire soutenu à l'Université de Zurich). canton de Lucerne ${ }^{39}$, forçant son vis-à-vis à plonger la tête dans la fontaine de l'infaillibilité papale (Unfehlbarkeit): de la poche de von Segesser, dépasse un livre titré « Le Kulturkampf de Segesser » (Der Kulturkampf von Segesser) ${ }^{40}$ (cf. fig. Io).

Le combat justifie l'intervention d'Evangelica, allégorie abominable incarnant l'ensemble des "forces obscures " ${ }^{4}$, et celle de l'allégorie du "danger de la religion » (Religionsgefahr), une furie échevelée ${ }^{42}$. Pour le Nebelspalter, les curés sont les acteurs principaux de la "Grande comédie des Lumières » (Grosse Aufklärungskomödie), selon l'inscription présente sur la banderole d'une image qui sera l'objet d'une réinterprétation, trente ans plus tard, dans la revue munichoise Jugend ${ }^{43}$. En I 878 , le pape en personne est visé à plusieurs reprises ${ }^{44}$. La question religieuse ne se dissocie pas de celle, également essentielle, d'une Constitution, constamment menacée par les "ultramontains ", selon le journal ${ }^{45}$. Dans les faits, le Kulturkampf est à l'origine d'articles d'exception dirigés contre les catholiques dans la nouvelle Constitution de I 874 .

Sur Philipp Anton von Segesser: Heidi Bossard-Borner, « Segesser von Brunegg, Philipp Anton von », Dictionnaire historique de la Suisse (19/04/2013); http://www. hls-dhs-dss.ch/textes/f/F4203.php.

Nebelspalter 1875/31, dessin pleine page non signé intitulé « Le grand combattant du Kulturkampf » (Der grosse Kulturkämpfer).

Nebelspalter 1875/9, dessin pleine page non signé intitulé « Le nouveau putsch zurichois » (Derneue "Züriputsch »).

Nebelspalter 1875/20, dessin de couverture non signé intitulé "Vous la reconnaitrez à ses Fruits » (An ihren Früchten sollt ihr sie Erkennen).

Nebelspalter 1875/44, dessin pleine page non signé intitulé « Les pacifiques du pays » (Die Stillen im Lande); Jugend 1905/19, dessin pleine page de Erich Wilke intitulé « Nous voulons être un seul peuple Fraternel » (Wir wollen sein ein einig Volk von Brüdern!); cf. Laurence Danguy, L'ange de la jeunesse - La revue Jugend et le Jugendstil à Munich, op. cit., planche 20.

Nebelspalter 1878/7, dessin pleine page non signé et sans titre; Nebelspalter $1878 / 23$, dessin de couverture non signé intitulé « Le pape part en vacances » (Der Papst geht in die Ferien).

Nebelspalter 1875/22, dessin de couverture non signé intitulé " J'avais un camarade! » (Ich hatt' einen Kameraden); cet anticléricalisme du Nebelspalter est et restera cependant de l'évolution antireligieuse qu'on observe en France; Guillaume Doizy, « De la caricature anticléricale à la farce biblique », Archives de sciences sociales des religions, 134, Paris, Ehess, 2006, p. 63-91. 


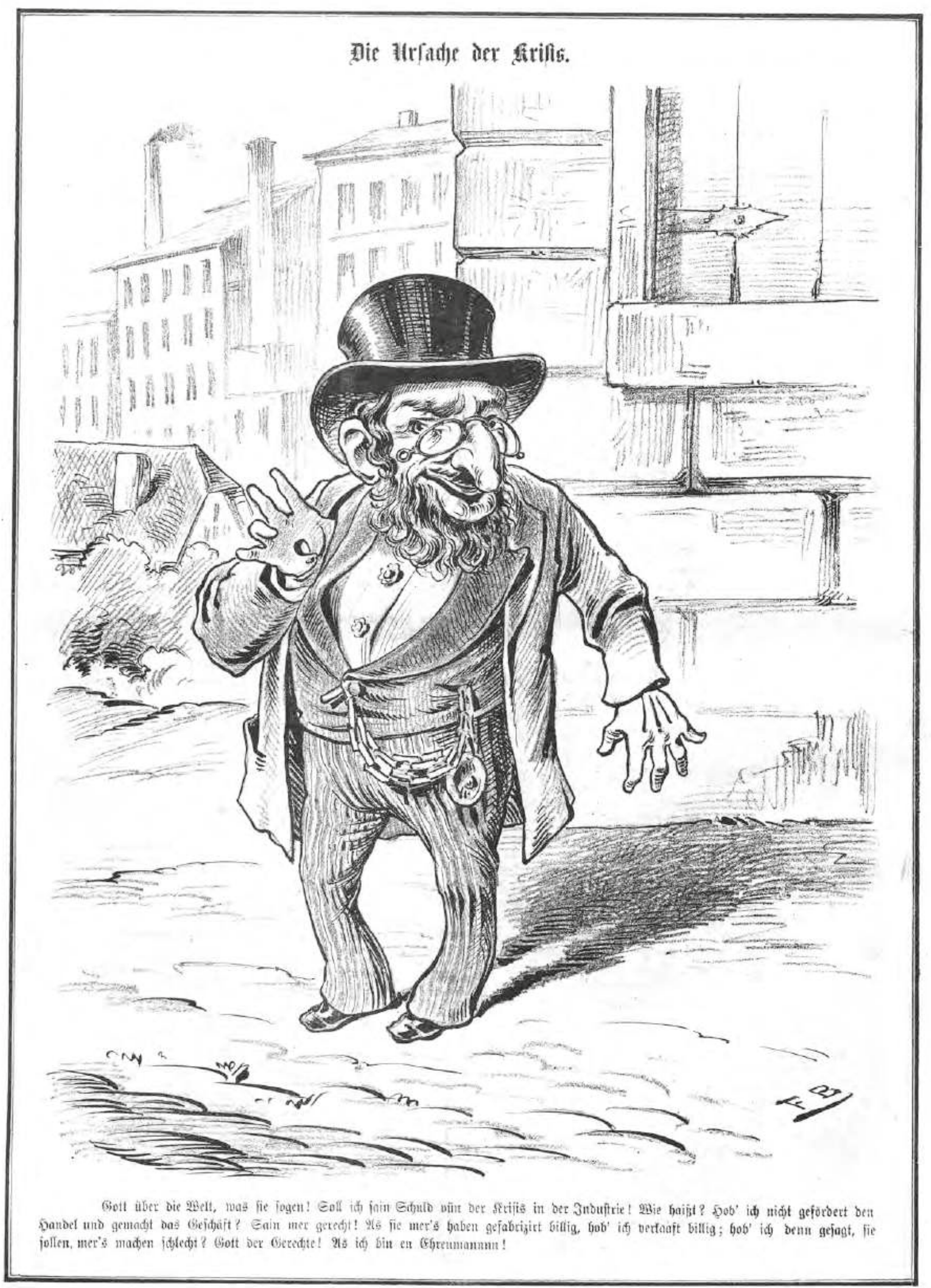

Fig. 9. Nebelspalter 1877/11, dessin pleine page en noir et blanc signé Boscovits senior intitulé « L'origine de la crise » (Die Ursache der Krisis). 


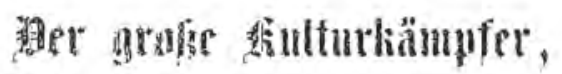

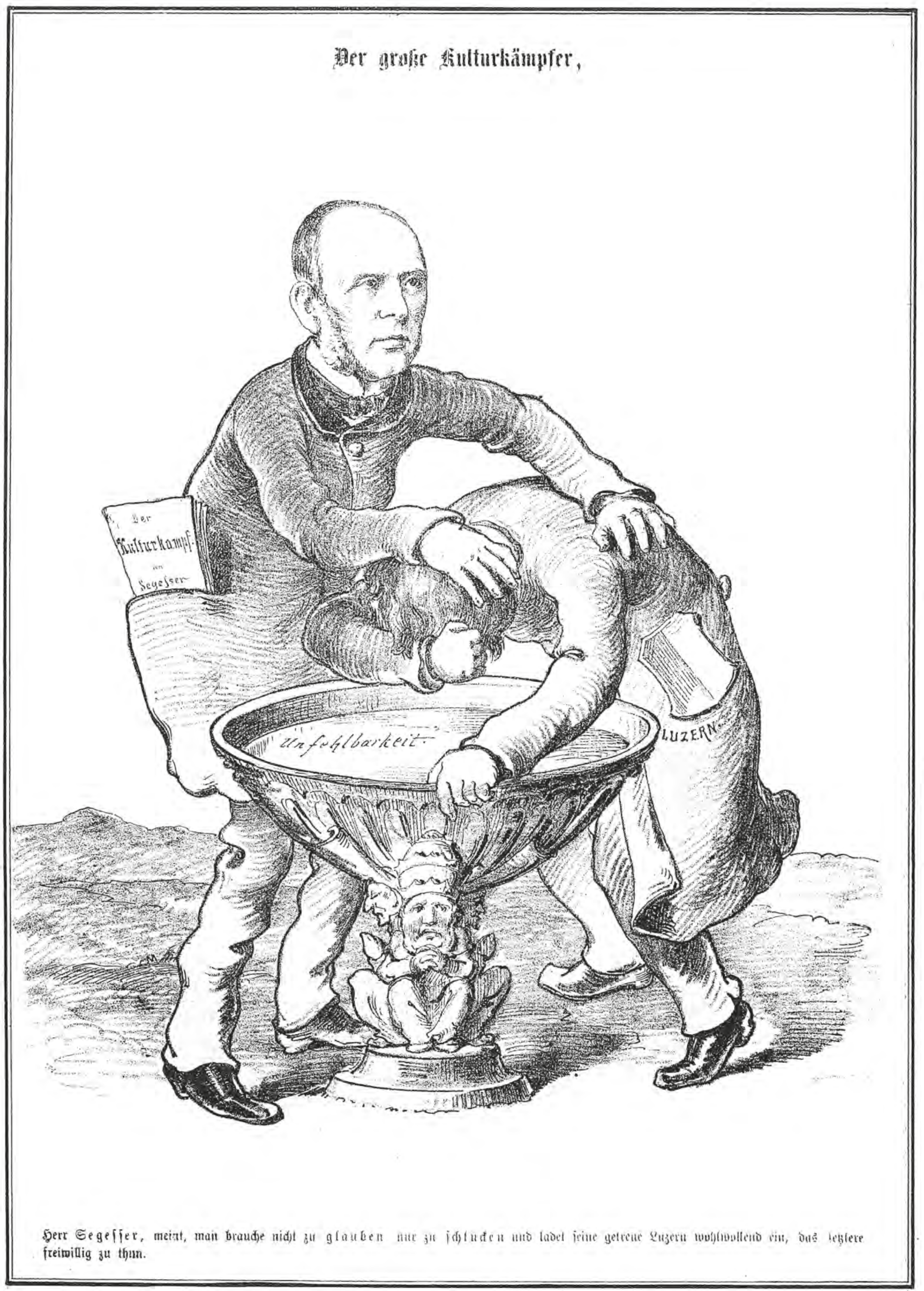

Fig. 10. Nebelspalter 1875/31, dessin pleine page en noir et blanc non signé intitulé « Le grand combattant du Kulturkampf » (Der grosse Kulturkämpfer). 
Les autres thématiques sont l'armée, les questions financières, bancaires et fiscales, l'arsenal législatif et la réforme électorale, la vie parlementaire ${ }^{46}$, l'industrie, les lois sur le commerce, les accords commerciaux, le Gothard et les transports ferroviaires, les lois sur les mœurs (alcool, tabac, mariage), l'émigration, à partir des années I 880 , la presse, l'éducation, la vie zurichoise ainsi que le dialogue entre les différentes parties culturelles et linguistiques du pays. Parmi ces thématiques, certaines prennent une dimension particulière.

La cohésion des différentes régions linguistiques est de celles-ci. Le thème est exemplarisé par la figure du gâteau qu'il faut découper ${ }^{47}$. Il est l'objet d'une attention qui ne se reverra plus par la suite. Le Tessin, à la vie politique instable, est très observé durant toutes ces années. Ceci, en particulier lors des transactions entre la papauté et la Confédération en I 884, générant de nombreuses compositions hostiles à l'Église, puis à l'occasion du référendum de I 886 sur le rattachement du Tessin à l'évêché de Bâle ${ }^{48}$.

L'organisation militaire, le coût de fonctionnement et le soldat inutile constituent les trois modes d'évocation du sujet militaire, également très présent. La recrue, fainéante et inefficace, ressortit d'ailleurs à un modèle décontextualisé, se prêtant à de petites scènes humoristiques 49 . Le genre se féminise en I 885 avec "Les dames à la mode préférées des militaires » (Militärliebliche Damenmoden), variations féminines de l'infanterie, de la cavalerie, de l'artillerie et du génie ${ }^{50}$.

La vie zurichoise est reléguée derrière les questions nationales, et traitée sous ses différentes facettes, de la loi sur l'usure, propice à des schèmes antisémites, à l'élargissement urbain via l'intégration de communes voisines, en I $885^{51}$. La croissance urbaine devient un thème privilégié. Dès cette époque, la ville est l'objet d'une iconographie particulière. La vie culturelle n'est en revanche que rarement thématisée ${ }^{52}$.

Progressivement, s'installe une condamnation du socialisme. La figure du socialiste apparaît pour la première fois en I 877 dans un dessin humoristique ${ }^{53}$. En I 88 I, le personnage du Nebelspalter se saisit de ses jumelles pour regarder, depuis la terre, l'arrivée de la comète de la social-démocratie portée par Hermann Greulich, l'un de ses principaux représentants en Suisse, très actif à Zurich ${ }^{54}$. Le Congrès socialiste, interdit à Coir, se tient alors à Zurich ${ }^{55}$. La revue, hostile aux extrêmes, quels qu'ils soient, dénonce au même moment les dangers nihiliste et réactionnaire. En I 886, l'anarchie

은

Nebelspalter 1880/8, dessin pleine page non signé intitulé « Jours de travai ordinaires dans la société. La recrue " (Normalarbeitstage aus der Gesellschaft. Der Rekrut)

Nebelspalter 1885/40, dessin pleine page de Boscovits senior intitulé « Les dames à la mode préférées par les militaires » (Militärliebliche Damenmoden).

Nebelspalter 1885/46, double-page de Boscovits senior intitulée « Sur la réunion de Zurich et de ses communes extérieures » (Zur Vereinigung von Zürich und seinen Ausgemeinden).

Cf. « 3.2.3. Chronique visuelle d'une ville: Zurich».

Nebelspalter $1877 / 20$, dessin non signé intitulé « Le petit socialiste " (Der kleine Socialist).

Nebelspalter 1881/26, dessin non signé intitulé « la comète » (Der Komet).

Cf. aussi « 3.2.1. Le face-à-face (helvétique) du Nebelspalter avec Helvetia » sur Greulich: Markus Bürgi, « Greulich, Herman », Dictionnaire historique de la Suisse, 2007 (17/07/2007); http://www.hls-dhs-dss.ch/textes/f/F3738.php. et la démagogie, sources de discorde (Zwietracht), sont énoncées comme les ennemies de l'ouvrier ${ }^{56}$.

Dans un premier temps, la modernité n'est présente qu'au travers des transports ferroviaires et des représentations d'une ville socialisée ${ }^{57}$. Elle ne s'invite vraiment qu'en I 886 , avec l'apparition du personnage du photographe et du télégraphe. La femme moderne se vêt bien sûr à la mode.

Il n'est guère fait de place à l'art, mises à part les mentions des expositions tournantes (Turnus) en I 877 et de l'exposition nationale de I 883 . L'année I 886 est marquée par le début des débats sur les subventions fédérales et le musée d'art de la ville de Zurich, le futur Kunsthaus ${ }^{58}$.

La présence étrangère est très largement dominée par les grands voisins, l'Allemagne et surtout la France. Celle-ci est notamment associée à Gambetta, jusqu'à la mort de celui-ci, fin I 882, puis au général Boulanger, dont l'ascension est vue d'un œil extrêmement méfiant. Bismarck, invariablement représenté avec trois poils sur le caillou, colle pour ainsi dire à l'Allemagne ${ }^{59}$ (cf. fig. II).

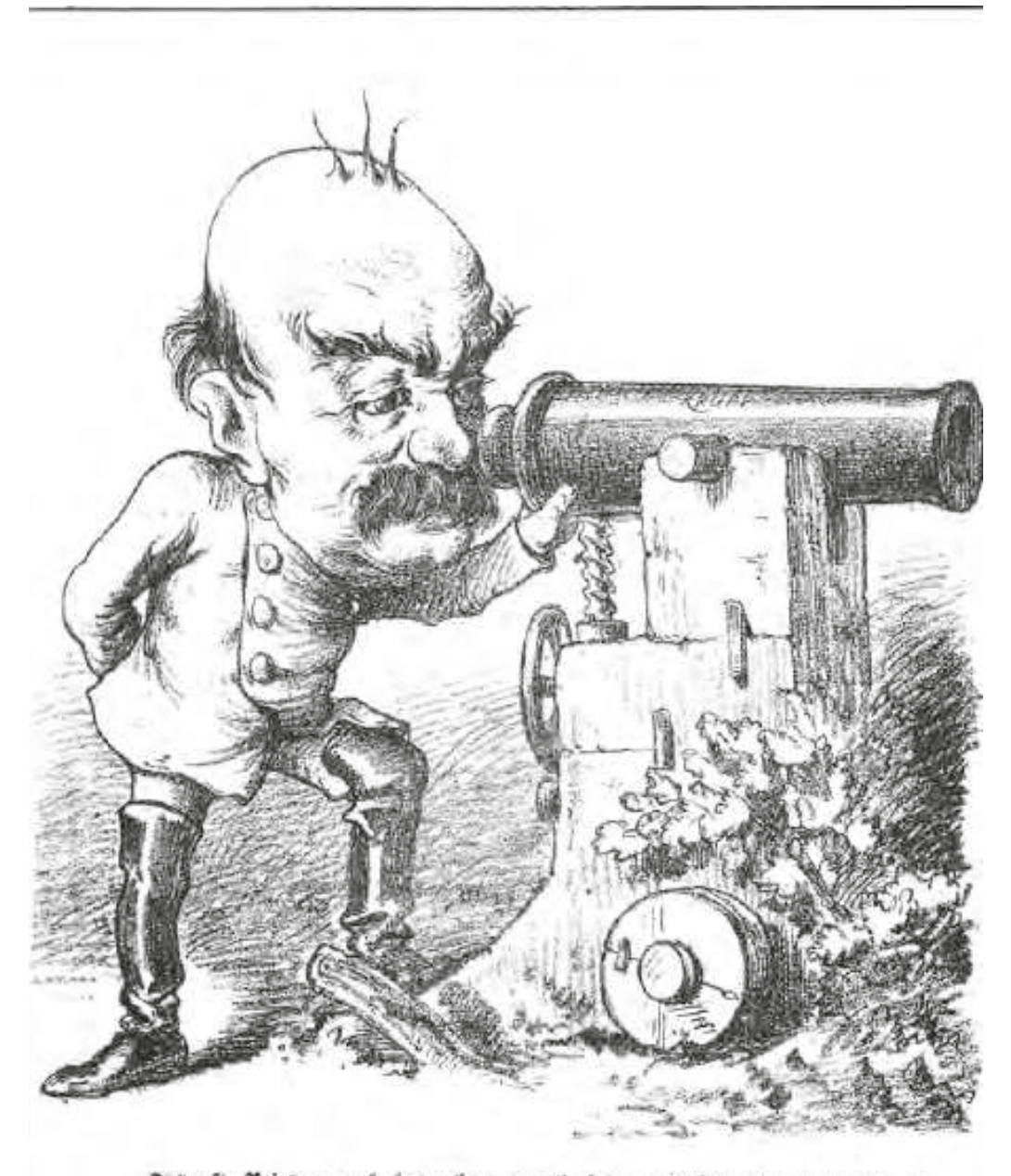

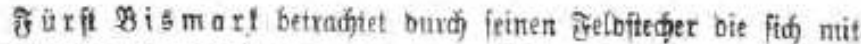

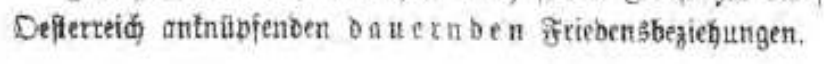

\begin{abstract}
Fig. 11. Nebelspalter $1875 / 8$, dessin anonyme
en noir et blanc et sans titre (dernière page).
Fig. 11. Nebelspalter $1875 / 8$, dessin anonyme
en noir et blanc et sans titre (dernière page).
\end{abstract}

\footnotetext{
Nebelspalter 1886/25, double-page de Boscovits senior intitulée « Mise en garde et avertissement » (Warnung und Mahnung).

Cf. « 3.2.3. Chronique visuelle d'une ville: Zurich».

Cf. « 4. DISCOURS SUR L'ART ».

L'iconographie s'installe dès 1875 ; voir par exemple, Nebelspalter 1875/8, dessin anonyme et sans titre (dernière page); Grand-Carteret, compilateur de l'iconographie de Bismarck en Europe, ne recense pas ce type pour la Suisse; John Grand-Carteret, Bismarck en caricatures, Paris, Perrin et Cie, 1890, p. 245-259.
}

\section{caillou, colle pour ainsi dire à l’Allemagnesg (cf. fig. Ir).}


La rivalité et l'esprit revanchard qui régissent les relations entre les deux pays sont sans cesse pointés. Les deux pays constituent aussi un relai du combat anticlérical du Nebelspalter; pour la France, avec la question de la séparation de l'Église et de l'État ${ }^{60}$; pour l'Allemagne, avec les suites du Kulturkampf et la montée du parti du Centre (Zentrum).

Les autres pays sont en nombre limité et doivent leur présence, soit à la question coloniale, soit à un événement important, soit à une situation préoccupante: l'Autriche-Hongrie, à la conclusion de la Duplice avec l'Allemagne en I 879; l'Espagne, lors de l'avènement de la Constitution en 1876 , puis lors de la crise monarchique de I $883^{61}$; les États-Unis aux lendemains des élections présidentielles de I 876 , I 880 et I 884 ; la Russie, dont le tsar est taxé de brutalité à l'égard du peuple avant même l'arrivée sur le trône d'Alexandre III en I 88I; l'Afrique du Sud en I 879 pendant la guerre anglozouloue; l'Angleterre en lien avec la question irlandaise.

À partir de I 880 , les appétits coloniaux de l'Angleterre, de la France et de l'Allemagne sont systématiquement dénoncés. Des pays ou territoires, tels que le Soudan, le Congo, l'Égypte, le Tonkin, le Cameroun et la Tunisie sont exhibés comme proies et objets de convoitise des grandes puissances européennes. Il s'agit ici de conforter le choix politique de la Suisse de rester dans ses Frontières. La question d'Orient est brûlante dès I 875 et le reste par la suite. Elle justifie, du reste, la première mention de la neutralité (suisse) en I $876^{62}$. Le canal de Suez fait son entrée en I 882, au moment où les Anglais en prennent le contrôle ${ }^{63}$, tandis que le projet d'un tunnel sous la Manche, entre Calais et Douvres, est thématisé à partir de I $884^{64}$. Les alliances sont regardées avec toujours davantage d'attention, la Duplice (Allemagne/AutricheHongrie) en I 879, la première Triplice en I 882 (Autriche-Hongrie, Allemagne, Italie). En I 886 , de nombreuses compositions évoquent un risque de guerre, de sorte que c'est le dieu Mars qui se tient à la porte de l'année i $887^{65}$.

\subsubsection{Un langage visuel et rhétorique très typé}

Les premières années, les choses importantes sont d'abord dites par le texte, de préférence en couverture. Durant cette période, celle-ci montre soit un texte, soit une caricature. Alors qu'en I 875 , les dessins ne sont qu'exceptionnellement signés, ils commencent à l'être davantage en I 876 et le sont assez fréquemment en I 886 par Boscovits senior, alors seul à œuvrer. Les archives révèlent que les dessinateurs ne légendaient généralement pas leur dessin mais il est à supposer qu'un dessinateur comme Boscovits senior, dont le graphisme est très lié à la légende, était pour le moins étroitement associé à cette tâche, la chose sera du reste attestée pour son fils,

Nebelspalter 1880/14, dessin pleine page non signé intitulé « De la galerie des peintures » (Aus der Gemäldegalerie).

Nebelspalter $1883 / 40$, dessin pleine page de Boscovits senior intitulé « La schnadahüperl d'Alphonse » (Alfons Schnadahüperl); Jean-Claude Drouin, "Les non-ralliés deux fois: les Blancs d'Espagne de 1883 à nos jours", dans Les ralliements, ralliés, traîtres et opportunistes du Moyen Âge à l'époque moderne et contemporaine, éd. Marc Agostino, Françoise Bériac, Anne-Marie Dom, Bordeaux, CROCEMC, p. 197-214.

Nebelspalter 1876/51, dessin non signé intitulé « La neutralité perd de sa valeur » (Die Neutralität fällt im Werthe); à signaler un travail universitaire réalisé à l'aide de caricatures du Nebelspalter: Daniel Aquillon, Dans la trace des impérialistes: les Suisses en Orient 1890-1914, 1980 (mémoire soutenu à l'Université de Genève).

Nebelspalter 1882/34 dessin pleine page non signé intitulé « L'important » (Der Wichtigmacher).

Nebelspalter $1884 / 22$, dessin pleine page de Boscovits senior intitulé « Peur inutile » (Unnütze Angst).

Nebelspalter 1886/51, dessin pleine page de Boscovits senior intitulé « Sur la situation » (Zur Situation).
Boscovits junior ${ }^{66}$. Conçue comme une accroche visuelle en appui au texte, l'image est alors présente sous la forme de caricatures de grand format ou d'icones accompagnant une rubrique.

Le langage visuel des premières années est celui de la caricature avec son lot de déformations, de types et ressorts comiques, de rhétorique antithétique (avant/après), d'insertions de légendes dans les dessins, d'animalisations, de réifications, l'usage, enfin, de figures types, dotées de leurs attributs et insérées dans des constructions spatiales fermées ${ }^{67}$. En I 880 , l'espace perspectif s'ouvre, les figures se rapprochent du lecteur et les effets architectoniques se font plus discrets. Les motifs, souvent idiomatiques, sont tracés d'un trait fin. L'espace est rempli à l'économie et le point de fuite décentré. Les motifs de prédilection sont alors le banc (pour la banque), le bateau politique, le boudoir (tout aussi politique) avec ou sans malade, l'essaim de guêpes, la toile d'araignée, l'urne de la vox populi, le balai pour chasser l'ennemi, l'armure des conservateurs, la tresse des mêmes conservateurs, les ciseaux de la censure, le journal anthropomorphe, les trains animés, pour n'en citer que quelques-uns. La plupart de ces motifs sont issus d'un fonds commun aux revues illustrées européennes; certains, tels la vache ou le train, très fréquents et pérennes, sont, par contre, endogènes.

Exogènes, les motifs sont l'objet d'une appropriation et parfois même d'une acculturation, tels le jeu de cartes transformé en jeu de Jass ${ }^{68}$ ou un arbre politique, aux avatars expressifs, chêne rongé par les hannetons des impôts en I $886^{69}$, pommier allemand menacé par les lois sociales de Bismarck en $\mathrm{I} 88 \mathrm{I}^{70}$ ou encore arbre aux pendus sur une couverture de la même année I $88 \mathrm{I}^{71}$. Tous ces motifs se prêtent à de multiples variations, la série des cartes anthropomorphes intitulée "L'Europe actuelle " (Das heutige Europa), entamée par Boscovits senior en I 886 en est sans doute l'expression la plus aboutie ${ }^{72}$.

L'éventail thématique ouvre sur des titres différenciés. Certains scandent l'année et affirment l'identité suisse et satirique du

Ce qu'enseigne la consultation des archives Boscovits.

Pour une approche globale de la caricature et du dessin humoristique, voir en première intention: Laurent Baridon et Martial Guédron, L'art et l'histoire de la caricature, Paris, Citadelles et Mazenod, 2006; Michel Melot, L'œil qui rit. Le pouvoir comique des images, Paris, Bibliothèque des arts, 1975; Michel Ragon, Le dessin d'humour. Histoire de la caricature et du dessin humoristique en France, Paris, Seuil, 1992 ; Bertrand Tillier, À la charge ! La caricature en France de 1879 à 2000, Paris, L'amateur, 2005; Werner Hofmann, La caricature de Vinci à Picasso, Paris, Somogy, 1958; Ernst Gombrich et Ernst Kris, Caricature with Sixteen Colour Plates, Londres, King Penguin Books, 1940; La caricature et si c'était sérieux, Paris, Nouveau monde, 2015; les numéros de la revue Ridiculosa, en particulier: Ridiculosa, 8 (2001), Les procédés de déconstruction de l'adversaire, éd. Bruno de Perthuis; Ridiculosa, 18 (2011), Les revues satiriques Françaises, éd. Jean-Claude Gardes, Jacky Houdré et Alain Poirier; Ridiculosa, Hors série (2014), La presse satirique dans le monde.

68 Le jass est un jeu de cartes ressemblant à la belote.

Nebelspalter 1886/20, dessin pleine page non signé intitulé « Pauvres hannetons » (Armer Maikäfer).

Nebelspalter 1881/16, dessin pleine page non signé intitulé "Les têtes brûlées » (Gebrannte Kinder)

Nebelspalter 1881/14, couverture non signée intitulée "Conséquences de toutes sortes " (Allerlei Konsequenzen); sur l'arbre politique en Suisse et dans le Nebelspalter: Laurence Danguy, François Lormant et Laurent Olivier, «L'arbre partisan. Représentation de l'arbre dans la communication des partis politiques », dans Forêt et communication: héritages, représentations et défis, éd. Charles Dereix, Christine Farcy, François Lormant, Paris, L'Harmattan, 2016, p. 311-314; Sur l'arbre aux pendus: Laurence Danguy et François Lormant, « Les arbres aux pendus ", Cahier d'études Forêt - Environnement et Société $x{ }^{e}{ }^{e}-x x^{e}$ siècle, éd. Andrée Corvol, $\mathrm{n}^{\circ} 20, \mathrm{CNRS}$ et Institut d'histoire moderne et contemporaine, 2010, p. 41-48.

Nebelspalter 1886/45, double-page en noir et blanc de Boscovits senior intitulée "L'Europe actuelle » (Das heutige Europa); cf. " 6.2. Intrigues suisses et influences Françaises dans le monde éditorial : Jean Nötzli, John Grand-Carteret et Cäsar Schmidt ». 


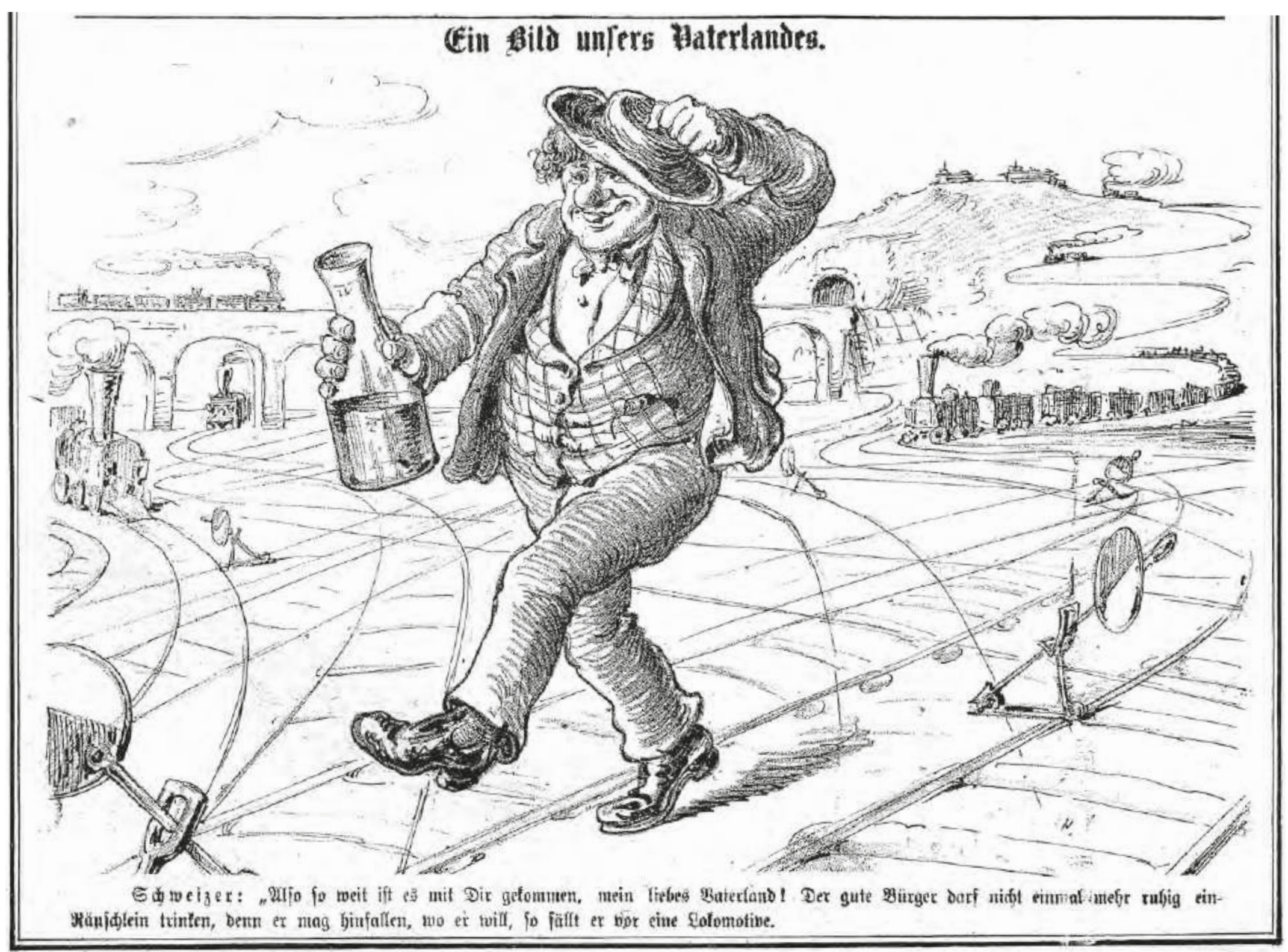

Fig. 12. Nebelspalter 1875/40, couverture en noir et blanc non signée intitulée « Une image de notre pays » (Ein Bild unsers Vaterlandes).

Nebelspalter: "Les images de l'hiver" (Winterbilder), le carnaval, la fête zurichoise des Sechseläuten, célébrant la fin de l'hiver, les Pâques, la saison des baignades (Zur Badesaison), la canicule (Hundstage) le concours de tir (Schützenfest), le festival de chant (Sängerfest), la saison de la chasse (Jagd-Saison). Des titres aux résonnances idiomatiques les complètent: "Le concombre acide " (Die saure Gurke), «Les fleurs du printemps »(Frühlingsblüten), "Les raisins acides" (Saure Trauben); tandis que d'autres participent du langage international de la caricature: " La course mondiale » (Das Wettrennen), "Les temps changent " (Die Zeiten ändern), "La vieille chanson » (Das alte Lied), « La soupe » (Die Suppe)" ou encore "Les nouvelles illustrées des journaux» (Illustrirte Zeitungsnachrichten). En I 880, la rhétorique de la civilisation fait son entrée en relation avec la question d'Orient ${ }^{73}$. En I 882, c'est au tour de celle de la culture, en lien, cette fois, avec le canal de Suez ${ }^{74}$.

Le procédé de l'étranger comme miroir de la Suisse sert à nourrir les peurs pour conforter les choix. L'Espagne, avec ses maux économiques et sociaux, sert de contre-exemple à une Suisse qui doit tout faire pour éviter un destin semblable ${ }^{75}$. Les conséquences

Nebelspalter 1878/6, dessin pleine page non signé intitulé « Mœurs pieuses » (Fromne Sitte).

Nebelspalter 1882/34, dessin pleine page non signé intitulé « Le prétentieux » (Die Wichtigmacher)

Nebelspalter 1883/10, dessin pleine page non signé intitulé « La main noire » (Die schwarze Hand). meurtrières des politiques coloniales, menées par la France, l'Allemagne et l'Angleterre sont épargnées à la Suisse qui a fait le choix du maintien dans ses frontières et de la neutralité ${ }^{76}$.

Les références humanistes sont alors nombreuses, avec un abus de citations latines dans les titres et les légendes, et d'emprunts au fonds religieux, recyclé à la mode anticléricale. Les types du moine et plus encore du jésuite côtoient celui du juif usurier, servant un antisémitisme qui sera présent tout du long de la période zurichoise. D'autres types plus légers, tels ceux de l'ivrogne (Sauser) ${ }^{77}$ et du chapardeur viennent contrarier le penchant rigoriste de la société zurichoise, hérité de la doctrine réformée de Zwingli ( I 484-I 53 I) (cf. fig. I2).

Les hommages aux grands hommes, politiciens, militaires, intellectuels ou artistes que commémore avec zèle le Nebelspalter jusqu'à la fin de la période fondatrice, sont présents dès l'origine. Les onze compositions de 1875 seront pourtant un record. Il s'agit d'un genre dans lequel s'implique jusqu'au personnage du Nebelspalter qui, en I 876 , portraiture le conseiller fédéral

Nebelspalter 1883/43, dessin pleine page non signé intitulé "Reconnu! » (Erkannt!).

Sur ce motif: Myriam Tsikounas, « Les représentations de l'alcoolique, des clichés du XIX ${ }^{e}$ siècle aux médias actuels", dans Les représentations de l'alcoolique, éd. Henri Gomez, Toulouse, Érès 2015, p. 16-44; Food \& History, n 1 , La Création ivre. L'alcool, moteur, motif et métaphore artistique, $X V^{\ominus}-X X^{\ominus}$ siècles, éd. Frédérique Desbuissons et Valérie Boudier, 2011. 
Numa Droz ${ }^{78}$. Qu'ils se trouvent en couverture, sur une doublepage ou en dernière page, avec ou sans texte laudatif, les hommages répondent à une iconographie très normée, ne dérogeant que rarement au portrait en médaillon. En I 880 , le président des États-Unis nouvellement élu, salué par un Nebelspalter lui rappelant les accords commerciaux, dénote une ouverture sur l'étranger ${ }^{79}$. En I 885 , la présence de Victor $\mathrm{Hugo}^{80}$ témoigne d'un élargissement du panthéon culturel. L'hommage à Papa Suchard en I $884^{81}$ est néanmoins très représentatif de la connotation très suisse du genre, durant toutes ces années où les questions intérieures sont prioritaires.

\subsubsection{L'installation d'un appareil allégorique}

L'allégorie est alors très présente, sous une forme très $\mathrm{XIX}^{\mathrm{e}}$ siècle qui revisite les types séculaires de Cesare Ripa, sans néanmoins s'en émanciper tout à fait, comme ce sera le cas au tournant du siècle. Boscovits senior en fait un usage immodéré, multipliant les figures féminines, ailées ou non, pour personnifier des valeurs, telles la morale, la justice ${ }^{82}$, la liberté ${ }^{83}$ ou des pays, avec pour vedettes la France ${ }^{84}$ et l'Allemagne ${ }^{85}$ ainsi que l'Europe, pour la première fois en scène en $\mathrm{I} 876^{86}$. Alors que le sexe de l'allégorie est traditionnellement déterminé par le genre du substantif, la loi n'est pas toujours respectée, comme lors des Pâques - toujours politiques dans le Nebelspalter - de l'année i 876, où l'industrie (Industrie), l'artisanat (Gewerbe), la panique (Panik) et la crise (Krise) sont féminins, tandis que le commerce (Handel) et la confiance (Vertrauen) sont masculins ${ }^{87}$ - l'artisanat, de genre masculin, devrait logiquement être figuré sous les traits d'un homme. L'apparition de certaines allégories est significative de l'évolution politique, tels la diplomatie, en $\mathrm{I} 878^{88}$; l'opinion publique, en I $880^{89}$; la démocratie, en I $882^{90}$; l'Assemblée fédérale (Bundesvesammlung), en I $882^{91}$; le progrès, en I $884^{92}$ et, toujours en 1884 , une $v o x$ populi qui prend les traits d'Helvetia ${ }^{93}$. Plus rarement, ces allégories portent leurs habits traditionnels, ceux de la poésie, par exemple ${ }^{94}$. Toutes ces figures, très majoritairement féminines, ont en commun de rejoindre les déclinaisons de l'iconographie de la femme développée dans la revue. Articulée

${ }_{78} \quad$ Nebelspalter 1876/3, dessin en noir et blanc de Boscovits senior intitulé « Comment le Nebelspalter a quand même saisi Numa Droz » (Wie der Nebelspalter Numa Droz doch bekommen hat).

Nebelspalter 1880/45, dessin pleine page de Boscovits senior intitulé « Général James A. Garfield, le nouveau président des États-Unis) (General James A. Garfield, der neue Präsident der Vereinigten Staaten).

- Nebelspalter 1885/22, double-page en noir et blanc de Boscovits senior intitulée "Victor Hugo ».

Nebelspalter 1884/4, dessin de couverture non signé intitulé «Papa Suchard ».

Nebelspalter 1875/30 couverture non signée intitulée « Blamatus ille ».

Nebelspalter 1883/31, dessin pleine page de Boscovits senior intitulé « Jubilé de la Haute école zurichoise » (Jubiläum der Zürcher Hochschule).

84 Nebelspalter 1876/15, couverture de Boscovits senior intitulée « Français » (französisch).

" Nebelspalter 1876/49, dessin pleine page de Boscovits senior intitulé « Entre fleurs " (Unter Blumen).

" Nebelspalter 1876/21, dessin signé « $A \mathrm{~N}$ » intitulé «La rencontre des trois empereurs » (Die drei Kanzler-Zusammenkunft).

Nebelspalter 1876/16, dessin pleine page de Boscovits senior intitulé « Joyeuses Pâques » (Frohe Ostern).

Nebelspalter 1878/1, dessin pleine page de Boscovits senior intitulé « Le maître de l'année 1878 » (Der Jahresregent von 1878).

${ }_{89}$ Nebelspalter 1880/19, dessin pleine page de Boscovits senior intitulé «C'est dangereux » (Gefährlich ist's).

Nebelspalter $1882 / 10$, dessin pleine page de Boscovits senior, sans titre.

Nebelspalter 1882/50, dessin pleine page non signé intitulé «La véritable ménagère » (Die richtige Haushälterin).

92 Nebelspalter $1884 / 17$, dessin pleine page de Boscovits senior intitulé « Une belle image » (Ein schönes Bild).

Nebelspalter 1884/20, dessin pleine page de Boscovits senior intitulé «Belles perspectives, non? » (Schöne Aussichten, was?).

94 Nebelspalter $1883 / 18$, dessin pleine page non signé intitulé "L'oubliée de l'exposition » (Die Verlassene an der Ausstellung). autour des types de la (bonne) ménagère, de l'ingénue et de la mégère, celle-ci ne coïncide que partiellement avec les archétypes hantant le XIX ${ }^{\mathrm{e}}$ siècle, de madone, de muse et de séductrice ${ }^{95}$. La composante domestique est, en effet, particulièrement prononcée dans le Nebelspalter.

Le personnage du Nebelspalter apparait très souvent durant cette première décennie, avec une variation annuelle de sept à seize occurrences. Boscovits senior, son unique créateur, joue avec son apparence, quoiqu'assez peu. Il déplace tout au plus les boutons de sa jaquette ou soustrait le chapeau. Parfois, cependant, le personnage se transforme à l'occasion d'un rôle, est mêlé, par exemple, à un archange dans une composition anticléricale ${ }^{96}$ ou coiffé d'une toque de cuisinier pour présenter une exposition culinaire ${ }^{97}$. Le Nebelspalter se trouve la plupart du temps dans des dessins politiques, où il incarne la fonction critique de la revue. Il prend alors position mais rarement de manière frontale: ce n'est pas pour rien qu'il se présente, soit de biais, soit dans un coin de l'image ${ }^{98}$.

Les icones, de la taille d'une vignette, sont dérivées des personnages du bandeau originel et représentent une extension narrative du personnage du Nebelspalter. Alors qu'elles ne sont pas nommées dans le premier numéro, c'est chose faite au fil des numéros pour une série de figures typiques de la vie zurichoise ou plus largement suisse, avec Herr Feufi (Monsieur cinq) et Fran Stadtrichter (Madame la juge de ville), se faisant des confidences sur la vie citadine; Chueri et Nägeli, agissant de même mais sur un mode plus familier; Stanislaus et Ladislaus, deux moines s'échangeant des missives. D'autres personnages apparaissent plus tard, en I 877 : le professeur qui restera sans nom, le braillard mal embouché (Düsterer Schreier) ainsi que le bouffon préposé à la boîte aux lettres (Briefkasten), rubrique obligée de toute revue illustrée, où les missives émanent le plus souvent de la rédaction. Plusieurs lettres conservées dans les archives Nötzli indiquent que l'éditeur y publiait des textes et même des messages à l'intention de ses correspondants ${ }^{99}$. En I 880, apparaît le rédacteur, associé au feuilleton. À ce moment, l'ensemble des icones est installé, à l'exception d'Eulalia, femme lettrée, apparaissant en I 893, en réponse aux mouvements d'émancipation féminine. Ces icones contribuent à l'identité de la revue. Il arrive, du reste, que l'une d'elles reçoive la place d'honneur, comme Stanislaus sur une couverture de I $884^{100}$.

Helvetia est moins souvent présente que le Nebelspalter et d'une relative rareté, entre trois et huit occurrences annuelles. Comme lui, elle doit tout au crayon de Boscovits senior, qui la décline dans ses tenues habituelles, de matrone, de paysanne et de guerrière. Son iconographie souffre de quelques exceptions, dictées par le contexte. Elle se mélange ainsi à une allégorie de la justice pourvue d'une épée et d'une balance, les yeux bandés, pour soutenir le discours anticlérical d'Emil Welti ${ }^{101}$. Helvetia

Anne Higonnet, "Archétypes », dans Histoire des femmes en Occident, tome 4, éd. Georges Duby, Geneviève Fraisse, Michelle Perrot, Paris, Plon, 1991, p. 250. Nebelspalter $1878 / 7$, dessin non signé et sans titre.

Nebelspalter 1885/39, double-page de Boscovits senior intitulée « Exposition culinaire » (Kochkunstausstellung).

98 Cf. pour plus de détails « 3.2.1. Le face-à-face (helvétique) du Nebelspalter avec Helvetia ».

Voir notamment une lettre de Franck Buchser ainsi que plusieurs lettres de Henri van Muyden: cotes 2.62 et 1.14 du fonds Nötzli.

100 Nebelspalter 1884/20, dessin de couverture.

101 Nebelspalter $1880 / 21$, dessin pleine page de Boscovits senior intitulé « Curieuses expériences » (Kuriose Erfahrungen). 
laisse très exceptionnellement la place à Guillaume Tell, son équivalent masculin ${ }^{102}$.

Quant à Chronos, ses apparitions se limitent alors à sa présence dans le bandeau entre i 875 et I 880 .

\subsection{7-1899: ouverture, couleur et premier Jugendstil sous l'ère Nötzli}

En I 887 , survient un premier tournant dans l'histoire du Nebelspalter avec l'apparition de la couleur. Une série de changements intervient, par ailleurs: de I 887 et I 900 , on compte quatorze nouveaux dessinateurs - dont Heinrich Jenny, Henri van Muyden, Emil Dill, Willy Lehmann-Schramm et Otto Maehly -; en I 889, une nouvelle technique de reproduction est choisie; on opte pour une forte ouverture internationale ainsi que pour un positionnement beaucoup plus artistique; enfin, le langage graphique évolue sensiblement. Pour le reste, une relative stabilité règne. Hormis un court partage de la responsabilité entre l'éditeur Jean Nötzli et Alfred Beetschen de la fin I 895 au début I 897, la rédaction reste la même. Le format et le cadre au trait demeurent, qui préservent l'apparence de la maquette, ainsi que la politique de prix et de distribution. En revanche, l'arrivée du Jugendstil, menace deux éléments essentiels de la couverture: le titre et le personnage du Nebelspalter, dont le monopole n'est plus garanti.

\subsubsection{Identité, maquette et technique - Changements techniques et oscillations du titre}

Le passage à la couleur permet une stabilisation progressive de la maquette. À l'occasion du deuxième dessin en couleur, un encart annonce le principe d'un double-numéro hebdomadaire " comportant un feuillet artistique finement exécuté " (mit einem fein ausfegührten Kunstblatt), le présent numéro consistant en un «numéro d'essai » (Probenummer) ${ }^{103}$. La formule n'est cependant appliquée que l'année suivante, en I 888 . Un numéro compte dès lors huit pages, à de rares exceptions, comme le numéro de la fête nationale du $\mathrm{I}^{\text {er }}$ août en I89I, ne comptant que quatre pages ou l'année i 896 comprenant quelques numéros de dix pages.

Si le sous-titre ne change pas, le titre devient, par contre, incertain avec l'apparition des couvertures Jugendstil, à l'été I $897^{104}$. Publiées à un rythme (à peu près) mensuel, en alternance avec la formule classique, celles-ci sont, hormis le titre, entièrement couvertes par l'image. Le schéma-type est celui d'une jeune femme, jouant d'une main, d'un doigt ou d'une baguette avec le titre "Nebelspalter ", qui devient inconciliable avec l'article masculin "Der ». On lira donc désormais soit Der Nebelspalter (pour la formule classique), soit Nebelspalter (pour la formule rénovée); ceci jusqu'à l'abandon définitif du modèle originel, en I908 (cf. fig. I3).

\footnotetext{
102 Georg Kreis, Helvetia im Wandel der Zeiten. Die Geschichte einer nationalen Repräsentationsfigur, Zurich, Verlag Neue Zürcher Zeitung, 1991, p. 32-33.

о3 Nebelspalter 1887/41, encart intitulé « À nos lecteurs » (An unsere Leser).

104 Nebelspalter 1897/29, couverture de W. Lehmann-Schramm.
}

Fin I 889, le Nebelspalter fait paraître un long encart valorisant un nouveau procédé de reproduction, présenté comme une amélioration rendue nécessaire en raison de nouvelles ambitions artistiques:

Le Nebelspalter doit, de ce fait, également adopter un nouveau procédé de réalisation technique, qui permettra de restituer plus fidèlement que jamais les dessins ${ }^{105}$.

Il s'agit très probablement du procédé Gillot, dérivé de la zincographie. La technique consiste à fixer par décalque l'image sur le métal, puis à monter celle-ci en relief au moyen de morsures par l'acide, l'image étant protégée par une matière grasse, à cette époque la gélatine bichromatée. D’un maniement complexe, le procédé permet de modifier l'échelle des dessins, de rendre leur reproduction rapide et de minorer les coûts, une manne pour un éditeur ${ }^{106}$.

Une manne pour un éditeur mais pas pour un dessinateur, et Henri van Muyden s'en plaint à plusieurs reprises dans la correspondance qu'il entretient avec Jean Nötzli. Ainsi le I 6 avril I890:

Mais soyez sans inquiétude, je vous reste fidèle, et n'ai seulement qu'un regret, c'est que le procédé que vous employez pour la reproduction de vos gravures soit si imparfait ${ }^{107}$.

Puis, à nouveau quelques mois après, le I 6 novembre I 890 :

C'est un peu la faute du procédé lithographique et des encres grasses, si mes dessins manquent du flott et du chic, que vous désirez. Mais ce flott et ce chic, je m'efforce de vous les donner dans mes derniers dessins ${ }^{108}$.

La période est aux expérimentations, y compris typographiques: le texte entre dans l'espace de l'image ${ }^{109}$; les caractères sont placés, serrés au milieu de la page ${ }^{110}$; le texte est calé en coin de page ${ }^{111}$; le cadre est épaissi ${ }^{112}$. Toutes expériences sans suivi.

Les doubles-pages sont désormais bien installées. Durant cette période, leur fréquence quasi-mensuelle est à peu près stable, avec un record de douze doubles-pages pour l'année i 888. À partir de I 899, où l'on ne compte plus que six doubles-pages, leur nombre baisse sensiblement.

\subsubsection{Distribution, politique commerciale et lectorat - En avant toute}

L'année i 887 marque un tournant dans la politique commerciale. La liste des points de vente suisses et étrangers disparaît définitivement, signe d'un système de distribution désormais bien rodé. L'arrivée de la couleur ouvre sur un système de prix différencié, avec un prix du numéro en couleur à 50 cts. contre 25 cts. pour les numéros en noir et blanc. La politique commerciale s'affine. Comme auparavant, les abonnements sont à souscrire dans les bureaux de postes et les librairies. Les prix en sont

\footnotetext{
( « Der Nebelspalter » muss in Folge dessen auch in der technischen Ausführung zu einem neuen Verfahren greifen, welche hinwieder die Zeichnungen vortrefflicher, als bisher, wiedergeben wird.); Nebelspalter 1889/51, encart en couverture; cf. aussi « 6.4. Passions d'artistes: Richard Kissling, Evert van Muyden, Henri van Muyden et Jean Nötzli ».

.6 Laurent Bihl, La Grande Mascarade parisienne. Production, diffusion et réception des images satiriques dans la presse périodique illustrée parisienne entre 1881 et 1914, op. cit., p. 212-217.

Cote 1.14 de la succession Nötzli, lettre du 16 avril 1890.

${ }_{108}$ Cote 1.14 de la succession Nötzli, lettre du 16 novembre 1890

109 Nebelspalter $1887 / 20$

Nebelspalter $1888 / 46$

Nebelspalter $1891 / 22$

À plusieurs reprises durant l'année 1892.
} 
Zürich 1897. XXIII. Jahrgang N.52. 25. Dezember.

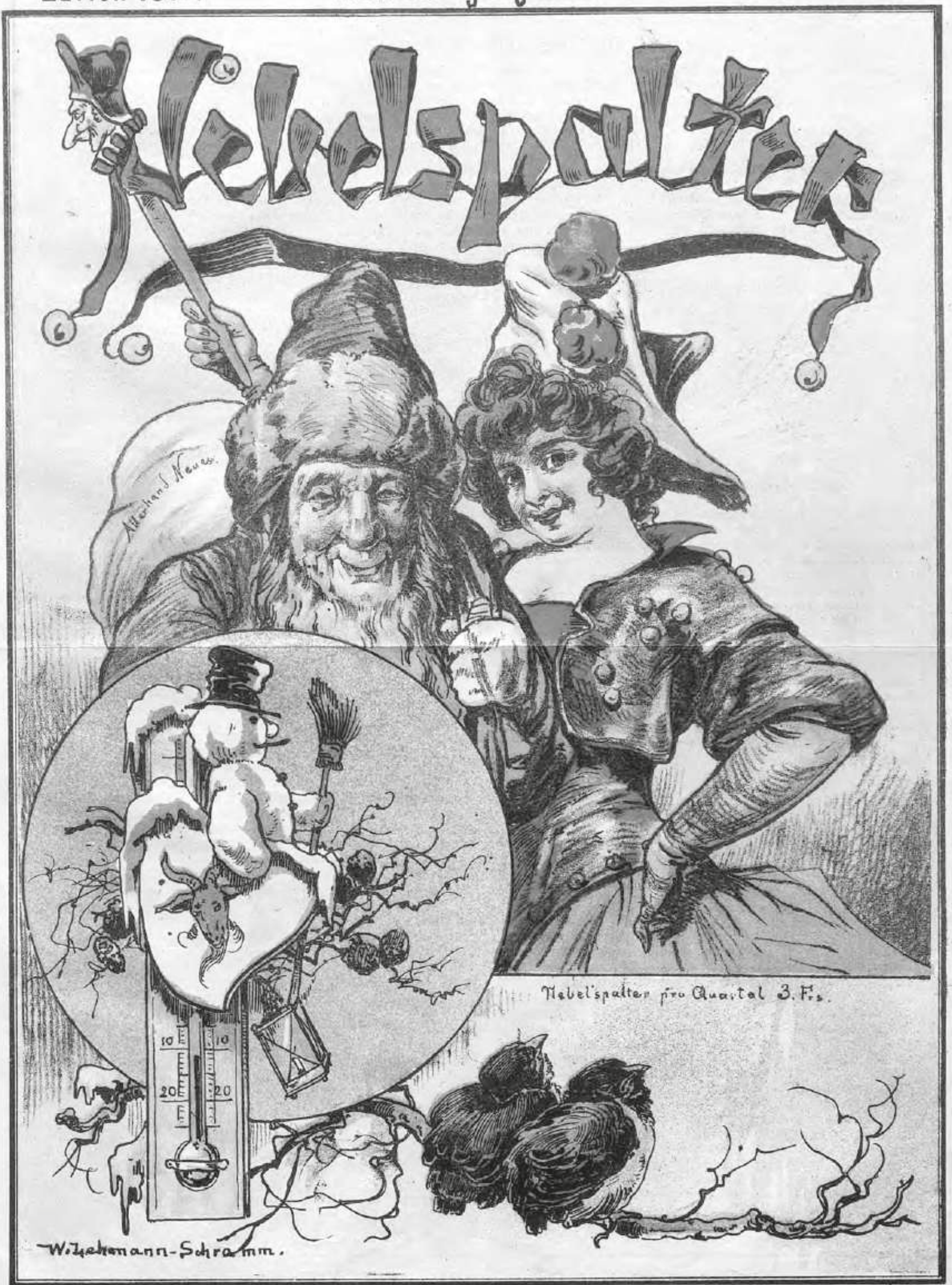

Fig. 13. Nebelspalter 1897/52, couverture en couleur de Willy Lehmann-Schramm. 
inchangés, 3 Fr. pour trois mois, 5,50 Fr. pour six mois et Io Fr. pour un an, pour la Suisse; 7 Fr. pour six mois et I3,50 Fr. pour un an pour tous les pays de la poste internationale (für alle Staaten des Weltpostvereins), sans différenciation désormais de la zone géographique. En I 895, au moment de l'arrivée d'Adolf Beetschen à la rédaction littéraire, un point de vente parisien apparaît, « chez Mme Lelong, kiosque ıо, rue des Capucines en face le Grand Café ${ }^{113}$. En I 889 , le prix des insertions publicitaires, réduit en I 886 à 20 cts. la ligne pour la Suisse et 25 cts. la ligne pour l'étranger, augmente à nouveau, passant à 30 cts. la ligne pour la Suisse et $50 \mathrm{cts}$. la ligne pour l'étranger. Les annonceurs étrangers doivent à présent s'adresser à l'agence Adolf Steiner à Hambourg, dont le nom disparaît en I 894. Vers la fin I 897, une différence est établie entre annonces et réclames, ces dernières devenant beaucoup plus onéreuses avec un prix de I Fr. la ligne ${ }^{114}$.

La communication via les encarts s'intensifie également à partir de I 887 . Elle est comme auparavant basée sur le prix, une tendance qui ne serait assujettie à aucun parti et une fidélité au programme originel. Des reproductions en couleur sont régulièrement proposées, portraits officiels, tel celui du général Hans Herzog pour 80 cts. ${ }^{115}$ ou de hauts lieux suisses, comme la vue du parlement à Berne, rendue dans un format spécial et composant une "décoration de pièce magnifique " (prächtiger Zimmerschmuck ${ }^{116}$. En tout état de cause, le Nebelspalter comporte « chaque mois une grande image politique en couleur et trois pages d'illustrations par semaine » (allmonatlich ein grosses politisches Farbenbild und wöchentlich 3 Seiten Illustrationen $)^{117}$. Certains arguments sont plus ponctuels: la vente d'une reliure, l'accroissement du nombre de collaborateurs ${ }^{118}$, l'arrivée du nouveau rédacteur en chef Adolf Beetschen ${ }^{119}$ ou la présence de numéros spéciaux ${ }^{120}$. À partir de I 889, le Nebelspalter se déclare supérieur "à toute autre feuille humoristique suisse ou étrangère " (als irgend ein Witzblatt des In-und Auslandes) ${ }^{121}$. Les encarts sont versifiés ${ }^{122}$, certains permettent une lecture « à deux vitesses ", tel un très long argumentaire scandé de mots en gras, formant une sorte de chapelet commercial:

"Au monde entier! Abonnez-vous - le périodique humoristique - satirique - et illustré - Der Nebelspalter - magnifiques images en couleur tous les mois - Io Fr. par an - Feuille d'annonces - Le service d'expédition du Nebelspalter ${ }^{123}$.

Sous l'influence Jugendstil, les encarts deviennent essentiellement visuels : en I 895 , une élégante fait la promotion du journal sur une page entière ${ }^{124}$; en I 897 , elle s'associe au personnage du Nebelspalter ${ }^{125}$; et, quelque temps plus tard, aux icones des rubriques ${ }^{126}$. Le Nebelspalter s'invite alors régulièrement

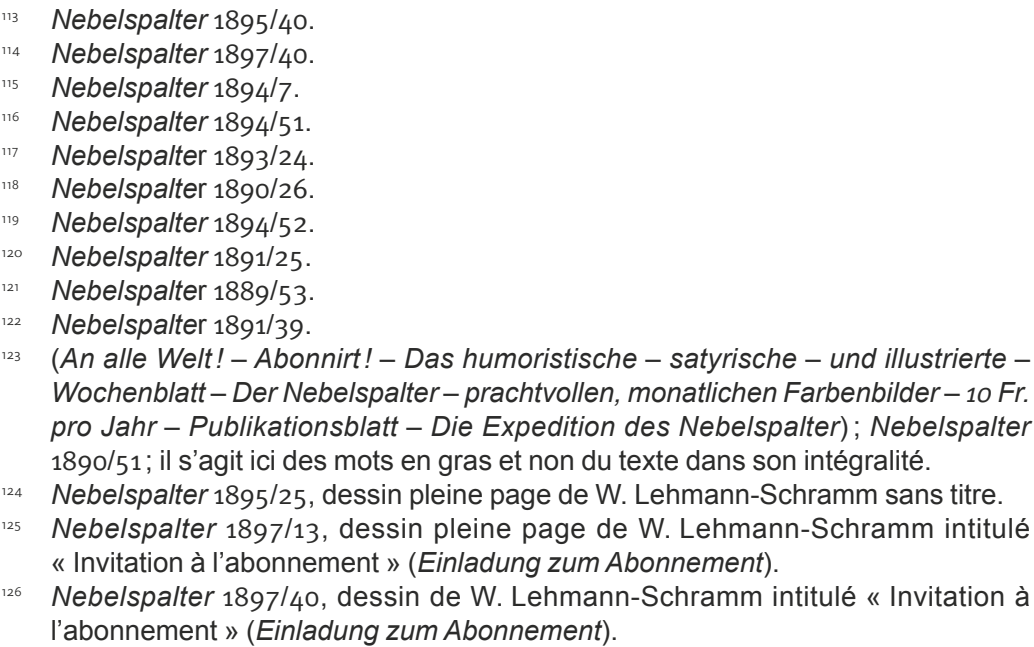

(An alle Welt! - Abonnirt! - Das humoristische - satyrische - und illustrierte Wochenblatt - Der Nebelspalter - prachtvollen, monatlichen Farbenbilder - $10 \mathrm{Fr}$ pro Jahr - Publikationsblatt - Die Expedition des Nebelspalter); Nebelspalter $1890 / 51$; il s'agit ici des mots en gras et non du texte dans son intégralité.

24 Nebelspalter 1895/25, dessin pleine page de W. Lehmann-Schramm sans titre.

125 Nebelspalter $1897 / 13$, dessin pleine page de W. Lehmann-Schramm intitulé « Invitation à l'abonnement » (Einladung zum Abonnement).

26 Nebelspalter 1897/40, dessin de W. Lehmann-Schramm intitulé « Invitation à l'abonnement » (Einladung zum Abonnement).

en couverture, faisant l'article du Musée national de Zurich, en $1898^{127}$.

Le premier numéro spécial est publié en I 89 I à l'occasion des 600 ans de la Confédération ${ }^{128}$. Les numéros spéciaux ne sont cependant systématisés que quatre ans plus tard, en I 895: «Le prochain semestre verra quelques numéros spéciaux de grand style » (Das kommende Semester bringt einige Festnummern grossen Stils) ${ }^{129}$. Avec ces numéros événementiels, « l'expression ponctuelle de la marque du titre ${ }^{130}$, le journal affine son identité; plutôt tardivement, comparé à d'autres revues, puisque la pratique débute ailleurs dans les années i 880 , et aussi plus rarement, deux fois par an, environ ${ }^{131}$. Les numéros sont dédiés à des personnages ou des événements nourrissant l'identité nationale, le poète zurichois Conrad Ferdinand Meyer (I 825-1 898), en I $895^{132}$; le peintre Arnold Böcklin (I827-I90I), en I $897^{133}$; la Tonhalle, la grande salle de concert zurichoise, inaugurée en I $895^{134}$; l'exposition nationale de Genève, organisée en I $896^{135}$; le Musée national de Zurich, inauguré en I 898. Ce dernier événement donne lieu à une couverture de Willy Lehmann-Schramm montrant un couple de jeunes paysans devant un paysage alpin du plus pur Heimatstil (style du terroir) ${ }^{136}$.

Seule une estimation chiffrée du public est possible pour cette époque: selon Bruno Knobel, qui a visiblement obtenu des renseignements de première main, celui-ci se chiffrait, autour de I900, à un millier d'abonnés ${ }^{137}$.

\subsubsection{Thèmes et tendance - Ouverture et modernité}

Cette grosse décennie précédant le passage au siècle est marquée par une inflexion dans la tendance. La ligne politique reste la même, quoiqu'un peu moins marquée par l'anticléricalisme et davantage par l'antisémitisme. Tout est bon pour laisser libre cours à un anticléricalisme endémique, très focalisé sur la figure du conservateur et omnipotent Georges Python ${ }^{138}$ : la visite du pape à Lucerne, en I 888 comme la fondation, en I 889, de l'université de Fribourg, à l'initiative du même Python, un lieu « maudit » qui devient omniprésent dans le journal. L'antisémitisme est surtout lié à la nationalisation du réseau ferré, au rite de l'abattage cascher, discuté en I 892 et I $893^{139}$, ainsi qu'à la question sioniste, à la fin des années I 890. Au contraire de l'anticléricalisme, l'antisémitisme n'est cependant jamais un thème en soi mais s'intègre à d'autres propos. Les centres d'intérêts se diversifient. Le champ de l'art s'invite dans les années I 890 et davantage de pays lointains sont intégrés. Certains thèmes typiques de la modernité font leur

\footnotetext{
Nebelspalter 1898/26, dessin pleine page de W. Lehmann-Schramm intitule "Quelques curiosités supplémentaires pour le Musée national » (Auch einige Merkwürdigkeiten für's Landesmuseum).

Nebelspalter $1891 / 25$, encart.

129 Nebelspalter $1895 / 26$, encart en couverture.

3o Laurent Bihl, La Grande Mascarade parisienne. Production, diffusion et réception des images satiriques dans la presse périodique illustrée parisienne entre 1881 et 1914, op. cit., p. 256.

lbid., p. 256-257.

Nebelspalter $1895 / 41$

Nebelspalter $1897 / 42$

Nebelspalter $1895 / 42$

Nebelspalter $1896 / 18$

Nebelspalter 1898/26, couverture de W. Lehmann-Schramm.

Bruno Knobel, Die Schweiz im Nebelspalter, Rorschach, Nebelspalter-Verlag, 1974, p. 5.

Cf. Pierre-Philipe Bugnard, "Python, Georges », Dictionnaire historique de la Suisse (12/04/2012); http://www.hls-dhs-dss.ch/textes/f/F3943.php.

139 Nebelspalter 1892/34, dessin pleine page de Emil Dill intitulé « Sur la question de l'abattage » (Zur Schlachtfrage).
} 

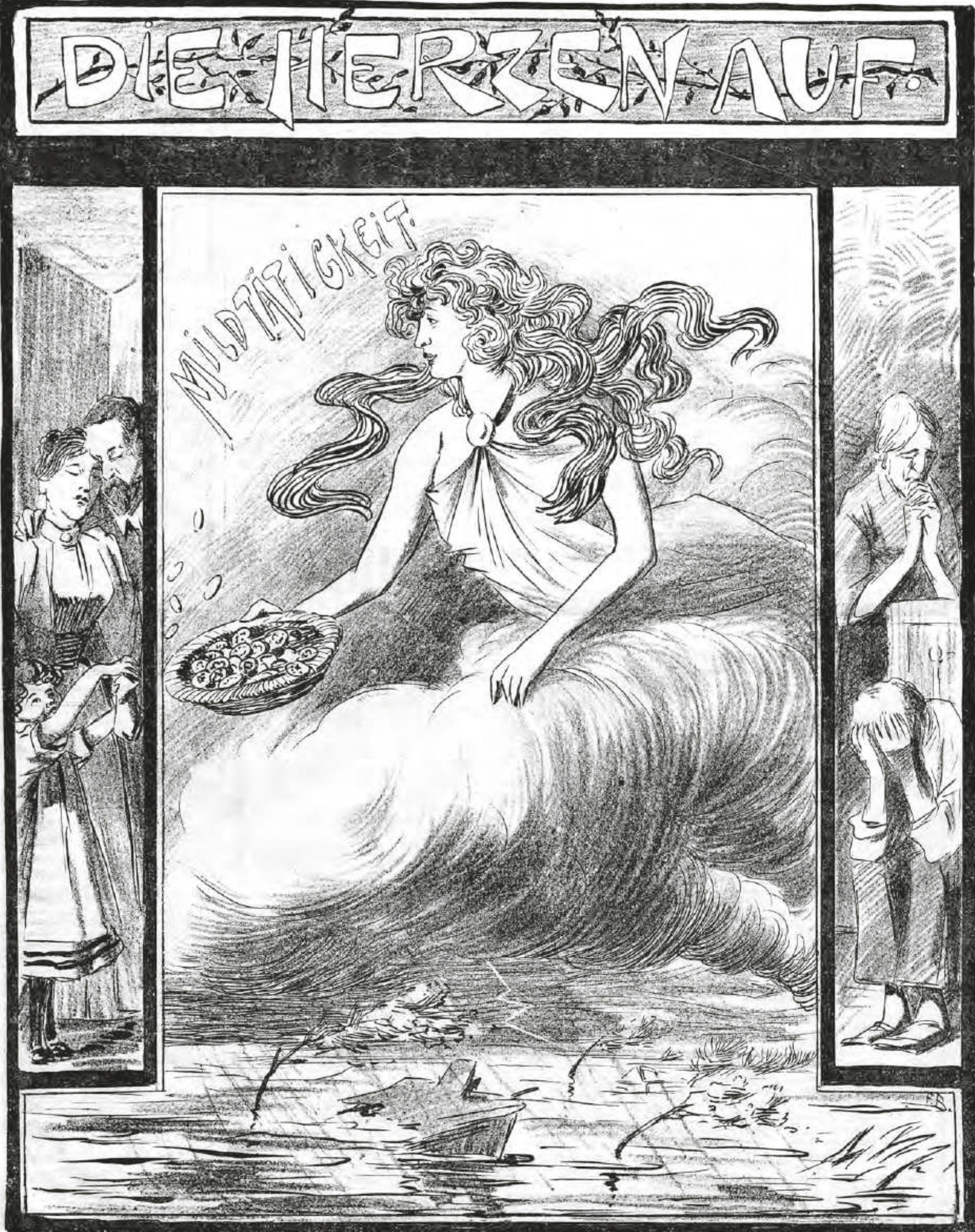

$\Rightarrow$ für die pon Gagel und Ueberfonemmung Geimgeiuchten!

Fig. 14. Nebelspalter 1897/32, dessin pleine page en noir et blanc de Boscovits senior intitulé « À votre bon cœur » (Die Herzen auf). 
entrée. Dès I 887 , l'armée est raillée, phénomène qui va s'étendre à d'autres symboles suisses.

Les thèmes liés à la Suisse n'évoluent guère ${ }^{140}$. Ce sont les questions cléricales, traitées avec un zèle jamais démenti; les questions ferroviaires, croquées de manière intensive, puisque se pose régulièrement le problème de la capitalisation du réseau ferré; celles bancaires, avec le projet d'une banque centrale, soutenue par la revue à partir de I 894 ; celles fiscales; le fonctionnement et le budget de l'armée, regardés tour à tour avec cynisme ou humour; l'organisation et le financement de l'école jusqu'en I 899, année d'une votation qui ne règle toujours pas la question; le fonctionnement du parlement; les nombreuses élections référendaires; les accords commerciaux; la liberté de la presse et les congrès annuels des journalistes (Journalistentag); le Gothard, avec la question des fortifications, en I 89 I ; la neutralité, de manière aigue lors de la première conférence de La Haye, en I 899; le droit d'asile, de manière quasi-constante; le budget fédéral; l'identité des cantons; le système électoral, avec l'apparition du débat sur la proportionnelle, fin I 890, alors appelée "Bacillus proporticus » ${ }^{141}$, puis qualifiée de « juif errant » (ewige Jude), en I 899, pour indiquer un mal qui ne cesse de revenir ${ }^{142}$.

À ces thèmes fondateurs s'ajoutent d'autres questions, certaines discutées sur la durée, telle que la propriété intellectuelle ou le monopole du tabac; d'autres plus ponctuelles, telle la loi sur les alcools en I 887 ; l'émigration des Suisses (attirés par un mirage $)^{143}$; la durée du travail, en I 890 ; la réunification de Bâle (Bâle-Ville et Bâle-Campagne), en I 898 ; les événements du Tessin et le procès qui s'ensuit, en I 890 et I $89 \mathrm{I}$; la commémoration des 600 ans de la Confédération, occasion à un numéro thématique en I $89 \mathrm{I}^{144}$; le procès du bateau «Le Mont Blanc » à Lausanne, en I 892 ; la crémation, en I 896 et I 899 . De grands événements sont relatés, la visite du pape à Lucerne, en I 888 ; la journée des ouvriers (Arbeitertag) à Olten, en I 890 ; le grand incendie de Grindenwald, en I 892; la visite de Guillaume II, en I 893; le licenciement d'Ulrich Wille de l'armée suisse, en I $896^{145}$.

Des préoccupations sociétales voient le jour : la dénonciation des violences familiales, en I 887 ; de manière croissante, à partir de I 890 , le thème de la pauvreté en lien avec l'inflation; le projet longtemps discuté d'une assurance maladie et accident, à partir de I 893; celui de la retraite, en I 894; le travail des enfants, en I 897; un appel à la générosité pour les victimes des inondations, en I $897^{146}$ ou encore les conditions de travail des ouvriers sur le chantier du tunnel du Simplon, en I $899^{147}$ (cf. fig. I4).

Les affaires zurichoises sont assidûment suivies sous leurs chantier, ses développements urbanistiques sont suivis de près, notamment le rattachement des communes extérieures, discuté en I $89 \mathrm{I}^{148}$ et effectif en I $893^{149}$, alors que la construction des lignes de tramway forme une chronique avec des points forts, comme l'inauguration de la ligne crémaillère du Dolderbahn en I 895. Les projets controversés font les délices des dessinateurs, tel le monument en hommage à Pestalozzi, inauguré en I 899. Les théâtres et salles de spectacle, notamment le théâtre de la ville et la Tonhalle, inaugurée en I $895^{150}$, occupent une place de choix dans les affaires culturelles, tout comme les expositions. L'aspect social est présent mais relativement marginal, avec les colonies de vacances, en I 887 ; une critique féroce de la police, de tout temps; les prix des loyers, en I 894 ; l'initiative lancée par le mouvement pour le relèvement moral (Sittlichkeitsbewegung), en I $897^{151}$; les inondations de I 899. Les fêtes de carnaval et des Sechseläuten signent le début d'une décennie festive. Les impôts, jugés excessifs, représentent un leitmotiv. Des événements particuliers sont rapportés, la naissance du quotidien Tages-Anzeiger, en I 893 et le troisième Congrès socialiste international.

Les obsessions politiques sont alors l'anticléricalisme, le capitalisme et l'anarchie. Un peu comme l'antisémitisme, l'anarchie, qui inquiète beaucoup, est thématisée en lien avec d'autres problématiques, comme le droit d'asile, en I $888^{152}$. Au capitaliste est volontiers opposée la figure du paysan ${ }^{153}$.

La modernité s'affiche au travers des motifs de la vie urbaine, de l'émancipation des femmes et du tourisme, en particulier dans les Alpes. En I 895, deux nouveaux-venus, le Volapük (une langue universelle) $)^{154}$ et le régime végétarien, font leur apparition ${ }^{155}$ (cf. fig. I5).

En I 896, le périodique rend compte de la tenue des premiers jeux olympiques modernes à Athènes. Le tourisme commence alors à remettre en question l'identité suisse ${ }^{156}$.

Les questions artistiques et culturelles prennent de l'importance avec les débats sur les subventions fédérales; ceux autour de la construction d'un musée national, inauguré en r 898 : les expositions itinérantes (Turnus) : le Salon Buchser, organisé à Berne en I 890 ; le monument à Guillaume Tell, sculpté par Richard Kissling et inauguré en I 895 ; l'exposition nationale de I 896 à Genève ${ }^{157}$.

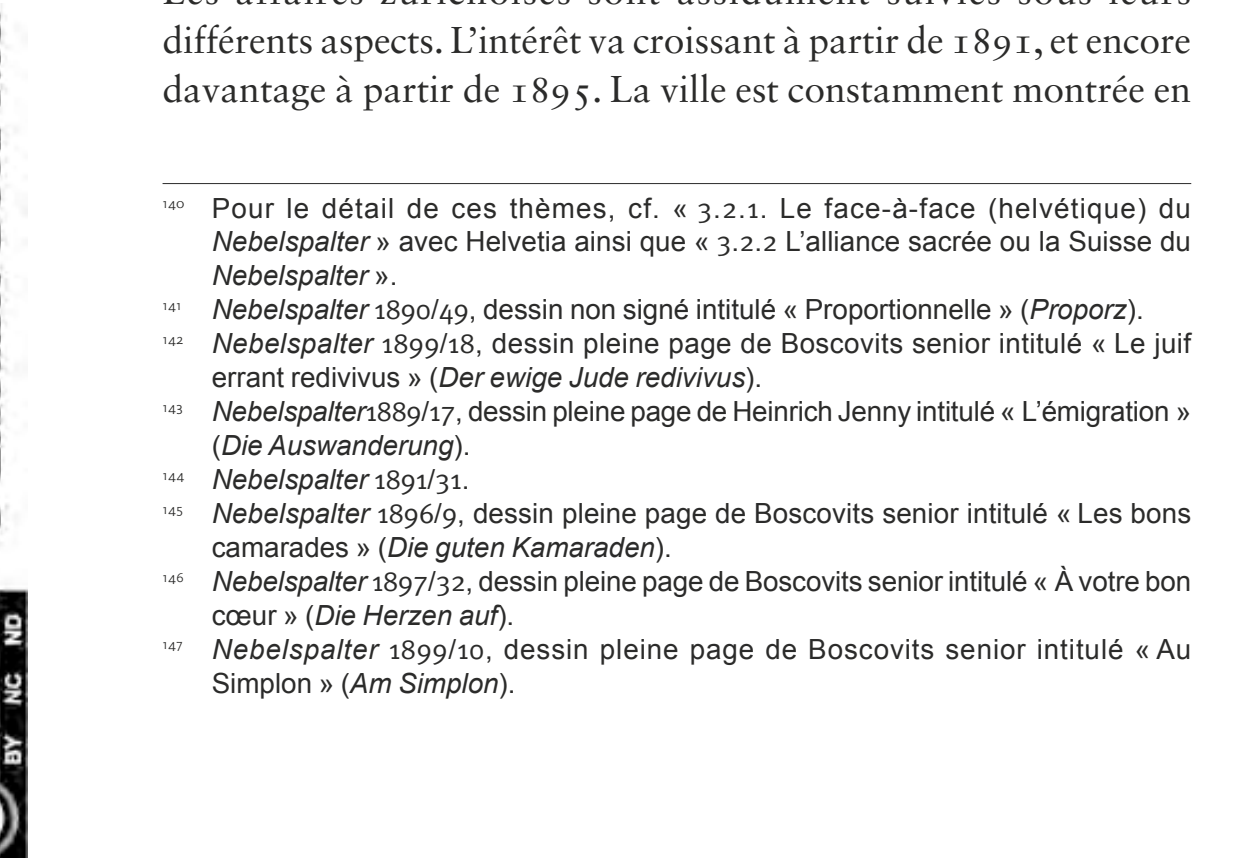

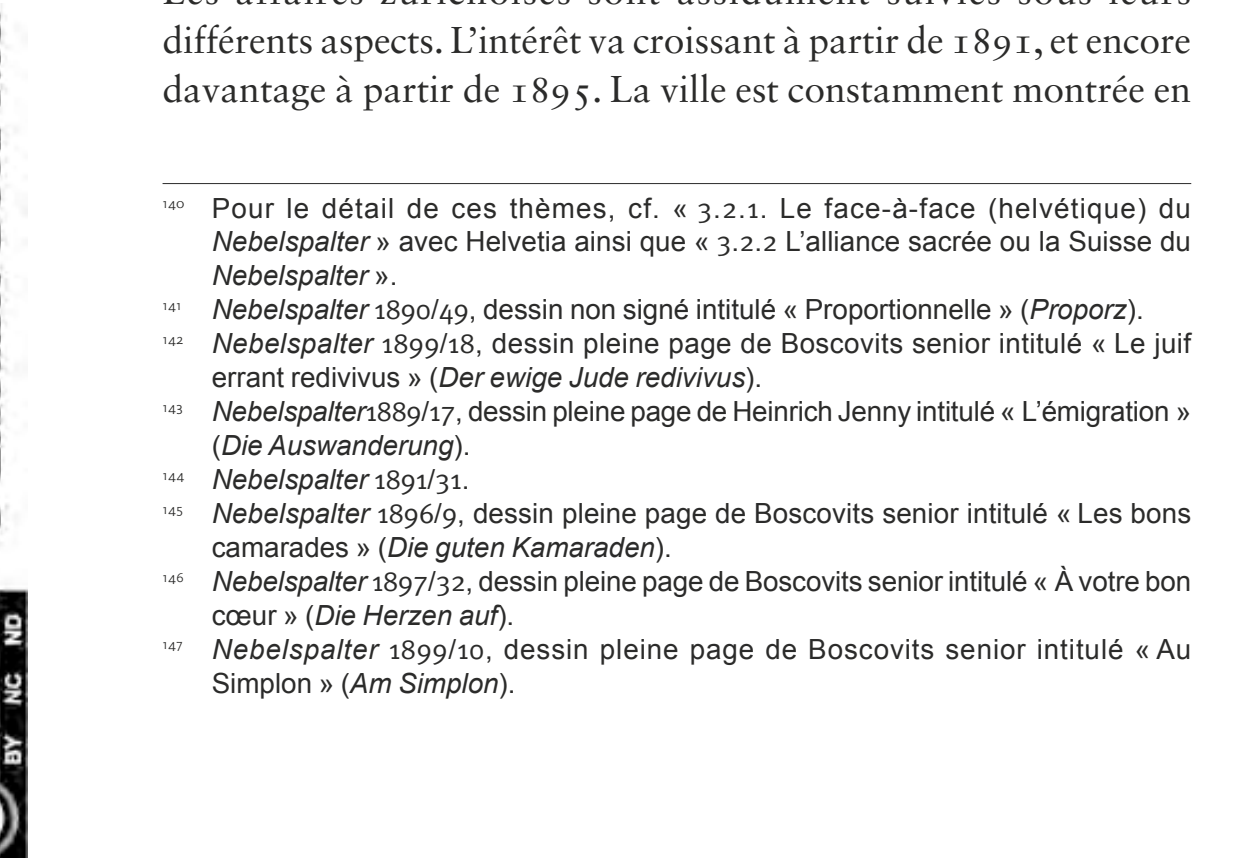

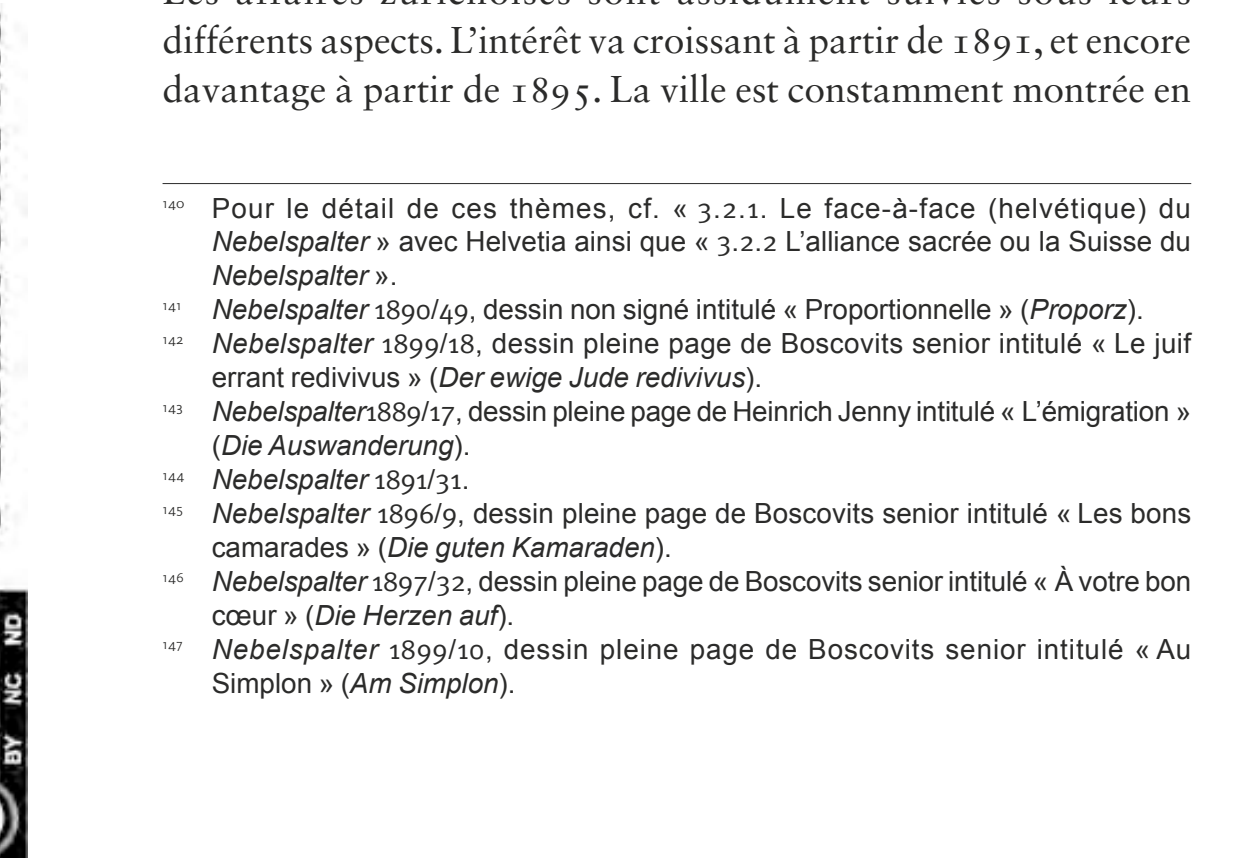

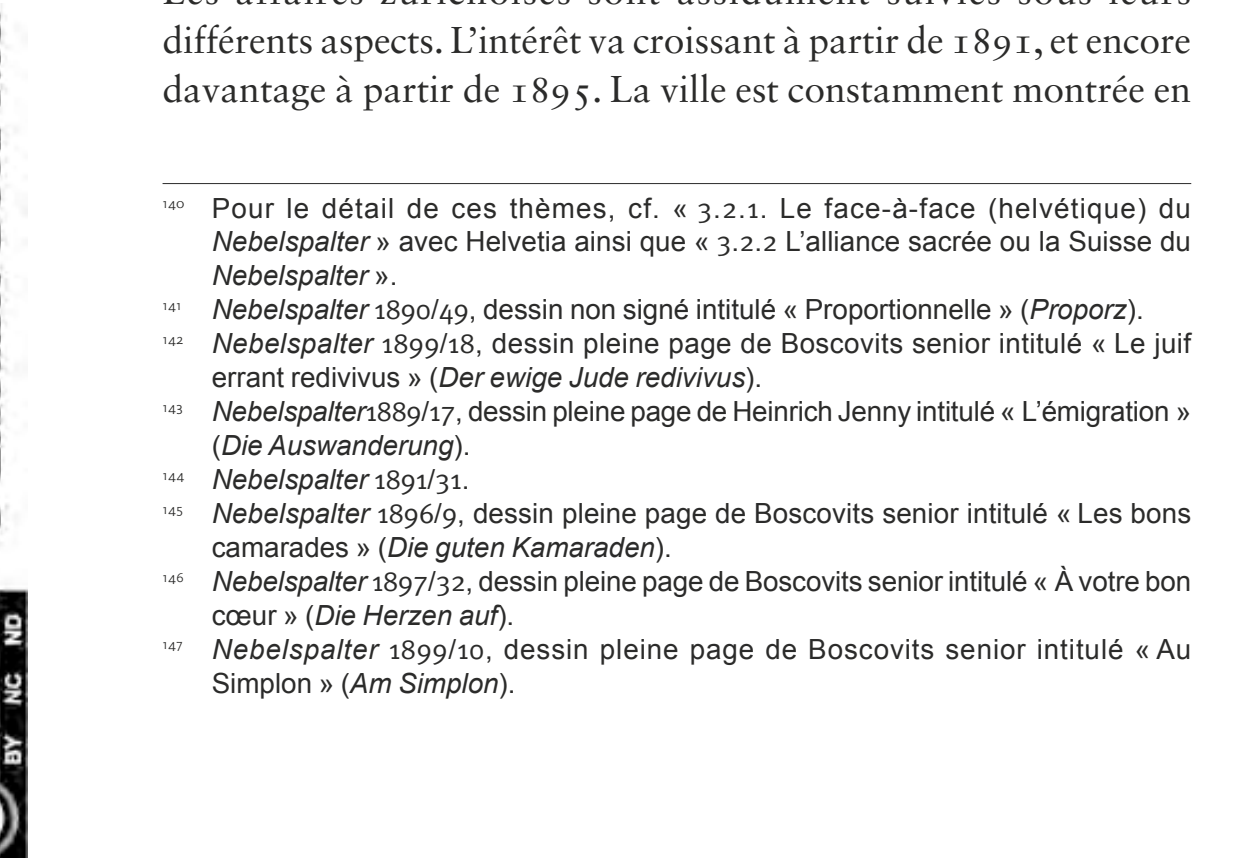

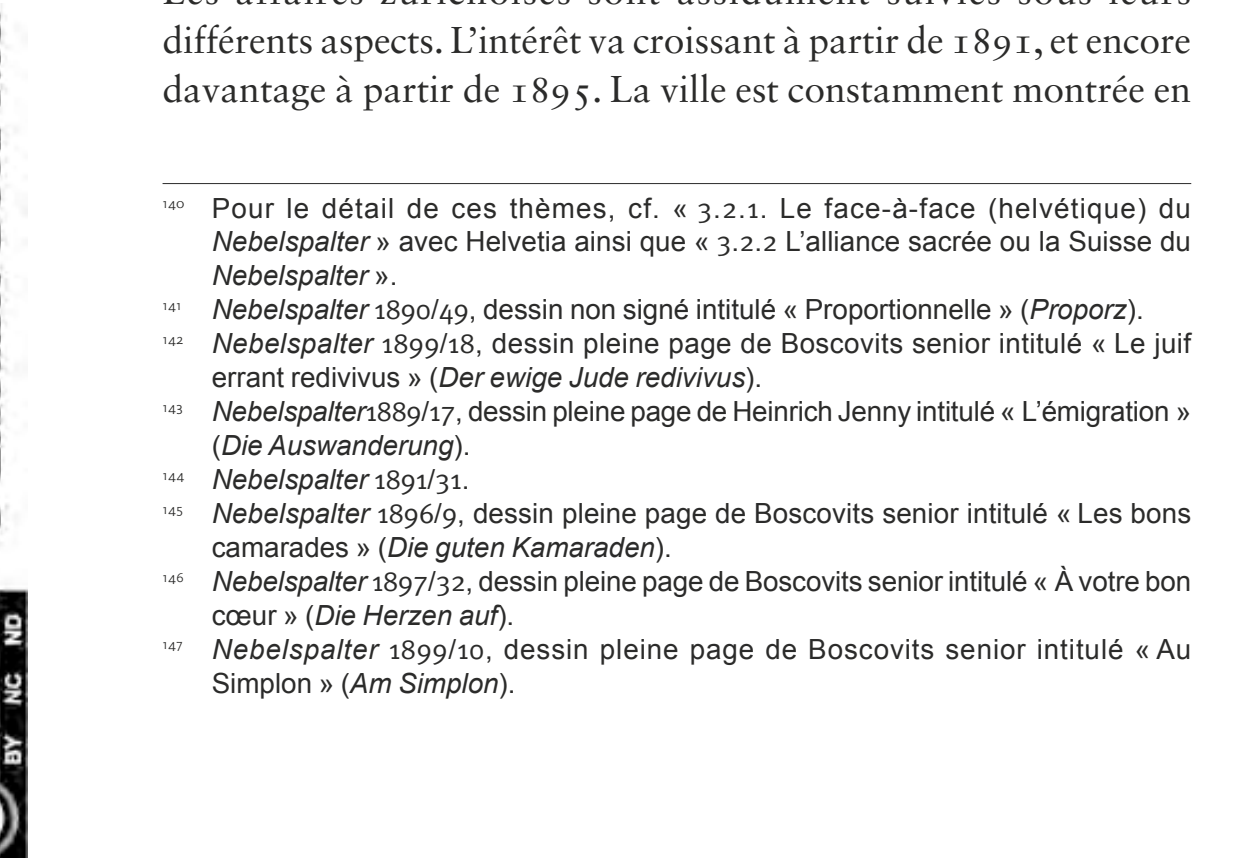

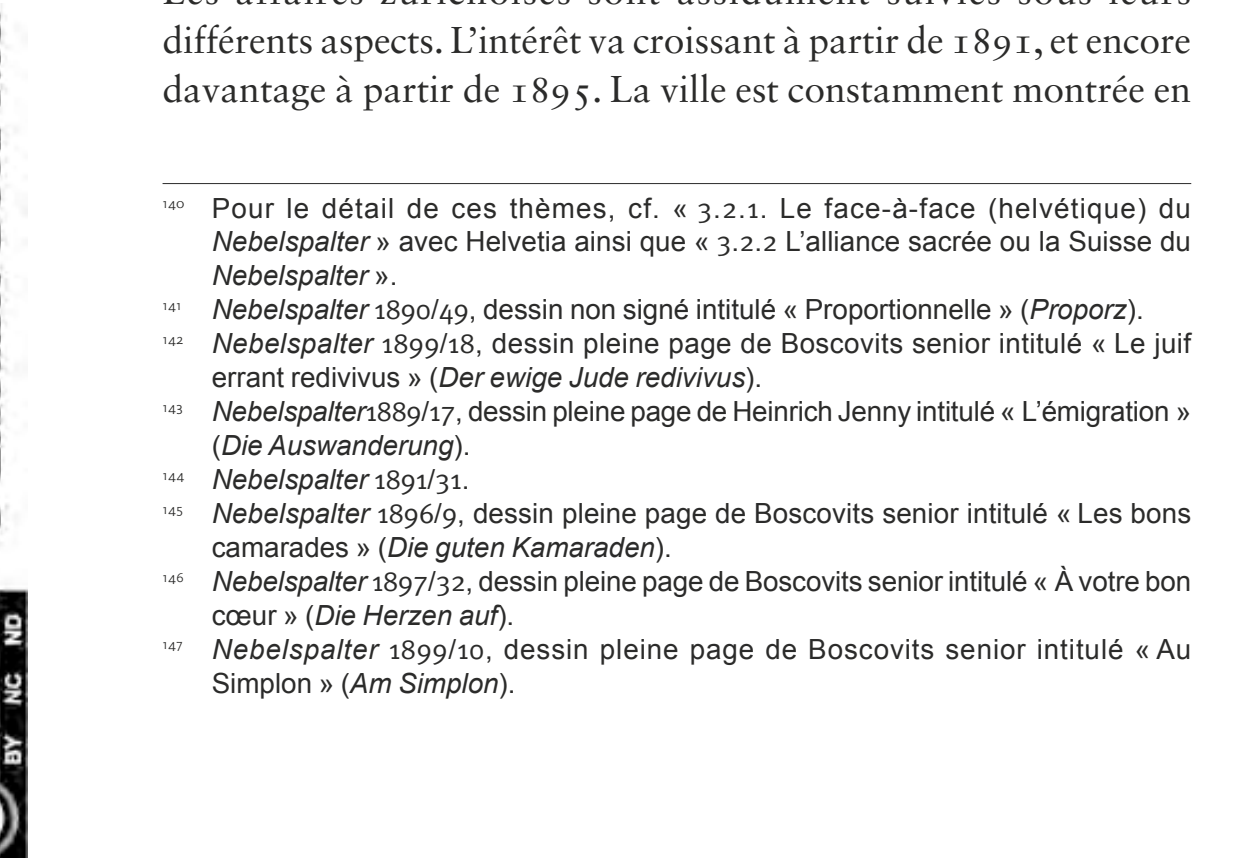

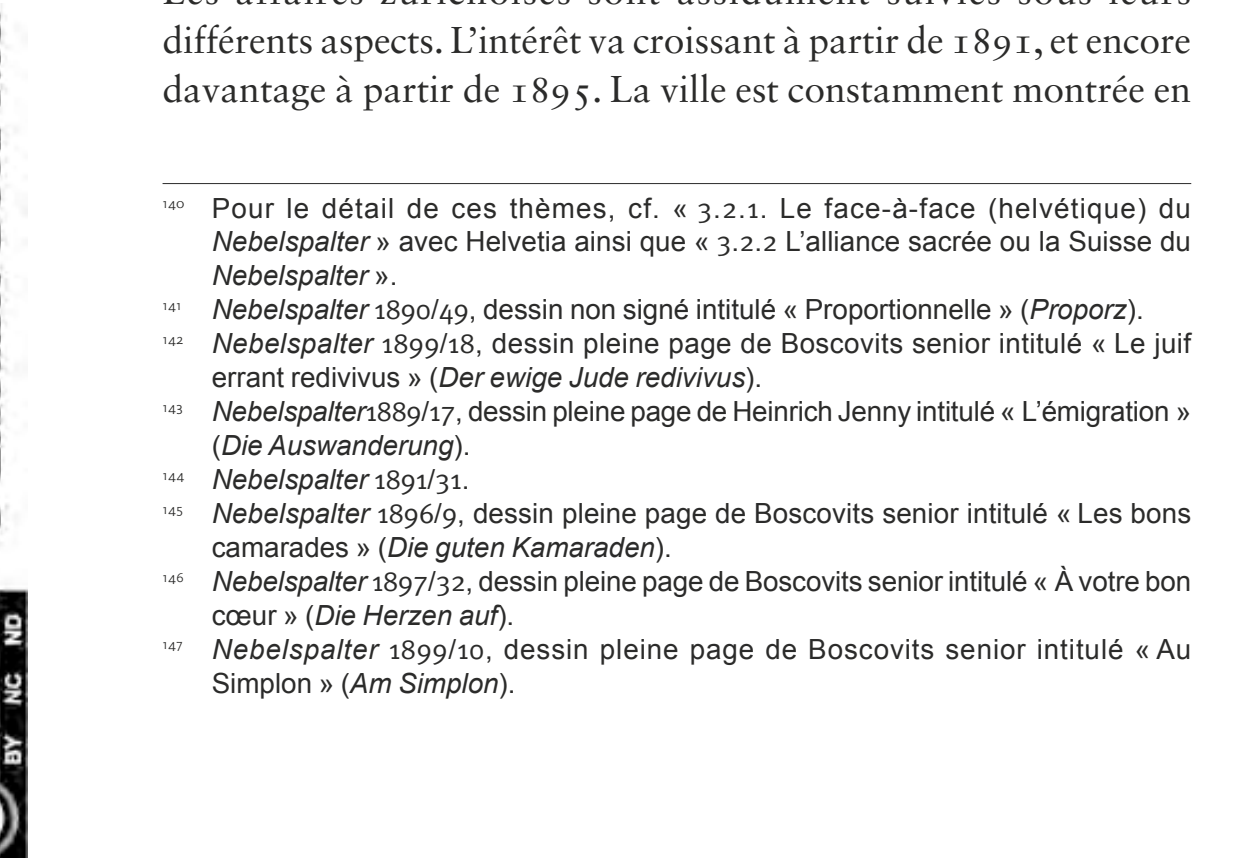

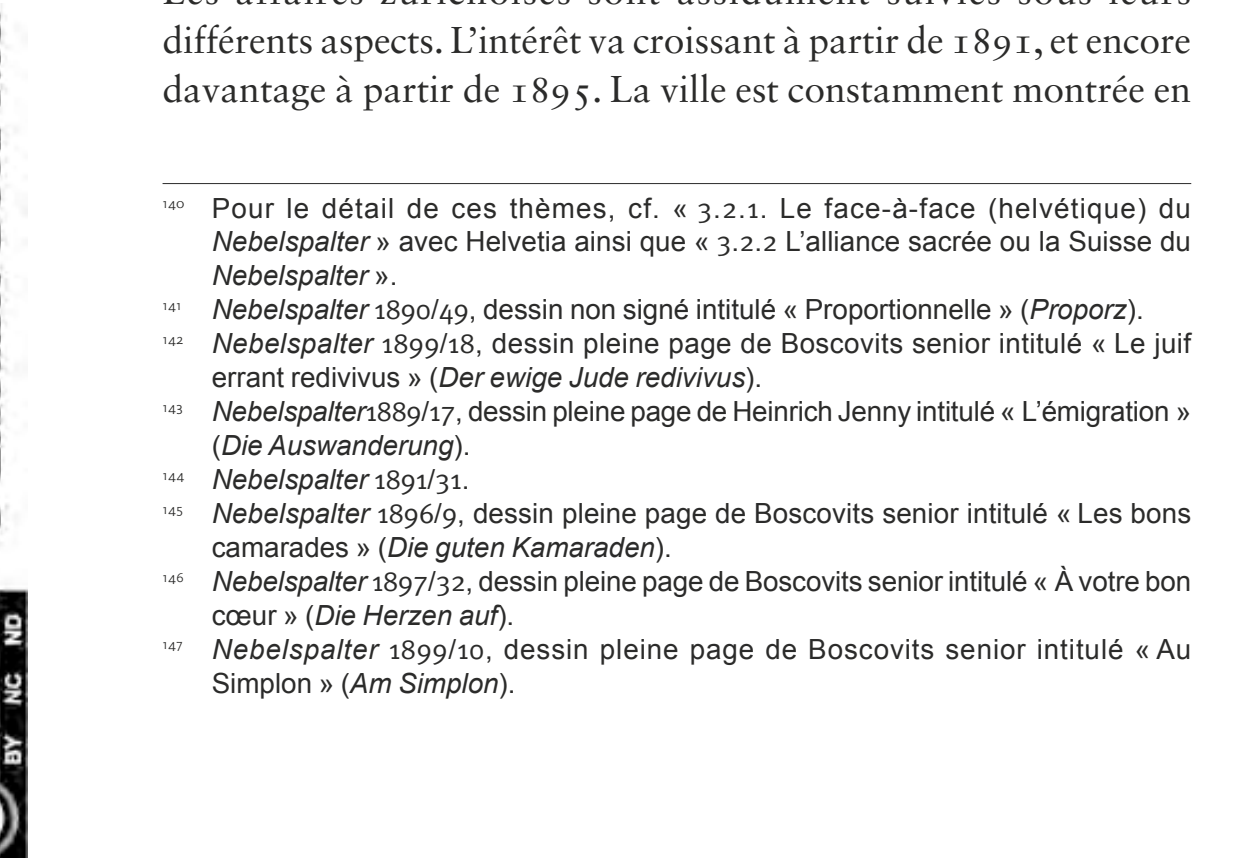

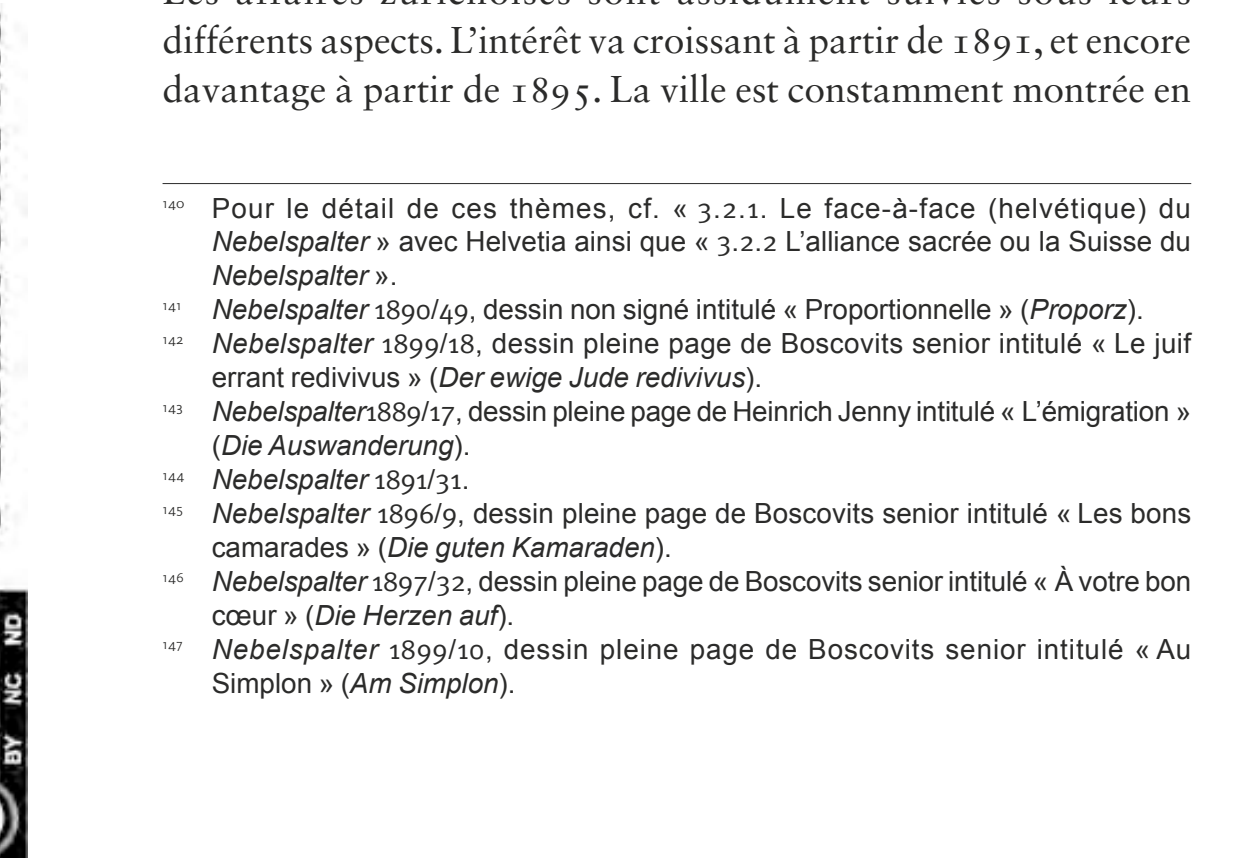

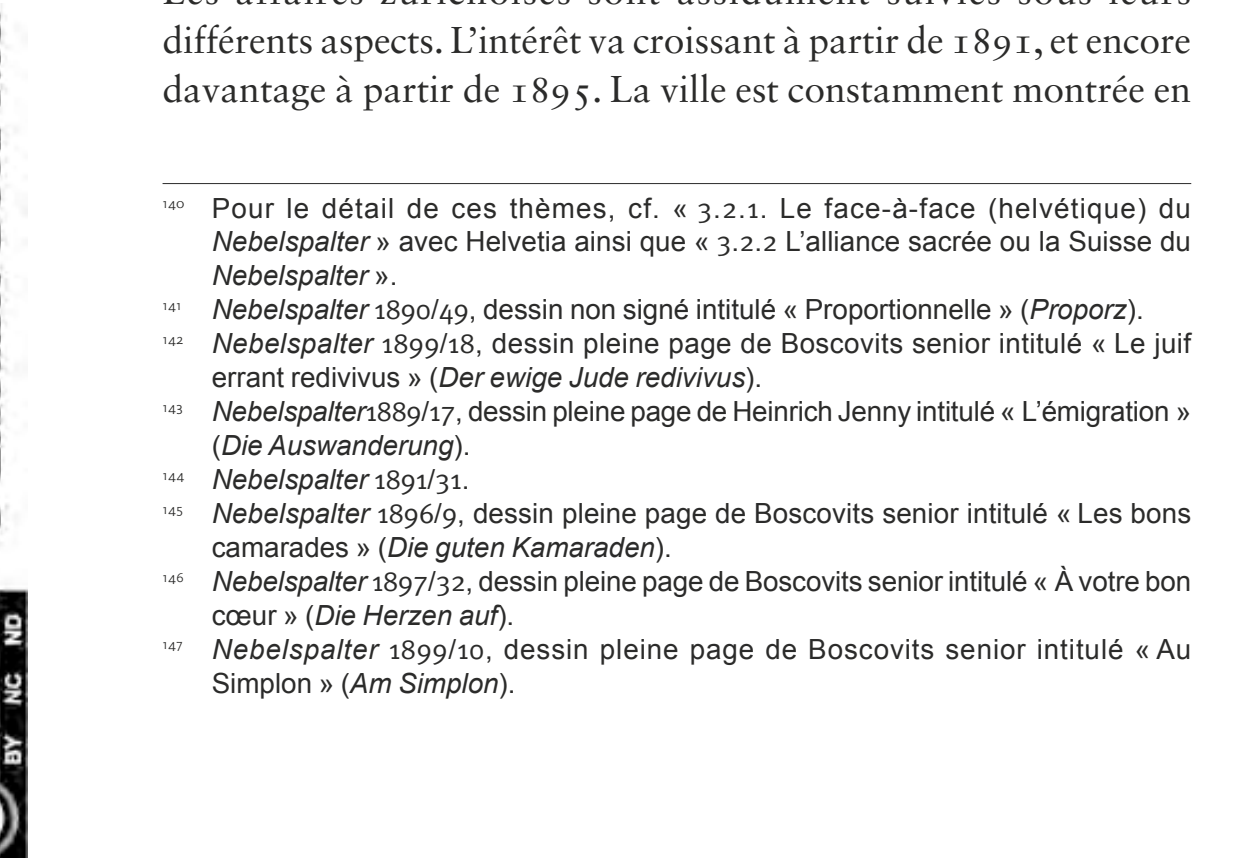

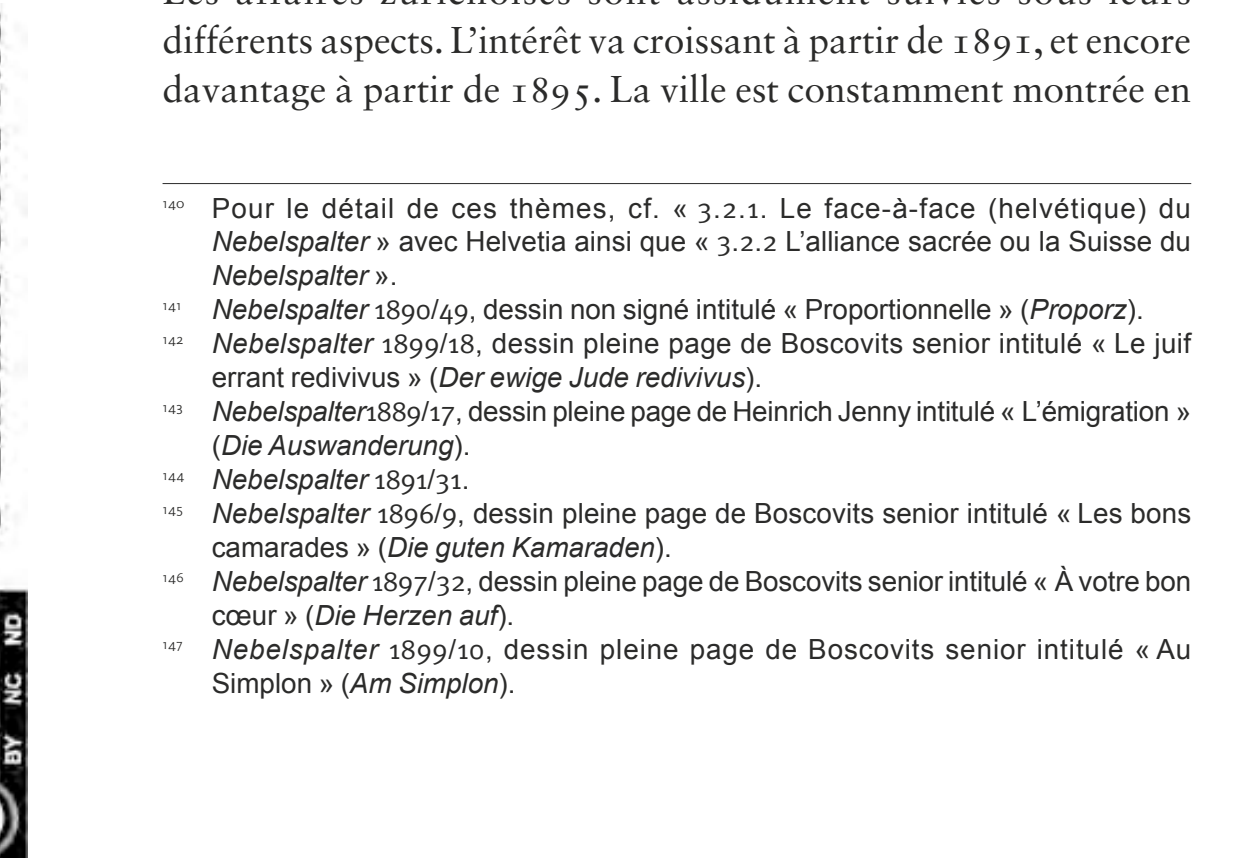

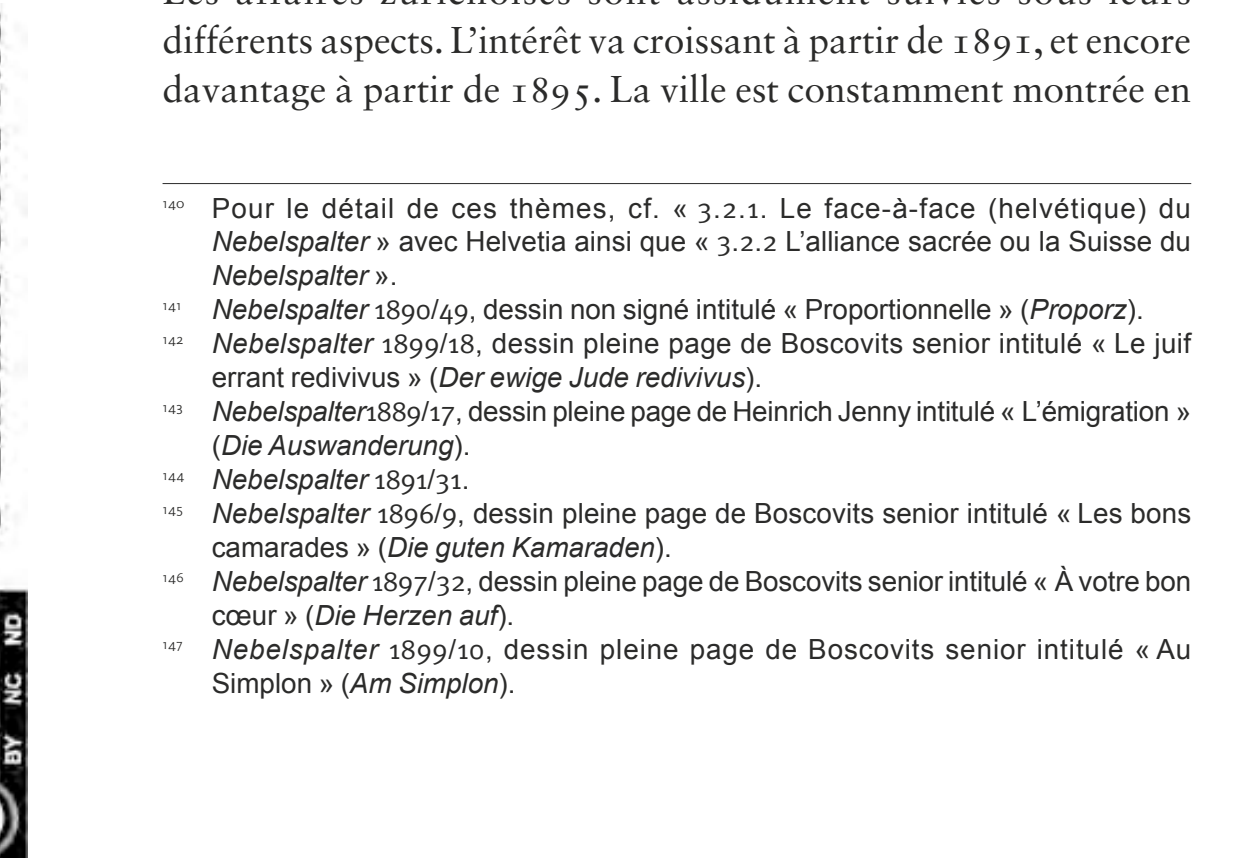

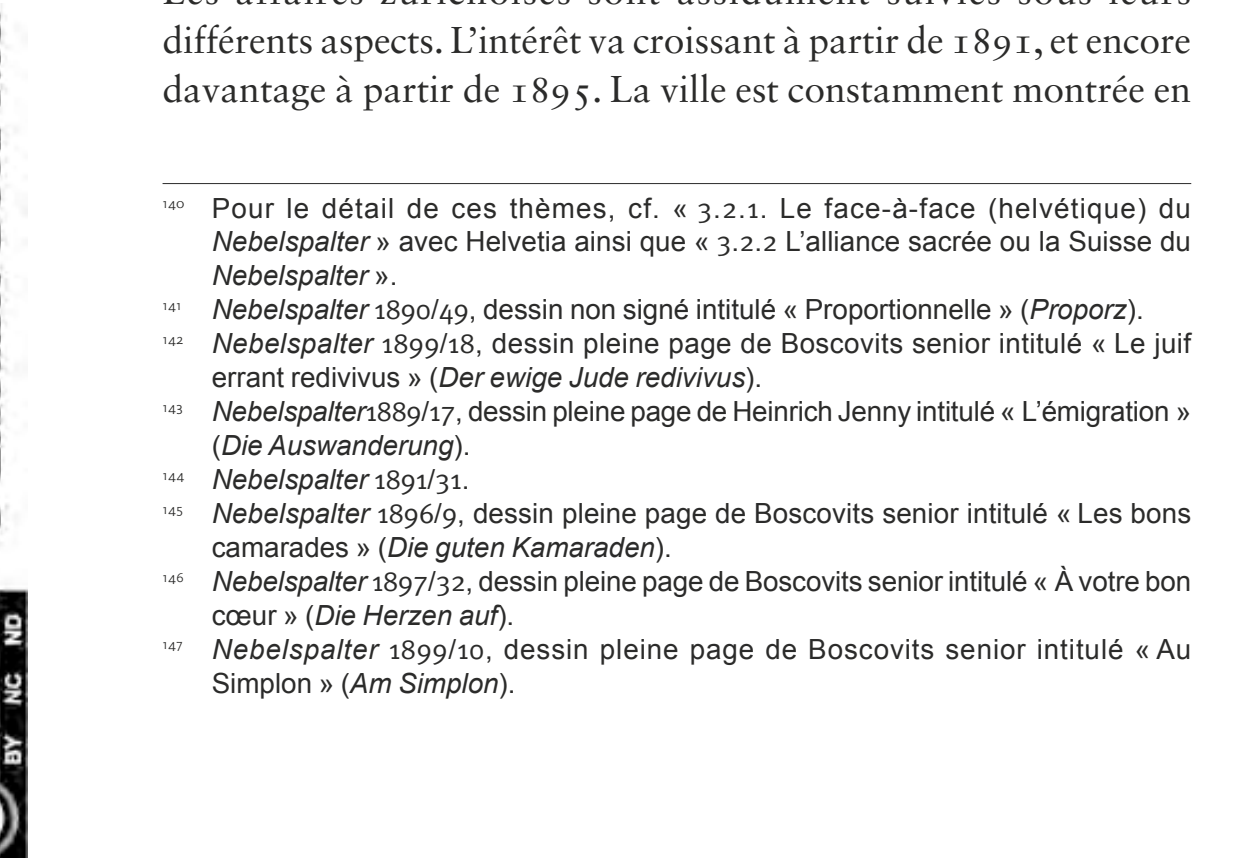

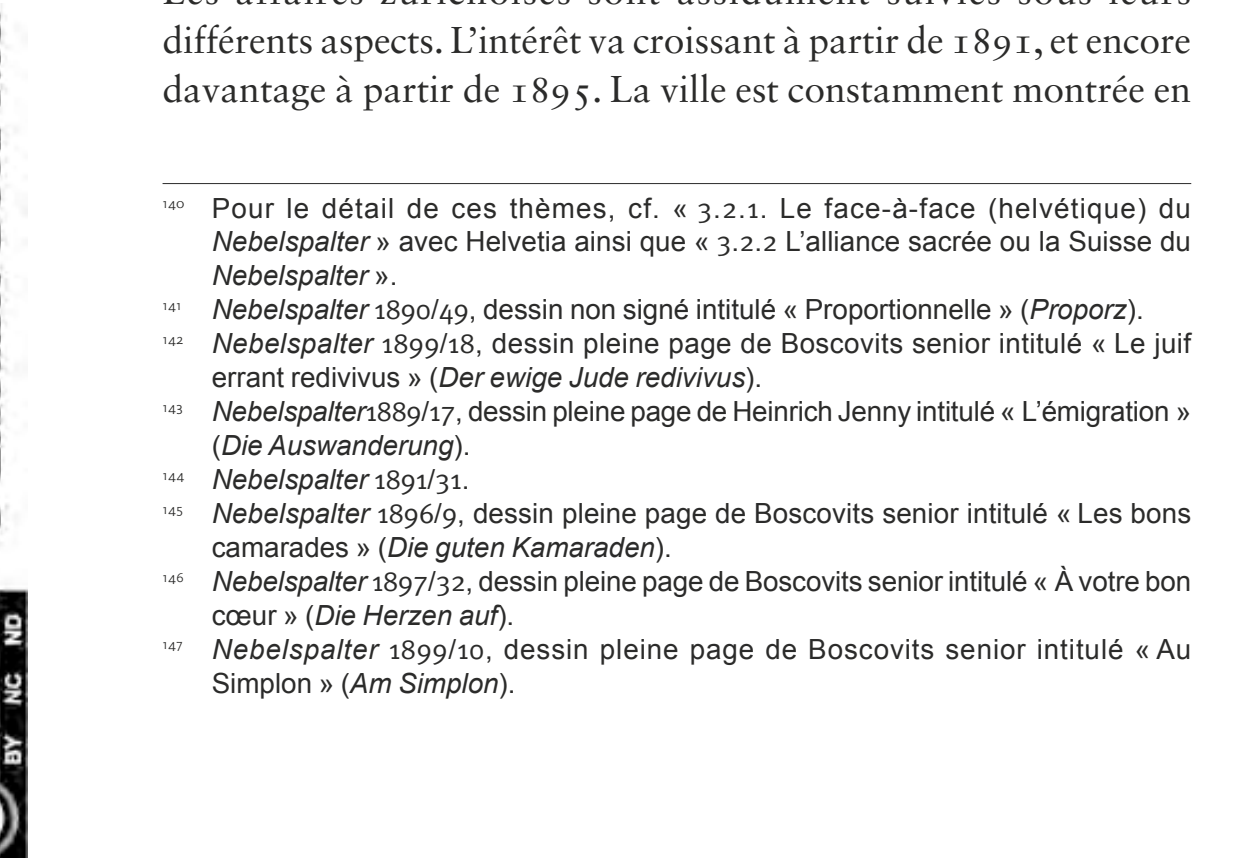

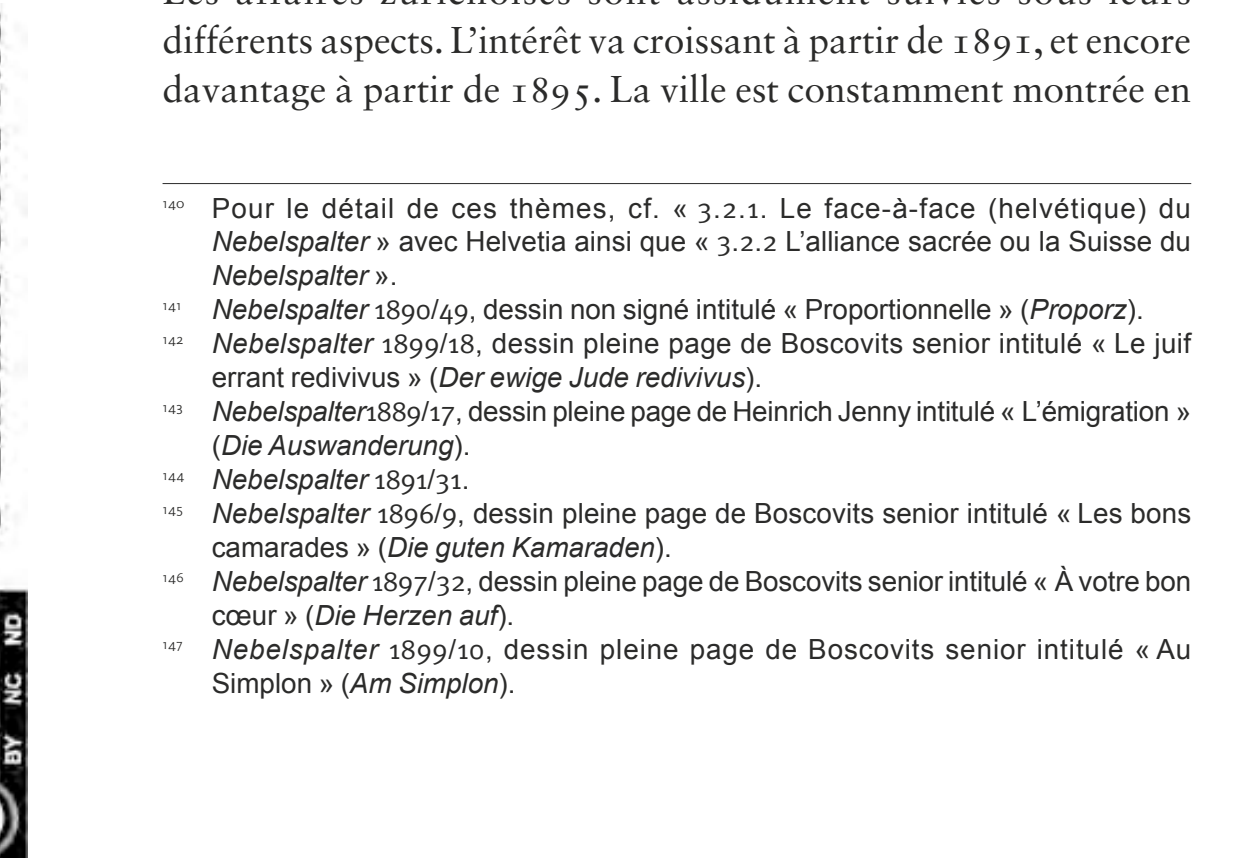

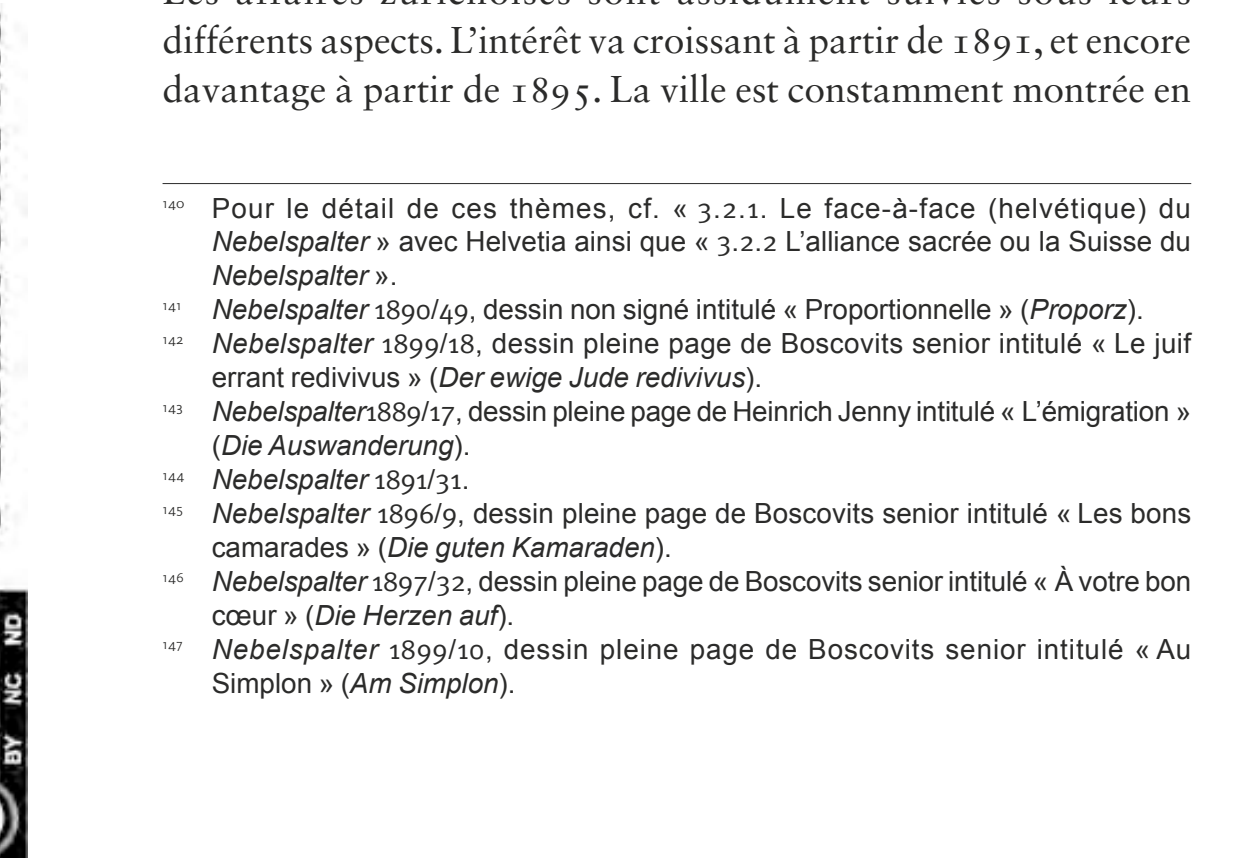

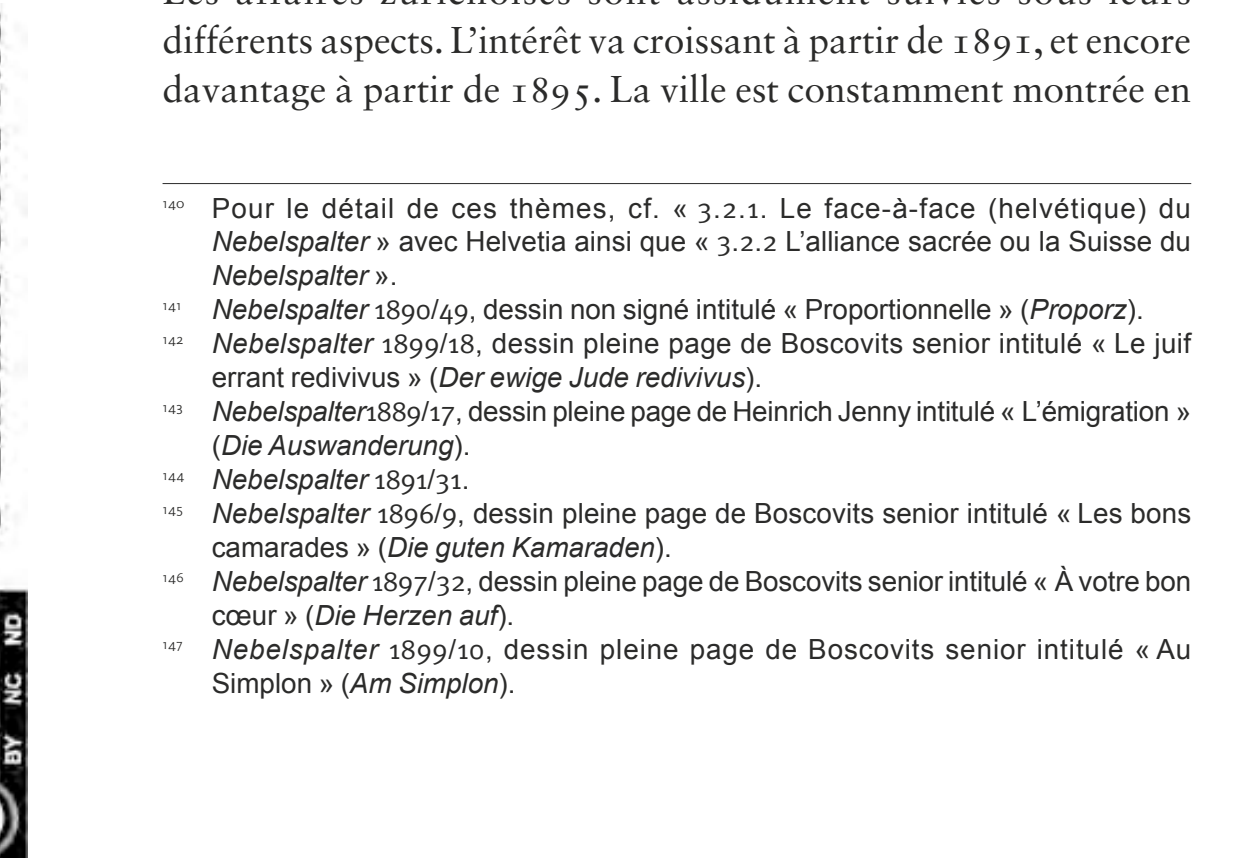

Nebelspalter 1891/6, double-page non signée intitulée « Le regroupement de Zurich et des communes extérieures » (Die Vereinigung von Zürich und Ausgemeinden).

49 "Zürich (Gemeinde) », Dictionnaire historique de la Suisse (25/01/2015); http:// www.hls-dhs-dss.ch/textes/d/D171.php

II s'agit de la grande salle de concert de Zurich à laquelle est consacré un numéro spécial ( $\left.\mathrm{N}^{\circ} 42\right)$.

Philipp Sarasin, « Prostitution », Dictionnaire historique de la Suisse (12/04/2012) http://www.hls-dhs-dss.ch/textes/f/F16559.php

${ }_{52}$ Nebelspalter $1888 / 20$, dessin pleine page de Heinrich Jenny intitulé « Dehors l'opinion loyale » (Des loyalen Meinung drauß').

153 Nebelspalter 1893/14, dessin pleine page de Boscovits senior intitulé «Plein air » (Freiland).

${ }^{54}$ Nebelspalter 1888/20, dessin pleine page de Boscovits senior intitulé « Comment le Volapük vit le jour » (Wie das Volapük entstand).

155 Nebelspalter 1895/38, dessin pleine page de W. Lehmann-Schramm intitulé "Ballade dominicale de végétariens » (Vegetarianers Sonntag-NachmittagSpaziergang).

Sur les caricaturistes et la modernité: Solange Vernois, « Caricature et modernite à la Belle Époque: les trois synthèses », Ridiculosa 14 (2007), Caricature(s) et modernité(s), éd. Alain Deligne et Jean-Claude gardes, p. 91-106.

57 Cf. sur ces différents points « 4.1. La question de l'art Suisse » ainsi que « 4.2. Rendre compte des expositions et régler ses comptes via les expositions ». 


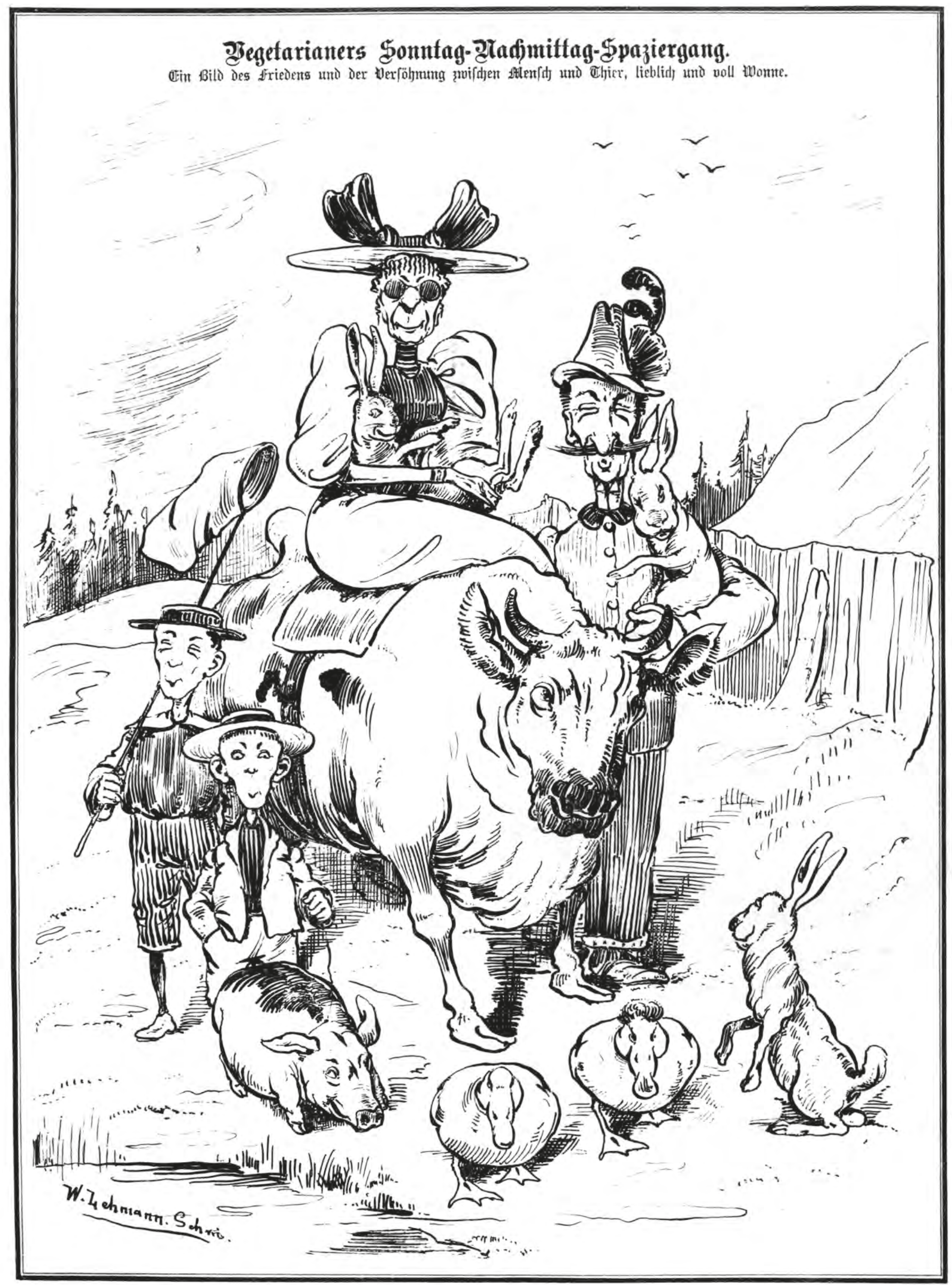

Fig. 15. Nebelspalter 1895/38, dessin pleine page en noir et blanc de Willy Lehmann-Schramm intitulé « Ballade dominicale de végétariens » (Vegetarianers Sonntag-Nachmittag-Spaziergang). 
En I 887, la part des compositions consacrées à l'international croît de manière importante. Dans un contexte de fortes tensions entre les états européens et de gros appétits coloniaux, les alliances et leurs éventuels renversements sont suivis de très près. Ceci d'autant que s'exprime une peur de la guerre en I 888 , réitérée en I 892 et I 894 . À cette date, l'Italie, l'Allemagne, la France, la Russie, l'Autriche, la Suisse (plus petite que les autres) et l'Angleterre sont représentées comme « les gladiateurs modernes " (Die modernen Gladiatoren), prêtant serment à un paon juché sur l'autel du chauvinisme ${ }^{158}$ (cf. fig. I6).

Cette crainte n'est pas vraiment apaisée par la perspective de la première conférence de La Haye de I 899, organisée à l'initiative de Nicolas II et dont l'objectif premier est le désarmement: le diable se glisse sous la table afin de mettre le feu aux poudres ${ }^{159}$. En I 899 , le constat n'est guère plus optimiste et l'ange de la paix est fermement raccompagné dehors ${ }^{160}$. Durant cette période, on n'en finit pas de commenter les rapprochements et dissensions entre les pays européens, d'ironiser et de s'interroger avec une grande méfiance sur les intentions de la Triplice. Helvetia réaffirme, du reste, à l'Allemagne, l'Autriche-Hongrie et l'Italie (la Triplice) le principe de sa neutralité éternelle ${ }^{161}$. En I 895 , la sempiternelle question d'Orient refait surface avec un sultan superstar, plus ridicule qu'effrayant ${ }^{162}$, ceci jusqu'à ce que la guerre gréco-turque de I 897 (guerre des trente jours) éclate, devenant l'un des conflits les plus couverts par la revue. D'autres conflits bénéficient d'un traitement important: la première guerre sino-japonaise, en I 894 et I 895 , restituant une image effrayante du Japon; la présence italienne en Éthiopie, entre I 894 et I 896; la guerre d'indépendance à Cuba, en I 895 ; l'invasion de Madagascar par les Français, en I 895 ; la conquête du Soudan par l'Angleterre, à partir de I 896; la guerre hispano-américaine en I 898 ainsi que l'évolution des événements au Transvaal qui conduisent à la seconde guerre des Boers, fin 1899 .

Autant que les événements, les rivalités font peur, qu'elles soient nourries par des projets d'expansions coloniales ou par des rancœurs. La compétition entre la France et l'Angleterre est particulièrement suivie, en particulier lors du partage du Siam, où les deux pays s'opposent au nom de la culture et de la civilisation ${ }^{163}$. C'est également le cas des manœuvres coloniales au Maroc. Une autre rivalité inquiète, celle entre la France et l'Allemagne, qui se cristallise autour de l'Alsace-Lorraine. Les deux pays sont d'ailleurs consacrés « ennemis héréditaires » (Erblich belastet) en $1895^{164}$ (cf. fig. I7).

Ce sont toujours les voisins français et allemands qui forment l'ossature de la présence étrangère, quoique l'Angleterre, l'Italie, l'Autriche-Hongrie et la Russie prennent de l'importance, ainsi que, progressivement, les États-Unis. La France et l'Allemagne

Nebelspalter 1894/17, double-page de Boscovits senior intitulée « Les gladiateurs modernes » (Die modernen Gladiatoren).

59 Nebelspalter 1898/43, dessin pleine page de W. Lehmann-Schramm intitulé « Sur la conférence de paix » (Zum Friedenscongress).

160 Nebelspalter 1899/31, dessin pleine page de W. Lehmann-Schramm intitulé "L'ange de la paix se retire de la Haye " (Der Abzug des Friedensengels aus dem Haag).

61 Nebelspalter 1892/31, dessin pleine page non signé intitulé « Toujours neutre » (Immer neutral)

162 Nebelspalter 1897/5, dessin pleine page de W. Lehmann-Schramm intitulé « II en sait quelque chose » (Der kennt's).

63 Nebelspalter 1893/32, dessin pleine page de Bocovits senior intitulé « Au nom de la culture » (Im Namen der Kultur).

${ }_{164}$ Nebelspalter 1895/19, dessin pleine page de Boscovits senior intitulé « Ennemis héréditaires » (Erblich belastet). occupent alternativement le premier rang, la première nettement en I 889, la seconde en I 890, I 893 et I 894 . À partir de I 897, c'est néanmoins la Russie qui devient le géant européen. Boscovits senior dessine un Nicolas II énorme sur sa carte «L'Europe actuelle ${ }^{165}$. Auparavant, les désirs guerriers d'Alexandre III, les pogroms, la famine auront donné lieu à des charges particulièrement violentes.

Les autres pays et entités politiques doivent essentiellement leur présence aux affaires coloniales ainsi qu'à de multiples conflits. Ces pays et régions qui apparaissent plus ou moins furtivement sont: l'Espagne, la Bulgarie, la Belgique, la Hongrie, la Bohême, la Pologne, l'Irlande, la Crète, la Turquie, le Maroc, l'Abyssinie, le Soudan, L'Égypte, l’Éthiopie, le Transvaal, le Brésil, le Chili, le Venezuela, Cuba, Hawaï, Madagascar, les Philippines, la Chine, le Japon, la Corée, le Laos, le Siam, le Cambodge et l'Inde.

La France continue d'être associée au général Boulanger, jugé revanchard et nocif. Son départ en I 889 est salué mais les suites politiques du boulangisme effraient jusqu'en I 89 I. En I 889 , le centenaire de la Révolution est célébré ${ }^{166}$. Les accords commerciaux conclus entre la Confédération et la France en I 892, considérés comme désavantageux, pèsent sur l'image autocratique de cette dernière. Les relations de la France avec la Russie sont scrutées avec méfiance durant toute cette période, en lien, en particulier, avec ce qui va devenir le scandale de Panama. La « crise de Panama » (Panama-Krisis) est évoquée pour la première fois en mars I $887^{167}$, puis à nouveau début I $889^{168}$. Au mois de septembre I 892, le terme de "scandale de Panama " surgit, à la suite des révélations de l'antisémite Édouard Drumont dans le quotidien La libre-parole ${ }^{169}$. Bien qu'ayant constamment dénoncé les " arrangements » autour du canal de Panama, qui ont pour effet la ruine de milliers de souscripteurs, le Nebelspalter fait botter les fesses de Drumont par Alexandre III ${ }^{170}$, liquidant d'un seul coup les deux abominables. À la différence d'une partie de la presse française, l'affaire ne déclenche pas ici de schèmes antisémites ${ }^{171}$. À la fin de l'année, Panama figure parmi les dangers que doit affronter le gouvernement Français ${ }^{172}$. L'année suivante, en I893, la revue relaie le procès qui ébranle la République ${ }^{173}$. L'instabilité parlementaire est, du reste, un sujet d'inquiétude permanent. Lélection de Sadi Carnot, le 3 décembre i 887, avait pourtant été saluée avec un portrait pleine page, un honneur rarement consenti à un étranger ${ }^{174}$. Carnot est le «chouchou " français de la revue, qui ne montre un tel enthousiasme pour aucun autre président. Son action entre I 887 et I 894 est néanmoins critiquée à plusieurs reprises, ce qui n'empêche pas la condamnation très ferme de son assassinat par l'anarchiste italien Sante Geronimo Caserio, le 25 juin I 894 . Ce sont, en fait, « deux victimes » (zwei

Nebelspalter 1897/39, double-page de Boscovits senior intitulée «L'Europe actuelle » (Das heutige Europa); cf. « 3.1.2. 1887-1914: Déclinaisons d'un univers en expansion et d'une Europe impuissante ».

Nebelspalter 1889/19, double-page de Boscovits senior intitulée « Sur le centenaire de la Révolution Française » (Zum Centenaire des Französischen Revolution). Nebelspalter 1887/12, couverture non signée.

Nebelspalter 1889/2, dessin pleine page de Heinrich Jenny intitulé «La crise de Panama » (Die Panama-Krisis).

${ }_{69}$ Sur le scandale de Panama, voir en premier lieu: Jean-Yves Mollier, Le scandale de Panama, Paris, Fayard, 1991.

Nebelspalter 1892/37, dessin pleine page non signé intitulé « Drumont \& Cie ». Bertrand Tillier, La Républicature. La caricature politique en France 1870-1914 Paris, Cnrs, 1997, p. 91-92.

Nebelspalter 1892/52, dessin non signé intitulé « Maintenant, c'est vraiment parti! » (Nun ist's aber recht losgegangen!).

Nebelspalter 1893/11, dessin pleine page de Boscovits senior intitulé «Le procès de Panama » (Der Panamaprozess).

14 Nebelspalter 1887/50, dessin pleine page de Boscovits senior intitulé « Sadi Carnot, le nouveau Président de la France » (Sadi Carnot, derneue Präsident Frankreichs). 
-5is Die modernen Gladiatoren. Wer

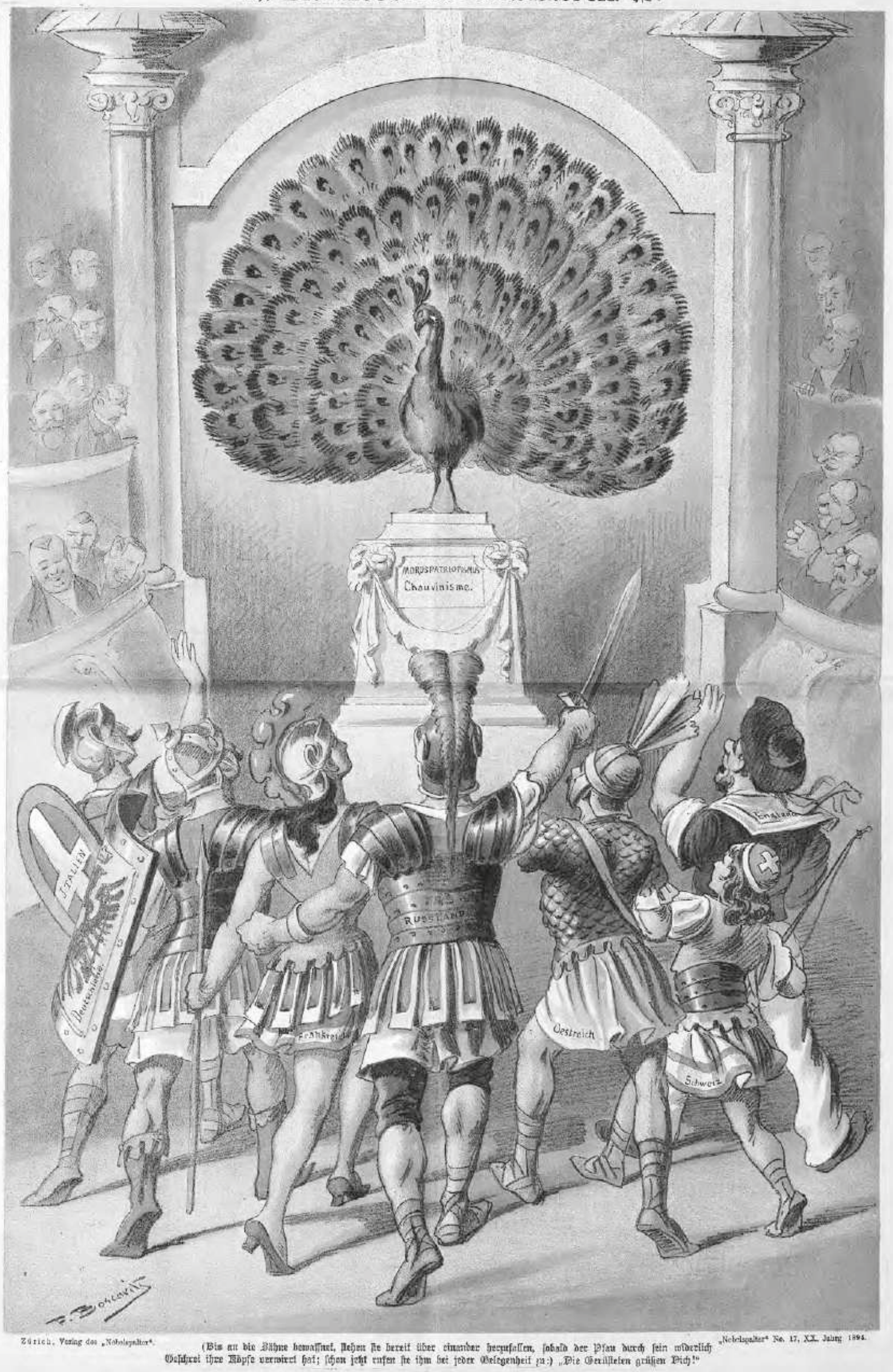

Fig. 16. Nebelspalter 1894/17, double-page en couleur de Boscovits senior intitulée « Les gladiateurs modernes »(Die modernen Gladiatoren). 


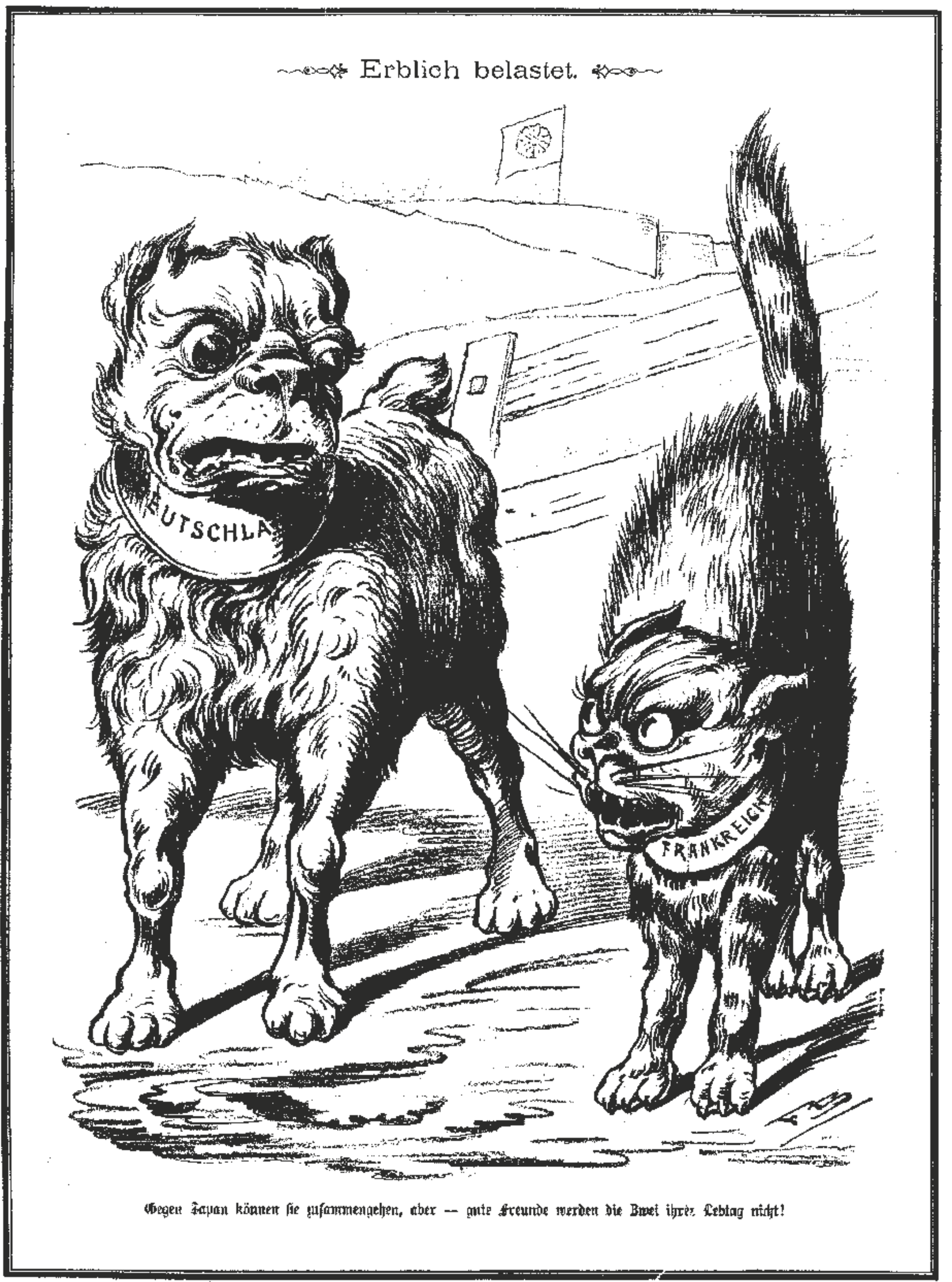

Fig. 17. Nebelspalter 1895/19, dessin pleine page en noir et blanc de Boscovits senior intitulé « Ennemis héréditaires » (Erblich belastet). 


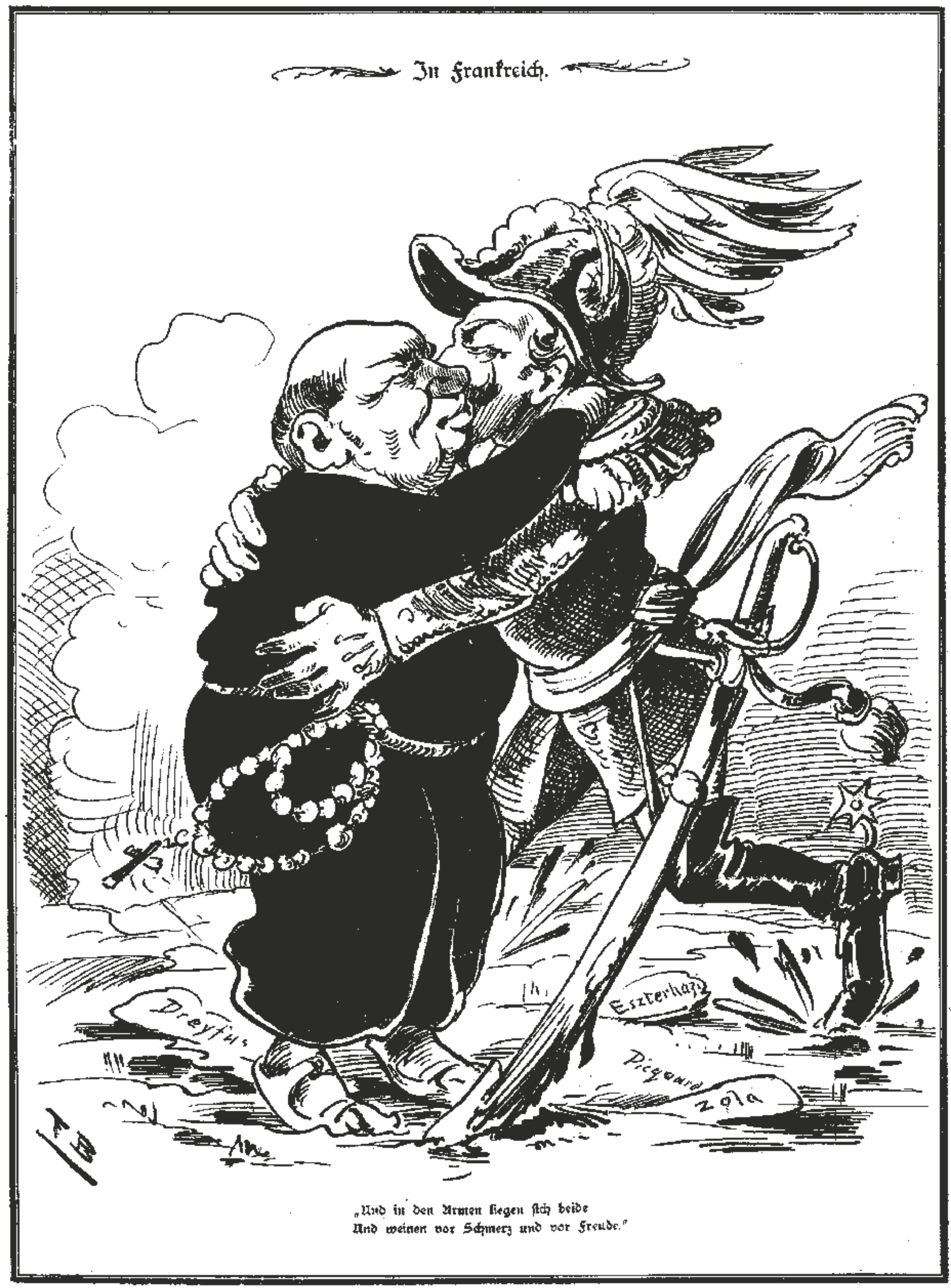

Fig. 19. Nebelspalter 1898/33, dessin pleine page en noir et blanc de Boscovits senior intitulé « En France » (In Frankreich). 
Opfer) qui sont représentées, Carnot, auquel est promise la gloire éternelle et l'anarchie, poignardée ${ }^{175}$ (cf. fig. I 8 cahier couleur). Ni l'élection de Félix Faure, en I 895, guère aimé du Nebelspalter qui lui reproche son esprit revanchard, ni la mort de celui-ci, en I 899, ne sont commémorées de la même façon.

L'affaire Dreyfus fait son apparition au début de l'année I 895 dans un numéro daté du I 9 janvier, juste après la condamnation au bagne à perpétuité du capitaine Dreyfus, le 22 décembre I 894. Elle est alors présentée comme l'un des dossiers explosifs que doit affronter le président Casimir Perrier ${ }^{176}$. Elle ne quittera plus les pages de la revue jusqu'en I906, date de la réhabilitation de Dreyfus, avec cependant des pics de présence en I 898 et I 899 , au moment de la publication de l'article «J'accuse...! » d'Émile Zola dans L'Aurore et du procès de Rennes; ceci, du reste, à l'image d'une bonne partie de la presse européenne ${ }^{177}$. Le traitement de l'affaire Dreyfus est d'un déchiffrage assez complexe, car il mêle et répercute des points de vue divers, et transmet finalement une position hybride, frisant l'ambiguité. Certes, les différentes étapes historiques et médiatiques se retrouvent: la présentation d'un Dreyfus convaincu d'espionnage, représentant un danger pour la République $^{178}$; puis, à partir de la fin $\mathrm{I} 897$, une mise en question de la culpabilité de Dreyfus, après les révélations dans la presse de l'identité du vrai coupable, l'officier Esterhazy, et d'un premier article de Zola dans Le Figaro ${ }^{179}$; la dénonciation d'une posture de l'État couvrant l'armée aux dépens de la vérité, après la publication de l'article « J'accuse....! » de Zola dans L'Aurore, le I 3 janvier I $898^{180}$; la critique de la première condamnation de Zola, le 23 février I 898 ; puis de la seconde condamnation, le I 8 juillet I 898 , et de ses suites dans l'opinion ${ }^{181}$; le procès de Rennes, à l'été I $899^{182}$; la recherche d'un apaisement au prix, s'il le faut, d'un enterrement de l'affaire ${ }^{183}$. Mais, ces différents épisodes sont restitués d'un point de vue qui ne dépend pas que de la connaissance de l'affaire ni d'une posture idéologique qui pourrait être hâtivement qualifiée de dreyfusiste, un parti en faveur de Dreyfus, une fois son innocence connue, s'interrogeant sur les rouages ayant permis de tels développements. Non, comme toujours, le Nebelspalter s'approprie la cause en fonction de ses intérêts propres. À l'image d'une partie de la presse française (dreyfusiste), les caricatures thématisent une collusion institutionnelle entre l'armée et le clergé ${ }^{184}$, induisant l'idée

\footnotetext{
Nebelspalter 1894/27, double-page de Boscovits senior intitulée « Deux victimes » (Zwei Opfer).
}

76 Nebelspalter 1895/3, dessin pleine page de Boscovits senior intitulé « À Paris » (In Paris); numéro du 19 janvier 1895 . On donne ici les dates des dessins, essentielles pour le suivi de l'affaire.

77 La littérature sur l'affaire Dreyfus est pléthorique, on se référera cependant en priorité et sans caractère d'exhaustivité à : John Grand-Carteret, L'affaire Dreyfus et l'image, Paris, Flammarion, 1898; Ridiculosa 1 (1994), L'affaire Dreyfus dans la caricature internationale; Bruno de Perthuis, « Images de la justice au temps de l'Affaire Dreyfus », Société et représentations, La justice en images, 18 (2004) Raymond Bachollet, Les cent plus belles images de l'Affaire Dreyfus, Paris, Dabecom, 2006; Bertrand Tillier, Les artistes et l'affaire Dreyfus (1898-1908), Paris, Champ Vallon, 2009; Marc Martin, « Les journalistes et l'affaire Dreyfus », L'affaire Dreyfus et le tournant du siècle (1894-1-910), éd. Laurent Gervereau et Christophe Prochasson, Paris, Musée d'histoire contemporaines, BDIC, 1994, p. 116-127.

${ }_{178}$ Nebelspalter 1895/3, dessin pleine page de Boscovits senior intitulé « À Paris » (In Paris); numéro du 19 janvier 1895.

79 Nebelspalter 1898/6, dessin pleine page de Boscovits senior intitulé « Carnaval » (Carneval); numéro du 5 février 1898.

180 Nebelspalter 1898/8, double-page de Boscovits senior intitulée "Justitia en France »; numéro du 19 février 1898.

81 Nebelspalter 1898/30, dessin de Boscovits senior intitulé " II l'ont - eu » (Sie haben ihn - gehabt); numéro du 23 juillet 1898; Nebelspalter 1898/39, dessin de Boscovits senior intitulé « Revision »; numéro du 24 septembre 1898.

${ }_{182}$ Nebelspalter $1899 / 38$, dessin pleine page de W. Lehmann-Schramm intitulé «Consolation » (Trost); numéro du 23 septembre 1899.

${ }_{183}$ Nebelspalter 1903/7, dessin pleine page de Boscovits senior intitulé « Au travail » (An der Arbeit); numéro du 14 février 1903.

${ }_{184}$ Nebelspalter 1898/33, dessin pleine page de Boscovits senior intitulé « En France » (In Frankreich); numéro du 13 août 1898. d'un fonctionnement pareillement vicié des institutions autochtones (cf. fig. I9).

Et lorsque, à peu près à la même époque, Guillaume II, est dessiné se tenant obstinément à l'écart de l'affaire et disant (en français): «Vous ne me mettrez jamais dans ce potage » ${ }^{185}$, les accusations de la presse française sont effectivement relayées, mais la revue charge surtout l'empereur allemand (cf. fig. 20 cahier couleur). À la différence de la presse française ou même allemande, le Nebelspalter fait dans la retenue et rien ne choque vraiment dans ces dessins qui reprennent et adoucissent des motifs visibles ailleurs, la lumière (de la vérité), la soupe (mauvaise), le train (de la vérité) ou l'oiseau en cage. Une chose cependant frappe dans l'iconographie de l'affaire Dreyfus : la manière dont est escamotée la figure du capitaine, presque toujours absent ou à l'arrière-plan de la grosse trentaine de compositions sur le sujet. Dans l'une des rares compositions à faire exception, Dreyfus est un insecte englué dans une toile d'araignée, guetté par une araignée agrégeant les têtes de différents protagonistes; autant dire qu'il incarne toutes les ramifications de l'affaire ${ }^{186}$ (cf. fig. 2I).

À tel point que l'on peut légitimement se demander si cette dépersonnalisation de l'affaire ne vise pas un évitement de la judéité de Dreyfus - une sorte de tabou que se seraient fixé les dessinateurs - ou qui leur aurait été dicté. À la même époque, pourtant, une autre figure ouvre sur des charges antisémites: Edmond de Rothschild, au cœur de la question sioniste qui apparaît en I 895, alors que les premiers congrès sionistes se tiennent à Bâle, respectivement en I 897 et I 899 . La confusion sciemment entretenue avec la banque Rothschild - objet de nombreuses caricatures - permet de laisser cours à un antisémitisme très violent ${ }^{187}$.

L'Allemagne, c'est avant tout Guillaume II, champion incontesté des caricatures, dès son accession à la fonction impériale, le I 5 juin I 888, l'année des trois empereurs (Guillaume I ${ }^{\text {er }}$, Frédéric III et Guillaume II), une situation inédite dont rend compte la revue ${ }^{188}$. L’année n'est pas finie que Guillaume II est montré revenant de voyage dans un faste excessif ${ }^{189}$. Une tendance s'amorce alors qui va s'accroître à mesure que les ambitions coloniales et guerrières de l'empereur vont se préciser - et donc faire peur -; ceci surtout après la démission de Bismarck, au printemps I 890. Alors que s'installe un culte de l'ancien chancelier, totalement effectif après la mort de celui-ci, le 30 juillet I 898 , et que l'on prédit que le siège de l'artisan du Reich ne trouvera pas de remplaçant à la hauteur ${ }^{190}$, l'image de Guillaume II se dégrade encore un peu plus. Il devient un souverain autoritaire, peu compétent, doté d'une tendance mégalomaniaque et surtout malaimé ${ }^{191}$. Un autocrate qui voudrait même annexer la Suisse ${ }^{192}$ (cf. fig. 22).

\footnotetext{
Nebelspalter 1898/1, dessin pleine page de Boscovits senior intitulé « Affaire Dreyfus »; numéro du $1^{\text {er janvier } 1898 .}$

186 Nebelspalter 1899/32, dessin pleine page de Boscovits senior intitulé « Le procès Dreyfus » (Dreyfus-Prozess); numéro du 12 août 1899.

7 Nebelspalter 1895/36, dessin pleine page de W. Lehmann-Schramm intitulé « La colonie Rothschild en Palestine » (Rothschilds Judenkolonie in Palästina).

${ }_{188}$ Respectivement: Nebelspalter 1888/12, double-page de Boscovits senior sans titre; Nebelspalter 1888/26, dessin pleine page de Heinrich Jenny intitulé « L'Allemagne en deuil » (Deutschlands Trauer).

${ }_{189}$ Nebelspalter 1888/44, dessin pleine page de Heinrich Jenny intitulé « Le retour de l'empereur Guillaume » (Kaiser Wilhelm's Heimkehr).

190 Nebelspalter 1898/32, dessin pleine page de Boscovits senior intitulé « Venus de tous côtés » (Allerseits zugegeben)

${ }_{191}$ Nebelspalter 1898/49, dessin pleine page de Boscovits senior intitulé « Différence de température » (Temperaturunterschied)

.2 Nebelspalter 1897/13, dessin non signé intitulé « II provoque » (Provozirt).
} 


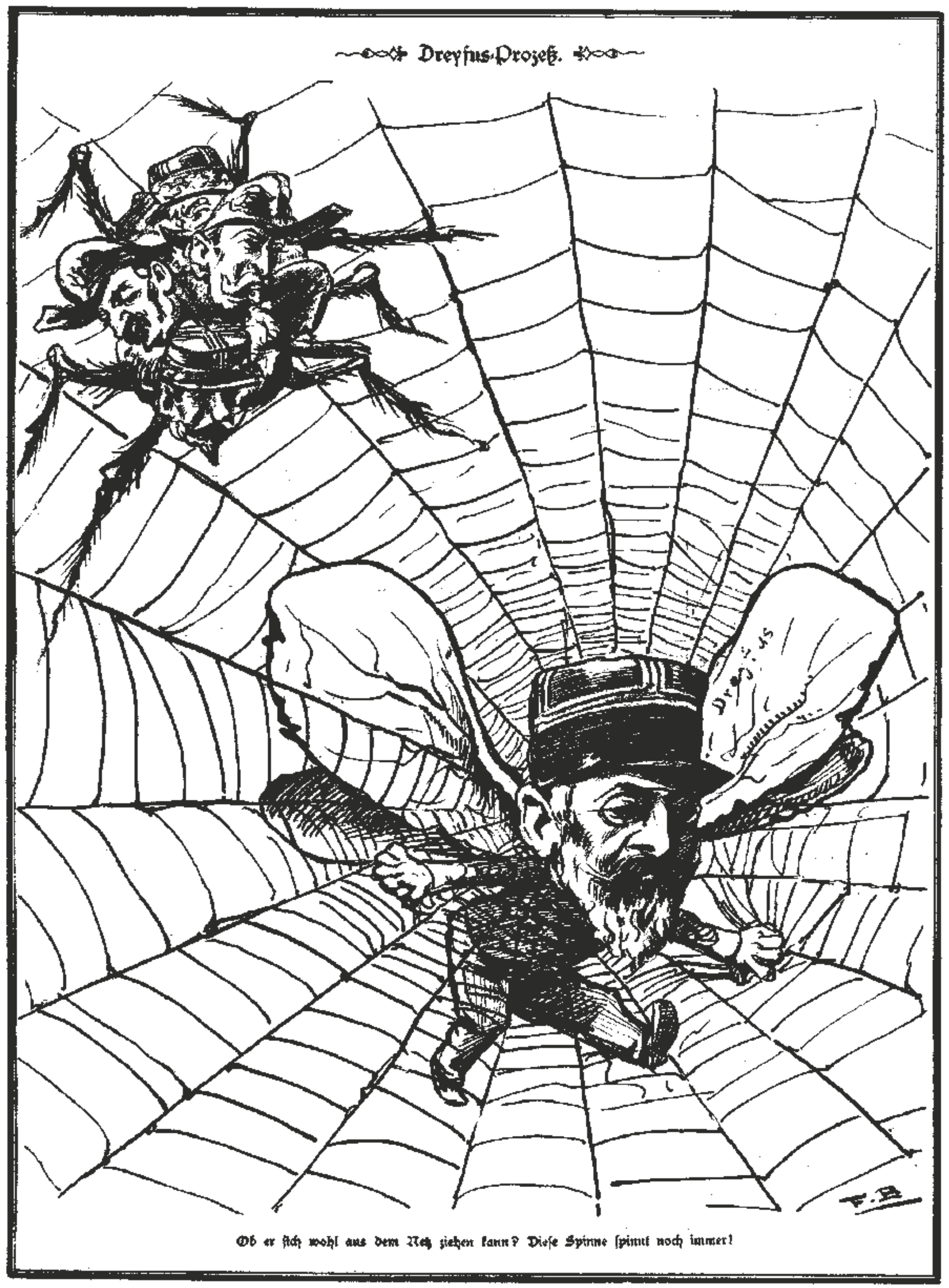

Fig. 21. Nebelspalter 1899/32, dessin pleine page en noir et blanc de Boscovits senior intitulé « Le procès Dreyfus » (Dreyfus-Prozess). 


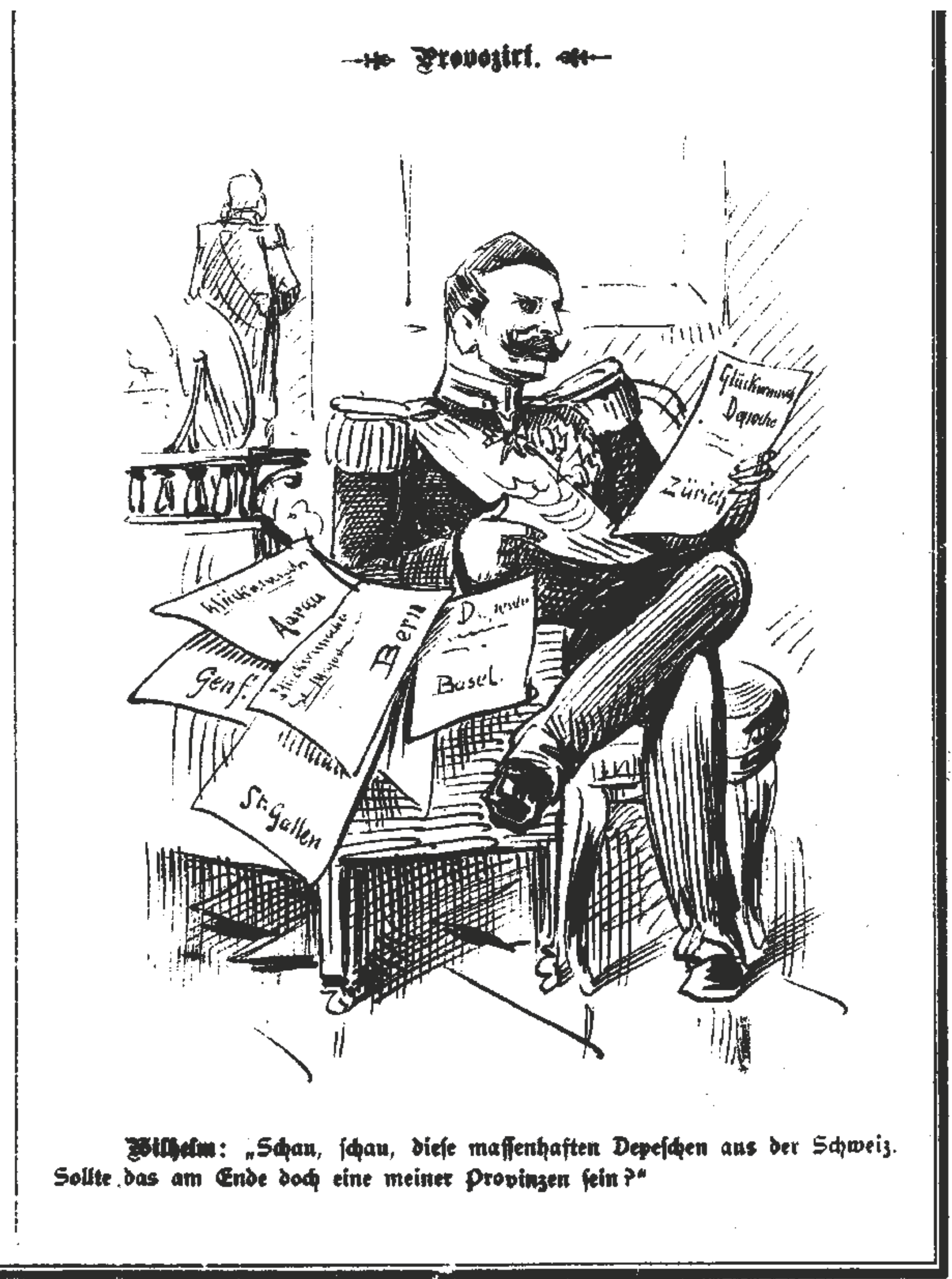

Fig. 22. Nebelspalter 1897/13, dessin en noir et blanc non signé intitulé « Il provoque » (Provozirt). 
Le pays suscite, plus généralement, beaucoup d'inquiétudes et peu d'admiration. Il est considéré comme un pourvoyeur d'anarchistes venant chercher refuge en Suisse; ses appétits coloniaux, notamment après I 890 sont regardés avec méfiance; son nouveau chancelier, Leo von Caprivi, ne convainc pas face à la popularité de Bismarck ${ }^{193}$; pas plus, du reste, que Chlodwig zu HohenloheSchillingsfürst (dit communément Hohenlohe) qui lui succède, le 9 octobre I $894^{194}$; la contagion d'une vie parlementaire agitée est redoutée, sans toutefois amener à prendre parti dans le projet de loi sur les partis révolutionnaires (Umsturzvorlage), en I $895^{195}$. L'ascension du socialiste Auguste Bebel alarme. L'affaire Kotze, mettant en cause les mœurs de l'entourage impérial entre I 89I et I 896, intéresse peu ${ }^{196}$. L'Allemagne n'est vue qu'à travers le prisme des intérêts helvétiques.

\subsubsection{Rhétorique - Continuité et variations}

Les titres des compositions reflètent les thématiques. Comme auparavant, certains thèmes aux titres fixes servent à affirmer l'identité suisse et satirique du Nebelspalter: "Les images de l'hiver " (Winterbilder), le carnaval, la fête zurichoise des Sechseläuten, les Pâques, "la saison de la baignade "(Zur Badesaison), "La saison de la chasse " (Jagd-Saison). La deuxième tendance est celle des titres " parlants », accompagnant, de manière récurrente, l'actualité. En grande partie, ceux-ci ne sont pas nouveaux: "La chasse a commencé » (Die Jagd hat begonnen), "Les temps changent " (Die Zeiten ändern) ou encore "Nouvelle journalistique illustrée " (Illustrierte Zeitungsnachricht).

À la faveur d'une évolution un peu canaille dans l'esprit Belle Époque, une kyrielle de compositions thématisent la figure de l'ivrogne avec des titres en rapport, tels « Ivrogne en bonne route » (Sauser in Stadium) et autres "Fantasme d'ivrogne " (Sauser Phantasie). L'émancipation féminine laisse également des traces avec les «Femmes modernes" (Moderne Frauen), en I 896 $6^{197}$. Les icones accompagnant les rubriques des pages intérieures s'enrichissent, du reste, en I893, de la figure d'Eulalia, caricature de la femme moderne.

Le système de citations humanistes, généralement en français ou en latin, se pérennise, avec des titres comme "Persus redivivus" ou "Tempora mutantur », voire la référence à une œuvre célèbre, telles «La chasse au bonheur» (Die Jagd nach dem Glück) du peintre allemand Rudolf Henneberg (I825-1876) ou la «Danse macabre » (Totentanz) de Holbein ${ }^{198}$.

Les légendes, plus que les titres, sont révélatrices de tâtonnements dans le positionnement. À la fin de I 887 , apparaît la première composition humoristique dépourvue de légende. Elle est signée Pastarella (E.V Muyden) ${ }^{199}$. Dès I 889, cohabitent des compositions

93 Nebelspalter $1891 / 52$, dessin pleine page de Boscovits senior sans titre (dernière page du numéro)

4 Nebelspalter 1896/4, dessin non signé intitulé « Dans les ateliers de l'empire » (In der Reichswerkstätte).

Nebelspalter $1895 / 15$, dessin pleine page de Boscovits senior intitulé « Nul besoin de consolation » (Nicht zu trösten).

196 Nebelspalter 1894/28, dessin pleine page non signé intitulé « Sur le nettoyage allemand de la langue » (Zur deutschen Sprachreinigung); sur l'affaire Kotze, en première intention: Wolfgang Wippermann, Skandal im Jagdschloss Grunewald: Männlichkeit und Ehre im deutschen Kaiserreich, Darmstadt, Primus-Verlag, 2010.

Nebelspalter 1896/32, dessin pleine page de W. Lehmann-Schramm.

Cf. à ce sujet " 5.2. S'enrichir du "grand art" ».

Nebelspalter 1887/51, dessin pleine page signé Pastarella intitulé « Conséquences de chiens » (Hundekonsequenzen). aux légendes très longues avec d'autres elliptiques, à la limite de la décontextualisation. À partir de I 897, les légendes des dessins liés à Zurich sont très souvent écrites en dialecte. L'année suivante, en I 898, celles-ci sont concurrencées par des légendes bilingues, en français et en allemand. Apparaissant en début d'année, ces légendes bilingues disparaissent en cours d'année, pour revenir furtivement au début de l'année I 899. Ces écarts linguistiques et thématiques dénotent la volonté de cibler un large public que l'on aimerait voir s'étendre de Zurich à la Suisse romande, et peut-être - qui sait - à la France. Cet effort restera pourtant isolé, hormis quelques jeux de mots lettrés, comme en I902, un rapprochement entre « corps de ballet » et « corps de balai » ${ }^{200}$.

Jusqu'en I 892, l'humour est plutôt gentillet. Il prend ensuite un tour plus grinçant. En I 893, la rhétorique de la culture et de la civilisation revient, cette fois en relation avec le Siam ${ }^{201}$. Promise à un bel avenir, en particulier durant la Première Guerre mondiale, cette rhétorique est reprise en I 895 pour traiter du Japon ${ }^{202}$. Avec l'arrivée de nouveaux dessinateurs dans les années I 890, les emprunts au fonds religieux se multiplient. À partir de I 894, le terme " fin de siècle " envahit la revue; un an plus tard, c'est au tour de «philistins " (Philister). Tous deux sont très goûtés des revues germaniques ${ }^{203}$. On rencontre, enfin, quelques singularités, comme, en I 898, durant ce court moment où le Nebelspalter rêve à la Romandie, une parodie d'une lettre en français fédéral (le français parlé par les Suisses non Francophones), intitulée «Le départ du Weltschlande » ${ }^{204}$.

\subsubsection{Langage visuel - Jugendstil, Belle Époque et caricature}

À partir de I 887, les dessins sont régulièrement signés ${ }^{205}$, à deux exceptions : d'une part, les sujets sensibles, les questions engageant l'autorité fédérale, les affaires bancaires, certains scandales locaux ainsi que, à partir des années I 890 , les questions artistiques; d'autre part, certaines compositions peu valorisées, les pages à quatre dessins, par exemple. Courant I 888, les trois dessinateurs alors actifs, Boscovits senior, Evert van Muyden (Pastarella) et Heinrich Jenny, usent tant de leur signature que d'un monogramme. L'année suivante, en I 889, ces mêmes dessinateurs multiplient les signatures, installant une pratique qui va se poursuivre des années durant. Les autres dessinateurs n'useront jamais de ce qui apparaît comme le privilège des anciens. Cette même année, Heinrich Jenny indique pour la première fois le lieu, Soleure (Solothurn), où a été créé le dessin. À partir de I 892, le monogramme concurrence sérieusement la signature. L'année suivante, en I 893, certains artistes, Otto Maehly, Hans Wirz et Willy Lehmann-Schramm, se mettent à mentionner la date, et parfois le lieu. LehmannSchramm est l'artiste jouant le plus de sa signature, notamment à partir de I 895 , tronquant celle-ci de diverses manières, livrant différents monogrammes, dont l'un, à partir de I 899, dans un cartouche, repris ensuite par plusieurs dessinateurs. L'usage du pseudonyme est durant toute cette période en net recul, ce que

Nebelspalter 1902/43, dessin signé d'un monogramme intitulé «Écrit un peu autrement, mené un peu autrement » (Ein wenig anders geschrieben, ein wenig anders getrieben!).

201 Nebelspalter 1893/32, dessin pleine page de Boscovits senior intitulé « Au nom de la culture » (Im Namem der Kultur).

202 Nebelspalter 1895/17, dessin pleine page de Emil Dill intitulé « Le saint Georges japonais » (Der japanische St. Georg).

${ }_{203}$ Cf. Laurence Danguy, L'ange de la jeunesse - La revue Jugend et le Jugendstil à Munich, op. cit., p. 126-131.

204 Nebelspalter 1898/17, texte intitulé « Le départ du Weltschlande »; le terme "Weltschlande » est un néologisme désignant le pays (Land) des Suisses romands (Welsch), malicieusement rapproché de « Monde » (Welt).

205 À l'exception de l'année 1896, sans qu'il y ait d'explication évidente du phénomène. 
confirme, en I 895, Henri van Muyden en abandonnant celui de Pastarella, qu'avait également utilisé son Frère Evert ${ }^{206}$.Toutes ces pratiques vont dans le sens d'une valorisation de l'image et du dessinateur ${ }^{207}$.

Deux mutations visuelles se produisent entre I 887 et I 900 . L'année I 887 signe un premier tournant visuel, avec l'arrivée de la couleur et un langage qui se renouvelle sous l'impulsion de Evert van Muyden, très actif aux côtés de Boscovits senior et de Emil Graf. Le dessin de Boscovits senior, qui reste jusqu'à l'arrivée de Willy Lehmann-Schramm le premier maître d'œuvre de la revue, se nourrit de celui de ces deux artistes. Ce premier tournant visuel est confirmé en I 888 et I 889 avec l'expansion de la couleur mais surtout l'arrivée de Heinrich Jenny et Henri van Muyden, introduisant à leur tour de nouveaux motifs et formules. Un deuxième changement important se produit à partir de I 890 avec l'assimilation des esthétiques Jugendstil et Belle Époque. Le virage Jugendstil - pour utiliser une commodité de langage - est dans l'air du temps, puisque les esthétiques Art nouveau s'imposent alors largement dans l'univers des revues illustrées européennes. À partir de I 893, il est très largement mené par Willy LehmannSchramm. Ce dernier donne le ton et prend la tête des nouveaux dessinateurs, Fritz Boscovits (Boscovits junior), Emil Dill, Otto Maelhy ainsi que Hans Wirz, arrivés respectivement en I 889 , I 890, I 892 et I 893 .

L'influence Belle Époque introduit une certaine légèreté avec le thème de la mode ${ }^{208}$ ainsi qu'un discours sociétal, dont les figures du gueux, de la danseuse et du travailleur sont emblématiques dès I 890 . À partir de I 895, s’y agrègent la figure de la cocotte, puis, quelques années plus tard, celle du bourgeois nanti. Les nombreuses petites caricatures de mœurs où sont confrontés hommes et femmes peu avant le tournant du siècle, ainsi que les représentations sociabilisées d'une ville, parfois très sombre, visibles dès le début des années I $890^{209}$, ont la même origine Belle Époque. Une certaine vision duelle de la société s'installe, qui oppose le monde festif des élégantes, des cafés et des belles-de-nuit à un univers d'où suintent violence et misère ${ }^{210}$. Un dessin de Henri van Muyden de la fin I 892 est typique de cette tendance. Il montre un pauvre hère, à l'expression canaille plutôt sympathique, attendant, un bâton à la main, un riche bourgeois pour le dépouiller de son manteau de fourrure ${ }^{211}$ (cf. fig. 23).

\footnotetext{
206 «Pastarella » est le pseudonyme successivement employé par Evert et Henri van Muyden; il convient de corriger l'affirmation de Peter Métraux d'une collaboration exclusive de Boscovits senior durant cette période: Peter Métraux, Die Karikatur als publistische Ausdruckform untersucht am Kampf des " Nebelspalters » gegen den Nationalsozialismus 1933-1945, Berlin, 1966, p. 25 ; cf. aussi « 6.4. Passions d'artistes: Richard Kissling, Evert van Muyden, Henri van Muyden et Jean Nötzli ».

${ }^{207}$ Voir aussi « 1.5. Ambitions voilées et assumées: de la délimitation avec les champs de l'art et de la presse $"$.

${ }_{208}$ Nebelspalter 1890/22, dessin pleine page de Henri van Muyden intitulé « Modes $1890 »$ (Moden 1890).

${ }^{209}$ Voir à ce sujet: Laurence Danguy, «Confisquée par l'image: la ville des revues germaniques autour de $1900 »$, dans Représenter la ville: entre cartographie et imaginaire, éd. Pierre-Yves Le Pogam et Martine Plouvier, Paris, CTHS, 2013. p. 83-105.

${ }_{210}$ À ce sujet: Alain Corbin, Les Filles de noce. Misère sexuelle et prostitution (XIX siècle), Paris Flammarion, 1982.

Nebelspalter 1892/53, dessin pleine page de Henri van Muyden.
}

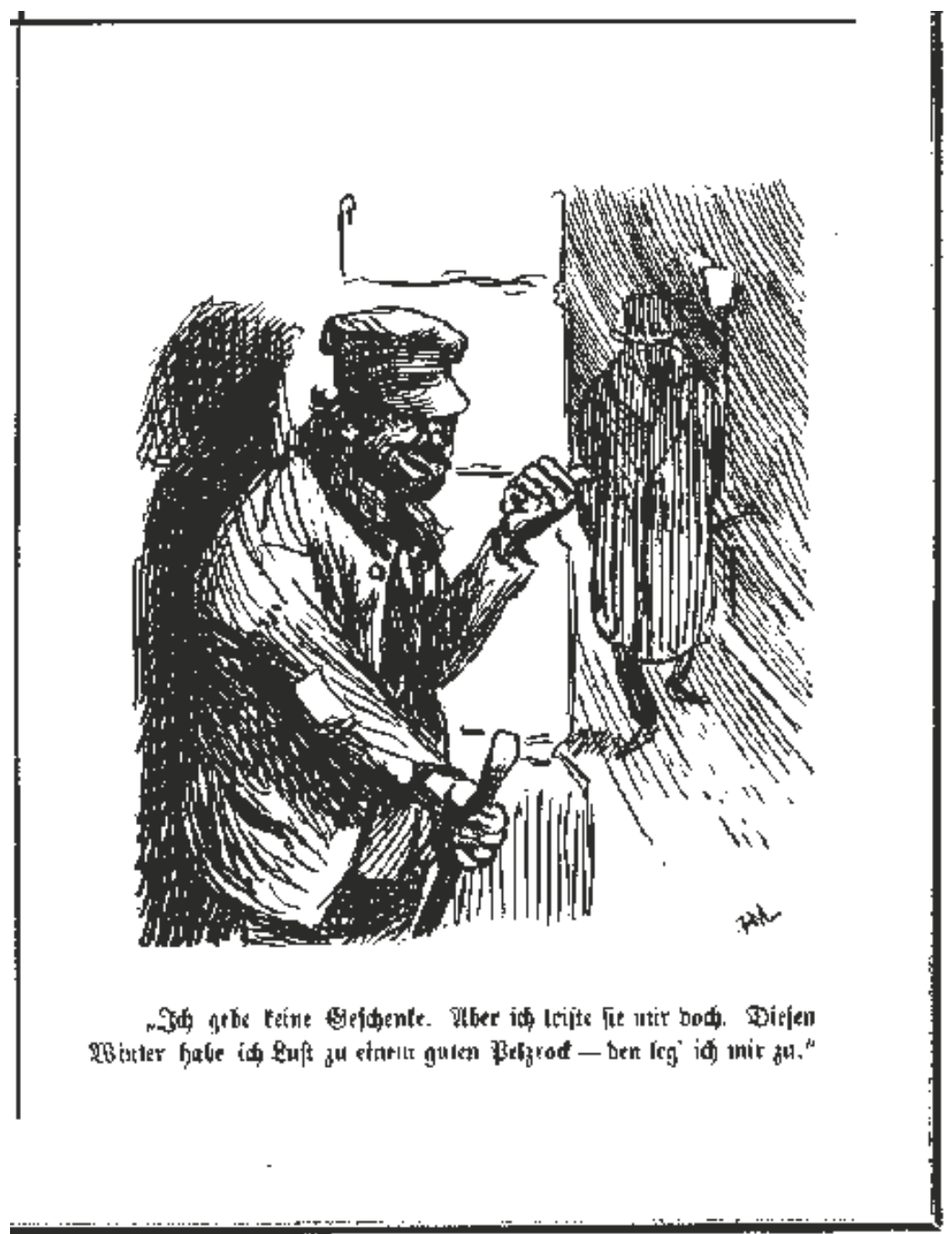

Fig. 23. Nebelspalter 1892/53, dessin en noir et blanc de Henri van Muyden.

Le trait s'allège, les procédés de déformation s'estompent, disparaissent dans certains cas, le propos surtout se décentre.

Les prémices du Jugendstil sont légèrement plus tardives. Elles commencent à poindre en I 89I dans les dessins que Boscovits junior envoie de Munich, où il perfectionne sa formation, tel un tableau de beuverie formé de panneaux encastrés les uns dans les autres ${ }^{212}$. Cette influence Jugendstil s'exprime par des motifs et thèmes très typés, la femme, le chevalier, les fleurs et autres éléments végétaux et animaliers stylisés. Il consiste également en une révision des principes de composition, un nouveau cadrage, un rapprochement des figures, un raccourcissement de la perspective, un aplanissement des registres, des couleurs, y compris le noir et le blanc, traités en aplats, et une forte tendance à la décontextualisation. Perceptible à partir de I 890 , plus nettement à partir de I 892, la pâte Jugendstil devient manifeste à partir de I 894, peu après l'arrivée de Willy Lehmann-Schramm, en I 893. Le dessinateur allemand fait entrer le Jugendstil dans le Nebelspalter au travers de motifs floraux et animaliers, une utilisation des cercles rappelant Mucha mais surtout via la figure féminine, déclinée sans relâche. Celle-ci bouscule fortement l'allégorie, comme dans une composition de I 894 intitulée "Automne" (Herbst), où une élégante à moitié fée est assise dans un cerceau, l'une des formalisations du cercle à la Mucha ${ }^{213}$ (cf. fig. 24).
Nebelspalter 1891/32, dessin pleine page de Boscovits junior intitulé « La misère de l'aubergiste » (Wirthsmisere).

${ }_{213}$ Nebelspalter $1894 / 40$, dessin pleine page de W. Lehmann-Schramm intitulé «Automne » (Herbst). 


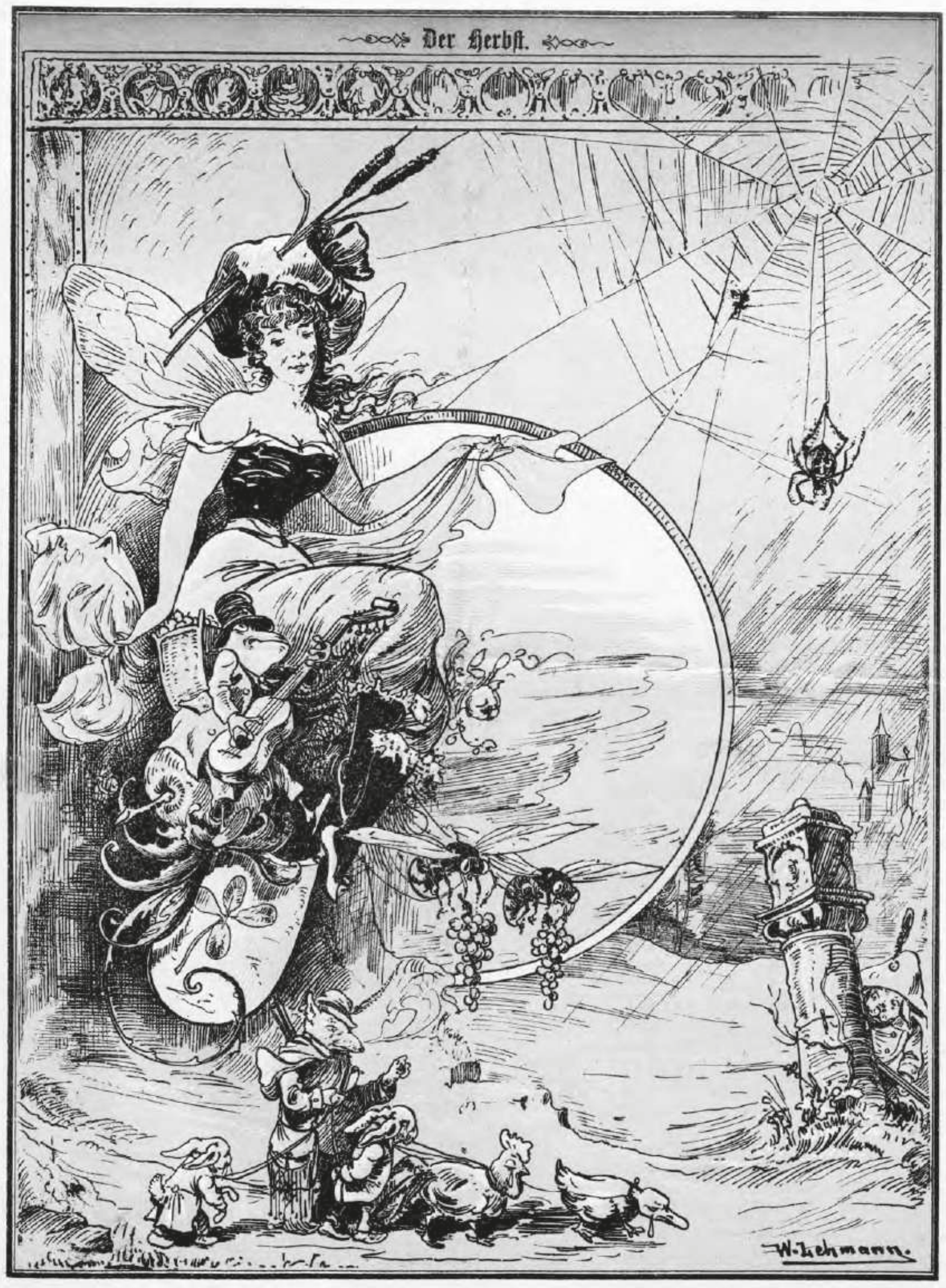

Fig. 24. Nebelspalter 894/40, dessin pleine page en couleur de Willy Lehmann-Schramm intitulé « Automne »(Herbst). 
L'année I 896 marque une nouvelle étape avec l'intégration de modèles en provenance des deux revues munichoises Jugend et Simplicissimus, dont la réception est internationale ${ }^{214}$. Lehmann-Schramm et Boscovits junior, les deux représentants de cette tendance, signent dès lors des dessins humoristiques, des caricatures, des dessins de mœurs et des salons caricaturaux dans la plus pure veine Jugendstil. L'image, parfois séparée en différents registres, selon une influence japonisante, présente des figures sinueuses, peu détaillées, dans une ambiance joyeuse, à peine contextualisée. Ces dessins sont parfois parés d'ornements floraux, tel le pêcheur un peu benêt de Willy Lehmann-Schramm ${ }^{215}$.

De nouveaux motifs et thèmes voient le jour, les uns liés à un esprit Belle Époque, venus de France, les autres au Jugendstil, en provenance des pays germaniques, et plus spécialement de Munich. Il faut ici se souvenir que le Jugendstil n'est pas une "simple " adaptation de l'Art nouveau mais une véritable acculturation avec sa dimension créative, tandis que le langage des revues Belle Époque réalise une synthèse de l'Art nouveau, du symbolisme et de la tradition caricaturale. L'origine des dessinateurs joue un rôle important. Sans surprise, les Frères van Muyden, originaires d'une Suisse romande tournée vers la France, optent plutôt pour la version Belle Époque, tandis que l'Allemand LehmannSchramm est attiré par le Jugendstil, tout comme les Boscovits, liés à Munich par des liens familiaux et artistiques ${ }^{216}$. Les choses ne sont cependant pas si tranchées. À partir des années I 890, les dessinateurs puisent sans compter à ces deux sources, pour offrir progressivement une synthèse, formant après I 900 une sorte de Jugendstil helvétique. L'apparition de la couverture imagée en I 897 déclenche un processus d'acculturation et les éléments figuratifs typiques du Jugendstil, femme, figures mythologiques, éléments végétaux, vont être systématiquement remplacés par des éléments autochtones ${ }^{217}$.

Parallèlement, la batterie de motifs idiomatiques ou ressortissant au fonds caricatural européen, la plupart déjà présents la décennie précédente, demeure. Le langage visuel reste, en effet, massivement redevable à la presse satirique du $\mathrm{XIX}^{\mathrm{e}}$ siècle. Les motifs vedettes sont désormais ceux de la perceuse, de l'orgue, de la poule et des poussins - pour représenter la Suisse et les 7 conseillers fédéraux ${ }^{218}$-, des monnaies et journaux animés. À partir de I 888 , ces motifs se multiplient, de sorte qu'il devient difficile d'en dresser un inventaire. Certains frappent par leur singularité et leur puissance iconique, tels la machine servant à éteindre les incendies, la Jungfrau (un sommet alpin) anthropomorphisée et le téléphérique, qui apparaissent tous en I 889 ; la vache, le train ou les escargots, pour représenter une Suisse lente et peut-être trop placide; le python pour figurer Georges Python (I 856 I927), représentant puissant des catholiques conservateurs, très présent dans la revue. D'autres sont clairement le fruit d'une confrontation avec les revues satiriques européennes, comme la

${ }^{214}$ Voir « 5.1. Le Nebelspalter, la caricature et les revues illustrées européennes ». Nebelspalter 1896/37, dessin pleine page de W. Lehmann-Schramm intitulé « Le pêcheur dépourvu d'intelligence » (Der unkluge Fischer).

${ }_{216}$ Voir aussi «1.2 Décryptage de la fondation et de la vie éditoriale: focus sur Boscovits senior $»$

Voir aussi « 2.3.7 Les couvertures Jugendstil, l'affirmation d'une identité ». On est ici assez loin du style synthétiste identifié par Julien Schuh dans les revues satiriques françaises de la même époque: Julien Schuh, «Autour du Rire: généalogie et diffusion du synthétisme graphique dans l'espace médiatique fin de siècle ", dans L'Europe des Revues (1860-1930) II - Réseaux et circulations des modèles, éd. Evanghélia Stead et Hélène Védrine, Paris, Presse Universitaire de Paris-Sorbonne, 2018, p. 595-613.

${ }_{218}$ Nebelspalter 1887/19, dessin anonyme intitulé (en français) « Embarras de Richesse ॥. lutte d'insectes géants de Heinrich Jenny, en I $889^{219}$; le motif de l'autruche, apparaissant en I890; celui du cirque, de la balance, du parapluie, de la tourte et de la maison; de la fontaine « à pognon "; les portraits physiognomoniques, apparaissant en $\mathrm{I} 89 \mathrm{I}^{220}$; mais aussi le salon caricatural ${ }^{221}$. D'autres, enfin, sont liés au progrès technique et s'installent dans la durée, comme le ballon dirigeable, le vélocipède, apparaissant en I 89 I ou encore la figure du photographe, apparaissant en I 894.

Les doubles-pages sont la plupart du temps en couleur. Elles se présentent comme des synthèses de la scène politique suisse ou internationale, soit à l'occasion d'un moment privilégié de l'année, le début ou la fin, carnaval, Pâques ou Pentecôte; soit en relation avec un événement, telle la publication du «J'accuse » d'Émile Zola, en I $898^{222}$; soit, encore, en lien avec une question sensible, tels les accords commerciaux avec la France, en I $892^{223}$ ou un budget militaire jugé trop important, en I 89 $\mathrm{I}^{224}$. Ces doubles-pages sont aussi le lieu où se déploient des motifs déjà présents durant la décennie précédente, le bateau (politique), indifféremment suisse ${ }^{225}$ ou français ${ }^{226}$, le cirque (politique), qui devient international après avoir été suisse et européen ${ }^{227}$, le jeu de Jass ${ }^{228}$, la figure de l'ivrogne (Sauser) ${ }^{229}$ ou les cartes anthropomorphes. Les citations artistiques, littéraires ou mythologiques s'y multiplient et l'on fait bon usage du référentiel religieux, avec, par exemple, un cortège de dirigeants en faux anges ${ }^{230}$; ainsi que du fonds populaire des contes $^{231}$. À l'occasion, Helvetia s'y montre en Lilie Helvetia ${ }^{232}$ et le Nebelspalter y prend place plus souvent qu'à son tour.

Les doubles-pages accueillent volontiers les hommages aux grands hommes. En i 888, on y honore la mémoire de l'empereur allemand Guillaume I ${ }^{\text {er } 233}$ ainsi que le président de la Confédération, Wilhelm Friedrich Hertenstein ${ }^{234}$. Les hommages peuvent également se trouver en couverture ou en dernière page. Le genre ne connaît guère d'évolution, hormis une discrète ouverture vers l'étranger. Il reste étanche au Jugendstil. Plusieurs chefs d'État y sont représentés à l'occasion de leur élection. Les hommes politiques, les militaires, les intellectuels, écrivains et artistes, continuent d'y prendre place, selon des codes iconographiques toujours aussi stricts.

\footnotetext{
Nebelspalter 1889/21, dessin sans titre de Heinrich Jenny.

220 Nebelspalter 1891/49, double-page en couleur non signée intitulée « La tête la plus intéressante du jour » (Der interessanteste Kopf vom heutigen Tage).

22 Sur ces types d'images, cf. « 4.3. Le salon caricatural du Nebelspalter ou la critique de la modernité » et « 6.2. Intrigues suisses et influences françaises dans le monde éditorial : Jean Nötzli, John Grand-Carteret et Cäsar Schmidt ».

22 Nebelspalter 1898/8, double-page de Boscovits senior intitulée « Justitia en France ».

${ }_{223}$ Nebelspalter 1892/49, double-page de Boscovits senior intitulée «Sur les accords commerciaux franco-suisses » (Zum Französich-schweizerischen Handelsvertrag).

${ }_{24}^{24}$ Nebelspalter 1891/44, double-page de Boscovits senior intitulée « Budget militaire » (Militär Budget).

225 Nebelspalter 1896/2, double-page de Boscovits senior intitulée « Voyage dangereux » (Gefährliche Fahrt).

${ }_{226}$ Nebelspalter 1895/4, double-page de Boscovits senior intitulée « Au gouvernail de la France» (An Frankreich's Ruder).

${ }_{22}$ Nebelspalter 1895/49, double-page de Boscovits senior intitulée "Circus international $»$.

${ }_{228}$ Nebelspalter 1889/52, double-page de Boscovits senior intitulée « Le joueur de Jass heureux " (Der selige Jasser).

229 Nebelspalter 1892/43, double-page de Boscovits senior intitulée « Ivrogne en bonne route » (Sauser im Stadium).

230 Nebelspalter 1898/53, double-page de Boscovits senior intitulée « Vœux pieux » (Frommer Wunsch).

31. Nebelspalter 1896/52, double-page de W. Lehmann-Schramm intitulée « L'arbre de Noël des grands » (Der Christbaum der Grossen).

${ }^{32}$ Nebelspalter 1895/37, double-page de Boscovits senior intitulée «Lili Helvetia ».

${ }_{233}$ Nebelspalter 1888/12, double-page de Boscovits senior sans titre.
}

${ }^{234}$ Nebelspalter 1888/50, double-page de Boscovits senior sans titre. 
$\gg$ O, bieje Jugend!

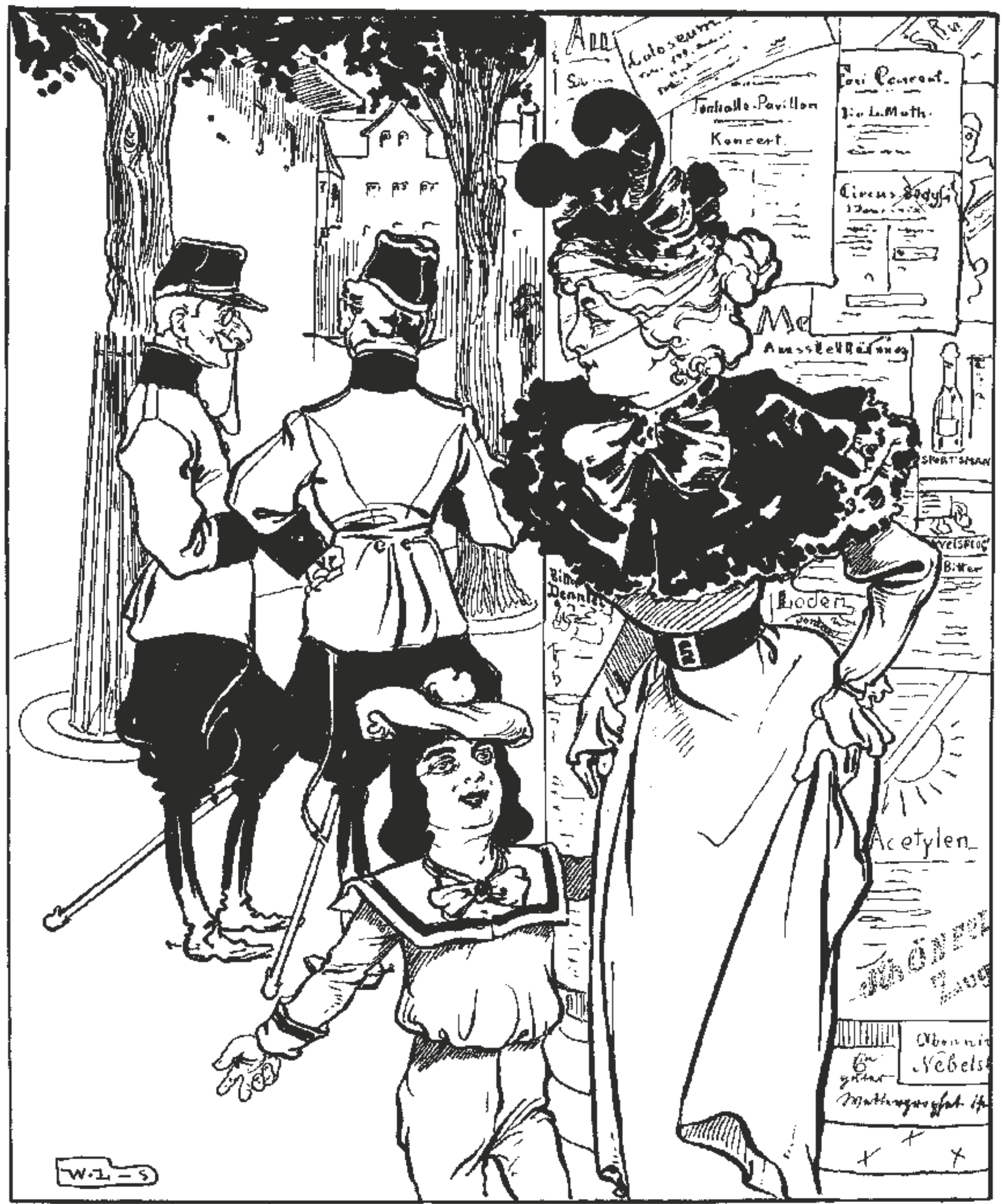

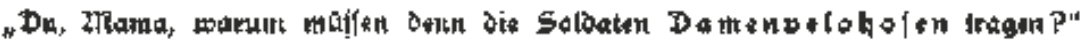

Fig. 25. Nebelspalter 1899/27, dessin pleine page en noir et blanc de Willy Lehmann-Schramm intitulé « Ô, cette jeunesse ! » (O, diese Jugend) 
2.3.6. La constellation allégorique du Nebelspalter - Allégorie, femme et un monde à soi

Plus encore que lors de la période précédente, la femme et l'allégorie se contaminent, alors que l'on assiste à une nette dissociation de l'image féminine avec, d'un côté, la mégère, repoussante, de l'autre, la coquette, éventuel objet de désir. La fonction maternelle est désormais exceptionnelle. Ainsi, un dessin de I 899 de Lehmann-Schramm mettant en scène une femme et son fils valorise davantage la toilette que la relation à l'enfant ${ }^{235}$ (cf. fig. 25).

Dans les années I 890, les types féminins s'ordonnent selon des orientations stylistiques différenciées : les représentations ouvertement négatives, s'adossant au fonds caricatural; celles Belle Époque et Jugendstil, fournissant les images d'élégantes, avec ou sans connotation morale. L'esthétisation en hausse n'empêche pas une très forte présence des représentations misogynes, où la femme est, au choix, mégère, idiote ou intrigante. Ces deux derniers types sont, du reste, en phase avec l'image de la femme, finalement très creuse, véhiculée par le Jugendstil ${ }^{236}$. Il faut enfin relever que le Nebelspalter ne fournit que très peu de représentations de liseuse, pourtant un topos de la presse illustrée et plus largement de l'art de cette époque, ne montrant qu'une seule fois une femme lisant le Nebelspalter dans une représentation, au reste, plus tardive ${ }^{237}$. La femme du Nebelspalter ne lit pas.

Les allégories deviennent instables, qu'elles incarnent une valeur traditionnelle, comme la charité, la paix, la justice ou la poésie, ou moderne, telle la famine, l'opinion publique ou la presse. Même les allégories des pays, villes ou régions sont concernées. Lorsque celles-ci sont féminines, Gallia, Germania, Italia, Europe, Turica (pour Zurich), Berna (pour Berne), par exemple, elles reprennent l'un des deux types dominants de l'iconographie de la femme. Le choix d'une mégère ou d'une jolie femme est bien sûr le moyen d'apporter une connotation négative ou positive. L'Europe en crise de Boscovits senior sera ainsi une vieille femme laide et sombrement vêtue ${ }^{238}$ (cf. fig. 26).

À partir de I 892, la tendance à l'esthétisation est très nette et il n'est pas rare qu'une femme à la mode vienne parler politique, telle Marianne sous le crayon de Boscovits senior ${ }^{239}$. À partir de I 895, Willy Lehmann-Schramm habille les allégories des pays européens à la mode Jugendstil, comme lors de l'inauguration du canal de Kiel, où la France, l'Italie, l'Allemagne, la Russie et l'Angleterre sont toutes figurées sous les traits de jeunes femmes élégantes; ceci, en partie contre l'usage, qui prescrit pour la Russie et l'Angleterre un représentant masculin ${ }^{240}$. En I 899, le dessinateur introduit un système suivi d'allégories politiques: d'une image à l'autre, se retrouve la même figure. L'allégorie des saisons, qui apparaît en I 894, ressortit à l'influence Jugendstil et plus

\footnotetext{
${ }_{235}$ Nebelspalter $1899 / 27$, dessin pleine page en noir et blanc de W. LehmannSchramm intitulé « Ô, cette jeunesse! », ( $O$, diese Jugend).

${ }^{236}$ Voir à ce sujet: Laurence Danguy, « De l'art de caricaturer la femme : la campagne anti-symboliste de la revue Jugend », Textes et Contextes, $n^{\circ} 3$, Maison des sciences de l'homme de Dijon, 2009; François Le Guennec et Nicholas-Henri Zmelty (éd.), La Belle Époque des femmes? (1889-1914), Paris, L'Harmattan, 2013.

${ }_{237}$ Nebelspalter 1904/51, double-page de Boscovits senior intitulée « Un conte d'hiver » (Ein Winter-Märchen).

${ }_{238}$ Nebelspalter $1894 / 41$, dessin sans titre de Boscovits senior.

239 Nebelspalter 1892/14, dessin pleine page de Boscovits senior intitulé «Les dynamites parisiennes » (Die Pariser Dynamiter).

${ }_{240}$ Nebelspalter $1895 / 26$, dessin pleine page de W. Lehmann-Schramm intitulé « Mécontent » (Missvergnügt).
}

exactement à sa composante vitaliste ${ }^{241}$. À ce moment, la femme Jugendstil est en train de supplanter sa concurrente Belle Époque. Toutes deux apparaissent si ce n'est vraiment dénudées du moins découvertes ${ }^{242}$. Cette érotisation reste néanmoins très en retrait de la majorité des revues européennes où les nus sont pléthore.

L'appareil allégorique du Nebelspalter devient instable. Dans un premier temps, le Nebelspalter prend place dans des compositions Jugendstil sans que son iconographie ou sa portée sémantique ne soient affectées. Il reste l'observateur ou l'acteur d'une scène politique soumise à sa critique, le premier promoteur de la revue et le personnage principal de la " famille du Nebelspalter ", cette série de petits personnages mêlant personnages réels, notamment Jean Nötzli et Boscovits senior, et fictifs, les personnages des icones des pages intérieures ainsi que des figures types, telle celle de l'ecclésiastique ${ }^{243}$. Le premier dérèglement de l'iconographie du Nebelspalter intervient en I 893 sous le crayon de Hans Wirz. Le Nebelspalter à vélo, sa plume en bandoulière, est interpellé par un pauvre hère: pour la première fois, il quitte son monde immuable et intemporel pour la modernité, incarnée par la bicyclette ${ }^{244}$ (cf. fig. 27).

De nouveaux dessinateurs, Hans Wirz, Adolf Sulzberger et Lehmann-Schramm, revoient progressivement son visage, dont les traits deviennent incertains - cheveux longs ou courts, visage poupin ou non, imberbe ou avec moustache - ce qui favorise une mutation graphique et symbolique. Lehmann-Schramm, l'un de ses créateurs les plus assidus, l'introduit dans des scènes festives, très Jugendstil, où il partage la vedette avec une élégante chevauchant une bouteille pour fêter l'année I $893^{245}$. Au fil des représentations, la femme tend à se substituer au Nebelspalter, lui empruntant d'abord ses attributs, puis son apparence complète (à l'exception des caractères sexués), comme dans un encart de l'année $1897^{246}$. De temps à autre, le personnage reprend son ancienne apparence. Ce processus de décontextualisation a une influence décisive sur la portée sémantique du personnage. Lorsqu'à la toute fin I 899, il apparaît en couverture pour rendre hommage au créateur des icones, le professeur Albrecht disparu en I 897, sa fonction est uniquement représentative: il n'agit plus mais constitue une simple redondance du journal qu'il tient dans les mains ${ }^{247}$ (cf. fig. 28 cahier couleur).

Chronos, l'allégorie du temps, est dans la revue une figure particulièrement importante, puisque le personnage accompagne le Nebelspalter dans la première version du bandeau, où il tient un bouclier portant l'inscription «En avant» (Vorwärts). Après la refonte du bandeau en I 880 , Chronos disparaît pour ne réapparaitre qu'à l'occasion de la nouvelle année I 888 avec une allure soudain plus délurée. En compagnie du Nebelspalter et d'une série d'acteurs de la vie politique, il fait marcher la

\footnotetext{
Cf. Laurence Danguy, « Le cas de l'ange dans la revue Jugend - recharge sacrale et profanation d'apparence » in Actes du colloque De la profanation $x I x^{e}-x x^{e}$ siècle, Université de Paris I -CIRHAC, 2009, https://hicsa.univ-paris1.fr/ documents/pdf/CIRHAC/La\%2oprofanation_\%20Danguy\%20REVISE.pdf.

${ }_{242}$ Nebelspalter 1894/13, dessin pleine page de W. Lehmann-Schramm intitulé « De la politique quotidienne » (Aus der Tagespolitik)

${ }_{243}$ Nebelspalter 1892/1, double-page en couleur de Boscovits senior intitulée « 1892 ».

24 Nebelspalter $1893 / 29$, dessin pleine page de Hans Wirz intitulé « Justice locale » (Heimliche Gerechtigkeit).

245 Nebelspalter 1894/52, dessin pleine page de W. Lehmann-Schramm intitulé « À la nouvelle année! » (Prosit Neujahr).

${ }_{246}$ Nebelspalter 1897/40, encart de W. Lehmann-Schramm.

247 Nebelspalter 1899/39, couverture de Boscovits junior.
} 


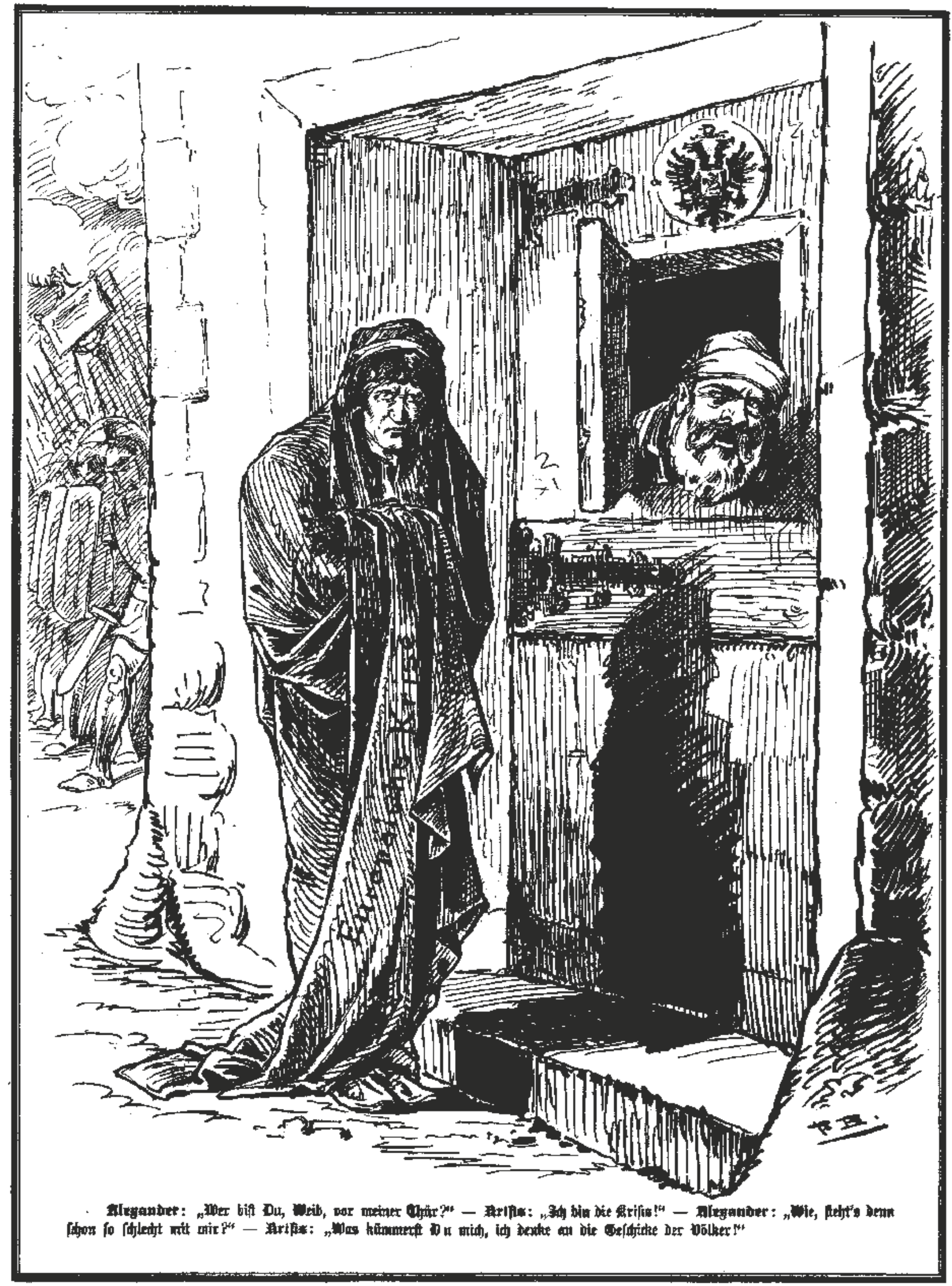

Fig. 26. Nebelspalter 1894/41, dessin pleine page en noir et blanc et sans titre de Boscovits senior. 
Seimlitfe Gerediftigheif.

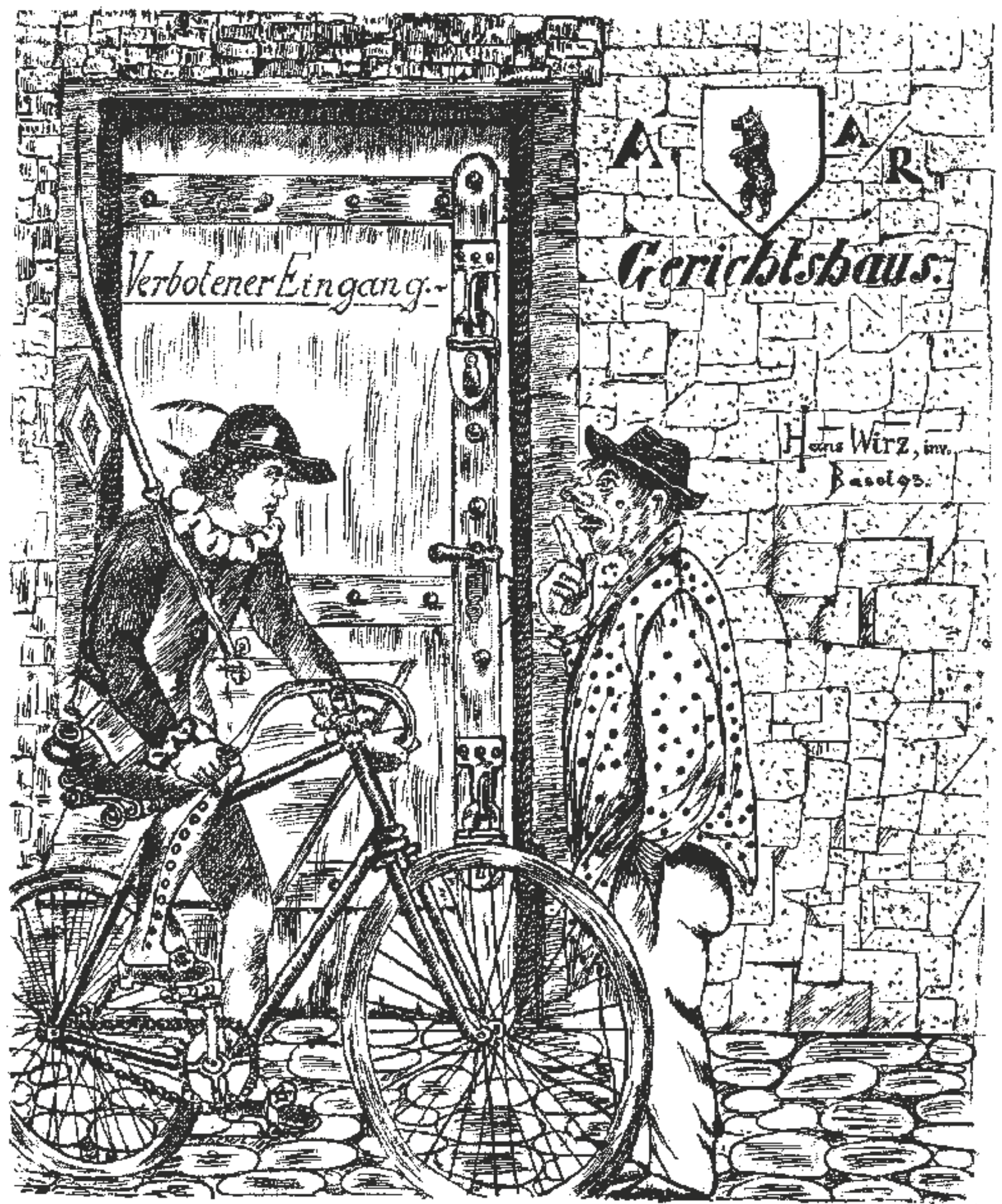

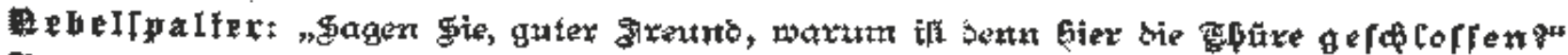

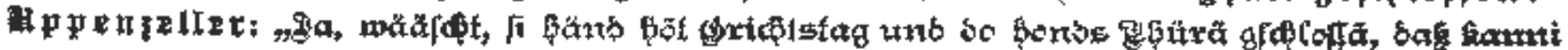

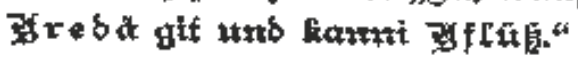

Fig. 27. Nebelspalter 1893/29, dessin pleine page en noir et blanc de Hans Wirz intitulé « Justice locale » (Heimliche Gerechtigkeit). 
machine à caricatures ${ }^{248}$. Par la suite, Chronos va plutôt endosser le costume Belle Époque, devenant le balayeur un peu souillon de l'année I $893^{249}$.

Helvetia, qui partage si souvent la scène avec le Nebelspalter, est, en fait, la seule allégorie qui résiste à cette tendance moderniste. Sans doute est-elle symboliquement trop chargée pour être traitée à la légère. Pour l'essentiel, sa garde-robe se limite - encore - aux tenues traditionnelles de la matrone, de la guerrière et de la paysanne ${ }^{250}$. Il y a néanmoins de rares exceptions d'une iconographie plus festive, tel le calendrier de l'année I 89 I, où la dame est vêtue d'une tenue légère et plutôt affriolante ${ }^{251}$. Durant cette période, Helvetia ne s'inscrit que deux fois, à la fin des années I 890, dans des compositions Jugendstil et chaque fois à l'initiative de Willy Lehmann-Schramm ${ }^{252}$. Son rôle et sa fonction sont toujours préservés.

\subsubsection{Les couvertures Jugendstil, l'affirmation d'une identité}

Dix ans après l'introduction de la couleur, le Nebelspalter connaît une nouvelle révolution visuelle avec l'arrivée, le I 7 juillet I 897 , d'une couverture imagée en couleur, délaissant un modèle vieux de plus de vingt ans. Les nouvelles couvertures, qui paraissent en alternance avec le modèle ancien environ une fois par mois, s'affranchissent du bandeau et du personnage du Nebelspalter. Elles conservent, cependant, dans un premier temps - jusqu'en I 90I - le sempiternel cadre au trait, hésitant ensuite à s'en départir. L'événement s'inscrit dans le processus de conquête des esthétiques Jugendstil, entamé depuis le début des années I 890, plus ou moins parallèlement à l'arrivée des influences Belle Époque. La couverture devient un laboratoire où sont testées des innovations, qui gagnent ensuite les pages intérieures, et le lieu où le Nebelspalter affirme son identité Jugendstil. Le Nebelspalter s'y énonce helvétique, satirique et (secondairement) esthétique.

Le créateur principal de ces couvertures, Willy Lehmann-Schramm, est le promoteur historique du Jugendstil dans le Nebelspalter. Entre I 897 et I 899, il fournit vingt-trois couvertures contre quatre pour Boscovits junior et deux pour Boscovits senior - et aucune pour les autres. Lehmann-Schramm s'emploie à installer une version acculturée du Jugendstil. Les éléments Belle Époque, perdurant dans les pages intérieures jusqu'en I90I, sont chassés de la couverture. Aucune trace d'ivrognes, d'ouvriers ou de filles perdues, de traits hachurés pour signifier une quelconque profondeur, de trognes énormes et autres chats noirs, d'essais de couleurs dramatiques ou grotesques: l'image est plane, la ligne est courbe, les thèmes festifs ou pour le moins ironisés. Les modèles, ce sont les couvertures à succès de la revue munichoise Jugend $^{253}$. La seconde couverture de Lehmann-Schramm montre ainsi un chevalier avec sa belle, accompagnés de Pan jouant de sa flûte, surplombés de l'inscription « Nebelspalter » se détachant en lettres d'or sur un cercle emprunté à Alfons Mucha, l'un des

Nebelspalter 1888/1, double-page en couleur de Boscovits senior intitulée «À la nouvelle année 1888 ! » (Prosit Neujahr 1888!).

249 Nebelspalter 1892/53, dessin pleine page de Henri van Muyden intitulé « 1893 ». ${ }_{250}$ Sur les déclinaisons féminines d'Helvetia: Georg Kreis, Helvetia im Wandel der Zeiten. Die Geschichte einer nationalen Repräsentationsfigur, op. cit., p. 65-74; Gianni Haver, L'image de la Suisse, Le Mont-sur-Lausanne, Lep, 2011, p. 26-27. Nebelspalter $1890 / 52$, double-page sans titre de Boscovits senior.

${ }_{252}$ Nebelspalter 1897/6, dessin pleine page intitulé " Titre de gloire » (Ruhmesblatt); Nebelspalter 1898/40, dessin pleine page intitulé « Elle ose enfin » (Sie rafft sich endlich auf).

${ }^{253}$ Laurence Danguy, L'ange de la jeunesse - La revue Jugend et le Jugendstil à Munich, op. cit., p. 67-81. fers de lance de l'Art nouveau 254 (cf. fig. 29 cahier couleur). L'image rappelle les multiples compositions de Jugend montrant des chevaliers romantiques mais surtout sa première couverture, créée par Fritz Erler ${ }^{255}$. Le chevalier de Lehmann-Schramm trace en lettres d'or le titre du Nebelspalter, formant des volutes de brouillard au-dessus des Alpes suisses. La belle est ici désignée sur le bas de sa robe comme "Dame Politique " (Frau Politik) et sur la flûte de Pan est inscrit le mot "satire " (Satire). C'est à celles-ci que prête serment le Nebelspalter et ce, devant un paysage suisse.

Ce message est, de fait, constamment décliné. Il détermine le travail conceptuel dans le choix des formes et des motifs, alors que les couleurs, tout à fait uniques parmi les revues illustrées, $s^{\prime}$ accordent aux autres pages ${ }^{256}$. Sur la première couverture de Lehmann-Schramm ${ }^{257}$, se trouvent un militaire, une paysanne et une cible de tir, trois symboles de l'identité helvétique ${ }^{258}$. Les couvertures célèbrent la Suisse et sont très peu reliées à Zurich. On fête ainsi l'inauguration du Landesmuseum (Musée national), en I 898 et le Pacte fédéral du I ${ }^{\text {er }}$ août I 29I, à l'été I $899^{259}$.

L'un des aspects les plus singuliers consiste dans le travail d'adaptation des motifs et des ornements Jugendstil. Le bébé est transformé en promoteur de l'humour et de la satire sur la couverture du carnaval I $898^{260}$; les ornements, essentiellement animaliers et autochtones, deviennent des escargots, des guêpes, des moineaux ou encore une cigogne accompagnant le lapin de Pâques (l'équivalent de la poule en milieu germanique) ${ }^{261}$; les motifs végétaux, plutôt rares, sont (re-) contextualisés, par exemple en feuilles de vigne pour fêter le vin nouveau ${ }^{262}$ (cf. fig. 30 cahier couleur). Le personnage du Nebelspalter est ici très présent. Décliné trois fois sur une même couverture, avec son visage habituel, en Arlequin et en Pan, il présente les différentes facettes de la revue ${ }^{263}$. Courant I 899, la connotation Heimatstil s'accentue avec la multiplication des figures folkloriques. La dernière couverture de I 899 montrant Jean Nötzli fêtant la naissance du bébé Nebelspalter le $\mathrm{I}^{\mathrm{er}}$ janvier I 875 est d'une facture très traditionnelle ${ }^{264}$.

\subsubsection{En voir de toutes les couleurs}

I 887 signe l'arrivée de la couleur ${ }^{265}$, après un essai isolé et somme toute assez curieux de coloriage dans les tons bruns d'une doublepage sur l'exposition nationale de $\mathrm{I} 883$ à Zurich ${ }^{266}$. Ce passage à la couleur se produit dans un contexte d'expérimentation de nouvelles techniques d'impression - notamment, le procédé Gillot - et un début d'élargissement de l'équipe des dessinateurs. Les trois images

\footnotetext{
${ }_{254}$ Nebelspalter 1897/31, couverture de W. Lehmann-Schramm.

Jugend 1896/1-2, couverture de Fritz Erler; cf. « 5.1. Le Nebelspalter, la caricature et les revues illustrées européennes ».

Cf. « 2.3.8. En voir de toutes les couleurs ».

Nebelspalter 1897/29, couverture de W. Lehmann-Schramm.

Gianni Haver, L'image de la Suisse, op. cit., p. 100-105.

259 Nebelspalter 1899/30, couverture de W. Lehmann-Schramm.

${ }^{260}$ Nebelspalter 1898/8, couverture de Boscovits junior; sur le motif du bébé dans le Jugendstil, cf. Laurence Danguy, L'ange de la jeunesse - La revue Jugend et le Jugendstil à Munich, op. cit., p. 281-295.

${ }^{261}$ Nebelspalter 1898/15, couverture de W. Lehmann-Schramm

${ }^{262}$ Nebelspalter 1898/43, couverture de W. Lehmann-Schramm.

263 Nebelspalter 1897/36, couverture de W. Lehmann-Schramm.

264 Nebelspalter 1899/52, couverture de Boscovits senior.

265 Il faut corriger sur ce point l'assertion de Peter Métraux qui date l'arrivée de la couleur de 1889; Peter Métraux, Die Karikatur als publistische Ausdruckform untersucht am Kampf des « Nebelspalters » gegen den Nationalsozialismus 19331945, op. cit., p. 25.

${ }_{266}$ Nebelspalter 1883/17, double-page en couleur de Boscovits senior intitulée "Exposition nationale suisse à Zurich, 1 mai au 30 septembre 1883 " (Schweizerische Landesausstellung in Zürich 1. Mai bis 30. September 1883).
} 


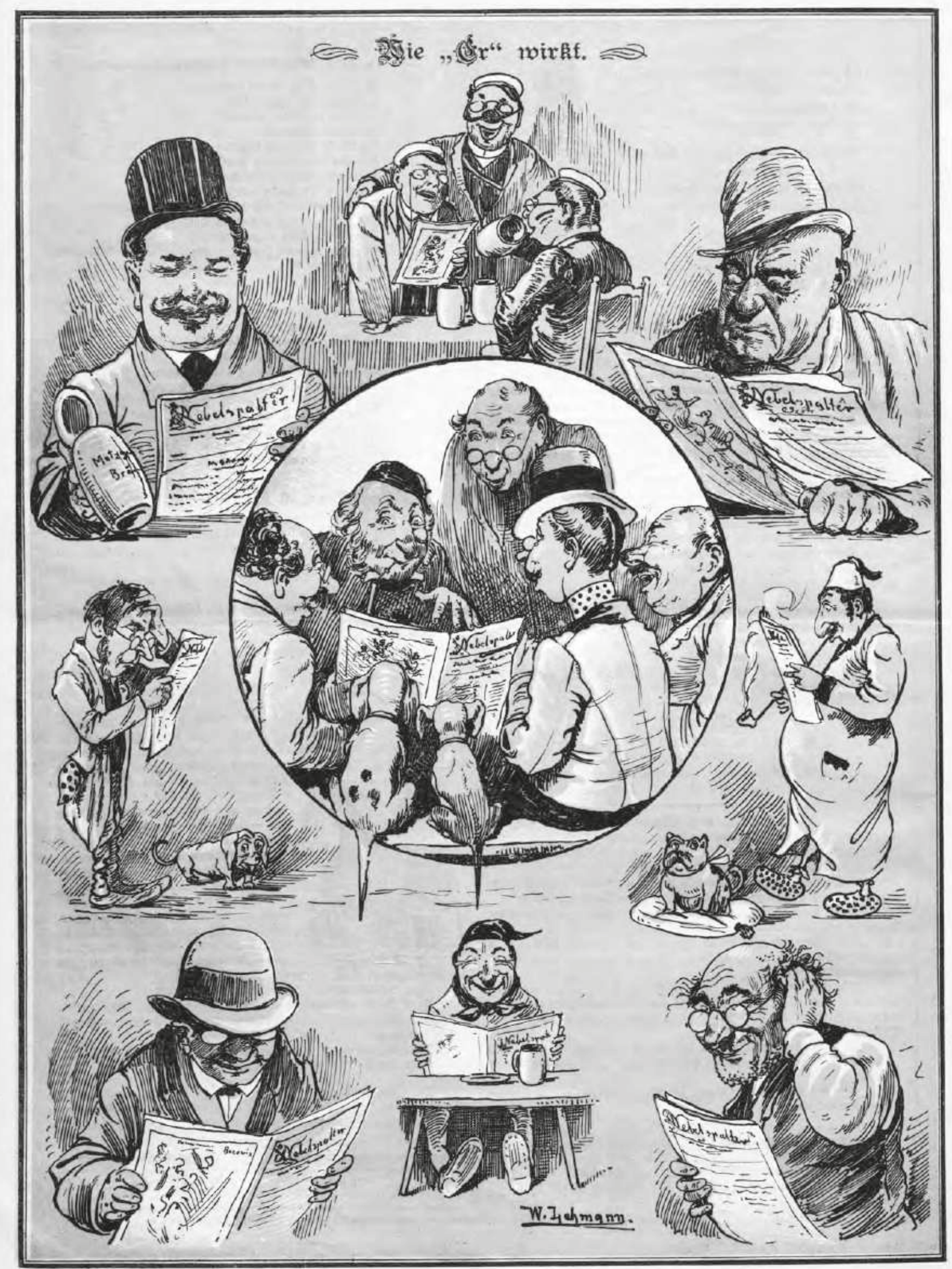

Fig. 33. Nebelspalter 1894/9, dessin pleine page en couleur de Willy Lehmann-Schramm intitulé « Comment "il" agit » (Wie «er » wirkt). 
en couleur paraissant cette année-là sont des doubles-pages d'une facture conventionnelle, relevant de registres très représentatifs de cette période: l'hommage nécrologique ${ }^{267}$; l'hommage politique du président de la Confédération, Numa Droz, portraituré d'après photographie ${ }^{268}$ ainsi qu'une caricature très colorée de la vie politique Française, mettant en scène le motif traditionnel du bateau politique, en l'occurrence une République attirée par l'empire (Kaiserreich), la royauté (Königtum), le socialisme (Sozialismus) et l'esprit de revanche (Revanche) ${ }^{269}$ (cf. fig. 3 I cahier couleur). On sait, au reste, par les archives que Jean Nötzli est l'instigateur du portrait de Numa Droz ${ }^{270}$. Dans ces images, la couleur apparaît sous des combinaisons différentes: une association de brun et de bleu ciel, utilisée pour colorier discrètement un dessin au trait fin; un brun permettant un effet photographique; la répartition de cinq couleurs, rouge, vert, jaune, brun et bleu pour animer la feuille, à la façon d'une image d'Épinal.

Tout étant mesure dans le Nebelspalter, la couleur s'y installe progressivement sous diverses combinaisons. Elle reste en retrait vis-à-vis du noir et blanc. La couleur représente un argument marketing puissant, justifiant un prix plus élevé au numéro jusqu'en I907, date du passage définitif à la couleur. Jusqu'en I 890, son usage est limité aux doubles-pages. Ces compositions très investies ne sont pourtant pas toutes en couleur. Dix sur douze sont en couleur en I 888 , onze sur douze en I 889 , huit sur dix en I 890 , toutes selon la formule à cinq couleurs, introduite en I 887 pour la caricature politique (jaune, bleu, rouge, vert et brun). Le rouge cède parfois la place à un magenta d'un effet tout à fait saisissant, comme en I 888 dans "La chasse au bonheur » (Die Jagd nach dem Glück) ${ }^{271}$ (cf. fig. 32 cahier couleur).

En I 89I, intervient un premier changement: en plus des doublespages, les pages intérieures du numéro I I sont en couleur. Placées en vis-à-vis, elles sont bichromes, orange clair pour la partie supérieure, vert-de-gris pour la partie inférieure ${ }^{272}$. Cette expérimentation sans lendemain constitue la première tentative d'une conception unitaire de la maquette. Cette année I89I, trois formules chromatiques cohabitent: les compositions à cinq couleurs, dont les teintes deviennent plus vives, les images bichromes (orange et vert; vert et bleu; vert et brun) ainsi qu'un noir et blanc mêlé de brun. Mis à part quelques compositions à trois couleurs, les images sont, jusqu'en I 894, essentiellement à cinq couleurs ou à dominante de brun, avec des expériences isolées, telle une double-page de I 893 conçue sur le modèle d'une carte postale, dont le propos est de dénoncer une fiscalité écrasante. Le trait bleu est ici rehaussé de rouge ${ }^{273}$.

Il faut attendre I 894 pour voir durablement la couleur à l'intérieur du numéro. À deux reprises, les pages intérieures bichromes (orangé et bleu) sont placées en vis-à-vis dans un numéro où la dernière page est également en couleur, comme lors de l'expérience de I89I. Le mordoré fait son entrée la même année,

\footnotetext{
Nebelspalter 1887/31, double-page non signée intitulée " Malheur à la Jungfrau » (Das Unglück an der Jungfrau).

${ }^{68}$ Nebelspalter 1887/41, double-page de Boscovits senior intitulée « Dr. Numa Droz ».

${ }^{269}$ Nebelspalter 1887/49, double-page de Boscovits senior intitulée « S'ils ont de la chance... »(Ob sie Wohl glück vorüber kommen).

270 Cf. « 6.3. Quand politique, art et satire se mêlent: Numa Droz et Jean Nötzli ».

27 Nebelspalter 1888/23, double-page en couleur de Boscovits senior intitulée « La course à la fortune » (Die Jagd nach dem Glück); sur cette image, voir le développement « 5.2 S'enrichir du « grand art».

Nebelspalter 1891/11.

Nebelspalter 1893/31, double-page de Boscovits senior
}

à l'occasion du numéro rooo du Nebelspalter. La couverture ainsi qu'une page isolée, thématisant l'effet censément produit par le Nebelspalter sur ses lecteurs ${ }^{274}$, montrent cette teinte promise à une fortune exceptionnelle et qui partage dès lors la vedette avec les compositions à cinq couleurs (cf. fig. 33).

Le principe d'une coloration de la couverture des numéros spéciaux s'établit: il est repris en 1895 pour le numéro consacré au poète Conrad Ferdinand Meyer (I 825 -I 898 ) 275, $^{27}$ puis pour celui célébrant la nouvelle salle de concert zurichoise, la Tonhalle ${ }^{276}$ ainsi qu'en I 896, à l'occasion de l'ouverture de l'exposition nationale ${ }^{277}$. La bichromie, la plupart du temps à base de bleu, devient plus fréquente et le mordoré s'impose. En I 897, les couvertures Jugendstil reprennent des combinaisons chromatiques déjà existantes, le noir et blanc augmenté d'une couleur, les cinq couleurs ou la bichromie. Elles permettent une conception unitaire de la maquette comme dans les numéros 42 et 49 , où toutes les images sont en couleur. La couverture, la double-page intérieure et la dernière page sont dans les mêmes tons, de brun, dans le premier cas; de gris/vert, dans le second. Ce n'est toutefois pas systématique et deux combinaisons peuvent cohabiter dans un numéro, comme dans le numéro 29 avec le bronze pour la couverture et la dernière page, et les cinq couleurs pour la doublepage centrale ${ }^{278}$. En I 898, apparaît une nouvelle formule en noir et blanc, où le noir est traité comme une couleur.

\subsection{0-1906:}

\section{Jugendstil versus Heimatstil - Retour aux fondamentaux}

La mort de Jean Nötzli, le 2 I avril I900, met fin à une période de stabilité éditoriale exceptionnelle, non seulement dans l'histoire de la revue mais plus largement au sein des revues illustrées européennes. Elle ouvre sur une période de flottement et de frilosité, l'indéboulonnable Boscovits senior, qui partage un temps la responsabilité éditoriale avec Edwin Hauser, entravant, peutêtre malgré lui, les innovations. Le graphisme suit une évolution Jugendstil marquée par une appropriation massive. Il s'ensuit un glissement vers un Heimatstil, dont il est courant de considérer qu'il tient lieu en Suisse de Jugendstil ${ }^{279}$, ce qui ne peut être tout à fait validé pour le Nebelspalter qui réalise une synthèse de plusieurs courants Art nouveau. L'époque est en fait paradoxale: d'un côté, le cadre au trait, symptôme manifeste d'une volonté de contenir, est sérieusement menacé, indiquant une ouverture; de l'autre, s'observent différents signes de replis, visuel, identitaire et idéologique, une politique commerciale plutôt molle et peu de nouveaux dessinateurs. Enfin, certains traits demeurent inchangés, le format, la périodicité hebdomadaire, la qualité du papier ainsi que la technique.

\footnotetext{
Nebelspalter 1894/9, dessin de W. Lehmann-Schramm intitulé "Comment "il" agit » (Wie « er » wirkt)

Nebelspalter $1895 / 41$.

Nebelspalter $1895 / 42$.

Nebelspalter $1896 / 18$

Nebelspalter 1897/29.

279 Cf. Jacques Gubler, "Suisse. La présence discrète de l'Art nouveau », dans L'architecture de l'Art nouveau, éd. Frank Russel, Paris, Berger-Levrault, 1995 , p. 159-170.
} 


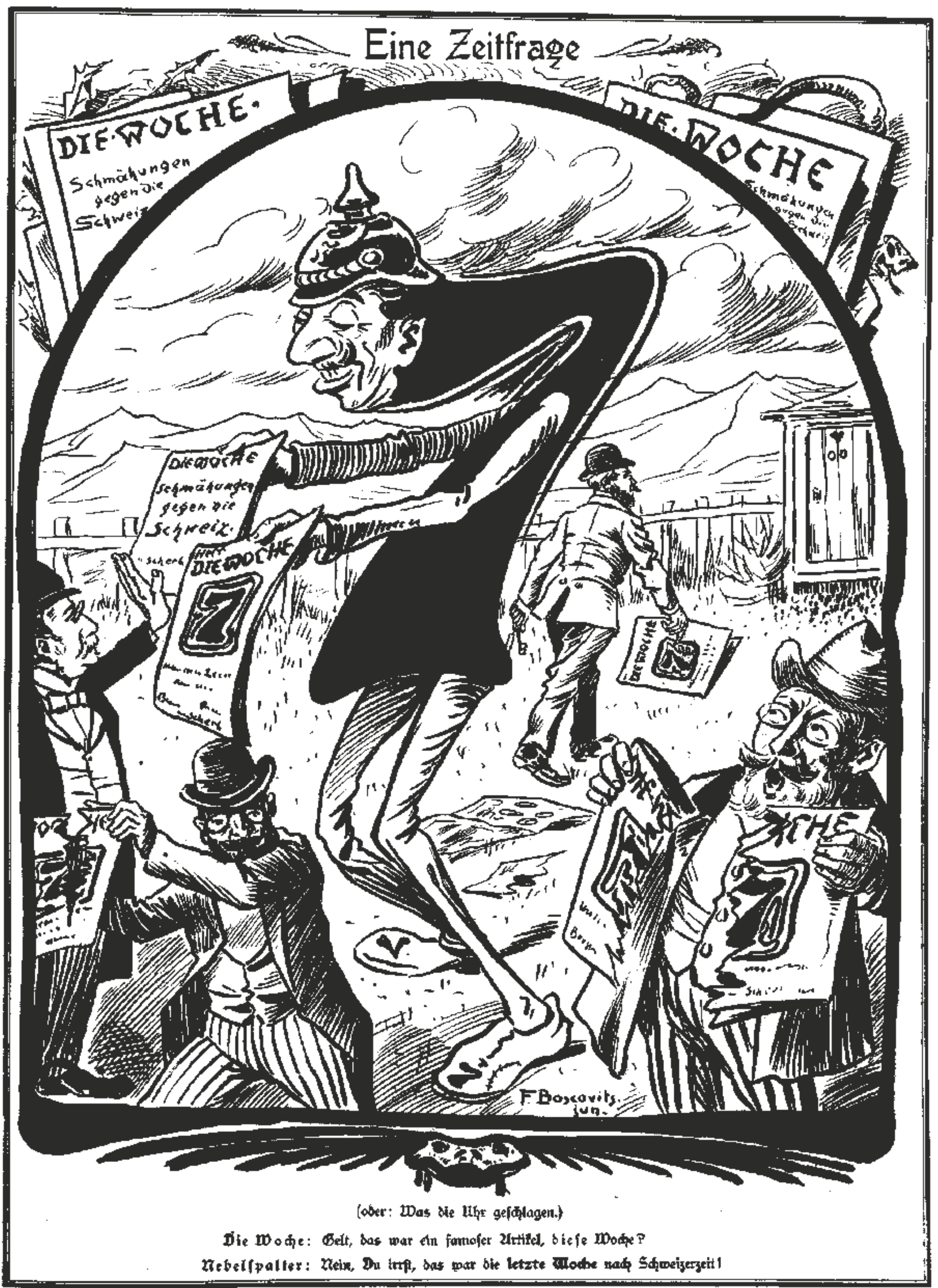

Fig. 34. Nebelspalter 1901/24, dessin pleine page en noir et blanc de Boscovits junior intitulé « Une question de temps » (Eine Zeitfrage). 


\subsubsection{Identité, maquette et technique - \\ Menace sur le cadre au trait}

Ce n'est guère le nombre de pages qui modifie l'aspect de la maquette durant cette période mais bien plutôt la présence de couvertures imagées fortement typées, la poursuite d'une recherche unitaire pour les numéros en couleur ainsi que la disparition progressive du cadre au trait. De I 900 à I903, un numéro compte, en effet, huit pages et, à partir de I904, entre huit et dix pages, les pages supplémentaires étant dues à l'augmentation du volume de la publicité. Le sous-titre reste le même. Les numéros s’intitulent soit Nebelspalter (sans article) pour les couvertures imagées entre neuf et douze selon les années, soit Der Nebelspalter pour les couvertures élaborées selon la formule originelle.

La suppression du cadre au trait est un événement majeur dans l'histoire du Nebelspalter. Il s'agit du symptôme le plus visible de l'émancipation - relative - d'un contenu très contrôlé, fonctionnant lui-même en miroir d'une société rigoriste, marquée par les exigences morales du réformateur zurichois Ulrich Zwingli (I484-I 53 I $)^{280}$. Cette attaque faite au cadre est progressive et se déroule en quatre étapes. Une première amorce de suppression est, en fait, légèrement antérieure à 1900 avec le redoublement, à l'intérieur de l'image, du cadre extérieur, en I $899^{281}$. Cette formule est répétée à plusieurs reprises en 1900 par les Boscovits senior et junior ainsi que par Willy Lehmann-Schramm, et gagne la couverture $^{282}$. Ce cadre intérieur, diversement tracé, est ensuite repoussé lors d'une deuxième étape. Le geste est littéral dans une caricature de Boscovits junior, thématisant l'action de Lord Kitchener au Transvaal pendant la seconde guerre des Boers, où des soldats poussent le cadre ${ }^{283}$. Une troisième étape consiste à faire sauter le cadre, ce que fait pour la première fois Willy Lehmann-Schramm en I90I dans une couverture très Jugendstil montrant un chevalier et sa belle chevauchant vers le lecteur ${ }^{284}$. À partir de ce moment, les dessinateurs jouent indifféremment du cadre intérieur et du cadre extérieur, parfois avec extravagance. Pour montrer la soumission de l'hebdomadaire Die Woche à l'empereur Guillaume II, Boscovits junior fait aspirer l'empereur par le cadre 285 (cf. fig. 34).

À l'occasion des vendanges, il remplace le cadre au trait par un cadre de bois servant de treille ${ }^{286}$. Longtemps, néanmoins, ce cadre sera maintenu dans les pages intérieures et son effacement ne sera pas systématique en couverture.

Les expériences typographiques continuent: l'insertion d'un cadre avec un texte aux caractères très serrés, faisant office de seconde légende ${ }^{287}$; le placement aéré de légendes avec des

Sigmund Widmer, Zürich. Eine Kulturgeschichte, Band 5 Fromme Ketzer, Zurich, Artemis Verlag, 1977, p. 35-46; les propos de l'auteur dans ce qui est présenté comme un ouvrage critique témoignent de la forte imprégnation des doctrines de Zwingli dans les mentalités.

Nebelspalter 1899/22, dessin de Boscovits junior intitulé « Des élections agitées » (Wahl um Triebe)

${ }_{282}$ Nebelspalter 1900/27, couverture de Boscovits junior

${ }_{283}$ Nebelspalter 1901/2, dessin pleine page de Boscovits senior intitulé « Kitchener télégraphie, Knox poursuit sans cesse De Wet » (Kitchener telegraphirt, Knox verfolge beständig Dewet).

${ }_{284}$ Nebelspalter 1901/22, couverture de W. Lehmann-Schramm.

${ }_{285}$ Nebelspalter 1901/24, dessin pleine page de Boscovits junior intitulé « Une question de temps » (Eine Zeitfrage).

Nebelspalter 1901/40, couverture de Boscovits junior.

Nebelspalter 1902/31, dessin pleine page de Boscovits senior intitulé «Vieille nouvelle vérité » (Alte neue Wahrheit). caractères romains contrastant avec ceux gothiques du titre ${ }^{288}$; des couvertures liant poème et images ${ }^{289}$; la conception séquentielle d'une page présentant une série de petites images numérotées et titrées, assorties d'un texte très dense.

Les doubles-pages sont présentes à un rythme annuel, variant entre sept et onze occurrences, avec une chute soudaine à trois occurrences en I907. Elles sont généralement créées à l'occasion de la nouvelle année, du carnaval, des Sechseläuten, des Pâques, de la Pentecôte et de Noël et sont exclusivement signées par les Boscovits, surtout le père (senior).

\subsubsection{Distribution, politique commerciale et lectorat - Statu quo}

La politique commerciale est stable, voire atone. Le prix au numéro, les formules d'abonnement, les modalités de distribution et le tarif des annonces restent les mêmes. Le point de vente parisien est par contre supprimé en I900, peu après la mort de Jean Nötzli ${ }^{290}$. Comme auparavant, un numéro coûte 30 ou 50 cts., selon qu'il est ou non en couleur, un abonnement 3 Fr. pour 3 mois, 5,5 Fr. pour 6 mois et ro Fr. pour un an, pour la Suisse; 7 Fr. pour six mois et I 3,50 Fr. pour un an, pour l'étranger.

Les encarts se raréfient à trois par an au maximum et parfois aucun, ce qui signe une rupture dans la stratégie commerciale. Ils ne présentent pas d'innovations, hormis une bande dessinée invitant à l'abonnement en I900 291. Des formules visuelles, des produits dérivés, reliure ou vue du palais fédéral, sont recyclés, ainsi qu'un argumentaire bien rodé, souvent sous une forme raccourcie. À la fin I 905 , une jeune femme, redite des figures Jugendstil, lève son verre à la nouvelle année et invite à l'abonnement:

Avec la nouvelle année, le Nebelspalter entame sa $32^{\text {ème }}$ année de parution et, fidèle à son programme, mettra toute sa force à toujours tenir haut, malgré les difficultés, la bannière du progrès, portée par un humour sain et une satire mordante 292 .

Très exceptionnellement, un sursaut intervient, comme la proposition en I 905 d'une nouvelle reliure à tout abonné et des conditions spéciales d'insertions publicitaires ${ }^{293}$. Quant aux numéros spéciaux, ils deviennent une denrée rare et ne font plus partie de l'argumentaire commercial.

Une indication sur l'ampleur du lectorat, à prendre avec précaution, est fournie en I 905 au travers d'un encart proposant une reliure "demandée de toute part par les abonnés " (um einem vielseitig geäusserten Wunsche unserer Abonnenten zu entsprechen), vendue à hauteur de 3500 exemplaires un chiffre susceptible de refléter la fourchette basse des abonnés ${ }^{294}$.

\footnotetext{
${ }_{288}$ Nebelspalter 1903/5, dessin pleine page de W. Lehmann-Schramm intitulé « La cacophonie » (Die Katzenmusik).

${ }_{289}$ Nebelspalter 1902/32, couverture de W. Lehmann-Schramm avec un poème de Ernst Meyer-Leibstadt.

290 Nebelspalter 1900/21.

${ }_{291}$ Nebelspalter 1900/26, dessin pleine page de Boscovits junior intitulé « Une histoire lugubre de nœud de mouchoir qui se termine bien » (Eine schauerliche Sacktuchknopf-Geschichte mit gutem Ausgang).

292 (Der Nebelspalter beginnt mit Neujahr seinen 32sten Jahrgang und wird, seinem bisherigen Programm treubleibend, die ganze Kraft dareinlegen, durch alle Schwierigkeiten hindurch das Panier des Fortschritts stets hoch zu halten, getragen von gesundem Humor und scharfer Satyre); Nebelspalter 1905/52, dessin pleine page de Boscovits junior intitulé «À la nouvelle année! » (Prosit Neujahr!).

${ }_{293}$ Nebelspalter 1905/04, encart

294 Nebelspalter 1909/39, encart.
} 


\section{Der Kebenslauf der שaurst.}

Bilder ohne toorte.
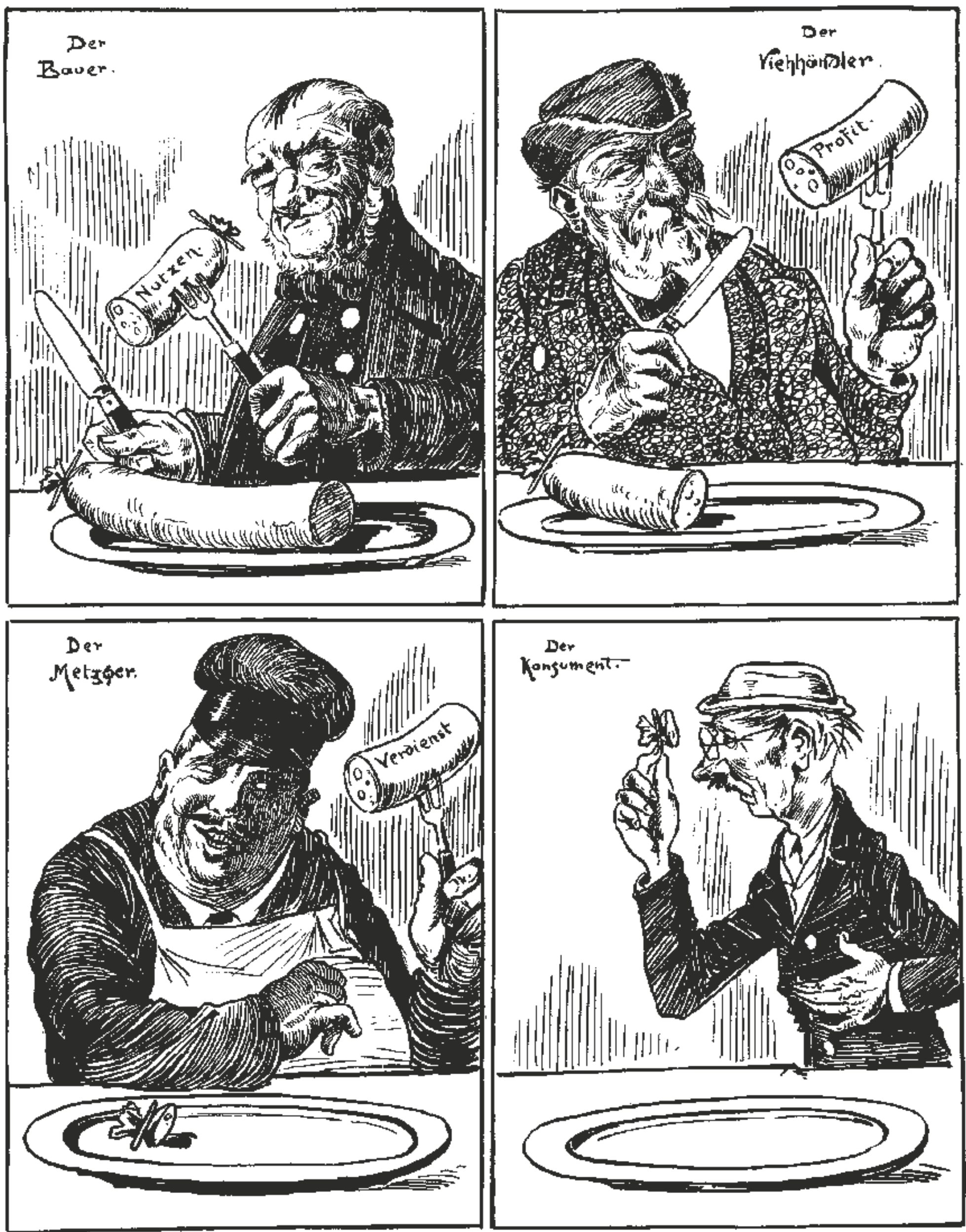

Fig. 35. Nebelspalter 1904/25, dessin pleine page en noir et blanc non signé intitulé « Le curriculum vitae de la saucisse » (Der Lebenslauf der Wurst). 


\subsubsection{Tendance et thèmes - Recentrage}

Le Nebelspalter se positionne à présent comme un périodique de tendance libérale, essentiellement dédié aux questions politiques et sociétales. Il ne s'agit pas, cependant, de défendre ou promouvoir sans réserve une cause libérale qui passe après les intérêts suisses. Une composition de 1904, intitulée "Le curriculum vitae de la saucisse » (Der Lebenslauf der Wurst) dénonce ainsi les dérives libérales. Elle montre la petite part restant au consommateur, après que le paysan, le marchand de bestiaux et le boucher se sont servis ${ }^{295}$ (cf. fig. 35 ).

D’une manière générale, le regard est plus sociétal, politique et légèrement recentré sur la Suisse. Cette focalisation sur les questions politiques correspond à un certain désengagement artistique. L'association de l'antisémitisme et de l'anticapitalisme se confirme. L'anticléricalisme est essentiellement lié à l'étranger, l'Allemagne et la France, et devient virulent au moment de l'élection de Pie X, en $1903{ }^{296}$. On ne lâche pas davantage l'ennemi fribourgeois lors des débats incessants sur l'école ou plus encore sur la proportionnelle, en I900 et I90I. Il s'agit cependant d'un anticléricalisme d'entretien, conforme au positionnement originel du périodique, et attendu par le lecteur. L'antisémitisme est désormais, comme l'anticléricalisme, intégré aux synthèses de la vie politique, ce qui témoigne d'une certaine banalisation. D'un autre côté, c'est à cette époque qu'interviennent les dénonciations les plus fermes des persécutions antisémites, en particulier en I903, lors du pogrom de Kirschinew ${ }^{297}$. Ceci dit, il ne faut pas s'y tromper, le propos dominant est alors une critique du très détesté « Niki », l'empereur Nicolas II.

Les thèmes liés à la Suisse sont d'abord les questions ferroviaires, bancaires, sur l'armée, les réformes électorales, les accords commerciaux ainsi que l'immigration, les lois de protection et de justice sociale, l'école et la liberté de la presse. Sur le front sociétal, le mouvement pour le relèvement moral (Sittlichkeitsbewegung), la prostitution, ainsi que les effets du progrès sur l'identité suisse sont les thèmes de prédilection. Cette dernière préoccupation est à l'origine de la pléthore de dessins sur le tourisme. Les symboles de la Suisse sont bradés à n'en plus finir. Dans « Là-haut, dans la montagne » (Auf-in die Berge!), à droite du sommet, le touriste peut s'essayer sans danger à un saut pour 50 centimes; à gauche, il peut s'offrir une bière munichoise ${ }^{298}$. Le " grand " événement culturel est l'exposition universelle de Paris en I900, et donc la participation de la Suisse ${ }^{299}$, tandis que le mémorial de Morgaten, qui ne sera pourtant inauguré qu'en I908, est déjà l'objet de beaucoup d'attentions ${ }^{300}$.

\footnotetext{
Nebelspalter 1904/25, dessin pleine page non signé intitulé « Le curriculum vitae de la saucisse » (Der Lebenslauf der Wurst).

296 Cf. « 3.2.1. Le face-à-face (helvétique) du Nebelspalter avec Helvetia » ainsi que « 3.2.2. L'alliance sacrée ou la Suisse du Nebelspalter ».

297 Nebelspalter 1903/22, dessin pleine page de W. Lehmann-Schramm intitulé « Au sujet du génocide des juifs à Kischinew » (Zum Judenmord in Kischinew).

${ }_{298}$ Nebelspalter 1901/30, dessin pleine page de W. Lehmann-Schramm intitulé "Là-haut, dans la montagne » (Auf - in die Berge!).

299 Cf. « 4.2. Rendre compte des expositions et régler ses comptes via les expositions ».

300 Nebelspalter 1904/29, dessin signé «Tschuppen » et intitulé « Le mémorial de la bataille de Morgarten et ses différents projets et phases " (Das MorgartenSchlachtdenkmal in seinen verschiedenen Projekten und Phasen); Sur la bataille de Morgaten, essentielle dans la mémoire collective suisse, ainsi que le monument: Josef Wiget, "Morgarten, guerre de », Dictionnaire historique de la suisse (05/11/2015); http://www.hls-dhs-dss.ch/textes/f/F8726.php.
}

Quelques thématiques forment l'essentiel des affaires zurichoises, bien représentées parmi les affaires intérieures: les théâtres et cabarets, avec l'ouverture, en I900, du cabaret Corso ${ }^{301}$, plus généralement les fêtes, carnaval et les Sechseläuten, le mouvement pour le relèvement moral (Sittlichkeitsbewegung), les élections, la pression fiscale, la croissance urbanistique, tel l'aménagement des quais de Seefeld (un quartier de Zurich) en 1905 ou la redéfinition des arrondissements (Kreis) en I90 ${ }^{302}$. Les inondations de I 899 et $\mathrm{I} 900$ donnent lieu à une série de dessins humoristiques ${ }^{303}$. À partir de 1904, les débats sur le Kunsthaus (le musée des Beauxarts) débutent ${ }^{304}$. Il n'est pas rare que la ville serve de cadre à une question sociétale, débattue au niveau national, telle la construction de crématoriums ${ }^{305}$, ou politique, comme le droit d'asile et le danger anarchiste. " Le lion zurichois bien tranquille " (Der gemütliche Züri-Leu) se fait ainsi surprendre, chez lui, par ces deux invités surprise ${ }^{306}$.

Bien plus que les conservatismes, les véritables dangers sont le capitalisme, l'anarchie et le socialisme. Pour le Nebelspalter, qui s'assure du soutien d'Helvetia, les socialistes entrainent le chariot suisse dans la direction inverse des libéraux, garantissant, eux, le progrès social (sozialer Fortschritt). La légende de la double-page enjoint, cependant, libéraux et sociaux-démocrates à se rapprocher, signe si ce n'est d'un flottement dans la ligne idéologique du journal, d'une incertitude des sympathies du lectorat ${ }^{307}$.

La modernité, c'est d'abord la mode, supportant plus que jamais un discours social, une multitude de scènes urbaines ainsi que la présence insistante du vélocipède. Cette modernité, inquiétante, sans doute, génère de nombreux dessins humoristiques, tel un tableau à petites scènes de Boscovits junior, "Les joies de la Pentecôte" (Pfingst-Freunden). La foule se rue à la gare pour pratiquer le golf, l'alpinisme, la conduite automobile, le cyclisme ou encore la navigation ${ }^{308}$ (cf. fig. 36).

Les débats sur l'art moderne, certaines figures dominantes du paysage artistique, tels Hodler et Amiet, la construction du Kunsthaus ainsi que l'attribution des subventions fédérales se retrouvent dans des dessins isolés mais surtout au travers du salon caricatural ${ }^{309}$.

Durant cette période, les alliances entre les États et surtout leurs renégociations sont régulièrement décryptées. Tel est le cas des hésitations de la Chine en I $903^{310}$ et des coalitions fluctuantes entre la France, la Russie, l’Angleterre, la Russie et l'Italie, en I 904. La domination de la Triplice par l'Allemagne, laissant pour peu de chose l'Italie et l'Autriche-Hongrie, est un sujet d'inquiétude en

Tanja Tenzl, « Corso-Theater, Zürich ZH », dans Theaterlexikon der Schweiz, volume 1, éd. Andreas Kotte, Zurich, Chronos Verlag, 2005, p. 411-412.

${ }_{302}$ Respectivement: Nebelspalter 1905/34, dessin pleine page de Boscovits junior intitulé « Une image à tiroir » (Ein Vexierbild); Nebelspalter 1903/7, couverture de Boscovits senior intitulée "La nouvelle division des arrondissements zurichois » (Die Zürcher neue Kreiseinteilung).

${ }_{303}$ Cf. « 3.2.3. Chronique visuelle d'une ville: Zurich ».

${ }_{304}$ Cf. « 4.5. Plaider et batailler pour la pierre à Zurich: le Kunsthaus et le Musée national suisse ».

305 Nebelspalter 1906/51, dessin pleine page de Boscovits junior intitulé « Le nouveau crématorium à Zurich » (Das neue Krematorium in Zürich).

306 Nebelspalter 1906/25, dessin pleine page de Boscovits senior intitulé « Le lion zurichois bien tranquille » (Dergemütliche Züri-Leu).

7 Nebelspalter 1906/37, double-page sans titre de Boscovits senior.

${ }_{308}$ Nebelspalter 1903/22, dessin pleine page de Boscovits junior intitulé «Les joies de la Pentecôte » (Pfingst-Freunden).

${ }^{309}$ Cf. « 4. DISCOURS SUR L'ART ».

310 Nebelspalter 1903/7, dessin pleine page de W. Lehmann-Schramm intitulé « En chine » (In China) 


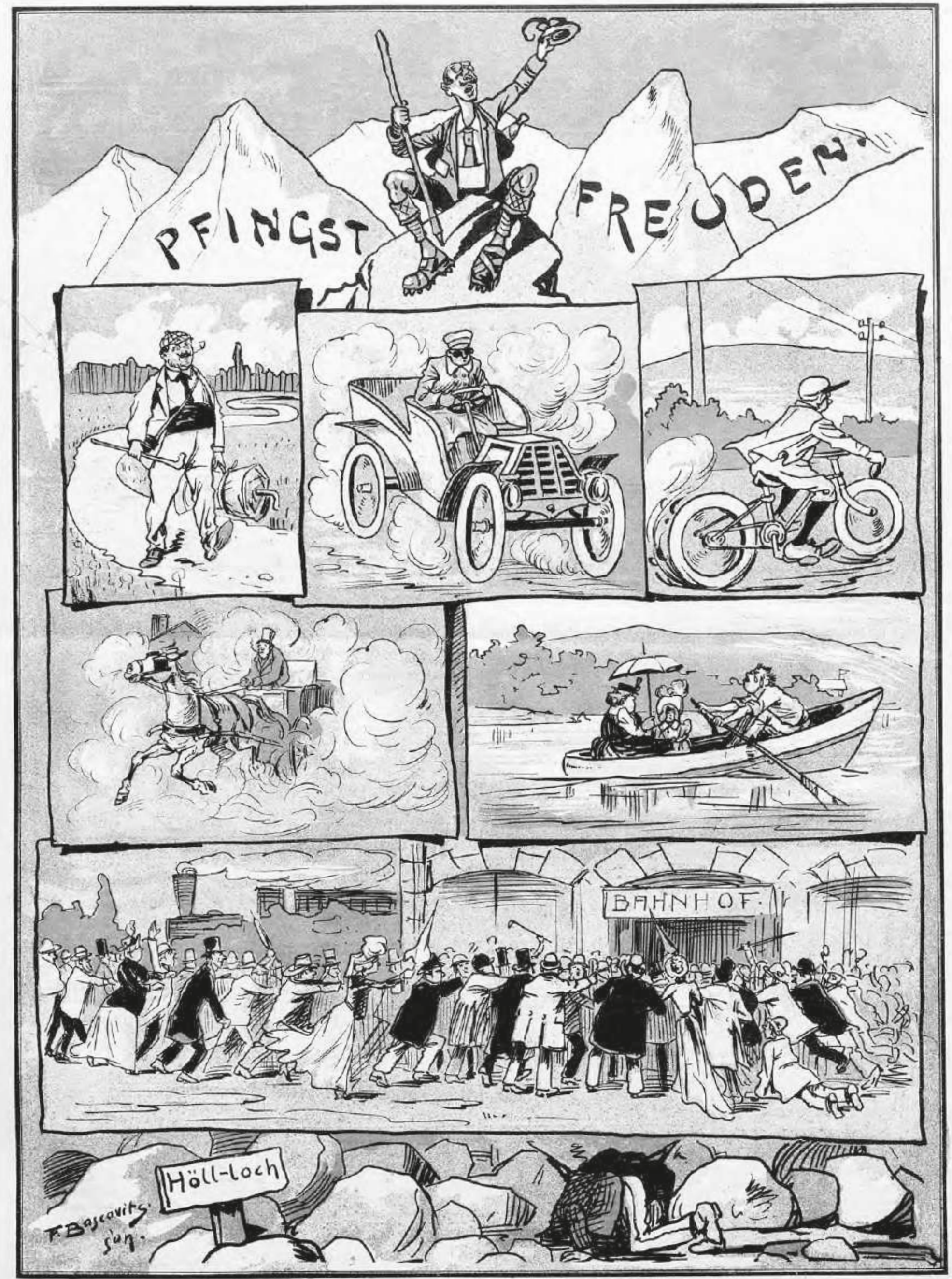

Fig. 36. Nebelspalter 1903/22, dessin pleine page en couleur de Boscovits junior intitulé « Les joies de la Pentecôte » (Pfingst-Freunden). 


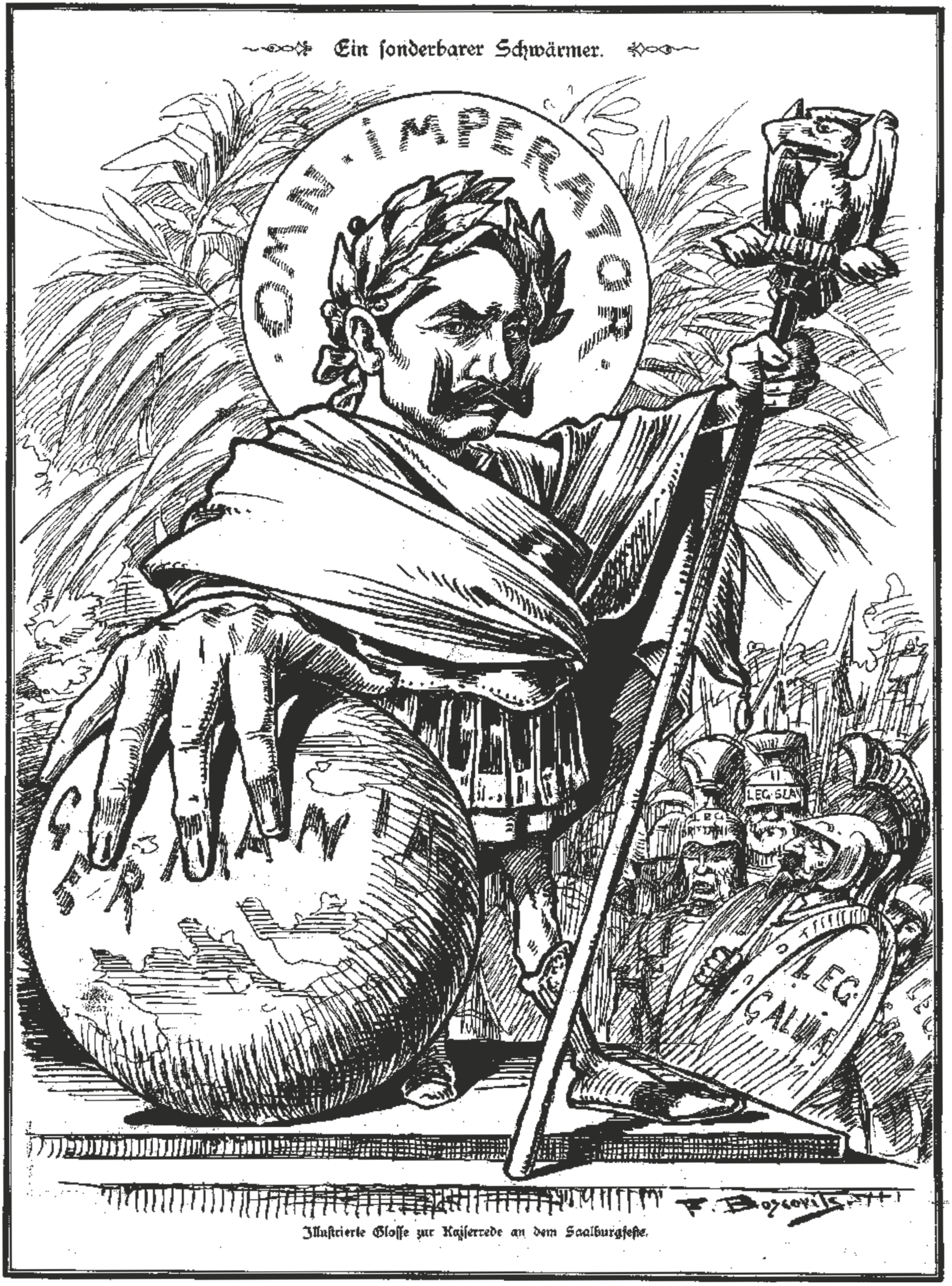

Fig. 37. Nebelspalter 1900/42, dessin pleine page en noir et blanc de Boscovits senior intitulé « Un drôle de passionné » (Ein sonderbarer Schwärmer). 
I $906^{311}$. Les conflits, en germes ou avérés, sont restitués en termes critiques: le Transvaal et la Seconde guerre des Boers, entre I900 et I903, la guerre russo-japonaise, en I904 et I905. La question des Balkans est sensible à partir de I902 mais surtout en I903.

Chaque pays reçoit une place bien circonscrite. L'Allemagne et dans une (bien) moindre mesure la France sont les plus représentées. Ils sont très sérieusement concurrencés par l'Angleterre en I90I, l'Empire ottoman à partir de I903, et plus encore la Russie en I 90 I et à partir de I903. Si la présence de la France est variable, ce n'est jamais le cas de l'Allemagne, grâce à l'attachement passionnel à la figure de Guillaume II. Il faut aussi noter la participation très discrète du troisième voisin, l'Italie, essentiellement redevable à des intérêts convergents avec la Suisse, la question ferroviaire en I900, le libre-échange en I904 ou encore l'affaire Silvestrelli en $1902^{312}$.

Rien n'est épargné à Guillaume II, l'objet de caricatures souvent très agressives, dénonçant son autoritarisme, ses intrigues, ses ambitions maritimes mais plus encore son omnipotence ${ }^{313}$ (cf. fig. 37 ).

Le chancelier von Bülow, présenté comme la marionnette de l'empereur, vient enrichir la galerie des affreux ${ }^{314}$. L'Allemagne inquiète par ses visées belliqueuses ainsi que par la montée en puissance des socialistes ${ }^{315}$; ceci, encore plus à partir de 1905 , où August Bebel, taxé de propager les méthodes de la Russie révolutionnaire, prend de l'importance ${ }^{316}$. Cette même année I 905, la crise marocaine est copieusement couverte avec le voyage de Guillaume II au Maroc ${ }^{317}$. Le traitement plutôt important de la Lex Heinze, une loi sur les mœurs, à la durée de vie pourtant très courte $^{318}$, est tout à fait singulier, puisqu'il ne s'agit, en définitive, que d'une mesure à caractère social dans un pays étranger. Cela montre à quel point le Nebelspalter se sert de l'étranger pour nourrir ses propres combats, et met en évidence le rôle de miroir politique endossé, à cette époque, par l'Allemagne.

L'intérêt pour les affaires françaises est plus large. La question du Concordat de I 80 I - avec une focalisation sur la figure de Émile Combes -, aboutissant fin I 905 à la loi de séparation entre l'Église et l'État, est regardée avec une certaine gourmandise ${ }^{319}$ (cf. fig. 38 ).

De I900 à I906, quelques dessins thématisent les derniers développements de l'affaire Dreyfus. La mort de Zola en I902, notamment, est l'occasion d'y revenir, avec la mise en évidence de l'article «J'accuse ${ }^{320}$. Un seul dessin rend compte en I 906 de

\footnotetext{
Nebelspalter 1906/17, dessin de W. Lehmann-Schramm intitulé « La Triplice » (Der Dreibund).

${ }_{312}$ Nebelspalter 1902/16, dessin pleine page de W. Lehmann-Schramm intitulé « Le travail » (Die Arbeit); sur l'affaire Silvestrelli: Verdiana Grossi, « Silvestrelli affaire », Dictionnaire historique de la Suisse (10/01/2011); http://www.hls-dhs-dss. $\mathrm{ch} / \mathrm{textes} / \mathrm{f} / \mathrm{F} 17248 . \mathrm{php}$

'13 Nebelspalter 1900/42, dessin pleine page de Boscovits senior intitulé « Un drôle de passionné » (Ein sonderbarer Schwärmer).

314 Nebelspalter 1900/43, dessin pleine page de W. Lehmann-Schramm intitulé « Sur le changement de ministre en Allemagne » (Zum Ministerwechsel in Deutschland). Nebelspalter 1904/4, dessin pleine page de W. Lehmann-Schramm intitulé « Les mauvais garnements allemands " (Aus der deutschen Kinderstube).

Nebelspalter 1905/45, dessin pleine page de Boscovits junior intitulé « Cours de russe » (Russenkurs).

Et donc à partir du numéro 13 .

318 II s'agit d'une mesure législative de circonstance, promulguée en 1899 à l'occasion d'une affaire de proxénétisme, retirée un an plus tard. Le but réel de la Lex Heinze était d'entraver la liberté artistique et plus généralement celle de la presse: Laurence Danguy, L'ange de la jeunesse - La revue Jugend et le Jugendstil à Munich, op. cit., p. 32.

319 Nebelspalter 1903/22, dessin pleine page de Boscovits senior intitulé « II est sérieux » (Er macht ernst).

${ }_{320}$ Nebelspalter 1902/41, dessin pleine page de Boscovits senior intitulé « Le géant et les pygmées » (Die Riese und die Pygmäen).
}

la réhabilitation de Dreyfus et de sa réintégration dans l'armée, et encore de manière indirecte. "La pauvre Sara Bernhard » (Die arme Sara Bernhard) montre l'actrice, elle-même juive et soutien de Zola, se lamenter de ne pas avoir encore obtenu la légion d'honneur, alors qu'elle a pris parti pour Dreyfus. Son prénom (Sara et non Sarah) ainsi que le nom de Dreyfus (orthographié Dreifuss [trépied]), jouant de l'homonymie comme souvent dans la presse allemande, sont écorchés. La charge antisémite est à peine voilée ${ }^{321}$. À partir de 1904, les emprunts russes, encouragés par le Président Émile Loubet pour des raisons stratégiques, commencent à être sérieusement mis en question, et ceci très fréquemment ${ }^{322}$. Clémenceau, nouveau Président du conseil, fait son apparition fin $1906^{323}$.

L'Angleterre est constamment accusée de barbarie et d'impérialisme. Sa présence en Afrique du Sud est violemment condamnée, et vue comme un danger pour la couronne britannique. L'ascension de Kitchener est regardée sans complaisance. Les pertes humaines des guerres de colonisation sont dénoncées. Tout ceci vaut au roi Édouard VII d'être figuré en paon ${ }^{324}$. La revue s'engage sans équivoque aux côtés de Paul Krüger sur la question du Transvaal ${ }^{325}$ (cf. fig. 39 cahier couleur).

La Russie fait partie des pays qui sont toujours présents, d'abord pour ses appétits envers la Corée, puis sur le thème de la libération du peuple, à partir de $\mathrm{I} 90 \mathrm{I} \mathrm{I}^{326}$; de son alliance diplomatique avec la France; de la Mandchourie, à partir de I902; de la guerre contre le Japon, en I904 et I905 mais surtout des violences tsaristes. Nicolas II est ironiquement présenté comme «le bon petit père » (Das gute Väterchen) ${ }^{327}$, et qualifié de " criminel de masse " (Massenmörder) après la révolution d'octobre I905. Les termes sont alors on ne peut plus clairs: "Le Nebelspalter souhaite également au petit père un bon départ de la Russie » ${ }^{328}$.

À partir de I900, le Japon se hisse au rang des puissances qui comptent dans l'équilibre mondial. L'Europe se montre dans les jeux d'alliance ${ }^{329}$. D'autres pays ou régions stratégiques apparaissent sporadiquement à l'occasion d'élections, de crises de régime ou de conflits, et notamment: en I900, le Soudan, la Chine, la Suède et la Macédoine; en I90I, l'Empire austro-hongrois, les États-Unis et les Philippines; en I902, la Belgique, les Antilles, l'Abyssinie, le Venezuela, la Serbie mais surtout l'Empire austrohongrois; en I903, la Bulgarie, la Corée, la Chine et la Macédoine; en I904, l'Empire austro-hongrois, la Serbie, la Mandchourie, le Tibet et les États-Unis; en I905, les États-Unis, l'Espagne, la Norvège et l'Empire austro-hongrois; en I 906, les États-Unis, l'Empire austro-hongrois, l'Abyssinie, la Chine et l'Arménie.

Nebelspalter 1906/31, dessin pleine page de Boscovits senior intitulé « La pauvre Sara Bernhard » (Die arme Sara Bernhard); le numéro est daté du 4 août 1906. 222 Nebelspalter 1904/9, dessin pleine page de Boscovits junior intitulé « Le résultat » (Das Resultat).

${ }^{323}$ Nebelspalter 1906/42, dessin pleine page de Boscovits senior intitulé "Clémenceau ».

324 Nebelspalter 1901/51, dessin pleine page de Boscovits junior intitulé «Quand le paon anglais se met aussi à faire le fier » (Wenn der englische Pfau jetzt auch stolz thut)

${ }_{325}$ Nebelspalter 1902/37, dessin pleine page de Boscovits junior intitulé « Un homme seul » (Ein einsamer Mann).

6 Nebelspalter 1901/15, dessin pleine page de W. Lehmann-Schramm intitulé «Sur le mouvement de liberté en Russie » (Zur Freiheitsbewegung in Russland).

${ }^{227}$ Nebelspalter 1903/40, dessin pleine page de W. Lehmann-Schramm intitulé « Le bon petit père » (Das gute Väterchen).

${ }_{328}$ (Auch der Nebelspalter wünscht Väterchen eine glückliche Abreise aus Russland) ; Nebelspalter 1905/45, dessin pleine page de W. Lehmann-Schramm intitulé « Le Criminel de masse russe » (Der russische Massenmörder).

329 Cf. « 3.1. Une iconographie du monde ». 


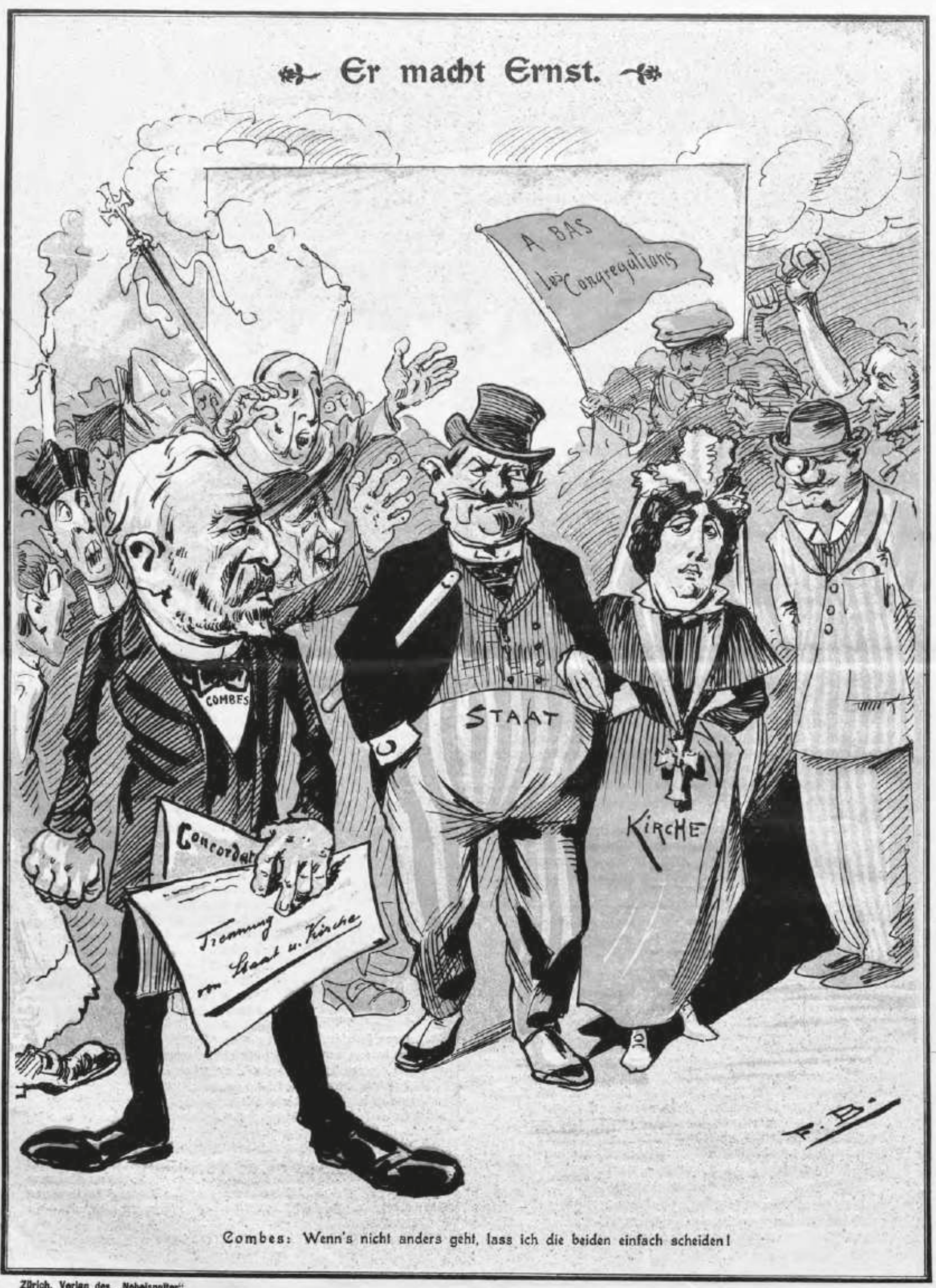

Zlirich, Voriag det „Nobeispoiterit

Fig. 38. Nebelspalter 1903/22, dessin pleine page en noir et blanc de Boscovits senior intitulé « Il est sérieux » (Er macht ernst). 


\subsubsection{Rhétorique - L'empreinte de la politique}

Les titres se répartissent en deux catégories : ceux collant à l'actualité et donnant en quelques mots le cœur du propos; ceux s'inscrivant dans une logique sérielle, déjà présente les décennies précédentes. Ce sont « Les chants du printemps » (Frühlingslieder), "La saison de la baignade " (Badesaison) et autres "Images d'automne» (Herbstbilder). On retrouve également "La course au bonheur " (Die Jagd nach dem Glück), " Hier et aujourd'hui » (Einst und jetzt), "Ivrogne en bonne route » (Sauser im Stadium), "Canicule politique»(Politische Hundstage). D'autres titres reflètent l'époque, tels "Culture moderne" (Moderne Kultur) et "Images de la rue "(Strassenbilder). Des séries, parfois savoureuses, apparaissent, telle celle "Des courageux» (Gemütsmenschen). Différentes légendes cohabitent, certaines longues et informatives, d'autres accrochant le dessin d'un ou deux mots.

Titres et légendes incluent comme auparavant des références humanistes, en Français ou en latin. Certaines sont néanmoins autochtones, tel le «Guillaume Tell » de Schiller, alors que la nationalité allemande de l'auteur est à l'évidence occultée. Le dialecte est alors réservé aux questions zurichoises.

En I900, la rhétorique du tournant de siècle, trop esthétique et datée, est sur le déclin. Les guerres, même lointaines, effraient. L'étranger comme miroir de la Suisse est un procédé courant, en particulier la Chine, qui inquiète ${ }^{330}$. Les conflits sont pensés face aux notions de culture et de civilisation, violemment mises en cause. Le concept de civilisation, jugé dévoyé, constitue l'objet d'un éditorial en I90I ${ }^{331}$, puis en I $903^{332}$. Le terme de "péril jaune" (gelbe Gefahr) apparaît en I905, à l'occasion de la guerre russojaponaise ${ }^{333}$. L'antisémitisme, avec une prégnance de l'association du juif et du capital ${ }^{334}$, le dispute alors à un anticléricalisme en lien avec l'Allemagne et la France, ainsi qu'avec l'élection du pape Pie X, en 1903 .

\subsubsection{Langage visuel - Acculturation du Jugendstil et recyclage de formules anciennes}

Les dessins sont généralement signés, comme toujours à l'exclusion de certains thèmes sensibles, financiers ou politiques, engageant dans ce dernier cas l'État ou le canton. Les artistes signent soit d'une signature, complète ou tronquée, soit d'un monogramme. Les Boscovits, Lehmann-Schramm mais aussi Kälin Küpfer usent de ces différentes possibilités. Les essais sont cependant plus rares. Boscovits junior se distingue en multipliant les pseudonymes, Fritzli, Moritz ou Fritz.

L'impression générale est celle d'un recul esthétique, régulièrement contredit par de soudaines réalisations novatrices: une nouvelle organisation spatiale, une image se rapprochant fortement du lecteur, un jeu sur le cadre. Celles-ci ont pour créateurs des dessinateurs anciens ainsi que quelques nouveaux, en particulier

\footnotetext{
330 Nebelspalter 1900/31, dessin pleine page de Boscovits junior intitulé « En Chine comme à Zurich, il y a des personnalités populaires » (Populäre Menschen gibt's in China und Zürich); cf. également " 3. UN MONDE AUX DÉCLINAISONS PLURIELLES ».

${ }_{331}$ Nebelspalter 1901/33, texte non signé intitulé "Civilisation et humanité » (Zivilisation und Humanität).

332 Nebelspalter 1903/41, texte non signé intitulé « Civilisation » (Zivilisation).

333 Nebelspalter 1905/23, dessin pleine page de W. Lehmann-Schramm intitulé « Le péril jaune » (Die gelbe Gefahr)

334 Nebelspalter 1900/2, dessin pleine page de Boscovits senior intitulé «L'épine dans l'œil » (Der Dorn im Auge)
}

Josef Kälin Küpfer, qui remplace Lehmann-Schramm en I 900, ainsi que Otto Maehly, à partir de I906. Durant cette période, l'équipe ne dépasse pas six dessinateurs; une partie n'est repérable qu'au travers d'un monogramme ne permettant pas l'identification. Les Boscovits s'essaient volontiers à de nouveaux effets stylistiques, surtout Boscovits junior qui exploite différentes grilles, avec une prédilection pour un trait Jugendstil très enveloppant, évoluant, à partir de 1905, vers un Heimatstil assumé. L'importance de Boscovits junior croît avec l'arrivée de son père aux commandes éditoriales. À partir de I903, celui-ci s’impose aux dépens de Lehmann-Schramm, qui dessine maintenant des femmes aux allures de cocotte. Plus encore que les Boscovits, le dessinateur allemand charge ses compositions d'un antisémitisme sévère. À partir de I902, l'influence de modèles français, dont celle de Gustave Henri Jossot (I 866-I95 I) ${ }^{335}$ est manifeste.

Une esthétique originale, développée à partir du Jugenstil, s'installe à partir de I900, et surtout de I902. Les années I900 et I90 I voient ainsi la résorption des éléments Belle Époque dans un Jugendstil soumis à un processus d'assimilation, manifeste dans la couverture de carnaval de l'année i900. Le costume d'arlequin dessiné par Boscovits junior renferme les membres de la famille du journal, le Nebelspalter et les personnages des icones des pages intérieures ${ }^{336}$ (cf. fig. 40 cahier couleur). À partir de I903, les éléments Jugendstil se raréfient et sont intégrés au langage caricatural. À l'automne I903, Boscovits junior livre une chasse politique intitulée "La chasse est ouverte» (Die Jagd hat begonnen ${ }^{337}$, tout à fait représentative de ce processus syncrétique. De petites scènes montrant les péripéties d'un chasseur et de différents personnages emplissent l'image. Certains de ces personnages présentent un corps déformé, selon les codes caricaturaux, avec des membres courts et une grosse tête, d'autres sont rendus d'un trait souple et minimaliste, à la mode Jugendstil.

Des motifs anciens sont, par contre, revus d'après la nouvelle esthétique. Pour railler les dispositions législatives sur les mœurs, Boscovits junior dessine des paragraphes anthropomorphes et ondulants ${ }^{338}$. À partir de I904, la tendance s'accentue. Le motif du chat noir, conjointement hérité du parisien Théophile Steinlen et du munichois Thomas Theodor Heine (dessinateur du Simplicissimus), prend place dans une synthèse de la scène internationale zurichoise. L'animal est à la fois présent dans le titre, "Ambiance gueule de bois » (Katerstimmung), d'après un jeu de mot allemand sur le mot chat (Kater) et gueule de bois (également Kater), et dans l'image ${ }^{339}$ (cf. fig. 4I).

Les marqueurs iconographiques de l'identité suisse et les références aux traditions festives sont récurrents. Motifs alpins, bergers, vaches, croix et drapeau helvétiques, Schützenfeste (concours de tir) s'invitent dans les images, voire en sont le thème. Ils remplacent assez systématiquement les femmes, figures mythologiques et autres ornements végétaux du Jugendstil. Le Heimatstil est ici

\footnotetext{
Sur Jossot, cf la thèse d'Henri Viltard, le catalogue d'exposition ainsi que le site consacré à l'artiste: Henri Viltard, Jossot et l'épure décorative (1866-1951): caricature entre anarchisme et islam, Paris, Ehess, 2005 ; Michel Dixmier et Herni Viltard, Jossot. Caricatures: de la révolte à la fuite en Orient (1866-1951), Paris, Bibliothèques, 2010; http://gustave.jossot.free.fr/index.html

Nebelspalter 1900/9, couverture de Boscovits junior.

Nebelspalter 1903/37, dessin pleine page de Boscovits junior intitulé « La chasse est ouverte » (Die Jagd hat begonnen).

338 Nebelspalter $1903 / 24$, dessin pleine page de Bocovits junior intitulé « À propos de la nouvelle loi zurichoise sur les bonnes mœurs » (Zum Zürcher Sittlichkeitsgesetz).

339 Nebelspalter 1904/9, dessin pleine page de Boscovits junior intitulé « Ambiance gueule de bois » (Katerstimmung).
} 


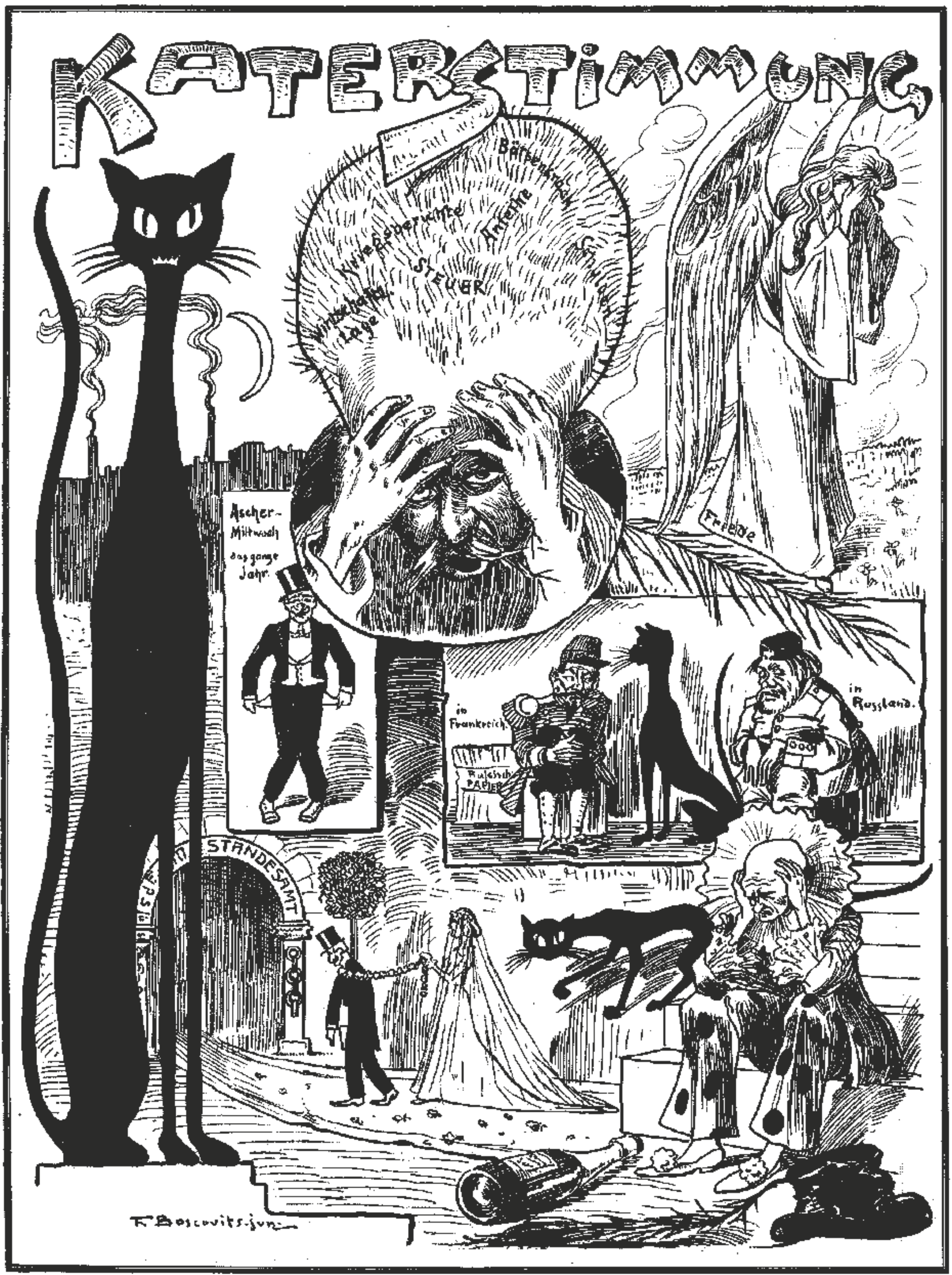


adapté au médium de la revue, ses contraintes de format et de planéité, son caractère éphémère, ses exigences économiques et la pluralité de ses concepteurs. Cette version helvétisée du Jugendstil reste très proche de la caricature et ménage une place inhabituelle à la laideur, à cette esthétique du laid, constitutive de la caricature ${ }^{340}$.

Cette laideur est essentiellement nourrie par le maintien d'éléments archaïsants : une image - hormis la couverture - encore strictement contenue dans son cadre; une couleur ne recherchant pas l'effet mais traitée avec parcimonie dans des combinaisons souvent ternes; une maquette pour l'essentiel inchangée; une dynamique satirique qui reste très dépendante de la légende ainsi que la survivance, assez insolite, de procédés caricaturaux anciens. Sur les pages s'étalent toujours autant de journaux animés, de corbeaux anticléricaux, de cuisine, boudoir, balance et soupe politiques, de nids de guêpes, de vaches « helvétiques » et de petits garçons pour figurer les cantons suisses. Les motifs idiomatiques font encore recette, jouant souvent sur l'homonymie, comme le sempiternel banc pour la banque (Die Bank, dans les deux cas) ${ }^{341}$.

La modernité est là pourtant, avec les motifs de la bicyclette et de l'artisan, ou un train qui est désormais moins politique que sociétal. Ces motifs sont soit traités à l'ancienne, telles des jumelles géantes ${ }^{342}$, soit selon l'esthétique Jugendstil, comme le chewinggum anthropomorphisé ${ }^{343}$.

L'imagerie anticléricale est rénovée par de nouveaux dessinateurs, tel Kälin Küpfer, fournissant des compositions brossées dans un trait serré ${ }^{344}$. Certains thèmes sont profanisés ${ }^{345}$. À l'occasion de la Pentecôte 1903, Boscovits senior dessine une allégorie de la justice (Gerechtigkeit) à l'allure bien religieuse ${ }^{346}$. Fonds religieux et mythologique fournissent de nombreux thèmes et motifs, telle l'arche de Noé ${ }^{347}$ ou une forêt aux arbres animés, bien serrés, servant de théâtre à une satire zurichoise ${ }^{348}$. Les centaures et autres animaux mythiques sont, cependant, avant tout redevables à un Jugendstil réactivant des références pseudo-historiques ${ }^{349}$.

L'iconographie devient plus sociétale et plus politique. Certains thèmes, tel que le tourisme alpin, sont l'objet d'un traitement ambigu entre critique et soutien à l'identité suisse. L'iconographie urbaine est duelle, avec d'une part, une ville socialisée; de l'autre, des compositions idylliques, chargées de l'insouciance Jugendstil 350 . Les conquêtes coloniales génèrent la figure très dégradée du nègre, monnaie courante à cette époque ${ }^{351}$. Ce thème permet la rénovation de motifs anciens, tels les chapeaux Jugendstil de Willy LehmannSchramm, animant une critique acerbe des appétits coloniaux

\footnotetext{
34 Michel Melot, « Le laid idéal », Les cahiers de médiologie, $n^{\circ}$ 15, 2003/1, p. 149-160. ${ }^{341}$ Nebelspalter 1902/6, dessin pleine page de Boscovits senior intitulé «Sous le banc » (Unter der Bank).

${ }^{342}$ Nebelspalter 1904/39, dessin pleine page de Boscovits junior intitulé « Vue inversée » (Verkehrte Ansicht).

343 Nebelspalter 1905/39, dessin pleine page de W. Lehmann-Schramm intitulé « Les hommes chewing-gum » (Die Gummi-Männer).

344 Nebelspalter 1900/31, dessin pleine page de Josef Kälin Küpfer intitulé «Au cloître » (Im Kloster)

345 Sur la notion de profanisation: Alain Cabantous, Histoire du blasphème en Occident: $x V l^{e}-x I x^{e}$ siècle, Paris, Albin Michel 1998, p. 207.

${ }^{46}$ Nebelspalter 1903/22, couverture de Boscovits senior.

${ }_{347}$ Nebelspalter 1900/12, dessin pleine page de Boscovits junior intitulé « La nouvelle arche » (Die neue Arche).

${ }_{348}$ Nebelspalter 1901/5, dessin de Boscovits junior intitulé « Sur la place de Zurich » (Im Zürcher Platzspitz).

349 Laurence Danguy, L'ange de la jeunesse - La revue Jugend et le Jugendstil à Munich, op. cit., p. 173-313.

350 Cf. « 3.2.3. Chronique visuelle d'une ville: Zurich ».

${ }^{351}$ Nebelspalter 1903/27, dessin pleine page non signé intitulé « En Somalie » (Im Somaliland).
}

européens ${ }^{352}$, mais aussi de nouveaux schémas de composition, comme des suites narratives, inspirées de la bande dessinée ${ }^{353}$ (cf. fig. 42).

Les conflits, en particulier celui du Transvaal, la guerre russojaponaise ou les violences du régime tsariste, alimentent une imagerie de la violence. À la suite de la Révolution russe de 1905 , une iconographie du danger révolutionnaire émerge. Elle est organisée d'après un fonds allégorique et mythologique, avec le motif de l'hydre ${ }^{354}$, le dieu Mars, les allégories de l'anarchie et de la misère ou encore une boite de Pandore étiquetée "Politique » (Politik), ouverte par Chronos ${ }^{355}$. Certains éléments inédits, comme le spectre ou la bombe, rencontrent l'imaginaire contemporain ou une réalité plus prosaïque ${ }^{356}$.

Les doubles-pages continuent de livrer des synthèses de la vie politique suisse et internationale, et de mettre en lumière une question importante, tel le référendum (approuvé) du 23 novembre I902 sur le financement de l'école primaire par la Confédération. Entourée des garnements incarnant les cantons, Helvetia porte à cette occasion la devise «L'éducation du peuple est la libération du peuple»(Volksbildung ist Volksbefreiung) ${ }^{357}$. Les hommages aux grands hommes prennent toujours place sur ces doubles-pages, de même que la célébration de l'armée ainsi que, dans un tout autre registre, le calendrier du Nebelspalter. Le lieu est également fréquenté par le personnage du Nebelspalter qui soutient, en 1905 , le règlement de la paix russo-japonaise dans une composition assez curieuse. D'un graphisme vieillot, elle adopte une combinaison de bleu et de rouge plutôt ancienne ${ }^{358}$.

Il arrive, cependant, que les doubles-pages soient un lieu moins conformiste, avec un traitement humoristique de l'armée 359 et des caricatures de mœurs ${ }^{360}$. L'Europe s'y montre pour la première fois sous la forme d'une femme au parapluie, un motif typique de l'Art nouveau ${ }^{361}$ (cf. fig. 43 cahier couleur). En I904, une double-page introduit une rupture de ton qui ne sera pas sans conséquences. Les statues de quatre grands héros de l'histoire suisse y sont présentées côte à côte. Une échelle est plantée devant chaque piédestal, de sorte qu'à chaque grand homme est associé un personnage: l'enchanteur du peuple (Der Volksbeglücker) à Guillaume Tell; le lieutenant (Der Herr Leutenant) à Hans Waldmann (I 435I489), chef d'armée et bourgmestre de Zurich; le pasteur (Der Herr Pfarrer) au réformateur Ulrich Zwingli; le professeur (Der Herr Professor) à Johann Pestalozzi (I746-I 827), pionner de la pédagogie moderne ${ }^{362}$. Pour la première fois, de grandes figures de la Confédération sont écornées.

\footnotetext{
Nebelspalter 1900/13, dessin pleine page de W. Lehmann-Schramm intitulé « On continue de civiliser » (Es wird fort civilisiert).

${ }_{353}$ Nebelspalter 1900/13, dessin pleine page de Boscovits junior intitulé « Le valeureux guerrier » (Der tapfere Krieger).

354 Nebelspalter 1906/30, dessin pleine page de W. Lehmann-Schramm intitulé « Un drôle de zouave » (Sonderbare Heilige).

355 Nebelspalter 1906/20, double-page sans titre de Boscovits senior.

${ }_{356}$ Nebelspalter 1906/36, dessin pleine page de W. Lehmann-Schramm intitulé « Le voyage à l'étranger du petit père » (Väterchens Auslandreise).

57 Nebelspalter 1902/47, double-page de Boscovits senior intitulée « Au sujet du 23 novembre » (Zum 23. November).

${ }^{358}$ Nebelspalter 1905/23, double-page en couleur de Boscovits senior intitulée "Pentecôte 1905 » (Pfingsten 1905).

359 Nebelspalter 1900/37, double-page en noir et blanc de Boscovits senior intitulée « Images de manœuvres » (Manöverbilder).

${ }_{360}$ Nebelspalter 1900/48, double-page de Boscovits senior intitulée « 1900 - Un jour de la vie d'un recenseur » (1900 Ein Tag aus dem Leben Volkzählers).

${ }_{361}$ Nebelspalter 1903/5, double-page de Boscovits senior sans titre; le motif est plusieurs fois décliné par la suite.

${ }_{362}$ Nebelspalter 1904/48, double-page de Boscovits senior intitulée « Les Anciens et
} les Nouveaux » (Die Alten und die Neuen). 


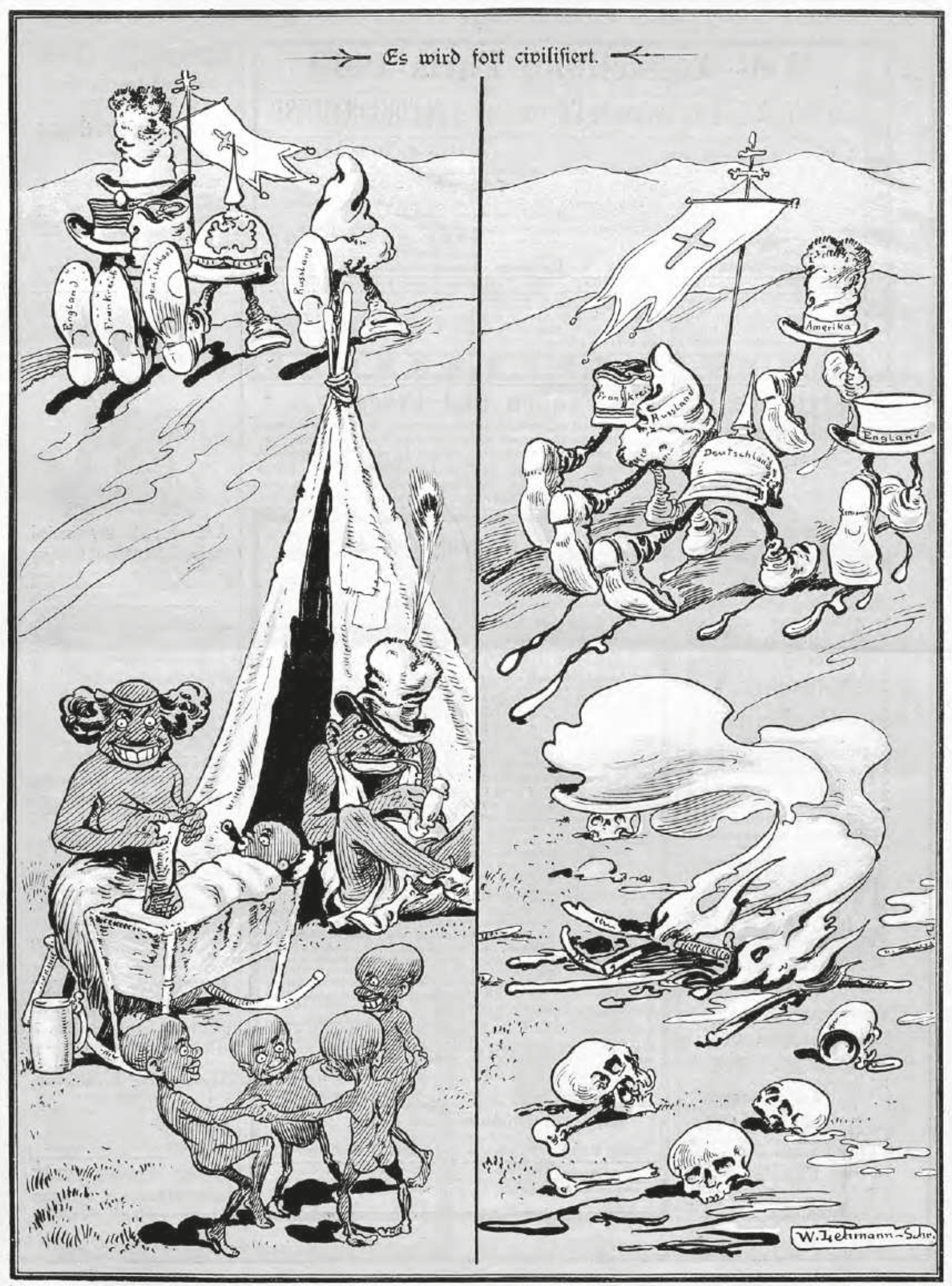

Fig. 42. Nebelspalter 1900/13, dessin pleine page en couleur de Willy Lehmann-Schramm intitulé « On continue de civiliser » (Es wird fort civilisiert). 
D'ailleurs, le genre des hommages aux grands hommes commence à être mis à mal. Il est aussi moins fréquent, avec trois à huit occurrences annuelles. Si les bénéficiaires demeurent inchangés personnalités politiques, militaires, écrivains, artistes et figures de la vie zurichoise -, l'iconographie, jusqu'ici très normée, se dérègle et seul l'hommage nécrologique à Jean Nötzli, en I900, respecte les anciens $\operatorname{codes}^{363}$. Même la commémoration des directeurs des réseaux ferrés suisse $(\mathrm{SBB})$ et la célébration du jubilé du directeur du chœur masculin de Zurich, Carl Attenhofer (I 837-I9I4), deux compositions de I90I, s'affranchissent de la règle: ici, les portraits en médaillon sont reliés; là, le cadre a sauté ${ }^{364}$. Le texte prend la primauté sur une image devenue accessoire et instable. Le portrait de petite taille reste la forme la plus fréquente mais celui-ci est volontiers inséré dans une composition pluri-thématique, comme dans les hommages nécrologiques au dramaturge norvégien Henrik Ibsen (I 828-1906) ${ }^{365}$ et au consul suisse à Berlin, Arnold Roth $^{366}$. Helvetia s'invite, quant à elle, dans le portrait de Friedrich von Schiller ${ }^{367}$. L'hommage nécrologique à Arnold Böcklin est dépourvu d'image ${ }^{368}$. L'ironie fait une entrée discrète. Pour son soixantième anniversaire, le poète autrichien Peter Rosegger (I843-I9I8) se présente avec une certaine indolence, la tête appuyée sur une main ${ }^{369}$.

\subsubsection{La femme, le nu et l'allégorie}

Le nu fait son apparition. La couverture du premier numéro de l'année I90I, dessinée par Willy Lehmann-Schramm, présente une jeune femme aux cheveux ornés de fleurs, parée d'une robe antiquisante, laissant voir ses seins ${ }^{370}$ (cf. fig. 44 cahier couleur). Elle tient d'une main une plume; de l'autre, l'aiguille d'une pendule très exactement pointée sur le chiffre $\mathrm{I} 2$. Le dessin est un dégradé de gris, rehaussé de rouge; le titre Nebelspalter, en rouge sur fond noir, s'encastre dans la pendule; au niveau des hanches de la femme, le chiffre I90 I se détache en rouge, en rappel du titre. En bas de l'image, deux oiseaux noirs quittent l'image. Le message est clair: le Nebelspalter s'impose en lettres rouges sur la noirceur et engage le siècle en chassant les oiseaux de mauvais augure. Ce qui est plus incertain, est la nature de la figure, à mi-chemin entre une femme idéalisée et érotisée, typique du Jugendstil, et une allégorie dont la nature n'est pas nette: s'agit-il de la victoire, du progrès, du temps ou bien encore de la revue elle-même? L'évolution festive du carnaval (Carneval), jusqu'à présent politique et qui s'appelle désormais "Fasching ", et l'ouverture, en I900, du cabaret zurichois Corso ${ }^{371}$ autorisent cette érotisation des figures féminines. Celle-ci gagne tous les types de compositions, jusqu'à une représentation érotisée du sommet alpin de la Jungfrau ${ }^{372}$ (cf. fig. 45).
Non seulement la femme se dénude mais sa moralité se détériore. La femme perdue apparaît. Le fait le plus frappant est cependant un double mode de présence: en couverture, la femme est valorisée, tandis que les femmes manipulatrices, mégères et cocottes remplissent les pages intérieures. Au fil des années, la présence de la femme diminue.

L'évolution de l'allégorie suit celle de la femme, et, comme elle, se raréfie progressivement. Les allégories s'apparentent à ce point aux représentations féminines qu'il est indispensable de les nommer dans l'image, qu'elles soient de facture traditionnelle ou Jugendstil. La répartition entre les deux variantes stylistiques ne correspond à aucune logique apparente: l'allégorie d'un pays, d'une vertu, d'un concept politique ou éthique peut aussi bien ressortir à l'une ou à l'autre. Les allégories ne sont pas exclusives et se mélangent volontiers aux personnages historiques, comme, en I 900, une Marianne Jugendstil avec le sénateur Auguste Mercier, dessiné, lui, de manière beaucoup plus traditionnelle ${ }^{373}$.

L'iconographie de l'Europe est mouvante ${ }^{374}$. Les allégories politiques concurrencent les symboles animaliers et les personnages historiques, puisqu'un pays dispose de différents modes de présence. En I903, l'Allemagne est indifféremment représentée par Germania, le Michel Allemand (Der deutsche Michel), l'aigle prussien ou Guillaume II, voire par un simple casque à pointe ${ }^{375}$. Lehmann-Schramm poursuit son "feuilleton politique ", avec des allégories revenant dessin après dessin. Certaines de ses caricatures sont particulièrement efficaces, comme les canons vivants incarnant les grandes puissances ${ }^{376}$. Génériquement, ceux-ci sont situés entre l'allégorie, le portrait et le motif. C'est encore le dessinateur allemand qui est à l'origine d'une allégorie de la Révolution (russe) prenant les traits d'une femme noire, monstrueuse, aux cheveux hirsutes et aux mains griffues, ayant pour corps une cage-araignée 377 (cf. fig. 46).

L'allégorie du peuple apparaît sous une forme instable, souvent en relation avec Nicolas II. Les allégories des nations étrangères sont à présent souvent dévoyées.

Même Helvetia n'échappe pas tout à fait à ce processus de dérégulation iconographique et subit maintenant l'influence Jugendstil. Boscovits senior la mêle à Athéna, l'une des références du Jugendstil viennois ${ }^{378}$. Elle prend les habits de la modernité en conduisant le camion fédéral, le conseiller fédéral Ludwig Forrer à ses côtés ${ }^{379}$. Son enlaidissement, en I906, par Boscovits senior, qui la montre souffrant chez le dentiste, est plus significatif encore. Cette dégradation représentationnelle est inédite ${ }^{380}$.
363 Nebelspalter 1900/17, couverture de Boscovits senior

364 Nebelspalter 1901/14, double-page de Boscovits senior; Nebelspalter 1901/23, double-page de Boscovits senior.

365 Nebelspalter 1906/22, double-page de Boscovits senior intitulée «Pentecôte $1906 »$ (Pfingsten 1906).

${ }_{366}$ Nebelspalter 1904/16, dessin pleine page de Boscovits senior intitulé « Dans le chagrin le plus profonde » (In tiefstem Leid).

367 Nebelspalter 1905/18, dessin pleine page de Boscovits senior intitulé « Friedrich Schiller ».

${ }_{368}$ Nebelspalter $1901 / 3$, encart.

369 Nebelspalter 1903/31, dessin sans titre de Boscovits senior.

370 Nebelspalter 1901/1, couverture en couleur de W. Lehmann-Schramm.

371 Tanja Tenzl, « Corso-Theater, Zürich ZH », dans Theaterlexikon der Schweiz, vol. 1, op. cit., p. 411-412.

${ }_{372}$ Nebelspalter 1901/43, dessin de Boscovits junior intitulé « 1923, Le train de la Jungfrau est achevé » (Jungfraubahn 1923 beendet).

\footnotetext{
3 Nebelspalter 1900/6, dessin de Boscovits junior intitulé «Le nouveau papa de la France » (Der neueste Papa Frankreichs).

374 Cf. « 3.1.2. 1887-1914: déclinaisons d'un univers en expansion et d'une Europe impuissante ".

35 Nebelspalter 1903/1, dessin de Boscovits junior intitulé « Le laboratoire de la cour royale et impériale » (Das kaiserlich-königliche Hof-Laboratorium).

376 Nebelspalter 1906/26, dessin de W. Lehamm-Schramm intitulé « Gare! » (Vorsicht!).

77 Nebelspalter 1906/40, dessin de W. Lehamm-Schramm intitulé « La fuite à l'étranger de Niki » (Niki's Flucht ins Ausland).

${ }^{378}$ Nebelspalter $1900 / 28$, dessin pleine page de Boscovits senior intitulé « D'après un modèle connu » (Nach bekanntem Muster).

379 Nebelspalter 1906/16, dessin de Boscovits junior intitulé « Sous le signe de l'automobile » (Im Zeichen des Automobils).

380 Nebelspalter 1906/17, dessin de Boscovits senior intitulé « Le dernier amendement
} à la loi » (Zur neuesten Gesetzesnovelle). 
Jungfraubabin 1923 beendet.

Fut bober Hip. (Im Ursoreththell).

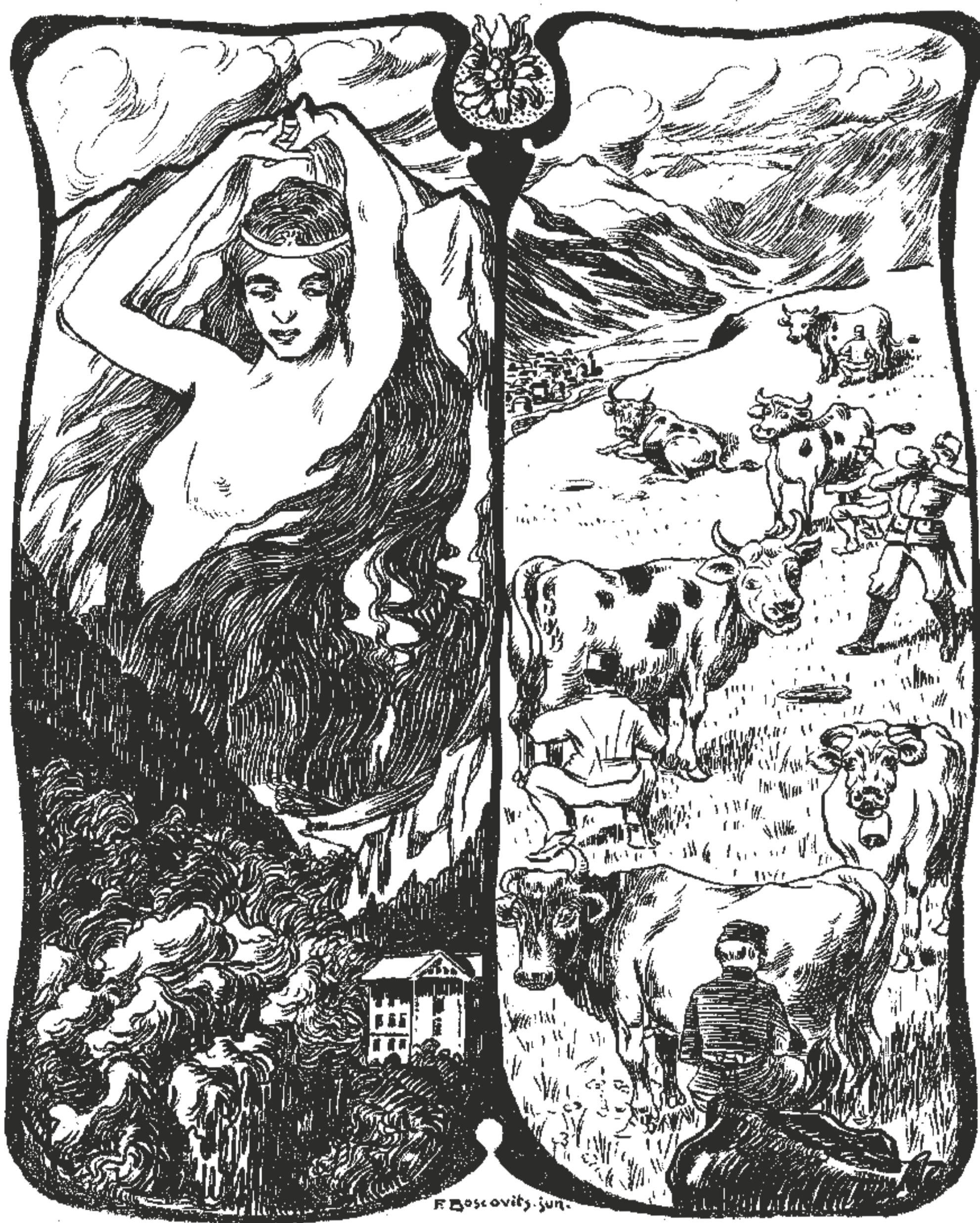

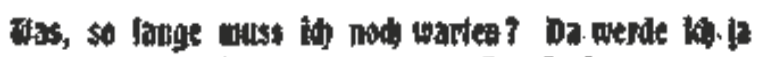

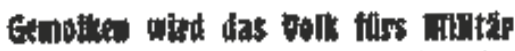

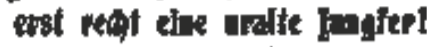

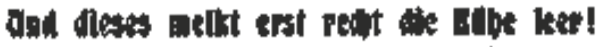




\section{Riki's fludt ins Hustand.}

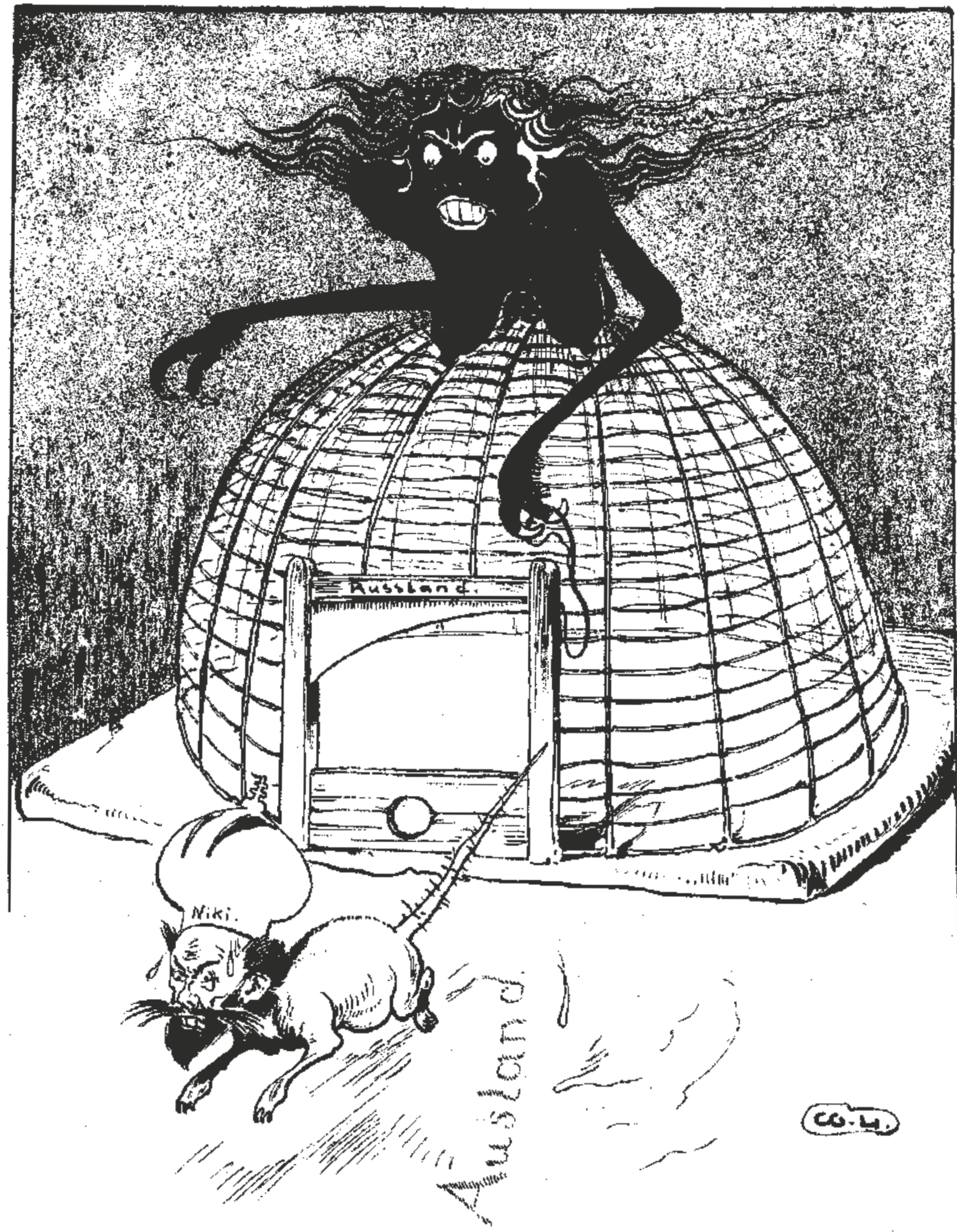

Die Revolution: „Jetzt ist mir die Ratte dow nod ausgekommen"

Fig. 46. Nebelspalter 1906/40, dessin pleine page en noir et blanc de Willy Lehamm-Schramm intitulé « La fuite à l'étranger de Niki » (Nikis Flucht ins Ausland). 


\section{Hut Feil! -}

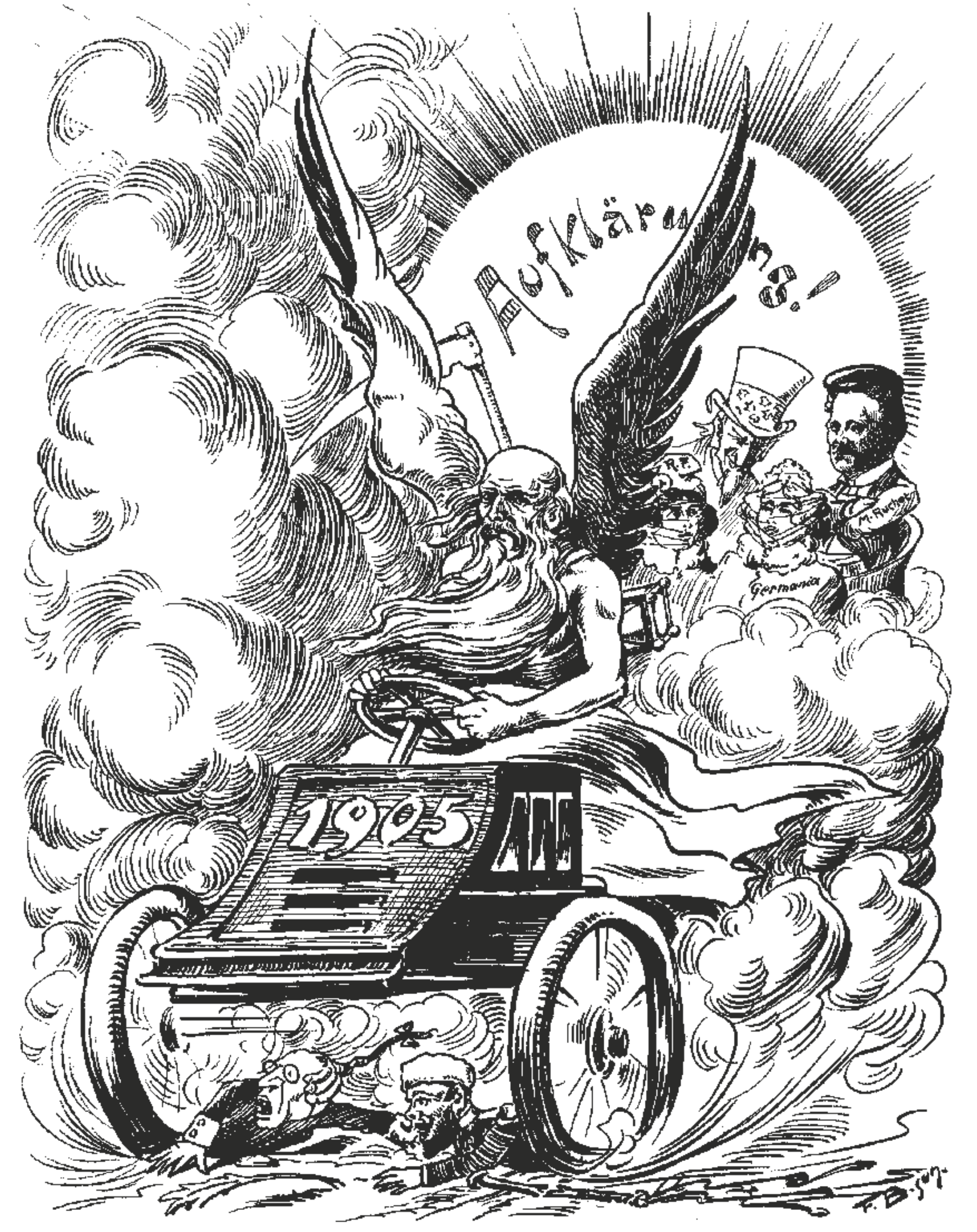

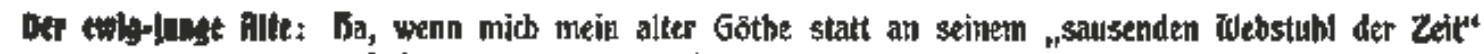
auf den ${ }_{n} 5$ a usenden Hut" seben kợnnte!

Fig. 47. Nebelspalter 1904/52, dessin en noir et blanc de Boscovits junior intitulé « Vive l'auto ! » (Aut Heil !). 
Chronos est lui-aussi "passé » à l'esthétique Jugendstil sur une couverture de $1900^{381}$. L'année suivante, une allégorie féminine des « temps nouveaux » (neue Zeit) lui vole ses ailes et le remplace pour ouvrir l'année I90I ${ }^{382}$. Chronos apparaît néanmoins très régulièrement dans des caricatures, soit sous une forme Jugendstil, soit sous une apparence plus traditionnelle. Lié à l'" esprit du temps » (Zeitgeist), il est en prise avec la modernité. D'ailleurs, il pilote une automobile ${ }^{383}$ (cf. fig. 47).

La présence du personnage du Nebelspalter est alors relativement constante, entre quatre et huit occurrences par an, avec une chute soudaine en I906, où il n'apparaît qu'à deux reprises. Le personnage réintègre son ancien rôle et son iconographie traditionnelle; il redevient l'observateur engagé de la vie politique nationale et, moins souvent, internationale. Les prises de position à l'international sont, du reste, trompeuses. Très souvent, le pays tiers agit comme miroir (inversé) de la (bonne) Suisse, tel l'engagement britannique au Transvaal en $1902^{384}$. Le Nebelspalter ne perd pas tout appétit festif mais le réserve aux occasions spéciales, comme le carnaval. Il est fortement concurrencé par le motif du journal de papier qui tend à prendre une véritable dimension allégorique. Le phénomène est patent à l'occasion de l'exposition universelle, où c'est au journal que s'adresse le protagoniste de l'image ${ }^{385}$; il n'est néanmoins que le résultat d'une évolution amorcée dès le début des années I 890 , alors qu'une couverture de I 899 posait déjà explicitement l'équivalence entre les deux modes de présence ${ }^{386}$.

\subsubsection{Du Heimatstil en couverture - Le Jugendstil helvétique}

L'occurrence mensuelle des couvertures imagées se confirme en I904. Jusqu'en I903, Lehmann-Schramm et Boscovits junior créent à peu près le même nombre de couvertures, tandis que Boscovits senior en fournit une de temps à autre, à l'occasion de la mort de Jean Nötzli, en I900 ${ }^{387}$, ou lorsqu'il veut s'essayer à la figuration d'une élégante ${ }^{388}$. La plasticité graphique de Boscovits junior aidant, ses couvertures ne diffèrent que très peu de celles de Lehmann-Schramm, sauf dans l'intégration, à deux reprises, du japonisme, très probablement d'après le modèle de la revue Jugend ${ }^{389}$. Boscovits compose dans deux registres différents, une caricature politique et une célébration de la chasse, une image à trois registres, formant des séquences narratives isolées ${ }^{390}$. À partir du début 1903 , et conformément à la suprématie qu'il exerce sur son collègue allemand ${ }^{391}$, Boscovits junior devient le fournisseur exclusif des couvertures Jugendstil. Le processus d'appropriation se poursuit selon trois directions: une attention particulière portée à la caricature politique; un travail général sur le Jugendstil qui continue d'être "helvétisé "; ainsi que l'autonomisation

\footnotetext{
Nebelspalter 1900/4, couverture de W. Lehamm-Schramm.

382 Nebelspalter 1901/1, double-page de Boscovits senior intitulée «Entrée » (Einzug).

${ }^{383}$ Nebelspalter 1904/52, dessin de Boscovits junior intitulé « Vive l'auto! » (Aut Heil!).

${ }^{384}$ Nebelspalter 1902/35, dessin pleine page de Boscovits junior intitulé « Culture moderne » (Moderne Kultur).

385 Nebelspalter 1900/10, dessin pleine page de Boscovits senior intitulé « Exposition de bétail à Paris » (Viehausstellung in Paris); cf. aussi « 4.2. Rendre compte des expositions et régler ses comptes via les expositions ».

Nebelspalter 1899/39, couverture de Boscovits junior.

Nebelspalter 1900/17, couverture de Boscovits senior.

${ }_{388}$ Nebelspalter 1902/6, couverture de Boscovits senior.

${ }^{389}$ La revue Jugend est l'un des lieux en Allemagne où s'exerce la réception très contrariée du symbolisme; Laurence Danguy, L'ange de la jeunesse - La revue Jugend et le Jugendstil à Munich, op. cit., p. 131-141.

390 Nebelspalter 1901/44, couverture de Boscovits junior; Nebelspalter 1903/48, couverture de Boscovits junior.

391 Cf. « 1.3. La domination Boscovits ».
}

d'un Heimatstil, que l'on peut à proprement parler qualifier d'helvétique.

L'année I900 s'ouvre ainsi avec une couverture d'un genre nouveau, une caricature de la scène politique internationale. Le Chronos aux ailes géantes, dessiné par Lehmann-Schramm, fait office de sculpteur: il enfonce des figurines dans un globe. La couverture est légendée, ce qui est rarement le cas: "La terre ne cesse de tourner, pourtant le travail ne s'arrête jamais » ${ }^{392}$. Cette orientation n'est pas vraiment confirmée, avec seulement quatre occurrences jusqu'en I904, alors que cette année-là, la série des signes du zodiaque livre quelques exemplaires fameux du genre. Parmi ceux-ci, une image très goûteuse, d'inspiration idiomatique, présente un Zurichois tondu comme un mouton, une fois ses impôts payés ${ }^{393}$ (cf. fig. 48).

Ce type d'images ouvre sur les créations esthétiquement les plus intéressantes.

La deuxième tendance prolonge l'entreprise d'acculturation du Jugendstil, entamée les années précédentes. Pour une bonne part, il s'agit d'adapter des modèles de la revue Jugend, comme une couverture de Boscovits junior au printemps I900. S'inspirant d'une parodie symboliste, le dessinateur trace d'un trait fin et sinueux un galant se déclarant à sa belle. À l'arrière-plan, ces quelques lignes, mêlant titre, légende et message publicitaire: « NEBELSPALTER. IL FAUT BIEN QUE LE PRINTEMPS ARRIVE. Der Nebelspalter 3 Fr. par semestre » ${ }^{394}$. Comme souvent lors des transferts artistiques, une partie sémantique est perdue, ici, la critique pourtant sévère du symbolisme dans Jugend ${ }^{395}$. Ce type de transposition est légion et prend autant de formes qu'il y a de modèles. L'introduction de la composante vitaliste ainsi que le travail sur l'allégorie sont deux tendances fortes. Courant I900, Boscovits junior entame une série de couvertures sur les mois de l'année et les saisons, qu'il thématise au travers de figures féminines s'éloignant de l'allégorie. La Suisse s'incarne, ici, en une jeune paysanne représentant l'été ${ }^{396}$; là, en une femme militaire très séduisante ${ }^{397}$ (cf. fig. 49 cahier couleur). À la toute fin I90I, la série devient régulière. D'une image à l'autre, le modèle féminin est souvent le même, très probablement l'épouse de l'artiste, Lily. C'est essentiellement dans ce genre que s'observe une influence viennoise, perceptible dans des ornements géométriques et un rendu hiératique des figures ${ }^{398}$ (cf. fig. 44). À partir de I906, un certain érotisme pointe, lorsqu'une demi-mondaine fume en têteà-tête avec un homme d'âge mur en costume, formant ce brouillard que chaque numéro du Nebelspalter doit dissiper ${ }^{399}$.

En I90I, débute une autre phase. Du Jugendstil, n’est conservé que le principe d'une couverture illustrée, en couleur et changeante, ainsi que celui d'un titre ornemental. Les pages présentent des motifs helvétiques, figures, décors naturels ou architecturaux, dans des mises en scène, des cadrages et des couleurs très conventionnels.

\footnotetext{
(Und immer gehet die Erde den Lauf, Doch höret die Arbeit niemals auf!) Nebelspalter 1900/4, couverture de W. Lehmann-Schramm.

393 Nebelspalter $1904 / 13$, couverture non signée.

394 «NEBELSPALTER. ES MUSS DOCH FrÜHLING WERDEN. Der Nebelspalter per. Quartal 3 Frs »; Nebelspalter 1900/13, couverture de Boscovits junior.

5 Laurence Danguy, L'ange de la jeunesse - La revue Jugend et le Jugendstil à Munich, op. cit., p. 131-141; cf. aussi « 5.1. Le Nebelspalter, la caricature et les revues illustrées européennes ».

396 Nebelspalter 1902/28, couverture de Boscovits junior.

Nebelspalter 1902/37, couverture de Boscovits junior.

Nebelspalter 1901/1, couverture de W. Lehmann-Schramm.

Nebelspalter 1906/4, couverture de Boscovits junior.
} 
Zürich,1904. XXX.Jahrgang № 13.

26. März .

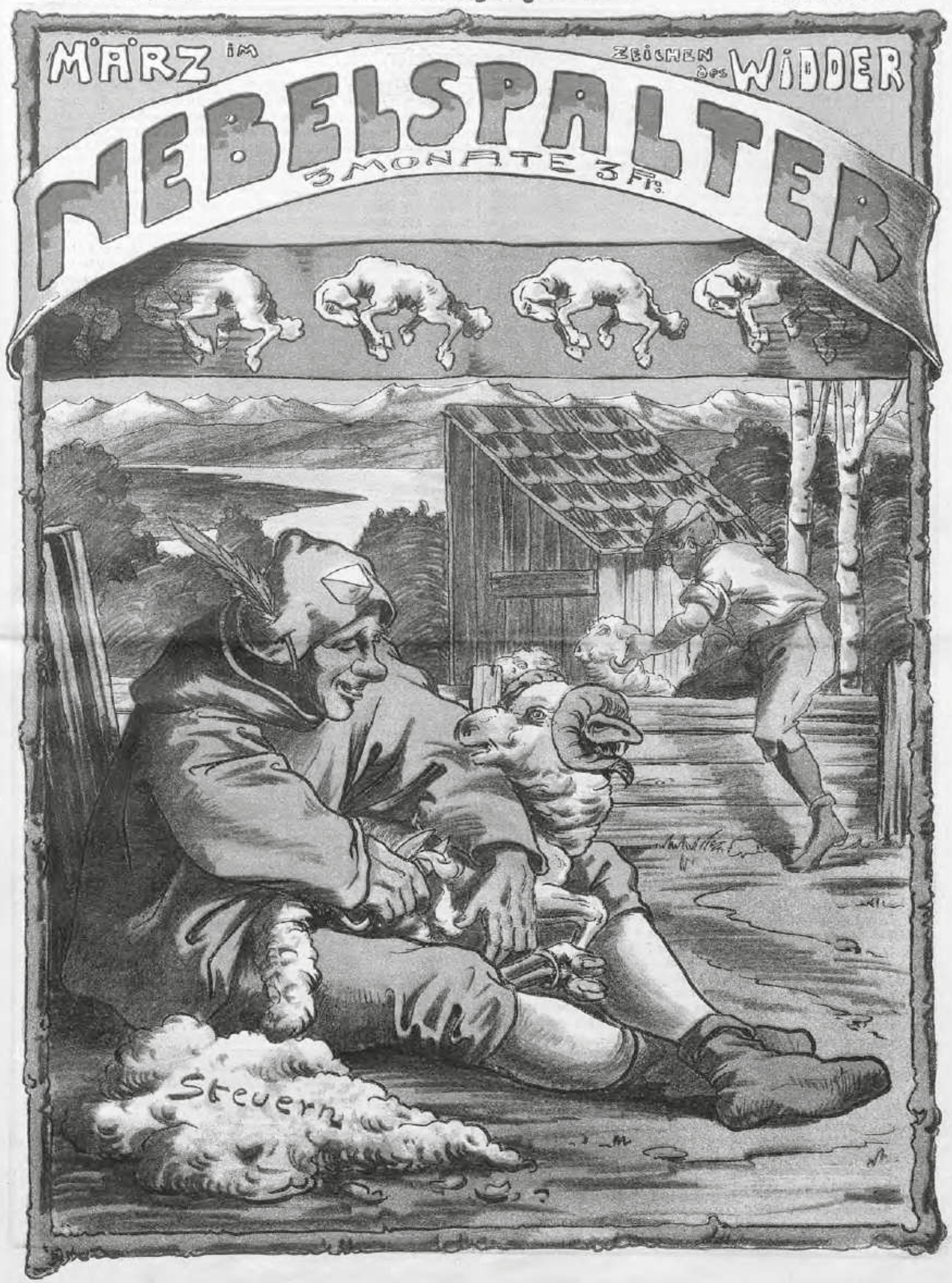

Fig. 48. Nebelspalter 1904/13, couverture en couleur non signée. 
Un couple de paysans tire ainsi son chapeau au spectateur devant un paysage alpin. À leurs pieds, se trouve un écu aux armoiries suisses. L'inscription " Nebel-spalter» (brouillard-fendre) est séparée non par un tiret mais par une cible de tir, un signet visuel helvétique ${ }^{400}$ (cf. fig. 50 cahier couleur). Parfois, l'image illustre un texte versifié. À l'été I 902, un dessin très Heimatstil de LehmannSchramm montre un jeune homme bien mis, prenant congé de sa dulcinée devant un paysage montagneux. L'image illustre un poème de Ernst Meyer-Leibstadt de la même tonalité, une version suisse des poésies Jugendstil, un ode à l'helvétisme, pour ainsi dire.

\subsubsection{Les aléas de la couleur}

En ce qui concerne la couleur, comme pour d'autres aspects, les changements sont discrets, pour ne pas dire timorés, et le plus important d'entre eux consiste en l'installation, à la fin de l'année I90I, de numéros en couleur présentant une conception vraiment unitaire. À partir de ce moment, un numéro comprend une couverture, une double-page et une dernière page, partageant la même gamme chromatique, alors que les pages intérieures intègrent souvent une couleur supplémentaire. Cette conception très maîtrisée de la maquette implique une coloration postérieure des dessins, au moment de la fabrication du journal. Il est en effet très improbable que les dessinateurs aient reçu en amont des consignes sur les couleurs. Dans un premier temps, le principe ne souffre que de très rares exceptions; à partir de 1906, cependant, s'observe le retour à une conception semi-unitaire. La présence de la couleur s'accroît et les combinaisons se diversifient. Alors qu'en I900 et I90I, les compositions à trois et cinq couleurs cohabitent avec le noir et blanc augmenté d'une ou deux couleurs, les couvertures de l'année I902 innovent, avec une bichromie en dégradé, telle une déclinaison de bleu et vert-de-gris pour le numéro 47, célébrant le mois de novembre ${ }^{401}$. Le noir et blanc à deux couleurs est traité parfois très finement, comme dans le numéro 37, se fermant par un hommage au sud-africain Paul Kruger ${ }^{402}$ (cf. fig. 39). En I 903, des essais de couleur dans les pages publicitaires sont effectués, qui vont se poursuivre plusieurs années.

Le rouge, associé aux pertes humaines des conflits au Transvaal, prend cette même année 1903 une connotation sanguinaire qui sera reprise durant la Première Guerre mondiale. Il est, plus généralement, à la base des expérimentations les plus audacieuses, combiné au noir et blanc et associé au jaune et/ou au bleu. Les compositions à cinq, quelquefois six couleurs, sont généralement liées à un thème traditionnel, presque toujours suisse. Ceci amène à penser que cette combinaison multicolore est très prisée du public ${ }^{403}$.

De nouvelles teintes apparaissent, tels l'anis, le rose pâle, le gris plomb et le mauve; leur mode d'application varie, en aplats, au trait, en dégradés ou en fondus. La bichromie, rare durant toute cette période, absente même en I90I, I903 et I905, est très largement supplantée par le noir et blanc. Celui-ci est réservé à des thèmes moins consensuels, et, de plus en plus, traité comme la couleur, avec des effets de contraste. À partir de I904, il prend place dans des formules bichromes, présentes sous deux versions, en superposition de couleurs ou en dégradé. Il arrive que celles-ci

${ }_{400}$ Nebelspalter 1901/27, couverture de W. Lehmann-Schramm.

401 Nebelspalter 1902/47, couverture de Boscovits junior.

${ }_{402}$ Nebelspalter 1902/37, couverture de Boscovits junior.

${ }_{403}$ Nebelspalter 1903/44, dessin pleine page de W. Lehmann-Schramm intitulé « Le virus de l'impôt au travail » (Der Steuerbazillus an der Arbeit). comportent une couleur supplémentaire, en général le rouge. Associé à une, deux, voire trois couleurs, le noir et blanc génère des compositions esthétiquement fortes, qui ne se confondent pas avec celles à trois ou cinq couleurs, où le noir n'est présent que pour assurer un cerne et le blanc pour signifier un espace ${ }^{404}$.

\subsection{7-1912: remous, hésitations et révisions}

Dans l'histoire du Nebelspalter, l'année 1907 marque un tournant aussi décisif que l'année i 887 . Il ne s'agit cependant plus d'ouvrir mais de recadrer une formule éditoriale, enkystée sur le plan visuel comme sur celui des idées. Le changement correspond à l'arrivée d'Alfred Beetschen, associé pour la deuxième fois à la conception du Nebelspalter, cette fois non plus avec Jean Nötzli (I895-I 897) mais avec Boscovits senior, et ceci jusqu'à la fin I 9I 2. La disparition durant cette période des icones qui rythment la maquette depuis de nombreuses années et sont devenues bien veillottes est tout aussi marquante que le passage (enfin) définitif à la couleur. L'heure est à un retour au texte, expliquant la disparition des couvertures Jugendstil, donnant la primauté à l'image. Désormais, les couvertures font la part belle à des caricatures longuement légendées, dont l'entendement est moins immédiat. Les choses ont été fermement prises en mains jusque dans la politique commerciale. Comme souvent, les informations sur le public sont maigres, le corpus laissant transparaitre un lectorat mixte, plutôt progressiste et relativement jeune.

\subsubsection{Identité, maquette et technique - Le temps de la refonte}

En I907, la maquette est l'objet d'une série de changements, occasionnant une forte impression d'hétérogénéité, également nourrie, il est vrai, par le graphisme de nouveaux dessinateurs. Le plus visible d'entre eux consiste dans les remaniements de la couverture mais la quasi-totalité de la maquette est concernée. Seuls le titre et le nombre de pages, régulièrement de huit et exceptionnellement de six, dix ou douze, restent identiques. Même le bandeau subit une mue en I9 Io, avec une nouvelle présentation des informations commerciales.

L'arrivée d'Alfred Beetschen coïncide avec une relégation de l'image à une fonction essentiellement illustrative. Cette priorité donnée au texte génère une révision du lien entre image et texte. De nombreux dessins sont pourvus de longues légendes, dont il faut prendre connaissance pour l'entendement adéquat des caricatures. Titres et légendes sont, en outre, émaillés de citations. À la fin I9I2, après l'arrivée de Rudolf Huber et Fritz Ebersold à la rédaction, le nom du dessinateur est mentionné au-dessus de l'image. Les icones, qui accompagnaient les rubriques depuis des décennies, disparaissent au cours de l'année 1907.

L'absence de cadre tend à devenir la règle, même si de nombreuses pages intérieures sont encore enserrées dans un cadre tiré au trait, et que les expériences sur le cadre se poursuivent. En I908, les personnages tentent à plusieurs reprises de s'en affranchir

\footnotetext{
${ }^{404}$ Nebelspalter 1904/26, dessin pleine page de W. Lehmann-Schramm intitulé « Les
} victimes » (Die Opfer). 
«physiquement ", le poussant avec leur ventre ${ }^{405}$, du doigt ${ }^{406} \mathrm{Ou}$ l'empoignant carrément de leurs mains ${ }^{407}$. Certaines images sont, du reste, assez fameuses, telle une caricature de I909 intitulée "L'opinion suisse" (Schweizermeinung) sur l'identité du découvreur du pôle nord. Un bon Suisse - un type costaud avec un chapeau mou et un jeu de Jass - attrape du fond de l'image le cadre de la scène, où Frederick Cook et Robert Peary s'empoignent ${ }^{408}$ (cf. fig. 5 I cahier couleur). En I9I 2, un policier repousse le cadre de la couverture montrant la visite de Guillaume II ${ }^{409}$.

Sous la houlette de Boscovits junior, une nouvelle organisation visuelle apparaît, début I907. La typographie devient plus aérée, intègre de nouveaux ornements, et les dessins sont manifestement ajustés au texte ${ }^{410}$. Les caricatures de mœurs sont de petite taille et munies d'un titre bref. À partir du numéro I7, divers essais d'organisation typographique se succèdent. À la fin I9I2, après le changement rédactionnel, la typographie des pages 5 et 6 est à nouveau revue, modifiant substantiellement l'aspect de la maquette ${ }^{411}$.

Les doubles-pages connaissent une baisse drastique. De onze occurrences pour les années I 905 et I906, elles passent à trois en I907. Hormis en I904, où elles sont au nombre de quatre, elles ne dépassent jamais ce chiffre, devenant même uniques en I9Io, I9I I et I9I2.

\subsubsection{Distribution, politique commerciale et lectorat - Recadrage}

La fin de l'année I907 dénote un recadrage de la politique commerciale, postérieur cependant au changement de rédaction, avec notamment une unification tarifaire ${ }^{412}$. Un prix unique de 30 cts. vaut pour tous les numéros, désormais en couleur, ainsi que pour les annonces, quel qu'en soit le commanditaire. Les réclames restent à I Fr. la ligne. Les prix de l'abonnement sont revus, passant de 3 Fr. à 3,50 Fr. pour trois mois, 5,5 Fr. à 6 Fr. pour six mois et Io Fr. à I I Fr. pour un an. Il n'est plus question d'un abonnement pour l'étranger. Les informations sont réduites, le nom de l'imprimeur disparaît; il réapparaît en I9Io, à l'occasion de la modification typographique du bandeau; ceci, de même que le tarif de 50 cts. pour les annonceurs étrangers et le nom de l'agent, Rudolf Mosse ${ }^{413}$.

Les numéros spéciaux sont exceptionnels et ne participent pas à l'argumentaire commercial. Ils ne sont à vrai dire présents qu'en I9 I 2, à l'occasion de la visite de Guillaume II en Suisse et du Congrès de Bâle, une conférence de paix organisée à l'initiative du parti socialiste ${ }^{414}$. Les encarts publiés par le Nebelspalter sont rares et même complètement absents en I908 et I9Io. Jusqu'en I9I 2, ils ne présentent aucun renouvellement rhétorique. Cette

\footnotetext{
Nebelspalter 1908/16, dessin pleine page de Boscovits junior intitulé «Bon conseil » (Guter Rat).

406 Nebelspalter 1908/45, dessin pleine page de Boscovits junior intitulé «Au temps du vol aérien » (Im Zeitalter des Fliegens).

407 Nebelspalter 1908/40, dessin pleine page signé d'un monogramme intitulé « Artiste en voyage » (Fahrende Künstler).

408 Nebelspalter 1909/38, dessin pleine page de Boscovits junior intitulé « Opinion suisse » (Schweizermeinung).

409 Nebelspalter 1912/36, couverture non signée intitulée « Comment on se mobilisa pour recevoir l'empereur » (Wie für den Kaiserempfang mobilisiert wurde).

Nebelspalter $1907 / 14$

Nebelspalter 1912/49.

Nebelspalter 1907/14 et Nebelspalter 1907/15.

Nebelspalter 1910/14.

Nebelspalter 1912/35 et Nebelspalter 1912/47.
}

année-là, les zurichois sont invités à participer à un appel d'offres pour fêter l'expansion de la ville qui atteint 200000 habitants ${ }^{415}$.

L'innovation réside dans la forme. En I907, le passage à la couleur est l'objet d'un poème et la photographie s'invite dans la publicité, avec une réclame pour une fabrique de meubles lucernoise ${ }^{416}$. L'année marque, du reste, un tournant avec une augmentation sensible du volume publicitaire et la publication régulière de publicités esthétisées. Celles-ci concernent des boissons alcoolisées, dont le champagne Strub et des produits de santé, tels le fortifiant Amol et la lotion dentaire Odol, trois produits générant des campagnes publicitaires importantes dans la presse germanique. Ces publicités sont d'ailleurs signées: celles pour les vins sans alcool de Meilen portent les signatures des Boscovits senior ${ }^{417}$ et junior ${ }^{418}$. L'année I9 I I s'avère faste: la marque Amol offre un festival d'encarts, qui agissent comme des affiches et s'appuient sur les clichés de l'époque, des petites filles modèles aux sauvages africains, tandis qu'Odol est l'objet d'une caricature de Boscovits junior, dans laquelle deux personnalités de la scène bernoise confrontent leur points de vue ${ }^{419}$.

Les spiritueux, produits d'hygiène et de santé, les recueils de conseils intimes à destination des couples et des femmes sont alors très présents parmi les publicités, laissant entrevoir un lectorat mixte, plutôt progressiste et relativement jeune. Aucune conclusion ne peut, par contre, être tirée de la mention d'une reliure à 3500 exemplaires dans un encart de I909, puisque celui-ci était déjà présent en I906, si ce n'est une vente moins heureuse que prévue.

\subsubsection{Durcissement de tendance et primauté à la politique}

Un des changements majeurs concerne la tendance qui devient nettement plus patriote. Le positionnement est plus national que zurichois, avec une très faible présence, toutefois, de la Suisse romande et du Tessin. Ce changement se produit, en fait, en direction de la Suisse au sens du territoire et de l'identité nationale. Le Nebelspalter flirte alors avec le nationalisme, sensible au travers des débats autour du référendum sur la nouvelle organisation militaire de 1907, de la très forte présence d'Helvetia mais également avec l'abandon des tableaux synthétiques mêlant la Suisse au reste monde. Parallèlement, l'usage du dialecte augmente, parfois même dans des dessins qui ne sont pas liés à la Suisse. En I9I 2, une caricature oppose ainsi un ivrogne parlant en dialecte à un bourgeois hautain parlant le haut-allemand (Hochdeutsch $)^{420}$. Confrontant une figure fétiche du journal (l'ivrogne) à son repoussoir originel (le bourgeois conservateur), la composition affiche un choix identitaire qui passe par l'option linguistique, puisque l'on parlait alors le haut-allemand dans les milieux bourgeois afin de se distinguer du peuple. Jusqu'en I9 I I, l'antisémitisme est assez peu présent et essentiellement en relation avec la capitalisation du réseau ferré suisse, selon l'équation « juif = capitaux ". On observe ensuite le retour d'un antisémitisme " ordinaire ", avec une sévère accentuation en I9 I 2, ainsi que celui de l'anticléricalisme, revivifié exactement à la même époque. Cet anticléricalisme se montre sous trois visages : un frein au progrès;

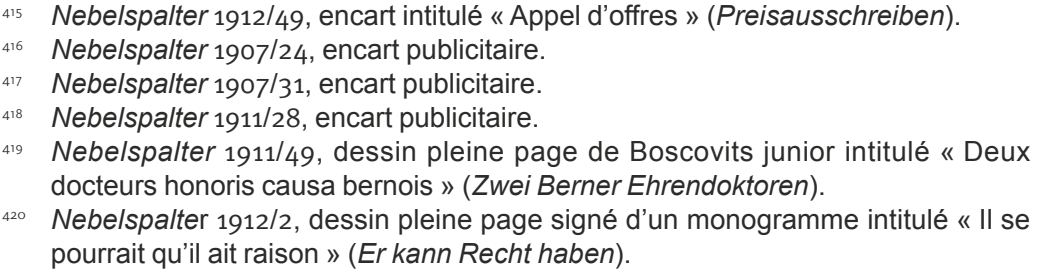

419 Nebelspalter 1911/49, dessin pleine page de Boscovits junior intitulé « Deux docteurs honoris causa bernois " (Zwei Berner Ehrendoktoren).

420 Nebelspalter 1912/2, dessin pleine page signé d'un monogramme intitulé « II se pourrait qu'il ait raison » (Er kann Recht haben). 


\section{Romm' ich beute nicht so komm' ich morgen.}

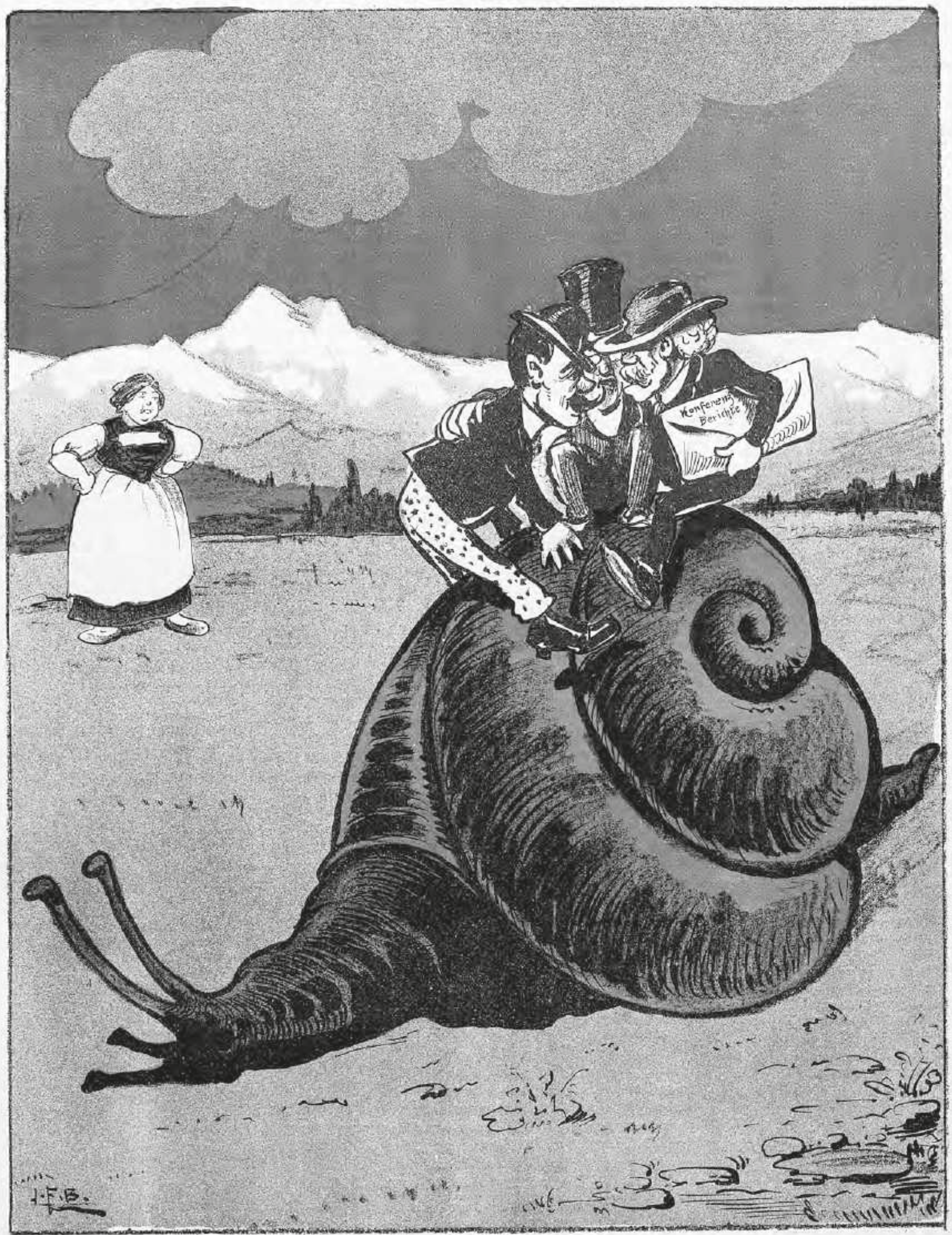

Die internationale Gotthardkonferenz ift auch heute zu keinem beitimmten Ergebnis gelangt.

Fig. 53. Nebelspalter 1909/17, dessin pleine page en couleur de Boscovits senior

intitulé « Si ce n'est pas pour aujourd'hui, c'est pour demain » (Komm'ich heute nicht so komm' ich morgen). 
une critique constante de l'autorité papale; un danger politique redoutable, comme lorsqu'un moine, représentant masqué du parti (allemand) du Centre, poignarde dans le dos le chancelier Bernhard von Bülow, à la veille de la démission de celui-ci dans le cadre de l'affaire du Daily Telegraph ${ }^{421}$ (cf. fig. 52 cahier couleur).

Les thèmes politiques dominent, tandis que certaines questions sociétales, liées à la Suisse, acquièrent une visibilité importante. Alors que le regard sur l'étranger est critique, celui sur les affaires intérieures est beaucoup moins sévère et plutôt conservateur. De nombreux thèmes des décennies précédentes sont réactualisés, les affaires militaires, dont la très discutée loi militaire de I907, défendue par le Nebelspalter ${ }^{422}$; celles législatives, notamment la création du code civil en I907; la capitalisation du réseau ferré; les accords commerciaux; les élections fédérales et locales, dont celles zurichoises, toujours très discutées; le mode de scrutin avec la question toujours présente de la proportionnelle; les questions d'urbanisation; la politique culturelle, dont le financement des théâtres zurichois; le financement du Gothard, notamment à l'occasion des négociations précédant la conférence internationale de $1909^{423}$. Helvetia s'indigne de la lenteur de l'escargot suisse sur lequel sont perchés les trois négociateurs du rachat de la ligne du Gothard par la Confédération ${ }^{424}$ (cf. fig. 53).

D'autres questions sont dictées par l'actualité : l'assurancemaladie; la législation sur l'alcool; les organes de protection des monuments, de la nature et des animaux, respectivement le Heimatschutz, le Naturschutz et le Tierschutz ${ }^{425}$; les débats sur l'immigration, des Calabrais et des Allemands, notamment. Une citoyenneté accordée de manière sélective, et, en tout cas, refusée aux agitateurs politiques est prônée ${ }^{426}$.

Certains personnages sont sous les feux de la rampe, l'écrivain Carl Spitteler, le pédagogue Johann Pestalozzi, le politicien Ludwig Forrer, le dramaturge Franz Wedekind, le fondateur de la Croix-Rouge, Henri Dunant, Ernst Laur, chef de l'Union suisse des paysans, Eugen Huber, auteur du code civil suisse ou encore le prix Nobel de physiologie en I909, Emil Theodor Kocher.

La quasi-disparition des thèmes festifs, carnaval et Sechseläuten, est sans doute l'un des éléments les plus frappants. Les questions artistiques deviennent marginales. La modernité occupe une place discrète et plutôt négative. La ville est du reste moins présente. C'en est fini des visions idylliques qui avaient marqué les années Jugendstil ${ }^{427}$. L'un des modes les plus intéressants de la visibilité urbaine est maintenant le café littéraire ${ }^{428}$ (cf. fig. 54).

Une critique sociale, opposant l'opulence des riches à la misère des pauvres, s'exprime, comme dans «La fraicheur de l'été chez

Nebelspalter 1909/28, dessin pleine page d'Emil Huber intitulé « Sic transit gloria mundi »; numéro du 10 juillet 1909.

2 À ce sujet: Jean-Jacques Langendorf et Pierre Streit, Face à la guerre. L'armée et le peuple suisses 1914-1918/1939-1945, Gollion, Infolio, 2007, p. 52-66.

«3 Gard Benz, "Gothard, convention du », Dictionnaire historique de la Suisse (06/12/2005); http://www.hls-dhs-dss.ch/textes/f/F17251.php.

4 Nebelspalter 1909/17, dessin pleine page de Boscovits senior intitulé « Si ce n'est pas pour aujourd'hui, c'est pour demain » (Komm'ich heute nicht so komm' ich morgen)

425 Nebelspalter 1910/41, couverture de Boscovits senior intitulée « Une Triplice suisse » (Ein Schweizer Dreibund).

Nebelspalter 1910/38, dessin pleine page de Boscovits senior intitulé « Sur la naturalisation facilitée » (Zur Erleichterten Einbürgerung).

Cf. « 3.2.3. Chronique visuelle d'une ville: Zurich».

Nebelspalter 1911/14, dessin pleine page signé « H M » intitulé « Au café littéraire » (Im Literaten-Café). le pauvre et chez le riche " (Sommerfrische bei Arm und Reich) de Willy-Lehmann-Schramm ${ }^{429}$. La mode, les loisirs et le tourisme mais également les affaires culturelles gagnent des pages ${ }^{430}$. Sous l'influence des revues allemandes, le thème estudiantin apparait, tandis que l'armée est présentée avec une ironie parfois crasse, comme lorsqu'un lieutenant s'adressant à ses soldats en chemise est félicité pour avoir pensé au désarmement ${ }^{431}$ (cf. fig. 55).

La dénonciation des dangers bolchevique, socialiste et anarchiste, mis sur le même plan, s'apparente à un leitmotiv. Les activités de l'Allemand August Bebel et du Suisse Hermann Greulich sont, en tant que menaces les plus proches, examinées à la loupe.

La critique des affaires internationales est acide. Les alliances continuent d'être scrutées, d'autant que le risque de guerre en Europe inquiète, qui se voit confirmé avec la première guerre balkanique (I9I2-I9I3). Dès I907, la course aux armements est l'objet d'une attention soutenue. «Le pacifique Michel » observe ainsi, les poings sur les hanches, les représentants de la France, du Japon, de l'Angleterre et de l'Espagne, avancer sur un canasson, tels de nouveaux Don Quichotte ${ }^{432}$. En I9I I, même si le ton est toujours goguenard, les recherches d'alliance des uns et des autres sont suivies par un Mars doté de grosses jumelles ${ }^{433}$. Dans cette constellation, l'Allemagne, la France et la Russie sont les pays les plus représentés, suivis par l'Angleterre, les États-Unis, le Maroc, et, plus ponctuellement, la Belgique, le Portugal, la Bulgarie, l'Autriche-Hongrie, la Serbie, la Perse, la Bosnie-Herzégovine (officiellement annexée par l'Autriche-Hongrie en I908), l'Espagne et la Chine. D'autres pays et régions politiques font une apparition fugitive: le Japon, la Hongrie, la Hollande, la Grèce, le Danemark, le Congo, la Crète, le Monténégro, la Mandchourie et l'Albanie.

L'Allemagne, avec son omniprésent et omnipotent Guillaume II, est en position de champion avec deux points d'orgue, la visite officielle de l'empereur en I9 I 2 et l'affaire Eulenburg-Harden. Le traitement de la venue de Guillaume II en I9 2 reflète l'émoi causé par la visite de l'empereur du 3 au 6 septembre I9 2 à Zurich, Berne et Bâle. L'enthousiasme est à son apogée à Zurich, où la colonie allemande représente 21,2\% de la population ${ }^{434}$. Le Nebelspalter consacre à la visite (avant, pendant et après), de nombreuses compositions, jusqu'à un numéro spécial, dont la couverture, fait frappant, est l'une des moins réussies de tout le corpus ${ }^{435}$. Tous les personnages de la composition, président de la Confédération compris, sont ridicules avec leur corps exagéré et figé, et une foule que peine à restituer le dessinateur. Il est vrai que le sujet se prête difficilement à l'ambivalence avec laquelle est d'ordinaire croquée la figure impériale. Quant à l'affaire Eulenburg-Harden, l'un des scandales de l'Allemagne wilhelminienne, elle est à l'origine de huit

429 Nebelspalter 1907/33, dessin pleine page de W. Lehmann-Schramm intitulé La Fraicheur de l'été chez le pauvre et chez le riche » (Sommerfrische bei Arm und Reich).

430 Sur les loisirs en tant que phénomène historique, voir ; Alain Corbin et alii, L'avènement des loisirs (1850-1960), Paris, Aubier, 1996.

${ }_{431}$ Nebelspalter 1911/33, dessin pleine page de Boscovits junior intitulé « En provenance de l'école militaire de Herisau » (Aus der Rekrutenschule in Herisau). 42 Nebelspalter 1907/15, dessin pleine page de W. Lehmann-Schramm intitulé « Le Michel pacifique » (Der Friedliche Michel).

${ }_{433}$ Nebelspalter 1911/37, dessin pleine page non signé intitulé « Perspectives pacifiques » (Friedliche Aussichten).

${ }_{434}$ Philippe Kaenel, « Suisse-Allemagne (1848-1918): identités et neutralité du point de vue de la caricature », Revue suisse d'art et d'archéologie, volume 60, 2003, p. 99-112.

435 Nebelspalter 1912/35, couverture de Boscvits senior intitulée «Apparition du souverain » (Einzug der Souveräne). 


\section{Im Literaten-Café.}

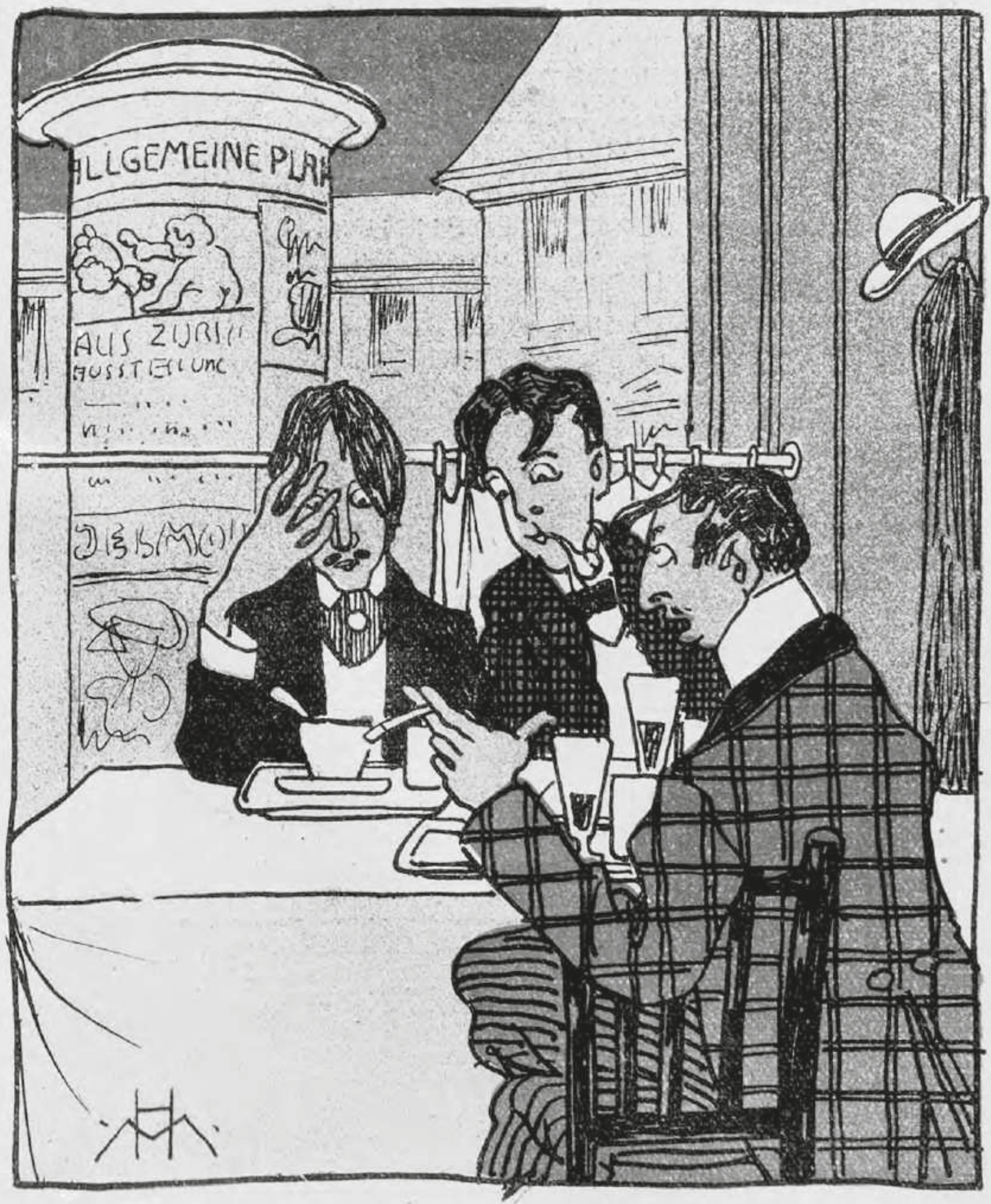

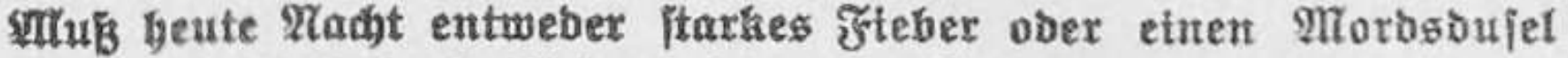
geyabt yaben! 'Träum' id vou Subermann uno bab' midy mit bem Rexl ganz gut unterhatten? 
Hus der Rekruteníchule in Gerisau.

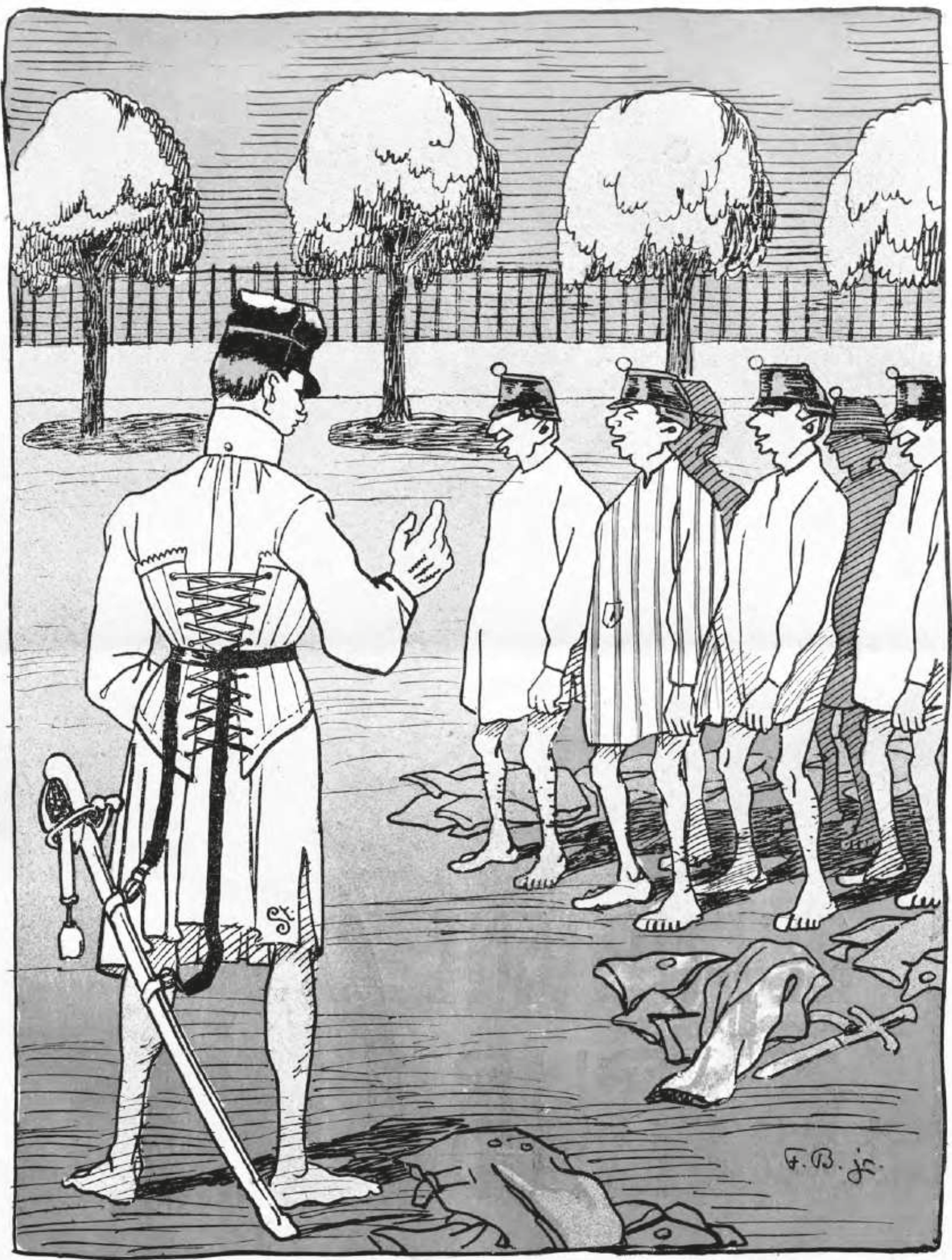

Bravo, Бerr Leutnant! Endlid einmal einer, der ans Abrüsten denkt.

Fig. 55. Nebelspalter 1911/33, dessin pleine page en couleur de Boscovits junior intitulé «En provenance de l'école militaire de Herisau » (Aus der Rekrutenschule in Herisau). 
compositions en l'espace d'un an, espacées entre le 2 novembre I907 et le 7 novembre I908. La première est signée de Boscovits senior, tandis que la dernière, une simple demi-page, est anonyme; son format montre que l'affaire retombe ${ }^{436}$. À la différence des caricatures françaises, où l'affaire est prétexte au dévoilement d'autres affaires de mœurs, les caricatures du Nebelspalter s'en tiennent au séisme provoqué par les révélations en cascade, selon lesquelles l'entourage de l'empereur serait homosexuel, notamment son conseiller, le Prince Eulenburg ${ }^{437}$. Elles mettent également en avant le polémiste Maximilian Harden, instigateur du scandale, comme dans "Le théâtre berlinois " (BerlinerTheater), parodie de ce qui est vu comme un tapage. Eulenburg, dessiné en empereur, interpelle Harden: "Le fils au père; veux-tu donc vivre éternellement ? ${ }^{438}$ (cf. fig. 56).

Les appétits coloniaux sont toujours critiqués. La France, l'Allemagne et l'Italie sont dénoncées en I9 I c comme les bouchers de l'Afrique ${ }^{439}$, tandis que la guerre italo-turque (I9 I II9I2) est rapportée de manière peu amène. Certains événements tragiques, tel le séisme de Messine en I908, donnent lieu à des images pathétiques, plutôt rares dans la revue ${ }^{440}$ (cf. fig. 57 cahier couleur).

\subsubsection{Rhétorique - On monte le ton}

Différents types d'humour cohabitent, l'humour gentillet, l'humour grivois, celui plus grinçant de la satire politique. En I909, le ton se durcit avec l'apparition d'un humour cynique et l'exacerbation des grivoiseries. Ces différents humours font appel à des procédés rhétoriques différents, certains anciens, d'autres nouveaux, transparaissant dans les titres des compositions. La série des « Courageux » (Gemütsmenschen), commencée en I 906 et s'achevant en I9 I I, revient, tout comme celle des « Anomalies zoologiques »(Zoologische Abnormitäten).

Des titres anciens reviennent sans pour autant entrer dans une logique sérielle, la " Nouvelle illustrée des journaux » (illustrierte Zeitungs-Notiz), "Sur la dernière mode »(Zur neuesten Mode), «Les images de la saison » (Saisonbilder), «D'après un modèle connu » (Nach berühmten Müster), les variations autour du thème de l'éducation (Kinderstube) ou du cirque international (Zirkus international). D'autres sont nouveaux, comme "Linge sale» (Schmützige Wäsche) ou encore « Entre médecins » (Ärtze unter sich). L'un d'eux, «Dans la rue » (Auf der Strasse) reflète une nouvelle inflexion sociétale. Quelques titres renouvellent simplement le genre, tels ceux animaliers, très goûtés, autour de la «Philosophie animale» (Tierphilosophie). Les compositions de mœurs ont des titres en relation, "Toujours honnête " (Nur immer ehrlich), "Impossible » (Unmöglich) ou encore « Eh bien, eh bien? » (So, so?).

${ }^{436}$ Respectivement: Nebelspalter 1907/44, dessin pleine page de Boscovits senior intitulé « Des fantômes en plein soleil » (Gespenster im Sonnenschein); Nebelspalter 1908/45, dessin non signé intitulé « Le paratonnerre »(Der Blitzableiter).

${ }^{437}$ Sur l'affaire Eulenburg-Harden: Norman Domeier, Der Eulenburg-Skandal: eine politische Kulturgeschichte des Kaiserreichs, Francfort-sur-le-Main, Campus 2010; Norman Domeier, Gewinner und Verlierer: Beiträge zur Geschichte der Homosexualität in Deutschland im 20. Jahrhundert, Göttingen, Wallstein, 2015.

${ }_{438}$ "Der Filius zum Fili : "Willst Du denn ewig leben?" »; Nebelspalter 1908/29, dessin peine page signé «G. St. » intitulé « Théâtre berlinois » (Berliner-Theater).

439 Nebelspalter 1911/40, dessin non signé intitulé «Les bouchers africains ou la nouvelle histoire du monde » (Die afrikanischen Metzger oder die neuste Weltgeschichte).

${ }_{440}$ Nebelspalter 1909/2, dessin pleine page de Boscovits senior intitulé « Au-delà du Gothard » (Jenseits des Gotthard).
Titres mais surtout légendes multiplient des références servant à créer une connivence entre gens de bonne éducation. Aux côtés de Goethe, Gottfried Keller, Richard Wagner, Georg Büchmann, Dante, Heinrich Heine, Joseph Haydn, prennent désormais place des écrivains vivants, tels que Tolstoï et Hermann Sudermann, tandis que dans le domaine de l'art, Millet côtoie la Vénus de Milo ${ }^{441}$. Les références sociétales sont également plus contemporaines, comme une couverture dédiée, certes ironiquement, à Auguste Forel (I 848-I93 I), défenseur des théories hygiénistes ${ }^{442}$.

On continue, par ailleurs, d'abuser du terme de "philistins » (Philister), de la métaphore de l'âne de Buridan, des procédés antithétiques, du discours sur la civilisation, à présent en rapport avec les guerres balkaniques. L'adjectif «turc» (türkisches) fait son entrée en I908 pour désigner quelque chose de bizarre, vaguement relié à la question d'Orient.

Dans le registre politique, le procédé du tiers commentateur se généralise. Il prolonge celui de l'étranger comme miroir de la Suisse, rôle alors tenu par l'Allemagne, la France, la Belgique et la Chine. Signe des temps, en I9 Io, à l'occasion du débat sur la naturalisation, la rhétorique du bon et du mauvais étranger s'installe.

Certains procédés rhétoriques, bien qu'anciens dans l'univers des revues satiriques, font leur entrée dans le Nebelspalter, comme l'abécédaire et la série des timbres. Du fonds religieux, sont extraites et détournées figures et thématiques, telles Salomé (pour la tête coupée) ou Judith (pour la même raison). Ces figures ne sont jamais valorisées en elles-mêmes, l'ange, par exemple, est toujours un vecteur satirique.

\subsubsection{Victoire du Heimatstil et confinement de l'image à l'illustration satirique}

Les dessins sont, dans un premier temps, presque toujours signés d'un monogramme, ce qui rend l'identification du dessinateur difficile et témoigne d'une moindre valorisation des dessinateurs. À partir de I908, seuls les dessinateurs piliers, les Boscovits et Lehmann-Schramm, signent de temps à autre de leur nom, Lehmann-Schramm signant uniquement "Schramm » à partir de I906. Ceux-ci usent également de différents monogrammes ou de pseudonymes, Boscovits junior signe avec un prénom - à cette époque, Maxli ou Rudi-, lorsqu'il s'essaie au genre enfantin. Certaines années, en I 909 et I 9 I I, les dessins sont moins régulièrement signés et des monogrammes n'apparaissent qu'une seule fois. En I9 I I, le monogramme tend à se "rétrécir " à deux lettres imbriquées l'une dans l'autre. En I9I2, seuls les portraits de personnalités ou les compositions spécialement valorisées, telles les doubles-pages, montrent une signature complète. Cette année-là, la couverture critiquant la visite de Guillaume II ne porte pas de signature, preuve que certains thèmes restent sensibles, la susceptibilité de l'empereur allemand étant connue ${ }^{443}$. À partir du numéro 49, à l'occasion du passage de témoin de Boscovits senior à Rudolf Huber et Fritz Ebersold, le nom du dessinateur est mentionné sur l'image, redoublant bien souvent le monogramme.

\footnotetext{
${ }_{441}$ Sur cet aspect, voir " 5.2. S'enrichir du « grand art ».

442 Nebelspalter 1907/49, couverture de Boscovits junior intitulée « Les trains fédéraux ultra-modernes, libre d'après le Dr. Forel » (Modernster eidg. Eisenbahnzug, Fre nach Dr. Forel).; Koelbing-Waldis Vera, « Forel, Auguste », Dictionnaire historique de la Suisse; http://www.hls-dhs-dss.ch/textes/f/F14365.php.

${ }_{443}$ Nebelspalter 1912/36, couverture non signée intitulée « Comment on se mobilisa pour recevoir l'empereur » (Wie für den Kaiserempfang mobilisiert wurde).
} 
Berliner-Cheater. - क्षे

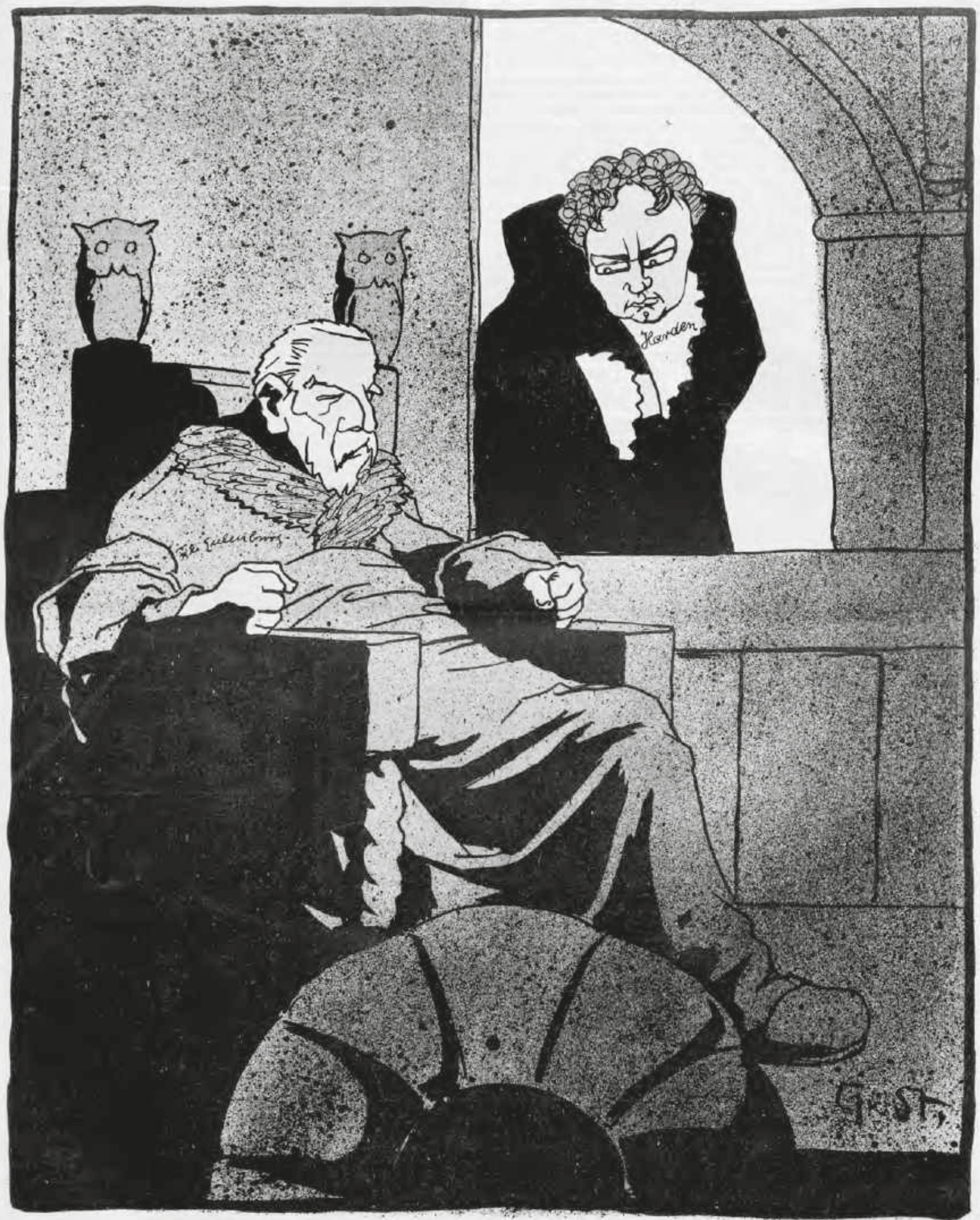

Der Filius zum Fili: „willit Du denn ewig leben?"

Fig. 56. Nebelspalter 1908/29, dessin peine page en couleur signé « G. St. » intitulé « Théâtre berlinois » (Berliner-Theater). 
Hormis Boscovits junior qui expérimente la forme séquentielle, les innovations sont rares jusqu'à l'arrivée, courant 1907, de nouveaux dessinateurs. Parmi ceux-ci, l'un signant "G v St » fournit des compositions où des personnages aux traits accusés sont cadrés de très près sur un fond en aplats; un autre, signant « MMM », quadrille la page de son trait fin pour livrer des caricatures de mœurs très proches des dessins des revues françaises. L'augmentation du nombre de dessinateurs crée une impression d'hétérogénéité, d'autant que Boscovits junior a tendance à ajuster sa manière sur celle des nouveaux arrivés. L'année I908 connaît une hausse considérable du nombre de dessinateurs, qui passent à vingt, contre neuf en I907. Du reste, l'impression visuelle du début et de la fin de l'année diffère. Certains dessinateurs, tel Josef Kälin Kupfer, introduisent une manière nouvelle, un trait soudain plus vif, un cadrage plus proche ${ }^{444}$. De nombreux crayons ne sont qu'éphémères et s'adaptent - sur demande de la rédaction ? - au conformisme stylistique du Nebelspalter. En I909, LehmannSchramm quitte la revue. Cette perte d'un dessinateur pilier, resté fidèle au Jugendstil, est compensée par l'arrivée de nombreux artistes, et l'on comptera dès lors et jusqu'en I9I 2 entre vingt et trente-deux dessinateurs. Quelques dessinateurs donnent alors une impulsion décisive, Paul Thessing et ses figures longilignes tracées sur un fond coloré ainsi que Emil Huber, dont le graphisme est étonnamment proche de celui du Français Gustave Henri Jossot ${ }^{445}$. En I9IO, les dessins de Boscovits senior se caractérisent par leur archaïsme. À partir de I9I I, Stock avec ses élégantes et Wilfried Schweizer dans un genre plus acide, sont les seuls à apporter de la nouveauté. Les dessins d'artistes pourtant très actifs se remarquent à peine, tellement ceux-ci sont conventionnels, tels ceux d'un certain « HW », auteur prolixe de caricatures de mœurs.

L'année I907 signe une évolution visuelle dont le passage à la couleur n'est que l'élément le plus évident. L'effort de recadrage porte également sur la place de l'image, qui se voit minorée. Celle-ci réintègre le territoire de la satire et les effets visuels sont soumis au texte. Pour la première fois depuis les débuts du Nebelspalter, la compréhension directe de l'image est compromise, tant les dessins sont liés à un contexte historique, très souvent exposé en détail, gênant l'accès à l'image. Le lecteur ne regarde plus le dessin sans chercher à comprendre une légende dominante. Il est plus que probable que les dessins soient désormais conçus d'après le texte ou au moins après que la teneur en a été fixée. On est bien loin du fonctionnement de nombreuses revues satiriques, où un dessin est utilisé en fonction des besoins, la légende faisant pour ainsi dire la caricature ${ }^{446}$. Autre conséquence de cette nouvelle donne: une réception nécessairement limitée des caricatures, puisque le lecteur doit disposer des références souvent locales de la légende.

La prévalence de la composante textuelle est cependant qualitative et non quantitative. La présence de l'image est, en effet, accrue. Sauf exception et quel qu'en soit le format, l'image endosse une fonction illustrative. Les dessins humoristiques gagnent du terrain, s'étalant verticalement sur un côté de la page, avec ou sans rapport avec l'autre moitié. Les compositions esthétiques et les synthèses de la vie politique disparaissent presque entièrement. Ces dernières ne concernent que l'international. Les icones, escortes des rubriques

${ }_{444}$ Nebelspalter 1908/47, dessin pleine page signé « JKK » intitulé « Et la lumière éternelle les éclaire " (Und das ewige Licht leuchte ihnen).

${ }_{445}$ Cf. « 5.1. Le Nebelspalter, la caricature et les revues illustrées européennes ».

${ }_{446}$ Les usages sont en fait relativement différenciés mais il s'agit, cependant, d'une pratique courante; Laurent Bihl, La grande mascarade parisienne; production, diffusion et réception des images satiriques dans la presse périodique illustrée parisienne entre 1881 et 1914, op. cit., p. 20, 145-146, 458, 502. depuis des décennies, disparaissent au cours de l'année 1907. Présentes jusqu'au numéro I 5 , elles sont ensuite remplacées par des lettrines. Elles réapparaitront en I9I3.

Le Heimatstil fait son entrée dans les pages intérieures. Les garçonnets en culotte courte (les petits Suisses), la croix helvétique, le paysan, la femme en costume traditionnel et bien sûr les motifs alpins sont foison. Les montagnes sont maintenant davantage qu'un signet visuel de l'identité helvétique et symbolisent la Suisse dans de nombreuses caricatures. Ce succédané du Jugendstil détermine le traitement des personnages et des ornements, une fleur stéréotypée, toujours la même, encadre ainsi systématiquement les titres. De fades scènes de mœurs, créées par des dessinateurs de passage, s’y ajoutent. Les expériences sur le cadre au trait n'en finissent pas.

Dans ce magma stylistique, les canons de la caricature sont toujours en vogue, avec les éternelles déformations, animalisations et formules idiomatiques, tel un jeu de mots sur les termes «masseur» et « ma sœur» dans une caricature de I907, intitulée «Présentations» (Vorstellung): « Madame Isa Chaud, ma sœurMonsieur Fort, également masseur ». La légende tombe à ce point à plat que l'on se demande si elle n'a pas été importée de France ou de Suisse romande sans davantage de précautions ${ }^{447}$. Les motifs phares sont pour une bonne partie des redites, le train, la cuisine politique (éventuellement diabolique), la soupe, l'escargot (suisse), le cheval, le théâtre de marionnettes, la cage aux fauves, la maison de poupée, eux aussi tous politiques, la tresse, le nid de guêpes, les carottes animées, la voiture pour figurer "l'esprit du temps » (Zeitgeist), les portraits physiognomoniques, les ballons et autres engins volants, omniprésents en I9 I I, et, bien sûr, l'inébranlable figure de l'ivrogne (Sauser).

D'autres motifs sont, par contre, nouveaux, tel l'hôtel Helvetia, promis à un bel avenir, l'oiseleur et ses oiseaux symbolisant les cantons - le recentrage sur la Suisse stimulant visiblement la créativité -, la main de la fatalité, le bal international, la pierre qui écrase, le moulin géant (qui broie), tandis que l'avion concurrence la voiture pour signifier la modernité. Les figures du mendiant et de l'élégante (elle, ancienne) témoignent de l'ambivalence face à une ville s'urbanisant rapidement.

En I909, les synthèses de la vie politique deviennent polymorphes. Ce sont, soit des images présentant côte à côte des personnalités politiques et des allégories; soit des petites scènes qui se suivent; soit des scènes de théâtre ou de cirque. Une iconographie de la violence, alimentée par les guerres et les révolutions, continue de se développer. Après les barils de poudre et autres squelettes et explosifs, apparaît, en I 908 , le taureau de la révolution (portugaise). La guerre italo-turque (I9II-I9I2) produit des scènes de bombardements. Le genre autorise des propos négatifs, décalés vis-à-vis du propos primaire, ainsi que le développement de types racistes, comme à l'occasion de la crise marocaine de I905. L'iconographie des conférences de paix forme une sorte de contrepartie à ces images agressives.

À partir de I908, les doubles-pages se présentent selon une version rénovée, introduite par Boscovits senior avec « Le chant des manœuvres"(Manöverlied). L'image se déploie sur le côté droit de la page. Elle consiste en une superposition de petits

Nebelspalter 1907/28, dessin signé « LK » intitulé « Présentations » (Vorstellung). 
tableaux humoristiques, illustrant un texte versifié, imprimé sur le quart droit de l'image. Ici aussi le texte devient prépondérant ${ }^{448}$. Le changement des hommages aux grands hommes est plus radical. C'en est quasiment fini des hommages classiques avec l'organisation d'un texte autour d'un portrait en médaillon. Désormais, les "grands hommes » sont figurés dans des images " ordinaires", se singularisant uniquement par une composition rigide et un ton solennel. On trouve quelques exceptions, tel l'hommage très conventionnel à Pestalozzi, en I909449.

\subsubsection{Recul de la représentation féminine et désinvestissement de l'allégorie}

La version désormais très affadie du Jugendstil a une double conséquence: non seulement la présence féminine baisse mais la qualité représentationnelle des figures se dégrade. La sublimation de la figure féminine ne survit pas à la disparition des couvertures imagées. Les représentations sont à présent connotées négativement, quand bien même le traitement esthétique est positif. Ainsi, même les élégantes, esthétiquement bien mieux traitées que les mégères, intrigantes, idiotes et calculatrices, elles figurées à peu de frais, sont discréditées pour leur légèreté et leur vénalité, soit par la mise en scène, soit par la légende, voire les deux. C'est, du reste, le sens du discours sur la mode. La récurrence de Fraulein Tini, une écervelée ne pensant qu'à sa tenue, dans les caricatures de mœurs est l'un des signes de ce durcissement ${ }^{450}$.

L'agressivité est parfois ouverte, comme dans une caricature où une femme au physique disgracieux est assimilée à une truie:

Madame l'aubergiste, le rôti de porc est dur » - « La responsable, c'est la truie »- «Certes, c'est bien pour ça que je m’adresse à vous ${ }^{451}$.

Historiquement, ce recul correspond à une réaction aux mouvements d'émancipation traversant la société, et dont l'un des promoteurs est le socialiste Hermann Greulich ${ }^{452}$, détesté du Nebelspalter. L'antibolchevisme et l'hostilité envers le féminisme convergent dans la stigmatisation de l'étudiante russe. Courant I907, celle-ci est associée à plusieurs reprises à la révolution et à la mort, et figurée en tueuse ${ }^{453}$. Le thème de l'émancipation est à ce point central qu'il appelle la venue d'Helvetia, très ambiguë sur la question ${ }^{454}$. L'institutrice se prête à ce discours misogyne: un dessin anonyme de I9I I la montre aussi incapable dans ses fonctions que dans ses devoirs familiaux ${ }^{455}$.

Les allégories sont en très net recul et se désolidarisent de la représentation féminine. Elles s'appauvrissent sémantiquement comme esthétiquement, les créations sont rares, y compris dans le champ politique, où allégories et personnalités continuent d'être mêlées. L'iconographie du deutscher Michel est cependant

Nebelspalter 1908/37, double-page de Boscovits senior intitulée «Images de manœuvres » (Manöverlied).

49 Nebelspalter 1909/25, dessin pleine page de Boscovits senior.

${ }_{450}$ Cf. par exemple Nebelspalter 1908/44, dessin de Boscovits junior intitulé « La dernière mode " (Zur neuesten Mode).

${ }^{451}$ (Sie, Frau Wirtin, der Schweinbraten ist aber hart -» "Daran ist die Sau Schuld. » " Na ja, drum reklamiere ich ja bei Ihnen...); Nebelspalter 1908/48, dessin signé d'un monogramme intitulé «Au restaurant » (Im Restaurant).

${ }_{452}$ Markus Bürgi, « Greulich, Herman », Dictionnaire historique de la Suisse, 2007; http://www.hls-dhs-dss.ch/textes/f/F3738.php.

${ }_{453}$ Cf. par exemple Nebelspalter 1907/27, dessin signé «ED » intitulé « Jadis et maintenant » (Einst und jetzt).

${ }^{54}$ Nebelspalter 1908/13, couverture de Boscovits senior.

45 Nebelspalter 1911/11, dessin pleine page anonyme intitulé « L'institutrice mariée » (Die verheiratete Lehrerin). adaptée par Paul Thessing, qui crée une figure de grand benêt ${ }^{456}$. L'inventivité se fait dans les marges avec une allégorie masculine du Rhin tout à fait singulière, une sorte d'empereur romain se dégageant des eaux ${ }^{457}$. On observe sporadiquement des figurations archaïsantes, comme l'allégorisation malheureuse des organes de protection de la nature, des animaux et du patrimoine (Naturschutz, Tierschutz, Heimatschutz), représentés par deux Suisses costauds et une femme en toge ${ }^{458}$. L'apparition d'Helveticus - un type ordinaire - en I9 Io représente une singularité symptomatique de l'époque ${ }^{459}$.

Qui dit Helveticus dit Helvetia et, comme attendu, celle-ci voit sa présence croître en I907, l'année de l' "helvétisation » du Nebelspalter. Elle passe alors à dix-neuf occurrences contre sept en I906. Sa présence reste ensuite élevée, sans être aussi soutenue, pour soudain reculer en I9I I. Si Helvetia choisit son lieu pour ses apparitions, une couverture ou une pleine page, son iconographie, son rôle et les contextes dans lesquels elle apparaît sont d'une très grande variété. Elle prend ses habits traditionnels pour rappeler à l'ordre les protagonistes du financement de la ligne du Gothard ${ }^{460}$; agit en actrice des séries de timbres de Boscovits junior ${ }^{461}$; endosse son armure pour suivre l'engagement suisse au Maroc ${ }^{462}$; se vêt élégamment d'une robe à la mode, ourlée des armoiries des cantons pour étudier le code civil ${ }^{463}$ et d'une tenue très respectable pour se mêler des questions bancaires ${ }^{464}$. C'est en matrone, toutefois, qu'elle défend la nouvelle loi militaire de $1907^{465}$. Pour fêter la nouvelle année I908, Helvetia se fait très coquette et embarque dans un ballon dirigeable, mené par Chronos ${ }^{466}$. Durant cette période, tout est possible, jusqu'à figurer Helvetia face à Germania en équilibriste très court vêtue, à l'occasion de la conférence douanière germano-suisse de I $908^{467}$, et même de la montrer en mégère, lavant son linge avec ses collègues ${ }^{468}$ (cf. fig. $5^{8}$ ).

Tendanciellement, la présence du personnage du Nebelspalter est, par contre, en baisse, oscillant entre une et sept occurrences. Son iconographie ainsi que sa fonction d'observateur politique et de propagandiste du journal sont quasi inchangées ${ }^{469}$, mises à part les variations de couleur de son costume et de ses cheveux. Le personnage est très fortement concurrencé par le motif du journal de papier. Une certaine dérision pointe dans un dessin de I9I0, créé à l'occasion du quatre-vingtième anniversaire de

456 Nebelspalter 1909/14, dessin pleine page de Paul Thessing intitulé «Peur de l'invasion anglaise » (Englische Invasionsfurcht)

${ }_{457}$ Nebelspalter 1908/47, couverture de Boscovits junior

${ }_{458}$ Nebelspalter 1910/41, couverture de Boscovits senior.

459 Nebelspalter 1910/22, couverture signée « NP » intitulée « Le seul moyen » (Der einzige Mittel).

${ }_{460}$ Nebelspalter 1907/32, couverture de Boscovits senior intitulée « Un bon lait de vache » (Eine gute Milchkuh).

${ }_{461}$ Nebelspalter 1907/28, dessin pleine page de Boscovits junior intitulé « Les dernières esquisses pour les timbres suisses » (Neueste Entwürfe für schweizerische Briefmarken); Nebelspalter 1907/48, dessin pleine page de Boscovits junior intitulé "Le "petit" Tell dans les nouveaux timbres postes » (Der « kleine» Tell in neuen Markenbildern).

${ }_{462}$ Nebelspalter 1907/26, couverture de Boscovits junior.

${ }_{463}$ Nebelspalter 1907/52, couverture de Boscovits junior

464 Nebelspalter 1907/23, couverture de Boscovits senior.

465 Nebelspalter 1907/6, dessin pleine page de Boscovits senior intitulé « Au sujet de la nouvelle loi militaire suisse » (Zum neuen schweizerischen Wehrgesetz).

${ }_{466}$ Nebelspalter 1908/1, dessin pleine de Boscovits junior intitulé « Bonne chance pour l'atterrissage! » (Glück ab!).

${ }_{467}$ Nebelspalter 1908/21, dessin pleine page de Boscovits junior intitulé «Dans le cadre de la conférence germano-suisse sur les questions douanières » (In der deutsch-schweizer. Zollfragen-Konferenz).

${ }_{468}$ Nebelspalter 1909/3, dessin pleine page de Boscovits junior intitulé « Linge sale » (Schmutzige Wäsche)

${ }_{469}$ En 1910, sous le crayon d'un nouveau dessinateur, son apparence - visage et chevelure - est par contre différente; Nebelspalter 1910/43, dessin signé « NFG » intitulé « Sur le référendum » (Zur Abstimmung). 
Jn der deutîch-íbweizer. Zollfragen-Fonferenz

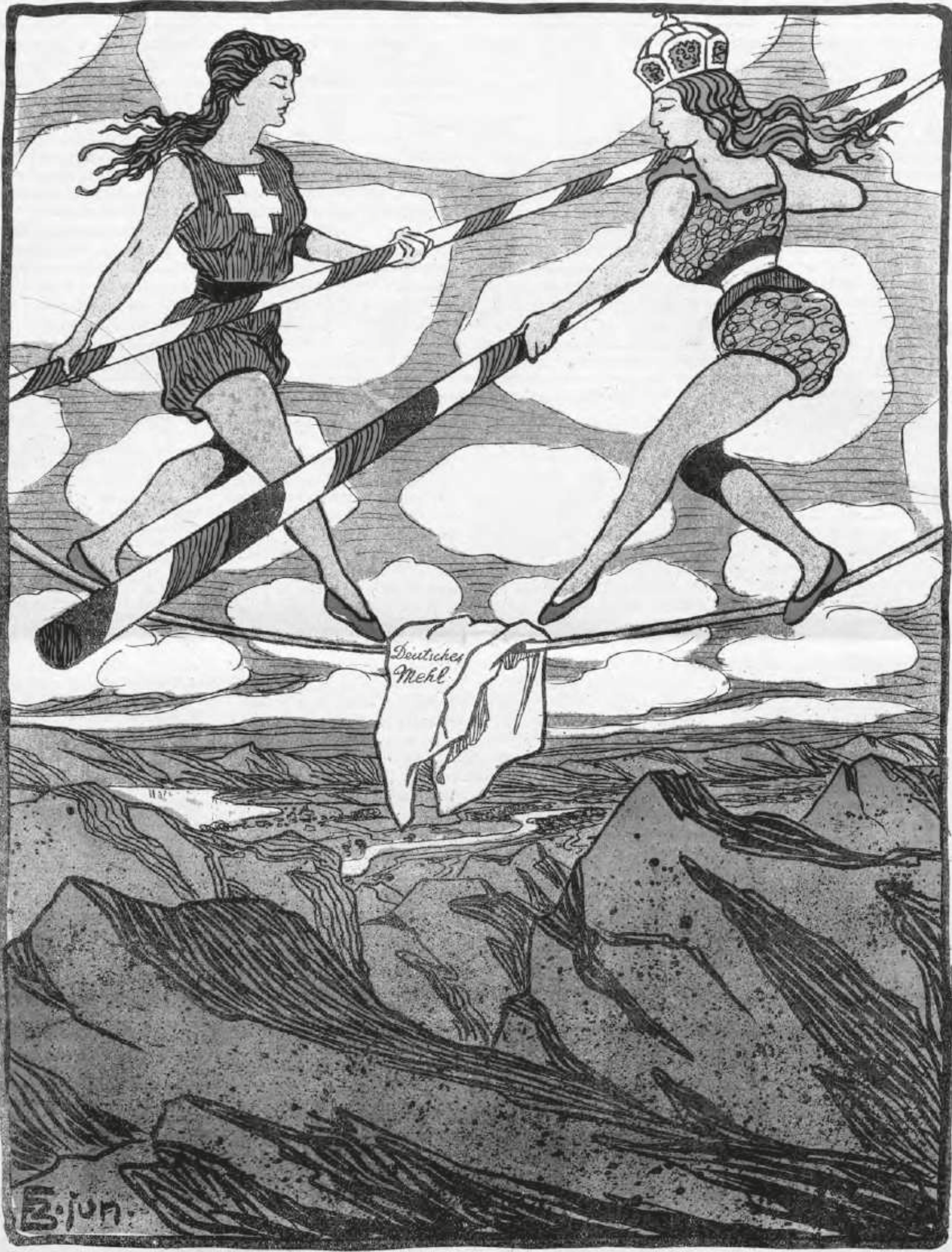

wird man sid so entgegenkommend als möglich zeigen.

Fig. 58. Nebelspalter 1908/21, dessin pleine page en couleur de Boscovits junior intitulé « Dans le cadre de la conférence germano-suisse sur les questions douanières » (In der deutsch-schweizer. Zollfragen-Konferenz). 
Paul Heyse et intitulé "Encore un Nebelspalter» (Auch ein Nebelspalter $)^{470}$. L'écrivain est représenté en mercenaire, l'épée à main, devant des nuages parsemés de feuillets, le poète Gottfried Keller lui lançant une couronne de laurier. En I9I2, l'unique apparition du personnage est sensationnelle. Cédant la rédaction à Rudolf Huber, Boscovits senior se représente en Nebelspalter ${ }^{471}$. Un an plus tôt, Prince carnaval (Prinz Carnaval) est entré en scène: il sera le successeur du personnage du Nebelspalter à partir de I922, lors de la deuxième vie du périodique à Rorschach ${ }^{472}$.

\subsubsection{La valse des couvertures}

Révolution, s'il en est, l'année I907 signe à la fois la disparition de la couverture traditionnelle et celle de la couverture Jugendstil. Fin donc, et de la couverture montrant le personnage du Nebelspalter, et des couvertures imagées, où texte et image se répondent selon le principe Jugendstil. Ce changement de couverture se fait avec beaucoup d'hésitations, puisque cinq modèles coexistent sur une courte période. Il s'inscrit également dans un processus de conquête de la couleur; les couvertures s'accorderont d'ailleurs aux autres pages. L'affaire est sous le contrôle des Boscovits. À une exception près ${ }^{473}$, le père et - surtout - le fils signent toutes les couvertures de I907. La formule qui l'emporte s'installera jusqu'en I9 I3. Une chose mérite alors l'attention : l'abandon du cadre au trait autour de la page, avec un maintien occasionnel limité à l'image.

Dans un premier temps, jusqu'au numéro I3, l'alternance entre couverture traditionnelle et couverture Jugendstil se poursuit, à raison de trois pour une. Les couvertures Jugendstil, d'occurrence mensuelle, sont donc au nombre de trois. Les deux premières, un portrait du Nebelspalter et une célébration du carnaval ${ }^{474}$, sont d'une veine festive. La troisième représente une singularité dans le corpus Jugendstil. Ses tons violet et roux sont plutôt rares, mais c'est surtout la mise en scène et l'expression lointaine de la jeune femme qui retiennent l'attention. La jeune élégante, dotée d'un parapluie et accompagnée d'un toutou, marche devant un muret surplombé d'une grille. Devant celui-ci, sont plantés deux arbres fruitiers au rendu ornemental: quasi-identiques, ils semblent plus objets que végétaux et leur feuillage schématique se prolonge en une arche végétale, formant un cadre à l'image. Le caractère figé de la scène, le regard absent de la jeune femme, les couleurs automnales - alors que l'on est en mars - évoquent les œuvres symbolistes. Les arbres, par contre, sont repris de l'appareil ornemental de Julius Diez qui en parsème la revue Jugend ${ }^{475}$. Une autre référence s'impose, cependant, une œuvre d'Édouard Manet, acquise par Hugo von Tschudi pour la Nationalgalerie de Berlin en I 896, rapidement célèbre en milieu germanique ${ }^{476}$, le très fameux «Dans la serre » ( I 879), dont Boscovits senior reprend une partie des éléments, la grille et le personnage féminin, notamment. C'est

${ }_{470}$ Nebelspalter 1910/12, dessin de Boscovits junior intitulé « Aussi un Nebelspalter » (Auch ein Nebelspalter).

${ }_{471}$ Nebelspalter 1912/48, dessin pleine page de Boscovits senior intitulé « Au revoir » (Zum Abschied); sur cette image, cf. «1.2. Décryptage de la fondation et de la vie éditoriale : focus sur Boscovits senior » ainsi que « 5.5. Se citer soi-même plus que de mesure ".

${ }_{472}$ Nebelspalter 1911/10, dessin pleine page non signé intitulé « Ça manquait! » (Das fehlte noch!); Cf. également « 5.5. Se citer soi-même plus que de mesure ».

Nebelspalter 1907/34, couverture signée d'un monogramme.

474 Nebelspalter 1907/4, couverture de Boscovits junior; Nebelspalter 1907/7, couverture de Boscovits junior

475 Laurence Danguy, L'ange de la jeunesse - La revue Jugend et le Jugendstil à Munich, op. cit., p. 57-63.

36 Sur l'importance du travail d'acquisitions de Hugo von Tschudi, notamment concernant Manet: Thomas W. Gaehtgens, Mathilde Arnoux et Friederike Kitschen (éd.), Perspectives croisées. La critique d'art franco-allemande 1870-1945, Paris, Maison des sciences de l'homme, 2009. cependant la dernière fois que le dessinateur joue ainsi des styles et des références pour une couverture sur le point de quitter le domaine esthétique ${ }^{477}$ (cf. fig. 59).

Une deuxième version de la couverture ne dure que huit numéros. Du numéro I4 au numéro 2 I, elle constitue une sorte de compromis entre une couverture traditionnelle et une couverture imagée, sauf que l'image se présente désormais comme une caricature sans prétentions esthétiques. L'organisation visuelle, les procédés rhétoriques de subordination de l'image à la légende et de dégradation des figures sont ceux de la caricature. Alors que le bandeau, repris du format original, est en noir et blanc, l'image est en couleur. À vrai dire, la formule n'est pas tout à fait nouvelle et apparaît de temps à autre à partir de I90I, sous une forme un peu différente, puisque toute la page est alors en noir et blanc ${ }^{478}$.

La troisième et la quatrième version sont, en fait, deux étapes successives d'une même formule. Du numéro 2 I au numéro 34, bandeau comme image sont en couleur, alors que le titre passe en noir et blanc à partir du numéro 35 . Sur le bandeau, le personnage du Nebelspalter disparaît et les lettres du titre s'alignent à présent en majuscules bien droites. Le bandeau est raccourci sur la hauteur, laissant davantage de place à l'image, ce qui profite aux effets esthétiques. Le registre est celui de la satire, avec une exception, un hommage à Giovanni Segantini (I 85 8-r 899), l'une des icones de l'art suisse, bien qu'officiellement apatride ${ }^{479}$.

Dans ce processus de recherche, la couverture du numéro 22 a valeur de symptôme: la dernière apparition du personnage du Nebelspalter dans le bandeau de titre se produit entre deux essais d'une formule peinant à s'installer ${ }^{480}$.

\subsubsection{Passage définitif à la couleur}

Il ne faudrait pas croire que le passage à la couleur aille de soi, même après une présence de deux décennies. Là encore, la revue se distingue de ses contemporaines. Le numéro I I de l'année I907 est le dernier en noir et blanc. Au numéro I4, Alfred Beetschen, artisan du virage textuel, présente la mue du Nebelspalter dans un poème en sept strophes, intitulé « Le Nebelspalter métamorphosé à ses fidèles"(Der metamorphosierte Nebelspalter an seine Getreuen). Les deux premières strophes condensent la rhétorique bien rôdée d'une équipe de collaborateurs menée par les Boscovits senior et junior (Die Bosco's sen. und junior), s'adressant au lectorat helvétique:

Le monde est chaque jour plus coloré.

Chacun se décore à son goût ;

Moi aussi, après 33 ans,

Je change de peau

Avec un joyeux jeu de couleurs

Ni trop, ni trop peu

Je viens à la rencontre des jeunes et des anciens

Qui, avec moi, ont vite fait de dissiper le brouillard ${ }^{481}$.

\footnotetext{
477 Nebelspalter 1907/13, couverture de Boscovits junior.

${ }_{478}$ Cf. Nebelspalter 1901/36; Nebelspalter 1903/7; Nebelspalter 1903/26.

479 Nebelspalter 1907/37, couverture de Boscovits junior.

480 Nebelspalter 1907/22, couverture de Boscovits junior.

${ }^{481} \quad$ (Die Welt wird bunter mit jedem Tag, / Ein jeder schmück sich wie er mag; Auch mich, nach 33 Jahren, / lasst in ein ander Haütlein fahren! / Mit einem frohen Farbenspiel, / Zu wenig nicht und nicht zu viel, / Komm' zu den Jungen ich und Alten, / Die rastlos mit mir Nebel spalten.); Nebelspalter 1907/14, texte d'Alfred Beetschen intitulé « Le Nebelspalter métamorphosé à ses fidèles » (Der metamorphosierte Nebelspalter an seine Getreuen).
} 
Zürich, 1907 XXXIII.Jahrgang № 13.

30. Mărz .

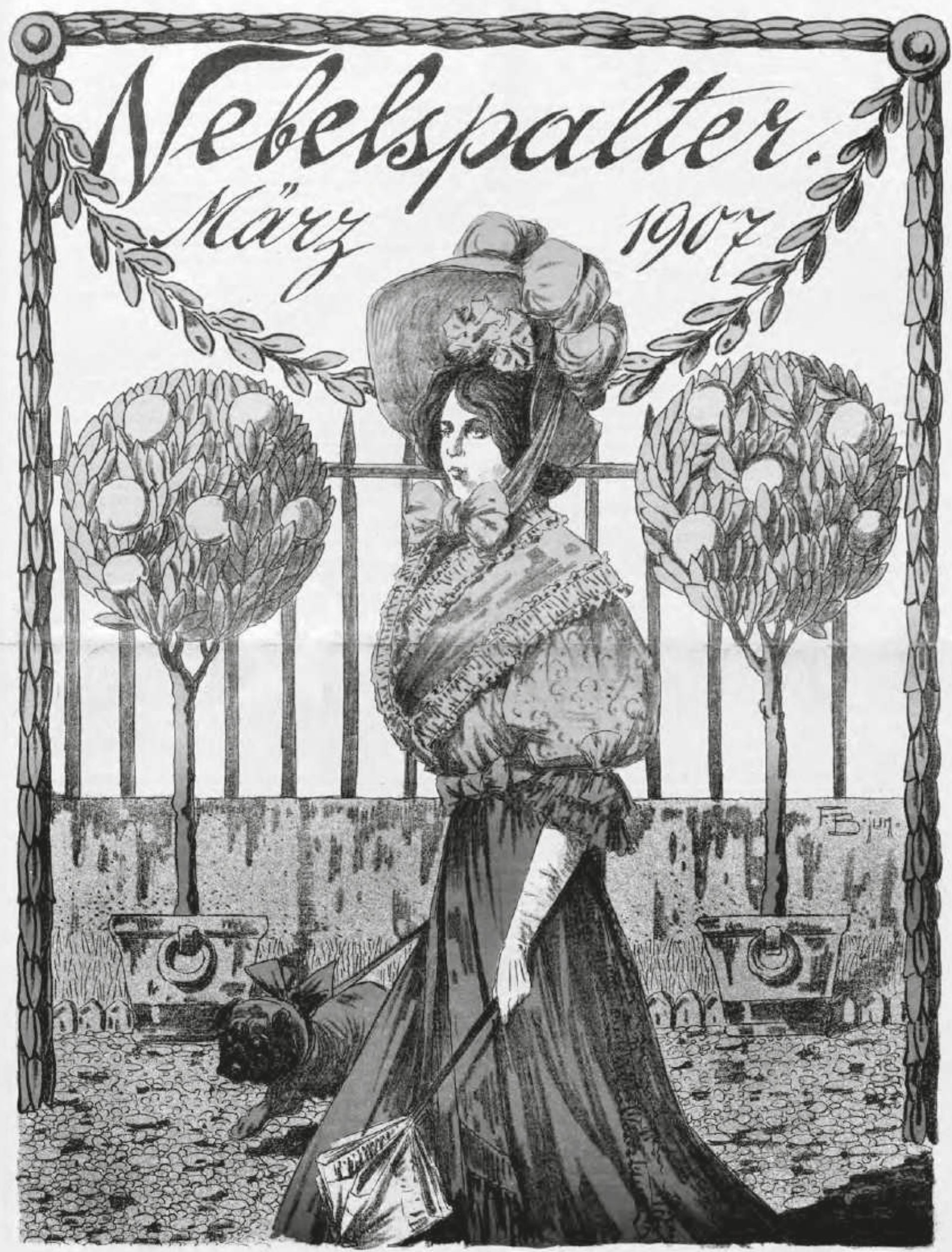

With v, Butz z Cig 


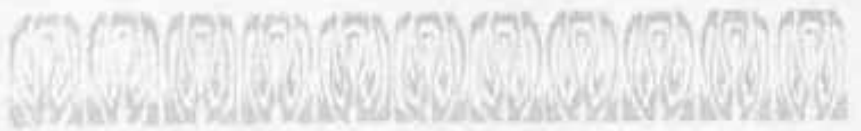

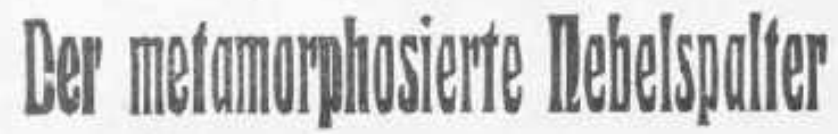

ลก

seine Getreuen.

(6)

Die Ulelt wird bunter mit jedem tag,

Ein jeder schmückt sid wie er mag;

Aud mid, nad 33 Jahren,

Casst in èn ander Fäutlein fabren!

Init einem frohen Farbenspiel, $\mathrm{Zu}$ wenig niont und nicht $\mathrm{zu}$ viel, Komm zu den Jungen ith und Alten, Die rastlos mit mir Mebel spaiten.

Wen idh auf's Korn nahm schwarz auf weiss, Den mach' id jetzt in Buntdruck heiss; In Regenbogenfarbenbildem

will id den grauen Alltag scbildern.

An meines Klüftleins ITlodeschnitt Sieht man's: 's hält mit dem Zeitgeist Sdritt Der Thebelspaiter; Stift und Feder Sie ziebn mit frishem IThut vom Leder.

Die Bosco's sen. und iunior, ITit ibrea ein vielstimm'ger Chor Von unentwegten MTitarbeitern, Von Witzebolden, taptern Streitern,

Betreten jetzt beim Frühlingsnahn In neuer Aufmachung den Plan; IIIt Cintentässern, Farbentöpien Zu Leibe geht's den alten Zöpien,

Die man nod heut' sieht bier und da Jm Garten der Felvetia.

$\epsilon_{s}$ sei, wer mittun mag zum Frommen Der Ceute von Seldwyl - willkommen I

R. Betshen.

Fig. 60. Nebelspalter 1907/14, texte d'Alfred Beetschen intitulé « Le Nebelspalter métamorphosé à ses fidèles » (Der metamorphosierte Nebelspalter an seine Getreuen) et dessin en couleur de Boscovits junior intitulé « Une autre manière de voir les choses » (Auch eine Ansicht).
Huch eine Hneicbt.

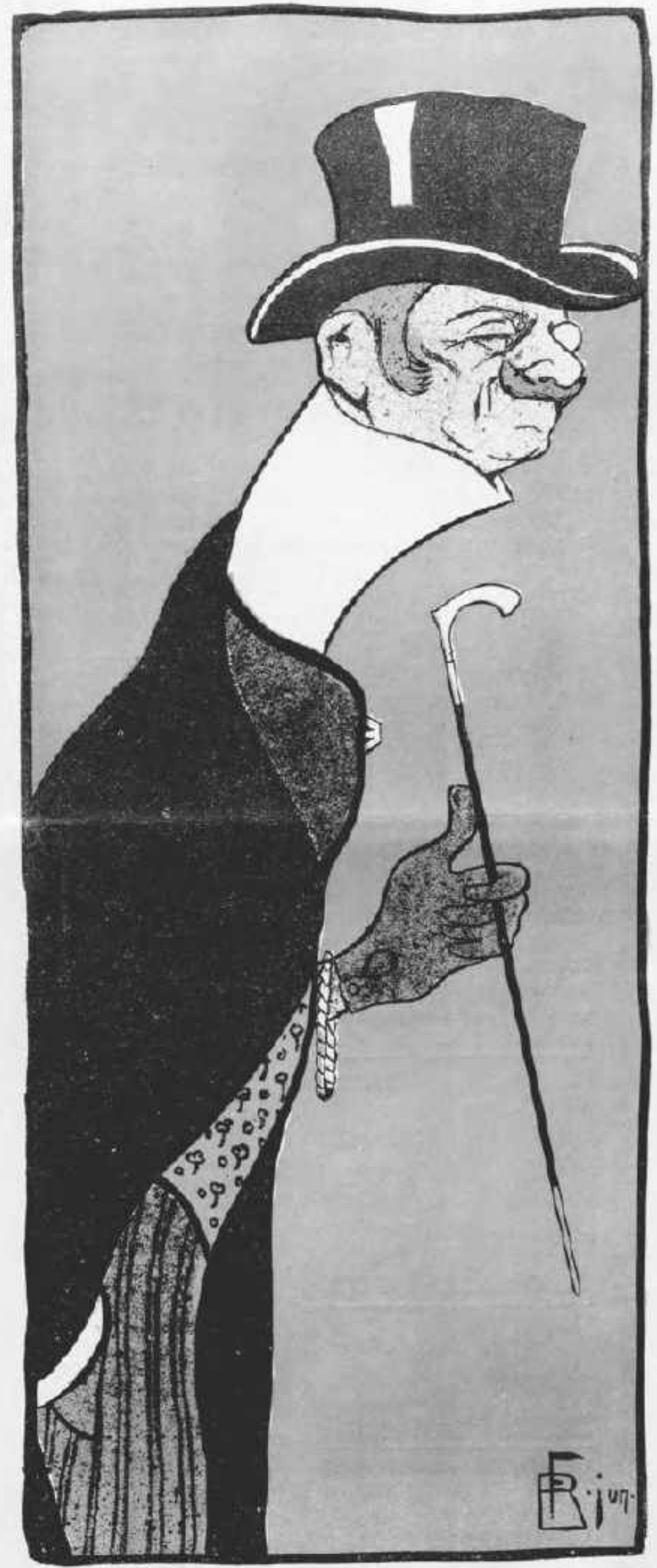

Da frūnden sit wieder tine neue Geselischatt: Colssen s chaft und toalt - Total flberlîssig. ich komme mit der bälfe von ieder sanz fenos aus - D albwissen und balt weit. 
Le texte de Beetschen est bordé en haut et en bas par des ornements typographiques stylisés, des lotus très proches des ornements des revues munichoises. Marrons, ils sont assortis au fond de l'illustration placée en vis-à-vis, une figure de souteneur de Boscovits junior, particulièrement réussie ${ }^{482}$ (cf. fig. 60).

En fait, le changement est surtout quantitatif, puisque l'on passe d'un numéro sur quatre en couleur à une permanence de celle-ci. L'année I 907 compte ainsi 39 couvertures et I 22 pages isolées en couleur alors que 1906 totalisait I I couvertures, Io doubles-pages et I 6 pages isolées en couleur. L'impression de couleur est accrue par la présence, à partir du numéro I 5 , de demi-pages et quarts de page en couleur. Pour le reste, les combinaisons des années précédentes sont reprises, soit une couleur unique et dégradée (marron-bronze), soit, le plus souvent, une bichromie qui fait un retour en force sous de multiples combinaisons (vert et jaune; marron et vert; rouge et vert; vert et orange). Quelques rares compositions comportent trois couleurs (jaune, rouge et bleu). Au cours de cette année 1907, sont menées quelques expérimentations, un noir et blanc dégradé incluant du rouge ainsi qu'une nouvelle combinaison de mauve et de rouge.

I 908 voit l'abandon des compositions à trois, quatre ou cinq couleurs, devenues rares. À quelques exceptions près, en particulier dans la publicité, où sont régulièrement testés une typographie ou des contours en couleur, généralement bleus, seules deux formules sont retenues: une bichromie, où les couleurs (marron et gris; orange et gris; orange et vert; rose et vert; rouge et vert; jaune et vert; bleu et vert; violet et vert; jaune et vert; jaune et orange; jaune et marron; marron et bleu; rouge et marron; orange et marron; rose et bleu; orange et bleu; bleu et rouge) se rejoignent et se fondent en milieu de page, ou un noir et blanc intégrant une autre couleur (rose, gris, brun, orange, vert ou bleu), le noir étant parfois en aplats. En I909, deux couleurs sont quelquefois intégrées au noir et blanc, en particulier chez Emil Huber ${ }^{483}$ (cf. fig. 52). En I9 I I, la formule bichrome n'est plus seulement déclinée en fondus mais également avec des couleurs en aplats ${ }^{484}$ (cf. fig. 6I cahier couleur). L'année I9I 3 ne voit pas de véritables novations, si ce n'est une bichromie de couleurs en aplats (bleu et rouge) parfois très soutenues, et une hausse du noir et blanc avec deux ou trois couleurs. La manière dont est présente la couleur laisse penser que les dessins sont livrés en noir et blanc et coloriés ensuite. En I909, le rouge confirme son investissement comme couleur de la révolution et de la violence.

\subsection{3-1921: l'image en perte et la Première Guerre mondiale}

L'année I9I3 entame le dernier cycle de vie du Nebelspalter zurichois. L'arrivée à la tête de la rédaction de Rudolf Huber et Fritz Ebersold, fin I 9I 2 débouche, début I9I3, sur une nouvelle refonte du périodique. Titre, maquette, tendance, positionnement

\footnotetext{
${ }_{482}$ Nebelspalter 1907/14, dessin de Boscovits junior intitulé « Une autre manière de voir les choses » (Auch eine Ansicht).

${ }_{483}$ Nebelspalter 1909/28, dessin pleine page de Emil Huber intitulé « Sic transit gloria mundi ».

${ }^{484}$ Nebelspalter 1911/45, dessin pleine page signé « Stock » intitulé « Le record de hauteur » (Der Höhenrekord).
}

et langage visuel sont modifiés. Les deux changements éditoriaux qui suivent, le départ de Ebersold début I9I3, laissant Huber seul aux commandes, puis la prise en main par Jean Frey en I9I9, ne modifient plus guère les choses, si ce n'est dans le sens d'un appauvrissement et d'un durcissement. L'augmentation à deux reprises du prix sans explications, insolite dans l'histoire de la revue, avec un unique précédent en I907, illustre, à elle seule, la fuite en avant de la rédaction, dont les efforts pour retenir le public restent vains. Bien que Jean Frey ne prenne les commandes qu'en I9I9, son influence se ressent plus tôt, dans une ligne politique durcie et un marketing indigent. L'image, qui, en dehors des années de guerre, s'efface peu à peu, correspond à la présence déclinante de la revue.

\subsubsection{Identité, maquette et technique - Recul}

Courant I9I3, la maquette est l'objet de remaniements importants, liés aux mouvements rédactionnels. Le plus voyant d'entre eux consiste en la refonte de la couverture au numéro 3. On délaisse la formule introduite en I907, où le titre ainsi que les données commerciales et rédactionnelles s'inscrivaient en caractères serrés et strictement ordonnés sur trois colonnes, placées au-dessus d'une caricature. Le titre s'étale à présent en caractères gothiques; une série d'informations commerciales sont supprimées, dont les adresses de la rédaction et des annonceurs; progressivement, des textes versifiés prennent place; enfin et surtout, le soustitre est modifié, perdant la mention «illustré » (illustriert). Le Nebelspalter n'est plus un «hebdomadaire illustré humoristique et satirique "(Illustriertes humoristisch-satirisches Wochenblatt) mais une "revue humoristique et satirique " (bumoristischsatyrische Wochenschrift) ${ }^{485}$ (cf. fig. 62).

Ces changements vont tous dans le sens d'une requalification en faveur du texte et d'un retour aux origines, dont le gothique est le marqueur visuel.

Cette année I9I3, un début de désorganisation de la maquette intervient avec un empiètement de la publicité sur le texte à partir de la troisième page. À de très rares exceptions, un numéro compte huit pages. Des thèmes humoristiques apparaissent en couverture, tandis que la dernière page n'est plus forcément consacrée à une caricature politique mais régulièrement à un dessin de mœurs. Celui-ci est, soit un dessin pleine page, soit un assemblage de plusieurs dessins. En pages intérieures, par contre, les caricatures politiques se substituent aux dessins de mœurs. Les dessins de petite taille se multiplient et la page à quatre dessins devient la norme.

Les noms des dessinateurs continuent d'être indiqués sur des images accompagnées de textes brefs, à la typographie serrée. Les légendes indiquent que dessins et textes sont, sauf exception, composés séparément. Dans le cas d'une composition à deux voix, où le dessinateur ne s'ajuste pas au rédacteur ou vice-versa, les noms du dessinateur et du rédacteur sont mentionnés, telle la couverture du numéro 40, où T.S. Salis est cité comme créateur de l'image et Martin Salander comme celui du texte ${ }^{486}$. À partir du numéro Io, les icones réapparaissent, et ceci définitivement, nouvel indicateur passéiste. La question du cadre n'est pas tout

\footnotetext{
Nebelspalter1913/3, couverture de Wilfried Schweizer intitulée « Aviation militaire (Mitäraviatik).

"Nebelspalter 1913/40, couverture intitulée « Fumée d'altitude » (Höhenrauch), dessin de T.S. Salis et texte de Martin Salander.
} 


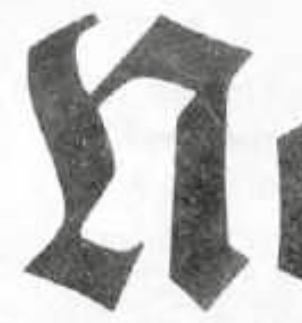

26r. 3. 39. Jahrgong.

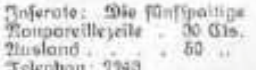

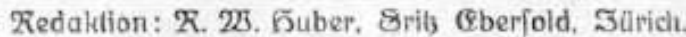

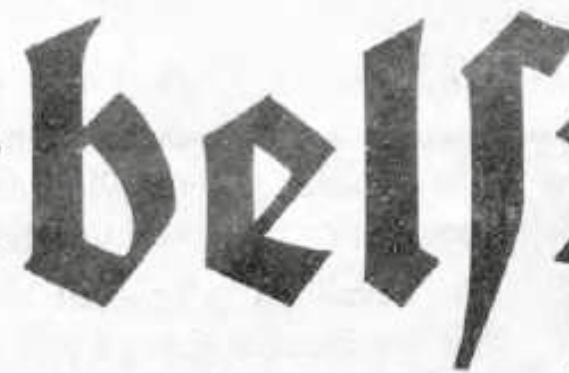

Sumoriftifch-Fatprifche 23ochen[chrift

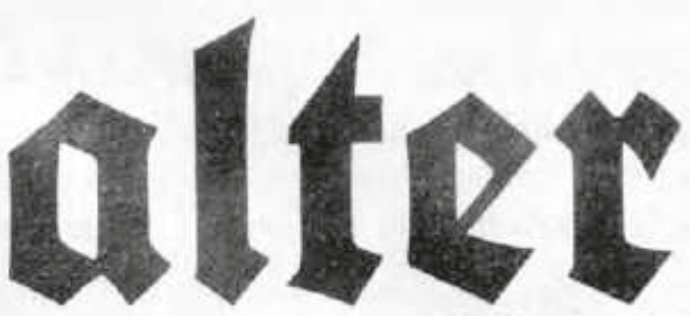

18. Januar 1913

\section{Tilitäraviatik}

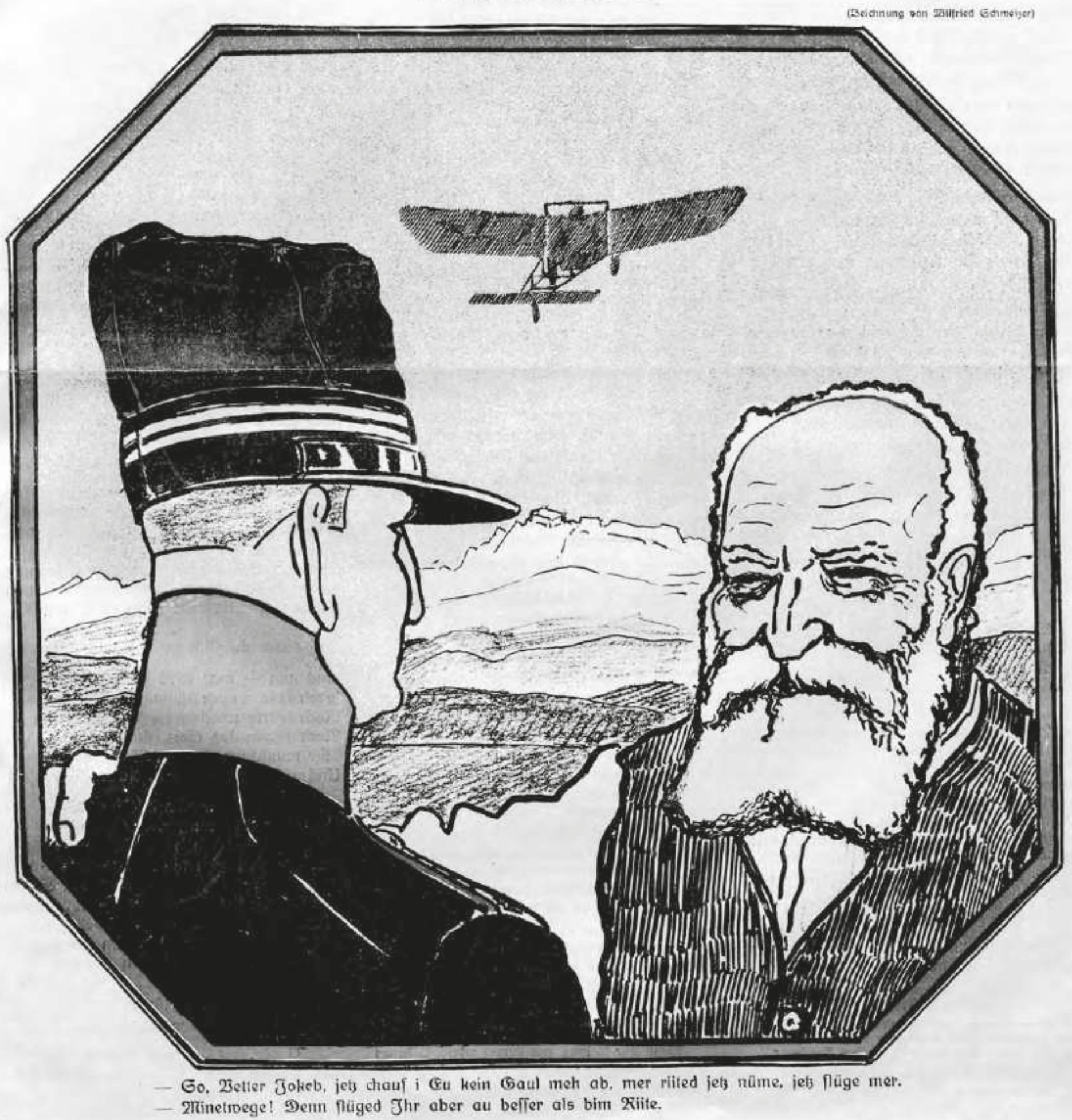

Fig. 62. Nebelspalter 1913/3, couverture en couleur de Wilfried Schweizer intitulée « Aviation militaire » (Mitäraviatik). 
à fait réglée: au numéro 28, Wilfried Schweizer fait marcher son personnage sur le cadre d'une satire de la fête du tir, l'un des fondements identitaires de la Suisse ${ }^{487}$ (cf. fig. 63 cahier couleur). La typographie ne présente, quant à elle, que des changements mineurs : comme ailleurs, on revient à des formules anciennes. Vers la fin de l'année I9I3, à partir du numéro 45, le bandeau connaît une deuxième évolution, qui sera pérenne: les noms des rédacteurs, éditeur et imprimeur disparaissent et sont reportés au bas de l'avant-dernière page. À partir du numéro suivant, l'indication «Zurich » (Zürich), suivie de la date, apparaît au centre du bandeau.

Durant les huit années restantes de la période zurichoise, de I9I4 à I92I, la maquette perd en qualité visuelle et objectale. L'objet revue se dégrade dans une dynamique qui n'est pas générée par la guerre mais aggravée par celle-ci. Quelques éléments, la couverture et son bandeau, le format et la périodicité, ne sont pas affectés, sauf au cours de l'année I9I 4 où la parution est interrompue par la guerre. Cette année-là, seuls 47 numéros paraissent. À partir de I9I4, le nombre de pages augmente, variant de huit à douze, selon que des suppléments sont insérés ou non. Ceux-ci deviennent plus fréquents. L'épaississement des numéros est toujours au profit du texte, la part des dessins restant limitée à quatre pages. De I9I 5 à I9I7, un numéro compte parfois seize pages, grassement nourries d'encarts et de publicités. Le nombre de pages décroît cependant au cours du second semestre de I9 I 8, passant de douze à dix pages. Cet amincissement, dû à une réduction du volume publicitaire, se confirme les années suivantes. À partir de I9I9, un numéro compte huit pages.

La qualité du papier baisse à partir de I9 I 5, en relation avec la crise du papier. La désorganisation de la maquette intervient à la fin I9I 5 , à partir du numéro 43 , avec des images à la répartition soudain anarchique et l'ajout de publicités en fin de numéro. En I9I 7, les images ne sont parfois plus côte à côte. En I9I 8 , à partir du numéro 24 , les icones des rubriques, réintroduites en I9I3, présentent différents formats. À partir de I9I9, la maquette se dérègle tout à fait, les pages sont totalement remplies, donnant l'impression d'une absence de mise en page. Des petites caricatures parsèment la feuille et les légendes informent du contexte du dessin. Cette impression chaotique est renforcée par l'usage de différentes typographies sur une même page. Le numéro 20 de l'année I9I9 porte sous le titre la mention "Fondé par Jean Nötzli et Fritz Boscovits" (Gegründet von Jean Nötzli und Fritz Boscovits), produisant un effet bizarre, puisque le prénom Fritz est plutôt associé au fils, encore actif à cette époque, qu'au père, mort l'année précédente. La mention du nom du dessinateur devient irrégulière. Elle disparait totalement en I92 I. À ce moment-là, la maquette, en plus d'être désorganisée, donne, en raison de couleurs pâles et d'un manque de contraste, une impression de fadeur. Durant toute cette période, les doubles-pages n'auront été qu'au nombre de quatre, une en I9I4, deux en I9I 5 et une en I920. Un fait retient l'attention: la survivance du cadre au trait, apparaissant subrepticement sous la forme d'une ligne à peine appuyée.
2.6.2. Distribution, politique commerciale et lectorat - Sursauts et fuite en avant

Fin I9I 3 , les noms des partenaires commerciaux disparaissent et le prix au numéro est mis en exergue dans le coin droit de la couverture ${ }^{488}$. Les prix vont augmenter à deux reprises, en I9I7 et en I9I9, sans explications de la part de la rédaction. En I9I7, le prix de l'abonnement trimestriel, au centre de l'argumentaire commercial du Nebelspalter, est maintenu à 3,50 Fr. mais l'abonnement semestriel passe de $6 \mathrm{Fr}$. à $6,50 \mathrm{Fr}$., et l'abonnement annuel de I I Fr. à I 2,50 Fr. En I 9 I9, tous les prix sont concernés: le prix de l'abonnement trimestriel, stable depuis I907, passe, au numéro 20 , de 3,50 Fr. à 4 Fr., tandis que les abonnements trimestriel et semestriel passent respectivement de 6,50 Fr. à $8 \mathrm{Fr}$. et de I 2,50 Fr. à I $5 \mathrm{Fr}$. Le prix au numéro passe de 30 à $40 \mathrm{cts}$. dans le numéro suivant.

La politique des encarts rédactionnels reprend avec la photographie d'un personnage clownesque, exhortant les annonceurs à insérer: "Insérez dans le Nebelspalter " (Inserieren Sie im Nebelspalter) ${ }^{489}$ (cf. fig. 64).

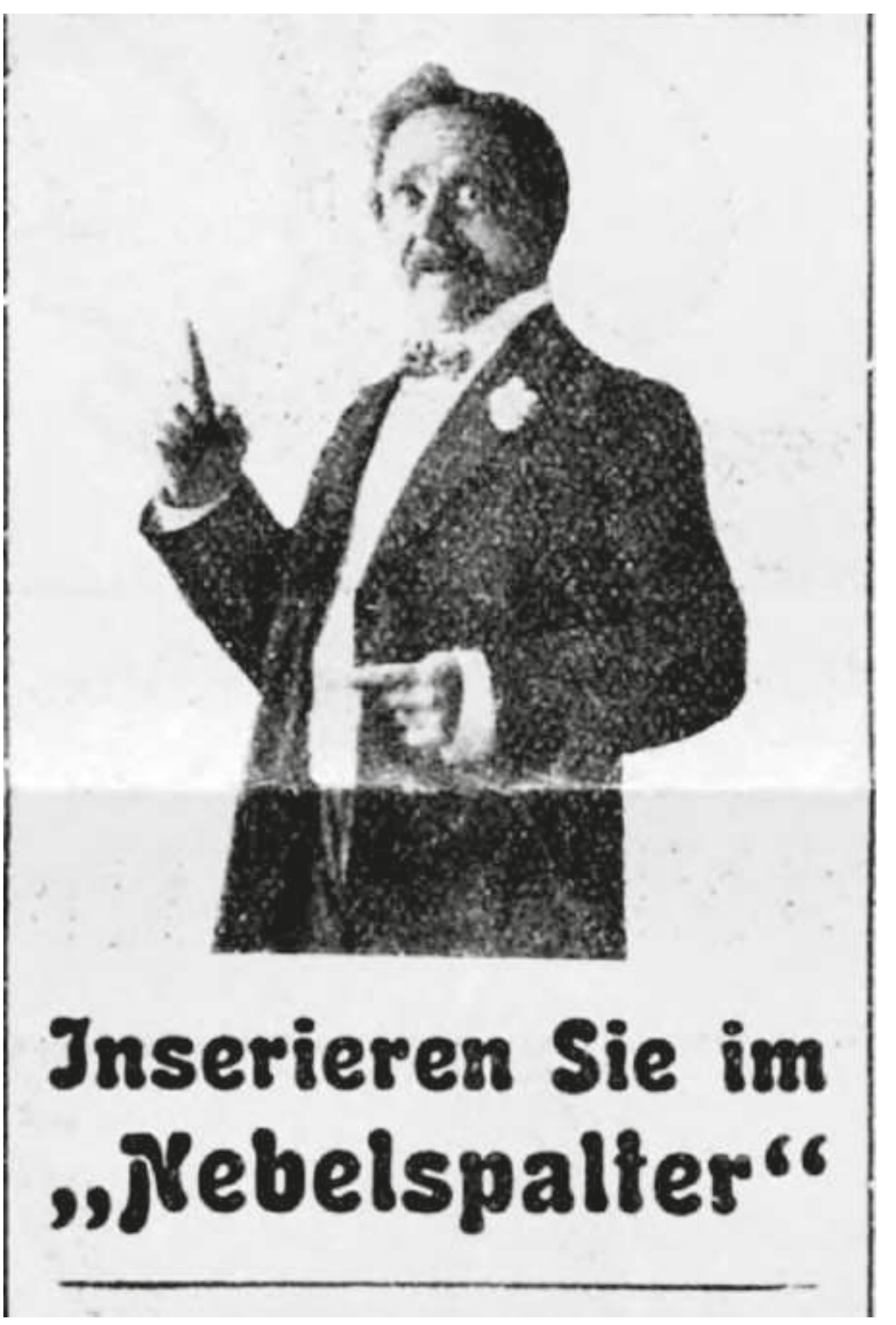

Fig. 64. Nebelspalter 1913/8, encart photographique. 
Gu[tav, der Frotektionsleutnant

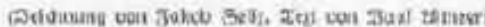

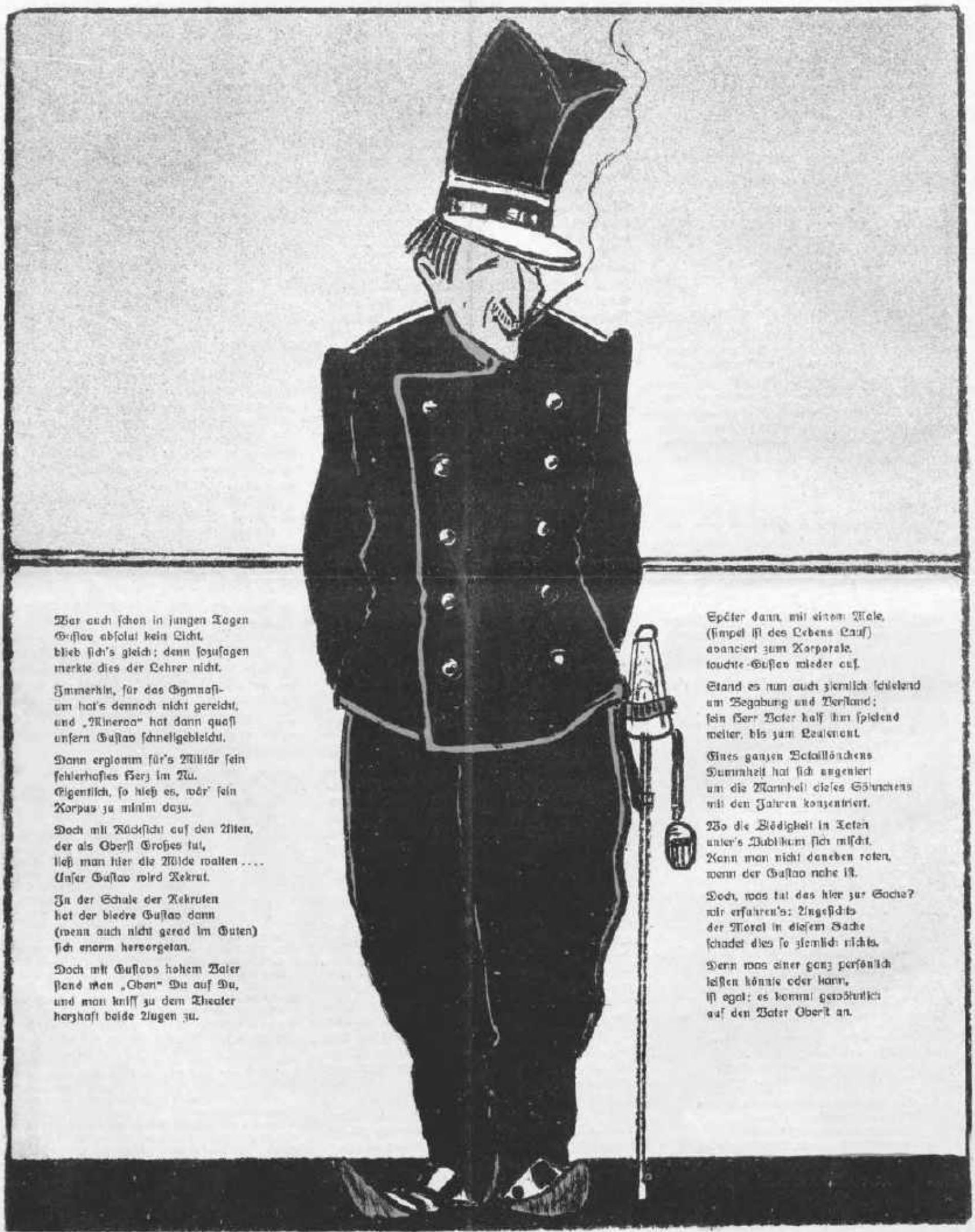

Fig. 65. Nebelspalter 1913/26, composition pleine page de Jakob Selig (image en couleur) et Paul Altheer (texte) intitulée « Gustave, le lieutenant protecteur » (Gustav, der Protektionsleutnant). 
Un abonnement dominical est proposé en I9I $3^{490}$; divers cadeaux sont promis aux abonnés, très souvent un porte-revue ${ }^{491}$. En I9I4, un encart versifié est pour la première fois en zurichois (Züridütsch). Cet usage du dialecte en dit long sur le périmètre de la revue à cette époque, plus ou moins réduit au canton de Zurich. Les encarts des années de guerre portent la trace du conflit: deux d'entre eux thématisent la confiscation du journal en I9 I $5^{492}$, naturellement avantageuse en terme d'image pour une revue satirique, tandis qu'en I9I6, l'argumentaire chargé d'appâter les abonnés repose sur une supposée recommandation du Nebelspalter par des belligérants « dont les opérations sont empêchées par un épais brouillard " (deren Operationen durch dichten Nebel bebindert werden) ${ }^{493}$. En I9I 8, trois encarts concernent l'emprunt de guerre national, dont l'un signé «Boscovits » 494 . De nombreux encarts sont le reflet d'initiatives sans lendemain, telle l'organisation d'une soirée littéraire avec les auteurs du Nebelspalter ${ }^{495}$; des appels d'offres farfelus ou une apologie de l'humour, au début de l'année I9I $8^{496}$. À partir de I9I 5, un bandeau très sobre indique un prix au numéro de 30 cts., les modalités de distribution du journal " disponible dans les librairies, les kiosques et auprès des crieurs de journaux " (in Buchhandlungen, Kiosks und bei den Strassenverkäufern erhältlich) ainsi qu'un surcoût de 20 cts. pour un acheminement postal. En I920 et I92 I, ce bandeau constitue le seul encart commercial.

Les produits dérivés signent leur grand retour. C'est un véritable festival de "produits Frey ", avec, en I9I3, une carte de la suisse $^{497}$; en I9I 5 , un livre sur le Général Wille ${ }^{498}$ ou encore des portraits des généraux Dufour, Wille et Herzog ${ }^{499}$; en I9 I6, une publication en russe ${ }^{500}$; en I9I 7, un tableau mural des horaires des trains et des bateaux ${ }^{501}$ ainsi qu'un calendrier Joggeli vanté comme « le plus grand calendrier de la Suisse » (Der größte Kalender der $\left.S_{c h w e i z}\right)^{502}$; en I9I 8, on retrouve la plupart de ces produits. Certains encarts sont estampillés Nebelspalter. Ils proposent des gains, comme le récit de guerre d'un légionnaire, en $19 \mathrm{I} 7^{503} \mathrm{ou}$ des produits à la vente, tel un atlas de guerre au prix de Io Fr. ${ }^{504}$

Le Nebelspalter et Jean Frey sont associés, avant même que l'imprimeur ne prenne officiellement la tête de la revue au début I9I9. En I9I7, le portrait du Président Decoppet par Boscovits senior est ainsi vendu par « les éditions du Nebelspalter (Jean Frey) à Zurich " (Verlag des "Nebelspalter " [Jean Frey] in Zürich) ${ }^{505}$. Tous ces encarts disparaissent presque complètement à la fin I9I9. Quant aux numéros spéciaux, ils sont quasi absents de cette dernière période, hormis un numéro de carnaval en I9I 3 et un numéro dédié aux heures de fermeture des établissements (un thème récurrent) en I9I $6^{506}$.

\footnotetext{
90 Nebelspalter 1913/31, encart

Nebelspalter 1913/14, encart.

492 Nebelspalter 1915/24, encart intitulé «Audience auprès du censeur " (Audienz beim Zensor); Nebelspalter 1915/25, encart intitulé «Appel d'offres » (Preisausschreiben)

493 Nebelspalter 1916/1, encart.

494 Nebelspalter 1918/23, encart; Nebelspalter 1918/24, encart; Nebelspalter 1918/25 encart.

495 Nebelspalter 1915/33, encart; Nebelspalter 1915/45, encart.

${ }_{496}$ Nebelspalter 1918/13, encart intitulé « Humour » (Humor).

${ }_{497}$ Nebelspalter 1913/31, encart.

498 Nebelspalter 1915/9, encart.

499 Nebelspalter 1915/26, encart.

Nebelspalter 1916/11, encart.

Nebelspalter $1917 / 9$, encart.

Nebelspalter 1917/44, encart.

Nebelspalter 1917/1, encart.

Nebelspalter 1915/26, encart.

Nebelspalter $1917 / 7$, encart.

Nebelspalter 1913/6 et Nebelspalter 1916/47.
}

Davantage encore que les encarts, la publicité témoigne d'un déclin. En I9I3, les assurances vieillesse et les caisses d'épargne remplacent les produits intimes à destination des femmes et des couples. Manifestement, le public vieillit. Courant I9I4, le volume de la publicité augmente. Il s'agit d'une illusion d'optique: l'omniprésence des encarts vantant les services et produits de Jean Frey ne peut tromper sur une baisse globale des insertions, patente à partir de I 9 I 8, et qui entraine une réduction du nombre de pages.

La perte d'audience est au reste confirmée par la mention d'un tirage à 4IOO exemplaires en I9I3 dans un encart sur la lecture dominicale ${ }^{507}$. Le chiffre est naturellement à prendre avec précaution. Il est cependant plutôt en accord avec les indications commerciales de 1909 d'une reliure tirée à 3500 exemplaires et est à rapprocher des indications fournies par Ernst Löpte-Benz, de 380 abonnés lors de la reprise de la revue en $1920^{508}$.

\subsubsection{Tendance et thèmes - Repli et ambigüité}

La tendance, tout en restant dans le cadre libéral-patriote, dénote à présent une certaine ambiguité. D'une part, le contenu plus politique, l'usage du dialecte, l'investissement des questions intérieures et la part qui leur est réservée, montrent un fort engagement sur le terrain national, voire un repli - il faut le souligner, amorcé dès avant la guerre -; de l'autre, l'entreprise $\mathrm{d}$ ' " helvétisation » des années précédentes est arrêtée et le système référentiel "helvétique " largement délaissé, voire moqué. Le sommet alpin de la Jungfrau sert à présent à critiquer la mode et surtout ses adeptes ${ }^{509}$. En I9I3, l'aviation militaire est raillée à plusieurs reprises et le soldat devient une figure savoureuse, une sorte de déclinaison re-contextualisée du bon gars, un peu idiot, traînant dans la rue ${ }^{510}$ (cf. fig. 65).

Les fêtes populaires et les concours de tirs sont passibles du même traitement. Le déclenchement de la Première Guerre mondiale modifie cet état de choses en clarifiant le positionnement politique de la revue, qui se range à la cause nationale, mais observe longtemps un traitement idéologique ambigu à l'égard des belligérants. Après la guerre, l'antisémitisme, jusque-là discret, fait un retour spectaculaire, en relation notamment avec la figure du profiteur et la thématique du sionisme ${ }^{511}$.

Les thèmes politiques et les questions sociétales continuent de dominer. La bureaucratie, le scrutin proportionnel, la fiscalité, le projet d'une révision de la loi sur la Banque nationale, le règlement des postes, l'émigration, l'armée ainsi que les péripéties autour du Gothard sont au cœur des débats intérieurs. Sur le front sociétal, la dénonciation de la misère et du chômage, avec leur lot de pauvre hères, produit quelques dessins saisissants, tel « Chômage ", à la fin I9I $3^{512}$ (cf. fig. 66).

\footnotetext{
Nebelspalter 1913/31, encart commercial

Knobel, Bruno, Die Schweiz im Nebelspalter. Karikaturen 1875 bis 1974 , Rorschach, Nebelspalter-Verlag, 1974, p. 5, 8.

509 Nebelspalter 1913/20, dessin pleine page de Boscovits junior intitulé « La Jungfrau à la mode » (Die Jungfrau à la mode).

510 Nebelspalter 1913/26, composition pleine page de Jakob Selig (image) et Paul Altheer (texte) intitulée " Gustave, le lieutenant protecteur » (Gustav, der Protektionsleutnant)

Cf. « 3.3.1. Se situer vis-à-vis d'un conflit étranger ».

512 Nebelspalter 1913/44, dessin de Karl Czerpien intitulé "Chômage » (Arbeitslosigkeit).
} 


\section{2rrbeitslofigkeit}

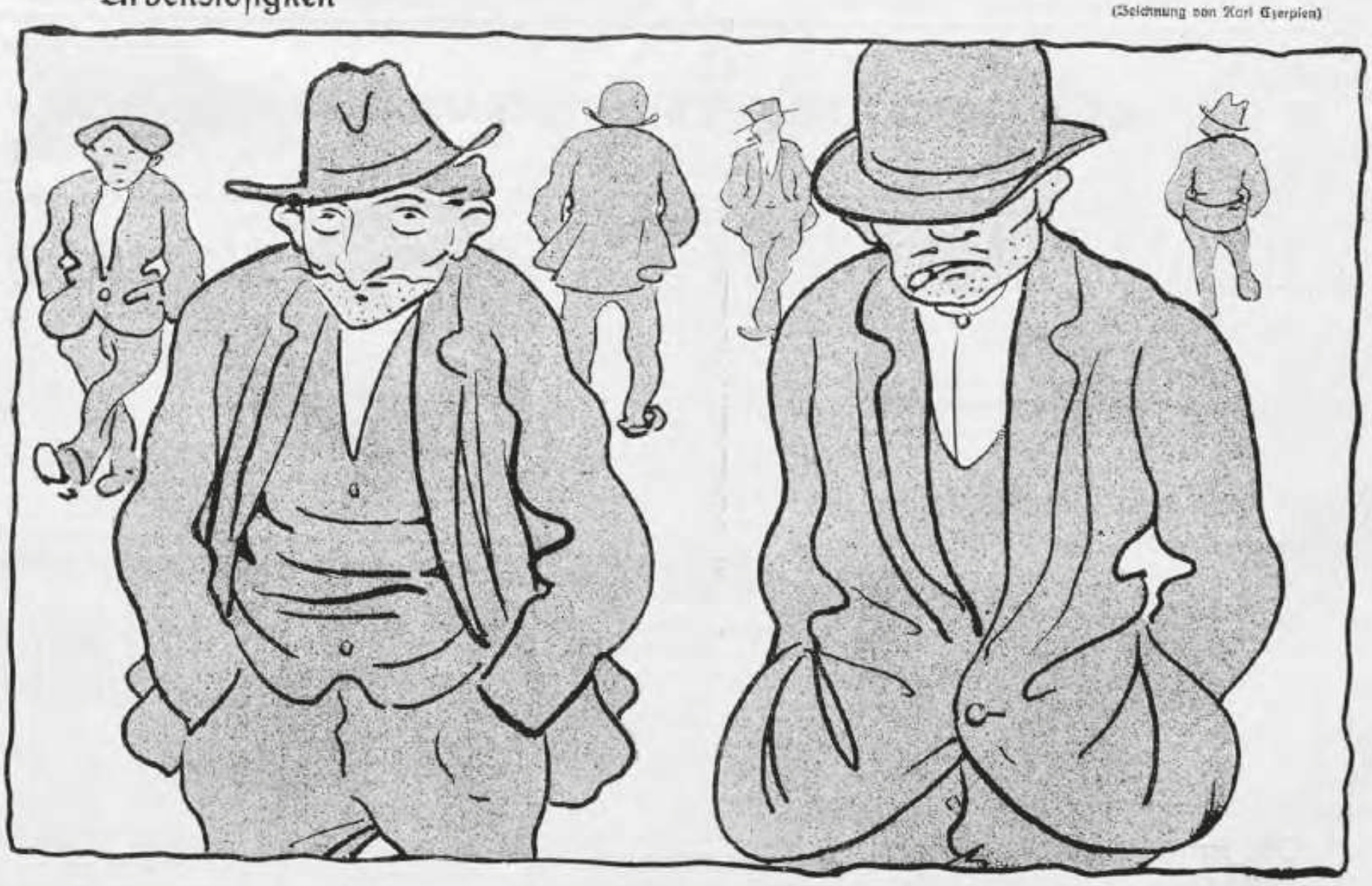

Die Konkurrenз roird mir 34 großj, ich gehe lieber roieder arbeiten.

Fig. 66. Nebelspalter 1913/44, dessin en couleur de Karl Czerpien intitulé « Chômage » (Arbeitslosigkeit)

Une nouvelle flambée anticléricale, le mouvement pour le relèvement moral (Sittlichkeitsbewegung) et l'émancipation des femmes, toujours aussi mal vue, sont d'autres thèmes prégnants. Des hommes manifestent en masse à Zurich contre le vote des femmes sur une couverture du début I9I3. Prince carnaval, successeur annoncé du personnage du Nebelspalter ${ }^{513}$, les tance avec des propos assez ambigus:

Nebelspalter; Ne nous énervons pas, mes très chers Messieurs! Ce n'est
qu'une question de forme. Nos lois permettent déjà les associations
de femmes ${ }^{514}$.

Les affaires zurichoises, électorales, culturelles, sociétales et urbanistiques, sont âprement discutées ${ }^{515}$. L'automobile engendre de nouveaux problèmes ${ }^{516}$, tout comme les deux-roues fonçant dans la Bahnhofstrasse, l'artère principale et très chic de Zurich ${ }^{517}$. Parmi les affaires culturelles et les débats artistiques, le projet de décorations murales de l'Université, qui devait échoir au très contesté Ferdinand Hodler - ce qui ne sera finalement pas le cas -, est fermement discuté deux années durant, à partir de I9I $4^{518}$.

Cf. « 5.5. Se citer soi-même plus que de mesure ».

(« Nebelspalter: Nur keine Aufregung, werteste Herren! Es handelt sich nur um eine Formsache. Unsere Gesetze machen ja ohnehin schon die Frauenvereine. »); Nebelspalter 1913/12, couverture de Karl Czerpien intitulée « Le droit de vote des femmes » (Das Frauenstimmrecht).

Cf. « 3.2.1. Le face-à-face (helvétique) du Nebelspalter avec Helvetia » ainsi que " 3.2.2. L'alliance sacrée ou la Suisse du Nebelspalter ».

Nebelspalter 1914/11, couverture de Boscovits junior intitulée « La $1485^{\text {ème }}$ amende automobile de l'année 1913 » (Die 1485 Automobil-Bussen des Jahres 1913).

Nebelspalter 1914/27, dessin pleine page de Boscovits senior intitulé « Du Zurich le plus sombre » (Aus dem dunkelsten Zürich).

La première de ces compositions se trouve dans le premier numéro de 1914 ; Nebelspalter 1914/1, dessin pleine page de Karl Czerpien intitulé «Bijou de I'Université »(Universitätsschmuck); cf. également Gabriela Christen,
Le socialisme est le thème politique vedette. Tout est bon pour en dénoncer les méfaits. L'appel à la grève générale du $\mathrm{I}^{\mathrm{er}}$ mai I9I3 est tourné en ridicule dans une composition où le rouge, couleur de ceux que l'on appelle les rouges (die Roten), domine ${ }^{519}$.

La modernité se montre au travers des sports et de la danse, football, hockey sur glace et tango. Lorsque le football apparaît pour la première fois, c'est cependant pour servir de trame rhétorique aux élections zurichoises, réputées "sportives " ${ }^{20}$. De même, quand le tango, la dernière coqueluche en matière de danse, attire les foudres du clergé, cela permet une charge anticléricale ${ }^{521}$. Les débats sur l'art sont quasi-inexistants, hormis des propos acerbes sur l'art contemporain, comme à l'endroit de Picasso ${ }^{522}$. L'attention se porte surtout sur l'exposition nationale à Berne en I9I4, initialement prévue en I9I3, qui est couverte par de très nombreuses caricatures. Certaines sont prétexte à des prises de position connexes, hostiles, par exemple, au circuit officiel de l'art ${ }^{523}$.

Ferdinand Hodler - Unendlichkeit und Tod: Monumentale Frauenfiguren in den Zürcher Wandbildern, Berlin, Reimer, 2008, p. 33-40; Michèle Jägi, Zürcher Universitätsgebäude, Gesellschaft für Schweizeriche Kunstgeschichte, Berne, 2005; voir aussi le chapitre 4

Nebelspalter 1913/17, composition de Wilfried Schweizer (dessin) et Martin Salander (texte) intitulée « Le programme de la fête du $1^{\text {er }}$ mai. Grève générale de 1913 » (Maifeier-Programm. Generalstreik 1913).

Nebelspalter 1914/13, couverture de Boscovits senior intitulée « Sur les élections au conseil municipal zurichois » (Zur Zürcher Stadtratswahl).

Nebelspalter 1914/7, dessin de Karl Czerpien intitulé « Le danger du tango » (Tangonot).

Nebelspalter 1913/14, dessin pleine page de Boscovits junior intitulé « Art maison » (Heimkunst).

Nebelspalter 1914/29, dessin de Karl Czerpien intitulé "La médaille de l'exposition » (Die Ausstellungsmedaille); sur l'exposition nationale de Berne en 1914, en premier lieu: Georg Kreis, "Expositions nationales », Dictionnaire historique de la Suisse (05/02/2008); http://www.hls-dhs-dss.ch/textes/f/F13796. php?topdf $=1$. 
À l'international, l'Allemagne est surreprésentée par rapport aux autres pays, notamment avec l'incident de Saverne. Paul Thesing rend compte des conséquences désastreuses du traitement injurieux de la minorité alsacienne par le sous-lieutenant et baron Günter von Forster. Le terme insultant de «Wackes » est repris par la presse, générant l'un des dessins les plus efficaces - quoique grossier - du Nebelspalter: Forster est forcé de sentir ce qu'il a répandu à terre ${ }^{524}$. L'Allemagne est suivie par la France et la Russie, dont le tsar est (encore et toujours) dessiné en massacreur fou par Karl Czerpien ${ }^{525}$ (cf. fig. 67).

Les guerres balkaniques et leurs effets délétères sur le climat international sont suivis de près. Dans ce contexte, l'Europe et les négociations en faveur de la paix prennent de l'importance ${ }^{526}$. La présence de l'Angleterre est ténue et très liée aux suffragettes. Les autres pays et entités politiques représentés avant le début du conflit sont la Belgique, le Mexique, la Chine, les États-Unis et l'Italie. Parmi les pays des Balkans, l'Albanie, la Grèce et la Turquie sont les entités politiques les plus exposées.

La guerre rebat les cartes. Une part considérable des compositions concernent directement - plus de la moitié - ou indirectement le conflit ${ }^{527}$. En I9I4, seule une caricature porte sur les affaires zurichoises, qui se voient reléguées au second plan. Les questions strictement intérieures se limitent dans un premier temps au budget, aux tarifs postaux et aux chemins de fer. Le scrutin proportionnel, le danger socialiste, la révision de la loi sur la Banque centrale, la bureaucratie, l'éducation, l'émancipation et les affaires zurichoises forment les thématiques réapparaissant progressivement aux côtés des sujets liés à la guerre, la critique des belligérants, l'approvisionnement, la neutralité, le fossé culturel et l'indépendance de la presse. Le thème de la censure est réactivé. La présence étrangère, à l'exception très notable de la Révolution russe de I9I7, objet de compositions à charge ${ }^{528}$, est entièrement vue à l'aune de la guerre, y compris le sort de l'Irlande ou du Mexique qui servent à défendre le choix de la neutralité (noninterventionniste et pacifique) de la Suisse.

Après la guerre, le règlement du conflit et ses suites sont concurrencés par un antibolchevisme virulent. " Le bolchevisme menace chacun d'entre nous" (Der Bolchevismus bedroht jeden!) de Alfred Hirschler, montrant un "rouge " visant le lecteur de son révolver, est, en ces temps pourtant bien fades, l'une des images les plus fortes du corpus ${ }^{529}$ (cf. fig. 68 cahier couleur). L'Allemagne, très présente, bénéficie d'une compassion dont la contrepartie est la critique acide des Français, des Anglais et des Américains. L'Europe décharnée côtoie les horreurs de la Révolution russe. Le Japon inquiète. Les questions culturelles et artistiques sont quasiment absentes, et l'hommage nécrologique à Hodler constitue une exception ${ }^{530}$. Le regard porté sur le monde est plus amer que jamais ${ }^{531}$.

${ }^{24}$ Nebelspalter 1913/49, dessin de Paul Thesing intitulé «Le lieutenant "Wackes" (Der « Wackes »-Leutnant); sur l'incident de Saverne, en premier lieu: David Schoenbaum, Zabern 1913: Consensus Politics in Imperial Germany, Londres, George Allen \& Unwin, 1982

${ }_{525}$ Nebelspalter 1914/10, dessin pleine page de Karl Czerpien intitulé « La garantie de la paix » (Die Garantie des Friedens).

Cf. « 3.1. Une iconographie du monde ».

Cf. « 3.3. La Première Guerre mondiale : la "drôle" de querre d'un périodique ».

${ }_{528}$ Nebelspalter 1917/28, dessin pleine page de Boscovits senior intitulé « La révolution russe » (Die russische Revolution).

29 Nebelspalter 1920/34, dessin pleine page de Alfred Hirschler intitulé «Le bolchevisme menace chacun d'entre nous » (Der Bolchevismus bedroht jeden!).

530 Nebelspalter 1918/22, dessin pleine page de Boscovits senior intitulé « À la porte du paradis " (An der Himmelspforte).

${ }^{3} 31$ Cf. « 3.3.4. L'après-guerre: ressassements en images ».

\subsubsection{Une rhétorique clivée}

Le ton change, il devient plus noir, plus mordant. Jusqu'à la guerre, les fêtes de tir et plus encore l'armée sont l'objet de moqueries répétées. L'usage du dialecte est massif. Les références humanistes, certes plus rares mais souvent indirectes, tel le titre "Parsifal et l'industrie du tourisme " (Parsifal und Fremdenindustrie) ${ }^{532}$, supposent un lectorat particulièrement cultivé. Le procédé de l'étranger comme miroir, maintenant les Balkans, est plus que jamais en vogue. Il se prolonge par la figure de l'étranger. Dans une couverture de I9I 3 , un étranger (Fremder) interpelle le propriétaire $\mathrm{du}$ restaurant de la gare au sujet d'une note excessive ${ }^{533}$. Certains titres saisonniers demeurent, tels "Sechseläuten ", mais la plupart sont circonstanciés. Quelques mots qualifient un état ou une situation, "Sales temps » (Schlechte Zeiten) ou "Monument universel à la démocratie »(Bureaukratie-Weltdenkmal).

La guerre réoriente la rhétorique. La censure impose des procédés très indirects, que le sujet soit national ou international. L'étranger en miroir est plus que jamais un recours, et les tournures ambigües se multiplient, notamment un décalage net entre le titre et la légende, devant attirer l'attention du lecteur et participer à son édification. À mesure que la guerre se prolonge, le discours devient plus direct. La rhétorique de la culture et de la civilisation s'impose. Le discours sur les affaires intérieures, éloignées de la guerre, ne changent, par contre, guère. L'usage du fonds religieux est très révélateur de cette rhétorique clivée: pathétique pour les compositions liées à la guerre, il reste pour les autres thématiques satirique. L'aprèsguerre voit se maintenir ce double fonctionnement, preuve s'il en est d'une difficulté à terminer la guerre ${ }^{534}$.

Un mouvement de balancier s'observe entre des années où sont privilégiés les caricatures politiques, les caricatures de mœurs ou les dessins humoristiques, indice d'une reconquête difficile du lectorat. En I9I3, l'humour est choisi pour la couverture, alors que la dernière page est réservée à une caricature politique ou de mœurs. Si le réinvestissement politique de I9I4 peut être mis sur le compte de la guerre, ce n'est pas le cas du retour à l'humour en I9I 635. En I9I7, une partie des pages intérieures livrant un propos critique, voire agressif, disparaît et il est assez fréquent que la dernière page soit de nouveau une caricature de mœurs. L'année suivante, en I9I 8 , les compositions légères, voire grivoises sont mises à l'honneur.

À partir de I9I9, les propos sont dominés par l'agressivité et le ressentiment vis-à-vis de l'Entente ${ }^{536}$. Ils sont aussi plus politiques et sociétaux. Les légendes des dessins tombent souvent à plat. Il arrive, du reste, qu'elles soient mal placées. En I9I9, à cinq numéros de distance ( 12 et I 9 ), deux dessins comportent la même légende, le second à bon escient, au contraire du premier ${ }^{537}$. Ce type d'erreurs confirme la pratique de légendes faites à l'avance, sur lesquelles viennent se greffer les dessins. Enfin, alors que les références très soutenues et complexes de l'année I9I3

\footnotetext{
Nebelspalter 1913/19, couverture de Boscovits junior intitulée « Parsifal et l'industrie du tourisme » (Parsifal und Fremdenindustrie).

3 Nebelspalter1913/10, couverture de Wilfried Schweizer intitulée «Le point sensible » (Aus den « Zahn » gefühlt).

34 Cf. plus généralement « 3.3. La Première Guerre mondiale: la "drôle" de guerre d'un périodique ».

Cf. « 3.3.2. Rire en guerre ».

536 Cf. « 3.3.4. L'après-guerre: ressassements en images ».

${ }_{537}$ Nebelspalter 1919/12, dessin de Alfred Hirschler intitulé "Armistice » (Waffenstillstand); Nebelspalter 1919/17, dessin de Alfred Hirschler intitulé « Négociations de paix » (Friedenverhandlungen).
} 
Die Garantie des Sriedens

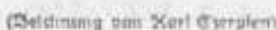

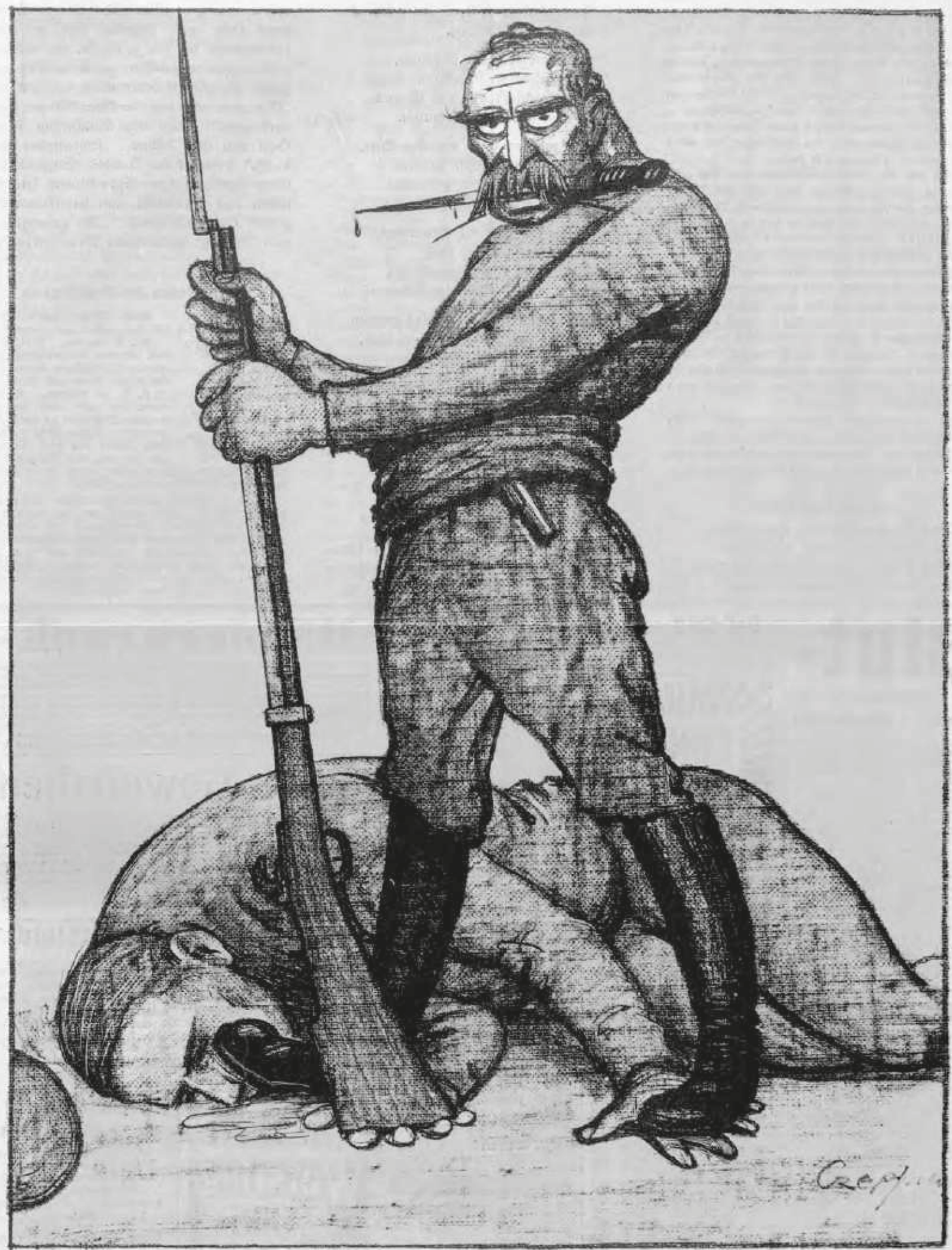

Fig. 67. Nebelspalter 1914/10, dessin pleine page en couleur de Karl Czerpien intitulé « La garantie de la paix » (Die Garantie des Friedens). 
s'adressaient à un lectorat parfaitement cultivé et au fait des choses, celles de I92 I sont directes et sans fioritures.

\subsubsection{Le chant du cygne de l'image}

De I9I3 à I9I 8 , le nom du dessinateur est indiqué sur le dessin. Un monogramme le redouble parfois dans l'image. La mention devient ensuite irrégulière pour disparaitre totalement en I $92 \mathrm{I}$, où certains dessins ne sont plus signés, ce qui rend l'authentification impossible.

Les dessinateurs vont et viennent, créant une impression hétéroclite. Le nombre de dessinateurs est relativement stable jusqu'en I9I9, oscillant entre douze et dix-neuf, pour passer à dix en 1920 et remonter à douze en I92 I. À cette date, seule une poignée de dessinateurs sont vraiment actifs. Chaque année voit au minimum le départ de cinq dessinateurs, ce qui est inhabituel dans l'histoire du périodique. Durant toute cette période, Boscovits junior emprunte aux nouveaux dessinateurs. Le talent de ces derniers est très variable, certains s'en tiennent à faire du « Boscovits modernisé », s'alignant visiblement sur le « style » du Nebelspalter, tandis que d'autres font preuve d'inventivité. Tel est le cas, par ordre d'arrivée et pour ne citer que les nouveaux crayons, de Karl Czerpien, Walter Lilie, Arthur Treichler, Karl Schlegel, H. Henrik, S. Mohr, Frieda Liermann - une des rares femmes artistes -, Victor Straus et H. Bindschedler. Karl Czerpien avec ses contours appuyés, sa démesure et son génie de la mise en scène, Paul Thessing et ses figures à peine tracées, emplissant une image où se mêlent aplats, espaces vides et crayonnés ${ }^{538}$ mais aussi Victor Straus et sa tendance au pathos religieux sont de ces artistes dont les contributions très personnelles se reconnaissent au premier coup d'œil. Emil Huber, qui ne fait pas que « du Jossot » mais s'exerce à différentes manières, appartient à la même catégorie de dessinateurs caméléons que Boscovits junior. Peu de ces dessinateurs sont passés à la postérité.

Le changement rédactionnel de la fin I9 2 modifie la cartographie visuelle. Rebaptisée au numéro 3 de l'année I9 I3, la revue se dote d'une nouvelle couverture, vitrine de son repositionnement. La mue, qui peut a priori sembler limitée à une épuration visuelle certaines informations sont supprimées - et au choix des lettres gothiques pour le titre et le sous-titre, est plus importante qu'il n'y paraît. La page accueille désormais une image volontiers humoristique et non plus politique. Cette recherche d'attractivité est néanmoins très ambiguë. D'un côté, le graphisme est assez vieillot, en grande partie à cause de couleurs mal maîtrisées, la typographie du titre archaïsante, la légende régressive, du fait d'un usage courant du dialecte; de l'autre, le jeu sur le cadre est, au contraire, souvent ludique. La première de ces couvertures montre ainsi deux personnages cernés par un cadre épais, rouge et hexagonal, s'entretenant en dialecte de l'aviation militaire ${ }^{539}$ (cf. fig. 62).

La vétusté de la maquette engendre une impression globale de vieillissement, qui ne doit pas masquer la disparité des dessins. Le langage visuel est difficile à caractériser. Il s'agit, pour partie d'un reliquat du Jugendstil; pour partie, d'un conglomérat de styles et manières. Du Jugendstil, il ne reste ni esprit festif, ni ambiance

\footnotetext{
${ }_{538}$ Nebelspalter 1913/3, dessin pleine page de Paul Thesing intitulé « Diplomates » (Diplomaten).

539 Nebelspalter 1913/3, couverture de Wilfried Schweizer.
}

idyllique, ni travail sur l'ornement mais une simplification des figures cadrées près du lecteur, une ironie aussi, dont les jeux sur le cadre sont emblématiques. Le champion de ce Jugendstil édulcoré est Boscovits junior. Le reste est redevable à des dessinateurs pour qui le Nebelspalter est un lieu d'exercice éphémère ou occasionnel, parmi d'autres revues ${ }^{54^{\circ}}$. Il y a un contraste saisissant entre le remplissage de la page à l'économie par Paul Thesing, les figures disproportionnées à cernes épais de Karl Czerpien, le travail sur les lignes et aplats de Wilfried Schweizer, l'application bien vieillotte de Boscovits senior et la page entièrement couverte de figures et détails de Herman Hintermeister ${ }^{541}$. De manière surprenante, des traces symbolistes subsistent dans cette période tardive, telle une couverture de la fin I9I3, signée de Walter Lilie pour le dessin et de Victor Hardung pour le texte. Le poète allemand, actif, entre autres, dans la revue Jugend, est familier de ce type de composition ${ }^{542}$.

Nombre de procédés traditionnels de la caricature sont encore présents: l'animalisation et la déformation des personnes, la réification, l'animation des objets, les changements d'échelle, l'inversion des rôles et du message. On retrouve les motifs de l'escargot politique, qui fait maintenant la course avec ses congénères ${ }^{543}$, de la longue vue, de la tresse, de l'homme de paille, de la pompe à fric, des chapeaux, balance, fauteuil, soupe et abattoir, comme l'escargot tous politiques, du timbre poste, des œufs de Pâques et de l'éternel ivrogne (Sauser). Des thèmes, figures et motifs moins anciens se pérennisent, tels les engins volants, l'ouvrier, le pressoir à loi ou encore les matchs de football. Des figures et motifs apparaissent, comme le phonographe et le diplomate, ce dernier au début de l'année I9I $4^{544}$.

De nouveaux procédés sont introduits, souvent sans bonheur, comme les bulles partant des lèvres des personnages de Karl Czerpien ${ }^{545}$. Certains sont raffinés mais d'une efficacité incertaine. Une couverture de Karl Czerpien du début de l'année I9I 4 en est un bon exemple. Intitulée "Exportation " (Export), elle met en scène un homme corpulent, en gros plan sur le côté droit de l'image, devant un panneau en bois indiqué comme un entrepôt (Speicher). Une ouverture dans le panneau libère en contrebas une scène sportive. Trois figures lointaines jouent au croquet, tandis que l'homme, les yeux rivés vers le lecteur, se félicite (cf. fig. 69):

Je dis une chose: nous n'aurons finalement d'autre choix que d'envoyer les socialistes en Sibérie et d'exporter le bon air des Alpes vers la Prusse ${ }^{546}$.

La composition met en abyme la figure du capitaliste, rendue familière et positive par la mise en scène et la légende. Le capitaliste, généralement maltraité par la revue, sert ici de base de tir contre la cible encore plus détestée des socialistes - un procédé assez machiavélique, dont on ne peut dire s'il aura fonctionné.

\footnotetext{
44. Cf. « 1.4. La configuration artistique et sociétale des dessinateurs ».

Nebelspalter 1913/28 dessin pleine page de Hermann Hintermeister intitulé « Sur les travaux de la rive gauche » (Zum Umbau der Linksufrigen).

${ }_{542}$ Nebelspalter 1913/44, couverture de Walter Lilie et Victor Hardung intitulée «Automne » (Herbst); cf. également Laurence Danguy, L'ange de la jeunesse. La revue Jugend et le Jugendstil à Munich, op. cit., p. 186.

543 Nebelspalter 1913/3, dessin de Boscovits senior intitulé « Un concours » (Ein Wettlauf).

544 Nebelspalter 1914/17, dessin pleine page de Paul Thesing intitulé « Nos diplomates » (Unsere Diplomaten).

${ }_{545}$ Nebelspalter 1914/28, couverture de Karl Czerpien intitulée « Les adventistes à Zurich » (Die Adventisten in Zürich).

${ }^{546}$ (Ich sag's ja: es wird uns schließlich doch nichts anderes übrig bleiben, als die Sozialisten nach Sibirien und die Freie Alpenluft nach Preußen zu exportieren.): Nebelspalter 1914/10, couverture de Karl Czerpien intitulée «Exportation » (Export).
} 
20. 10. 40. Jahrgang.

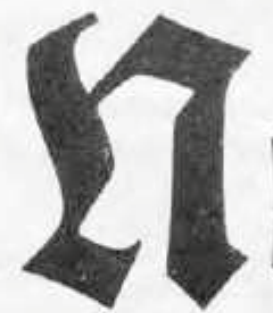

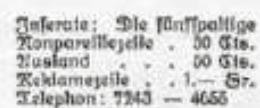

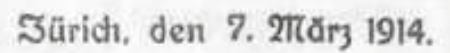
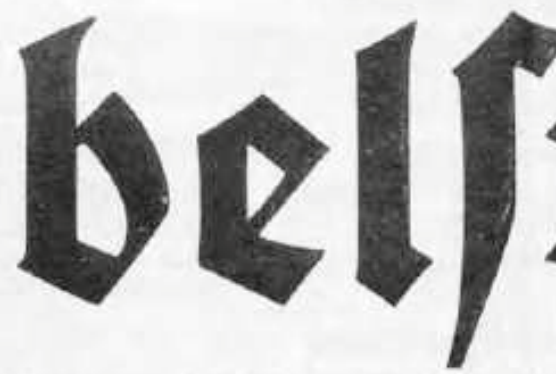
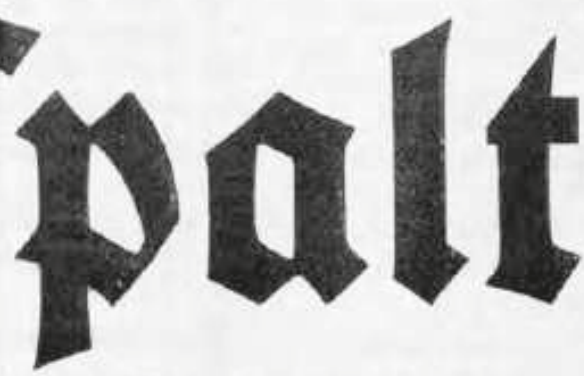

Einzelnummer 30 Cis.

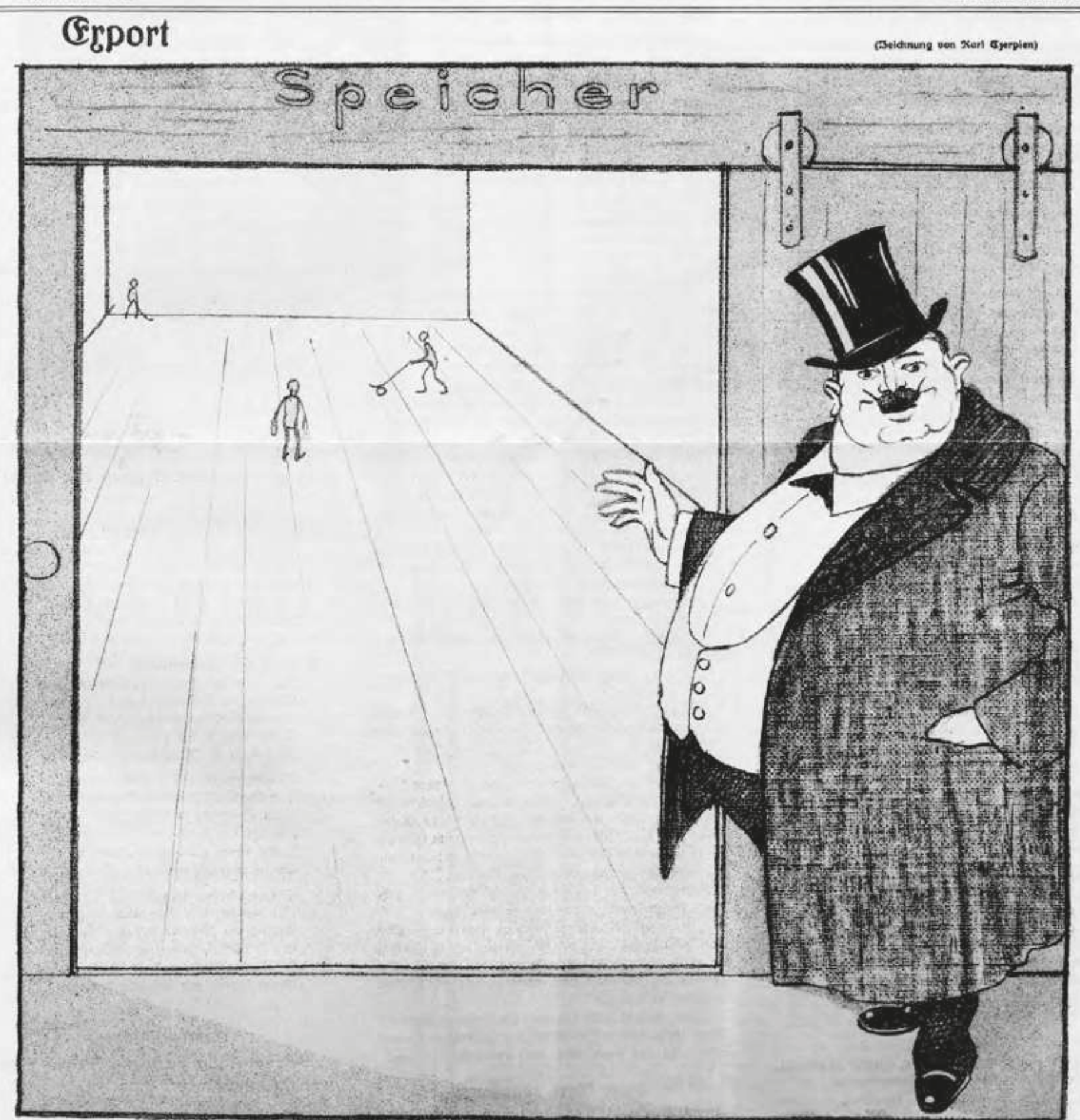

-Jh fag's ja: es roird uns [chlieblich doch nidits anderes übrig bleiben, als die Gozialifen nach Glbirien und die freie 2llpenluft nadi ¥reufien 3 u epportieren."

Fig. 69. Nebelspalter 1914/10, couverture en couleur de Karl Czerpien intitulée «Exportation » (Export). 
Les tensions internationales autour des Balkans, les affaires coloniales ainsi que les violences du régime tsariste continuent de nourrir une iconographie de la violence et d'être le prétexte à des schèmes racistes et sexistes. L'Europe a le vent en poupe ${ }^{547}$.

La guerre introduit une rupture. Dans un premier temps, un repli esthétique s'observe et les motifs de l'identité helvétique se multiplient, le paysan, le garçonnet en culotte courte, la croix helvétique, la femme en costume traditionnel, les Alpes mais aussi la figure du soldat, cette dernière reprenant progressivement une coloration humoristique. Le conflit, puis son règlement, engendre ensuite de nouveaux thèmes, motifs et figures, des scènes de guerre, de misère, de folie destructive et de pouvoir, d'êtres décharnés et de profiteurs $^{548}$. Dans leur majorité, les dessins sont moins soignés, conséquence probable du départ de dessinateurs importants et de la réduction des moyens financiers. En I 9 I 5 , plusieurs compositions dénotent une reviviscence du Jugendstil avec la réintégration d'un fonds médiéval, à l'honneur dans les années i 895-I905. Ceci se produit dans d'autres revues germaniques ${ }^{549}$. Une couverture de Boscovits junior est très représentative de cette tendance. Au centre, un poème intitulé «Chanson populaire »(Volkslied) prend place dans une sorte de mandorle, tandis que dans le pourtour, un troubadour chante pour sa belle ${ }^{550}$. La dernière année zurichoise, I 92 I, voit le retour de procédés caricaturaux abandonnés depuis longtemps, comme l'identification des personnages au moyen d'une inscription dans la figure. Autre signe de débandade: en I9I 8 , à partir du numéro 24, les icones des rubriques, réintroduites en I9I3, sont reformatées; des icones agrandies cohabitent désormais avec d'anciennes icones plus petites sans que l'on ait pris la peine de les uniformiser.

L'année I9I 3 ne compte qu'une double-page ${ }^{551}$ et un hommage à un grand homme. Signés par Boscovits senior, ils reprennent des formules délaissées les années précédentes ${ }^{552}$. Deux des trois doubles-pages de la période de guerre glorifient l'armée. La dernière double-page de l'époque zurichoise, en I920, sur le cabaret Corso, se situe dans la ligne des compositions Belle Époque ${ }^{553}$. Les hommages aux grands hommes sont rares, se limitant à la célébration du nouveau consul suisse à Rome en I9I 4 et à l'accès à la présidence de la Confédération par Giuseppe Motta en I9I $5^{554}$.

\subsubsection{Divorce de la femme et de l'allégorie}

La représentation de la femme est désormais largement dissociée de l'allégorie. Dans un premier temps, elle est surtout liée à la question de l'émancipation féminine, très présente jusqu'à la guerre. Hostile au mouvement, le périodique véhicule une image

Cf. « 3.1.2. 1887-1914: déclinaisons d'un univers en expansion et d'une Europe impuissante $"$

548 Cf. « 3.3. La Première Guerre mondiale: la "drôle" de guerre d'un périodique ».

549 Laurence Danguy, « Le $7^{\text {ème }}$ emprunt de guerre allemand dans la revue Jugend un cas de syncrétisme opportun » dans Images militantes, images de propagande, éd. Christian Amalvi, Paris, éditions du CTHS, 2010, p. 103-117.

50 Nebelspalter 1915/34, couverture de Boscovits junior et Kurt Robischek.

${ }_{551}$ Nebelspalter 1913/10, double-page de Boscovits senior intitulée « À propos de la convention du Gothard » (Zum Gotthardvertrag).

552 Nebelspalter 1913/24, dessin pleine page de Boscovits senior intitulé « Hommes d'État suisses » (Schweizerische Staatsmänner)

553 Nebelspalter 1920/1, double-page de S. Mohr intitulée « Un énorme succès au théâtre du Corso à Zurich » (Ein grosser Sensations-Erfolg im Corso-Theater in Zürich).

${ }_{554}$ Nebelspalter $1914 / 47$, dessin pleine page de Boscovits senior intitulé « Le nouveau consul suisse à Rome »(Der neue schweizerische Gesandte in Rom) et Nebelspalter 1915/1, dessin de Boscovits senior intitulé « Le nouveau président de la Confédération » (Der neue Bundespräsident). dépréciative de la femme, ouvrant sur des types iconographiques dépourvus de séduction. Les suffragettes sont ainsi, au choix, une femme maigre aux traits disgracieux et aux seins pendants ou une matrone à la pilosité exagérée ${ }^{555}$ (cf. fig. 70).

Ce type de représentation cohabite avec celui de la femme de petite vertu et donc de petite moralité, prétexte à des représentations érotisées ${ }^{556}$. Ce second type survit à la guerre, et Boscovits senior en personne dessine une belle en petite tenue demandant à être rémunérée en tickets de rationnement plutôt qu'avec un billet de vingt francs ${ }^{557}$. Le dessinateur H. Henrik introduit à partir de I9I 6 une variante préfigurant les dessins des années vingt, d'un érotisme tout à fait inhabituel dans le Nebelspalter ${ }^{558}$. Le dénudement se retrouve chez les élégantes que fournit S. Mohr à partir de I9I 7. Il va du reste gagner les allégories, telle celle du mois d'août I 9 I 855 . À vrai dire, le lien entre allégorie et représentation féminine est ici très ténu et relève du prétexte à la création d'un nu. S. Mohr répète d'ailleurs le schéma pour représenter l'automne et l'hiver ${ }^{560}$.

L'allégorie est présente, sous une forme peu créative et peu investie, ce dont témoigne l'usage indifférencié par Boscovits senior d'une figure quasi identique pour incarner la paix et Germania - encore qu'une visée propagandiste en faveur de l'Allemagne ne peut être ici exclue ${ }^{561}$. L'allégorie est également polymorphe. Différents concepts sont incarnés sans beaucoup de conviction ou talent, non seulement par des femmes, tels la paix, le printemps ou la mort blanche (dans les montagnes) ${ }^{562}$ mais aussi par des hommes, tels l'hiver ou la proportionnelle (Der Proporz), cette dernière par un éphèbe ${ }^{563}$; voire même par des monstres, telle la rumeur en I9I $4^{564}$ (cf. fig. 7I).

Quelques rares allégories de pays voient leur iconographie renouvelée durant la guerre: Marianne devient une patineuse blonde, dotée d'une cocarde sous le crayon de Treichler; l'Entente prend corps avec Boscovits junior; un dessinateur signant « F.M. » vêt ses protagonistes de costumes traditionnels.

La présence d'Helvetia et du Nebelspalter est représentative du dernier cycle de vie du Nebelspalter zurichois, en ce qu'elle est essentiellement liée aux affaires intérieures. Les deux personnages ne "reprennent du service extérieur " qu'après la guerre, uniquement, du reste, dans une dynamique réflexive, mettant en valeur les choix suisses. Tous deux sont quasi absents la dernière année de parution, en I92I. Helvetia est néanmoins présente une

\footnotetext{
Nebelspalter 1914/23, dessin pleine page de Paul Thesing intitulé « Dans la ménagerie des suffragettes » (In der Suffragetten-Menagerie).

56 Nebelspalter 1914/8, dessin de Karl Czerpien intitulé « L'année du mauvais commerce » (Das schlechte Geschäftsjahr).

${ }_{57}$ Nebelspalter 1917/42, dessin de Boscovits senior intitulé « L'amour pour le pain quotidien » (Die Liebe ums tägliche Brot).

${ }_{558}$ Nebelspalter 1917/44, dessin de Henrik intitulé « Toute I'histoire de Baptiste » (Die ganze Geschichte Battist).

559 Nebelspalter 1918/34, dessin de Henrik intitulé « Août » (August).

560 Nebelspalter 1918/38, dessin de Henrik intitulé « Automne » (Herbst); Nebelspalter 1918/51, dessin de Henrik intitulé « Hiver » (Winter).

Nebelspalter 1917/1, couverture de Boscovits senior intitulée « Le bal de la nouvelle année » (Neujahrs-Ball) et Nebelspalter 1917/42, couverture de Boscovits senior intitulée «Panne » (Panne)

562 Nebelspalter 1914/2, dessin pleine page de Hermann Hintermeister intitulé «La mort blanche » (Der Weiße Tod).

${ }_{563}$ Nebelspalter 1914/26, dessin pleine page de Boscovits senior intitulé « La proportionnelle au Conseil national » (Der Proporz im Nationalrat).

564 Nebelspalter 1914/46, couverture de Boscovits senior intitulée « La rumeur » (Das Gerücht).
} 


\section{In der Guffragetten 2Tenagerie}

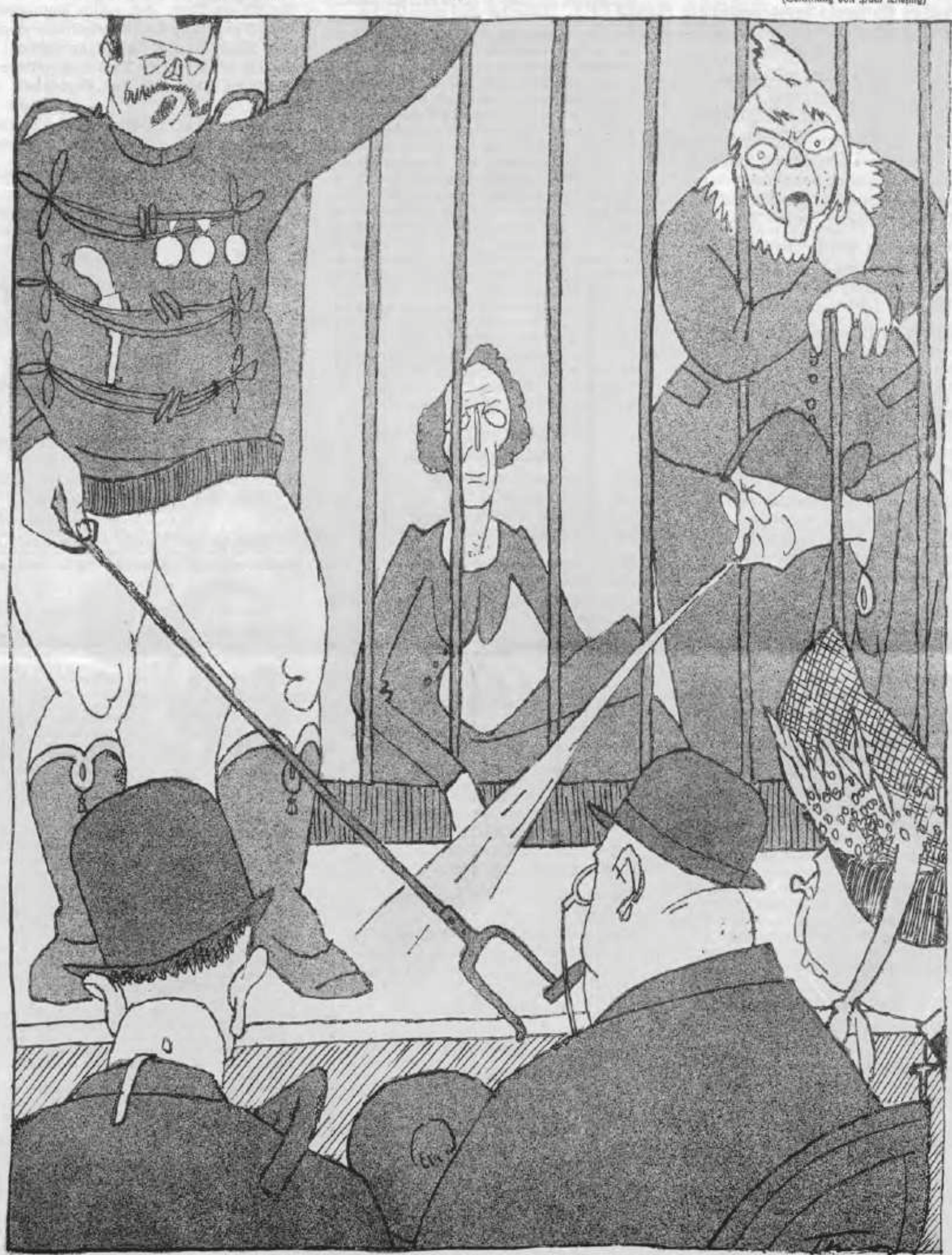

Die lieble 2tahrung der Beftien find gut zerkleinerle Correggios und gehadkte Iizians, foroie Gtüche alter Plapilken in Iomatenjauce.

Fig. 70. Nebelspalter 1914/23, dessin pleine page en couleur de Paul Thesing intitulé « Dans la ménagerie des suffragettes » (In der Suffragetten-Menagerie). 
Der Jroporz im 2lationalrat

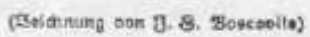

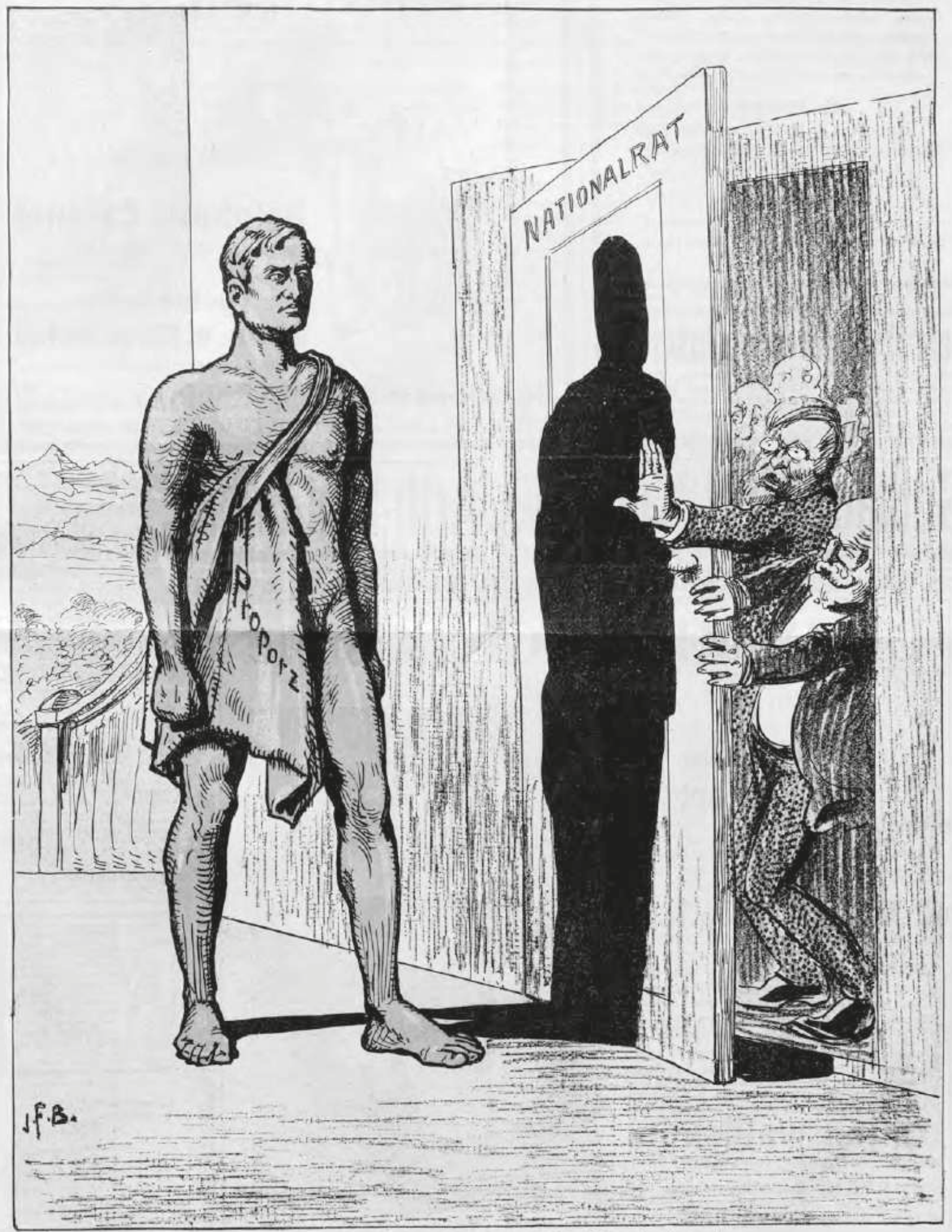

ger 27 ationalrat: Gie irren fich, hier find Sie nicht berlangt roorden.

Fig. 71. Nebelspalter 1914/26, dessin pleine page en couleur de Boscovits senior intitulé « La proportionnelle au Conseil national » (Der Proporz im Nationalrat). 


\section{Geiltänzerkünfte}

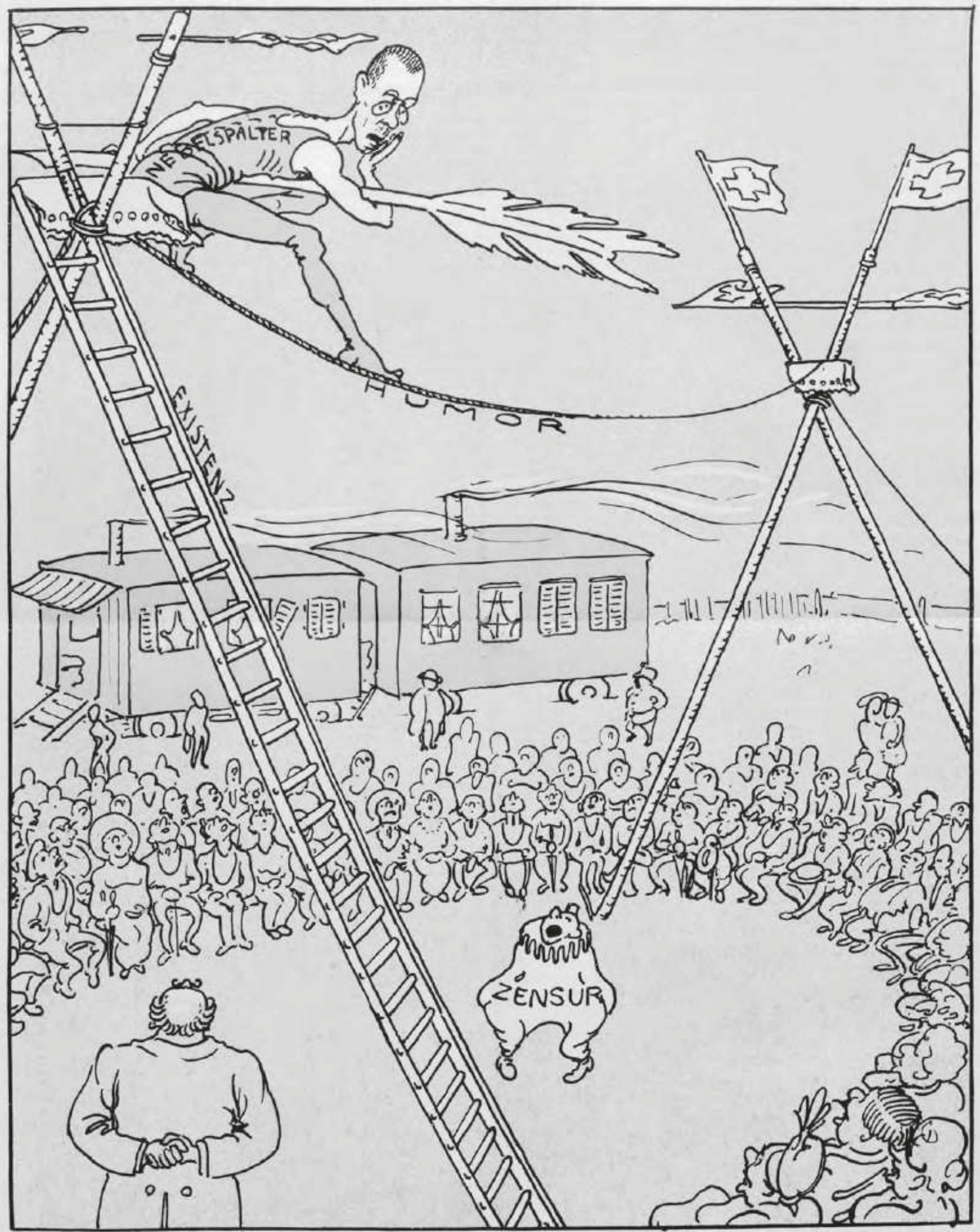

Der (Sloron: Ferr פirektor! Gagen Gie dem da oben, er foll roährend diefer 2tummer den 2Tund halten. es roird mir fonft focroindlig!

Fig. 72. Nebelspalter 1915/24, dessin pleine page en couleur de Karl Czerpien intitulé « L'art du funambule » (Seiltänzerkünste). 
fois sous une forme dégradée ${ }^{565}$ : elle quitte, pour ainsi dire, un navire en déroute.

Étonnamment, vu les temps guerriers, la présence d'Helvetia reste modérée jusqu'en I9I6, entre cinq et huit occurrences annuelles, pour soudain passer à vingt-deux occurrences en I9I6. Le fait est lié au repositionnement du journal, qui sort de sa réserve pour prendre parti en faveur de l'Allemagne ${ }^{566}$. Les années suivantes, la présence d'Helvetia reste modeste, entre une et dix occurrences. Jusqu'à la guerre, son iconographie résulte d'un compromis entre tradition et modernité: en I9I3, Helvetia apparaît dans une robe fleurie en compagnie des sept conseillers fédéraux, transformés en oiseaux pour l'occasion ${ }^{567}$; à l'aube de la guerre, elle prête son habit de ménagère orné d'une large croix au Président de la Confédération, Arthur Hoffmann ${ }^{568}$; quelques mois auparavant, elle s'était présentée en banquière de l'Europe ${ }^{569}$. Helvetia s'implique évidemment dans la guerre, ce qui, finalement, affecte assez peu son iconographie. Restant le plus souvent dans ses frontières, elle ne porte pas l'armure. Les innovations sont rares et presque toujours en relation avec un modèle émancipé, où l'apparence d'Helvetia se cale sur celle de la femme moderne, qu'il s'agisse d'incarner la neutralité ${ }^{570}$ ou de dramatiser le danger bolchevique ${ }^{571}$. Dans une caricature sur l'ambiguïté de la Suisse face au conflit, la dame apparaît statufiée ${ }^{572}$. À la différence de certaines allégories, telle Marianne, et conformément à son habitude, Helvetia arbore toujours une tenue très correcte. Durant toute cette période, elle est sérieusement concurrencée par Wilhelm Tell: il faut dire que le guerrier masculin s'accorde avec l'époque.

Comme Helvetia, le Nebelspalter s'efface progressivement du journal et connaît un rebond éphémère en I9I6. Trois modes de présence cohabitent: le personnage, redoublé ou non de son journal; le journal seul; ainsi qu'une affiche, une rareté dans le corpus, incluse dans les tribulations d'un ivrogne ${ }^{573}$. L'iconographie du personnage se délite peu à peu. En I9 I 5 , le Nebelspalter devient un funambule malingre sous le crayon de Karl Czerpien ${ }^{574}$; Boscovits senior le figure, en I9I6, en train de mendier ${ }^{575}$ (cf. fig. $\mathbf{7 2}^{2}$ ).

Surtout, il cède de plus en plus fréquemment la place à son successeur Prince carnaval ${ }^{576}$. Le Nebelspalter défend tout à la fois les intérêts du pays et ceux d'un journal qui doit composer avec la censure, renforcée en temps de guerre. Parfois, il se pose en instance morale et déplore les malheurs de la guerre.

Nebelspalter 1921/15, couverture de Boscovits junior intitulée « Ainsi l'entendent les Français » (So verstehen es die Franzosen!).

Cf. « 3.3.1. Se situer vis-à-vis d'un conflit étranger ».

567 Nebelspalter 1913/18, dessin de Hermann Hintermeister intitulé « Le prêt fédéral » (Das eidgenössische Anleihen).

568 Nebelspalter 1914/26, couverture Karl Czerpien intitulée « Augmentation des taxes postales? ॥ (Erhöhung der Posttaxen?).

${ }_{569}$ Nebelspalter 1914/11, dessin de Karl Czerpien intitulé « La Suisse en banquière de l'Europe » (Die Schweiz als Bankier Europas).

77 Nebelspalter 1915/25, dessin de Karl Czerpien intitulé « Le trust des importations » (Der Einfuhrtrust)

${ }^{571}$ Nebelspalter 1918/33, dessin pleine page de Boscovits junior intitulé « Notre situation » (Unsere Situation).

${ }_{72}$ Nebelspalter 1915/23, dessin de Boscovits senior intitulé « Patriotes par temps difficiles » (Patrioten in schwerer Zeit).

573 Nebelspalter 1913/3, dessin de Boscovits senior intitulé « Une proposition pratique » (Ein praktischer Vorschlag).

574 Nebelspalter 1915/24, dessin pleine page de Karl Czerpien intitulé « L'art du funambule » (Seiltänzerkünste).

575 Nebelspalter 1916/7, dessin de Boscovits senior intitulé « De la graisse » (Von der Schmiere).

${ }_{576}$ Au sujet de Prince Carnaval; cf. « 5.5. Se citer soi-même plus que de mesure ».

\subsubsection{Dilution de la couleur}

Pour la couleur comme pour le reste, cette dernière période de l'époque zurichoise montre un désinvestissement qui ne peut s'expliquer par le seul facteur économique mais illustre - et participe à - un état d'épuisement général. Ces années ne montrent aucune innovation, si ce n'est, dans les premiers temps, des teintes très vives, inédites jusque-là. La gamme chromatique est strictement la même. En I9 I3, alors que cohabitent des pages en noir et blanc intégrant deux ou trois couleurs avec des pages bichromes, les couleurs de ces dernières sont parfois très soutenues. La cohabitation des deux formules perdurent mais, à partir de I9I4, le noir et blanc augmenté d'une couleur est privilégié aux dépens de la bichromie. Il est de rares exceptions, tel le numéro 36 de l'année I9 I 4 montrant des compositions à cinq couleurs, de la couverture sur la situation européenne ${ }^{577}$ à la dernière page ironisant sur la journée d'un homme neutre ${ }^{578}$.

La fin de l'année I9I 5 marque une césure. À partir du numéro 46, le placement de pages publicitaires en fin de numéro compromet la conception (semi-)unitaire de la maquette: les couvertures et les dernières pages correspondent entre elles (et les pages intérieures de leur côté) mais ce n'est plus une évidence visuelle. À partir de I9I6, s'observe un appauvrissement de la couleur: une seule couleur est généralement intégrée au noir et blanc, et les compositions bichromes se font rares.

Un sursaut intervient en I9I7 mais il est paradoxal, avec le retour à des formules anciennes, notamment la bichromie. Les couleurs sont le plus souvent pâles, quelquefois intenses et le résultat esthétiquement incertain. Lorsque les dessins (des demi-pages et quarts de pages) sont superposés, il arrive que les couleurs débordent d'une case à l'autre, donnant l'impression d'une réalisation bâclée. Cette déficience est exploitée par Boscovits junior qui fait glisser le rouge d'un cadre à l'autre dans une composition où il transforme une Marianne en ange de la paix immaculés79; ceci témoigne du génie opportuniste du dessinateur. Un noir et blanc esthétisé, disparu depuis longtemps, réapparaît par ailleurs (cf. fig. 73).

Après la guerre, les expériences se font rares. Une couverture de la fin de l'année I9I9 est de celles-ci ${ }^{580}$. Le dessin à la mine de Karl Czerpien est entièrement colorié de rouge. Cette couleur domine d'ailleurs la maquette. Sa suprématie est liée à l'omniprésence du thème bolchevique. Durant les deux dernières années, I920 et I92 I, la règle devient cependant le noir et blanc augmenté d'une couleur, avec une présence marginale des pages bichromes. Une impression de pauvreté chromatique l'emporte alors.

\footnotetext{
Nebelspalter 1914/36, couverture de Boscovits junior intitulée « La situation européenne » (Die europäische Lage).

${ }_{578}$ Nebelspalter 1914/36, dessin en quatre tableaux de Boscovits junior intitulé « La journée d'un véritable neutre strict » (Tagesordnung eines streng Neutralen).

579 Nebelspalter 1917/49, dessin en quatre tableaux de Boscovits junior intitulé "Métamorphose " (Metamorphose).

580 Nebelspalter 1919/46, couverture de Karl Czerpien intitulée « Lénine, le favori »
} (Lenin, der Günstling). 


\section{Tetamorphofe}

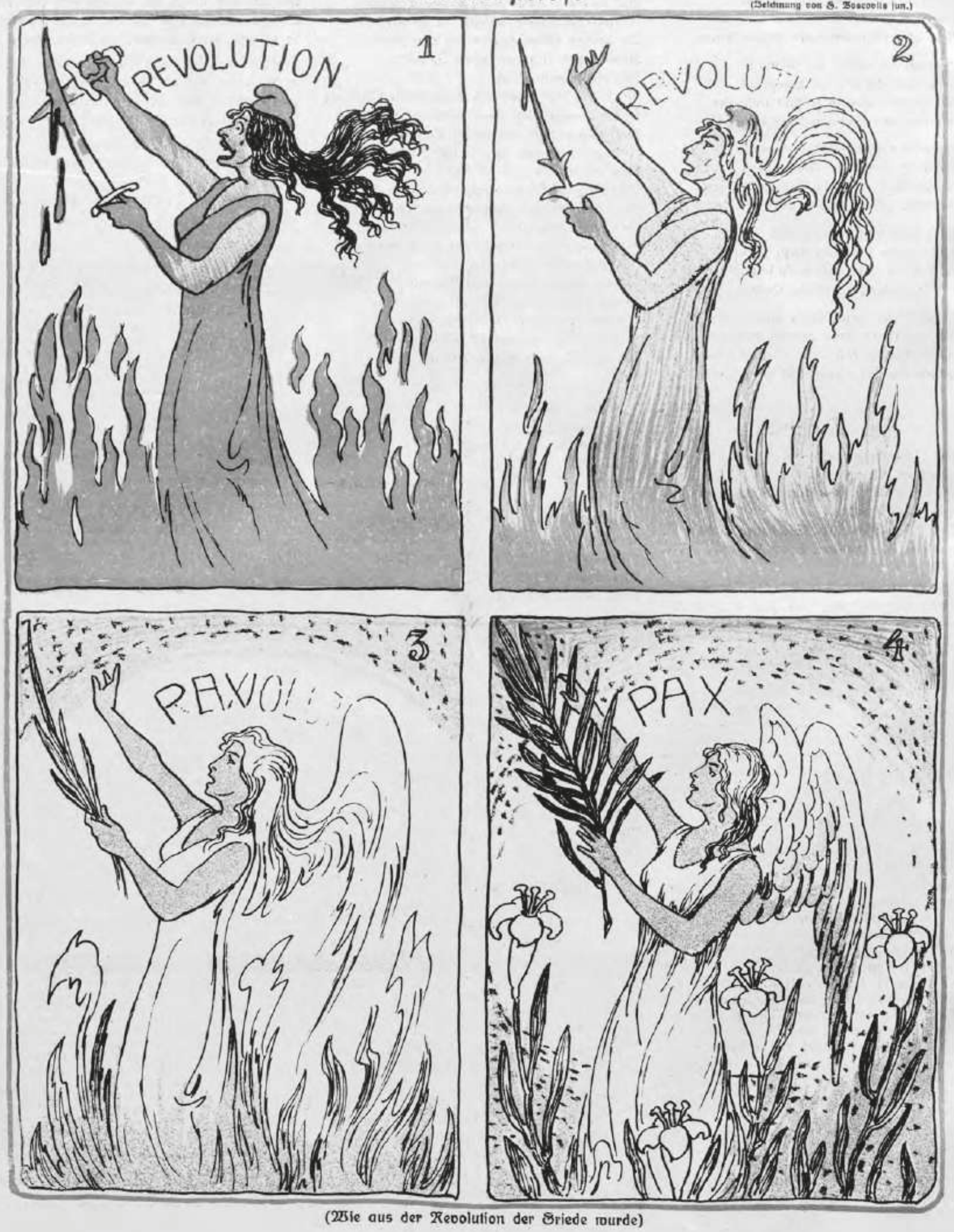

Fig. 73. Nebelspalter 1917/49, dessin en couleur, en quatre tableaux de Boscovits junior intitulé « Métamorphose » (Metamorphose). 


\section{DEUXIÈME PARTIE}

UN CERTAIN REGARD SUR LE MONDE 


\section{REGARD SUR UN MONDE AUX DÉCLINAISONS PLURIELLES}

Le regard que porte le Nebelspalter sur le monde entre I 875 et I $92 \mathrm{I}$ est l'histoire d'une vision autocentrée, qui s'ouvre à partir de I 887 jusqu'au déclenchement de la Première Guerre mondiale, où s'amorce un désenchantement. Ce regard vaut autant pour ce qu'il expose que pour ce qu'il ne montre pas, ou de manière biaisée. Quoi qu'il en soit, on ne saurait écrire l'histoire d'après les textes et les images du Nebelspalter. Ces documents sont des sources qui, en tant que telles, doivent être soumises à une critique rigoureuse. Elles transmettent un point de vue esthétisé, dont on espère qu'il atteindra, informera, divertira et surtout plaira au lecteur. Ces visées, en partie paradoxales, sont susceptibles d'exister dans une même composition, en outre passée au spectre déformant de la satire. Le monde selon le Nebelspalter est donc une image - iconographique ou/et mentale - façonnée par un rédacteur et/ou un dessinateur, et (r-) ajustée par la rédaction le « $\mathrm{r} »$ se justifiant selon le moment où celle-ci intervient dans le processus de création. Durant la Première Guerre mondiale, la moitié des contributions est consacrée à la guerre. Souvent regardés comme des documents d'histoire - et certes, les événements s'y retrouvent -, ces dessins résultent d'un regard très filtré. Ces images, qui sont pour beaucoup d'une qualité esthétique nettement supérieure à celles des années précédentes, peuvent être questionnées bien au-delà de leur (relative) qualité testimoniale et notamment quant aux moyens formels engagés pour transmettre, convaincre, effrayer et distraire dans une guerre des images qui se joue au niveau européen. On peut enfin s'interroger sur l'effondrement représentationnel au sortir du conflit, qui ne peut s'expliquer par la seule réduction des moyens financiers.

\subsection{Une iconographie du monde}

Le monde du Nebelspalter est un monde de papier. De papier, certes mais dont les propos et dessins restituent une vision qui évolue, tant par ses angles que par le périmètre qu'elle recouvre. Si l'on voulait employer une métaphore, ce serait celle du cercle ou plutôt des cercles. L'univers du Nebelspalter se présente, en effet, telle une sphère agrégeant des cercles concentriques. Ceux-ci ne sont pas tous visibles à l'origine, ils apparaissent au fil du temps. Les plus proches du centre, ceux zurichois et de la Suisse, sont les premiers à se montrer mais pour être vus, encore ont-ils besoin de la lumière des autres et surtout de leurs (grands) voisins, la France et l'Allemagne'. En d'autres termes, la Suisse (du Nebelspalter) ne s'éclaire qu'avec eux, elle a besoin de leur présence pour être explicitée. Les autres cercles, ceux de pays plus lointains, apparaissent progressivement. Le globe est le premier motif de la géographie du Nebelspalter, la focale étant souvent jetée sur une région ou une autre. Souvent du reste, un ou plusieurs personnages, parfois le Nebelspalter en personne, observent un pays, une région, une ville même depuis un endroit déterminé. Si les temps guerriers l'exigent, le globe sera utilisé, éclairé dans son entier. Pendant la Première Guerre mondiale, cependant, on ne convoquera qu'une partie de la batterie topographique, globes et cartes notamment, l'attention se portant plutôt sur les personnalités décisives, d'où une certaine survivance du portrait (géo-)physiognomonique, par ailleurs vieilli. Il est plusieurs manières de voir l'histoire et de la regarder. Le Nebelspalter regarde, pour sa part, via la lorgnette de ses intérêts, au sens propre et au sens figuré, et restitue son regard tout à la fois en mots et en images. Et ces dernières, étudiées ici, auront sans doute édifié efficacement les esprits.

\subsubsection{5-1886 : figures et motifs d'une ouverture a minima}

Le degré d'ouverture du Nebelspalter et son évolution peuvent être mesurés à l'apparition, la nature et la généralisation des globes, cartes et autres motifs topographiques dans les dessins. Les quatre premières années, de I 875 à I 879, toutes les représentations spatiales sont suisses, certaines zurichoises, et strictement topographiques, c'est-à-dire qu'elles restituent un lieu déterminé 2 . Le globe est le premier motif à apparaître, à la fin I 879, dans une image au graphisme saisissant. Alors que les maîtres de la politique européenne, accompagnés de quelques personnages de la revue, sont occupés à fêter quelque part sur la terre l'arrivée de l'année I 88 o, le personnage du Nebelspalter s'envole, accroché à une luneballon, dont un tiers est clair et les deux autres sombres. Sur la face claire, se trouvent les allégories de l'économie (Sparsamkeit)³, de la bonne conduite du peuple (Volkswohlfahrt) et de la satisfaction (Zufriedenheit), très régulièrement présentes dans les caricatures suisses, tandis que la face sombre montre les personnifications de la crise (Krise), de la guerre (Krieg), de la maladie (Krankheit), de

\footnotetext{
À ce sujet: Philippe Kaenel, «Suisse-Allemagne (1848-1918): neutralité et neutralisation du point de vue de la caricature ", Revue suisse d'art et d'archéologie, 1-2 (2003), p. 99-111 et Révolution et contre-révolution dans la gravure en Europe de 1779 à 1889 / Revolution und Gegenrevolution in der europäischen Bildpublizistik 1789-1889 / Revolution and Counter-revolution in European Prints from 1789 to 1889, éd. Wolfgang Cillessen, Rolf Reichardt, Hildesheim, Zurich, New York, G. Olms, 2010, p. 424-441. Cf. " 3.2. La Suisse versus Zurich: critique et iconographie ». Ce terme dans le sens d'une bonne gestion, d'être économe.
} 


\section{Der Mond ist Jahresregent fur 1880.}

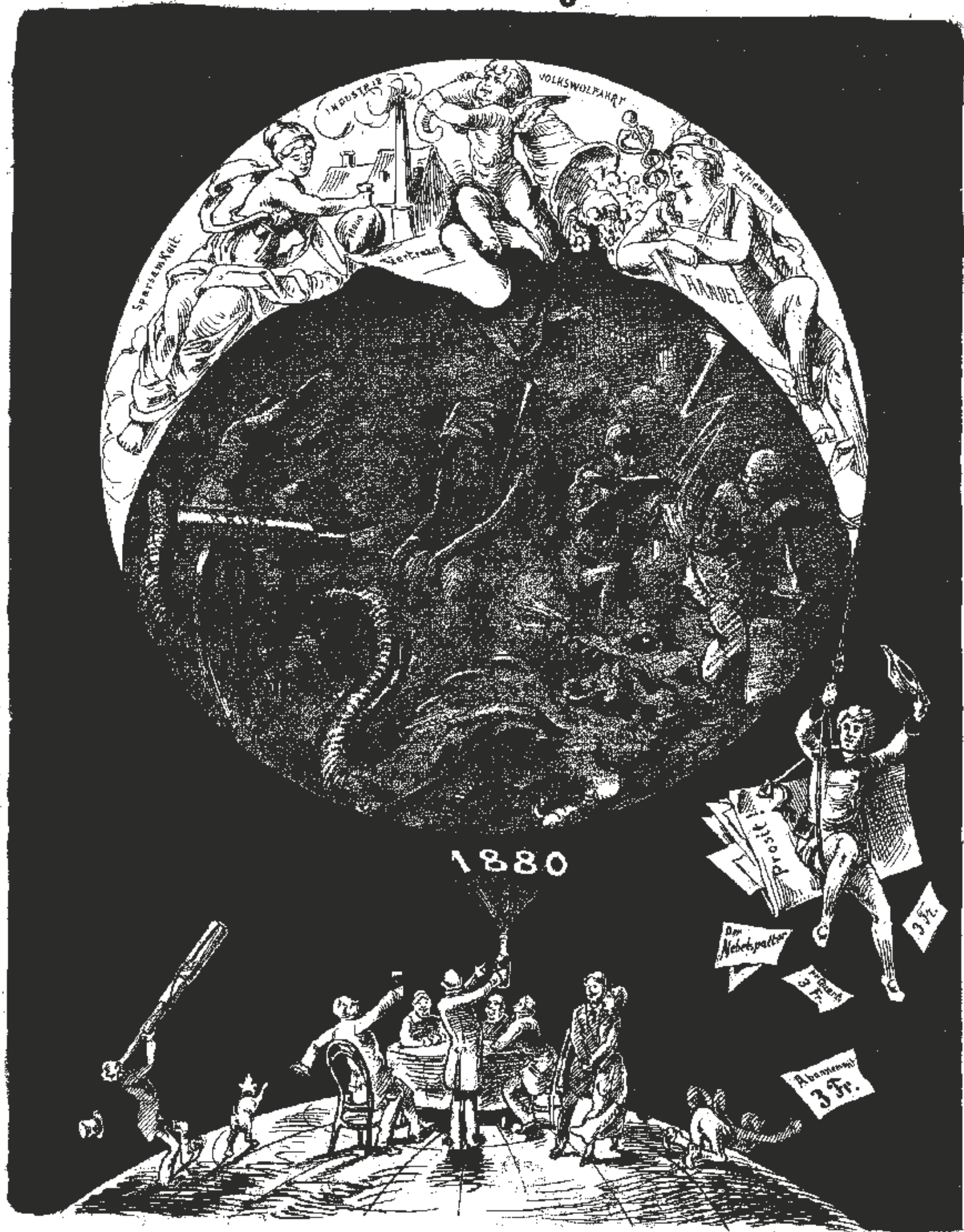

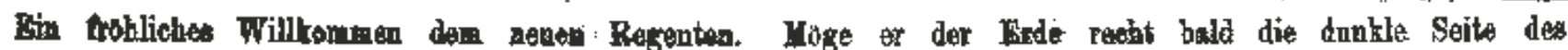

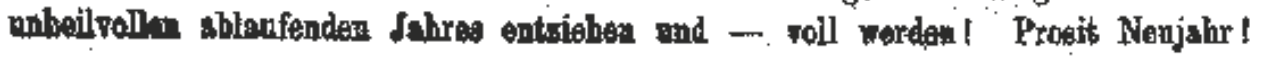

Fig. 74. Nebelspalter 1879/52, dessin pleine page en noir et blanc non signé, intitulé «La lune est régente de l'année 1880 » (Der Mond ist Jahresregent für 1880). 
la faim (Hunger) et de l'absence de revenus (Verdienstlos), celles-ci plus souvent reliées à l'actualité internationale ${ }^{4}$ (cf. fig. 74).

Boscovits senior, très certainement créateur de ce schéma de composition ${ }^{5}$, l'adapte ensuite à différents propos: pour montrer, en I 88 I, le "danger " socialiste; pour exprimer, en I 883 , le sentiment d'une instabilité politique; puis, en I 883 , pour inviter le lecteur à s'abonner' ${ }^{6}$.

La première carte date de la même année I 879 et est liée à l'Allemagne. Il s'agit d'une carte physiognomonique, calquée sur le visage de Bismarck, interrogeant ses intentions en matière d'alliances, de politique douanière et d'annexion, toutes questions très directement liées à la Suisse ${ }^{7}$. La fonction de miroir endossée par le regard sur l'international est manifeste; elle sera continue dans le Nebelspalter. D'autres cartes circonscrites à la Suisse ou l'Allemagne suivent. En I 882, le tsar Alexandre III, « bouffeur de Teutons » (Teutonenfresser $)^{8}$, marche sur la carte de l'Allemagne, tandis qu'en I 883 , la Suisse se présente comme une carte au relief montagneux, transpercée par les longs bâtons de ses voisins ${ }^{9}$. Quelques pays apparaissent progressivement, telles la France et l'Angleterre en I 883 , lors des premières discussions sur le tunnel sous la Manche ${ }^{10}$. Les cartes sont cependant rares à cette époque et l'on n'en compte que cinq entre i 879 et I 887 .

Si l'Europe apparaît tôt sous les traits d'une allégorie féminine en $1876^{11}$, puis sous une forme terrestre, au début 1886 , où elle fait figure de rocher prométhéen menacé par l'aigle de la Russie ${ }^{12}$, elle ne se transforme véritablement en territoire qu'à la fin I 886 . Boscovits senior livre alors la première version en noir et blanc de "L'Europe actuelle ", promise à un bel avenir ${ }^{13}$ (cf. fig. 75 ).

Dans cette carte anthropomorphe, chaque pays est allégorisé et doté d'attributs. Le genre est apparu au Royaume-Uni, dont il est longtemps resté l'apanage ${ }^{14}$, et est alors en phase avec la mode $^{15}$. Le cosaque russe, vraisemblablement repris d'une carte du dessinateur André Belloguet, "L'Europe animée ", créée après la déclaration de guerre du I9 juillet $\mathrm{I} 870^{16}$, est bien plus gros que n'importe quelle autre personnification, personnalité, symbole ou allégorie. Il tient dans la main un baril de dynamite sur lequel est juché Alexandre III, un pistolet à la main. L'allusion concerne les

Nebelspalter 1879/52, dessin pleine page non signé, intitulé « La lune est régente de l'année 1880 » (Der Mond ist Jahresregent für 1880).

Boscovits senior est alors le dessinateur quasi-unique de la revue.

Respectivement: Nebelspalter 1881/26, dessin pleine page non signé intitulé « La comète » (Der Komet); Nebelspalter 1883/10, dessin pleine page non signé intitulé « La main noire » (Die schwarze Hand); Nebelspalter 1883/52, dessin pleine page de Boscovits senior intitulé « Santé 1884! » (Prosit 1884).

Nebelspalter 1879/45, couverture non signée intitulée "Une étude de diplomate » (Eine Diplomaten-Studie).

Nebelspalter 1882/8, dessin pleine page de Boscovits senior intitulé « Le bouffeur de Teutons » (Der Teutonenfresser)

Nebelspalter 1883/47, dessin pleine page de Boscovits senior intitulé « L'Alberg est barré! » (Der Alberg ist durchstochen!): le numéro est mal numéroté (43).

Nebelspalter 1884/22, dessin pleine page de Boscovits senior intitulé «Peur inutile » (Unnütze Angst)

Nebelspalter 1876/21, dessin pleine page signé « $A N$ » intitulé « La réunion des trois chanceliers » (Die Drei Kanzler-Zusammenkunft)

Nebelspalter 1886/37, dessin pleine page non signé intitulé «Le nouveau Prométhée » (Der neue Prometheus).

Nebelspalter 1886/45, double-page en noir et blanc de Boscovits senior intitulée "L'Europe actuelle » (Das heutige Europa); sur cette carte cf. « 6.2. Intrigues suisses et influences françaises dans le monde éditorial : Jean Nötzli, John GrandCarteret et Cäsar Schmidt ».

Laurent Baridon, Un atlas imaginaire. Cartes allégoriques et satiriques, Paris Citadelles \& Mazenod, 2011, p. 79.

Christian de Bartillat et Alain Roba, Métamorphoses d'Europe. Trente siècles d'iconographie, Paris, Bartillat, 2000, p. 125.

6 Laurent Baridon, Un atlas imaginaire. Cartes allégoriques et satiriques, op. cit. p. 109. attentats qui menacent les Romanov ${ }^{17}$. De tous les personnages, l'empereur allemand est le seul à se tourner vers lui, la main levée; il est cependant entravé par les figures des lois sociales et le canon de la revanche tourné vers une France à la gueule ouverte. La Suisse n'est qu'un hérisson dans les pattes de l'Italie. Comme la plupart des autres pays, mises à part l'Angleterre et l'Autriche, la Suisse est minuscule et ne se remarque guère.

\subsubsection{7-1914: déclinaisons d'un univers en expansion et d'une Europe impuissante}

En I 887 , l'essentiel des types géographiques du Nebelspalter, le globe, le rocher, les différentes cartes, planes, bosselées, anthropomorphes ou physiognomoniques, est créé. Plutôt qu'à la création de nouveaux types, désormais assez rare, on assiste à une déclinaison de ceux-ci. Ainsi la face cartographiée de Bismarck en I 879 est réutilisée en I 88 I pour critiquer le système électoral devenant un visage défiguré par les nombreuses figures des politiciens s'y accrochant ${ }^{18}$; en I 886 , des idées de gloire nationale et de revanche envers l'Allemagne sont plaquées sur le visage du général Boulanger ${ }^{19}$; en I 889 , le visage d'un Bismarck songeur est doté d'une pipe au portrait de son fils, Herbert $^{20}$; en I 89 I, ce sont les différents visages d'un capital hideux qui sont montrés ${ }^{21}$ et, en I 896, la face de Guillaume II est passée, selon le sous-titre, " aux rayons $\mathrm{X}$ [et] photographiée à travers une caisse palatine de havanes ${ }^{22}$.

Le globe ne cesse d'être exploité, le plus souvent comme lieu de regroupement des responsables politiques, comme, en I 887, Giers, Crispi, Bismarck et Kalnoky ${ }^{23}$. Il sert également d'accessoire stratégique à Bismarck en $1889^{24}$. Un an plus tôt, Bismarck l'avait, en nouvel Atlas, porté sur ses épaules: il s'y détachait alors l'inscription "Europa ", à cette époque, l'échelle du monde pour le Nebelspalter ${ }^{25}$. Les références à une Europe, d'une présence régulière et sans pics particuliers, se multiplient dès lors. Il faut plutôt en relever les absences en I89I, I895, I899, I90I, I902, I907 à I909, I9I I à I9I2, et une très forte présence durant et après la Première Guerre mondiale. Cette Europe est polymorphe: elle est tantôt une machine ${ }^{26}$, un chapeau ${ }^{27}$, un soleil ${ }^{28}$, tantôt une carte ou un bateau - le fameux bateau politique embarquant une ou plusieurs personnalités ou allégories, en général associées à un

Ibid., p. 121. La date de parution de la carte de 1887 est erronée.

Nebelspalter 1881/17, dessin pleine page son signé intitulé "Comme l'idéal de la division de la circonscription électorale » (Wie das Ideal der WahlkreisEintheilung).

Nebelspalter 1886/47, dessin pleine page de Boscovits senior intitulé « Généra Boulanger » (General Boulanger).

Nebelspalter 1889/10, dessin pleine page de Boscovits senior intitulé « Une petite heure à penser clairement » (Ein Stündchen in sichtbaren Gedanken); sur cette image: John Grand-Carteret, Bismarck en caricatures, Paris, Perrin, 1890, p. 253. Nebelspalter 1891/49, double-page en couleur non signée et sans titre.

(Durch Röntgens X-Strahlen durch eine Pfälzerhavannahcigarrenkitze hindurch photographirt); Nebelspalter 1896/8, double-page en couleur de Boscovits senior intitulée « L'empereur Guillaume » (Kaiser Wilhelm).

Nebelspalter 1887/35, dessin pleine page de Boscovits senior intitulé « La raison de l'éclipse de soleil » (Die Ursache der Sonnenfinsternis).

Nebelspalter 1889/12, dessin pleine page de Heinrich Jenny intitulé « L'horloger » (Der Uhrmacher).

Nebelspalter 1888/49, dessin pleine page de Boscovits senior intitulé « Le nouvel Atlas » (Der neue Atlas).

Nebelspalter $1889 / 27$, dessin en noir et blanc non signé intitulé « La soupape de sécurité » (Das Sicherheitsventil).

Nebelspalter 1890/46, dessin pleine page de Emil Dill intitulé « En voilà un qui serait rapidement consolé » (Einer, der bald getröstet wäre).

s Nebelspalter 1904/50, dessin pleine page de W. Lehmann-Schramm intitulé « Aurore » (Morgenrot) 


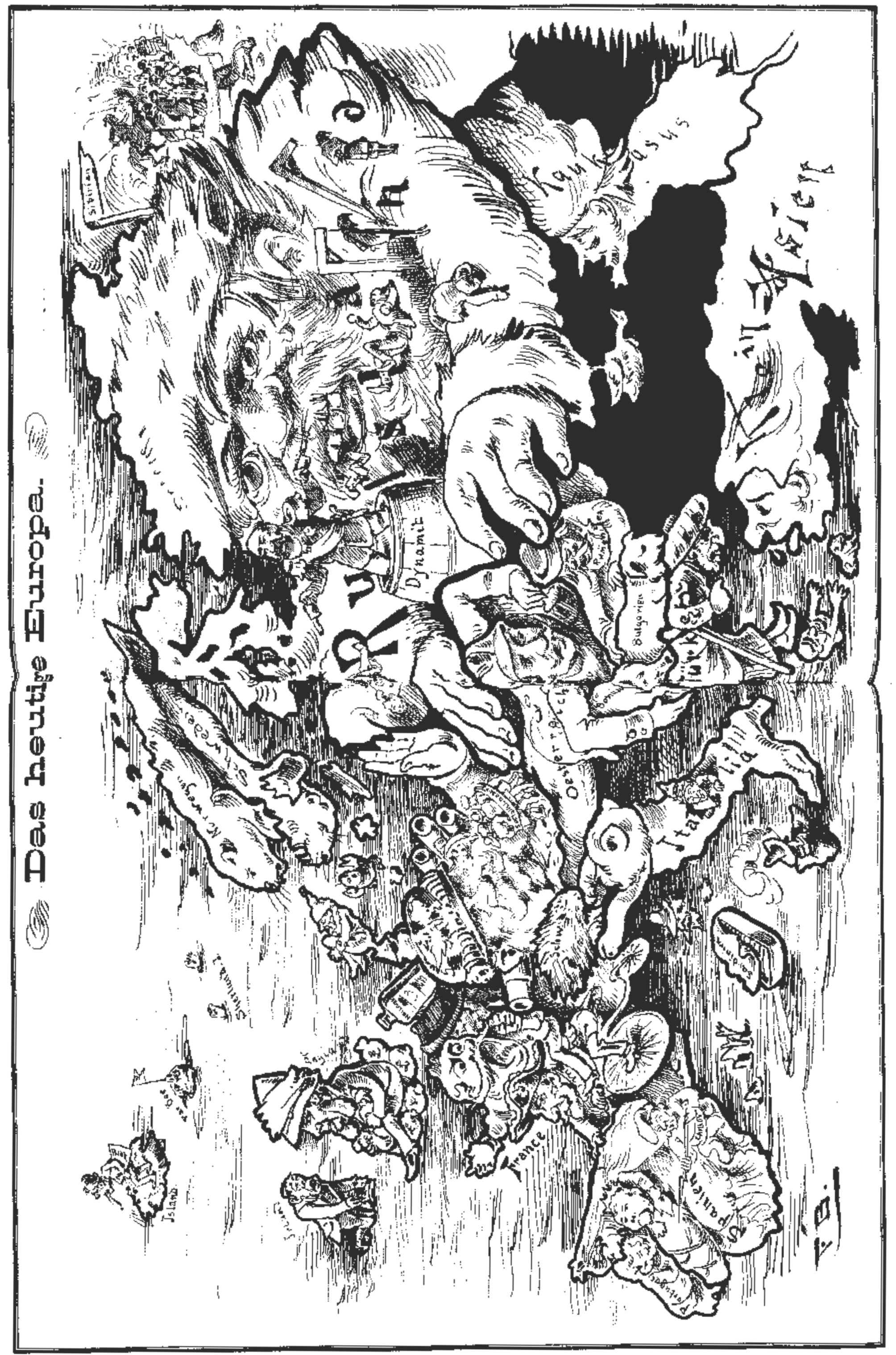




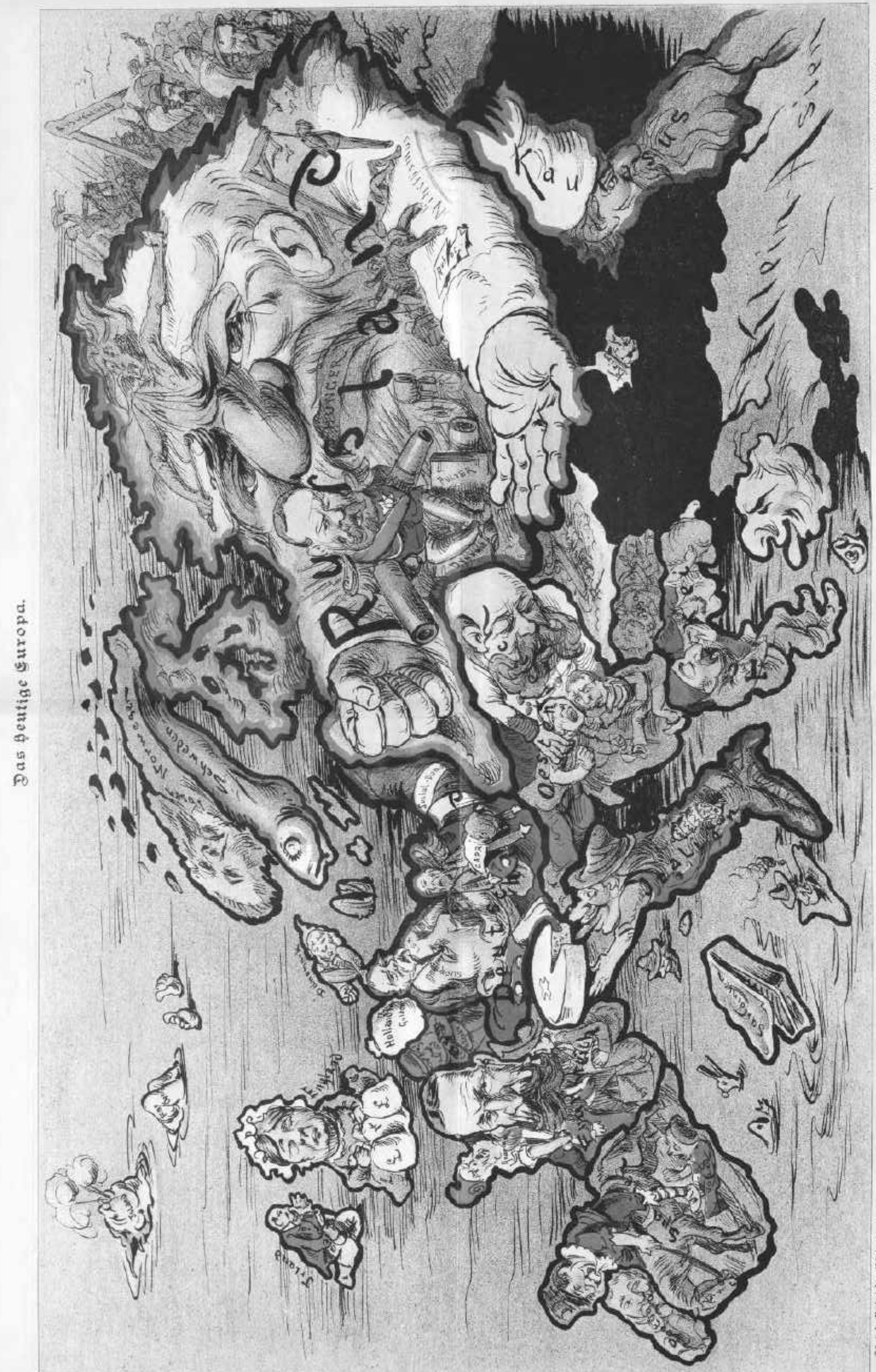


(seul) pays. En I 893, Caprivi, Kalnoky, Russky, Italiani et Sady sont ainsi les « Les grandes puissances en maillot de bain ${ }^{29}$.

Boscovits senior remploie, ainsi, à deux reprises sa composition cartographiée, "L'Europe actuelle » de I 886. Il l'actualise en en changeant les visages et en variant les attributs. En I 892, la Suisse est un fromage bien tentant pour l'Italie, la France est menacée par l'anarchie (Anarchie) et les confins de la Russie - toujours aussi terrible avec ses canons et la famine (Hunger), et surtout sans personne désormais pour arrêter le tsar - montrent l'émigration forcée des juifs ${ }^{30}$ (cf. fig. 76).

En I 897, la Russie adopte les traits de Nicolas II; l'argent de la France récolté pour l'emprunt russe (Französich. Geld Russiche Anliehen) lui permet de tenir en laisse la France, l'Allemagne et l'Autriche, c'est-à-dire de mener la danse. La Suisse est alors simplement représentée par son drapeau ${ }^{31}$ (cf. fig. 77 cahier couleur).

Le plus souvent, cependant, l'Europe se présente comme une allégorie, distante de son origine mythique ${ }^{32}$. Ceci, à une exception notable: "L'enlèvement d'Europe " de Boscovits junior, une composition plutôt ambiguë, inspirée des décors muraux de l'Université de Zurich, alors en cours de réalisation ${ }^{33}$. Dans la partie inférieure de l'image, une femme au type oriental chevauche à demi nue Zeus, transformé en taureau et désigné comme «Scutari » (Skutari), en présence d'une série d'allégories vaguement statufiées et alignées dans la partie supérieure. Au centre, l'Europe, entourée de part et d'autre par la Russie, la France, l'Autriche, l'Allemagne, l'Angleterre et l'Italie s'écrit: «Tout ceci est contraire à la mythologie! Zeus-Nikita en enlève une autre et c'est moi qui suis spoliée! »34 (cf. fig. 78 ).

Comme d'autres, cette image, thématisant l'incertitude que fait peser le siège de Scutari sur l'Europe, éclaire une région géopolitique et reflète l'inquiétude de la revue vis-à-vis de l'Europe. Mieux que le globe ou la carte, le mode allégorique permet, en effet, de figurer l'aspect interrelationnel, de figer une actualité ou d'exprimer un point de vue via l'association d'autres éléments figuratifs et d'une légende. Ce mode de représentation est retenu pour illustrer l'un des leitmotivs de la revue en matière de politique internationale: la dénonciation du colonialisme. Europe en armure et rayonnante surplombe l'arrière-plan de la composition, l'inscription «Allez de l'avant et protégez la civilisation et la religion "se détachant autour de sa tête. À l'avant-plan, partent en guerre, bras-dessus bras-dessous et sourire aux lèvres, les personnifications de l'Angleterre (Bull), de l'Autriche, de la Russie, de l'Amérique, de la France, de l'Allemagne, de l'Espagne et de l'Italie, ces deux dernières isolées et en retrait ${ }^{35}$. Selon l'époque et le propos, l'Europe - qui n'a pourtant pas toujours été féminine au cours de

Nebelspalter 1893/33, dessin de Boscovits senior intitulé « Les grandes puissances assises dans le bain » (Die Grossmächte sitzen im Bade).

Nebelspalter 1892/15, double-page de Boscovits senior intitulée «L'Europe actuelle » (Das heutige Europa).

Nebelspalter 1897/39, double-page de Boscovits senior intitulée « L'Europe actuelle » (Das heutige Europa).

Christian de Bartillat et Alain Roba, Métamorphoses d'Europe. Trente siècles d'iconographie, op. cit., p. 110.

Michèle Jägi, «Zürcher Universitätsgebäude », Gesellschaft für schweizerische Kunstgeschichte, Bern, 2005.

(Europa; Das ist gegen alle Mythologie! Zeus-Nikita stiehlt eine andere, und ich bin die Bestohlen); Nebelspalter 1913/18, dessin pleine page de Boscovits junior intitulé « Le rapt d'Europe » (Raub an Europa).

(Geht hin, beschützet Zivilisation und Religion); Nebelspalter 1900/28, dessin pleine page de Josef Kälin Küpfer intitulé « Le début I » (Der Anfang I). son histoire ${ }^{36}$ - oscille entre différents types féminins, allant de la mégère à la séductrice. Les variantes les plus fameuses sont celles de la période Jugendstil, dont la femme au parapluie ${ }^{37}$.

La mise en scène de l'Europe témoigne, par ailleurs, de l'ouverture mesurée sur le monde du Nebelspalter. La plupart des dessins montrent l'Europe centrée sur elle-même, qu'elle soit figurée comme une entité (une allégorie, un globe ou une carte) ou représentée par les différentes puissances qui la composent. Elle ne fait que sporadiquement commerce avec des puissances extraeuropéennes, jamais avant I 887 et pour la première fois en I 890 avec les États-Unis ${ }^{38}$ ainsi qu'avec le Japon ${ }^{39}$; ensuite, en I 900 , avec l'Asie ${ }^{40}$; puis, en I904, avec l'Inde, la Chine et le Japon ${ }^{41}$. Il arrive au Nebelspalter en personne de se rendre au chevet de l'Europe malade ${ }^{42}$ mais très rarement à Helvetia de se mêler à ses représentants, ce qu'elle fait par exception lors de la distribution des cadeaux à la Noël I $893^{43}$. Fait hautement intéressant, l'Europe est une source d'inquiétude permanente; pas une fois, elle n'est célébrée pour sa force protectrice. Au contraire, à la fin I904, elle incarne un vain espoir de paix, puisqu'elle se révèle impuissante à empêcher les conflits meurtriers: le soleil de l'union européenne (Europ. Union) brille au-dessus du mausolée de la paix des peuples (Volker Frieden), tandis qu'au premier plan, Chronos, l'esprit du temps (Zeitgeist), fauche les crânes des empires ${ }^{44}$. En I9I3, l'Europe constatera son impuissance à réparer l'ange de la paix ${ }^{45}$.

À partir de $\mathrm{I} 887$, le globe est l'autre forme particulièrement fréquente, à parité avec l'Europe et loin devant les cartes. Comme pour l'Europe, ce sont plutôt les années d'absence qu'il convient de noter: I 89 I, I 893 et I 894, I 897 et I 899, I90 I, I904, I 907 et I908, I9 I0 à I9I3. Celles-ci recoupent en partie celles où l'Europe disparaît. L'explication est double: soit les affaires du monde passent au second plan; soit elles sont traitées de manière plus concrète dans des images mettant en scène personnifications et personnalités politiques, qui sont autant de déclinaisons satiriques de la famille européenne ${ }^{46}$. Du globe, rien n'est vraiment stable, ni sa forme, entière ou tronquée, ni son statut, terre, accessoire géopolitique, siège, ventre ou bulle de savon, pas plus que sa contextualisation. Le globe participe à vrai dire de la géographie idéologique du Nebelspalter, qui se comprend en termes politiques et satiriques, d'où ses liens étroits avec l'humour. En I 889, il est ainsi une bulle de savon formée par le Nebelspalter mais menacée par la pointe de Friede - l'allégorie de la paix - sur laquelle est piqué

\footnotetext{
Michael Wintle, The image of Europe. Visualizing Europe in Cartography and Iconography throughout the Ages, Cambridge, Cambridge University Press, p. 315 et seq.

Nebelspalter 1903/5, double-page de Boscovits senior sans titre.

Nebelspalter 1890/42, dessin pleine page Henri van Muyden intitulé « Tempora mutantur».

Nebelspalter 1890/46, dessin pleine page de Emil Dill intitulé « En voilà un qui serait rapidement consolé » (Einer, der bald getröstet wäre).

40 Nebelspalter 1900/26, dessin pleine page de W. Lehmann-Schramm intitulé « Les sœurs ennemies » (Die feindlichen Schwester).

Nebelspalter 1904/40, dessin pleine page de W. Lehmann-Schramm intitulé " Tempête » (Sturm).

Nebelspalter 1892/3, dessin pleine page de Boscovits junior intitulé « Gravement malade » (Schwer krank); sur cette image, cf. « 5.1. Le Nebelspalter, la caricature et les revues illustrées européennes ".

Nebelspalter 1893/51, dessin pleine page de W. Lehmman-Schramm intitulé "Mère Europe offre des cadeaux à ses enfants pour Noël » (Mutter Europa beschenkt ihre Kinder zur Weihnacht).

${ }^{44}$ Nebelspalter 1904/50, dessin pleine page de W. Lehmman-Schramm intitulé «Aurore » (Morgenrot).

Nebelspalter 1913/21, dessin pleine page de Paul Thesing intitulé «L'ange de la paix en pièces détachées » (Der Zusammensetzbare Friedensengel).

${ }_{46}$ Michael Wintle, The image of Europe. Visualizing Europe in Cartography and Iconography throughout the Ages, op. cit., p. 390-396.
} 


\section{Raub an Europa}

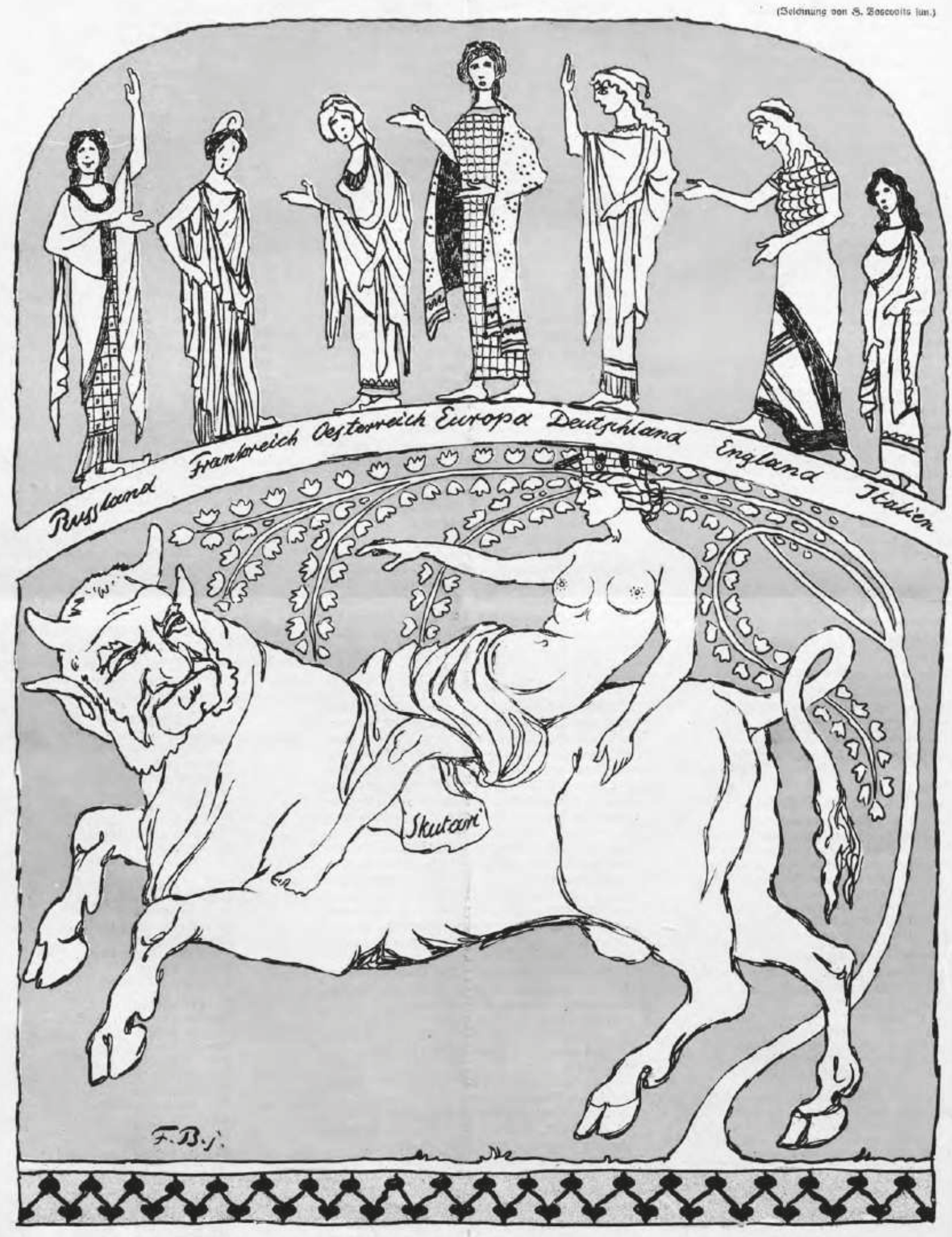

Quropa: Das in ja gegen alle 2ripthologie! इeus-2tikita ftiehlt eine andere, und ich bin die Seftohlene!

Fig. 78. Nebelspalter 1913/18, dessin pleine page en couleur de Boscovits junior intitulé « Le rapt d'Europe » (Raub an Europa). 
Zürich,1900. XXVI.Jahrgang N. 4 .

27 Januar.

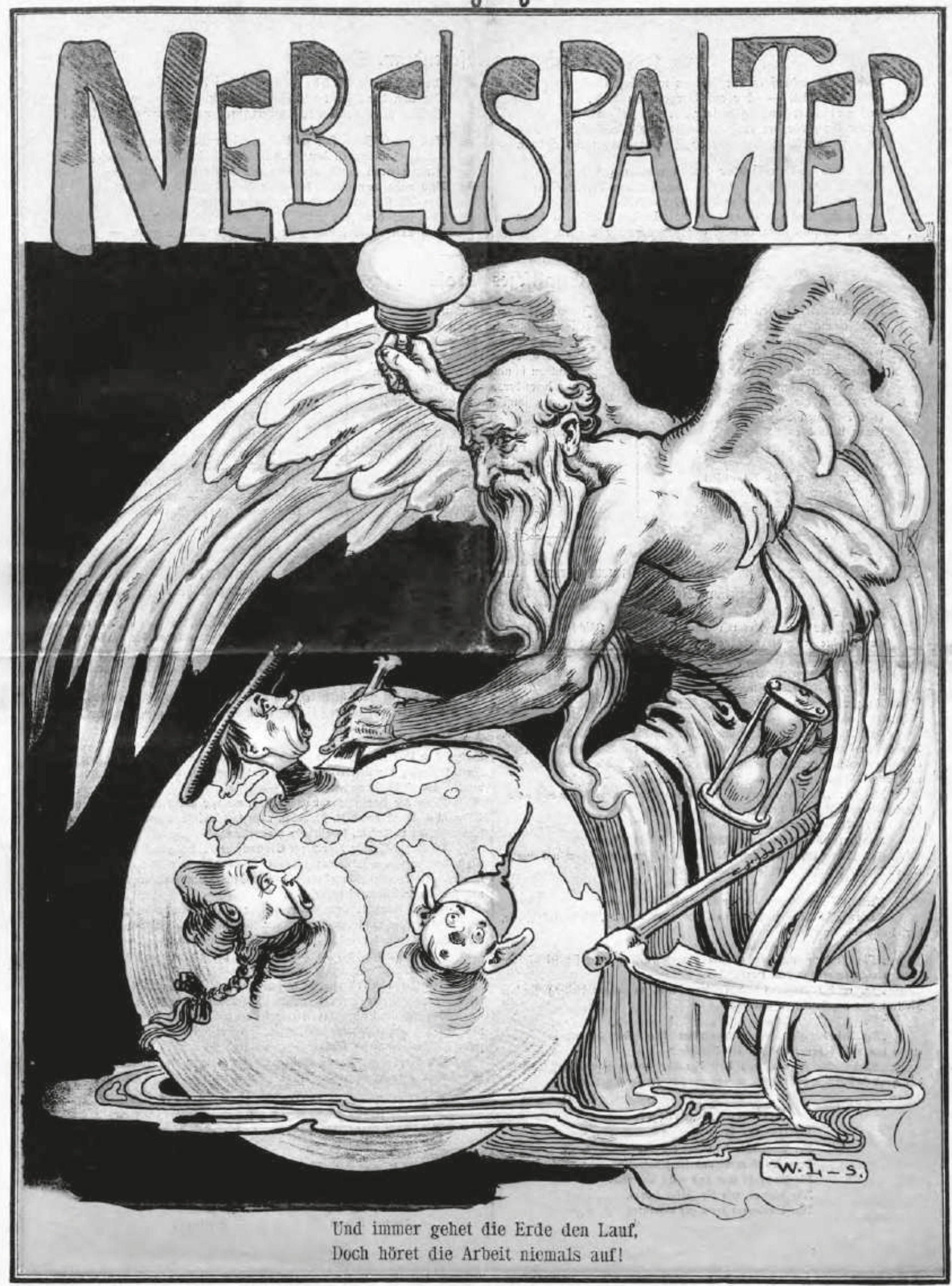

Fig. 79. Nebelspalter 1900/4, couverture en couleur de Willy Lehmman-Schramm. 
un bonnet phrygien ${ }^{47}$. Ce même globe est au centre d'expéditions polaires médiatiques et copieusement raillées ${ }^{48}$. Il n'en renseigne pas moins sur la manière de voir du Nebelspalter, sur ses repères géographiques et ses craintes. Représenté dans sa totalité, il est soit un objet contrôlé par un membre de la famille du Nebelspalter, son personnage sautant sur sa surface dans un encart publicitaire en I 89649 ou Chronos y plantant ses figurines en I90050; soit un objet de dérision; soit dominé par un personnage surpuissant, Bismarck en I $889^{51}$ ou Guillaume II en I $890^{52}$; soit un endroit indéterminé sur lequel s'abat une catastrophe, l'épidémie de grippe en I $890^{53}$ ou le krach boursier en I $895^{54}$ (cf. fig. 79).

Lorsque le globe est tronqué, le territoire présenté se déduit des figures qui en occupent la surface ou qui lui sont associées: Crispi et Nicolas II, auxquels il sert de trône en I 895 et I $899^{55}$; le sultan qui flotte dessus en $1903^{56}$; Édouard VII dont il forme le corps en $1906^{57}$.

À la différence des cartes, le globe est rarement spécifié géographiquement et, lorsque c'est le cas, toujours de manière surdéterminée: l'Europe, en I $888^{58}$; l'Afrique, en I $888^{59}$; le Transvaal, en $1900^{60}$, c'est-à-dire les zones menaçant l'équilibre du monde. Une unique fois, ce globe, plutôt européen, est surplombé d'un personnage suisse, et encore s'agit-il d'Helvetia, un indice, s'il en faut, du peu de poids (auto-)crédité au pays dans les affaires du monde ${ }^{61}$

Les cartes de pays sont plus rares. On en compte douze entre I 887 et I9I 4. Six cartes sont liées à la Suisse ${ }^{62}$, dont deux à Zurich, et six cartes représentent d'autres pays. Ces derniers sont très rarement extra-européens. Il faut ainsi attendre I 896 pour voir apparaître les États-Unis ${ }^{63}$ et 1898 pour le Canada ${ }^{64}$, la Chine et le Japon ${ }^{65}$, présences confirmant l'ouverture au monde du Nebelspalter à ce moment-là. Ces cartes sont de nature et forme diverses. Certaines sont réalistes, plates ou en relief; d'autres, pseudo-mimétiques,

Nebelspalter $1889 / 43$, dessin pleine page non signé et sans titre.

Nebelspalter 1909/37, dessin pleine page Boscovits junior intitulé « Du pôle nord et du pôle sud » (Vom Nord- und Südpol).

Nebelspalter 1896/26, dessin pleine page sans titre de W. Lehmman-Schramm.

Nebelspalter 1900/4, couverture de W. Lehmman-Schramm.

Nebelspalter 1889/12, dessin pleine page de Heinrich Jenny intitulé « L'horloger » (Der Uhrmacher).

Nebelspalter 1890/15, dessin pleine page de Henri van Muyden intitulé « Nostalgie printanière » (Frühjahrsehnsucht).

53 Nebelspalter 1890/1, dessin pleine page de Heinrich Jenny intitulé « La grippe » (Die Influenza).

Nebelspalter 1895/47, dessin pleine page de Boscovits senior intitulé « Une visite s'annonce » (Es meldet sich Besuch an).

${ }_{5}$ Nebelspalter 1895/2, dessin pleine page de W. Lehmann-Schramm intitulé "Sur la situation » (Zur Situation) et Nebelspalter 1899/12, dessin pleine page de W. Lehmann-Schramm intitulé « Figures amusantes connues » (Bekannte Lustspielfiguren).

56 Nebelspalter 1903/34, dessin pleine page de Boscovits senior intitulé « D'une lune décroissante " (Vom abnehmenden Mond).

Nebelspalter 1906/15, dessin pleine page de W. Lehmann-Schramm intitulé « Le premier violon » (Die erste Geige).

Nebelspalter 1888/49, dessin pleine page de Boscovits senior intitulé « Le nouvel Atlas " (Der neue Atlas).

Nebelspalter 1888/52, dessin pleine page non signé intitulé « Les puissances intelligentes » (Die klugen Mächte).

Nebelspalter 1900/48, couverture de W. Lehmann-Schramm.

Nebelspalter 1890/13, dessin pleine page de Heinrich Jenny intitulé « C'est de plus en plus beau! » (Es wird immer schöner!).

Marco Ratschiller note avec justesse que la carte est pour la Suisse un mode de présence marginal, essentiellement déictique; Marco Ratschiller, Bedrohte Schweiz: nationale Selbstbilder, Fremdbilder und Feindbilder in der "Nebelspalter »-Karikatur des 20. Jahrhunderts: eine semiotische Untersuchung, 2004 (mémoire soutenu à l'université de Fribourg), p. 117.

${ }_{3}$ Nebelspalter 1896/7, dessin signé d'un monogramme intitulé "Sur la crise cubaine » (Zur Cuba-Frage).

${ }_{4}$ Nebelspalter 1898/16, dessin pleine page de Boscovits senior intitulé « Le tailleur bienveillant » (Der Woh/wollende Schneider); la légende originale est bilingue. Nebelspalter 1898/51, dessin pleine page de Boscovits junior intitulé « La mouche grasse » (Die fette Fliege). telles les cartes en morceaux du continent américain et de Cuba ${ }^{66}$ ou encore celle de la Triplice ${ }^{67}$; d'autres, encore, sont carrément fantaisistes, tel le gâteau électoral de Zurich ${ }^{68}$, une carte animalière sur les appétits féroces des grandes puissances ${ }^{69}$, ou une carte paysagère illustrant les enjeux économiques des réseaux ferrés suisses $^{70}$ (cf. fig. 80).

Toutes ces cartes expriment un point de vue ou une actualité politique forte, tel le traçage ironique d'un pseudo-limes romain, caricaturant les positions politiques de l'opposant républicain espagnol Ruiz Zorilla (I 833-I895). Plantés de part et d'autre de l'Europe, deux guerriers, l'un vêtu en romain, l'autre en viking, se narguent en brandissant leur bouclier, portant respectivement l'inscription « Latins» (Romane) et «Germains » (Germane $)^{71}$.

De I 887 à la Première Guerre mondiale, cette iconographie du monde enregistre quelques rares novations. À partir de I 888 , la montagne anthropomorphe est ainsi utilisée pour figurer différents sommets suisses, de préférence la Jungfrau ${ }^{72}$. Le motif prend rapidement une dimension esthétique, grotesque et même érotique, affaiblissant le propos politique. Deux autres nouveautés apparaissent, qui sont liées à des personnifications ou des personnalités politiques, voire des allégories morales: les allégories « à la mode », présentant à partir de I900 des personnifications européennes tout à fait pimpantes ${ }^{73}$ ainsi que la pyramide des valeurs européennes, apparaissant l'année suivante, en I90 I, où le roi écrase le travail (Arbeit), l'art (Kunst), la science (Wissenschaft), les militaires (Militär), les classes moyennes (Mittelstand) et jusqu'au capital (Kapital) ${ }^{74}$. Le cirque international, très tôt présent, puisque sa première occurrence date de $1877^{75}$, prend désormais une ampleur inédite. Dans « Le nouveau truc dans le cirque Europe » de 1907, personnalités politiques et allégories présentent avec brio leurs tours ${ }^{76}$ (cf. fig. 8I).

\subsubsection{4-1921: embrasement et no man's land d'un univers en perdition}

L'imminence, puis le déclenchement de la Première Guerre mondiale n'ouvre pas, comme on pourrait s'y attendre, sur une profusion de cartes et globes, et encore moins sur des novations, très rares durant cette période. Le Nebelspalter reste alors en marge de « La Grande Guerre des cartes » ${ }^{77}$. Les trois motifs présents, l'Europe, sous forme

Nebelspalter 1898/16, dessin pleine page de Boscovits senior intitulé « Le tailleur bienveillant » (Der Wohlwollende Schneider).

Nebelspalter 1904/42, dessin pleine page de W. Lehmann-Schramm intitulé « Le maitre-tailleur allemand à l'ouvrage " (Der deutsche Schneidermeister an der Arbeit).

Nebelspalter 1911/23, couverture de Boscovits junior intitulée « Géométrie électorale dans la première circonscription » (Wahlkreisgeometrie im I. Kreis).

Nebelspalter 1898/51, dessin pleine page de Boscovits junior intitulé « La mouche grasse » (Die fette Fliege).

Nebelspalter 1905/4, double-page de Boscovits senior intitulée « À chacun le sien » (Jedem das Seine).

Nebelspalter 1890/4, dessin de Heinrich Jenny intitulé « Le rêve pour le futur » (Der Zukunfts-Traum).

Respectivement: Nebelspalter 1888/25, dessin pleine page de Boscovits senior intitulé « Calomnie » (Verleumdung); Nebelspalter 1889/44, dessin pleine page de Boscovits senior intitulé « Consentement négatif » (Verneinende Bejahung).

Nebelspalter 1900/14, dessin pleine page de Boscovits junior intitulé « Modes printanières européennes » (Europäische Frühjahrsmoden).

Nebelspalter 1901/18, dessin pleine page de W. Lehmann-Schramm intitulé « Une pyramide européenne! » (Eine europäische Pyramide!)

Nebelspalter 1877/48, dessin pleine page non signé intitulé « L'acrobate français » (Der französische Akrobat)

Nebelspalter 1907/20, dessin pleine page de Boscovits junior intitulé « Le nouveau truc dans le cirque Europe » (Der neueste Trik im Zirkus Europa).

Selon le titre du chapitre de Laurent Baridon consacré à la profusion des cartes durant la Première Guerre mondiale; Laurent Baridon, Un atlas imaginaire. Cartes allégoriques et satiriques, op. cit., p. 137 et seq. 


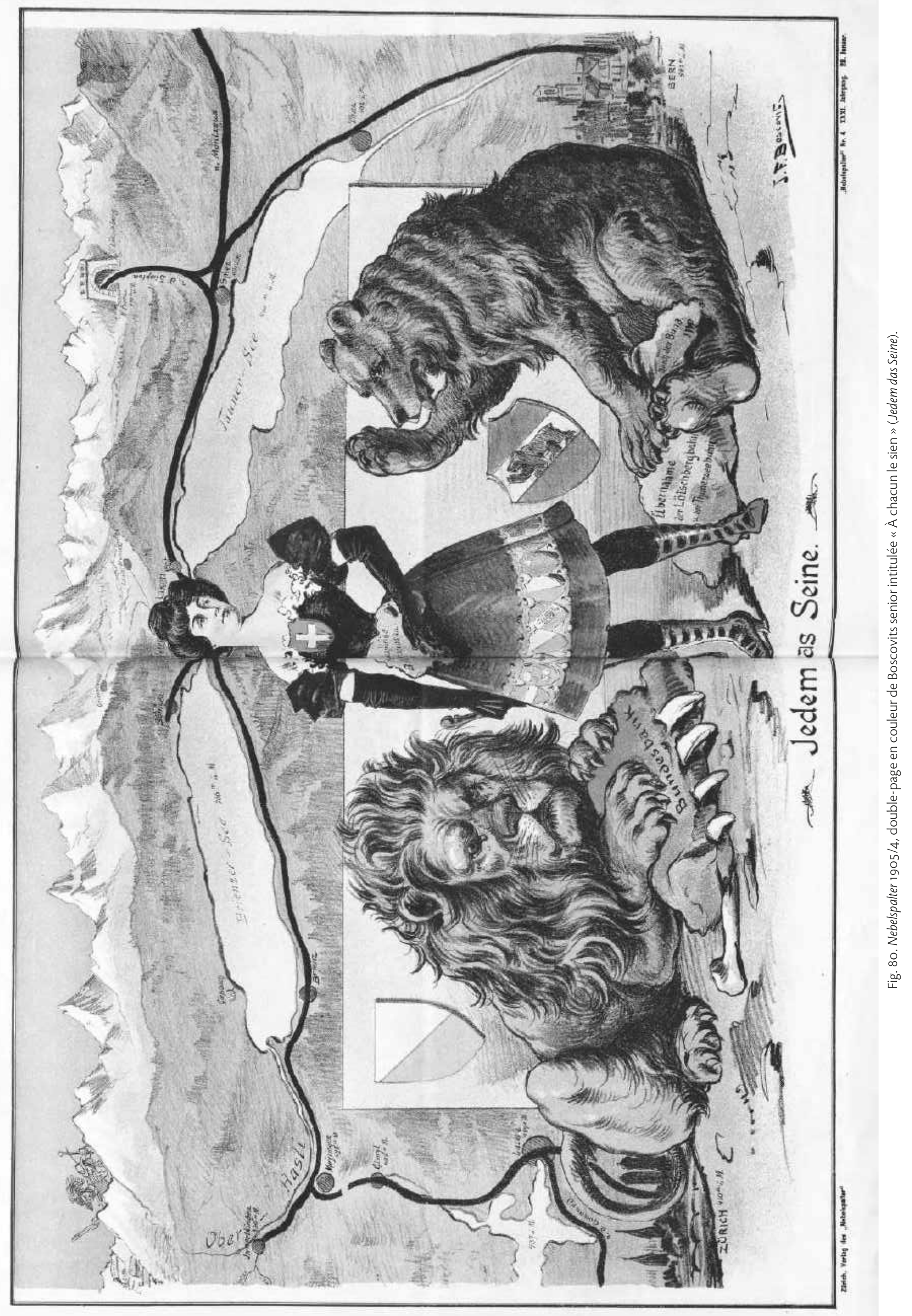


Der neueste Crik im Zirkus Europa.

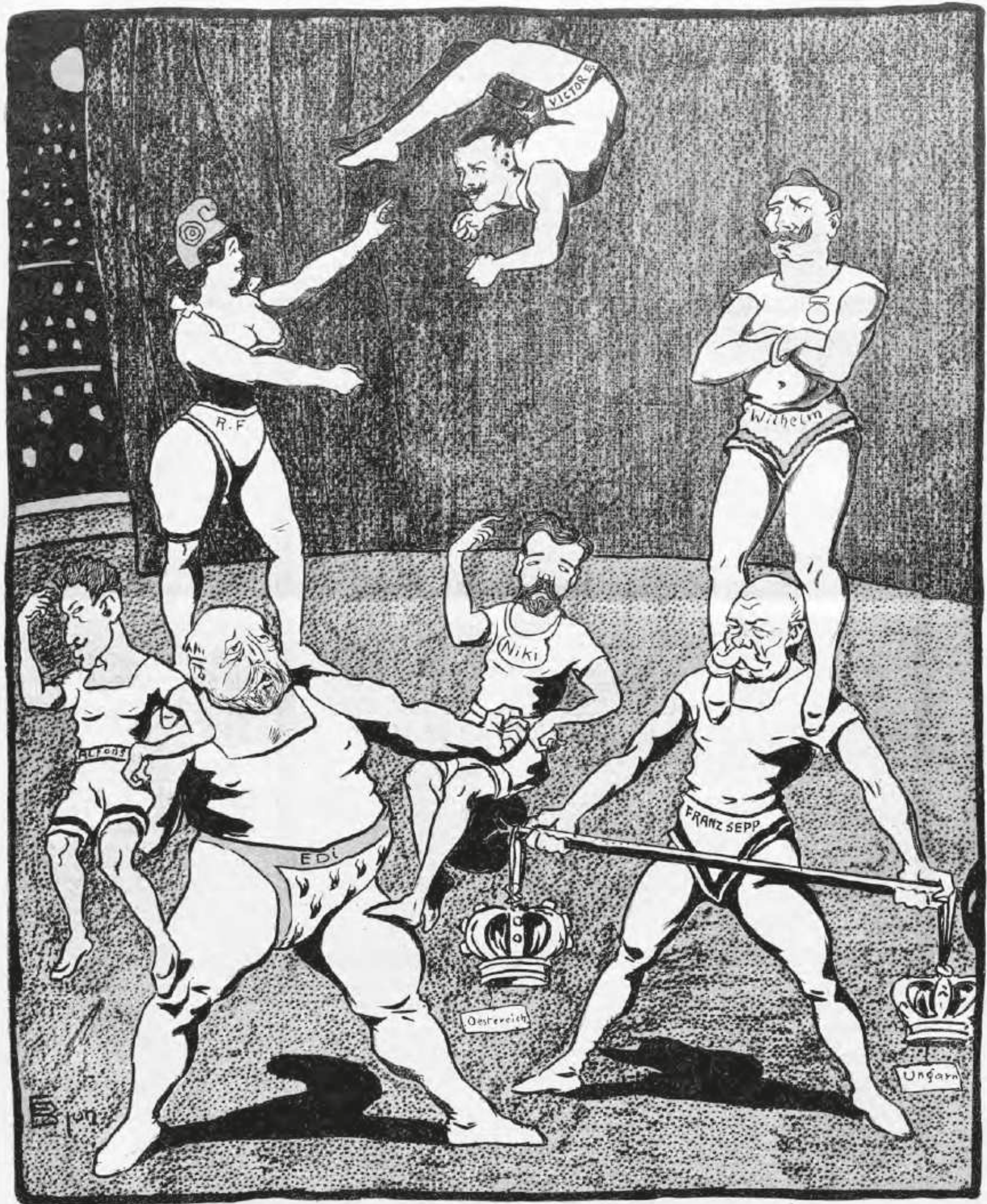

Ђe! — Ђoppla! — Voilà! 
de carte et d'allégorie, le globe et les Alpes sont des adaptations ou des reprises de motifs préexistants. Tous sont présents autour du début de la guerre. Une première carte précède la guerre de quelques semaines. Il s'agit du dernier avatar de "L'Europe actuelle » de Boscovits senior, une version très simplifiée, représentative de la perte de qualité graphique de cette époque. Elle thématise les rumeurs d'une coalition menée par le roi belge. Le point de fuite est à présent placé sur la Suisse, où se tient un paysan, figure typique de la Confédération. Les représentants de petits pays européens - la Belgique, la Hollande, le Danemark, la Norvège, la Suède, le Monténégro, la Serbie, la Bulgarie, la Grèce et la Roumanie - tendent la main dans sa direction. Le dessin, intitulé « Une alliance de nains ", thématise l'inquiétude face à l'insignifiance de la Suisse dans le jeu international ${ }^{8}$. C'est avec les Alpes en feu qu'entre en guerre le Nebelspalter. La couverture du $I^{\text {er }}$ août est ambiguë. Elle montre deux hommes en tenue de paysans au faîte d'une montagne, allumant un feu, se conformant apparemment aux usages de la fête nationale, à trois détails près: le feu dégage une fumée abondante, le fond de l'image est rouge et le cadre formé de barbelés. La composition alpine de Boscovits junior marque on ne peut plus clairement le repli identitaire du pays 79 (cf. fig. 82 cahier couleur). Quelques semaines plus tard, le même Boscovits junior livre une couverture très colorée, intitulée « La situation européenne » (Die europäische Lage). Un globe, légèrement décentré sur la gauche, emplit un ciel sombre et très nuageux. Une dame élégante, au chapeau marqué du nom de l'Europe, y est juchée, sa main appuyée sur l'Afrique, le continent le plus visible. La sphère est poussée par deux noirs à l'accoutrement improbable ainsi que par un militaire asiatique aux traits exagérés, l'iconographie typique du japonais ${ }^{80}$. L'image propose une combinaison plutôt inhabituelle: le globe et l'allégorie de l'Europe.

Durant la guerre, l'Europe est le motif le plus représenté, essentiellement en tant qu'allégorie féminine. Elle apparait vingttrois fois sous cette forme contre huit fois pour toutes les autres variantes, carte, monument ou porte. Son iconographie varie entre les types de l'élégante, de la ménagère et de la petite fille, et ne cesse d'évoluer. Hormis une unique référence à son origine mythologique en I9I 5, où le diable est opposé à Jupiter, son ravisseur originel ${ }^{81}$, cette Europe allégorisée est relativement peu présente avant I9I 6 . Elle est dès lors très régulièrement malade et souvent alitée. En I9I7, son mal empirant, Europe, jeune femme dénudée dans un décor rougeoyant, demande de l'aide à l'oncle américain Jonathan, détenteur de l'argent qui manque à sa mortelle industrie ${ }^{82}$ (cf. fig. 83 ).

Europe réapparait ensuite en petite fille ayant cassé ses jouets ${ }^{83}$, pour succomber, peu après, devant des hyènes marchant vers sa dépouille ${ }^{84}$. Une seule fois, Europe est martiale, à l'aube de I9I 8 , et le Nebelspalter l'enjoint à avoir honte ${ }^{85}$. Europe est toujours

Nebelspalter 1914/27, dessin pleine page de Boscovits senior intitulé « Une alliance de nains? » (Ein Bund der Zwerge?).

Nebelspalter 1914/31, couverture de Boscovits junior intitulée « Le premier août » (Der erste August).

Nebelspalter 1914/36, couverture de Boscovits junior intitulée « La situation européenne » (Die europäische Lage).

Nebelspalter 1915/8, dessin de Boscovits senior intitulé «Le destin d'Europe » (Das Schicksal Europas).

Nebelspalter 1917/3, couverture de Henrik intitulée «L'Europe mourante » (Die sterbende Europe).

${ }_{83}$ Nebelspalter 1917/14, dessin de Boscovits senior intitulé « La "dame Europe" » (Die " Dame Europa »).

4 Nebelspalter 1917/30, couverture de Henrik intitulée « L'autre danger » (Die andere Gefahr).

Nebelspalter 1918/1, dessin pleine page de Karl Czerpien intitulé « Un appel à la vanité féminine » (Ein Appel an die Eitelkeit des Weibes). davantage désespérée, se revigorant uniquement pour entamer une danse macabre, peu avant l'armistice ${ }^{86}$. Hagarde, amaigrie, vêtue de haillons, son apparence ne bouge plus guère.

Si la carte sert à décrypter la diplomatie en I9 I4, elle endosse à nouveau une valeur spéculative en I9I 5, lorsqu'il s'agit d'interroger les intentions de l'Italie ${ }^{87}$. Durant le conflit, la carte est le plus souvent un accessoire, rare et assez vague, servant, par exemple, en I9 I5, à mettre en images les manœuvres du général von Hindenburg ${ }^{88}$. Lorsqu'elle est spécifiée, cette carte est européenne, à l'exception tout à fait notable d'une carte en relief montrant les sommets (suisses) atteints par les prix de la viande (Fleischpreiserhöhung), du lait (Milchpreiserhöhung), de l'alimentation (Lebensmittelpreiserhöhung), du pain (Brotpreiserhöhung), de la rente foncière (Grundzinserhöhung) et des impôts (Steuern) ${ }^{89}$. Après la guerre, le bébé de la Société des Nations se penche sur une carte pour redéfinir les frontières de la Haute-Silésie ${ }^{90}$.

Les représentations physiognomoniques se raréfient, se limitant à une cartographie guerrière, plaquée en I9 I 5 sur le visage du ministre des Affaires étrangères anglais, Sir Edward Grey ${ }^{91}$ et à la double-face du gagnant de la guerre, représenté en perdant une fois l'image inversée ${ }^{92}$.

Nombreuses sont, par contre, - une petite vingtaine - les représentations d'un globe qui, du fait de l'extension mondiale du conflit, est le plus souvent montré dans son entier. Comme la figure de l'Europe, le globe n'apparaît vraiment qu'à partir de I9 16, l'année du "tournant idéologique » du Nebelspalter ${ }^{93}$. Les représentations révisent des schémas préexistants, qui sont adaptés à la situation. Le globe est à présent en feu, lorsque, en I9I6, Atlas, perdu dans l'univers, prend celui-ci dans ses mains en s'en référant à la conférence de la Haye ${ }^{94}$; quand, la même année, il sert d'accessoire à saint Pierre pour commenter l'entrée en guerre de la Roumanie ${ }^{95}$; lorsque des diablotins se réjouissent de la pagaille qui va encore augmenter avec l'implication des États-Unis, en I9I $7^{96}$ ou quand Méphisto en personne rit de ce monde en feu, en $1920^{97}$. Le globe continue de supporter scènes et personnages mais avec des variations iconographiques importantes. Entier, il sert de base, en I9I6, aux représentants des puissances neutres, dont le placement en tous sens laisse comprendre que ceux-ci ont perdu toute orientation ${ }^{98}$; en I9 I 8 , le globe sert de piste de danse

Nebelspalter 1918/42, dessin pleine page de Boscovits junior intitulé « Les dernières cadences » (Die letzten Takte).

Nebelspalter 1915/10, dessin pleine page de Boscovits junior intitulé « Le point d'interrogation européen » (Das europäische Fragezeichen).

${ }_{88}$ Nebelspalter 1915/38, dessin pleine page de Karl Czerpien intitulé « Rumeurs de paix » (Friedensgerüchte).

89 Nebelspalter 1917/26, dessin pleine page de Henrik intitulé « Situation critique » (Schwierige Lage).

9 Nebelspalter 1921/36, dessin pleine page signé d'un monogramme intitulé «Le bébé de la Société des Nations et la Haute-Silésie » (Der Völkerbundssäugling und Ober-Schlesien).

Nebelspalter 1915/41, couverture de Boscovits senior intitulée " Sir Edward Grey ». Nebelspalter 1921/4, couverture de Boscovits junior intitulée « Le gagnant de la guerre » (Der Kriegsgewinnler).

Cf. « 3.3.1. Se situer vis-à-vis d'un conflit étranger».

Nebelspalter 1916/24, dessin pleine page de H. Henrik intitulé « $1916 »$.

Nebelspalter 1916/37, dessin pleine page de Boscovits junior intitulé « Le partage de la terre » (Die Teilung der Erde).

Nebelspalter 1917/17, dessin pleine page de Karl Czerpien intitulé « La guerre mondiale » (Der Weltkrieg).

Nebelspalter 1920/16, couverture de Alfred Hirschler.

${ }_{98}$ Nebelspalter 1916/28, dessin pleine page de Boscovits senior intitulé « Un truc mexicain-américain » (Amerikanisch-Mexikanisches). 
20. 3. 43. Jahrgang.
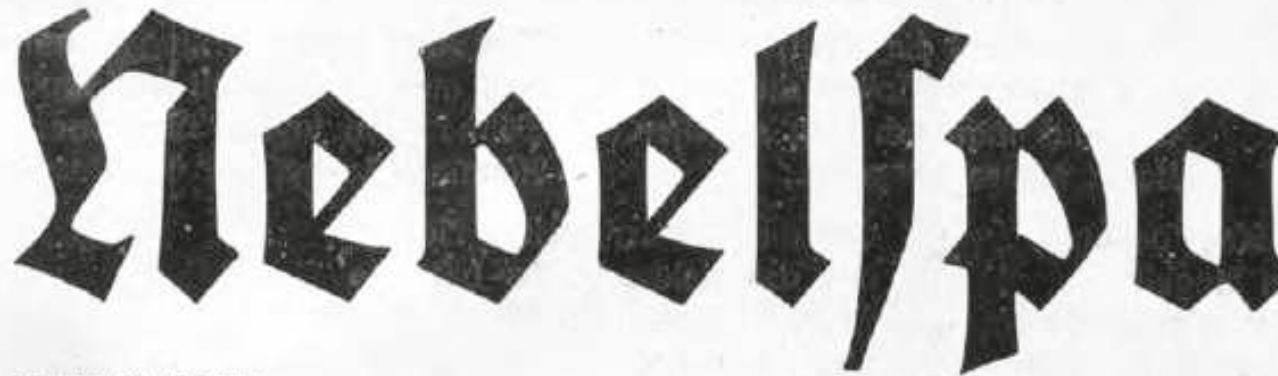

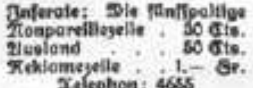

Fumoriftifch-[atyrifche Wochen[chrift
Cinzelnuminer 30 cts.

\section{Die Iterbende Curope}

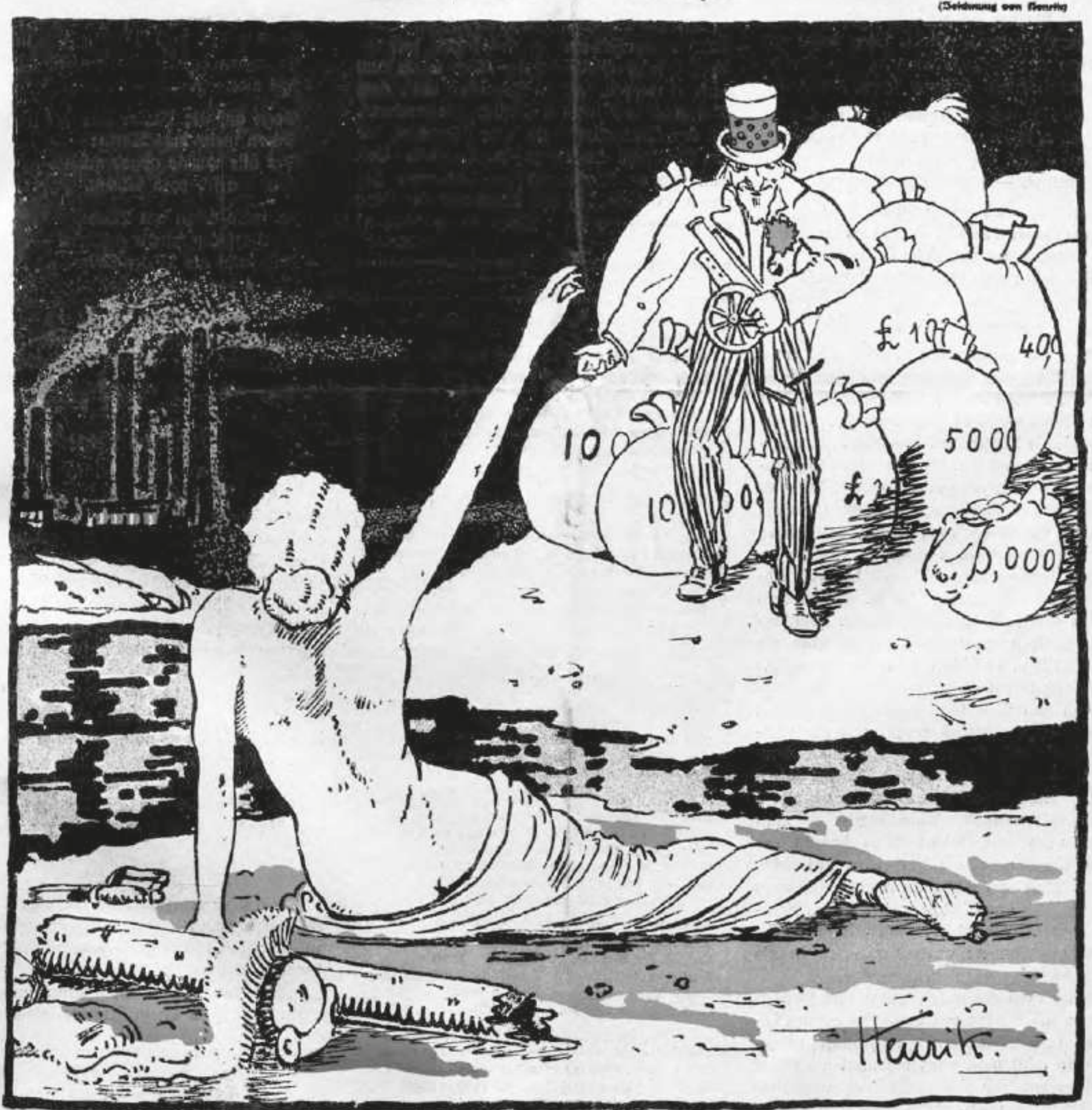

„5ilf!" - ...Jahle!- 


\section{Das Joch}

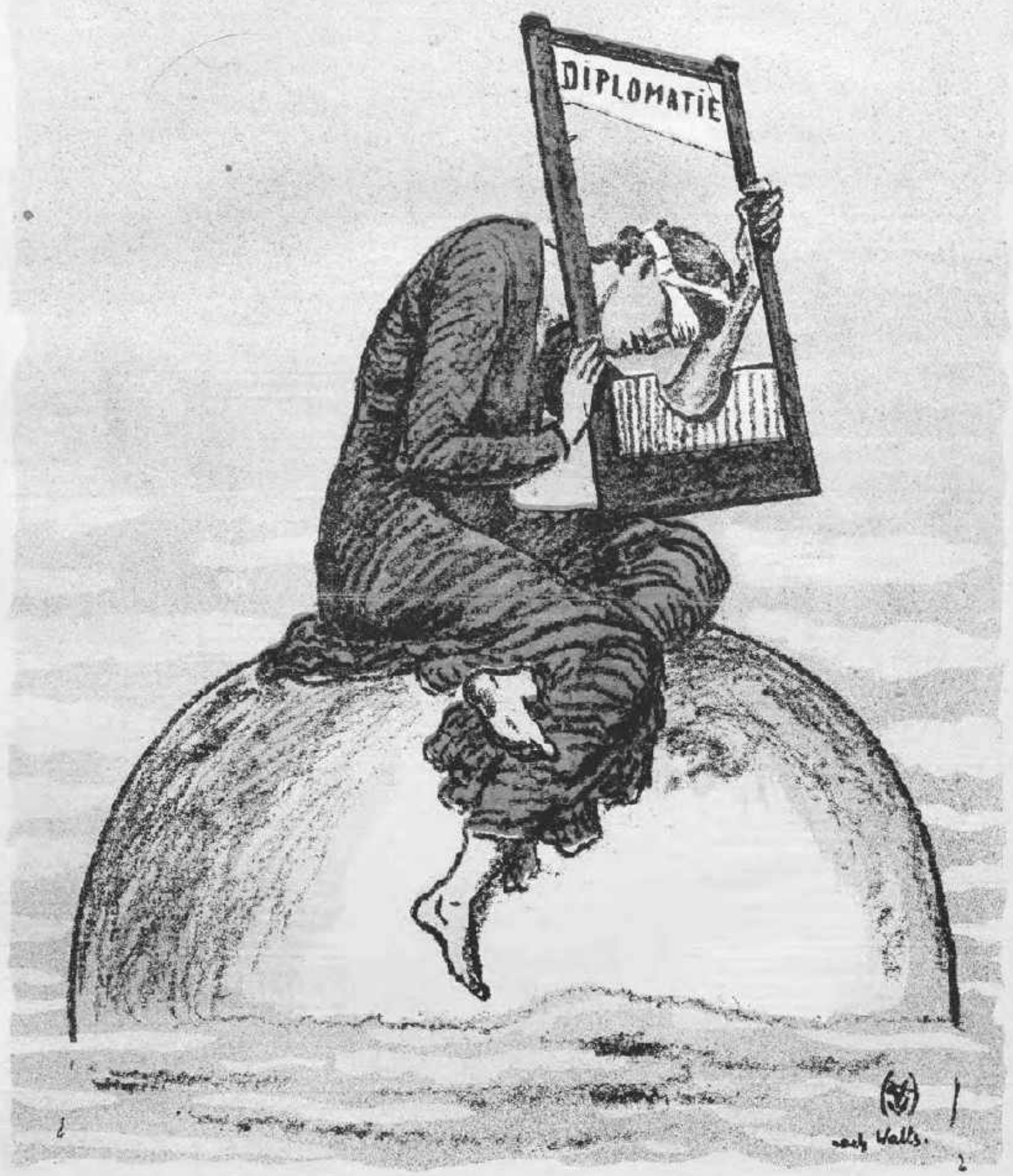

Europas dauernde Ẻedrângnis.

Fig. 84. Nebelspalter 1920/38, dessin pleine page en couleur de Victor Straus intitulé « Le joug » (Das Joch). 
pour de nouvelles danses macabres ${ }^{99}$; en I919, il devient le siège des puissants, américains, japonais et surtout anglais ${ }^{100}$; en I920, à nouveau tronqué, la moitié visible de ce globe forme une sorte de no man's land où est assise une Europe condamnée. Jeune femme aux yeux bandés, celle-ci est assise sur une sphère flottant on ne sait où ni comment, sa tête passée dans le cadre d'une guillotine marquée de l'inscription " diplomatie » ${ }^{101}$ (cf. fig. 84).

Deux fois seulement, le globe est associé à la Suisse : lors de la critique des neutres en I9 I $6^{102}$ ainsi qu'à l'occasion de la visite du premier ministre britannique Lloyd George à Lucerne, à l'automne I920. Le ministre anglais, représenté en Atlas, propose alors à Helvetia d'échanger son globe contre la croix helvétique ${ }^{103}$. Un autre fait est remarquable: Europe n'est pas une seule fois associée au globe durant la guerre; elle ne lui est liée qu'avant et après le conflit. On ne retrouve donc pas le type popularisé par Daumier d'une Europe chancelant sur un globe assimilé à une bombe ${ }^{104}$, pourtant sémantiquement conforme à bien des compositions.

D’une manière générale, ce n'est que vers la fin de la guerre que commencent à apparaître des innovations iconographiques, dont quelques-unes concernent le globe: son association à des danses macabres, son embrasement, mais surtout une image de I9I7 particulièrement efficace, où la sphère, enserrée dans une toile d'araignée, est représentée au milieu du cosmos. Ce double procédé permet de montrer un destin tout à la fois unique et fatal, et de déplacer la figure classique de l'observateur à la longue vue, qui se trouve désormais sur une autre planète pour regarder une terre, devenue, pour ainsi dire, étrangère à elle-même ${ }^{105}$. Hormis la carte économique suisse de I9I7, toutes les autres novations concernent l'Europe, sa figuration enfantine, sa pétrification en une pietà monumentale ${ }^{106}$, réinterprétation moderne des sculptures du $\mathrm{XIX}^{\mathrm{e}}$ siècle ${ }^{107}$, ainsi que sa figuration récurrente en porte, reprenant plus ou moins clairement le contenu du télégramme du général von Moltke du 3 I juillet I9I4 (Ante portas) ${ }^{108}$ (cf. fig. 85).

L'après-guerre engendre, enfin, un arbre carte pour représenter une Hongrie amputée d'une partie de son territoire ${ }^{109}$.

Durant cette période, on notera la rareté de la présence de la Suisse alors que les représentations en lien avec la guerre sont nombreuses. La Suisse pèse moins que jamais dans les affaires du monde.

9 Nebelspalter 1918/34, couverture de S. Mohr intitulée « Celui qui danse sur la terre » (DerErdballtänzer); Nebelspalter 1918/42, dessin pleine page de Boscovits junior intitulé « Les dernières cadences » (Die letzten Takte).

100 Nebelspalter 1919/29, couverture de Alfred Hirschler intitulée « Le gagnant » (Der Sieger); Nebelspalter 1919/47, couverture de Alfred Hirschler.

Nebelspalter 1920/38, dessin pleine page de Victor Straus intitulé « Le joug » (Das Joch).

${ }_{102}$ Nebelspalter 1916/28, dessin pleine page de Boscovits senior intitulé « Un truc mexicain-américain » (Amerikanisch-Mexikanisches).

103 Nebelspalter 1920/36, dessin pleine page de Alfred Treichler intitulé « Lloyd George à Lucerne » (Lloyd George in Luzern).

104 Christian de Bartillat et Alain Roba, Métamorphoses d'Europe. Trente siècles d'iconographie, op. cit., p. 120.

105 Nebelspalter 1917/32, couverture de Boscovits senior intitulée « L'araignée » (Die Spinne).

o6 Nebelspalter 1918/44, dessin pleine page de Boscovits senior intitulé « L'Europe "reconnaissante" » (Das « dankbare » Europa)

107 Michael Wintle, The image of Europe. Visualizing Europe in Cartography and Iconography throughout the Ages, op. cit., p. 351-368.

108 Nebelspalter 1918/45, couverture de Boscovits senior intitulée «Ante portas »; Nebelspalter 1920/18, dessin pleine page de Boscovits junior intitulé « L'Europe a besoin de calme " (Europa braucht Ruhe); Nebelspalter 1917/1, dessin de Karl Czerpien intitulé « Ceux qui félicitent l'Europe en 1917 » (Europas Gratulanten für 1917); sur ce point: « 3.3.1. Se situer vis-à-vis d'un conflit étranger ».

o9 Nebelspalter 1920/4, couverture de M. Raquette intitulée « La paix » (Der Frieden).

\subsection{La Suisse versus Zurich: critique et iconographie}

La Suisse du Nebelspalter est celle de créateurs œuvrant sous contrôle. Leurs créations sont passées dans un filtre dont le calibre et les couleurs varient selon l'époque et la fortune du titre. Parfois, ce filtre est revendiqué, comme lorsqu'intervient le personnage du Nebelspalter ${ }^{110}$. Sa présence met alors en évidence le locuteur, le journal, donc. Quand le Nebelspalter rencontre Helvetia, il devient clair que l'on est en face d'une affaire importante. Mais, attention, certaines déclarations d'intention se font en toute discrétion, et l'absence de signature peut être un indicateur tout aussi puissant que ne l'est la mise en scène allégorique. Quoi qu'il en soit, la Suisse du Nebelspalter est en soi un objet d'histoire ${ }^{111}$. Ce sont des morceaux choisis qui sont présentés ici.

Il est, par ailleurs, beaucoup question de Zurich dans le Nebelspalter. Toutes périodes confondues, le sujet vaut les affaires de la Confédération. Cette présence de la ville évolue, cependant, à la fois quantitativement et qualitativement. Si la question quantitative peut être réglée à coup de chiffres, issus de relevés fastidieux, ce n'est pas le cas du mode de présence, qui est une affaire assez complexe à apprécier. Deux méta-modes de présence cohabitent: le dit et le montré. Mais, ce n'est pas parce que ces deux modes sont liés dans une composition qu'il y a coïncidence du propos. Non contente de contrarier le verbe, l'image soutient souvent un discours propre, que l'on peut analyser composition par composition et qui forme, image après image, une sorte de suite narrative ou plus exactement un contrepoint au texte. Ceci, en particulier, durant les années Jugendstil, où l'image domine la partition. Alors, la ville, dont la présence est longtemps architectonique, et pour tout dire assez discrète, emplit l'image, prenant une coloration sociale tout à la fois sombre et festive.

\subsubsection{Le face-à-face (helvétique) du Nebelspalter avec Helvetia}

La part des compositions consacrée à la Suisse renseigne sur le positionnement éditorial et l'ouverture sur le monde du périodique. Ces deux facteurs ne s'équivalent pas et il faut distinguer ce qui relève d'une évolution générale, d'un repli sur les affaires intérieures, dicté par des calculs éditoriaux, comme c'est le cas à partir en $1907^{112}$. Alors que la première décennie est quantitativement nettement dominée par les affaires suisses, à partir de la fin des années I 880 , seule la moitié des compositions concernent les affaires intérieures - dont celles zurichoises. Cette part ne varie dès lors que très peu. Si l'on considère que le nombre total des dessins de la revue se chiffre dans les vingt-mille et que, parmi ceux-là, environ la moitié concerne l'actualité (le reste est essentiellement formé de dessins humoristiques), on peut évaluer à environ 5000 le nombre de dessins en relation avec la Suisse.

Les dessins du Nebelspalter ne rendent pas compte, loin s'en faut, d'une réalité «objective ». Ce sont des images façonnées par des artistes pour une revue zurichoise, soumises à des procédés iconiques et qui visent une intention rhétorique et esthétique.

\footnotetext{
Rappelons que le Nebelspalter en italiques désigne la revue et en caractères romains (Nebelspalter) le personnage allégorisant celle-ci.

Pour une histoire de la Suisse via le Nebelspalter; Bruno Knobel, Die Schweiz im Nebelspalter. Karikaturen 1875 bis 1794, Rorschach, Nebelspalter-Verlag, 1974. Cf. « 2.5. 1907-1912: remous, hésitations et révisions ».
} 


\section{Europa braucht Ruhe}

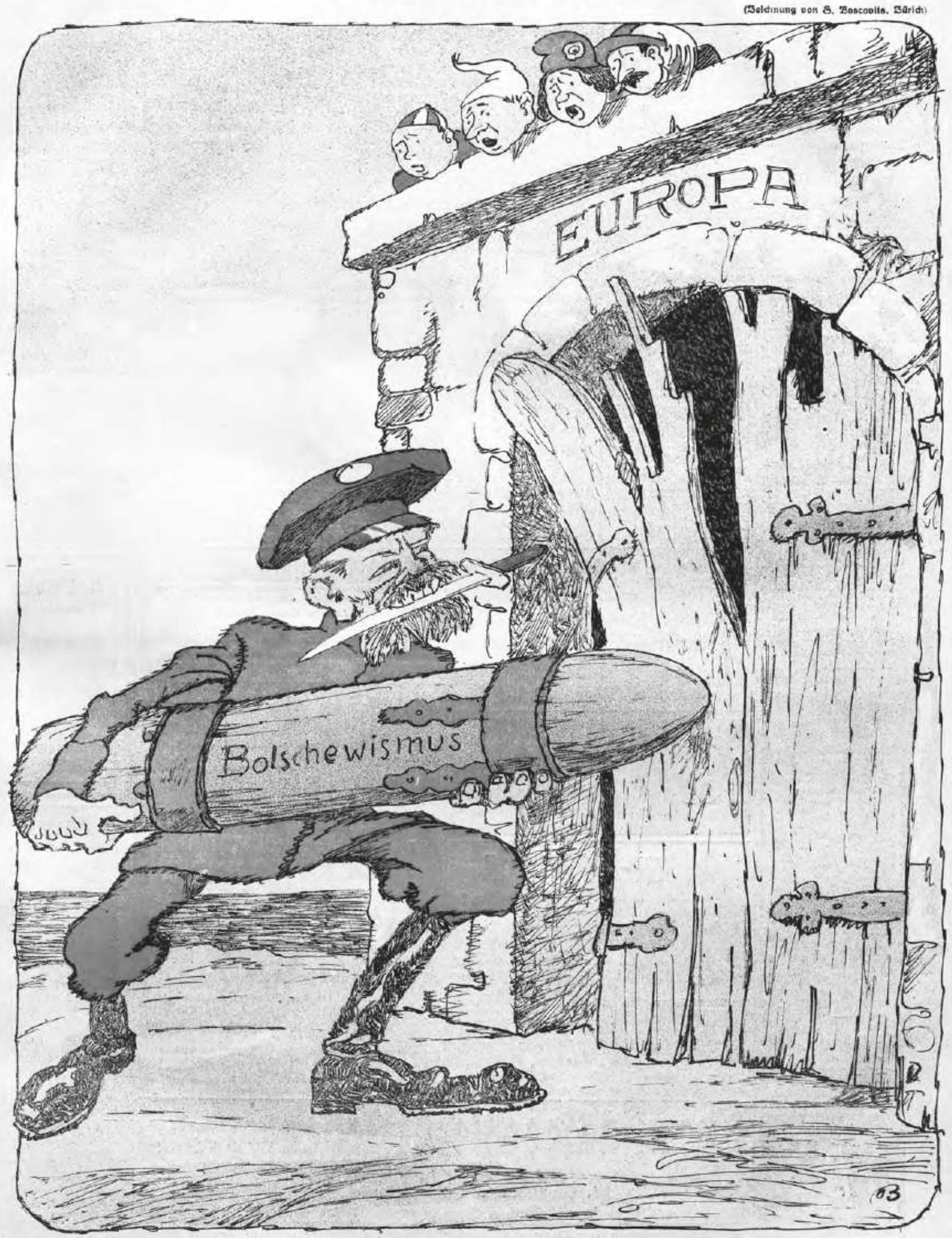

„2Jenn uns der Kerl nur endich in Ruhe ließje. -. 
Créées en fonction d'un horizon d'attente ${ }^{113}$, elles transmettent un regard extrêmement filtré. À ceci, s'ajoutent des problèmes de réception. Beaucoup de références factuelles mais aussi culturelles sont maintenant difficilement disponibles. Il n'est qu'à considérer notre appréciation actuelle, plutôt conservatrice, d'une tendance jadis revendiquée comme libérale pour comprendre à quel point notre perception est biaisée. Raconter la Suisse du Nebelspalter zurichois engage une attention de tous les instants, portée tout à la fois au contexte et à une image qu'il convient d'analyser finement. Et, puisque la "vérité " ne s'approche guère par la norme mais bien plutôt par les écarts, autant ne considérer - mais en le disant que les plus investies, les plus évidemment orientées de ces images, celles mettant en scène le Nebelspalter et Helvetia ${ }^{114}$.

Durant la période zurichoise, le périodique thématise de manière récurrente des problématiques formant une trame sur laquelle vient se greffer l'actualité. Ces grands thèmes, ce sont la Constitution et ses différents outils, le jeu électoral, l'unité territoriale, la question cléricale, les échanges commerciaux, les transports - réseau ferré et Gothard, essentiellement -, les mesures de protection sociale, les questions financières et leurs instruments de régulation, l'armée, l'éducation, la presse et les lieux de plaisir. Cette somme correspond, en bonne partie, aux assises identitaires de la Suisse et bien des histoires générales se déclinent ainsi ${ }^{115}$. Trois thèmes de cette liste ne s'inscrivent néanmoins pas dans ce schéma: l'école, la presse et les lieux de divertissement. La raison de leur présence est autre. Les deux premiers, l'éducation et la presse, rencontrent un engagement personnel de l'éditeur Jean Nötzli et du dessinateur Johann Friedrich Boscovits, dont on trouve trace dans les archives et qui perdure après la mort de Nötzli, en $1900^{116}$; quant au troisième, les lieux de plaisir, il s'agit d'une composante de nombreuses revues satiriques de l'époque ${ }^{117}$. Tous ces thèmes suscitent (et méritent) l'apparition des personnages du Nebelspalter et d'Helvetia, séparément ou en couple, mais, de façon différenciée.

Pour commencer, Helvetia. Celle-ci s'impose dans l'image. Soit elle en occupe le milieu ou au moins une part importante; soit elle y trône; soit elle est juchée sur un piédestal, assez souvent placé au centre; soit, enfin, elle est dotée d'attributs de pouvoir ou de force - un écu, une épée ou une couronne, cette dernière éventuellement faite de laurier -, tous éléments historiquement gagnés à la fin du XviII siècle, alors qu'Helvetia devient un symbole national ${ }^{118}$. Différentes combinaisons sont possibles. L'iconographie d'Helvetia s'en tient, pour l'essentiel, aux types de la matrone, de la guerrière et de la paysanne. Elle n'est dégradée qu'à de rares exceptions ${ }^{119}$. Ce n'est pas un point de vue qu'exprime

Selon le concept au cœur de la théorie de la réception, formalisée par Jauss Hans-Robert Jauss, Pour une esthétique de la réception, Paris, Gallimard, 1999, p. 23-134.

14 Nombre de publications de vulgarisation mais aussi scientifiques, anciennes ou plus récentes, à vrai dire la quasi-totalité, s'appuient sur le Nebelspalter en laissant apparaître un sérieux manque de distance. La critique de ces sources, utilisées pour étayer un propos déjà formalisé, est souvent faible et parfois même inexistante.

Un petit ouvrage de vulgarisation historique, très populaire, disponible en français et en allemand, en est sans doute la meilleure preuve : Joëlle Kuntz, L'histoire suisse en un clin d'œil, Carouge-Genève, Zoé, 2006.

Cf. « 2. CYCLES DE VIE D'UN ORGANE BOURGEOIS À L'IDENTITÉ COMPLEXE ».

À ce sujet: Laurent Bihl, La Grande Mascarade parisienne. Paris, Nouveau monde (à paraître).

18 Georg Kreis, Helvetia im Wandel der Zeiten. Die Geschichte einer nationalen Repräsentationsfigur, Zurich, Neue Zürcher Zeitung, 1991, p. 32-34

19 Georg Kreis, Helvetia im Wandel der Zeiten. Die Geschichte einer nationalen Repräsentationsfigur, op. cit., p. 11-24 et 65-74; Gianni Haver, L'image de la Suisse, Le Mont-sur-Lausanne, Lep, 2011, p. 26-27; cf. également « 2.3.6. La constellation allégorique du Nebelspalter-Allégorie, femme et un monde à soi ».
Helvetia mais une vérité dont il n'est pas à douter, du moins, telle la présentent ses créateurs.

Helvetia est étroitement associée à la Constitution ainsi qu'aux principes qui en sont dérivés: le droit d'asile, à vrai dire plus ancien ${ }^{120}$ et régulièrement jugé trop généreux ${ }^{121}$; la naturalisation, qu'il convient d'accorder avec précaution ${ }^{122}$; la neutralité, qu'il faut régulièrement défendre et réaffirmer ${ }^{123}$; les élections fédérales, dont est déploré le caractère politicien ${ }^{124}$ et le code civil, institué entre I907 et I9I $2^{125}$. En gestionnaire avisée, elle surveille le budget fédéral ainsi que l'attribution des subventions ${ }^{126}$, s'intéresse aussi à un projet de loi sur la poste ${ }^{127}$. Elle donne son opinion sur les accords commerciaux, à renégocier incessamment avec la France, l'Allemagne et l'Italie ${ }^{128}$, ainsi que sur la banque centrale, longtemps désirée et qui n'est créée qu'en I905, pour devenir effective en $1907^{129}$ (cf. fig. 86).

Bonne personne, elle s'engage en 1876 , lors de sa première apparition, en faveur de la vaccination ${ }^{130}$; l'assurance maladieaccident et la couverture invalidité, toutes deux défendues des années durant ${ }^{131}$; l'école primaire, dont le financement par la Confédération est refusé par le peuple à plusieurs reprises ${ }^{132}$ ainsi que la loi sur les faillites (Concoursgesetz), en I $889^{133}$. Autorité suprême, elle garantit l'unité territoriale ${ }^{134}$, y compris en célébrant

Walter Kälin, «Asile », Dictionnaire historique de la Suisse (18/12/2002); http:// www.hls-dhs-dss.ch/textes/f/F10374.php.

C'est le cas les deux fois où Helvetia apparaît en liaison avec le thème; Nebelspalter 1889/25, dessin pleine page de Boscovits senior intitulé «En voisines » (Nachbarlich); Nebelspalter 1905/33, dessin pleine page de Boscovits senior intitulé « Impudence » (Frechheit).

${ }_{22}$ Nebelspalter 1910/38, dessin pleine page de Boscovits senior "Sur une naturalisation facilitée » (Zur erleichterten Einbürgerung).

${ }_{123}$ Nebelspalter 1915/25, dessin pleine page de Karl Czerpien intitulé « Le trust des importations » (Der Einfuhrtrust).

${ }_{124}$ Nebelspalter 1913/22, dessin de Hermann Hintermeister intitulé « Sur les élections du Conseil fédéral » (Zur Bundesratswahl).

Cf. notamment Nebelspalter 1907/52, couverture de Boscovits junior intitulée « Un bon livre est le meilleur des cadeaux de Noël » (Ein gutes Buch ist das beste Weihnachtgeschenk).

Nebelspalter 1895/18, dessin pleine page non signé intitulé « Sur la situation actuelle » (Zur heutigen Situation).

Nebelspalter 1907/22, couverture de Boscovits junior.

128 Nebelspalter $1891 / 52$, dessin pleine page de Heinrich Jenny intitulé « Sur la guerre douanière » (Zum Zollkrieg).

129 Jakob Tanner, «Banque nationale suisse », Dictionnaire historique de la Suisse (22/03/2016); http://www.hls-dhs-dss.ch/textes/f/F13747.php; pas moins de cinq contributions sur ce thème font intervenir Helvetia entre 1880 et 1907, la dernière étant pour se féliciter de l'arrivée de « La nouvelle banque dans le jardin du peuple suisse » (Die neue Bank im schweizer. Volksgarten), selon le titre de la couverture; Nebelspalter 1907/23, couverture de Boscovits senior.

Nebelspalter 1876/20, dessin non signé intitulé « Mère Hevetia et le vaccinateurs » (Mutter Helvetia und die Impfer).

Les deux mesures sont âprement défendues par le Nebelspalter des décennies durant, donnant lieu à deux interventions d'Helvetia; Nebelspalter 1899/1, dessin pleine page de Boscovits senior intitulé «Question délicate » (Heikle Frage) Nebelspalter 1904/21, couverture de Boscovits senior. L'assurance maladie et accident n'est adoptée qu'en 1912; "Assurance maladie », Bernard Degen, Dictionnaire historique de la Suisse (22/10/2001); http://www.hls-dhs-dss.ch/ textes/f/F16608.php; l'assurance invalidité ne rentre en vigueur qu'en 1960 Bernard Degen, «Assurance invalidité », Dictionnaire historique de la Suisse (11/06/2007); http://www.hls-dhs-dss.ch/textes/f/F16612.php.

Si le Nebelspalter se désole du résultat de 1882, infructueux, il milite, par contre dans le cadre de la votation du 23 novembre 1902, dont le résultat est positif Nebelspalter 1902/47, double-page de Boscovits senior intitulée « Sur le 23. Novembre » (Zum 23. November); voir aussi François Guex, «Vue d'ensemble sur les institutions scolaires en Suisse », Annuaire de l'instruction publique en Suisse, volume 1,1910.

${ }_{133}$ La loi sur les faillites, approuvée par votation populaire, le 17 novembre 1889, est défendue en 1889 par quatre contributions engageant Helvetia; « Arrêté du conseil fédéral relatif à la votation populaire sur la loi fédérale du 11 avril 1889 concernant la poursuite pour dettes et la faillite. (Du 23 août 1889) ", Feuille fédérale, 1889, vol. 3, cahier 37, p. 1170-1171.

34 Avec cinq contributions, dont deux concernant le Tessin et deux autres paraissant en temps de guerre. 


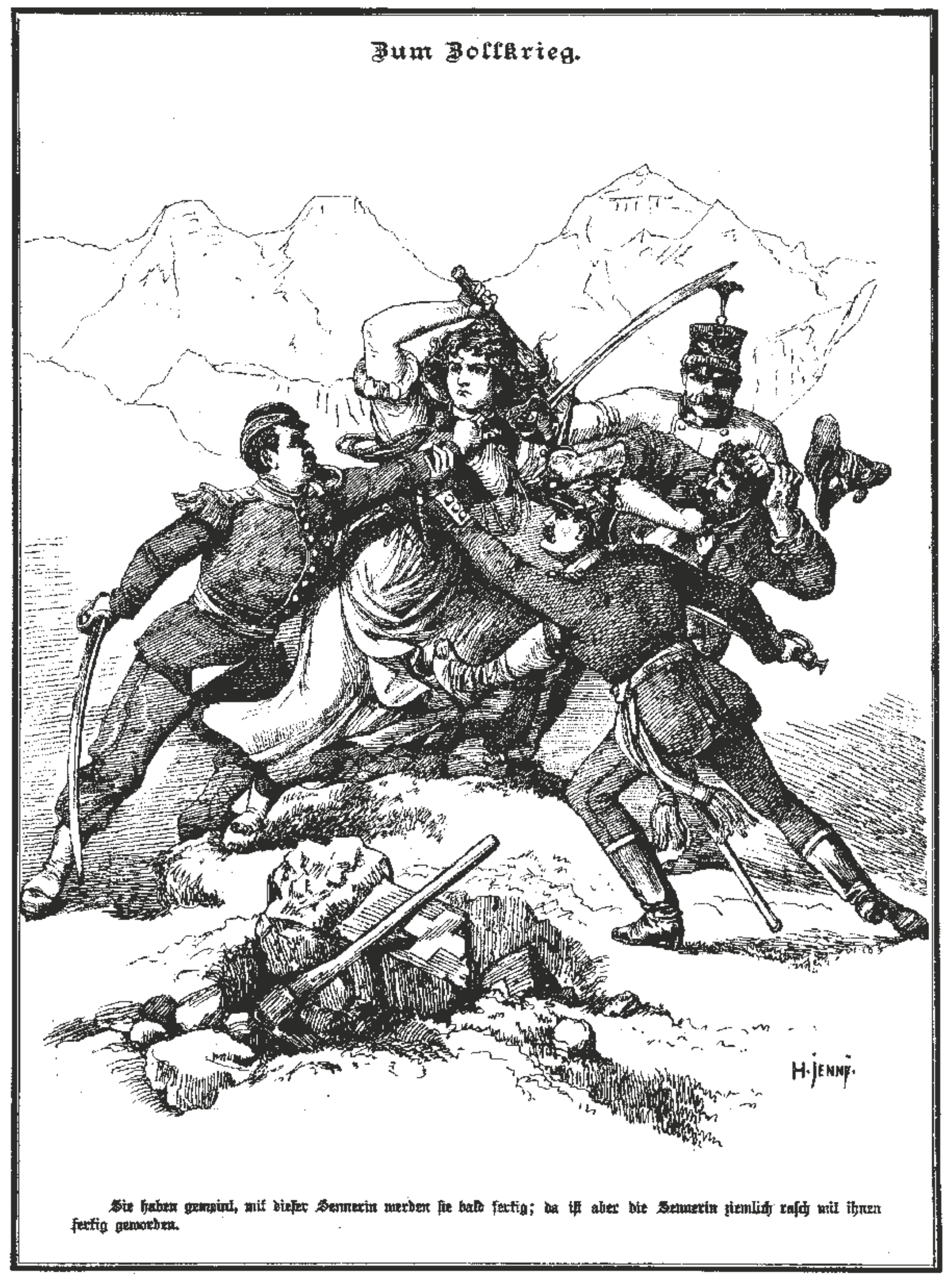

Fig. 86. Nebelspalter 1891/52, dessin pleine page en noir et blanc de Heinrich Jenny intitulé « Sur la guerre douanière » (Zum Zollkrieg). 
les cantons ${ }^{135}$ et veille à la paix sociale ${ }^{136}$. Sensible à l'aménagement du territoire, elle se réjouit du chantier du Gothard, essentiel dans la géographie suisse ${ }^{137}$ et se penche, non sans quelque partialité zurichoise, sur la localisation de l'aéroport ${ }^{138}$. Helvetia bataille dès qu'il est question du transport ferroviaire, dont la gestion et le financement sont à surveiller et si possible à transférer au niveau fédéral ${ }^{139}$, et de la question cléricale, en digne représentante du Kulturkampf $f^{140}$. Tôt, elle s'oppose à l'anarchie ${ }^{141}$ mais plus tardivement au bolchevisme ${ }^{142}$. C'est en grande prêtresse qu'elle ouvre les expositions nationales, celles de I 883 à Zurich et de I 896 à Genève ${ }^{143}$.

Le personnage du Nebelspalter apparaît sous des modalités différentes. Il s'introduit en observateur, logé dans le coin de l'image avec son attirail d'écrivain; se tient au loin avec des jumelles; surgit d'un taillis ou d'une fenêtre. Il n'hésite pas à interpeller ses vis-à-vis, les saluer de son chapeau, leur signaler d'un geste de la main un objet ou une question. Ce n'est qu'exceptionnellement qu'il se présente frontalement, lorsqu'il s'agit, dans le numéro du 22 octobre ı9ıo, d'appeler à se prononcer contre l'élection proportionnelle du Conseil national ${ }^{144}$. Longtemps, l'iconographie, très normée du Nebelspalter ne souffre guère d'écarts, si ce n'est quelques variations dans les attributs. Elle se dérègle cependant à partir des années Jugendstil. Le Nebelspalter est alors transformé en personnage festif et parfois même féminisé ${ }^{145}$.

Le Nebelspalter est globalement lié aux mêmes thèmes qu'Helvetia mais il les aborde autrement. Dessiné pour transmettre un point de vue, il donne l'opinion de la rédaction, assumée comme subjective. Une semaine avant de s'exprimer contre l'élection proportionnelle $\mathrm{du}$ Conseil national, en I9I0 ${ }^{146}$, il lève le voile (dans l'image, un drap) sur l'alliance contre nature qu'un tel mode de scrutin recèlerait - entendre le rapprochement entre les socialistes et les conservateurs catholiques. "La belle alliance ", titre de la couverture, un noir et blanc colorié de rouge, est, d'ailleurs, dotée

135 Il est cependant plus rare qu'Helvetia s'intéresse à un canton en particulier.

${ }_{136}$ En 1880 , elle est présentée comme pacificatrice; Nebelspalter 1880/4, dessin pleine page non signé, intitulé « En pacificatrice » (Als Friedenstifterin).

37 Le début du percement du tunnel, le 29 février 1882, est l'objet d'une double-page commémorative; Nebelspalter 1880/10, double-page de Boscovits senior intitulée " En souvenir du percement du Gothard. 29 février 1880 » (Zur Erinnerung der Gotthard-Durchstich. 29. Februar 1880).

${ }_{138}$ Soit Dübendorf (près de Zurich), soit Frauenfeld, soit Berne; Nebelspalter 1913/39, couverture de Boscovits senior.

39 Helvetia apparaît dans cinq contributions liées aux chemins de fer, célébrant en grande pompe le succès de la votation en faveur d'une nationalisation Nebelspalter 1898/19, double-page de Boscovits senior intitulée "Les chemins de fer suisses au peuple suisse » (Die Schweizerbahnen dem Schweizervolk); «Message du Conseil fédéral concernant la votation fédérale du 20 février 1898 (rachat des chemins de der). (Du 18 mars 1898.) ", Feuille fédérale, 1898, vol. 1, cahier 14, p. 589-594.

140 Une fois en lien avec les jésuites fribourgeois; Nebelspalter 189o/10, dessin pleine page de Boscovits senior intitulé « La foi rend heureux » (Der Glaube macht selig): une autre fois dans un contexte électoral, où les ultramontains sont opposés aux libéraux; Nebelspalter 1890/13, dessin pleine page de Heinrich Jenny intitulé "C'est de plus en plus beau » (Es wird immer schöner).

41 Nebelspalter 1898/40, dessin pleine page non signé intitulé « Elle se dresse enfin » (Sie rafft sich endlich auf).

${ }_{42}$ Nebelspalter 1918/33, dessin pleine page de Boscovits junior intitulé « Notre situation » (Unsere Situation).

43 Célébrées par deux doubles-pages de Boscovits senior; Nebelspalter 1883/17 et Nebelspalter 1896/18; cf. « 4.2. Rendre compte des expositions et régler ses comptes via les expositions $»$.

144 Nebelspalter 1910/43, dessin pleine page signé d'un monogramme intitulé «Sur le référendum » (Zur Abstimmung).

Cf. « 2.4.6. La femme, le nu et l'allégorie ».

46 Nebelspalter 1910/43, dessin pleine page signé d'un monogramme intitulé « Sur le référendum » (Zur Abstimmung). d'une légende univoque: "Image sans paroles éclairée en noir et blanc ${ }^{147}$ (cf. fig. 87 ).

Pour la deuxième fois, le peuple va rejeter, le 23 octobre I9Io, la proportionnelle, qui ne sera adoptée que le I 3 octobre I9 I 8 , à l'occasion d'un troisième référendum ${ }^{148}$. Le Nebelspalter se conforme à l'idée, alors dominante, de la nécessité d'un pouvoir fort, excluant ce mode de scrutin ${ }^{149}$, qui profiterait, en outre, à ses ennemis politiques. La proportionnelle est de ces questions revenant sans cesse - un marronnier, en termes journalistiques - et qui sont l'objet de très nombreuses compositions à partir de $\mathrm{I} 890$.

Le personnage privilégie les territoires polémiques, dont ceux de la presse, de la liberté d'expression et du progrès. Bien des compositions dénoncent l'attitude de certains organes de presse, notamment la presse allemande, jugée complaisante vis-à-vis des affaires allemandes et agressive envers la Suisse; ou encore certains titres de la presse conservatrice, tel le Vaterland lucernois ${ }^{150}$. Le Nebelspalter intervient pour juger, voire pour prononcer des sentences sans appel dans un domaine où il se pose comme une autorité. En I 878, alors que le Kulturkampf est loin d'être lettre morte ${ }^{151}$, il commente, circonspect, la création d'une association dont il souhaite qu'elle tienne à l'écart l'ennemi clérical, désigné comme «Le grand prêtre de la saleté » (Der «Hohepriester » des Schmutzes) ${ }^{152}$. Il est toujours prêt à se moquer de l'ennemi ultramontain et de son insuccès à la chasse, de ses tirs infructueux ${ }^{153}$. Fin I 884, il constate, goguenard, l'échec de journaux « ennemis » (entendre conservateurs) - la Liberta, la Allgemeine Schweizer Zeitung, Das Vaterland, le Berner Volkszeitung - qui se sont unis, sans succès, pour brûler le progrès (Fortschritt) ${ }^{154}$. En I 899, à l'occasion du congrès allemand des journalistes à Zurich, le personnage, intransigeant, salue un parterre de littérateurs et de notables à la mine fermée. Il se tient devant un tableau représentant une prison menant à la gloire; deux portraits en médaillon sont placés de part et d'autre: d'une part, un éditeur (Verleger) tenant une bourse, de l'autre, un journaliste, les bras croisés, la plume dans la bouche, empêché dans son travail par la censure (Censur). Un encart, à l'avant-plan droit de l'image, renferme les créatures dépitées qui n'ont pas été invitées à la fête (Nicht zum Fest geladen): le serpent de mer (Seeschlange), les concombres au vinaigre (Saure Gurken) et autres palmipèdes. Le Nebelspalter, ironique et caustique, conspuant la censure, salue l'assemblée par ces mots:

\footnotetext{
(Bild ohne Worte in schwarz-roter Beleuchtung); Nebelspalter 1910/42, couverture signée d'un monogramme intitulée « La belle alliance ».

${ }_{48}$ «Du système majoritaire au système proportionnel: I'histoire des premières élections à la proportionnelle en 1919 ", Confédération suisse; https://www.ch.ch/ fr/elections2015/50e-edition-retrospective/du-majoritaire-au-proportionnel/ ; consulté le 15 avril 2016.

149 Regina Wecker, "Neuer Staat - neue Gesellschaft. Bundesstaat und Industrialisierung (1848-1914) », dans Die Geschichte der Schweiz, éd. Georg Kreis, Bâle, Schwabe, 2014, p. 463; Roland Ruffieux, "La suisse des radicaux (1848-1914) », dans Nouvelle Histoire de la Suisse et des Suisses, tome 3, éd. Jean-Claude Favez, Lausanne, Payot, 1983, p. 66; Peter Gilg, "Systèmes électoraux », Dictionnaire historique de la Suisse (29/04/2015); http://www.hlsdhs-dss.ch/textes/f/F26454.php.

Nebelspalter 1881/30, dessin pleine page non signé intitulé « La tâche des tireurs lors de la fête fédérale de tir » (Die Aufgabe der Schützen am Eidgenössischen Schützenfest); Nebelspalter 1912/42, couverture de Boscovits senior.

À ce sujet: Marija Borer-Cifric, Der « Nebelspalter » als kulturhistorische und politische Quelle des Kulturkampfes der Jahre 1875-1890, 1999 (mémoire soutenu à l'Université de Zurich).

${ }_{152}$ Nebelspalter $1878 / 40$, dessin pleine page non signé intitulé « L'association des journalistes suisses » (Der schweizerische Journalistenverein).

153 Nebelspalter 1882/48, dessin pleine page non signé intitulé « Malchance à la chasse » (Jagdpech)

${ }^{54}$ Nebelspalter $1884 / 50$, dessin pleine page de Boscovits senior intitulé « II doit être
} brulé » (Der muss verbrannt werden). 


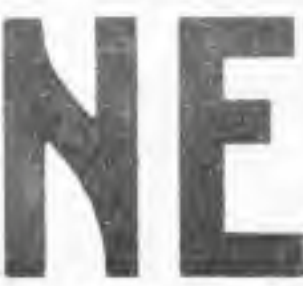

Кr. 42, 36. Jakrg.
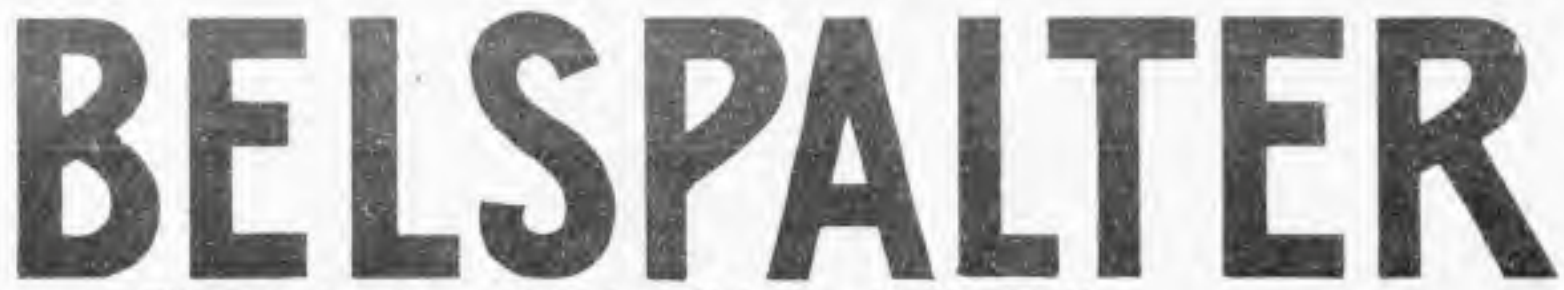

Jllustriertes humoristisch-satirisches Wochenblatt.

15 Oktober 1810

Verlag und Administration
J. F. Boscovits, Weldmannstrasse 4, ZORICH

Abonnement

3 Monata Fr. 3.50, 6 Monato Fr, 6. - 12 Monate Fr. 11.Einzelne Nummer $30 \mathrm{Cts}$

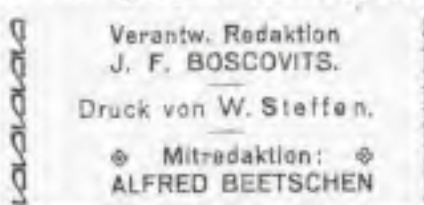

Alleinige Anzeigenannahme

Annencen-Expedition RUDOLF MOSSE, Zorich, sowio deran Filialen und Agenturen Anzeigen

Die 4 gespaltene Patitzolito odor deren Raum $30 \mathrm{Cts}$. Iur Anzeigan auslarndischen Ursprungs $50 \mathrm{Cts}$

Ca belle alliance.

Ueth. Batz k Cis

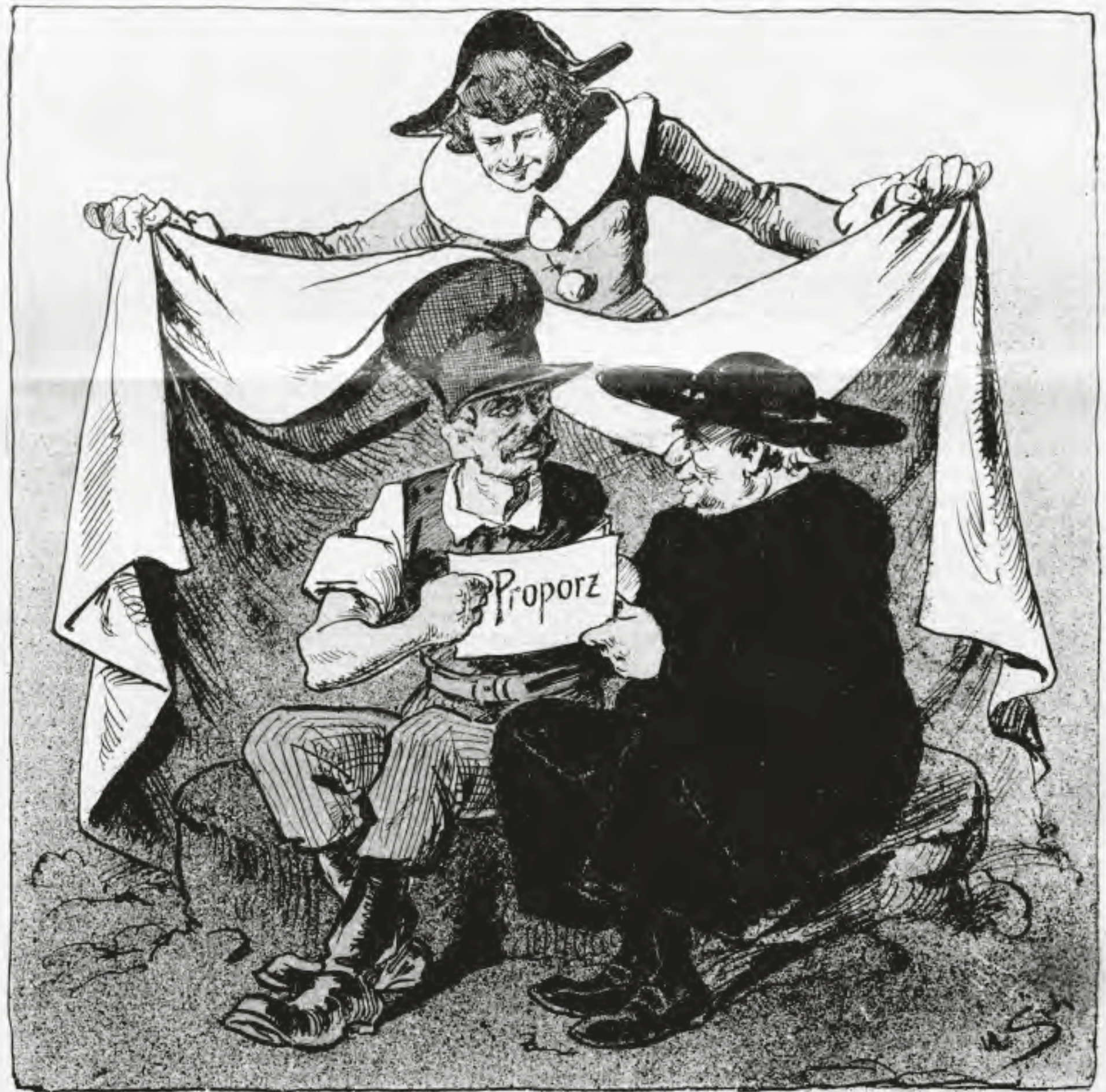

Bild oine Worte in Ífwarz-roter Beleuditung.

Fig. 87. Nebelspalter 1910/42, couverture en couleur signée d'un monogramme intitulée «La belle alliance ». 
Bienvenue aux héros de la plume! Ici vous salue, sur le chemin de la gloire une petite heure joyeuse. Profitez-en bien! Ici, la vue est libre libre comme partout où la bienfaisante fille des cieux passe le balaie! 155

Bien plus tard, à l'automne I9I4, ce sera cette fois de la censure militaire dont il sera question ${ }^{156}$.

Le Nebelspalter s'inquiète tôt du socialisme, suivant, en I 88 I, à l'aide de jumelles immenses l'activisme de Herman Greulich ${ }^{157}$ ou observant, méfiant, depuis une fenêtre, en I907, l'arrivée des étudiantes russes, suspectées d'introduire l'idéologie bolchevique à l'Université ${ }^{158}$. Il est, par ailleurs, toujours sur ses gardes devant le danger réactionnaire. La fête fédérale de tir est, en I 88 I, l'occasion de charger la réaction (Reaction), un dragon à binocles envoyant son souffle fétide sur la cible de la patrie (Vaterland): "C'est une vieille histoire, pourtant elle est toujours (malheureusement) éternellement nouvelle ${ }^{159}$ (cf. fig. 88 ).

Il n'hésite pas davantage à tancer la politique (Frau Politik), une femme de mauvaise volonté:

«Tu es fidèle à toi-même, ma chère politique. Ton sens de la propreté outrepasse toutes les limites; mais, que dirais-tu, pour une fois, de laver les escaliers en partant du haut au lieu de commencer par le bas, ça irait vite et ils seraient propres "; ce à quoi, l'intéressée répond : « Je le sais bien mais cela ne me convient pas $»^{160}$.

Il s'agit ici de mettre en cause la moralité des dirigeants politiques. Comme toutes les compositions de cette teneur, le dessin n'est pas signé. Lors des années Jugendstil, le Nebelspalter change, cependant, de registre. Il s'introduit dans les lieux festifs par le biais des encarts publicitaires, où il partage la vedette avec la figure féminine, confirmant la nouvelle option esthétique ${ }^{161}$.

\subsubsection{L'alliance sacrée ou la Suisse du Nebelspalter}

Pour les grandes causes, Helvetia et le Nebelspalter vont s'allier. Leur union est scellée dans le premier numéro. Le Nebelspalter se présente alors à Helvetia, entourée des acteurs et symboles de la vie politique suisse ${ }^{162}$. Dans ces compositions, une petite vingtaine pour la période zurichoise, le Nebelspalter se met au service d'Helvetia, soit en lui servant de cavalier; soit comme

(Willkommen ihr Helden der Feder! Euch grüsset hier, am Wege zum Lorbeer, ein frohgesinntes Stündchen. Lebt es! Hier ist die Aussicht frei-frei wie überall, wo die segensreiche Himmelstochter den Besen führt!) ; Nebelspalter 1899/26, doublepage de Boscovits senior intitulée «Sur le congrès allemand des journalistes à Zurich » (Zum deutschen Journalistentag in Zürich)

${ }_{156}$ Nebelspalter 1914/38, dessin pleine page de Boscovits senior intitulé « Sous le signe de la censure » (Im Zeichen der Zensur); cf. « 3.3.1. Se situer vis-à-vis d'un conflit étranger $»$.

57 Nebelspalter 1881/26, dessin pleine page, non signé intitulé « La comète » (Der Komet); Markus Bürgi, « Greulich, Herman », Dictionnaire historique de la Suisse, 2007 (17/07/2007); http://www.hls-dhs-dss.ch/textes/f/F3738.php.

${ }_{158}$ Nebelspalter 1907/47, couverture de Boscovits junior intitulée « La Russe disparue » (Die verschwundene Russin).

159 (Es ist eine alte Geschichte, doch bleibt sie [leider] ewig neu!); Nebelspalter 1881/30, dessin pleine page non signé intitulé « La tâche des tireurs lors de la fête fédérale de tir » (Die Aufgabe der Schützen am Eidgenössischen Schützenfest).

${ }^{60}$ (Nebelspalter. "Du bist immer die gleiche, meine liebe Politik. Dein Reinlichkeitsgefühl übersteigt alle Grenzen; aber, was meinst du, wenn du nun einmal die Treppe von oben, statt von untern zu waschen anfingest, dann ging es rasch und sie würde sauber! » - Politik "Das Weiß ich schon, aber es passt mir nicht! »); Nebelspalter 1885/32, dessin pleine page non signé intitulé « Sur les concombres au vinaigre » (Zur sauren Gurke).

${ }_{61}$ Cf. « 2.3.6. La constellation allégorique du Nebelspalter-Allégorie, femme et un monde à soi ».

162 Nebelspalter 1875/1, dessin en noir et blanc non signé intitulé « Santé Maman! » (Prosit Mamma!); cf. « 2.1. 1875 : un premier numéro fixant les choses: maquette, tendance, thèmes, identité visuelle et commerciale ». conseiller, en attirant son attention sur un fait, un personnage, une constellation, comme dans les récurrents "Raisins acides» (Saure Trauben $)^{163}$; soit en consignant les événements à l'aide de sa plume ${ }^{164}$; ou encore en accomplissant pour elle une besogne, mettant de l'ordre, par exemple dans la gestion des chemins de fer à l'automne $\mathrm{I} 875^{165}$. Exceptionnellement, le Nebelspalter demande assistance à Helvetia, comme en I 875 , où il requiert son aide pour enfoncer la porte de Bâle, barrée par les conservateurs ${ }^{166}$.

Leur combat commun porte sur la Constitution, le code civil, les élections, l'unité territoriale, l'armée (dont le service militaire), les échanges commerciaux ainsi que les transports - train et Gothard. Helvetia est aiguillonnée par l'insolence du Nebelspalter et leur apparition commune ne peut manquer d'éveiller l'intérêt du lecteur. L'alliance révèle les thèmes jugés fondateurs par le périodique, pour ne pas dire "sacrés". Les positions qui sont prises ne sont jamais démenties, de sorte que l'on peut dire qu'il s'agit là de "la Suisse du Nebelspalter ". Dans le choix des thèmes comme dans la manière de les aborder, se ressent, plus qu'ailleurs, le moralisme de la revue.

Le duo se forme sans surprise, en I905, lorsqu'il s'agit d'établir le code civil. Alors qu'Helvetia, vêtue en matrone, est occupée à confectionner le code civil (Eidg. Civilgesetzbuch) de la Confédération, déjà relié par la justice (Gerechtigkeit), l'ordre (Ordnung) et le bien public (Gemeinwohl), le Nebelspalter, désigné dans la légende comme apprenti (Der Lebrbub), arrive par un escalier, à l'arrière de l'image, avec une amphore marquée " équité » (Billigkeit): " Madame la maîtresse, que nous n'oublions pas le liant... ${ }^{167}$ À vrai dire, l'ouvrage, en projet depuis la République helvétique, n'est encore qu'un vœu pieu. Il sera élaboré sur la base des quatre volumes du System und Geschichte des schweizerischen Privatrechts (Système et histoire du droit privé suisse) publiés entre I 886 et I 893 par le juriste Eugen Huber (I849-I923). Adopté par le Parlement en I907, il n'entrera en vigueur qu'en I9I2. Et encore, augmenté des lois d'introduction édictées par les cantons ${ }^{168}$ - on est en Suisse. À Noël I907, Helvetia, très élégante, félicite ses deux enfants, le conseil des États (Ständerat) et le conseil national (Nationalrat): « Merci, chers enfants. C'est vraiment un bon livre - on comprend ce qu'il contient ${ }^{169}$. Une légende dont on ne saisit tout à fait le sens qu'en voyant Germania (l'allégorie de l'Allemagne) se désespérer dans une bulle, à gauche de l'image, devant son propre code civil. C'est toujours de manière relative, par rapport à ses « grands " voisins, que se construit l'identité suisse.

Helvetia comme le Nebelspalter apparaissent à l'occasion des élections fédérales, c'est-à-dire d'un côté, celles du Conseil fédéral; de l'autre, celles de l'Assemblée fédérale. Cette dernière, « autorité

\footnotetext{
Nebelspalter 1877/40, dessin pleine page de Boscovits senior intitulé « Raisins acides » (Saure Trauben); Nebelspalter 1881/39, dessin pleine page de Boscovits senior intitulé « Raisins acides » (Saure Trauben).

Nebelspalter 1904/13, double-page de Boscovits senior intitulée « Petits moments du mois de mars » (Märzenweilchen).

15 Nebelspalter 1875/46, dessin non signé intitulé «Le département fédéral des chemins de fer » (Das eidgen. Eisenbahndepartement).

Nebelspalter 1875/6, dessin non signé, sans titre.

17 (Der Lehrbub: Frau Meisterin, dass wir auch den "Leim » nicht vergessen...) Nebelspalter 1905/31, dessin pleine page de Boscovits senior intitulé « Le liant » (Das Bindemittel).

${ }_{168}$ Bernhard Schnyder, "Code civil (CC) », Dictionnaire historique de la Suisse (02/08/2005); http://www.hls-dhs-dss.ch/textes/f/F30734.php.

169 (Dank, liebe Kinder. Das ist ja wirklich ein gutes Buch - man versteht, was darin ist) Nebelspalter 1907/52, couverture de Boscovits junior intitulée « Un bon livre est le meilleur cadeau de Noël » (Ein gutes Buch ist das beste Weihnachtsgeschenk).
} 


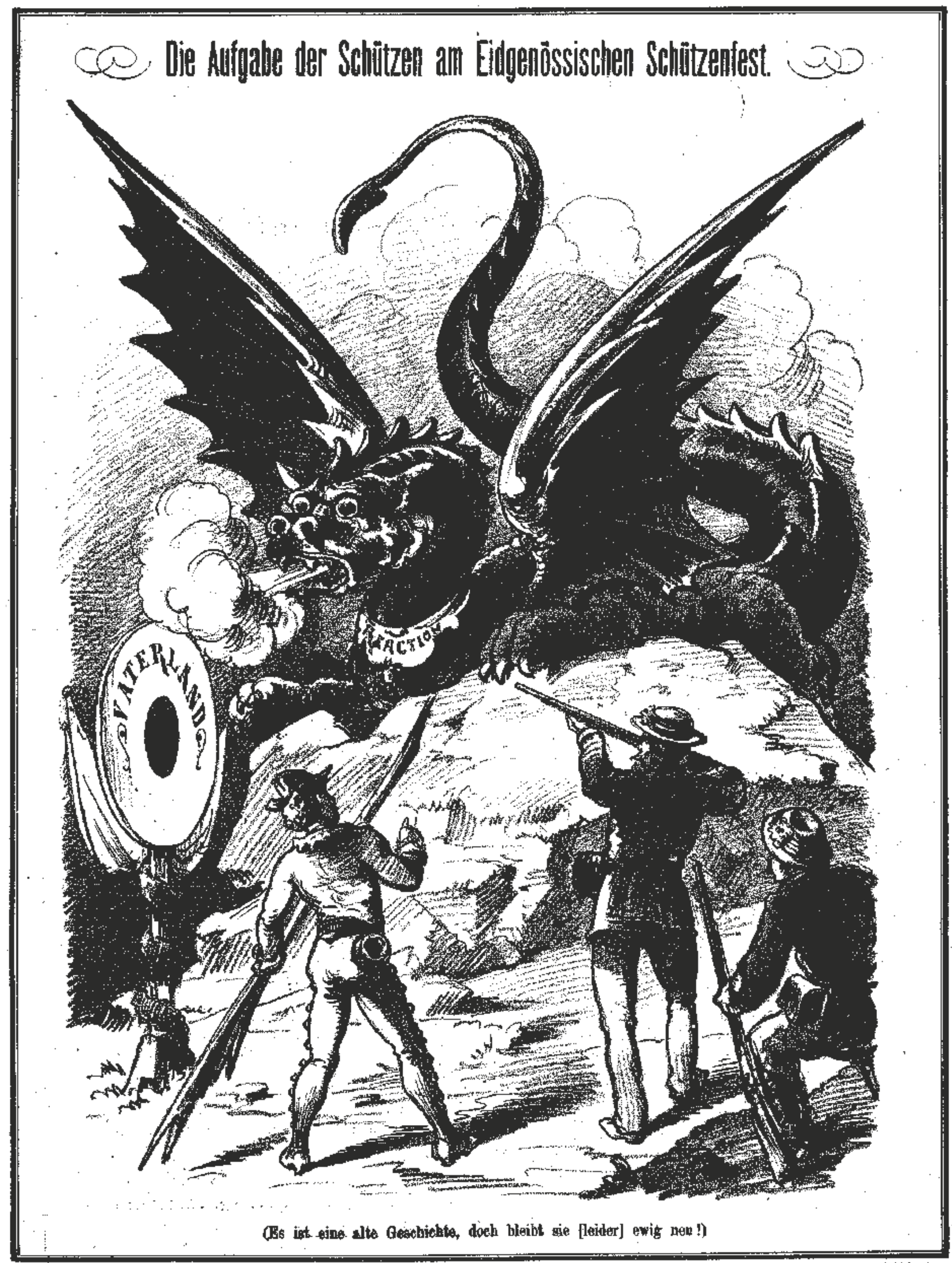

Fig. 88. Nebelspalter 1881/30, dessin pleine page en noir et blanc non signé intitulé « La tâche des tireurs lors de la fête fédérale de tir » (Die Aufgabe der Schützen am Eidgenössischen Schützenfest). 
suprême de la Confédération ", est supérieure au Conseil fédéral, puisque les membres du Conseil agissent en fonction de la législation adoptée par l'Assemblée. Celle-ci surveille en outre les actes des membres du Conseil. Selon le système bicamériste en vigueur depuis la Constitution fédérale de I 848 , et surtout depuis celle de I 874, l'Assemblée fédérale se compose du Conseil national et du Conseil des États, dont les membres sont élus par le peuple selon une périodicité et un mode de scrutin variable, tous les trois ans pour le Conseil national jusqu'en I93 I, et ceci au système majoritaire jusqu'en I9I7. Le système est censé apporter une juste représentation des régions et des forces politiques ${ }^{170}$. Cette composante ne sera cependant assurée qu'en I9I 8 avec l'adoption par le peuple de la représentativité proportionnelle. L'Assemblée fédérale élit, en outre et à titre individuel, les sept représentants du Conseil fédéral, qui choisissent à leur tour leur président, primus inter pares, pour un mandat annuel. À chaque début de législature, l'Assemblée fédérale conforte les conseillers fédéraux pour un mandat de quatre ans et, sauf circonstances exceptionnelles, les conseillers mettent eux-mêmes un terme à leur mandat ${ }^{171}$. Les élections des conseillers fédéraux et de leur président sont suivies très attentivement par le Nebelspalter, puisque particulièrement centrées sur les personnes, objets de prédilection de la caricature. Début I $88 \mathrm{I}$, la disparition du conseiller radical Fridolin Anderwert, Thurgovien d'origine, ouvre sur une élection qui se déroule dans un climat particulier. Anderwert s'est donné la mort le 25 décembre I 880 , peu après avoir été élu à la présidence du Conseil, malade, fatigué par une série de combats politiques et très atteint par une campagne de presse agressive, dont le Nebelspalter s'est fait le champion ${ }^{172}$. Les deux derniers numéros de l'année i 880 (le second daté du 25 décembre, jour du suicide) renferment plusieurs caricatures et satires mettant en cause la probité et les mœurs de l'homme politique, dont on moque en outre la corpulence ${ }^{173}$. Cinq numéros plus loin, le Nebelspalter et Helvetia sont dessinés sur un bout de terre, près de Berne, un fauteuil vide décoré de la croix helvétique, installé dans un no man's land (cf. fig. 89).

Le couple dirige ses regards vers les cieux où se détache une nuée de bien curieux papillons, une quinzaine en tout, leur nom indiqué sur leurs ailes. Il s'agit des prétendants présumés à la succession d'Anderwert. Le Nebelspalter s'entretient avec Helvetia:

Regarde bien, chère mère, comme de tous les vents il se forme un essaim pour occuper la place vide et tu es toujours à te plaindre que tu manques du bois! - Pouh, ça va barder avant que l'un d'entre eux ne s'assoie ${ }^{174}$.

\footnotetext{
Martin Graf, "Assemblée fédérale », Dictionnaire historique de la Suisse (08/10/2015); http://www.hls-dhs-dss.ch/textes/f/F10081.php.

Urs Altermatt, « Conseil fédéral », Dictionnaire historique de la Suisse (09/07/2015) http://www.hls-dhs-dss.ch/textes/f/F10085.php.

72 La campagne de presse du Nebelspalter est relayée par le Volksblatt von Andelfingen et la Züricher Post; Roger Blum, « Joseph Fridolin Anderwert (1828 1880) », dans Die Schweizer Bundesräte. Ein biographisches Lexikon, éd. Urs Altermatt, Zurich, Artemis \& Winkler, 1991, p. 207-211; André Salathé, «Anderwert, Fridolin », Dictionnaire historique de la Suisse (28/03/2007); http://www.hls-dhsdss.ch/textes/f/F4052.php?topdf=1.

13 Nebelspalter 1880/51, dessin pleine page non signé intitulé « La dignité devient un fardeau » (Würde bringt Bürde); Nebelspalter1880/52, texte signé « Nebelspalter » intitulé « Pater peccavi! »; Nebelspalter 1880/52, texte non signé intitulé « Épitre d'adieu en rimes d'un représentant du peuple à son ami » (Abschieds-Epistel eines reimenden Volksvertreters an seinen Freund).

74 (Schau nur liebe Mutter, welch ein Schwarm sich hier aus allen Winden gebildet, um den leeren Platz zu occcupiren und doch jammerst Du immer, es fehlte Dir an Holz! Puh, welch eine Schlacht wird's absetzen, bis Einer absitzt!); Nebelspalter 1881/5, dessin pleine page non signé intitulé « Une nouvelle apparition » (Eine neue Naturerscheinung)
}

Le vaudois Louis Ruchonnet, vice-président du Conseil national, est élu le 3 mars I 88 I pour prendre la succession d'Anderwelt, après que Karl Hoffmann a refusé le mandat, le 22 février ${ }^{175}$. Pas un mot, jamais, ne sera dit de la disparition d'Anderwelt dans le Nebelspalter. Ainsi en va-t-il aussi d'un périodique aimant à traquer les vices des politiciens sans faire toujours montre de beaucoup de moralité, et dont l'engagement durant les campagnes électorales peut s'avérer douteux.

L'unité du pays représente l'une des causes essentielles défendue par le Nebelspalter et Helvetia. Celle-ci est constamment mise à l'épreuve par les rivalités entre cantons, Berne et Zurich surtout, dont les chamailleries sont suivies avec délectation par le périodique. Cette rivalité se double de celle entre les cantons (en tant qu'unités politiques) et la Confédération, de sorte que la cible n'est pas toujours claire. Les tensions entre les différentes régions linguistiques représentent toutefois la menace la plus forte. Il ne s'agit plus alors de querelles de clocher ou de contestation de l'autorité centrale mais d'un risque de fracture nationale qui, quand l'heure est grave, requiert l'intervention du Nebelspalter et d'Helvetia. Entre I 875 et I922, cela se produit à deux reprises: en I 890 , lors de la révolution tessinoise et en I9I 6 , après deux années de guerre, alors que le fossé entre Alémaniques et Romands se creuse ${ }^{176}$.

La révolution tessinoise du i I septembre i 890 est un coup d'état perpétré par quelques représentants et militants radicaux contre le gouvernement conservateur, résultant des luttes politiques tessinoises, anciennes, incessantes et extrêmement agressives ainsi que de l'exaspération des radicaux envers le système électoral mis en place par les conservateurs, ayant permis à ces derniers de conserver le pouvoir depuis I 875. En I 884, Le Nebelspalter, préoccupé par la tournure des événements, avait déjà fait intervenir Helvetia pour remettre de l'ordre ${ }^{177}$. Une initiative constitutionnelle demandant l'élection du Conseil d'État par le peuple et la modification des cercles électoraux met le feu aux poudres, à la fin de l'été I 890 . Après avoir occupé l'arsenal de Bellinzone, une colonne armée, accompagnée d'une foule agitée, donne l'assaut au siège du gouvernement dans le centre-ville; plusieurs fonctionnaires et représentants conservateurs sont arrêtés et le conseiller d'État Luigi Rossi est mortellement blessé par un coup de pistolet. Les insurgés installent un gouvernement provisoire radical. Les événements provoquent une intervention militaire des autorités fédérales, qui envoient un commissaire, le colonel Arnold Künzli, pour rétablir l'ordre ${ }^{178}$. Le Nebelspalter rend attentivement compte des événements. Le numéro 38 , daté du 20 septembre I 890 , ouvre sur un éditorial intitulé « Fratelli Ticinesi! », en appelant au ralliement à la patrie. La revue ferme ce même numéro par un dessin de Henri von Muyden, où l'opposition (radicale) prend une correction, au nom du pacte fédéral ${ }^{179}$. Le message est, en fait, assez ambigu: la brutalité d'État est dénoncée mais la cause patriotique énoncée comme supérieure. La double-page de ce numéro «tessinois » est intitulée "Putsch tessinois»(Tessiner Putsch). Il s'agit d'une

\footnotetext{
Roge-Charles Logoz, "Louis Ruchonnet (1834-1893) », dans Die Schweizer Bundesräte. Ein biographisches Lexikon, Zurich, op. cit., p. 232-237.

Cf. « 3.3.1. Se situer vis-à-vis d'un conflit étranger ».

Nebelspalter 1884/48, double-page non signée intitulée « Ceci est notre avis sur l'affaire tessinoise » (Das ist unsere Meinung über die Tessiner Affaire).

18 Marco Marcacci, "Révolution tessinoise », Dictionnaire historique de la Suisse (29/03/2010); http://www.hls-dhs-dss.ch/textes/f/F43029.php.

79 Nebelspalter 1890/38, couverture intitulée "Fratelli Ticinesi! »; Nebelspalter $1890 / 38$, dessin pleine page de Henri von Mudyen intitulé « Sur le commerce
} tessinois » (Zum Tessinerhandel). 


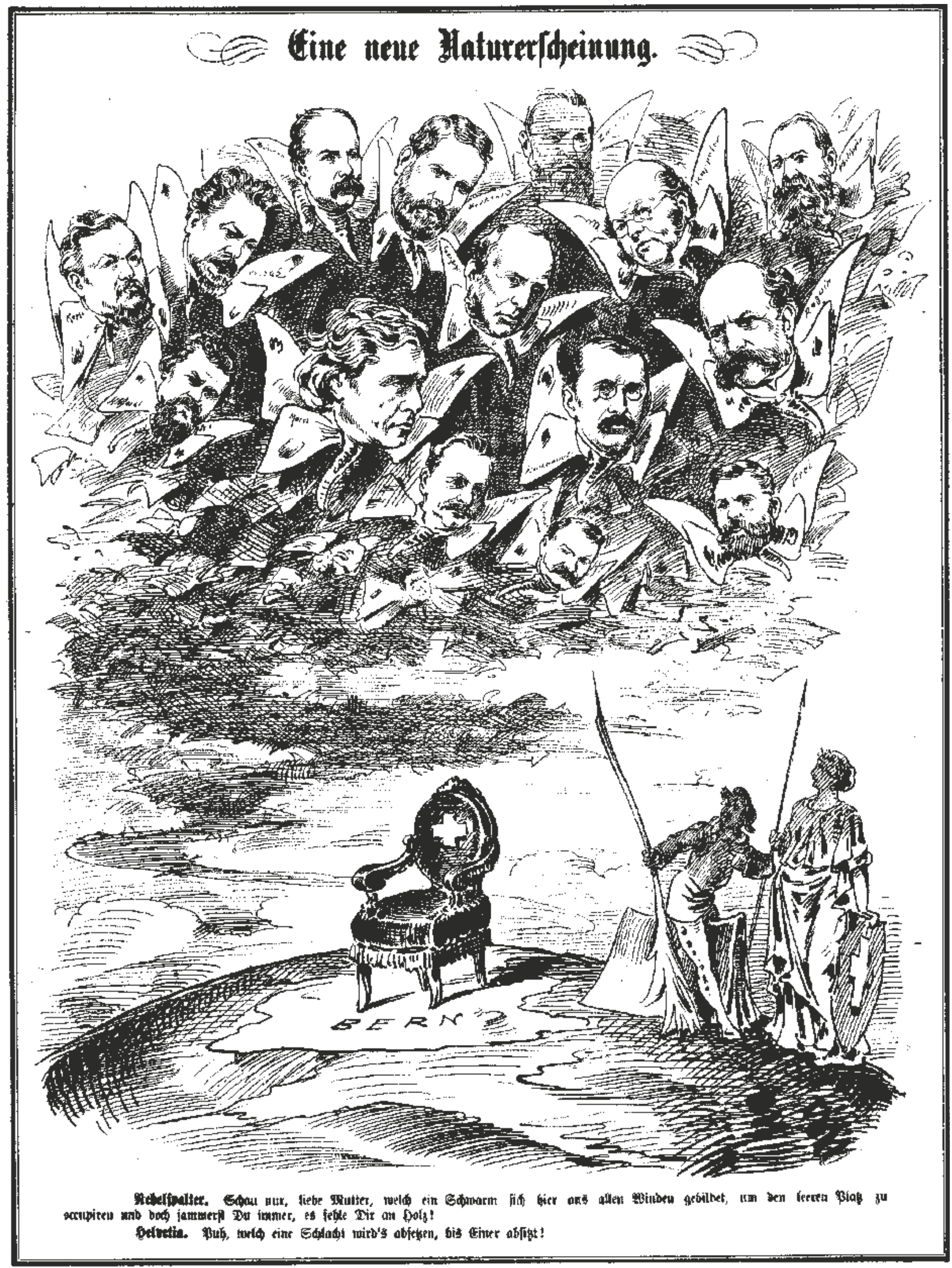

Fig. 89. Nebelspalter 1881/5, dessin pleine page en noir et blanc non signé intitulé « Une nouvelle apparition » (Eine neue Naturerscheinung). 
composition synthétique de Boscovits senior, typique des prémices du Jugendstil, se présentant comme un assemblage de dessins de formats différents. Helvetia et le Nebelspalter y apparaissent tous deux, quoique dans deux tableaux différents, séparés par l'urne de la vox populi. À gauche, Helvetia, vêtue d'une armure ornée d'une croix helvétique, tance des hommes défilant avec armes et pancartes, ces dernières marquées aux cantons de Lucerne et d'Uri: "Maintenant on reste bien tranquille, il n'y aura pas de séparatisme "; à droite, le Nebelspalter s'adresse, quant à lui, au colonel Künzli ainsi qu'au Prof. Dr. Schneider, envoyé de Zurich pour faire office de juge d'instruction ${ }^{180}$ : "Messieurs, vous avez remarquablement réglé vos affaires, envoyez directement la facture à Berne, où l'on attend impatiemment de régler le coût de cette belle affaire ». Le Nebelspalter ne prend finalement guère partie, se contentant de semoncer les uns et les autres. Comme souvent dès que le danger n'est plus imminent, une ironie moralisatrice prévaut ${ }^{181}$. L'ordre compte autant que la nouvelle constitution (cantonale) demandée sur l'urne de la vox populi, "Référendum sur la nouvelle constitution " (Abstimmung über die neue Verfassung), qui aboutira à la réforme constitutionnelle de I 892 introduisant la proportionnelle. Appliquée pour la première fois sur le territoire, celle-ci ouvrira sur un exécutif comprenant radicaux et conservateurs ${ }^{182}$.

Dès I798, la République helvétique (I798-I803) proclame le principe du service militaire obligatoire. Les compétences sont partagées entre une troupe helvétique, chargée d'assurer l'ordre intérieur et une armée de milice, à laquelle on confie la défense du pays. Durant le demi-siècle qui suit, le système connaît plusieurs inflexions et aménagements, notamment la mise en place d'une armée fédérale, formée de contingents cantonaux selon le Règlement militaire de I 8 I 7 , élaboré d'après le Pacte fédéral de $\mathrm{I} 8$ I 5 . La Constitution de $\mathrm{I} 848$ réaffirme le système militaire obligatoire, aboli un temps durant la Médiation (I803-I 8 I3 $)^{183}$ Le système n'est cependant pas rigoureusement appliqué et la loi fédérale sur l'organisation militaire de I 850 ne fait qu'esquisser une armée centralisée. Dans son projet de Constitution fédérale, le conseiller fédéral Emil Welti prévoit une centralisation radicale de la défense. Il reprend les recommandations du général Hans Herzog, fondées sur le constat d'une impréparation de certains contingents pour garantir les frontières lors de la guerre francoallemande de I 870-I 87 I. Le projet est rejeté par le peuple en I 872 et la Constitution de I 874 se présente comme un compromis. Le service obligatoire entre enfin dans les faits. Mais si le pouvoir de légiférer en matière militaire appartient désormais à la Confédération, une partie du fonctionnement de l'armée et certains corps restent dévolus aux cantons. Cette organisation hybride n'est pas toujours bien acceptée par l'opinion publique. Le budget de fonctionnement, très important, l'est encore moins. Les critiques sont d'autant plus féroces que l'armée forme l'un des fondements identitaires de la Suisse moderne et que les citoyens

\footnotetext{
8० « Message du conseil fédéral à l'assemblée fédérale concernant l'intervention fédérale armée au Tessin et la situation politique dans ce canton. (Du 22 septembre 1890.) », Feuille fédérale suisse, 1890, vol. 4, cahier 40, p. 161-221.

181 ("Nur fein stillgesessen, es wird nicht gesonderbündelt »; " Meine Herren, Sie haben Ihre Sache vorzüglich gemacht. Schicken Sie die Rechnung gef. Direkt nach Bern, man wartet dort mit Ungeduld darauf die Kosten für diese liebliche Affaire zu zahlen »); Nebelspalter 1890/38, double-page de Boscovits senior intitulée « Putsch tessinois » (Tessiner Putsch).

182 Marco Marcacci, « Révolution tessinoise », Dictionnaire historique de la Suisse (29/03/2010); http://www.hls-dhs-dss.ch/textes/f/F43029.php.

${ }_{183}$ La Médiation est la période durant laquelle l'acte de Médiation élaboré par la Consulta et Napoléon Bonaparte sert de loi fondamentale à la Suisse. À ce sujet: Andreas Fankhauser, "Médiation », Dictionnaire historique de la Suisse (29/12/2009): http://www.hls-dhs-dss.ch/textes/f/F9798.php.
}

s'y identifient fortement ${ }^{184}$. Les dessins sur l'armée représentent ainsi l'un des thèmes favoris du Nebelspalter. La revue fonctionne comme un "miroir partisan ». Dysfonctionnements, couardise, réformes absurdes, gaspillages sont pointés sans relâche. Début juin I 876, le Nebelspalter rencontre ainsi Helvetia pour l'entretenir du train de vie de l'armée et de la taxe d'exemption. Enfin, pas tout à fait: le personnage ne rencontre pas officiellement Helvetia mais la «Suisse » (Schweizerin) - un personnage qui n'apparaît jamais, sinon -, et qui ressemble en tout point à Helvetia dans ses habits de matrone. La jeune femme vigoureuse, coiffée d'une couronne de lauriers porte une robe dont le corsage est orné de la croix helvétique. Elle verse l'eau d'un baquet frappé de l'inscription « Extravagances militaires » (Militairextravaganzen) ainsi qu'un bébé désigné comme "Taxe militaire » (Militairsteuer) dans la rivière des référendums (Referendumsbach). Le Nebelspalter et Helvetia entament un dialogue: "Arrête, que fais-tu là ? / Je vide la baignoire / C'est bien mais il ne faut pas jeter le bébé avec l'eau du bain » ${ }^{185}$ (cf. fig. 90).

En application de la Constitution de I 874, prévoyant qu'une loi fédérale peut être soumise à une votation facultative ${ }^{186}$, une votation populaire est organisée le 9 juillet I 876 afin d'éprouver la loi élaborée par l'Assemblée fédérale du 23 décembre 1875 . Celle-ci prévoit une taxe d'exemption du service militaire, une possibilité de compensation financière à qui ne souhaite pas effectuer son service militaire. Le projet de loi est rejeté à une nette majorité $(54,5 \% \text { contre } 45,8 \%)^{187}$, enregistrant cependant un score très favorable dans le canton de Zurich, de plus de $70 \%{ }^{188}$. Le principe de cette taxe, défendu par le Nebelspalter, est une nouvelle fois rejeté lors d'une seconde votation populaire, le 2 I octobre I877, mais finit par entrer en vigueur le 7 octobre I 878 , faute d'une demande valide de nouvelle votation qui aurait à nouveau pu suspendre la loi - le dépôt est déclaré caduque ${ }^{189}$. Dès lors, le caractère obligatoire du service militaire est relativisé. En I 893, le Nebelspalter plaidera, cette fois, auprès d'Helvetia pour une votation en faveur d'une année de service pour les recrues ${ }^{190}$. Par contre, jamais la revue ne prend de parti net dans le débat courant durant la deuxième partie du XIX ${ }^{\mathrm{e}}$ siècle et jusqu'à la Première Guerre mondiale, entre partisans de la "nation en armes » et défenseurs du modèle prussien, basé sur l'éducation et l'instruction, notamment le drill ${ }^{191}$. Le périodique ne fait que stigmatiser les deux options.

\footnotetext{
${ }^{84}$ Hans Senn, "Armée », Dictionnaire historique de la Suisse (09/06/2008); http:// www.hls-dhs-dss.ch/textes/f/F8683.php; Philippe Kaenel, François Vallotton, "Représenter la guerre en Suisse. Du soldat au général », dans Les images en guerre, éd. Philipe Kaenel, François Valloton, Lausanne, Antipodes, 2008, p. 8.

${ }_{185}$ (Nebelspalter/ " Halt, was machst du da?" / Schweizerin "Ich leere die Badewanne! » / Nebelspalter " Schon recht, aber man muss das Kind nicht mit dem Bade ausschütten »); Nebelspalter 1876/23, dessin pleine page non signé intitulé « Sur la loi de l'impôt militaire » (Zum Militärsteuergesetz).

186 Bernard Degen, « Référendum populaire », Dictionnaire historique de la Suisse (03/05/2012); http://www.hls-dhs-dss.ch/textes/f/F10387.php.

187 «Votation populaire du 09.07.1876. Votation populaire. Tableau récapitulatif », Confédération Suisse; https://www.admin.ch/ch/f/pore/va/18760709/det16.html (état 05.07.2016).

836443 acceptants pour 14361 rejetants; «Message du Conseil fédéral à la haute Assemblée fédérale concernant la votation populaire du 9 juillet 1876 sur la loi fédérale du 23 décembre établissant une taxe d'exemption du service militaire », Feuille fédérale, 1876, volume 4, cahier 53, p. 553-557.

189 «Rapport du Conseil fédéral à la haute Assemblée fédérale concernant les demandes de votation populaire au sujet de la loi sur la taxe d'exemption du service militaire. (Du 3 décembre 1878.) ", Feuille fédérale, 1878, vol. 4, cahier 55 , p. $475-478$.

Nebelspalter 1893/23, dessin pleine page de Hans Wirz intitulé « Une année de service pour les recrues » (Zum einjährigen Rekrutendienst).

Jean-Jacques Langendorf et Pierre Streit, Face à la guerre. L'armée et le peuple
} suisse 1914-1918 / 1939-1945, Gollion, Infolio, 2007, p. 37-39. 


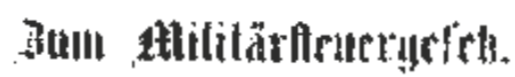

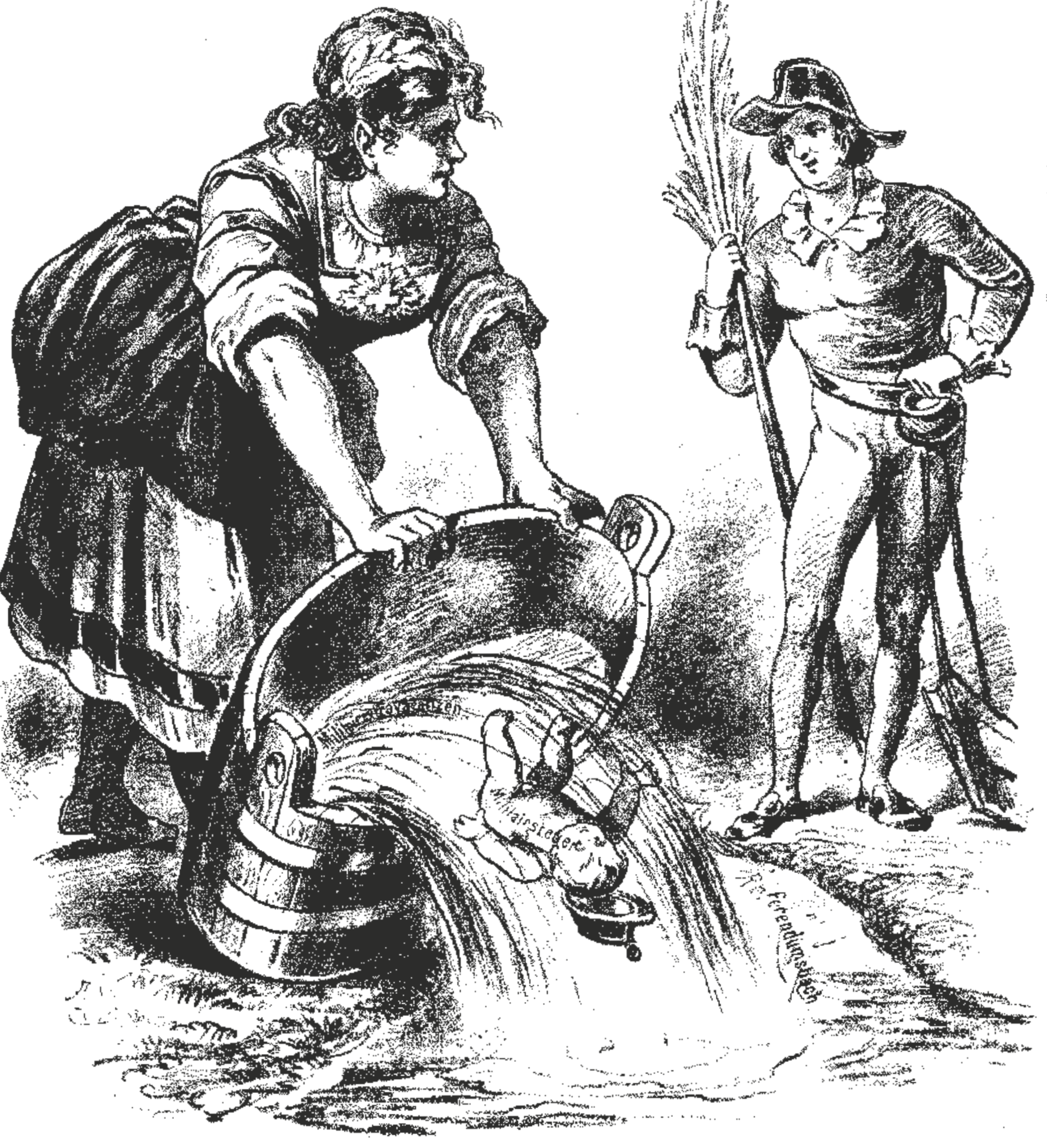

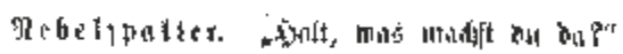

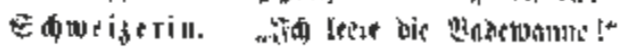

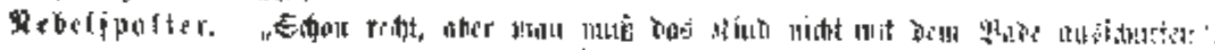

Fig. 90. Nebelspalter 1876/23, dessin pleine page en noir et blanc non signé intitulé « Sur la loi de l'impôt militaire » (Zum Militärsteuergesetz). 
Enclavée du fait de son relief alpin, la Suisse entretient un rapport singulier avec sa géographie. D’une bonne circulation, dépendent commerce, exportations et importations, mais aussi des échanges non marchands, biens culturels et personnes, ce qui n'est pas sans générer quelques inquiétudes. Un lieu concentre toutes les passions: le col du Gothard. Reliant les cantons d'Uri et du Tessin, situé sur la ligne de partage des eaux de la Reuss et du Tessin, il est, au XIX ${ }^{\mathrm{e}}$ siècle, considéré - à tort - comme le col alpin le plus important. Carrefour des régions linguistiques et culturelles du pays, il condense des symboles ayant contribué à la construction de son mythe au cours des siècles: il est le toit de l'Europe, une route de transit (via delle genti), un lieu de pèlerinage (à la chapelle saint Gothard), l'emblème de l'indépendance mais aussi de l'unité et de l'identité nationales ${ }^{192}$. Lié aux origines et au développement de la Confédération, il est donc ancré dans la mémoire collective nationale. L'ancienneté et l'importance de son rôle politique et économique, tenues jusqu'il y a peu pour considérables, ont cependant été relativisées par l'historiographie récente, notamment pour le Moyen Âge. Longtemps, le Gothard constitue également une manne. Avant que ne soit construite une voie carrossable dans la première moitié du XIX ${ }^{\mathrm{e}}$ siècle, il fallait pour assurer son passage s'acquitter d'un impôt collecté par les associations de muletiers. Les intérêts économiques se déplacent ensuite du côté des entrepreneurs et des financiers, impliqués dans la construction de routes et des chemins de fer. À la suite du nouvel équilibre géopolitique généré par les unifications italienne et allemande dans les années I 8707I ainsi que du développement des voies ferrées et routières, le Gothard prend une importance stratégique, et l'on imagine un programme de fortifications. Le chantier est l'objet d'une doublepage dans le dernier numéro de l'année i 885 (le numéro de Noël), non signée, comme la plupart des dessins " sensibles ». Intitulé "Sur les fortifications du Gothard» (Zur Befestigung des Gotthard), le dessin présente une organisation antithétique: dans le volet gauche, Italia interpelle Helvetia devant la frontière italienne, marquée par une borne, tandis que le Nebelspalter surgit des montagnes avec tout son attirail; dans le volet droit, le Nebelspalter se tient aux côtés d'Helvetia, alors qu'à l'arrière-plan, un grand nombre d'ouvriers est occupé à la construction de fortifications. Le Nebelspalter prolonge la réponse d'Helvetia à Italia, commentée ensuite par cette dernière:

Mais qu'as-tu en tête, chère petite sœur? Tu m'assures régulièrement de ton affection et pourtant du veux fortifier la frontière avec moi! / Eh, ne t'emporte pas, ce n'est pas du tout contre toi mais... Mais, il s'agit d'une précaution amicale pour occuper à nouveau un joli nombre de tes enfants / Si tu l'entends ainsi, alors je suis satisfaite. Venez-leur en aide! ${ }^{193}$

La construction du premier fort à Airolo, début d'une série de travaux de fortifications en I 886 qui ne s'achèvera qu'en I920, est sur le point de commencer. L'humour - ou la tentative d'humour du Nebelspalter dénote avant tout un sentiment de supériorité de la Suisse sur sa voisine, l'Italie, dont il essaie d'abuser le jugement. Le procédé du tiers (étranger) permet, comme souvent, d'éviter la question des nombreuses dissensions internes.

\footnotetext{
« Saint-Gothard, col du », Dictionnaire historique de la Suisse (17/05/2016); http:// www.hls-dhs-dss.ch/textes/f/F7466.php.

(Italia: «Aber, was hast du nur vor, liebes Schwesterchen? Immer und immer versicherst du mich von deiner Liebe und doch willst du die Grenze gegen mich befestigen! » Helvetia: « Eh, aber, so rege dich doch nicht so auf, das geht gar nich gegen dich sondern das ist... » Nebelspalter: "Sondern das ist eine freundliche Vorsorge, um wieder eine hübsche Zahl deiner Kinder zu beschäftigen »; Italia: "Ja, dann bin ich zufrieden, wenn du's so meinst, Helfet sie a! »); Nebelspalter 1885/52, double-page non signée intitulée « Sur les fortifications du Gothard » (Zur Befestigung des Gotthard).
}

Si le réseau ferré suisse compte à présent parmi les plus denses du monde, la situation fut longtemps chaotique, fournissant de la copie au Nebelspalter qui fait des gorges chaudes des avatars et péripéties liés à la construction, l'exploitation et le financement des chemins de fer. Jusqu'à la Première Guerre mondiale, il n'est pas une année où le thème n'apparaisse, souvent plusieurs fois. Pour commencer, le pays prend du retard par rapport à ses voisins et encore davantage vis-à-vis de l'Angleterre, nation pionnière dans le processus d'industrialisation où les trains circulent depuis I 825 . En Suisse, le premier train (Saint-Louis-Bâle) ne circule, en effet, qu'en I 844 , et encore à l'initiative des chemins de fer d'Alsace (français). Ce sont des entrepreneurs, industriels et banquiers, dotés de mandats politiques à Berne et à Zurich, qui, comprenant l'importance des trains pour le développement économique du pays, sont à l'origine de la création du réseau. Dès le début, les désaccords sont importants sur le mode de capitalisation - public ou privé - et de gestion - fédéral ou cantonal - et c'est la vision du zurichois Alfred Escher, partisan d'un réseau privé, allant jusqu'à créer une banque à cette fin, le Crédit Suisse ${ }^{194}$, qui l'emporte. La loi fédérale de 1852 abandonne aux cantons la construction et l'exploitation du réseau, renonçant à toute planification en matière de tracé, de coordination, de réalisation technique et de politique tarifaire. Le financement est composé de capitaux privés ainsi que de subventions communales et fédérales. Cet excès de confiance dans les bonnes volontés conduit à des aberrations de toute part: des tronçons restent sans prolongement, horaires et tarifs ne sont pas ajustés mais surtout les capitaux manquent. En I 86I, les quatre cinquièmes des compagnies ferroviaires font face à des difficultés financières et plusieurs d'entre elles, alémaniques et romandes, dépendent de capitaux étrangers, notamment français, injectés dans la perspective d'une liaison transalpine. La guerre de I870-7 I est un déclencheur, mettant en évidence les faiblesses des réseaux privés, les concessions cantonales ne garantissant ni l'approvisionnement ni l'acheminement rapide des troupes. La deuxième loi fédérale de 1872 corrige, en partie, cet état de fait en transférant l'ensemble des compétences à la Confédération. L'étatisation des chemins de fer devient un thème politique majeur, relayé avec zèle par le Nebelspalter. En I 873, une division des chemins de fer est intégrée au Département fédéral du commerce, qui prend le nom de "Département fédéral des chemins de fer et du commerce ${ }^{195}$. Fin I 875 , au terme de la première année de parution, une couverture présente le Nebelspalter et Helvetia réjouis, le premier, sa plume à la main, vidant, avec l'aide de son compagnon, la caisse du "départ des chemins de fer » (Eisenbahn-Depart) de ses occupants, concessionnaires privés et autres employés indésirables; la seconde, tenant d'une main les rênes d'une locomotive à vapeur, de l'autre son bouclier frappé de la croix helvétique. Ils prennent les choses en mains au nom du pays, et comme ils l'entendent, c'est-à-dire en «faisant du vide » : «Le département fédéral des chemins de fer doit être logé dans de nouveaux locaux. Le Nebelspalter qui s'y entend à tirer, fait à ce sujet une proposition tout à fait d'actualité ", tel est le texte que restituent, accolés, titre et légende ${ }^{196}$. Si l'on se réjouit de la solution fédérale, il n'est pas pour autant question de signer

\footnotetext{
4 Markus Bürgi, « Escher, Alfred (vom Glas) », Dictionnaire historique de la Suisse (20/03/2006); http://www.hls-dhs-dss.ch/textes/f/F3626.php.

Hans-Peter Bärtschi et Anne-Marie Dubler, "Chemins de fer », Dictionnaire historique de la Suisse (16/07/2015); http://www.hls-dhs-dss.ch/textes/f/F7961. php.

196 Nebelspalter 1875/46, couverture non signée intitulée et légendée "Das eidgen. Eisenbahndepartement soll in neue Räume untergebracht werden. Der Nebelspalter, der sich auf ziehen versteht, macht hiefür obigen, gewiss zeitgemäßen, Vorschlag!».
} 
un chèque en blanc à une gestion toujours regardée de très près. Helvetia et le Nebelspalter s'en mêlent à nouveau en I 890: "Tu vois, Helvetia, ce sera comme ça quand les téléphériques n'auront plus besoin de concession! / Peut-être, mais dans mes vieux jours, je ne pourrai plus apprendre à danser sur une corde ${ }^{197}$. L'image montre des téléphériques - un motif appelé à devenir un topos du Nebelspalter - nombreux, instables, faisant verser leurs occupants. Les téléphériques sont contrôlés par des étrangers copieusement typés; en haut de l'image, un cycliste, juché sur un engin à vapeur tire l'unique locomotive au drapeau suisse. Le premier téléphérique commercial n'est alors qu'en projet. Il ne sera mis en service qu'en I $908 \mathrm{au}$ Wetterhorn ${ }^{198}$. Le véritable sujet de la caricature est le risque d'une prise de contrôle étrangère des infrastructures.

En Suisse, comme ailleurs en Europe, deux visions politiques s'affrontent à partir de la première moitié du XIX ${ }^{\mathrm{e}}$ siècle sur les échanges commerciaux: l'une, libre-échangiste, est liée à une posture libérale et défend la liberté des échanges; l'autre, protectionniste, résulte d'une conception nationale du marché et prône des droits de douane pour garantir certains pans de l'économie. Ne faisant guère le poids face à ses partenaires et voisins, la Suisse opte pour l'option libérale, au point qu'il n'est fait que peu de cas des demandes de droits de douane protectionnistes en période de crise, comme c'est le cas pour l'industrie cotonnière, l'artisanat et l'agriculture, déstabilisés dans les années I 870. À la création de l'État fédéral, la conclusion d'accords commerciaux et douaniers, auparavant laissée aux cantons, est transférée à la Confédération, et les droits de douane intérieurs sont abolis pour être repoussés aux frontières. La Suisse peine à s'intégrer au système d'accords européens de libre-échange, faute de compensations à offrir à ses partenaires commerciaux. Dans les années I 880 et I 890, le Conseil fédéral est amené à réviser le tarif douanier à plusieurs reprises pour améliorer la situation concurrentielle du pays ${ }^{199}$. C'est ainsi qu'Helvetia doit lire dans les « Raisins acides » (Saure Trauben) de I88I, une composition synthétisant tout ce qui est dur à " avaler » et présentée par le Nebelspalter, la mention "clause de la nation la plus favorisée " (Meistbegünstigung). Il s'agit du tarif moins-disant qu'elle a dû accorder à l'ensemble de ses partenaires, en application des accords commerciaux (Handelsverträge ${ }^{200}$. Courant I 89 I, la Suisse est intégrée, avec la Belgique et l'Italie, aux accords commerciaux centre-européens, inaugurés à la fin de I 890 par l'Autriche-Hongrie et l'Allemagne, visant à l'uniformisation des tarifs. Une votation populaire, organisée le $\mathrm{I} 8$ octobre $\mathrm{I} 89 \mathrm{I}$, en valide le principe à une très large majorité ${ }^{201}$. Les accords, qui garantissent des tarifs modérés entre les États parties pendant douze ans, entrent en vigueur le $\mathrm{I}^{\mathrm{er}}$ février I 892. Ils ont un effet d'entrainement, puisque la Serbie, la Roumanie et la Russie adhèrent au système entre I 892 et I 894. Les traités avec les pays d'Europe orientale sont conclus de manière à entrer simultanément en vigueur le 3 I décembre 1903.

\footnotetext{
(Nebelspalter: "Siehst Du, Helvetia so wirds herauskommen, wenn die schwebenden Bahnen keine Konzession bedürfen! / Helvetia: "Vielleicht, aber deshalb kann ich auf meine alten Tage doch nicht mehr lernen seiltanzen »); Nebelspalter 1890/5, dessin pleine page de Boscovits senior sans titre.

${ }_{198}$ Hans-Peter Bärtschi, "Chemins de fer de montagne et transports par câbles », Dictionnaire historique de la Suisse (11/02/2015); http://www.hls-dhs-dss.ch/ textes/f/F13900.php.

199 Margrit Müller et Patrick Halbeisen, « Libre-échange », Dictionnaire historique de la Suisse (03/04/2014); http://www.hls-dhs-dss.ch/textes/f/F26193.php.

200 Nebelspalter 1881/39, dessin pleine page de Boscovits senior intitulé « Raisins verts » (Saure Trauben).

${ }^{201}$ De 220004 voix contre 158934 voix; « Message du conseil fédéral à l'assemblée fédérale concernant la votation populaire du 18 octobre 1891 sur le tarif des douanes et le monopole des billets de banque. (Du 24 novembre 1891) ", Feuille Fédérale Suisse, 1891, vol. 5, cahier 50, p. 517-526.
}

Un système d'accords s'étend ainsi dans un espace allant d'Anvers au lac Léman, puis à Vladivostok ${ }^{202}$. La première double-page de l'année I 893 documente le ressenti des négociations, côté suisse et vu du Nebelspalter. Elle présente la France et la Suisse, dos-à-dos (cf. fig. 9I).

Une barrière sépare les deux femmes. Légèrement ouverte à l'avant-plan, celle-ci est redoublée par une borne marquée « RF » (République française), à gauche et par la croix helvétique, à droite, ainsi que par un arbre dont les branches sont nues et garnies d'une toile d'araignée côté français, et fleuries côté suisse. La France est une élégante, nonchalamment assise, portant le bonnet phrygien. Elle est entourée de caisses marquées " Fragile » et " Paris », dont l'une est remplie de bouteilles. Une locomotive arrive à l'arrièreplan. La fumée qui s'en dégage soutient le médaillon-portrait d'un Mercure faisant grise mine. Le dieu du commerce et des voyages tient dans une main un caducée, de l'autre un sac, d'où s'échappent des pièces. Helvetia est une matrone respectable à la tête couronnée de lauriers, debout, de trois-quarts, devant un paysage alpin. L'air courroucé, elle tient un document marqué "tarif général " (Generaltarif). Plusieurs caisses, un fromage énorme, une machine se trouvent à ses côtés. Le Nebelspalter, muni de sa plume et de son journal, est assis contre ce bric-àbrac. À l'arrière, se détachent trois personnages, chapeautés et couronnés, d'après le schéma iconographique des trois mages. Le premier porte un sac marqué "Vienne » (Wien), le deuxième, une caisse marquée "Allemagne ", le troisième, une énorme bouteille désignée comme du "Chianti ». La légende restitue le dialogue entre la France et Helvetia:

Eh, ma sœur, ne soit pas fâchée à ce point et ne m’abandonne pas à mes plaintes. Ce n'est pas ma faute - la faute incombe à la - la - la Chambre des députés. / Dis-donc à ta Chambre des députés qu'elle en termine avec cette soupe --! Toi, amie unique, regarde, j'en ai maintenant trois comme toi devant ma maison! ${ }^{203}$

Le système d'accords ne va pas sans grincements, suspicions et coups de bluff. Tout du long de l'année I 892, le principe du libreéchange est ainsi âprement discuté dans le Nebelspalter, rendant compte de difficultés avec l'Italie mais surtout avec la France. Cette dernière se trouve au cœur des discussions à la fin de l'année I 892 et durant toute l'année I 893 .

\subsubsection{Chronique visuelle d'une ville : Zurich}

Plus finement encore que ne le font les compositions thématisant la Suisse, celles consacrées à Zurich informent l'ouverture sur le monde du périodique. Ce monde, c'est ici le cercle suisse, dont Zurich est l'épicentre, ce que rappelle, du reste, l'inscription «Zurich » sur la couverture, juste avant la date. C'est également un univers sociétal, délivrant thématiques et figures, dont les plus emblématiques sont les petites icones en tête des rubriques, reprenant des personnages typiques de la vie zurichoise, Herr Feufi (Monsieur cinq) et Frau Stadtrichter (Madame la juge de ville), d'une part, Chueri et Nägeli, d'autre part, chaque

\footnotetext{
Fritz Halm, "Quelques aspects de la politique commerciale suisse », Revue économique et sociale : bulletin de la Société d'Etudes Economiques et Sociales, volume 17 (1959), p. 75-76.

203 (France: « Geh', Schwester, sei doch nicht so böse und lass' mich nicht in meinem Jammer, Ich bin nicht schuld - schuld ist allein die - die - die Deputiertenkammer. „) / Helvetia: "Sag's deiner Deputiertenkammer, die esse diese Suppe aus - -! Du einz'ge Freundin, schau, ich habe nun deren drei vor meinem Haus! »); Nebelspalter 1893/1, double-page sans titre de Boscovits senior.
} 


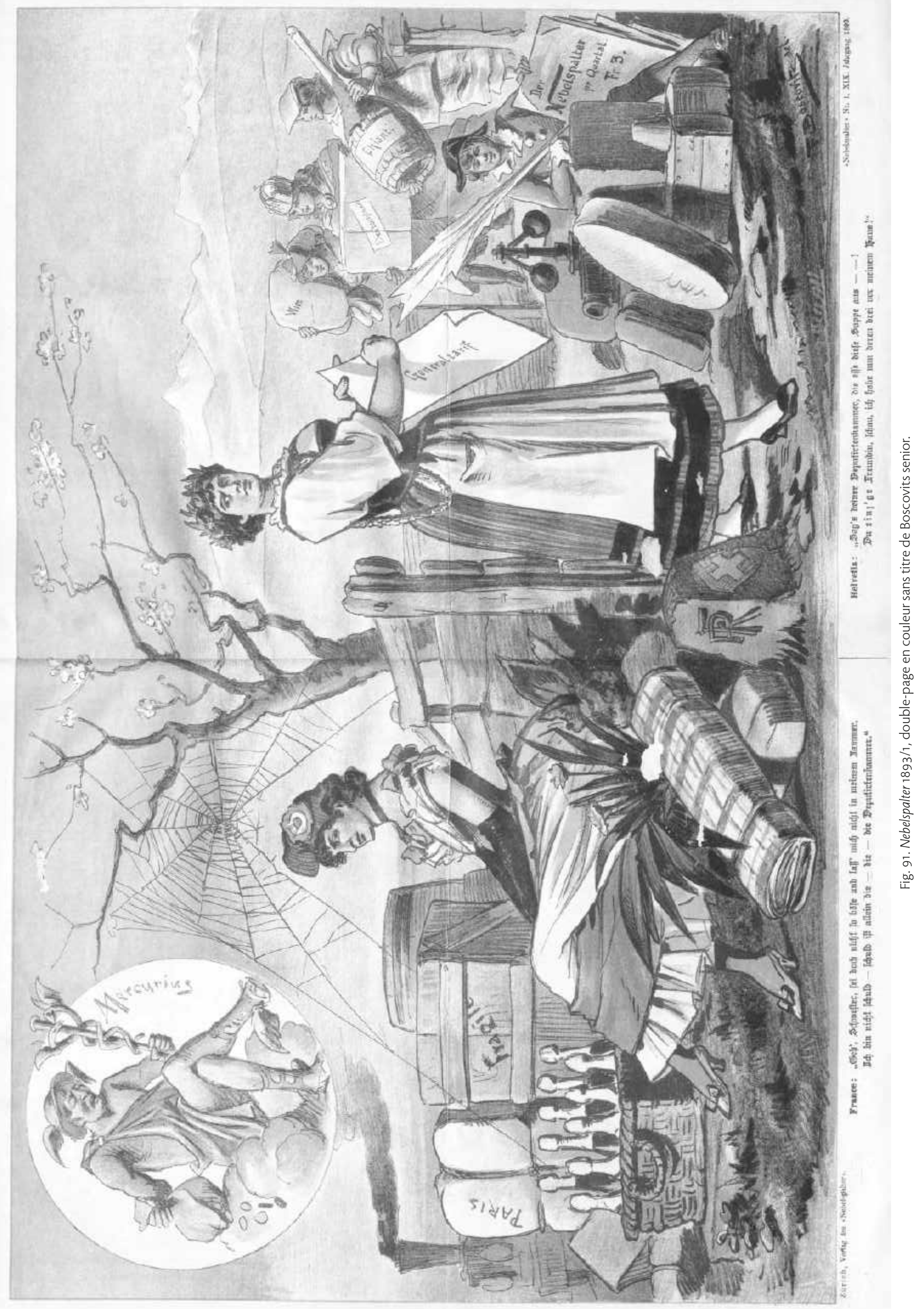




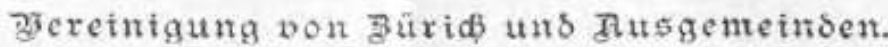

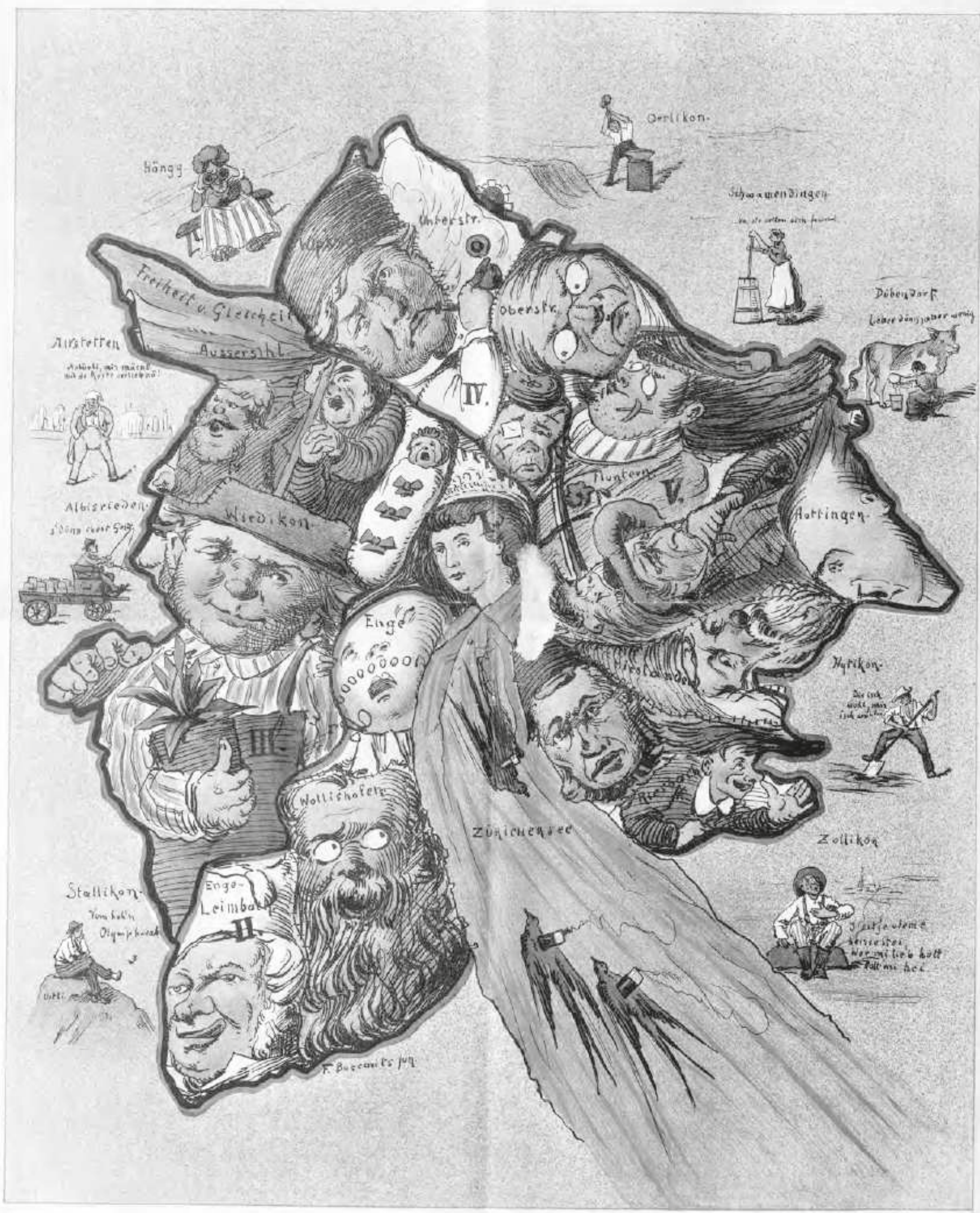

Buf Dafi has of

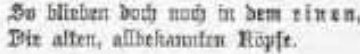

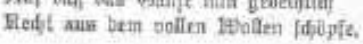


couple se faisant des confidences sur la vie locale ${ }^{204}$. L'éventail thématique des dessins est large et comprend les affaires électorales, fiscales, urbaines et sociétales Les affaires zurichoises ne sont en aucun cas l'objet d'un exposé factuel, "objectif ", d'événements ou de questions d'actualité ${ }^{205}$ mais, au contraire, une chronique passionnée, parfois même passionnelle, de prises de positions politiques, urbanistiques et sociétales. On s'intéresse particulièrement aux jeux politiciens à l'occasion des élections, en nombre record en $1905^{206}$; au budget et surtout à la gestion qui en est faite; aux impôts; à la vie des banques, comme lors de l'affrontement entre Zurich et Berne pour abriter la Banque nationale en I $899^{207}$; aux découpages et redécoupages d'une cité qui ne cesse de croître, en population et en territoire, intégrant en I 892 des communes limitrophes, un élargissement thématisé par Boscovits junior dans une carte anthropomorphe ${ }^{208}$ (cf. fig. 92).

Les affaires urbanistiques sont l'occasion de partis pris tranchés, tel l'aménagement des quais en $\mathrm{I} 88 \mathrm{I}^{209}$ ou l'arrivée du tramway dans le quartier de Wiedikon ${ }^{210}$. Les questions de société comprennent une critique constante de la bourgeoisie locale: à partir de I 885 , apparaît la mode; quelques années plus tard, on dénonce la misère d'une partie de la population et promeut un univers nocturne, dont ne sera finalement dévoilé que très peu au-delà des mentions récurrentes à l'heure de fermeture des établissements (Polizeistunde). En toute chose, le Nebelspalter se caractérise par la mesure. Sauf, parfois, en matière d'antisémitisme, lorsque le Nebelspalter montre à un étranger une rue intitulée «Les rois du monde » (Die Könige der Welt), où déambulent des personnages au type sémite très prononcé ${ }^{211}$.

En terme strictement quantitatif, la présence zurichoise ne connaît pas de variations très importantes. Elle se cale, en fait, sur celle de la Suisse. Elle est ainsi très forte la première décennie, puis pendant les années Jugendstil où elle change de nature, se réduit ensuite jusqu'au " virage de I907 ", où elle connaît un regain, et s'accentue encore durant la guerre. Il faut, par contre, se garder de considérer la présence visuelle zurichoise sans en distinguer les différentes modalités. Car, cette présence s'inscrit selon divers types se constituant progressivement. Longtemps, la ville se borne à servir de cadre discursif ou de repère géographique. Progressivement, elle relève d'une géographie culturelle et esthétique, avec l'apparition d'éléments du paysage urbain, nourrissant une image socialisée de la ville. Cependant, autour de I900, la ville subit, à la faveur du Jugendstil, un processus de décontextualisation. Visuellement polymorphe, elle ressort alors conceptuellement à différents niveaux de préhension, esthétique, politique, culturel, sociologique, idéel et, finalement,

La terminaison en « $\mathrm{i}$ » est typique du dialecte zurichois; sur les icones, cf. « 2.2.5 L'installation d'un appareil allégorique ».

205 Sur l'histoire de Zurich, on voudra bien se reporter à la chronique en treize tomes de Sigmund Widmer, chacun dédié à une époque; Sigmund Widmer, Zürich. Eine Kulturgeschichte, Zurich, Artemis, 1975-1986.

206 Nebelspalter 1905/5, dessin pleine page de Boscovits junior intitulé «L'année zurichoise des élections par excellence » (Das Züricher Wahljahr par excellence).

Nebelspalter 1899/27, dessin pleine page de Boscovits senior intitulé « Toujours à courir après les billets » (Nur immer nach Noten); la Banque nationale suisse ne sera fondée qu'en 1907 avec un siège partagé entre Zurich et Berne.

${ }_{208}$ Nebelspalter 1892/38, double-page en couleur de Boscovits junior intitulée "Réunion de Zurich et de ses communes extérieures » (Vereinigung von Zürich und Ausgemeinden)

${ }^{209}$ Nebelspalter 1881/35, dessin pleine page non signé intitulé « L'aménagement des quais zurichois » (Zürcher Quaibauten).

210 Nebelspalter 1898/51, dessin de Boscovits junior intitulé "Comme c'est dommage! » (O, wie Schade!).

${ }^{211}$ Nebelspalter $1877 / 50$, dessin pleine page non signé intitulé « Les rois du monde » (Die Könige der Welt). assez peu topographique ${ }^{212}$. À partir de $\mathrm{I905}$, la ville prend une coloration nettement plus sociale. Ces images participent de l'identité de la revue, avec toutefois une efficacité variable, sans adéquation évidente avec la première accroche visuelle. Une image visuellement agressive n'aura pas nécessairement eu l'impact le plus important auprès du lecteur, et les critères de suggestion, de connivence - cette connivence qu'Henri Bergson analyse dans Le Rire -, de répétition, aussi, auront fabriqué tout l'efficace des signets visuels. Plus généralement, on peut penser que ces images zurichoises ont correspondu à un horizon d'attente du lectorat autant qu'elles ont concouru aux représentations collectives.

L'élément architectural est ainsi longtemps la seule forme sous laquelle apparaît la ville dans le Nebelspalter. Son rôle est de localiser et/ou de fournir un cadre au propos thématisé dans l'image. Ce mode de présence est le plus anciennement représenté dans l'univers des revues illustrées. Dans «Petit séminaire à Küsnacht ", caricature datant de I875, les bâtiments situent ainsi la fuite des pensionnaires du séminaire vers la liberté dans une petite localité proche de Zurich, Küsnacht ${ }^{213}$. Cette liberté est assimilée à une vie urbaine, figurée au travers de ses lieux de sociabilité, la pension (Zimmer zu vermiethen) et l'auberge (Gasthaus), où peuvent loger et se restaurer les fuyards. Ce sont là les premiers éléments d'une ville socialisée. Lorsque ces éléments architecturaux structurent des dessins plus polémiques, ils perdent, par contre, l'essentiel de leurs repères de sociabilité, alors qu'il y reste très souvent le repère visuel de l'église. Celui-ci émerge ainsi du profil de Zurich dans une caricature de la même année I 890 , dénonçant un interdit frappant une pièce d'Ibsen ${ }^{214}$ (cf. fig. 93).

L'image reprend une célèbre gravure de Dürer, issue de son cycle de l'Apocalypse: "Les quatre cavaliers de l'Apocalypse " ${ }^{215}$; l'une de ces deux églises - éléments évidemment rajoutés au modèle, le Grossmünster, devient avec ses deux tours caractéristiques l'emblème de la ville, quelques années plus tard, dans une modernité aimant se présenter au travers de repères architecturaux. Cette polarisation autour des églises dénote l'importance de la composante religieuse dans la formation identitaire de Zurich, très marquée par la doctrine du réformateur Ulrich Zwingli. À la même époque, cette affirmation de l'identité architecturale se fait, en effet, dans d'autres contextes au travers d'édifices résolument modernes. C'est ainsi la tour Eiffel qui domine l'arrière-plan parisien d'une caricature sur le boulangisme ${ }^{216}$. Une ville n'équivaut pas à une autre, et la Grossstadt, la grande ville, selon la théorisation qu'en fera Georg Simmel en I903, d'après le concept de métropole des géographes allemands ${ }^{217}$, est volontiers assimilée à un édifice issu de la modernité, ce qui n'est jamais le cas de Zurich. À la différence de Berlin ou de Paris, Zurich conserve - et propage - avant tout une identité provinciale.

\footnotetext{
${ }_{12}$ Pour une version plus détaillée: cf. Laurence Danguy, « Confisquée par l'image la ville des revues germaniques autour de 1900 », dans Représenter la ville : entre cartographie et imaginaire, éd. Pierre-Yves Le Pogam et Martine Plouvier, Paris, CTHS, 2013, p. 83-105

${ }^{213}$ Nebelspalter $1875 / 34$, dessin en noir et blanc non signé intitulé « Petit séminaire à Küsnacht » (Konvikt un Küsnacht).

${ }^{4}$ Nebelspalter $1890 / 15$, dessin pleine page sans titre de Boscovits senior

Albrecht Dürer, Les quatre cavaliers de l'Apocalypse, 1498, gravure; voir aussi " 5.2. S'enrichir du "grand art" ».

${ }_{216}$ Nebelspalter 1890/20, dessin pleine page de Henri van Muyden intitulé « Sur la fin du boulangisme » (Des Boulangismus Ende).

${ }^{217}$ Thierry Paquot, "Georg Simmel, la ville moderne comme " état d'esprit », dans Le territoire des philosophes - Lieu et espace dans la pensée au xx siècle, éd. Thierry Paquot, Paris, La découverte, 2009, p. 331.
} 


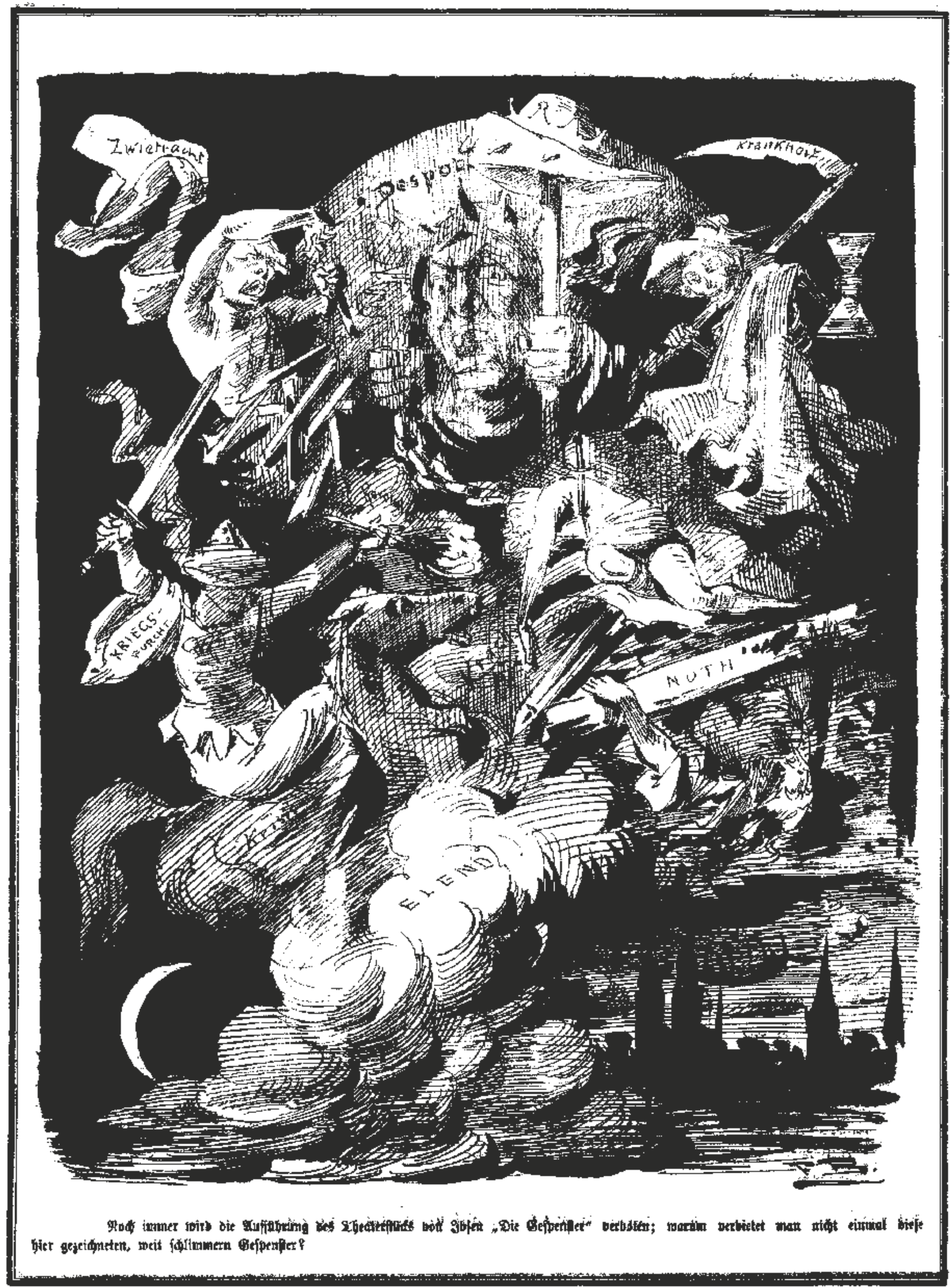

Fig. 93. Nebelspalter 1890/15, dessin en noir et blanc pleine page sans titre de Boscovits senior. 


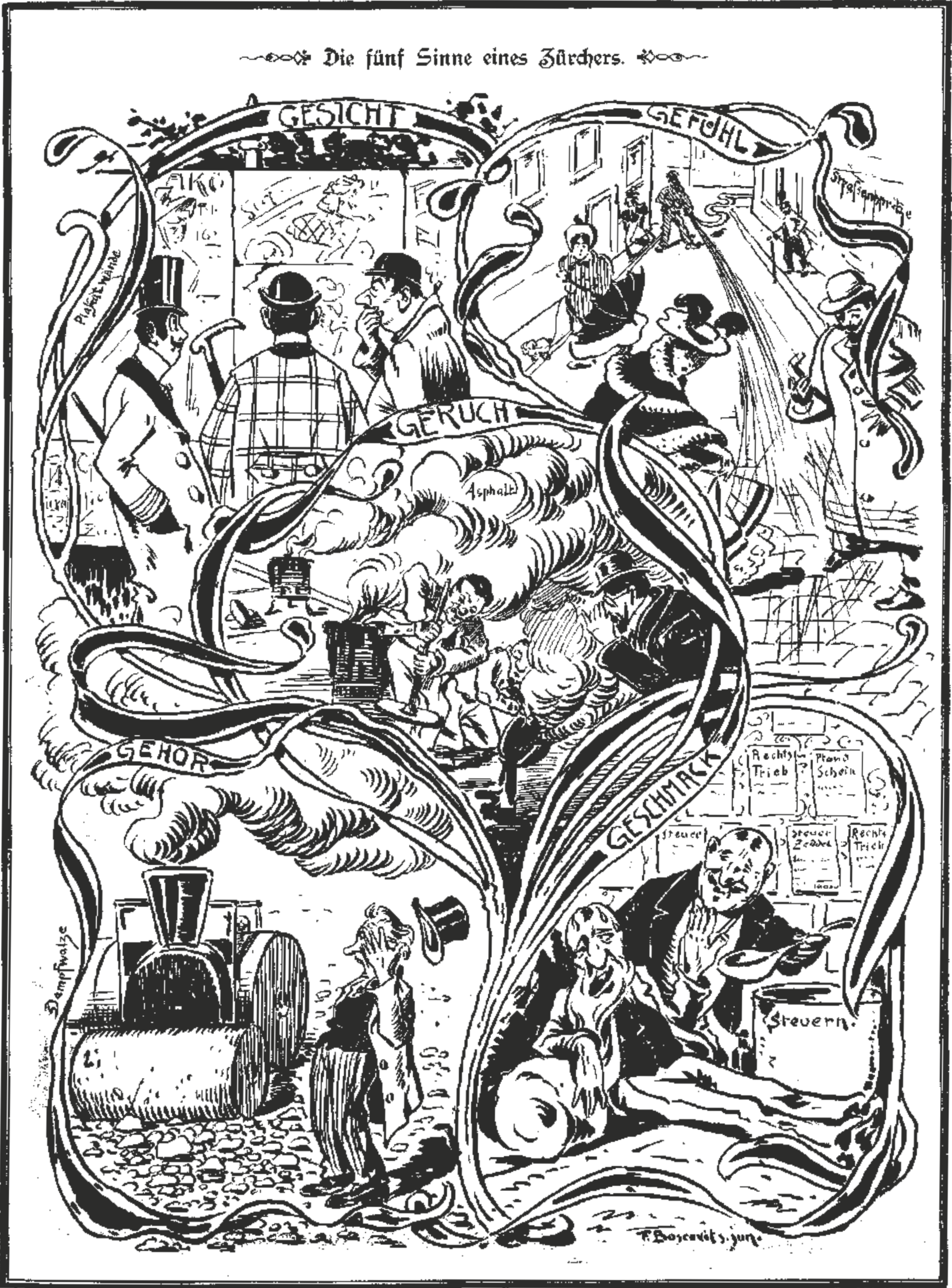

Fig. 94. Nebelspalter 1898/16, dessin pleine page en noir et blanc de Boscovits junior intitulé « Les cinq sens d'un zurichois » (Die fünf Sinne eines Zürchers). 
Ce recours aux profils architecturaux disparaît cependant progressivement. En I 895, on n'en trouve à peine trace, si ce n'est coincé dans le coin supérieur droit d'une chronique facétieuse du mois d'Avril, où une statue de lion - emblème héraldique de la ville - se détache devant le profil de la Zurich ${ }^{218}$. Une équation visuelle est, du reste, posée dans l'image entre Zurich et le Nebelspalter, avec la superposition de ces éléments architecturaux et du personnage de la revue. L'ère Jugendstil avec son processus de décontextualisation et d'allégorisation effréné est alors effective et, en I 895, le Nebelspalter s'identifie à sa ville de parution. Le profil sert désormais tout au plus à poser, avec un schématisme très Jugendstil, la limite de la ville avec l'espace naturel de la campagne ${ }^{219}$ dans le "Vélo amélioré ", où les deux zones, ainsi distinguées, sont envahies par la modernité des usines et la manie cycliste $^{220}$. On le retrouve également dans quelques compositions phares, telle une couverture de Boscovits junior dénonçant, en I 904 , l'accumulation des impôts ${ }^{221}$.

Vers I 890, on observe un autre mode de présence de la ville, consistant en une socialisation de la rue organisée autour d'une surreprésentation des affiches. Cette présence n'est pas tout à fait nouvelle mais devient massive ${ }^{222}$. Dans une caricature datant de I 890, intitulée "Un commerce florissant ", des murs d'affiches servent ainsi de cadre visuel à une critique du financement du réseau ferroviaire suisse, un sujet n'imposant en rien ce motif iconographique ${ }^{223}$. L'affiche comme sujet de la représentation est la plupart du temps contredite par le texte, même au mépris de l'évidence visuelle. Un dessin de I 897 intitulé «En prévention » en témoigne ${ }^{224}$. La légende indique que le placardage d'affiches a pour but d'entraver le voyeurisme endémique du passant, voyeurisme qui se pose donc comme le sujet énoncé de la composition. Il est ainsi très fréquent de voir cohabiter dans l'image deux sujets, l'un écrit, l'autre visuel, initiant une dialectique profitant toujours à l'image dans ces années de primauté visuelle, où le lecteur aura surtout retenu le mur d'affiches. Un an plus tard, en I898, on trouve à nouveau le thème de l'affiche dans une esthétique très Jugendstil, conjuguant arabesque, ornementation et segmentation d'un espace perspectif raccourci à une vision idéalisée de la ville. "Les cinq sens d'un Zurichois » synthétise, autour du thème du goudronnage des rues, les topoï de la modernité zurichoise : désœuvrement du bourgeois, mode féminine et transformation de la ville 225 (cf. fig. 94).

Via le jeu des consonances Gesicht-Gefühl-Geruch-GehörGeschmack (Mine-sensation-odorat-ouie-goût), des comiques de situation et de l'esthétisation, est restituée une version idyllique de l'urbanité moderne. Dans deux des cinq registres ménagés

${ }_{218}$ Nebelspalter 1895/14, double-page de Boscovits senior intitulée « Temps d'avril » (Aprilenwetter)

Jean-Louis Vieillard-Baron, « Henri Bergson, l'espace urbain et l'espace naturel », dans Le territoire des philosophes - Lieu et espace dans la pensée au xxe siècle, op. cit., p. 86-87.

220 Nebelspalter 1897/47, dessin non signé intitulé « Vélo amélioré » (Verbessertes Velo).

Nebelspalter 1904/4, couverture de Boscovits junior.

${ }_{222}$ Sur l'installation progressive du « mur-image » dans l'imagerie; Ségolène Le Men, "Le XIX siècle de l'image », dans Peut-on apprendre à voir, éd. Laurent Gervereau, Paris, École nationale Supérieure des Beaux-arts, 1999, p. 165-174; Réjane Bargiel et Ségolène Le Men (éd.), La Belle Époque de Jules Chéret. De l'affiche au décor, Paris, Les arts décoratifs et BnF, 2010; Nicholas-Henri Zmelty, L'affiche illustrée au temps de l'affichomanie (1889-1905), Paris, Mare et Martin, 2014 .

223 Nebelspalter 1890/32, dessin pleine page de Boscovits senior intitulé « un commerce florissant » (Ein blühendes Geschäft).

224 Nebelspalter 1897/50, dessin en noir et blanc de Boscovits junior intitulé «En prévention » (Vorsorglich).

${ }_{22}$ Nebelspalter 1898/16, dessin pleine page de Boscovits junior intitulé «Les cinq sens d'un zurichois » (Die fünf Sinne eines Zürchers). dans l'image (Mine et goût), sont représentés des murs tapissés d'affiches. Dans le premier registre (Gesicht-Mine), l'affiche est indiquée comme le sujet de la représentation au moyen d'une inscription glissée de biais dans le cadre végétal, selon un procédé usuel de la caricature: "murs d'affiches " (Plakat-Wände). L'indication a pour but d'inciter le lecteur à la réflexion et la profusion d'affiches se pose ici - par exception - comme le terme d'une critique de la ville moderne.

Contrepoint de ces murs criblés d'affiches, le mobilier urbain socialise pareillement la rue. De la même manière, il ne s'offre pas vraiment comme sujet iconographique, même lorsqu'il occupe le centre de l'image, comme c'est le cas d'une colonne d'affichage dans une caricature portant sur une votation populaire intitulée «Elle a aussi de bons moments " ${ }^{226}$. La colonne, placée au centre, structure ici une image dont le propos lui échappe. Cette colonne d'affichage, la Litfabsäule, selon sa dénomination allemande, n'enferme pas l'image, à la différence du mur. Elle peut même introduire une seconde image. En I 899, une caricature de mœurs gentillette sur le thème de l'innocence enfantine montre un enfant demandant à son élégante de mère pourquoi les soldats portent les culottes que les femmes revêtent pour faire de la bicyclette ${ }^{227}$. Le titre de l'image, "Ô cette jeunesse!" (O diese Jugend!), est un clin d'œil à la revue munichoise Jugend, preuve, parmi d'autres, de l'intensité des échanges entre les deux revues ${ }^{228}$. Sans être à proprement parler une mise en abyme, le dessin établit un lien référentiel avec le périodique munichois, puisque qu'il en réinterprète une couverture. Dans le modèle, la colonne permet la mise en abyme de la revue à travers le regard que porte une élégante sur une affiche de Jugend; elle autorise dans le même temps une citation du Bar aux Folies Bergère de Manet ${ }^{229}$, avec le surgissement d'un homme coiffé d'un haut de forme, à la limite de l'espace esthétique ménagé par la colonne ${ }^{230}$ (cf. fig. 95).

Par cet emboitement médial, Zurich est présentée comme une ville d'art, liée au Jugendstil munichois et au maître de la modernité esthétique, Édouard Manet.

Ce type d'images visuellement organisé autour de la colonne d'affichage participe d'une vision idyllique qui devient la modalité dominante de la figuration de Zurich à l'approche de l'année I900. Bien des compositions n'entretiennent qu'un lien très distant avec les éléments architecturaux et dénotent une décontextualisation toujours plus prononcée. Celle-ci trouve son accomplissement dans des représentations festives de carnaval, de cafés et cabarets, s'affranchissant de toutes références physiques, c'est-à-dire de l'élément architectural. Ce tableau idyllique est ainsi transmis dans le Nebelspalter en I 899 avec « Le danger rend astucieux ", évocation euphémisée des inondations zurichoises, tout à fait décalée avec son ton humoristique, qui réunit dans la bonne humeur les habitants, quels que soient leur âge, leur sexe ou leur classe sociale ${ }^{231}$. L'élément architectural se limite alors à un rendu minimaliste des immeubles. La scène est à peu de

\footnotetext{
Nebelspalter 1897/19, dessin pleine page de Boscovits senior intitulé « Elle a aussi de bons moments » (Sie hat auch gute Momente).

Nebelspalter 1899/27, dessin pleine page de Willy Lehmann-Schramm intitulé « Ô, cette jeunesse! » (O, diese Jugend!).

${ }_{228}$ À ce sujet, cf. " 5.1. Le Nebelspalter, la caricature et les revues illustrées européennes ».

229 Édouard Manet, Un bar aux Folies Bergère, 1881-82, huile sur toile, $96 \times 130 \mathrm{~cm}$, Londres, Courtaud Institute.

230 Jugend 1898/49, couverture de Oskar Graf.

231 Nebelspalter 1899/2, dessin pleine page de Willy Lehmann-Schramm intitulé « Le danger rend astucieux » (Not macht erfinderisch).
} 


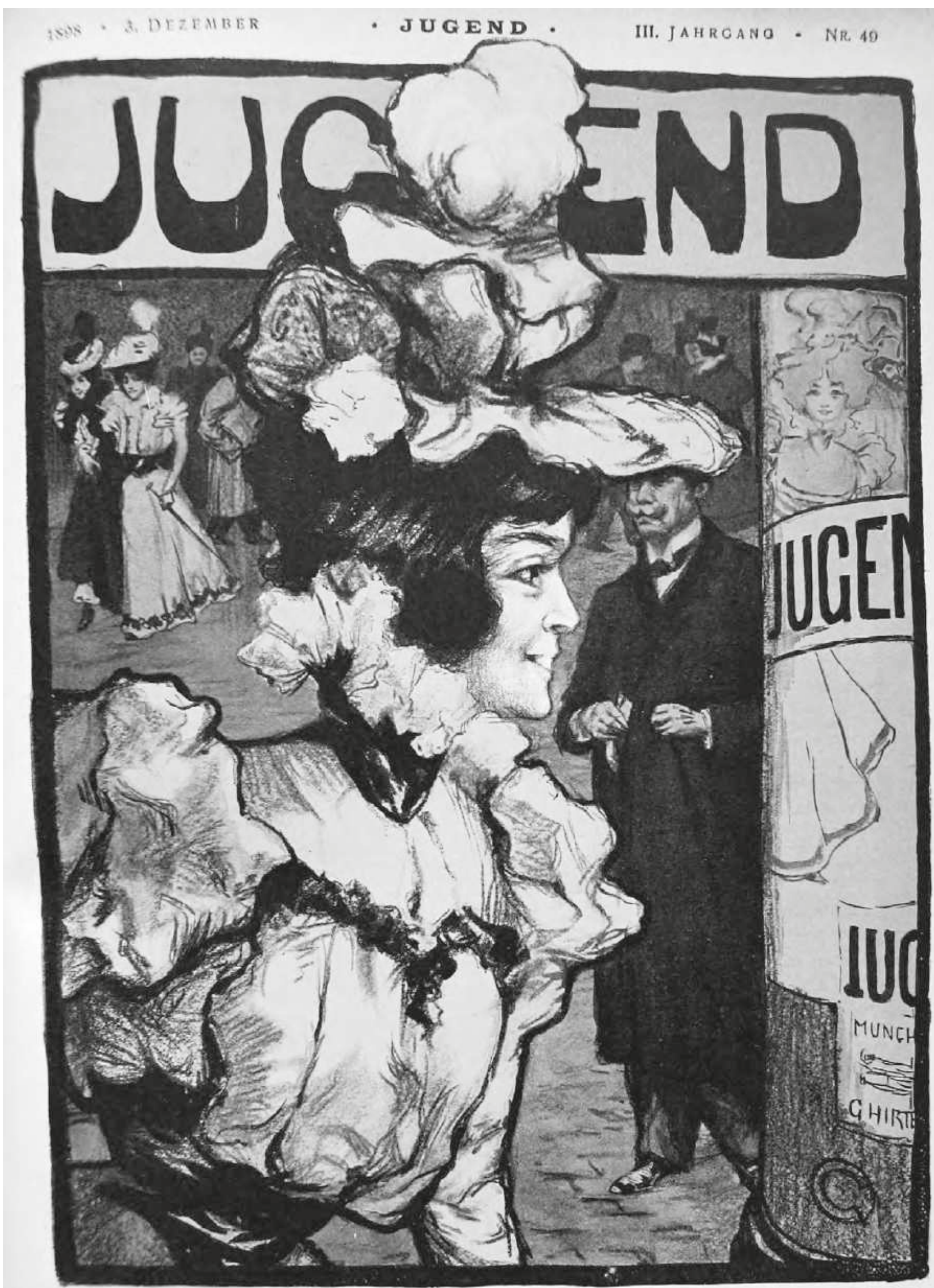

Münchner illustrierte Wochenschrift für Kunst und Leben, - G. Hirth's Verlag in München \& Lelpzig. 


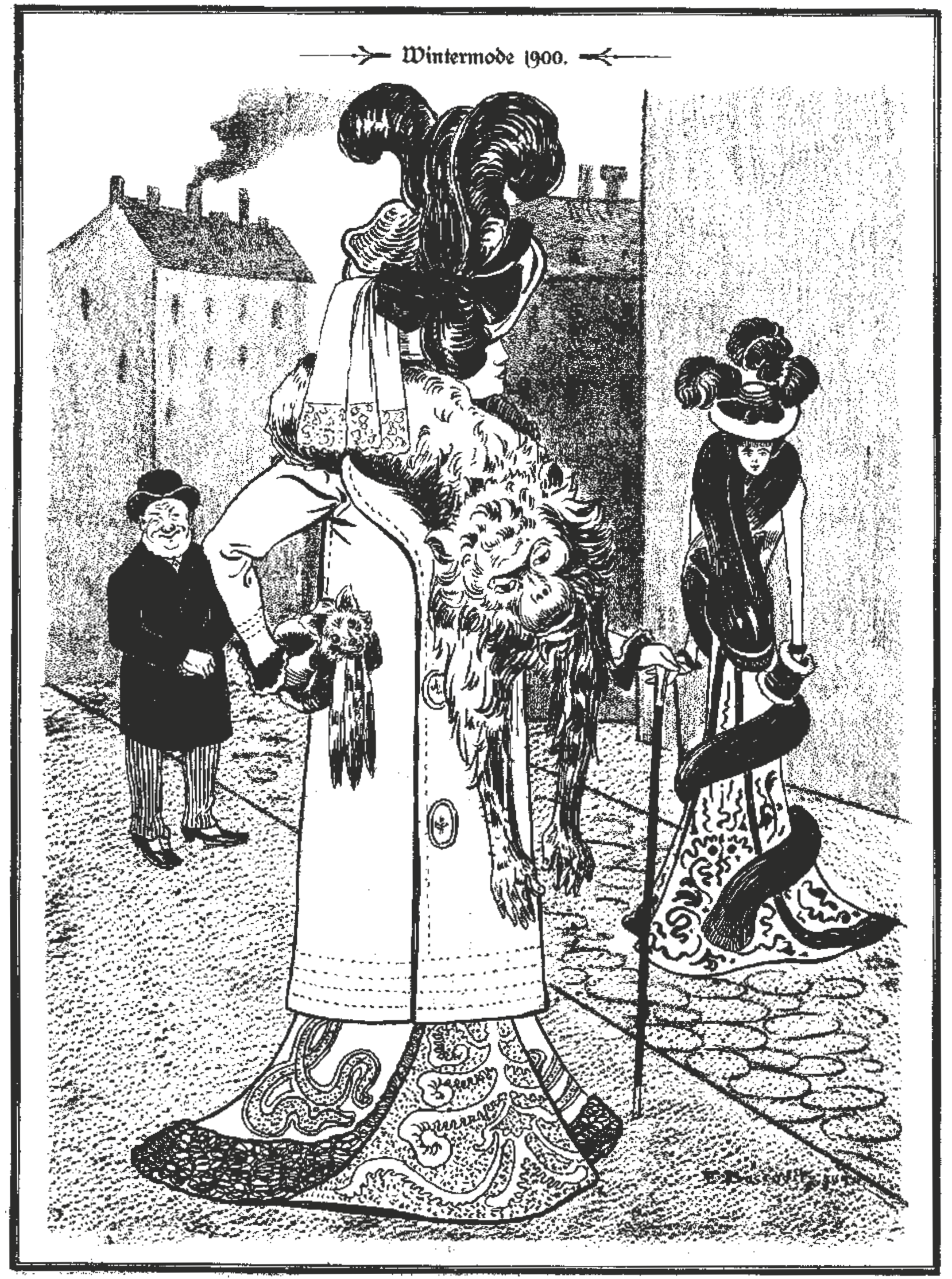

Fig. 96. Nebelspalter 1900/2, dessin pleine page en noir et blanc de Boscovits junior intitulé « Mode d'hiver 1900 » (Wintermode 1900). 


\section{- Merkwürdige Menschenrassen. t*}

(Frei naath Darvin.)

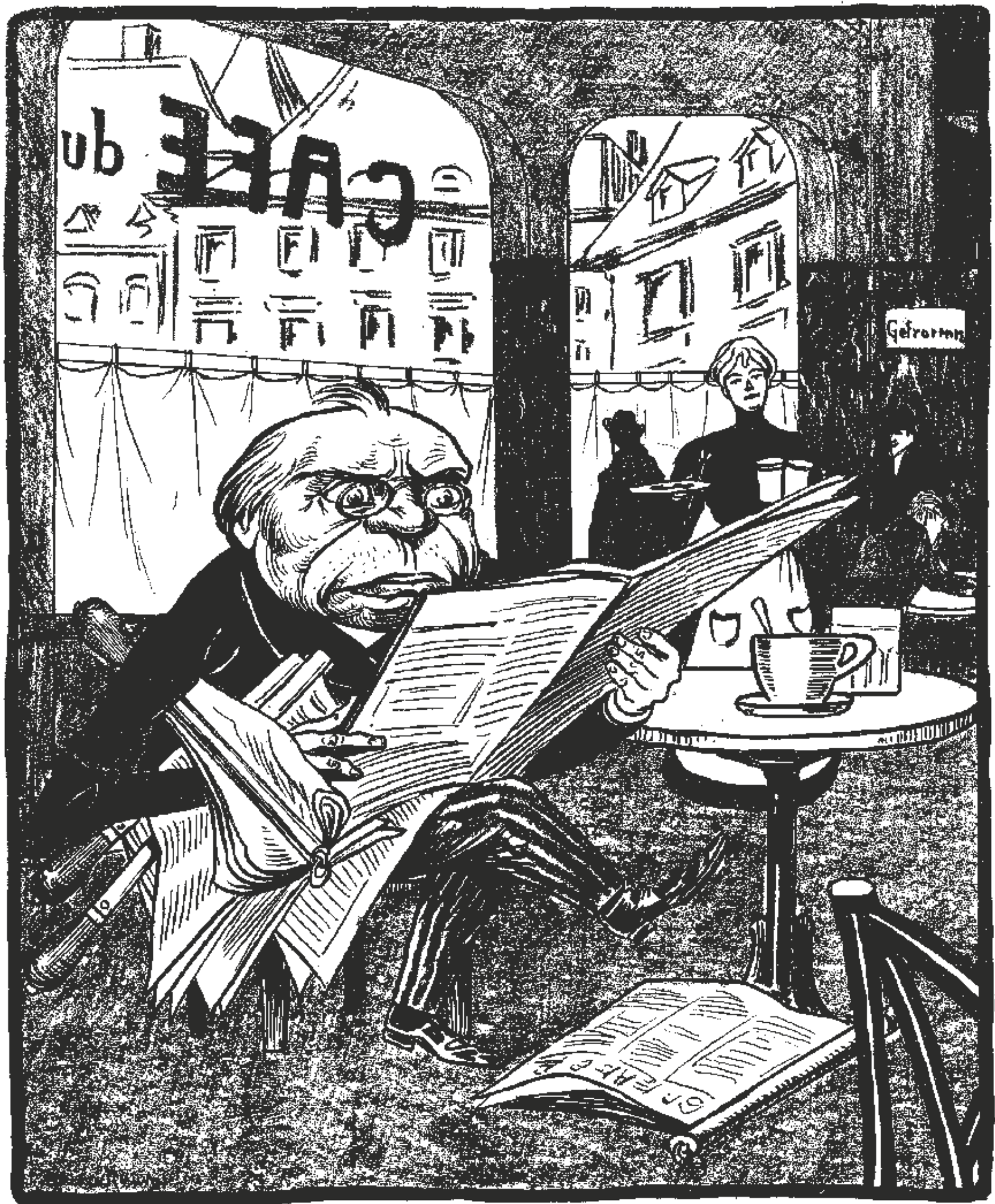

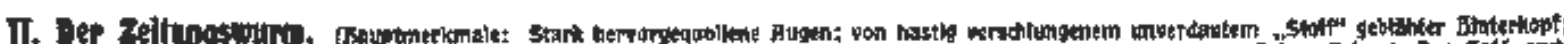

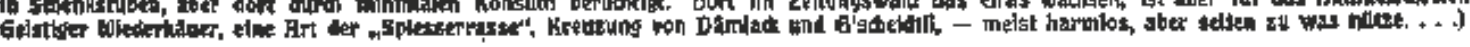


Jürich, deine Wohltaten unterhalten dich

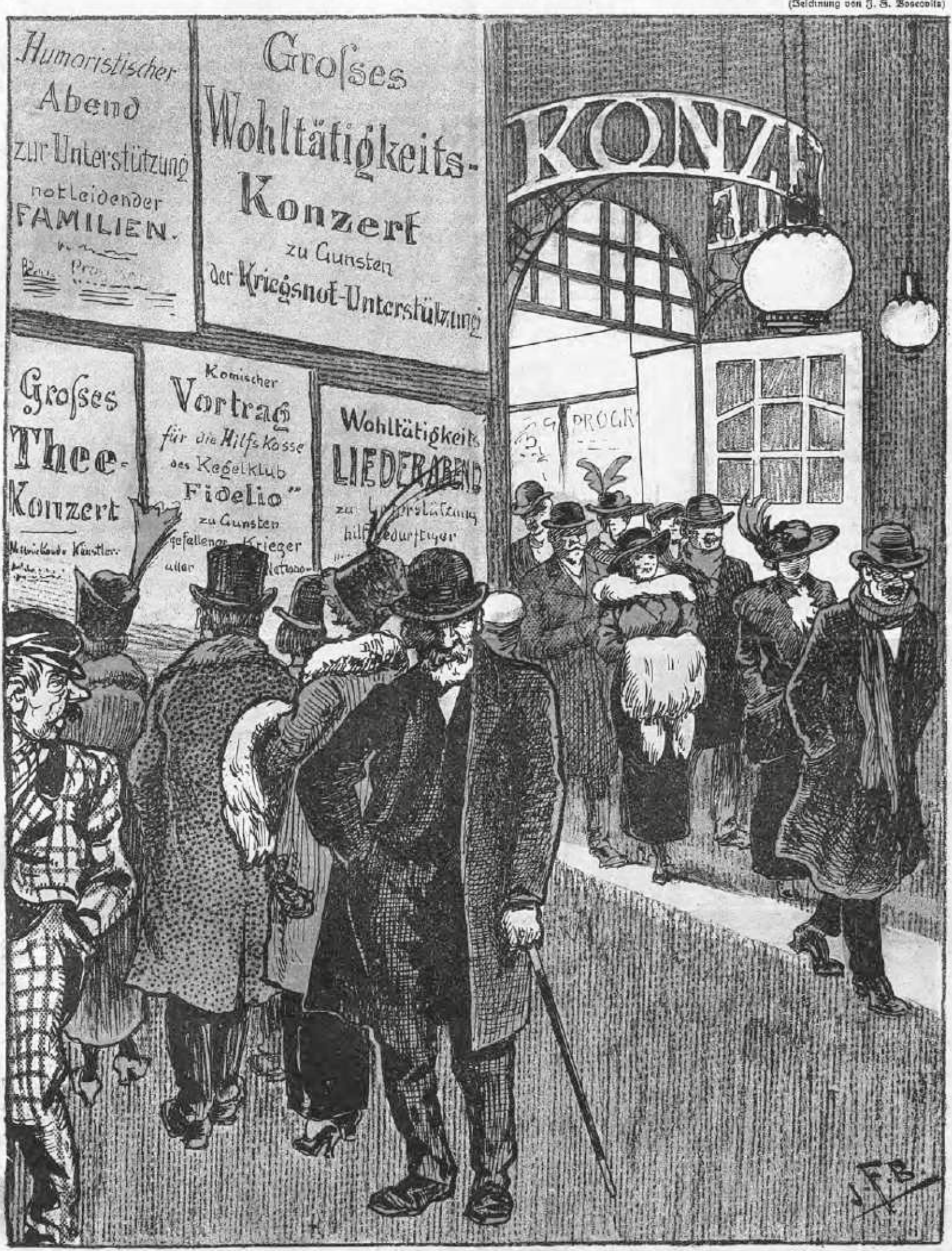

"Go viel Underhaltig hämmer bim @id no nie gha, roie dä 23inter."

Fig. 98. Nebelspalter 1915/9, dessin pleine page en couleur de Boscovits senior

intitulé « Zurich, tes œuvres de bienveillance te distraient » (Zürich, deine Wohltaten unterhalten dich). 
chose près répétée l'année suivante, en I900, avec «La Venise suisse ou Zurich », les parapluies, wagons de tramway et autres embarcations improvisées remplaçant les échasses, tandis que le décor urbain y est restitué avec un trait encore plus schématique ${ }^{232}$. L'humour s'y révèle le choc de la modernitée ${ }^{233}$. Parfois, enfin, des compositions thématisent une mode Belle Époque, vêtement de la modernité, comme dans "Mode d'hiver I900". Les belles dames sont cependant moins reliées à Zurich par les immeubles de l'arrière-plan que par le lion, symbolisant la ville, porté par l'une d'entre elles en guise d'étole - sauf que satire oblige, le lion tient d'un singe symbolisant la cupiditée 234 (cf. fig. 96).

Cette présence Jugendstil se prolonge après le tournant du siècle pour s'épuiser progressivement avec un traitement graphique affadi et une idéalisation nettement moins prononcée. À partir de 1905 , une inflexion s'observe. La plupart des anciens modes de présence se perpétuent mais prennent une coloration sociale. C'est particulièrement frappant des images de carnaval. En I 906, à chaque schéma positif est ainsi opposée une contrepartie: au vieux beau, l'endetté; à la danseuse court-vêtue, les miséreuses mal vêtues; à la belle de nuit, l'ouvrière, œuvrant toutes deux la nuit; aux bourgeois, les balayeurs, côte à côte au petit matin ${ }^{235}$. La rue devient menaçante. Elle accueille la question brûlante des syndicats menaçant les industriels ${ }^{236}$. Sous le crayon de nouveaux dessinateurs, tel Stock pointant le théâtre comme lieu de rendezvous, la critique de la bourgeoisie devient mordante ${ }^{237}$. La série des «Images de rue " (Strassenbilder), entamée en I 895 et thématisant les questions de société, notamment les différences de richesse, prend alors de l'ampleur ${ }^{238}$. Une ville sombre s'installe non seulement dans le propos mais également graphiquement. La figure du buveur (Sauser) en vient à être plus inquiétante qu'amusante. De nombreuses compositions sur l'heure de fermeture des établissements montrent une ville noire. Boscovits junior s'aligne sur cette tendance dans une couverture intitulée «Extinction des feus » (Lichtertlöschen). L'image, probablement crayonnée au fusain, montre un personnage tapi dans l'ombre, attendant que les lanternes rouges ne s'éteignent ${ }^{239}$. Une nouvelle série apparaît, du reste, sur ce thème, intitulée « Depuis la face la plus sombre de Zurich» (Aus dem dunkelsten Zürich).

Durant cette période, une seconde orientation consiste en un nouvel investissement des lieux de sociabilité. Le café, lieu de lecture, prend une importance inédite. Un dessin de I905, issu de la série «Drôles de races humaines " (Merkwürdige Menschenrassen), présente ainsi un homme à la tête énorme, en train de dévorer des journaux dans un café2 240 (cf. fig. 97).

${ }_{232}$ Nebelspalter 1900/6, dessin pleine page de Boscovits junior intitulé «La Venise suisse Zurich » (Schweizerisches Venedig Zürich).

${ }^{233}$ J'emprunte la formule à Olivier Ratouis et Martin Baumeister; Olivier Ratouis et Martin Baumeister, " Rire en ville. Rire de la ville. L'humour et le comique comme objets pour l'histoire urbaine contemporaine ", Histoire urbaine, Rire en ville, 31 (2011), éd. Olivier Ratouis et Martin Baumeister p. 5-18.

${ }_{234}$ Nebelspalter 1900/2, dessin pleine page de Boscovits junior intitulé « Mode d'hiver $1900 »$ (Wintermode 1900).

235 Nebelspalter 1906/7, dessin pleine page de Boscovits junior intitulé « Contreparties de carnaval » (Karnevals-Gegensätze).

${ }_{236}$ Nebelspalter 1906/14, dessin pleine page de Boscovits junior intitulé « L'union fait la force » (Einigkeit macht stark).

Nebelspalter 1911/20, dessin pleine page signé "Stock » intitulé « Après la fermeture du théâtre " (Nach Theaterschluss).

${ }^{238}$ Nebelspalter 1905/22, dessin pleine page de Boscovits junior intitulé « Images de la rue » (Strassenbilder).

${ }_{239}$ Nebelspalter 1914/1, couverture de Boscovits junior intitulée « Extinction des feux » (Lichterlöschen).

${ }_{240}$ Nebelspalter 1905/6, dessin pleine page de Boscovits junior intitulé « Drôles de races humaines » (Merkwürdige Menschenrassen).
Une variante plus élitiste montre des littérateurs en train de refaire le monde, à la manière des décadents parisiens durant les années I $880^{241}$ (cf. fig. 54).

Pendant la guerre, la ville est le lieu d'un discours indirect sur le conflit et ses effets sur la population. Les modes de présence sont inchangés: un mur d'affiches mettant en scène la multiplication des spectacles en soutien aux victimes de guerre ${ }^{242}$; la figuration de ces spectacles autour du même thème de la générosité ${ }^{243}$; le mobilier urbain pour promouvoir le Nebelspalter via une affiche publicitaire apposée sur une colonne ${ }^{244}$; une ville en désordre, intitulée "L'Europe en I930" (Europa I930), pour s'inquiéter de l'avenir de l'Europe ${ }^{245}$ (cf. fig. 98).

Ce type de discours continue après la guerre et l'on recourt à nouveau à l'affiche pour aborder la question du ravitaillement ${ }^{246}$. Dans l'une des dernières images zurichoises, la ville n'est cependant identifiable qu'au travers de la légende en dialecte ${ }^{247}$.

\subsection{La Première Guerre mondiale : la « drôle » de guerre d'une revue}

Durant la Première Guerre mondiale, plus de la moitié des contributions concerne directement la guerre et, parmi le reste, une bonne partie ses conséquences. Les pays non (encore) impliqués dans la guerre sont, du reste, très peu représentés. Le traitement de la guerre est chose compliquée et ce sont une série de questions qui se posent à la rédaction et aux dessinateurs. Comment rendre compte d'une guerre à laquelle on ne participe pas? Quel point de vue adopter qui ne mette en danger la cohésion de la nation? Quelle part réserver aux affaires intérieures? Comment transmettre un discours malgré la censure? Comment montrer la guerre? Est-il possible d'en rire et, si oui, comment? Comment, enfin, prendre sa place dans la guerre des images qui se joue en Europe? Ces défis vont générer des pages à la teneur et à l'iconographie inédites, traçant un chapitre à part dans l'histoire du Nebelspalter. On observe ainsi des coups d'éclats parfois remarquables, qui sont aussi le champ du cygne de la revue zurichoise. Pour soutenir son discours, la revue génère une imagerie qui adapte des schémas iconographiques anciens, en invente de nouveaux, infléchit également des modèles exogènes. Ces images se distinguent de celles d'autres revues européennes, moins en raison d'une censure plutôt accommodante que par le fait qu'elles émanent d'une revue paraissant dans un pays qui n'est pas en guerre et dont l'identité graphique est très affirmée. Archaïsme et novations se côtoient, faisant alterner jeux de contrastes et bichromie, allégories et citations. Aux défis représentationnels, la revue répond invariablement par la distance:

\footnotetext{
Nebelspalter 1911/14, dessin pleine page signé d'un monogramme intitulé « Dans le café littéraire » (Im Literaten-Café).

Nebelspalter 1915/9, dessin pleine page de Boscovits senior intitulé «Zurich, tes œuvres de bienveillance te distraient » (Zürich, deine Wohltaten unterhalten dich).

${ }^{243}$ Nebelspalter 1915/10, couverture de Boscovits senior intitulée « Zurich et son évolution » (Zürich und seine Entwicklung).

244 Nebelspalter 1916/29, dessin pleine page de Boscovits junior intitulé « Rassemblement pour la paix mondiale » (Weltfriedens-Kundgebung).

${ }_{245}$ Nebelspalter 1916/24, dessin pleine page de Boscovits junior intitulé « L'Europe en 1930 » (Europa 1930).

246 Nebelspalter 1920/3, dessin pleine page de M. Raquette intitulé « Trois profonds soupirs » (Drei Stoßseufzer).

${ }^{247}$ Nebelspalter 1920/33, dessin pleine page de M. Raquette intitulé « De toute façon » (So wie so).
} 
7\%. 32 . 39. Jahrgang.

Shilich, den 15. Geptenbe" 1914.

Ginjelnummer 30 Sts.

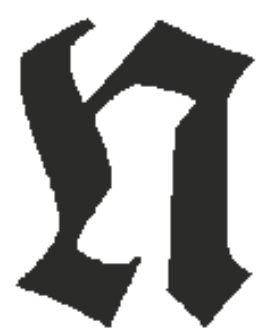

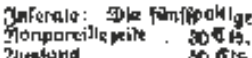

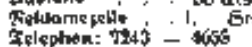

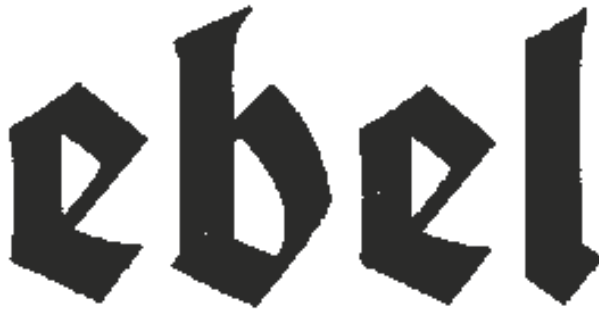

Sumorifti|ich-jatprifche Wochenifctrift
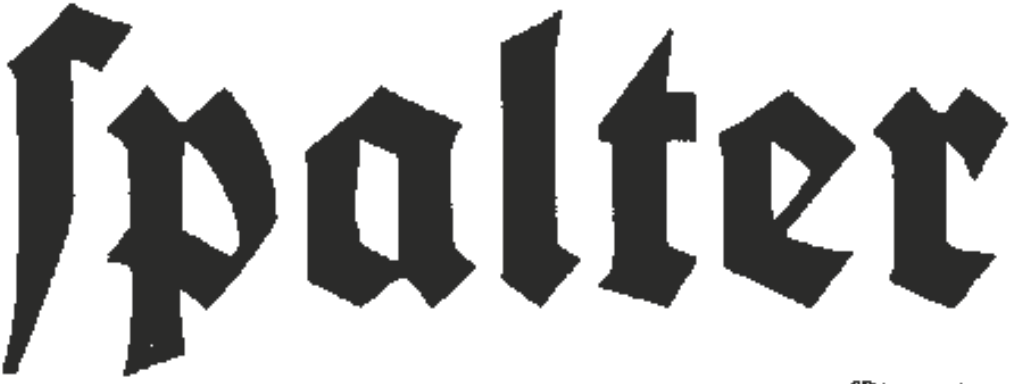

4 thanate ise is 50

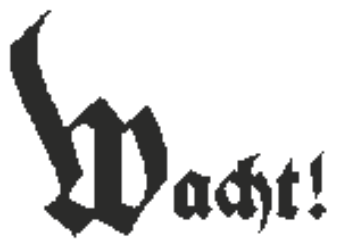

Jim G Gten und ium Weflen flammen die Seuer einer befen Glut.

Qs prallen 201ker jứh yufammen:

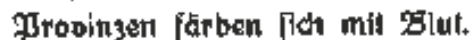

2Tan hatle lang gentug gefprechant

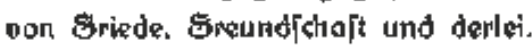
2tum ift mil eins der Bau gebrodien. and meilhin dröhnd dos Xriegsgefoltrei.
Bergethen 1|li, toas than gapredig1:

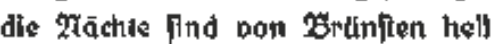
Than hot fich der Xultur entledigt und mordet heule malionell. 266ir fiehn gerüflat an den Zoren;

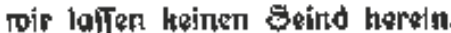
Zoir haben's allefomt gefthrooran und fehen flark soie Gtahl und Gtein.
TReg drouben Krieg und Glend roülen.. 2hip fithn amt For und hallen pracht. Wir merden unfre fseimat hdien bis neu des Briedeng Gontre tacht.
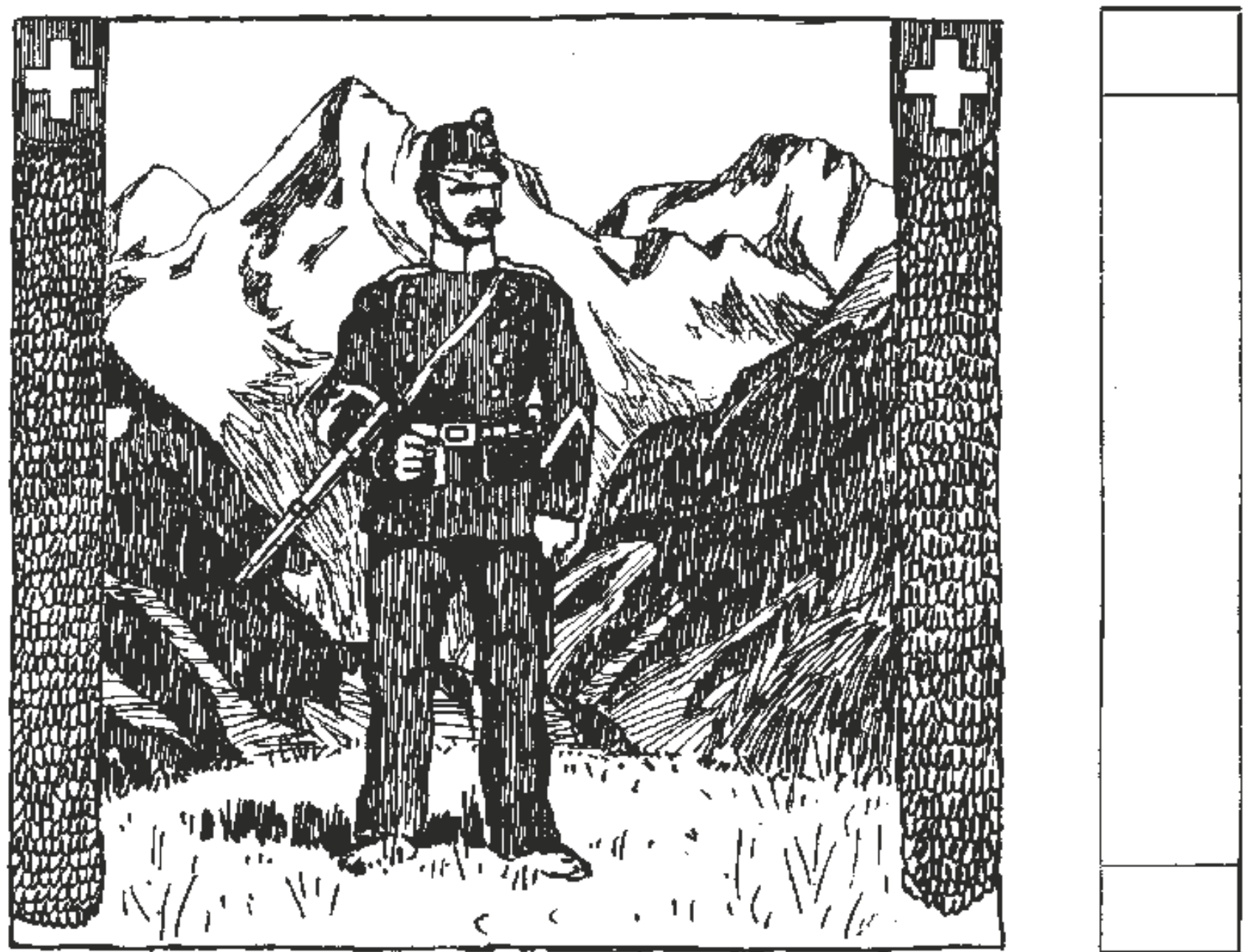
distance critique pour la ligne idéologique; distance de l'objet sur lequel s'exerce le rire; distance conceptuelle et formelle vis-à-vis de la violence. La guerre pose également d'une autre manière la question de l'identité suisse, d'un pays pris dans une tourmente dont il entend se protéger. Elle remet en cause les principes de la neutralité et du droit d'asile. Le conflit avançant, le pays repense sa position et ses acteurs s'interrogent sur une médiation en faveur de la paix. Le choix de la neutralité n'empêche pas la société d'être contaminée dans son entier, du fait des conséquences économiques subies par la population, mais également par des comportements opportunistes ou violents menaçant la cohésion sociale. Le Nebelspalter entame alors une attaque en règle des profiteurs, virant à l'obsession. L'après-guerre est la chronique désenchantée d'une douleur et d'un ressentiment, dont on ne sait s'ils valent pour un monde blessé, pour la Suisse ou pour une revue montrant les stigmates du déclin.

\subsubsection{Se situer vis-à-vis d'un conflit étranger}

Le I ${ }^{\text {er }}$ août I9I4, le Nebelspalter consacre, comme à l'accoutumée, sa couverture à la fête nationale ${ }^{248}$ (cf. fig. 82). Celle-ci adopte, cependant, une apparence singulièrement dramatique. Deux hommes, au milieu des montagnes, se tiennent devant un feu énorme qui colore de rouge l'image entière. Il s'agit, en fait, bien davantage d'une référence à une Europe qui s'enflamme aux portes de la Suisse qu'au feu qu'on allume ce jour-là sur tout le territoire, en signe de fête. Ce type de représentation se retrouve, d'ailleurs, dans l'imagerie des cartes postales de guerre ${ }^{249}$. Plusieurs semaines se passent avant que la revue ne paraisse à nouveau, le I 5 septembre. Un texte explicatif a d'ailleurs été publié début août pour en exposer la raison: la mobilisation de certains membres de la rédaction, comme cela a été le cas entre le 3 et le 7 septembre I9I 4 pour l'ensemble des Suisses en âge de combattre ${ }^{250}$. La couverture du numéro daté du I 5 septembre offre une organisation visuelle encore plus inhabituelle que celle du numéro du I ${ }^{\text {er }}$ août ${ }^{251}$ (cf. fig. 99).

Dépourvue de couleur, elle allie un texte du rédacteur en chef, Paul Altheer, et une image représentant un soldat suisse devant un paysage alpin. Le dessin qui n'est pas signé, chose inhabituelle à cette époque, réactive pour l'occasion la figure emblématique de la sentinelle, qui sera régulièrement présente dans la culture visuelle de l'époque ${ }^{252}$. Le texte, intitulé «Veillez! " (Wacht!), en appelle à la mobilisation des patriotes devant le danger que constitue une guerre. La peur que relaie alors le périodique est que les belligérants prennent en tenailles la Suisse.

L'encart comme la couverture annoncent le traitement singulier d'un conflit international qui ne concernera jamais militairement la Suisse, protégée par sa Déclaration de neutralité du 4 août I 9 I $4{ }^{253}$. Jusque là, la revue s'est surtout contentée de stigmatiser les différentes parties, s'inquiétant, courant I9I4, des tensions accrues entre l'Allemagne et la France. «Il suffit que l'on montre

${ }_{248}$ Nebelspalter 1914/31, couverture de Boscovits junior intitulée « Le premier août » (Der erste August).

249 Georg Kreis, Schweizer Postkarten aus dem Ersten Weltkrieg, Baden, Hier und Jetzt, 2013, p. 82-87.

${ }^{250}$ Nebelspalter 1914/30, feuillet; Jean-Jacques Langendorf et Pierre Streit, Face à la guerre. L'armée et le peuple suisse 1914-1918/1939-1945, op. cit., p. 84-85. Nebelspalter 1914/32, couverture non signée intitulée « Veillez! » (Wacht!).

${ }_{252}$ Philippe Kaenel et François Vallotton, « Représenter la guerre en Suisse: du soldat au général », op. cit., p. 17-22.

253 "Conseil fédéral. Procès-verbal de la séance du 4 août 1914 ", Documents diplomatiques de la Suisse, vol. 6, p. 32 , document $\mathrm{n}^{\circ}{ }^{16}$; au sujet de la neutralité; "Neutralité », Dictionnaire historique de la Suisse (http://www.hls-dhs-dss.ch/ textes/f/F16572.php). de la bonne volonté des deux côtés et tout ira bien »: telle est la légende gentillette d'un dessin montrant un Français et un Allemand à couteaux tirés. L'usage de la couleur bleue dans ce dessin, intitulé « Rapprochement franco-allemand ", ne transmet pas l'idée d'un risque de guerre imminent ${ }^{254}$; c'est en effet la couleur rouge, associée au sang et au dieu Mars ${ }^{255}$, qui colore les images dès l'ouverture du conflit (cf. fig. IOO).

Le prime positionnement d'observateur du Nebelspalter avec la figure de la sentinelle est fidèle à la profession de foi originelle ${ }^{256}$. Il dénote aussi un patriotisme qui saisit l'ensemble de la presse européenne et fait des journaux, auparavant les plus critiques envers leur gouvernement, des défenseurs farouches de la patrie ${ }^{257}$. Même si la Suisse est militairement à l'écart, elle ne s'en situe pas moins géographiquement au centre des hostilités et sa distance critique est à l'image de sa distance géographique, c'est-à-dire minime. D'autant que la guerre va progressivement changer la donne et amener le journal à prendre position dans les domaines économique, financier, social et même moral. Au fil des mois d'un conflit que, ici comme ailleurs, l'on croyait bref, regards et préoccupations évoluent ${ }^{258}$.

Selon la conférence de la Haye de I907, souveraine en la matière, la neutralité d'un État ne s'impose pas à la presse ${ }^{259}$. Il incombe donc au dit État de régler éventuellement la question, ce à quoi s'emploie la Confédération en organisant progressivement la censure. Le I ${ }^{\text {er }}$ août I9I4, la liberté de la presse est suspendue et la communication d'informations militaires dépend du bureau de presse de l'état-major: on en appelle dans le même temps à l'autocensure. Le 30 septembre I9I4, un arrêté fédéral permet la suspension des journaux mettant en danger les relations avec les autres pays ${ }^{260}$. Le Nebelspalter prend alors position dans un dessin intitulé "Sous le signe de la censure » (Im Zeichen der Zensur). Un groupe d'hommes réuni autour d'un canon marqué "Zensur» fait face à une troupe de journaux anthropomorphes, selon un schéma souvent utilisé, notamment lors du numéro I 000 du Nebelspalter en I894 ${ }^{261}$. Le Vaterland, Der Bund, la Neue Züricher Zeitung, la Gazette de Lausanne, le Corriere der Ticino, La Suisse, le Zürcher Post, le Popolo, et bien sûr le Nebelspalter représentent ici la presse suisse. Deux journaux se trouvent à terre, en mauvais point: la Schaffhauser Zeitung et le Gugus. La légende en dialecte ridiculise l'opération: "Les tireurs: “Aïe! Pourvu que nous n'ayons pas touché le mauvais?” „262. Le

${ }^{254}$ (Man muss auf beiden Seiten nur etwas guten Willen zeigen, dann wird's schon gehen); Nebelspalter 1914/11, dessin pleine page de Paul Thesing intitulé " Rapprochement franco-allemand » (Deutsch-französische Annäherung).

255 Michel Pastoureau et Dominique Simonnet, Le petit livre des couleurs, Paris, Panama, 2005, p. 29.

256 Cf. « 2.1. 1875: un premier numéro fixant les choses: maquette, tendance, thèmes, identité visuelle et commerciale ».

${ }^{257}$ William A. Coupe, German political satires from the Reformation to the second world war (1500-1848), New-York, Kraus international publications, 1987, vol. 5-6, p. XIII-XIV.

${ }_{258}$ Sacha Zala, « Krisen, Konfrontation, Konsens (1914-1949) », dans Die Geschichte der Schweiz, éd. Georg Kreis, op. cit., p. 495-498.

259 Georg Kreis, Zensur und Selbstzensur. Die Schweizerische Pressepolitik im Zweiten Weltkrieg, Frauenfeld, Huber, 1973, p. 249.

${ }^{260}$ Alexandre Elsig, "Les aléas de la censure », dans 14/18. La Suisse et la Grande Guerre, éd. Roman Rossfeld, Thomas Buomberger et Patrick Kury, Baden, Hier \& Jetzt, 2014, p. 52-53; Alexandre Elsig, "Zwischen Zwietracht und Eintracht. Propaganda als Bewährungsprobe für die nationale Kohäsion », dans Die Schweiz und der Grosse Krieg, éd. Roman Rossfeld, Thomas Buomberger et Patrick Kury, Baden, Hier \& Jetzt, 2014, p. 83.

Cf. «1.5. Ambitions voilées et assumées: de la délimitation avec les champs de l'art et de la presse ».

${ }_{262}$ (Die Schützen; " Ohä »! Oh mir ietz echt nüd de falsch troffe hand?); Nebelspalter $1914 / 38$, dessin pleine page de Boscovits senior intitulé « Sous le signe de la censure » (Im Zeichen der Zensur). 


\section{Deut|ch - franzö|ị che 2/nnäherung}

(Beldinumg bat Waut Theping)

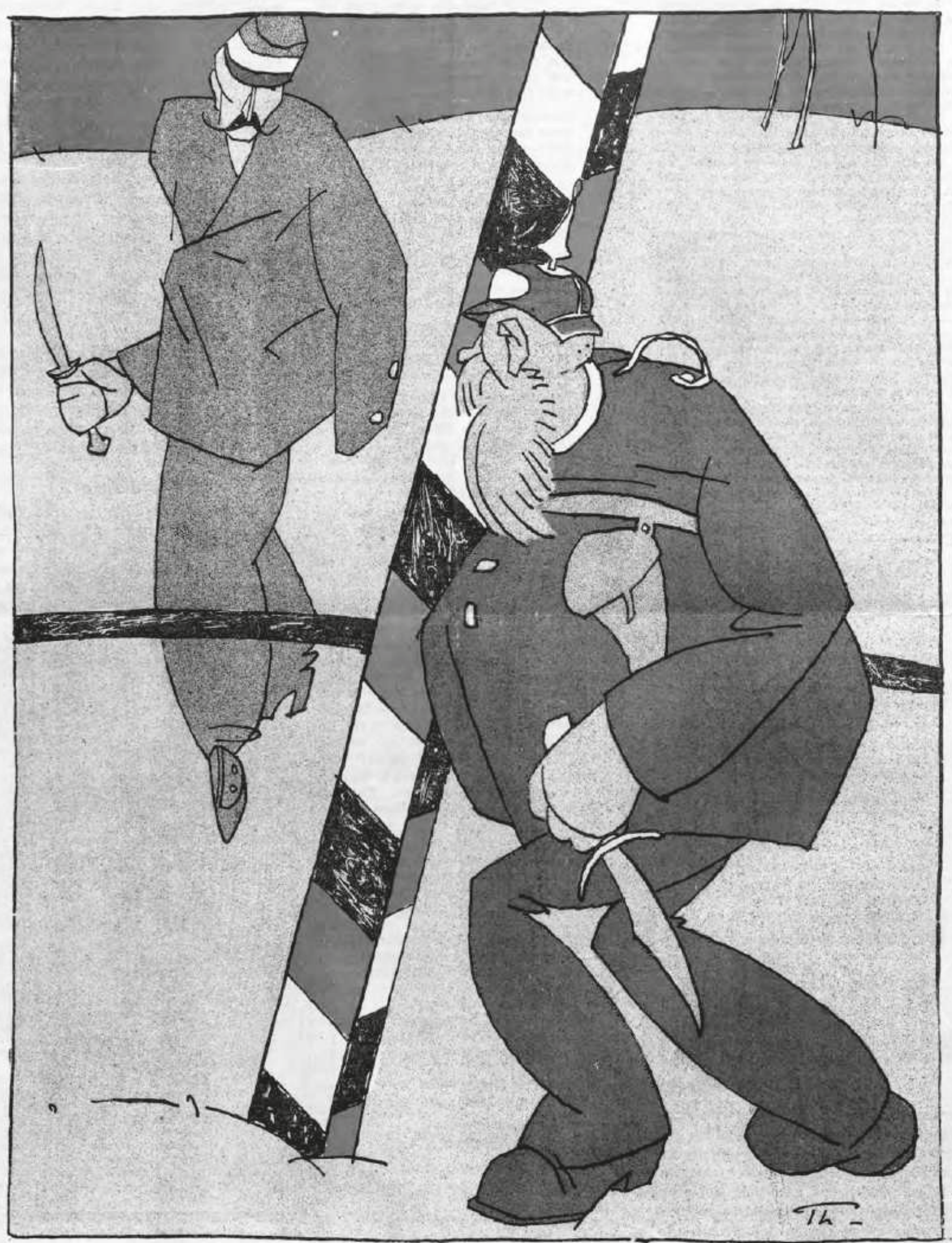

Tan muß̧ auf beiden Geiten nur etroas guten 2 zillen zeigen, dann roird's fchon gehen.

Fig 100. Nebelspalter 1914/11, dessin pleine page en couleur de Paul Thesing intitulé « Rapprochement franco-allemand » (Deutsch-französische Annäherung). 
dessin fait précisément référence à un arrêté fédéral en date du 7 octobre I9I4, interdisant Gugus pour toute la durée de la guerre, sous le motif que ce titre satirique compromet les bonnes relations avec les états voisins ${ }^{263}$. Un avertissement est également donné à la Schaffhauser Zeitung, assorti d'une menace d'interdiction en cas de récidive. Au cours du mois de juillet I9 I 5 , la censure politique s'institutionnalise avec la mise en place d'une commission fédérale de contrôle de la presse ${ }^{264}$. Ceci dit, la confiscation du numéro 2 I du Nebelspalter, en date du 22 mai I9 I 5, titrant sur Gabriele d'Annunzio, représente une aubaine publicitaire pour le journal, qui ne manque pas l'occasion de faire intervenir son personnage: «Alors cher Nebelspalter, que dis-tu de la confiscation de ton avant-dernier numéro ? Rien du tout, sinon ce numéro-ci serait aussi confisqué! » ${ }^{265}$

Très vite pointe une critique de la neutralité qui ne cédera pas durant tout le conflit et qui s'étend à l'ensemble des états neutres. Karl Czerpien fournit, début août I9 I 5, l'une des compositions les plus saisissantes de la guerre, "La cour faite aux neutres " (Das Werben um die Neutralen) ${ }^{266}$ (cf. fig. Io I cahier couleur). Son propos premier est de dénoncer les manœuvres des belligérants à l'égard des états neutres, la Suisse mais aussi les États-Unis, la Belgique, le Danemark, l'Espagne, la Norvège, la Suède, le Vatican ainsi que nombre de petits pays extra-européens. Un crâne emplit l'espace d'une image dominée par la couleur rouge. Dix figures sont dispersées dans la composition où elles forment deux groupes: d'une part, quatre hommes en costume, juchés au sommet du crâne, parvenus là au moyen d'une échelle; d'autre part, six figures dispersées à l'avant-plan de l'image, un espace strié, indéterminé. Toutes les figures sont semblables, des hommes vêtus d'un costume noir, coiffés d'un chapeau noir, au visage indifférencié, sans contact visuel ni avec le spectateur ni entre eux. Seul l'orateur perché sur le crâne où il tient tribune fait exception. Des traits sont donnés à son visage, il a les yeux ouverts et sa main dépasse du cadre de l'image, dans un geste un peu ridicule. L'espace carré au sommet du crâne est une allusion au "tribunal des neutres ${ }^{267}$, dont on recherche la caution morale. Le crâne est repris de la tradition du memento mori, locution latine signifiant «souviens-toi que tu vas mourir". L'idée trouve un fort écho au sein du christianisme et le motif est traditionnellement glissé dans les vanitas. Il a, du reste, déjà été employé lors des deux guerres des Boers ${ }^{268}$. Il est ici mis en avant pour obliger à voir le caractère meurtrier de la guerre. D'autres éléments formels rendent le dessin saisissant: l'inversion d'échelle entre l'homme et le crâne, indiquant que c'est la mort qui domine et non l'homme; l'usage exclusif de la couleur rouge, installant l'idée de guerre, de violence et de sang; le caractère indifférencié de figures apparaissant comme des pantins déshumanisés; le décalage entre le titre et l'image. Le titre ne recouvre, en effet, que partiellement la portée sémantique du dessin, la dénonciation des manœuvres en direction des neutres. Le message s'impose, en fait,

${ }_{263}$ Philippe Kaenel, « Suisse-Allemagne (1848-1918): identités et neutralité du point de vue de la caricature », Zeitschrift für schweizerische Archäologie und Kunstgeschichte, 60 (2003), p. 103.

${ }^{264}$ Alexandre Elsig, "Zwischen Zwietracht und Eintracht. Propaganda als Bewährungsprobe für die nationale Kohäsion », op. cit., p. 83.

${ }^{265}$ (« Na, lieber Nebelspalter, was sagst du denn dazu, dass deine vorletzte Nummer konfisziert wurde? " "Gar nix sage ich, sonst würde diese Nummer auch konfisziert! »); Nebelspalter 1915/23, dessin de Boscovits senior intitulé « Sur la confiscation » (Zur Konfiskation).

266 Nebelspalter 1915/34, dessin de Karl Czerpien intitulé « La cour faite aux neutres » (Das Werben um die Neutralen).

${ }^{267}$ Selon les termes de Raoul Mortier; Raoul Mortier, Au tribunal des neutres, À la gloire de la France, Paris, Dunot et Pinat, 1917.

${ }_{268}$ Cf. « 5.5. Se citer soi-même plus que de mesure » ainsi que « 3.3.3. Montrer la guerre et renoncer au rire $»$ visuellement: une dénonciation générale et totale de la guerre, et, au-delà, une responsabilité des puissances neutres.

Dès avant la guerre, la Confédération fait figure de banquière de l'Europe ${ }^{269}$. Au début de l'année I9 I4, Karl Czerpien figurait déjà une Helvetia disgracieuse et clivée, réservant ses sourires et son argent aux étrangers mais les refusant aux pauvres Suisses ${ }^{270}$. Avec la guerre, le topos se perpétue. Peu après le déclenchement des hostilités, Boscovits senior montre ainsi une Helvetia gigantesque, distribuant des actions sans valeur aux petits Suisses. La composition porte à nouveau le titre « La Suisse comme banquière de l'Europe " (Die Schweiz als Bankier Europas) ${ }^{271}$. La neutralité n'a, de fait, pas permis au pays de rester à l'écart de la guerre économique, puisque celui-ci est dépendant des exportations pour les denrées alimentaires et les matières premières. La réaction défensive du pays pose comme priorité la préservation des intérêts suisses dans tous les domaines ${ }^{272}$. Les numéros s'enchaînent qui mêlent des dessins thématisant les pénuries et un recentrage nécessaire sur la population suisse, rendant encore plus mal assuré l'humour du périodique. "Du charbon et des pommes de terre" (Koble und Kartoffeln), une conversation entre deux bourgeois, en offre une synthèse:

As-tu également assisté à cet exposé où l'on apprend à faire du combustible avec du papier. «Crétinerie! Je sais depuis longtemps que l'on peut brûler du papier. Il vaudrait mieux que quelqu'un m'explique comment faire des pommes de terre avec du papier! » ${ }^{273}$

Cette priorité nationale remet en cause le droit d'asile, composante de l'identité politique suisse, qui s'est affirmée quelques décennies auparavant pour compenser une neutralité peu attractive sur le plan diplomatique ${ }^{274}$. Cette (jeune) tradition est vite écornée, dans un premier temps plutôt indirectement. À l'automne I9I4, "Mesure d'assistance » (Hilfsaktion) montrant un pauvre hère face à un employé est ainsi légendé:

«Alors, vous demandez de l'aide? Êtes-vous Belge, Français ou Allemand? » « Suisse! » « Dans ce cas, je regrette. Nous avons surtout prévu des choses pour les étrangers $»^{275}$.

À partir de I9I6, le propos devient plus direct. La politique d'accueil des réfugiés est très régulièrement mise en cause, avec comme argument assumé le préjudice causé aux Suisses.

Si la neutralité diplomatique est périlleuse, celle des esprits est tout bonnement impossible. Des tensions existent dès le début du siècle

\footnotetext{
Roman Rossfeld et Tobias Straumann (éd.), Der vergessene Wirtschaftskrieg Schweizer Unternehmen im ersten Weltkrieg, Zurich, Chronos, 2008, p. 30.

Nebelspalter 1914/11, dessin de Karl Czerpien intitulé "La Suisse comme banquière de l'Europe » (Die Schweiz als Bankier Europas).

Nebelspalter 1914/35, dessin de Boscovits senior intitulé «La Suisse comme banquière de l'Europe » (Die Schweiz als Bankier Europas).

$2 / 2$ Roman Rossfeld et Tobias Straumann (éd.), Der vergessene Wirtschaftskrieg. Schweizer Unternehmen im ersten Weltkrieg, op. cit., p. 23-24, 29-31. Sur le sujet voir aussi Roman Rossfeld, "Seul le puissant à des droits. L'économie suisse pendant la Première Guerre mondiale », dans 14/18. La Suisse et la Grande Guerre, Roman Rossfeld, op. cit., p. 144-171.

${ }^{273}$ (" Bist du auch in dem Vortrag gewesen, wo man erfährt, wie man aus Papier, Heizmaterial machen kann? " "Dummes Zeug! Daß man Papier verbrennen kann, Weiß ich schon lange. Es soll mir lieber jemanden erklären, wie man aus Papier Kartoffeln macht! »); Nebelspalter 1914/41, dessin de Boscovits junior intitulé « Du charbon et des pommes de terre » (Kohle und Kartoffeln).

${ }^{274}$ Georg Kreis, « Die Schweizerische Flüchtlingspolitik der Jahre 1933-1945 », Schweizerische Zeitschifft für Geschichte, Bâle, Schwabe \& Co., 47, 4, p. 571.

25 ("Also, Sie wollen unterstützt sein? Sind Sie ein Belgier, Franzos oder Deutsche? " "Ein Schweizer! " " Ja, dann muss ich sehr bedauern. Wir haben es vor allen Dingen auf die Ausländer abgesehen. »); Nebelspalter 1914/42, dessin de Boscovits junior intitulé « Mesure d'assistance » (Hilfsaktion).
} 
entre les minorités latines et la majorité alémanique. La guerre les amplifie, chaque partie regardant toujours davantage vers son voisin, alors que la polémique est régulièrement alimentée par les affaires et les choix politiques, dont celui du très germanophile commandant de corps Ulrich Wille nommé chef suprême de l'armée, le 3 août I $914{ }^{276}$. Le terme "fossé » est utilisé pour la première fois par la Gazette de Lausanne en octobre I9I4 ${ }^{277}$. Dans le Nebelspalter, le thème n'apparaît pourtant qu'à la fin I9I 5 avec "Le Lien suisseromand » de Karl Czerpien ${ }^{278}$. Le dessin, qui ne thématise que les sympathies romandes, dénote un changement de ton en faveur de l'Allemagne. Il faut dire que les propagandes étrangères, qui se sont organisées au cours des six premiers mois en s'appuyant sur des organes locaux, contribuent à la radicalisation des esprits ${ }^{279}$.

Jusqu'en I9I6, les belligérants sont, en effet, renvoyés dos à dos et aucune des parties ne reçoit ouvertement de sympathies. Un parti pris pro-germanique est toutefois décelable en creux. L'Allemagne, sans être épargnée par la critique, n'est jamais l'objet d'attaques aussi violentes que ne le sont les pays de l'Entente, en particulier l'Angleterre. Boscovits junior croque un soldat de dos, l'allure dégingandée, que son chapeau, ses cheveux roux et sa pipe signalent comme un soldat britannique. L'homme est face à une horde d'énergumènes aux types physiques très marqués, certains très noirs, l'un vêtu d'un costume traditionnel, un autre asiatique (un Japonais), un autre encore totalement hirsute, le dernier coiffé d'un turban. Au premier plan, un singe à la gueule ouverte montre le soldat. Tout ce beau monde tient une arme dans la main, qui un fusil, qui un sabre, qui un bout de bois. La légende rapporte les propos du soldat poussant de la main le cadre de l'image, en direction du titre, "Le combat pour la culture européenne " (Der Kampf um die europäische Kultur) : "Il faut que s'impose une bonne fois pour toute la supériorité de notre culture européenne ${ }^{280}$ (cf. fig. I02).

Le dessin se rapporte aux troupes coloniales de l'Angleterre, dont il dénonce l'argument de défense de la culture européenne, utilisé pour légitimer le combat. Cet argument est, en fait, présent dans le Nebelspalter en relation avec l'Angleterre depuis les années I $880^{281}$. L'agressivité de l'image passe par de multiples vecteurs: l'utilisation de schèmes racistes; l'association des soldats coloniaux au singe; l'équivalence de ce dernier avec le mensonge (énoncé par le soldat), conformément à une symbolique usuelle; le décalage entre la représentation, le titre et la légende; la figuration de l'ennemi en un soldat britanique ridicule, jusque dans son geste pour repousser le cadre. Figure d'opérette, menteur, celui-ci ne peut défendre une culture européenne, revendiquée par l'Allemagne, alors que les deux parties soutiennent un patriotisme culturel,

Ceci dit, les Alémaniques n'étaient pas tous favorables à un homme ne parlant pas un mot de dialecte; Jean-Jacques Langendorf et Peter Streit, Face à la guerre. L'armée et le peuple suisses 1914-1918/1939-1945, op. cit., p. 69-80.

Alexandre Elsig, "Zwischen Zwietracht und Eintracht. Propaganda als Bewährungsprobe für die nationale Kohäsion », op. cit., p. 72.

${ }_{278}$ Nebelspalter 1915/47, couverture de Karl Czerpien intitulé « Le lien suisseromand »; le titre est en français; cf. " 3.3.1. Se situer vis-à-vis d'un conflit étranger».

279 À ce sujet, voir Alexandre Elsig, "Propagande allemande et renouveau patriotique: l'enjeu médiatique des Feuilles suisses du dimanche (1915-1918) ", Relations internationales, 153 (2013), p. 66-67 ainsi que Alexandre Elsig, « Zwischen Zwietracht und Eintracht. Propaganda als Bewährungsprobe für die nationale Kohäsion », op. cit., p. 70-101; pour la version française « Entre discorde et concorde. La cohésion nationale à l'épreuve des propagandes ", dans 14/18. La Suisse et la Grande Guerre, op. cit., p. 72-101.

${ }^{280}$ (Nun muss sich wolhl über die Überlegenheit unserer europäischen Kultur endgultig herausstellen!); Nebelspalter 1914/33, dessin pleine page de Boscovits junior intitulé "Le combat pour la culture européenne " (Der Kampf um die Europäische Kultur).

Cf. « 2.2.4. Un langage visuel et rhétorique très typé ». cristallisé dans les notions de culture et de civilisation ${ }^{282}$. Pendant les deux premières années du conflit, l'Angleterre condense ainsi l'agressivité. Les choses changent ensuite et l'ennemi principal devient la France, puis les États-Unis, à partir de I9I7, date de leur entrée en guerre. Des topö̈ nourrissent les charges contre ces ennemis majeurs. On fait dire au soldat sénégalais, traité de renégat dans le titre: "Tu sais, mon frère, même si je me bats aussi pour un Français blanc, à l'intérieur, je suis resté un bon noir », auquel son vis-à-vis, figuré en sauvage, répond: "Et extérieurement, non ? " ${ }^{283}$. Vis-à-vis des Américains, la rhétorique de la cupidité et de l'hyporcrisie domine. Dans « Le saint dollar » (Der Heilige Dollar), l'oncle Joanathan se jette sur des sacs d'or marqués " justice » (Gerechtigkeit), "liberté » (Freibeit) et "humanité » (Menschlichkeit). La légende nous apprend que ce sont les valeurs défendues devant le Congrès par le Président Wilson, le 2 avril I9 I 7, quelques jours seulement avant l'entrée en guerre des États-Unis ${ }^{284}$. Qu'il s'agisse de l'Angleterre, de la France ou des États-Unis, la propagande ne fait chaque fois qu'exacerber une agressivité ancienne.

D'autres épisodes de la guerre, telle la réception du discours de Carl Spitteler, témoignent, cependant, d'une certaine difficulté du Nebelspalter à se situer. Spitteler prononce un discours intitulé « Notre point de vue suisse », le I4 décembre I9I4 à l'Université de Zurich, à l'invitation de la Nouvelle société helvétique. Il s'y prononce en faveur d'une unité de la Suisse neutre, qui ne tienne pas compte des inclinations personnelles ${ }^{285}$. Le Nebelspalter ne s'empare de l'événement que le 27 mars I9 I 5 . La couverture intitulée «Galerie des orateurs célèbres » (Galerie berühmter Redner) fait partie d'une série visant à décrédibiliser certains politiciens et intellectuels, dans l'ordre, le conseiller d'État Dr Wettstein, Carl Spitteler, Else Spiller, journaliste engagée en faveur des mouvements féministes et de l'abstinence, le politicien Robert Seidel, l'écrivain Paul Willi Bierbaum. Ces séries, alors très courantes dans les revues ${ }^{286}$, ont vocation à réaffirmer la ligne éditoriale, graphique et satirique d'un titre, ce qui explique, au moins en partie, le décalage de quatre mois entre le discours et la couverture ${ }^{287}$. Carl Spitteler prend place dans un décor de théâtre, ses lunettes dans une main, s'appuyant de l'autre à la table devant lui. Sur celle-ci, sont posés une carafe et un verre d'eau, deux attributs usuels de l'orateur. Deux angelots tiennent une couronne de laurier derrière la tête de l'écrivain, ce qui dans le langage volontiers inversé de la caricature signifie que celui-ci n'est pas un ange. Le discours est perçu en Suisse alémanique comme antiallemand et très mal vécu, au contraire de la Suisse romande, où il est largement saluée 288 .

Stéphane Audouin-Rouzeau et Annette Becker, 14-18 Retrouver la Guerre, Paris, Gallimard, 2000, p. 164-181.

${ }_{283}$ ("Weißt du, Bruder, wenn ich auch für Weißes Franzose kämpfe, innerlich bin ich doch guter Schwarzer geblieben! » - « Und äußerlich nicht? »); Nebelspalter 1916/15, dessin de Boscovits junior intitulé « Le renégat »(Der Renegat).

${ }^{284}$ Nebelspalter 1917/17, dessin signé « BAHR » intitulé « Le saint dollar » (Der heilige Dollar).

${ }_{285}$ Georg Kreis (éd.), Die Geschichte der Schweiz, op. cit., p. 496; Alain Clavien, "Les intellectuels suisses et la Grande Guerre. Un engagement vigoureux », dans 14/18. La Suisse et la Grande Guerre, op. cit., p. 106.

286 Willy Lehmann-Schramm est, par exemple, l'auteur d'une tellle série parue au milieu des années 1890 dans le Neue Postillon; Mattias Fischer, Ferdinand Hodler in Karikaturen und Satire - Parla caricature et la satire, Sulgen, Benteli, 2012 ; plus précisément sur l'œuvre: p. 91.

Nebelspalter 1915/13, couverture de Boscovits junior intitulée « Galerie des orateurs célèbres » (Galerie berühmter Redner).

${ }_{288}$ Andreas Kley, « Magistrale Demonstration der nationalen Einigkeit. Politische Reden während der Ersten Weltkriegs », dans Der vergessene Krieg. Spuren und Traditionen zur Schweiz im Ersten Weltkrieg, éd. Konrad J. Kuhn et Béatrice Ziegler, Baden, Hier \& Jetzt, 2014, p. 199-200; Roman Rossfeld et Tobias Straumann (éd.), Der vergessene Wirtschaftskrieg. Schweizer Unternehmen im ersten Weltkrieg, op. cit., p. 30-31. 


\section{Der Kampf um die europäifche Kultur}

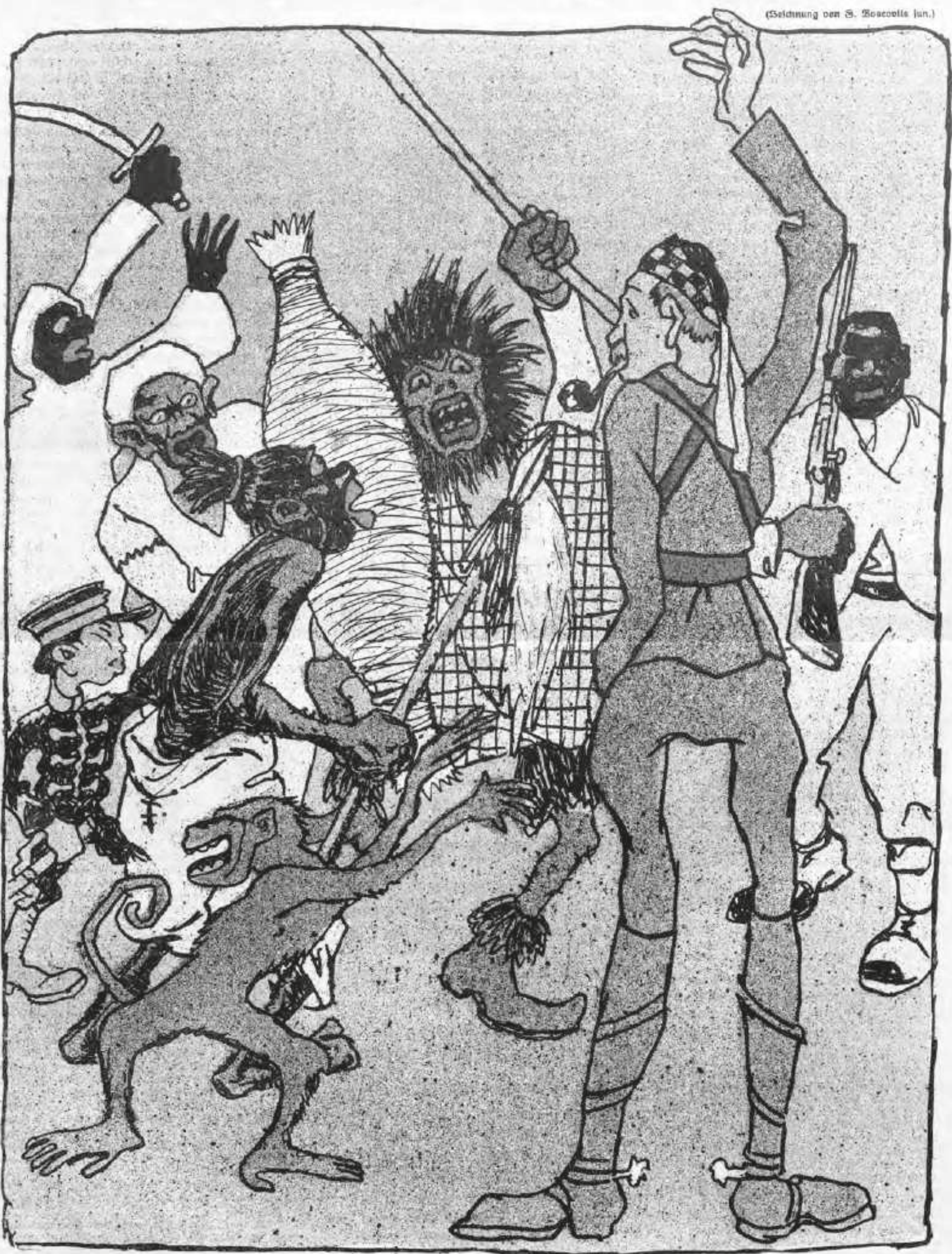

Tun muß̧ fich wohl oder äbel die Cleberlegenheit unferer europäịchen Kultur endgültig herausftellen! 
Sa réception négative ne dépasse finalement pas l'animosité envers un intellectuel régulièrement présenté comme pédant, et qu'il est donc aisé de figurer en « donneur de leçon » neutraliste.

Le traitement de la très emblématique affaire des colonels est plus net. Il s'agit de l'une de ces affaires qui secouent l'opinion publique suisse et participent à la division du pays ${ }^{289}$. Deux hauts officiers de l'état-major général, le chef de la section des services de renseignements de l'armée, le colonel Friedrich von Wattenwyl et son collaborateur, le colonel Karl Egli ont transmis dès le début du conflit le bulletin journalier de l'état-major général et des dépêches diplomatiques décryptées par les services suisses aux contiennent des données sur les intentions militaires des Alliés. L'affaire est découverte par un cryptographe, André Langie, qui, jugeant la neutralité suisse violée, transmet l'information à deux journalistes romands. Ceux-ci préviennent le conseiller fédéral Camille Decoppet. Le Conseil fédéral et le général Ulrich Wille sont informés en décembre I9 I 5 , les deux colonels sont éloignés. Sous la pression de parlementaires, de la presse et de l'opinion publique de la Suisse romande, le Conseil fédéral ordonne le I I janvier I9 6 une enquête administrative. Le I 8 janvier, le général Wille accepte la comparution des deux officiers devant un tribunal militaire mais refuse leur condamnation qu'il juge nuisible à l'image de l'armée suisse. Le lendemain, le Conseil fédéral décide de les soumettre à une procédure judiciaire complète. Le procès se tient à Zurich, les accusés défendent leur position, contestant une stricte neutralité, selon eux régulièrement bafouée par l'Entente, ce qui délivrerait les parties neutres de leurs devoirs. Pour finir, le 28 février, le tribunal déclare les colonels non coupables sur le plan pénal, soulignant qu'ils ont agi pour le bien du pays, et les renvoie à l'autorité militaire pour une éventuelle décision disciplinaire. Le général Wille les condamne à vingt jours d'arrêt de rigueur et le Conseil fédéral les suspend de leur fonction ${ }^{290}$. Boscovits junior fournit quelques jours avant le jugement une couverture intitulée "Il parle d'expérience» (Er spricht aus Erfahrung). Deux soldats échangent des propos dans la cour d'une caserne: "Je crois que le mieux serait que le procès soit public. - Ah, pourquoi ça ? - Bah, parce que trop d'affaires militaires secrètes sont rendues publiques en Suisse » 291 (cf. fig. I03).

Boscovits instille par le jeu des regards des deux militaires, croqués de très près, les conditions d'une complicité avec le attachés militaires allemands et austro-hongrois. Ces dépêches

\footnotetext{
lecteur. Le coloris, un noir et blanc légèrement verdi, identique à

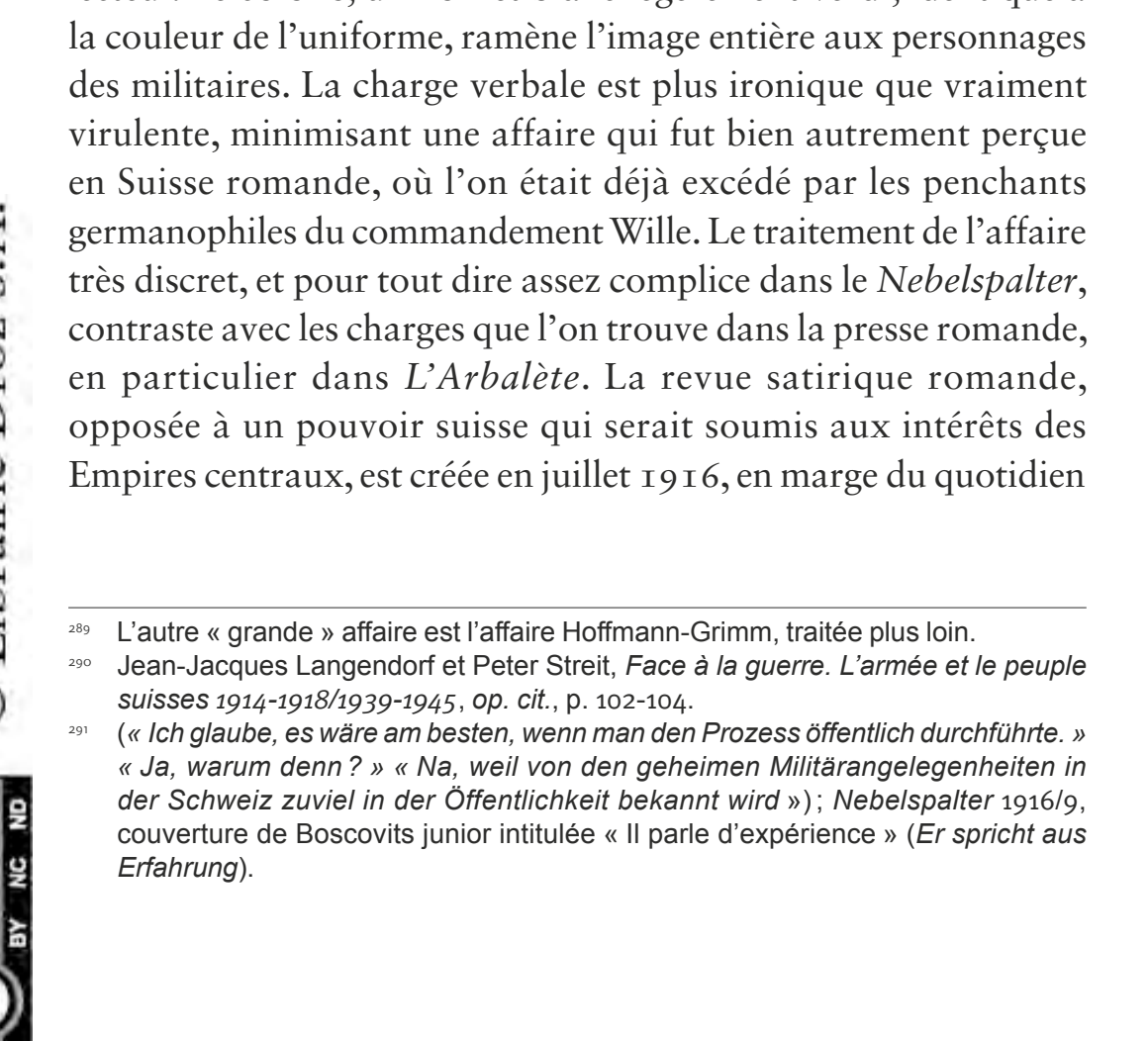

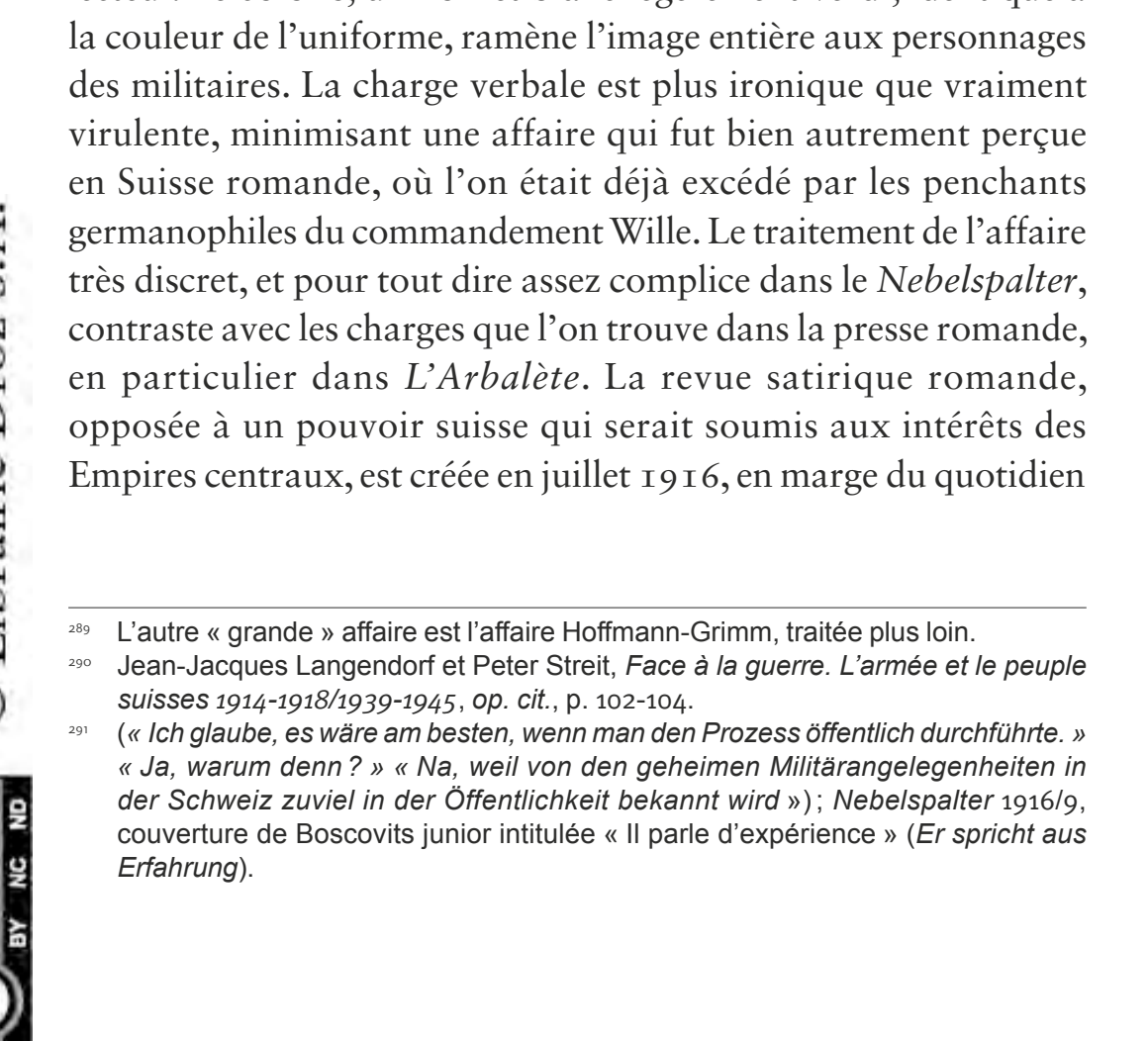

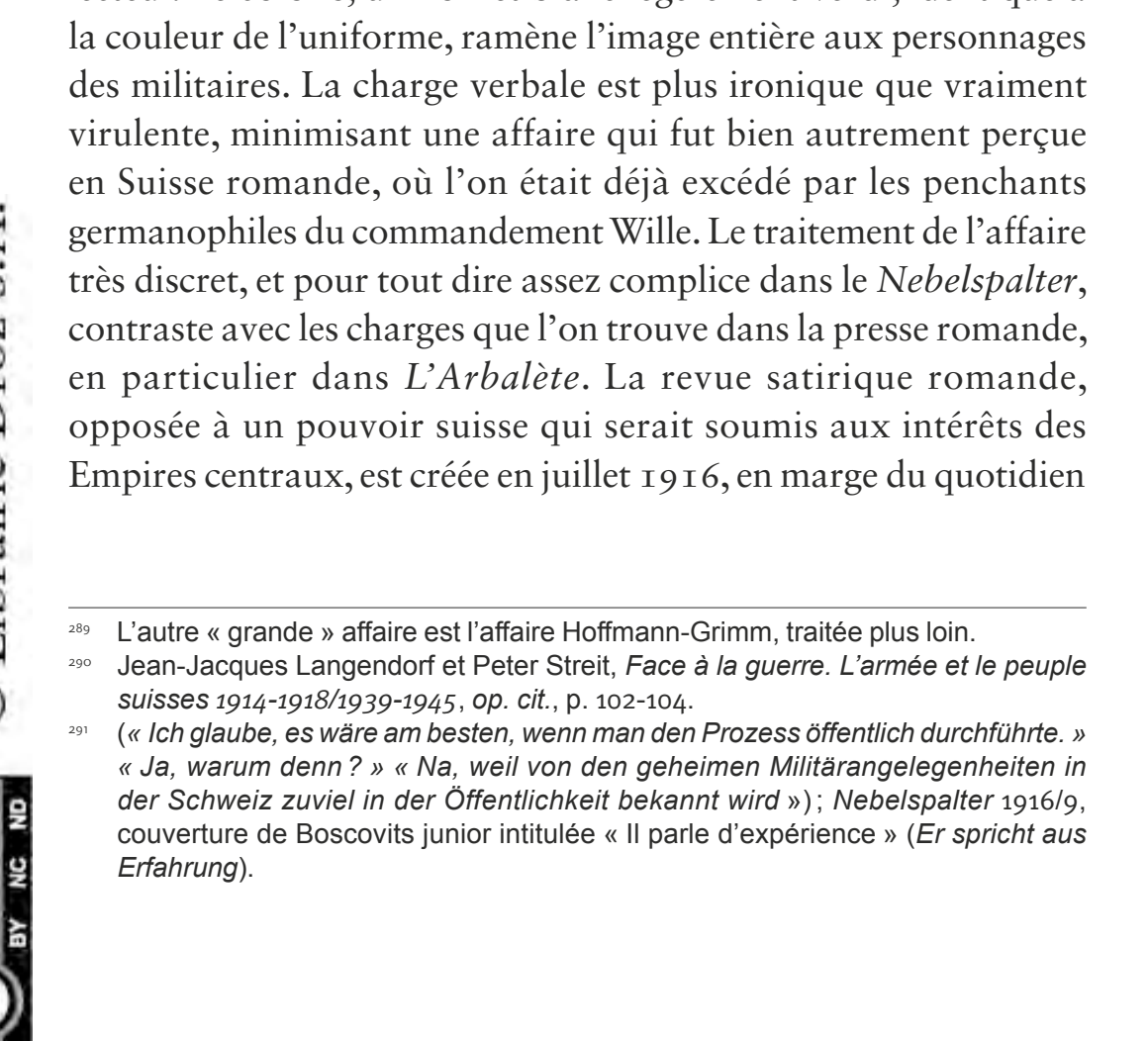

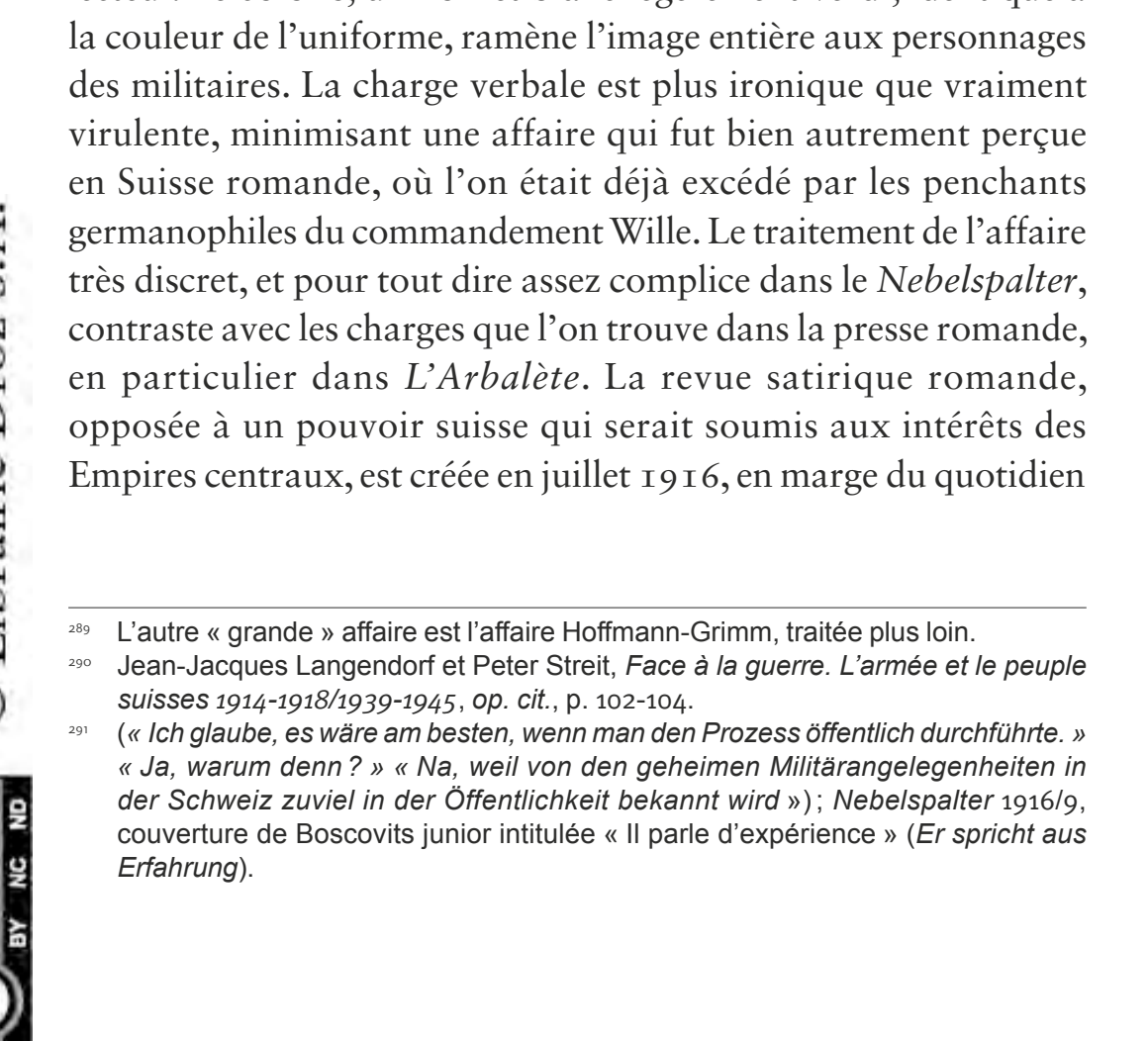

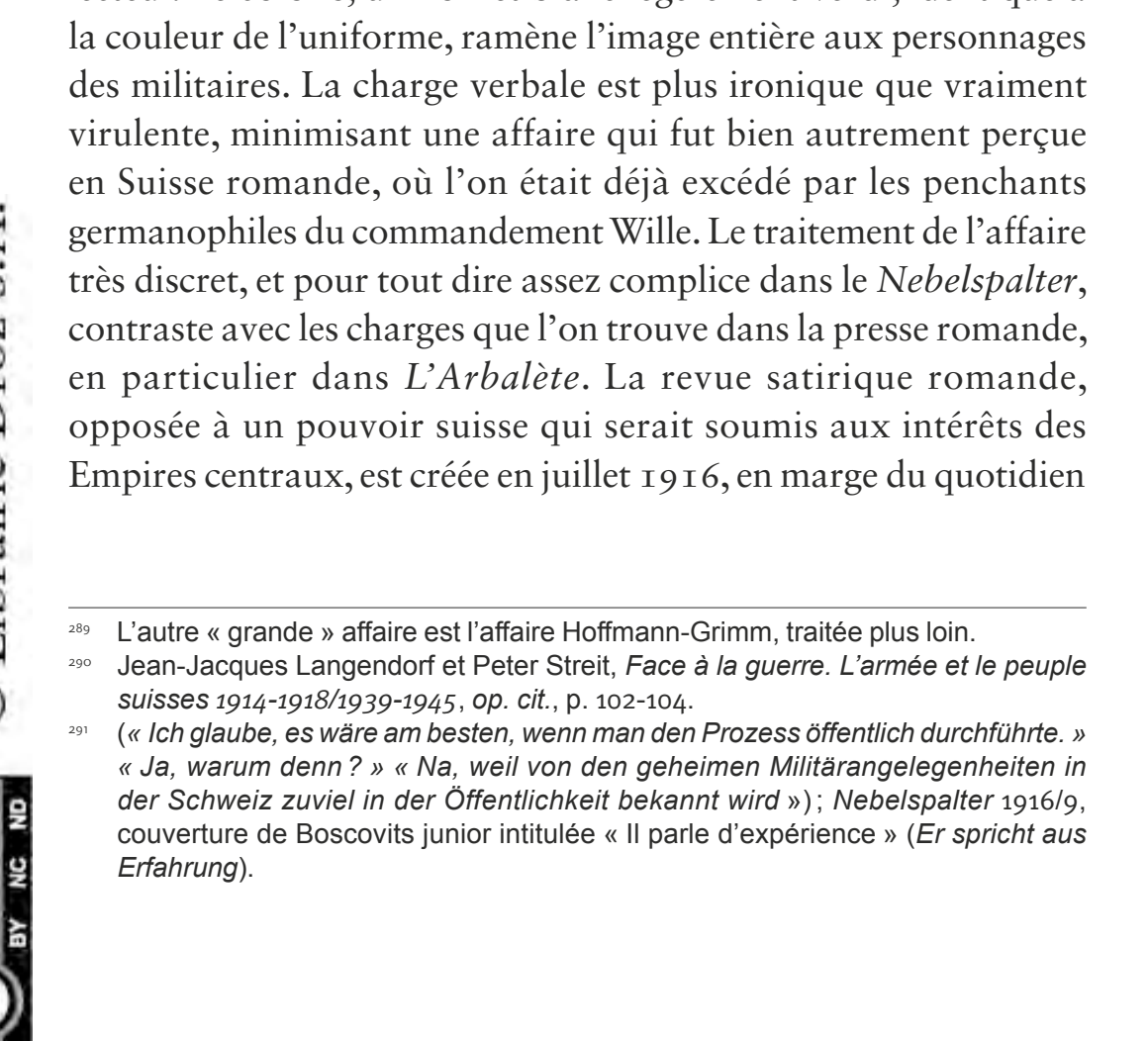

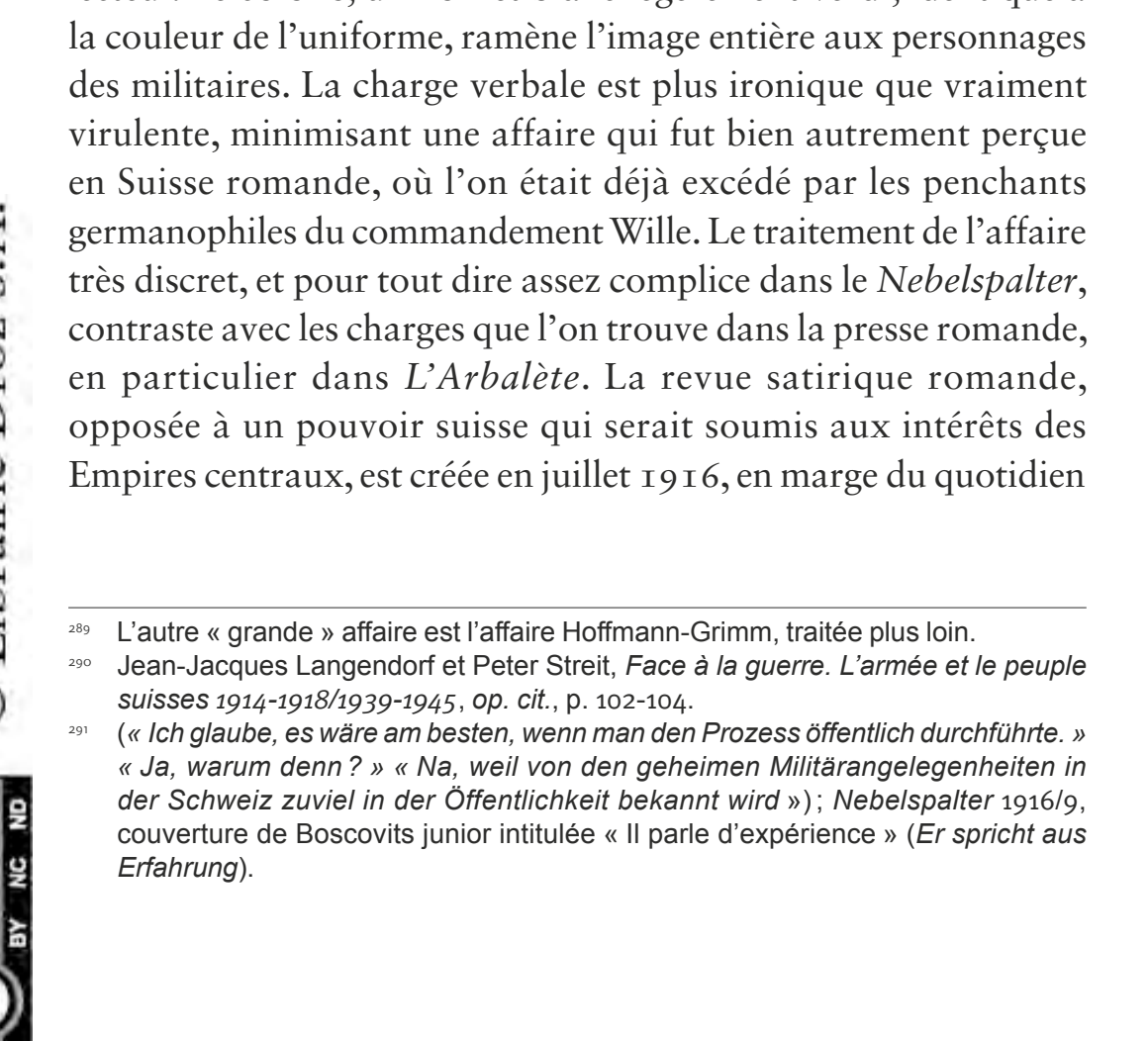

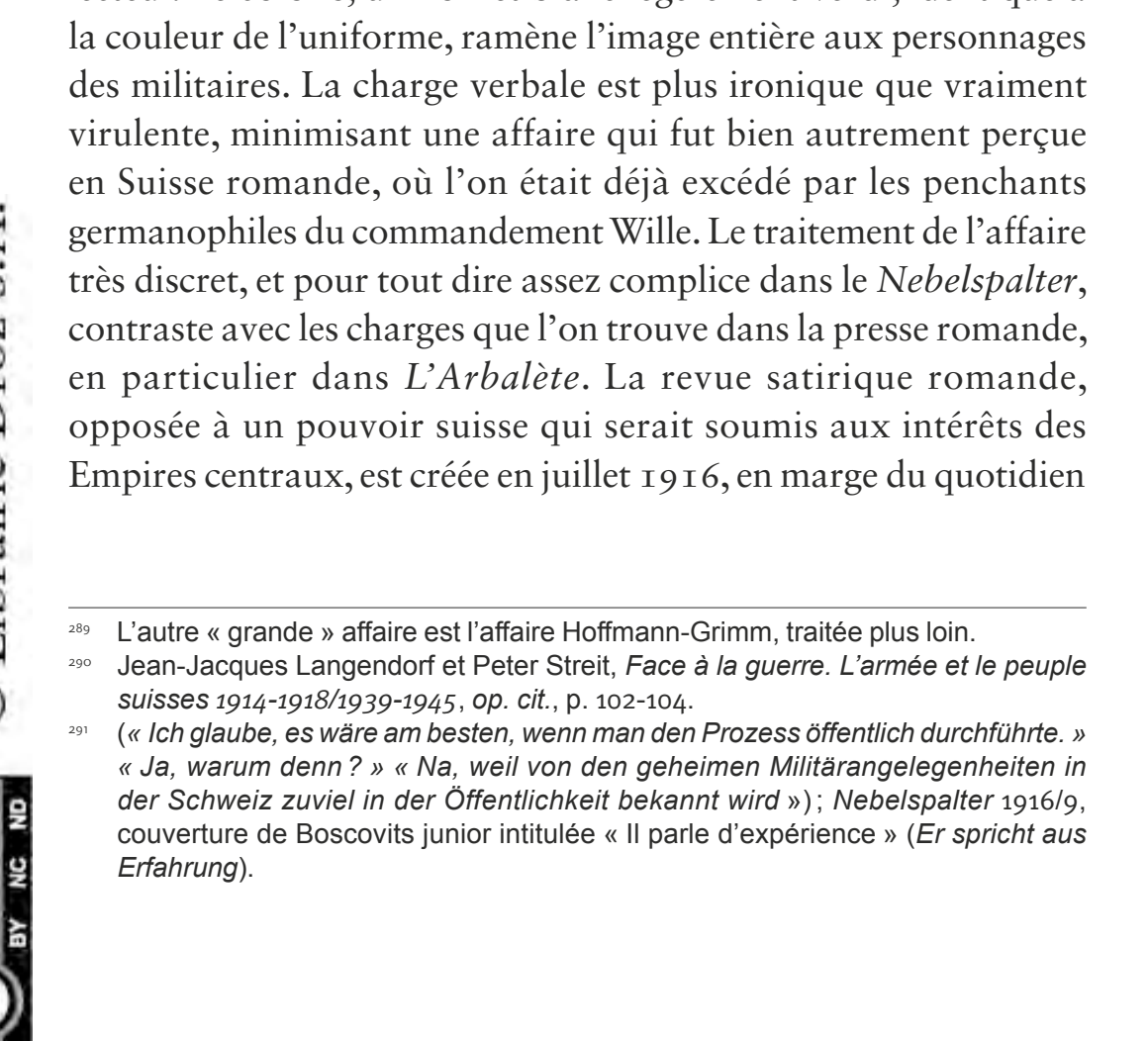

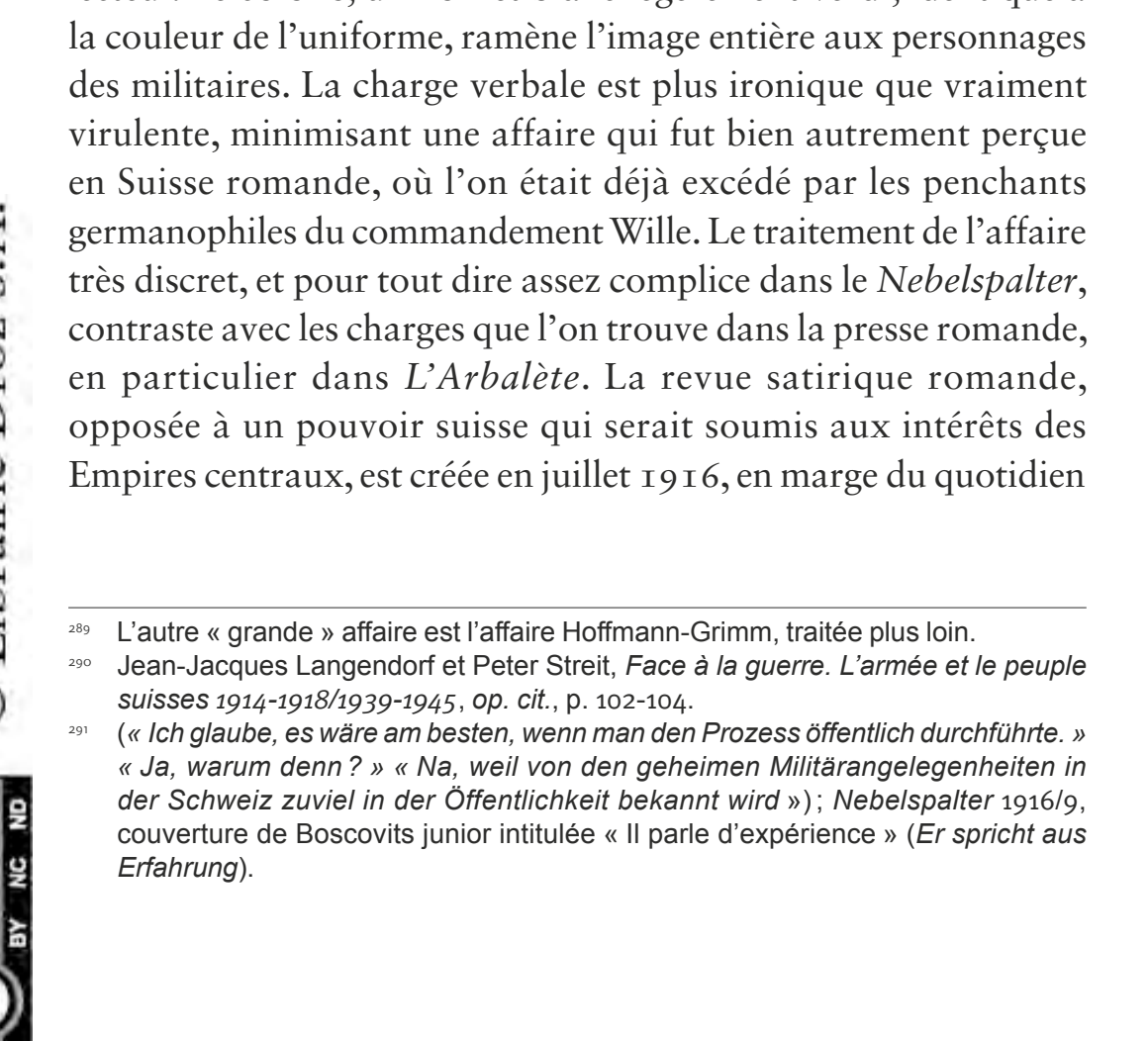

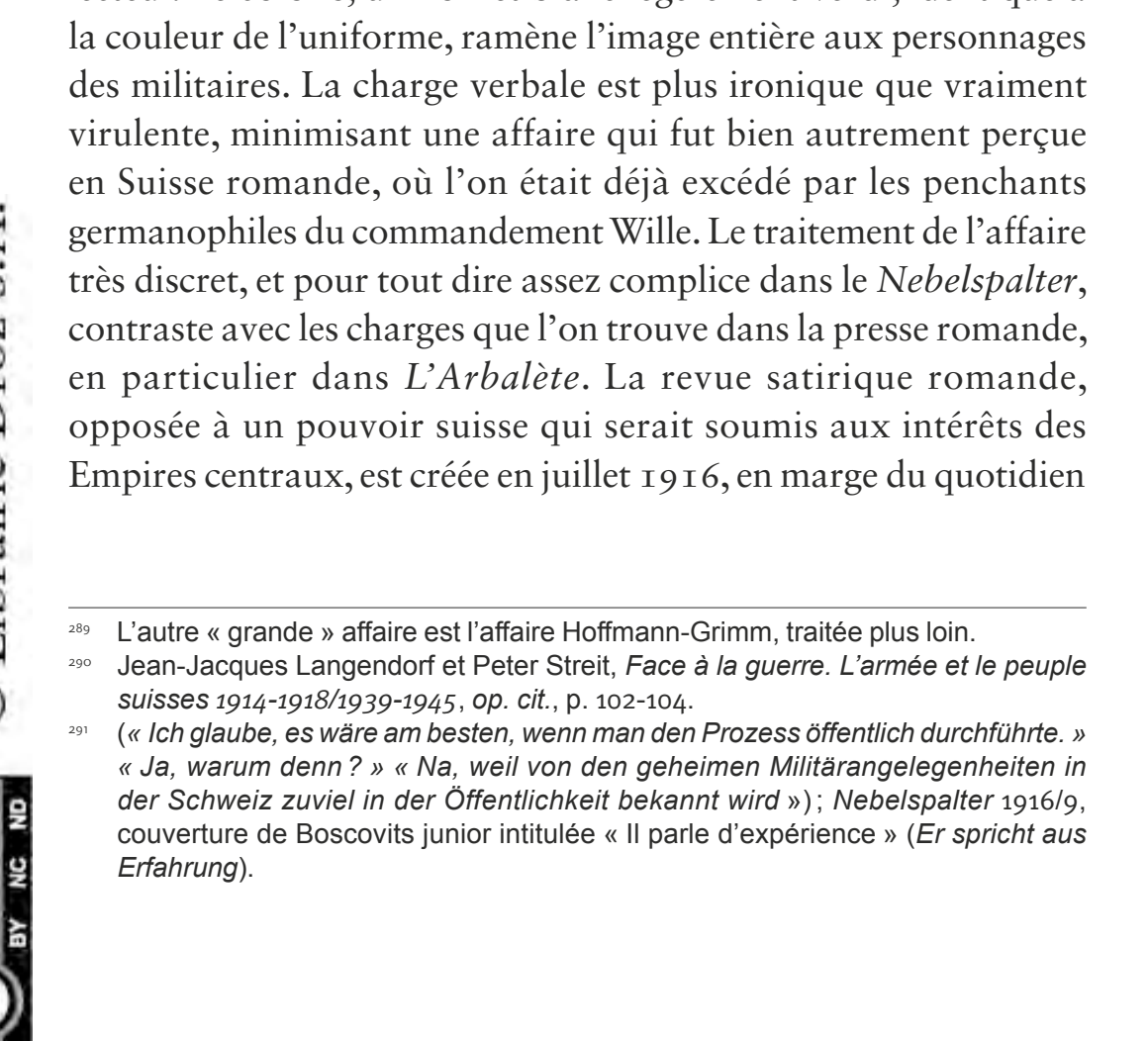

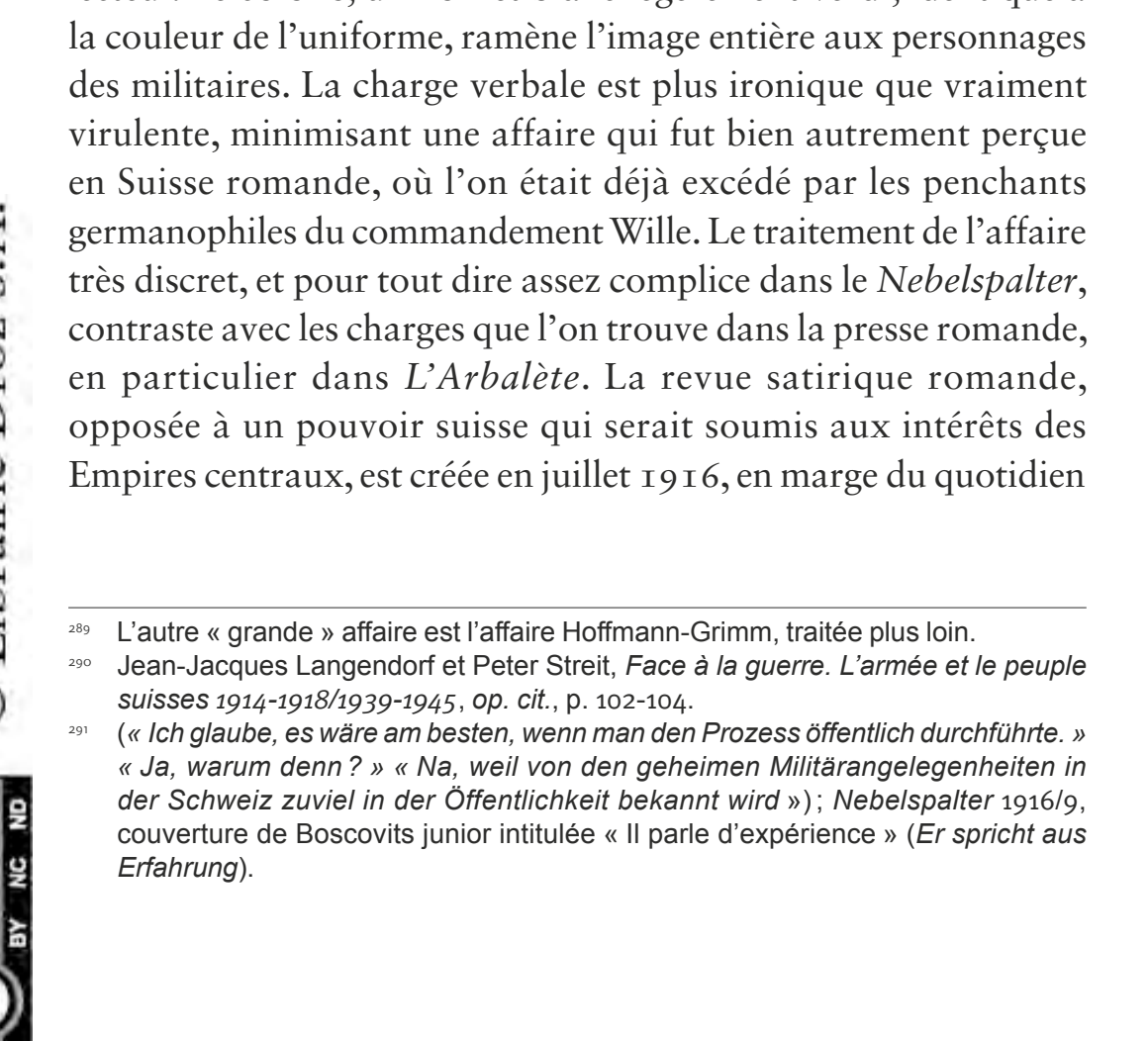

la couleur de l'uniforme, ramène l'image entière aux personnages
des militaires. La charge verbale est plus ironique que vraiment
virulente, minimisant une affaire qui fut bien autrement perçue
en Suisse romande, où l'on était déjà excédé par les penchants
germanophiles du commandement Wille. Le traitement de l'affaire
très discret, et pour tout dire assez complice dans le Nebelspalter,
contraste avec les charges que l'on trouve dans la presse romande,
en particulier dans L'Arbalète. La revue satirique romande,
opposée à un pouvoir suisse qui serait soumis aux intérêts des
Empires centraux, est créée en juillet I9 I 6, en marge du quotidien
L'autre « grande » affaire est l'affaire Hoffmann-Grimm, traitée plus loin.
Jean-Jacques Langendorf et Peter Streit, Face à la guerre. L'armée et le peuple
suisses 1914-1918/1939-1945, op. cit., p. 102-104.
(" Ich glaube, es wäre am besten, wenn man den Prozess öffentlich durchführte. »
" Ja, warum denn? " Na, weil von den geheimen Militärangelegenheiten in
der Schweiz zuviel in der Öffentlichkeit bekannt wird»); Nebelspalter 1916/9,
couverture de Boscovits junior intitulée « II parle d'expérience » (Er spricht aus
Erfahrung).

la couleur de l'uniforme, ramène l'image entière aux personnages
des militaires. La charge verbale est plus ironique que vraiment
virulente, minimisant une affaire qui fut bien autrement perçue
en Suisse romande, où l'on était déjà excédé par les penchants
germanophiles du commandement Wille. Le traitement de l'affaire
très discret, et pour tout dire assez complice dans le Nebelspalter,
contraste avec les charges que l'on trouve dans la presse romande,
en particulier dans L'Arbalète. La revue satirique romande,
opposée à un pouvoir suisse qui serait soumis aux intérêts des
Empires centraux, est créée en juillet I9 I 6, en marge du quotidien
L'autre « grande » affaire est l'affaire Hoffmann-Grimm, traitée plus loin.
Jean-Jacques Langendorf et Peter Streit, Face à la guerre. L'armée et le peuple
suisses 1914-1918/1939-1945, op. cit., p. 102-104.
(" Ich glaube, es wäre am besten, wenn man den Prozess öffentlich durchführte. »
" Ja, warum denn? " Na, weil von den geheimen Militärangelegenheiten in
der Schweiz zuviel in der Öffentlichkeit bekannt wird»); Nebelspalter 1916/9,
couverture de Boscovits junior intitulée « II parle d'expérience » (Er spricht aus
Erfahrung).

la couleur de l'uniforme, ramène l'image entière aux personnages
des militaires. La charge verbale est plus ironique que vraiment
virulente, minimisant une affaire qui fut bien autrement perçue
en Suisse romande, où l'on était déjà excédé par les penchants
germanophiles du commandement Wille. Le traitement de l'affaire
très discret, et pour tout dire assez complice dans le Nebelspalter,
contraste avec les charges que l'on trouve dans la presse romande,
en particulier dans L'Arbalète. La revue satirique romande,
opposée à un pouvoir suisse qui serait soumis aux intérêts des
Empires centraux, est créée en juillet I9 I 6, en marge du quotidien
L'autre « grande » affaire est l'affaire Hoffmann-Grimm, traitée plus loin.
Jean-Jacques Langendorf et Peter Streit, Face à la guerre. L'armée et le peuple
suisses 1914-1918/1939-1945, op. cit., p. 102-104.
(" Ich glaube, es wäre am besten, wenn man den Prozess öffentlich durchführte. »
" Ja, warum denn? " Na, weil von den geheimen Militärangelegenheiten in
der Schweiz zuviel in der Öffentlichkeit bekannt wird»); Nebelspalter 1916/9,
couverture de Boscovits junior intitulée « II parle d'expérience » (Er spricht aus
Erfahrung).

la couleur de l'uniforme, ramène l'image entière aux personnages
des militaires. La charge verbale est plus ironique que vraiment
virulente, minimisant une affaire qui fut bien autrement perçue
en Suisse romande, où l'on était déjà excédé par les penchants
germanophiles du commandement Wille. Le traitement de l'affaire
très discret, et pour tout dire assez complice dans le Nebelspalter,
contraste avec les charges que l'on trouve dans la presse romande,
en particulier dans L'Arbalète. La revue satirique romande,
opposée à un pouvoir suisse qui serait soumis aux intérêts des
Empires centraux, est créée en juillet I9 I 6, en marge du quotidien
L'autre « grande » affaire est l'affaire Hoffmann-Grimm, traitée plus loin.
Jean-Jacques Langendorf et Peter Streit, Face à la guerre. L'armée et le peuple
suisses 1914-1918/1939-1945, op. cit., p. 102-104.
(" Ich glaube, es wäre am besten, wenn man den Prozess öffentlich durchführte. »
" Ja, warum denn? " Na, weil von den geheimen Militärangelegenheiten in
der Schweiz zuviel in der Öffentlichkeit bekannt wird»); Nebelspalter 1916/9,
couverture de Boscovits junior intitulée « II parle d'expérience » (Er spricht aus
Erfahrung).

la couleur de l'uniforme, ramène l'image entière aux personnages
des militaires. La charge verbale est plus ironique que vraiment
virulente, minimisant une affaire qui fut bien autrement perçue
en Suisse romande, où l'on était déjà excédé par les penchants
germanophiles du commandement Wille. Le traitement de l'affaire
très discret, et pour tout dire assez complice dans le Nebelspalter,
contraste avec les charges que l'on trouve dans la presse romande,
en particulier dans L'Arbalète. La revue satirique romande,
opposée à un pouvoir suisse qui serait soumis aux intérêts des
Empires centraux, est créée en juillet I9 I 6, en marge du quotidien
L'autre « grande » affaire est l'affaire Hoffmann-Grimm, traitée plus loin.
Jean-Jacques Langendorf et Peter Streit, Face à la guerre. L'armée et le peuple
suisses 1914-1918/1939-1945, op. cit., p. 102-104.
(" Ich glaube, es wäre am besten, wenn man den Prozess öffentlich durchführte. »
" Ja, warum denn? " Na, weil von den geheimen Militärangelegenheiten in
der Schweiz zuviel in der Öffentlichkeit bekannt wird»); Nebelspalter 1916/9,
couverture de Boscovits junior intitulée « II parle d'expérience » (Er spricht aus
Erfahrung).

la couleur de l'uniforme, ramène l'image entière aux personnages
des militaires. La charge verbale est plus ironique que vraiment
virulente, minimisant une affaire qui fut bien autrement perçue
en Suisse romande, où l'on était déjà excédé par les penchants
germanophiles du commandement Wille. Le traitement de l'affaire
très discret, et pour tout dire assez complice dans le Nebelspalter,
contraste avec les charges que l'on trouve dans la presse romande,
en particulier dans L'Arbalète. La revue satirique romande,
opposée à un pouvoir suisse qui serait soumis aux intérêts des
Empires centraux, est créée en juillet I9 I 6, en marge du quotidien
L'autre « grande » affaire est l'affaire Hoffmann-Grimm, traitée plus loin.
Jean-Jacques Langendorf et Peter Streit, Face à la guerre. L'armée et le peuple
suisses 1914-1918/1939-1945, op. cit., p. 102-104.
(" Ich glaube, es wäre am besten, wenn man den Prozess öffentlich durchführte. »
" Ja, warum denn? " Na, weil von den geheimen Militärangelegenheiten in
der Schweiz zuviel in der Öffentlichkeit bekannt wird»); Nebelspalter 1916/9,
couverture de Boscovits junior intitulée « II parle d'expérience » (Er spricht aus
Erfahrung).

la couleur de l'uniforme, ramène l'image entière aux personnages
des militaires. La charge verbale est plus ironique que vraiment
virulente, minimisant une affaire qui fut bien autrement perçue
en Suisse romande, où l'on était déjà excédé par les penchants
germanophiles du commandement Wille. Le traitement de l'affaire
très discret, et pour tout dire assez complice dans le Nebelspalter,
contraste avec les charges que l'on trouve dans la presse romande,
en particulier dans L'Arbalète. La revue satirique romande,
opposée à un pouvoir suisse qui serait soumis aux intérêts des
Empires centraux, est créée en juillet I9 I 6, en marge du quotidien
L'autre « grande » affaire est l'affaire Hoffmann-Grimm, traitée plus loin.
Jean-Jacques Langendorf et Peter Streit, Face à la guerre. L'armée et le peuple
suisses 1914-1918/1939-1945, op. cit., p. 102-104.
(" Ich glaube, es wäre am besten, wenn man den Prozess öffentlich durchführte. »
" Ja, warum denn? " Na, weil von den geheimen Militärangelegenheiten in
der Schweiz zuviel in der Öffentlichkeit bekannt wird»); Nebelspalter 1916/9,
couverture de Boscovits junior intitulée « II parle d'expérience » (Er spricht aus
Erfahrung).

la couleur de l'uniforme, ramène l'image entière aux personnages
des militaires. La charge verbale est plus ironique que vraiment
virulente, minimisant une affaire qui fut bien autrement perçue
en Suisse romande, où l'on était déjà excédé par les penchants
germanophiles du commandement Wille. Le traitement de l'affaire
très discret, et pour tout dire assez complice dans le Nebelspalter,
contraste avec les charges que l'on trouve dans la presse romande,
en particulier dans L'Arbalète. La revue satirique romande,
opposée à un pouvoir suisse qui serait soumis aux intérêts des
Empires centraux, est créée en juillet I9 I 6, en marge du quotidien
L'autre « grande » affaire est l'affaire Hoffmann-Grimm, traitée plus loin.
Jean-Jacques Langendorf et Peter Streit, Face à la guerre. L'armée et le peuple
suisses 1914-1918/1939-1945, op. cit., p. 102-104.
(" Ich glaube, es wäre am besten, wenn man den Prozess öffentlich durchführte. »
" Ja, warum denn? " Na, weil von den geheimen Militärangelegenheiten in
der Schweiz zuviel in der Öffentlichkeit bekannt wird»); Nebelspalter 1916/9,
couverture de Boscovits junior intitulée « II parle d'expérience » (Er spricht aus
Erfahrung).
}

la Tribune de Lausanne ${ }^{292}$. L'affaire des colonnels fait la couverture le 5 août, plusieurs mois, donc, après les événements. À la vue des deux militaires, le lion de Lucerne grogne : «Les miens, au moins, avaient tenu leur serment ! ${ }^{293}$.

Nous sommes, ceci dit, en I9I6. Un tournant s'observe. Ce qui est dit et montré avant et après cette date diffère notablement. La position pro-germanique du Nebelspalter, jusque là plutôt discrète, devient manifeste ${ }^{294}$. Cette césure ne peut s'expliquer par la seule reprise du Nebelspalter par l'éditeur germanophile Jean Frey en I9I3, connu, entre autres, pour avoir édité un album du Nebelspalter, destiné à l' "édification » des consciences des pays neutres ${ }^{295}$. Elle procède plutôt d'un glissement progressif de tendance, très probablement en relation avec l'intensification de la propagande allemande dans le pays, mais surtout avec les difficultés croissantes rencontrées par le pays. L'économie suisse subit toujours davantage les conséquences de la guerre économique, encore agravées après la Conférence économique interalliée de Paris en juin I9I6, établissant le blocus de l'Allemagne et des empires centraux ${ }^{296}$. Le chef d'état-major Sprecher émet dans son "Rapport sur la situation militaire de la Suisse au début de l'année I9 6 " (Bericht über die militärische Lage der Schweiz auf Anfang des Jahres I9I6) le constat d'une menace intérieure finalement plus importante que celle d'une agression par les belligérants ${ }^{297}$. La guerre fait, en effet, payer un lourd tribut à la population, souffrant d'une inflation galopante des prix de l'alimentation et des vêtements, de la pénurie de logement ainsi que d'un chômage en forte hausse. En I9 18, l'index général des prix indiquera une augmentation de I00 \% ; un sixième de la population se trouvera dans une situation d'urgence ${ }^{298}$. Au fil des pages, sont dénoncées et déplorées ces difficultés, parfois dans des compositions synthétiques, comme "L'état critique " (Schwierige Lage) de Henrik, où est dénoncé tout à la fois le coût de l'alimentation, du pain, de la viande, du lait, de l'argent et des taxes ${ }^{299}$.

Cette seconde période dénote des inquiétudes accrues quant à l'état de l'Europe. On en appelle incessamment à la raison des uns et des autres afin que puisse se conclure la paix. Dans le chiffon rouge (Das rote Tuch), le taureau des puissances en guerre (Die Kriegführenden Mächte) fonçant sur le chiffon rouge des

Jean-Pierre Chuard, Des journaux et des hommes, Aspects de l'histoire et de l'évolution de la presse en Suisse romande, Lausanne, Cabédita, 1993, p. 191-199.

293 L'Arbalète 1916/4, couverture de Edmond Bille intitulée « Les Pères et les fils III ».

294 À l'exception de Marco Ratschiller qui exclut une germanophilie manifeste et continue, il s'agit d'un point mal estimé dans la littérature, rendant schématiquement compte de la position pro-germanique du Nebelspalter durant la Première Guerre mondiale; Ratschiller, Marco, Bedrohte Schweiz: nationale Selbstbilder, Fremdbilder und Feindbilder in der « Nebelspalter »-Karikatur des 20. Jahrhunderts: eine semiotische Untersuchung, op. cit., p. 80.

25 À partir du numéro 3 de l'année 1913, Jean Frey devient éditeur et imprimeur du Nebelspalter; cf. également Alexandre Elsig, "Propagande allemande et renouveau patriotique: l'enjeu médiatiques des Feuilles suisses du dimanche (1915-1918) », op. cit., p. 66-67.

296 Roman Rossfeld et Tobias Straumann (éd.), Der vergessene Wirtschaftskrieg. Schweizer Unternehmen im ersten Weltkrieg, op. cit., p. 23-28.

${ }^{297}$ Generalstabschef Theophil Sprecher von Bernegg, Gesammelte Schriften (édité par Daniel Sprecher), volume 1, Zurich, 2002, p. 393-406; cité d'après JeanJacques Langendorf et Peter Streit, Face à la guerre. L'armée et le peuple suisses 1914-1918/1939-1945, op. cit., p. 95-96.

${ }_{298}$ Bruno Knobel, Die Schweiz im Nebelspalter. Karikaturen 1875 bis 1914, op. cit., p. 65-66; Jean-Claude Favez (éd.), Nouvelle histoire de la Suisse et des Suisses, op. cit., p. 686; Volker Reinhardt, Geschichte der Schweiz, Munich, Beck, 2006, p. 106; Pierre Renouvin, La crise européenne et la Première Guerre mondiale, Paris, PUF, 1969, p. 344-345; Roman Rossfeld et Tobias Straumann (éd.), Der vergessene Wirtschaftskrieg. Schweizer Unternehmen im ersten Weltkrieg, op. cit., p. 38-45.

299 Nebelspalter 1917/26, dessin pleine page de Henrik intitulé «Situation critique » (Schwierige Lage); sur ce dessin: « 3.1.3. 1914-1921: embrasement et no man's land d'un univers en perdition ». 
To. 9. 42. Jahrgang.

Särich, den 26. Šebruar 1916

Einzelnummer $30 \mathrm{Gls}$.
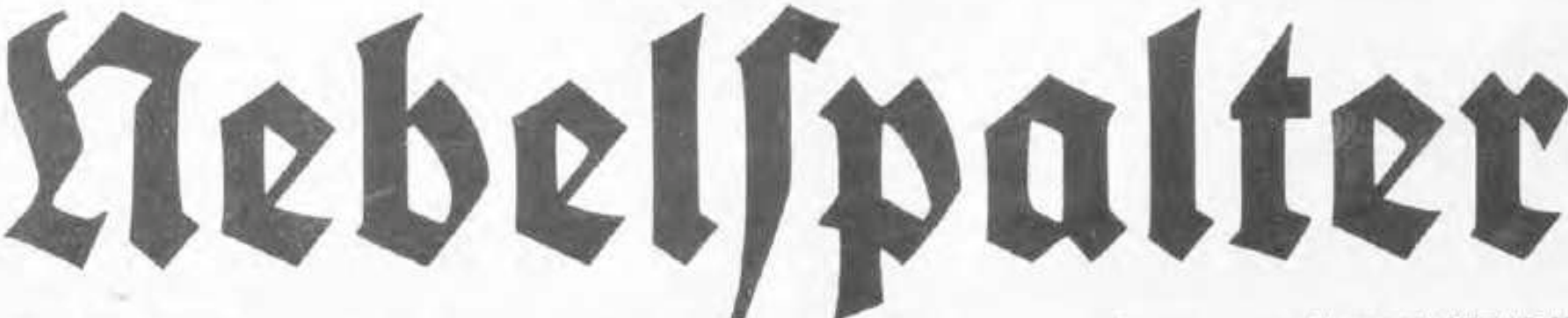

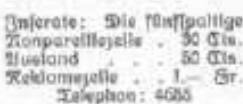

Sumoriftifch-Fatprifche Wochen[chrift

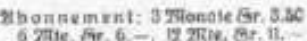

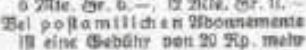
nile Tedite oorbehatien.

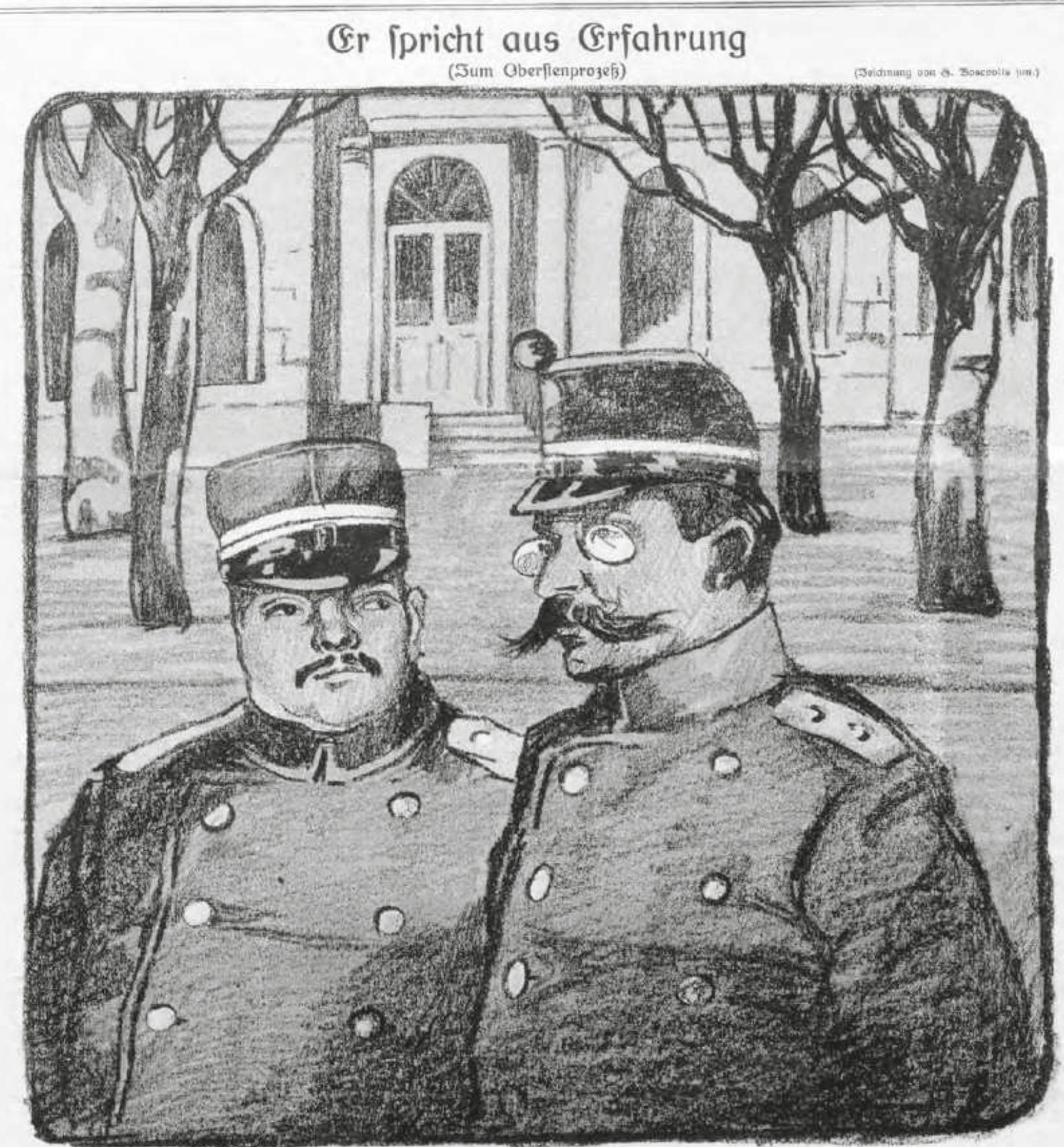

-gd glaube, es roäre am beflen, wenn man den Trozę óffentlich durchführte."

-... Sa, Ioarum denn?"

.2ta, reeil oon den geheimen 2rilitärangelegenheiten in der Gdhroeiz zuviel in der Geffentlichtkit bekannt roird."

Fig. 103. Nebelspalter 1916/9, couverture en couleur de Boscovits junior intitulée « ll parle d'expérience » (Er spricht aus Erfahrung). 
propositions de paix (Friedensvorschläge) n'est pas nommé ${ }^{300}$. La césure idéologique entre la Suisse romande, pro-française et la Suisse alémanique, pro-allemande devient un thème récurrent. En I9I7, Boscovits senior dessine une carte de "La Suisse - Une représentation symbolique " (Die Schweiz. Eine symbolische Darstellung) fonctionnant en miroir ${ }^{301}$ (cf. fig. I04).

Le spectateur est invité à retourner la carte. En haut, un homme en costume, coiffé d'un haut de forme, fume la cigarette, dans une main, une élégante, dans l'autre, une bouteille de vin étiquetée « La Côte ". Sur son écharpe aux couleurs de la Confédération (rouge et blanche), se lit l'inscription "Welsch » ${ }^{302}$; au-dessus de la femme, se lit «Entente ». En bas, un homme en costume, coiffé d'un chapeau mou, tient dans une main un jeu de cartes, dans l'autre un boc de bière. Il fume un cigare. Son écharpe prolonge celle du Welsch mais il y est inscrit "Allemand "(Deutsch); au-dessus de sa bière, on lit "Empires centraux»(Mittelmächte). Pour sa caricature, Boscovits s'appuie sur le motif de la carte à jouer, très présent dans la tendance archaïsante du Jugendstil munichois. Il adapte le motif au contexte suisse, en choisissant la carte du roi du jeu de Jass, une variante du jeu de belote. Les figures représentées sont bien réelles, ce qui n'a pu échapper au spectateur de l'époque. Il s'agit du Président (alémanique) de la Confédération, Edmund Schulthess ainsi que de son Vice-président (romand), Félix-Louis Calonder. Les deux hommes ont des sympathies opposées. L'image, dite symbolique dans son titre, s'appuie également sur une série de clichés culturels : la bière, le vin, les femmes, la cigarette et le cigare. Faut-il comprendre que c'est le Président qui «a les cartes en main » ? L'expression allemande équivalente signifierait plutôt " avoir un atout dans sa manche », littéralement des «cartes cachées " (verdeckten karten). Il est malaisé de savoir quel impact a pu avoir cette image à la réception à présent difficile, dont l'on ne reconnaît plus spontanément les figures. Elle dénote, en revanche, l'adhésion du Nebelspalter à un courant de pensée traversant la société suisse. Une opposition s'est progressivement formée contre les infiltrations étrangères et en faveur d'une identité suisse. Tous les apports exogènes sont concernés, idées comme personnes. Il s'agit des prémices de la notion de défense spirituelle qui se développera dans les années trente, alors qu'on sera en présence de nouvelles flambées propagandistes ${ }^{303}$.

Le périodique reflète également la tentation d'une médiation suisse. L'affaire Grimm-Hoffmann, au retentisssement Grimm, conseiller national, membre dirigeant de la Commission socialiste internationale, se rend à Stockholm, puis à Petrograd, sous le prétexte de préparer le retour des réfugiés russes dans leur pays. Il est en fait secrètement soutenu par le conseiller fédéral Arthur Hoffmann, chef du Département politique, qui agit sans le consentement de ses collègues. Grimm entend préparer une paix international, est ainsi suivie de près. Au printemps I9 I7, Robert

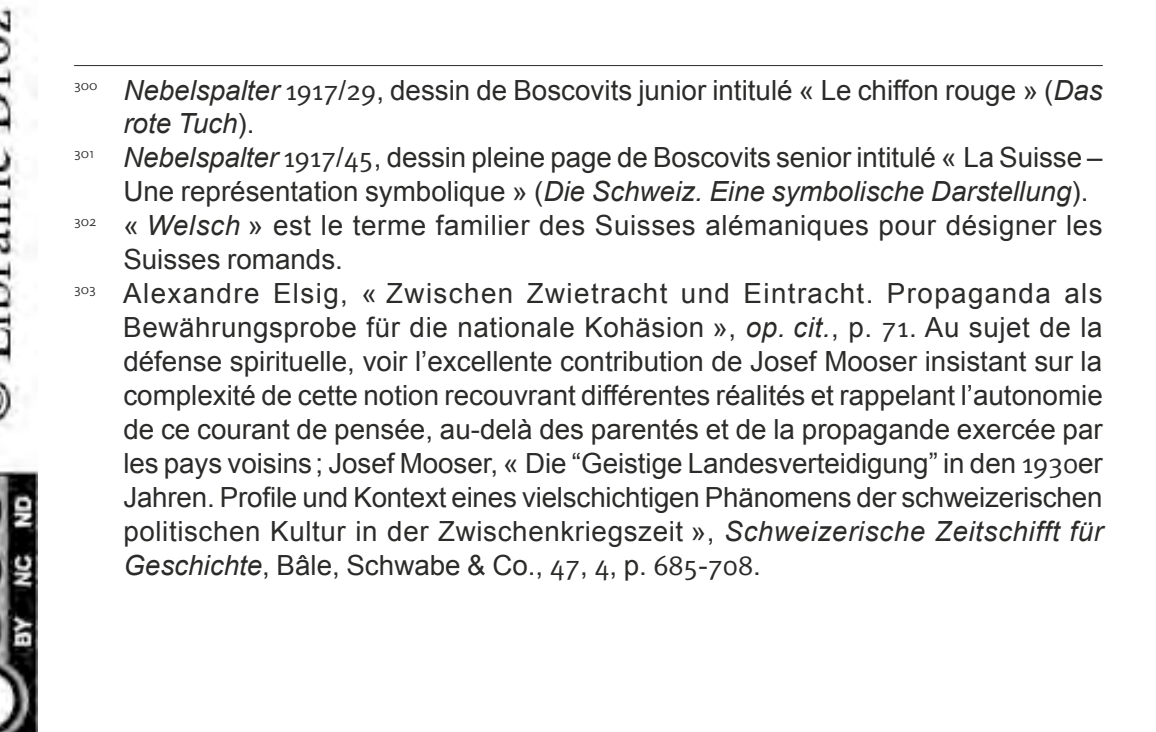

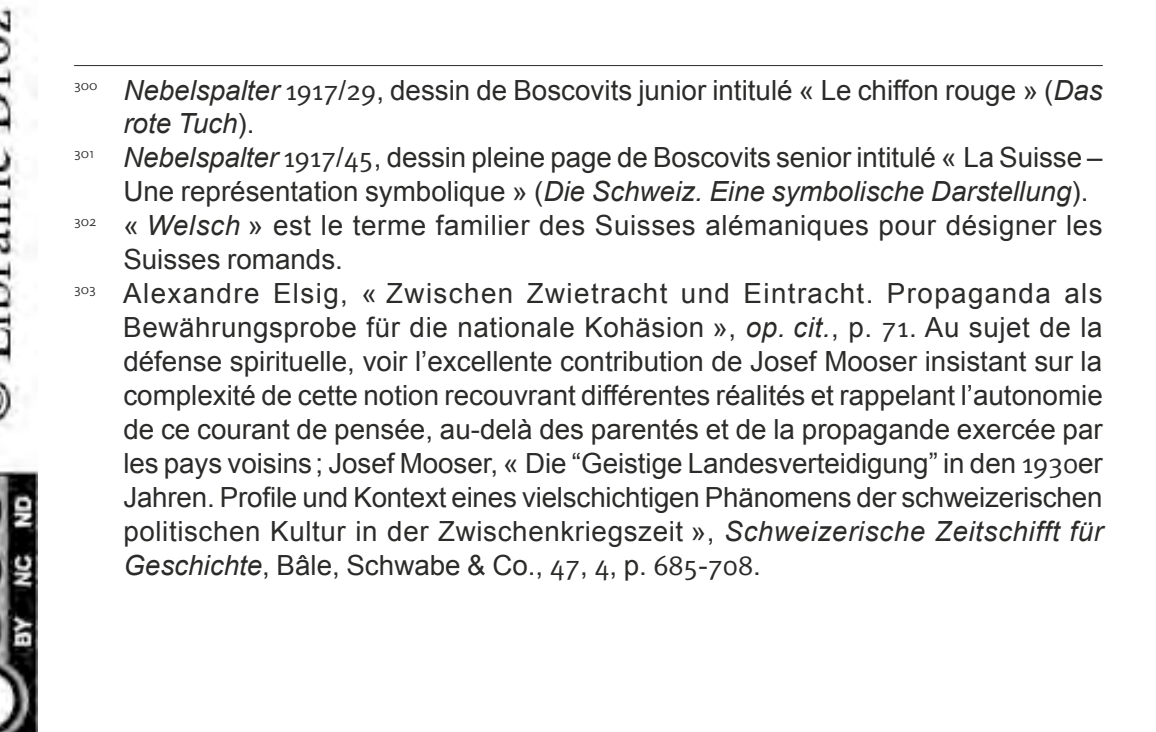

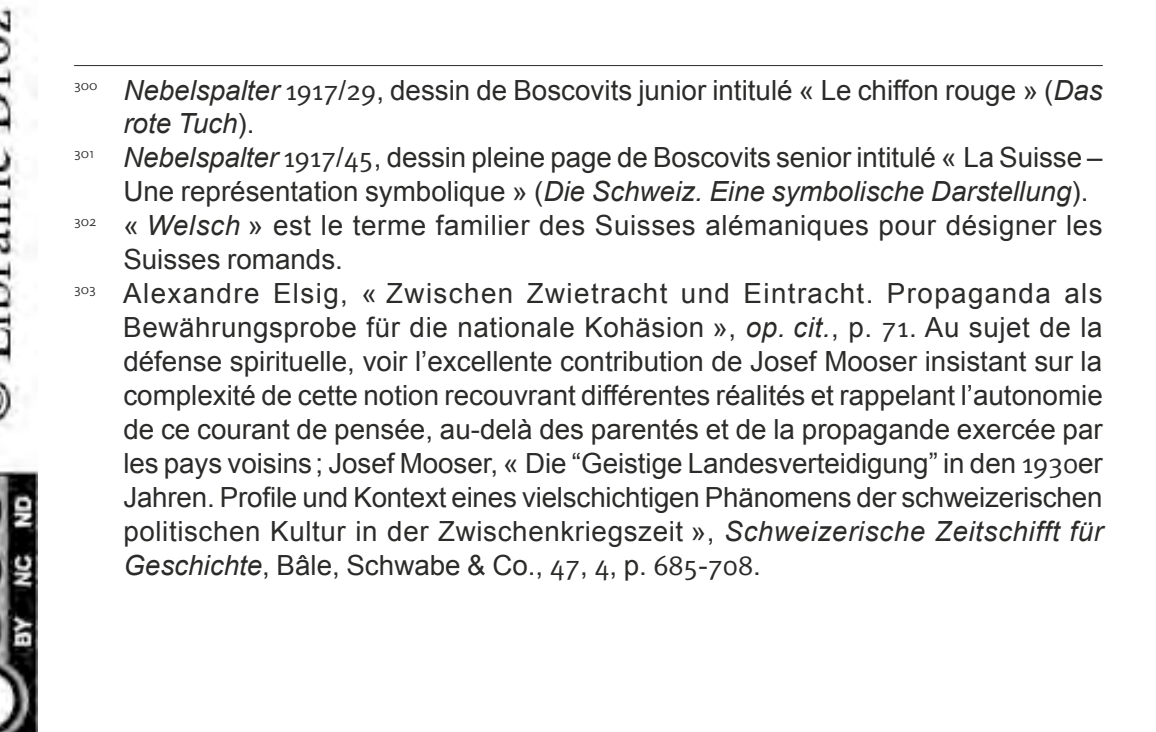

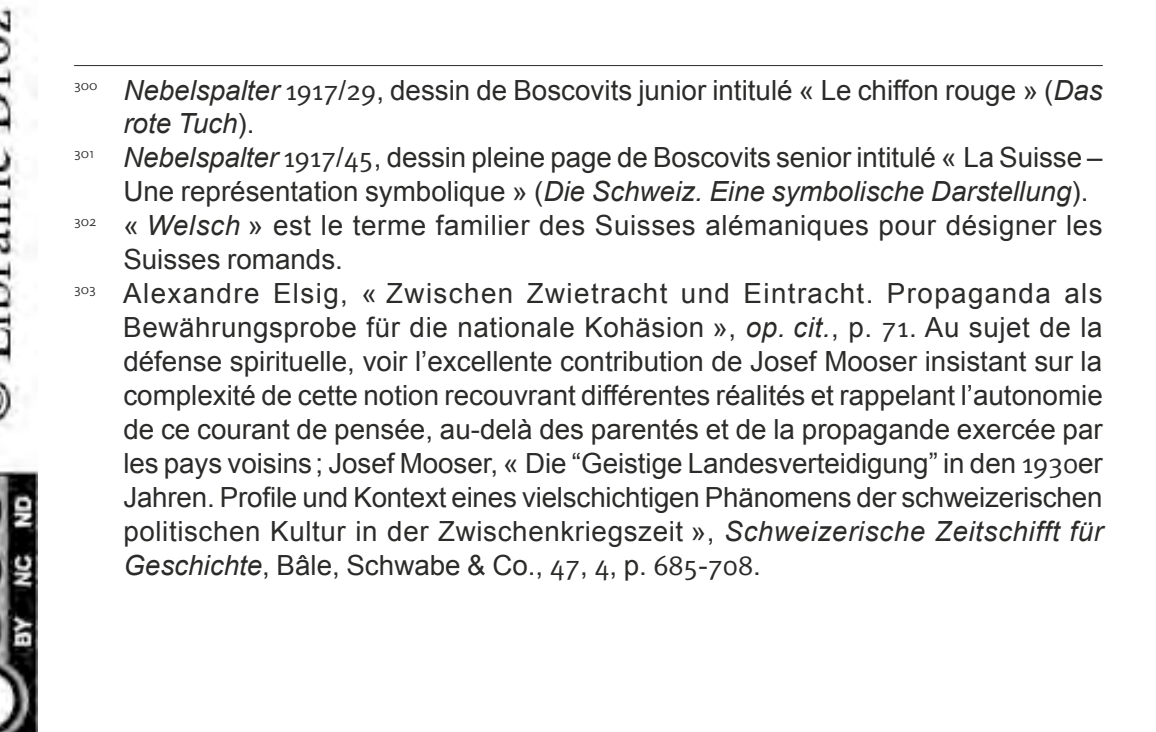

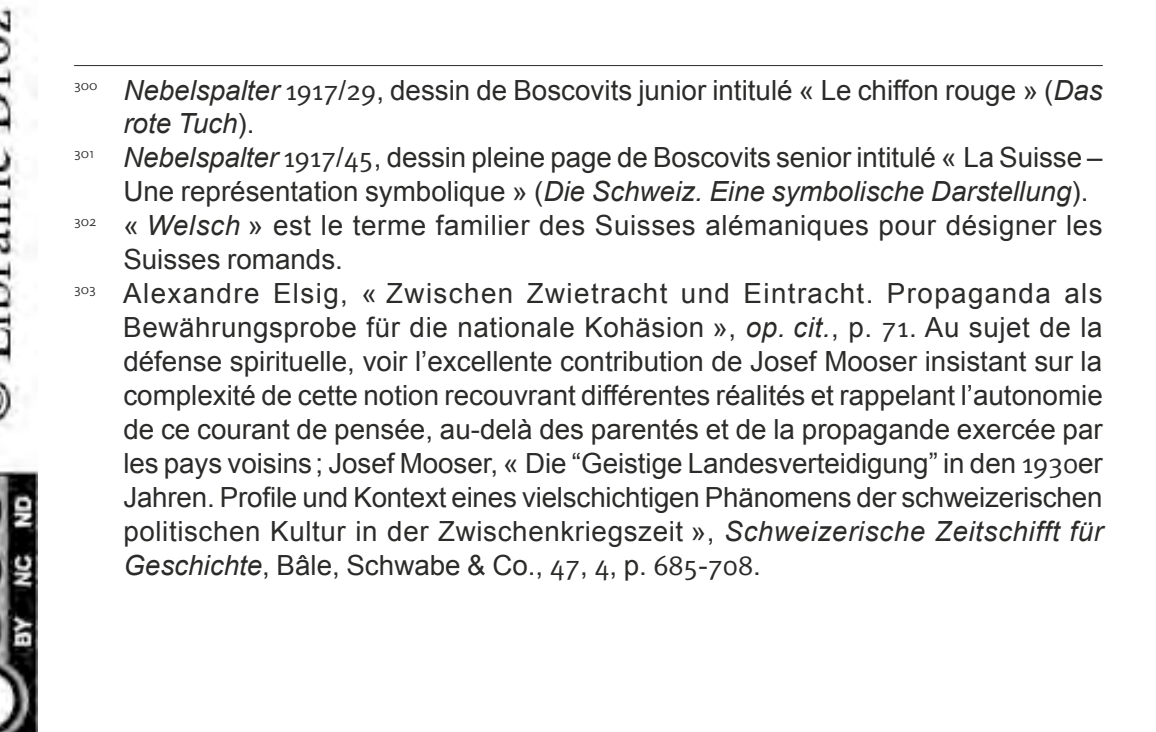

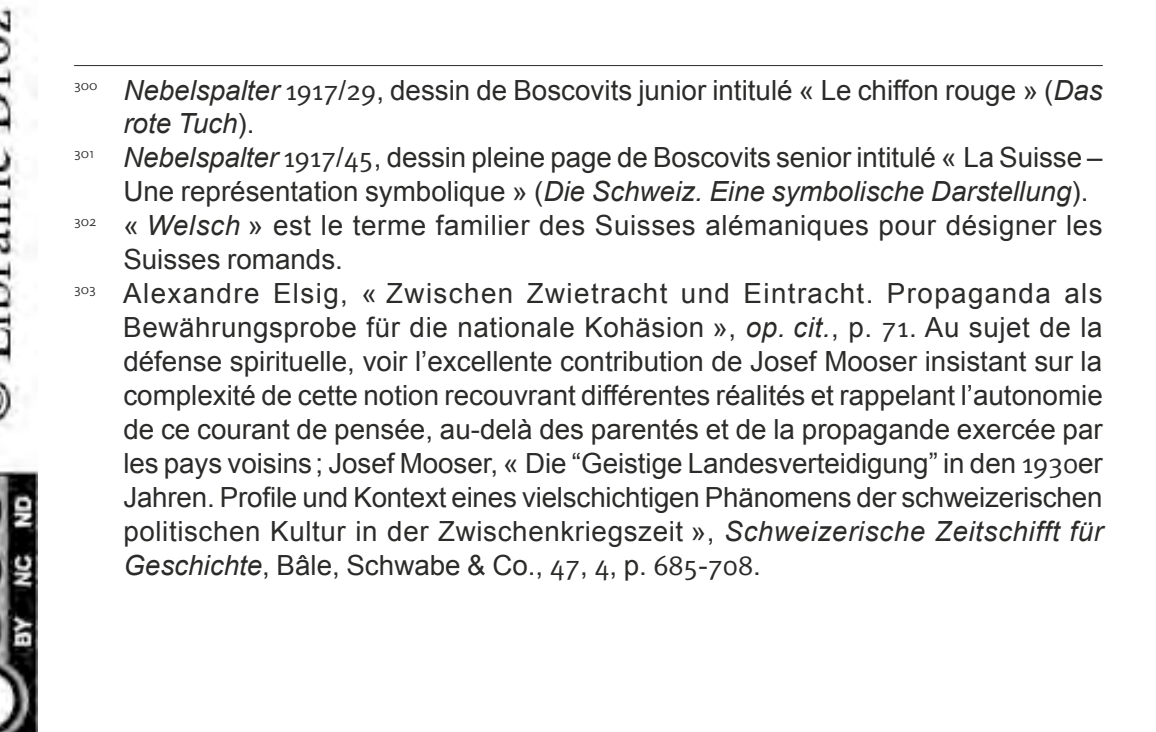

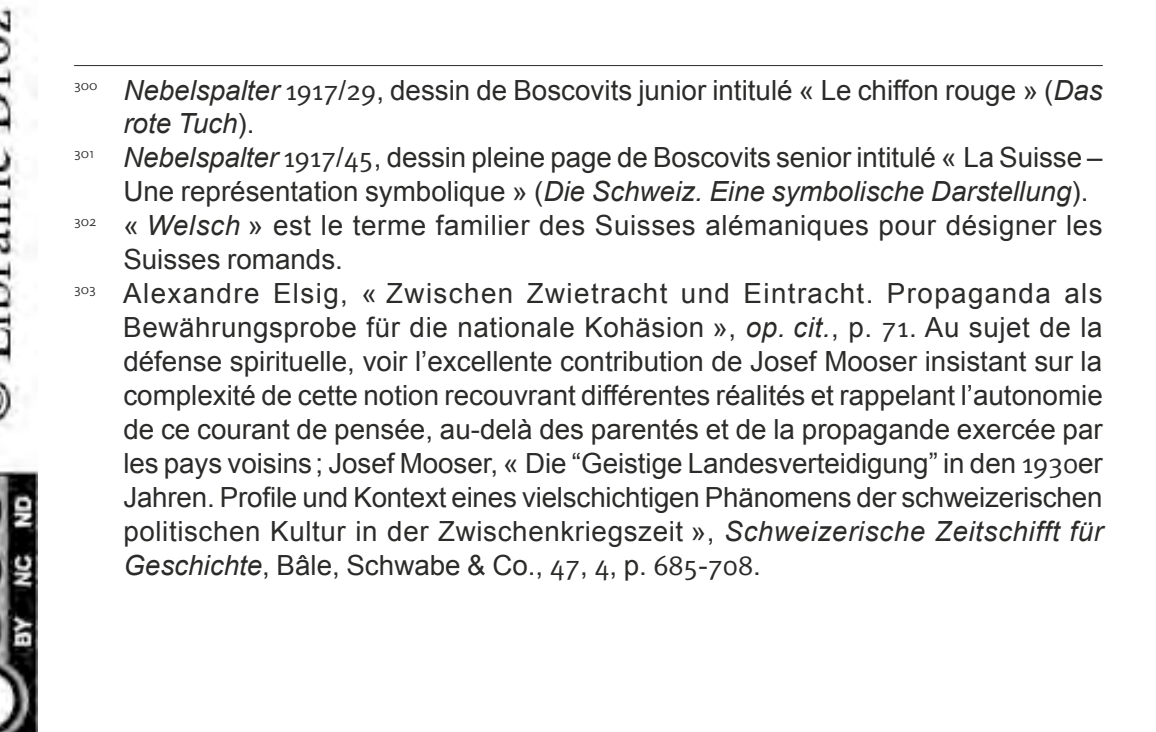

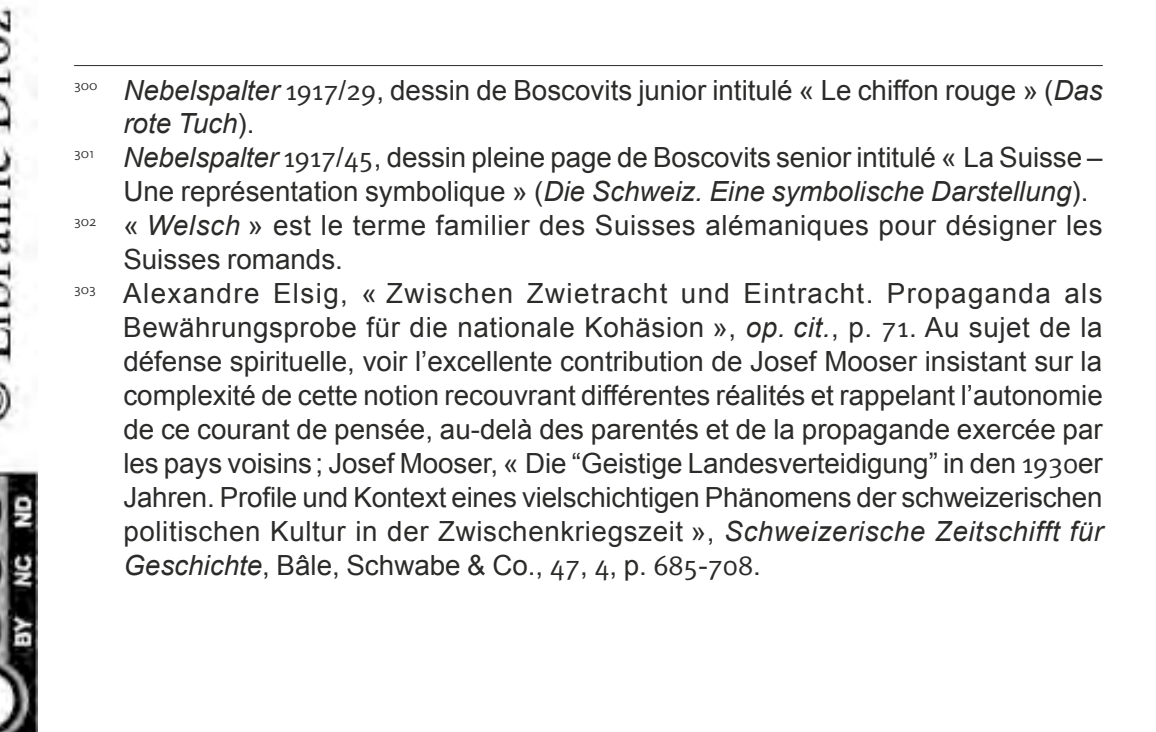

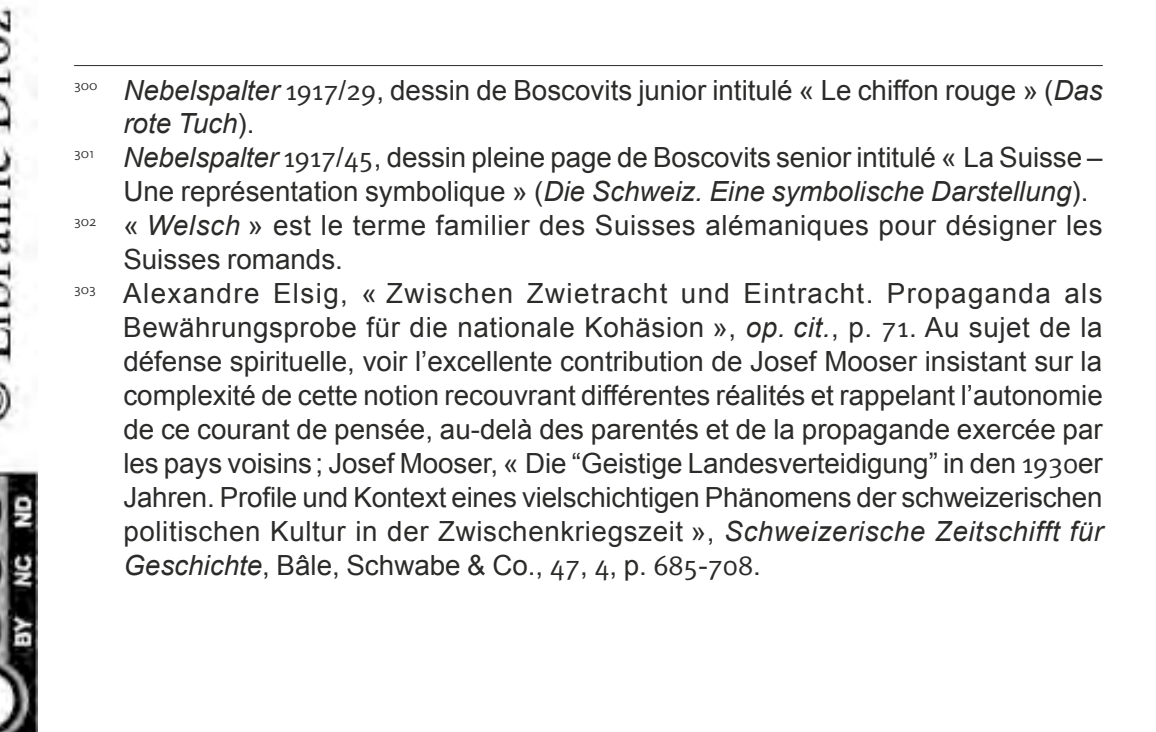

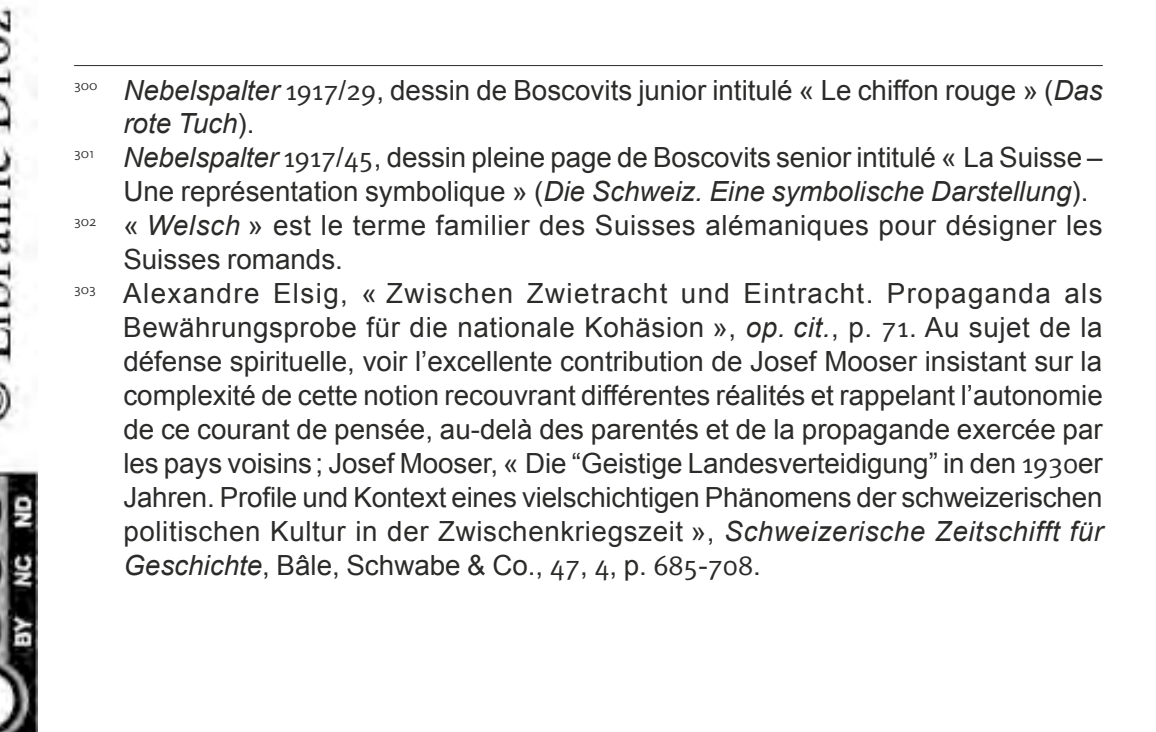

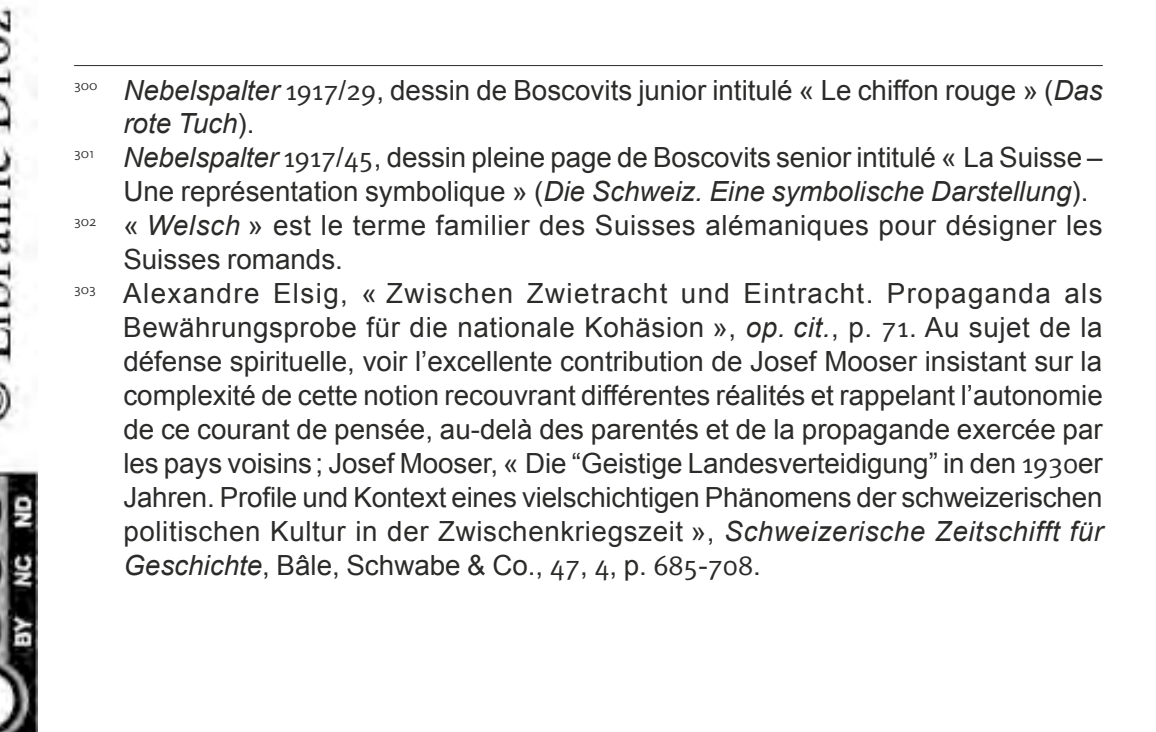

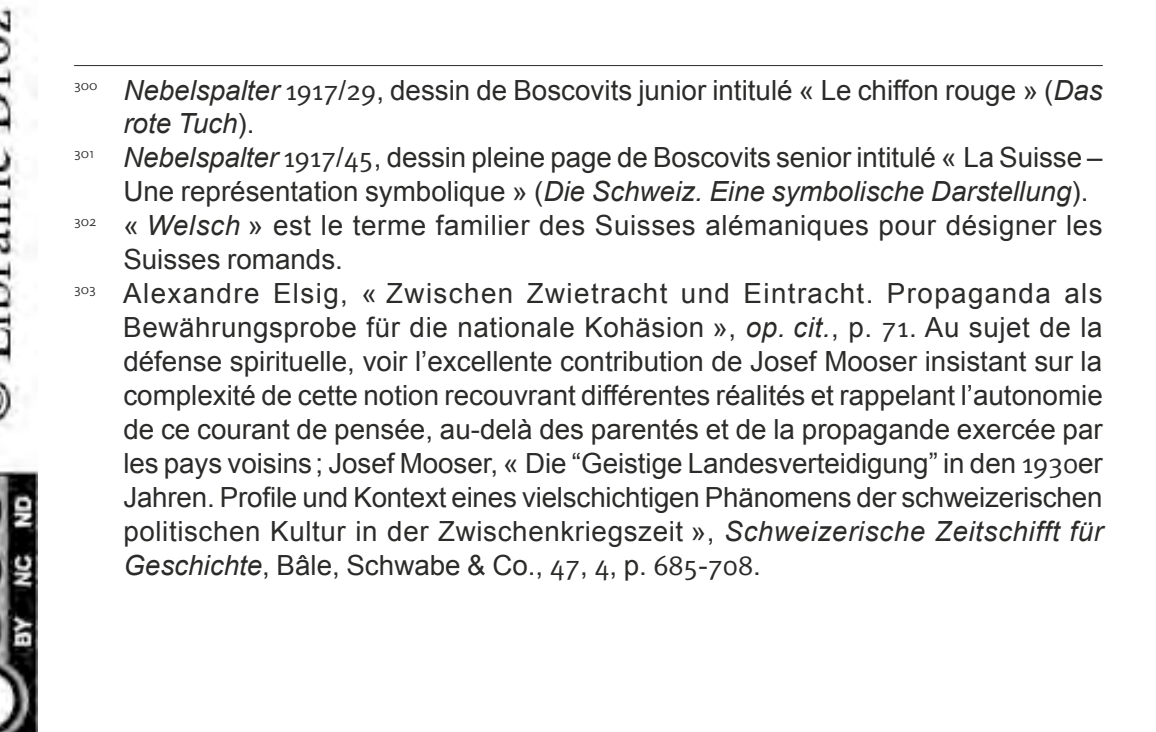

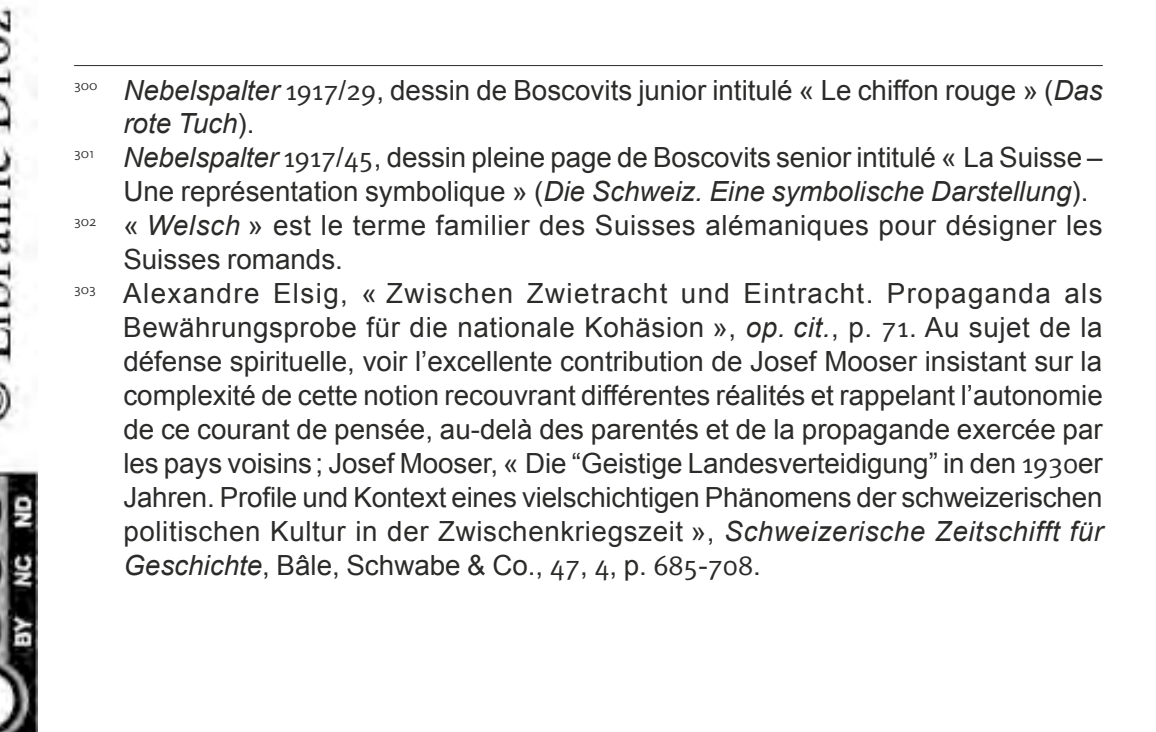

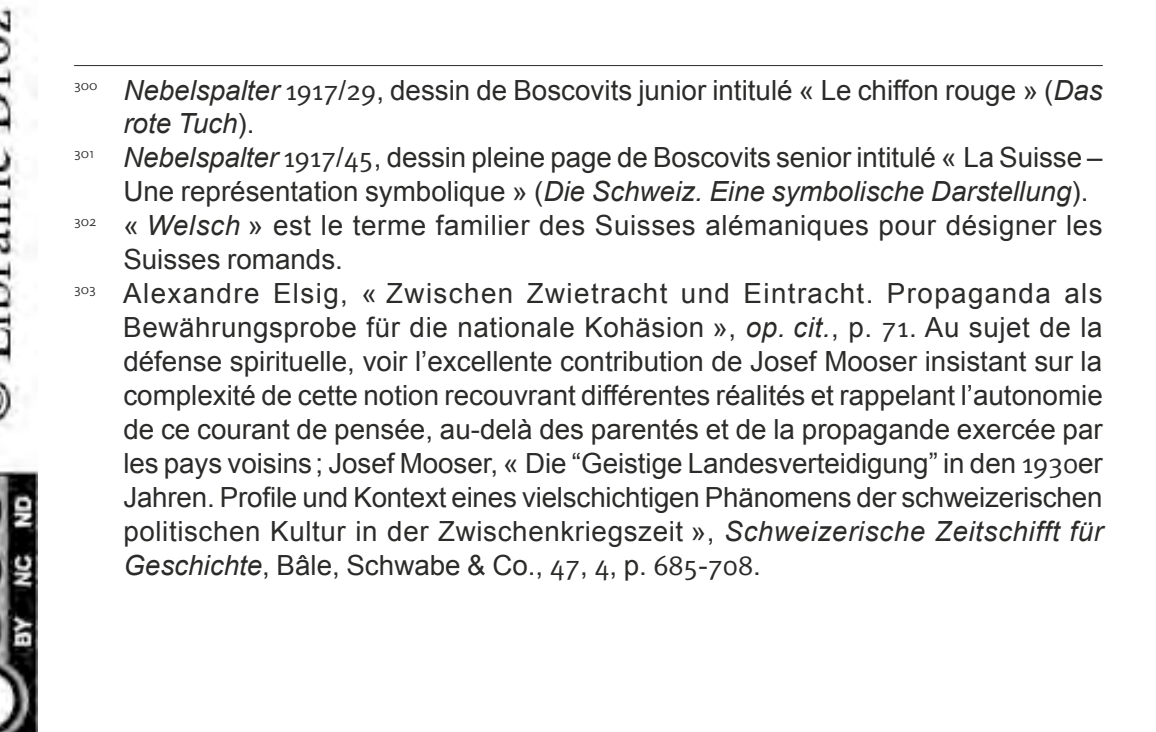

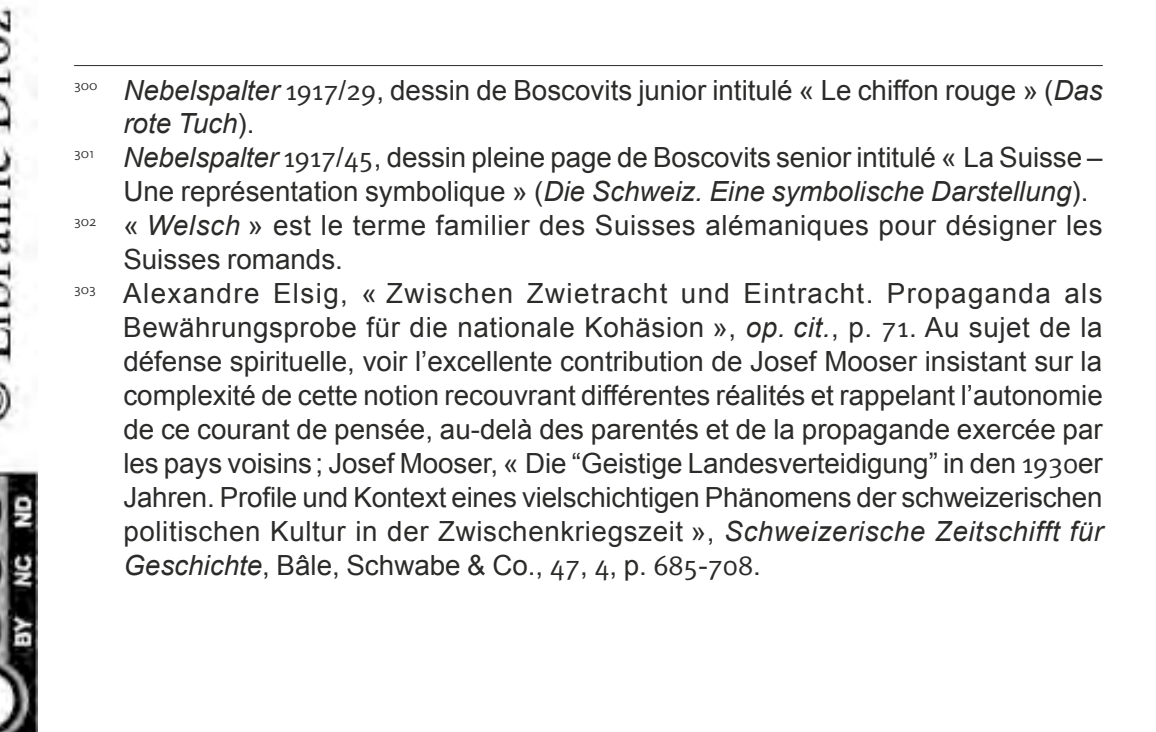

séparée entre l'Allemagne et la Russie, et télégraphie dans ce sens à Hoffmann, le 26 mai. La réponse de Hofmann est interceptée et parvient au ministre français de l'armement, Albert Thomas, en visite à Pétrograd, qui transmet celle-ci au gouvernement provisoire russe. Grimm est prié de quitter immédiatement la Russie. Le I 8 juin, le Conseil fédéral est saisi de l'affaire. Le lendemain, Hoffmann démissionne. Les Alliés voient dans l'initiative suisse une grave entorse à la neutralité et critiquent vivement le pays. L'affaire est très mal perçue en Suisse romande et au Tessin ${ }^{304}$. Le Nebelspalter en fait sa une le 30 juin. Hoffman est représenté à terre, en Achille, une flèche plantée dans son talon marqué de l'inscription "Amour de la paix " (Friedensliebe). La légende du dessin de Boscovits senior, intitulé "HoffmannAchille (Hoffmann-Achilles), est empathique: "C'est le seul endroit où il était vulnérable " ${ }^{305}$. Comme pour l'affaire des colonels, le Nebelspalter montre une bienveillance qui n'est pas partagée par la presse romande. Le numéro du 30 juillet I9I 7 de L'Arbalète ouvre ainsi sur une couverture de Edmond Bille, l'un de ses fondateurs, intitulée très ironiquement "Fleurs et regrets ${ }^{306}$. La motivation de Hoffman était, semble-t-il, de sauver économiquement le pays ${ }^{307}$.

Les conséquences du conflit sont aussi morales. L'inquiétude grandit concernant les facteurs et comportements menaçant l'équilibre social. Des grèves, découlant d'une prolétarisation et d'une radicalisation des ouvriers et des employés, se délenchent courant I9I 8 en plusieurs endroits du pays ${ }^{308}$. Elles sont l'objet d'un traitement ambigu, une ironie parfois très critique. " La liberté, telle qu'ils l'entendent (sur les manifestations zurichoises du I 4 juin) » (Freiheit, die sie meinen! [Zu den Zürcher Strassendemonstrationen vom I4. Juni]), un titre sériel connoté négativement, est une condamnation sans appel des débordements de rue ${ }^{309}$. La charge des profiteurs vire à l'obsession et devient le premier thème des affaires intérieures. Au début de l'année I9I 8 , une composition signée du Nebelspalter, fait devenu rare, résume l'état de la Suisse après quatre années de guerre. La nouvelle apparence de la monnaie (Das neue Münzbild) - un symbole qui en dit long sur les composantes de l'identité nationale - présente les nouvelles images du pays: le parangon du dernier Suisse, indiqué comme fragile; le révolutionnaire; le gouvernement fédéral accompagné d'un point d'interrogation; la neutralité qui n'a pas empêché les divisions entre les partisans de la France et de l'Allemagne, lesquels s'invectivent dans le bas de l'image ( "Sale Boche! Chaibe Welsche» [sale romand]); le profiteur qui révise la devise suisse en un «Un pour tous, tout pour un » (Einer für Alle. Alle(s) für einen $)^{310}$. La revue réserve enfin une part importante aux affaires intérieures, éloignées de la guerre. Il importe de réaffirmer que l'on reste en dehors de la tourmente mondiale.

Catherine Guanzini, « Grimm-Hoffmann, affaire », Dictionnaire historique de la Suisse (17/07/2007): http://www.hls-dhs-dss.ch/textes/f/F17333.php.

305 (Es war die einzige Stelle, an der er verwundbar war.); Nebelspalter 1917/26, dessin de Boscovits senior intitulé « Le talon d'Achille d'Hoffmann » (HoffmannAchilles).

306 L'Arbalète 1917/1, couverture de Edmond Bille intitulée « Fleurs et regrets ».

307 Catherine Guanzini, « Grimm-Hoffmann, affaire », op. cit.

${ }_{308}$ Roman Rossfeld et Tobias Straumann (éd.), Der vergessene Wirtschaftskrieg Schweizer Unternehmen im ersten Weltkrieg, op. cit., p. 43-44; Thomas Buomberger, "Rhétorique de combat, peur de la révolution et gardes civiques. La grève générale de novembre 1918 », dans 14/18. La Suisse et la Grande Guerre, op. cit., p. 336-365; Sacha Zala, « Krisen, Konfrontation, Konsens (1914-1949) », dans Die Geschichte der Schweiz, op. cit., p. 498-500.

309 Nebelspalter 1918/25, dessin de Boscovits junior intitulé «La liberté, telle qu'ils l'entendent (sur les manifestations zurichoises du 14 juin) » (Freiheit, die sie meinen! [Zu den Zürcher Strassendemonstrationen vom 14. Juni]).

310 Nebelspalter 1918/12, dessin pleine page non signé intitulé « La nouvelle apparence de la pièce de monnaie » (Das neue Münzbild). 
Die Gchroei3

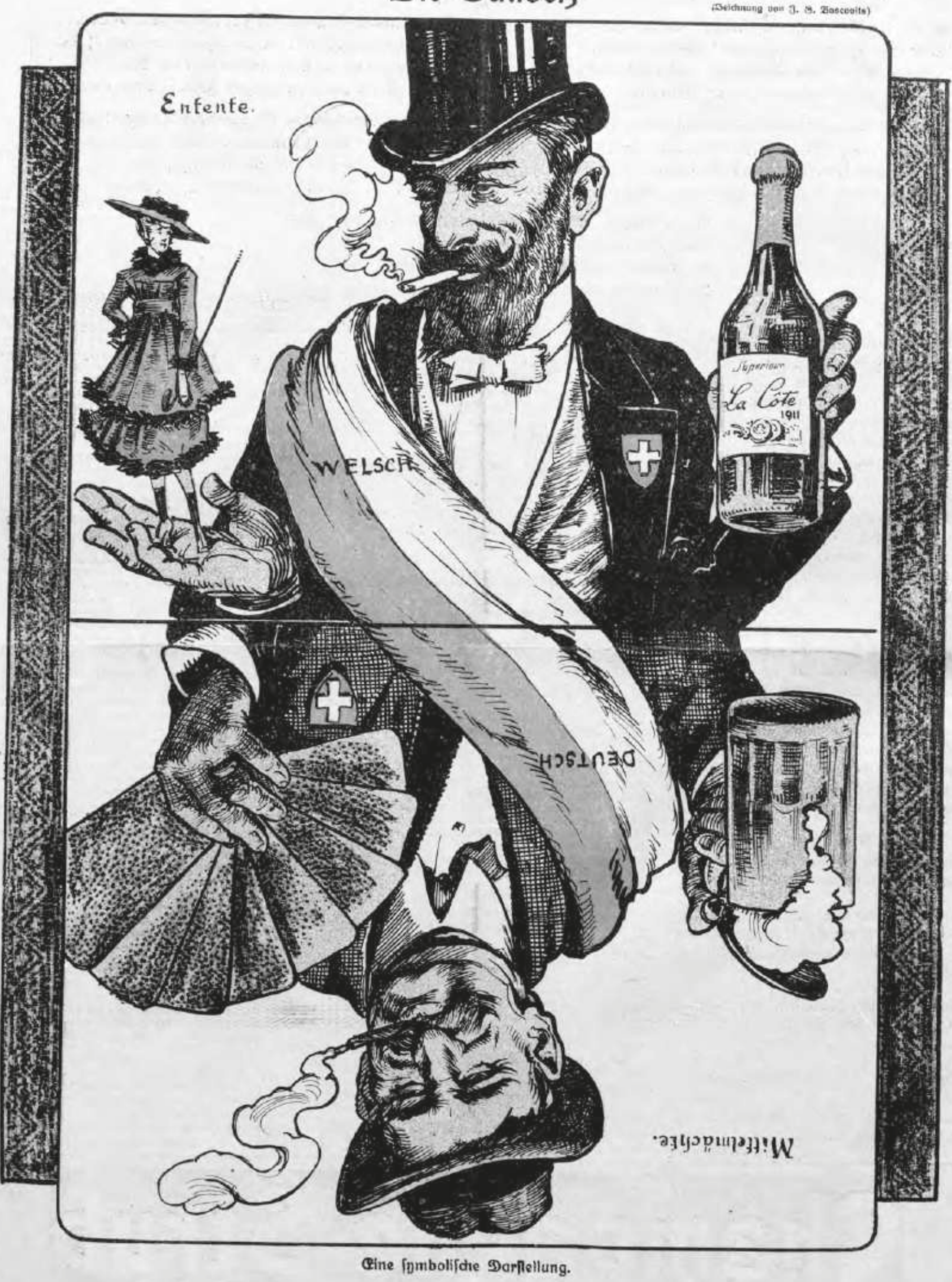

Fig. 104. Nebelspalter 1917/45, dessin pleine page en couleur de Boscovits senior

intitulé «La Suisse - Une représentation symbolique » (Die Schweiz. Eine symbolische Darstellung). 
44. Jahrgang. To. 45.
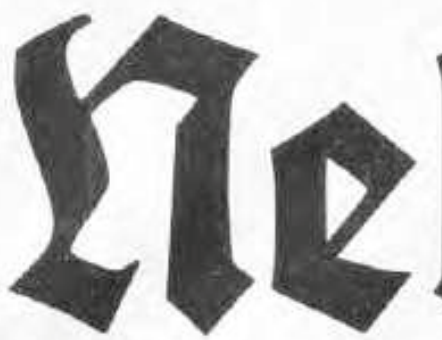

Zürich, den 9. Tovember 1918.

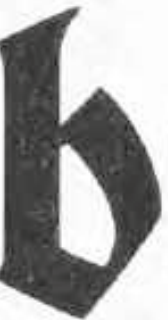

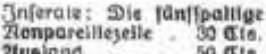

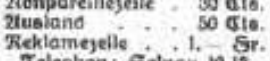

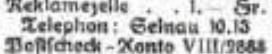

Einzelnummer $30 \mathrm{Cts}$.

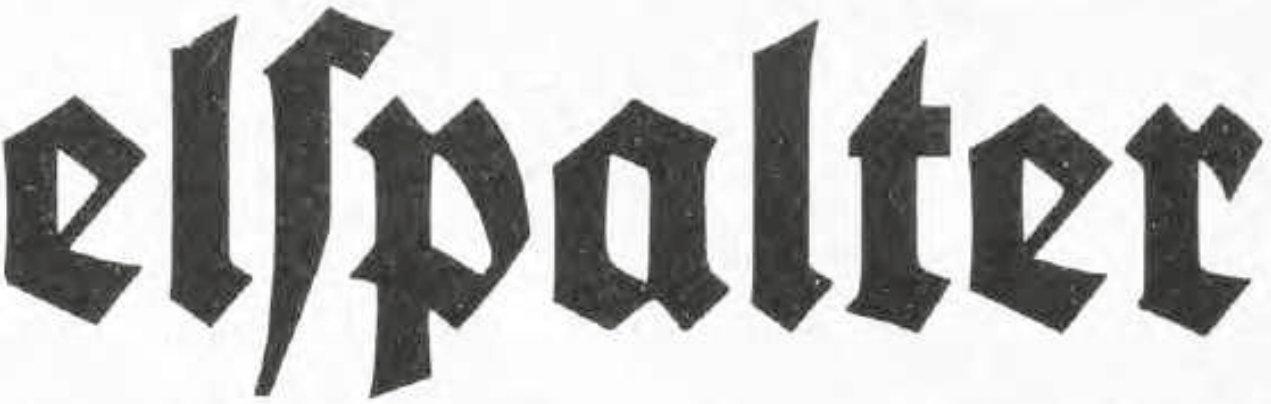

24 6 onnement: 0 Thonaie $\mathrm{Sr}, 3.5 \mathrm{~S}$

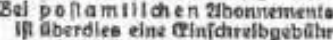

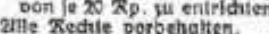

3

\section{Ante portas.}

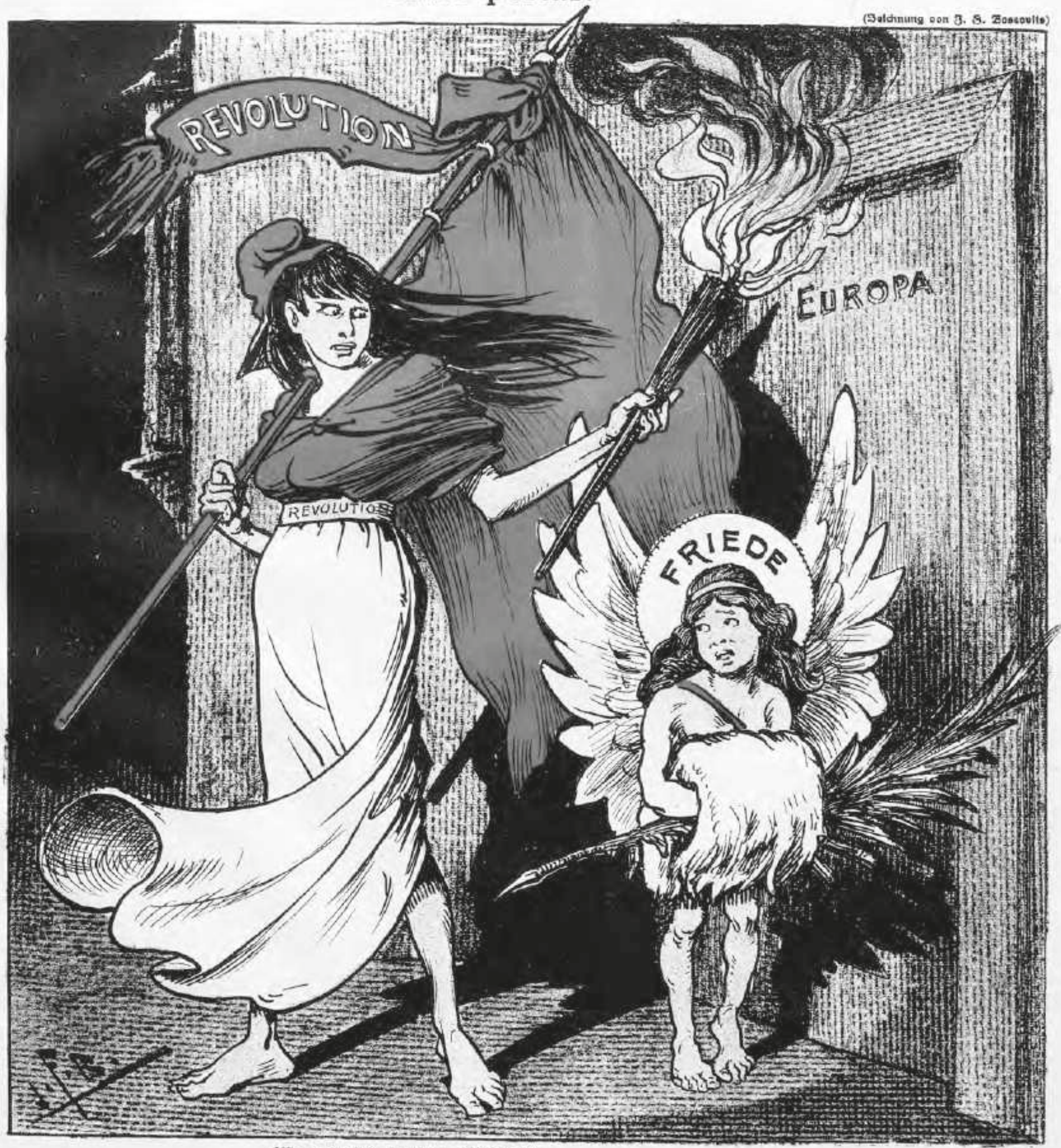

„20as machlt du hler, Kleiner?"

..2Ttich friept; ich pehe fachon fo lange oor der Iüre....

.Jch auch! Jah roill eudh fohon roarm machen." 
Bien des compositions du Nebelspalter sont cependant moins nettes idéologiquement, et d'une efficacité visuelle incertaine. La dernière couverture de la guerre, datée du 9 novembre I9I8, intitulée «Ante Portas », en est un exemple. "Que fais-tu là petit ? - J'ai froid, cela fait si longtemps que j'attends devant la porte. Moi aussi, je veux vous chauffer ${ }^{311}$ (cf. fig. I05).

Tel est l'échange entre un petit ange de la paix misérable et un peu ridicule, et une jeune femme flamboyante. La femme tient d'une main l'étendard de la révolution, de l'autre, un flambeau. Elle a un petit air de La liberté guidant le peuple de Delacroix ${ }^{312}$. Il s'agit cependant de la Révolution (Revolution), selon l'inscription sur sa ceinture. La porte devant laquelle tous deux attendent est celle de l'Europe. L'ombre de la femme ainsi que la fumée que dégage la torche forment une masse sombre, auprès de laquelle l'ombre du petit Friede - l'allégorie allemande de la paix - est bien ténue. Le titre de l'image est une référence au télégramme envoyé le 3 I juillet I9I 4 par le chef d'état-major de l'armée allemande, le général von Moltke, au chef d'état-major suisse, Théophile Sprecher von Bernegg, en raison d'un accord secret entre les deux hommes, passé en I9I2. Moltke devra prévenir Sprecher de l'imminence d'une déclaration de guerre ${ }^{313}$. Le dessinateur remploie ici une formule diplomatique mettant en évidence les liens entre la Suisse alémanique du Nebelspalter et les puissances centrales. Il s'agit d'alerter sur le danger d'une révolution mondiale, introduit par une guerre quasi perdue. Le leitmotiv, développé les années précédentes en relation avec la condamnation du socialisme, sera repris à n'en plus finir les années suivantes ${ }^{314}$. Un décor architectonique, comme on n'en voit plus guère dans les revues à cette époque, forme le fond de la scène. L'une des deux allégories, Friede, est ancienne, tandis que l'autre, la Révolution, a été récemment forgée. Cette image mêlant archaïsme et modernité résume l'économie visuelle et idéologique du Nebelspalter des années de guerre.

\subsubsection{Rire en guerre}

L'encart informant le lectorat des raisons de la suspension de la publication déplore également un manque général d'inclination au rire, nécessaire à la lecture d'une "littérature humoristique " (bumoristische Literatur) ${ }^{315}$. La guerre et le rire ne font pas bon ménage; l'évidence est ici rappelée. Impossible, cependant, pour une revue satirique de renoncer à cette composante identitaire. Qu'il y ait plusieurs rires est chose connue, comme l'est aussi le potentiel de désacralisation du rire ${ }^{316}$. Or, la guerre est « chose sacrée ", par respect des morts, et vertu patriotique, deux valeurs intégrées par le Nebelspalter. L'équation du rire est, en fait, résolue par la distance vis-à-vis de l'objet. Mais celle-ci va se modifier au fil du temps. Au début de la guerre, le choix est fait de ne rire que de ce qui ne concerne pas la guerre. En soi, cela montre la difficulté, formelle, psychique et morale, pesant sur la représentation de la guerre. Très vite, cependant, des thèmes et figures « risibles ", liés à la guerre émergent. Ceux-ci sont de quatre types: l'autodérision d'un pays qui joue à la guerre sans la faire; la charge de

\footnotetext{
" ("Was macht du hier, Kleiner? " " Mich friert; ich stehe schon so langer vor der Türe... ». "Ich auch! Ich will auch euch schon warm machen. »); Nebelspalter 1918/45, couverture en couleur de Boscovits senior intitulée « Ante Portas ».

Eugène Delacroix, La liberté guidant le peuple, 1830, Paris, musée du Louvre.

313 Jean-Jacques Langendorf et Peter Streit, Face à la guerre. L'armée et le peuple suisses 1914-1918/1939-1945, op. cit., p. 82-84.

314 Pour une vue plus objective de l'instabilité générée par la guerre: Sönke Neitzel, Weltkrieg und Revolution. 1914-1918/19, Berlin, Be.bra Verlag, 2008.

Nebelspalter 1914/30, encart.

316 Henri Bergson, Le rire - Essai sur la signification du comique, Paris, Presses Universitaires de France, 1956.
}

personnages historiques servant d'épouvantails; la dépréciation de types ne pouvant susciter l'empathie; les absurdités d'une bêtise universelle. Vers la fin de la guerre, la guerre ne prêtant décidément plus à rire, on s'en retourne au choix initial des seules affaires intérieures.

Le thème de la Suisse en guerre est une manne pour les humoristes qui en font une guerre d'opérette. Jusqu'au début de I9 16, il s'agit du thème préféré des dessinateurs, d'autant que l'armée fait partie des cibles d'élection, comme c'est le cas pour nombre de revues satiriques de l'espace européen. Tant le soldat que l'armée en général sont l'objet de moqueries, avec toutefois une limite posée par une sorte de "tabou patriotique ", lié au processus de construction identitaire de la Suisse après la Constitution de I 874. Dans l'iconographie satirique, l'armée est ainsi une entité vague $^{317}$ et, sauf scandale, dont la fameuse affaire des colonels, les gradés sont épargnés. Le second semestre de I9I4 est émaillé de compositions où l'on voit les soldats, soit jouer à la guerre comme dans "Le perpétuel exercice » (Der ewige Übung), soit tirer un mâle bénéfice de leur uniforme, comme dans "Congé " (Urlaub), dessin néo-Jugendstil en noir et rouge, où des soldats sont accueillis par des baisers devant une croix helvétique ${ }^{318}$. Dans l'imagerie des cartes postales, le sujet est bien plus sérieux ${ }^{319}$.

Lors des premiers mois de guerre, on rit franchement de la neutralité. Un chérubin s'entretient avec saint Pierre dans " La neutralité dans les cieux " (Die Neutralität im Himmel) : "Que fait-on maintenant qu'on a prescrit la victoire à tous les peuples? - On a raccroché le téléphone " ${ }^{320}$. Dans « La journée d'un neutre strict " (Tagesordnung eines streng Neutralen), un personnage plutôt bonhomme se sustente en lisant successivement le Times, Le Figaro et la Berliner Zeitung, avant de s'attaquer, une fois dans son lit, aux titres suisses (allemands), le Züricher Post, la Neue Zürcher Zeitung et Der Bund ${ }^{221}$ (cf. fig. I06).

Rire de la neutralité est une manière d'y souscrire, puisque l'on montre ainsi qu'avec elle, le rire est préservé. Le rire se grippe cependant dès l'automne I9I4 lorsque les conséquences de la guerre commencent à peser sur la population: la neutralité n'est plus ressentie comme protectrice. L'autruche de Boscovits senior, marquée de la croix suisse et de l'inscription "Confédération" (Eidgenossenschaft), plonge la tête dans le tas de sable de la "neutralité " (Neutralität) ${ }^{322}$. La césure idéologique entre la Suisse romande et la Suisse alémanique, résultat de cette neutralité improbable, constitue une source d'inquiétude, déclenchant un rire rare et grinçant. Dans « Le lien suisse-romand ", rien ne prête à rire dans l'image et certainement pas son modèle, L'unanimité de Ferdinand Hodler (I9I3), l'œuvre d'un peintre ayant pris parti un an plus tôt pour les Alliés en condamnant les bombardements

\footnotetext{
Philippe Kaenel et François Vallotton, « Représenter la guerre en Suisse: Du soldat au général », op. cit., p. 11-16.

8 Respectivement: Nebelspalter 1915/2, dessin pleine page de Emil Huber intitulé "Le perpétuel exercice » (Der ewige Übung); Nebelspalter 1914/38, dessin pleine page de Max S. intitulé « Congé » (Urlaub)

Georg Kreis, Schweizer Postkarten aus dem Ersten Weltkrieg, op. cit., p. 136-137.

320 ("Was machen wir nun, wo wir von allen Völkern um Siege angehalten werden?" "Wir haben das Telephon abgehängt! »); Nebelspalter 1914/34, couverture de Boscovits junior intitulée « La neutralité dans les cieux » (Die Neutralität im Himmel).

${ }^{321}$ Nebelspalter 1914/36, dessin pleine page de Boscovits junior intitulé « La journée d'un neutre strict » (Tagesordnung eines streng Neutralen).

${ }_{322}$ Nebelspalter 1914/40, couverture de Boscovits senior intitulée " Neutralité » (Neutralität)
} 


\section{Tagesordnung eines ftreng 2leutralen}

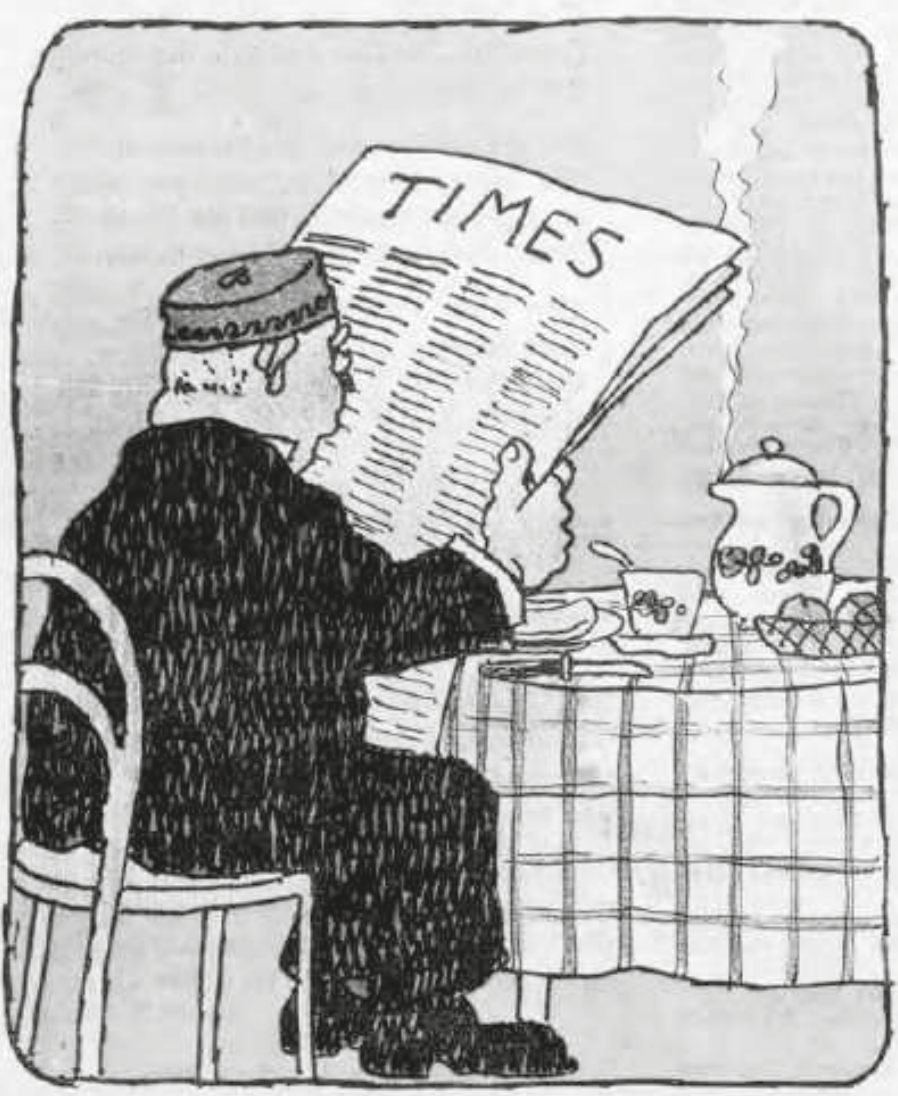

1. 2Torgens: Beefleak (engl.), ruffifder Zee. „Simes".

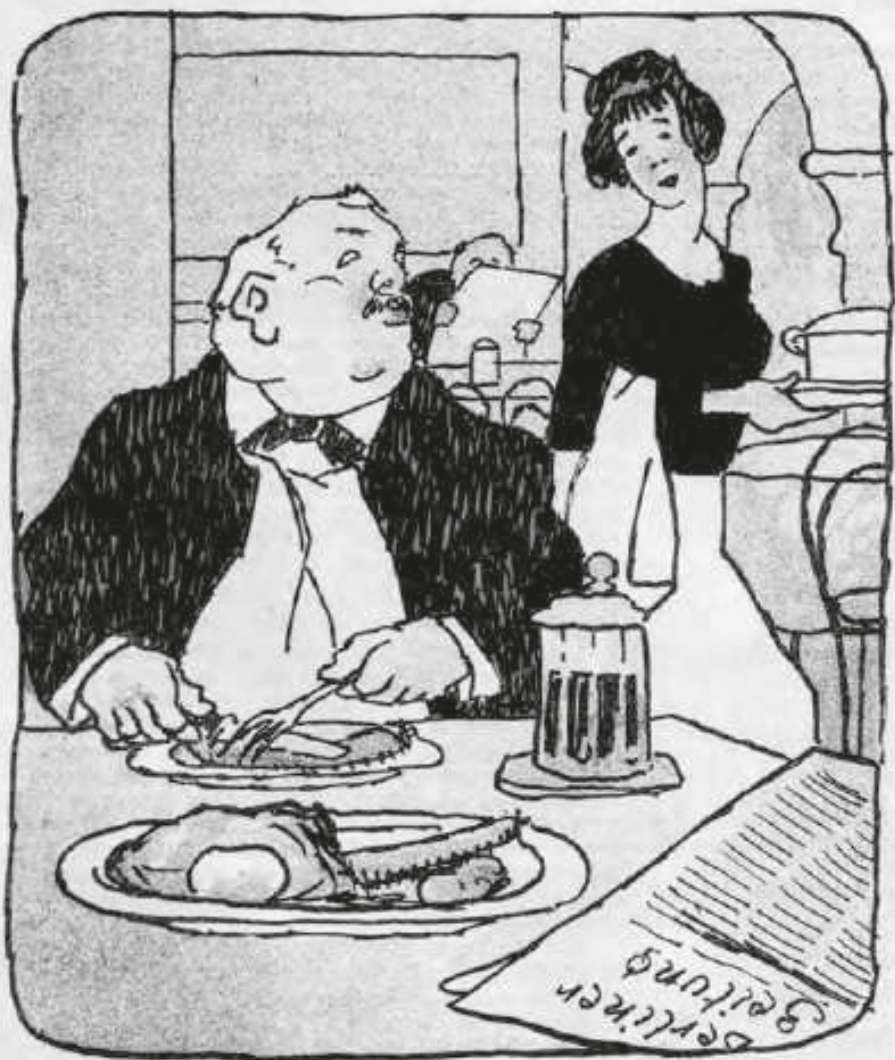

3. 2Ubends: 8rankfurterli oder 2Bienerli (echit) mit Gauerkraut. 2Ranctner Bier. _Berliner Iageblatt-

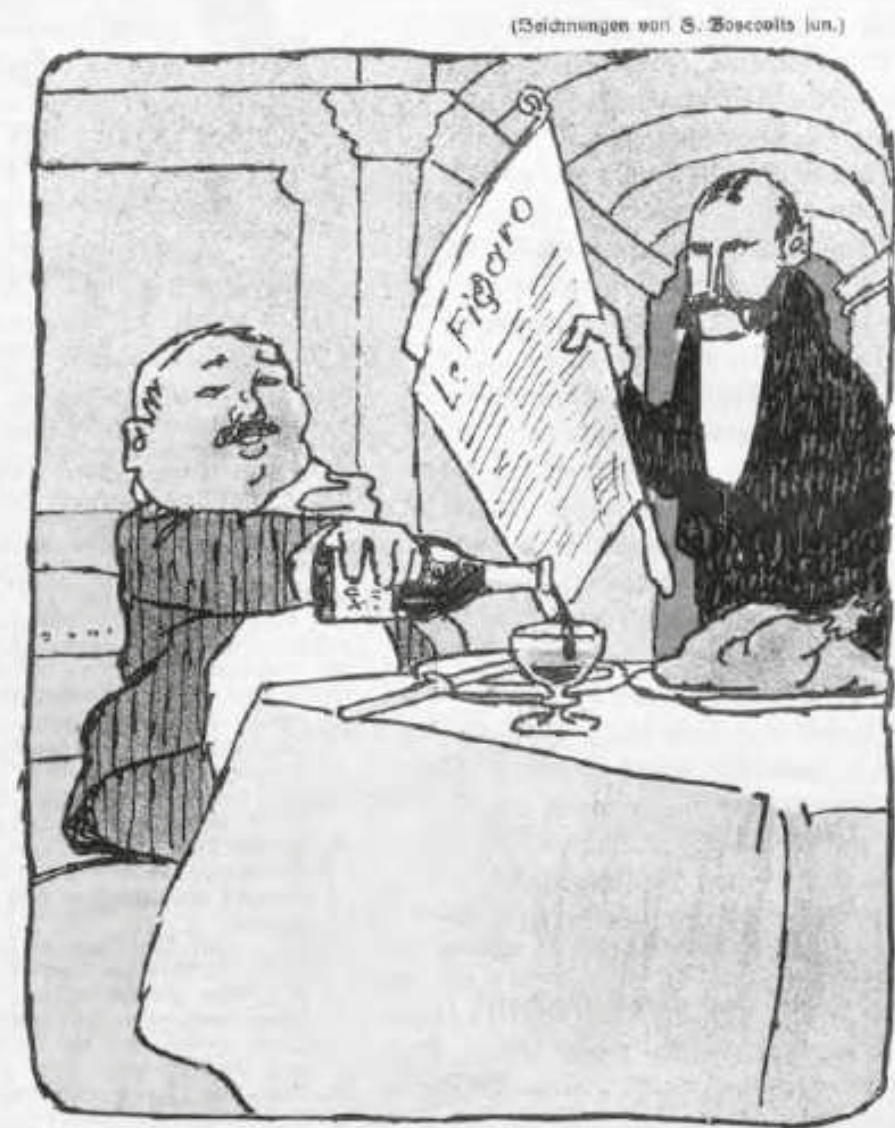

2. 2Tittags: Poulet Bresse, Bordeaur. „Sigaro“.

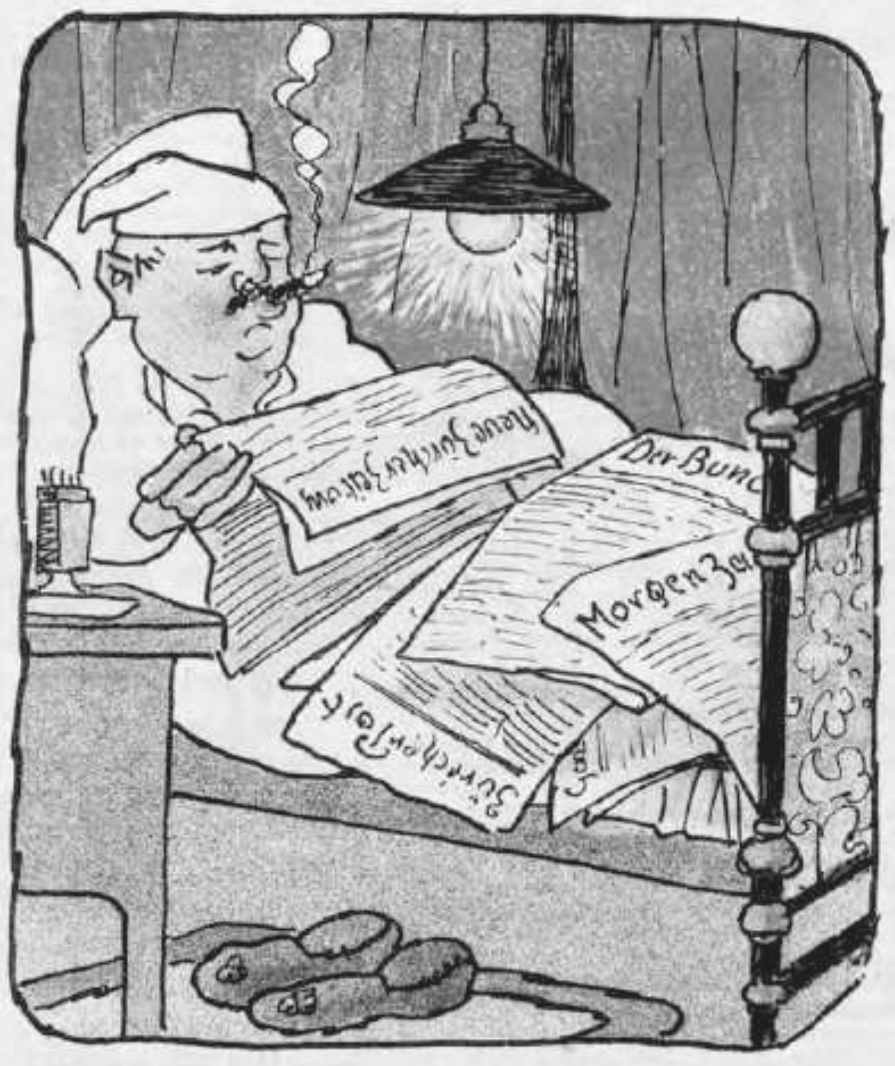

4. Ta dits: Gtumpen. Diverfe Gdhoizer Seiturfgen.

Fig. 106. Nebelspalter 1914/36, dessin pleine page en couleur de Boscovits junior intitulé « La journée d'un neutre strict » (Tagesordnung eines streng Neutralen). 
de la cathédrale de Reims ${ }^{323}$. Le rire n'est dû ici qu'à la légende, restituant les propos d'Helvetia à la vue d'un groupe de figures indistinctes, levant le bras en direction du drapeau français:

J'ai désormais donné à mes fils drapeau, arme et épée et ils ont encore une main libre pour offrir leurs sympathies à l'étranger. Je vais devoir introduire une interdiction d'exportation pour cet article 324

Alors que les effets de la guerre économique ne prêtent guère à rire, l'un de ses instruments, la Société suisse de surveillance économique (SSS) est l'objet de railleries nourries. Cet organe de droit privé, constitué en octobre I9I 5 pour éviter que des marchandises en provenance de l'Entente ne parviennent aux empires centraux via la Suisse, est surnommé par la population "Souveraineté suisse suspendue ${ }^{325}$. Aucune des très nombreuses compositions chargeant la SSS n'est aussi mordante que la couverture colorée de rouge de Karl Czerpien, à la mi-février i916. "La nouvelle entreprise ou Beaucoup de bruit pour rien » (Die neue Firma oder Viel Lärm um nichts) montre Marianne et Iwan au travail dans la «Boucherie charcuterie Entente », sous la surveillance de John Bull, selon les indications du dessin, toutes en français dans le texte. Les trois crochets en S, suspendus au-dessus de l'étal portent les trois S de la "Société Suisse de Surveillance comique ». Ceux-ci portent à leur tour des sacs remplis de pièces. La scène est observée par de jeunes Suisses, l'un deux distingué par la croix helvétique ${ }^{326}$ (cf. fig. 107).

Quelques personnalités choisies condensent les attaques. Sympathie germanophile obligeant, l'empereur Guillaume II perd sa primauté parmi les cibles satiriques ${ }^{327}$, pour disparaître complètement. Au fil des événements, les figures changent. En I9 I4, l'essentiel des attaques se concentre sur le Président américain Wilson. En I9I 5, Gabriele D’Annunzio, Nicolas II et, à nouveau, Wilson sont très présents. En I9I6, viennent s'y ajouter Ferdinand I Ier de Roumanie et Elefthérios Venizélos. En I9I 7, on trouve à nouveau Wilson, Ferdinand $\mathrm{I}^{\text {er }}$ et Nicolas II en ligne de mire. En I9I 8, ce sont toujours les mêmes, avec, en plus, le Président français Georges Clémenceau. D’autres personnalités sont concernées de manière anecdotique, mais nul ne concentre autant la moquerie et l'agressivité que le Président américain Wilson, bien avant, du reste, que les États-Unis ne rentrent officiellement en guerre, le 6 avril I9I7.

Des années durant, Wilson sert de bouc émissaire. En juillet I 9 I 5 , on le voit en pantin dégingandé, la bouche tordue, s'arracher les cheveux sur une couverture intitulée "Wilson dans la difficulté" (Wilson in Nöten). Le titre présente un jeu de mots autour des mots Nöten et Noten, le second signifiant tout à la fois billet et note (diplomatique). La légende, placée au-dessus du dessin, est

${ }_{323}$ Oskar Bätschmann, " Hodler, Ferdinand » [2008, 2011], SIKART Lexikon zur Kunst in der Schweiz; http://www.sikart.ch/kuenstlerinnen.aspx?id=4000055, consultation le 13.9.2013.

324 (Helvetia: Jetzt habe ich meinen Söhnen Fahne, Gewehr und Schwert gegeben, und sie haben immer noch eine Hand frei, ihre Sympathien ans Ausland zu verschenken; ich werde auch auf diesen Artikel ein Ausfuhrverbot setzen müssen.); Nebelspalter 1915/47, couverture de Karl Czerpien intitulée " Le lien suisse-romand »; le titre est en français; cf. aussi « 3.3.1 Se situer vis-à-vis d'un conflit étranger $»$.

32 Roman Rossfeld, «Seul le puissant à des droits. L'économie suisse pendant la Première Guerre mondiale », dans 14/18. La Suisse et la Grande Guerre, op. cit., p. 148; Roman Rossfeld et Tobias Straumann (éd.), Der vergessene Wirtschaftskrieg. Schweizer Unternehmen im ersten Weltkrieg, op. cit., p. 34-37.

326 Nebelspalter 1916/8, couverture de Karl Czerpien intitulée « La nouvelle entreprise ou Beaucoup de bruit pour rien » (Die neue Firma oder Viel Lärm um nichts).

327 Philippe Kaenel, « Suisse-Allemagne (1848-1918): identités et neutralité du point de vue de la caricature », op. cit. censée rapporter les propos de Wilson: "Bon Dieu! Nous ne pouvons faire la guerre à l'Allemagne sans nuire à notre commerce neutre de livraison des armes. " ${ }^{328}$. Wilson vient d'adresser deux notes diplomatiques à l'Allemagne pour exiger réparations à la suite du torpillage du paquebot britannique Lusitania par un sousmarin allemand, le 7 mai I 9 I 5. Plus d'une centaine d'Américains y ont trouvé la mort ${ }^{329}$. À l'approche de l'entrée en guerre des États-Unis, les charges se font plus nombreuses. "Wilson en prestidigitateur» (Wilson als Verwandlungskünstler) s'appuie en I9I7 sur l'alliance alors très en vogue du politique et du cirque. Karl Czerpien présente le Président dans quatre rôles différents: en Mercure (Als Merkur), un obus dans la main; en ange de la paix (Als Friedensengel), portant sur son habit l'inscription «Pack's » et un papier marqué « Note»; en Mars (Als Mars); et, enfin, en joueur de mandoline avec la légende « Couplet final: abandonné, abandonné, je suis abandonné " 330 . Le dessin repose sur la rhétorique de la cupidité et de l'hypocrisie, fonctionnant visuellement sur l'instabilité et la transformation. L'entrée effective dans la guerre conduit à des attaques incessantes, parfois plusieurs dans le même numéro. Wilson est ainsi au centre d'une couverture intitulée « Les clowns de la paix au théâtre des variétés américain "(Die Friedensklown am amerikanischen Variété) ${ }^{331}$. Le ressort comique est inchangé. La hargne est telle qu'on ne lâche pas la proie Wilson, alors même que celui-ci s'est retiré de la vie politique, à la fin de l'année I920. En I92I, on continue ainsi de l'accuser d'avoir saboté la paix. Wilson est alors présenté sous une apparence dégradée, nu, des ailes atrophiées dans le dos et un bandage autour de la tête ${ }^{332}$.

Les figures soustraites à l'empathie représentent une autre catégorie. Le rire est agressif à l'égard des noirs, des profiteurs et des monarques déchus, toutes figures échappant à l'identification. Le nègre - selon la terminologie de l'époque - est, surtout jusqu'en I9I 6, au centre de nombreuses caricatures contre les puissances coloniales alliées. On montre volontiers les indigènes en cannibales, comme dans les "Réflexions cannibales" (Kannibalistische Bedenken). Un homme en costume traditionnel y lit le Times, entouré de soldats, tandis qu'à l'arrière-plan, plusieurs personnes sont réunies autour d'un feu, parmi elles, une femme rongeant un os. Le dessin est surmonté d'un commentaire: "Les Anglais se sont assurés le service de 200 Maoris contre les Allemands » et pourvu d'une légende: "Mon Dieu, Par tous les Ancêtres! Si les Allemands sont aussi coriaces que l'écrivent nos amis anglais, alors ils ne constituent pas une nourriture de choix pour nous. »333 (cf. fig. I08)

(Goddam! Also Krieg können wir mit Deutschland nicht führen, sonst schädigen wir unser neutrales Waffenlieferungsgeschäft.); Nebelspalter 1915/25, couverture de Boscovits senior intitulée "Wilson dans la difficulté » (Wilson in Nöten).

329 Volker Berghahn, Der erste Weltkrieg, Munich, C. Beck, 2009, p. 47; sur le naufrage: Willi Jasper, Lusitania: Kulturgeschichte einer Katastrophe, Berlin, Be.bra, 2015.

30 (Schlusscouplet: Verlassen, verlassen, verla-ha-se-hen bin!); Nebelspalter 1917/9, dessin de Karl Czerpien intitulé « Wilson en prestidigitateur » (Wilson als Verwandlungskünstler)

${ }^{331}$ Nebelspalter 1917/10, couverture de Boscovits senior intitulée « Les clowns de la paix au théâtre des variétés américains » (Die Friedensklown am amerikanischen Varieté).

332 Nebelspalter 1921/2, dessin signé d'un monogramme intitulé "Coup d'œil rétrospectif sur l'année de paix 1920 » (Rückblick auf das Friedensjahr 1920).

333 ("Die Engländer haben die Dienste von zweihundert Mooris gegen die Deutschen angenommen »; "Goddam! Bein den Großen Vätern! Wenn die Deutschen gar so zäh sind, wie unsere englischen Freunde schreiben, so sind sie keine besonderes Fressen für uns. "); Nebelspalter 1914/34, dessin de Boscovits senior intitulé « Réflexions cannibales » (Kannibalistische Bedenken). 
20. 8. 42. Jahrgang.

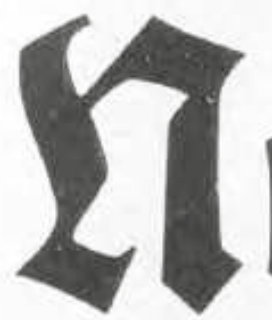

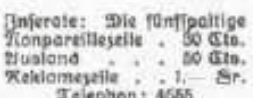

Jürich, den 19. Sebruar 1916.
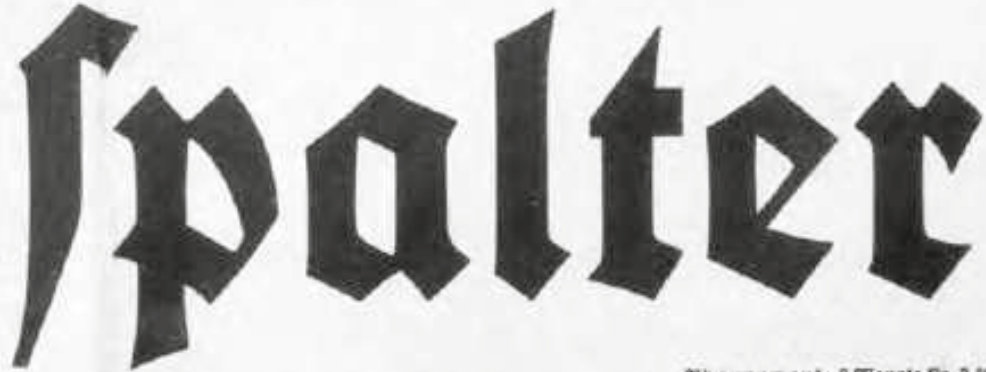

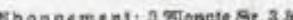

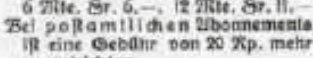
vilie Rechite sorbenaliten.

\section{Die neue Sirma}

Viel Lärm um nichts

Seidunurig oon Xarl Gyorpient)

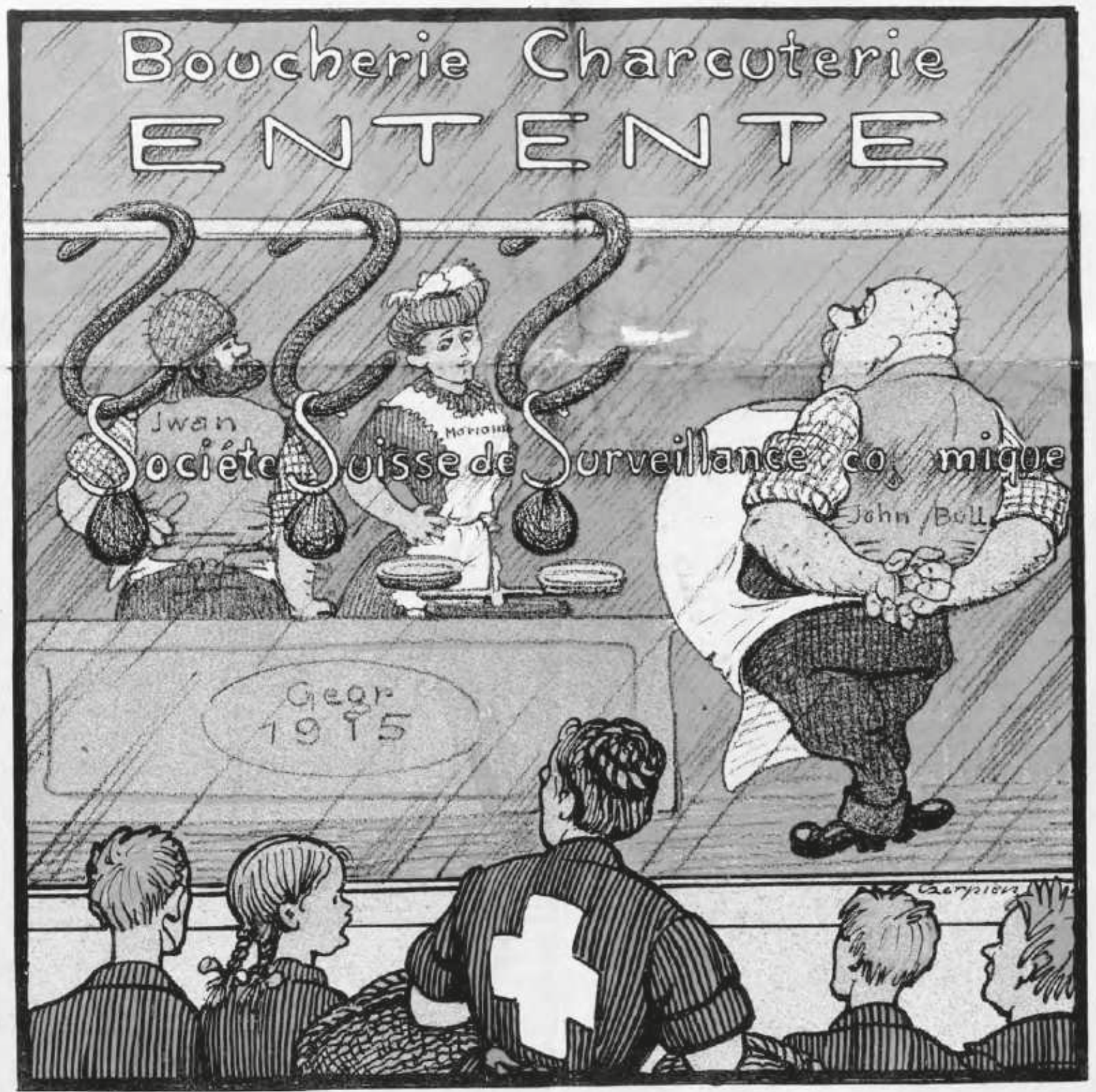

Fig. 107. Nebelspalter 1916/8, couverture en couleur de Karl Czerpien

intitulée « La nouvelle entreprise ou Beaucoup de bruit pour rien » (Die neue Firma oder Viel Lärm um nichts). 


\section{Kanibalifche Bedenken}

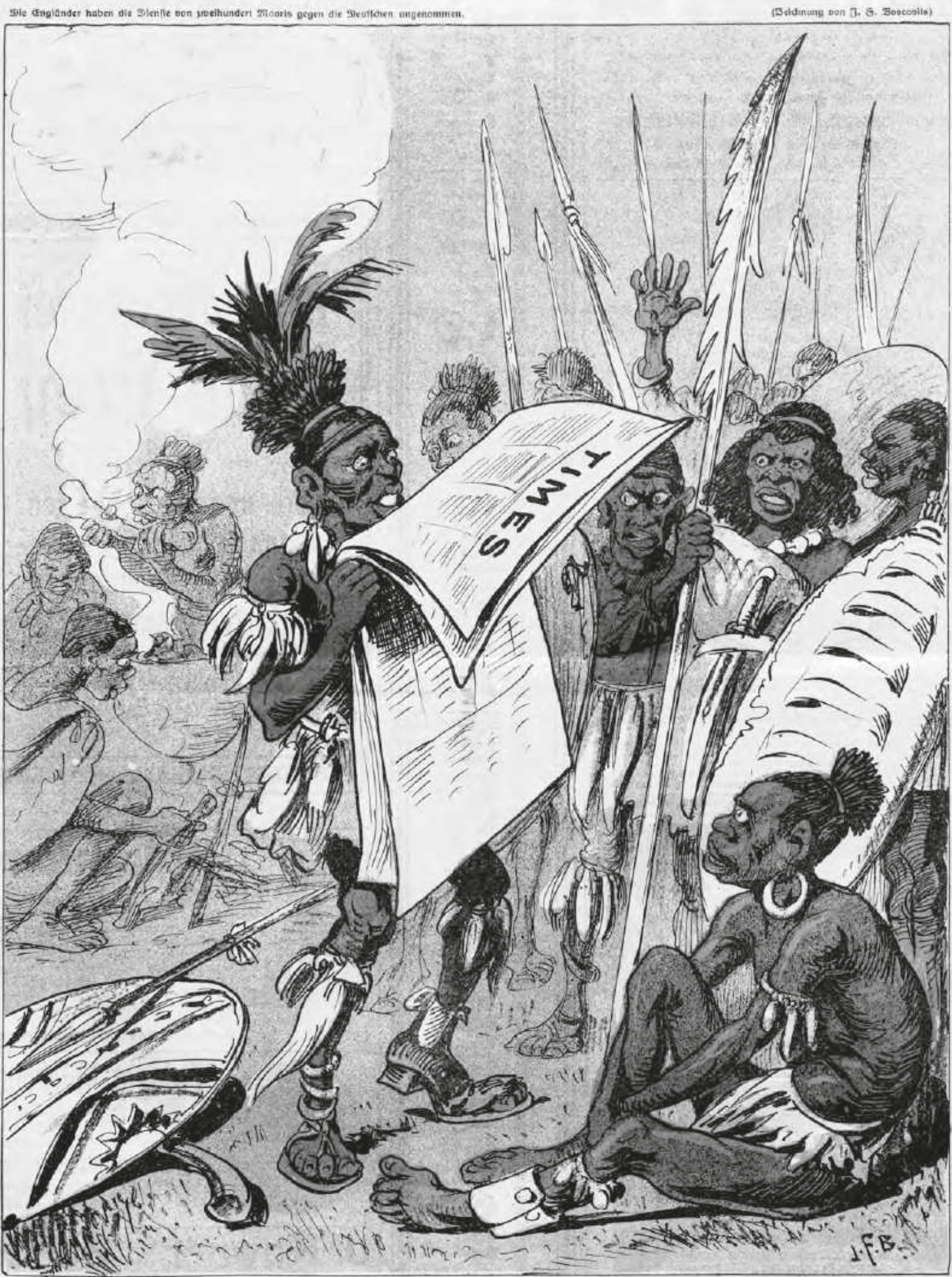

Goddam! Zei den grojen 23ätern! 25enn die Deutichen gar to 3äh find, roie unfere englifchen Sreunde fdureiben, fo find fie kein befonderes sreflen für uns."

Fig. 108. Nebelspalter 1914/34, dessin pleine page en couleur de Boscovits senior intitulé « Réflexions cannibales ( Kannibalistische Bedenken). 


\section{Der modernifierte 2Terkur}

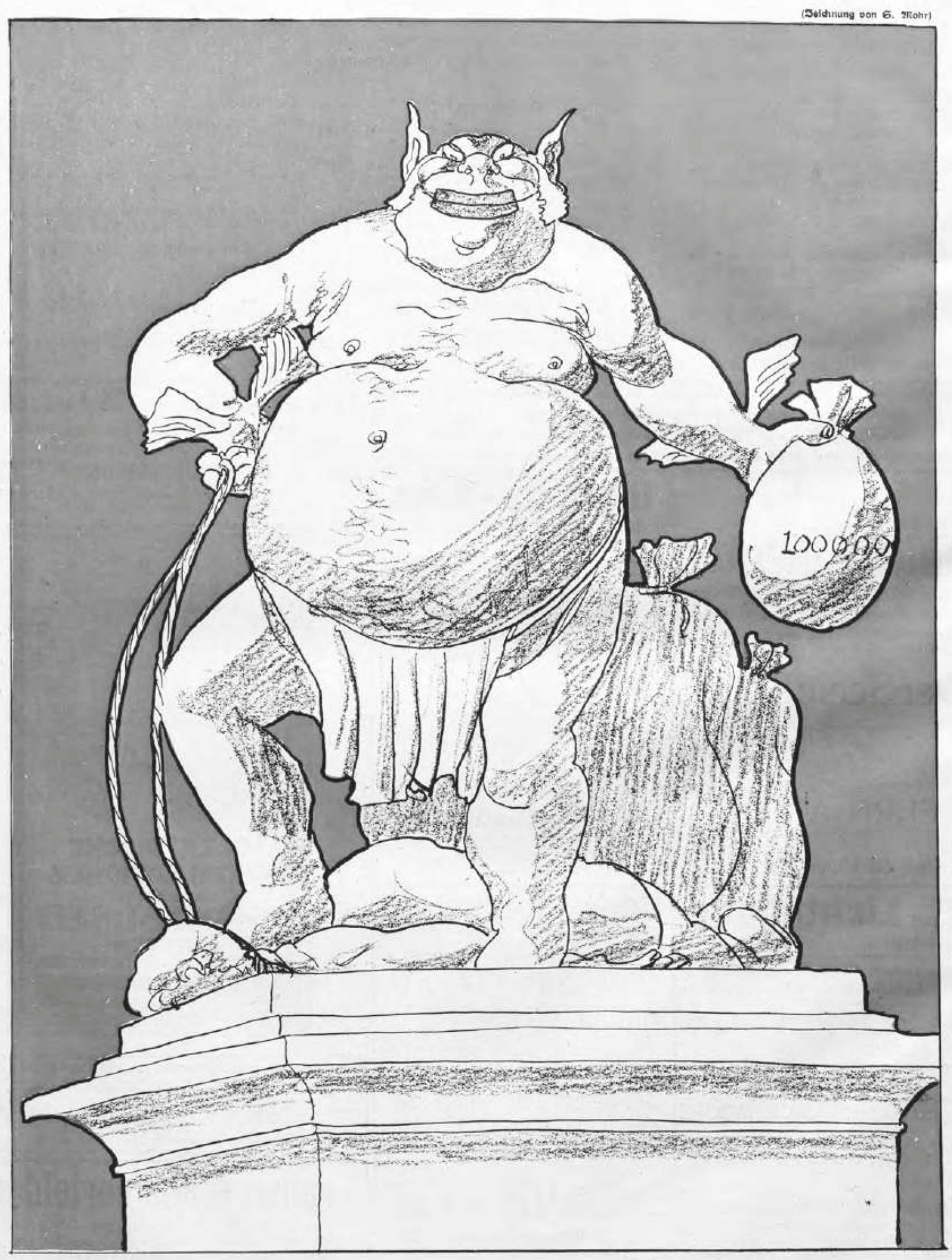

And es rourde dem neuen Gotte des Fandels ein Denkmal im Reiche der Gchieber errichtet!

Fig. 109. Nebelspalter 1918/35, dessin pleine page en couleur de S. Mohr intitulé « Mercure modernisé » (Der Modernisierte Merkur). 
L'effet comique vient du rendu grotesque du repas, supposé cannibale, de la légende commentant les qualités gustatives des Allemands, mais surtout de la représentation d'un sauvage lisant le Times. Le but est de dénier aux Alliés les concepts de civilisation et de culture que se disputent les deux parties.

On se moque sans retenue des profiteurs, incarnant l'amoralité. Les charges, continues pendant la guerre et encore plus fréquentes ensuite, sont sévères. Fin I9I4, c'est un militaire qui est ainsi épinglé dans "Pour la Patrie » (Für's Vaterland), assis devant son livret de dépenses. Les charges sont deux fois moins nombreuses que les recettes. "Pourvu que ces "sales temps" durent encore", indique la légende ${ }^{334}$. Ce rire envers les profiteurs, très souvent des capitaines d'industrie, est très grinçant. "Et l'on érigea au royaume des profiteurs un monument à la gloire du nouveau dieu du commerce», telle est la légende du "Mercure modernisé » (Der Modernisierte Merkur) de S. Mohr; un dieu du commerce énorme, juché sur un piédestal, tel le veau d'or ${ }^{335}$ (cf. fig. Io9).

L'effet comique est assuré par la posture, le grotesque de la figure et sans doute aussi par la composante antisémite, classiquement associée au veau d'or. Le même S. Mohr fournit avec son "Crépuscule des profiteurs» (Schieberdämmerung) l'un des dessins de guerre les plus raffinés. Un homme au visage simiesque, emmitouflé dans des vêtements de prix s'avance aux côtés d'une jeune femme élégante. Un groom malingre, appuyé contre le bord opposé de l'image écoute les propos de l'homme: "Ma petite mimi, si la paix vient à venir, tu devras te limiter un peu » ${ }^{336}$.

À partir de I9I7, lorsque les monarchies et les empires chancellent, les rois et empereurs déchus deviennent une manne quasi-inépuisable. "Les sacrifiés " (Die Geopferten) montre un Mars la gueule ouverte, une épée à la main, en train de se reposer dans les enfers, tourné vers cinq personnages. Ce sont, à la queue leu leu, Albert (Albert I ${ }^{\text {er }}$, roi de Belgique), Nikita (Nicolas I ${ }^{\text {er }}$ de Monténégro), Peter (Pierre Ir de Serbie), Niki (Nicolas II) et Constantin (Constantin I ${ }^{\text {er }}$, roi des Hellènes). La légende ne rapporte pas les paroles du dieu de la guerre mais les pensées des souverains:

Si Monsieur Mars règne encore longtemps sur le monde, que nous restera-t-il? Qui sait combien de couronnes tombent encore et qui viendra prendre place dans la file?337

Leur placement, leur stature et leur allure empruntée, comparée à celles d'un Mars très à l'aise, rendent les personnages ridicules. La fin des puissants flirte parfois avec le tragique. Dans "Les rois » (Die Könige) de S. Mohr, le rouge est la seule couleur d'un dessin montrant les monarques regroupés sur une ile, au milieu d'une mer de squelettes: "C’est une époque, où les rois doivent être solidaires (Extraits de la soi-disant lettre de l'empereur Charles au

${ }_{334}$ (Wenn nur diese "schlechten Zeiten » noch recht lange dauern); Nebelspalter 1914/40, dessin de Boscovits junior intitulé « Pour la Patrie » (Für's Vaterland).

335 (Und es wurde dem neuen Gottte des Handels ein Denkmal im Reiche der Schieber errichtet); Nebelspalter 1918/35, dessin de S. Mohr intitulé « Mercure modernisé » (Der Modernisierte Merkur).

336 (Wenn jetzt der Frieden kommt, wirst du dich schon ein bisschen einschränken müssen, Mimili!); Nebelspalter 1918/8, dessin pleine page de S. Mohr intitulé «Crépuscule des profiteurs » (Schieberdämmerung).

337 (Regiert Herr Mars noch lang die Welt, was mag uns noch gedeihen? Wer Weiß, wie manche Kröne fällt und wenn er vor das Faktum stellt, sich diesen anzureihen?); Nebelspalter 1917/25, couverture de Boscovits junior intitulée « Les sacrifiés » (Die Geopferten). roi Ferdinand) ", indique la légende ${ }^{338}$. Le comique ne tient ici qu'à légende et à la posture précaire des monarques (cf. fig. I IO).

La responsabilité de ces derniers est, en fait, le véritable thème de la composition. Lorsque les monarchies cèdent, le thème prend un nouvel essor. Dans le numéro du 9 novembre I9 I 8, l'empereur Charles ${ }^{\text {er }}$ tremble sur son trône, alors que l'empire austrohongrois se disloque sous ses pieds ${ }^{339}$.

L'absurdité est davantage un trait grotesque qu'un thème et repose sur la manière de mettre en scène ou d'opposer ${ }^{34^{\circ}}$. Un des topos les plus fréquents est de renvoyer les belligérants dos à dos ou plutôt corne contre corne, comme les deux boucs à l'automne I9 I 4 dans «Le chemin vers le bonheur » (Der Weg des Glückes), en équilibre sur une branche tendue au-dessus d'un précipice: "Comme les deux chèvres ici sur le pont étroit et fragile, les peuples s'en vont sur le chemin du bonheur... Chaque chèvre est comme un bouc et pense gagner à la fin, jusqu'à ce que les deux se retrouvent à gigoter dans l'eau " ${ }^{341}$. La couverture de Boscovits senior, « libre d'après G. Doré » (frei nach Gustave Doré), selon son créateur, joue sur plusieurs leviers: le rapport de force entre les deux bêtes, d'une part; l'image, mais surtout le texte du modèle, une illustration des fables de la Fontaine par Gustave Doré, "Les deux chèvres » 342. Gustave Doré est alors, faut-il le rappeler, « le plus illustre des illustrateurs ${ }^{343}$, concourant au succès jamais démenti des très célèbres fables de Lafontaine. Le schéma visuel est, d'ailleurs, le même début I9I7 dans "Trop tard » $(Z u$ spät), sauf qu'il ne s'agit plus de caprins mais de soldats sur le point de chuter, qui s'exclament: " Nous aurions peut-être dû conclure la paix »344.

\subsubsection{Montrer la guerre et renoncer au rire}

Le versant opposé au rire est la monstration de la violence, impliquant, la plupart du temps, de renoncer au rire. Pour figurer cette guerre irreprésentable, du fait de sa dimension industrielle, son caractère statique, sa violence extrême ${ }^{345}$, les moyens formels et psychiques manquent aux artistes. On a, d'ailleurs, souvent utilisé la métaphore du silence, reprise par Philippe Dagen dans son livre pionner ${ }^{346}$. La symbolisation est difficile. Certains artistes sont dans l'incapacité de fournir des images, d'autres idéalisent la réalité, par déni ou pour se conformer aux attentes

38 "Dies ist eine Zeit, in der die Könige zusammenstehen müssen. » (Aus dem angeblichen Briefe Kaiser Karls an der König Ferdinand); Nebelspalter 1918/31 dessin pleine page de S. Mohr intitulé « Les rois » (Die Könige).

339 Nebelspalter $1918 / 45$, dessin pleine page de S. Mohr intitulé « Le grand tremblement de terre » (Das grosse Erdbeben).

${ }^{340}$ Laurence Danguy, « Retour sur les thèses de Wolfgang Kayser sur le grotesque », EIRIS, L'image satirique, notes de lecture, 2008; https://eiris.eu/index. php?option=com_content\&view=article\&id=121:le-grotesque-sa-mise-en-formedans-la-peinture-et-la-posie\&catid $=47 \&$ Itemid $=76$.

${ }^{341}$ (Wie die beiden Geißen hier auf der schmalen, schwachen Brücke, machen es die Völker auch auf dem Weg nach ihrem Glücke...Jede Geiß steht wie ein Bock und vermeint am End'zu siegen; bis sie alle beide dann zappeln in dem Wasser liegen.); Nebelspalter 1914/44, couverture de Boscovits senior intitulé « Le chemin vers le bonheur » (Der Weg des Glückes).

${ }^{342}$ Gustave Doré, Les deux chèvres, illustration de Les fables de Jean de La Fontaine, Paris, Louis Hachette, 1867, tome 2, p. 298.

343 Philippe Kaenel, Le métier d'illustrateur 1830-1880, Genève, Librairie Droz, 2005 p. 391.

${ }^{344}$ (Wir hätten vielleicht doch Frieden schließen sollen); Nebelspalter 1917/7, dessin de Karl Czerpien intitulé « Trop tard » (Zu spät).

345 À tel point que celle-ci représente le tiers de l'ouvrage de Annette Becker et Stéphane Audouin-Rouzeau; Stéphane Audouin-Rouzeau et Annette Becker, 14-18 Retrouver la Guerre, Paris, Gallimard, 2000.

${ }_{346}$ Philippe Dagen, Le silence des peintres. Les artistes face à la Grande Guerre, Paris, Fayard, 1996. Pour une synthèse sur les représentations et la figurabilité de la guerre, cf. Nicolas Beaupré, « Monstration de l'expérience et expérimentation artistique et littéraires dans la guerre moderne », dans Les images en guerre (19141945). De la Suisse à l'Europe, op. cit., p. 39-51. 


\section{Die Könige}

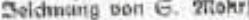

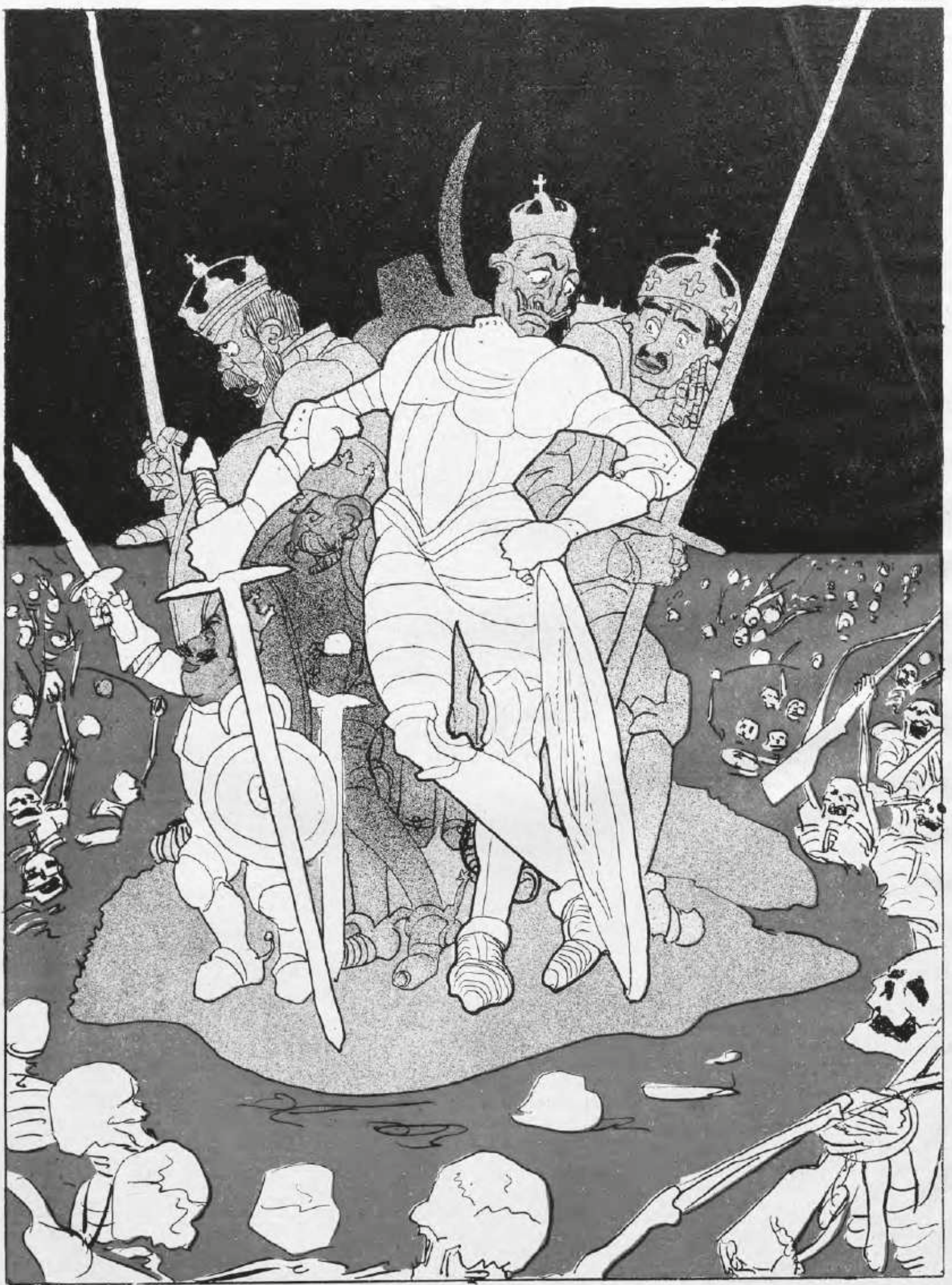

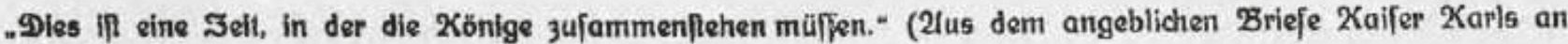
Xönig S̈erdinand). 
de leur commanditaire, dans le cas des peintres de guerre ou des dessinateurs de cartes postales ${ }^{347}$. Quelques-uns innovent, en particulier ceux se confrontant physiquement à la guerre, tels Maurice Denis, Otto Dix ou Félix Vallotton, pour ne citer que trois artistes aux arrière-plans culturel et idéologique différents ${ }^{348}$. Vallotton, par exemple, choisit l'outrance pour ses planches gravées, rassemblées dans un album intitulé "C'est la guerre». On sait, du reste, comment la guerre a façonné les mouvements avant-gardistes.

Une revue illustrée, liée à l'actualité ne peut ignorer la guerre et se doit même de la montrer ${ }^{349}$. Dans le cas du Nebelspalter, il s'agit de représenter une guerre qui se passe ailleurs, dans laquelle le pays n'est pas directement impliqué et dont il faut se tenir à distance idéologiquement. Il ne sera jamais question de restituer la réalité. Un système de représentation s'installe, cependant, qui va donner une visibilité au conflit et en dénoncer la folie meurtrière. Différents leviers iconographiques et rhétoriques, plusieurs référentiels, religieux, mythologique et humaniste, sont mobilisés. Ceci autour d'un nombre restreint de genres et thèmes, revivifiés pour l'essentiel, très souvent combinés à une rhétorique basée sur la litote.

Les référentiels religieux et mythologiques regroupent des récits anciens dont la trame narrative est organisée autour d'un moment particulièrement pathétique. Reposant sur une culture classique, dont dispose le lecteur-type du Nebelspalter, ils offrent l'avantage d'une distance temporelle et émotionnelle. Ils ne s'équivalent pas pour autant, la référence religieuse étant émotionnellement plus proche du lecteur que celle mythologique. Que celui-ci soit ou non croyant est d'ailleurs assez secondaire, puisque le XIX ${ }^{\mathrm{e}}$ siècle - qui pour la plupart des historiens, rappelons-le, se termine avec la Première Guerre mondiale - est un siècle encore très religieux ${ }^{350}$. Le référentiel religieux est utilisé - et l'on peut se demander avec quel degré de conscience - lorsqu'il s'agit d'impliquer fortement le lecteur, tandis que celui mythologique fait l'objet d'un usage plus distancié et sert, soit à distraire, soit à susciter la réflexion. De tous les sujets religieux, les figures et thèmes christiques sont les plus fréquents. Ceci s'explique, d'une part, par la constellation confessionnelle zurichoise, très largement protestante, excluant par conséquent les représentations mariales et peu ou prou les anges, et correspond, d'autre part, à la culture visuelle de l'époque. Dans le champ visuel, la figure christique s'autonomise alors du religieux et est volontiers détournée, caricaturée et instrumentalisée ${ }^{351}$.

${ }^{347}$ Voir les illustrations de Georg Kreis, Schweizer Postkarten aus dem Ersten Weltkrieg, op. cit.; ou encore le site de Patrick Bondallaz et Alexandre Elsig: http:// www.14-18.ch.

${ }^{448}$ Sur ces artistes (français, allemand et suisse) et la Première Guerre mondiale, cf. entre autres et en français: Christian Derouet, Oto Dix: dessins d'une guerre à l'autre, Paris, Gallimard 2003; Jean-Jacques Breton, Vallotton: « il fut lui-même », Paris, Hugo image, 2013; Fabienne Stahl, « Maurice Denis dans la Grande Guerre », Revue LISA/LISA e-journal, Vol. X-n¹, p. 15-33.

349 Joëlle Beurier conceptualise cette monstration de la violence dans la presse illustrée publiant des clichés photographiques; Joëlle Beurier, Photographier la Grande Guerre. France-Allemagne. L'héroïsme et la violence dans les magazines, Rennes, Presses universitaires de Rennes, 2016.

350 Sur la prégnance de la culture religieuse du lectorat des revues germaniques Laurence Danguy, L'ange de la jeunesse - La revue Jugend et le Jugendstil à Munich, Paris, Maison des sciences de l'homme, Philia, 2009; Laurence Danguy, "Mésusages christiques en terre bavaroise - La figure de Jésus dans la revue Jugend à l'époque wilhelminienne », dans Jésus en représentations - De la Belle Époque à la postmodernité, éd. Alain Boillat, Jean Kaempfer et Philippe Kaenel, Gollion, infolio, 2011, p. 125-144 ; Laurence Danguy, « Rhétorique anticléricale et enjeux sacraux autour d'une caricature de Jugend », Ridiculosa, 15 (2008), p. 311326.

${ }^{351}$ À ce sujet: Alain Boillat, Jean Kaempfer et Philippe Kaenel (éd.), Jésus en représentations - De la Belle Époque à la postmodernité, Gollion, infolio, 2011.
Le dessin de Walter Lilie, " Guerre et culture » (Krieg und Kultur), est typique de cette présence dans la propagande européenne, et plus encore germanique. Le fond de l'image consiste en un paysage en ruines, où l'on reconnait une église bombardée et un bâtiment marqué «école» (Schule). À l'avant-plan, un colosse nu frappe à coup de marteau la statue d'un Christ en croix, manifestement soustraite à l'église. Sur le socle de la statue se lit "Aimez vos ennemis " (Liebet eure Feinde). La légende est un avertissement "Peuple d'Europe, prenez garde à vos biens sacrés »352 (cf. fig. I I I cahier couleur). Le dessin laisse entendre que l'ennemi est un sauvage, stigmatisé visuellement par la nudité, qui incarne la menace pesant sur la Kultur allemande. C'est à nouveau un Christ de souffrance, portant couronne d'épines et croix, qui apparaît dans les cieux de "Vision » (Vision), à l'été ı918. Sa croix fait écho à celles plantées en très grand nombre dans la terre, au bas de l'image. Le champ couvert de croix est, au reste, un motif récurrent des peintures de guerre, symbolisant la masse des vies perdues. La légende reprend un verset de l'Évangile selon saint Luc: "Que la paix soit sur la terre " (Und Friede auf Erden!) ${ }^{353}$ La figure christique, présente tout du long de la guerre, s'ajuste à la ligne idéologique et soutient, à présent, un discours empathique. Tout comme le dessin de Walter Lilie du début de la guerre, la composition de Henrik, intitulée " I9I6 ", présente un colosse nu faisant démonstration de sa force: debout, quelque part dans le cosmos, il tient de ses mains un globe en feu, la Terre. Sa posture et l'expression de son visage sont plus ironiques que menaçantes. La légende livre son identité:

Atlas: si nous n'étions pas toujours occupés en haut et que nous ne devions pas nous en tenir à la convention de La Haye, nous pourrions jeter ce truc dans l'atmosphère, telle une grenade 354 .

La référence mythologique soutient un propos ambigu, intégrant au drame d'un monde en feu un comique de situation.

La culture humaniste propose également des références plus récentes, empruntées à la littérature et aux beaux-arts. Pour iconiser la violence, tout est bon, pourvu que le contenu soit narrativement adéquat et l'œuvre reconnaissable. Les œuvres doivent donc ressortir à un fonds commun, qui, autre temps autres mœurs, demande à présent un effort d'identification et de documentation. Dante et Gustave Doré étaient alors bien plus connus qu'à présent, l'un comme nectar d'une culture humaniste, que l'on se plait à savoir partagée dans le monde germanophone ${ }^{355}$; l'autre comme illustrateur ${ }^{356}$. Il n'est ainsi pas douteux que la couverture créée par Boscovits senior au début de l'année I9I 5 d'après les illustrations de L'Enfer de Dante par Gustave Doré ait bénéficié d'une réception adéquate. "Le combat des peuples" (Der Ring der Völker) entend dénoncer les luttes fratricides en réinterprétant la lutte des démons du Chant XXII de l'Enfer ${ }^{357}$.

(Völker Europas, wahret eure heiligsten Güter!); Nebelspalter 1914/40, dessin pleine page de Walter Lilie intitulé « Guerre et culture » (Krieg und Kultur).

353 Luc, 2.14; Nebelspalter 1918/29, dessin pleine page de Alfred Hirschler intitulé « Vision» (Vision)

${ }^{354}$ (Atlas: Wenn wir hier oben nicht anständiger wären und uns an die Haager Konvention halten würden, könnten wir so etwas als Handgranate in der Aether schleudern); Nebelspalter 1916/24, dessin pleine page de H. Henrik.

5 Theodor Ostermann, Dante in Deutschland: Bibliographie der deutschen DanteLiteratur 1416-1927, Heidelberg, Carl Winter Universitätsbuchhandlung, 1929, p. $337-371$.

Cf. «3.3.2. Rire en guerre ».

57 Dante Alighieri, L'enfer avec les dessins de Gustave Doré, Paris, Hachette, 1861, p. 325; Nebelspalter 1915/2, couverture de Boscovits senior intitulée « Le combat des peuples » (Der Ring der Völker); cf. également « 5.2. S'enrichir du "grand art" ". 


\section{Die Toteninjel}

(ङrei nach soccklin)

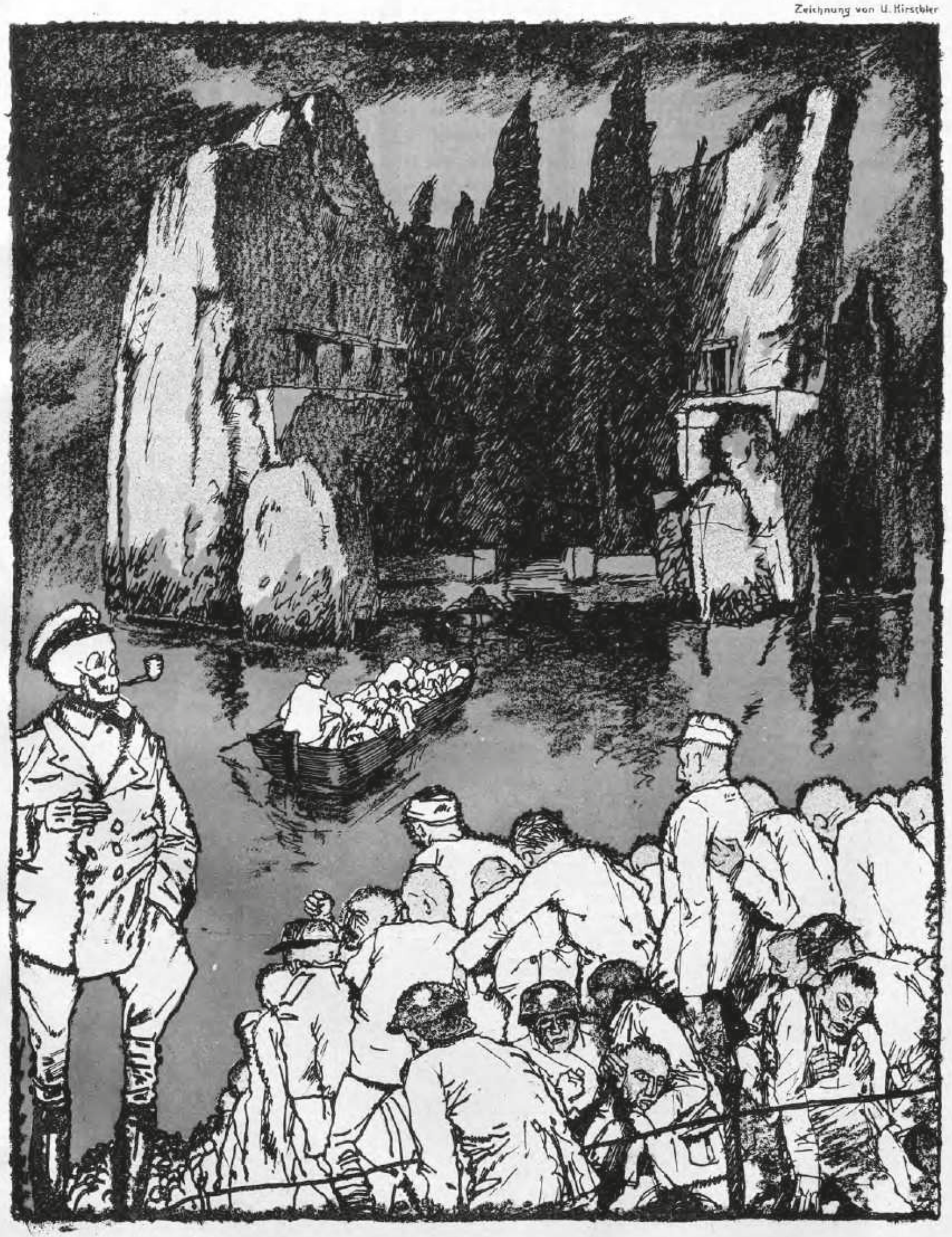

,2tur nicht drängeln: es komunt ein jeder dran!" 
Plus que tout autre artiste, cependant, Böcklin inspire les dessinateurs, et la guerre confirme cette inclination, avec notamment une énième interprétation de L'ile des morts (Die Toteninsel, I 880-I 886). L'œuvre a déjà été citée à plusieurs reprises ${ }^{358}$. En I9I 8, elle est adaptée au contexte de guerre par Alfred Hirschler. Du fait des déformations, il est difficile de déterminer quelle est celle des cinq versions ayant servi de base au dessin. Le dessinateur reprend la structure de la composition originale et en verticalise le format pour l'adapter au médium de la revue. Il rajoute une scène à l'avant-plan, une danse macabre dans la tradition des gravures de Holbein. Un squelette vêtu en gradé interpelle la masse des soldats agonisant à l'avant-plan, qui attendent d'embarquer pour l'ile des morts: "Ne poussez pas; votre tour va venir! »359 (cf. fig. I I 2)

Ce type de dénonciation de la guerre est rarement partisan. Il fournit les dessins qui, à présent, frappent l'imagination. Il n'est pourtant pas certain que cela ait été le cas à l'époque du conflit, où l'empathie, du fait de la menace, était certainement moindre. Les références à Böcklin sont parfois assez discrètes, telle une figure reprise de La guerre, survolant un champ de soldats morts. La légende "Du théâtre des opérations occidentales " (Vom westlichen Kriegsschauplatz), à l'automne I9 I4, quelque temps après la première bataille de la Marne, est acide: "Télégramme: Le calme le plus total règne sur l'ensemble du front " ${ }^{360}$. La Liberté guidant le peuple de Delacroix est, pour sa part, combinée à la figure de la grande faucheuse dans "Les deux côtés " (Die zwei Seiten), non dans une même image comme dans la révision de Böcklin par Alfred Hirschler, mais dans deux tableaux d'une composition fonctionnant sur un schéma antithétique ${ }^{361}$. Dans l'image supérieure, "la liberté guide le peuple » (Die Freiheit führt das Volk an), comme l'indique la légende; dans l'image inférieure, « le peuple guidé par la liberté »(Das von der Freiheit angeführte Volk) montre un squelette triomphant au milieu des cadavres, à la place de la liberté ${ }^{62}$. Nombreuses sont les citations à être insérées dans les compositions, tel le Mercure volant de Giambologna, prêtant son élan au Président Wilson ${ }^{363}$. L'exercice intellectuel garantit, en effet, une mise à distance émotionnelle.

La guerre emprunte, enfin, très largement à la tradition iconographique connue sous le terme de memento mori ${ }^{364}$. Celle-ci renferme notamment les modèles anciens de la danse macabre, de la grande faucheuse et du crâne. Cette iconographie, abondante et variée, n'est, à vrai dire, pas nouvelle dans les pages du Nebelspalter; elle s'est progressivement installée au fil des conflits $^{365}$. Les danses macabres sont volontiers modernisées, tel «Celui qui danse sur la terre » (Der Erdballtänzer), s'activant sur

\footnotetext{
${ }_{358}$ Cf. " 5.3. Le statut très particulier de Arnold Böcklin et Ferdinand Hodler ».

359 (Nur nicht drängeln: es kommt ein jeder dran!); Nebelspalter 1918/33, dessin pleine page en couleur de Alfred Hirschler intitulé « L'ile des morts " (Die Toteninsel).

360 (Telegramm: Es herrscht vollständige Ruhe auf der ganzen Front); Nebelspalter 1914/37, dessin pleine page de Boscovits senior intitulé « Du théâtre des opérations occidental » (Vom westlichen Kriegsschauplatz).

361 Ursula Koch, « La juxtaposition antithétique de deux images destinée à détruire l'objet représenté », Ridiculosa, 8 (2001), p. 24-25

${ }_{362}$ Nebelspalter 1917/35, dessin pleine page de Karl Czerpien intitulé « Les deux côtés » (Die zwei Seiten).

${ }_{363}$ Nebelspalter 1917/9, dessin de Karl Czerpien intitulé « Wilson en prestidigitateur» (Wilson als Verwandlungskünstler).

364 Sur le sujet: Frank Link (éd.), Tanz und Tod in Kunst und Literatur, Berlin, Drucker \& Humblot, 1993; Benjamin Delmotte, Le « memento mori » comme thème esthétique, Paris, PUF, 2010; Susanne Warda, Bild und Text in Totentänzen des Spätmittelalters und der Frühen Neuzeit, Cologne, Böhlau, 2011.

365 Cf. « 5.5. Se citer soi-même plus que de mesure ».
}

la terre, au milieu de l'univers ${ }^{366}$. "L'enjôleur » (Der Rattenfänger) fait, pour sa part, référence à la légende du joueur de flute de Hamelin, popularisée par les frères Grimm. La mort en personne ouvre ici un cortège disparate. Elle joue de la flute, avançant, tel un funambule, sur une corde tirée au-dessus d'un précipice, alors que les personnages choient les uns après les autres ${ }^{367}$.

Plus souvent, encore, la figure de la grande faucheuse est montrée seule. Elle apparaît tôt, après l'hécatombe de la première bataille de la Marne. Dans "Jour de récolte "(Erntetag), elle emplit l'espace entier du dessin; à ses côtés, des soldats minuscules gisent ou s'agitent, telles des fourmis dans un paysage dévasté et en flammes ${ }^{368}$ (cf. fig. II 3 ).

La grande faucheuse n'en finit pas d'intervenir d'une couverture à l'autre, pour souhaiter la bonne année en I9I $5^{369}$; pour commémorer la première année de guerre en compagnie d'un peuple affamé, à l'été I9I $5^{370}$; pour exprimer sa lassitude à la paix, au printemps I9I $6^{371}$; apparaissant, enfin, aux portes de la Suisse, sous une forme masculine, à l'été I9I $7^{372}$. Deux de ces dessins, non des couvertures, mais une page centrale et une dernière page, sont particulièrement impressionnants. Tous deux s'apparentent à des danses macabres. Le premier est créé pendant la bataille de Verdun, fin avril I9 16. La grande faucheuse de la "Diplomatie» de Karl Czerpien » bascule sur une immense faux, rougie par le sang d'hommes, tous semblables. Elle brandit une couronne de laurier marquée "au vainqueur » (Dem Sieger), en direction des diplomates et rois, perchés de part et d'autre ${ }^{373}$. Le second dessin est publié mi-juin I9I 8, après quatre années d'une guerre dont on ne voit pas la fin. Dans "Mort » (Tod) de Alfred Hirschler, les deux tiers inférieurs sont rouge vermillon. Il s'agit de la mare de sang dans laquelle s'enfoncent la mort ainsi qu'une règle. La mort adopte une posture et un accoutrement donquichottesques. Elle pointe sur la règle un chiffre avec son épée. À l'arrière-plan, se détache un paysage en ruines. La légende est explicite: « Ça ne suffit toujours pas! » 374 Le jeu des couleurs, le caractère émacié des figures, anthropomorphes et architecturales, la légende, l'aspect grotesque - mais en rien risible - de la mort, la disproportion des accessoires, épée et mesure, participent de l'efficace de cette image, parmi les plus impressionnantes de la guerre (cf. fig. I I 4 cahier couleur).

La dernière variante iconographique consiste en l'insertion d'un crâne, parfois accompagné d'autres indices morbides. Elle donne lieu à de nombreuses variations et recréations. Chacun des quatre carrés du dessin «Les quatre éléments »(Die vier Elemente), créé à l'automne I9I4, est dédié à un élément: l'air $(L u f t)$, l'eau (Wasser), le feu (Fener) et la terre (Erde), prétexte à une scène fatale. Les différents espaces sont liés au centre par un crâne cerné

\footnotetext{
Nebelspalter 1918/34, couverture de S. Mohr intitulée « Celui qui danse sur la terre » (Der Erdballtänzer).

${ }^{367}$ Nebelspalter 1918/39, couverture de Alfred Hirschler intitulée « L'enjôleur» (Der Rattenfänger).

${ }_{368}$ Nebelspalter 1914/35, dessin pleine page de Walter Lilie intitulé « Jour de récolte » (Erntetag).

369 Nebelspalter 1915/1, couverture de Boscovits junior intitulée « Vœux pieux » (Frommer Wunsch).

Nebelspalter 1915/31, couverture de Boscovits senior intitulée « Sur l'anniversaire de la première année de guerre » (Zum Jahrestag des Weltkrieges). Nebelspalter 1916/10, couverture de H. Frans intitulée «Le las » (Der Müde) Nebelspalter 1917/31, couverture de Boscovits junior intitulée « Le faucheur » (Der Schnitter).

373 Nebelspalter 1916/38, dessin pleine page de Karl Czerpien intitulé « Diplomatie ». 74 (Noch nicht genug!); Nebelspalter 1918/24, dessin pleine page de Alfred Hirschler
} intitulé « Mort » $(T o d)$. 


\section{Frntetag}

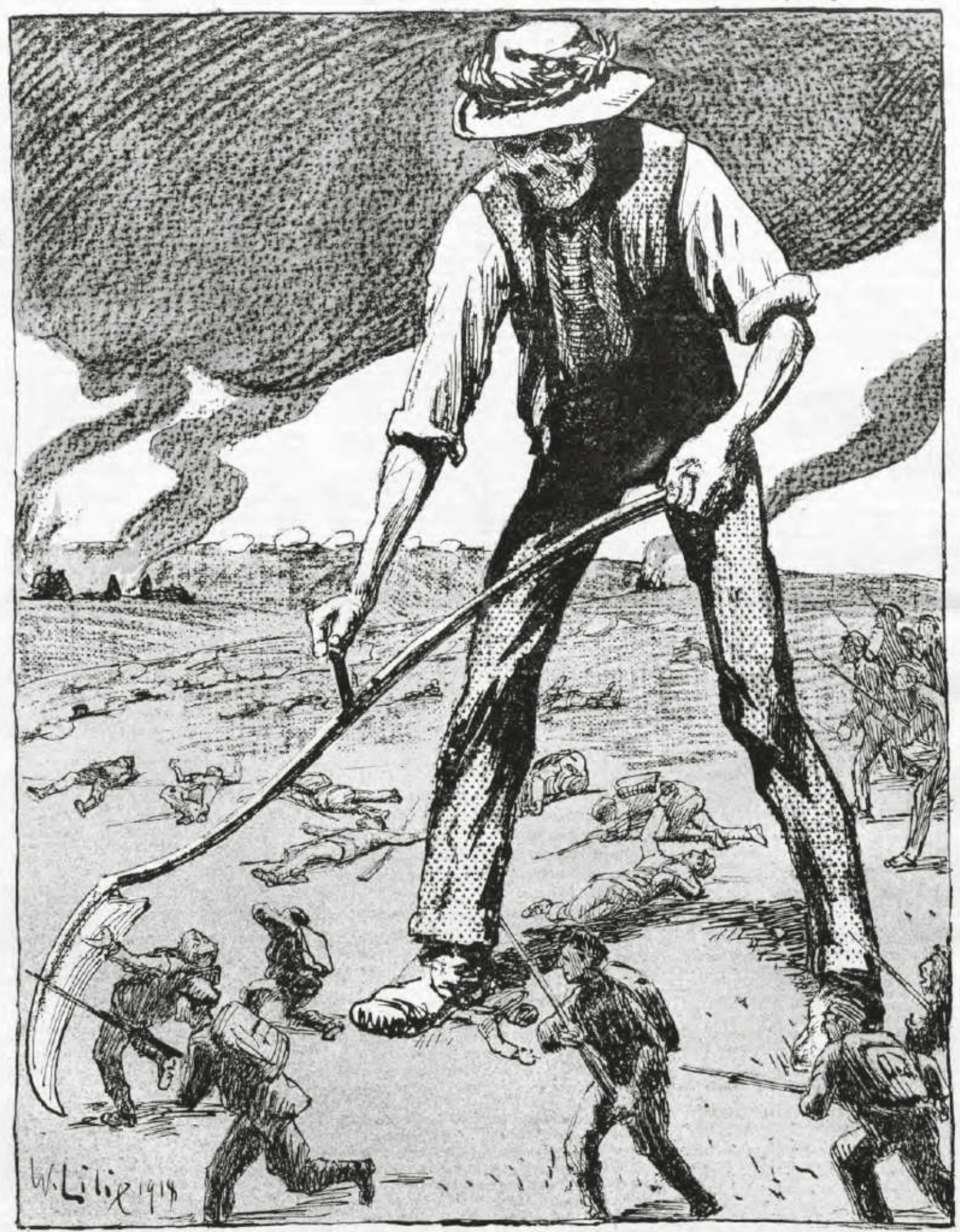

Fig. 113. Nebelspalter 1914/35, dessin pleine page en couleur de Walter Lilie intitulé « Jour de récolte » (Erntetag). 
Kriegsfrühling 1918

(Ђoidnumg von ข, Xreidalor)

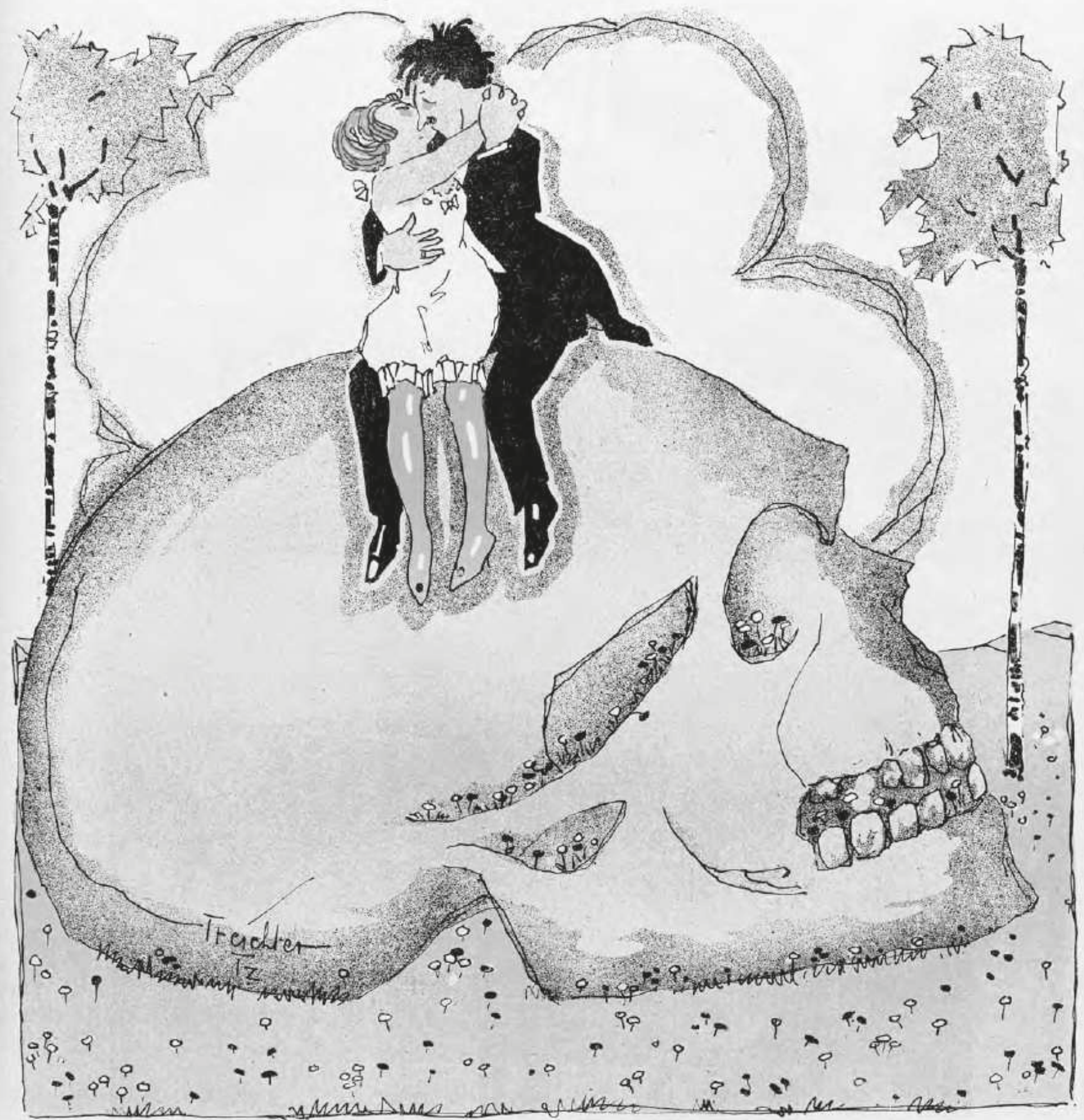


d'une couronne de laurier ${ }^{375}$. Le dessin est une condamnation radicale et non partisane de la guerre. Dans « Les palmes de la paix » (Friedenspalmen), un ange de la paix avance, une palme à la main, devant une montagne de crânes auxquels sont mêlées palmes et couronnes. Le crâne est ici démultiplié pour accompagner un ange de la paix mortifère ${ }^{376}$. En soi, l'efficacité de cette image assez terne est incertaine, mais sans doute la répétition du motif a-telle permis de marquer les esprits. "Printemps de guerre I9I 8 » (Kriegsfrübling I9I8) de Arthur Treichler est tout simplement stupéfiant: un couple s'embrasse gentiment au sommet d'un crâne géant ${ }^{377}$ (cf. fig. I I5).

C'est ici moins la présence du crâne qui agit que l'incongruité de son association à une scène intime et à un titre léger.

Un autre ressort de ce système référentiel repose sur le décalage entre une image à l'iconographie et aux moyens formels peu agressifs et une légende ou un titre au ton et à la teneur radicalement inverses; ou bien le contraire. Cet humour noir, basé sur un usage aigu de la litote, est rare. Il est généalogiquement redevable aux revues françaises et provoque dans le Nebelspalter, réputé consensuel, un certain effroi. Elle est, par exemple, à l'œuvre dans la légende "Du théâtre des opérations occidentales " (Vom westlichen Kriegsschauplatz), où l'hécatombe est lapidairement transmise par un pseudo-télégramme indiquant " le calme le plus total » ainsi que dans "Printemps de guerre I9I 8 » (Kriegsfrühling I9I 8) ${ }^{378}$. "Déjections de pigeons " (Taubenschießen) est de cette sorte. Un avion est en train de larguer des explosifs. Le texte, au-dessus de l'image, est ironique et factuel. Il répercute une interdiction des lâchers de pigeons par le département militaire. La légende est moins inoffensive: "Si simplement ils pouvaient également interdire le tir des pigeons, cela suffit amplement qu'ils tirent sur les hommes! »379 «La colombe de la paix de la Chaux-deFonds " (Die Friedenstaubevon La-Chaux-de-Fonds), qui fait écho au bombardement, par erreur, de la ville par l'aviation allemande, le I7 octobre I9I4, est de la même veine. La construction est antithétique: dans le panneau de gauche, un groupe de personnes lève les yeux au ciel en s'exclamant «Ah! Une colombe de la paix » (Ah! Eine Friedenstaube!); les mêmes s'enfuient dans le panneau de droite, pour échapper à l'explosion ${ }^{380}$. Au printemps I9 I 5 , une scène de front, située quelque part dans la campagne, frappe davantage. Au premier plan, des hommes - des Allemands, reconnaissables à leur casque - et un cheval gisent. Le dessin est titré « Ô, comme le printemps est beau » (Ô, wie wunderschön ist die Frühlingzeit) ${ }^{381}$. Mais «Fata Morgana », publiée en novembre I9I7, est sans doute la plus perturbante de ces compositions. Le titre définit une illusion optique. L'image présente une scène de désolation dans les tons rougeâtres, où gisent, se prosternent, s'effraient - selon le personnage - soldats, commandants de guerre,

Nebelspalter 1914/43, dessin pleine page de Boscovits junior intitulé « Les quatre éléments » (Die vier Elemente).

${ }_{376}$ Nebelspalter 1916/22, couverture de Boscovits senior intitulée « Les palmes de la paix » (Friedenspalmen).

Nebelspalter 1918/19, dessin pleine page de Arthur Treichler intitulé «Printemps de guerre $1918 »$ (Kriegsfrühling 1918).

${ }^{378}$ Nebelspalter 1914/37, dessin pleine page de Boscovits senior intitulé « Du théâtre des opérations occidental » (Vom westlichen Kriegsschauplatz); Nebelspalter 1918/19, dessin pleine page de Arthur Treichler intitulé « Printemps de guerre $1918 »$ (Kriegsfrühling 1918).

${ }^{379}$ (Wenn sie nur hier das Taubenschießen auch verbieten wollten! Es ist doch schließlich genug, wenn sie auf Menschen Schießen!); Nebelspalter 1914/33 dessin de Boscovits junior intitulé « Déjections de pigeons » (Taubenschießen).

380 Nebelspalter 1915/44, dessin pleine page de Boscovits junior intitulé « La colombe de la paix de la Chaux-de-Fonds » (Die Friedenstaube von La-Chaux-de-Fonds). Nebelspalter 1915/21, dessin de Boscovits senior intitulé « Ô, comme le printemps est beau » (Ô, wie wunderschön ist die Frühlingzeit). chefs d'état et profiteurs; à l'arrière-plan, dans un ciel rouge, se détache un ange de la paix immense et charmant ${ }^{382}$ (cf. fig. II6).

L'effet résulte des contradictions entre image et texte, mais également à l'intérieur de l'image, entre des éléments antagonistes.

\subsubsection{L'après-guerre: ressassements en images}

Au terme du conflit, suspension de la publication et « rappel au rire » se répètent. Après la signature de l'armistice, le I I novembre I9I 8, la revue ne paraît à nouveau pas durant trois semaines ${ }^{383}$. Quelque temps auparavant, un encart rappelant la nécessité de rire en ces temps difficiles a été publiée ${ }^{384}$. Un même parallèle s'observe également quant à un réflexe de repli patriotique. Une fois l'armistice signé, la revue se recentre un court temps sur les affaires intérieures. Ainsi, la couverture du numéro datée du 23 novembre I9 8 est consacrée aux affaires intérieures, tranchant avec les numéros précédents, ouvrant sans exception sur la guerre. La guerre reprend, cependant, immédiatement ses droits et, en I9 I9, la moitié des images le thématise, soit une proportion égale à celle des années de conflit. Même si la présence de la guerre recule à partir de I920, la revue continue d'ouvrir et de fermer l'année sur la guerre et ses conséquences, ce qui ne sera pas le cas en I92I.

Le parallèle entre les périodes de guerre et d'après-guerre s'arrête, toutefois, ici. Si certains thèmes qui ont traversé la guerre continuent d'exister sur une tonalité comparable - l'Europe en danger, le bolchevisme, l'épidémie (Seuche) et la faim (Hunger) -, d'autres revêtent une orientation plus nette. C'en est ainsi définitivement fini d'une ambiguité qui a marqué beaucoup des compositions de guerre: le discours tenu à l'endroit des profiteurs, des "gauchistes " de toute sorte, des actes et tractations des désormais ex-belligérants, de la désagrégation de l'Europe, de l'horreur de la guerre, est à présent univoque et la plupart du temps radical. Un soutien indéfectible envers l'Allemagne est maintenant affiché. Au jeu de quilles, la Suisse et ses habitants ne sont pas même épargnés. De nouveaux thèmes liés aux suites de la guerre apparaissent enfin: la crise économique, les bouleversements sociaux, la Société des Nations, les conflits dérivés de la Première Guerre mondiale, les traités de paix et les réparations, et, pour finir, la nouvelle carte de l'Europe et son lot de souverains déchus.

La dénonciation des maux liés à la guerre, de tout temps présente, se perpétue, une fois la guerre finie. "L'Europe reconnaissante " (Das dankbare Europa) de Boscovits junior ne laisse aucune ambiguïté quant " aux vrais vainqueurs de la Guerre mondiale » (Den wahren Siegern im Weltkriege), allégorisés et nommés dans un monument qui leur est dédié385: ce sont la faim (Hunger), l'épidémie (Seuche) et le bolchevisme (Bolchevism) (cf. fig. II7).

Le numéro clôturant l'année I9 8 renferme deux compositions montrant les augures sous lesquels s'ouvre l'année r9 I9: l'une, pathétique et dénuée de commentaires, montre la figure d'Europe en haillons devant un champ de ruines ${ }^{386}$; l'autre, explicite mais ambiguë, combine la légèreté du Jugendstil avec la représentation

\footnotetext{
${ }_{382}$ Nebelspalter 1917/43, couverture de S.Mohr intitulée « Fata Morgana ».

${ }^{383}$ Le numéro 45 est daté du 9 novembre, le numéro 46 est daté du 23 novembre.

384 Nebelspalter 1918/13, encart intitulé « Humour » (Humor).

${ }_{385}$ Nebelspalter 1918/44, dessin pleine page de Boscovits junior intitulé « L'Europe reconnaissante » (Das dankbare Europa).

${ }_{386}$ Nebelspalter 1918/51, couverture de Alfred Hirschler intitulée « En avant vers la nouvelle année » (Ins neue Jahr hinein).
} 
Ү(o. 43. 47. Jahrgang.

כärich, den 24. 2lovember 1917.

(Einzelnummer $30 \mathrm{c} / \mathrm{s}$.

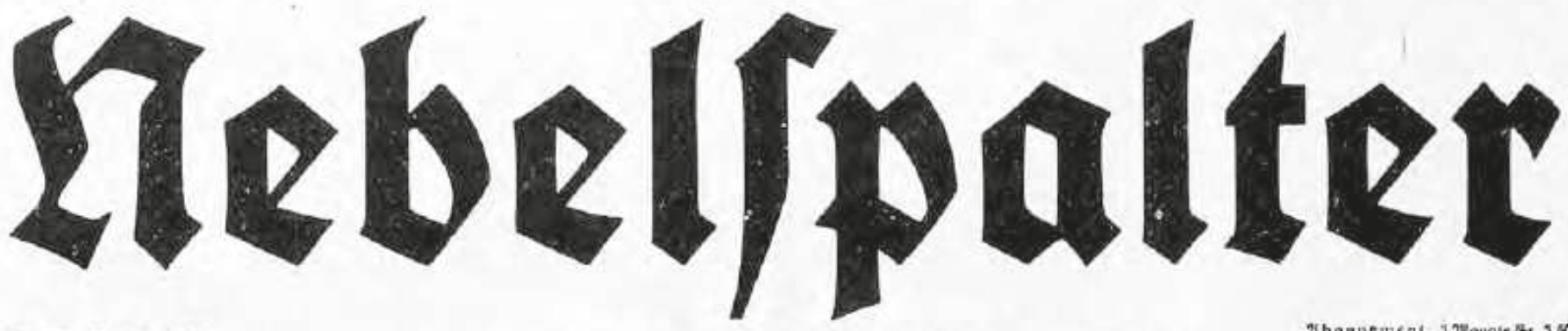

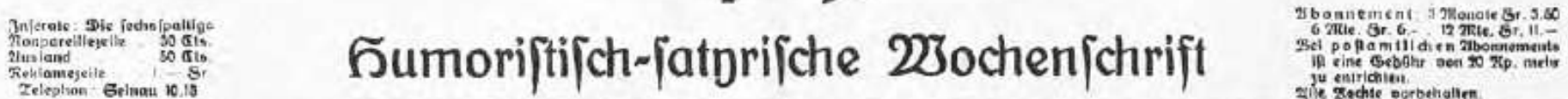

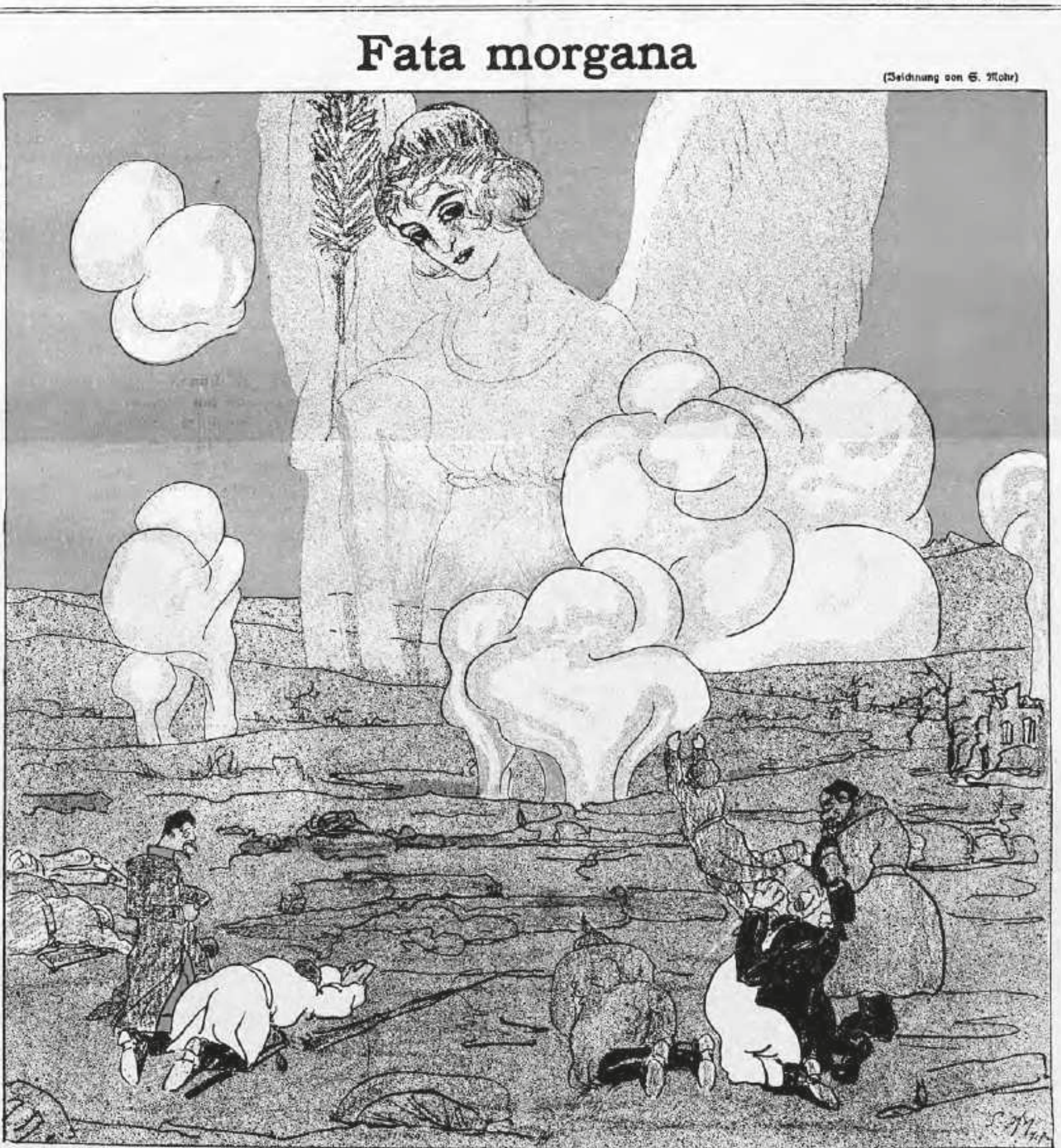

Fig. 116. Nebelspalter 1917/43, couverture en couleur de S.Mohr intitulée « Fata Morgana ». 


\section{Das „dankbare“ Europa.}

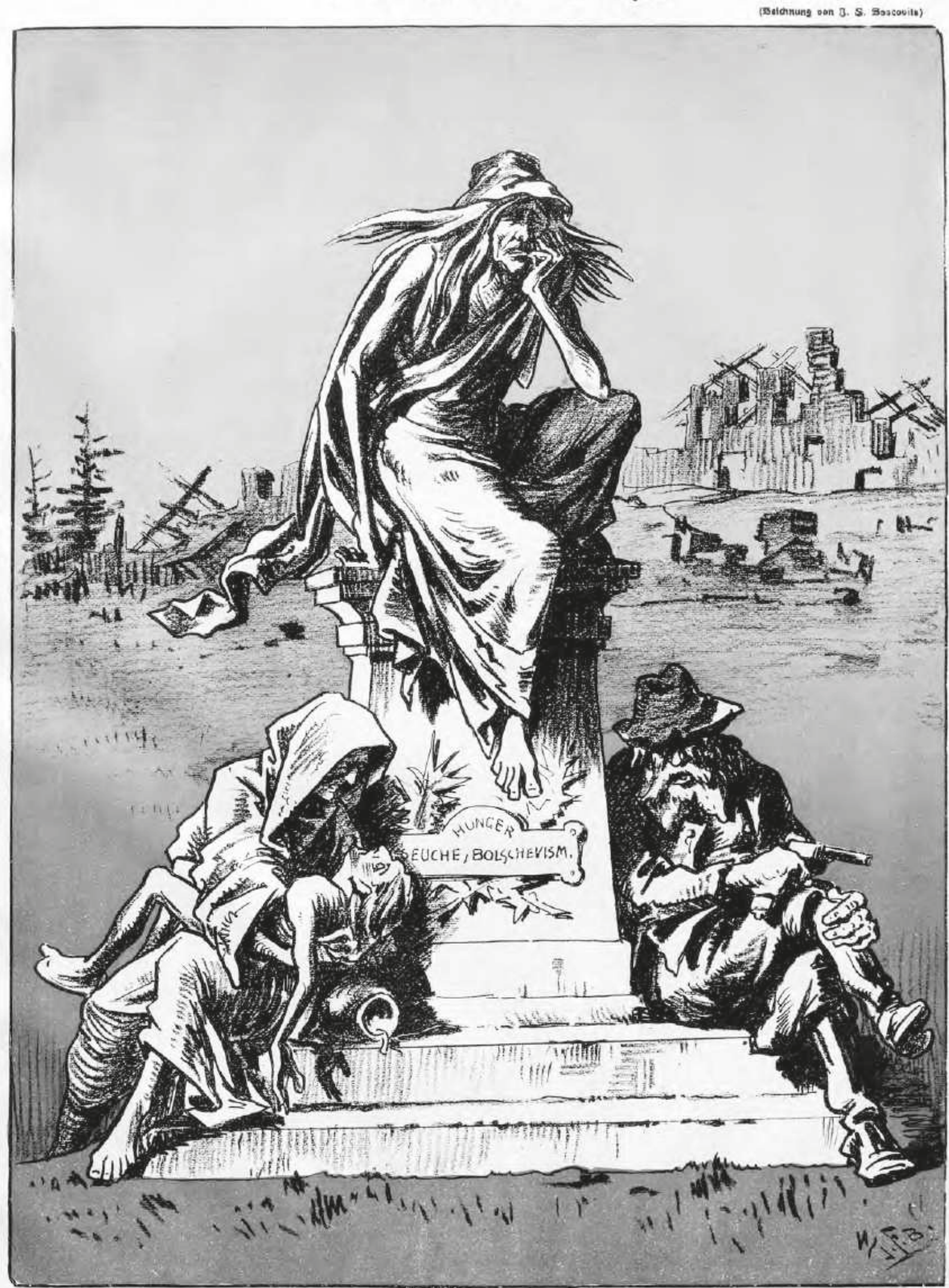

Den rohren Giegern im 23eltkriege. 
crue de squelettes et crânes ${ }^{387}$. Les maux de l'époque sont à nouveau nommés dans cette seconde image : misère (Elend), guerre (Krieg), épidémie (Seuchen) et famine (Hungersnot). Ces deux images ont en commun de refléter la réalité des combats, à l'inverse de nombreuses images des années de guerre. Tel est également le cas de la couverture qui ouvre l'année I9I9, où la figure grotesque d'un Chronos en ange de la paix surplombe un monde mis à feu et à sang ${ }^{388}$. Les cibles prennent progressivement une coloration plus idéologique et morale, et la «Boite de Pandore " (Die Buchse der Pandora) de la fin de l'année I9 I9 ${ }^{389}$ renferme, aux côtés de la guerre (Krieg), de l'indigence (Not) et des épidémies (Seuchen), la démagogie (Demagogentum), la terreur (Terror), la cupidité (Habgier) et la révolution (Revolution). À la fin de l'année I92I, "Les Champignons vénéneux » (Die giftigen Pilze) consisteront dans le militarisme (Militarismus), le bolchevisme (Bolchevismus) et les profiteurs (Schiebertum) ${ }^{390}$. À l'endroit de ces derniers, le Nebelspalter montre une rancœur toujours plus forte et les expose un à un: industriels de guerre, petits magouilleurs, Américains sans scrupules ou juifs cupides, tellement infâmes que même le diable ne peut les digérer dans "Indigeste"(Unverdauliches) ${ }^{391}$. Ceci dit, le mal suprême est un bolchevisme, incessamment montré du doigt et fréquemment assimilé au socialisme et au communisme. C'est néanmoins sur un mal plus fort encore que se conclut l'année I92 I : la famine. La sentence d'une caricature titrée « Plus puissant que Lénine » (Mächtiger als Lenin) est claire: "Là où je règne, se trouve le vrai communisme " ${ }^{392}$. Cette même année I92 I est dénoncée la pratique du tourisme de guerre, consistant à organiser des voyages sur les champs de bataille ${ }^{393}$, symptôme d'une perversion mémorielle, indiquant aussi une certaine distance émotionnelle vis-à-vis de la guerre.

Le règlement de la paix est une question qui occupe la rédaction de manière intensive. La Suisse, affaiblie économiquement, a tout intérêt à ce que la guerre cesse au plus tôt ${ }^{394}$. Le Président américain Wilson est vu comme le maître de la paix: "Si cela ne vous convient pas, je reprends le petit ", dit-il en parlant de Friede, l'allégorie de la paix ${ }^{395}$. Rares sont les compositions à la teneur positive, telle celle où l'armistice est présenté par l'ange de la paix comme le cadeau de Noël à l'Europe ${ }^{396}$. Jusqu'au Traité de Versailles, l'urgence d'un aboutissement des négociations devant le danger d'une Révolution mondiale est répétée ${ }^{397}$, tandis que l'on s'inquiète de la perspective de trop lourdes

Nebelspalter 1918/51, dessin pleine page de Boscovits junior intitulé « 1919 ».

${ }_{388}$ Nebelspalter 1919/1, couverture de Alfred Hirschler intitulée « Quand la paix arrive " (Wenn der Friede kommt).

389 Nebelspalter 1919/48, dessin pleine page de Boscovits junior intitulé « La boite de Pandore » (Die Buchse der Pandora).

390 Nebelspalter 1921/49, couverture signée « $A M$ » intitulée « Les champignons vénéneux » (Die giftigen Pilze).

${ }_{391}$ Nebelspalter 1920/36, dessin pleine page non signé intitulé «Indigeste » (Unverdauliches).

${ }^{392}$ (Wo ich herrsche, da ist wahrer Kommunismus); Nebelspalter 1921/50, dessin pleine page non signé intitulé « Plus puissant que Lénine » (Mächtiger als Lenin)

393 Nebelspalter 1921/16, couverture de Boscovits junior intitulée « Voyages sur les champs de bataille » (Schlachtfelder-Fahrten).

394 Jean-Claude Favez (éd.), Nouvelle histoire de la Suisse et des Suisses, op. cit., p. 686; Volker Reinhardt, Geschichte der Schweiz, Munich, Beck, 2006, p. 106 Pierre Renouvin, La crise européenne et la Première Guerre mondiale, op. cit. p. 344-345.

395 (Wenn es euch nicht passt, nehme ich den Kleinen wieder mit); Nebelspalter 1918/44, dessin pleine page de Alfred Hirschler intitulé "Comme il vous plaira » (Wie es euch gefällt); numéro daté du 2 novembre 1918; Nebelspalter 1918/48, couverture de S. Möhr intitulée «Wilson voyage à Paris » (Wilson fährt nach Paris).

396 Nebelspalter 1918/50, couverture en couleur de Boscovits junior intitulée « L'enfant Jésus » (Das Christkind).

${ }^{397}$ Nebelspalter 1919/15, dessin pleine page de Boscovits junior intitulé « À propos des négociations de paix » (Zu den Friedensverhandlungen); Nebelspalter 1919/16 dessin de Boscovits junior intitulé « CEuf de Pâques 1919 » (Ostereier 1919). réparations qui laisseraient l'Allemagne exsangue ${ }^{398}$, ainsi que de la pression imposée au Président allemand Friedrich Ebert, signataire du Traité ${ }^{399}$. Au lendemain de l'armistice, Victor Hardung, poète d'origine allemande, publie la « Prière pour les victimes assassinées " (Gebet der Gemordeten ${ }^{400}$. Peu après, un dessin montre des Allemands qui devront marcher pieds nus leur vie durant ${ }^{401}$. Ce penchant germanophile a pour pendant une violente critique des Alliés, en particulier la France ${ }^{402}$. Dans «Le ravissement du gagnant» (Die Wonne des Siegers), Foch apparaît comme un personnage honni, responsable de l'anéantissement du peuple allemand, figuré par une multitude de visages émaciés ${ }^{403}$. Plus que toutes autres figures, Wilson et Clémenceau sont regardés comme les responsables des morts, puis de la mauvaise conduite des négociations et, par conséquent, d'un échec annoncé de la paix ${ }^{404}$.

Une fois le Traité de Versailles signé, le 28 juin I9I9, à l'issue de la Conférence de Paris, le feu des critiques est encore plus nourri, et seule une composition isolée, "La paix » (Der Friede) de Henrik, d'une tonalité étonnamment émotionnelle, salue la paix ${ }^{405}$. Les attaques sont innombrables, qu'elles soient générales et visent les appétits territoriaux des vainqueurs ${ }^{406}$ ou ciblées, contre la France revancharde ${ }^{407}$, l'Angleterre et ses envies de toute-puissance ${ }^{408}$ ou les États-Unis, s'engraissant aux dépens des Allemands ${ }^{409}$. Le Traité de Versailles et ses conséquences funestes sont inlassablement dénoncés. À la fin de l'année I920, une caricature montre l'arbre de Noël des enfants allemands garni avec les « réparations » (Wiedergutmachung), l' " occupation colorée " [de la Ruhr] (Farbige Besatzung), [le Traité de] «Versailles » et les «vaches à lait de l'oncle Sam»(OnkelSam's Milch-Kühe $)^{410}$. Ces caricatures, où la composante raciste est fréquente, vont de paire avec une attitude pro-germanique encore plus prononcée après la signature du Traité de Versailles, et réactivée à chaque événement en relation avec son application: la conférence de Paris et ses conséquences sur la devise allemande ${ }^{411}$; la conférence de Londres, précisant les sanctions ${ }^{412}$; la conférence de Washington, réglant la question du désarmement ${ }^{413}$. Ces images fonctionnent

${ }_{398}$ Nebelspalter 1919/6, couverture de Alfred Hirschler intitulée « Réparations de guerre » (Kriegsentschädigung)

9 Nebelspalter 1919/21, composition de Alfred Hirschler intitulée "Le Traité de paix " (Der Friedensvertag).

400 Nebelspalter 1918/46, poème de Victor Hardung intitulé « Prière pour les victimes assassinées » (Gebet der Gemordeten).

Nebelspalter 1918/50, dessin de Karl Czerpien intitulé « Entre Allemands » (Unter Deutschen).

"Ne Nebelspalter 1919/16, couverture de Alfred Hirschler intitulée « La gloire ».

403 Nebelspalter 1919/15, dessin pleine page de Karl Czerpien intitulé « Le ravissement du gagnant » (Die Wonne des Siegers).

404 Nebelspalter 1919/21, couverture de Fr. Röpe intitulée « Les bienfaiteurs de l'humanité » (Die Beglücker der Menschheit); Nebelspalter 1919/7, couverture en couleur de S. Mohr intitulée "Les solides bases de la paix " (Die feste Friedensgrundlage); Nebelspalter 1919/22, dessin pleine page de Fr. Röpe intitulé "L'avorton de la paix » (Die Friedensmissgeburt).

${ }^{405}$ Nebelspalter 1919/27, dessin pleine page de Henrik intitulé « La paix » (Der Friede).

406 Nebelspalter 1919/27, dessin pleine page de Boscovits junior intitulé « La paix est conclue » (Der Friede ist geschlossen).

${ }_{407}$ Nebelspalter 1920/9, dessin pleine page de Boscovits junior intitulé «Politique française » (Französiche Politik).

${ }_{408}$ Nebelspalter 1919/29, couverture de Alfred Hirschler intitulée « Le gagnant » (Der Sieger).

409 Nebelspalter 1919/51, dessin de M. Raquette intitulé « De l'homme riche et du pauvre Lazare » (Vom reichen Man und armen Lazarus).

410 Nebelspalter 1920/52, dessin pleine page non signé intitulé « La fête des enfants » (Zum Feste der Kinder).

Nebelspalter 1921/6, dessin pleine page non signé intitulé «La conférence de Paris » (Pariser Konferenz).

${ }_{412}$ Nebelspalter 1921/13, dessin de M. Raquette intitulé «Londres et les sanctions » (London und die Sanktionen).

${ }_{413}$ Nebelspalter 1921/50, dessin pleine page non signé intitulé «La " grande » conférence de Washington » (Die « grosse » Konferenz in Washington). 
45. Jahrgang. 27o. 43 .
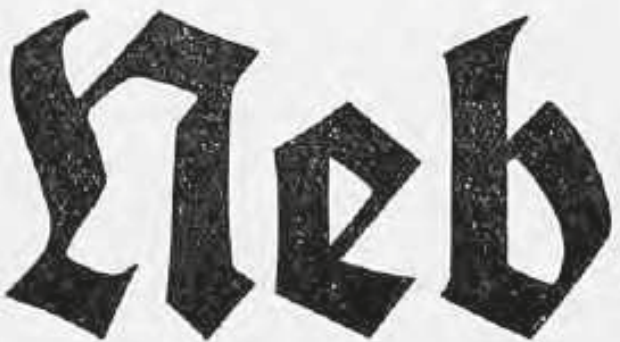

8
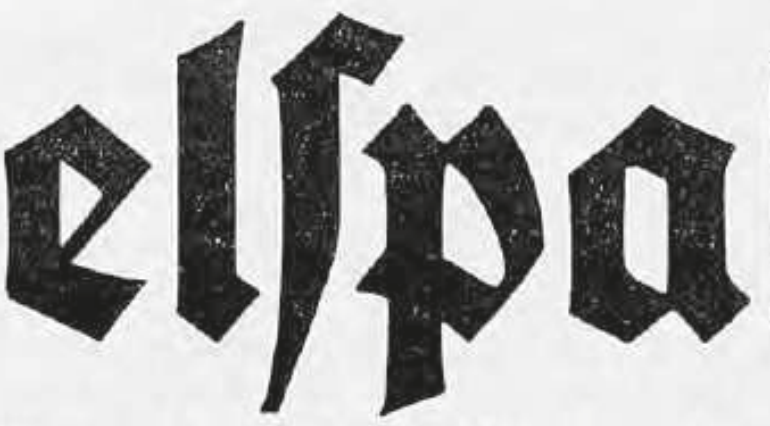

5umorifticl

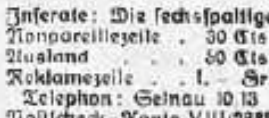

(Begründet oon Jean 2tößli und Srik Boscovits)$$
\text { Fopictiect }- \text { :oinau } 10 \text { is }
$$

Cinzelnummer $40 \mathrm{Cts}$.

\section{2lusberkauf in Wien}

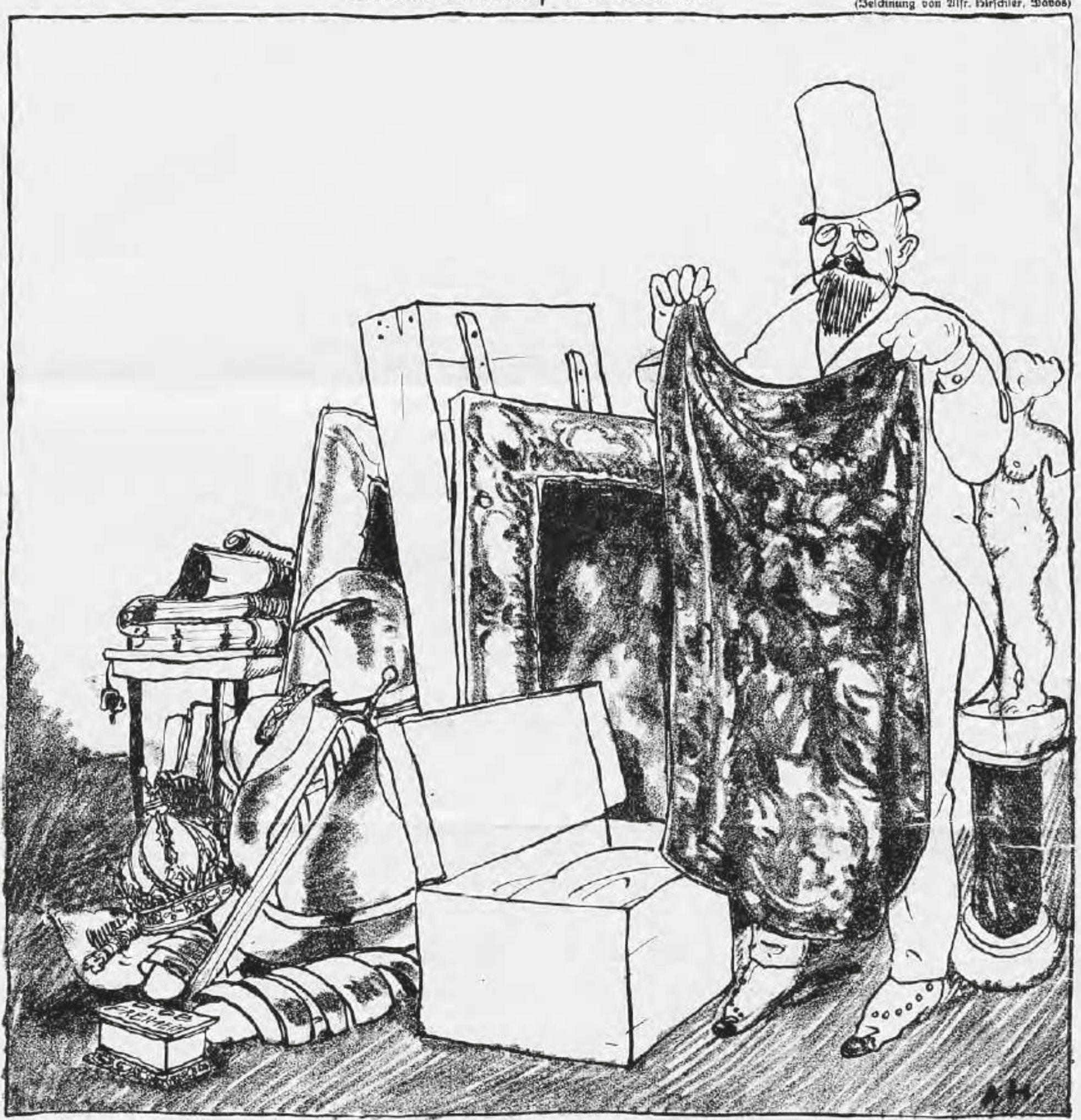

Zenner: Ferrliche Gobelins, alte guterhaltene Gemälde, Rüpungen, Kaiferkronen, Urkunden zu verkaufen!I! 
sur un ressort compassionnel: elles mettent en scène le personnage représentant l'Allemagne, le deutscher Michel, dans une position critique, écrasé, ligoté et bâillonné, carrément attaché au pilori de Versailles. À ses pieds gisent les réparations (Reparationen), les sanctions (Sanktionen), la Haute-Silésie (Oberschlesien), les mensonges sur les crimes de guerre (Kriegsverbrechenlügen) et la dépréciation monétaire (Geldentwertung).

Au cœur du programme du Président Wilson ${ }^{414}$, la Société des Nations est dès l'origine un objet de méfiance, avant de devenir un objet de défiance. Avant même sa fondation, les intentions sont suspectées douteuses, et l'on voit s'agiter autour d'un ange de la paix ingénu les représentants insincères des nations candidates $^{415}$. Lorsque la SDN siège pour la première fois, au début de l'année I920, elle est figurée en nourrisson dans les mains de Marianne, alors que l'Oncle Sam rit en coulisses, manière de dire que l'organisation est une créature hybride, mi-française, mi-américaine ${ }^{416}$. Une fois le siège de la SDN fixé à Genève, "L'ange de la paix à Genève " (Der Friedensengel in Genf) de Paul Thesing dénonce, parmi d'autres caricatures, la domination exercée par les Français, les Anglais et les Américains, maltraitant l'ange de la paix devant les Alpes suisses ${ }^{417}$. Le refus des États-Unis de rejoindre l'organisation en I92 I malgré les efforts de Wilson ne passe bien entendu pas inaperçu ${ }^{418}$, sans toutefois que l'épisode ne donne lieu à des charges répétées, comme on aurait été en droit de s'y attendre de la part d'un journal satirique très hostile aux ÉtatsUnis. Outre le reproche récurrent d'un manque d'efficacité ${ }^{419}$, la SDN est accusée de procéder à un partage absurde des territoires, telle la Haute-Silésie écartelée entre la Pologne et l'Allemagne ${ }^{420}$ ou le Tyrol partagé entre l'Autriche et l'Italie ${ }^{421}$.

L'une des thématiques les plus présentes consiste, en effet, dans la nouvelle géographie politique du monde, et surtout de l'Europe. Celle-ci est visuellement connectée à la tradition du memento mori. C'est d' "Une gueule de bois phénoménale » (Der grosse Katzenjammer) dont souffrent les souverains déchus se lamentant sur un crâne tenant lieu de globe ${ }^{422}$. Les caricatures concernant les changements territoriaux et politiques, en Autriche-Hongrie, en Russie, en Italie et en Turquie, sont légion ${ }^{423}$. Pour la renaissance de la Pologne, vue d'un mauvais œil dans le Nebelspalter, l'on convoque, une fois de plus, la Divine Comédie de Dante ${ }^{424}$. La chute des empires allemand et austro-hongrois stimule les crayons des dessinateurs. On s'intéresse de très près au nouveau destin républicain de l'Allemagne, en affichant une nostalgie de la Prusse bismarckienne ${ }^{425}$. La dislocation de l'Empire austro-hongrois

Maurice Baumont, La faillite de la paix (1918-1939), Paris, PUF, 1967, p. 50-51.

415 Nebelspalter 1918/47, dessin pleine page de S. Mohr intitulé «Société des Nations » (Völkerbund).

416 Nebelspalter 1920/8, dessin pleine page de S. Mohr intitulé « La Maman de la Société des Nations " (Die Völkerbunds-Mama).

${ }_{417}$ Nebelspalter 1920/50, dessin pleine page de Paul Thesing intitulé «L'ange de la paix à Genève » (Der Friedensengel in Genf).

${ }_{418}$ Nebelspalter 1921/18, dessin pleine page signé d'un monogramme intitulé « Viol de cadavre » (Leichenschändung).

${ }^{419}$ Nebelspalter 1921/41, dessin pleine page non signé intitulé « Société des Narions - Paix des peuples » (Völkerbund-Völkerfriede).

420 Nebelspalter 1921/44, dessin pleine page non signé intitulé « Au sujet de la division de la Haute-Silésie » (Zur Teilung Oberschlesiens).

${ }^{421}$ Nebelspalter 1921/36, dessin pleine page de Boscovits junior intitulé «En provenance du Tyrol allemand du sud » (Aus Deutsch-Südtirol).

422 Nebelspalter 1920/11, couverture de Alfred Hirschler intitulée « Une gueule de bois phénoménale » (Der grosse Katzenjammer).

${ }^{423}$ Nebelspalter 1919/35, dessin demi-page de S. Mohr intitulé «Phénomène astrologique » (Astrologisches).

424 Nebelspalter 1921/21, couverture de Boscovits junior intitulée « Les 600 ans de la naissance de Dante » (Dante-6oo Jahrfeier).

${ }_{425}$ Nebelspalter 1919/45, dessin pleine page de M. Raquette intitulé « La plante bizarre » (Der seltsame Pflanze). fascine et inquiète. La "Liquidation à Vienne » (Ausverkauf im Wien), où l'on brade tapisseries des Gobelins, peintures, armures et couronnes impériales, en est l'une des nombreuses illustrations ${ }^{426}$ (cf. fig. I I 8).

L'on se moque des souverains déchus avec une assiduité particulière à l'endroit de Guillaume II, qui fait son retour satirique dans les pages du Nebelspalter, et de Charles I. Selon le Nebelspalter, cesdeux-là aimeraient bien reprendre du service ${ }^{427}$. La brève prise de Fiume par Gabriele d'Annunzio est également tournée en ridicule ${ }^{428}$. Une vive inquiétude s'exprime quant à l'avenir d'une Europe empoisonnée par l'esprit de guerre, un fardeau trop lourd, selon Victor Straus, pour lui permettre de sortir de l'abîme ${ }^{429}$.

La guerre n'a pas épargné la société suisse et le Nebelspalter juge sévèrement les traces sociétales et idéologiques qu'elle y a laissées ${ }^{430}$. Les thèmes du danger de la révolution, de la neutralité, de la césure idéologique entre les Suisses romands et les Suisses alémaniques, des profiteurs se perpétuent après la guerre. Pour le périodique, la fin de la guerre doit d'abord coïncider avec un redressement moral, un «bon coup de balai » pour chasser les profiteurs ${ }^{431}$. Ce doit être l'occasion d'un repositionnement du pays dans le sens du droit et de la justice (Recht und Gerechtigkeit), et non du socialisme, du bolchevisme et autre impérialisme ${ }^{432}$. La thématique des profiteurs relève de l'obsession. Ceux-ci sont pointés page après page, des exilés financiers au fabricant de munitions, ces derniers clairement associés aux morts de la guerre dans «Remords" (Gewissenbisse). Deux squelettes chevauchant le franc, l'un vêtu de l'uniforme allemand, l'autre, de l'uniforme français, volent à la rencontre d'un fabricant de munitions ${ }^{433}$ (cf. fig. II9).

L'autre rappel de la réalité humaine de la guerre se fait au travers des quelques compositions dénonçant les soldats suisses morts pour la France, ayant, selon le Nebelspalter, mis en péril l'unité et la neutralité du pays. Dans "La gloire qui chante " (le titre est en français), un soldat brandissant un drapeau suisse tombe au combat $^{434}$ (cf. fig. I 20 cahier couleur). Comme le fait remarquer Hans Jenny, le propos est tendancieux, qui tait les Suisses tout aussi nombreux engagés côté allemand ${ }^{435}$. On s'inquiète cependant plus encore de la menace bolchevique aux portes de la Suisse, propice à une entrée dans l'image de Guillaume Tell ${ }^{436}$. La crainte est nourrie par la pénurie ${ }^{437}$ et les licenciements dans les usines, alors

426 Nebelspalter 1919/43, couverture de Alfred Hirschler intitulée « Liquidation à Vienne » (Ausverkauf im Wien).

27 Nebelspalter 1921/46, dessin pleine page non signé intitulé « Hohenzollern et Habsbourg » (Hohenzollern und Habsburg).

${ }_{428}$ Nebelspalter 1919/39, couverture de M. Raquette intitulée "César II devant Fiume » (Cäsar II. Vor Fiume).

429 Nebelspalter 1920/26, dessin pleine page de B. Strauss intitulé « Le relèvement de l'Europe » (Europas Wiederaufstieg).

430 Roman Rossfeld et Tobias Straumann (éd.), Der vergessene Wirtschaftskrieg. Schweizer Unternehmen im ersten Weltkrieg, op. cit., p. 46-48.

31 Nebelspalter 1918/48, dessin pleine page de Boscovits senior intitulé « Lorsque la paix s'invite » (Wenn der Friede Einkehr hält)

${ }_{432}$ Nebelspalter 1918/49, dessin pleine page de Boscovits junior intitulé « Nouvelle orientation » (Neuorientierung).

${ }_{433}$ Nebelspalter 1919/1, dessin pleine page de P. Bachmann intitulé « Remords » (Gewissenbisse).

${ }^{434}$ Nebelspalter 1919/22, couverture de Fr. Röpe intitulée « La gloire qui chante ».

435 Hans A Jenny, 111 Jahre Nebelspalter. Ein satirischer Schweizerspiegel, Rorschach, Nebelspalter-Verlag, 1985, p. 114.

${ }_{436}$ Nebelspalter 1919/37, couverture de Boscovits junior intitulée "L'hydre » (Die Hydra).

${ }_{437}$ Nebelspalter 1919/13, couverture de P. Liermann intitulée « Économie de charbon » (Kohlenersparnis) 


\section{Gervillensbiाle}

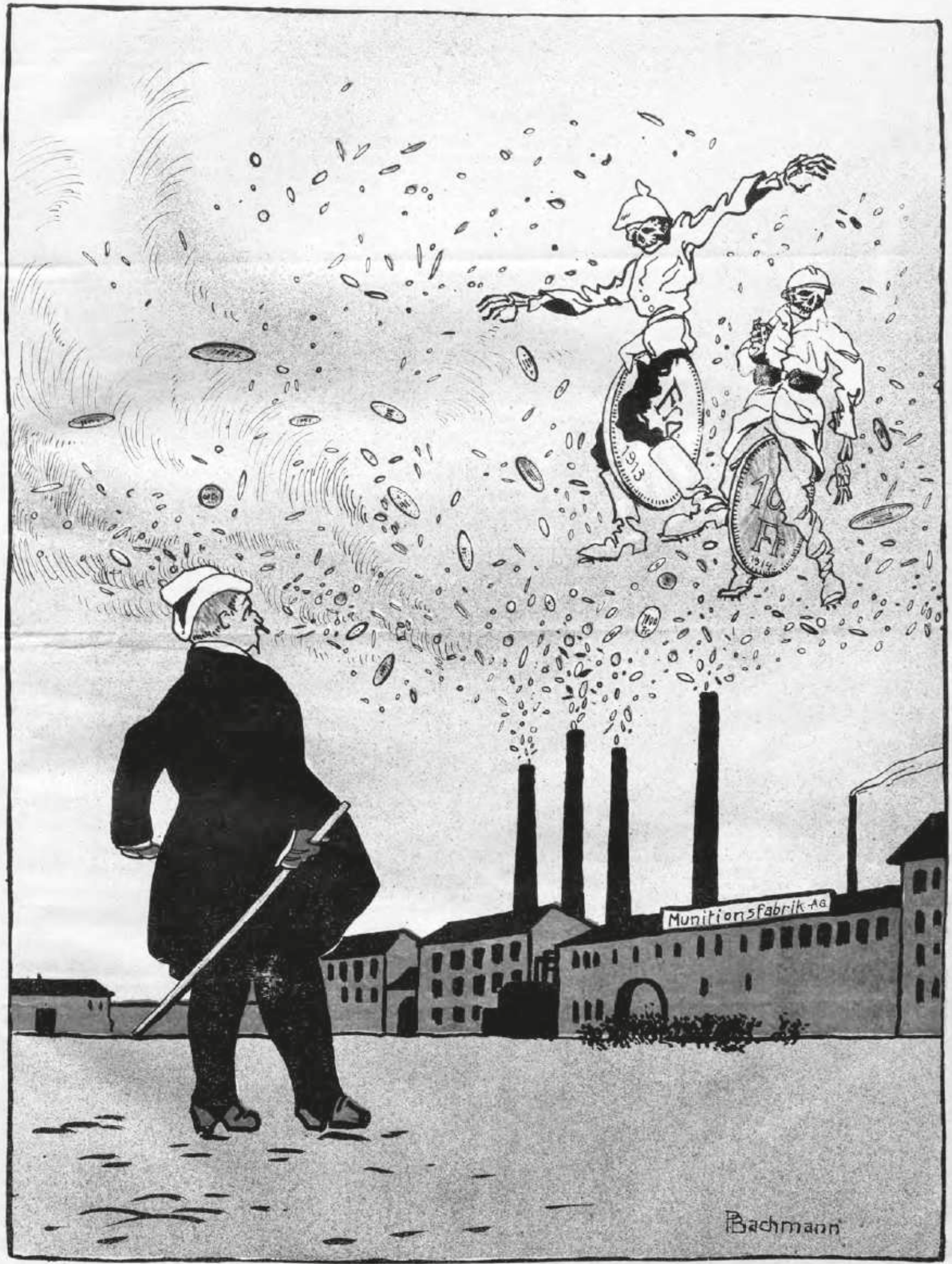

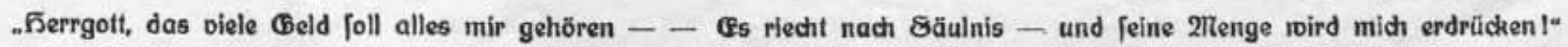


que les banquiers, eux, s'engraissent, selon les caricaturistes ${ }^{438}$. L'engrenage de la baisse des salaires et de la consommation est régulièrement dénoncé 439 .

À l'issue de la guerre se pose la question du rôle de la Suisse vis-à-vis de la Société des Nations. Le Nebelspalter suit, caustique, les négociations de la Confédération autour du principe de neutralité différentielle et des règles du commerce ${ }^{440}$. On s'y interroge aussi sur la place de la Suisse aux côtés des autres pays et surtout du géant américain ${ }^{441}$. Lorsque l'entrée de la Suisse dans la SDN est confirmée par le peuple à la faveur d'un référendum très disputé le I 6 mai I $920^{442}$, le Nebelspalter en profite pour rappeler le calvaire des Allemands soumis aux réparations, avec une citation de Golgotha et un deutscher Michel littéralement écrasé ${ }^{443}$. L'autre aspect passablement commenté concerne le choix du siège à Genève ${ }^{444}$. Sporadiquement, enfin, sont thématisés les conflits territoriaux de la zone franche de Genève 445 et la question des rives du $\operatorname{Rhin}^{446}$.

Pendant deux bonnes années, la présence de la guerre se prolonge donc avec une intensité comparable à celle des années de conflit. Elle y est cependant d'une qualité différente, à la fois mémorielle et réactualisée. Dans le premier cas, on revient sur les événements, avec, par exemple, le resurgissement de la figure du Maréchal Foch; dans le second, la guerre se prolonge, soit à travers une opération de jugement, tel un parti pris pro-germanique fort; soit via une confrontation avec la réalité sociale d'une société aux fondements dégradés; soit, enfin, en relation avec l'actualité des traités de paix. Le propos se focalise, en fait, sur certains thèmes engageant la Suisse, quand bien même ceux-ci ne lui apparaissent pas liés à première vue: la réorganisation politique, économique et sociale de l'Europe; les nouveaux rapports de force entre puissances; le danger révolutionnaire; l'émergence avec les profiteurs d'une nouvelle classe sociale. Côté graphisme, la période laisse peu de place à l'invention et dénote un infléchissement de schémas et figures iconographiques préexistants, telle la mobilisation d'un fonds religieux et d'un répertoire "bolchevique », qui s'est constitué dans les années précédentes, ou encore la renégociation des figures du deutscher Michel et de l'Europe. Le souci premier est d'alerter l'opinion sur une situation politique, sociale et économique minée. Le propos n'a visiblement pas convaincu. Pourtant, lorsque l'on regarde à présent une caricature de I9I9 intitulée "À propos des négociations de paix » $(Z u$ den Friedensverhandlungen) montrant une paix non encore conclue en I939, l'on serait tenté, à la faveur d'une lecture téléologique, de parler d'une certaine vision du Nebelspalter ${ }^{447}$.
${ }_{438} \quad$ Nebelspalter 1921/46, dessin pleine page signé d'un monogramme intitulé « En Suisse » (In der Schweiz).

${ }^{439}$ Nebelspalter 1921/30, dessin pleine page non signé intitulé « Le circuit » (Der Kreislauf).

440 Jean-Claude Favez (éd.), Nouvelle histoire de la Suisse et des Suisses, op. cit., p. 686-690; Nebelspalter 1920/19, couverture de Boscovits junior intitulée «Au sujet de la Société des Nations » (Zum Völkerbund).

${ }_{441}$ Nebelspalter 1920/5, dessin pleine page de S. Mohr intitulé « Le pendule du nouvel ordre » (Das Pendel der neuen Ordnung).

${ }_{442}$ Jean-Claude Favez (éd.), Nouvelle histoire de la Suisse et des Suisses, op. cit., 1998 , p. 687.

${ }_{443}$ Nebelspalter 1920/21, couverture de Alfred Hirschler intitulée «Après le référendum sur la Société des Nations » (Nach der Abstimmung über den Völkerbund).

444 Nebelspalter 1920/26, couverture de Alfred Hirschler sans titre.

445 Nebelspalter 1920/21, dessin pleine page signé d'un monogramme intitulé «La question de la zone » (Zur Zonenfrage).

${ }_{446}$ Nebelspalter 1919/32, dessin pleine page de S. Mohr intitulé «Au bord du Rhin Magnifique! » (Am Rhein - O wie herrlich!).
${ }_{447}$ Nebelspalter 1919/13, dessin pleine page de S. Mohr intitulé «À propos des négociations de paix » (Zu den Friedensverhandlungen). 


\section{TROISIÈME PARTIE}

\section{CULTURE, ART ET POLITIQUE: DISCOURIR ET PRENDRE SA PLACE}




\section{Zürich 1899. XXV. Jahrgang NN.58. 30 Dezember.}

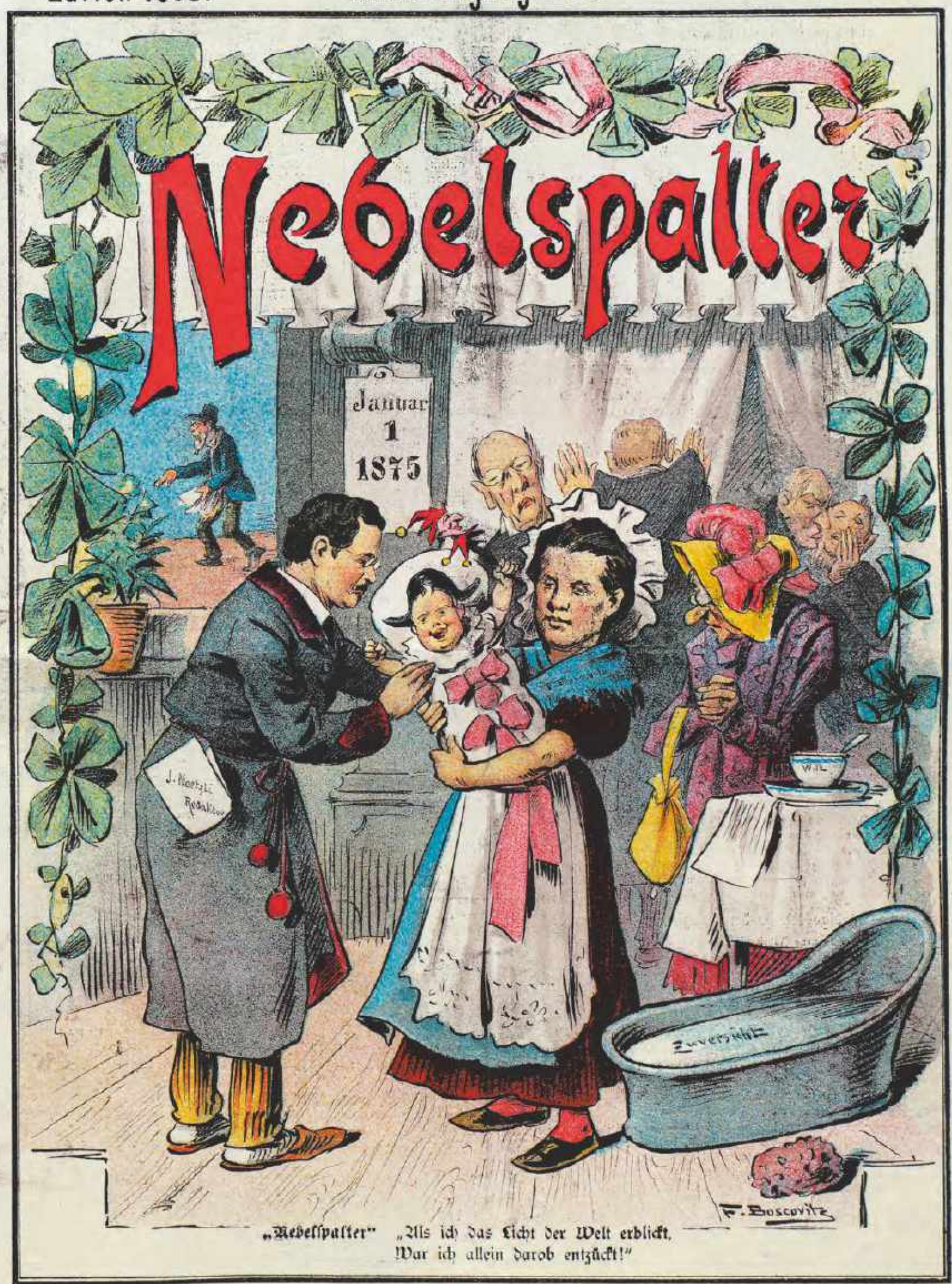

Fig. 1. Nebelspalter 1899/52, couverture en couleur de Boscovits senior. 


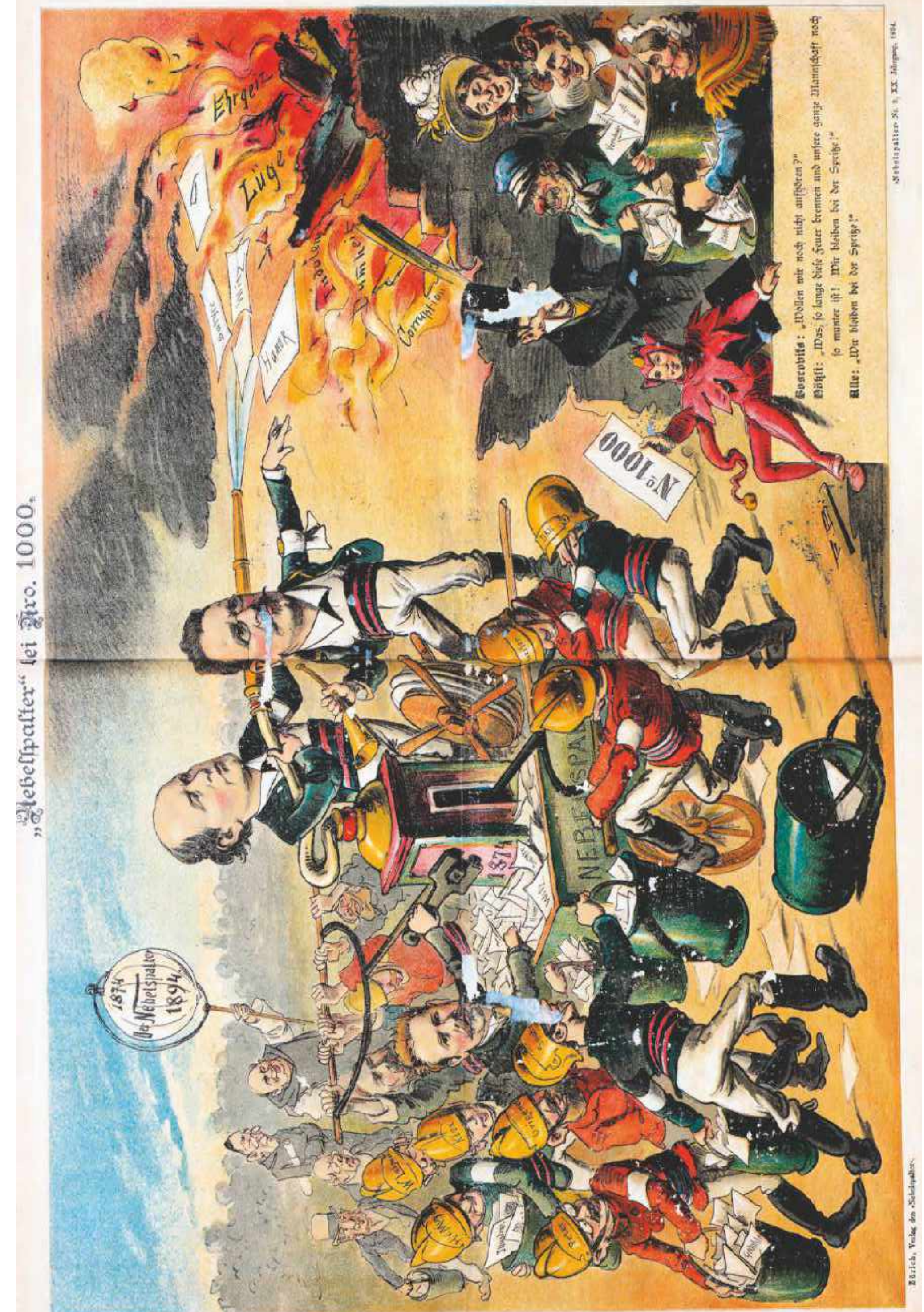




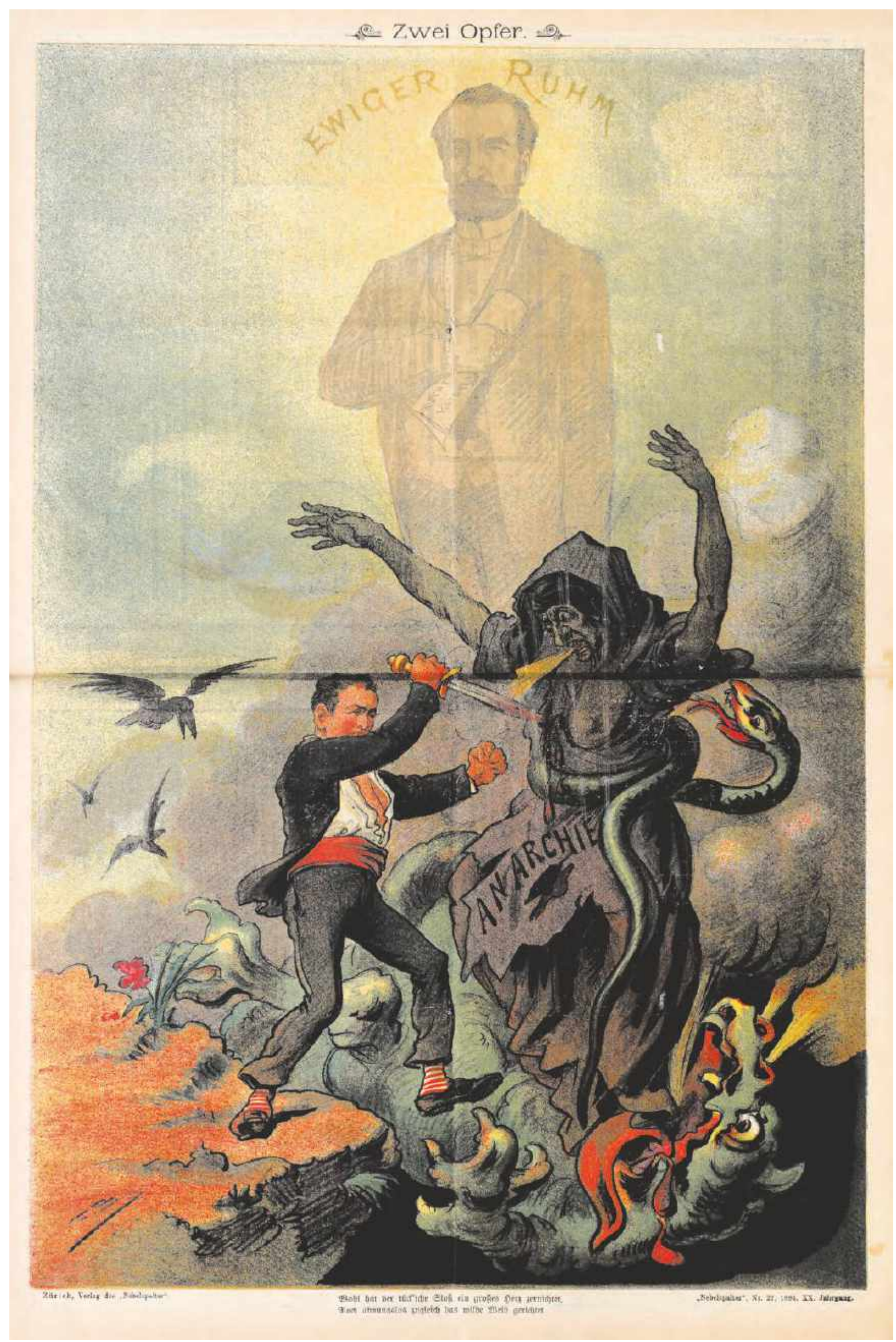

Fig. 18. Nebelspalter 1894/27, double-page en couleur de Boscovits senior intitulée « Deux victimes » (Zwei Opfer). 


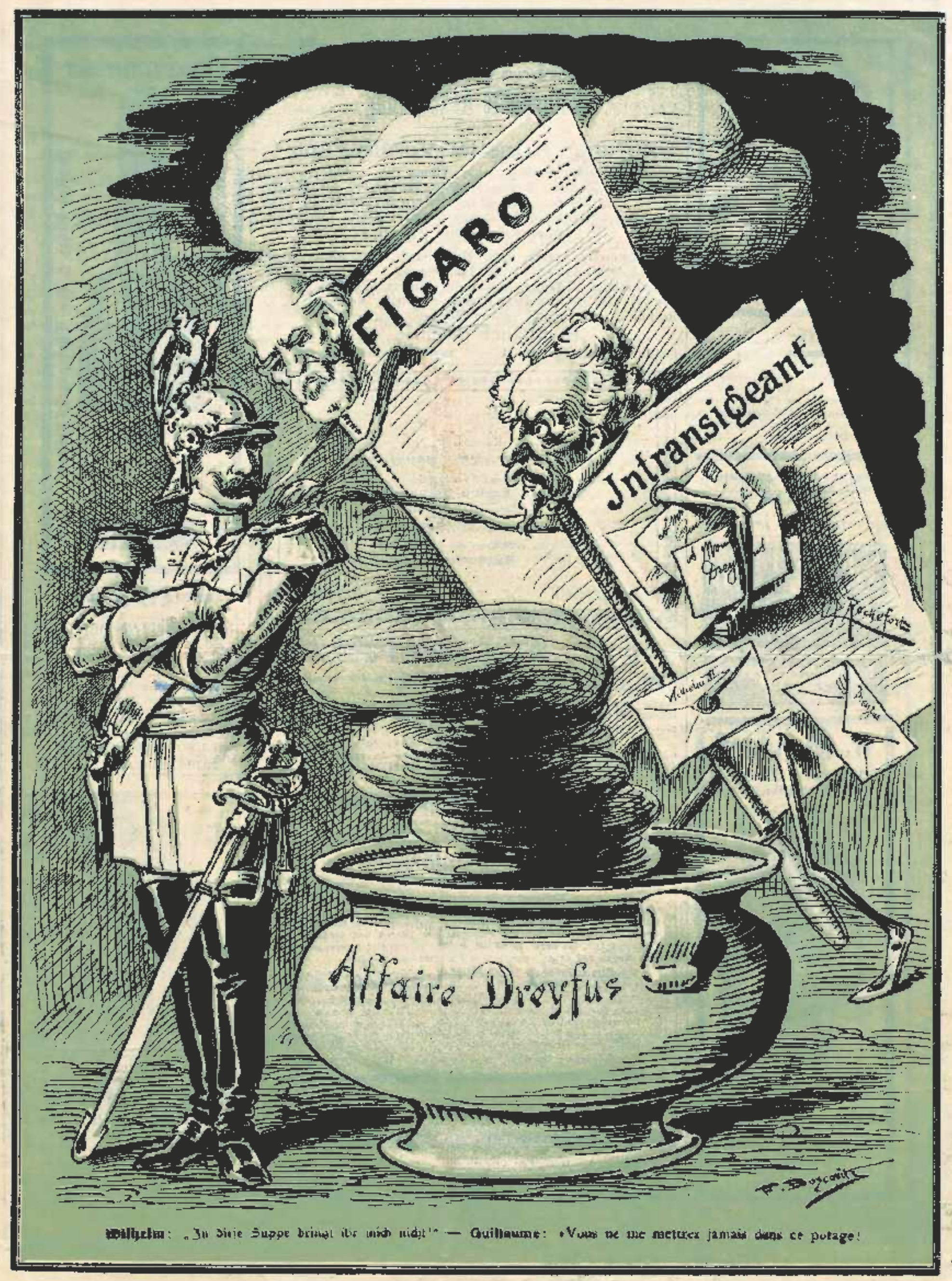

Fig. 20. Nebelspalter 1898/1, dessin pleine page en couleur de Boscovits senior intitulé « Affaire Dreyfus ». 
Zürich 1899.

XXV.Jahrgang N:39.

30. September.

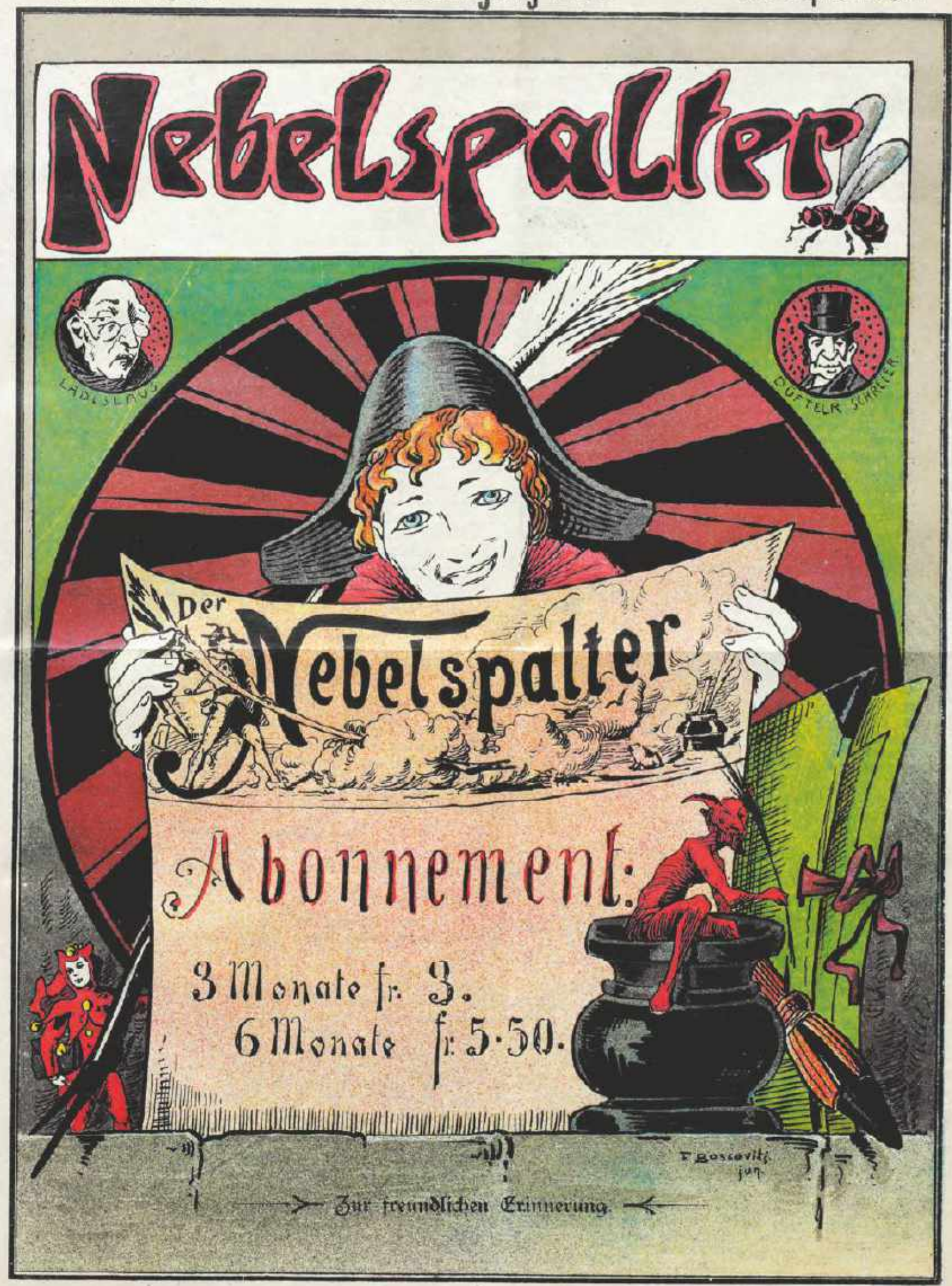

Fig. 28. Nebelspalter 1899/39, couverture en couleur de Boscovits junior intitulée « À la nouvelle année 1888 ! » (Prosit Neujahr 1888 !). 


\section{Zürich $1897 . \quad$ XXIII. Jahrgang N. $31 . \quad$ 31 Juli.}

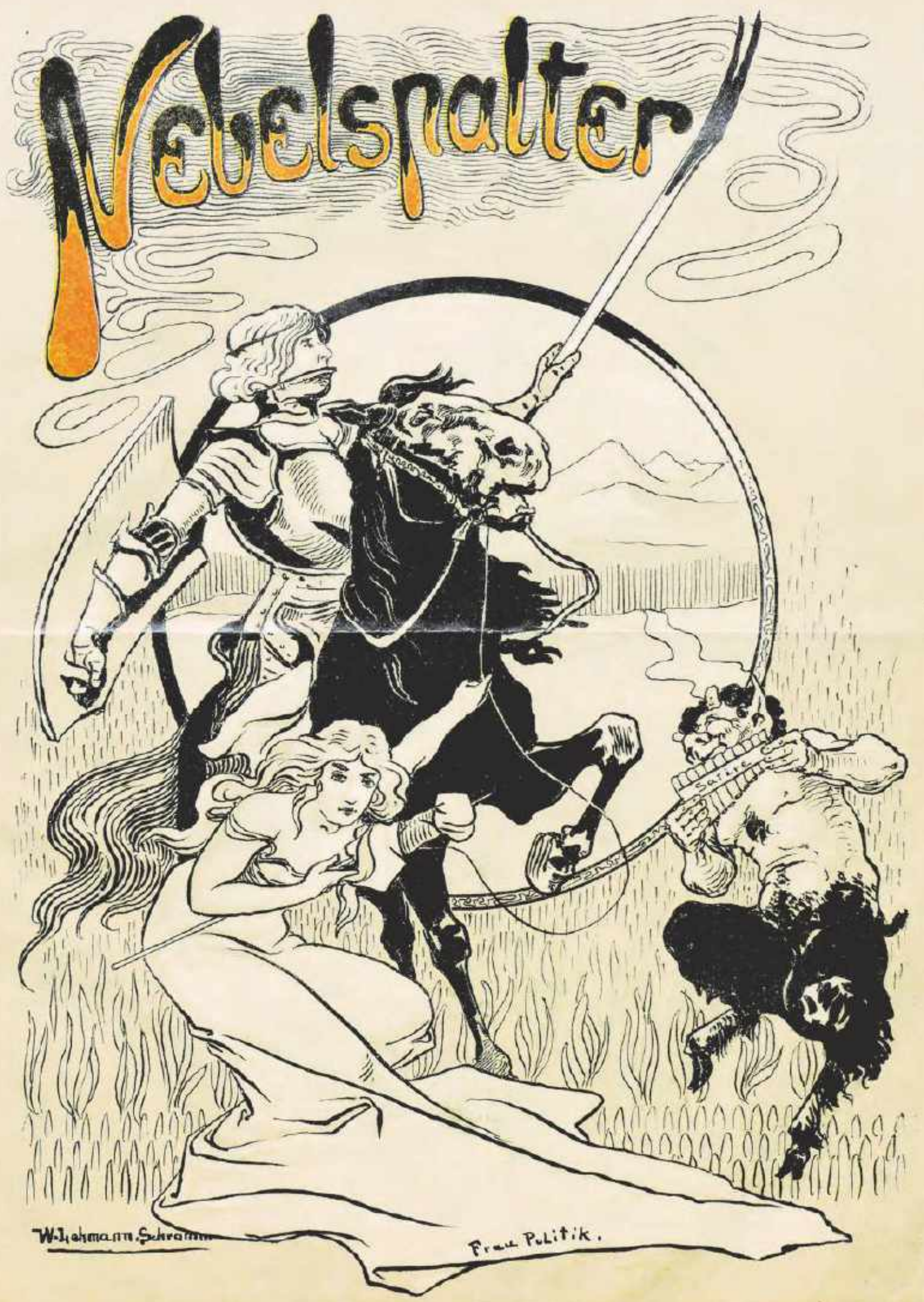

Fig. 29. Nebelspalter 1897/31, couverture en couleur de Willy Lehmann-Schramm. 


\section{Zürich $1898 . \quad$ XXIV.Jahrgang N.15. 9. April.}

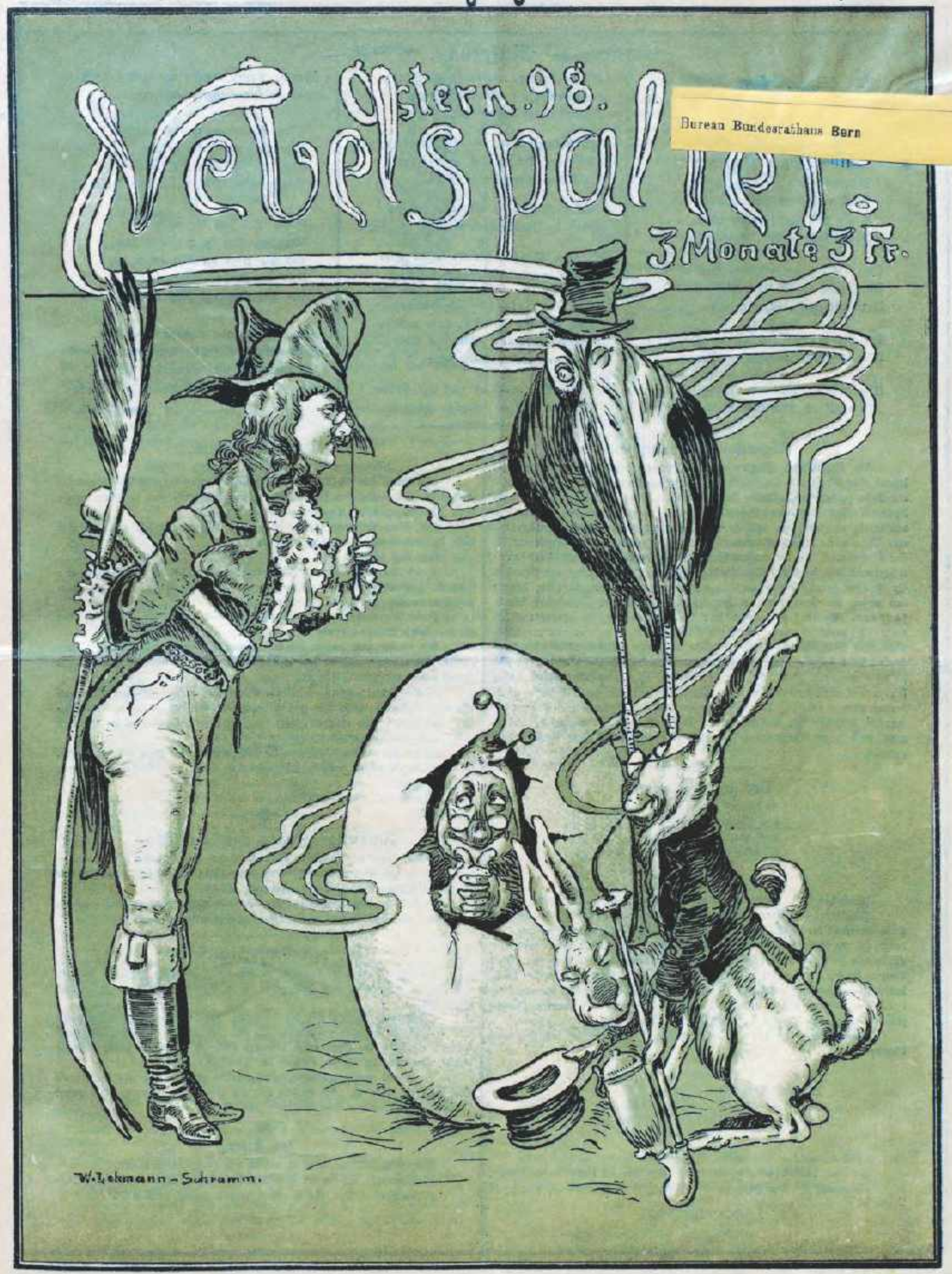

Fig. 30. Nebelspalter 1898/15, couverture en couleur de Willy Lehmann-Schramm. 


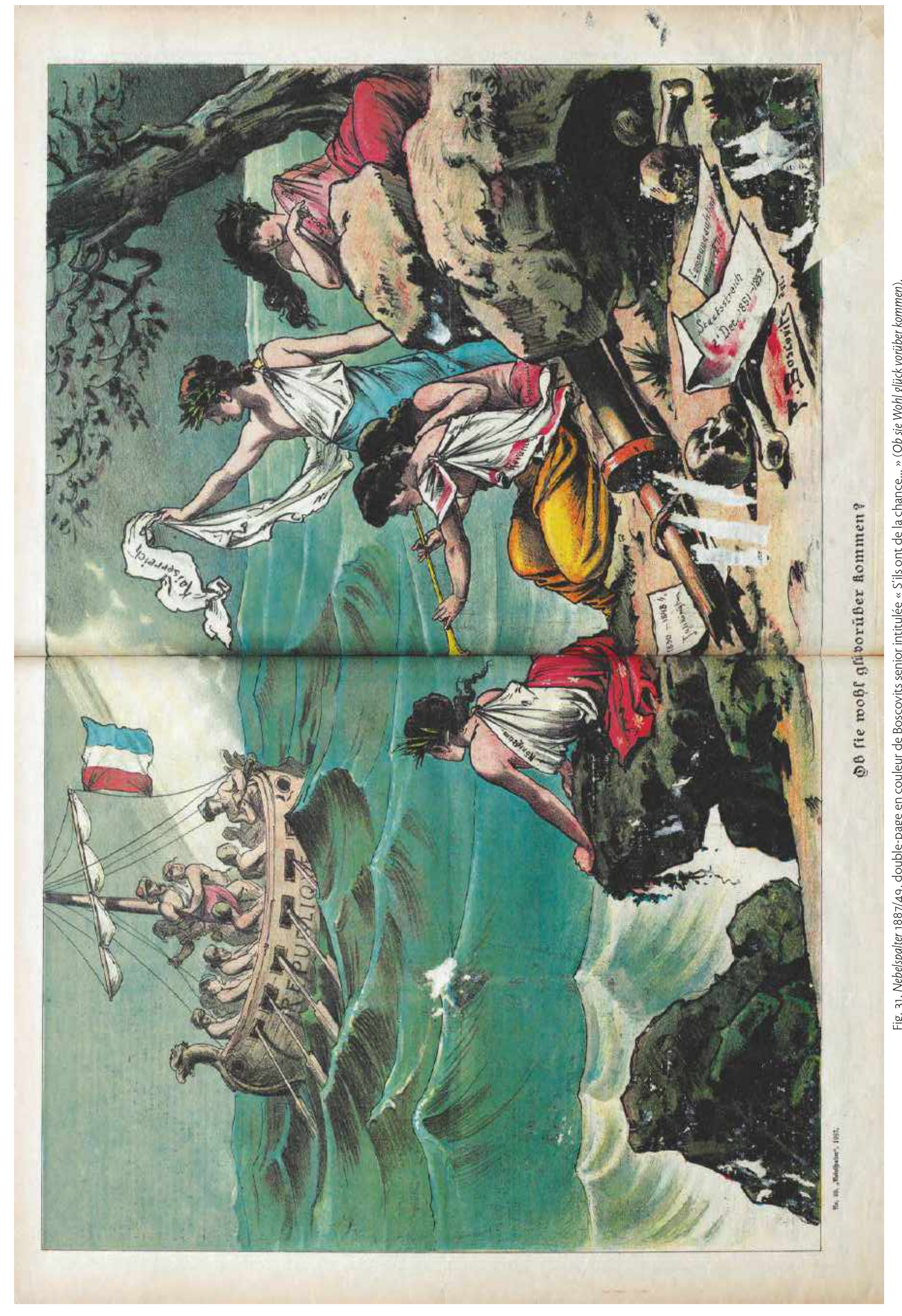




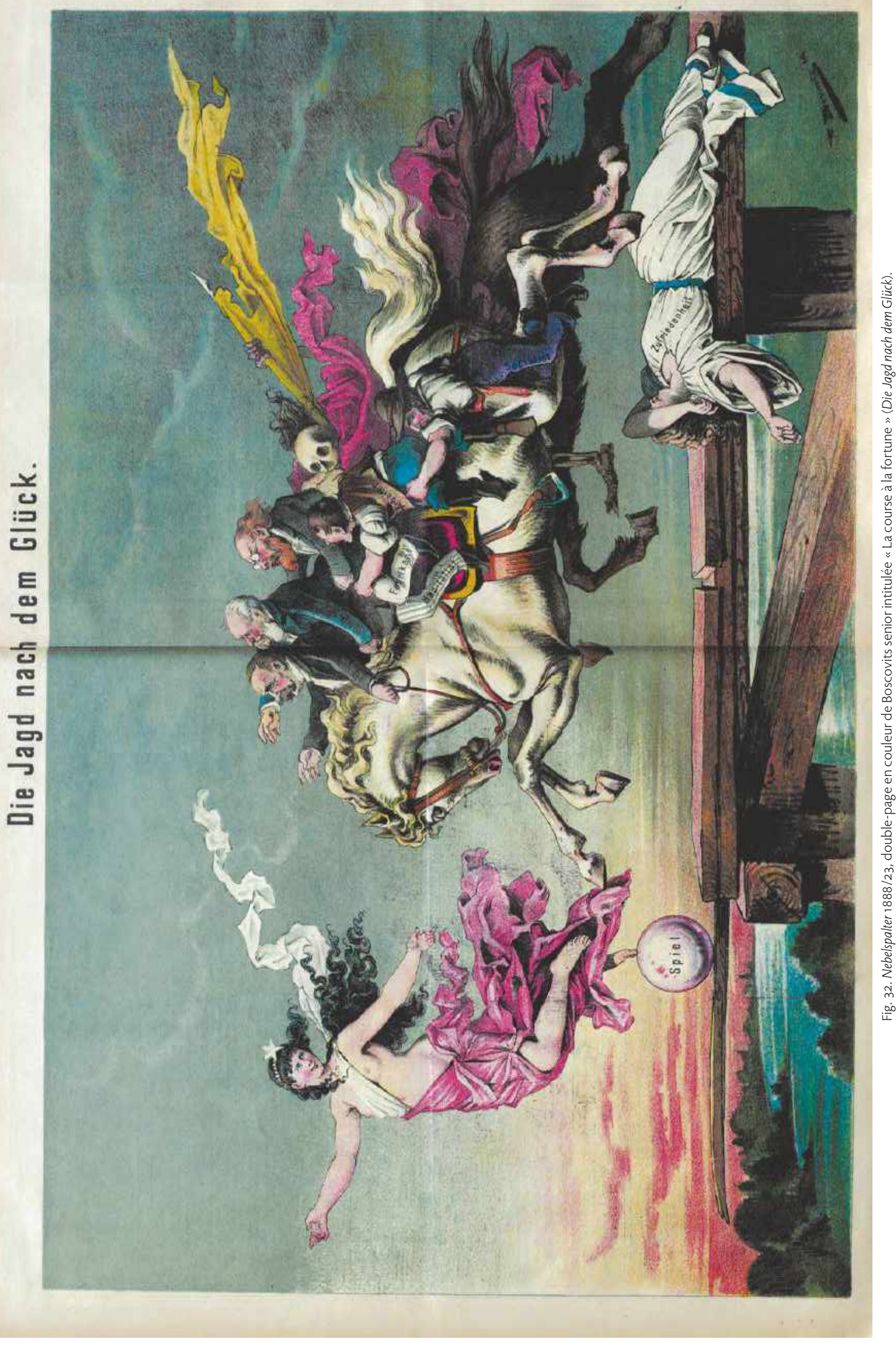




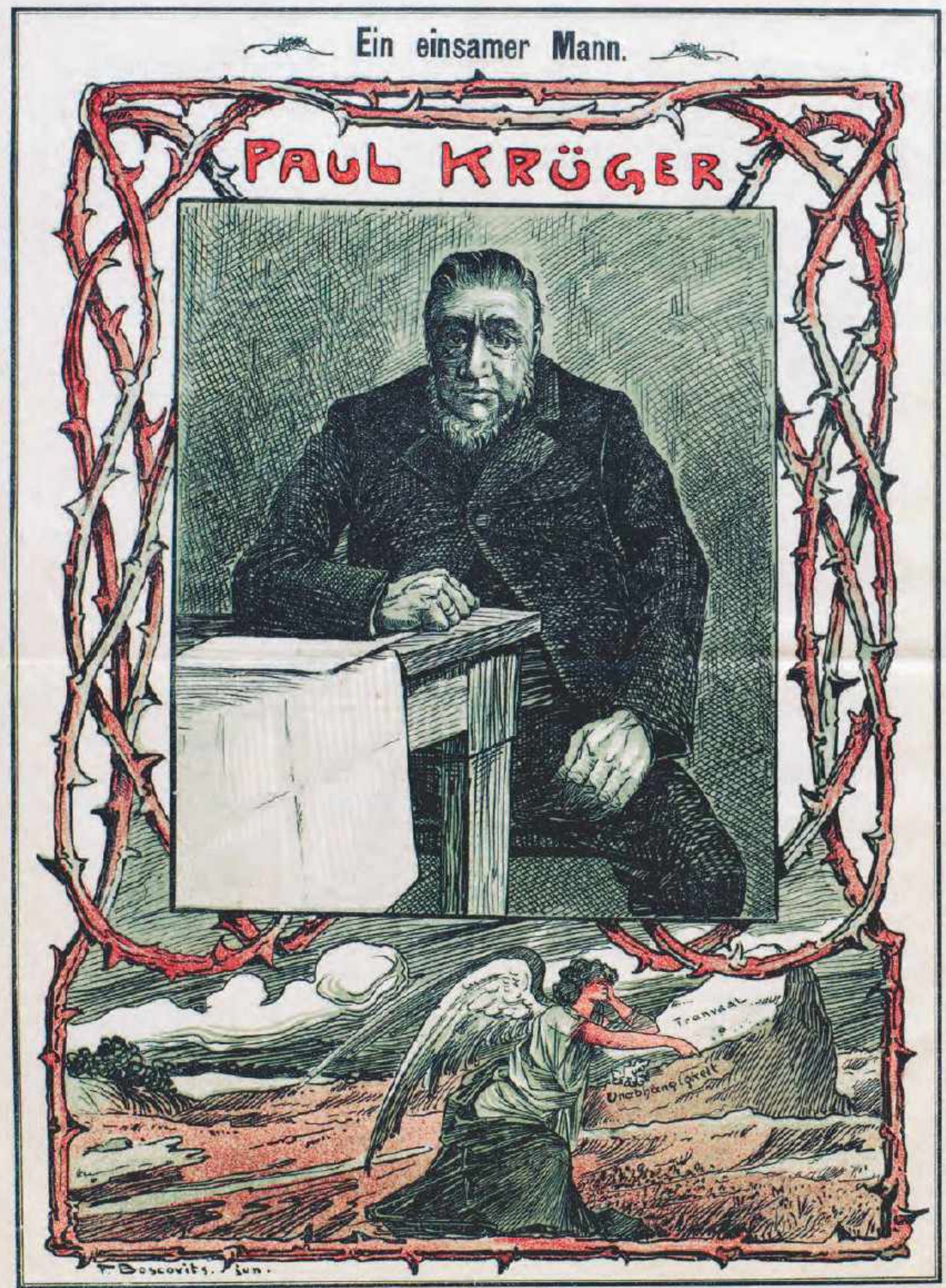

Fig. 39. Nebelspalter 1902/37, dessin pleine page en couleur de Boscovits junior intitulé « Un homme seul » (Ein einsamer Mann). 

Zürich, 1900.
XXVI.Jahrgang N 9.
3. März .

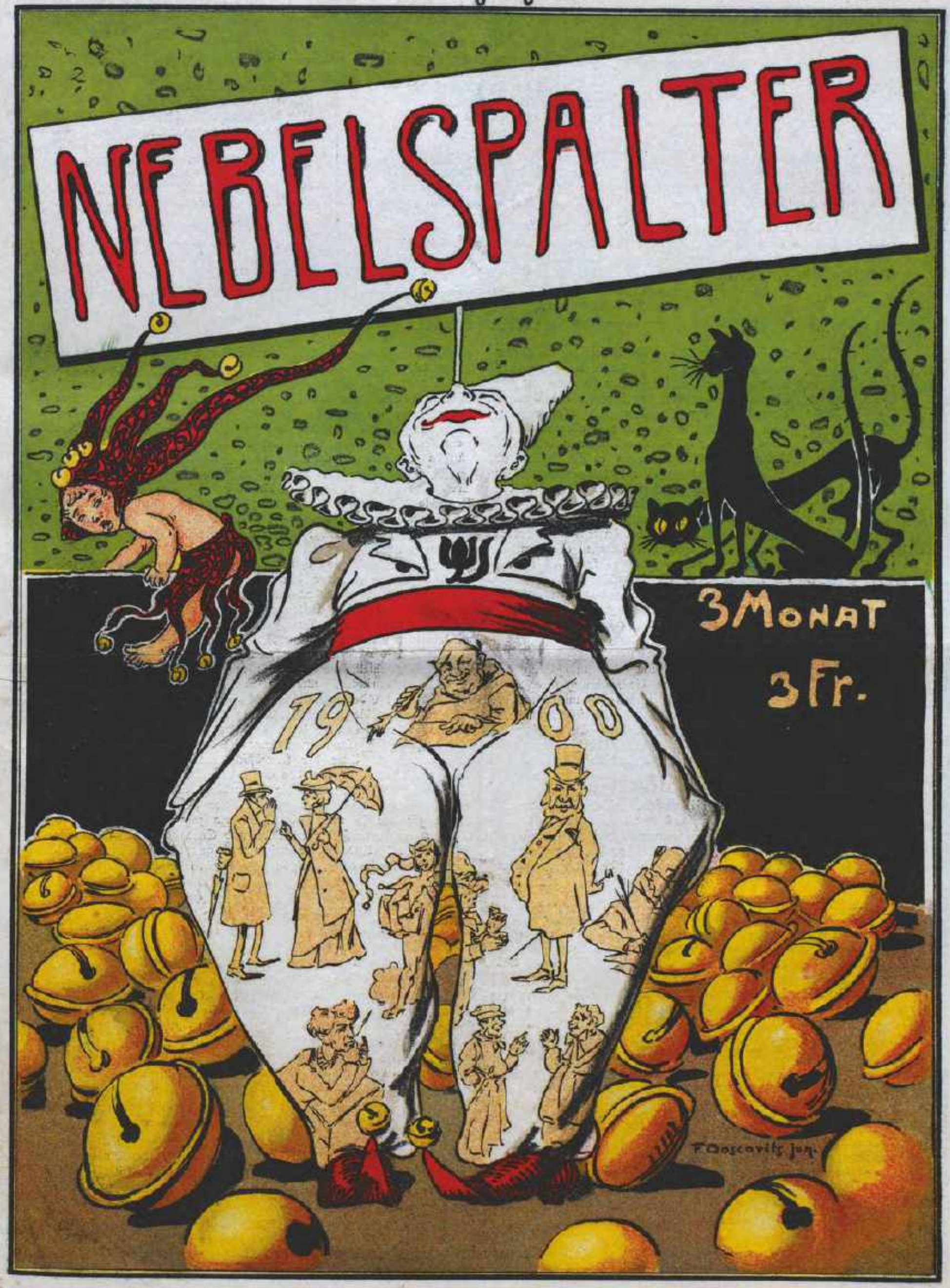

Fig. 4O. Nebelspalter 1900/9, couverture en couleur de Boscovits junior. 


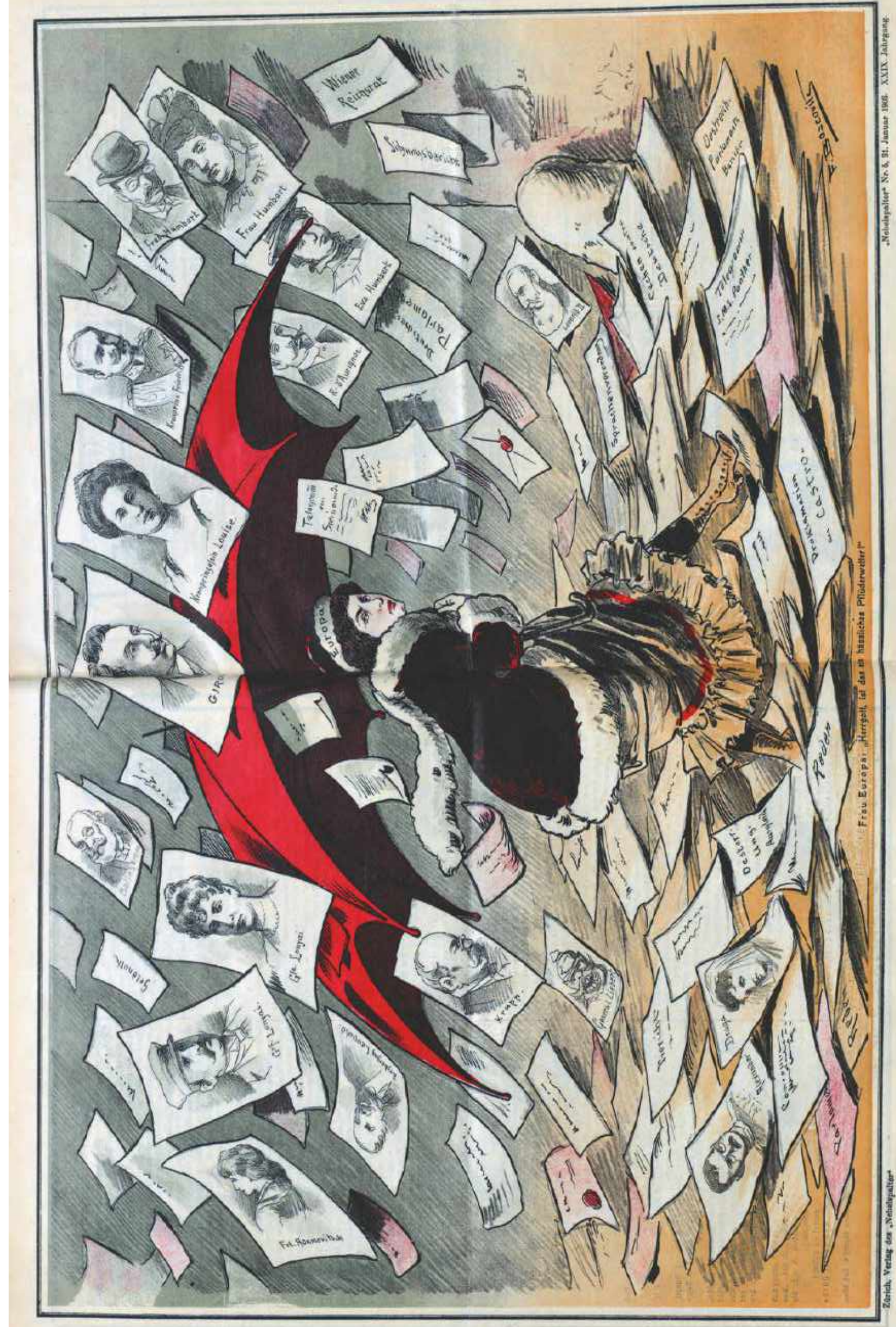




\section{Zürich,1901. XXVII. Jahrgang N.1.}

5. Januar.

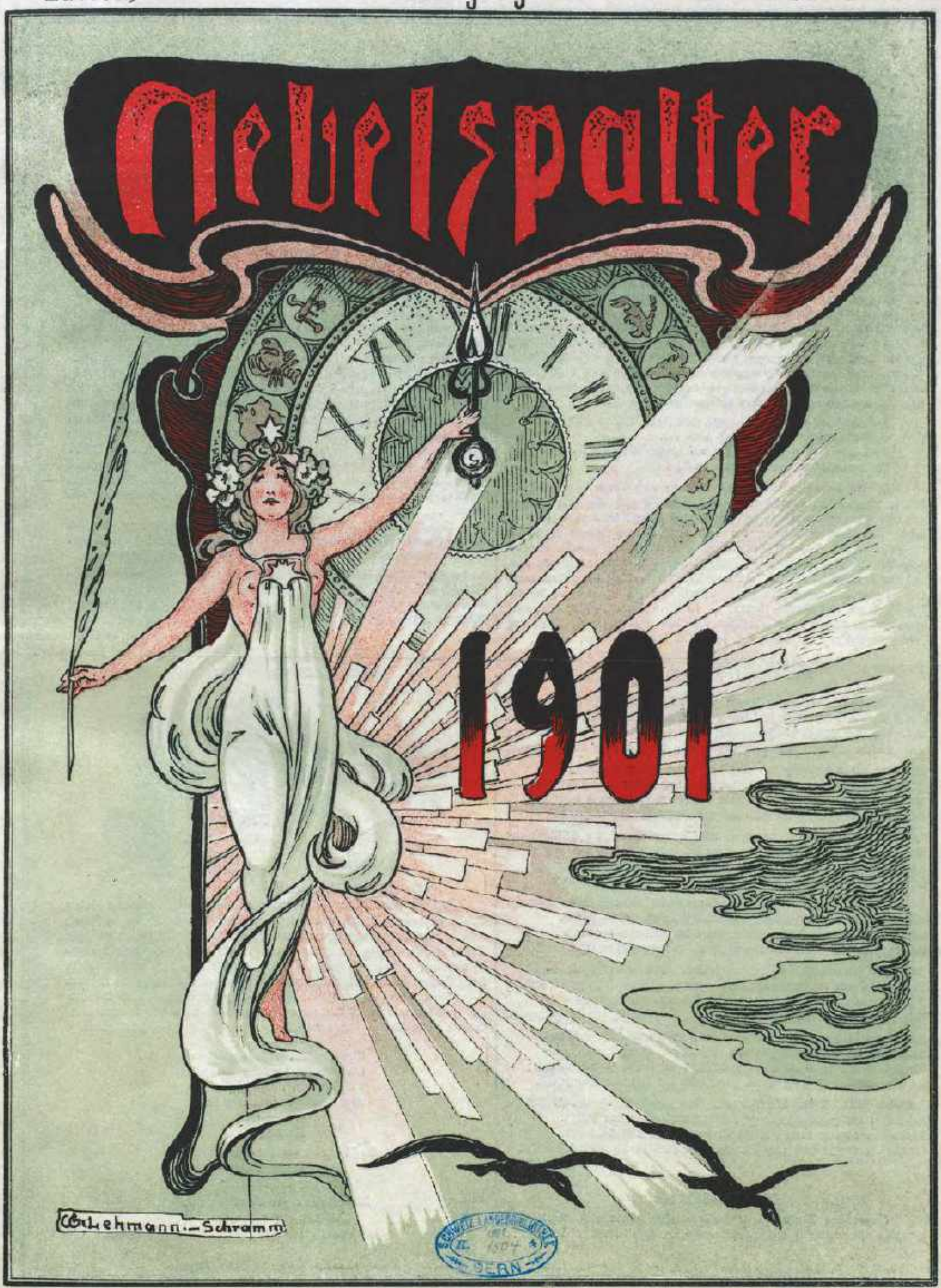

Lith J.Butz, EStmb Rectiolete. 
Zürich, 1902. XXVIII.Jahrgang N0.28.

12 Juli .
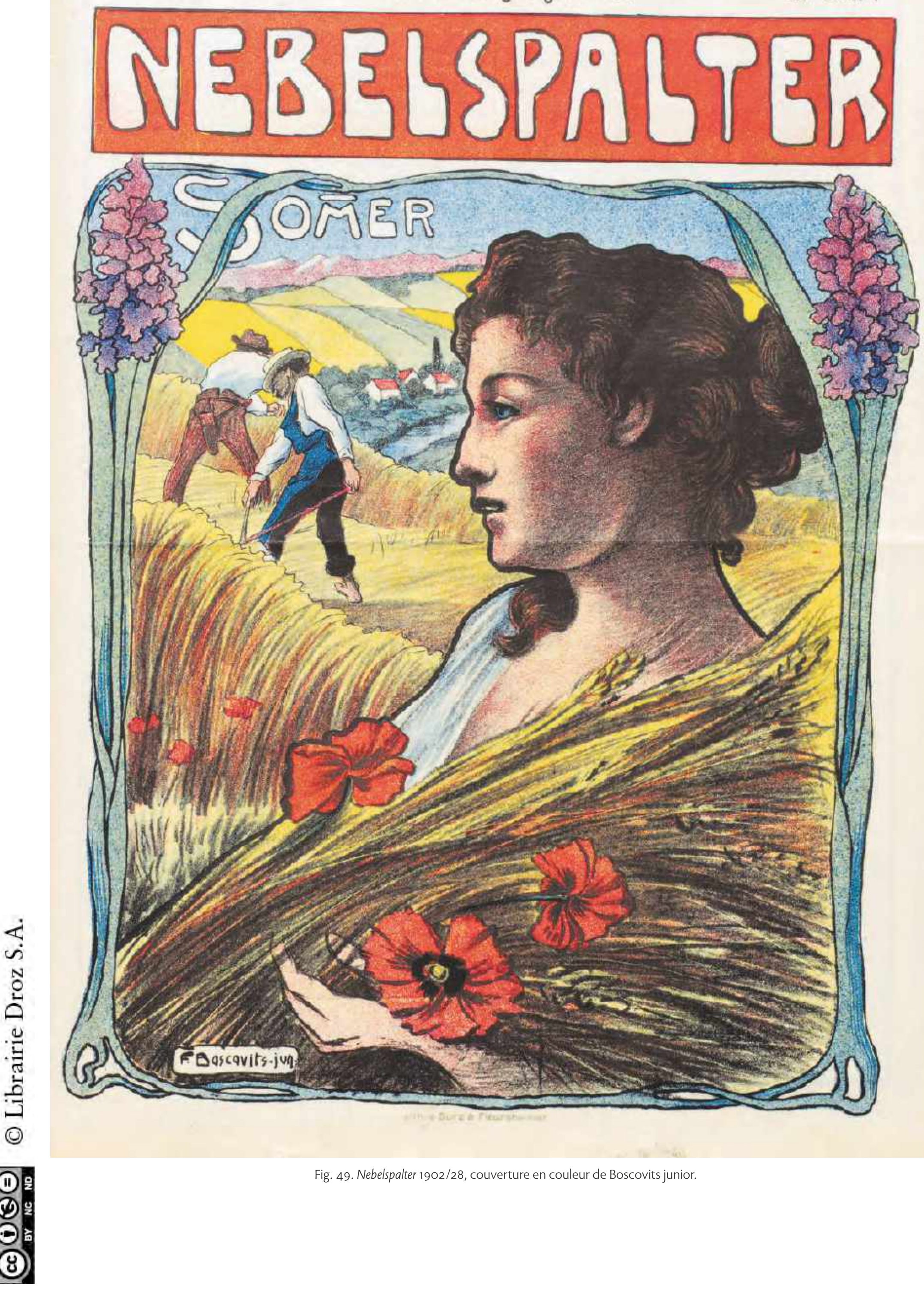

Fig. 49. Nebelspalter 1902/28, couverture en couleur de Boscovits junior. 
Zürich, 1901.

XXVII. Jahrgang №.27.

6. Juli.

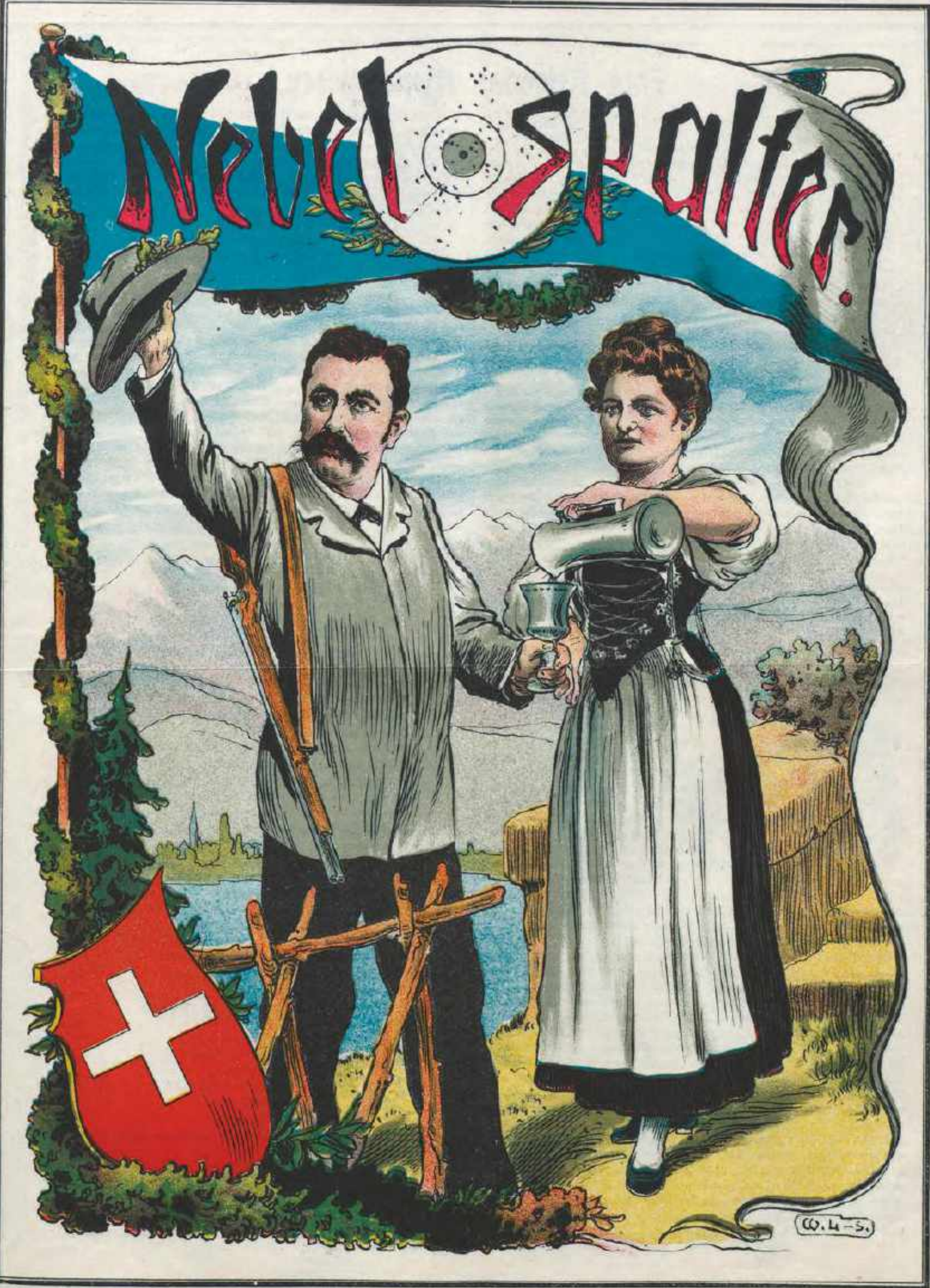

Fig. 50. Nebelspalter 1901/27, couverture en couleur de Willy Lehmann-Schramm. 


\section{-2) Scheizermeinung. -}

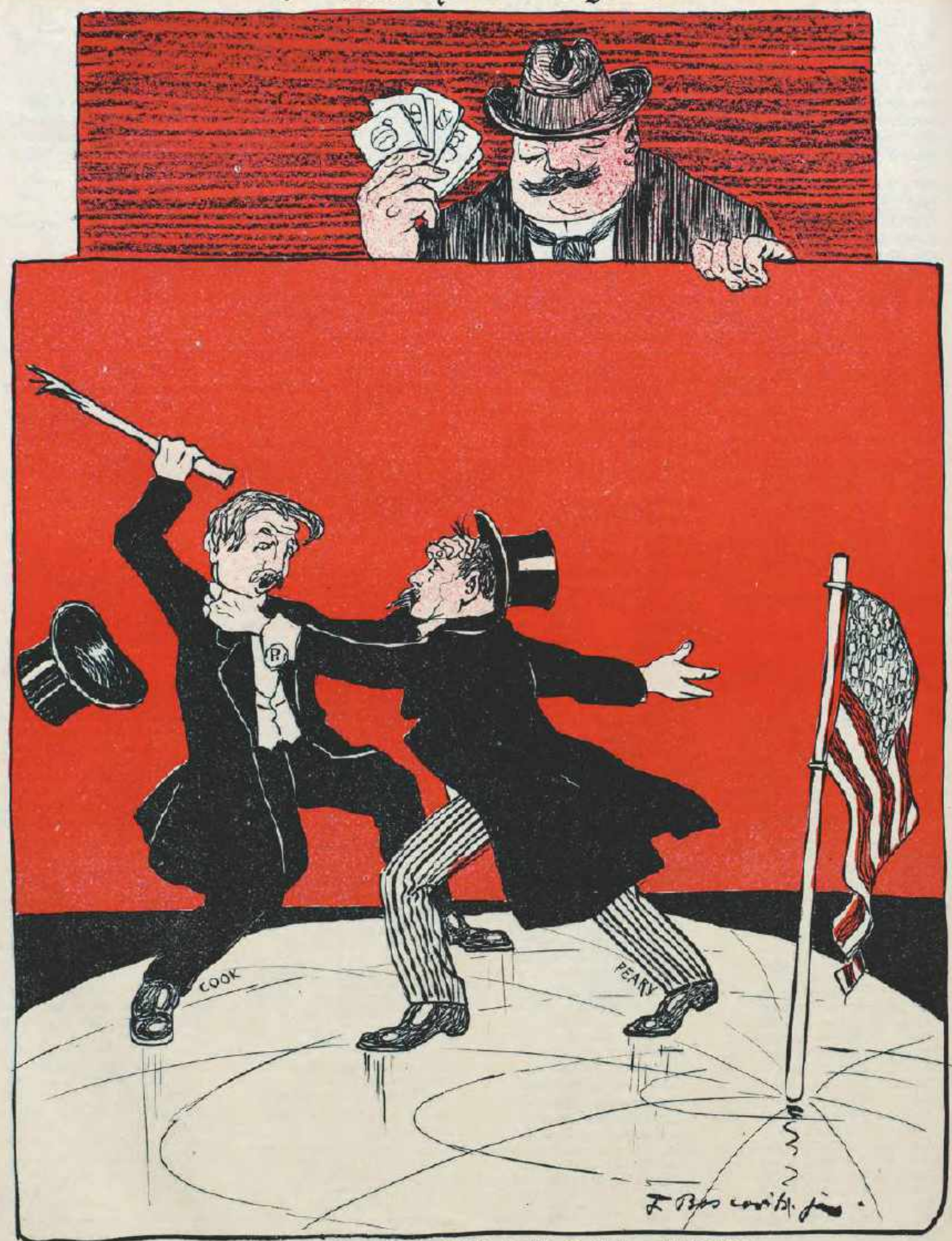

Crumpfhuber: "Welch traurig Shaulpiel fur die Welt, dies Streiten und dies Baffien!

So homnt's nur, wenn der "Dritte" fehlt - lonit wären fie friedlich jaffen I"

Fig. 51. Nebelspalter 1909/38, dessin pleine page en couleur de Boscovits junior intitulé « Opinion suisse » (Schweizermeinung). 
* Sic transit gloria mundi.

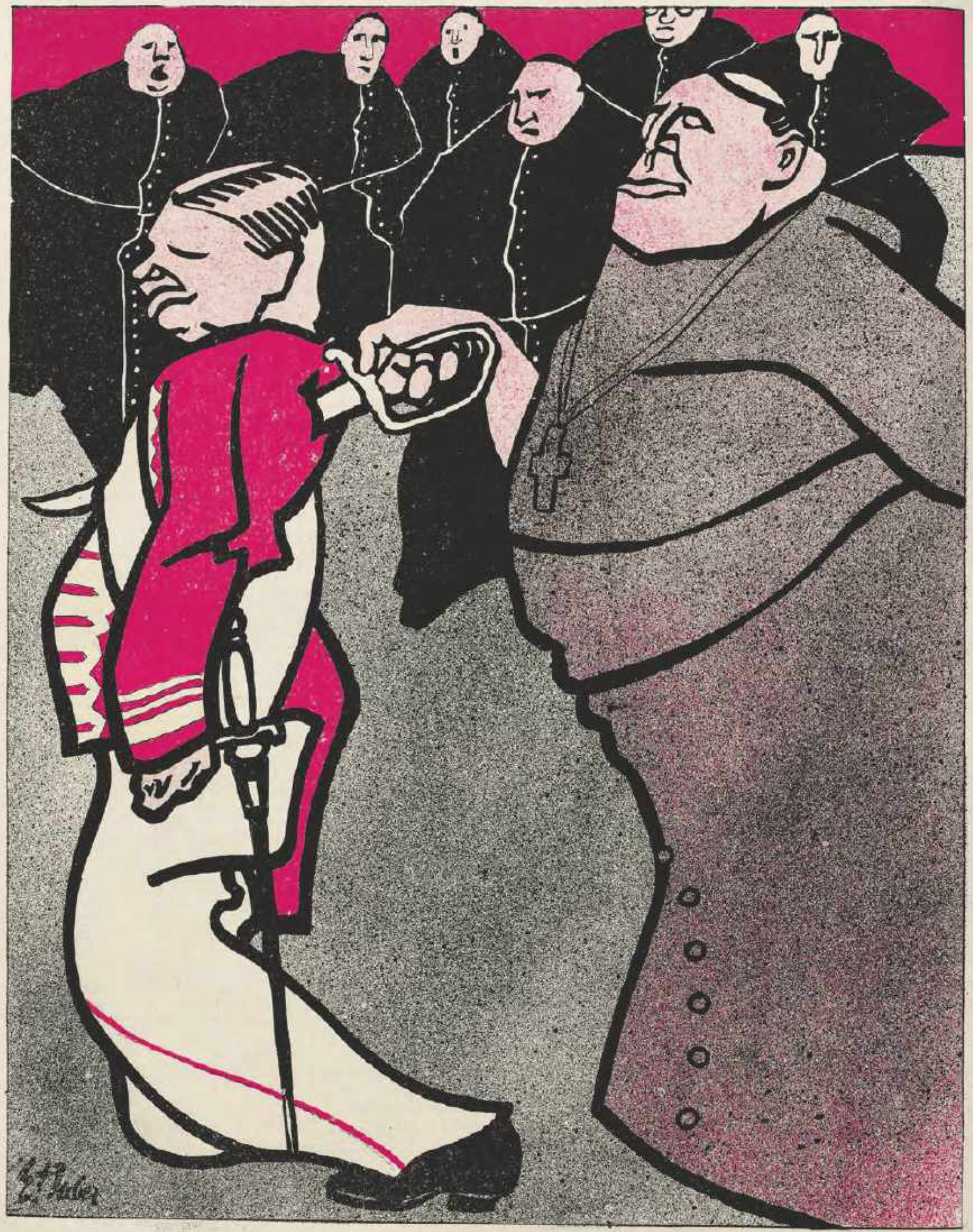

Das war Bülow's Fall!

Fig. 52. Nebelspalter 1909/28, dessin pleine page en couleur d'Emil Huber intitulé « Sic transit gloria mundi ». 
Jenleits des Gottbard.

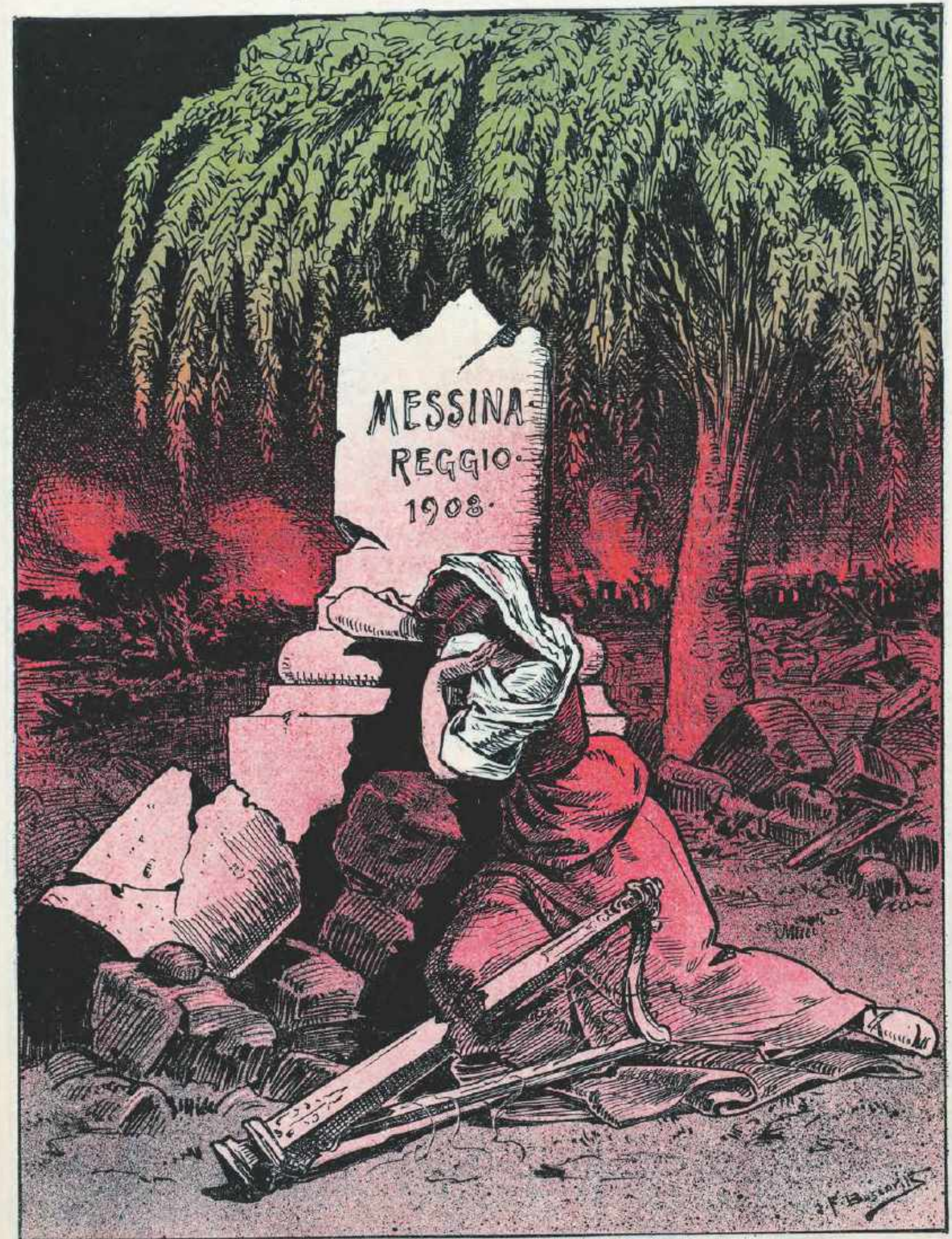

,.Kennit Du das Cand? - Dahin, dabin, _ _ " Dahin!

Fig. 57. Nebelspalter 1909/2, dessin pleine page en couleur de Boscovits senior intitulé « Au-delà du Gothard » (Jenseits des Gotthard). 


\section{Der Föhenrekord.}

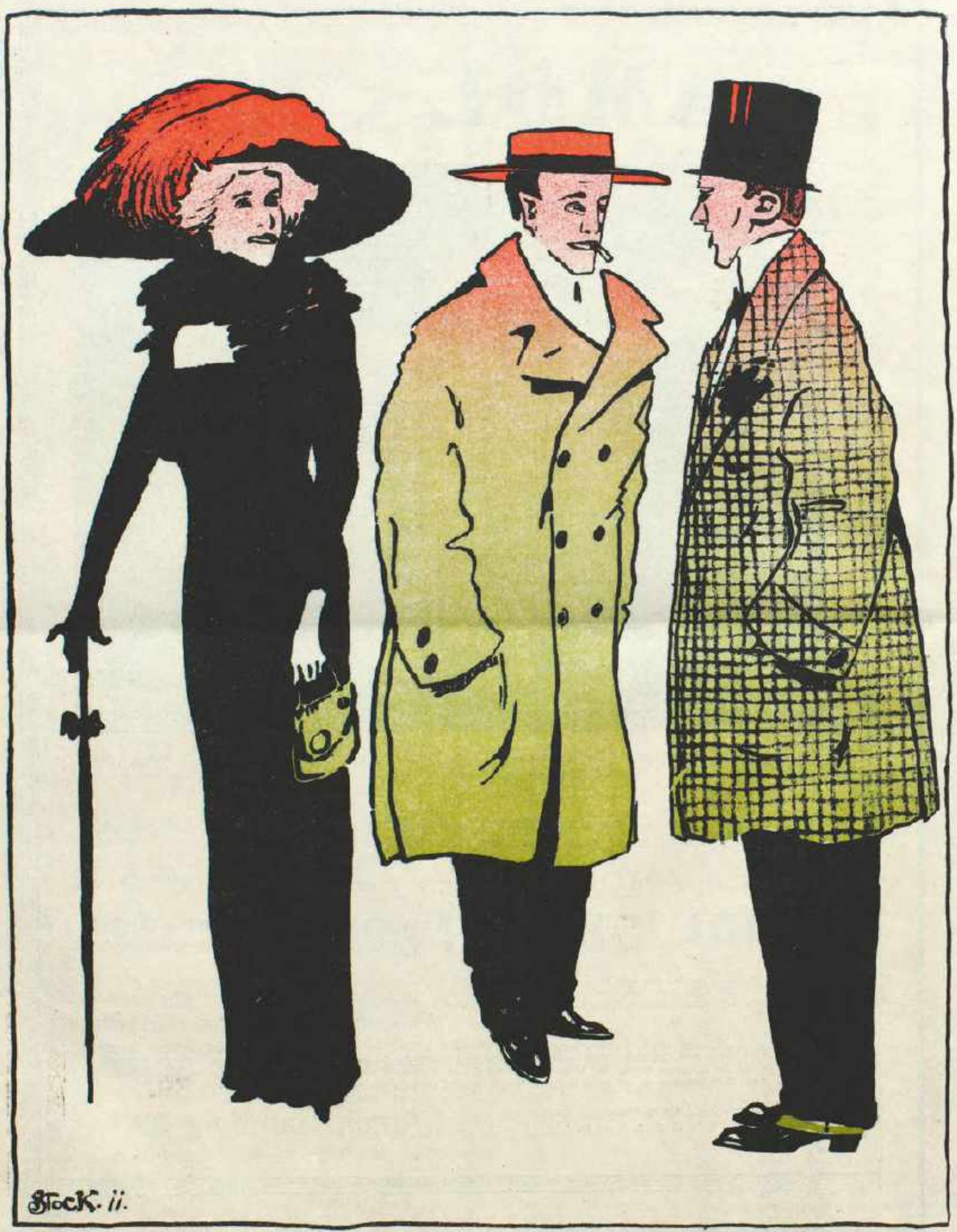

WeiBt Du fdon, daB Max den 5obhenrehord erzielt hat? - Was, hat der sid auf die Aviatik geworfen? Hd nein, aber seine Sđulden baben dle Maximalbobe Ibon erreidt!

Fig. 61. Nebelspalter 1911/45, dessin pleine page en couleur signé «Stock » intitulé « Le record de hauteur » (Der Höhenrekord). 

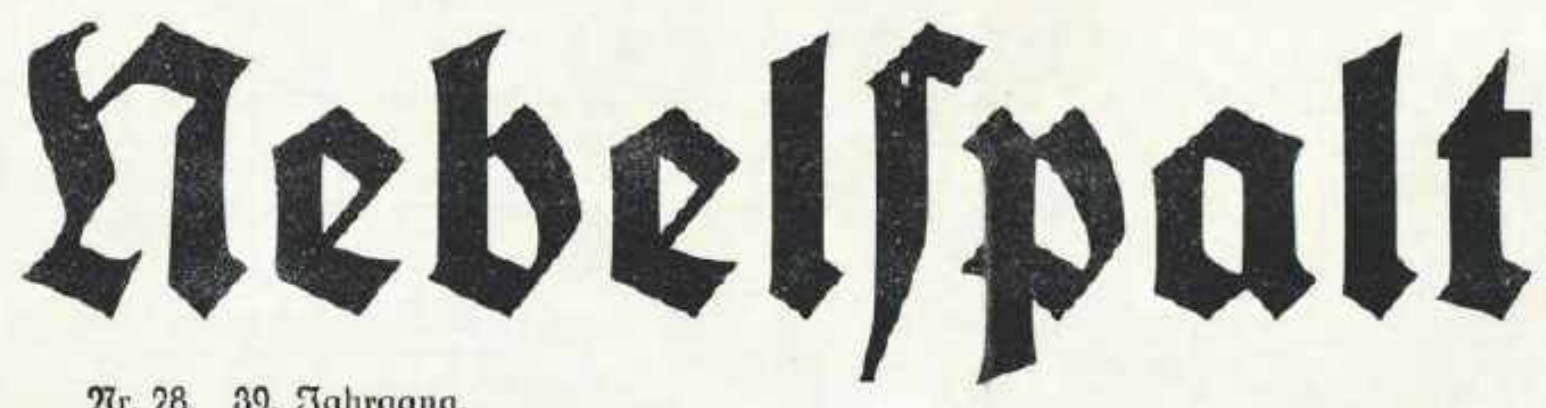

27. 28. 39. Jahrgang.

Fumori|ti|ch-Fatyri|che Wochen[chrift

12. Juli 1913 ,

\begin{tabular}{|c|c|c|}
\hline 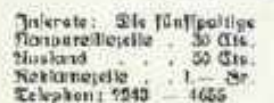 & Fumorifti|ch-fatyri|che Wochenichrift & 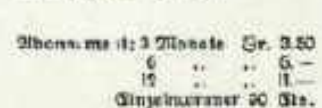 \\
\hline
\end{tabular}

Kedation: 2. 23. Fuber. Grütlifir. 21. Jürich. (Iel. 1401).

Druck und 2Jerlag pon J̈ean Sren in Sürich.

Gchüßenfefte

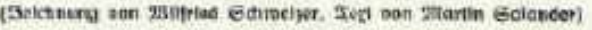

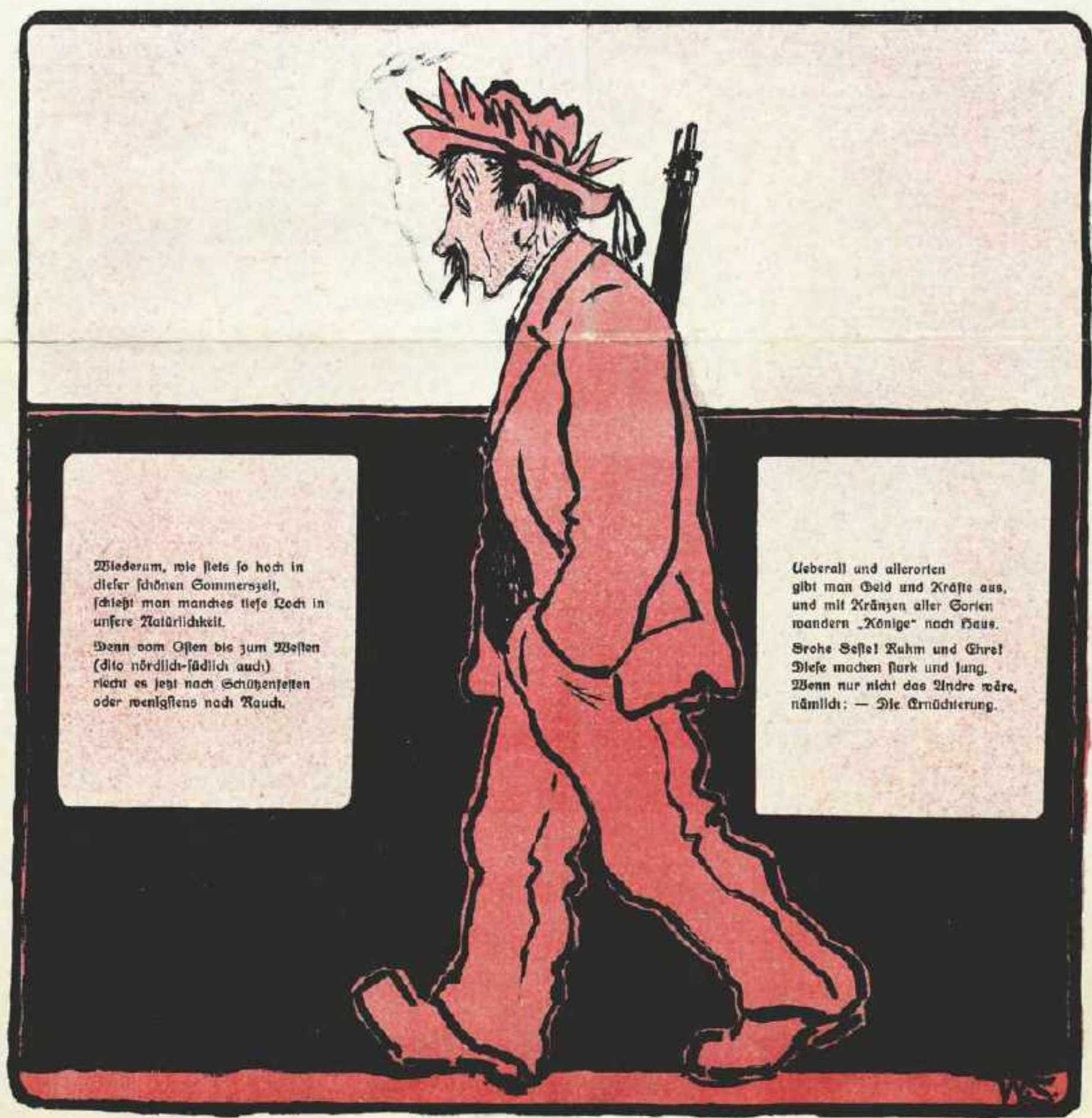

Fig. 63. Nebelspalter 1913/28, couverture en couleur intitulée « Concours de tir » (Schützenfeste), dessin de Wilfried Schweizer et texte de Martin Salander. 


\section{Der Rolicheroismus bedroht jeden!}

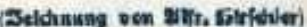

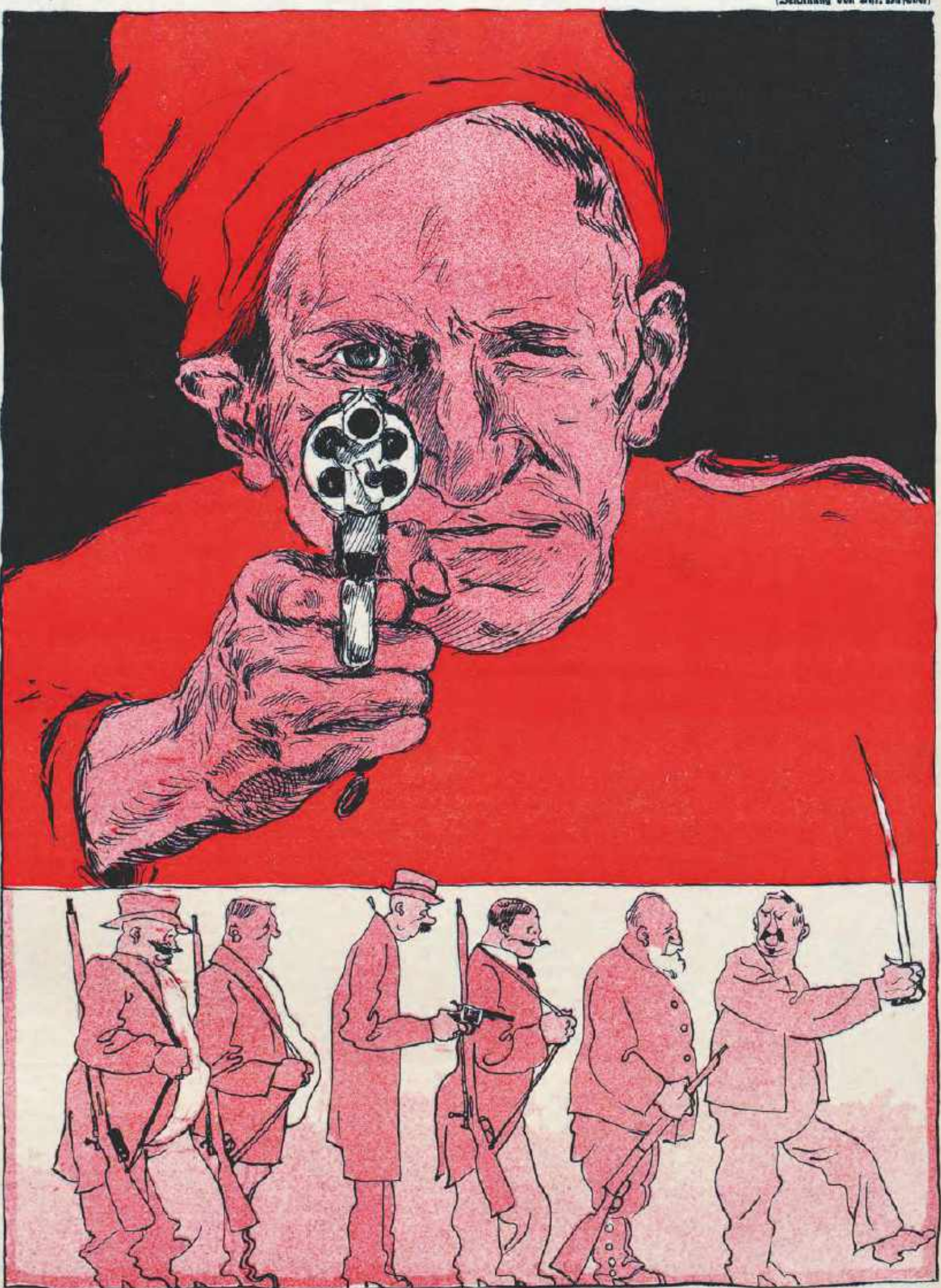

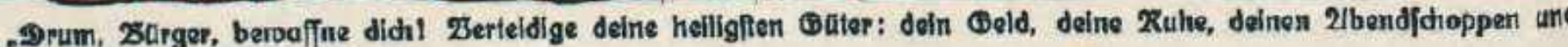
delnen \$ugeriab! !* 


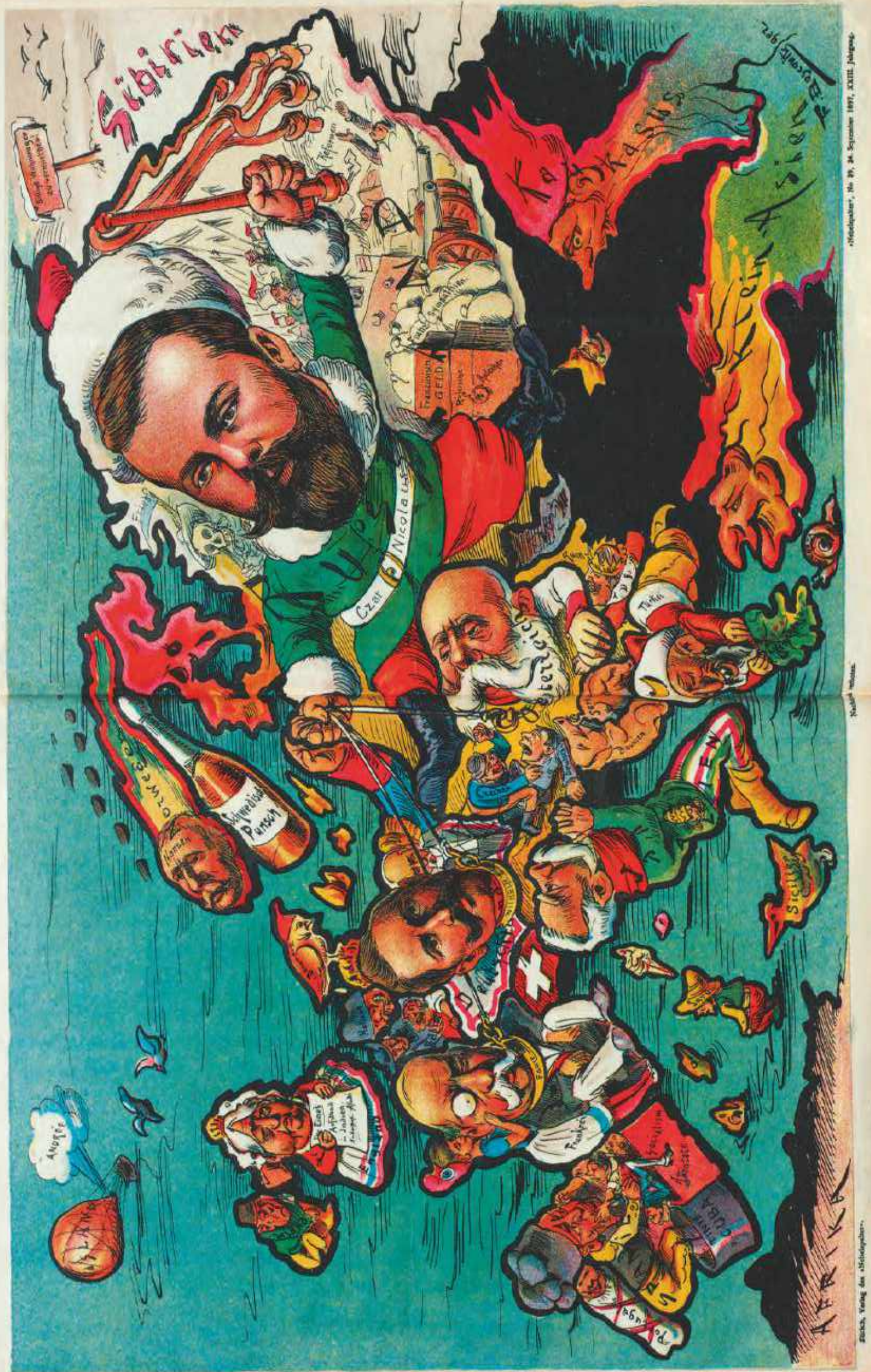


20. 31. 40. Jahrgang.

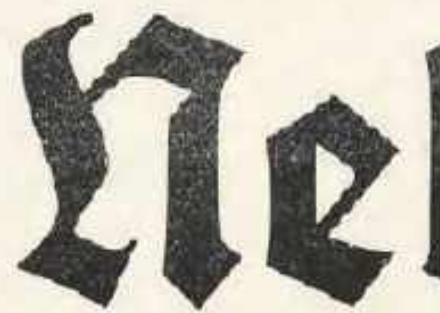

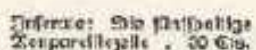

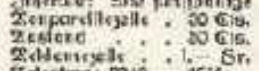

3ïrich, den 1. 2luguft 1914
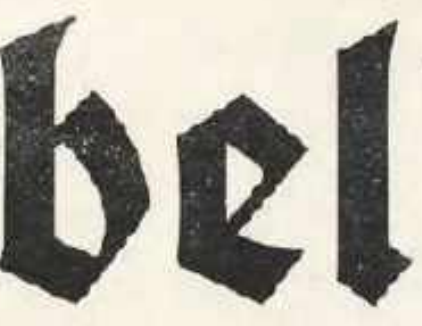

p Fumoriftifch-jatyrifche 23ochenjchrift
Ginzelnumner 30 Gts.

\section{Der erite 2luguit}

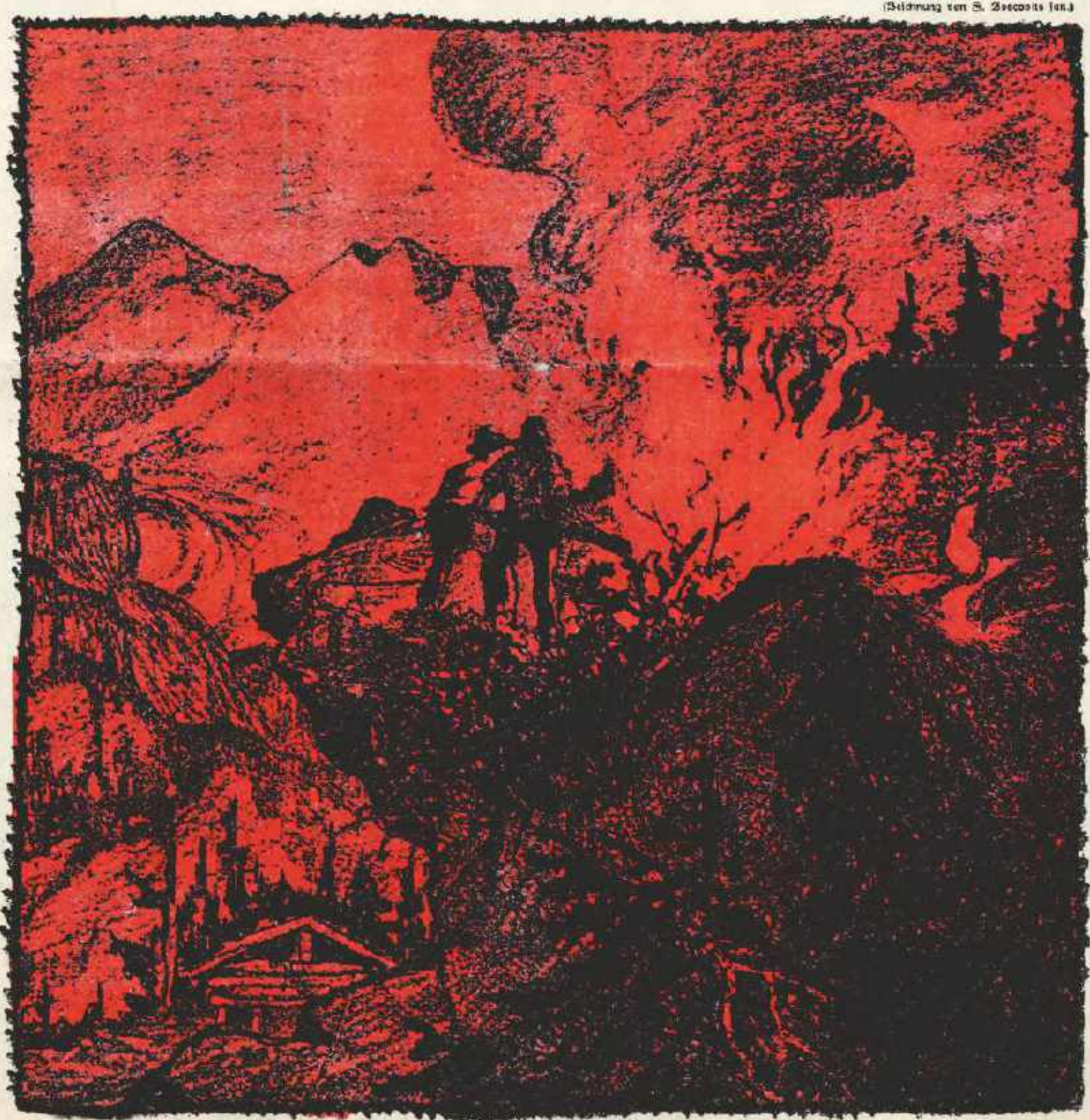

Fig. 82. Nebelspalter 1914/31, couverture en couleur de Boscovits junior intitulée « Le premier août » (Der erste August). 
Das Werben um die Teutralen

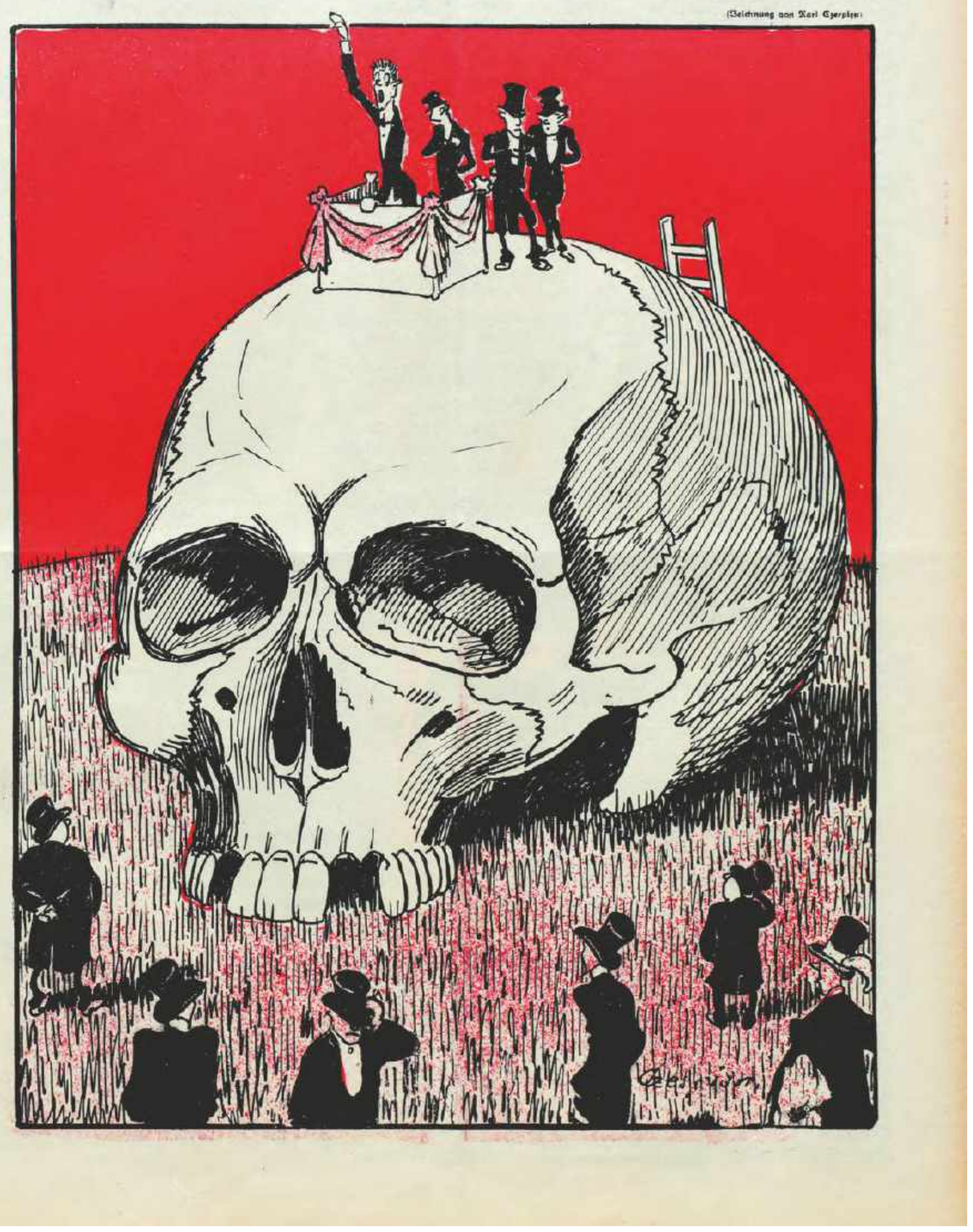

Fig. 101. Nebelspalter 1915/34, dessin pleine page en couleur de Karl Czerpien intitulé « La cour faite aux neutres » (Das Werben um die Neutralen). 


\section{Krieg und Kultur}

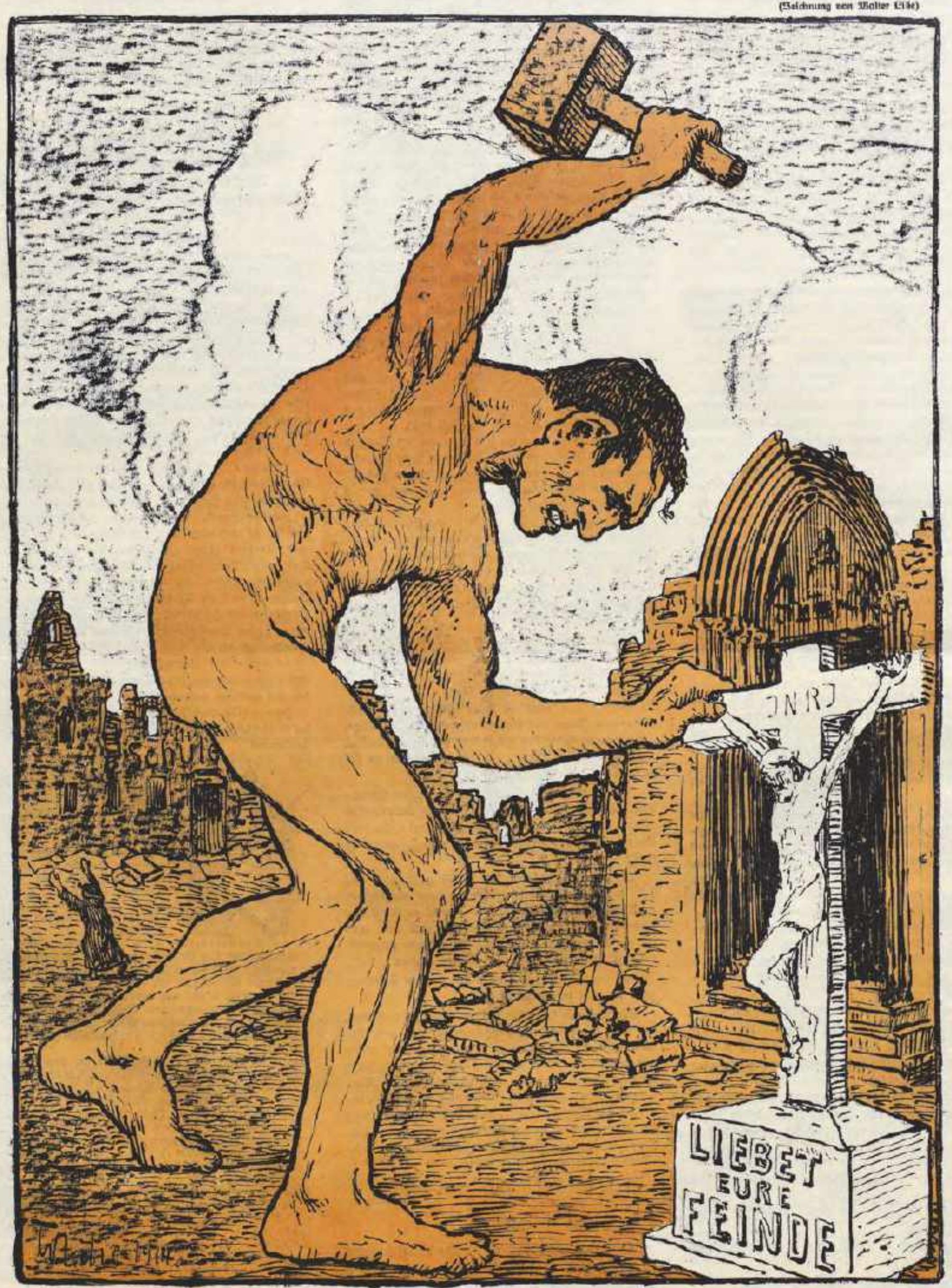

„20lker Guropas, roahret eurs helligiten Bater 1" 
Iod

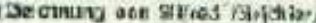

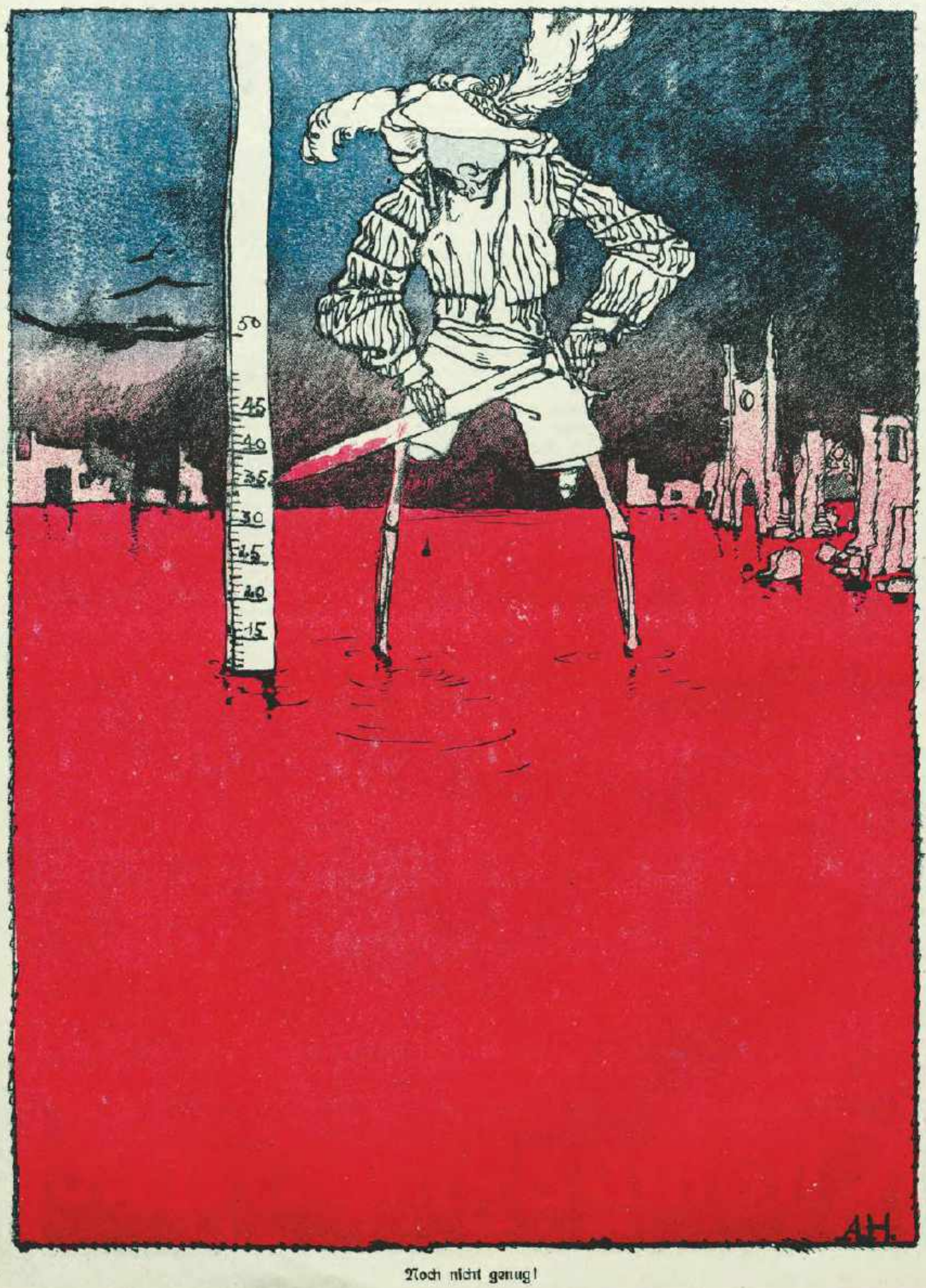

Fig. 114. Nebelspalter 1918/24, dessin pleine page en couleur de Alfred Hirschler intitulé « Mort »(Tod). 

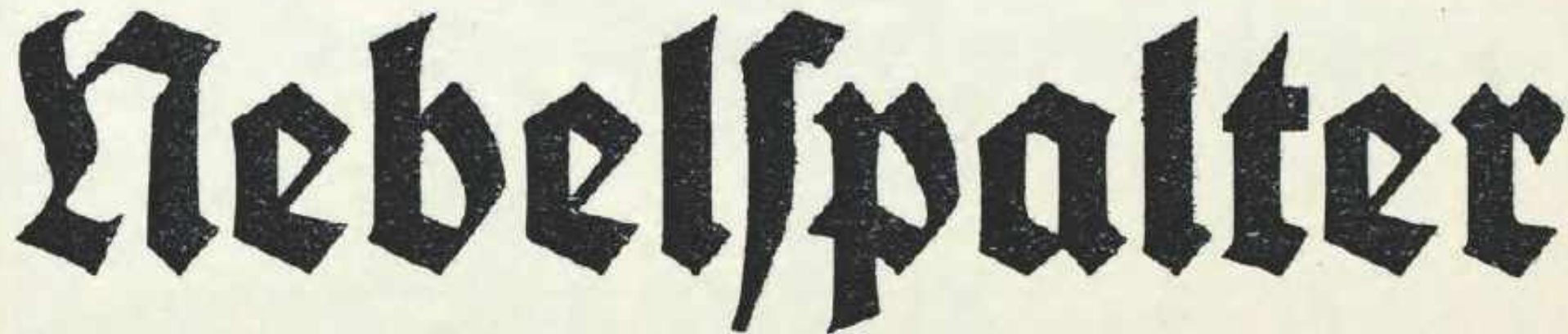

Fumoriftifch-Fatyrifche 2Jochenichrift

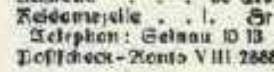

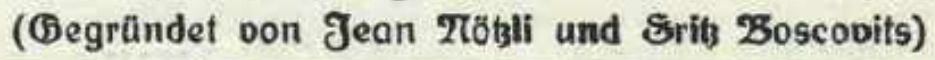

ขbonnemen 1: a Mhonate 5ir 4zol $2 \pi 0.8$.

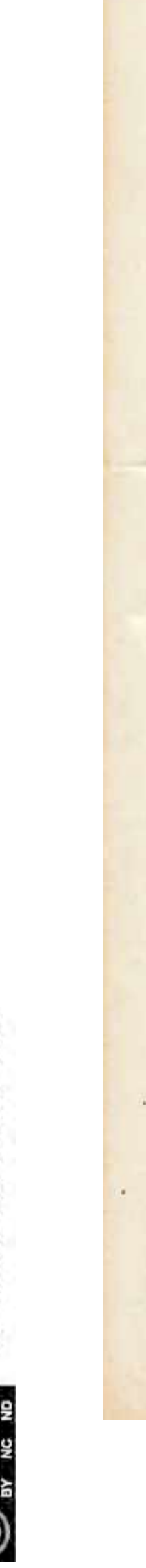

"La gloire qui chante"

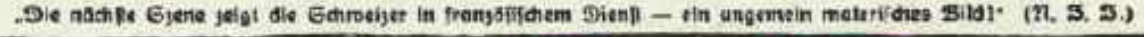

(Beidunung oon Sr, Fope, Jorida)

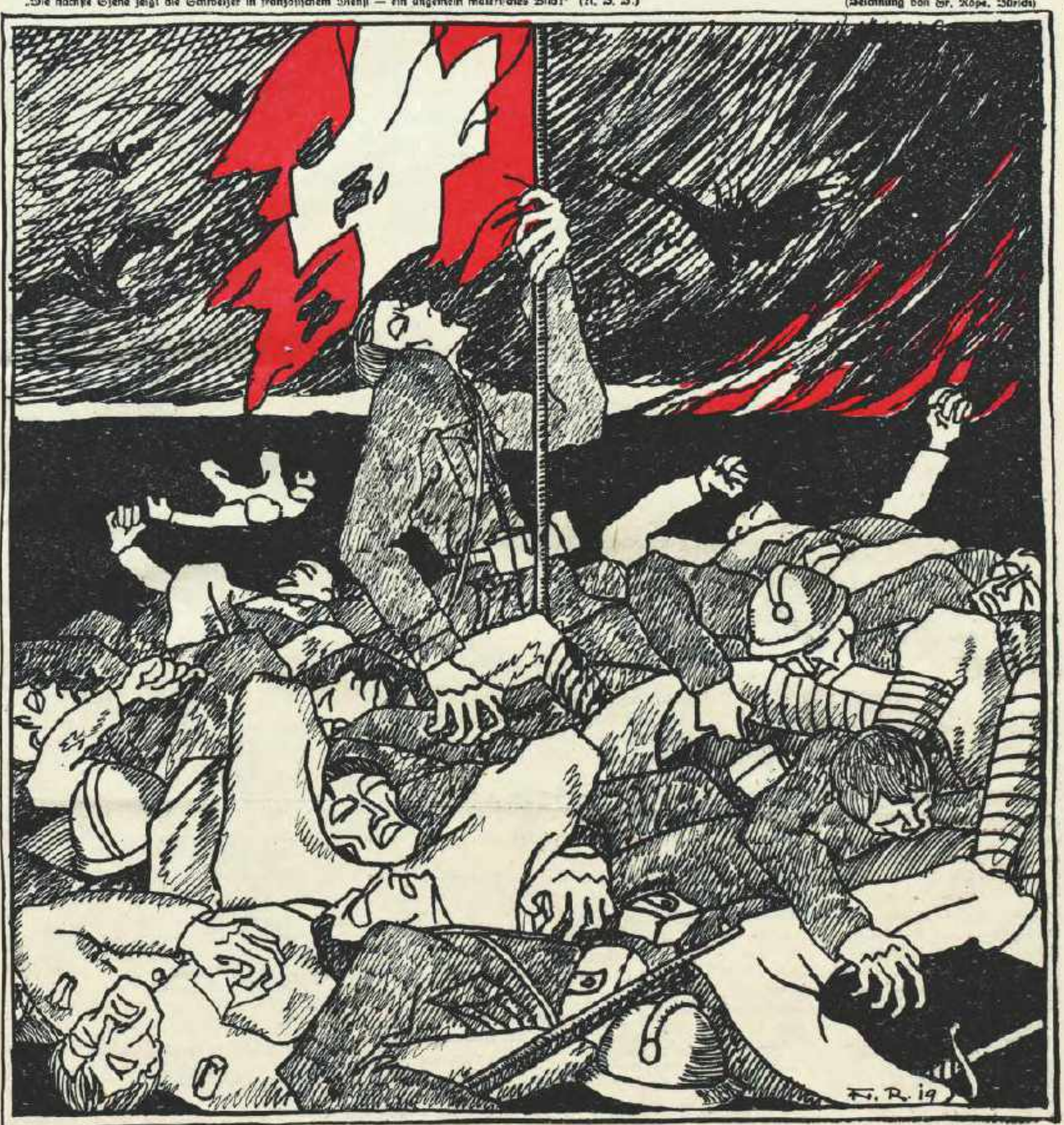

Helvetia, morituri de salutant ]

(Won 10,000 Gdhreizern, die den Sranzolen ju. helfer" pat bemagigt fuhiten, find $6000 \mathrm{im}$ Zellkrieg gefallen.) 


\section{Zürich, 1904.}

XXX.Jahrgang №44.

29. October.

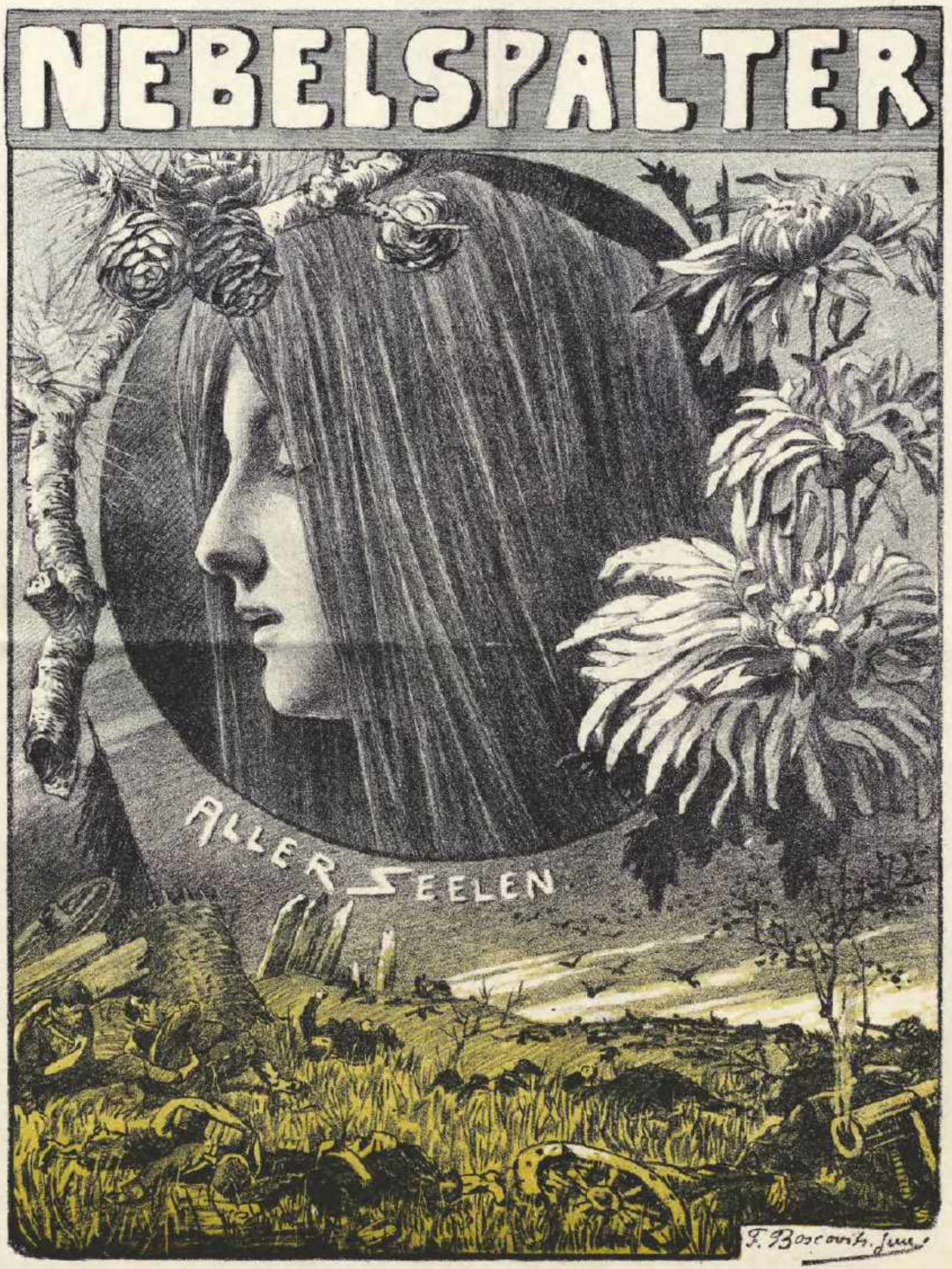

Fig. 131. Nebelspalter 1904/44, couverture en couleur de Boscovits junior. 


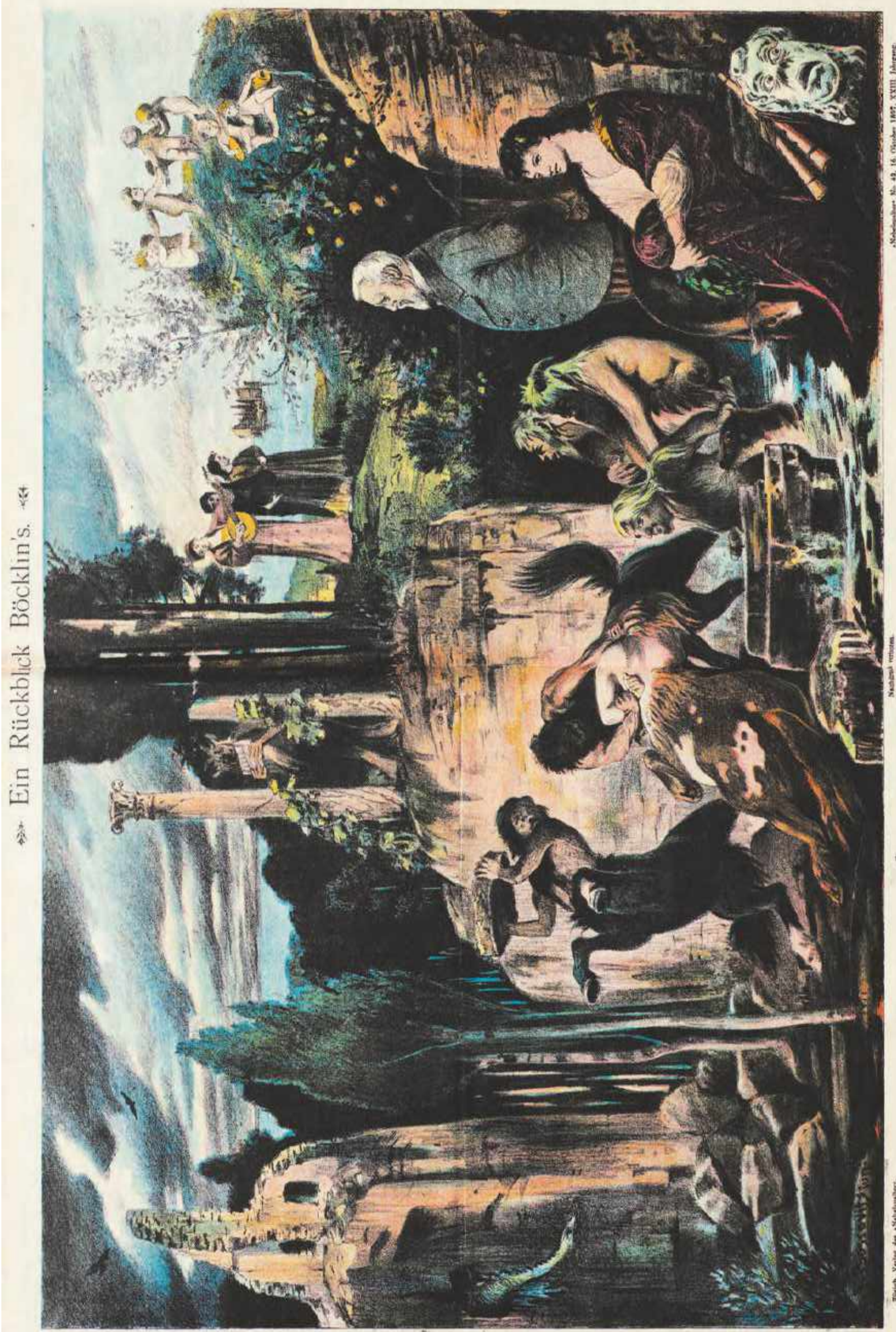




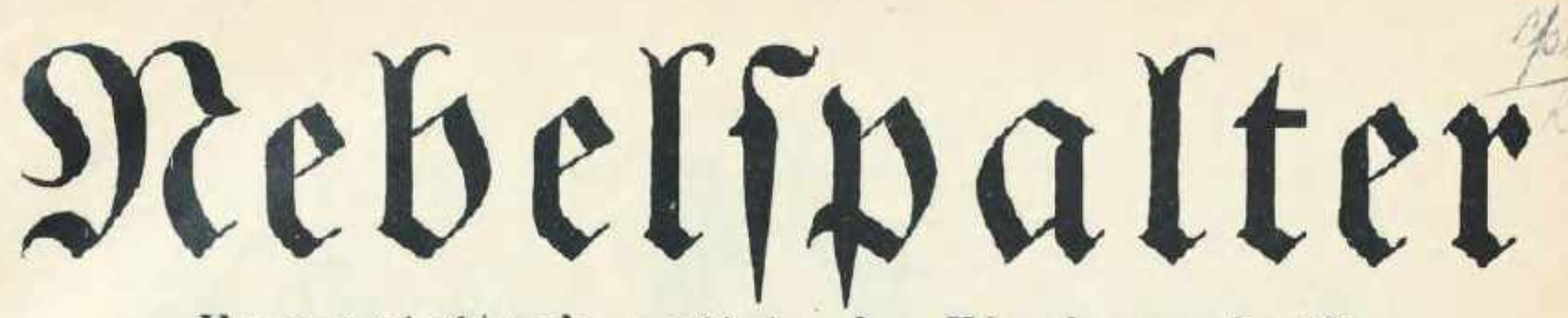

Humoristisch-satirische Wochenschrift

\begin{tabular}{|c|c|c|}
\hline Borschath, +. Jantad 1922 & 18. Jahrgang Xr. I & Einzelnummer jo $\mathrm{Cta}$ \\
\hline
\end{tabular}

I) $A$ \& $h$ LEI D

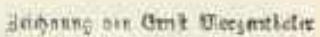

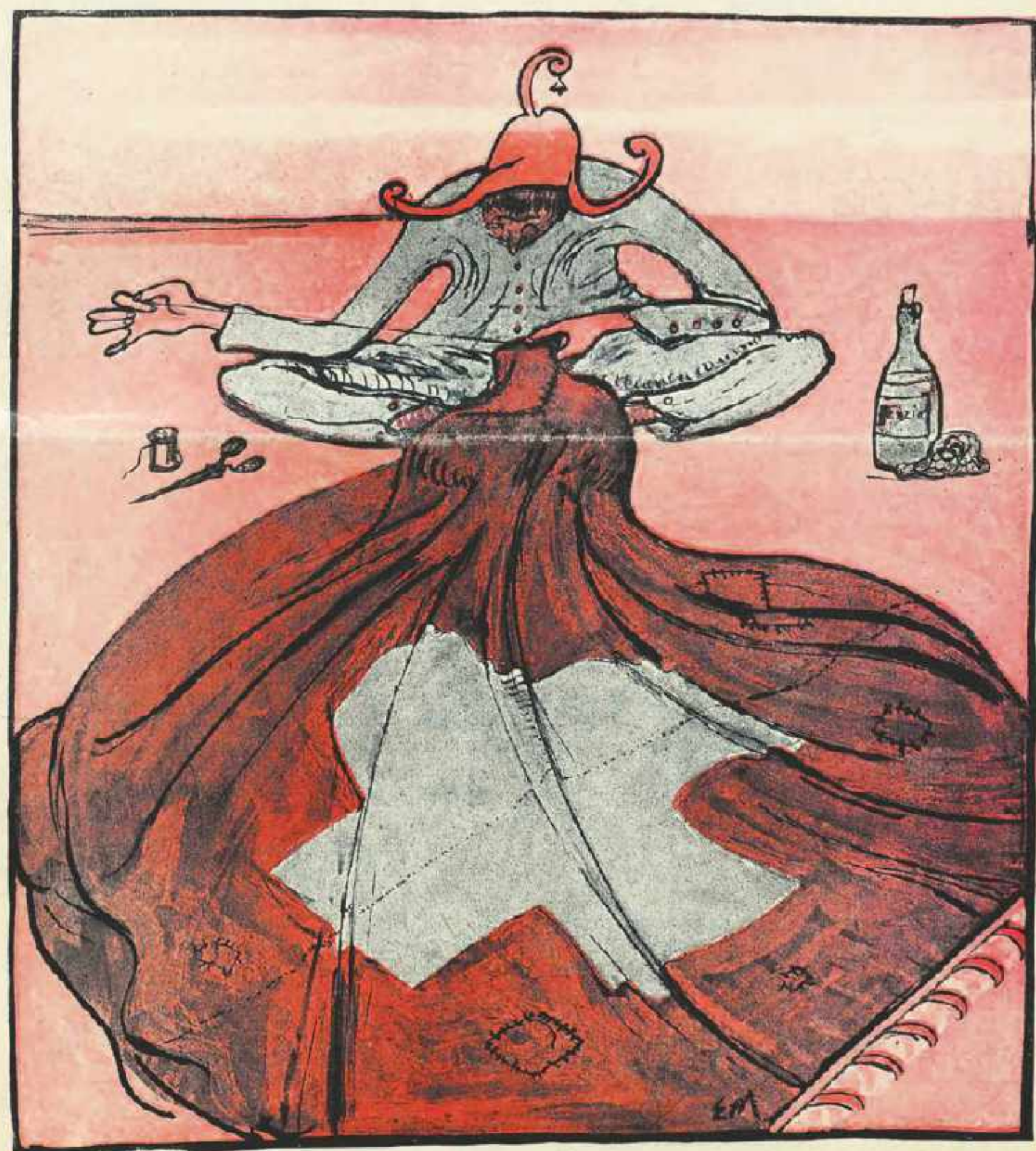

Seber filctt an Dir berum Seber bentt babel an fich

Ino bice meiftere fortectlich bumm Bicl su wenig auch on Dias

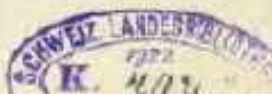

(IR. $49 \%$. 


\section{Zürich, 1901. \\ XXVII.Jahrgang №44. \\ 2 November.}
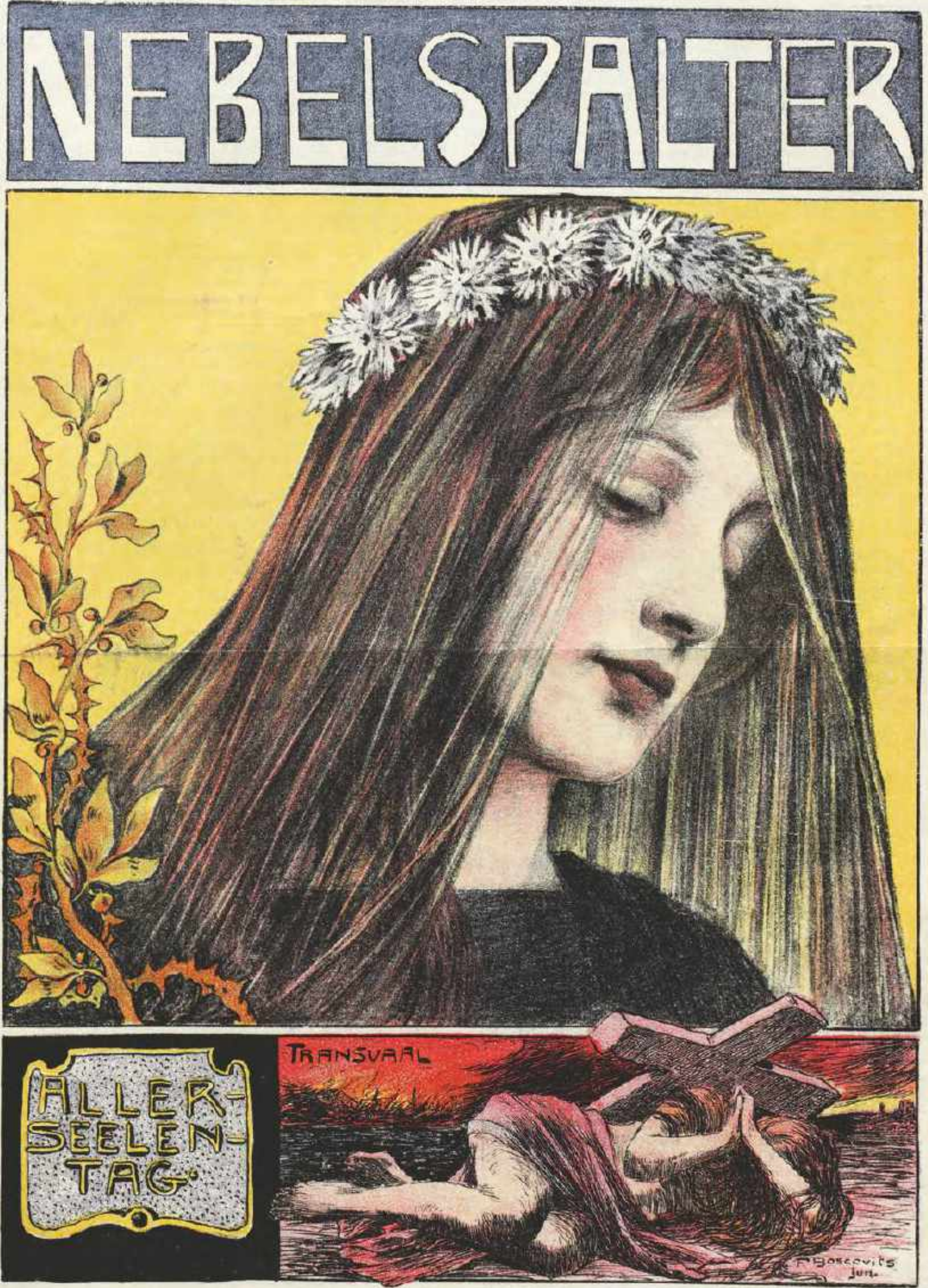

Fig. 146. Nebelspalter 1901/44, couverture en couleur de Boscovits junior. 


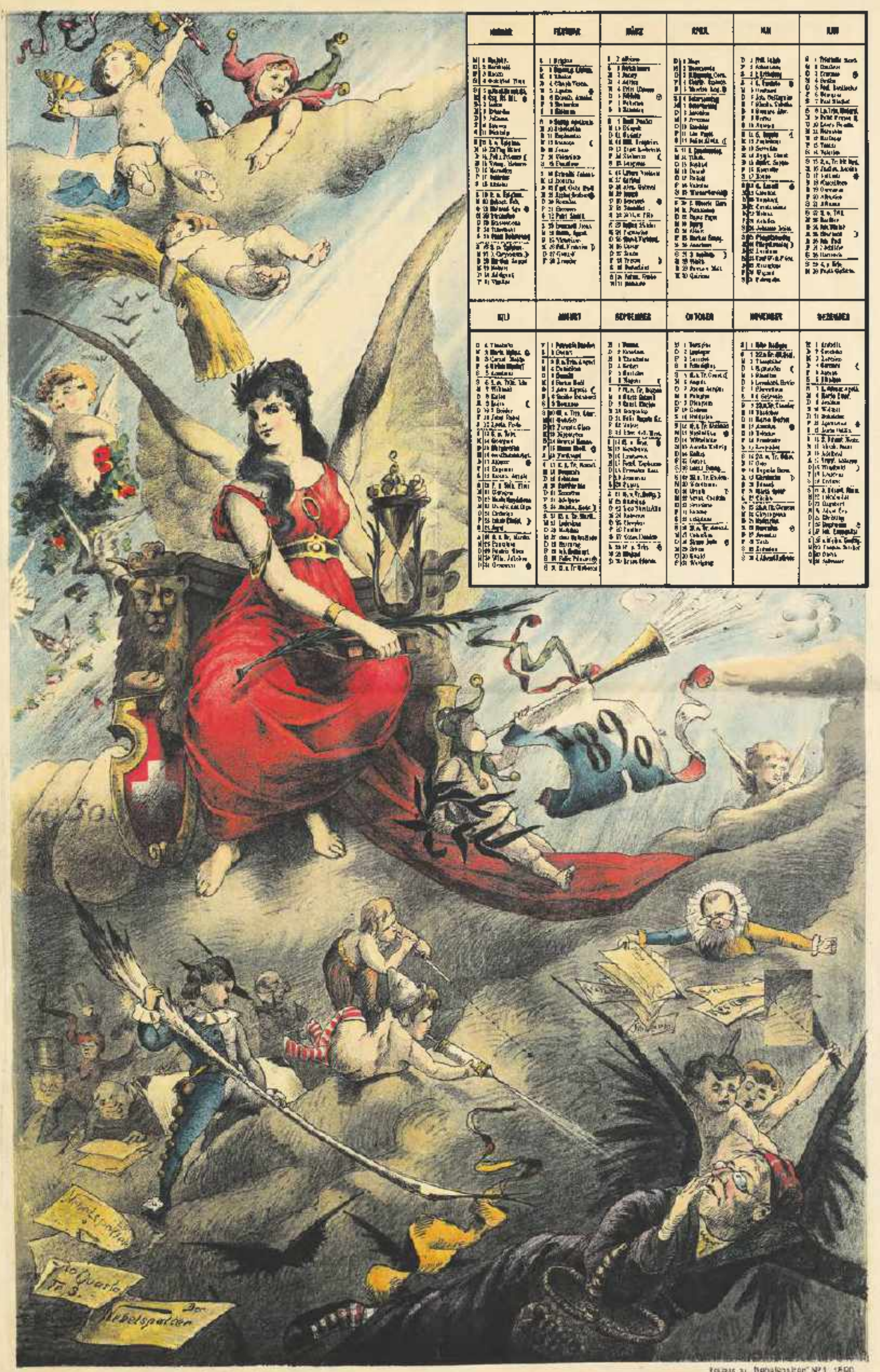

Fig. 150. Nebelspalter 1890/1, double-page en couleur de Boscovits senior. 


\section{DISCOURS SUR L'ART}

Les premières positions artistiques du Nebelspalter s'inscrivent dans le contexte tout à fait singulier en Europe d'une quasiabsence d'institutionnalisation de l'art, un manque cruel de structures de formation, hors l'académie de Genève, contraignant les artistes à se former à l'étranger, un niveau de subventions publiques très bas, guère d'espaces d'exposition qui soient spécifiquement dédiés à l'art, ainsi que des associations artistiques récentes, ne représentant les intérêts corporatistes auprès de la Confédération que depuis I 848. Cet état des lieux témoigne d'une difficile intégration du critère artistique dans l'identité nationale ${ }^{1}$, contrastant avec la situation des voisins français, allemand et italien ${ }^{2}$. Durant la période zurichoise du Nebelspalter, on observe une structuration progressive du champ de l'art, avec la mise en place d'une politique nationale de subventions et de gratifications, l'intensification des expositions et la création de lieux d'exposition appropriés. Parallèlement, se constituent des collections privées et une organisation marchande via les galeries ${ }^{3}$. Le moment est celui de revendications très fortes de la part des artistes et plus largement des acteurs du champ de l'art, l'importance des enjeux symboliques et financiers ouvrant fréquemment sur des luttes sans merci.

L'entrée du Nebelspalter dans le débat artistique est relativement tardive et parfois marquée par une certaine ambiguïté. Les interventions prennent différentes formes : la sensibilisation du public aux manifestations artistiques, internationales, nationales ou zurichoises; une activité critique, en particulier au travers des salons caricaturaux; un positionnement politique en faveur d'un art national et de structures adéquates. La question de l'art national domine alors les débats. Elle est documentée via les archives par un échange épistolaire entre Jean Nötzli et Franck Buchser, l'un des acteurs essentiels de l'institutionnalisation de l'art, dont on trouve les échos et prolongements dans les pages de la revue. Enfin, un élément difficile à mettre en évidence et qui a pourtant son importance est la retenue du Nebelspalter, voire son silence sur certains pans de la vie artistique. Sont concernés à des degrés

Cf. Hans A. Lüthy, «L'art en Suisse 1890-1945 », dans L'art en Suisse 1890-1980, éd. Hans A Lüthy et Hans-Jörg Heusser, Payot, Lausanne, 1983, p. 9-10; Valentine von Fellenberg, "Die nicht realisierte Schweizerische Kunstakademie », dans Das Kunstschaffen in der Schweiz, 1848-2006, éd. Juerg Albrecht, Zurich, Benteli, 2006. p. 247-257; Valentine von Fellenberg et Laurent Langer, « La formation des artistes suisses à l'École des Beaux-Arts de Paris de 1793-1863: enjeux et méthodes ", dans Les artistes étrangers à Paris. De la fin du Moyen Age aux années 1920, éd. Marie-Claude Chaudonneret, Berne, Peter Lang, 2007. p. 177192.

Voir pour l'Allemagne: Wolfgang J. Mommsen, Bürgerliche Kultur und künstlerische Avantgarde 1870-1918 - Kultur und Politik im deutschen Kaiserreich, Berlin, Propyläen Verlag, 1994. En 1883, Emmanuel Dejung indique des budgets artistiques très supérieurs pour l'Italie et la France. Même le budget artistique du Montenegro serait supérieur à celui de la Suisse; Emmanuel Dejung, « 15 Briefe des Malers Frank Buchser an Jean Nötzli Redaktor des « Nebelspalters » über den eidgenössischen Kunstkredit », Jahrbuch für solothurnische Geschichte, 50 (1977), p. 155.

Hans A. Lüthy, « L'art en Suisse 1890-1945 », op. cit., p. 9-34. divers les Turnus, pourtant réguliers et très populaires jusque dans les années I $890^{4}$, les expositions de la Société suisse des femmes peintres, sculpteurs et décoratrices, la plupart des mouvements avant-gardistes internationaux, dont le mouvement Dada, certes zurichois d'origine mais qui rencontre alors peu d'écho en Suisse 5 , les nouvelles associations d'artistes fondées après la guerre ${ }^{6}$, alors que la discrétion sur la Sécession conservatrice de Lucerne en I 906 ne manque pas de poser la question du repli identitaire du Nebelspalter à ce moment de son existence.

\subsection{La question de l'art suisse}

Ce n'est qu'à la mi-ı 885 qu'on trouve pour la première fois dans le Nebelspalter une mention, somme toute discrète, d'un art national dans une petite caricature intitulée "Pressentiment» (Abnung). Un homme attaquant au marteau la statue d'Helvetia est interpellé par un personnage en costume, visiblement interloqué:

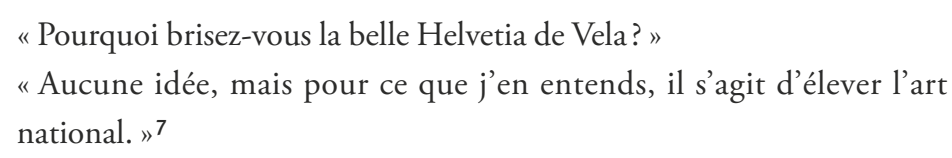

La légende se réfère à une statue créée par le sculpteur Vincenzo Vela (I 820-I89I) pour le concours de tir fédéral (Eidgenössiche Schützenfest) de Lugano, en $\mathrm{I} 883^{8}$. L'artiste tessinois est alors une personnalité exposée, jouissant d'une notoriété importante, tant nationale qu'internationale. Il a participé à de nombreuses expositions, a été membre du Grand Conseil et de nombreuses commissions artistiques. En I 883, à l'occasion de l'exposition d'art suisse de Zurich, Vincenzo Vela avait déjà fait l'objet d'une citation assez inhabituelle, tant par sa précision graphique que par le caractère très malveillant de la légende. Un bas-relief intitulé «Les victimes du travail » (Le vittime del Lavoro) (I 882-83), à présent considéré comme une œuvre majeure ${ }^{9}$, y était ironiquement désigné comme "perle de l'art suisse » (Perle schweizerischer Kunst). Selon la légende, l'œuvre ne tiendrait sa puissance que de

\footnotetext{
Paul-André Jaccard, «Turnus », Dictionnaire historique de la Suisse (07/01/2014 http://www.hls-dhs-dss.ch/textes/d/D24559.php.).

Hans A. Lüthy, « L'art en Suisse 1890-1945 », op. cit., p. 32.

Lukas Gloor, « Künstlervereine », Dictionnaire historique de la Suisse (14/04/2011); http://www.hls-dhs-dss.ch/textes/d/D17073.php.

( "Warum schlägt Ihr denn die schöne Vela'sche Helvetia entzwei? » "Wissen thu'ich es nicht, aber so viel ich höre, geschieht das zur Hebung der nationalen Kunst! »); Nebelspalter 1885/28, caricature en noir et blanc de Boscovits senior. Georg Kreis, Helvetia im Wandel der Zeiten. Die Geschichte einer nationalen Repräsentationsfigur, Zurich, Neue Zürcher Zeitung, 1991, p. 105.

Giorgio Zanchetti, «Vela, Vincenzo », Sikart, 1998, actualisé le 14.09.2011; http:// www.sikart.ch/Kuenstlerlnnen.aspx?id=4023476.
} 
sa portée illustrative de la dureté du travail, manière assez radicale de lui nier toute valeur esthétique ${ }^{10}$.

Dans les deux cas, le propos est ambigu. Il relaie cependant l'existence d'un débat sur l'art suisse, présent depuis le début du siècle dans les cercles artistiques ${ }^{11}$. La question prend soudain toute sa place à la fin de l'année r 886 via un éditorial cette fois univoque. Le texte, intitulé "L'art suisse » (Die schweizerische Kunst), est anonyme.

L'art suisse

Dans un coin sombre

De la salle du Conseil des États,

Enveloppé d'un vêtement plissé,

Se tient, silencieux, notre art, l'art suisse.

Son deuil lui mouillant les yeux,

Ses joues collées par l'affliction,

Sur ses lèvres, s' esquisse

Un sourire pessimiste

« Dois-je encore longtemps faire office de vachère

Avec, dans mon pays, tout juste de quoi vivre

Là, où les produits usinés

Tuent tout élan?

Pégase sous le joug,

Dois-je continuer à tirer la charrue

Alors que je pourrais devenir un enfant de l'amour

Pour le peuple fidèle?

L'épicier, les bonnes grâces

Doivent-ils avoir mon destin

Dans leurs mains maigres et sèches

Là où je trouverais une terre riche

Et tant de compréhension?

Là où mon aspiration et ma vie

Pourraient porter bénédiction

Et avec toute la bonne volonté

Apporteraient aussi un vrai talent

Pour que, comme d'autres Républiques,

Notre Suisse soit une étoile claire,

À laquelle l'art donne ses lumières?

Ou bien mes disciples

Parés de laurier

Devront continuer de le chercher à l'étranger

Et être montrés d'un doigt moqueur

Et qu'on dise: "ce sont les vrais!

Voulant être à la pointe,

Ils piétinent l'art!"

Quand viendra le jour

Qui me rendra enfin justice?»

Écoute! Soudain, là, retentit dans la salle

La voix de Gobat, virile, excellente

Qui plaide en faveur de l'art

Faisant battre fort les cœurs

Un vent traverse la salle

Tel des battements d'ailes puissants

Et l'art se dresse, joyeux

Ses yeux brillant d'audace.

Nebelspalter 1883/37, dessin en noir et blanc de Boscovits senior intitulé «"Les victimes du travail”. Relief de Vincenzo Vela » («Die Opfer der Arbeit » Relief von Vincenz Vela).

Hans A. Lüthy, « L'art en Suisse 1890-1945 », op. cit., p. 9.
Pour un court instant seulement

Avant de s'affaisser en pleurs

Repliés dans ses larmes

Quelques bonnes paroles pour Gobat - éconduit! ${ }^{12}$

Le texte revient sur l'échec essuyé par le conseiller national Albert Gobat (I843-I9I4) lors de sa plaidoirie devant le Parlement en faveur d'un soutien plus important à l'art. Gobat relaie alors les revendications des artistes, en particulier celles de la ligue de Franck Buchser (I 828-I 890), dite Buchseriade, dont celui-ci est le viceprésident. Sa création, un an plus tôt, est motivée par les manœuvres du conseiller fédéral Karl Schenk (I823-I895), profitant de la désunion des associations artistiques pour réviser à la baisse les propositions budgétaires ${ }^{13}$. L'éditorial du Nebelspalter répercute l'indignation de Franck Buchner ${ }^{14}$, qui entretient une correspondance avec Jean Nötzli depuis la fin I 879, où la question de l'art suisse, "notre bonne cause " (unsere gute Sache), est largement présente ${ }^{15}$. Buchser dit, du reste, à Nötzli vouloir jouer dans cette affaire le rôle de "dissipateur de brouillard " (Spalter des Nebels $)^{16}$. Peintre suisse, vif de tempérament, "fort en gueule » et grand voyageur, Buchser jouit alors d'une confortable renommée. Cofondateur avec Rudolf Koller (I 828-I905) et Ernst Stückelberg (I83 I-I903) en I 866 de la Société des peintres et artistes suisses (Gesellschaft schweizerischer Maler und Bildhauer), il se singularise par un engagement opiniâtre en faveur d'une meilleure reconnaissance de l'art suisse ${ }^{17}$. Il vise notamment l'organisation d'un salon d'art suisse en place des seules expositions itinérantes (Turnus), où les artistes étrangers seraient surreprésentés et les artistes suisses mal choisis. En fait, Buchser est déçu par l'éditorial. Il reproche à son ami de ne pas oser nommer le conseiller Schenk, selon lui le grand ennemi de l'art suisse: « Pourquoi n'oses-tu pas citer le grand obstacle par son nom, et le ridiculiser? ${ }^{18}$.

(Die schweizerische Kunst / Schweigsam sitzt in dunkler Ecke / In dem hohen Ständesaale / Eingehüllt in faltige Gewandung / Uns're Kunst, die Schweizerkunst. / Aus dem Auge glüht ihr Trauer, / Von den Wangen blickt ihr Kummer, / Und um ihre blassen Lippen / Spielt ein pessimistisch Lächeln. / "Soll ich länger noch als Stallmagd / Hier im Land mein Dasein fristen, / Wo die Dutzendfabrikate / Jede Höhere Regung tödten? / Soll, ein Pegasus im Joche / Fürder ich am Pfluge ziehen, / Wo ich sonst ein Kind der Liebe / Für das treue Volk könnt werden? / Soll der Krämer mein Geschicke, / Soll die Gunst mich in den magern, / In den dürren Händen halten, / Wo ich sonst so reichen Boden / Und so viel Verständnis fände ? / Wo mein Streben und mein Leben / Segenbringend wirken könnte, / Und in all'das gute Wollen / Auch ein rechtes Können brächte, / Dass, wie and're Republiken, / Uns're Schweiz ein heller Stern wär, / Dessen Leuchten ihm die Kunst gab? / Oder sollen meine Jünger, / Die der Lorbeer schmückt auch ferner/Ihn im fremden Lande suchen, / Dass man höhnisch mit dem Finger / Zeig und spricht: "das sind die wahren! / Wollen an der Spitze geben / Und die Kunst zertreten sie!" / Wann wird einst der Tag erscheinen / Der mein Recht mir endlich bringt? „ / Horch! Da plötzlich schallt im Saale / Gobat' Wort und männlich tüchtig / Bricht er für die Kunst die Lanze, / Dass die Herzen alle pochen / Und mir mächt'gem Flügelschlage / Durch den Saal es rauschend ziehet. / Und die Kunst erhebt sich freudig / Aus den Augen blitzt's ihr kühn. / Doch nur eine kleine Weile / Und dann bricht sie weinen wieder / Schluchzend in sich selbst zusammen / Gobat wurde abgespiesen, abgewiesen!); Nebelspalter 1886/49, couverture.

Emmanuel Dejung, « 15 Briefe des Malers Frank Buchser an Jean Nötzli Redaktor des "Nebelspalters" über den eidgenössischen Kunstkredit », op. cit., p. 155-156. Ibid., p. 155

Cote 2.62 de la succession Nötzli ; les quinze lettres présentes dans les archives ne sont pas conservées sous leur forme originale mais ont été recopiées, ceci avant qu'Emmanuel Dejung, descendant de Jean Nötzli, n'en publie une version largement commentée (cf. article cité plus en avant). Celui-ci relate, du reste, dans la postface le cheminement et l'état de conservation des documents, indiquant également qu'il manque les propres lettres de Nötzli. Il est probable que la correspondance qui s'arrête le 13 mars 1888 , un peu plus de deux ans avant la mort de Franck Buchser, soit incomplète; cf. également « 6.1. La leçon des archives Nötzli : un éditeur et ses réseaux ».

Cote 2.62 de la succession Nötzli, lettre non datée.

Hans A. Lüthy, « Buchser, Frank », SIKART, 1988, actualisé 2011; http://www. sikart.ch/kuenstlerinnen.aspx?id=4022827.

1 (Warum wagst Du nicht, den grossen Hemmschuh beim Nahmen zu nennen, und ihn lächerlich zu machen?); cote 2.62 de la succession Nötzli, lettre du 5 décembre 1886; Schenk est dénoncé de cette manière tout du long de la correspondance. 
La protestation des cercles artistiques se faisant toujours plus vive, le conseiller fédéral Karl Schenk présente le 3 juin I 887 au Conseil fédéral une proposition d'une teneur nettement plus favorable. Elle est adoptée de justesse le 22 décembre $1887^{19}$ et débouche sur un arrêté fédéral entrant en vigueur le I 8 avril I 888 . Les trois premiers articles fixent durablement le cadre institutionnel de l'art suisse :

\begin{abstract}
Article premier
La Confédération participe à l'avancement et à l'encouragement des arts en Suisse par l'organisation d'expositions artistiques nationales et périodiques ayant lieu dans la règle tous les deux ans et par l'achat d'œuvres de l'art national propres à orner les édifices publics ou à enrichir les collections publiques. Elle peut en outre faire exécuter des monuments publics d'un caractère historique et national ou en subventionner l'exécution. Elle peut allouer des subsides à des artistes de mérite pour leur permettre de compléter leurs études dans des centres artistiques.
\end{abstract}

Art. 2

Dans ce but, une somme de Ioo ooo francs sera inscrite chaque année au budget fédéral. Cette somme pourra être augmentée, si le besoin s'en fait sentir et si la situation financière de la Confédération le permet.

Si le crédit alloué pour une année n'est pas employé dans le courant de celle-ci, la somme restant disponible sera, en vue de son emploi ultérieur, versée dans un fonds spécial à créer sous le nom de "Fonds suisse des beaux-arts ", au sujet duquel il sera fourni un compte annuel

\section{Art 3}

La répartition annuelle, entre les destinations prévues à l'article premier, du crédit alloué et son emploi dans chaque cas particulier ont lieu par le Conseil fédéral, sur la proposition du Département fédéral de l'intérieur, qui, dans toutes les questions importantes, recourra à l'examen et au préavis d'artistes et d'autres experts nommés par le Conseil fédéral.

Les dispositions à prendre pour l'exécution du présent arrêté feront l'objet d'un règlement, qui sera élaboré par le Conseil fédéral ${ }^{20}$.

La partie paraît alors gagnée et, de fait, Buchser verra se tenir peu avant sa mort, au printemps I 890 , la première exposition nationale suisse des beaux-arts à Berne, couramment désignée Salon Buchser ${ }^{21}$. Cependant, les craintes qu'il formule aussitôt après l'adoption des mesures de soutien à l'art suisse, dont il redoute que leur application ne soit régie par des enjeux de pouvoir et des pratiques clientélistes pour ne devenir qu'une bataille pour un «fonds de reptiles » (Reptilienfonds) ${ }^{22}$, se concrétisent assez rapidement. Le peintre souhaite de son ami Nötzli des coups d'éclat journalistiques. Début mars I 888, en pleine polémique sur la constitution de la commission artistique par le Conseil fédéral, Buchser exhorte Nötzli qu'il juge trop timoré: « Es-tu perdu pour notre cause? ${ }^{23}$.

Emmanuel Dejung, " 15 Briefe des Malers Frank Buchser an Jean Nötzli Redaktor des "Nebelspalters" über den eidgenössischen Kunstkredit », op. cit., p. 155-157; Emmanuel Dejung indique par erreur juin 1887 et non décembre 1887. 442.1 Arrêté fédéral concernant l'avancement et l'encouragement des arts en Suisse du 22 décembre 1887.

Paul-André Jaccart, «Turnus, Expositions nationales suisses des beaux-arts, SPSAS, SSFPSD, Expositions Nationales Suisses: listes des expositions et des catalogues », Revue suisse d'art et d'archéologie, 4 (1986), L'art suisse s'expose, éd. Karl Schwegler, p. 446; Emmanuel Dejung, «15 Briefe des Malers Frank Buchser an Jean Nötzli Redaktor des "Nebelspalters" über den eidgenössischen Kunstkredit », op. cit., p. 172.

22 Emmanuel Dejung reproduit dans son article un extrait d'une lettre de Buchser à un ami bâlois: " 15 Briefe des Malers Frank Buchser an Jean Nötzli Redaktor des "Nebelspalters" über den eidgenössischen Kunstkredit », op. cit., p. 158

${ }_{3}$ (Bis du eigentlich für unsere gute Sache verlohren?); cote 2.62 de la succession Nötzli, lettre du 12 mars 1988.
Buchser est injuste avec Jean Nötzli qui reste fidèle à la ligne de son journal d'une agressivité maîtrisée mais n'en relaie pas moins les revendications des artistes ${ }^{24}$. Le journal publie ainsi une composition d'après le post-scriptum d'une lettre de Buchser du I 2 mars I 888 , où le peintre dit envoyer un billet à [Heinrich] Jenny en vue d'un dessin dans un prochain numéro ${ }^{25}$. La composition s'intitule "Art suisse" (Schweizerische Kunst) (cf. fig. I2I).

Une jeune femme, désignée comme l'art, est enchaînée à un roc, les attributs de l'artiste, palette, ciseaux et marteau, dans ses mains; à l'arrière-plan, se détache le cheval ailé, Pégase. Plusieurs personnages tentent de tirer la femme à eux, qui par la robe, qui par ses chaînes, alors qu'au premier plan un singe joue de la lyre, symbolisant un art dominé par la cupidité. Outre une palette, la femme tient dans sa main gauche un sac marqué « Io० o०० francs art » (Fr I00 o00 Kunst). Des hommes se pressent pour en recevoir le contenu, entourés de pancartes et inscriptions "faveur" (Gunst), " exposition Paris I 889 " (Ausstellung Paris I 889) et " critique » (Kritik). La légende est acide:

Art suisse / L'art vient du talent, / C'est pourquoi il n'est pas important / Que des gens sans talent / Parlent autant d'art ${ }^{26}$.

Quelques semaines plus tard, un autre dessin intitulé « La nouvelle commission artistique " (Die neue Kunstkommission) est publié, cette fois dépourvu de signature ${ }^{27}$. Représentant une perruque à neuf tresses, son propos est d'exprimer des craintes sur la composition de la commission, chaque tresse figurant un membre. Cette fois, les craintes sont vaines, puisque la ligue de Buchser sera intégrée à la commission, alors que la santé déclinante de l'artiste l'empêchera de prendre toute sa part aux travaux ${ }^{28}$. À sa mort, Buchser bénéficie d'un portrait en couverture, accompagné d'un texte signé « Nebelspalter » rappelant son engagement pour l'art suisse ${ }^{29}$

Des années durant, la revue continuera de dénoncer les dysfonctionnements d'un système où l'on retrouve toujours les mêmes noms, dans les commissions comme parmi les bénéficiaires des subventions ${ }^{30}$, et où l'on fait un usage inique des crédits. Tel est le propos d'une double-page en couleur de I 888 , dont la rareté à cette époque ne peut qu'attirer l'attention du lecteur. Le dessin particulièrement soigné et coloré représente des couples mariés descendant l'escalier d'honneur. Plus que tout, cependant, c'est un couple de cornus statufiés qui attire l'œil, manière de présenter l'art comme le cocu de l'affaire. Il s'agit ici de dénoncer la volonté fédérale d'affecter des subventions importantes pour la décoration des salles des mariages ${ }^{31}$. Parfois la critique prend un tour humoristique et s'intègre à un propos plus large, comme

Nebelspalter 1908/9, couverture de Boscovits senior intitulée "Cauchemar " (Alpdrücken).

Cote 2.62 de la succession Nötzli, lettre du 13 mars 1888 ; il s'agit de la dernière lettre de la succession Nötzli, ce qui ne préjuge pas d'une suite qui n'aurait pas été conservée.

${ }^{26}$ (Schweizerische Kunst / Von Können stammt die Kunst, Drum ist's wie blauer Dunst, / Wenn Leute, die das Können missen, / So viel von Kunst zu reden wissen.); Nebelspalter 1888/14, dessin pleine page de Heinrich Jenny intitulé « Art suisse » (Schweizerische Kunst).

Nebelspalter 1888/21, dessin non signé intitulé "La nouvelle commission artistique » (Die neue Kunstkommission).

Emmanuel Dejung, « 15 Briefe des Malers Frank Buchser an Jean Nötzli Redaktor des "Nebelspalters" über den eidgenössischen Kunstkredit », op. cit., p. 159.

Nebelspalter 1890/49, couverture.

Paul-André Jaccard, «Turnus, Expositions nationales suisses des beaux-arts, SPSAS, SSFPSD, Expositions Nationales Suisses: listes des expositions et des catalogues », op. cit., p 436-436.

Nebelspalter 1888/49, composition double-page en couleur de Heinrich Jenny intitulée « Le temple fédéral des mariages » (Der eidgenössische Heirathstempel). 


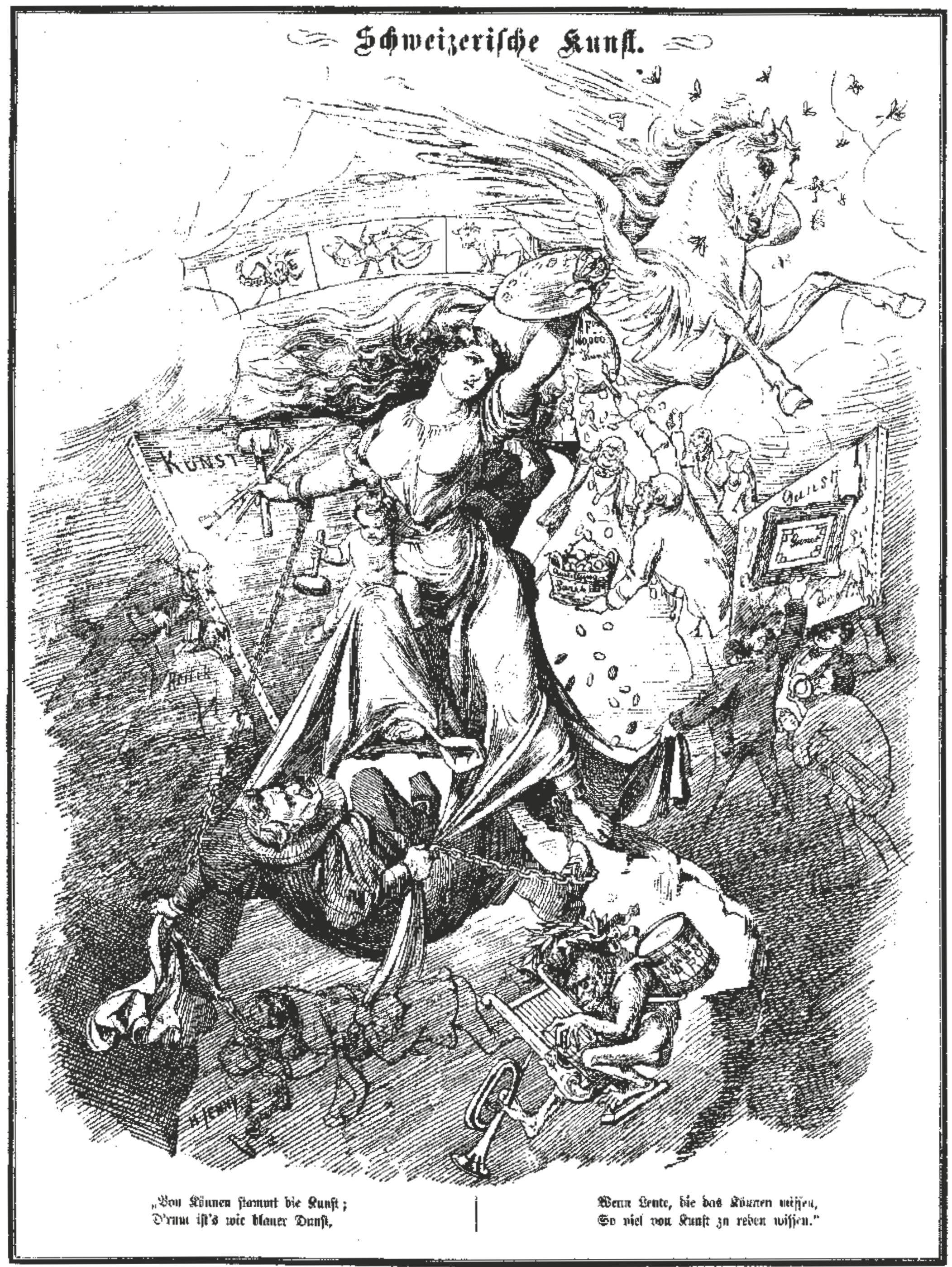

Fig. 121. Nebelspalter 1888/14, dessin pleine page en noir et blanc de Heinrich Jenny intitulé « Art suisse »(Schweizerische Kunst). 


\section{Hunstjustiž. - - Ko}

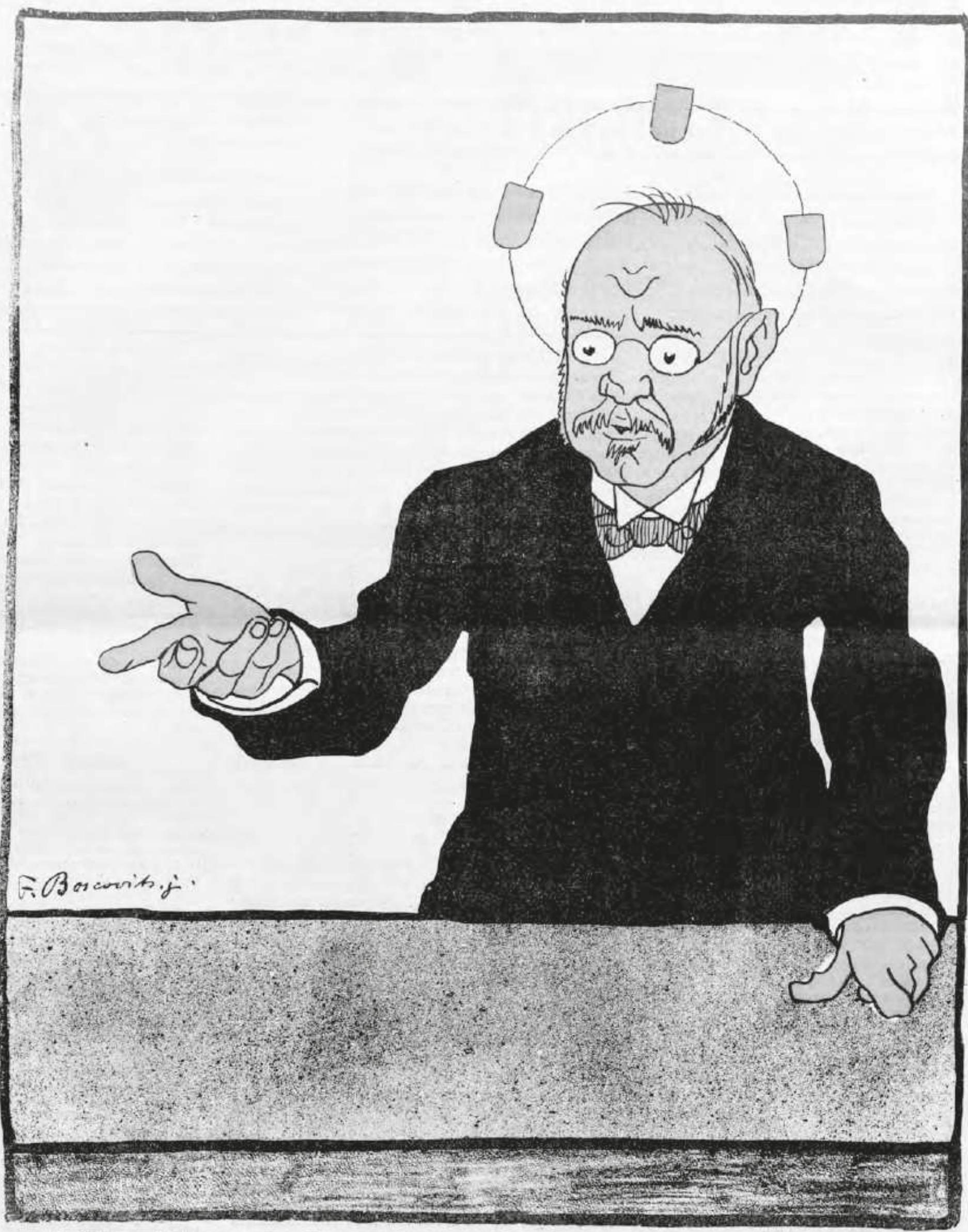

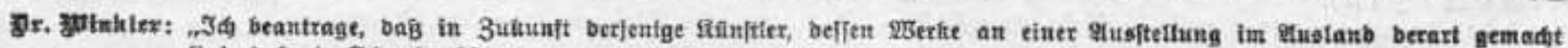

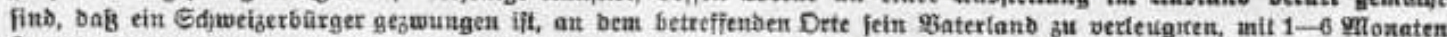

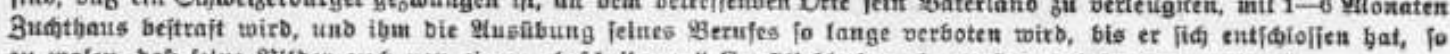

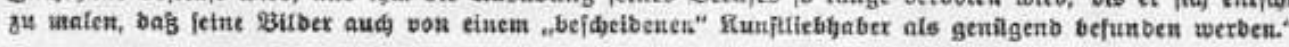

Fig. 122. Nebelspalter 1911/44, dessin pleine page en couleur de Boscovits junior intitulé « Justice artistique » (Kunstjustiz). 
dans un dessin de 1893 où Boscovits senior se portraiture en représentant de la corporation des artistes, tendant son écuelle pour recevoir sa part des subventions fédérales ${ }^{32}$. Certaines de ces critiques sont féroces, tel "L'idéal artistique suisse " (Das schweizerische Kunstideal) de Henri van Muyden, agglutinant des artistes flagorneurs autour d'une poupée de paille portant l'inscription "Subvention artistique $200000 \mathrm{~F}$ " (KunstSubvention $200000 \mathrm{~F})^{33}$. Différents topoï sont ainsi déclinés jusqu'en I908: la chasse aux subventions ${ }^{34}$, l'attribution douteuse de celles-ci ${ }^{35}$, les disputes entre artistes ${ }^{36}$, le détournement de fonds ${ }^{37}$ et les réajustements budgétaires, dont pâtit parfois le budget artistique ${ }^{38}$.

À partir de I9I I, la garde se déplace vers une dérive que n’avait probablement pas anticipée Franck Buchser. En I 906, des courants ultra-conservateurs, coalisés en front anti-hodlériste ${ }^{39}$, traversent la Société suisse des sculpteurs et peintres, ouvrant sur une sécession bien mal nommée, dite Sécession de Lucerne ${ }^{40}$. En I 9 I I, celle-ci crée la polémique en raison du pamphlet réactionnaire rédigé par le Dr. Johann Winkler, notable de la ville de Lucerne ${ }^{41}$ et ancien juge fédéral ${ }^{42}$. L'événement donne lieu à une caricature saisissante de Boscovits junior (cf. fig. I22).

Intitulée « Justice de l'art » (Kunstjustiz), elle montre le Dr Winkler tenant tribune, la tête auréolée, ce qui ne présage jamais rien de bon dans la satire. Les propos qui lui sont prêtés ne sont pas sans rappeler le très célèbre discours du I 8 décembre I90 I de l'empereur allemand Guillaume II, «L'art véritable » (Die wahre Kunst $)^{43}$, qui avait mis en émoi les milieux artistiques allemands ${ }^{44}$ :

Dr. Winkler: Je demande que dans le futur les artistes dont les œuvres exposées à l'étranger, forçant ainsi un ressortissant suisse à renier sa patrie, soit puni d'une peine de prison de I à 6 mois, et qu'il lui soit

Nebelspalter 1893/51, dessin double-page en couleur de Boscovits senior intitulé "Instantané de la vie politique suisse » (Die schweizerische Politik zur Stunde).

Nebelspalter 1894/24, dessin pleine page de Henri van Muyden intitulé «L'idéal artistique suisse » (Das schweizerische Kunstideal).

${ }^{4}$ Nebelspalter 1895/14, double-page en couleur de Boscovits senior intitulée "Temps d'avril » (Aprilenwetter); Nebelspalter 1895/18, dessin pleine page non signé intitulé « Sur la situation actuelle » (Zur heutigen Situation).

Nebelspalter 1891/18, dessin pleine page de Boscovits senior intitulé « Une prise agréable? » (Eine Prise gefällig?); Nebelspalter 1896/3, dessin anonyme intitulé "Raisins verts » (Saure Trauben) "; Nebelspalter 1907/15, dessin pleine page en couleur de Boscovits senior intitulé «D'après de célèbres modèles » (Nach berühmten Mustern); Nebelspalter 1907/43, couverture de Boscovits junior intitulée « L'art regarde vers les provisions » (Kunst geht nach « Eingemachtem »); Nebelspalter 1908/9, couverture de Boscovits senior intitulée "Cauchemar » (Alpdrücken)

Nebelspalter 1891/34, dessin pleine page de Heinrich Jenny intitulé « Les frères ennemis (à propos des artistes helvétiques et de la dispute sur la commission)» (Die feindliche Brüder [zum helvetischen Künstler und Kunstkommissionstreit]);

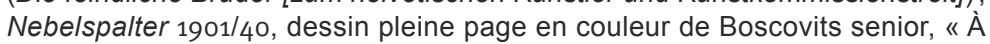
propos de notre dispute entre artistes » (Zu unserem Künstlerstreit).

Nebelspalter 1905/27, dessin en noir et blanc de Boscovits senior intitulé " L'encouragement de l'art selon le Dr. Eisenbart » (Dr. Eisenbarts « Kunstpflege »).

Nebelspalter 1904/31, dessin pleine page de Boscovits senior intitulé « Une économie domestique bien maigre » (Schmale Haushaltung).

Philippe Kaenel, « La réception de l'œuvre de Hodler en Suisse romande et en France ", dans Ferdinand Hodler. Die Forschung. Die Anfänge. Die Arbeit. Der Erfolg. Der Kontext, éd. Oskar Bätschmann, Matthias Frehner et Hans-Jörg Heusser, Zurich, SIK-ISEA, 2009, p. 239.

Pascal Ruedin, «Berne-Paris-Vienne-Munich, et retour. Institutions artistiques, identité nationale et modernité en Suisse autour de 1900 », dans 1900 Symbolisme et Art nouveau dans la peinture suisse, éd. Christoph Vögele, Matteo Bianchi et Pascal Ruedin, Solothurn, Kunstmuseum, 2000, p. 32.

Gregor Egloff, « Winkler, Johann », Dictionnaire historique de la Suisse (3/02/2012), op. cit.

Hans A. Lüthy, «L'art en Suisse 1890-1945 », op. cit., p. 25.

" Die wahre Kunst - 18. Dezember 1901 »; Penzler, Die Reden Kaiser Wilhelms II. In den Jahren 1901- Ende 1905, Leipzig, Verlag von Philipp Reclam jur., n. d., p. $57-63$.

Laurence Danguy, L'ange de la jeunesse - La revue Jugend et le Jugendstil à Munich, Paris, Maison des sciences de l'homme, 2009, p. 147-149. interdit d'exercer son métier jusqu'à ce qu'il se décide à peindre de telle manière que ses tableaux soient également jugés suffisants pas un «modeste» amateur ${ }^{45}$.

\subsection{Rendre compte des expositions et régler ses comptes via les expositions}

Cinq types d'expositions sont présents dans les pages du Nebelspalter: les expositions suisses des beaux-arts, organisées par la Société suisse des beaux-arts et ses relais locaux, dites Turnus, existant depuis I 840 ; les expositions nationales suisses des beauxarts, placées sous l'égide de la Confédération, dont le salon Buchser en I 890 est la première occurrence; les expositions nationales suisses avec une section réservée aux beaux-arts, présentes pour la première fois à Zurich en $\mathrm{I} 883^{46}$; les expositions zurichoises, organisées à partir de I 895 par le Künstlerhaus, plus rarement par le Zürcher Kunstverein; et, pour finir, les expositions universelles, ayant toutes lieu hors de Suisse. Deux grandes absentes sont à déplorer: les expositions organisées, à partir de I903, par la Société suisse des femmes peintres, sculpteurs et décoratrices (SSFPSD), à mettre sur le compte de la ligne conservatrice de la revue, peu favorable à l'émancipation féminine ainsi que les expositions organisées par la Société des peintres et artistes suisses (SPSAS), fondée par Franck Buchser, Rudolf Koller et Ernst Stückelberg en I 866, dont la première édition voit le jour en I905, c'est-à-dire à la veille de la scission débouchant sur la Sécession conservatrice de Lucerne.

Présence ne signifie pas égalité de traitement. Si le Nebelspalter rend compte des expositions, c'est néanmoins de manière sélective. La qualité de la couverture, voire même son existence, diffère selon les manifestations et les périodes. L'exposition itinérante (Turnus) de I 877 et l'exposition nationale de I 883 à Zurich, auxquelles est donnée une visibilité importante, représentent deux exceptions qui ne doivent pas tromper. La première est prétexte à l'exercice du salon caricatural et surtout à l'affirmation de l'identité artistique du Nebelspalter ${ }^{47}$; on souligne copieusement la portée événementielle de la seconde, première du genre ${ }^{48}$. Toutes deux rencontrent les intérêts symboliques d'une revue, alors attachée à affirmer son identité artistique et zurichoise. Longtemps, en effet, les expositions sont essentiellement prétexte à un propos

(Dr. Winkler: « Ich beantrage, dass in Zukunft derjenige Künstler, dessen Werke an einer Ausstellung im Ausland derart gemacht sind, dass ein Schweizerbürger gezwungen ist, an dem betreffenden Orte sein Vaterland zu verleugnen, mit 1-6 Monate Zuchthaus bestraft wird, und ihm die Ausübung seines Berufes so lange verboten wird, bis er sich entschlossen hat, so zu malen, dass seine Bilder auch von einem "bescheidenen" Kunstliebhaber als genügend befunden werden. »); Nebelspalter 1911/44, dessin pleine page en couleur de Boscovits junior intitulé « Justice artistique » (Kunstjustiz).

Paul-André Jaccard, "Turnus, Expositions nationales suisses des beaux-arts SPSAS, SSFPSD, Expositions Nationales Suisses: listes des expositions et des catalogues », op. cit.

Cf. « 4.3. Le salon caricatural du Nebelspalter ou la critique de la modernité ».

Nebelspalter 1883/17, double-page de Boscovits senior intitulée "Exposition nationale suisse à Zurich. $1^{\text {er }}$ mai au 30 septembre 1883 " (Schweizerische Landesausstellung in Zürich 1. Mai bis 30. September 1883); Nebelspalter 1883/21, double-page de Boscovits senior intitulée «Le comité central de l'exposition nationale suisse » (Das Central-Comité der Schweizerischen Landesausstellung); Nebelspalter $1883 / 23$, double-page en noir et blanc de Boscovits senior intitulée " La foule devant le jury » (Das Gedränge vor der Jury). 
politique, façon de signifier que l'on est attentif à leur tenue mais plus encore au contexte politique. L'exposition universelle de 1878 de Paris ouvre ainsi sur un dessin de Boscovits senior montrant le Nebelspalter dans une sorte de mandorle et tenant une pancarte avec l'inscription-titre "Ce que nous avons oublié d'exposer à l'exposition universelle " (Was wir vergessen haben auszustellen zur Weltausstellung); au-dessous, une série de cartes livre un tableau de la situation politique: les 22 lois des cantons, l'unité suisse, le budget miliaire, le financement du réseau ferré, la pléthore de votations ainsi que le manque de courage de la presse suisse ${ }^{49}$. L'absence des quatre expositions universelles de Sidney (I 879), Melbourne (I 880), Anvers (I 885) et Barcelone ( 1888 ) reflète le périmètre international du Nebelspalter, alors essentiellement limité à ses voisins. L'exposition universelle de I 889 à Paris fonctionne, en partie, comme celle de I 878 , c'est-à-dire tel un écran servant à dénoncer le déséquilibre des relations commerciales entre la France et la Suisse ${ }^{50}$ ainsi que le boulangisme ${ }^{51}$. Elle est néanmoins également propice à une charge contre l'art suisse, dont la fuite à toutes jambes serait motivée par le caractère horrible des œuvres ${ }^{52}$. Pour la première fois, la question artistique est mise en avant. Elle le sera à nouveau en I 890 à l'occasion du salon Buchsner avec un humour assez décalé. La caricature de Henri van Muyden comporte quatre volets, dont l'un sur l'accrochage des tableaux, assorti d'un dialogue passablement acide. L'homme s'adresse à son épouse:

«Saperlipopette, regarde là-haut, à quelle hauteur ont été accrochés mes petits tableaux!» «Ce n'est pas plus mal pour toi, tu peux ainsi plus facilement éviter les critiques. " ${ }^{33}$

La mise en lumière de cette exposition est cependant inhabituelle et s'explique par l'engagement de Jean Nötzli aux côtés de Franck Buchser. Elle est du reste à rapporter à l'absence de couverture des expositions itinérantes durant cette période, connaissant pourtant leur âge d'or ${ }^{54}$. Malgré les huit occurrences zurichoises jusqu'en $192 \mathrm{I}^{55}$, celles-ci ne seront présentes qu'à deux reprises dans le Nebelspalter ${ }^{56}$. Si l'exposition universelle de Chicago de I 893 bénéficie d'une visibilité assez importante, le traitement en est cependant exclusivement politique, qu'il s'agisse de se moquer des déclarations officielles sur le choléra soudain quasiment disparu du pays ${ }^{57}$, de mettre en avant un coût exorbitant ${ }^{58}$ ou d'en tirer une caricature antisémite ${ }^{59}$.

Nebelspalter 1878/18, dessin pleine page de Boscovits senior intitulé « Au sujet de l'exposition universelle » (Zur Weltausstellung)

Nebelspalter 1888/33, dessin non signé intitulé «Au sujet de l'exposition universelle » (Zur Weltausstellung).

Nebelspalter 1889/22, dessin pleine page signé « Pastarella » intitulé « Ecce homo!».

Nebelspalter 1889/32, dessin pleine page de Heinrich Jenny intitulé « À l'exposition parisienne " (An der Pariser Ausstellung).

3 ("Sapperlot, da schau'mal her, wie hoch hinauf sie mein Bildchen gehängt haben! " "Um so besser für dich, du entgehst so leichter den Kritikern. »); Nebelspalter 1890/24, dessin pleine page de Henrry van Muyden intitulé « Salon artistique à Berne » (Kunstsalon in Bern).

Paul-André Jaccard, « Turnus », op. cit.

Ibid., p. 437-446.

Nebelspalter 1898/28, dessin pleine page de Boscovits junior intitulé « Exposition d'art suisse à la bourse de Zurich » (Schweizerische Kunstaustellung in der Börse Zürich) et Nebelspalter 1901/21, dessin pleine page non signé intitulé « Une lettre » (Ein Brief).

Nebelspalter 1892/41, dessin pleine page de Henri van Muyden intitulé « Très vraisemblable » (Sehr wahrscheinlich).

s Nebelspalter 1893/21, dessin pleine page de Henri van Muyden intitulé «À Chicago " (In Chicago).

59 Nebelspalter 1893/15, dessin pleine page non signé intitulé « Une bonne excuse » (Eine gute Ausrede)
Il faut attendre I 896 pour observer un tournant dans le traitement des expositions, alors que débutent les expositions du Künstlerhaus et que se tient l'exposition nationale à Genève. Cette dernière bénéficie d'une attention tout à fait inédite: un numéro spécial est consacré à l'ouverture ${ }^{60}$. Le changement est autant dans la forme que dans le fond. Certes, l'exposition génère son lot de caricatures humoristiques, tel un parapluie fort joliment cadré pour illustrer le temps pluvieux lors de la journée d'ouverture ${ }^{61}$, et la double-page colorée du numéro spécial répond à une organisation iconographique inchangée, devenue en I 896 singulièrement passéiste. Helvetia, la tête surplombée de l'inscription Post Tenebras Lux (Après les ténèbres la lumière), la devise de la ville de Genève, y rend un hommage aux participants. La légende honore spécialement l'un d'entre eux, un jeune enfant tenant une palette de peintre, son corps demi-nu couvert d'épines:

[Helvetia] «Approchez, approchez, que je vous accorde à tous ma faveur! Comme je suis fière de t'offrir la première couronne de lauriers, toute dorée, à toi enfant de douleurs qui a jadis tant souffert, ici, pour la première fois, art suisse. " ${ }^{62}$

Willy Lehmann-Schramm réserve, pour sa part, à l'exposition deux feuillets dans la plus pure esthétique Jugendstil ${ }^{63}$, concourant à l'esthétisation de l'événement.

De toutes les expositions de l'époque zurichoise, l'exposition universelle de I900 à Paris est la plus médiatisée, non seulement au travers de dessins mais aussi d'une multitude de textes et insertions publicitaires. Cette présence correspond à un succès phénoménal avec plus de 50 millions de participants ainsi qu'à la forte implication de la Suisse, en particulier avec son village suisse $^{64}$, par ailleurs moqué dans une caricature de W. LehmannSchramm ${ }^{65}$. La composition la plus savoureuse précède de quelques semaines le début de l'exposition. Intitulée « Exposition de bétail à Paris » (Viehausstellung in Paris), elle met en abyme non seulement le journal lui-même mais son lecteur. Une vache en habits d'intérieur, confortablement assise dans un fauteuil en train de lire le Nebelspalter bougonne (cf. fig. I23):

ben, ils nous font des règlements aussi stricts si nous voulons aller à Paris? Il faudrait être de [gros] bœufs pour y aller! ${ }^{66}$

À cette date, l'attention des dessinateurs est essentiellement focalisée sur la scène zurichoise et ceux-ci privilégient le salon caricatural, devenu le genre préféré des dessinateurs pour exercer leur activité critique ${ }^{67}$. Ceci, à quelques exceptions notables, dont

Nebelspalter $1896 / 18$

Nebelspalter 1896/19, dessin non signé intitulé « Un pour tous » (Einer für Alle!). (Helvetia: Heran, heran! Euch alle trönet meine Gunst! Wie bin ich stolz, den ersten goldenen Lorbeer, Dir zu reichen, Du Schmerzenskind einst sondergleichen, nun hier zum ersten Mal, die schweizerische Kunst!); Nebelspalter 1896/18, doublepage en couleur de Boscovits senior intitulée «À l'occasion de l'ouverture de l'Exposition nationale suisse à Genève, $1^{\text {er }}$ mai 1896 " (Zur Eröffnung der Schweizerischen Landesausstellung in Genf, 1. Mai 1896).

Nebelspalter 1896/18, dessin pleine page de Willy Lehmann-Schramm intitulé "Expositions de coqs » (Ausstellungs-Gigerln); Nebelspalter 1896/37, dessin pleine page de Willy Lehmann-Schramm intitulé « Images de l'exposition de Genève » (Bilder von der Genfer Ausstellung).

4 Ruedi Brassel-Moser, "Expositions universelles », Dictionnaire historique de la Suisse (27/03/2006); http://www.hls-dhs-dss.ch/textes/f/F13797.php.

Nebelspalter 1900/20, dessin pleine page en couleur de Willy Lehmann-Schramm intitulé « À Paris pour l'exposition universelle » (Nach Paris zur Weltausstellung). (Also, solch scharf Bestimmungen machen sie für uns, wenn wir nach Paris kommen wollen? Da müsste man ja en Rindvieh sein, wenn man gehen würde!) Nebelspalter 1900/10, dessin pleine page en noir et blanc de Boscovits senior intitulé « Exposition de bétail à Paris » (Viehausstellung in Paris).

Marta Sironi, Ridere dell'arte. L'arte moderna nella grafica satirica europea tra otto e novecento, Milano-Udine, Mimesis Edizioni, 2012 p. 58 


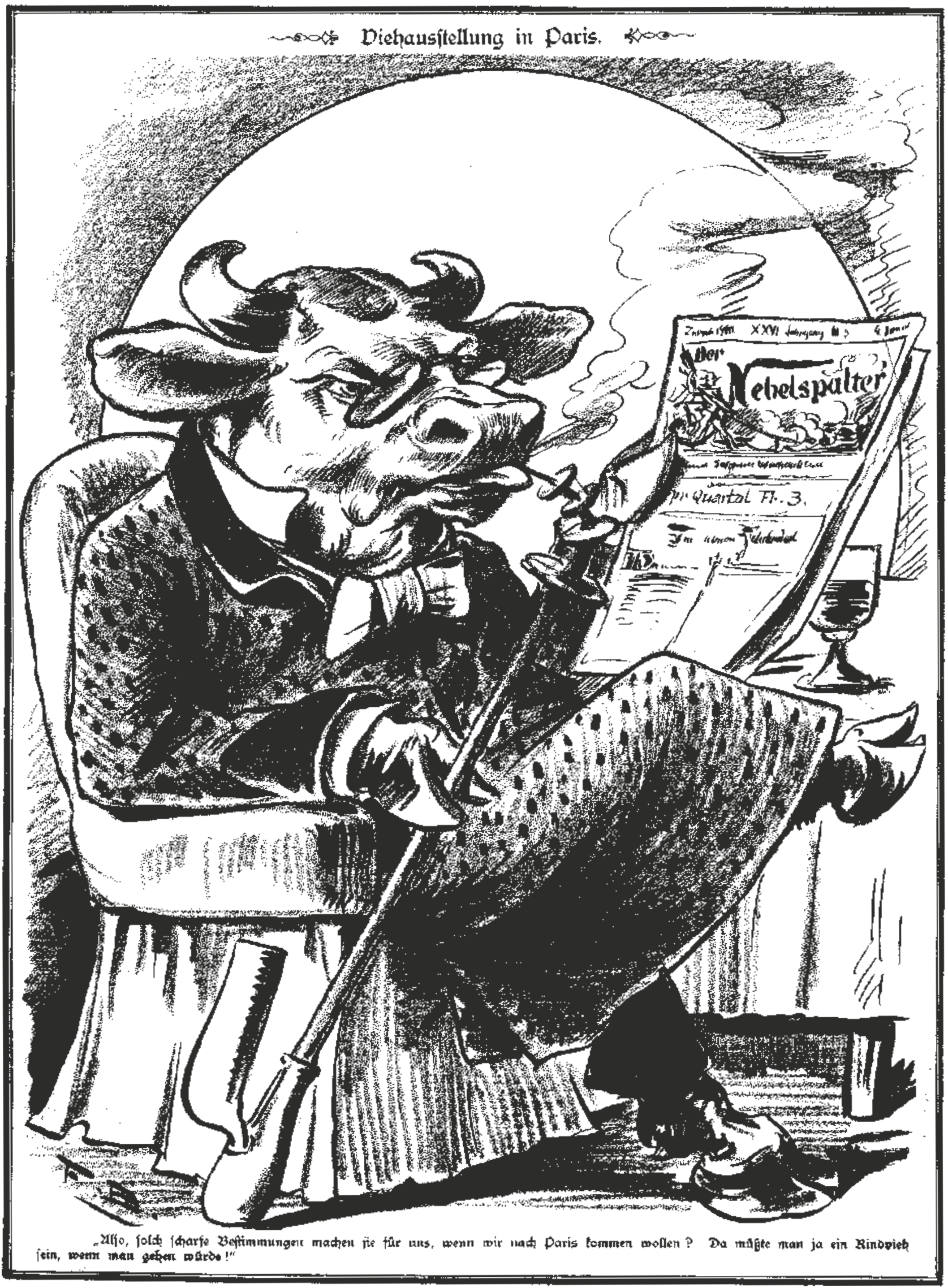

Fig. 123. Nebelspalter 1900/10, dessin pleine page en noir et blanc de Boscovits senior intitulé « Exposition de bétail à Paris » (Viehausstellung in Paris). 
une citation de La peste (Die Pest, I 898) de Böcklin ${ }^{68}$ pour saluer une exposition née grâce à la fondation Gottfried Keller ${ }^{69}$.

\subsection{Le salon caricatural du Nebelspalter ou la critique de la modernité}

La forme du salon caricatural est apparue dans les revues illustrées parisiennes au cours des années I 840 . Durant la saison des salons (fin avril, début mai), on présentait ainsi sous les titres Le Salon pour Rire, Revue comique, L'bumour de l'art, Une promenade au Salon un compte rendu satirique de la manifestation officielle ${ }^{70}$. Le salon caricatural ne fonctionne, du reste, que de manière référentielle, la réception du dessin requérant la connaissance de l'exposition "réelle » et du livret l'accompagnant ${ }^{71}$. Dans le Nebelspalter, le salon caricatural connaît plusieurs phases: une phase primitive, où il est présent de manière sporadique; une deuxième époque entre I 896 et I 905 , où il s'affiche très régulièrement en lien avec la scène artistique zurichoise; un champ du cygne en I9I3, avec une dernière occurrence, particulièrement instructive.

Boscovits senior introduit tout d'abord le salon caricatural à deux reprises, en I 877 et en I 886. Il s'appuie alors sur des modèles parisiens, qu'il adapte au contexte local ${ }^{72}$. En I 877 , son dessin intitulé «Dans l'exposition d'art suisse » (In der Schweizerischen Kunstaustellung) n'est pas signé73. Le fait dénote un sujet sensible, la parodie d'une exposition artistique itinérante, se tenant cette année-là à Bâle et Saint-Gall (cf. fig. I24).

Le dessin aligne huit œuvres numérotées, renvoyant au livret accompagnant l'exposition de Saint-Gall ${ }^{74}$. À chaque numéro est associé un commentaire ironique:

Catalogue 229 « Souvenir de Sorrent » mais très mince. 233 « Rebecca à la fontaine » ou la juive ligotée par la peur devant la possibilité d'un léger

Nebelspalter 1904/47, dessin pleine page signé d'un monogramme intitulé «Au sujet de l'exposition d'art de la fondation Gottfried Keller » (Zur Kunstausstellung der Gottfried Keller-Stiftung).

En 1890, Lydia Welti-Escher lègue son patrimoine à la Confédération dans le but de créer la fondation Gottfried Keller, permettant d'enrichir notablement les acquisitions des musées suisses; Claude Lapaire, « Gottfried Keller, fondation », Dictionnaire historique de la Suisse (5/04/2007); http://www.hls-dhs-dss.ch/ textes/f/F11909.php.

Marta Sironi, Ridere dell'arte. L'arte moderna nella grafica satirica europea tra otto e novecento, op. cit., p. 33

Denys Riout, « Les salons comiques », Romantisme, 75 (1992), p. 53; sur le salon caricatural dans la presse, voir aussi: Emmanuel Pernoud, "Les beaux-arts à l'épreuve du kiosque », dans La Civilisation du journal. Histoire culturelle et littéraire de la presse française au XIXe siècle, éd. Dominique Kalifa, Philippe Régnier, Marie-Ėve Thérenty et Alain Vaillant, Paris, Nouveau Monde, 2011, p. 1569-1577 Marie Luise Buchinger-Früh, Karikatur als Kunstkritik. Kunst und Künstler in der Salonkarikatur des « Charivari » zwischen 1850 und 1870, Francfort-sur-le-Main, Peter Lang, 1989.

Cette acculturation du salon caricatural parisien suppose la recherche d'un nouveau lexique, adapté au lieu de la réception; Vanja Strukelj et Francesca Zanella, Dal progetto al consumo. Le arti in mostra nell'Italia dell'Ottocento, Parme, Monte Università Parma, 2011, p. 283-292.

Boscovits senior est alors l'unique dessinateur, ce qui ne laisse aucun doute sur sa paternité.

Schweizerische Kunstaustellung in St. Gallen 1887 vom 20. Mai bis 10. Juin. Katalog der ausgestellten Kunstwerke, Saint-Gall, Buchdruckerei von M. Kälin 1877; chaque ville recevant le Turnus conçoit un catalogue, alors que le choix des œuvres présentées diffère partiellement d'une ville à l'autre : Paul-André Jaccard, "Turnus, Expositions nationales suisses des beaux-arts, SPSAS, SSFPSD, Expositions Nationales Suisses: listes des expositions et des catalogues ", op. cit., p. 437-439. jet de torpille. - I 27. "Étude d'un mendiant ». Où seul le mendiant se procure de beaux cadres pour ses études. - 45 "La place Saint-Marc de Venise ", tout à fait adaptée comme enseigne des consulats italiens. - 290. "Le bouc renversé ». L'artiste a abattu le bouc. [L'artiste a fait une grosse bourde] - I. "Vierge sur le chemin de Mürren ». Pensé avec beaucoup de douceur. - 23. "Famille de poules ». Vraiment très artistiquement réalisé. Vue cependant un peu trop réaliste. - I I 5 . «Donne-nous notre pain quotidien!»Amen ${ }^{75}$.

La dernière image est censée parodier une œuvre du peintre munichois August Heyn (I 837-I920). Placée au milieu de la page, en bas, il s'agit d'un feuillet dépourvu de cadre, titré dans le coin supérieur gauche "Der Nebelspalter ». Il montre le personnage du Nebelspalter en prières devant un rôti marqué "Abonnement ", accompagné d'une bouteille de vin. La revue prend alors ostensiblement sa place dans l'univers visuel de la satire.

Boscovits ne réitère l'exercice que neuf ans plus tard, en I 886, titrant sa composition, cette fois signée mais non légendée, quasiment à l'identique « De l'exposition artistique suisse » (Von der schweizerischen Kunstausstellung $)^{76}$. Le propos est différent, il s'agit désormais de dénoncer la faiblesse de l'engagement fédéral en faveur de l'art, quelques mois avant l'éditorial sur l'art suisse ${ }^{77}$.

L'exercice du salon caricatural ne reprend qu'en i 896. Lorsque les compositions sont signées, elles le sont à présent, soit de Willy Lehmann-Schramm, soit de Boscovits junior. L'arrangement et le trait, la rhétorique aussi parfois, sont à présent calqués sur les salons caricaturaux de la revue munichoise Jugend $^{78}$. Les tableaux se chevauchent souvent, correspondent entre eux, parfois sur toute la hauteur, comme avec le liquide répandu par un équilibriste maladroit, dont le créateur, Boscovits junior, nous dit dans le sous-titre qu'il est, comme l'ensemble des œuvres caricaturées, très amélioré par rapport à l'original ${ }^{79}$. Le genre est désormais surtout réservé aux expositions zurichoises, organisées par le Künstlerhaus Zürich, fondé en I 895, ainsi que, plus rarement, par le Zürcher Kunstverein, plus anciennement établi, depuis I 853 . Les deux associations, faute de bâtiment adapté, organisent leurs expositions dans une salle provisoire de la Börsenstrasse ${ }^{80}$ où se tiennent également les expositions itinérantes nationales (Turnus). Fidèle au fonctionnement de la satire, la critique est négative, à l'exception du soutien en I 899 au projet d'un espace d'exposition zurichois qui deviendra le Kunsthaus. La cible est toujours la même, les représentants de l'art moderne (Moderne), avec une concentration sur deux figures, Ferdinand Hodler et Cuno Amiet (I868-I96I).

(Katalog 229. "Erinnerung an Sorrent», aber eine sehrmagere - 233. "Rebecca am Brunnen » oder die Jüdin in den Fesseln der Angst vor dem leicht losgehen könnenden Torpedo. - 127. "Studie eines Bettlers. "Wo nur der Bettler die schönen Rahmen zu seinen Studien herbekommt. - 45. "St. Markusplatz in Venedig », sehr passend als Aushängeschild für italienische Konsulate. - 290. " Der gestürzte Bock ». Der Künstler hat den Bock geschossen. - 1. « Jungfrau am Wege an Mürren ». Sehr zart gedacht. - 23. « Hühnerfamilie ». Recht künstlerisch aufgefasst; nur etwas zu realistische Anschauung. - 115. "Unser heutiges Brod gib' uns täglich! " Amen.); Nebelspalter 1877/27, dessin pleine page non signé intitulé « Dans l'exposition d'art suisse » (In der Schweizerischen Kunstaustellung). Nebelspalter 1886/17, double-page de Boscovits senior intitulée « De l'exposition artistique suisse » (Von der schweizerischen Kunstaustellung).

Emmanuel Dejung, " 15 Briefe des Malers Frank Buchser an Jean Nötzli Redaktor des "Nebelspalters" über den eidgenössischen Kunstkredit », op. cit., p. 156. Cf. « 5. 1. Le Nebelspalter, la caricature et les revues illustrées européennes ». « Gegenüber den Originalen starke verbesserte Copien »; Nebelspalter 1897/7. dessin pleine page de Boscovits junior intitulé « Dans l'exposition d'art de la Zürcher Kunstverein » (In der Kunstausstellung des Zürcher Kunstvereins). Histoire de la Zürcher Kunstgesellschaft et de la collection du Kunsthaus; http:// www.kunsthaus.ch/fr/informations/la-compagnie/histoire. 


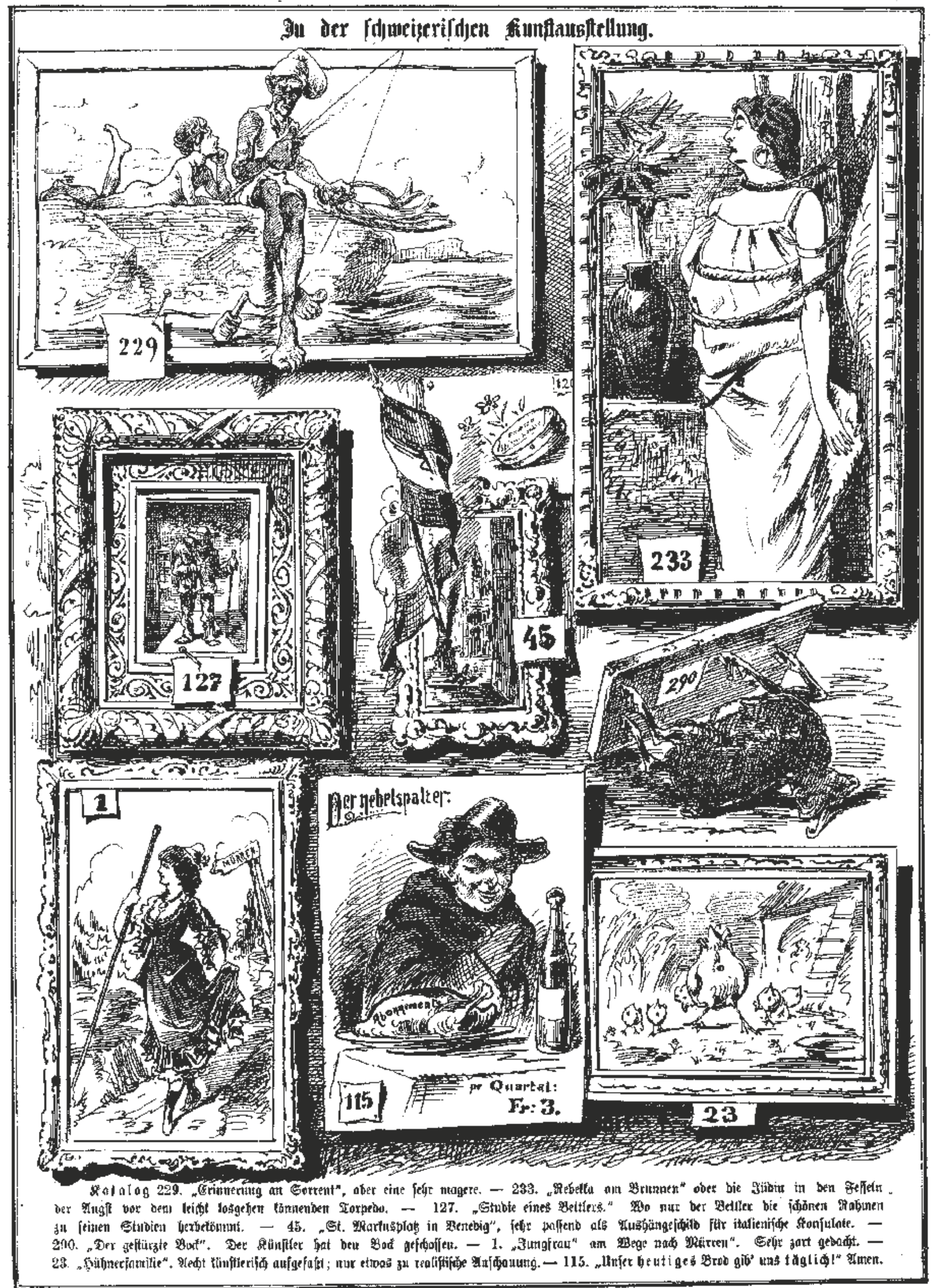

Fig. 124. Nebelspalter 1877/27, dessin pleine page en noir et blanc non signé intitulé « Dans l'exposition d'art suisse » (In der Schweizerischen Kunstaustellung). 


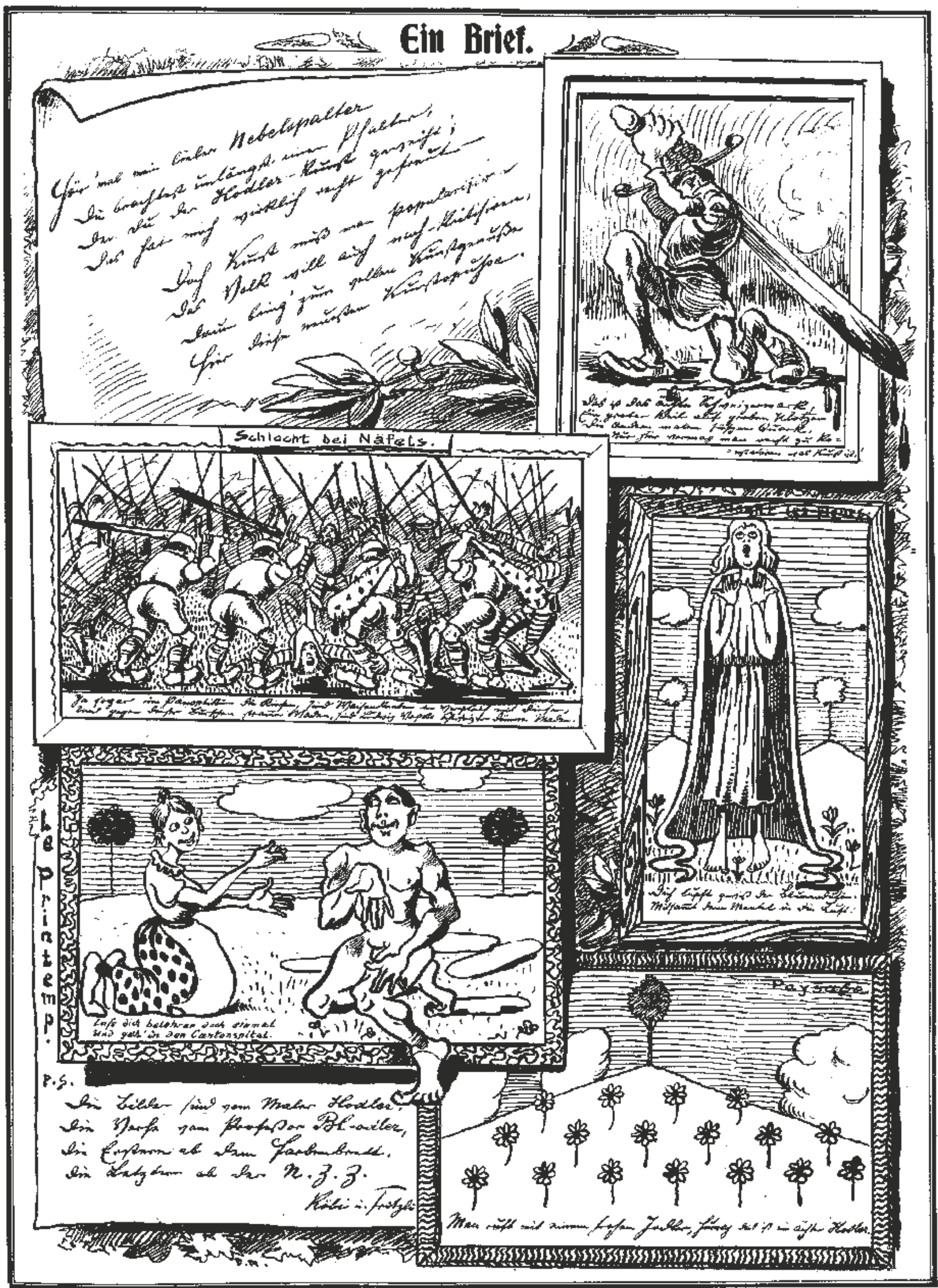

Fig. 125. Nebelspalter 1901/21, dessin pleine page en noir et blanc non signé intitulé « Une lettre » (Ein Brief). 
En I 897, le Guillaume Tell (г 897) de Hodler est transformé en une publicité de produit pour la barbe ${ }^{81}$. Son placement au centre et au milieu, à hauteur du spectateur dans une installation réelle, indique Hodler comme cible principale et renseigne sur l'importance de celui-ci dans le paysage artistique suisse. Hodler est depuis peu membre de la toute récente Künstlervereinigung (association d'artistes) zurichoise. Il est, au reste, l'une des cibles privilégiées des revues illustrées de l'espace franco-germanique, certaines suisses, Le Sapajou, Guguss, Der neue Postillon, beaucoup allemandes, tels Ulk, Jugend, Kladderadatsch, Lustiger Blätter, ou encore autrichienne, tel, Der Floch, pour ne citer que les plus impliquées ${ }^{82}$. En I90I, à l'occasion du Turnus zurichois, le salon caricatural est entièrement dédié à Hodler ${ }^{83}$ (cf. fig. I 25).

La composition, très certainement de Boscovits junior, au vu de la signature «Fritzli », se présente comme une lettre ouverte, garnie d'images, dont le but, nous dit-on, est pédagogique: «Il faut bien pourtant populariser l'art, le peuple veut également exercer sa critique" (Doch Kunst muss man popularisieren / Das Volk will auch nach-kritisieren). La numérotation du catalogue n'est pas reprise, au contraire des titres à peu près respectés et donnés en page 8 du catalogue original: " Hodler, Ferdinand, Genf [Genève]. 86. Printemps (29I) 4000 Fr./ 87. Paysage (227) I ooo Fr./Ce que disent les fleurs (89) I 500 Fr. / 89. Épisode de la bataille de Näfels $(283) 2000$ Fr. ${ }^{84}$

À ces tableaux sommairement nommés quoique maltraités avec zèle, le dessinateur ajoute une figure de guerrier passablement ridicule, histoire de faire comprendre au lecteur que la lettre adressée au Nebelspalter s'inscrit dans la polémique hodlériste qui traverse la Suisse, et qui va courir jusqu'à la Première Guerre mondiale ${ }^{85}$. La recette appliquée aux œuvres est chaque fois identique, le ridicule via la déformation et une légende absurde, trouvant son apothéose avec la parodie du Printemps. Les deux jeunes gens de l'œuvre originale sont copieusement enlaidis par l'exagération de courbes sinueuses et dotés de visages hébétés, ce à quoi vient s'ajouter la légende: "Laisse-toi donc instruire et va à l'hôpital cantonal » (Lass dich belehren doch einmal und geb'in den Cantonspital). L'attention dont bénéficie alors Hodler est ambiguë. Le Nebelspalter se réfugie derrière la forme du salon caricatural pour ne pas prendre clairement position sur les questions artistique et institutionnelle ${ }^{86}$.

\footnotetext{
Nebelspalter 1897/51, dessin pleine page de Boscovits junior intitulé « Exposition d'artistes suisses au Künstlerhaus de Zurich » (Ausstellung der Schweizerkünstler im Künstlerhaus Zürich).

Mattias Fischer, Ferdinand Hodler in Karikaturen und Satire - Par la caricature et la satire, Sulgen, Benteli, 2012; cf. en particulier p. 82-83.

Nebelspalter 1901/21, dessin pleine page non signé intitulé « Une lettre » (Ein Brief).

${ }_{84}$ L'intitulé exact des œuvres est La bataille de Näfels, Ce que disent les fleurs, Le printemps et Paysage d'été; ces œuvres qui ne sont pas nécessairement parmi les plus connues sont reproduites, parfois dans une version ultérieure, dans le catalogue de l'exposition mettant en parallèle Ferdinand Hodler et Cumo Amiet, montrée à Solothurn et Hambourg; Christoph Vögel et Ortrud Westheider, Ferdinand Hodler und Cuno Amiet. Eine Künstlerfreundschaft zwischen Jugendstil und Moderne, Munich, Hirmer Verlag, 2011; voir aussi Mattias Fischer, Ferdinand Hodler in Karikaturen und Satire - Par la caricature et la satire, op. cit., p. 106-108.

Philippe Kaenel, «La réception de l'œuvre de Hodler en Suisse romande et en France », op. cit., p. 237-241.

Pascal Ruedin, «Berne-Paris-Vienne-Munich, et retour. Institutions artistiques, identité nationale et modernité en Suisse autour de 1900 », op. cit., p. 31-33; sur ce dessin, avec une interprétation et des traductions en partie différentes: Mattias Fischer, Ferdinand Hodler in Karikaturen und Satire-Par la caricature et la satire, op. cit., p. 106-108.
}

Quant à Cuno Amiet, il est à peine moins bien traité que Ferdinand Hodler en unique victime de l'un des derniers salons caricaturaux du Nebelspalter, en I905. Le prénom de l'artiste, présent dans le titre, est déformé avec un « $\mathrm{K}$ » en place de « $\mathrm{C}$ », « Kuno Amiet au Künstlerhaus » (Im Künstlerhaus Kuno Amiet $)^{87}$, probablement pour mettre en évidence les liens du peintre avec les pays germaniques, alors qu'il vient d'exposer l'année précédente, en I 904, à la XIX Sécession viennoise. La composition de Boscovits junior s'appuie sur quelques-unes des 40 œuvres exposées par l'artiste, dont il offre une satire assez méchante: La colline jaune (I903) est légendée " tout ce qui est jaune n'est pas or » (nicht alles ist Gold was gelb ist) et le Grand hiver (1904), " La puce dans la neige » (Der Floh im Schnee). Le dessin n'en constitue pas moins une critique assez fine de l'œuvre d'Amiet, mettant en relief quelques-unes de ses caractéristiques et influences, une réception du japonisme, un goût avéré pour le motif du jardin ainsi qu'une influence hodlérienne, à son apogée lors de la Sécession de I904, pointée ici au travers d'une schématisation outrancière des figures. C'est, du reste, sans doute sa proximité avec Hodler qui vaut un tel hommage à Amiet, par ailleurs élève de Heinrich Jenny, collaborateur important du Nebelspalter à la fin des années I 880 , proche de Franck Buchser ${ }^{88}$. Et peut-être aussi un succès jalousé.

À deux exceptions près, où la composition est polarisée sur une personnalité, le « Prof. Heinrich » en I896, dont le nom n'est plus guère identifiable mais le tableau placé au centre ${ }^{89}$ et Ferdinand Hodler en I90I, la restitution de la numérotation originelle des œuvres préserve la structure référentielle. Le langage visuel et rhétorique ne connaît guère d'évolution, sauf à tendre toujours davantage vers le grotesque et une certaine vulgarité, et donc une agressivité croissante. En I905, le salon caricatural d'une exposition du Künstlerhaus sous-titré « Mixtum compositum alles Modernen " cadre ainsi deux personnages accoudés sur un pont en train de vomir et de s'exclamer: "Mon Dieu, je me sens mal! Moi aussi! » (Herrgott ist mir schlecht! - Mir auch!--) ${ }^{90}$

Progressivement, le dessinateur émerge pour ainsi dire du dessin. Des spectateurs perplexes sont ainsi introduits dans l'image par Boscovits junior en I904, dont l'un regarde conjointement le livret et les tableaux, tout en étant tourné vers le spectateur ${ }^{91}$; le même focalise un an plus tard une mégère aux mains chaussées de gants

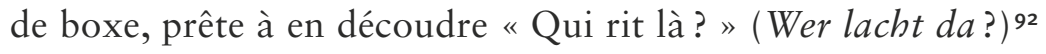
(cf. fig. I26).

Ceci, jusqu'à une ultime composition où deux hommes sont cadrés en gros plan devant des pastiches de Matisse, placardés comme des affiches. Intitulé "Art moderne » (Moderne Kunst), le dessin a pour auteur L. Marrug, l'un de ces artistes dont il est à présent impossible de retrouver la trace ${ }^{93}$ (cf. fig. I27).

Nebelspalter 1905/7, dessin pleine page de Boscovits junior intitulé « Kuno Amiet au Künstlerhaus » (Im Künstlerhaus Kuno Amiet).

Paul Müller, « Amiet, Cuno », SIKART, 2004; http://www.sikart.ch/KuenstlerInnen. aspx?id=4000011.

89 Nebelspalter 1896/11, dessin pleine page de Willy Lehmann-Schramm intitulé « Kuno Amiet au Künstlerhaus » (Kuno Amiet im Künstlerhaus).

Nebelspalter 1905/40, dessin pleine page de Boscovits junior intitulé « Depuis le Künstlerhaus. Mixtum compositum alles Modernen » (Aus dem Künstlerhaus. Mixtum compositum alles Modernen).

Nebelspalter 1904/15, dessin pleine page de Boscovits junior intitulé « $3^{\text {ème }}$ Série au Künstlerhaus » (3. Serie im Künstlerhaus).

${ }_{92}$ Nebelspalter 1905/36, dessin pleine page de Boscovits junior intitulé « Du beau en provenance du Künstlerhaus » (Schönes aus dem Künstlerhaus).

Sa signature apparaît dans le Nebelspalter en 1913 et 1914. 


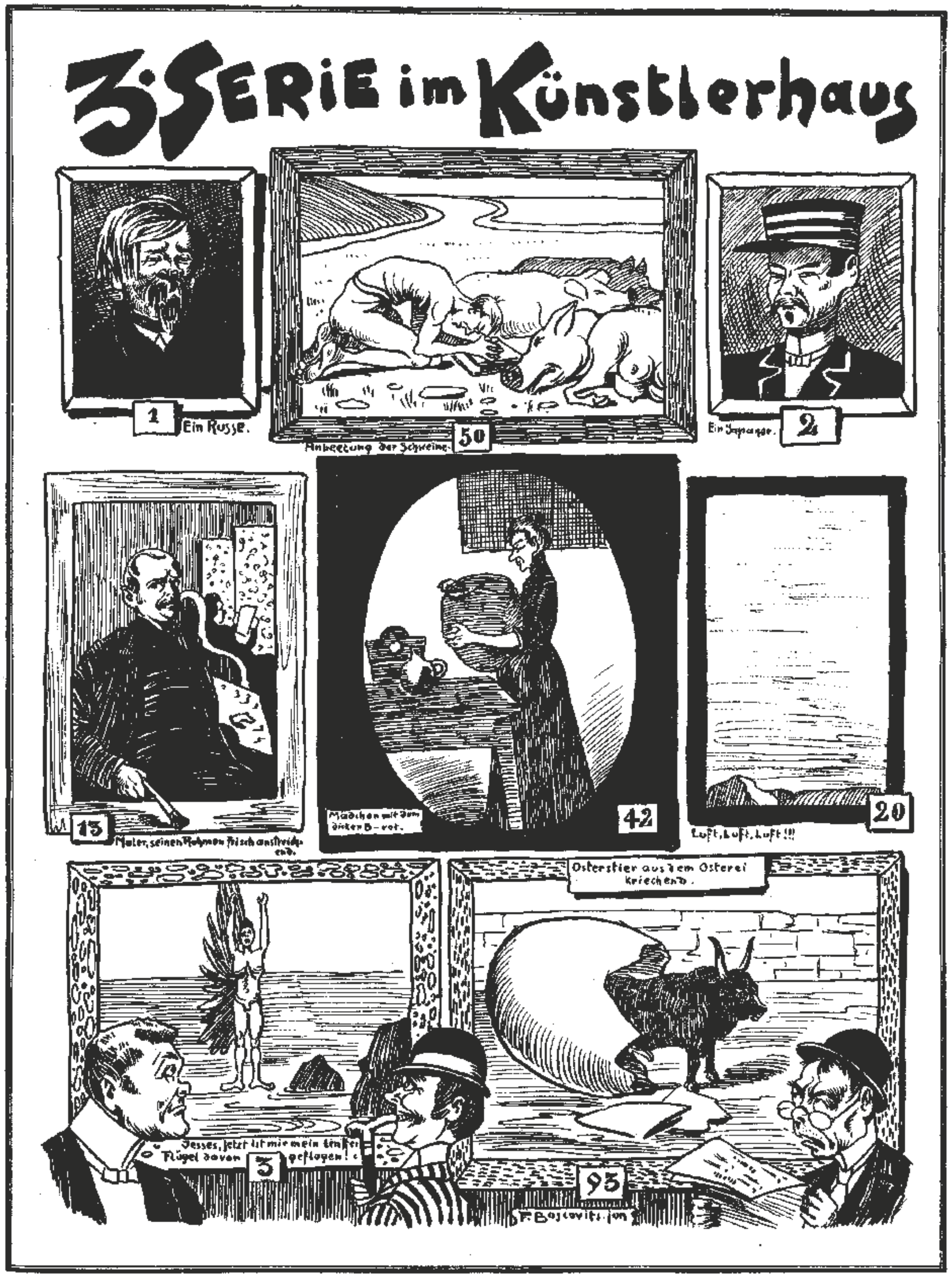

Fig. 126. Nebelspalter 1904/15, dessin pleine page en noir et blanc de Boscovits junior intitulé « $3^{\text {ème }}$ Série au Künstlerhaus » (3. Serie im Künstlerhaus). 
Tloderne Kunit

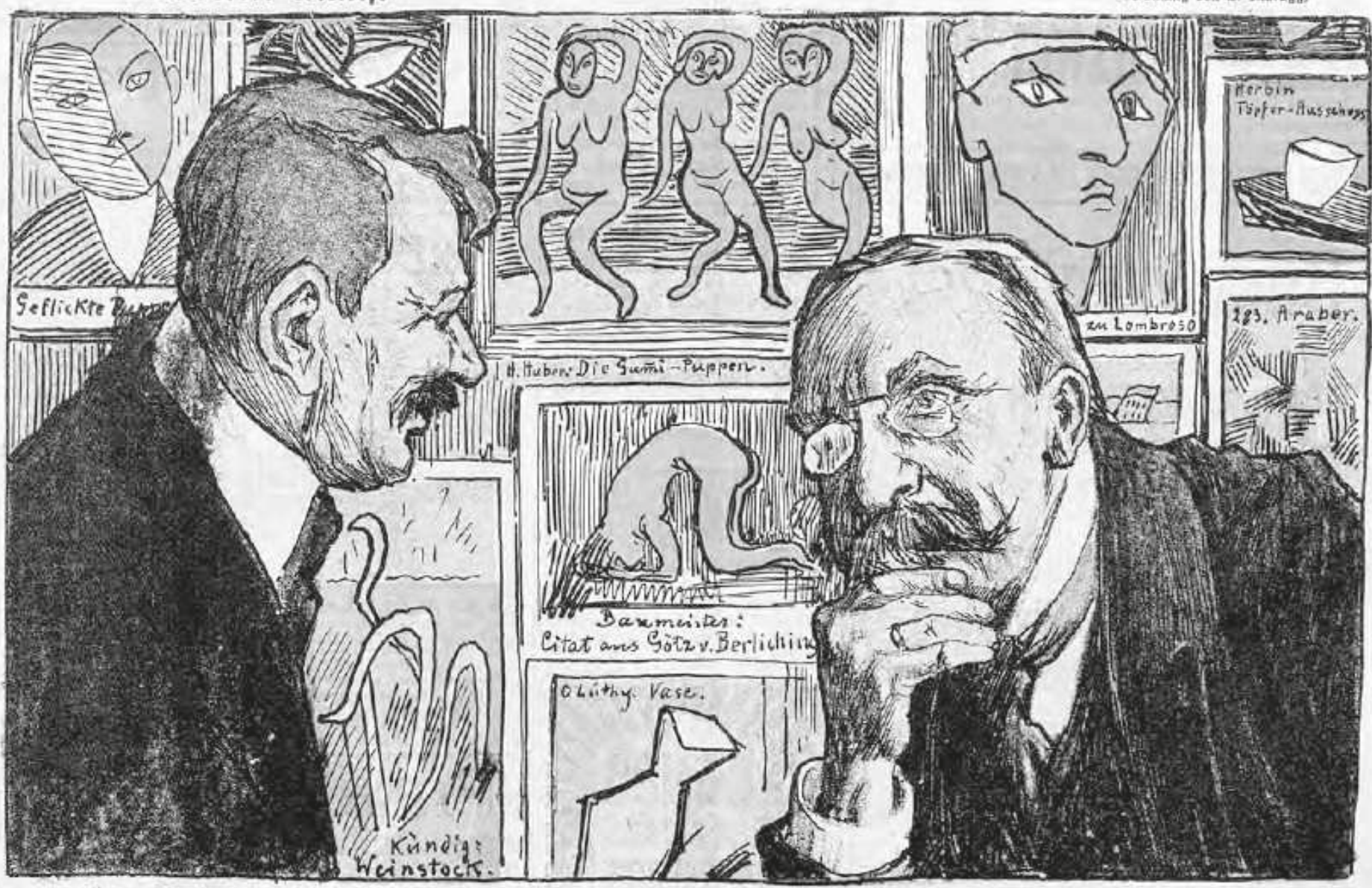

„2tein, Zerehrtefler, folche Silder gehören in keine Kunjtausftellung, das if keine 2Cunft! Die Reute können ja roder zeichnen noch malen."

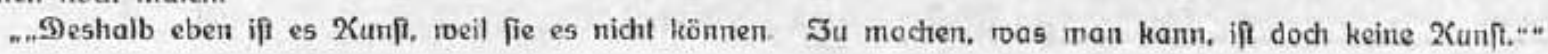

Fig. 127. Nebelspalter 1913/37, dessin en couleur de L. Marrug intitulé « Art moderne » (Moderne Kunst).

La légende restitue le dialogue entre les deux personnages:

Non, très cher, ce genre d'images n'a pas sa place dans une exposition d'art, ce n'est pas de l'art! Ces gens ne savent ni dessiner ni peindre. - C'est bien pour cette raison que c'est de l'art, parce qu'ils en sont incapables. Faire ce dont on est capable est facile [est de l'art] ${ }^{94}$.

En un titre et deux répliques, le sort de l'art moderne est scellé. Ce sera la seule fois qu'aura été intégrée ou plus exactement désintégrée une modernité dépassant les frontières helvétiques. En apparence, néanmoins, puisque les rares noms déchiffrables sont suisses, tel celui de Hermann Huber ( I 888-I937), peintre zurichois d'une certaine notoriété alors sous influence fauviste ${ }^{95}$. Le salon caricatural du Nebelspalter s'achève en règlement de compte.

\subsection{Le couple Arnold Böcklin et Ferdinand Hodler}

Arnold Böcklin (I827-I90I) et Ferdinand Hodler (I 853 -I9I8) occupent une place à part dans le Nebelspalter. Les deux artistes

" "Nein, Verehrtester, solche Bilder gehören in keine Kunstausstellung, das ist keine Kunst! Die Leute können weder zeichnen noch malen." "Deshalb eben ist es Kunst, weil sie es nicht können. Zu machen, was man kann, ist doch keine Kunst." "; Nebelspalter 1913/37, dessin en couleur de L. Marrug intitulé « Art moderne » (Moderne Kunst).

SIKART, Dictionnaire biographique de l'art suisse, Zurich, NZZ, 1998, p. 511 ont en commun d'incarner la modernité suisse aux yeux des critiques et du public de l'époque, d'une manière cependant beaucoup plus polémique dans le cas de Hodler. Le fait tient au moment et à la façon dont celui-ci fait son entrée dans le champ artistique. Hodler, qu'une génération sépare de Böcklin, s’impose en effet de manière tonitruante au moment où les enjeux financiers et de pouvoir sont au plus fort ${ }^{96}$. La querelle qu'il déclenche avec ses figures de guerriers pour l'exposition nationale de Genève en I 896 mais surtout avec son projet de décoration pour la salle d'armes du Musée national suisse de Zurich en I 897 est sans précédent dans l'histoire suisse ${ }^{97}$. C'est, du reste, avec cette dernière affaire qu'il entre dans le Nebelspalter sous le crayon de Willy Lehmann-Schramm. Intitulé "Reconnaissance sanglante » (Blutige Anerkennung) ${ }^{98}$, le dessin montre trois hommes en habit, à l'embonpoint certain, présentant avec force cérémonie une saucisse à un peintre. Ce dernier, reconnaissable à sa palette, son habit bohème et ses cheveux longs, porte bas son chapeau. La légende nous éclaire sur la scène:

Les bouchers apportent au peintre Hodler son acceptation comme membre d'honneur à la suite de leur reconnaissance du bain de sang de Marignan, en le priant de peindre quelque chose de semblable pour l'abattoir, juste un peu moins sanglant ${ }^{99}$.

\footnotetext{
Philippe Kaenel, «La réception de l'œuvre de Hodler en Suisse romande et en France », op. cit., p. 231-232.

Oskar Bätschmann, « Hodler, Ferdinand », Dictionnaire sur l'art en Suisse, 2008 actualisé 2012 ; http://www.sikart.ch/Kuenstlerlnnen.aspx?id=4000055.

Nebelspalter 1897/10, dessin de Willy Lehmann-Schramm intitulé « Reconnaissance sanglante » (Blutige Anerkennung).

"Die Metzger bringen dem Maler Hodler in Anerkennung seines bei Marignano angerichteten Blutbades die Aufnahme als Ehrenmitglied, mit der Bitte, im Schlachthause etwas Ähnliches zu malen, nur weniger blutig. »; Nebelspalter
} 
Le dessin se limite ici au registre humoristique. À ce stade de son histoire, le Nebelspalter est particulièrement attentif aux questions artistiques et entend se positionner comme défenseur d'une modernité suisse " raisonnable ", c'est-à-dire défendable par ses dessinateurs et recevable par ses lecteurs, et s'il est impossible d'ignorer Hodler, en parler s'apparente à un exercice d'équilibriste.

Si Böcklin, qui bénéficie d'une notoriété bien installée, constitue une icône qui n'est jamais mise en danger dans la revue, il n'en est pas de même de Hodler, dont le mode de présence alterne entre pastiche de son œuvre et caricature de sa personne, même si l'artiste ne peut évidemment être tout à fait dissocié de son œuvre ${ }^{100}$. À vrai dire, il n'est pas vraiment de discours sur la figure consensuelle de Böcklin autre que laudatif. Lorsque le peintre est associé à Hodler, il endosse un rôle de caution artistique et morale.

Deux caricatures restituent le couple formé par Arnold Böcklin et Ferdinand Hodler. La première date de I90I, alors que la polémique contre Hodler fait rage, autant en réaction à ses créations artistiques qu'à son omniprésence et celle de ses amis dans les instances décisionnelles, dans le jury de l'exposition universelle de I900, d'abord, puis autour des décisions du jury de l'Exposition suisse des beaux-arts de Vevey, en I 90 I. Il s'ensuit une sorte de réédition de la querelle des Anciens et des Modernes, à présent nommés « les jeunes » et " les vieux » ${ }^{101}$, que l'on retrouve dans un dessin de Willy Lehmann-Schramm. Intitulée "Hodler et ses amis" (Hodler und seine Freunde), la page est truffée d'indications, dont l'identité des deux principaux protagonistes (cf. fig. I28).

Hodler gravit l' "échelle de la gloire»(Rubmesleiter) avec difficulté pour rejoindre Böcklin qui l'attend au somment d'une montagne, à la «hauteur idéale de l'art »(ideale Kunsthöhe). Au-dessous, se pressent des hommes à l'expression contrariée. Sur l'un d'eux, se détache l'inscription " orientation artistique ancienne " (alte Kunstrichtung). Böcklin s'adresse à Hodler : "Monte-donc ici, ils ne pourront plus rien te faire, ils ont fait pareil avec moi jadis ${ }^{102}$. Le propos est ici favorable à Hodler, incarnant les jeunes, les Moderne, et surtout critique envers les «vieux ». Böcklin, mort peu de temps auparavant et avec lequel la critique n'a pas été tendre quelque trente années plus tôt, représente une sorte de sauveur ${ }^{103}$.

La seconde caricature date de I907. Signée de Boscovits senior, elle montre deux ours en conversation, l'un portant un collier marqué "Berlin », l'autre une écharpe aux couleurs de la ville de Berne. L'intérêt du dessin réside dans la légende, un dialogue entre l'ours berlinois et l'ours bernois, ou plus précisément entre l'éditeur allemand Rudolf Mosse (I843-I920), notamment de la revue satirique berlinoise $U l k^{104}$ et la ville de Berne, symbolisée par le Berner Mutz.

1897/10, dessin de Willy Lehmann-Schramm intitulé « Reconnaissance sanglante » (Blutige Anerkennung).

- Sur les citations et le traitement satirique de son œuvre cf. « 4.4. Le couple Arnold Böcklin et Ferdinand Hodler. »

Philippe Kaenel, « La réception de l'œuvre de Hodler en Suisse romande et en France », op. cit., p. 238-239.

102 (Böcklin: "Komm nur herauf, hier können sie Dir nichts wollen, mit mir haben sie es früher auch so gemacht! »); Nebelspalter 1901/19, dessin pleine page de Willy Lehmann-Schramm intitulé « Hodler et ses - amis! » (Hodler und seineFreunde!).

${ }_{103}$ Voir aussi ; Mattias Fischer, Ferdinand Hodler in Karikaturen und Satire - Par la caricature et la satire, op. cit., p. 105

104 Ursula E. Koch, Der Teufel in Berlin. Von der Märzrevolution bis zu Bismarcks Entlassung. Illustriert politische Witzblätter einer Metropole 1848-1890, Cologne,
L'ours berlinois de Monsieur Mosse: «Comment peux-tu oser laisser un barbouilleur comme Hodler aller à Iéna pour un soi-disant tableau d'histoire germanique!! Une telle impudence républicaine!! » L'ours bernois (Berner Mutz) : « Mais ne pleure pas comme ça! C’est vachement bien! Tu voudrais être un athénien de la [rivière] Spree et tu ne sais même pas que les couches de Böcklin pour lesquelles le roi Scherl [le faux roi des aulnes] donnerait à présent un million ont toutes séché en Suisse! ${ }^{105}$

La légende fait référence à la commande en I 907 d'une peinture murale pour l'Aula de l'Université de Iéna, qui sera réalisée en I $909^{106}$. Elle vise, en fait, l'appréciation des Allemands sur Böcklin, "oubliant " volontiers sa nationalité suisse. Si la position du Nebelspalter dénote une certaine ambiguïté, le dialogue laisse néanmoins transparaître le statut d'artiste national des deux peintres, imprégnant, du reste, aujourd'hui encore, l'historiographie de l'art suisse ${ }^{107}$.

Les très nombreux dessins et textes documentant la présence de Hodler, plus d'une vingtaine, permettent de retracer les moments clés de l'histoire hodlérienne, vue de Suisse alémanique. Plus de la moitié des dessins concernent sa personne. L'agressivité des caricatures est à la hauteur de la fascination exercée par l'artiste. En I 899, une double-page ironise sur les nombreux aménagements de la peinture murale de la Retraite de Marignan (I896-I900) ${ }^{108}$. Quelques mois plus tard, un dessin dénonce l'absurdité d'un recours auprès du Conseil fédéral ${ }^{109}$, amené à trancher dans la polémique sans fin entre amateurs d'art et acteurs institutionnels, ce qui aboutira à une décision en faveur de la finalisation du projet $^{110}$. En I90 I, Böcklin est appelé au secours de l'artiste dans une querelle hodlériste qui bat toujours son plein ${ }^{111}$, tandis qu'un (pseudo-)salon caricatural des auvres de Hodler par Boscovits junior livre un nouvel épisode de la saga. L'intitulé est on ne peut plus clair, "Le nouvel hodlérisme » (Die neue Hodlerei). La légende restitue des propos prêtés au conseiller d'État bernois, alors que le Conseil vient de faire l'acquisition de quatre œuvres de Hodler, surnommées les " Hodler d'honneur " (Ehren-Hodler). Elle est fondée sur le topos de la brutalité sanglante des œuvres de Hodler, dont le Nebelspalter use sans modération:

Informationspresse c. w. Leske, 1990, p. 219.

${ }^{5}$ (Der Berliner Bär des Hernn Mosse: "Wie kannst du dir erdreisten, 'nen Pinselfritze wie den Hodler, nach Jena gehen zu lassen, um germanische Historienbilder zu mimen!! SOOO 'ne republikanische Unverschämtheit!!! » / Berner Mutz: " Nume nid e so brüelet! Aber cheibe guet isches mi Gottstüri! Du wott'sch e "Spree-Athener" sy und weisch nid emal, dass d'em Böcklin syni Windle, für die der "Scherlkönig" hüt e Million gäb, o i d'r Schwyz tröchnet worde sy! »): Nebelspalter 1907/41, couverture de Boscovits senior intitulée « Dans la fosse aux ours internationale » (Im internationalen Bärengraben).

106 Oskar Bätschmann, « Hodler, Ferdinand », op. cit.

${ }_{107}$ II s'agit d'un topos de l'historiographie de l'art suisse tant pour Böcklin que pour Hodler, alors que l'historiographie de l'art allemande est souvent très floue sur la nationalité de Böcklin, inclus dans le panthéon germanique des Moderne.

8 Nebelspalter 1898/49, double-page de Boscovits junior intitulée "Une issue. Les images de Hodler au musée national » (Ein Ausweg. Die Hodlerbilder im Landesmuseum); Oskar Bätschmann, "Hodler, Ferdinand », op. cit.; Mattias Fischer, Ferdinand Hodler in Karikaturen und Satire - Par la caricature et la satire, op. cit., p. 88-89.

Nebelspalter 1899/25, dessin de Boscovits junior intitulé « Nouvelle critique d'art à Zurich » (Neue Kunstkritik in Zürich); sur ce dessin et l'opposition des cercles conservateur zurichois, cf. Mattias Fischer, Ferdinand Hodler in Karikaturen und Satire - Par la caricature et la satire, op. cit., p. 97.

Pascal Ruedin, « Berne-Paris-Vienne-Munich, et retour. Institutions artistiques, identité nationale et modernité en Suisse autour de 1900 », op. cit., p. 29. Nebelspalter 1901/19, dessin pleine page de Willy Lehmann-Schramm intitulé « Hodler et ses - amis! » (Hodler und seine - Freunde!). 


\section{$\infty$ hodler und seine - Freunde!}

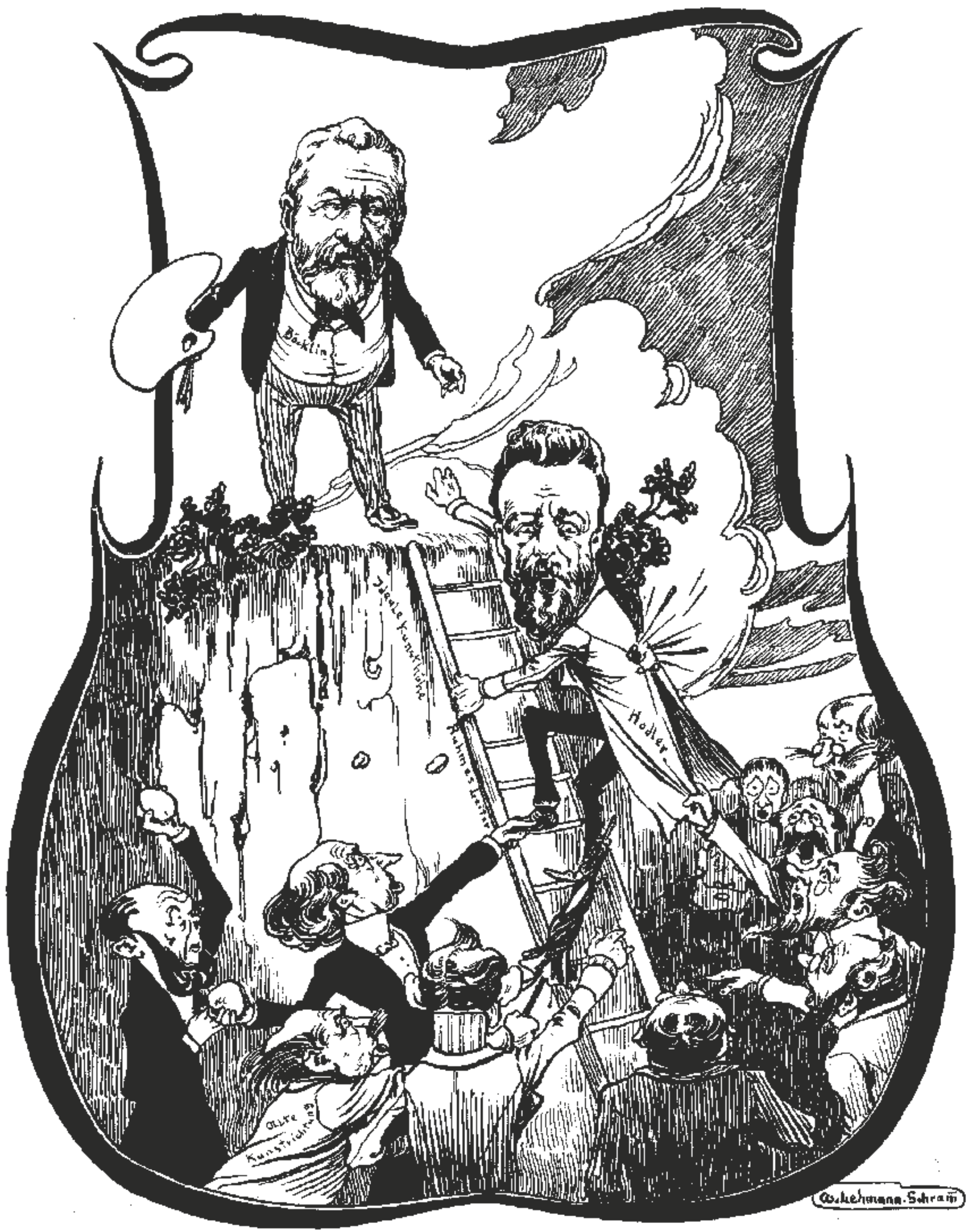

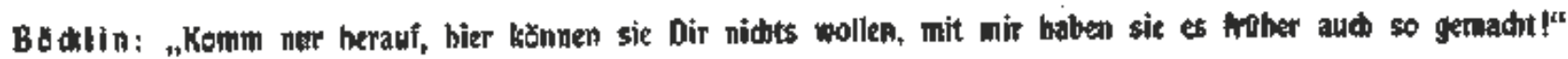

Fig. 128. Nebelspalter 1901/19, dessin pleine page en noir et blanc de Willy Lehmann-Schramm intitulé « Hodler et ses - amis ! (Hodler und seine - Freunde !). 
Nous voulons avec l'achat de ces épisodes meurtriers pour une somme de 30000 francs mettre un terme aux bains de sang ${ }^{112}$.

En I908, l'exposition de onze tableaux à la Société des Amis des Arts de Francfort ${ }^{113}$ sert de prétexte à une caricature antisémite dans laquelle un négociant d'art juif se demande si l'achat des tableaux sera d'un bon rendement ${ }^{114}$. En I9 I I, la mise en service de nouveaux billets de cent francs dessinés par Hodler, et dont il dénoncera du reste la paternité en raison du non-respect du motif initial ${ }^{115}$, est le thème d'un dessin anonyme, intitulé « Les nouveaux billets de cent francs " (Die neuen «Hunderter»). La légende, fort méchante, retrace un dialogue entre deux hommes. Elle met implicitement en question la valeur de l'art hodlérien:

- et ceci est un vrai Hodler, il vaut Io ooo francs

— Hein? J'ai également un vrai Hodler mais il ne vaut que cent francs! ${ }^{116}$

Ici comme ailleurs, l'agressivité pointe sous un humour peu convaincant. Le propos n'est guère plus amène lorsque Hodler, figuré devant son Tell, reçoit en I9 I3, la légion d'honneur de l'État français, sur proposition du Président Raymond Poincaré ${ }^{117}$. La légende est rédigée en français: «Une petite décoration au grand décorateur ${ }^{118}$.

En I9I4, la teneur change soudain et devient nettement favorable à Hodler. Le peintre est alors en but aux représailles allemandes, après avoir signé un manifeste condamnant le bombardement de la cathédrale de Reims par l'artillerie allemande. Considéré comme un traître, ses œuvres sont bannies des musées allemands ${ }^{119}$ mais, parallèlement, sa cote monte ${ }^{120}$. "Les premières relations commerciales entre l'Allemagne et la France" (Die ersten Handelsbeziehungen zwischen Deutschland und Frankreich) montre ainsi un Allemand fermement décidé à céder à un Français les œuvres de Hodler "pour un prix acceptable » $(z u$ jedem annehmbaren Preis!) ${ }^{121}$. Czerpien met alors le doigt sur la double réception française et allemande d'un artiste, fin stratège, composant avec différentes aires culturelles (suisse, allemande et française) et donc avec autant de marchés. En I9 I6, une caricature de Boscovits junior indique les conditions de la commande du portrait du Général Ulrich Wille "par un "gros industriel” " (von einem Großindustriellen $)^{122}$. Le dessinateur fait

\footnotetext{
« Wir wollen durch Ankauf dieser mörderischen Episoden für Fr. 30000 weiterem Blutvergießen ein Ende machen. »; Nebelspalter 1901/31, dessin pleine page de Boscovits junior intitulé « Le nouvelle hodlérisme » (Die neue Hodlerei); sur ce dessin, voir aussi (avec une traduction différente): Mattias Fischer, Ferdinand Hodler in Karikaturen und Satire - Par la caricature et la satire, op. cit., p. 109.

Sylvie Patry (éd.), Ferdinand Hodler 1853-1918, Réunion des musées nationaux, 2007, p. 18.

14 Nebelspalter 1908/9, dessin signé « LM » intitulé « Hodler à Francfort » (Hodler in Frankfurt); sur le dessin, cf. Mattias Fischer, Ferdinand Hodler in Karikaturen und Satire - Par la caricature et la satire, op. cit., p. 140.

Sylvie Patry (éd.), Ferdinand Hodler 1853-1918, op. cit., p. 18

116 (- und das ist en echter Hodler, der ist 10.000 Franken wert. - So? Ich habe hier auch einen echten Hodler der ist aber nur 100 Franken wert! ); Nebelspalter 1911/42, dessin non signé intitulé "Les nouveaux billets de cent francs » (Die neuen « hunderter»).

Oskar Bätschmann, « Hodler, Ferdinand », op. cit.

18 Nebelspalter 1913/5, dessin de Wilfried Schweizer intitulé « Ferdinand Hodler, officier de la légion d'honneur française " (Ferdinand Hodler, Offizier der französischen Ehrenlegion); cf. Mattias Fischer, Ferdinand Hodler in Karikaturen und Satire - Par la caricature et la satire, op. cit., p. 202.

Oskar Bätschmann, « Hodler, Ferdinand », op. cit.

20 Mattias Fischer, Ferdinand Hodler in Karikaturen und Satire - Par la caricature et la satire, op. cit., p. 226.

Nebelspalter 1914/44, dessin de Karl Czerpien intitulé « Les premières relations commerciales entre l'Allemagne et la France » (Die ersten Handelsbeziehungen zwischen Deutschland und Frankreich).

122 Nebelspalter 1915/12, dessin de Boscovits junior intitulé « Hodler et Wille » (Hodler
} und Wille). allusion à la commande de Willy Russ, directeur de la fabrique Suchard, d'origine allemande ${ }^{123}$, alors que le peintre est en train de conquérir définitivement son statut de peintre national (suisse) ${ }^{124}$. À l'occasion de la mort de Hodler, en I9 8 , un encart signé du rédacteur en chef Paul Altheer salue le peintre par ces mots:

Son œuvre est et reste pour nous le signe de la victoire de la fière force suisse, qui vise les hauteurs et atteint les sommets, quand elle crée pour elle et seulement pour elle $e^{125}$.

Une semaine plus tard, Ferdinand Hodler bénéficie de l'accueil de saint Pierre:

Bienvenue, maître Hodler! Nous désirons depuis longtemps une nouvelle image de la situation mondiale ${ }^{126}$.

\subsection{Plaider et batailler pour la pierre à Zurich : le Kunsthaus et le Musée national suisse}

Une autre question va également être l'objet de débats enflammés, celle des grands musées dont doit se doter la Confédération, c'està-dire, du point de vue du Nebelspalter, le Musée national suisse et le musée d'art de la ville de Zurich, le futur Kunsthaus.

Une boutade. C'est sous cette forme qu'apparaît la question de la création d'un musée d'art pour la ville de Zurich en I 886 ; elle sert de prétexte à moquer le chantier urbain du Bauschänzli, un aménagement à la pointe du lac, taxé de " projet sublime » (sublimes Projekt). Boscovits senior, auteur du dessin, fait naviguer devant une construction vaguement baroque aux airs d'opéra la barque du "progrès ", selon l'inscription apposée sur le journal du rameur ${ }^{127}$. Il n'est évidemment nul hasard à ce que la question surgisse la même année que l'éditorial sur l'art suisse ${ }^{128}$. Elle ne réapparaitra cependant que treize ans plus tard, en I 899, à l'occasion d'une votation zurichoise soumettant au peuple l'existence d'un musée d'art, alors que plusieurs métropoles suisses se sont déjà dotées de musées, Bale, la première, avec l'achèvement du bâtiment de l'Augustinergasse en I $849^{129}$. Le Nebelspalter prend alors partir en faveur d'un oui, défendu par le lapin de Pâques (l'équivalent de la poule dans les pays germaniques) dans l'une de ces compositions synthétiques que fait paraître la revue lors des rendez-vous importants du calendrier politique. Alors que le Nebelspalter est ravi devant ses œufs marqués « abonnement »

\footnotetext{
${ }^{23}$ Philippe Kaenel et François Vallotton, «Représenter la guerre en Suisse: du soldat au général », dans Les images en guerre, éd. Philippe Kaenel et François Vallotton, Lausanne, Antipodes, 2008, p. 36.

${ }^{24}$ Philippe Kaenel, « La réception de l'œuvre de Hodler en Suisse romande et en France », op. cit., p. 241-245.

${ }^{25}$ (Sein Werk besteht und bleibt für uns das Zeichen / des Sieges jener stolzen Schweizerkraft, / die Höchstes will und Größtes kann erreichen, wenn sie für sich, nur für sich selber schafft!); Nebelspalter 1918/21, encart de Paul Altheer intitulé "Ferdinand Hodler».

« Willkommen, Meister Hodler! Wir wünschen uns schon lange ein neues Bild der Weltlage! »; Nebelspalter 1918/22, dessin pleine page de Boscovits senior intitulé "À la porte du paradis » (An der Himmelspforte).

17 Nebelspalter $1886 / 3$, dessin pleine page de Boscovits senior intitulé « Pratique " (Praktisch).

28 Nebelspalter 1886/49, couverture.

129 Marc Fehlmann et Josef Brülisauer, «Musées. 2 Les débuts des musées », Dictionnaire historique de la Suisse (28/10/210); http://www.hls-dhs-dss.ch/ textes/f/F24561.php.
} 
et que le peuple suisse devra se réjouir avec les œufs du "crédit » (Kredit), de la «confiance" (Vertrauen) et du «travail » (Arbeit), le lapin de Pâques offre à la ville de Zurich un œuf d'où sort un «bâtiment pour l'art "(Kunstgebäude), une construction massive, garnie de coupoles ${ }^{130}$. Souhait vain, cependant, et ce sera rien moins qu'une danse macabre qui illustrera quelque temps plus tard le refus populaire ${ }^{131}$. À la fin de l'année I 899, l'allégorie de Zurich, Turica et celle de la Kunstgesellschaft doivent rendre la santé au Künstlerhaus, un enfant bien mal en point, puisque toujours sans maison. La réalité qu'exprime Boscovits junior dans son salon caricatural ${ }^{132}$ est celle d'expositions qui devront continuer de se dérouler dans des lieux inappropriés ou qui leur sont transitoirement affectés. Un an plus tard, Boscovits junior revient à la charge dans le cadre d'une série sur la vie zurichoise, «Les cinq sens à Zurich" (Die fünf Sinne in Zürich). Dans le médaillon central, un homme-maison assis sur un tabouret tente péniblement de se lever. La légende éclaire son attitude: "Il ne filtre rien sur une nouvelle maison des artistes " (Man hört nichts vom neuen Künstlerhaus) ${ }^{133}$. Boscovits junior réactualise le sujet en I904, à l'occasion de Pâques. Alors que le peuple suisse récolte cinq œufs cette année-là, la "confiance »(Vertrauen), la « chance » (Glück), le «bien-être " (Woblstand), la "paix » (Friede), le «travail » (Arbeit), que Russe et Japonais s'échangent des œufs explosifs, un escargot avance au premier plan, portant sur sa coquille l'œuf du "nouveau Künstlerhaus de Zurich » (Neues Künstlerhaus Zürich) ${ }^{134}$. La métaphore est reprise à la Noël, où la Künstlergesellschaft reçoit en cadeau un bâtiment sur le toit duquel évolue un immense escargot. Pour la première fois, la future construction reçoit son nom définitif de Kunsthaus. La légende nous apprend que «La Künstlergesellschaft aurait enfin reçu cette chose-là » ${ }^{135}$.

À cette date, l'architecte Karl Moser (I860-I936) a obtenu, après maintes péripéties, annulation de concours et révisions du projet, la commande ferme du musée, qui ne se limite pas à des salles d'exposition et de conservation mais comprend également un espace pour l'association, une bibliothèque, des archives et bureaux ainsi qu'une salle de réception ${ }^{136}$. Les fonds sont réunis à la fin I906 et l'ange de Noël tient à bout de bras une maquette du musée: «ce que l'ange de Noël doit enfin apporter aux Zurichois " ${ }^{137}$. Le bâtiment n'a cependant pas sa forme définitive. La construction, inspirée de l'architecture viennoise avec son style néobaroque et sa décoration sécessionniste ${ }^{138}$, ne sera présentée dans le Nebelspalter qu' "À l'occasion de l'inauguration du Kunsthaus de Zurich, le I7 avril I9 Io»(Zur Eröffnung des Kunsthauses in Zürich, I7. April I9IO). Boscovits junior, qui

130 Nebelspalter 1899/13, dessin pleine page de Boscovits senior intitulé « OEufs de Pâques » (Ostergeschenke).

Nebelspalter 1899/35, dessin pleine page de Boscovits senior intitulé « Aussi une danse macabre » (Auch ein Totentanz).

2. Nebelspalter 1899/48, dessin pleine page de Boscovits junior intitulé « Exposition de Noël au Künstlerhaus de Zurich » (Weihnachtsausstellung im Künstlerhaus in Zürich).

${ }_{133}$ Nebelspalter 1900/44, dessin pleine page de Boscovits junior intitulé «Les cinq sens à Zurich » (Die fünf Sinne in Zürich).

134 Nebelspalter 1904/14, dessin pleine page de Boscovits junior intitulé « CEufs de Pâques » (Ostereier).

135 (Die Kunstgesellschaft hätt' beinah' endlich erhalten - dieses da!); Nebelspalter 1904/50, dessin pleine page de Boscovits junior intitulé «Cadeaux de Noël » (Weihnachtsgeschenke).

136 Sonja Hildebrand, "Kunsthaus Zurich », dans Karl Moser. Architektur für eine neue Zeit 1880 bis 1936, éd. Werner Oechslin et Sonja Hildebrand, Zurich, Gta Verlag, 2010, p. 133-134

37 (Was der Weihnachtsengel den Zürchern endlich bringen soll); Nebelspalter 1906/51, dessin pleine page de Boscovits senior intitulé « Noël 1906 » (Weihnachten 1906).

Sonja Hildebrand, « Kunsthaus Zurich », op. cit., p. 134 aura suivi toute l'affaire, fournit alors une page dans les tons bleutés, inspirée des images de la revue Ver Sacrum (I898-1903), organe de la Sécession viennoise. Trois troncs d'arbre se dressent dans l'image, deux bordent symétriquement l'image, le troisième émerge du toit du bâtiment. Ils servent de supports aux médaillons contenant les portraits des géniteurs du projet, Karl Moser et le Président de la Kunstgesellschaft, Paul Ulrich, eux-mêmes reliés par la face d'Athéna, déesse grecque protégeant les artistes ${ }^{139}$ (cf. fig. I 29).

Zurich a certes attendu longtemps son musée mais peut alors se prévaloir de posséder l'un des musées les plus importants de son temps ${ }^{140}$.

L'idée d'un musée national n'est, à dire vrai, pas nouvelle. Le projet de collectionner et de préserver les biens culturels est apparu sous la République helvétique (I798-I803). Il n'est cependant vraiment envisagé que sous la Confédération ${ }^{141}$, placée devant la nécessité de créer une structure permettant de garder à l'intérieur des frontières les témoignages de ses traditions et les objets archéologiques. En I 880 , le projet est rejeté une première fois par le Parlement. C'est en fait le succès de l'exposition nationale à Zurich en I 883 qui enclenche un renversement favorable des opinions ${ }^{142}$. Une bataille pour décider du lieu du nouveau musée s'engage alors, qui dure quasiment vingt ans ${ }^{143}$. À l'été I 888 , elle justifie l'entrée en scène du Nebelspalter avec un éditorial intitulé "Où doit être le musée national? » (Wo soll das Nationalmuseum stehen?), concluant que plus que le lieu ce sont les intentions qui importent:

Oui, c'est là que doit être le musée / À l'endroit où une banque ne pourra jamais voir le jour / Là où quand quelqu'un fait un don / Il ne pense qu'à une bonne ouvre! / Il doit être là / Là est vraiment sa place ${ }^{144}$.

Trois années durant, entre I 888 et I 89 I, jusqu'à ce que le choix en soit définitivement arrêté, dessins et textes thématisent régulièrement la querelle, sans jamais cependant remettre en cause le bien-fondé du projet. Le conseiller fédéral Karl Schenk entre à nouveau en scène. Fort de son cinquième mandat, il est en charge, à côté des affaires artistiques, de la santé, de l'économie forestière, des statistiques, de la question de l'alcool et du très épineux dossier du musée national ${ }^{145}$. Au début et à la fin de l'année i 889 , Schenk est représenté dépassé par la question de la localisation mais plus encore par celle de la constitution des collections ${ }^{146}$. La querelle entre les villes candidates, Zurich, Berne, Lucerne et Bale, est thématisée à plusieurs reprises, parfois en présence d'Helvetia ${ }^{147}$. Celle-ci intervient sous le crayon de Heinrich Jenny pour calmer l'impatience des deux derniers concurrents en lice, Zurich et Berne,

Nebelspalter 1910/18, dessin pleine page de Boscovits junior intitulé « Feuille commémorative » (Gedenkblatt).

Sonja Hildebrand, « Kunsthaus Zurich », op. cit., p. 132

Pour mémoire, la Confédération voit le jour en 1848.

142 François de Capitani, "Musée national suisse », Dictionnaire historique de la Suisse; http://www.hls-dhs-dss.ch/textes/f/F10350.php.

Marc Fehlmann, Josef Brülisauer, « Musée - 2 Les débuts des musées », op. cit.

${ }_{144}$ (Ja, da soll das Museum steh'n, / Wo niemals kann ein Bank entsth'n, / Wo, jeder, wenn er etwas schenkt, / An's gute Werk nur selber denkt! / Da soll es sein, / Da nimmt's die recht'ge Stelle ein! ); Nebelspalter 1888/24, éditorial non signé, intitulé " Où doit être le musée national ? » (Wo soll das Nationalmuseum stehen?).

Herman Böschenstein, "Carl Schenk », dans Die Schweizer Bundesräte. Ein biographisches Lexikon, éd. Urs Adermatt, Zurich, Artemis \& Winkler, 1991, p. 168-173.

Nebelspalter 1889/4, dessin pleine page de Heinrich Jenny intitulé « Sur la querelle du Nationalmuseum » (Zum Nationalmuseumstreit); Nebelspalter 1889/49, dessin pleine page de Boscovits senior intitulé «Plongé dans le doute " (In Zweifeln). Nebelspalter 1890/47, dessin non signé intitulé « Le Musée national » (Das Nationalmuseum) 
* Gedenkblatt. - <

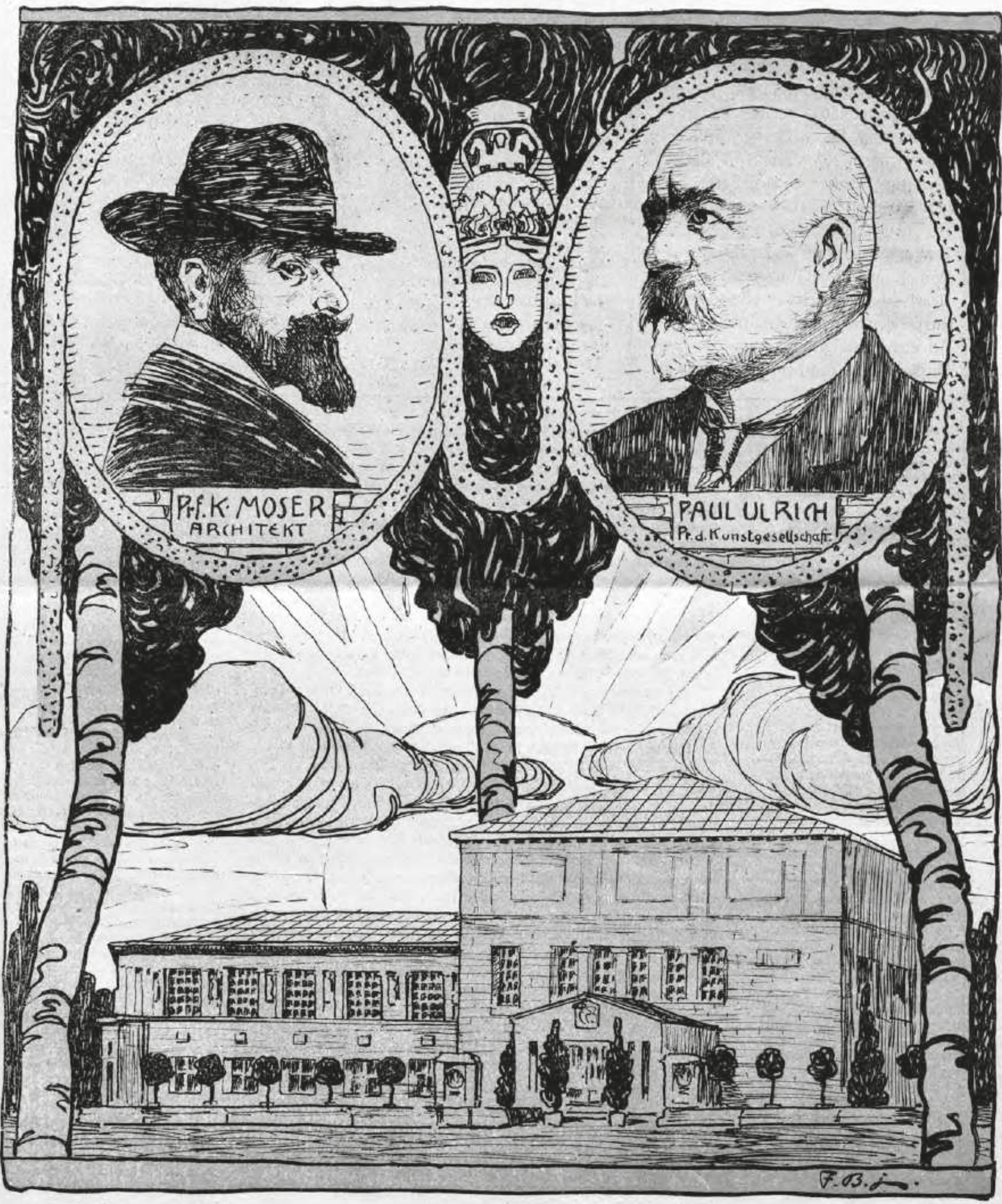

Zur Gröffnung des Kunsthauses in Zürich, 17. April 1910. 
pris dans une lutte acharnée, alors que les gaillards incarnant Lucerne et Bâle sont à terre, exclus du jeu ${ }^{148}$ (cf. fig. I30).

La question est tellement sérieuse que le Nebelspalter s'en entretient avec Turica, l'allégorie de Zurich ${ }^{149}$; elle tourne à ce point au ridicule que le musée national se transforme en un œuf de Pâques que se disputent la poule de Zurich et celle de Berne ${ }^{150}$.

Toute une iconographie combattive se développe autour du thème, qui trouve son apothéose chez Emil Dill représentant la querelle dans le cirque de la Confédération, le Parlement, où n'en finissent pas de s'écharper les conseillers fédéraux ${ }^{151}$. Au moment de la décision en faveur de Zurich, en I89I, un petit texte en fait l'annonce ${ }^{152}$. Il porte le titre allemand "Das Landesmuseum" et non "Das Nationalmusem ", plus explicitement national. Ce n'est pas tout à fait une exception dans le corpus mais cela retient l'attention. Est-ce le signe que le Musée national suisse (Schweizerisches Nationalmuseum) ne pourra remplir tout à fait ses ambitions, faute d'une collaboration de tous les cantons, puisque les musées cantonaux accueilleront souvent des collections d'intérêt national ? Ou celui d'une demi-victoire, la ville de Berne se dotant en I 896, deux ans avant l'inauguration du Musée zurichois en I 898, de son Musée d'histoire, concurrent honorable de l'institution zurichoise, jusque dans l'architecture historiciste du bâtiment ? 153

\subsection{La maigre réception des mouvements contemporains}

Pas un mot sur Dada, le futurisme et l'expressionnisme, quelques rares citations ou propos sur le cubisme et le fauvisme, rien sur le vorticisme, pas plus que sur les Arts and Crafts, les paysagistes français ou anglais. Une maigre réception du symbolisme s'opposant à celle massive du Jugendstil, l'une et l'autre cependant tout aussi muettes. Tel est le maigre bilan de la réception de l'activité artistique contemporaine dans le Nebelspalter, frappée de nullité durant le premier quart de siècle et, ensuite, entièrement dépréciative. La littérature n'est d'ailleurs guère mieux logée même si c'est un courant littéraire, le décadentisme, qui est le premier mouvement d'expression contemporain à être reçu en I 89I dans l'un de ces tableaux humoristiques synthétisant les «calamités » du moment ${ }^{154}$.

De l'esprit fin de siècle, thématisé à partir des années I 890 et associé à la France - "Formez les bataillons », ainsi débute un éditorial intitulé «Fin de Siècle » ${ }^{155}$-, n’est retenu qu'un

\footnotetext{
Nebelspalter 1891/2, dessin pleine page de Heinrich Jenny intitulé « Musée national » (Landesmuseum).

49 Nebelspalter 1891/9, double-page de Boscovits senior intitulée « Musée national » (Nationalmuseum)

- Nebelspalter 1891/13, dessin pleine page de Boscovits senior intitulé « Souffle printanier » (Frühlingswehen).

Nebelspalter 1891/14, dessin pleine page de Emil Dill intitulé « Un vœu respectable » (Würdiger Wunsch).

152 Nebelspalter 1891/26, texte non signé intitulé «Le musée national » (Das Landesmuseum)

3 Marc Fehlmann, Josef Brülisauer, « Musée - 2 Les débuts des musées », op. cit. Nebelspalter 1891/4, dessin pleine page non signé intitulé « Notre préféré du moment » (Unser jetzige Liebling).

Nebelspalter 1892/19, éditorial non signé intitulé « FIN DE SIÈCLE ».
}

monde déréglé politiquement et moralement, illustré par un tueur, par ailleurs très chic, et une fille émancipée à faire peur ${ }^{156}$. Aucun propos explicite sur le symbolisme, pourtant corrélé aux esthétiques fin de siècle et qui s'installe alors partout en Europe. Comme dans l'Allemagne wilhelminienne, la réception en est contrariée $^{157}$. Elle s'opère à travers le Jugendstil et se limite à quelques couvertures, telle celle de Boscovits junior dénonçant en 1904 la guerre russo-japonaise ${ }^{158}$ (cf. fig. I3 I cahier couleur). Le principe d'un visage féminin de profil ceint dans un médaillon, surmontant une représentation différente - ici un champ de bataille - est dérivé des très populaires couvertures montrées par la revue Jugend au tournant du siècle ${ }^{159}$. La connotation doloriste et l'association onirique déclenchée par les yeux clos de la figure correspondent à cette part symboliste que recèle le Jugendstil, et qui doit également au préraphaélisme. Cette présence discrète se prolonge, en revanche, étonnamment tard et l'on voit en I9I 3 une couverture montrant un poème de Victor Hardung (I 86II9I9), illustré par Walter Lilie (I876-I924), deux représentants du symbolisme d'expression germanique. Le paysage automnal, symétriquement organisé, où évolue une figure féminine isolée répond au texte intitulé "Automne» $(\text { Herbst })^{160}$.

Quant au japonisme, élément nourricier de l'impressionnisme et des esthétiques fin de siècle, il est également l'objet d'une réception intégrée, parcimonieuse et non explicite. Celle-ci s'observe dans de rares couvertures ou des dessins de petite taille, tel un dessin humoristique sur le bon usage du vin de bordeaux ${ }^{161}$. Willy Lehmann-Schramm, auteur de la composition, aligne trois dessins à la structure identique, un panneau inférieur blanc étiré, surmonté d'une petite fenêtre, un peu moins large que le plan inférieur. Dans le deuxième dessin, un homme se tient à la fenêtre et arrose de vin deux commères aux allures de geisha, dessinées d'un trait sinueux.

Le seul mouvement contemporain à être explicitement cité est, en fait, le cubisme. Il est l'objet d'une caricature fort méchante de l'année I9I2, intitulée "La peinture cubique au Kunsthaus » (Die Kubische Malerei im Kunsthaus), alors que l'adjectif cubiste (kubistisch) est écorché dans le titre en "cubique"(kubisch). Deux hommes s'y entretiennent devant une peinture, l'un replet, engoncé dans un pardessus, l'autre mince et impeccablement vêtu d'un costume noir, très probablement un acheteur et un critique: "Que dites-vous de la manière de ces artistes? - Ces artistes, il faudrait les arrêter! »162

Le propos résume à lui seul le rapport du Nebelspalter à l'art contemporain.

\footnotetext{
Nebelspalter 1892/13, dessin de Henri van Muyden intitulé « Fin de siècle ».

Laurence Danguy, L'ange de la jeunesse - La revue Jugend et le Jugendstil à Munich, op. cit., p. 131-141.

Nebelspalter 1904/44, couverture de Boscovits junior.

159 À ce sujet: Michael Weisser, Titelblätter der "Jugend »: Dokumente zur gesellschaftlichen Situation und Lebensstimmung in der Jahrhundertwende, Munich, Heyne, 1981.

160 Nebelspalter 1913/44, couverture de Walter Lilie et Victor Hardung intitulée «Automne » (Herbst).

Nebelspalter 1899/21, dessin en noir et blanc de Willy Lehmann-Schramm intitulé "L'usage à point nommé de la bouillie bordelaise réduit au silence jusqu'aux serpents à sonnette » (Rechtzeitige Anwendug von Bordeauxbrühe bringt selbst Klapperschlangen zum Schweigen).

${ }_{162}$ (Was sagen Sie zur Auffassung dieser Künstler? - Diese Künstler sollte man abfassen!); Nebelspalter 1912/5, dessin signé « HW » intitulé « La peinture cubiste au Kunsthaus » (Die " kubische » Malerei im Kunsthaus).
} 


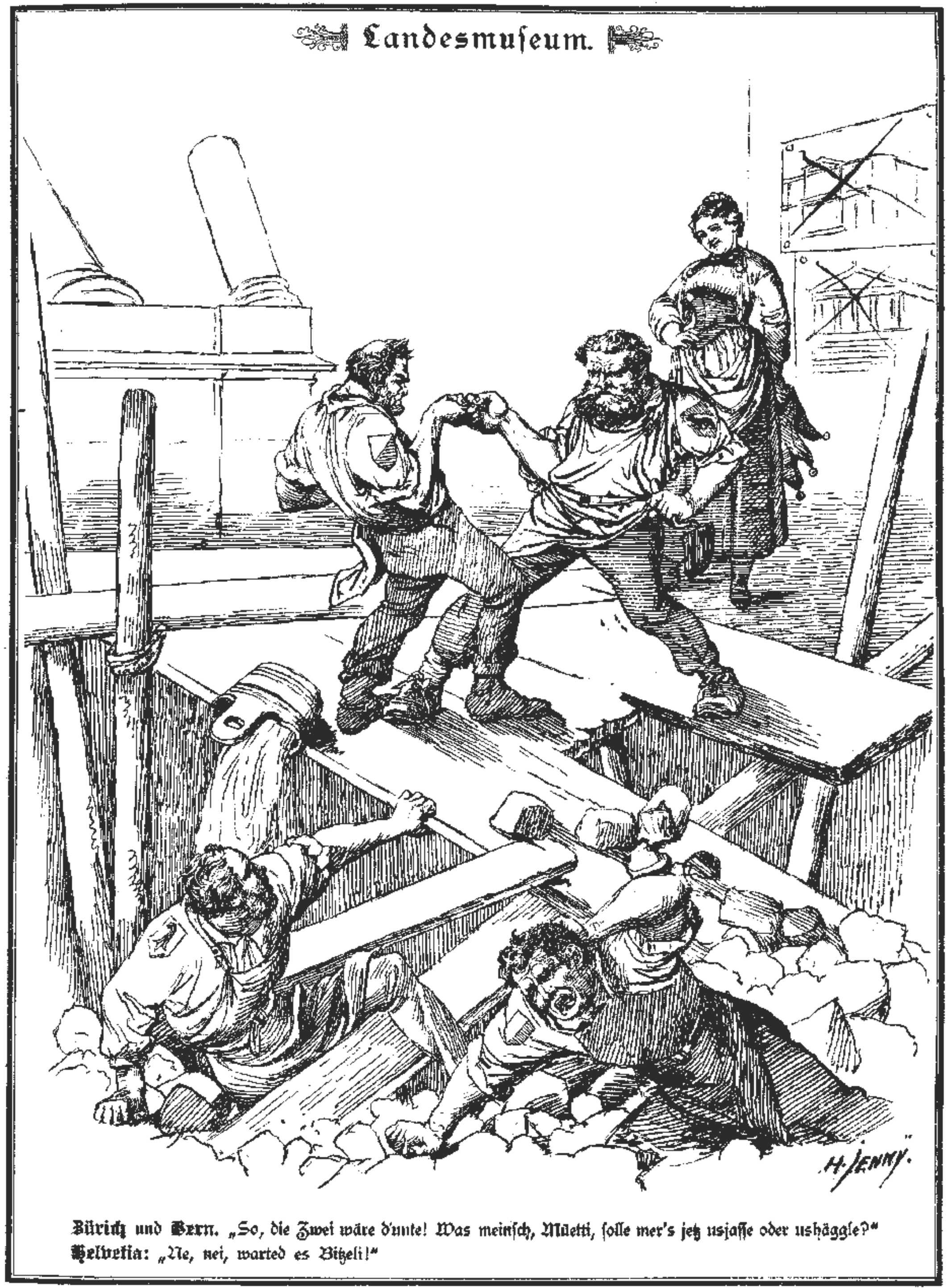

Fig. 130. Nebelspalter 1891/2, dessin pleine page en noir et blanc de Heinrich Jenny intitulé « Musée national »(Landesmuseum). 


\section{EMPRUNTS, TRANSFERTS ET AUTORÉFÉRENTIALITÉ}

La nature hybride d'une revue illustrée, qui iconise le verbe (met en image un propos) et verbalise le visuel (dit d'après des images, montrées ou non), sans que ces deux composantes puissent être facilement isolées, sa situation sociétale à la croisée des champs de l'art, de la littérature populaire et de la presse, font qu'elle aura plusieurs types de modèles. La maquette d'un périodique constitue un premier type de modèle. Cette maquette sert de référence lors de l'élaboration du nouveau périodique et des révisions et ajustements intervenant au fil du temps. Dans les deux cas, le modèle offre un appui au nouveau concept. Les images de revues, échues d'une manière ou d'une autre sous les yeux d'un dessinateur, représentent une deuxième sorte de modèle. Au moment de faire son propre dessin, celui-là s'en inspire, n'en livrant cependant qu'exceptionnellement une version à l'identique ou même très approchante. Les œuvres artistiques constituent un troisième modèle, servant de point de départ à une recréation graphique. Le dessinateur s'appuie alors sur un tableau, une sculpture, une gravure, voire une œuvre architecturale, inscrits dans un panthéon, représentant donc une référence, au sens commun du terme, avec une forte valeur normative. Déformant et reformant son modèle, l'artiste procède à une transposition rendue nécessaire par les contraintes physiques de la revue, en particulier son format, sa palette chromatique et sa bi-dimensionnalité. La déformation du modèle est toujours relative, car sa reconnaissance est nécessaire à la bonne réception de l'image. Celle-ci suppose une culture visuelle partagée entre dessinateurs et lecteurs, que l'on peut, du reste, évaluer à travers le nombre et le type de citations. Le registre plus ou moins dévalué de la nouvelle œuvre décide de son caractère de citation ou d'hommage. Le modèle rhétorique - ou sémantique - forme une quatrième sorte de modèle. Un mode de communication, un ton, des artifices, des référents, une structure de discours sont transposés, plus ou moins fidèlement.

Ces différents types de modèles se retrouvent dans le Nebelspalter, illustrant la réalité d'une Suisse s'imprégnant des créations européennes, fournissant également son tribut à l'activité bouillonnante des revues illustrées. Le journal se trouve ainsi à l'initiative à plusieurs reprises, avec des images que l'on va retrouver "aménagées" dans d'autres revues illustrées; sur d'autres supports physiques, dans le cas d'un transfert médial; re-sémantisées lorsqu'elles sont reprises dans un schéma de circulation interne, pas nécessairement pour le même type de propos ni par le même dessinateur. Dans l'exercice auto-citationnel, cas limite de la circulation de modèles, le Nebelspalter fait, en effet, preuve d'un zèle singulier ${ }^{1}$.

Sur les modèles, voir aussi : Laurence Danguy, "Le Nebelspalter zurichois (1875/1921): histoire, modèles et réseaux », dans L'Europe des Revues (1860-

\subsection{Le Nebelspalter, la caricature et les revues illustrées européennes}

Comme la plupart des revues, le Nebelspalter n'a pas de modèle unique. Jean Nötzli et Johann Friedrich Boscovits, associés lors de la genèse du titre ${ }^{2}$, ont, de toute évidence, porté leur regard sur les paysages éditoriaux suisse, français, anglais et allemand. Un modèle s'impose, néanmoins, plus que tout autre, celui de la revue Fliegende Blätter ${ }^{3}$, bien connue de l'éditeur du Nebelspalter, Jean Nötzli, pour y avoir collaboré quelques années auparavant ${ }^{4}$. Les Fliegende Blätter, qui débutent leur parution à Munich en I 844, sont l'une des rares revues satiriques pérennes en Europe après Le Charivari parisien et le Punch londonien. À ce titre, elles acquièrent valeur de prototype et servent de modèle à nombre de revues européennes. Pour créer le marqueur identitaire du Nebelspalter, le bandeau sur lequel se détachent le nom du titre et sa personnification, Boscovits senior ${ }^{5}$ s'appuie, lui aussi, sur la revue munichoise. Il transforme le harpiste du bandeau de titre en un jeune homme doté d'un imposant couvre-chef, d'une plume et d'un encrier, qui va dès lors personnifier la revue. Il reprend de surcroît le bouffon ainsi que les personnages haut en couleur qui l'accompagnent ${ }^{6}$ (cf. fig. 5).

Ceci dit, le bouffon possède une histoire plus ancienne. Il apparaît ainsi en I 829 comme vignette du Berliner Eulenspiegel, Zeitschrift von und für Narren (Le Till espiègle berlinois, revue de bouffons, pour les bouffons), en référence au personnage éponyme, très anciennement documenté dans la littérature populaire du Nord de l'Allemagne7. Quant à la personnification du Nebelspalter

1930) II - Réseaux et circulations des modèles, éd. Evanghelia Stead et Hélène Védrine, Paris, Presse Universitaire de Paris-Sorbonne, 2018, p. 99-117.

Cf. «1.2. Décryptage de la fondation et de la vie éditoriale: focus sur Boscovits senior».

Sur les Fliegende Blätter: Ursula E. Koch, « Die Münchner Fliegenden Blätter vor, während und nach der Märzrevolution 1848: "ein deutscher Charivari und Punch?" ", dans Politik, Porträt, Physiologie. Facetten der europäischen Karikatur im Vor- und Nachmärz, éd. Hubertus Fischer et Florian Vaßen, Bielefeld, Aisthesis Verlag, 2010, p. 199-255.

Peter Métraux, Die Karikatur als publistische Ausdruckform untersucht am Kampf des «Nebelspalters » gegen den Nationalsozialismus 1933-1945. Berlin, 1966, p. 25 .

Cf. «1.2. Décryptage de la fondation et de la vie éditoriale: focus sur Boscovits senior $»$.

Ursula E. Koch, « Die Münchner Fliegenden Blätter vor, während und nach der Märzrevolution 1848: "ein deutscher Charivari und Punch?" », op. cit., p. 37, 200. Ursula E. Koch, Der Teufel in Berlin. Von der Märzrevolution bis zu Bismarcks Entlassung. Illustriert politische Witzblätter einer Metropole 1848-1890, Cologne, Informationspresse c. W. Leske, 1990, p. 219-223. 


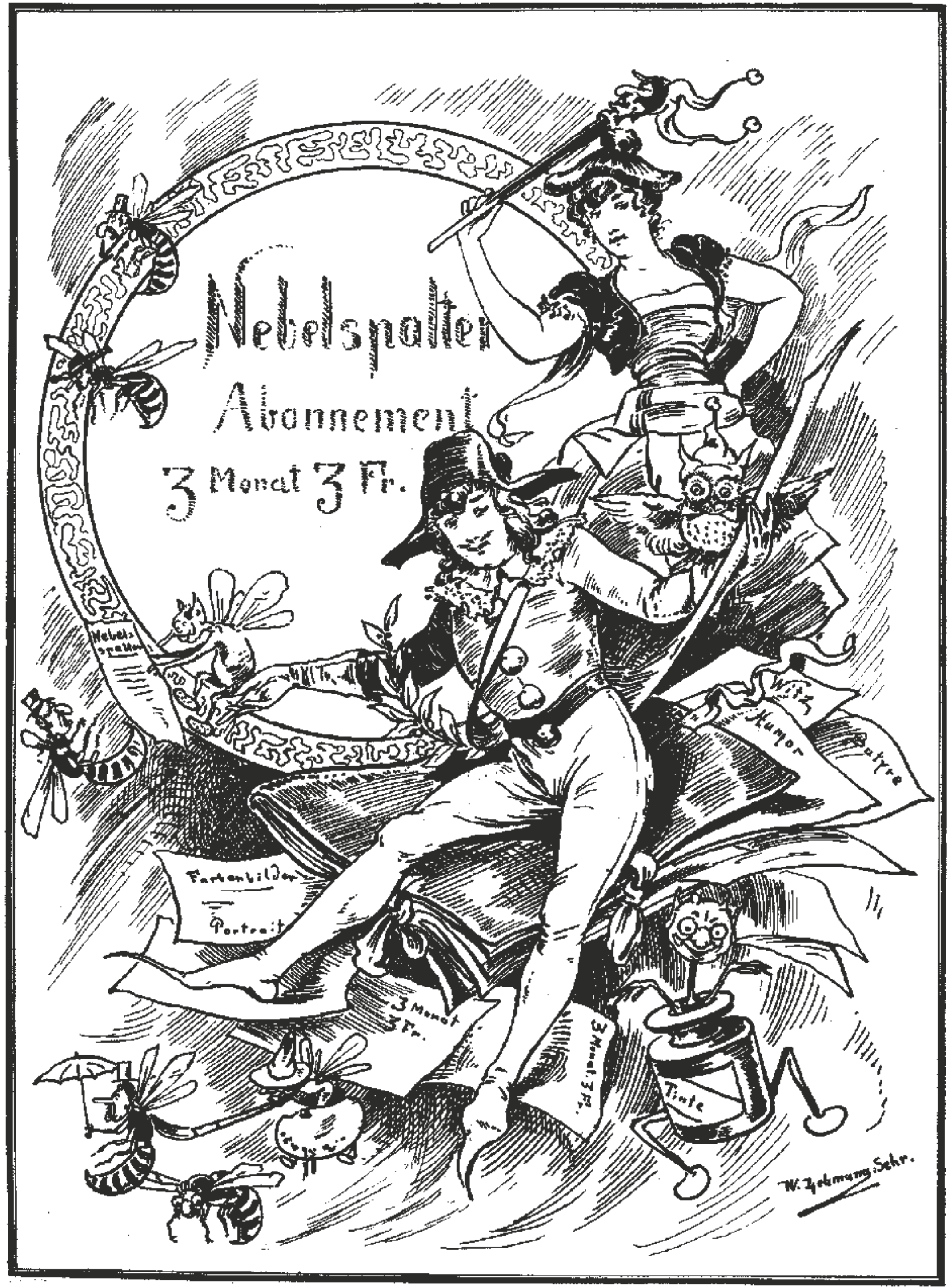

Fig. 132. Nebelspalter 1895/39, dessin pleine page en noir et blanc de Willy Lehmann-Schramm, sans titre 


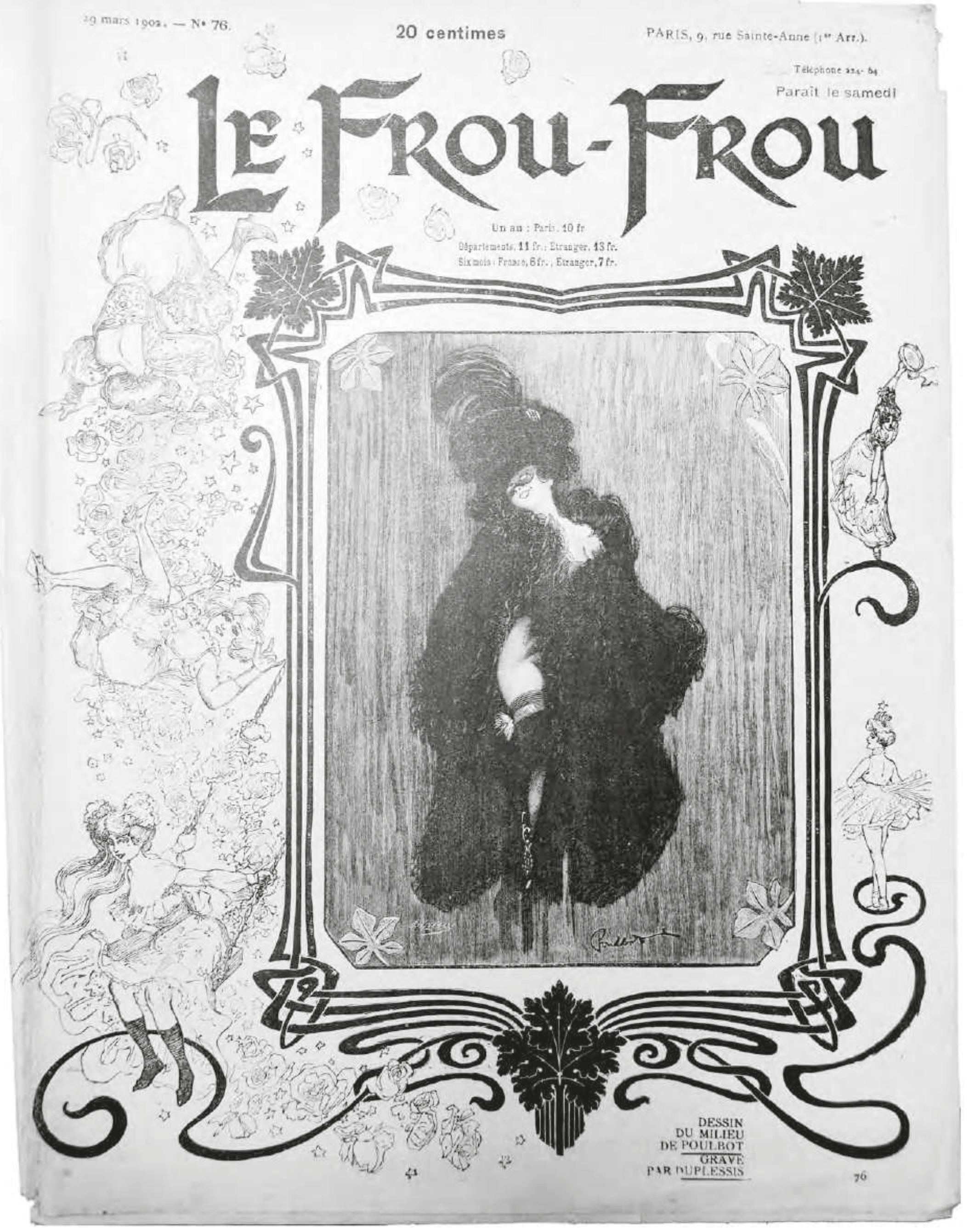

Fig. 133. Le Frou Frou, 29 mars 1902, n 76, couverture de Poulbot. 
- le Nebelspalter en d'autres termes ${ }^{8}$-, elle s'appuie, à l'instar des petits personnages, sur une seconde source iconographique. Toutes ces figures sont dérivées des types de la commedia dell'arte, très vivaces dans l'univers satirique. Dans le monde des revues, on aime à frayer avec les canons artistiques et littéraires. Si les petits personnages ne peuvent être ramenés à un type précis, le Nebelspalter représente un complexe syncrétique, agrégeant et modifiant les personnages du Capitan et de Scapino de la commedia dell'arte ${ }^{9}$. Les petits personnages sont, cependant, plus directement inspirés de ceux créés par le rédacteur en chef de la revue satirique berlinoise Ulk, sorte d'équivalent septentrional des Fliegende Blätter, commençant de paraître en I 872 . Pour animer sa revue, Sigmund Haber (I835-I895) invente, en effet, des figures comiques d'inspiration idiomatique: Paula Erbswurst, Nunne, Luitpolde von Seeflauge et sa correspondante Hildegard Stoobkübel, le Dr. Entoutcas et Frau Rentier Schladeberg. Leur rôle est d'intervenir, plus ou moins à-propos, sur l'actualité sociale et politique. Ils rencontrent une forte adhésion auprès du lectorat ${ }^{10}$.

Le modèle du Nebelspalter va lui-même circuler, puisqu'en I 896, le dessinateur de la première couverture de la revue munichoise Jugend, Fritz Erler (I 868-I940), reprend le personnage créé par Boscovits senior en I 875 en l'adaptant au contexte munichois et à l'esthétique Jugendstil, propagée par le nouveau périodique ${ }^{11}$. À nouveau, cependant, le modèle de la composition ne sera pas unique. Pour son patineur inscrivant le nom de Jugend sur le ciel étoilé de Munich, Fritz Erler s'est, en effet, également inspiré de la revue anglaise The Studio, très lié aux Arts and Crafts et d'une réception considérable en Europe ${ }^{12}$. Aubrey Beardsley (I 872-I 898) signe en avril I 893 la première couverture ${ }^{13}$ : celle-ci montre des arbres très modern style, autour desquels s'enroule une banderole sur laquelle se détache le nom de la revue. Ce sont ces deux éléments du Nebelspalter et de The Studio que transforme et agrège Fritz Erler. Cet exemple de l'adaptation de modèles mixtes, à la fois maquette, images de revues et modèles figuratifs, est précieux, en ce qu'il illustre la multiplicité des références, au vu de leur nature (iconique, sémantique, objectale et rhétorique), de leur médium (la commedia dell'arte est à l'origine théâtre) et de leur géographie historique et culturelle. Des schémas de circulation inattendus et des mécanismes de transferts sémantiques et visuels sont ainsi mis en évidence ${ }^{14}$.

Plus encore, cette première couverture de Jugend sert à son tour de modèle à l'une des premières couvertures Jugendstil du Nebelspalter, dessinée en I 897 par Willy Lehmann-Schramm ${ }^{15}$. Comme le jeune homme de Jugend, le chevalier du Nebelspalter trace de sa main gauche le nom de la revue en lettres d'or. Cependant, alors que dans le cas de Jugend, cela se passait devant le ciel étoilé de Munich, signifiée par sa très emblématique

Rappelons que l'on distingue le titre du Nebelspalter, en italiques, et sa personnification, en lettres romaines (Nebelspalter).

Si l'on s'appuie sur les types recensés en 1860 par Maurice Sand: Maurice Sand, Masque et bouffon (comédie italienne), Paris, Lévy, 1862; je dois ici remercier Melody Barblan Wirths.

Ursula E. Koch, Der Teufel in Berlin. Von der Märzrevolution bis zu Bismarcks Entlassung. Illustriert politische Witzblätter einer Metropole 1848-1890, op. cit., p. 219-223.

Jugend 1896/1-2, couverture de Fritz Erler.

Linda Koreska-Hartmann, Jugendstil - Stil der Jugend - Auf den Spuren eines alten, neuen Stil und Lebensgefühls, Munich, Deutscher Taschenbuch Verlag, 1969 , p. 24.

The Studio 1893/1, couverture de Aubrey Beardsley.

Cf. pour davantage de détails: Laurence Danguy, « Le Nebelspalter zurichois (1875/1921): histoire, modèles et réseaux », op. cit.

Nebelspalter 1897/31, couverture de Willy Lehmann-Schramm; cf. également " 2.3.7. Les couvertures Jugendstil, l'affirmation d'une identité ». cathédrale, la Frauenkirche, les lettres du Nebelspalter sont des volutes de brouillard au-dessus des Alpes suisses - ce brouillard qui, selon son nom, doit être dissipé. La belle est, en outre, désignée sur le bas de sa robe comme «Dame Politique "(Frau Politik), tandis que sur la flûte de Pan est inscrit le mot « satire » (Satire). Si les acteurs des deux revues se ressemblent, leur rôle est différent; la revue zurichoise les subordonne très clairement non à une esthétique mais à la satire. Enfin, le cadre est fixé sans ambiguïté: nous sommes en Suisse (cf. fig. 29).

Bien d'autres modèles, issus ou non de l'univers des revues illustrées, sont identifiables. Pour la création de l'un de ses types féminins, Lehmann-Schramm s'inspire ainsi des Lustige Blätter, créées en octobre i 886 à Hambourg sur le modèle des revues satiriques viennoises, puis transférées en janvier I 887 à Berlin. La jeune femme chapeautée, brandissant une tête de bouffon, accompagnant le Nebelspalter dans ses activités de promotion (invitation à l'abonnement), voire s'y substituant, est une reformulation du personnage principal du bandeau créé par Theodor Zasche, une élégante coiffée d'un chapeau d'arlequin devant un cercle sombre (cf. fig. I32).

La jeune dame assise est en train de disperser des feuillets. Au centre du bandeau, un bâton de bouffon s'enroule autour de la lettrine «B » de «Blätter ${ }^{16}$. À partir de I90I, outre les revues germaniques, les revues de cabaret parisiennes, dont le très populaire Le Frou Frou, laissent leur empreinte au travers d'une iconographie féminine soudain plus dénudée (cf. fig. I33).

Celle-ci est d'abord le fait de l'illustrateur allemand Willy Lehmann-Schramm qui développe une iconographie de la cocotte, parfois proche d'une "simple » prostituée, comme dans « L'air de la grande ville » $\left(\right.$ Großstadtluft ${ }^{17}$, présente aussi dans les images promouvant le cabaret zurichois Corso face aux ligues de vertu (Besittlichungs-Vereine) ${ }^{18}$ (cf. fig. I34).

On trouve chez Honoré Daumier (I 808-I879) l'une des sources pérennes d'inspiration des artistes de la première et de la seconde génération. En I 897, Willy Lehmann-Schramm reprend un dessin de Daumier, Tiens peuple, tiens bon peuple, en veux-tu, en voilà, initialement publié en I 835 dans Le Charivari ${ }^{19}$ pour une caricature intitulée "Dans Ioo ans à Zurich » (In Ioo Jahren in Zürich). Le dessinateur retient des éléments iconographiques et sémantiques: le schéma général de composition distribuant verticalement deux groupes de personnages; la figure et surtout la gestuelle du harangueur; la charge sémantique du profiteur s'enrichissant aux dépens du peuple; la déclinaison de types outranciers. Dans la composition de W. Lehmann-Schramm, ce type outrancier est le Juif profiteur, qu'il ne cesse, du reste, de

\footnotetext{
Ursula E. Koch, Der Teufel in Berlin. Von der Märzrevolution bis zu Bismarcks Entlassung. Illustriert politische Witzblätter einer Metropole 1848-1890, op. cit., p. 263-269; Willy Lehmann-Schramm développe cette iconographie dans une série de compositions appelant à l'abonnement: Nebelspalter 1894/38, dessin pleine page de W. Lehmann-Schramm, sans titre ; Nebelspalter 1894/52, dessin pleine page de W. Lehmann-Schramm intitulé «Petit Jésus » (Christchindli); Nebelspalter 1895/39, dessin pleine page de W. Lehmann-Schramm, sans titre; Nebelspalter 1895/52, dessin de W. Lehmann-Schramm intitulé «Les vœux du Nebelspalter pour la nouvelle année » (Nebelspalter's Neujahrsgruß); Nebelspalter 1896/13, dessin pleine page de W. Lehmann-Schramm, sans titre; Nebelspalter 1896/37, dessin pleine page de W. Lehmann-Schramm, sans titre. Nebelspalter 1901/2, dessin pleine page de W. Lehmann-Schramm intitulé « L'air de la grande ville » (Großstadtluft).

Nebelspalter 1901/3, dessin pleine page de W. Lehmann-Schramm intitulé « Zurich sous le signe de la danse » (Zürich im Zeichen des Tanzes!).
} Le Charivari 1835, $1^{\mathrm{er}}$ avril. 


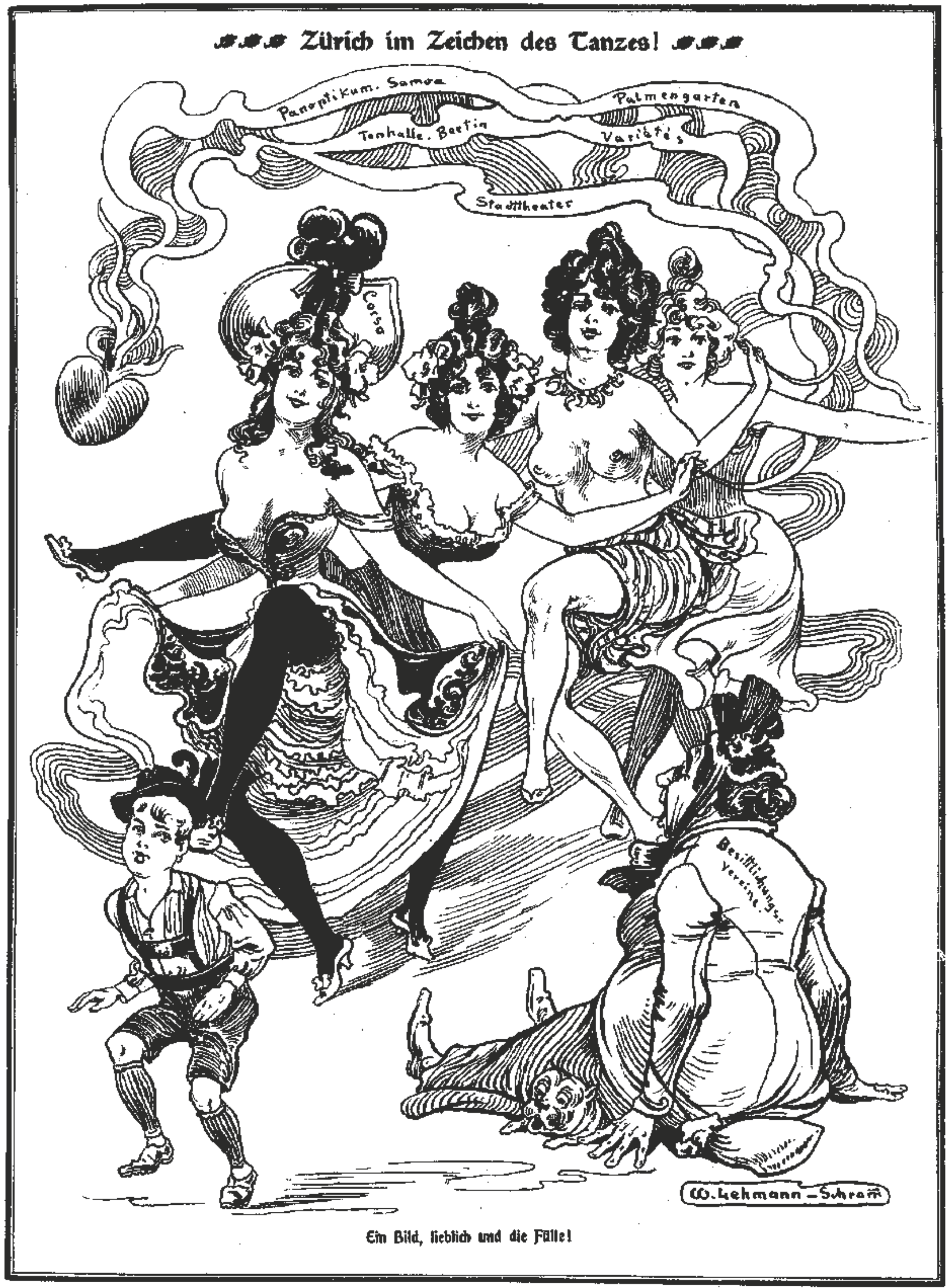


décliner dans ses dessins. La nouvelle composition comporte une charge antisémite, étrangère à l'original, confortée par le titre, les inscriptions dans l'image ainsi que par la légende:

Crieur: Entrez, entrez! Miracle des miracles! On a retrouvé au fin fond de l'Afrique le dernier zurichois encore vivant! Un véritable spécimen! ${ }^{20}$

Plus généralement, les dessinateurs s'essaient à construire des types de personnages, comme ceux développés par Daumier dans le registre politique et celui des mœurs. Nulle trace, en revanche, de Grandville (I 803-I 847) et Paul Gavarni (I 804-I 866), qui sont pourtant, avec Daumier, les caricaturistes français les plus copiés en Europe ${ }^{21}$.

Parmi les images de revues, Jugend et Simplicissimus tiennent une place privilégiée. Le vis-à-vis de deux caricatures, "Gravement malade " (Schwer Krank!), issue du Nebelspalter et «Dans le boudoir de Germania » (Im Boudoir Germania), en provenance de Jugend est riche d'enseignements. La première caricature, œuvre de Boscovits senior, est publiée au début de l'année $1892^{22}$; la seconde, dessinée par Arpad Schmidhammer (I857-I92 I), paraît durant le dernier tiers de l'année I900³ (cf. fig. I35 et I36).

Plusieurs choses peuvent être mises en évidence dans la réinterprétation du motif - somme toute ancien - du boudoir politique: la reprise du schéma global de composition; le caractère interchangeable des personnifications des revues (celle de Jugend à la place du Nebelspalter); celui tout aussi instable des entités politiques (Germania au lieu de l'Europe); une circulation de modèles contredisant l'importance historiographique des deux revues et leur impact supposé. Ici, comme dans le cas des couvertures, la chronologie place le Nebelspalter en position d'émetteur vis-à-vis de Jugend, fournissant une indication précieuse sur l'impact et la zone d'influence de la revue zurichoise.

La dynamique est, en revanche, inverse lors de la refonte de la maquette du Nebelspalter en 1907: la couverture du Simplicissimus de Albert Langen sert alors de modèle. Le Nebelspalter introduit également la thématique estudiantine, très prisée dans les caricatures de la revue satirique munichoise. Le modèle du Simplicissimus apparait, du reste, subrepticement en I908 dans une caricature de Boscovits junior, très lié à Munich par sa formation et ses origines familiales ${ }^{24}$. Le dessinateur intègre dans son dessin une pseudo-couverture de Simplicissimus, montrant une femme dénudée, pour condamner le rigorisme du pasteur protestant Otto Lauterburg ${ }^{25}$.

Ces modèles passent, enfin, par des réseaux que l'on pourrait qualifier de "naturels ", puisque que bien des dessinateurs

\footnotetext{
(Ausschreier: " Nur immer hereinspaziert! Wunder über Wunder! Im tiefsten Afrika wurde es gefunden, der einzig noch lebende Stadtzüricher. Wahres Musterexemplar! »); Nebelspalter 1897/29, dessin pleine page de Willy LehmannSchramm intitulé « Dans 100 ans à Zurich » (In 100 Jahren in Zürich).

Cf. plus largement sur cette question: Philippe Kaenel, « 1830-1848: la réception de l'œuvre de Daumier et Grandville en Suisse », Sociétés et Représentations, 10 (2000), éd. Christian-Marc Bosséno, Frank Georgi et Marielle Silhouette, p. 145161. Sur Daumier caricaturiste: Ségolène Le Men, Daumier et la caricature, Paris, Citadelles \& Mazenod, 2008

Nebelspalter 1892/3, dessin pleine page de Boscovits junior intitulé « Gravement malade » (Schwer Krank).

Jugend 1900/40, dessin en noir et blanc d'Arpad Schmidhammer intitulé « Dans le boudoir de Germania » (Im Boudoir Germania).

Cf. «1.2. Décryptage de la fondation et de la vie éditoriale: focus sur Boscovits senior » ainsi que «1.3. La domination Boscovits».

Nebelspalter 1908/52, dessin pleine page en couleur de Boscovits junior intitulé
} «Présents de Noël » (Weihnachtsgaben). travaillent dans différentes revues et sont, par ailleurs, euxmêmes lecteurs de revues. C'est sans doute ainsi qu'il faut comprendre l'influence toujours plus importante de Gustave Henri Jossot (I866-I95I), dessinateur très actif de L'assiette au beurre $^{26}$, sensible à partir de I 909 sous le crayon du dessinateur zurichois Emil Huber et qui perdure durant la Première Guerre mondiale.

Le genre du salon caricatural dessine une autre configuration. Si l'on rapproche une nouvelle fois le Nebelspalter des revues parisiennes et de Jugend, la revue zurichoise est alternativement en position d'émetteur et de récepteur. Lorsqu'en I 877, Johann Friedrich Boscovits senior introduit le salon caricatural dans le Nebelspalter, il s'appuie, selon toute évidence, sur les revues parisiennes, où le genre est apparu dans les années I 840 avant d'être popularisé par Le Charivari ${ }^{27}$. Boscovits l'adapte au contexte suisse, selon les mécanismes des transferts culturels et artistiques. Intitulée « Dans l'exposition d'art suisse » (In der Schweizerischen Kunstausstellung), la page est une satire du Turnus de $1877^{28}$ (cf. fig. I24). L'un des dessins, placé au milieu de la page, en bas, consiste en la parodie d'une œuvre du peintre munichois August Heyn (I 837-I920). Il se présente, à la différence des autres, comme un feuillet dépourvu de cadre. Titré dans le coin supérieur gauche «Der Nebelspalter ", il montre le personnage du Nebelspalter en prières devant un rôti marqué "Abonnement ", accompagné d'une bouteille de vin. La légende reprend le titre original donné par le livret de référence: "I I 5. "Donne-nous notre pain quotidien!” Amen. " ${ }^{29}$ Le salon caricatural est l'occasion d'un acte symboliquement fort, puisque le Nebelspalter assoie alors son identité artistique et satirique, tout en réaffirmant sa posture anticléricale. Si l'original d'August Heyn n'a pu être retrouvé, le dessin se rapproche de la manière du peintre munichois, mais a aussi un petit air "à la Daumier ", que l'on retrouve dans bien des compositions de Boscovits senior. Il rappelle notamment une planche parue dans le Charivari en I 85 I, dédiée à M. de Montalembert, intitulée Capucinade. La pauvreté contente montrant deux moines attablés devant un poulet. En France, Charles de Montalembert ( I 8I0-I 870), théoricien du catholicisme libéral, est à l'origine du parti catholique, soit tout ce qu'exècre le Nebelspalter ${ }^{30}$.

Quasiment vingt ans plus tard, le schéma de Boscovits est transposé dans l'un des salons caricaturaux paraissant dans Jugend, à l'occasion de chaque exposition importante ${ }^{31}$. L'acte symbolique est réitéré. «Les autoportraits du peintre Modeslaw Manierewicz» (Die Selbstporträts des Malers Modeslaw Manierewicz) ${ }^{32}$ alignent pareillement huit tableaux, cette fois sur

Sur cette revue : Élisabeth et Michel Dixmier, L'Assiette au Beurre, Paris, Maspéro 1974; Aristide Delannoy, L'Assiette au Beurre 1901-1912, Paris, Les Nuits rouges, 2007.

Denys Riout, «Les salons comiques » Romantisme, ${ }^{\circ} 75,1992$, p. 51.

Cf. « 4.3. Le salon caricatural du Nebelspalter ou la critique de la modernité ».

(115. « Unser heutiges Brod gib’ uns täglich! » Amen.); Nebelspalter 1877/27, dessin pleine page de Boscovits senior intitulé "Dans l'exposition d'art suisse » (In der Schweizerischen Kunstaustellung); Schweizerische Kunstaustellung in St. Gallen 1877 vom 20. Mai bis 10. Juni. Katalog der ausgestellten Kunstwerke, Saint-Galles, Buchdruckerei von M. Kälin, 1877.

Sur Montalembert: David Bellamy, Geoffroy de Montalembert (1898-1993). Un aristocrate en République, Rennes, Presses universitaires de Rennes, 2006; Sylvain Milbach, "Les catholiques libéraux et la presse entre 1831 et 1855 », Le mouvement social, 215 (2006), p. 9-34; Isabelle Saint-Martin, Art chrétien / Art sacré. Regards du catholicisme sur l'art. France, $X I x^{e}-x X^{\ominus}$ siècle, Rennes Presses universitaires de Rennes, 2014.

Linda Koreska-Hartmann, Jugendstil - Stil der Jugend - Auf den Spuren eines alten, neuen Stil und Lebensgefüh/s, op. cit., p. 210.

Jugend 1896/43, double-page en noir et blanc, non signée, intitulée «Les autoportraits du peintre Modeslaw Manierewicz » (Die Selbstporträts des Malers 
une double-page. Comme dans le Nebelspalter, le dernier tableau montre un simple feuillet, qui est la seule image à ne pas être encadrée. L'artiste a pris la place du Nebelspalter. Le dessin est ainsi légendé:

I 896. En page de titre de Jugend. Autoportrait de l'artiste au tableau de la vie du commun et autres choses y touchant. Admirable travail gravé tout en profondeur d'âme de la fin du siècle ${ }^{33}$.

La composition de Jugend est indiquée comme « mise à disposition par A.F. Seligmann, Vienne » (Zur Verfügung gestellt durch A.F. Seligman, Wien). Il s'agit d'un joli canulard, puisque Adalbert Franz Seligmann (I 862-I945), peintre, écrivain, illustrateur et critique d'art dans la revue viennoise Neue Freie Presse se pose en champion de la tradition ${ }^{34}$. De même que dans le Nebelspalter, le geste est esthétique.

Lorsqu'en I 896, le Nebelspalter revient à l'exercice du salon caricatural après une pause de quasiment vingt années - à l'exception d'une unique occurrence en i 886 -, le langage visuel est désormais celui du Jugendstil propagé par Jugend ${ }^{35}$. Le salon caricatural de I 877 du Nebelspalter continue, par ailleurs, de circuler. Conjointement avec "Les autoportraits du peintre Modeslaw Manierewicz » de Jugend, il sert de référence à la deuxième couverture de la revue bolognaise Italia ride. Fondée en I900, cette dernière a pour progamme la défense de l'Art nouveau italien, le liberty, et pour modèle, la revue Jugend ${ }^{36}$. Portant l'inscription "Ars Nova », la couverture montre une frêle jeune fille en prières devant le "saint livre " de Ruskin, appuyé contre une bouteille de laquelle sort un lis ${ }^{37}$. L'image est à la fois une reprise $\mathrm{du}$ troisième tableau des autoportraits du peintre "Modeslaw Manierewicz » vêtu en préraphaélite ${ }^{38}$ et du dessin montrant le Nebelspalter en prières devant son repas, un rôti accompagné d'une bouteille. L'auteur est annoncé comme Augusto Cezanne (1 856-I935), peintre paysagiste et portraitiste, impliqué à ce moment de sa carrière dans la fondation de la biennale de Venise et la défense des arts décoratifss ${ }^{39}$. On peut tout de même se demander s'il ne s'agit pas à nouveau d'une facétie. Le monogramme «AS » apposé dans le coin droit de l'image ressemble fort à celui d'un certain Arpad Schmidhammer, collaborateur pilier de Jugend ${ }^{40}$, dont il n'est pas du tout exclu qu'il ait été l'auteur des portraits du peintre Modeslaw Manierewicz ${ }^{41}$.

Modeslaw Manierewicz); le nom Modeslaw Manierewicz est un pseudonyme agrégeant les mots « Mode » (« mode ») et « Manier » (« manière »).

(1896: Als Titelblatt der Jugend. Selbstporträt des Künstlers nebst einer Darstellung des ganzen menschlichen Lebens und einiger angrenzender Dinge. Wundervoll seelisch vertiefte Griffelkunst vom Ende des Jahrhunderts.)

34 Laurence Danguy, L'ange de la jeunesse - La revue Jugend ou le Jungendstil à Munich, Paris, Maisons des sciences de l'homme, 2009, p. 122

Cf. « 4.3. Le salon caricatural du Nebelspalter ou la critique de la modernité ».

Marta Sironi, Ridere dell'arte. L'arte moderna nella grafica satirica europea tra otto e novecento, Milano-Udine, Mimesis Edizioni, 2012, p. 90-95.

Italia Ride 1900/2, couverture d'Augusto Sezanne intitulée " Ars Nova ».

${ }_{38} \quad$ Laurence Danguy, Vanja Strujkel et Francesca Zanella, « Circulations de modèles entre l'aire germanique et l'Italie au début $\mathrm{du} x \mathrm{xx}^{\mathrm{e}}$ siècle: ouvrir un champ de recherche », dans L'Europe des Revues (1860-1930) II - Réseaux et circulations des modèles, éd. Evanghelia Stead et Hélène Védrine, Paris, Presse Universitaire de Paris-Sorbonne, 2018, p. 145-164; Marta Sironi, Ridere dell'arte. L'arte moderna nella grafica satirica europea tra otto e novecento, op. cit., p. 93.

39 Hans Vollmer (éd.), Allgemeines Lexikon der bildenden Künstler, vol. 30, Leipzig, E. A Seemann, 1936, p. 556; E. Bénézit (éd.), Dictionnaire critique et documentaire des peintres, sculpteurs, dessinateurs et graveurs, Paris, Gründ, 1999, p. 725.

40 Laurence Danguy, L'ange de la jeunesse. La revue Jugend ou le Jugendstil à Munich, op. cit., p. 57-63.

Cette hypothèse est cependant contraire aux propos de Marta Sironi ; Marta Sironi, Ridere dell'arte. L'arte moderna nella grafica satirica europea tra otto e novecento, op. cit., p. 93.
Quant à la place que se rêvait le Nebelspalter parmi les revues, plusieurs indices nous sont fournis par la succession Nötzli et les archives Boscovits. Une partie date de la période I 887 -I 890 , alors que le journal dirigé par Jean Nötzli cherche à se positionner dans les champs de l'art et des revues illustrées; l'autre, plus tardive, de I 908 , correspond à un moment où la revue s'emploie de nouveau à redéfinir son positionnement. La correspondance entre les frères van Muyden et Jean Nötzli nous apprend ainsi que les deux frères souhaitaient s'appuyer sur les Fliegende Blätter pour leurs dessins - après tout, le modèle primitif du Nebelspalter, quinze ans plus tôt - mais que ce n'était pas l'orientation choisie par l'éditeur. Evert van Muyden expose son projet en ces termes à son ami Richard Kissling (I848-I9I9):

Bientôt je retournerai à Paris et il est probable que là je trouverai bien des sujets drôles dans la rue et ailleurs et compréhensibles pour tout le monde. Souvent ce sont les dessins sans texte, mais bien significatifs qui sont les plus drôles, comme on en voit souvent dans les Fliegende Blätter. Je pense que le rédacteur du Journal accepterait volontiers ce genre là, dans lequel peut être je réussirai mieux qu'ailleurs ${ }^{42}$.

Une lettre de Henri van Muyden indique toutefois que l'éditeur pensait plutôt au Journal amusant:

Seulement, je dois vous dire que si le genre des Fliegende Blätter ne plait pas à Zurich, celui du journal amusant me parait fort déplaisant et surtout superficiel, à part la facture ${ }^{43}$.

Fondé par Charles Philippon en I 856, repris par Louis Huart en I 862, Le journal amusant emploie de nombreux caricaturistes et est principalement orienté vers le genre humoristique ${ }^{44}$. Il paraît régulièrement à partir du Io juin I87I, et ce jusqu'en 1933. Cependant, après la fondation du Rire en 1893 , qui génère des dessins bien plus caustiques, tant par leur propos que par leur graphisme, le Journal amusant paraît soudain démodé 45 . C'est sans doute ce sentiment qu'anticipe Henri van Muyden.

Un autre indice nous est livré par le carton d'invitation dessiné par Boscovits junior pour un concert donné dans le cadre du Congrès suisse de la presse de I908 (Schweizer Pressetag I908) ${ }^{46}$ (cf. fig. I37).

On y voit un vendeur appuyé contre un chariot rempli de journaux, coiffé d'une casquette portant l'inscription «JOURNEAUX » ${ }^{47}$. Les journaux sont rangés dans cinq casiers. On distingue dans les trois casiers supérieurs les titres phares de la presse suisse alémanique: la Neue Zürcher Zeitung, le National-Zeitung, les Basler Nachrichten, Der Bund, les Aargauer Nachrichten, le S. Galler Tagblatt, le Züricher Post, Der Landbote; tandis que les deux casiers inférieurs sont principalement remplis de revues illustrées. Le casier du dessus est réservé aux titres suisses, dont deux nettement identifiables: le Nebelspalter et La Gazette de Lausanne. Celui du dessous comprend les titres étrangers: les revues munichoises Lüstige Blätter, Jugend et Simplicissimus,

Cote 1.14 de la succession Nötzli, lettre du 24 novembre 1887 ; voir pour la lettre en entier et le reste de la correspondance « 6.4 Passions d'artistes: Richard Kissling, Evert van Muyden, Henri van Muyden et Jean Nötzli ».

Cote 1.14 de la succession Nötzli, lettre du 16 avril 1890.

44 Solo (éd.), Dico Solo: Plus de 5000 dessinateurs de presse et 600 supports en France de Daumier à l'an 2000, Vichy, Aedis, 2004, p. 456-457.

Michaela Lo Feudo, « Journal amusant (1586-1933, Paris) », Ridiculosa, 18 (2011) Les revues satiriques françaises, p. 68-71; sur la revue Le Rire: Laurent Bihl, La Grande Mascarade parisienne. Paris, Nouveau monde (à paraître).

Le carton d'invitation se trouve dans les archives de la famille Boscovits. La faute d'orthographe est conforme à l'original. 
Godiver Arant.

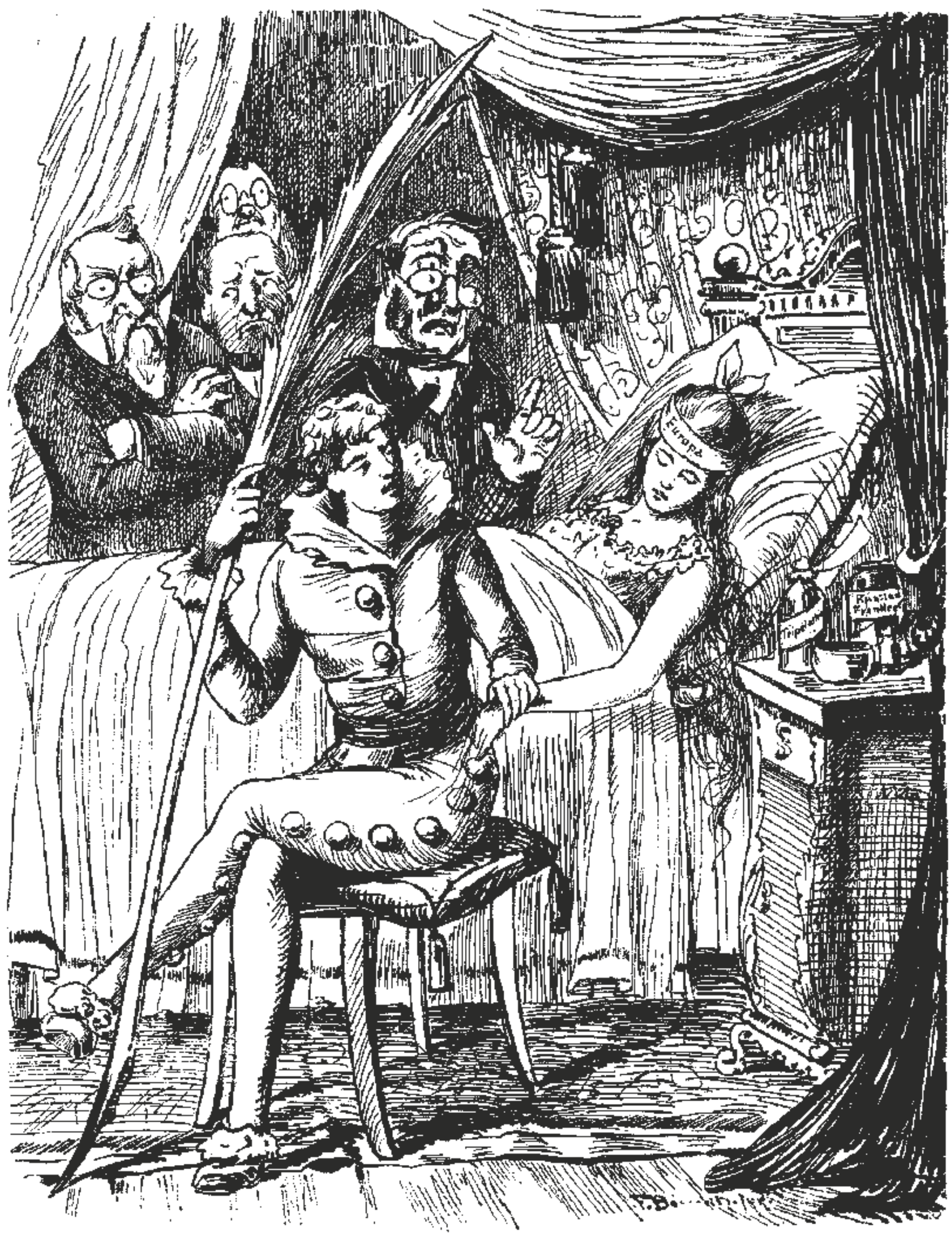

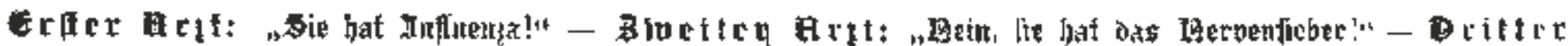

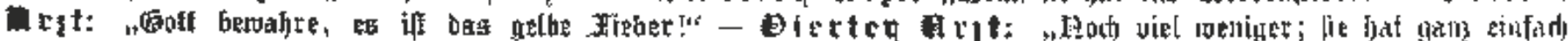

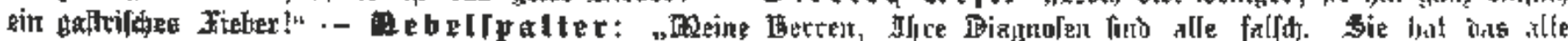

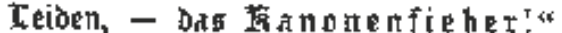




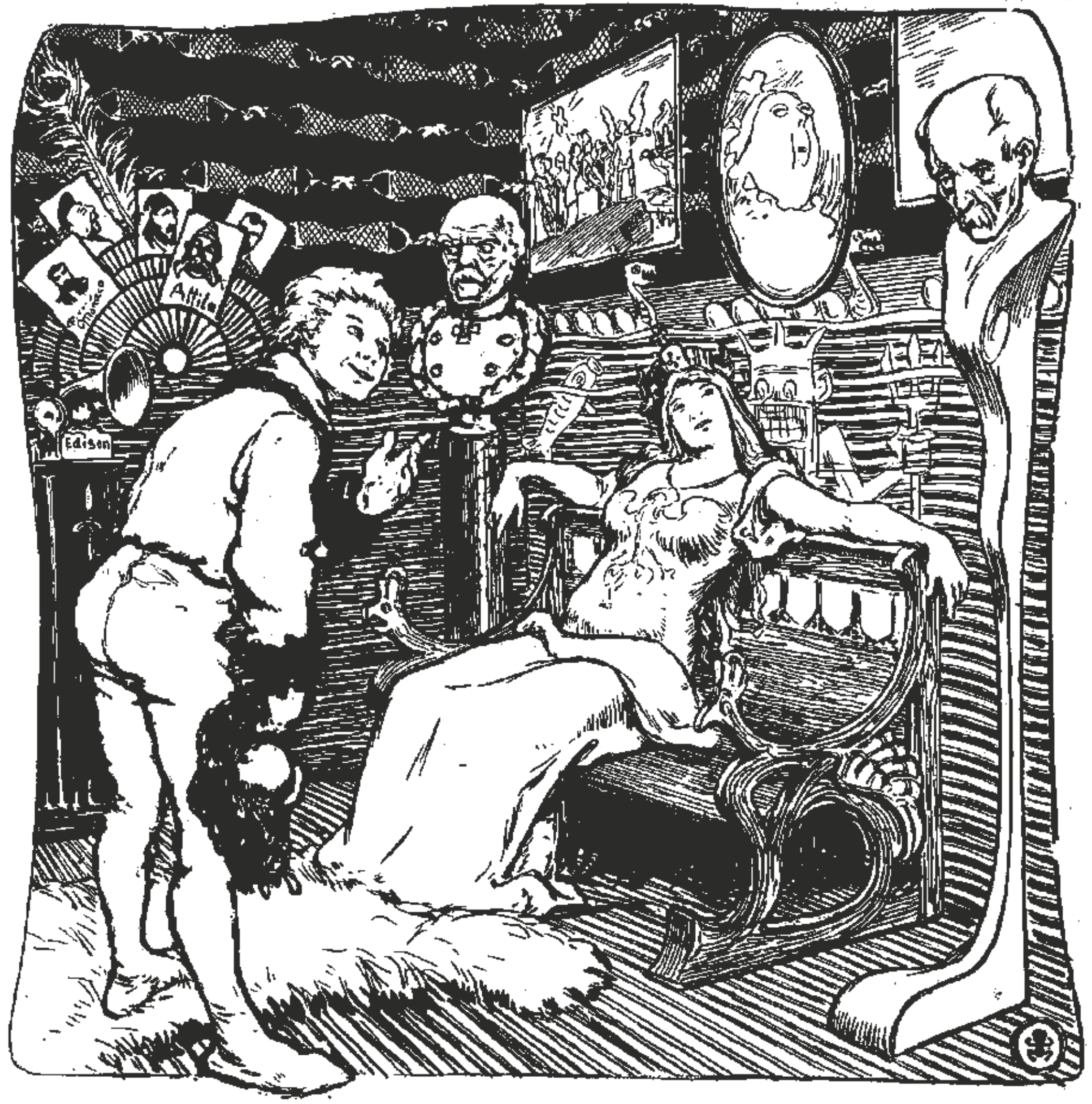

Im Boudoir Germania's

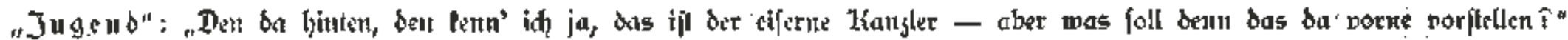
Betntania: "2ld bus ift nur fo eitre becoratipe figur." 


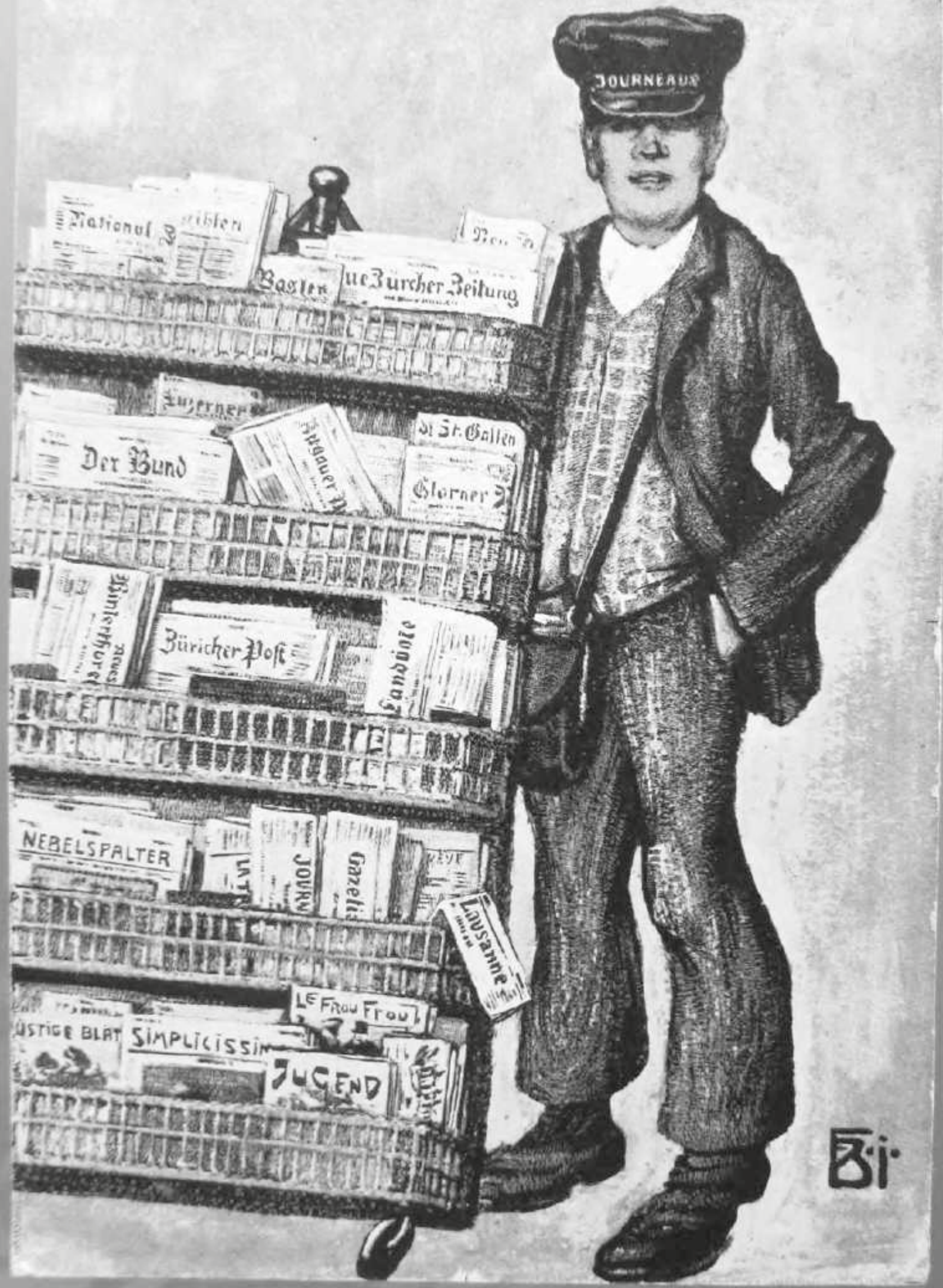

Fig. 137. Carton d'invitation de Boscovits junior pour un concert donné dans le cadre du Congrès suisse de la presse de 1908. 
ainsi que la revue parisienne Le Frou Frou; soit exactement les titres dont on reconnaît les traces dans le Nebelspalter, jusqu'au Simplicissimus, cité à plusieurs reprises dans la publicité en I 896 et I 897, puis dans une caricature de I 908 et, enfin, de nouveau, lors de sa confiscation par les autorités fédérales en I9 I $8^{48}$. Comment, dès lors, s'étonner de ce que Simplicissimus serve de modèle à la nouvelle maquette du Nebelspalter en I922, lors de sa reprise par Ernst Löpfe-Benz à Rorschach?

\subsection{S'enrichir du « grand art »}

Une multitude de références au « grand art " sont visibles dans le Nebelspalter et ce, dès l'origine 49 . Le fait n'est guère surprenant, puisque ses dessinateurs ont reçu une formation académique, où l'on s'exerce d'après des œuvres classiques. Ces modèles ressortissent soit à un fonds humaniste européen, soit à une culture contemporaine, l'un comme l'autre largement partagés dans l'aire culturelle germanique. Dans la plupart des cas, autant qu'un artiste, c'est une œuvre qui est citée pour sa notoriété et sa valeur rhétorique, selon un procédé s'apparentant à celui des citations textuelles ${ }^{50}$.

Les chefs-d'œuvre de la culture occidentale forment un premier fonds. Le très célèbre groupe du Laocoon apparait dans une dénonciation du parti antisémite en I $88 \mathrm{I}^{51}$; le Mercure volant de Giambologna sert à annoncer une année prospère en $1879^{52}$; l'Érasme de Hans Holbein le jeune (I497-I 543) illustre, en I 884, le procès Wackernagel, opposant un rédacteur des Basler Nachrichten au clergé catholique ${ }^{53}$; la Vénus de Médicis est utilisée en I 900 pour dénoncer la loi wilhelminienne sur les mœurs, dite Lex Heinze ${ }^{54}$; la Vénus de Milo est un ingrédient humoristique en I908 et I9I I ${ }^{55}$; Les Trois Grâces contribuent à moquer, en I907, le rapprochement entre le Président français Armand Fallières et les monarques espagnol et anglais, Alphonse XIII et Edouard VII. Dans ce dernier cas, le modèle est déformé au point qu'on ne peut trancher en faveur de la version de Raphaël ou de

Nebelspalter 1918/27, dessin en couleur de Boscovits junior intitulé « Journa interdit » (Zeitungsverbot)

49 Sur ce point: Marco Ratschiller, Bedrohte Schweiz: nationale Selbstbilder, Fremdbilder und Feindbilder in der "Nebelspalter 》 - Karikatur des 20. Jahrhunderts: eine semiotische Untersuchung, 2004 (mémoire soutenu à l'université de Fribourg), p. 121-122; Milena Oehy, Karikaturistische Bildzitate aus dem « Nebelspalter » von 1875 bis 1955, 2009 (mémoire soutenu à l'Université de Zurich, consultation réservée).

Sur cette problématique: Emmanuel Pernoud, «Les beaux-arts à l'épreuve du kiosque », dans La Civilisation du journal. Histoire culturelle et littéraire de la presse française au XIXe siècle, éd. Dominique Kalifa, Philippe Régnier, Marie-Ėve Thérenty et Alain Vaillant, Paris, Nouveau Monde, 2011, p. 1569-1577.

Nebelspalter 1881/2, dessin pleine page non signé intitulé « Laocoon » (Laokoon) Le groupe est nouvellement contextualisé par rapport à la caricature de Daumier dans Le Charivari en 1868; Ségolène Le Men, «Trois regards sur le Laocoon: la caricature selon Daumier, la photographie selon Braun, le livre d'histoire de l'art selon Ivins » ", Revue germanique internationale, 19 (2003), Le laocoon: histoire et réception, p. 195-203.

32 Nebelspalter 1879/1, dessin pleine page de Boscovits senior intitulé « Le régent de l'année » (Der Jahres-Regent).

Nebelspalter $1884 / 51$, dessin pleine page en noir et blanc de Boscovits senior intitulé « Au sujet du procès Wackernagel à Bâle » (Zum Wackernagelprozess in Basel).

${ }^{54}$ Nebelspalter 1900/11, dessin pleine page en noir et blanc de Boscovits junior intitulé « Lex Heinze »; sur le traitement de cette loi dans le Nebelspalter, cf. " 2.4.3. Tendance et thèmes - Recentrage ».

55 Nebelspalter 1908/21, dessin signé « G St » intitulé " La nature de l'art » (Das Wesen der Kunst); Nebelspalter 1911/45, dessin signé « AB » intitulé « Devant la Vénus de Milo » (Vor der Venus von Milo). celle de Rubens ${ }^{56}$. Plus que d'autres, Boscovits senior réinterprète l'œuvre d'Abrecht Dürer (I47 I-I 528). En I 890, il s'appuie sur une gravure issue du cycle de L'Apocalypse, Les quatre cavaliers de l'Apocalypse ( 1498 ) pour concevoir une caricature, critique combinée de l'interdiction de la pièce Les revenants d'Ibsen et de maux plus généraux de la société énumérés dans l'image: la discorde (Zwietracht), la maladie (Krankheit), le krach (Krach), la révolution (Revolution), la détresse (Noth), la peur de la guerre (Kriegsfurcht), la crise (Krisis), la misère (Elend) et le despotisme (Despostismus) ${ }^{57}$ (cf. fig. 93). En I9 I 8, Alfred Hirschler se réfère à cette même œuvre de Dürer pour dénoncer la pratique des usuriers dans une œuvre intitulée "Le cinquième cavalier de l'Apocalypse " (Der fünfte apokalyptische Reiter) ${ }^{58}$. Très peu de temps après, Boscovits junior recourt à nouveau au modèle pour un propos similaire, qu'il élargit aux profiteurs. Son dessin, intitulé "Compagnie raffinée " (Feine Gesellschaft) et légendé "Le cavalier, la mort et le diable " (d'après Dürer) (Ritter, Tod und Teufel [nach Dürer]), propose néanmoins une toute autre iconographie ${ }^{59}$ (cf. fig. 138 ).

D'autres œuvres plus récentes remplissent une fonction similaire, telle « La chasse au bonheur » (Die Jagd nach dem Glück) (I868) du peintre allemand Rudolf Henneberg ( I 825-I 876). L'œuvre est l'une des plus citées dans le Nebelspalter où elle soutient des propos aussi différents que la course au profit, en I $888^{60}$ (cf. fig. 32) et la concurrence effrénée pour l'obtention d'un siège de conseiller fédéral, en I90 ${ }^{61}$. La liberté guidant le peuple (I 830) d'Eugène Delacroix (I798-I 863) légitime, quant à elle, une revendication faite en I 892 au Président français Sadi Carnot (I 837-I 894) concernant les accords commerciaux avec la France ${ }^{62}$, ainsi qu'en I907, l'émancipation nécessaire face au très puissant clergé allemand $^{63}$. Dans ces deux derniers cas, la citation est très libre, et l'on ne retient de l'œuvre matrice que la figure allégorique de la liberté et le schéma global de composition. L'usage fait du Semeur ( 1850 ) de Jean-François Millet (I 874-I 875) est de la même veine, qu'il s'agisse de défendre la question céréalière, en $1908^{64}$ ou de dénoncer, à l'été I905, le choix de Serge Witte ( I 849-I 9I 5 ) comme négociateur de la paix, au terme de la guerre russo-japonaise ${ }^{65}$. Plus rarement, apparaît une œuvre moins consensuelle, telle La dame au cochon - Pornokrates (I 879) du belge Félicien Rops ( I 833-I 898). L'œuvre de cet artiste particulièrement sulfureux légitime un nu, sans doute érotique aux yeux du spectateur de l'époque, à l'occasion des chaleurs de l'été I9 I I ${ }^{66}$ (cf. fig. I39).

\footnotetext{
Nebelspalter 1907/25, couverture de Boscovits senior intitulée « Sur la nouvelle triple-alliance » (Zur neuen Tripelallianz).

Nebelspalter 1890/15, dessin pleine page de Boscovits senior en noir et blanc sans titre.

5 Nebelspalter 1918/27, couverture de Alfred Hirschler intitulée "Le cinquième cavalier de l'Apocalypse » (Der fünfte apokalyptische Reiter).

Nebelspalter 1918/35, dessin pleine page de Boscovits junior intitulé « Compagnie précieuse » (Feine Gesellschaft).

Nebelspalter 1888/23, double-page en couleur de Boscovits senior intitulée « La chasse au bonheur » (Die Jagd nach dem Glück).

Nebelspalter 1905/42, dessin en noir et blanc de Boscovits junior intitulé « Au suje des élections (Image sans légende) » (Zu den Wahlen [Bild ohne Worte]).

${ }_{62}$ Nebelspalter 1892/49, double-page en couleur de Boscovits senior intitulée «Au sujet de l'accord commercial franco-suisse » (Zum französisch-schweizerischen Handelsvertrag)

63 Nebelspalter 1907/47, dessin pleine page de W. Lehmann-Schramm intitulé «Et elle vient pourtant! » (Und sie kommt doch einmal).

Nebelspalter 1908/32, couverture signée « LM » intitulée « Indignation justifiée » (Gerechte Empörung)

Nebelspalter 1905/30, dessin pleine page de Boscovits junior intitulé « L'homme adéquat pour négocier la paix russe »(Der rechte Mann als russischer Friedensunterhändler).

" Nebelspalter 1911/33, dessin pleine page en couleur signé « $A R$ » intitulé "Par cette chaleur » (Bei dieser Hitze); sur Félicien Rops: Hélène Védrine, De l'encre dans l'acide: l'œuvre gravé de Félicien Rops et la littérature de la décadence,
} Paris, H. Champion, 2002. 


\section{Seine Gefellichaft}

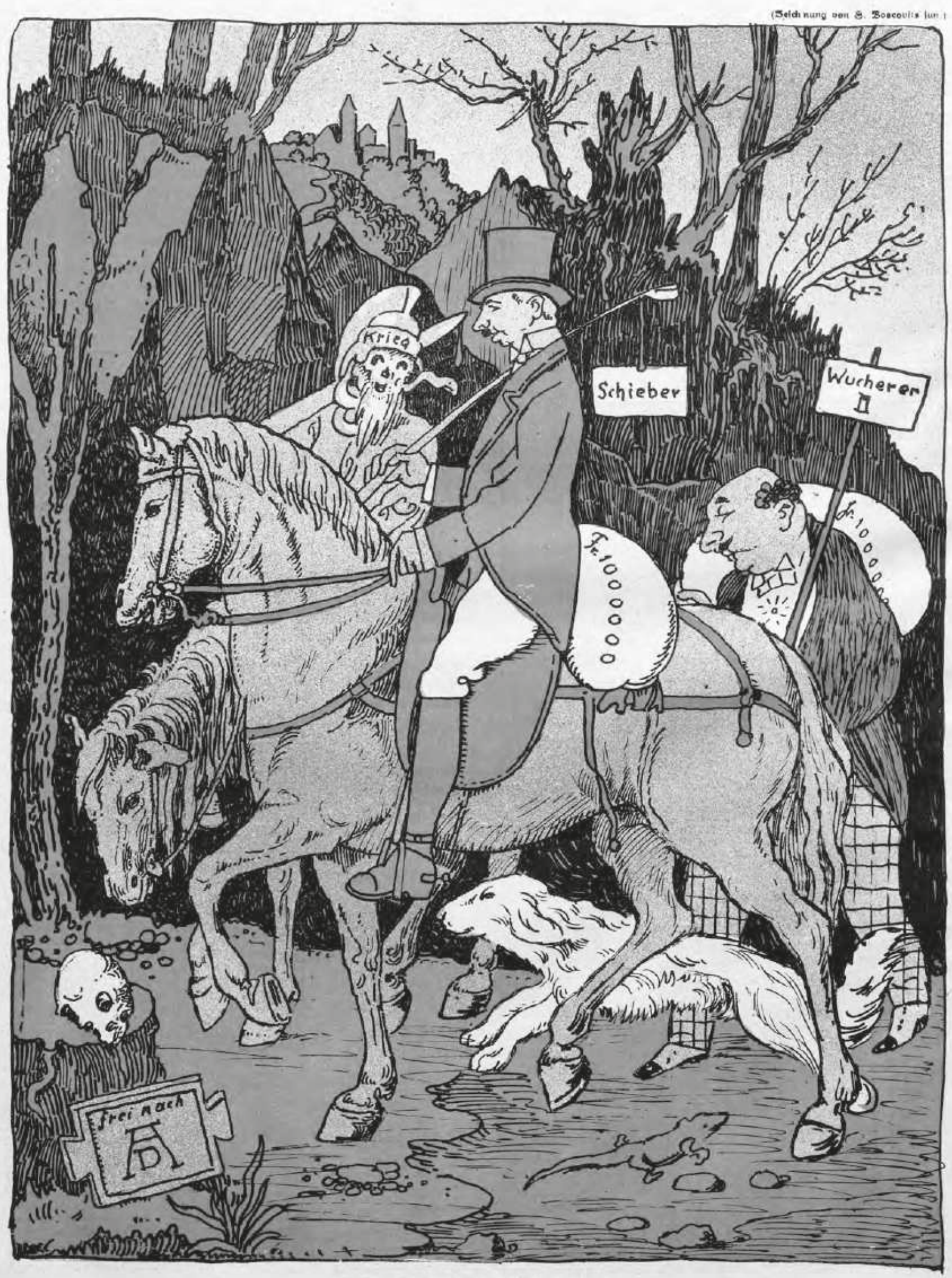

„Ritter, Iod und ฐeufel* (nach Darer).

Fig. 138. Nebelspalter 1918/35, dessin pleine page en couleur de Boscovits junior intitulé « Compagnie précieuse » (Feine Gesellschaft). 


\section{Bei dieser Fitze. -}

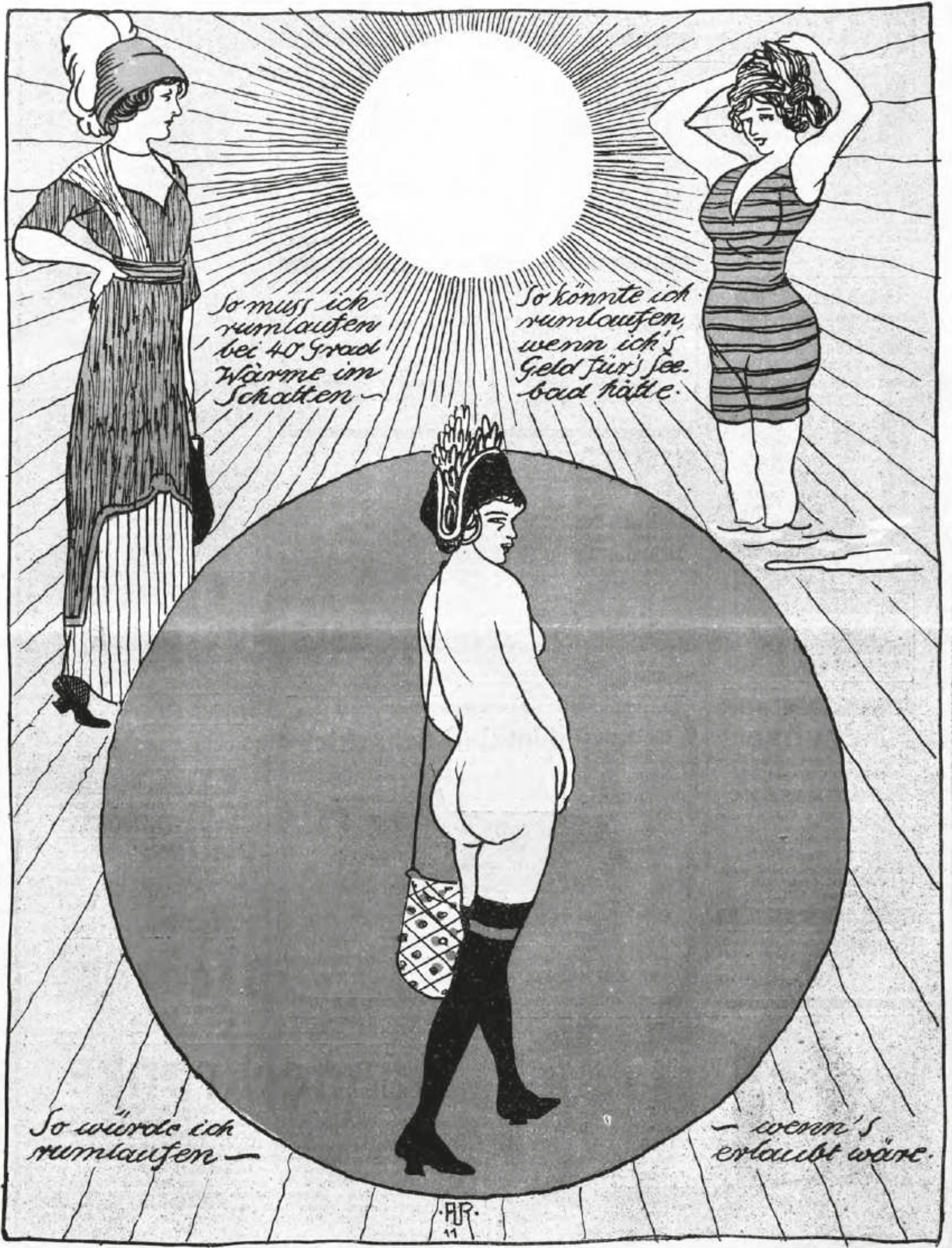

Fig. 139. Nebelspalter 1911/33, dessin pleine page en couleur signé «AR » intitulé « Par cette chaleur »(Bei dieser Hitze) 
20. 2, 41. Jahrgang.

Jürich, den 9. Januar 1915.

Einzelnummer $30 \mathrm{C} / \mathrm{s}$.

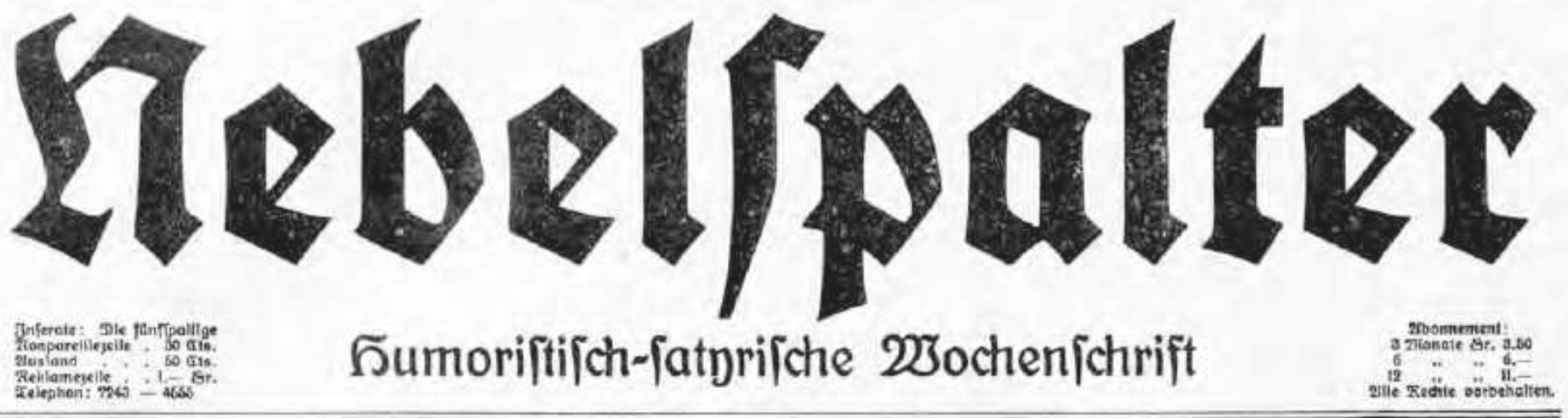

\section{Das Ringen der 23ölker}

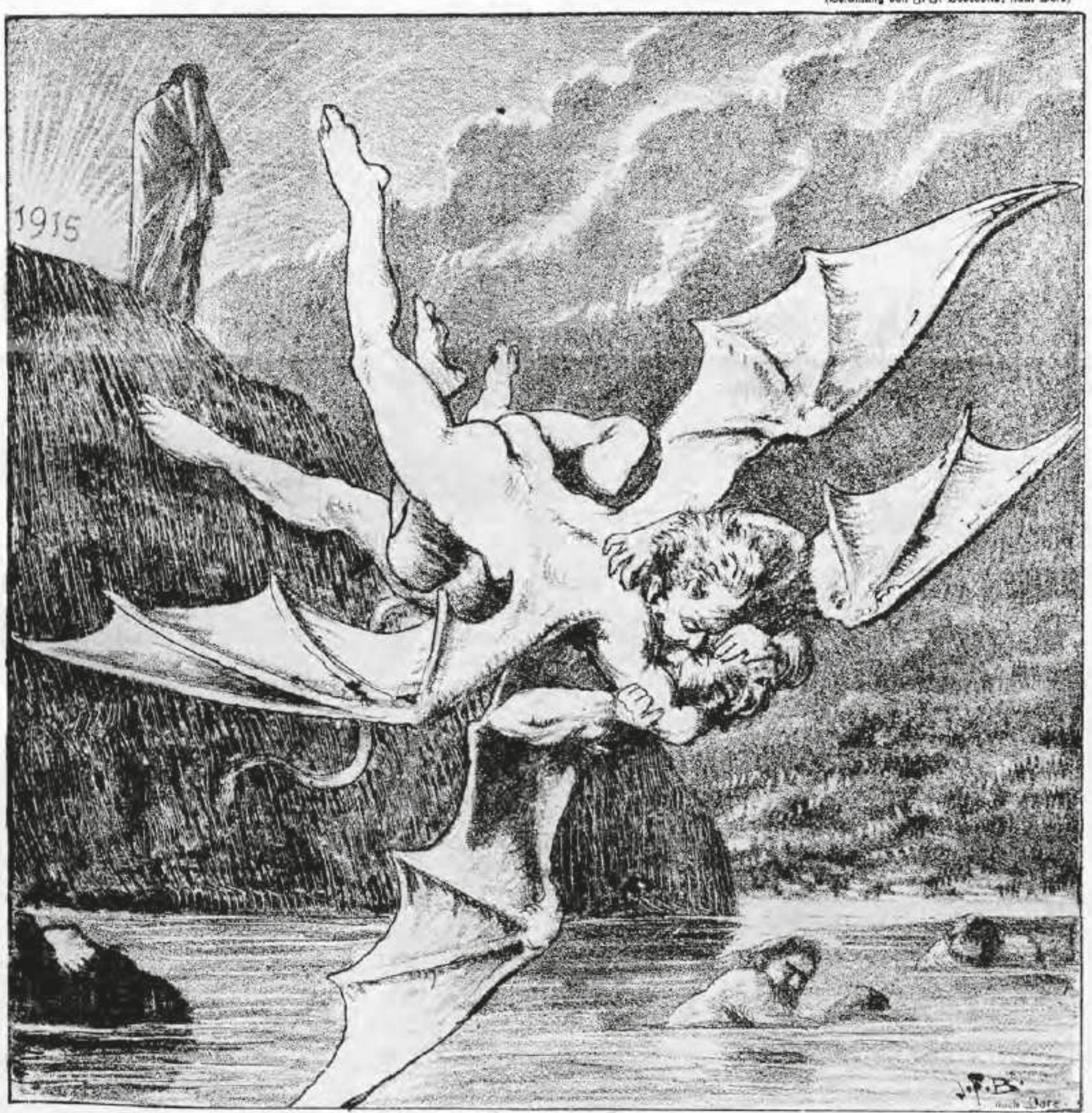

Fig. 140. Nebelspalter 1915/2, couverture en couleur de Boscovits senior intitulée « Le combat des peuples » (Der Ring der Völker). 
La plupart de ces citations possèdent une valeur positive, quand bien même l'œuvre-mère apparait très déformée. Leur sens doit être inversé et elles fonctionnent à rebours du message satirique. Il y a cependant quelques exceptions, où la citation est négative et s'aligne sur le propos satirique. La charge concerne alors autant le créateur de l'œuvre que le contenu manifeste de la caricature: tel est le cas de "La dernière sommation " (Das letzte Aufgebot) (I872) du peintre allemand Franz Deffreger (I835-I92I), représentant de l'école de Munich ayant tôt bénéficié d'une reconnaissance institutionnelle ${ }^{67}$. Sous le crayon féroce de Karl Czerpien, le tableau accroché aux murs d'un représentant du parti bavarois du Centre ne vaut pas davantage que l'ecclésiastique vertement critiqué ${ }^{68}$.

La Première Guerre mondiale est, enfin, une période où les citations se multiplient. Comme l'ensemble des artistes européens, les dessinateurs du Nebelspalter se trouvent devant la difficulté de représenter une guerre d'une dimension et d'une nature inédites ${ }^{69}$. Le recours aux citations constitue l'une des manières de contourner cette difficulté. La longue tradition des danses macabres, dérivées des gravures de Hans Holbein le jeune (I 497-I 543), est alors une source essentielle. En I9I 5, c'est cependant sur les illustrations de L'Enfer de Dante par Gustave Doré (I 832-I883) que s'appuie Boscovits senior pour dénoncer les luttes fratricides dans une couverture intitulée "Le combat des peuples »(Der Ring der Völker $)^{70}$ (cf. fig. I40).

Le premier inspirateur des dessinateurs est néanmoins Arnold Böcklin ${ }^{71}$.

\subsection{Le statut très particulier de Arnold Böcklin et Ferdinand Hodler}

Arnold Böcklin et Ferdinand Hodler peuvent se prévaloir à eux deux de plus de quarante citations.

Plus encore que d'autres revues germaniques, la munichoise Jugend ou la viennoise Ver Sacrum, le Nebelspalter met à l'honneur Arnold Böcklin. Selon le procédé usuel, les œuvres citées sont particulièrement connues et les citations répétées. L'œuvre avec laquelle Böcklin apparaît pour la première fois dans le Nebelspalter, "Dans le jeu des vagues » (Im Spiel der Wellen) (I 883 ), est ainsi citée à quatre reprises. Présentée l'année de sa création, en 1883 , au Salon de Berlin ${ }^{72}$, elle sert à ridiculiser, en I 888 , le véto de la police zurichoise à une rétrospective de l'œuvre de Böcklin pour atteinte aux bonnes mœurs. À la figure du centaure à l'arrière-plan de l'œuvre-mère, le dessinateur a substitué un policier brandissant un papier: "Interdit de se

« Deffreger, Franz von », Österreichisches Biographisches Lexikon 1815-1950, vol 1, Vienne, Verlag der Österreichischen Akademie der Wissenschaften, 1957, p. 74 Nebelspalter 1913/33, dessin pleine page en couleur de Karl Czerpien, intitule "Les bonnes mœurs en Bavière » (Die Sittlichkeit in Bayern).

Philippe Dagen, Le silence des peintres. Les artistes face la Grande Guerre, Paris, Fayard, 1996.

Nebelspalter 1915/2, couverture de Boscovits senior intitulée « Le combat des peuples » (Der Ring der Völker).

Cf. « 3.3.2. Rire en guerre » et « 3.3.3. Montrer la guerre et renoncer au rire ». Jules Laforgue (éd. par Mireille Dottin), Textes de critique d'art, Lille, Presses universitaires du Septentrion, 1988, p. 60-61 baigner sans vêtement!" (Verboten! Ohne Kleider zu baden!) ${ }^{73}$. Ce même tableau est ensuite cité trois fois, avec plus ou moins de fidélité envers la composition originale. Boscovits junior reprend la connotation morale de la première citation - sans doute de son père - dans deux caricatures. En I 899, un dessin humoristique sur les chaleurs de l'été, intitulé "Images brûlantes » (Hitz-Bilder), montre un spectateur transpirant à la vue du tableau indiqué «A. Böcklin » sur le haut du cadre ${ }^{74}$; en I 900 , le tableau soustitré « Le jeu de vagues de Böcklin » (Böcklin's Spiel der Wellen) est inclus, très déformé, dans un dessin à charge contre la très fameuse Lex Heinze, qui agite la société allemande ${ }^{75}$ (cf. fig. I4I).

En I908, l'association est différente: seule la structure d'ensemble est préservée, l'artiste précisant dans la signature « Bj libre d'après Böcklin " (BJ frei n. Böcklin). Il s'agit à présent d'illustrer les discussions franco-suisses sur la question frontalière. Le couple de la sirène et du centaure est ici tenu par un douanier français et Helvetia, reconnaissable aux croix de son vêtement:

Viens, mon enfant, mets donc ce bijou dans tes cheveux, crois-moi, il te va très bien! - Non, merci beaucoup! Loin de moi! Il est bien seyant, mais inconfortable ${ }^{76}$.

En I 897, un numéro spécial est consacré à Böcklin à l'occasion de ses soixante-dix ans. Toutes les pages sont des hommages au maître, jusqu'à une double-page en couleur de Boscovits junior intitulée "Retour sur l'œuvre de Böcklin » (Ein Rückblick Böcklin's) ${ }^{77}$. La composition agrège des citations de plusieurs œuvres, Le combat des centaures (Kentaurenkamf, I 872-73), Euterpe (I 872), Pan jouant de la Syrinx (Pan, die Syrinx blasend I 875) ainsi que, tout à fait à l'arrière-plan, l'œuvre phare de Böcklin, L'île des morts (Die Toteninsel, I880-I886) (cf. fig. I42 cahier couleur). Le très célèbre tableau aux cinq versions donne lieu dans le Nebelspalter à des recompositions diversement contextualisées, contribuant à la fortune de l'une des œuvres les plus copiées de l'aire germanique. En I 893, Boscovits senior glisse la référence dans "L'île des bienheureux » (Die Insel der Seligen), thématisant l'élection d'un conseiller fédéral ${ }^{78}$; en 1905 , le même Boscovits honore la mémoire du peintre allemand Adolf von Menzel (I8I 5-I905) fraîchement décédé, en le figurant sur une barque voguant à la rencontre de Böcklin ${ }^{79}$; en I91 8, l'œuvre est remaniée par Alfred Hirschler à des fins propagandistes ${ }^{80}$ (cf. fig. II 2). Quant au Combat des centaures, il illustre un référendum sur les tarifs douaniers en I903, avec toutefois l'ajout d'Helvetia et la transformation assez curieuse du paysage originel. Boscovits senior, qui signe son dessin «F. Boscovits libre d'après Böcklin » (F. Boscovits frei nach Böcklin) accorde, en effet, à celui-ci une note alpine ${ }^{81}$. Deux

\footnotetext{
Nebelspalter 1888/50, dessin en noir et blanc anonyme intitulé « Le jeu des vagues » (Das Spiel der Wellen).

Nebelspalter 1899/34, dessin pleine page en couleur de Boscovits junior intitulé " Images de chaleur » (Hitz-Bilder).

Nebelspalter 1900/11, dessin pleine page en noir et blanc de Boscovits junior intitulé « Lex Heinze ».

(Komm, Kind, nimm diesen Schmuck ins Haar, glaub'mir, er steht dir wunderbar! - Nein, merci beaucoup! Weg mit dem! Er ist zwar hübsch, doch unbequem!); Nebelspalter 1908/14, couverture en couleur de Boscovits junior intitulée "Pavillons suisses - Jeu de vagues » (Schweizerflaggen-Spiel der Wellen). Nebelspalter 1897/42, double-page en couleur de Boscovits junior intitulée « Retour sur l'œuvre de Böcklin » (Ein Rückblick Böcklin's).

Nebelspalter 1893/43, double-page en couleur de Boscovit senior intitulée "L'île des bienheureux » (Die Insel der Seligen).

Nebelspalter 1905/7, dessin pleine page en noir et blanc de Boscovits senior intitulé « L'île des morts (libre d'après Böcklin) » (Die Toteninsel [Frei nach Böcklin]).

Nebelspalter 1918/33, dessin pleine page en couleur de Alfred Hirschler, intitulé "L'ile des morts » (Die Toteninsel).

Nebelspalter 1903/8, double-page en couleur de Boscovits senior intitulé « La méchante épine " (Der böse Dorn).
} 


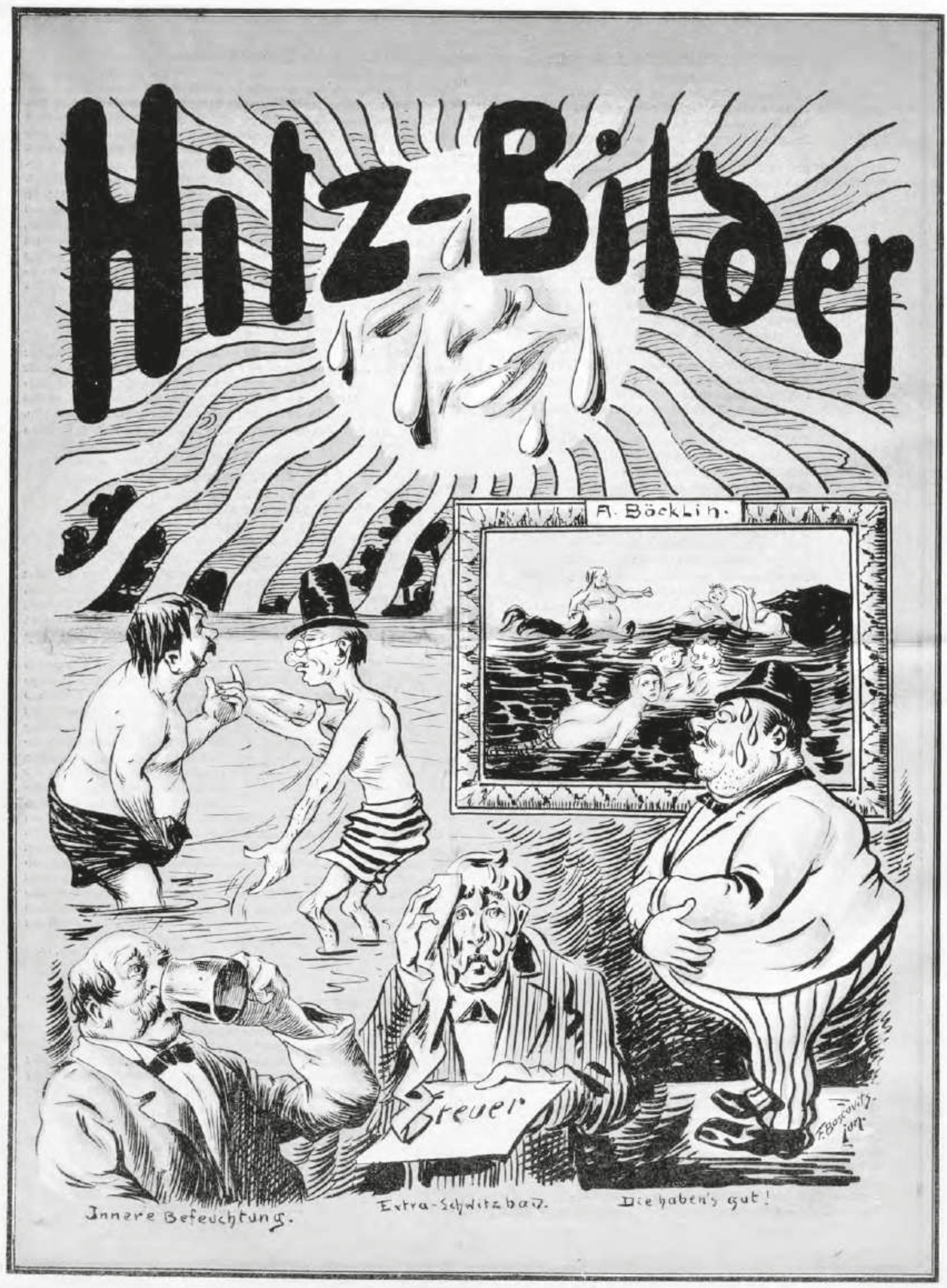

Fig. 141. Nebelspalter 1899/34, dessin pleine page en couleur de Boscovits junior intitulé « Images de chaleur » (Hitz-Bilder). 
autres œuvres de Böcklin dont la portée dramatique se prête à la charge satirique sont également l'objet de citations: La peste (Die Pest, I 898), en soutien à un plaidoyer pour l'art moderne, en $1904^{82}$, et La guerre (Der Krieg, I 896), qui permet de fournir une représentation du front, à l'automne I9I $4^{83}$, puis de dénoncer le danger communiste, en $1919^{84}$.

Ferdinand Hodler apparaît dans le Nebelspalter en I 897 avec l'affaire de la décoration de la salle d'armes du Musée national suisse de Zurich. Le dessin de Willy Lehmann-Schramm, « Reconnaissance sanglante "(Blutige Anerkennung) ${ }^{85}$ n'est pas, à proprement parler, une citation artistique mais la caricature d'un artiste à l'égard duquel le périodique montre une ambivalence continue $^{86}$. La concentration sur la personne de Hodler ne manque pas, du reste, de poser question sur une possible volonté de faire écran à l'œuvre, qui n'est thématisée que dans une petite moitié des compositions, toujours sur un mode dépréciatif, à l'exception d'un dessin postérieur à la mort de Hodler. Pour illustrer en I 920 la déception face au refus des autorités de dévaluer la monnaie, S. Mohr, collaborateur tardif du périodique, restitue de manière très fidèle "Les Âmes déçues » (I89I-92) dans une composition intitulée "Les déçus (libre d'après Hodler) " (Die Enttäuschten [frei nach Hodler]) ${ }^{87}$. En plein hodlérisme, une œuvre de la même veine, "Les las de vivre I » (vers I 892), avait pourtant été proprement dénaturée et les personnages, dotés d'une expression stupide, n'étaient reconnaissables qu'à leur posture et leur alignement ${ }^{88}$.

En plus de son caractère systématiquement dépréciatif, le corpus des citations hodlériennes se distingue par un nombre d'œuvres important ainsi que par sa continuité. Sont ainsi pastichés la Retraite de Marignan (I 896-I900) ${ }^{89}$, Guillaume Tell (I 897) ${ }^{90}$, Les Âmes déçues (I89I-92) ${ }^{91}$, Les las de vivre I (vers I 892) ${ }^{92}$, L'émotion II (I90I-I902)93, L'unanimité (I9I3) ${ }^{94}$, Le faucheur

Nebelspalter 1904/47, dessin pleine page signé «AB revid. » intitulé « Au sujet de l'exposition d'art de la fondation Gottfried Keller » (Zur Kunstausstellung der Gottfried Keller-Stiftung).

${ }_{3} \quad$ Nebelspalter 1914/37, dessin pleine page de Boscovits senior intitulé « Du théâtre des opérations occidental » (Vom westlichen Kriegsschauplatz).

${ }_{84}$ Nebelspalter 1919/51, dessin pleine page en noir et blanc de Boscovits junior intitulé «La dernière apparition de l'esprit du temps » (Die neueste ZeitgeistErscheinung).

${ }^{85}$ Nebelspalter1897/10, dessin de Willy Lehmann-Schramm intitulé « Reconnaissance sanglante » (Blutige Anerkennung).

Cf. « 4.4. Le couple Arnold Böcklin et Ferdinand Hodler ».

Nebelspalter 1920/16, dessin en couleur de S. Mohr intitulé « Les déçus (libre d'après Hodler) » (Die Enttäuschten [frei nach Hodler]); voir également Mattias Fischer, Ferdinand Hodler in Karikaturen und Satire - Par la caricature et la satire Sulgen, Benteli, 2012, p. 247.

\&8 Nebelspalter 1901/31, dessin pleine page de Boscovits junior intitulé « Le nouvelle hodlérisme » (Die neue Hodlerei).

${ }_{89}$ Nebelspalter 1898/49, double-page de Boscovits junior intitulée « Une issue. Les images de Hodler au Musée national » (Ein Ausweg. Die Hodlerbilder im Landesmuseum); Nebelspalter 1919/24, couverture de Ropaz intitulée " BerneParis. Au sujet de la réponse du Conseil fédéral » (Bern-Paris. Zur Antwort des Bundesrates); Nebelspalter 1919/37, couverture de Boscovits junior intitulée "L'hydre » (Die Hydra).

9o Nebelspalter 1897/39, dessin pleine page de Willy Lehmann-Schramm intitulé «Pas seulement grogner » (Nur nicht brummen); Nebelspalter 1907/48, dessin pleine page de Boscovits junior intitulé « Le "petit Tell" dans les nouvelles images de timbres » (Der " kleine Tell » in neuen Markenbildern); Nebelspalter 1913/5, dessin signé «WS » intitulé « Ferdinand Hodler, officier de la légion d'honneur » (Ferdinand Hodler, Offizier der französischen Ehrenlegion).

Nebelspalter 1920/16, dessin en couleur de S. Mohr intitulé « Les déçus (libre d'après Hodler) » (Die Enttäuschten [frei nach Hodler]).

Nebelspalter 1901/31, dessin pleine page de Boscovits junior intitulé « Le nouvelle hodlérisme » (Die neue Hodlerei).

Nebelspalter 1908/9, dessin signé « LM », intitulé « Hodler à Francfort » (Hodler in Frankfurt).

94 Nebelspalter 1913/17, composition de Wilfried Schweizer et Martin Salander intitulée « Programme de la fête du premier mai. Grève générale 1913 » (MaifeierProgramm. Generalstreik 1913); Nebelspalter 1914/17, dessin pleine page de De du verso du billet de 100 francs d'après Hodler ${ }^{95}$ ainsi que Le Bûcheron du billet de cinquante francs ${ }^{96}$, tous deux émis en I9I I. Un salon caricatural parodie, en outre, Le Printemps I ( I900-0I), Ce que disent les fleurs (I 893-94), La bataille de Näfels (I 896-97) et Paysage d'été (I903) ${ }^{97}$ (cf. fig. I25). Hodler est cité jusqu'à la fin de l'époque zurichoise et même au-delà. Un dessin préparatoire de Boscovits junior, postérieur à l'époque zurichoise, intitulé "Question stupides " (Blöde Fragen) ${ }^{98}$, rappelle furieusement le Tell de Willy Lehmann-Schramm de I 897. Un personnage gigantesque dans les tons mordorés y rugissait devant des spectateurs épouvantés, décrits (ironiquement) dans la légende comme « Le peuple enthousiasmé par le Guillaume Tell de Hodler » (Das begeisterte Volk von Hodler's " Guillaume Tell ») ${ }^{99}$. Le dessin attestait déjà de l'accession de Ferdinand Hodler au panthéon de l'art suisse, tandis que la puissance caricaturale de son œuvre ne cessera d'être confirmée au fil du temps, au travers justement de ce système de citations. À l'exception d'un dessin humoristique de $1907^{100}$, l'œuvre ne se détache que très tardivement de son créateur pour servir des thèmes étroitement liés à l'identité suisse: négociations internationales, monnaie ou référendum ${ }^{101}$.

\subsection{Transpositions médiales}

Le Nebelspalter s'assurant rapidement une place de choix dans le paysage artistique, ses images sont regardées avec attention, en particulier celles en couleur ou de grandes dimensions. Certaines sont, du reste, annoncées à l'avance via des encarts. Créées par des collaborateurs vedettes, elles thématisent des sujets " hors norme ", une exposition nationale, un personnage historique ou politique de premier plan - que l'on veut célébrer ou commémorer - ou représentent des synthèses de l'actualité politique internationale. La plupart du temps, le transfert médial est organisé à l'intérieur des éditions du Nebelspalter. Une illustration déjà existante est transposée sur un autre support et voit son usage modifié. Les images deviennent des portraits ou des affiches, susceptibles de servir à leur tour de modèles hors du champ de la presse illustrée. Reproduites dans des organes de presse étrangers, comme c'est le cas à plusieurs reprises au cours des premières décennies dans le Figaro parisien, le Secolo milanais ou encore dans les ouvrages sur la caricature de John Grand-Carteret ${ }^{102}$, elles touchent un autre public.

Bock intitulé « Le serment » (Der Schwur); Nebelspalter 1915/47, couverture de Karl Czerpien intitulée "Le lien suisse-romand».

Nebelspalter 1912/22, couverture de Boscovits senior intitulée « Aux foins » (Im Heuet).

Nebelspalter 1921/31, couverture non signée intitulée "Les initiatives [de référendum] ou le bûcheron » (Die Initiativen oder der Holzfäller).

Cf. " 4.3. Le salon caricatural du Nebelspalter ou la critique de la modernité ».

Dessin préparatoire non daté de Boscovits junior signé « Bosco » et intitulé "Questions stupides » (Blöder Fragen); archives de la famille Boscovits.

99 Nebelspalter $1897 / 39$, dessin pleine page de Willy Lehmann-Schramm intitulé "Pas seulement grogner » (Nur nicht brummen); sur la réception satirique de Hodler, voir également: Mattias Fischer, Ferdinand Hodler in Karikaturen und Satire - Par la caricature et la satire, op. cit.; sur ce dessin précis, p. 81.

${ }_{100}$ Nebelspalter $1907 / 48$, dessin pleine page de Boscovits junior intitulé «Le "petit Tell" dans les nouvelles images de timbres » (Der « kleine Tell » in neuen Markenbildern).

Nebelspalter 1919/24, couverture de Ropaz intitulée « Berne-Paris. Au sujet de la réponse du Conseil fédéral » (Bern-Paris. Zur Antwort des Bundesrates); Nebelspalter 1920/16, dessin en couleur de S. Mohr intitulé « Les déçus (libre d'après Hodler) » (Die Enttäuschten [frei nach Hodler]); Nebelspalter 1921/31, couverture non signée intitulée "Les initiatives [de référendum] ou le bûcheron » (Die Initiativen oder der Holzfäller).

Nebelspalter 1890/26, encart publicitaire. 


\section{(Clie's kommen kann fak}

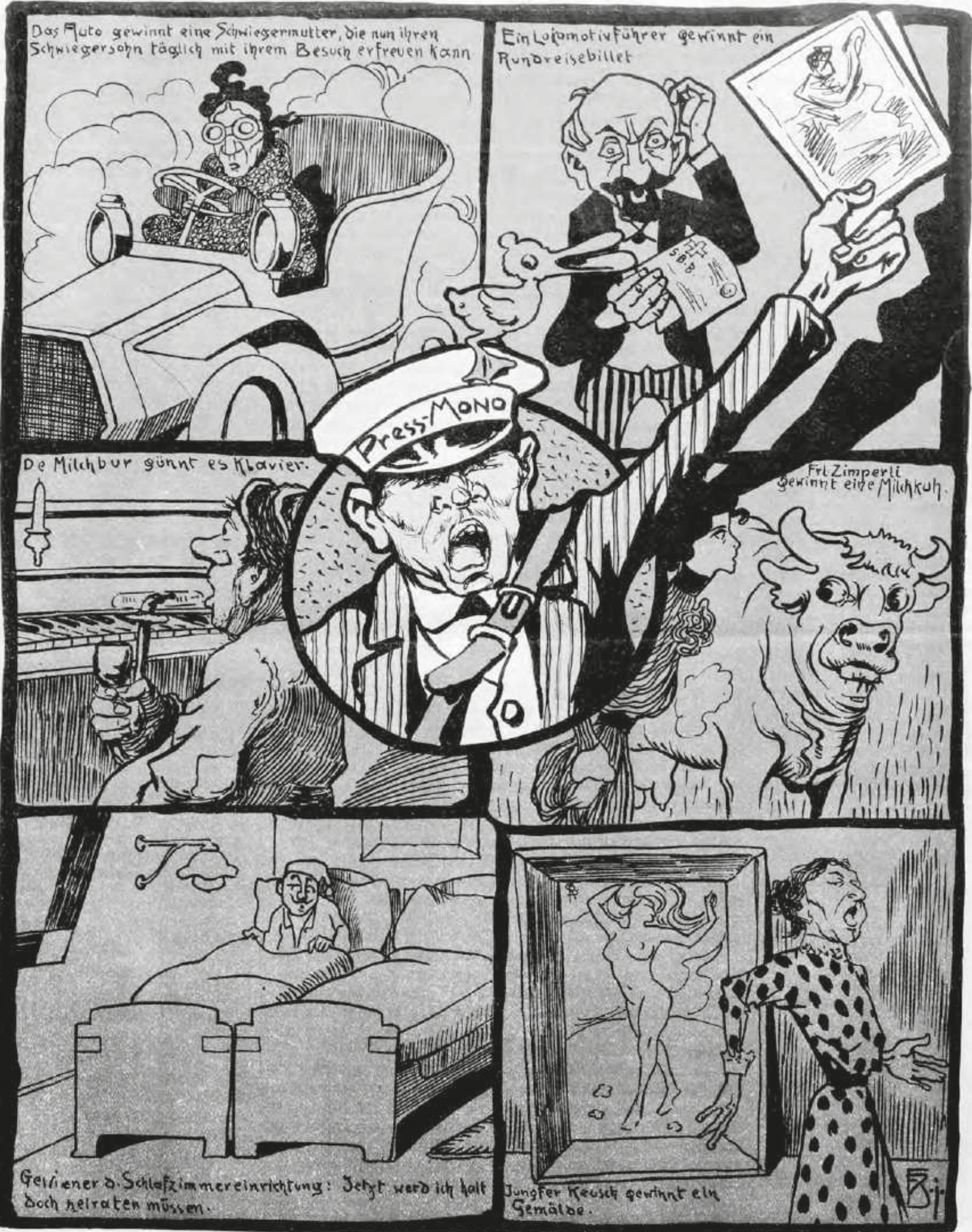

bei der Ziehung der $\tau_{\text {ombola-Gewinnste der "Schweizer-Presse. }}$

Fig. 143. Nebelspalter 1908/15, dessin pleine page en couleur de Boscovits junior intitulé « Comment ça peut venir » (Wiés kommen kann). 
En I 889, un portrait du poète Gottfried Keller ( I 8 I9-I 890), figure majeure de la culture helvétique ${ }^{103}$, est proposé à la vente. Publié quelque temps auparavant dans les pages du Nebelspalter, il est désormais vendu sous la forme d'une reproduction:

Gottfried Keller. La magnifique image en couleur de celui auquel nous avons rendu hommage et publiée dans notre dernier numéro peut être acquise - dans la limite des disponibilités - pour 50 cts. Expédition du Nebelspalter ${ }^{104}$.

La revue procède très régulièrement de cette manière et, en I 895 , un encart offre ainsi un choix d'images vendues à l'unité, à un prix variable, concernant, en vrac, le monument de Tell (par Kissling à Altdorf), un portrait du Dr. Heinrich Wettstein, le nouveau Palais fédéral, le général Herzog, les anciens conseillers fédéraux Wilhelm Herstentein et Antoine Ruchonnet ${ }^{105}$. En I9 I 5 , la reproduction du Général Wille sera même quasi-explicitement vendue en tant qu'affiche par Jean Frey, désormais éditeur et imprimeur de la revue. Un encart très verbeux compile alors des extraits louangeurs des fleurons de la presse locale, la Neue Zürcher Zeitung, le TagesAnzeiger, le Züricher Post et le Volksrecht, sur le dessin en couleur de Boscovits senior. On y vante le « portrait extraordinairement bon marché de Wille » ${ }^{106}$, accessible pour I,20 francs, puisque «quel est le Suisse ou la Suissesse qui ne souhaiterait l'avoir ? " 107 Quelques numéros plus loin, le portrait du Président de la Confédération, Gisuseppe Motta, vendu comme le "pendant parfait de celui de Wille " sous un format de $50 \times 32,5 \mathrm{~cm}^{108}$, confirme le commerce d'affiches. Il est, par ailleurs, amusant de reconnaître dans un dessin de Boscovits junior la figure du vendeur de journaux du carton d'invitation au concert donné dans le cadre du Congrès suisse de la presse de $1908^{109}$ (cf. fig. I37 et I43).

Enfin, le périodique cède parfois les droits des illustrations à d'autres éditeurs, comme pour «L'Europe actuelle " (Das Heutige Europa) de Boscovits senior, acquise en I 897 par l'éditeur zurichois Cäsar Schmidt pour la confection d'un calendrier ${ }^{110}$.

\subsection{Se citer soi-même plus que de}

\section{mesure}

Ceci étant, le premier modèle du Nebelspalter est, en fait, lui-même. Cette tendance, que l'on observe dans d'autres revues, à remployer un dessin, une trame narrative ou un schéma de composition est particulièrement prononcée dans le Nebespalter. On peut sans doute y voir, au même titre que le cadre au trait, le symptôme d'un fonctionnement frayant avec l'autarcie, ne pouvant être mis au seul compte d'une équipe restreinte. Bien sûr, les cas de remplois

\footnotetext{
${ }^{\circ 3}$ Ursula Amrein, "Keller, Gottfried », Dictionnaire historique de la Suisse (31/05/2012); http://www.hls-dhs-dss.ch/textes/f/F12024.php.

104 (Gottfried Keller. Das prachtvolle Farbenbild, welches von dem Gefeierten in unserer letzten Nummer erschienen ist, kann - so lange Vorrath - à 50 cts. bezogen werden. Expedition des « Nebelspalter »); Nebelspalter 1889/35, encart publicitaire.

Nebelspalter $1895 / 33$, encart publicitaire.

106 (" erstaunlich billige » Wille-Porträt); Nebelspalter 1915/9, encart publicitaire.

${ }^{\circ 7}$ (und welcher Schweizer und Schweizerin wollte das nicht?); ibid.

o8 (treffliches Pendant); ibid.

109 Nebelspalter 1908/15, dessin pleine page en couleur de Boscovits junior intitulé "Comment ça peut venir " (Wie's kommen kann).

${ }_{10}$ Cf. « 6.2. Intrigues suisses et influences françaises dans le monde éditorial : Jean Nötzli, John Grand-Carteret et Cäsar Schmidt ».
}

littéraux sont rares, et le cas de la publication de dessins quasiidentiques, comme ceux d'Emil Dill, publiés en I 892 à quelques semaines d'intervalles, constituent une exception. La première version est intitulée "Rêve d'un critique suisse " (Traum eines schweizerischen Kunstkritikers). Un homme replet, vêtu d'une longue robe, les mains dans le dos, attaché à un pilori, est en proie aux jets de projectiles d'un groupe d'hommes habillés en artistes ${ }^{111}$. Le pilori est, en fait, une plume; aux pieds de l'homme se trouve un tas de journaux, que l'un des hommes incendie. La seconde version est similaire à quelques détails près : l'orientation d'un pied, la couleur de la plume, quelques figurants et le monogramme de l'artiste. La partie textuelle est cependant différente. Le titre, "Le critique d'art suisse " (Der schweizerische Kunstkritiker), est placé en haut et non en bas de l'image, tandis que la légende - inexistante dans le premier dessin - met à présent en cause l'honnêteté du critique ${ }^{112}$. L'artiste a selon toute vraisemblance fournit deux esquisses et l'exemple confirme l'hypothèse d'une livraison de dessins bruts, dépourvus de titre et de légende.

À dire vrai, les apparitions récurrentes du personnage du Nebelspalter s'apparentent à cette logique de modèles, même si l'intention première est évidemment de donner une dimension allégorique au périodique. Cette composante est mise en évidence par la correspondance entre Henri van Muyden et Jean Nötzli. Dans son premier courrier à l'éditeur, en octobre I 889, l'artiste propose à Nötzli une double-page pour célébrer la nouvelle année, qu'il assortit d'une longue description:

De même je vous envoie un brouillon de grande page, que tenant à vous envoyer de suite, je vous communique tel quel. Ce serait les souhaits de bonne année du Nebelspalter. Le sujet représenterait le N. distribuant des numéros du journal etc. assis sur un volume ouvert également noté nebelspalter, avec les attributs encrier plume etc. ${ }^{113}$

Le «N. » fera ainsi au cours de sa longue carrière l'objet de contextualisations diverses et de nombreuses variations iconographiques, en matière de moustache, de costume, d'attributs ou de physionomie, sous le crayon de ses différents scénaristes.

Prince carnaval (Prinz Karneval) évolue selon les mêmes principes. Il va, du reste, progressivement se substituer au Nebelspalter, après une phase de syncrétisme où leurs traits tendent à se mélanger. Prince carnaval apparaît pour la première fois dans une composition anticléricale en I9 II ${ }^{114}$, revient courant I9I 3 pour s'immiscer dans le droit de vote des femmes ${ }^{115}$; puis, en I9I 5 , pour déplorer la guerre ${ }^{116}$. En I916, il surgit dans un coin de l'image pour interroger les belligérants sur leur but de guerre: il tient alors de sa main droite une plume et sous son bras gauche le journal, deux attributs du Nebelspalter ${ }^{117}$ (cf. fig. I44).

Nebelspalter 1892/27, dessin pleine page de Emil Dill intitulé « Rêve d'un critique suisse » (Traum eines schweizerischen Kunstkritikers).

Nebelspalter 1892/43, dessin pleine page de Emil Dill intitulé « Le critique d'art suisse » (Der schweizerische Kunstkritiker).

Cote 1.14 de la succession Nötzli, lettre du 10 octobre 1889.

Nebelspalter 1911/10, dessin pleine page en couleur non signé intitulé « Ça manquait encore » (Das fehlte noch!).

Nebelspalter 1913/12, couverture de Karl Czerpien intitulée « Le droit de vote pour les femmes » (Das Frauenstimmrecht).

Nebelspalter 1915/4, couverture de Boscovits junior intitulée «Prince carnaval, le renié » (Prinz Karneval, der Verleugnete).

Nebelspalter 1916/23, couverture en couleur de Karl Czerpien intitulée « Le but de guerre » (Das Kriegsziel) 
To. 23. 42. Jahrgang.

Särich, den 3. Juni 1916.

Einzelnummer 30 Ets.
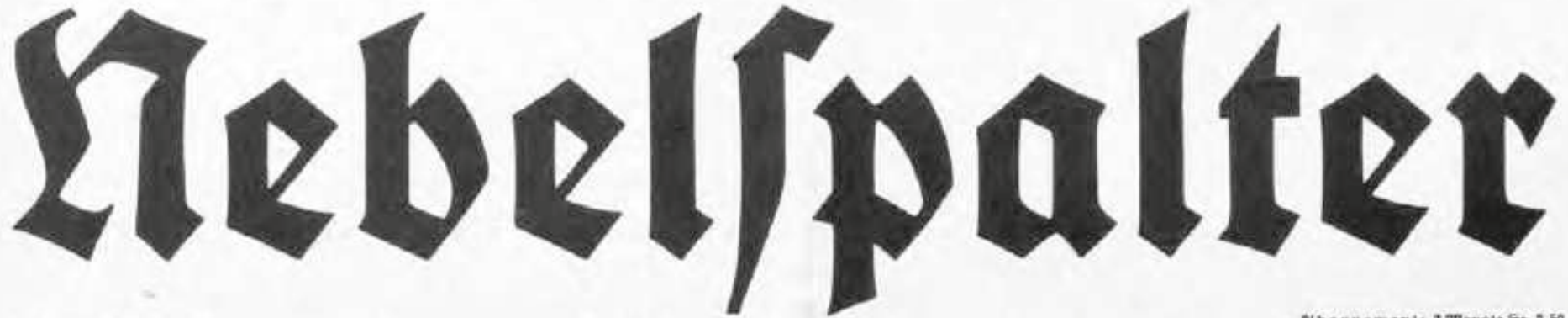

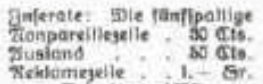

5umoriftifch-[atyrifche 23ochen[chrift

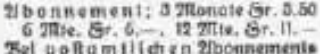

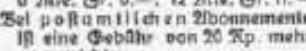

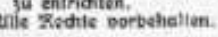

\section{Das Kriegsziel}

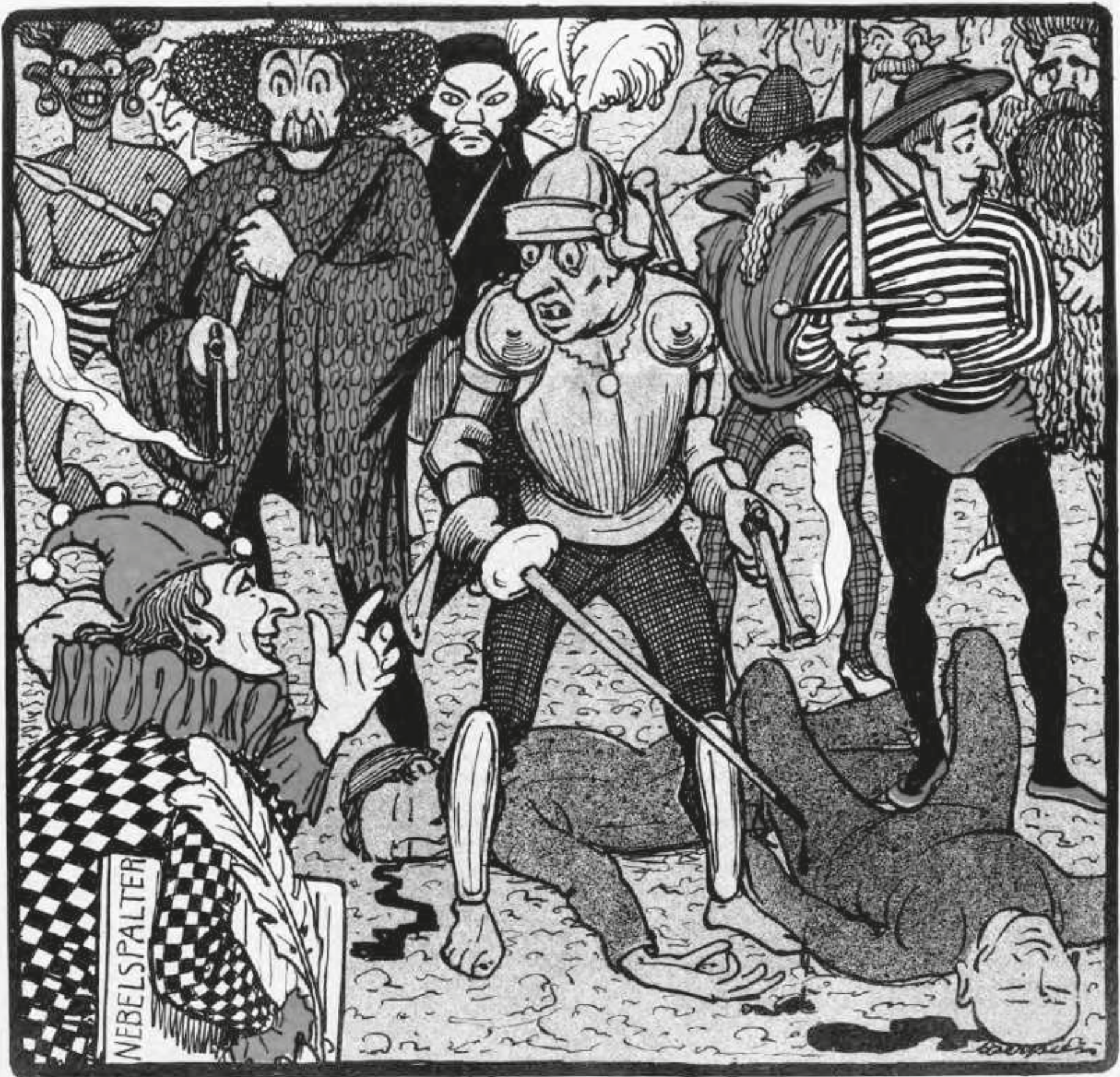

"WBas rooltt Shr denn?"

„.2Bir fuchen den Srieden!*. 
L'année suivante, en I9I7, il réintègre son rôle d'amuseur, à l'occasion de carnaval ${ }^{118}$, puis exhorte les belligérants à négocier la paix autour d'une table dans son costume de fête ${ }^{119}$. En I922, alors que la revue quitte Zurich pour Rorschach, où son nouveau patron, Ernst Löpfe-Benz, procède à un remaniement en profondeur, ce n'est plus le Nebelspalter qui occupe la couverture mais Prince carnaval, affairé à repriser la robe d'Helvetia (cf. fig. I45 cahier couleur):

Tout le monde s'emploie à te raccommoder / Et ce la plupart du temps avec force bêtise / Tout le monde pense alors à soi / Et bien trop peu à toi ${ }^{120}$.

Le statut de modèle interne vaut également pour les petits personnages des rubriques, en particulier les deux ecclésiastiques: Ladislaus et Stanislaus, Frau Stadrichter, Herr Feufi, Chueri et Nägeli. Les figures possèdent une épaisseur sémantique, qui se confirme après la disparition, en I 897 , du créateur des personnages de Stanilaus et Ladislaus, le Professeur Albrecht de Bienne ${ }^{121}$. Loin de disparaître avec lui, les figures lui survivent de longues années. Certaines images mettant en scène " la famille du Nebelspalter » montrent, par ailleurs, de fortes similarités. Quatre de ces images, composées à l'occasion de la nouvelle année, respectivement I 876, I 88 I, I 884 et I 892 , présentent ainsi un schéma de composition pyramidal, et ce malgré des créateurs différents: Boscovits senior et Emil Graf ${ }^{122}$.

Durant la période Jugendstil, les couvertures constituent un endroit privilégié pour l'exercice auto-citationnel. Il est fréquent qu'un artiste remploie, soit un motif, soit un schéma de composition qu'il avait auparavant créé. W. Lehmann-Schramm décline ainsi à trois reprises le motif - hautement Jugendstil - du chevalier et sa belle juchés sur un cheval, accompagnés ou non du dieu grec Pan, alors qu'une autre couverture focalise la seule figure de $\operatorname{Pan}^{123}$. Boscovits junior, champion de l'exercice, livre deux couvertures très ressemblantes à l'occasion de la Toussaint, en I90I et I904, avec le même visage diaphane d'une jeune fille à la longue chevelure et aux yeux baissés, dans le premier cas vers les victimes du Transvaal (cf. fig. I46 cahier couleur) et dans le second vers celles de la guerre sino-japonaise (cf. fig. I3 I $)^{124}$. La figure féminine servira plus tard d'allégorie des mois de décembre I 90 I et I $902^{125}$. Plus surprenant, cependant, est de constater un même schéma de composition pour deux couvertures de l'année I903, pourtant à première vue fort différentes: l'une célèbre le vin nouveau, l'autre la chasse. Alors que les couleurs, le costume

"18 Nebelspalter 1917/8, couverture de Boscovits senior intitulée « Le Prince carnaval inutile » (Der überflüssige Prinz Karneval).

Nebelspalter 1917/42, dessin pleine page en couleur de Boscovits junior intitulé "Procédé simplifié » (Vereinfachtes Verfahren).

${ }_{120}$ (Jeder flickt an Dir herum / Und dies meistens schrecklich dumm / Jeder denkt dabei an sich / Viel zu wenig auch an Dich); Nebelspalter 1922/1, couverture en couleur de Ernst Morgenthaler intitulée « La robe » (Das Kleid).

Nebelspalter 1897/14, encart nécrologique.

122 Nebelspalter 1876/1, dessin pleine page non signé intitulé « À l'année 1876! » (Prosit 1876); Nebelspalter 1881/52, dessin pleine page d'Emil Graf intitulé « À la nouvelle année! » (Prosit Neujahr); Nebelspalter 1884/1, dessin pleine page de Boscovits senior intitulé "À la nouvelle année! Le Nebelspalter et sa famille » (Prosit Neujahr Nebelspalter und Familie); Nebelspalter 1892/1, double-page de Boscovits senior intitulée « 1892 ».

${ }_{23}$ Nebelspalter 1897/31, couverture de W. Lehmann-Schramm; Nebelspalter 1899/12, couverture de W. Lehmann-Schramm; Nebelspalter 1899/26, couverture de W. Lehmann-Schramm; Nebelspalter 1901/22, couverture de W. LehmannSchramm.

124 Nebelspalter 1901/44, couverture de Boscovits junior; Nebelspalter 1904/44, couverture de Boscovits junior.

${ }_{125}$ Nebelspalter 1901/49, couverture de Boscovits junior; Nebelspalter 1902/50, couverture de Boscovits junior. et le paysage sont adaptés au propos, la forme de la figure et sa gestuelle, ainsi que la structuration du paysage sont identiques ${ }^{126}$.

La reprise conjointe d'un schéma de composition et d'une légende est, en revanche, exceptionnelle. C'est pourtant ce que fait Boscovits senior en I9I 2, lorsqu'il se portraiture en compagnie de son successeur à la tête du Nebelspalter, Rudolf Huber ${ }^{127}$. Boscovits puise alors dans une couverture légendée, qu'il avait créée en I 908 à l'occasion du retrait de la vie politique du Conseiller fédéral Joseph Zemp (I834-I908) et de sa passation de siège à Josef Anton Schobinger (I 849-I9 I I) ${ }^{128}$ (cf. fig. 2).

Le cas le plus frappant de cette circulation interne de modèles concerne l'iconographie de guerre. S'il est bien sûr des créations originales ou des références exogènes, une part importante de l'iconographie consiste en la reformulation d'une iconographie développée à l'occasion de conflits plus anciens: la guerre russoturque de I877-I878, la guerre sino-japonaise de I894-I895, l'expédition française à Madagascar en I 895, la crise de Fachoda opposant Français et Britanniques en I 898, les événements du Transvaal à la fin des années I 890, la seconde guerre des Boers de I 899 à I902, le soulèvement des Macédoniens en I900, les troubles au Maroc en I902, la guerre russo-japonaise de I904 et I 905 , les crises marocaines de I905 et I9I I, la guerre italoturque de I9I I, ainsi que les guerres balkaniques de I9I2-I9I3. Cette iconographie se nourrit également des représentations des calamités, comme l'épidémie de choléra en I 892, et des violences d'État, tels les pogroms russes de I891 puis de I903 (Kischivew), les exactions du régime tsariste, celles du régime ottoman et la répression de la révolte populaire par la monarchie espagnole en 1909 .

La guerre russo-turque de I 877-I 878 donne ainsi lieu à une bagarre entre deux soldats au bord d'un précipice ${ }^{129}$, dont le schéma tragico-comique est repris trente ans plus tard, en I9I7, par Karl Czerpien ${ }^{130}$. L'épidémie de choléra de I 892 fournit, quant à elle, la première danse macabre ${ }^{131}$, l'un des motifs les plus déclinés durant le premier conflit mondial. L'essentiel de cette iconographie s'est néanmoins formé en lien avec les massacres au Transvaal, la seconde guerre des Boers, la guerre russo-japonaise et les violences du régime tsariste. Une iconographie du champ de bataille avec son lot de cadavres, de ruines, de paysages désolés, de memento mori ${ }^{132}$ (cf. fig. IoI) et de danses macabres s'installe, qui sera reprise quasi-inchangée durant la Première Guerre mondiale (cf. fig. I47).

Enfin, la rhétorique de la culture et de la civilisation, constamment présente durant la Première Guerre mondiale, apparait dans le Nebelspalter autour de I880, respectivement en lien avec le

\footnotetext{
${ }_{126}$ Nebelspalter 1903/44, couverture de Boscovits junior; Nebelspalter 1903/48, couverture de Boscovits junior.

${ }_{27}$ (Freund, hier hast Du meinen Speer, meinem Arm wird er zu schwer); Nebelspalter 1912/48, dessin pleine page de Boscovits senior intitulé « Adieu » (Zum Abschied); cf. aussi « 1.2. Décryptage de la fondation et de la vie éditoriale : focus sur Boscovits senior $»$.

${ }_{128}$ Nebelspalter 1908/25, couverture de Boscovits senior intitulée « Le retrait de B. R. Zemp » (B.-R Zemp's Rücktritt).

29 Nebelspalter 1877/35, dessin en noir et blanc de Boscovits senior intitulé "À Schipkapass » (Am Schipkapass).

30 Nebelspalter 1917/7, dessin pleine page de Karl Czerpien intitulé « Trop tard » (Zu spät).

Nebelspalter 1892/37, dessin pleine page de Henri van Muyden intitulé « À propos de la situation » (Zur Situation).

${ }_{132}$ Nebelspalter 1905/32, dessin pleine page de Willy Lehmann-Schramm intitulé « C'est fait » (Es ist erreicht!); Nebelspalter 1915/34, dessin pleine page de Karl Czerpien, intitulé « La cour faite aux neutres » (Das Werben um die Neutralen).
} 


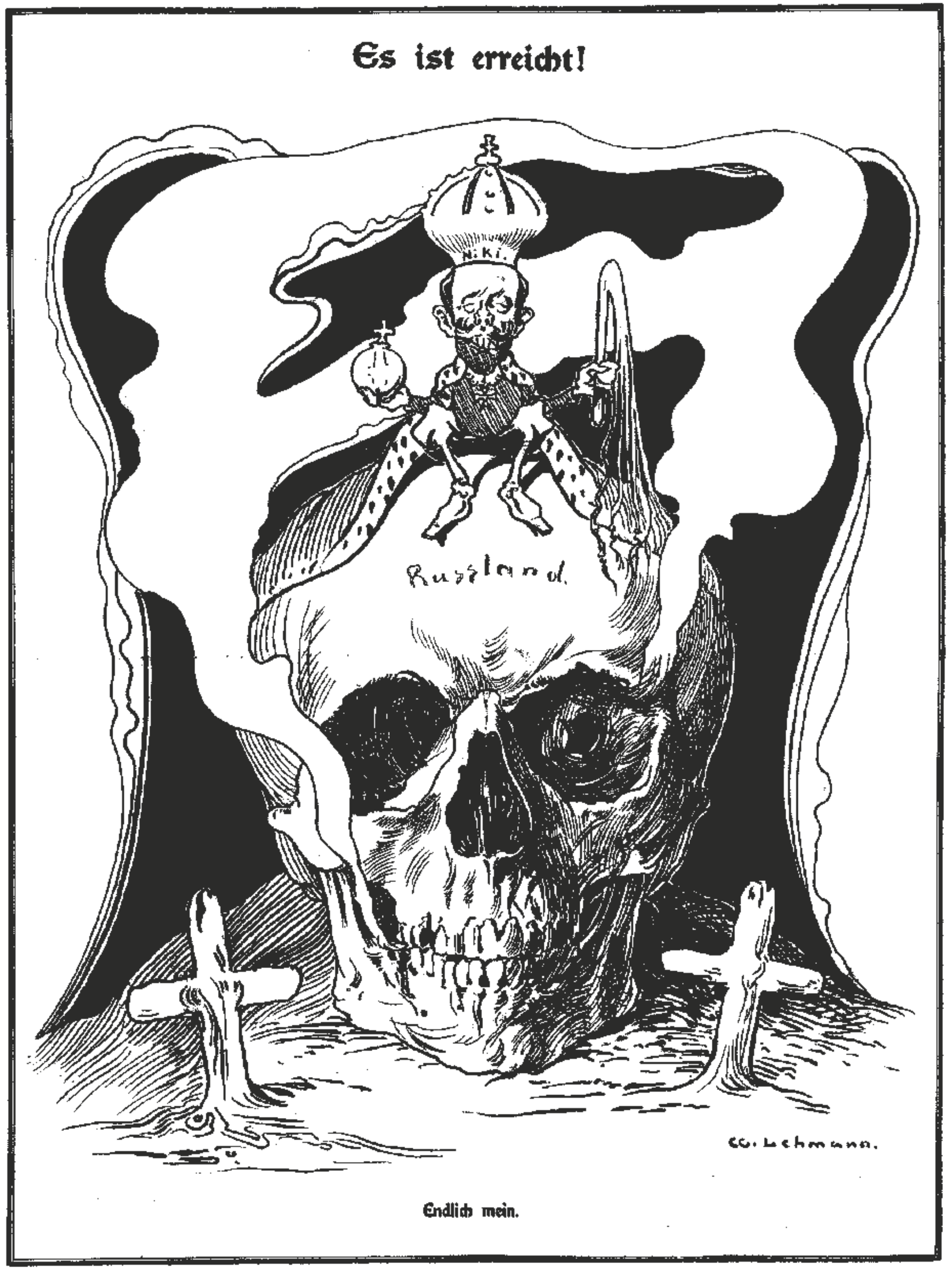

Fig. 147. Nebelspalter 1905/32, dessin pleine page en noir et blanc de Willy Lehmann-Schramm intitulé « C'est fait » (Es ist erreicht !). 
canal de Suez (pour la culture) et la question d'Orient (pour la civilisation) ${ }^{133}$. Elle n'est évidemment pas l'apanage du Nebelspalter. À l'occasion du massacre de Port Arthur, le major allemand Curt von François, figuré entre deux crânes, est ensuite désigné comme un pionnier de la culture (Kultur-Pionnier $)^{134}$. En I9 I2, ce sera au tour de la civilisation de faire un retour en force, en relation avec la première guerre balkanique. Une composition intitulée "Au temps de la civilisation " (Im Zeitalter der Zivilisation) montre ainsi la grande faucheuse à l'œuvre ${ }^{135}$.

Ces transferts culturels et artistiques courront jusqu'après la guerre, où l'on requerra d'autres modèles, comme la roue du supplice, introduite en I 882 à l'occasion d'un référendum sur l'école, pour dénoncer le traité de Versailles ${ }^{136}$.
133 Cf. « 2.2.4. Un langage visuel et rhétorique très typé ».

${ }_{134}$ Nebelspalter 1904/31, dessin pleine page de Boscovits junior intitulé « Un pionnier de la culture au travail » (Ein Kultur-Pionier an der Arbeit).
135 Nebelspalter 1912/46, dessin pleine page en couleur de Boscovits junior intitulé "Au temps de la civilisation » (Im Zeitalter der Zivilisation); sur le détail de cette iconographie de guerre et la question des reprises, cf. « 3.3. La Première Guerre mondiale : la « drôle » de guerre d'un périodique ».

136 Nebelspalter 1882/35, dessin pleine page de Boscovits senior intitulé «Le référendum » (Das Referendum); Nebelspalter 1919/6, couverture de Alfred Hirschler intitulée " Indemnités de guerre » (Kriegsentschädigung); Nebelspalter 1921/6, dessin pleine page non signé intitulé « La conférence de Paris » (Pariser Konferenz). 


\section{DES AFFAIRES DE RÉSEAUX}

Qui dit modèles, dit aussi réseaux, puisque les modèles empruntent des canaux de circulation qui s'entrecroisent, après avoir fréquemment convergé autour d'un lieu de publication qui n'est pas nécessairement une revue. Ceci est évident lorsqu'il s'agit de modèles issus du "grand art », dont l'accès peut être très différent: ateliers, expositions, galeries d'art, affiches ou reproductions; ces dernières circulant, du reste, également via des revues qui entendent faire œuvre de pédagogie auprès de leur public ${ }^{1}$. Mais cette dispersion des canaux de circulation est moins attendue pour des images de revues qui peuvent transiter par des vecteurs insolites, tels des cahiers confectionnés par des artistes ou des collectionneurs, compilant des dessins ${ }^{2}$. Ces images de revues voyagent, en outre, via des réseaux internationaux aux ramifications multiples ${ }^{3}$, du cercle de lecture au café, dont la cartographie est délicate à établir ${ }^{4}$. La difficulté s'accroit lorsque les dessins ont été transposés à d'autres médiums - calendriers, affiches, cartes postales - comme c'est fréquemment le cas à partir des années I 890, alors que s'impose une politique commerciale agressive, nécessaire à la survie des titres dans un univers hautement concurrentiel. Telle est la configuration où se tisse le cas tout à fait singulier de "L'Europe actuelle» (Das heutige Europa) de Johann Fritz Boscovits (Boscovits senior). Derrière ces canaux de circulation, se trouvent des hommes, et la part des passions n'est pas moins grande que celle de l'art - c'est une litote. Ce qui se joue dans les réseaux relève, en fait, moins de la part créative de l'activité artistique que de la part sociale, économique, symbolique et politique. Ce sont de véritables affaires qui ont pu être reconstituées grâce aux archives, d'enjeux éditoriaux et pécuniaires, de fidélité artistique et politique, d'ambition et de création. Celles-ci engagent invariablement l'éditeur du Nebelspalter autour duquel s'organise un Network extrêmement complexe. Elles ont en commun d'avoir un dénouement inattendu et une fin incertaine. Enfin, comme toujours avec les réseaux, il y est question d'argent, d'honneur, de pouvoir et de manipulation ${ }^{5}$.

\footnotetext{
Voir par exemple pour la revue Jugend: Laurence Danguy, L'ange de la jeunesse - La revue Jugend et le Jugendstil à Munich, Paris, Maison des sciences de I'homme, 2009, p. 89-90.

De tels cahiers compilant des illustrations du Nebelspalter ainsi que celles d'autres revues germaniques ont été retrouvés et sont de temps à autre mis en vente.

Ils sont de ces « réseaux transnationaux » dont Alain Clavien supposait l'existence en conclusion d'un article dressant un état des lieux des relations entre les revues suisses (surtout romandes et littéraires) avec la France; Alain Clavien, "Les revues suisses et la France: Paris si loin, trop proche », dans La Belle Époque des revues 1880-1914, éd. Jacqueline Pluet-Despatin, Michel Leymarie et JeanYves Mollier, Paris, Imec, 2002, p. 335-345

Sur ce point: Laurence Danguy, Vanja Strukelj, Francesca Zanella, «Circulations de modèles entre l'aire germanique et l'Italie au début du xxe siècle: ouvrir un champ de recherches ", dans L'Europe des Revues (1860-1930) II - Réseaux et circulations des modèles, éd. Evanghelia Stead et Hélène Védrine, Paris, Presse Universitaire de Paris-Sorbonne, 2018, p. 145-164; sur la question des fonds et bibliothèques locaux: Vanja Strukelj (éd.), Trieste Semiseria. Parodia, umorismo, satira nella cultura figurativa triestina tra Otto et primo Novecento, Trieste, Museo Revoltella, 2015

Voir sur les réseaux dans le monde des revues: Thomas Loué, « La revue », dans La civilisation du journal. Histoire culturelle et littéraire de la presse française au
}

\subsection{La leçon des archives Nötzli : un éditeur et ses réseaux}

Le 27 juin 2009, la Zentralbibliothek de Zurich fait l'acquisition de la succession Nötzli lors d'une vente aux enchères organisée par la très respectable maison zurichoise Falk-Falk, spécialisée dans les manuscrits suisses et rhéto-romans, l'histoire napoléonienne et, d'une manière générale, les ouvrages bibliophiliques et graphiques anciens ${ }^{6}$. Ces renseignements nous sont livrés par la liste des lots portés à la vente, éditée à l'usage des acquéreurs potentiels. Ce document, assez peu soigné mais fort intéressant, est versé à la succession Nötzli, une fois le référencement effectué par la Zentralbibliothek à l'automne 201 $2^{7}$. Deux lots en relation avec Jean Nötzli, numérotés 583 et 585 , y sont listés: le premier au prix de 200 Fr., le second à celui plus élevé de I 800 Fr. - néanmoins très abordable pour une institution helvétique. Le premier lot (583) comprend un numéro spécial, édité à l'occasion de la mort de Jean Nötzli ${ }^{8}$, le second ( 585 ) est ainsi présenté:

LETTRES. - Nötzli, J., Liasse de centaines de travaux écrits (surtout de la poésie festive), arrêts municipaux, décisions fiscales, jugements et lettres manuscrites à Jean Nötzli et son Nebelspalter, avec des commentaires positifs et négatifs. Dans I 5 enveloppes jaunes de grand format $\mathrm{A}_{5}$ de l'époque, triées et avec l'inscription manuscrite originale. Parmi les correspondants, il ne se trouve pas uniquement des personnalités de la Suisse, tels que des conseillers fédéraux et des conseillers d'État, des hommes politiques, des artistes, des rédacteurs d'autres journaux mais également des échanges intéressants avec des journaux européens et des rédacteurs ${ }^{9}$.

Le texte est accompagné d'un commentaire en italique:

$x x^{e}$ siècle, éd. Dominique Kalifa, Philippe Régnier, Marie-Ève Thérenty et Alain Vaillant, Paris, Nouveau Monde, 2011, p. 348-352; Evanghelia Stead et Hélène Védrine (éd.), L'Europe des Revues (1860-1930) II - Réseaux et circulations des modèles, op. cit.

Selon le descriptif de la page d'entrée de la liste des pièces mises aux enchères liste de vente de la maison Falk-Falk; succession Nötzli.

Information recueillie auprès du département des manuscrits (Handschriften) où est conservée la succession Nötzli.

Cf. Laurence Danguy, « Jean Nötzli, un éditeur zurichois et ses réseaux à la fin du XIXe siècle ", éd. Christiane Demeleunaere-Douyère, Les acteurs $d u$ développement des réseaux, Paris, CTHS, p. 65-77.

" BRIEFE. Nötzli J., Konvolut von Hunderten von gedruckten Arbeiten (vor allem Festpoesie), Gemeinde- und Steuerentscheide, Urteile und handschriftliche Briefe, an Jean NÖTZLI und seine NEBELSPALTER, mit positiven und negativen Kommentaren. In 15 sortieren, grösseren, gelben A5 Kuverts der Zeit mit der Originalbeschriftung. Unter den Absendern befinden sich nicht nur hochgestellte Persönlichkeiten der Schweiz wie Bundes- und Regierungsräte, Politiker, Kulturschaffende, Redakteure anderer Zeitungen, sondern enthalten sind auch interessante Briefwechsel mit europäischen Zeitungen und Redakteuren. »; liste de vente de la maison Falk-Falk; succession Nötzli. 
-- Font également partie de la succession épistolaire de NÖTZLI deux cahiers comportant des registres et en partie des transcriptions d'après original. Seuls quelques-uns des correspondants les plus connus seront ici nommés: J.C. HEER, Prof. JENNY, Frank BUCHSER, J.V. WIDMANN, Evert van MUYDEN, U. WILLE, GRAND CARTERET (du Figaro et auteur de livres d'histoire célèbres), Josef KÜRSCHNER (de Fels von Meer, éditeur d'ouvrages littéraires renommés) et d'autres. Cette collection est un document de la première heure, unique pour l'un des journaux satiriques les plus connus de la Suisse, le Nebelspalter, dont le fondateur et rédacteur en chef a été pendant 25 ans NÖTZLI. - Il est extrêmement rare qu'une collection de lettres et documents provenant d'un fondateur de journaux et d'un contenu aussi riche parvienne sur le marché ${ }^{10}$.

Si le lot est effectivement extraordinaire dans l'histoire, somme toute encore récente, des revues illustrées, l'examen des archives laisse rapidement apparaître que la succession est loin d'être dans son état original. Ainsi, les enveloppes dans lesquelles ont été rangés les documents comportent quatre écritures différentes, ce qui exclut que les commentaires soient tous d'origine. Certaines enveloppes sont vides, quoique annotées. Quid de leur contenu ? Le fonds ne comprend que de très rares documents personnels, ni photographies ni actes juridiques ou correspondance familiale. Une partie n'est pas constituée d'originaux mais a été recopiée; parmi celle-ci, deux cahiers, bien que pourvus de cotes $(2.62$ et 2.63), n'apparaissent pas dans l'inventaire officiel. Dans l'un de ces cahiers est recopiée la correspondance entre Jean Nötzli et Franck Buchser; l'autre est un inventaire inachevé des pièces de la succession. Ces dissonances mettent en évidence que la succession a déjà été dépouillée et très probablement expurgée d'un certain nombre de documents. Le fonds Nötzli doit être considéré comme une succession incomplète et, de ce fait, orientée dans une mesure et des conditions difficiles à reconstituer. Il est également manifeste que la censure ne s'est guère exercée sur les affaires éloignées, et de la famille et de Zurich. Les documents en langue étrangère, français ou italien, sont ainsi intacts. Une distance critique s'impose devant ce cas typique de contrôle mémoriel. Si le corpus de données référentielles existe bien en tant que tel, il ne conduit pas pour autant à des réseaux tout à fait complets et sincères ${ }^{11}$.

Le fonds Nötzli compte Io I références, ordonnées selon trois cotes principales, ne répondant à aucune logique évidente, si ce n'est la matérialité des cartons dans lesquels sont rangés les documents. Beaucoup de ces documents sont d'un déchiffrage extrêmement difficile, soit du fait d'une calligraphie compliquée, soit parce que l'encre est très jaunie. On a tenté de séparer les pièces relevant de la sphère privée (carton 3 ) de celles liées à l'activité professionnelle de Jean Nötzli (cartons I et 2), non sans une certaine confusion. La nature des pièces, leur date et leur localisation ainsi que, dans le cas d'une correspondance, l'identité du correspondant, ont été

\footnotetext{
« Zu diesem Briefnachlass NÖTZLI'S gehören auch 2 Hefte mit Regesten und zum Teil Umschriften; Nur einigen der bekanntesten Absender seien hier genannt wie J.C HERR, Prof. JENNY, Frank BUCHSER, J.V. WIDMANN, Evert van MUYDEN, U. WILLE, GRAND CARTERET (Von Le Figaro und Autor berühmter Kulturgeschichten), Josef KÜRSCHNER (von Fels zum Meer, Verfasser bekannter Literaturgeschichten) u.v.a. Diese Sammlung ist ein einmaliges frühes Dokument für eine der bekanntesten satirischen Zeitung der Schweiz, des NEBELSPALTERS, deren Gründer und Leiter NÖTZLI während der ersten 25 Jahre war. - Extrem selten, dass eine so in sich aussagekräftige Sammlung von Briefen und Dokumenten eines Zeitungsgründers auf dem Markt kommt. » ; liste de vente de la maison Falk-Falk; succession Nötzli ; les fautes d'orthographe sont conformes à l'original.

Cf. pour le détail : Laurence Danguy, « Jean Nötzli, un éditeur zurichois et ses
} réseaux à la fin du XIX ${ }^{e}$ siècle », op. cit. précisées lors du catalogage. Les documents se répartissent, en fait, en une correspondance d'affaires, comprenant les seules lettres des correspondants de Nötzli; une correspondance privée, également avec les seules lettres des correspondants; des documents comptables, des actes juridiques et des pièces officielles; des esquisses d'œuvres graphiques et littéraires, des poèmes et autres textes versifiés ayant pour auteur Jean Nötzli.

Une partie concerne la sphère privée. On y trouve quelques esquisses graphiques ${ }^{12}$ mais surtout des brouillons d'écrits ${ }^{13}$ ainsi que les lettres du Professeur Salomon Vögelin critiquant les travaux de Nötzli, sans doute à la demande de celui-ci ${ }^{14}$. L'ensemble témoigne d'ambitions littéraires. Quelques courriers documentent, du reste, les tentatives de Nötzli pour publier dans des organes de presse, tels la Schweizerische Rundschau ${ }^{15}$ ou Der Bund, où Nötzli cherchait à faire paraître un feuilleton ${ }^{16}$. Le reste de la correspondance est lié à des personnalités publiques, tels l'homme politique Numa Droz ${ }^{17}$ et (le futur général) Ulrich Wille ${ }^{18}$, transmettant à Nötzli ses salutations estivales. Aucune de ces lettres ne recèle de contenu intime ni même vraiment personnel. Il est manifeste que cette partie de la correspondance a été totalement soustraite à la succession. Les autres documents consistent en des reconnaissances de dettes, des actes juridiques, dont les statuts de la Société de la station des eaux de la ville de Küsnacht (Statuten der Gesellschaft für Wasserversorgung Küsnacht) ou ceux de l'association des aubergistes suisses (Statuten des Schweizerischen Wirthevereins $)^{19}$. Un certain nombre de documents - devis de construction et décisions fiscales - concernent des avoirs à Küsnacht ou des projets immobiliers non aboutis ${ }^{20}$. À vrai dire, le plus personnel de ces documents est probablement le carnet militaire de Nötzli ${ }^{21}$, où est reporté l'origine de l'éditeur, sa date de naissance et surtout où est consigné le fait qu'il payait une amende au lieu d'effectuer ses obligations militaires, une procédure, au reste, tout à fait régulière mais qui témoigne, dans le contexte suisse d'une forte adhésion aux valeurs et devoirs militaires ${ }^{22}$, d'un manque d'entrain à l'égard de l'armée.

L'autre partie, nettement plus importante numériquement, concerne la sphère professionnelle. Le classement des documents est, ici aussi, en partie aléatoire. Cette part est composée d'une correspondance, le plus souvent adressée au rédacteur Jean Nötzli ; de pièces comptables, très majoritairement des reconnaissances de dettes, dont l'une, par exemple, en faveur de l'imprimeur de la revue Steffen \& Coccini, classée dans la partie privée ${ }^{23}$; ainsi que de quelques brouillons de textes, destinés à être publiés dans le Nebelspalter ${ }^{24}$. Cette somme documente le Nebelspalter sous de multiples aspects: les aléas de sa vie éditoriale, tels que les démêlés et négociations avec les imprimeurs et les annonceurs, les collaborations avec les artistes, conflictuelles avec les frères Evert et Henri Van Muyden, artistes genevois en vogue à la fin des années I $890^{25}$, ou plus feutrées avec le professeur Heinrich

\footnotetext{
Cotes 3.3 et 3.4 de la succession Nötzli.

Cotes 3.1 et 3.2 de la succession Nötzli.

Cotes 2.60 et 2.61 de la succession Nötzli.

Cote 2.49 de la succession Nötzli.

Cote 2.38 de la succession Nötzli.

Cote 2.2 de la succession Nötzli.

Cote 1.10 de la succession Nötzli.

Cote 3.10 de la succession Nötzli.

Cotes 3.12-3.17 de la succession Nötzli.

Cote 3.5 de la succession Nötzli.

Joëlle Kuntz, L'histoire suisse en un clin d'œil, Carouge, Zoé, 2006, p. 11-19.

Cote 3.7 de la succession Nötzli.

Cotes 3.1-3.4 de la succession Nötzli.
}

Cote 1.14 de la succession Nötzli. 
Jenny ${ }^{26}$, collaborateur important de la seconde décennie. La correspondance rapporte également des contacts soutenus avec les cercles éditoriaux - presse comprise -, politiques et artistiques. Il s'y trouve ainsi une lettre d'Albert Fleiner de la Neue Zürcher Zeitung, contactant Jean Nötzli en I 890 pour participer au Congrès suisse des journalistes (Schweizerischer Journalistentag) ${ }^{27}$. Les contacts politiques concernent surtout Numa Droz, Emil Frey et Emil Welti, personnalités suisses de premier plan ${ }^{28}$. Les échanges avec des organes de presse suisses, dont la Illustrierte Zeitung, la Neue Zürcher Zeitung, la Schweizerische Hauszeitung et la Schweizerische Rundschau ${ }^{29}$, ou étrangers, dont Le Figaro, le Secolo milanais et la Neue Freie Presse viennoise ${ }^{30}$, sont nombreux. Leur nature est commerciale, artistique et littéraire, avec un certain mélange des genres. Les relations avec les cercles culturels institutionnels de Zurich, notamment avec le Musée national suisse et le Künstlerhaus de Zurich, ancêtre du Kunsthaus ${ }^{31}$, sont encore plus intensives. Leur teneur est toujours très courtoise: Jean Nötzli était un homme d'usages.

Cependant, la succession laisse se dessiner des zones grises dont on ne sait trop dire à quelle sphère elles ressortissent. Il en est notamment ainsi de la correspondance avec les cercles politiques et éditoriaux. Le cas le plus typique de cette convergence des deux sphères est sans doute celui des échanges épistolaires avec Numa Droz $^{32}$. La correspondance révèle des liens personnels, permettant à Nötzli d'obtenir des informations politiques inédites pour sa revue $^{33}$. Il s'agit ici d'une situation d'interactions individuelles, ne pouvant, selon la plupart des positions théoriques traditionnelles ${ }^{34}$, être identifiées comme un réseau. Ceci est néanmoins contredit par le point de convergence des échanges: le Nebelspalter. Ce dernier engage, en effet, un nombre important de concepteurs, relayant cette relation duelle ${ }^{35}$. Ces concepteurs sont à proprement parler agissants. Ils vont, en effet, à leur tour (re)présenter ou non Droz dans la revue, ceci sur un mode plus ou moins positif, et participeront à sa renommée. Derrière cette dyade, se trouve le pouvoir de la presse. Cette force centripète est parfaitement illustrée par la pratique de Jean Nötzli, chiffrant des messages dans la boîte aux lettres de sa revue (la Briefkasten) à destination de ses collaborateurs ${ }^{36}$.

Certains échanges sont de véritables affaires, de ces histoires qui sous-tendent les réseaux ${ }^{37}$. Ils permettent d'apprécier la qualité et la densité de ceux-ci, et mettent également en lumière leur nature complexe. Tel est le cas de la correspondance entre Jean Nötzli et Franck Buchser. Convaincu de la nécessité d'un engagement de la Confédération en faveur de la création artistique, ce dernier agit inlassablement dans ce sens auprès de ses collègues artistes, des cercles artistiques locaux et des autorités fédérales. En se tournant vers Nötzli, avec lequel il a des liens d'amitié, il cherche aussi

\footnotetext{
Cote 1.9 de la succession Nötzli.

Cote 2.16 de la succession Nötzli.

Cotes $1.10,2.2,2.3$ et 2.8 de la succession Nötzli.

Cotes $2.42,2.47,2.49$ et 2.50 de la succession Nötzli.

Cotes 1.8 et 2.46 de la succession Nötzli.

Cotes $1.30,2.23$ et 3.9 de la succession Nötzli.

Cf. « 6.3. Quand politique, art et satire se mêlent: Numa Droz et Jean Nötzli ».

Cote 2.2 de la succession Nötzli.

${ }^{34}$ Mark Granovetter, notamment, défend dans plusieurs de ses ouvrages la dyade comme formant déjà un réseau.

35 Harrison White théorise cette dimension extensive toujours présente dans la dyade; Harrison White, "Réseaux et histoires ", SociologieS [En ligne], Découvertes / Redécouvertes, Harrison White, mis en ligne le 17 octobre 2007 consulté le 4 juin 2015. URL: https://journals.openedition.org/sociologies/240.

36 Henri van Muyden y fait plusieurs fois allusion: cote 1.14 de la succession Nötlzi, lettres du 16 novembre 1890, du 8 décembre 1891, du 23 février 1892.

Harrison White, « Réseaux et histoires », op. cit.
}

à utiliser le vecteur de la presse. Les archives Nötzli montrent une correspondance privée restituant une dyade qui n'est que d'apparence. Elles dénotent, en filigranes, d'autres liens, privés ou institutionnels, hostiles ou amicaux, qui se nouent et se dénouent ${ }^{38}$. Une correspondance à trois voix, entre Jean Nötzli, John Grand-Carteret, historien de la caricature et collaborateur au Figaro et Cäsar Schmidt, éditeur zurichois révèle un autre type de constellation ${ }^{39}$. Nötzli endosse ici une position médiane entre celle de médiateur (Vermittler) et de troisième larron (Tertius gaudens $)^{40}$, permise par la labilité de la triade ${ }^{41}$.

Le fonds Nötzli forme, par ailleurs, un corpus de données relationnelles où neuf cercles sociaux peuvent être identifiés. Deux de ces cercles relèvent strictement de la sphère personnelle: le cercle académique (notamment celui des échanges avec le Professeur Salomon Vögelin) et celui de l'éducation (Jean Nötzli s'implique à titre personnel dans le débat sur l'école qui agite alors la société helvétique). Deux autres cercles correspondent à la sphère professionnelle: le cercle littéraire et celui de l'édition. Le reste, soit cinq cercles, ressortit à ces deux sphères, avec toutefois une dominante professionnelle: le cercle artistique, avec une part institutionnelle et l'autre individuelle; celui de la presse, où Nötzli compte des amis, des partenaires et des concurrents; le cercle politique, où il a des entrées officielles et moins officielles; celui de la gastronomie, où Nötzli entretient des contacts amicaux mais pour lequel il édite aussi un organe de presse, Der Gastwirth; celui des affaires, enfin, où Nötzli défend des intérêts privés et professionnels. Ces cercles recouvrent eux-mêmes des sousmilieux, plus ou moins diversifiés, ayant entre eux des connexions, assimilables à des réseaux contextuels, aux netdoms proposés par Harrison White ${ }^{42}$. Si les cercles nettement identifiés comme " privés » sont disjoints, les autres ont tendance à se recouper. Ces chevauchements sont, en partie, attendus, dans le cas des milieux politiques et de la presse suisse, mais moins attendus lorsqu'il s'agit des milieux politiques fédéraux et des milieux artistiques zurichois, où les échanges sont particulièrement denses. Cette particularité a une double explication. La première est contextuelle et tient à la situation historique du champ de l'art en Suisse, traditionnellement laissé à l'initiative privée mais entrant, à cette époque, dans un processus d'institutionnalisation ${ }^{43}$. La seconde est réticulaire et tient au rôle qu'entend jouer Nötzli dans ce processus. Son activité en réseau, en faveur d'un encouragement fédéral des artistes suisses, s'exerce dans les champs politique et artistique.

S'il est possible de restituer ces cercles - à peu près - objectivement, la cohérence des réseaux qui s'y organisent n'apparaît qu'une fois un point de vue choisi, un poste d'observation adopté ${ }^{44}$. Tous les cercles ne se comprennent certes pas d'après l'activité éditoriale de Jean Nötzli - une personne aussi investie soit-elle dans son

Cf. « 4.1. La question de l'art suisse ".

Cotes 1.7 et 1.8 de la succession Nötzli.

Michel Forsé, «Les réseaux sociaux chez Simmel: les fondements d'un modèle individualiste et structural », dans La Sociologie de Georg Simmel (1908). Éléments de modélisation sociale, éd. Liliane Deroche-Gurcel et Patrick Watier, Paris, PUF, 2002, p. 65.

Cf. « 6.2. Intrigues suisses et influences françaises dans le monde éditorial: Jean Nötzli, John Grand-Carteret et Cäsar Schmidt ».

Harrison White, "Réseaux et histoires », op. cit.

Hans A. Lüthy, «L'art en Suisse 1890-1945 ", dans L'art en Suisse 1890-1980, éd. Lüthy Hans A et Heusser Hans-Jörg, Lausanne, Payot, 1983, p. 9-10.

Je ne rejoins pas tout à fait la position de Harrison White pour qui les réseaux sont construits par les observateurs; il serait sans doute plus juste de dire que ces réseaux sont « reconstruits » par les observateurs; H. White, « Réseaux et histoires », op. cit. 
travail ne se réduit jamais à celui-ci - mais c'est néanmoins sa position à la tête du Nebelspalter qui permet d'éclairer la structure d'ensemble. Celle-ci témoigne de la vie du périodique ainsi que de la personnalité d'homo universalis de son patron, typique de la presse européenne de cette époque ${ }^{45}$. Les extensions géographiques de ces réseaux sont très contrastées. Elles sont beaucoup plus importantes pour les réseaux professionnels, répondant à une logique de communauté acquise d'intérêts idéels et matériels, que pour les réseaux privés, fonctionnant d'après une communauté traditionnelle, basée sur la proximité ${ }^{46}$. Alors que les réseaux réputés privés se cantonnent à la Suisse, dépassant rarement la Suisse alémanique, ceux dépendant, pour tout ou partie, de la sphère professionnelle s'étendent à la Suisse romande, à la France, à l'Allemagne, à l'Italie, aux États-Unis et à l'Autriche. À ceci, trois explications: un lectorat exilé qui se retrouve dans l'analyse politique proposée par le Nebelspalter ${ }^{47}$; la nature illustrée de la revue, rendant son accès possible par la seule image, sans nécessairement disposer de compétences idiomatiques ni même contextuelles - une caricature peut se regarder comme un dessin, indépendamment de sa légende; l'activisme relationnel de Jean Nötlzi, maître es-réseaux.

\subsection{Intrigues suisses et influences françaises dans le monde éditorial: Jean Nötzli, John Grand-Carteret et Cäsar Schmidt}

La correspondance de Jean Nötzli permet de reconstituer un réseau impliquant l'éditeur et rédacteur en chef du Nebelspalter, Jean Nötzli, le journaliste et historien de la caricature, John GrandCarteret ainsi que l'éditeur d'art zurichois, Cäsar Schmidt ${ }^{48}$. La présentation chronologique de cette correspondance émaillée de documents comptables est essentielle. L'affaire se joue en deux actes. Le premier implique Jean Nötzli et John Grand-Carteret, alors que Cäsar Schmidt vient s'ajouter dans le second. Couvrant dix-sept années, de I 880 à I 897, son déroulé laisse apparaître des intérêts artistiques, éditoriaux, symboliques et financiers.

\subsubsection{Acte un : correspondance entre Jean Nötzli et John Grand- Carteret de 1880 à 1891}

La première partie de la correspondance est constituée d'un échange de lettres entre Jean Nötzli et John Grand-Carteret, rédacteur au Figaro et auteur d'ouvrages sur la caricature germanique ${ }^{49}$. Le 22 mai I 880, John Grand-Carteret entame la correspondance en demandant à Jean Nötzli, alors à la tête du Nebelspalter depuis un peu plus de cinq ans, de lui faire régulièrement parvenir la revue:

\footnotetext{
Suzanne Gourdon, La « Jugend » de Georg Hirth: la Belle Époque munichoise entre Paris et Saint-Pétersbourg, Strasbourg, Centres d'Études germaniques, 1997, p. 272.

Michel Forsé, «Les réseaux sociaux chez Simmel: les fondements d'un modèle individualiste et structural », op. cit., p. 87-88.

Ce lectorat est l'objet d'attention particulière dans la politique commerciale du Nebelspalter.

Cotes 1.7 et 1.8 de la succession Nötzli.

C'est du reste en tant qu'auteur de livres sur la caricature, servant aujourd'hui encore de référence, que John Grand-Carteret est passé à la postérité.
}

Paris le 22 mai 1880 ( 50 rue Richer) / Monsieur et cher confrère, / Je viens vous prier de bien vouloir me faire parvenir les $n^{\circ}$ du Nebelspalter depuis Janvier si possible, et de m'en faire à l'avenir le service régulier. / M'occupant spécialement de la Suisse dans plusieurs journaux de Paris, je me ferai un plaisir de vous citer lorsque l'occasion s'en présentera et je vous adresserai également les numéros dans lesquels j’en aurai parlé. / En attendant l'avantage de vous lire, je vous présente mes salutations les plus cordiales. / John Grand-Carteret ${ }^{50}$.

Presque dix années se passent avant que la correspondance ne reprenne, le Io mars I 889, date à laquelle Grand-Carteret demande un numéro qu'il n'a pas reçu, faisant ensuite un compliment sur Heinrich Jenny (I 824-I89I) qui est venu rejoindre un an plus tôt le dessinateur vedette du Nebelspalter, Boscovits senior:

\begin{abstract}
Paris le Io mars I889 / Vous seriez bien aimable de me faire envoyer le $\mathrm{n}^{\circ}$ Io du Nebelspalter (2 mars) qui ne m’est pas parvenu, ce qui fait une lacune dans ma collection. / Je suis toujours avec le plus grand intérêt votre journal renforcé par le crayon si pittoresque, si personnel de H. Jenny qui a toujours conservé la même saveur. / Łe vous enverrai prochainement un article dans lequel je vous cite. / J Grand-Carteret ${ }^{51}$
\end{abstract}

Dans ces deux exemples, on comprend à demi-mot que l'avantage en capital symbolique - pour reprendre la terminologie de Pierre Bourdieu ${ }^{52}$ - promis par Grand-Carteret à Nötzli, c'est-à-dire de profiter de la notoriété du Figaro, dispense celui-ci d'honorer financièrement son abonnement.

L'année suivante, une nouvelle lettre de Grand-Carteret nous apprend la reprise dans Le Figaro de caricatures de Bismarck publiées par le Nebelspalter:

Paris le I6 juin I89o (6 rue Notre-Dame-de-Lorette) / Monsieur et cher confere/ Vous aurez vu très certainement le supplément du Figaro avec les caricatures sur Bismarck dont 2 du Nebelspalter qui ont eu ici un très grand succès. / Je vous envoye, aujourd'hui, le volume $\underline{\text { Bismarck }}$ en Caricatures $^{53}$, en vous priant de bien vouloir lui consacrer quelques lignes dans votre prochain $n^{\circ}$ et si possible un dessin. Je vous donnerai mon portrait si vous voulez le publier à cette occasion sous une forme humoristique. / Croyez je vous prie à mes meilleurs sentiments de confraternité. / J Grand-Carteret ${ }^{54}$.

\section{L'auteur rajoute en post-scriptum:}

Envoyer régulièrement votre journal à M. Bovin au Figaro. Il l'exposera dans la salle des dépêches ${ }^{55}$.

Le dessin souhaité est aussitôt réalisé par Emil Dill, l'un des crayons les plus intéressants de ces années-là ${ }^{56}$, et reproduit en dernière page du numéro du 2 I juin I 890 , une place de choix dans l'organisation de la revue. "Le nouvel oracle de Delphes » (Das moderne Orakel zu Delphi) présente un Bismarck fumant son éternelle pipe ${ }^{57}$ dans sa retraite de Friedrichruh, d'où il continue de s'exprimer après son départ de la chancellerie. Parmi les journalistes à ses pieds se trouve un représentant du Figaro dont

\footnotetext{
Cote 1. 8 de la succession Nötzli, lettre du 22 mai 1880.

Cote 1. 8 de la succession Nötzli, lettre du 10 mars 1889

Pierre Bourdieu, Raisons pratiques, Paris, Seuil, 1994, p. 161.

L'ouvrage est publié pour la première fois en 1890 aux éditions Perrin.

Cote 1. 8 de la succession Nötzli, lettre du 16 juin 1890.

Ibid.

Emil Dill collabore de manière certaine au Nebelspalter entre 1890 et 1893, puis en 1895, et peut-être en 1908 et 1909, années où l'usage du monogramme complique beaucoup l'authentification.

II s'agit alors d'un topos des très nombreuses caricatures de Bismarck.
} 
on ne distingue pas le visage ${ }^{58}$. Une semaine plus tard, un encart invitant les lecteurs à s'abonner, publié en couverture, reprend dans son argumentaire la présence de reproductions du Nebelspalter dans les plus grands journaux du monde, tels le Figaro parisien et le Secolo milanais, ainsi que dans le livre tout récemment paru de Johan Grand-Carteret, "Bismarck en caricatures » 59 . La rédaction du Nebelspalter tire visiblement profit de l'affaire; Grand-Carteret, de son côté, apprécie, remerciant Jean Nötzli dans une lettre du 5 juillet $\mathrm{I} 890$ :

J'ai vu ce que vous aviez déjà mis dans le Nebelspalter et vous en remercie ${ }^{60}$.

L'échange reprend à l'occasion d'une nouvelle publication de Grand-Carteret, le 29 mai I 89 I :

Monsieur et cher confrère, / Je vous adresse le nouveau volume que je viens de publier sous le titre de: Crispi, Bismarck et la Triple-Alliance en Caricatures ${ }^{61}$ faisant suite au Bismarck que vous avez reçu l'année dernière. / Vous y trouverez la reproduction d'une des amusantes caricatures du Nebelspalter. Vous me feriez grand plaisir en consacrant à ce volume une de vos prochaines illustrations. / Dans l'attente de votre réponse, je vous prie d'agréer, Monsieur et cher collègue, l'assurance de mes meilleurs sentiments, / J Grand-Carteret ${ }^{62}$.

Le dessin souhaité par Grand-Carteret n'a jamais pris place dans les colonnes du Nebelspalter, sans qu'il soit possible d'éclairer cette absence, pas plus que l'interruption de la correspondance durant six années.

\subsubsection{Acte deux: 1897, querelle autour de l'« Europe actuelle»}

La seconde partie de la correspondance concerne un dessin de Boscovits senior, "L'Europe actuelle " (Das heutige Europa), représentant une carte anthropomorphe (cf. fig. 77 ). Boscovits s'est fait depuis une dizaine d'années une spécialité de ce motif, toujours intitulé à l'identique. Les trois déclinaisons qu'il en fournit entre I 886 et I $897^{63}$ - la première en noir et blanc, les deux suivantes en couleur - s'étalent invariablement sur la doublepage centrale, un lieu particulièrement valorisé. Ce type de carte, apparu au XIX ${ }^{\mathrm{e}}$ siècle $^{64}$, est une traduction imagée de la montée des nationalismes ${ }^{65}$. Il s'inscrit dans une iconographie polymorphe de l'Europe, s'installant à partir de I 876 dans le Nebelspalter, dont les variations correspondent au ressenti de la question et de la politique européennes. Boscovits étant le dessinateur le plus important de la revue, il n'est rien d'étonnant à ce que l'éditeur d'art zurichois Cäsar Schmidt ait cherché à acquérir les droits de l'image très colorée pour la confection d'un calendrier. L'affaire

\footnotetext{
Nebelspalter 1890/25, dessin de Emil Dill intitulé « Le nouvel oracle de Delphes » (Das moderne Orakel zu Delphi).

" Die Gröbten Zeitungen der Welt bringen Abdrücke aus dem "Nebelspalter", so der Pariser "Figaro", der Mailänder "Secolo" und andere. Die Literatur über die Witzund humoristischen Blätter zählt den "Nebelspalter" zu den besten Erscheinung dieser Art und das erst vor einigen Tagen erschiene Buch von J. Grand-Cartere in Paris: "Bismarck en caricatures" widmet dem "Nebelspalter" auf einer Reihe von über ihn handelnden Blättern Worte lobendster Anerkennung, unser Abdruck von vier Vollbildern unserer verschiedenen Künstler » : Nebelspalter, 189o/26, couverture.

Cote 1. 8 de la succession Nötzli, lettre du 5 juillet 1890. L'ouvrage est publié aux éditions Delagrave en 1891.

Cote 1. 8 de la succession Nötzli, lettre du 29 mai 1891.

Cf. « 3.1. Une iconographie du monde ».

${ }^{64}$ Philippe Kaenel, « Suisse-Allemagne (1848-1918): neutralité et neutralisation du point de vue de la caricature », Revue suisse d'art et d'archéologie, 1-2 (2003), p. 108.

6 Michael Wintle, The Image of Europe. Visualizing Europe in Cartography and Iconography throughout the Ages, Cambridge, Cambridge University Press, 2009, p. 393
}

commence le 20 septembre I 897 . Une série de reçus nous informe de la requête de Schmidt en vue de l'acquisition des droits de l'image. S'ensuit une quittance faisant état de la cession des droits par Nötzli pour I 50 francs, ce qui représente une coquette somme. Le 9 octobre I 897, on trouve dans le livre de copies de Nötzli une lettre à l'attention de Cäsar Schmidt, répondant à son courrier de la veille:

En réponse à votre demande du 8 octobre, je vous assure que je n'ai en aucun cas donné au «Figaro » les droits de reproduction de "L'Europe actuelle » et que je n’ai, d'ailleurs, pas été sollicité en ce sens ${ }^{66}$.

Nötzli explique ensuite que le Figaro a reproduit de temps à autre des dessins du Nebelspalter de "manière tout à fait journalistique " ${ }^{67}$ et propose à Cäsar Schmidt de lui racheter les droits de l'image afin de résoudre le problème, et donc de lui reverser les I 50 francs des droits. Au verso de la lettre, se trouve la mention suivante « Caesar Schmidt: conflit en relation avec les illustrations du Nebelspalter dans le Figaro ». Il est difficile d'en identifier l'auteur ${ }^{68}$.

C'est à ce moment-ci qu'il faut considérer une lettre de GrandCarteret à Nötzli, datée du 2 I octobre et rédigée sur papier à en-tête du «FIGARO, 26, rue Drouot »:

Mon cher confrère, / L'administration du Figaro me communique une lettre de M. César Schmitt, libraire en votre ville et avec lequel je me souviens avoir eu d'excellents rapports, dont le contenu me surprend et m'étonne. / Ceci à propos de votre composition "L'Europe actuelle » reproduite dans le Figaro du 4 octobre avec la mention caricature de Boscovitz Nebelspalter de Zurich, comme je le fais chaque fois que je reproduis une image de votre journal, pensant naturellement vous êtes agréable en vous faisant ainsi profiter de la publicité du journal parisien. J'ajoute que cette image ne contenait aucune marque quelconque, aucune indication d'une propriété autre que la vôtre! / Comme j'ai depuis plus de six ans reproduit sans cesse avec votre assentiment soit dans mes volumes soit dans les journaux parisiens vos caricatures - j'ajoute même qu'à plusieurs reprises vous avez bien voulu m'en remercier - je viens vous prier de bien vouloir me faire savoir, par courrier, si vos intentions sont changées et si dans l'avenir il ne vous convient plus de voir vos caricatures reproduites avec la mention du Nebelspalter, naturellement. / Je ne voudrais pas cherchant avant tout à vous être agréable, aller ainsi à fin contraire de vos désirs, et me créer en même temps des réclamations désagréables. / Donc mon cher confrère un mot par courrier, me faisant savoir ce qu'il en est de cette affaire et ce que je dois en conclure pour l'avenir ainsi que pour le dessin en question. / Je profite de l'occasion pour vous féliciter à nouveau de la verve de vos images et je serais heureux si j'ai pu par nos reproductions contribuer à faire connaître le Nebelspalter / Croyez mon cher confrère à mes meilleurs sentiments. / J Grand-Carteret ${ }^{69}$.

Lettre à laquelle Nötzli répond le jour suivant, le 22 octobre I 897 :

Monsieur, / En réponse de votre honorée d'aujourd'hui, je viens vous dire que je vous serais très obligé de bien vouloir reproduire de temps en temps de nos caricatures du « Nebelspalter », toutefois en nommant la

\footnotetext{
(Auf Ihr Anfragen vom 8 Oct. teile ich Ihnen mit, dass ich dem « Figaro » in Paris keinerlei Erlaubnis zum Abdruck von " heutigen Europa » abgeben und von ihn keinerlei Anfragen erhalten haben); cote 1.7 de la succession Nötzli, lettre du 9 octobre 1897.

${ }_{67}$ (in der journalistisch anständigsten Form); ibid.

${ }_{68}$ (Streit wegen Abdrucks von Nebelspalterillustrationen im Figaro); Ia correspondance a de toute évidence été classée et expurgée de certains documents; on distingue plusieurs écritures dans les indications de classement, qui ne peuvent être authentifiées.

Cote 1.8 de la succession Nötzli, lettre du 21 octobre 1897.
} 
source comme vous l'avez déjà fait depuis des années. Quant au dernier tableau, «L'Europe actuelle », je dois vous dire que j'ai vendu le droit d'auteur (spécialement pour ce tableau) à la librairie Schmidt, mais comme je me souviens, ce n'était, qu'après que le « Figaro » a reproduit cette caricature. Comme vous avez bien mentionné le " Nebelspalter ", je ne crois pas que M. Schmidt y peut faire quelque chose et le mieux sera d'ignorer tout simplement sa lettre. Je désire vivement que nos bonnes relations restent les mêmes comme jusqu'à présent et s'il vous sera possible, Monsieur, de mentionner, soit dans le Figaro, soit dans vos volumes le "Nebelspalter ", je vous serais bien reconnaissant. / Agréer, Monsieur, mes civilités distinguées, / (sig) J. Nötzli ${ }^{70}$.

La chronologie des courriers tout comme le fait que Nötzli propose de racheter les droits sont parlants. Nötzli ment effrontément. Il sait pertinemment avoir vendu les droits avant la parution de l'image dans Le Figaro et tient avant tout à maintenir de bonnes relations avec Grand-Carteret, c'est-à-dire à conserver la publicité que lui procurent les reproductions dans Le Figaro ainsi que la reconnaissance assurée par les publications sur la caricature. L'ensemble, la première demande de Grand-Carteret concernant les numéros du Nebelspalter et ses différentes promesses de publicité, témoigne de la réalité humaine de réseaux qui se comprennent aussi en termes de rapports de force. Ceux-ci sont nettement à l'avantage de l'historien et journaliste parisien et au désavantage de l'éditeur d'art. Dans cette affaire, un élément qui apparaît en creux, n'est pas le moins important: à aucun moment, Boscovits, dont le dessin est au centre de l'affaire, ne semble avoir été consulté. Le dessinateur, en l'occurrence également co-fondateur du journal, n'existe littéralement pas dans cette affaire. Quant à l'arbitre, il semble que ce soit ici l'éditeur du Nebelspalter.

\subsection{Quand politique, art et satire se mêlent: Numa Droz et Jean Nötzli}

S'il est un homme politique au statut tout à fait singulier dans le Nebelspalter, c'est bien Numa Droz ( I 844-I 899). Conseiller fédéral élu à l'âge de 3 I ans en I 875 , puis Président du Conseil fédéral tour à tour en I 88 I et I $887^{71}$, celui-ci est choisi en I 876 pour la mise en scène du Nebelspalter portraiturant ses grands hommes ${ }^{72}$. Numa Droz est, de fait, l'une des rares personnalités politiques à toujours bénéficier d'un traitement favorable. Ceci est d'autant plus remarquable que Droz est romand et que la revue est généralement critique vis-à-vis de la Suisse romande. Il est vrai que l'intéressé, entré très tôt en politique, partage les convictions libérales-radicales du fondateur de la revue et se distingue par des actions politiques auxquelles celui-ci ne peut que souscrire: une loi ecclésiastique de I873, dite " loi Numa Droz ", ainsi que son engagement en faveur de l'art via son adhésion à l'association artistique de Franck Buchser, proche de Jean Nötzli, la ligue suisse de Beaux-arts (Schweizerische Kunstliga) ${ }^{73}$. Droz assure également

\footnotetext{
Cote 1. 8 de la succession Nötzli, lettre du 22 octobre 1897.

La présidence du Conseil fédéral est annuelle.

Nebelspalter 1876/3, dessin en noir et blanc de Boscovits senior intitulé « Comment le Nebelspalter a quand même saisi Numa Droz » (Wie der Nebelspalter Numa Droz doch bekommen hat); cf. « 2.2.4. Un langage visuel et rhétorique très typé ». Emmanuel Dejung, « 15 Briefe des Malers Frank Buchser an Jean Nötzli Redaktor des "Nebelspalters" über den eidgenössischen Kunstkredit », Jahrbuch für solothurnische Geschichte, 50 (1977), p. 172.
}

une continuité dans la politique étrangère de la Confédération en assumant de facto cinq ans durant les fonctions de ministre des affaires étrangères de I 888 à I 892 , date de son retrait de la vie politique. Après son second mandat de Président, il reste, en effet, contre l'usage, à la tête des affaires étrangères et instaure le "système Droz " 74 . La bienveillance de la revue repose, ceci dit, avant tout sur des liens personnels, révélés par la correspondance de Jean Nötzli. Celle-ci débute avec une lettre de Numa Droz sur papier à en-tête officiel:

\begin{abstract}
Le Président de la Confédération Suisse / Berne, le 23 août I 887 / Mon cher Jahrgänger, / Les critiques que vous adressez à ma photographie sont bien fondées, mais elles ne m'atteignent pas, car ce n'est pas moi qui ai voulu cette pose, je me suis laissé faire. / Pour vous être agréable, je suis allé hier chez le photographe, et me suis fait tirer deux fois de face. On me promet des épreuves pour les premiers jours, je vous les enverrai immédiatement. / Recevez, mon cher Jahrgänger, la nouvelle expression de mes sentiments distingués. / Droz 75 .
\end{abstract}

Selon toute évidence, Jean Nötzli a sollicité Numa Droz en vue de la réalisation par J.F. Boscovits senior d'un portrait qui sera l'une des premières compositions en couleur publiée en I 887 par le Nebelspalter ${ }^{76}$. Une fois celui-ci publié ${ }^{77}$, Numa Droz réagit à la publication par une lettre livrant en creux les états d'âme de Jean Nötzli sur son entreprise de presse ainsi que le point de vue de Numa Droz sur la presse en général et sur le Nebelspalter en particulier:

\begin{abstract}
Le Président de la Confédération Suisse / Berne, le 4 oct. I887 / Mon cher contemporain, / Votre tableau est parfaitement réussi. Veuillez présenter toutes mes félicitations à Monsieur Boscovitz, et recevoir vous-même mes meilleurs remerciements. / Ce que vous me dites des difficultés avec lesquelles doit compter en Suisse l'éditeur d'un journal illustré est parfaitement juste. Mais il ne l'est pas moins que vous avez réussi à faire vivre, contre toute attente, le Nebelspalter, lui assurant une place distinguée parmi les publications du même genre. Je vous en félicité sincèrement, et, fais les meilleures vœux pour la prospérité de votre entreprise. / Croyez-moi toujours, mon cher contemporain, / votre dévoué / $\mathrm{Droz}^{78}$.
\end{abstract}

Quelque temps plus tard, Numa Droz recense dans un autre courrier les affaires fédérales ayant trouvé une solution politique. La lettre est rédigée sur un papier à en-tête de la chancellerie:

Berne, le 7 décembre 1887 , Mon cher contemporain, / En réponse à votre honorée lettre du 5 courant, je vous envoie ci-joint l'arrêté sur la nouvelle organisation du Conseil fédéral. Quant aux affaires principales qui ont été traitées cette année, je puis vous indiquer rapidement: / l'adoption par le peuple et la mise en vigueur de la loi sur l'alcool; / l'adoption par le peuple et les cantons de la révision constitutionnelle permettant d'introduire les brevets d'invention; / la solution de l'affaire de Mariahilf; / la réforme des arrondissements électoraux, en vue de laquelle il a été décidé de procéder à un recensement du peuple en I 888 au lieu de I 890 ; / l'extension de la responsabilité civile et la préparation d'une loi sur l'assurance obligatoire contre les accidents; / la nouvelle organisation du Conseil fédéral; / les négociations pour le rachat du

Jean-Marc Barrelet, « Numa Droz 1844-1899 », dans Die Schweizer Bundesräte. Ein biographisches Lexikon, éd. Urs Altermatt, Zurich, Artemis \& Wickler, 1991 p. 218-222.

Cote 2.2 de la succession Nötzli, lettre du 23 août 1887

Cf. « 2.3.8. En voir de toutes les couleurs ».

Nebelspalter 1887/41, double-page de Boscovits senior intitulée « Dr. Numa Droz $»$.

Cote 2.2 de la succession Nötzli, lettre du 4 octobre 1887. 
Nord-Est; / l'échange des ratifications de la convention internationale pour la protection des droits d'auteur, donnant un nouveau Bureau international à Berne; / l'apaisement des luttes confessionnelles; / la révision du tarif des péages, en vue de réagir plus efficacement contre la politique économique des autres pays, etc.; / la dénonciation des traités de commerce avec l'Autriche et avec l'Italie. / Je ne sais si cette énumération vous suffira. Dans tous les cas, je demeure, mon cher contemporain, / votre dévoué Droz ${ }^{79}$.

Il est malaisé de savoir quel était le but initial de Jean Nötzli en exposant la requête à laquelle répond de toute évidence Numa Droz. Ce qui est certain en revanche, c'est que la liste déroulée par l'homme politique n'ouvrit pas sur l'une de ces compositions présentant une synthèse de la politique suisse, très souvent sur une double-page, comme on pourrait s'y attendre. Elle fut tout au plus reprise dans deux éditoriaux de la fin I 887 , l'un consacré à la nouvelle organisation du Conseil fédéral, l'autre à la révision du tarif des péages ${ }^{80}$. Certes, l'ensemble des thèmes avaient déjà été traité, très souvent, du reste, en intégrant la figure de Numa Droz, parfois de manière très savoureuse, comme lorsque Numa Droz rêve à toutes les recettes fiscales que va permettre l'adoption de la loi sur l'alcool ${ }^{81}$ ou lorsqu'il porte un toast aux différents représentants confessionnels réunis autour d'une table ${ }^{82}$ (cf. fig. 148 ).

Parmi ces compositions, une couverture, un peu antérieure au courrier de Numa Droz, thématise la question non abordée par celui-ci du déficit budgétaire: Numa Droz s’y sert à rebours de jumelles pour regarder les recettes et les dépenses ${ }^{83}$.

La lettre suivante est de dix années postérieure, sans qu'il soit possible d'établir s'il s'agit d'une interruption de la correspondance ou d'une lacune dans le fonds d'archives. Elle est rédigée sur papier simple, sans en-tête officiel, puisque Numa Droz, alors directeur du Bureau international des transports ${ }^{84}$, n'occupe plus de fonction officielle.

Berne, le 4 juillet 1897 / Cher Monsieur, / Rentré hier de Paris, j’ai trouvé votre aimable lettre du 30 juin. Je n'ai plus de photographies disponibles en ce moment, mais je vais en faire tirer du dernier cliché, et vous en enverrai, si vous le désirez. Il me semble d'ailleurs que vu la tournure que prennent les choses, la publication de mon portrait pourrait être différée, car mon acceptation est fort douteuse à supposer qu'on insiste encore auprès de moi, ce qui n'est pas non plus certain. / En tout cas, merci de votre gracieuse attention, et des vers et du dessin que vous m'avez consacrés et qui m’ont bien diverti. / Votre dévoué / Droz $^{85}$.
Le courrier fait référence à une éventuelle nomination de Numa Droz comme gouverneur de la Crète dans le courant de I 897 ainsi qu'à des compositions du Nebelspalter témoignant de la conviction d'une issue favorable de la candidature de Droz. Droz est alors devenu populaire dans les cercles internationaux et l'on songe à lui pour limiter l'influence du sultan. L'offre du poste de gouverneur lui est officiellement présentée le I7 juin I 897 par le ministre des affaires étrangères français, Gabriel Hanotaux, au nom des puissances protectrices de la Crète (l'Angleterre, la France, l'Italie et la Russie) ${ }^{86}$. Les vers dont parle Droz sont, en fait, un éditorial versifié, publié en couverture du numéro daté du 26 juin sous le titre «Le prince Numa Droz Pompilius» (Fürst Numa Droz Pompilius) ${ }^{87}$, en allusion au deuxième des sept rois de la monarchie romaine. Le dessin, intitulé «Où est Ariane?" (Wo ist Ariadne?), est, quant à lui, placé en dernière page du même numéro. Il montre Numa Droz en Hercule, faisant signe au minotaure abrité par la maison Crète. À l'arrière-plan, on distingue les personnifications des puissances européennes, notamment la Russie et l'Angleterre, tenant conjointement une fourche marquée "pleins pouvoirs»(Vollmacht). Numa Droz lance à leur adresse :

\footnotetext{
Messieurs, je vous remercie de me reconnaître en Hercule et de vouloir me doter des pleins pouvoirs en qualité de gouverneur de la Crète, mais ces écuries d'Augias me sont, comme à vous, trop grandes; on sait comme y entrer mais pas comment en sortir. Merci! ${ }^{88}$
}

Le topos est repris une semaine plus tard dans une synthèse de l'actualité. Dans un coin de l'image, Numa Droz, assis sur un rocher, les jambes croisées, se gratte la tête. Sur la pierre est gravée "J'y vais ou j'y vais pas?» (Soll ich - Oder soll ich nicht?). Une main coupée par le cadre de la composition lui tend un papier « À M. Numa Droz gouverneur de Crète » (A M. Numa Droz Gouverneur von Kreta). Boscovits senior ne savait pas encore que la candidature de Droz n'aboutirait pas, en raison de multiples péripéties et hésitations de la part de Droz face à sa situation personnelle, une opposition féroce de ses adversaires politiques en Suisse ainsi que des objections émises par la Russie ${ }^{89}$. Fin I 898, le Nebelspalter publie un dessin intitulé «La bonne petite place» (Das gute Plätzchen). Numa Droz s'y félicite de ne pas «y être allé ", sous-entendu "vu la situation " ${ }^{\circ}$. La correspondance de Jean Nötzli et Numa Droz s'est, pour sa part, achevée en juillet I 897; Droz décèdera en décembre I 899, quatre mois avant Jean Nötzli. L'échange témoigne, outre d'une sympathie évidente de Jean Nötzli pour Numa Droz, de l'influence que peuvent avoir des liens personnels sur le contenu d'une revue.

\footnotetext{
Cote 2.2 de la succession Nötzli, lettre du 7 décembre 1887

so Respectivement Nebelspalter $1887 / 49$, texte signé « Nebelspalter » et intitulé «À notre Conseil fédéral » (Unserem Nationalrath); Nebelspalter 1887/51, texte non signé intitulé « Celui qui s'est mis lui-même dans le pétrin... » (Wer sich die Suppe eingebrockt...).

${ }^{81}$ Nebelspalter 1887/20, dessin de Boscovits senior intitulé "Un cliché photographique » (Eine photographische Aufnahme).

${ }_{82}$ Nebelspalter $1887 / 15$, dessin pleine page en noir et blanc de Boscovits senior intitulé « Ô, comme c'est charmant! (Un instantané) » (O, wie lieblich ist's [Eine Augenblicks-Aufnahme]).

${ }_{83}$ Nebelspalter 1887/46, couverture non signée intitulée «Au sujet du déficit fédéral de 1888. Pour rendre le petit peuple favorable aux impôts » (Zum Bundesdefizit für 1888. Um das Völklein abgabenwillig zu machen).

${ }^{84}$ Jean-Marc Barrelet, « Numa Droz 1844-1899 », op. cit., p. 222-223.

85 Cote 2.2 de la succession Nötzli, lettre du 4 juillet 1897.
}

Jean-Marc Barrelet, « Numa Droz 1844-1899 », op. cit., p. 223.

Nebelspalter 1897/26, éditorial en couverture.

(Numa Droz: "Meine Herren, ich danke Ihnen, dass Sie mich als Herkules anerkennen und mit der nötigen Vollmacht als Kretagouverneur ausrüsten wollen, aber dieser Augiasstall ist mir, wie Ihnen, zu grob; da weib man nur, wie man hinein-aber nicht, wie man hinauskommt. Merci! »); Nebelspalter1897/26, dessin de Boscovits senior intitulé « Où est Ariane? » (Wo ist Ariadne?).

Samuel Robert, Numa Droz. Un grand homme d'État 1844-1899, Neuchâtel, Delachaux \& Niestlé, 1944, p. 145-150.

Nebelspalter 1898/46, dessin pleine page en couleur de Willy Lehmann-Schramm intitulé « La bonne petite place » (Das gute Plätzchen). 


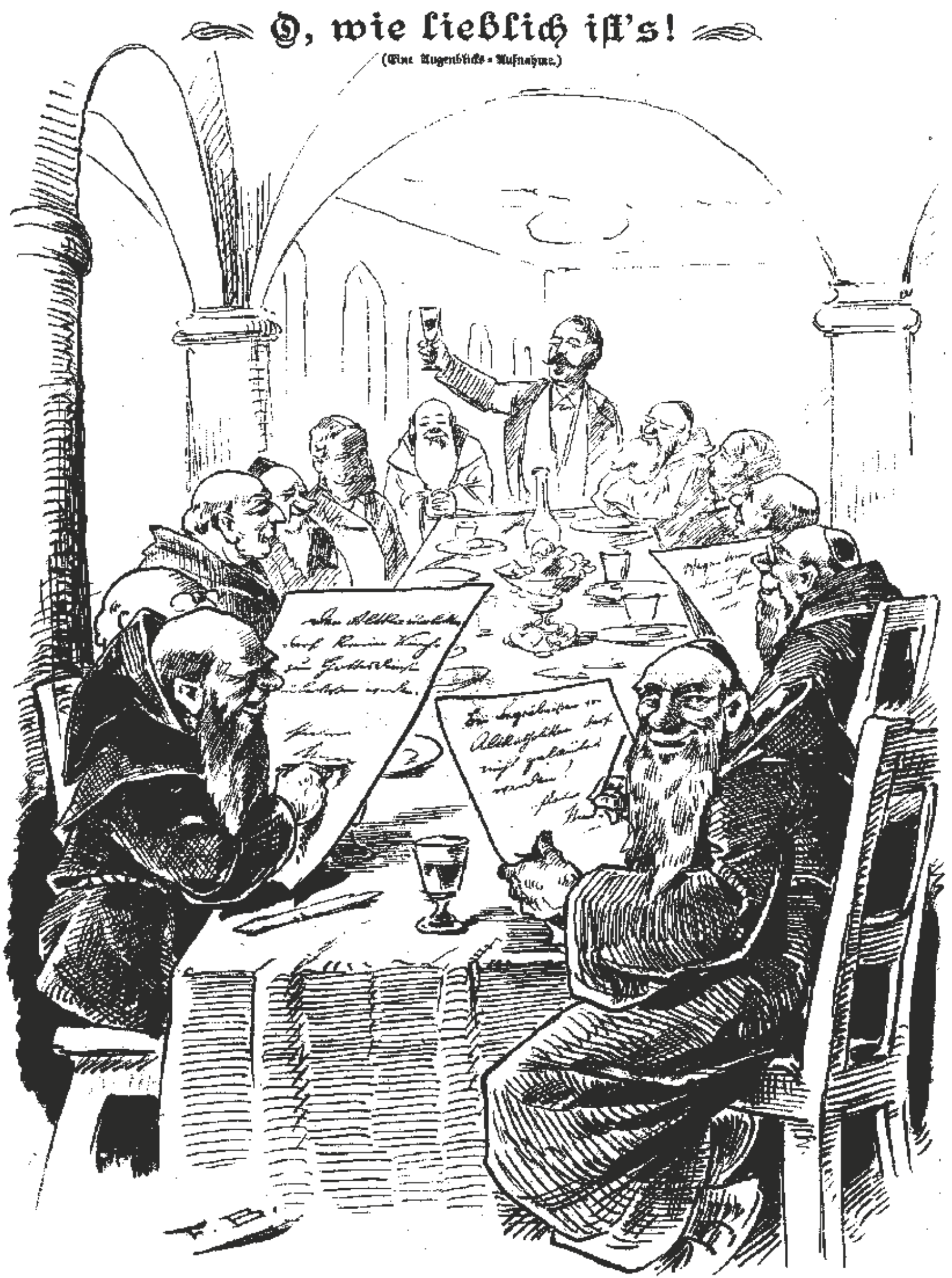

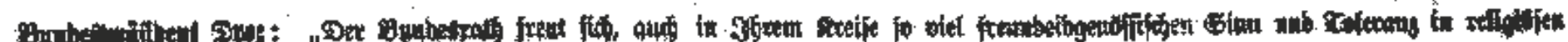

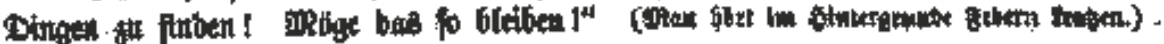




\subsection{Passions d'artistes : Richard Kissling, Evert van Muyden, Henri van Muyden et Jean Nötzli}

La correspondance Van Muyden formée de I 5 lettres assez verbeuses permet de renseigner assez finement un réseau d'artistes, certes marginal par rapport au gros des dessinateurs du Nebelspalter, majoritairement originaires de Suisse alémanique et impliqués dans d'autres réseaux, mais qui n'en est pas moins fort intéressant. Elle possède plusieurs particularités: elle est rédigée dans les trois langues parlées en Suisse - le français, l'allemand et l'italien -, quoique très majoritairement en français ${ }^{91}$; elle est en partie composée de lettres qui ne sont pas adressées à Jean Nötzli et dont la présence dans la succession ne trouve pas d'explications; elle documente l'étanchéité de réseaux ne passant que rarement la barrière de la langue, puisque durant six années, de I 887 à I 892 , le réseau romand ne croise pas une fois le réseau alémanique, hors la personne de Richard Kissling; elle documente les difficultés de positionnement des dessinateurs dans les champ de l'art et de la presse; elle donne une réalité à la pression économique subie par des artistes en voie d'autonomisation; elle révèle, une fois encore, les talents de dissimulateur de Jean Nötzli.

Cette correspondance débute en I 887 par une lettre de Evert van Muyden (I 853-I922) à Richard Kissling (I 848-I9I9), sculpteur suisse alémanique alors établi à Zurich. Après avoir suivi une formation académique complète, notamment à Rome et à Paris, Kissling s'est lié d'amitié avec Salomon Corrodi et Frank Buchser, qu'il a connus en fréquentant la colonie allemande à Rome. À cette époque, il est très bien intégré à la scène culturelle zurichoise, entretenant des liens amicaux avec des personnalités saillantes telles que Gottfried Keller, Arnold Böcklin et Rudolf Koller ${ }^{92}$. Le Nebelspalter valorise régulièrement Kissling. La lettre est en partie raturée et illustrée à l'endroit de la signature par un dessin montrant les deux artistes avec leurs outils, se serrant la main au-dessus d'un broc de bière géant. La fumée de leurs pipes se rencontre un peu à la manière des bulles d'une bande dessinée (cf. fig. I49).

Genève, le 24 novembre I 887 / Mon cher Kissling / Je viens te remercier vivement de ta bonne camaraderie, j'accepte ta proposition et je puis dire, sans qu'on me taxe de vanité que je pourrai faire mieux que les dessins que j'ai vus. / Donc, tu pourras en remerciant aussi M. Nötzli, lui dire que je ferai de mon mieux pour le satisfaire. / Dès que je pourrai je lui enverrai une page de 4 dessins, car je pense que c'est ce qu'il désire, ou bien une histoire drôle ou plusieurs tableaux formant une page. / Au moment où je lisais ta lettre j'étais occupé à faire une description écrite de la Campagne de Rome pour la Classe des Beaux-Arts, et précisément à l'endroit où j'ai décrit notre séjour à Nettuno dont je me souviens comme si c'était hier. / Tu ne me parles pas de tes travaux, ce qui m'aurait intéressé. Pour moi je finis deux tableaux avant de partir et j'ai encore des portraits à la plume à faire. J'ai beaucoup de succès avec ce genre de ritratti et je suis arrivé à les réussir en une seule séance et à la plume. Bientôt je retournerai à Paris et il est probable que là je trouverai bien des sujets drôles dans la rue et ailleurs et compréhensibles pour tout

On fait ici exception de langue rhéto-romane, très minoritaire.

Susanne Schröder, « Kissling, Richard », SIKART Dictionnaire sur l'art en Suisse, 1998, actualisé 2014; http://www.sikart.ch/KuenstlerInnen.aspx?id=4023455 le monde. Souvent ce sont les dessins sans texte, mais bien significatif qui sont les plus drôles, comme on en voit souvent dans les Fliegende Blätter. Je pense que le rédacteur du Journal accepterait volontiers ce genre là, dans lequel peut-être je réussirai mieux qu'ailleurs. En tout cas, s'il a des idées spéciales, tu me les communiqueras. D’après ta lettre, du reste, je vois que je puis agir librement. Sur la politique je pourrai aussi à l'occasion trouver quelque chose. / Nous avons un temps si noir que je ne peux pas peindre ce qui me désole. / Je regrette bien que le triste état de mes finances, car les temps sont bien durs, ne me permettent de temps en temps de voyager en Suisse. Depuis mon arrivée j’ai travaillé toujours, sans cesser même le dimanche, afin de reboucher les gros trous de ma bourse. / En voilà assez, on t'envoie beaucoup de cordiales salutations de chez moi et pour ma part je te serre cordialement la main en te remerciant toi d'abord et ton rédacteur ensuite. / Ton ami / Evert van Muyden. / Je signerai mes dessins Pastarella93.

Cette lettre est suivie d'une courte missive rédigée en italien adressée à un "Carrissimo Ricardo ", dont on comprend qu'il s'agit de Richard Kissling. La langue est sans doute un rappel de l'endroit où les deux artistes se sont rencontrés et témoigne du caractère manifestement extraverti de Evert van Muyden. Celui-ci informe Kissling de l'état de sa collaboration avec Jean Nötzli, auquel il vient d'envoyer deux dessins. La lettre atteste également de la proximité de Richard Kissling avec Jean Nötzli ainsi que de la disposition de van Muyden à adapter la manière de son dessin, en se limitant toutefois au graphisme sans s'occuper de la légende.

Cher Richard. / J'ai envoyé deux dessins à Monsieur Nötzli. Pour cette fois, j'ai réalisé des dessins à la plume sans clair-obscur ni texte. / Si Monsieur Nötzli le désire, je peux faire d'autres dessins dans une autre manière, en noir et blanc, c'est-à-dire avec des effets plus forts. Il me semble que les dessins envoyés contrasteront avec les autres, car faits dans une manière plus simple. Aies l'obligeance de dire à ton rédacteur que si ce genre de dessin ne lui plaît pas, je suis disposé à les faire dans une autre manière / Il peut faire le titre lui-même. J'espère que tu m'enverras de tes nouvelles et ton sentiment quand tu verras les dessins et je t'envoie mille poignées de main. / Evert van Muyden ${ }^{94}$.

La lettre suivante est rédigée en allemand dans une calligraphie compliquée, dérivée du gothique et usitée en zone germanophone. Son déchiffrage est extrêmement malaisé. Il y est question de " mon ami Richard Kissling " (Mein Freund Richard Kissling) et d'une adresse à Paris (Quai Voltaire n $\left.{ }^{\circ}\right)^{95}$.

Il faut attendre deux ans une nouvelle lettre, à nouveau en français, comme désormais le reste de la correspondance.

Genève, le io octobre 89 / Cher monsieur / Je vous envoie par le même courrier 2 dessins, qui vous plairont j'espère et que j'ai signés de mes initiales, je pense que nous n'y verrez pas d'inconvénient puisque d'ailleurs vous aviez l'intention de m'annoncer dans votre journal, où vous pouvez alors expliquer l'initiale H. v M. J'ai soigné ces dessins davantage et espère qu'ils frapperont. J'ai pris quelque chose de général

Cote 1.14 de la succession Nötzli, lettre du 24 novembre 1887.

(Carissimo Ricardo. / Mando al' Signore Nötzli, due disegni. Per questa volta ho fatto disegni alla penna senza chiaro oscuro e senza testo. / Si il signore Nötzli vuole, posso fare altri disegni in un'altra maniera sia con nero e bianco, dico con effetto più forte. Mi pare che i Disegni mandati farebbero contrasto con gli altri, essendo fatti in un'modo più semplice. Avrai dunque la compiacenza di dire al detto redattore, si questo genere di Disegni non gli piace, che son disposto a fargli in qualunque maniera. I II titolo lo puo fare lui. Spero che mi manderai delle tue notizie e del sentimento tuo quando verrai i disegni e ti mando mille strette di mani. / Evert van Muyden); cote 1.14 de la succession Nötzli, lettre non datée. Cote 1.14 de la succession Nötzli, lettre du 28 novembre 1887. 


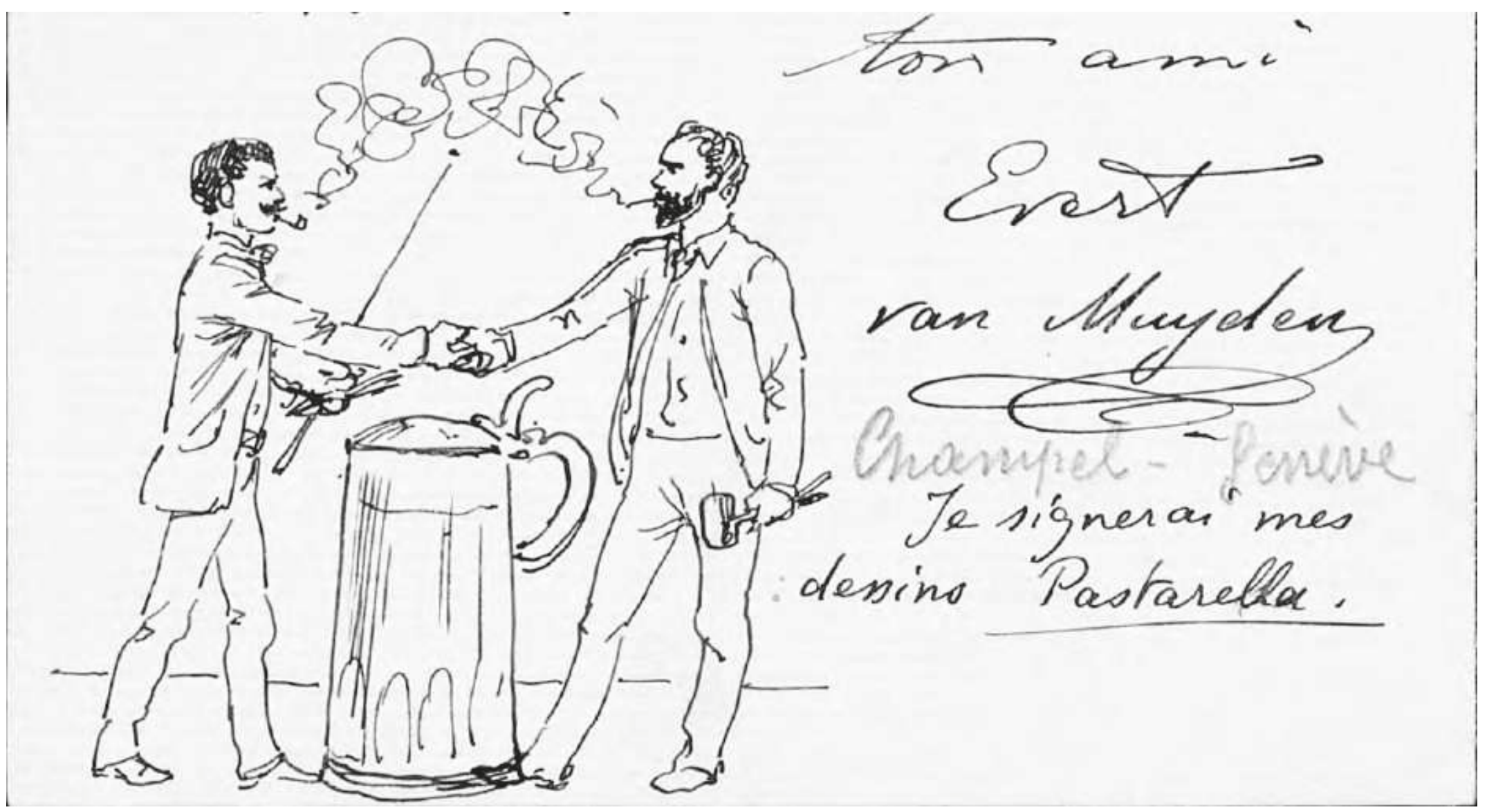

Fig. 149. Dessin de la lettre du 24 novembre 1887 de Evert van Muyden à Richard Kissling (Cote 1.14 de la succession Nötzli).

comme sujet, n'ayant rien encore sous la main comme politique suisse. De même je vous envoie un brouillon de grande page, que tenant à vous envoyer de suite, je vous communique tel quel. Ce serait les souhaits de bonne année du Nebelspalter. / Le sujet représenterait le N. distribuant des numéros du journal etc assis sur un volume ouvert également noté nebelspalter, avec les attributs encrier plume etc. D'un côté l'année I 889 qui s'en va, emmenée par le temps et poussée dehors par de gais amours, l'un d'eux lit attentivement assis sur d'anciens numéros etc. feuilles etc à droite, la nouvelle année fait son entrée emmenée par une troupe d'autres amours qui la font passer sous des guirlandes de fleurs. Au premier plan, même côté un amour versant le contenu d'une corne d'abondance. Au fond la vue de Zurich, dans le vague, quant au côté gauche, l'année finie s'enfoncerait dans les ténèbres etc. / Voyez si cela vous irait. Si oui, il serait nécessaire que me donniez des renseignements précis pour le procédé à employer en vue des couleurs, leur nombre (couleurs). L'encre irait-elle et les changements, inscriptions devises etc qui pourraient être ajoutées. Je vois là une jolie page à faire pour votre journal. Dans le cas où cette idée vous conviendrait, veuillez me la renvoyer je vous prie, avec vos remarques. / Et maintenant, monsieur, il ne me reste qu'à vous dire que je suis heureusement revenu après avoir séjourné un jour à Berne où j'ai été voir au Conseil National et aux États. - / Je suis fort en peine pour le moment de trouver des portraits de nos hommes d'état.- / Merci encore une fois pour la vraiment charmante hospitalité que j'ai reçue de vous et Mr Kissling à Zürich, dont je conserve le meilleur souvenir. Je vous lirai avec plaisir donc, et en attendant, je reste, cher monsieur, / votre tout dévoué collaborateur / H van Muyden / PS. Réflexion faite, j'ai signé mes deux dessins, mais pour la suite, je préférerai, en ce qui concerne les dessins politiques, signer de mes initiales HVM. Quant aux dessins autres, je signerai mon nom en entier. Je ne pense pas, que vous y voyez de l'inconvénient. / Bien à vous, / HVM ${ }^{96}$.

Cote 1.14 de la succession Nötzli, lettre du 10 octobre 1889; sur la question de la signature, évoquée dans cette lettre: cf. «1.5. Ambitions voilées et assumées: de la délimitation avec les champs de l'art et de la presse».
Si l'on ne dispose pas de la réponse de Jean Nötzli, l'étude du Nebelspalter nous livre cependant une partie de sa réaction. Peu de temps après, un encart paraît en couverture du numéro daté du I4 décembre I889:

À nos lecteurs. Avec le présent numéro un nouvel artiste se présente qui, en tant que collaborateur, livrera régulièrement des compositions. Il s'agit de Monsieur H. van Muyden de Lausanne, actuellement à Paris, bien connu dans les cercles artistiques comme dessinateur de premier rang. Celui-ci nous a déjà dans le passé confié sous le nom de « Pastarella » quelques contributions qui se sont fait brillamment remarquées. Que l'on se souvienne de "Bismarck en institutrice", "Boulanger sur le rocher », « Carnot », etc. Qui regarde ces images ainsi que le «Stanley » d'aujourd'hui devrait penser comme nous qu'un dessinateur de caricatures et de dessins humoristiques comme la Suisse en compte peu a rejoint l'équipe artistique du Nebelspalter. Messieurs le Professeur Jenny, F. Boscovits, sen. F. Boscovits, jun., entre autres, seront confortés dans leur collaboration, de telle manière que nous puissions prétendre à raison que le Nebelspalter dispose d'une équipe d'artistes comme aucun autre journal identique ou similaire. Le Nebelspalter doit, de ce fait, également adopter un nouveau procédé de réalisation technique, qui permettra de restituer plus fidèlement que jamais les dessins. Le volume du journal reste le même mais devrait, quoi qu'il en soit, s'accroître en cours d'année, au vu du nombre sans cesse croissant de ses amis. Nous offrirons, en outre, à nouveau chaque mois de grandes et belles images en couleur, comparables à celles ayant rencontré jusqu’à présent une forte adhésion. Pour ce qui est du texte, nous avons également attiré de nouveaux collaborateurs et nous nous félicitons de compter parmi nous les meilleurs et les plus renommés écrivains du pays. C'est ainsi que renforcé de toutes parts, le Nebelspalter aborde sa I $6^{\text {ème }}$ année de parution et espère rencontrer encore davantage la sympathie du public, proche comme lointain. Nous invitons donc à souscrire un abonnement sous des conditions inchangées (voir ci-dessus). Le présent numéro est la preuve de l'écho des insertions publicitaires du Nebelspalter. Les abonnements peuvent être contractés dans tous les bureaux de postes 
et librairies ainsi qu'auprès de l'expédition du Nebelspalter, Zurich, Bahnhofstrasse 98 , qui se recommande à vous ${ }^{97}$.

Il n'est pas si fréquent qu'un encart du Nebelspalter soit d'une telle ampleur. C'est cependant le cas à l'occasion des annonces importantes, souvent faites, comme ici, en début ou en fin d'année. La rédaction transmet en l'occurrence deux nouvelles d'importance: l'introduction d'un nouveau procédé de reproduction - très probablement le procédé Gillot ${ }^{98}$ - et l'arrivée officielle du dessinateur H. van Muyden alias Pastarella. H. van Muyden, c'est-à-dire Henri, et non Evert van Muyden dont on sait pourtant qu'il signe Pastarella, ainsi qu'il l'écrit dans sa lettre du 24 novembre I 887 où il remercie Richard Kissling pour sa médiation. Hors la signature, passablement équivoque et une calligraphie générale un peu différente, un autre indice conforte la réalité d'un changement de correspondant : la manière dont $\mathrm{H}$. van Muyden parle de Richard Kissling, dont il place l'hospitalité au même niveau que l'accueil que lui réserve Jean Nötzli, dénotant des liens plus distants que ceux du sculpteur avec son frère. Selon toute évidence, Evert van Muyden cesse sa collaboration en I 889 .

De fait, la correspondance est à partir de ce moment-là d'une autre tonalité, Son auteur révèle un tempérament ombrageux. Ce sera dès lors un échange nourri et passionné, où se mêleront les demandes de reconnaissance symbolique d'un artiste souffrant d'un manque de gratification, la critique des concurrents, les déclarations esthétiques en matière de hiérarchie des arts et de (bon) goût, les récits d'activités prestigieuses et plus alimentaires, les négociations financières et autres demandes de règlements d'honoraires, le tout fréquemment sur le ton de la mise en demeure. De cet échange, la dernière lettre, non datée, est parfaitement représentative:

Genève Champel 5 Chemin Bertrand / Monsieur Jean Nötzli Zürich / Cher monsieur / Excusez-moi, si je viens réclamer encore à propos de mes dessins. Mais ce matin, voyant que vous n'avez inséré qu'une mauvaise page charivarique en place des 2 dessins que je vous avais envoyés la semaine dernière, ma déception a été grande. Ils étaient d'actualités et

(An unsere Leser! Mit heutiger Nummer führt sich ein neuer Künstler, der aus künftig regelmäßig Beiträge liefert, als unser Mitarbeiter ein. Es ist dieß Herr H. van Muyden von Lausanne, gegenwärtig in Paris, als Zeichner ersten Ranges in der ganzen Künstlerschaft wohl bekannt. Derselbe hat uns schon früher unter dem Namen « Pastarella » einige Beiträge anvertraut, welche allgemeines Aussehen erregten. Wir erinnern an "Bismarck als Institutrice », "Boulanger auf dem Felsen », "Carnot » u. Wer diese Bilder, sowie das heutige, "Stanley », betrachtet, dürfte mit uns gleicher Meinung sein, daß hier ein Humor- und Karikaturenzeichner, wie die Schweiz wohl weinige kennt, in die Künstlerschaft des "Nebelspalter » eintritt. Die Herren Professor Jenny, F. Boscovits, sen, F. Boscovits, jun., u. a. werden fortfahren in ihrer Mitarbeiterschaft, wie bisher, so daß wir wohl mit Rech behaupten dürfen, der « Nebelspalter » verfüge über einen Stab von Künstlern, wie nirgend ein Blatt gleicher oder ähnlicher Art. "Der Nebelspalter » muss in Folge dessen auch in der technischen Ausführung zu einem neuen Verfahren greifen, welche hinwieder die Zeichnungen vortrefflicher, als bisher, wiedergeben wird. Der Umfang des Blattes bleibt der bisherige, dürtte sich aber, bei der stark wachsenden Zahl seiner Freunde, jedenfalls im Laufe des Jahres vergrößern. / Wir geben im Ferneren allmonatlich wieder große, schöne Farbenbilder, ähnlich wie die bisherigen, welche so reichen und allgemeinen Anklang fanden. Für den Text haben wir ebenfalls eine neue Anzahl von Mitarbeitern gewonnen und schmeicheln uns von den besten und bekanntesten Schriftstellern unseres Landes darunter zu finden. So tritt, nach allen Seiten verstärkt, der "Nebelspalter » seinen XVI. Jahrgang an und hofft in vermehrter Weise auch die Sympathie des Publikums in der Nähe, wie in der Ferne, zu finden. Wir laden deshalb zum Abonnement unter den bisherigen Bedingungen (dieselben siehe oben) ergebenst ein. Wie gesucht der « Nebelspalter » als Annoncenblatt ist, davon mag die heutige Nummer Beweis ablegen. Abonnements nehmen entgegen alle Postbüreaux \& Buchhandlungen, sowie die sich bestens empfehlende Expedition des Nebelspalter, Zürich, Bahnhofstrasse 98.); Nebelspalter 1889/51, couverture.

8 La difficulté de ce procédé était de faire correspondre les encres grasses avec le dessin au crayon bleu, censé ressortir à la composition. Sur ce procédé: cf. « 2.3.1. Identité, maquette et technique - Changements techniques et oscillations du titre $»$. clôturaient 2 événements. Croyez-bien que si je me voyais dans le corps de votre journal, remplacé de temps à autre par des dessins d'un ordre

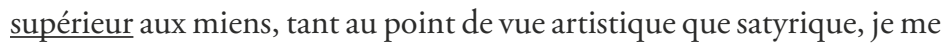
tairai, mais tel n'est pas le cas, et j'éprouve une sorte de blessure d'amourpropre, à être remplacé par des dessins tels que celui de Aus dem Dienst et son suivant. (ceci naturellement entre nous. - Je suis revenu de Paris dernièrement, et je me suis remis à travailler à votre intention avec l'idée de perfectionner mes dessins, mais très occupé à des travaux d'un ordre différent, je tiendrais à ce que le temps que je consacre à l'intention de votre journal, ne soit pas perdu; votre journal m'intéresse fort, et il me paraît que mes dessins ont contribué dans une certaine mesure à aider sa marche, ainsi que le prouve l'insertion de 3 de mes dessins dans les ouvrages de Grand-Carteret. - / Je serai dont heureux, de vous voir me consacrer toutes les semaines I page au moins, plus si vous pouvez, ou si vous n'insérez pas, de me renvoyer les dessins. Ceci bien entendu, s'entend que [je] de mon côté, je m'appliquerai davantage tant dans un genre que dans l'autre / Veuillez interpréter cher monsieur, tout ceci comme une conséquence de mon désir de contribuer à la bonne marche artistique de votre journal. / Quelques mots de vous, me disant la raison de ces non insertions qui sont pour moi une perte de temps, et de gain aussi. Ne pourriez-vous pas, si vous désirez le maintien du statu quo, me payez davantage, ce qui compenserait l'ennui des non insertions. I Pardonnez-moi, cher monsieur, la liberté que je prends de vous parler si franchement. / En attendant quelques mots de vous, je vous prie d'agréer ici, mes salutations bien dévouées. / H van Muyden ${ }^{99}$.

On ne peut que spéculer sur les raisons qui ont poussé Jean Nötzli à faire croire à un dessinateur unique. Evert et Henri van Muyden sont frères, issus d'une dynastie artistique romande, tous deux déterminés à y prendre leur place. Si, dans un premier temps, Evert réussit mieux que son frère, ainsi qu'en témoigne la longueur respective de leurs notices biobliographiques dans le Schweizerisches Künstler-Lexikon (Dictionnaire des artistes suisses) édité par Carl Brun ${ }^{100}$, aucun des d'eux ne connaitra une fortune équivalente au père. Alfred van Muyden (I 8I 8-I 898), originaire de Lausanne, est en effet reconnu comme portraitiste, peintre animalier et de genre. Il est également co-fondateur de la Société des amis des beaux-arts et est très impliqué dans les commissions des beaux-arts, municipales comme fédérales ${ }^{101}$. Des deux frères, seul Henri passera dans la postérité comme caricaturiste et collaborateur du Nebelspalter, où l'on verra ses dessins jusqu'en I $897^{102}$.

Quant à la proposition de Henri van Muyden en vue d'un dessin pour la nouvelle année, elle sera sans suite - enfin, pas tout à fait. L'année I 890 s'ouvre avec un numéro comptant une doublepage en couleur. Il s'agit d'un calendrier (protestant) illustré ${ }^{103}$ (cf. fig. I50 cahier couleur). On y voit le Nebelspalter assis

\footnotetext{
99 Cote 1.14 de la succession Nötzli, lettre sans date.

100 Carl Brun (éd.), Schweizerisches Künstler-Lexikon, vol. 2, Frauenfeld, Huber \& co, 1908, p. 463-464.

101 Hans Vollmer (éd.), Allgemeines Lexikon der bildenden Künslter von der Antike bis zur Gegenwart, vol. 25, Leipiz, E.A. Seemann, 1931 p. 302 ; Carl Brun (éd.), Schweizerisches Künstler-Lexikon, vol. 2, op. cit., p. 462-463.

${ }_{102}$ Ce n'est, du reste, pas systématiquement le cas. Il est désigné tel dans: E. Benézit, Dictionnaire critique et documentaires des peintres, sculpteurs, dessinateurs et graveurs de tous les temps et de tous les pays, vol. 10, Paris, Gründ, 1999, p. 54; Carl Brun (éd.), Schweizerisches Künstler-Lexikon, vol. 2, op. cit., p. 464 C'est sans doute ce dernier ouvrage, où les pseudonymes de «Pencil » et "Postarella » (avec une coquille orthographique) lui sont attribués, qui est à l'origine de la confusion entre les frères van Muyden. On retrouve cette erreur dans Le dictionnaire sur l'art en Suisse ainsi que dans le Dictionnaire historique de la Suisse; une incertitude demeure sur une deuxième phase de collaboration entre 1909 et 1912, où l'artiste aurait usé d'un nouveau monogramme.
} Nebelspalter 1890/1, double-page de Boscovits senior. 
sur un volume ouvert d'où s'échappent des feuillets, avec ses attributs, encriers et plume. Derrière lui, le peuple du Nebelspalter formé des personnages apparaissant dans le bandeau de titre. D'un côté, l'année I 889 qui s'en va, emmenée par le temps et poussée dehors par de gais amours. L'un deux, accoutré en savant, lit attentivement des feuillets du journal, etc. À gauche, la nouvelle année, représentée sous les traits d'une allégorie vêtue d'une robe rouge et couronnée de lauriers. Elle est assise sur le lion sculpté de Zurich et porte un sablier, faisant son entrée emmenée par une troupe d'autres amours, dont l'un lui jette des fleurs et l'autre porte le blé de la fertilité. Le fond est laissé dans le vague. Dans le côté droit, l'année finie s'enfonce dans les ténèbres etc. Soit à quelques détails près, notamment d'inversion, d'attributs et d'arrière-plan, la description faite par Henri van Muyden dans sa lettre du Io octobre I 889 où il essaie d'enlever la commande de cette image sûrement bien payée ${ }^{104}$. Sauf que l'auteur du dessin n'est finalement pas Henri van Muyden mais Boscovits senior. 


\section{CONCLUSION}

Entre I 875 et I92 I, le Nebelspalter observe une certaine unité, rompue en 1922 lors de sa prise en main par Ernst Löpfe-Benz et son déménagement à Rorschach, dans le canton de Saint-Gall. La revue est alors l'objet d'une profonde refonte éditoriale. De longues années, le périodique aura montré dans le bandeau supérieur de sa couverture un jeune homme chapeauté, avançant dans le brouillard, une énorme plume à la main, accompagné des acteurs d'une commedia des temps modernes. Progressivement, ceux-ci se seront installés dans les pages intérieures, s'y multipliant, alors qu'ils auront été effacés du bandeau, dans une seconde version, en I 880. Cela dit, même à l'intérieur, en tant qu'icones, leur place n'aura pas été garantie, puisqu'au fil du temps, ils se seront raréfiés, auront disparu, reparu, tels quels ou sous une nouvelle forme, symptômes des mues successives d'un périodique dont le cadre visuel et idéel est en fin de compte assez figé. Lorsque, durant les années Jugendstil, le décryptage sémantique du chapeau sera devenu délicat, Der Nebelspalter perdra, de la même façon, son article «Der» (le), qui assurait l'allégorisation. Mais pas d'un seul coup - rien n'est brutal dans l'histoire de la revue -, et l'on observera une période d'alternance d'une dizaine d'années avec des couvertures en noir et blanc, selon la formule originelle, et d'autres imagées, en couleur, apparues en I 897. De même, si l'on place en vis-à-vis la première et la dernière image du Nebelspalter zurichois, le bandeau de sa première couverture et la caricature clôturant le numéro 53 de l'année I92 I, qui pourrait affirmer avec certitude qu'elles ne sont pas issues d'un même numéro ? Les deux dessins montrent des figures devant un ciel menacé par la brume ou des nuages, ainsi qu'une kyrielle de personnages, dans une image soigneusement délimitée par un cadre au trait. Dans le premier cas, il s'agit des " affreux » fuyant devant la plume du Nebelspalter; dans le second, d'individus manifestant pancartes à la main contre la dureté de l'époque ${ }^{1}$. Comme dans toute revue, bandeau et couverture constituent les lieux les plus investis, où l'on montre et où l'on dénote, ici une certaine manière de se présenter et de représenter, étonnamment stable. Le temps du Nebelspalter a quelque chose de circulaire, d'antimoderne, en quelque sorte ${ }^{2}$.

Comme souvent à cette époque, la revue aura été l'affaire d'un homme, Jean Nötzli, enfin de deux, puisque Boscovits senior s'en avère le cofondateur et qu'il en prend après I900 officiellement le contrôle. Le rôle de Boscovits n'aura pourtant pas été aussi important que celui de Nötzli, homme de réseaux et fin stratège, on l'a vu. Cela dit, autant la succession Nöztli s'est montrée (relativement) disserte, autant les archives Boscovits n'ont laissé

Nebelspalter 1875/1, bandeau de la couverture; Nebelspalter 1921/53, dessin pleine page signé d'un monogramme et sans titre.

Octavio Paz, Point de convergence. Du romantisme à l'avant-garde, Gallimard, 1974 , p. 26-30. filtrer aucune information à ce sujet. Il faudra donc rester prudent face à ce qui peut être un effet d'optique de la dislocation des archives du périodique, dont la succession Nötzli n'est à l'évidence qu'un fade succédané. Mais, il faut se réjouir, et ceci sans mesure, de la réapparition - certes volontariste, car on aura beaucoup cherché - des deux fonds exploités durant les recherches. Ils n'ont, à notre connaissance, pas d'équivalent pour une revue de cette époque, et les enseignements qui ont pu en être tirés sur les hommes, les réseaux, le statut et les conditions économiques consentis aux dessinateurs, les accointances politiques, éditoriales et institutionnelles, sont par conséquent tout à fait exceptionnels.

Ces pans archivistiques ont été croisés, confrontés aux images du Nebelspalter, à un corpus, lui aussi exceptionnel, comptant dans les vingt mille dessins. Ces dessins ne sont ni simples ni communs, sans doute est-il utile de le souligner une dernière fois. Ils sont, rappelons-le, moins agressifs ou incisifs, si l'on préfère, que beaucoup de caricatures et dessins humoristiques d'autres revues satiriques européennes, pour lesquelles la censure n'est pas moins contraignante ${ }^{3}$. Cela, qu'on en considère l'iconicité ou la légende, ce qui suppose une entente, implicite ou explicite, entre la rédaction et les dessinateurs. Ils sont aussi très dépendants d'une tradition caricaturale, qui s'est affirmée et renforcée tout du long du XIX ${ }^{e}$ siècle, et dont ils ne s'affranchissent jamais tout à fait. On ne peut, en outre, que remarquer l'inscription timide du trait sur la page en noir et blanc durant la première décennie, puis la coloration très contrôlée de cette page; être frappé par cette bichromie en dégradés étrange, qui ne peut être qu'une simple histoire de technique. Que penser surtout de ce cadre au trait, à l'origine prolongement architectonique du bandeau de titre et qui ne commence à disparaître qu'après plus de trente ans, pour finalement revenir. Sa portée sémantique - il cadre littéralement les choses - semble d'ailleurs avoir été perçue par les artistes eux-mêmes, qui en jouent des années durant, bien au-delà de la mode Jugendstil. Ce cadre, Meyer Schapiro l'a démontré, est un signe iconique structurant ${ }^{4}$. Et lorsqu'il commence à disparaître, lentement à partir de I90I, voilà que c'est l'écriture gothique qui fait son entrée, en I9I3, toujours sur la couverture. Cet élément archaïsant est du reste repris en 1922 pour la couverture du Nebelspalter édité à Rorschach. Ces faits, si mineurs qu'ils puissent paraître, révèlent un rapport au passé - à quelles origines ? - à proprement parler atavique. Pensons qu'au moment où ces lignes

Sur ce point, cf. quoique très orienté sur la presse quotidienne: Jörg Requate Journalismus als Beruf. Entstehung des Journalistenberufs im 19. Jahrhundert. Deutschland im internationalen Vergleich, Göttingen, Vandenhoeck und Ruprecht, 1995.

Meyer Schapiro, «Sur quelques problèmes de sémiotique de l'art visuel: champ et véhicule dans les signes iconiques », dans Meyer Schapiro, Style, artiste et société, Paris, Gallimard, 1982, p. 7-14. 
sont écrites un éditeur, Marco Ratschiller, continue de faire vivre le Nebelspalter sous la forme d'un magazine et d'un site web, où le titre se détache avec ces mêmes lettres gothiques, devenues entretemps le signe d'une contre-culture.

Décrypter les images du Nebelspalter, au-delà de l'exercice iconographique de reconnaissance d'un motif, d'une figure ou d'un thème, de l'éclaircissement de la légende, est tout sauf aisé. L'étude de la symbolisation de l'espace, telle qu'on l'a menée avec le globe et les cartes notamment, n'a de sens que si l'on corrèle ces formes à une vision politique. De même pour les représentations de la ville, dont les éléments architecturaux et les topo $i ̈$ de la sociabilité n'informent le tissu social qu'une fois soustraits les schémas types fournis par d'autres revues européennes. Si ceux-ci sont esthétiquement intéressants, seuls les ajouts et remaniements renseignent l'histoire des idées. La représentation de la femme, quant à elle, ne prend sens que face aux évolutions sociétales - c'est une évidence - mais également dans un dialogue avec une allégorie relevant d'un système séculaire - Cesare Ripa, tout de même ${ }^{5}-$ auquel on prête des vertus de stabilité. Car l'époque est inquiète de son devenir, ce qui n'empêche pas les dessinateurs de fragiliser l'édifice allégorique en introduisant leurs personnages, la galerie des représentants, figurants et épouvantails du Nebelspalter. Si la pratique est usuelle dans les revues de l'aire germanique, le périodique zurichois bouscule, mine de rien, les conventions un peu plus que ses homologues.

L'utilisation de ces dessins, à présent. Toutes les images du Nebelspalter livrent, d'une manière ou d'une autre, un tribut à l'histoire de la Suisse, qu'elles traitent ou non de celle-ci; d'autant que quelque 5000 dessins thématisent une actualité suisse. Cette assertion est évidemment provocatrice. Les compositions du Nebelspalter ne peuvent être considérées comme des sources qu'au prix d'une sérieuse distance critique. Surtout quand l'on sait le caractère fallacieux des images satiriques, présentant une réalité filtrée, qu'il n'est pas si facile de décoder. Dans le cas du Nebelspalter, celles-là dénotent, de plus, très souvent une ambiguïé, les rendant d'un entendement difficile. Autant dire que la posture de nombre de publications, de vulgarisation mais aussi scientifiques, qui en font un usage démonstratif ou illustratif, est très périlleuse et ne peut certainement pas rendre compte de cette hyper-complexité de l'histoire suisse, justement pointée par Josef Mooser, très loin d'une réputation lisse ${ }^{6}$. Le Nebelspalter, comme l'histoire suisse, ne se livre pas facilement ${ }^{7}$.

Quant à la question des «grandes années » du Nebelspalter? Elle non plus ne trouve pas de réponse univoque. Tout dépend, en effet, de la manière dont on se place, même d'ailleurs à ne considérer que l'aspect visuel. Un (pur) historien de la caricature marquera une préférence pour les deux premières décennies, où la revue prend sa place dans ce que l'on appelle communément l'âge d'or des revues

Cesare Ripa, Iconologia: Overo Descrittione Di Diverse Imagini cavate dall'antichità, e di propria inventione, Rome, 1603 (fac-similé de 1970); Jean Baudoin, Iconologie ou explication nouvelle de plusieurs images, emblemes et autres figures hyerogliphiques de vertus, des vices, des arts, des sciences, des causes naturelles, des humeurs différentes et des passions humaines, Paris, Mathieu Guillemot, 1644 (fac-similé de 1999).

(Hyperkomplexität der Schweizer Geschichte); Josef Mooser, « Die "Geistige Landesverteidigung" in den $1930 e r$ Jahren. Profile und Kontext eines vielschichtigen Phänomens der schweizerischen politischen Kultur in der Zwischenkriegszeit », Schweizerische Zeitschifft für Geschichte, Bâle, Schwabe \& Co., 47, 4, 1997, p. 686.

Voir au sujet d'une zone de convergence entre l'histoire et l'histoire de l'art à propos des images: Kornelia Imesch et Alfred Messerli (éd.), Mit Klios Augen. Das Bild als historische Quelle, Oberhausen, Athena, 2013. européennes. Un historien de la culture arrêtera son choix sur la même époque mais pour des raisons différentes: la manne que représente la succession Nötzli ainsi que le rôle joué par la revue dans la structuration du champ de l'art suisse. Un historien, au sens classique du terme, retiendra les années de Première Guerre mondiale - les exemples se sont multipliés au cours de ces années de commémoration. Sans doute, ce seront les images bordant 1900 qui plairont à un large public, dont l'œil a été conditionné par les reproductions des affiches Art nouveau. Pour qui pratiquera, comme ici, une recherche sur l'image ressortissant aux Visual Studies, à la croisée de plusieurs champs disciplinaires, toutes ces images présentent un intérêt.

En I922, s'ouvre donc la seconde période historique du Nebelspalter. Elle court jusqu'en I953, date d'un changement rédactionnel, faisant basculer la revue vers sa forme actuelle de magazine. C'est un périodique exsangue que reprend l'éditeur Ernst Löpfe-Benz. L'ambition du jeune éditeur de 24 ans, futur représentant du parti libéral, est de (re-)donner à la Suisse une revue satirique de qualité ${ }^{8}$. Épaulée par quelques dessinateurs de génie - certains nouveaux, arrivant progressivement: Gregor Rabinovitch, Jakob Nef, Carl Böckli (Bö), Albert Lindegger (Lindi), Heinrich Danioth, Karl Arnold, Otto Baumberger, Ludwig Ehrenberger, Werner Büchi; d'autres plus anciens : Fritz Boscovits, Paul Bachmann et Ernst Morgenthaler ${ }^{9}$-, la nouvelle rédaction, d'abord confiée à Paul Altheer, puis à Carl Böckli à partir de I927, met tout en œuvre pour reconquérir le lectorat. Tablant sur une stabilité " éclairée ", qui ne se confonde pas avec immobilisme, la revue conserve deux éléments identitaires fondateurs : son titre «Nebelspalter» ainsi qu'un personnage pour l'allégoriser. Ce n'est plus cependant le Nebelspalter mais Prince carnaval (Prinz Carnaval), son concurrent depuis la fin de l'époque zurichoise. La première couverture de cette nouvelle ère le présente affairé à repriser la robe de Dame Helvetia (Frau Helvetia). «Tout le monde s'emploie à te raccommoder / Et ce la plupart du temps avec force bêtise / Tout le monde pense alors à soi / Et bien trop peu à toi ${ }^{10}$ : la légende a des allures de déclaration patriotique.

Plusieurs éléments de cette couverture concourent à une apparence renouvelée: la qualité du papier, la netteté de l'impression, un certain dépouillement aussi bien de l'image que du bandeau de la couverture, la mention du nom du dessinateur au-dessus du dessin, à droite, le placement du personnage au centre ainsi que son rendu en contre-plongée. Cette novation - il n'en est pas d'exemples dans le corpus zurichois - indique on ne peut plus clairement un changement de posture et de point de vue: le Nebelspalter reprend du galon et s'attèle à la tâche à la vue de tous. Le dessin emprunte peu au fonds caricatural: la légende ainsi qu'une simplification et une outrance formelles, avec un étirement de la robe et des membres du couturier. Plus généralement, il ne subsiste du répertoire traditionnel de la caricature qu'un petit choix de motifs récurrents: l'escargot, la monnaie et le garçonnet suisses, les allégories des pays, l'éternelle figure de l'ivrogne, ainsi que quelques principes : les métamorphoses, l'outrance ou l'inversion, mais plus les personnages à grosse tête, l'identification des figures dans l'image, les motifs idiomatiques ou autres procédés éculés.

\footnotetext{
Peter Métraux, Die Karikatur als publistische Ausdrucksform untersucht am Kampf des « Nebelspalters » gegen den Nationalsozialismus 1933-1945, op. cit., p. 26. Tous les dessinateurs ne sont évidemment pas cités ici.

" Jeder flick an Dir herum / Und dies meistens schrecklich dumm / Jeder denkt dabei an sich / Viel zu wenig auch an Dich »; Nebelspalter 1922/1, couverture de Ernst Morgenthaler intitulée « La robe » (Das Kleid).
} 
Si l'aspect général de la maquette ne connaît plus guère de modifications significatives, hormis un épaississement dû à une importance croissante des insertions publicitaires, elle n'est pas sans refléter des tâtonnements. Ainsi, on assiste, durant plusieurs années, à des allers-retours en couverture entre une option gothique et une option romane, révélateurs de difficultés persistantes à se situer entre tradition et modernité. Le lieu éditorial, lui-même, n'est pas vraiment fixe, et la double localisation jusqu'en I927, pour le rédacteur en chef Paul Altheer à Zurich, pour l'éditeur Ernst Löpfe-Benz à Rorschach, illustre cette identité incertaine ${ }^{11}$. Ce n'est en effet qu'avec l'arrivée à la rédaction de Carl Böckli que le Nebelspalter s'installe complètement à Rorschach. La solution que trouve la rédaction au terme de ces essais est d'abord linguistique: selon leur propos et leur destination, les compositions sont légendées, soit en haut-allemand, soit en dialecte suisseallemand. Carl Böckli procède à une standardisation en réalisant un compromis entre différents dialectes alémaniques: cette invention géniale permet une extension géographique du lectorat à l'intérieur de la Suisse alémanique ${ }^{12}$. La composante suisse, acquise à la fin de l'année I922, alors que le Nebelspalter devient une "revue humoristique et satirique suisse» (Schweizerische humoristisch-satirische Wochenschrift) n'est, en revanche, jamais remise en cause.

Alors que la dénonciation du nazisme du Nebelspalter durant le III ${ }^{\mathrm{e}}$ Reich est bien connue, notamment par la thèse de Peter Métraux, sa ligne politique, durant les années vingt et la première moitié des années trente l'est beaucoup moins. Le périodique constitue pourtant à cette époque une "poche de résistance helvétique » parmi la presse illustrée européenne. Débarrassé des composantes anticléricale et antisémite, le Nebelspalter soutient un discours très agressif à l'endroit de ce qu'il identifie comme des dérives autoritaires. Nazisme, communisme et fascisme, jusqu'aux visées hégémoniques des Etats-Unis, sont l'objet de charges très violentes. La revue frappe tous azimuts, générant et utilisant un complexe rhétorique, actualisé selon le contexte. Une couverture de Carl Böckli, publiée le 2 I mars I930, intitulée "Communisme contre fascisme "(Kommunismus gegen Faschismus), renvoie ainsi dos à dos les deux idéologies ${ }^{13}$. Un dessin anonyme daté du 29 novembre I929, intitulé « Terribles expériences d'un porteur de croix gammée » (Furchtbares Erlebnis eines Hackenkreuzlers), ne laisse, quant à lui, aucune ambiguité sur la condamnation précoce du nazisme ${ }^{14}$. Il est organisé comme une suite narrative sur le modèle de la bande dessinée : la première scène présente un homme en costume, portant au revers de son veston une croix gammée, dont l'attention est attirée par une personne en train de se noyer; l'homme va ensuite se dévêtir pour porter secours au malheureux; la scène conclusive montre le mouvement de recul de l'homme, lorsqu'il comprend que le noyé est juif, au vu de sa physionomie, un homme brun aux cheveux frisés ramenés en arrière, doté d'un nez fort et crochu, conforme aux codes usuels des représentations antisémites ${ }^{15}$. La connaissance de ces caricatures militantes est essentielle à la compréhension du Nebelspalter durant la Seconde Guerre mondiale, puis lors de la guerre froide. Le Nebelspalter

Cette double-localisation n'apparaît que sur la dernière page et non sur la couverture.

Bruno Knobel, Die Schweiz im Nebelspalter. Karikaturen 1875 bis 1974, op. cit. p. 145 .

Nebelspalter 1930/12, couverture de Carl Böckli intitulée « Communisme contre fascisme » (Kommunismus gegen Faschismus).

Cette dénonciation précoce est mal connue, car non identifiée par Peter Métraux, qui ne considère que les années où le nazisme est au pouvoir, à partir de 1933 Nebelspalter 1929/48, dessin anonyme intitulé « Terribles expériences d'un porteur de croix gammée » (Furchtbares Erlebnis eines Hackenkreuzlers). attaquera alors sans retenue le maccarthysme avec une rhétorique similaire à celle des compositions anticommunistes, comme dans une composition intitulée "Voici comment McCarthy se représentait les USA » (So stellte McCarthy die USA dar), publiée le I 8 mai I $950^{16}$.

Si la revue soigne un discours politique acerbe, elle ne renonce pas pour autant à ses ambitions artistiques et certainement pas à prendre sa place dans un univers des revues profondément remanié à l'issue de la Première Guerre mondiale. De très nombreux périodiques n'ont pas survécu au conflit ou en sont sortis considérablement amoindris, pour des raisons économiques, humaines et esthétiques ${ }^{17}$. La guerre a d'autre part permis à la photographie de consolider sa place dans les revues illustrées, au nom d'une objectivité dont on sait depuis à quel point elle est fallacieuse ${ }^{18}$. Le Nebelspalter évite cependant l'écueil d'un dessin concourant avec la photographie, mais publie, au contraire, des images contredisant la réalité. La photographie endosse un rôle discret et occasionnel de faire-valoir, se voyant sinon reléguée à une fonction commerciale, c'est-à-dire à une époque encore très marquée par les jugements de valeur du XIX ${ }^{\mathrm{e}}$ siècle, le contraire de l'art. Du récent passé, est tirée une autre leçon, qui est de ne pas rechercher un style " unitaire "-dans le Nebelspalter, une façon de lisser l'image par le cadrage, la couleur et une série de procédés caricaturaux -, limitant les écarts et évolutions, et comportant à terme le danger d'un discours antimoderne. Un dessin publié quelques semaines après la reprise du Nebelspalter, le I 5 février I922, "L'armée des chômeurs " (Das Heer der Arbeitlosen) est de la pure veine expressionniste ${ }^{19}$; une couverture postérieure de quelques mois, datée du I 8 juillet I 922, se présente comme un dessin futuriste ${ }^{20}$. Alliés à un discours social acide, ces choix vont permettre au Nebelspalter de rivaliser avec les grandes revues européennes de l'espace germanique. La partition va maintenant se jouer avec des revues satiriques ayant survécu à la guerre ou nouvellement créées, ainsi qu'avec des revues esthétisées, tel le berlinois Der Sturm, lié à l'expressionnisme. Le Nebelspalter va défendre la modernité helvétique, plus que jamais incarnée par Ferdinand Hodler, et soutenir un discours sur l'art suisse: la couverture d'un numéro spécial sur l'art (Sondernummer Kunst) de I930 aligne des vaches répliquées à n'en plus finir, emblèmes d'une auto-ironie crasse, qui devient une marque de fabrique ${ }^{21}$.

La dernière composante importante du Nebelspalter de cette seconde période est sociétale. L'éventail thématique est large, allant de la mémoire de la Première Guerre mondiale, encore très présente dans les années I920, jusqu'à une peur de la bombe atomique exprimée dans les années $1950^{22}$. Le propos n'est ni univoque ni très aisé à saisir. L'exemple le plus parlant est sans doute celui de l'émancipation féminine, sujet de nombreux

Nebelspalter 1950/20, dessin de F. Gilsi intitulé « Voici comment MacCarthy se représentait les USA » (So stellte McCarthy die USA dar).

Laurent Bihl, La Grande Mascarade parisienne. Production, diffusion et réception des images satiriques dans la presse périodique illustrée parisienne entre 1881 et 1914, op. cit., p. 163-174.

Joëlle Beurier, Photographier la Grande Guerre. France-Allemagne. L'héroïsme et la violence dans les magazines, op. cit., p. 13-19.

Nebelspalter 1922/7, dessin de A. Merkling intitulé « L'armée des chômeurs » (Das Heer der Arbeitlosen).

Nebelspalter 1922/7, couverture de A. Böckly intitulée « L'affiche du tournoi de gymnastique » (Das Turnfest-Plakat).

Nebelspalter 1930/19, couverture de Danioth; Knobel, Bruno, Die Schweiz im Nebelspalter. Karikaturen 1875 bis 1974, op. cit., p. 145

Nebelspalter 1950/ 36, dessin de Paul Bachmann intitulé « Sur la situation » (Zur Lage). 
textes et compositions. La revue renferme de manière continue entre I 923 et I953 une rubrique spécialisée, d'abord intitulée "La page de la femme» (Die Seite der Frau), puis «La femme d'aujourd'hui " (Die Frau von heute), alors qu'on revient dans les années 1950 à la première formule de "La page de la femme ». Sur deux ou trois pages sont publiés, sous un titre parfois illustré, des textes à destination des femmes, parlant des femmes et de leurs supposés centres d'intérêt. L'illustration du titre, lorsqu'elle existe, présente la femme dans une fonction typique - institutrice, laborantine, puis dactylo dans les années I950, par exemple -, alors que les textes, même lorsqu'ils affichent une thématique émancipatrice, fonctionnent sur des stéréotypes n'outrepassant en rien les représentations socialement admises. La femme au bain des années I920, apparemment en avance sur son temps, s'offre en fait au regard des hommes ${ }^{23}$. "La femme hypermoderne" (Die hypermoderne Frau) de I 953 fume sur un canapé rose au design extravagant, sous le regard désapprobateur d'un homme, à l'arrière-plan ${ }^{24}$. Elle apparaît comme émancipée jusqu'à ce qu'on remarque une des formes géométriques lui donnant son apparence cubiste. Placée au niveau des genoux, celle-ci représente un enfant, laissant finalement la fumeuse pour une madone moderne.

Les thèmes majeurs de ce discours sociétal sont la défense d'un "progrès raisonnable ", rejetant toute solution extrême et privilégiant les intérêts suisses; l'identité nationale, alors que s'élabore la notion de défense spirituelle ${ }^{25}$; le chômage de masse, qui génère des compositions nombreuses et souvent saisissantes; l'évolution des mœurs, l'essor des loisirs et l'immigration, ainsi que la société de consommation. Les publicités, très vite esthétisées et de grand format, souvent des photographies, deviennent un élément structurant de la maquette. Ces réclames pour des produits alimentaires, des fortifiants, des produits à raser, des appareils ménagers, des surgelés, des boîtes de conserve, des montres ou des cigarettes sont plastiquement souvent remarquables, et font de la revue un observatoire privilégié de la publicité moderne et de la culture visuelle en Suisse.

Toutes ces composantes - une maquette épurée, des dessins incisifs, une ligne politique claire, un libéralisme affirmé, une implication soutenue dans les questions sociétales, un rire maitrisé, un usage opportuniste du dialecte, en somme un virage réussi vers l'image de masse du $\mathrm{xx}^{\mathrm{e}}$ siècle assurent à nouveau au Nebelspalter un écho important: en I932, la revue tire à 9000 exemplaires par semaine; au milieu de la guerre, à 20000 exemplaires; en I945, on estime le tirage à 30000 exemplaires; au début des années I 960, à plus de 57000 exemplaires. C'est à ces tirages et à l'audience qui en découle que le Nebelspalter doit son statut actuel $\mathrm{d}^{\prime}$ « institution nationale $»^{26}$.
${ }_{23}$ Nebelspalter 1922/32, couverture de Fritz Boscovits.

Nebelspalter 1953/6, couverture de Paul Bachmann intitulée « La femme hypermoderne » (Die hypermoderne Frau).
Nebelspalter 1923/29, dessin de Otto Baumberger intitulé «Fête de la réconciliation politique » (Fest-Versöhnungs-Politik); Josef Mooser, « Die "Geistige Landesverteidigung" in den 1930er Jahren. Profile und Kontext eines vielschichtigen Phänomens der schweizerischen politischen Kultur in der Zwischenkriegszeit », op. cit., p. 685-708.

${ }_{26}$ (eine Art nationaler Institution); Peter Métraux, Die Karikatur als publistische Ausdruckform untersucht am Kampf des "Nebelspalters » gegen den Nationalsozialismus 1933-1945, op. cit., p. 28. 


\section{BIBLIOGRAPHIE SÉLECTIVE}

\section{Travaux académiques sur le Nebelspalter}

BORER-CIFRIC, Marija, Der "Nebelspalter " als kulturhistorische und politische Quelle des Kulturkampfes der Jahre 1875-1890, Zurich, 1999 (mémoire de licence).

DANGUY, Laurence et KAENEL, Philippe, « La plus ancienne revue satirique du monde. Genèse, histoire et visions du monde du Nebelspalter des années zurichoises (1875-1922)", Relations internationales I 53 (2013), p. 23-44.

DANGUY, Laurence, «L'immédiat après-guerre dans la revue satirique suisse Nebelspalter (1918-I92I)»Ridiculosa 20 (2014), p. 27-45.

DANGUY, Laurence, «Jean Nötzli, un éditeur zurichois et ses réseaux à la fin du XIX ${ }^{e}$ siècle ", dans Les acteurs du développement des réseaux, éd. Christiane DEMELEUNAERE-DOUYÈRE, Paris, CTHS, 2017, p. 65-77.

DANGUY, Laurence, «Le Nebelspalter zurichois (I875/192I): modèles et réseaux ", dans L'Europe des Revues II (I860-I930) II, éd. Evanghelia STEAD et Hélène VÉDRINE, Paris, Presse Universitaire de Paris-Sorbonne, 20 I 8 , p. 99-II7.

DANGUY, Laurence, «Johann Friedrich Boscovits, figure centrale du Nebelspalter des années zurichoises" dans Artistes en revues. Art et discours en mode périodique, éd. Laurence BROGNIEZ, Clément DESSY et Clara SADOUN-ÉDOUARD, Rennes, Presses universitaires de Rennes (2018).

DANGUY, Laurence, « Le salon caricatural du Nebelspalter ou le renversement des valeurs ", Actes du onzième colloque international IAWIS/AIERTI. La reproduction des images et des textes, éd. Kirsty BELL et Philippe KAENEL (en cours).

DEJUNG, Emmanuel, « I 5 Briefe des Malers Frank Buchser an Jean Nötzli Redaktor des "Nebelspalters " über den eidgenössischen Kunstkredit ", Jahrbuch für solothurnische Geschichte 50 (I977), p. I 5 I-175.

KREIS, Georg, "Zwischen Mangel und Überfluss, das Versorgungsproblem der Jahre 1939-1942 aus der Sicht des "Nebelspalters", dans Erinnern und Verarbeiten: zur Schweiz in den Jahren I933-I945, éd. Georg KREIS, Bâle, Schwabe Verlag, 2004, p. I I9-I 40.

MAGNIN, Nicolas, Bundesratskarikaturen im "Nebelspalter » von I875 bis 2004, Fribourg, 2005 (mémoire de licence).

MÉTRAUX, Peter, Die Karikatur als publizistische Ausdrucksform untersucht am Kampf des "Nebelspalters" gegen den Nationalsozialismus 1933-1945, Berlin, 1966 (thèse de doctorat).

OEHY, Milena, Karikaturistische Bildzitate aus dem "Nebelspalter » von I875 bis I955, Zurich, 2009 (mémoire de licence).

POTOCKI, Margarethe, «La neutralité face à la dictature: les stratégies du "Nebelspalter" suisse d'avant l'“Anschluss" en I 938 ", Ridiculosa 4 (I997), p. III-I 24 .

RATSCHILLER, Marco, Bedrohte Schweiz: nationale Selbstbilder, Fremdbilder und Feindbilder in der "Nebelspalter" - Karikatur des 20. Jahrhunderts: eine semiotische Untersuchung, Fribourg, 2004 (mémoire de licence).

\section{Travaux académiques s'appuyant sur le Nebelspalter de manière significative}

I4/I8 - Die Schweiz und der Erste Weltkrieg, éd. Roman ROSSFELD, Thomas HUOMBERGER, Patrick KURY, Baden, Hier+Jetzt, 2014.

AQUILLON, Daniel, Dans la trace des impérialistes: les Suisses en Orient I89oI9I4, Genève, 1980 (mémoire de licence).

DANGUY, Laurence, «Confisquée par l'image: la ville des revues germaniques autour de I900", dans Représenter la ville: entre cartographie et imaginaire, éd. Pierre-Yves LE POGAM et Martine PLOUVIER, Paris, CTHS, 20I3, p. 83-105.

DANGUY, Laurence, LORMANT François, OLIVIER Laurent, «L'arbre partisan. Représentations de l'arbre dans la communication des partis politiques ", dans Forêt et communication: héritages, représentations et défis, éd. Charles DEREIX, Christine FARCY et François LORMANT, Paris, L'Harmattan, 2016, p. 287-320.

DANGUY, Laurence, « Circulations de modèles entre l'aire germanique et l'Italie au début du Xx $x^{e}$ siècle: ouvrir un champ de recherches " (avec Vanja Strujkel et Francesca Zanella), dans L'Europe des Revues II (I860-1930) II, éd. Evanghelia STEAD et Hélène VÉDRINE, Paris, Presse Universitaire de Paris-Sorbonne, 20I8, p. I45-I64.

DOMEIER, Norman, « Der Eulenburg-Skandal (1906-1909) und seine antimonarchische und anti-homosexuelle Deutung in der Schweiz ", Traverse. Zeitschrift für Geschichte/Revue d'histoire, 201 5/3, p. 72-86.

ELSIG, Alexandre, «Entre discorde et concorde. La cohésion nationale à l'épreuve des propagandes ", dans I4/I8 - Die Schweiz und der Erste Weltkrieg, éd. Roman ROSSFELD, Thomas HUOMBERGER, Patrick KURY, Baden, Hier+Jetzt, 20I4, p. 72-IOI.

ELSIG, Alexandre, Les shrapnells du mensonge. La Suisse face à la propagande allemande de la Grande Guerre, Fribourg, 20I 4 (thèse de doctorat).

FISCHER, Mattias, Ferdinand Hodler in Karikaturen und Satire - Par la caricature et la satire, Sulgen, Benteli, $20 \mathrm{I} 2$.

HILBI, Georg M., Emil Dill: der Künstler als Chronist und Illustrator, Zurich, Chronos, 2017.

KAENEL, Philippe, Histoire de caricature en Suisse, Lausanne, Presses polytechniques et universitaires romandes, collection le savoir suisse, 2018.

KAENEL, Philippe, "Pour une histoire de la caricature en Suisse ", Nos monuments d'art et d'histoire 4 (I99I), p. 403-442.

KAENEL, Philippe, "Régénération, révolution, constitution. L'imagerie politique suisse", dans 1848 ; le carrefour suisse. Le pouvoir des images, éd. Philippe KAENEL, Zurich, Chronos Verlag, Lausanne, Payot, Lugano, Dadò, 1998, p. 43-84 (édition française).

KAENEL, Philippe, « Suisse-Allemagne (I848-19I8): neutralité et neutralisation du point de vue de la caricature ", in Zwischen Rhein und Rhone - Entre Rhin et Rhône-liens et ruptures, éd. Paolo BARBLAN, Arnold KOLLER et al., Zurich, Forum Helveticum, 2002, p. 100-106. 
KAENEL, Philippe, «Suisse-Allemagne (I848-I9I 8): neutralité et neutralisation du point de vue de la caricature ", Revue suisse d'art et d'archéologie I-2 (2003), p. 99-I I I.

KAENEL, Philippe, «L'histoire et les images. La figure de l'ouvrier en Suisse », Revue suisse d'histoire (2004), p. 20-56.

KAENEL, Philippe, VALLOTTON, François « Représenter la guerre en Suisse: du soldat au général ", dans Les images en guerre 19I4-I945: De la Suisse à l'Europe, éd. Philippe KAENEL et François VALLOTTON, Lausanne, Antipodes, 2008, p. 7-38.

KAENEL, Philippe, "Après I 848 : La France et l'Allemagne au regard de la presse satirique suisse", dans Révolution et contre-révolution dans la gravure en Europe de I779 à I889 / Revolution und Gegenrevolution in der europäischen Bildpublizistik I789-I889 / Revolution and Counter-revolution in European Prints from 1789 to I 889 , éd. Wolfgang CILLESSEN et Rolf REICHARDT, New Hildesheim, Zurich, New York, G. Olms, 20 Io, p. 424-44I.

KAENEL, Philippe, «Faire revivre l'histoire par l'imagerie vivante: John Grand-Carteret, Eduard Fuchs und die europäische visuelle Kultur um I 900 ", dans Mit Klios Augen. Bilder als historische Quellen, éd. Kornelia IMESCH OECHSLIN, Alfred MESSERLI, Julia BURCKHARDT et Mario LÜSCHER, Oberhausen, Athena, 2013, p. 85-108.

SCHRAMM, Julia, «Schweizerische Satire-Journale im Überblick. Von den Anfängen der Bildsatire bis zur Gegenwart ", Ridiculosa hors-série La presse satirique dans le monde (2013), p. 72-94.

WOLF, Walter, Faschismus in der Schweiz: Die Geschichte der Frontenbewegungen in der deutschen Schweiz 1930-1945, Zurich, Flamberg-Verlag, 1969 (thèse de doctorat).

\section{Publications de vulgarisation sur le Nebelspalter en provenance des éditions du Nebelspalter.}

Gegen rote und braune Fäuste: 380 Zeichnungen, gesammelt aus den NebelspalterJahrgängen 1932 bis 1948, Rorschach, E. Löpfe-Benz, I949.

Gegen rote und braune Fäuste: das Weltgeschehen von 1932 bis 1948 in 342 Karikaturen aus dem Nebelspalter, Rorschach, Nebelspalter-Verlag, 1970.

O du schöne, heile Schweiz: 99 Jahre Nebelspalter, Rorschach, NebelspalterVerlag I 973.

ALTHEER, Paul, Helvetiasgärtli: ein Hymnus in grosser Zeit: 36 Gedichte, erschienen im Nebelspalter, Zurich, Altheer, I940.

BÖCKLI, Carl, Figürli aus dem Nebelspalter, Rorschach, E. Löpfe-Benz, I 95 I. BÖCKLI, Carl, Bö-iges aus dem Nebelspalter, Rorschach, NebelspalterVerlag, 1962.

BÖCKLI, Carl, Euserein: 84 Zeichnungen und Verse aus dem Nebelspalter, Rorschach, Nebelspalter-Verlag, 1955.

BÖCKLI, Carl, go mal Bö: Zeichnungen und Verse aus dem Nebelspalter, Rorschach, Nebelspalter-Verlag, I959.

BÖCKLI, Carl, Ganze Schweiz: Sonnig und heiter. 25 fröbliche Geschichten aus dem Nebelspalter, Rorschach, Nebelspalter-Verlag, 1953.

BÖCKLI, Carl, Bö Helgeli : gesammelt aus dem Nebelspalter, Rorschach, E. LöpfeBenz, 1938.

BÖCKLI, Carl, Tells Nachwuchs: 62 Zeichnungen und Verse aus dem Nebelspalter, Rorschach, Nebelspalter-Verlag, I964.
BÖCKLI, Carl, Abseits vom Heldentum: Zeichnungen und Verse vom Bö aus dem «Nebelspalter», Rorschach, s. d. (vers I949).

BÖCKLI, Carl, Ich und anderi Schwizer: Zeichnungen und Verse aus dem "Nebelspalter», Rorschach, s. d. (1957).

BÖCKLI, Carl, Seldwylereien: 92 Zeichnungen und Verse vom Bö aus dem "Nebelspalter», Rorschach, s. d., (1949).

BÖCKLI, Carl, 84 Zeichnungen und Verse von Bö aus dem Nebelspalter, Rorschach, Nebelspalter-Verlag, I955.

GONZENBACH (von), Rolf, Landesplanung Ja oder Nein: eine knappe Auswabl aus den zablreichen Beiträgen in der Zeitschrift «Nebelspalter», Rorschach, E. Löpfe-Benz, I969.

JENNY, Hans (et al.), III Jahre Nebelspalter - Ein satirischer Schweizerspiegel, Rorschach, Nebelspalter-Verlag, 1985.

JOSS, Heinz, Mir Schwizer: 76 Zeichnungen aus dem Nebelspalter, Rorschach, Nebelspalter-Verlag, 1962.

KNOBEL, Bruno, Die Schweiz im Nebelspalter. Karikaturen I875 bis I974, Nebelspalter-Verlag, 1974.

SCHMEZER, Guido, Ein Berner namens... : 52 Verse aus dem Nebelspalter, Rorschach, Nebelspalter-Verlag, I96I.

TÜRMLER, S., «Oh, mein Türmlikon!»: 25 Städtebilder aus dem Nebelspalter, Rorschach, Nebelspalter-Verlag, I954.

WÄLTI, Walter, Wälti und seine Figuren aus dem Nebelspalter: Bilderbuch, Rorschach, Nebelspalter-Verlag, I95 I.

\section{Publications de vulgarisation} sur le Nebelspalter en provenance d'autres maisons d'édition

Darüber lachen die Schweizer Zeichner des «Nebelspalter», Constance, Kunstverein Konstanz, 1979 (catalogue d'exposition).

Otto Baumberger (I889-196I): Illustrationen Otto Baumbergers in der satirischhumoristischen Wochenschrift «Nebelspalter», Binningen, Arnold Erni, I990 (catalogue d'exposition).

BOHNE, Friedrich, Darüber lachen die Schweizer: Titelbilder, Karikaturen, Cartoons aus dem «Nebelspalter», Hanovre, Wilhelm Busch Wilhelm-BuschMuseum, 1973 (catalogue d'exposition).

KAIN, Thomas et SCHMID Regula, Fritz Boscovits (I87I-1965) - Ölgemälde, Uetikon am See, Fap, 2015.

KREISLER, Georg, Worte ohne Lieder: Satiren, Francfort-sur-le-Main, Ullstein, I988.

SAUTTER, Erwin A., Kurzgeschichten: im Nebelspalter erschienene Kurzbeiträge aus den Jahren 1983 und 1984 , Zumikon, E. A. Sautter, 1984.

SCHMID, Regula, Fritz Boscovits und der Nebelspalter, Baden, Hier und Jetzt, 2017.

THIEL, Andreas, Unbefleckte Sprengung, Zurich, Salis, 20 Io (contributions commentées par l'artiste).

WEBER, Ulrich, Das hohe C im Sektor D: III Nebelspalter-Wochengedichte, Zurich, Wado-Verlag, 1987.

WITSCHI, Peter, Jakob Nef, ein Appenzeller Nebelspalter, Herisau, Verlag Appenzeller Hefte, 2005 (catalogue exposition). 


\section{INDEX}

Aargauer Nachrichten 209

Adam, Mathilde 6

Afrique 30, 63, 8I, II 5, II 8,208

Albert I ${ }^{\mathrm{er}} \mathrm{I} 63$

Albrecht (Professeur) 51, 223

Alexandre III 30, 39, I09

Allemagne 2, 29, 30, 31, 32, 39, 43, 46, 51, 60, 63, 65, 69, 78, 81, 95, 99, 103, I07, I09, II2, I23, I27, I34, I47, I 50, I 52, I 54, I 59, I70, I73, I75, I97, 200, 203, 230

Alphonse XIII 2 I 3

Altheer, Paul 9, I 5, 92, I 47, I97, 240, 24I

Amiet, Cuno 60, I89, I92

Anderwert, Fridolin 129

Angleterre 30, 31, 39, 5 I, 60, 63, 78, 95, I09, I I 2, I33, I 50, I73, 233

Annunzio (D'), Gabriele I49, I 59, I75

Armée 29, 37, 43, 60, 63, 67, 93, 95, 99, I 23, I 27, I 29, I 3 I, I 50, I 52, I 57 , 228, 24I

Arnold, Karl 240

Art nouveau 47, 49, 54, 56, 57, 209, 240

Arts and Crafts 200, 206

Arx (von), Heinrich X

Asie 23, I I 2

Assemblée fédérale 23, 32, I 27, I 29, I 3 I

Association des aubergistes suisses 228

Assurance maladie-accident 37, I 23

Athéna 69, 198

Atlas I09, I I8, I 2 I, I 65

Attenhofer, Carl 69

Autriche-Hongrie 30, 39, 60, 78, I09, I I 2, I34, I75

Bachmann, Paul I6, I76, 240

Banque centrale (banque nationale) 37, 93, 95, I 23, I 37

Basler Nachrichten 209, 2 I 3

Bataille de Verdun 167

Baumberger, Otto 240

Beardsley, Aubrey 206

Bebel, August 46, 63, 78

Beetschen, Alfred I, 7, I 5, 33, 35, 75, 86, 88, 89

Belgique 39, 63, 78, 8 I, 95, I I 8, I34, I49, I63

Belle Époque 46, 47, 49, 5I, 54, 65, 99, I 45

Belloguet, André rog

Bergson, Henri I 37

Berliner Eulenspiegel 203

Berliner Zeitung I 57
Berna $5 \mathrm{I}$

Berner Mutz I95

Berner Volkszeitung I 25

Bernhard, Sarah 63

Beurmann Emil I 6

Bierbaum, Paul Willi I 50

Bille, Edmond I 54

Billet, B. I6

Bindschedler, H. I6, 97

Bismarck (von), Otto 29, 30, 43, 46, I09, I I 5, 230, 23 I, 236

Böckli, Carl 240, 24I

Böcklin, Arnold I0, I 3, 35, 69, I67, I89, I94, I95, 21 7, 219, 235

Böcklin, Carlo Io

Bolchevisme ( $v$ s antibolchevisme) 78, 84, 95, I03, I 25, I 27, I 70, I73, I75, I 77

Boscovits, Fritz (junior) I, 5, 6, 7, 9, I0, I I, I 3, I 4, I6, I7, 30, 47, 49, 54, 57, 58, 60, 6I, 65, 66, 70, 73, 76, 80, 8I, 83, 84, 85, 87, 88, 89, 93, 97, 99, Iог, I03, IO4, II2, II3, II 7, II 8, I22, I 36, I 37, I39, I40, I42, I43, I45, I 50, I 5 I, I 52, I 58, I70, I72, I85, I86, I87, I 89, I92, I93, I95, I97, I98, I99, 200, 208, 209, 2IO, 2I 2, 2I 3, 2I 4, 2I 7, 2 I $8,220,22 \mathrm{I}, 223,236,240$

Boscovits, Johann F. (senior) I, 5, 6, 7, 8, 9, IO, I I, I 2, I 3, I 5, I6, I7, I9, 22, $25,27,30,32,36,39,40,4 \mathrm{I}, 42,44,46,47,5 \mathrm{I}, 52,54,56,58,62,64,65$, $67,69,72,73,75,76,77,8$ I , 83, 86, 91 , 93, 97, 99, I03, I09, I Iо, I I I, I I 2, I I6, II 8 , I23, I 3 I, I 35 , I 44, I 54, I 55, I 56, I 57, I6 I, I63, I65, I 86, I 88 , I89, I95, I97, 203, 206, 208, 2I3, I36, 21 7, 22I, 223, 227, 230, 23I, 232, $233,234,236,238,239$

Boulanger, Georges (général) 29, 39, I09, 236

Brandstetter, Josef Leopold IX

Buchser, Franck I 4, 37, I 8 I, I 82, I 83, I 86, I 87, I92, 228, 229, 232, 235

Büchi, Werner 240

Büchmann, Georg 8I

Budget fédéral $37,123,183$

Bulgarie 39, 63, 78, I I 8

Bünzlin I 6

Bureau international des transports 233

Busch, Wilhelm I4

C'est la guerre de Vallotton I 65

Calonder, Félix-Louis I 54

Canada I I 5

Capitan 206

Caprivi (von), Leo 46, I I 2

Carnaval 3I, 37, 46, 49, 54, 58, 60, 65, 69, 73, 78, 86, 93, I 40, I 45, 223

Carnot, Sadi 39, 43, 213,236

Caserio, Sante Geronimo 39

Ce que disent les fleurs de Hodler I92, 2 I 9 
Centre (parti du) 30, 78,217

Cezanne, Augusto 209

Charles Ier I63, 175

Chine 39, 60, 63, 65, 78, 8I, 95, I I 2, I I

Chômage 93, 94, I 52, 242

Chronos I9, 22, 33, 5 I, 54, 67, 73, 84, I I 2, II I , I 73

Chueri et Nägeli 32, I34, 223

Clémenceau, Georges 63, I59, I73

Code civil 78, 84, I23, I 27

Combat des centaures de Böcklin 217

Commedia dell'arte 206, 239

Confédération XI, 22, 29, 35, 37, 39, 49, 56, 67, 78, 99, I03, I I 8, I 2 I, I 23 , I 27, I 29, I I I, I33, I34, I 47, I 49, I 54, I 57, I77, I8 I, I 83, I 86, I 89, I97, I98, 200, 22I, 229, 232

Conférence de Paris 173

Conférence de Londres 173

Conférence de Washington 173

Conférence économique interalliée de Paris de I9I6 I 52

Congrès de Bâle 76

Congrès des journalistes 37, I25, 229

Congrès sioniste 43

Congrès socialiste $29,37,76$

Congrès suisse de la presse 209, 2I 2, 22 I

Conseil fédéral I 27, I 29, I 34, I 52, I 54, I83, I95, 232, 233

Conseil national 22, IOI, I25, I 27, I29, 236

Constantin Ier 163

Constitution fédérale X, 26, I23, I27, I29, I3 I, I 57

Cook, Frederick 76

Corriere del Ticino 147

Corrodi, Salomon 235

Corso (cabaret) 60, 69, 99, 206

Crète 39, 78, 233

Cuba 39, II 5

Cubisme 200

Culture et civilisation (rhétorique) 39, 46, 65, 8 I, 95, I I 2, I 50, I I I, I63, I65, 223,225

Czerpien, Karl I2, I6, 94, 95, 96, 97, 98, I02, I03, I49, I 50, I 59, I60, I67, I97, 217, 222, 223

Dacho, F. 16

Dada I8I, 200

Dagen, Philippe 163

Danemark 78, II 8 , I 49

Danioth, Heinrich 240

Dans la serre d'Édouard Manet 86

Dans le jeu des vagues de Böcklin 217

Dante, Alighieri 8I, I65, I75, 217

Das Vaterland 125

Daumier, Honoré 9, I21, 206, 208

De Bock 16

Décadentisme 200

Decoppet, Camille 93, I 52

Défense spirituelle I 54, 242

Defregger (von), Franz Io

Delacroix, Eugène I 57, I67, 213

Denis, Maurice I65

Der Bund I 47, I 57, 209, 228
Der Floch 192

Der Gastwirth 229

Der Gukkasten IX, X, XI

Der Landbote 209

Der neue Postillon XI, I I, I92

Der Postheiri IX, X, XI, 5

Der Sturm 24I

Dier, Erhard I6

Dill, Emil 9, I I, I2, I6, I7, 33, 47, 200, 221, 230

Disteli, Martin IX, X, I4

Diveky (von), Josef I6

Divine comédie de Dante 175

Dix, Otto 165

Doré, Gustave 163, I65, 217

Dr. Entoutcas 206

Dreyfus (affaire) 43, 44, 63

Droit d'asile 37, 60, I 23, I47, I 49

Droz, Numa 32, 56, 228, 229, 232, 233

Drumont, Édouard 39

Dufour, Guillaume 93

Dunant, Henri 78

Duplice 30

Dupré, L. I6

Dürer, Albrecht I37, 2 I 3

Ebersold, Fritz I, 2, 7, I 5, 75, 81, 89

Ebert, Friedrich 173

École (question de l') 37, 60, 67, I23, I65, 225, 229

Edouard VII 63, II 5, 2 I3

Egli, Karl I 52

Ehrenberger, Ludwig 240

Élections fédérales 78, I 23, I 27

Épinal (image d') 56

Erler, Fritz 54, 206

Eschbach, J I6

Escher, Alfred I 33

Espagne 30, 31, 39, 63, 78, I I 2, I 49

Esterhazy, Ferdinand (Walsin) 43

États-Unis 23, 30, 39, 63, 78, 95, I I 2, I I 5, I I 8, I 49, I 50, I 59, I73, I 75, 230, 24I

Eulalia 32, 46

Eulenburg (zu), Philipp (Prince) 8I

Eulenburg-Harden (affaire) 78, 8I

Europe 2, 6, 23, 30, 32, 39, 5 I, 63, 69, 78, 95, 99, I03, I09, I IO, I I I, I I 2, I I 3, II 5, II7, II 8, II9, I II, I 22, I 33, I 34, I 45, I47, I49, I 52, I 57, I65, I70, I72, I73, I75, I77, I8I, 200, 203, 206, 208, 22 I, 227, 23 I, 232

Euterpe de Böcklin 217

Evangelica 26

Exposition nationale II, 23, 25, 29, 35, 37, 54, 56, 94, I25, I86, I87, I94, I98, 219

Exposition nationale suisse des beaux-arts I83, I86, I95

Exposition universelle 60, 73, I83, I86, I87, I95

Expressionnisme 200, 24I

Fables de La Fontaine 163

Fachoda (crise de) 223

Falk-Falk 227 
Fallières, Armand 2I3

Faure, Félix 43

Fauvisme 200

Felix, Hans ou Jacob I6

Ferdinand Ier de Roumanie I 59, I63

Fête nationale 38, I I 8, I 47

Fin-de-siècle 46, 200

Fleiner, Albert 229

Fliegende Blättter 5, I I, 203, 206, 209, 235

Foch, Ferdinand (maréchal) I73, I77

Fondation Gottfried Keller I 89

Forel, Auguste 8I

Forrer, Ludwig 69, 78

Forster (von), Günter 95

Frans, H. I6

Frau Politik (Dame politique) 54, I27, 206

Frau Rentier Schladeberg 206

Frau Stadtrichter 223

Frédéric III 43

Frey, Jean 2, 7, 9, I 5, 89, 93, I 52, 221, 229

Friedrichruh 230

Fürst, R. M. I6

Futurisme 200

Gallia 5 I

Gambetta, Léon 29

Ganz (photographe) 6,7

Gavarni, Paul 208

Gavroche 25

Gazette de Lausanne I47, I 50, 209

Germania 5I, 69, 84, 99, I 27, 208, 2 I I

Giers (de), Nicolas I09

Gillot (procédé) 33, 54, 237

Gobat, Albert I 82

Goethe (von), Johann Wolfgang 8I

Goppelsroeder, Ernst I6

Gothard 22, 23, 25, 29, 37, 78, 84, 93, I23, I 25, I 27, I 33

Graf, Emil 9, I2, I6, 47, 223

Grand conseil I 8 I

Grand-Carteret, John XI, 2I 9, 228, 229, 230, 23 I, 232, 237

Grandville, Jean-Jacques X, 208

Grèce 78,95 , I 18

\section{Grenzpost 5}

Greulich, Hermann 29, 78, 84, I 27

Grey, Edward I I 8

Grimm (frères) 167

Grimm, Robert I 54

Grimm-Hoffmann (affaire) I 54

Guerre italo-turque 8I, 83, 223

Guerre sino-japonaise 39, 223

Guerres balkaniques 78, 8I, 95, 223, 225,

Guguss' au Grand Théâtre XI, I92

Guillaume Ier 43, 49

Guillaume II 37, 43, 58, 63, 69, 76, 78, 8 I, I09, I I 5, I 59, I 75, I 86

Guillaume Tell 33, 67, I75

Guillaume Tell de Hodler I92, 2 I 9
Guillaume Tell de Kissling 37, 22 I

Guillaume Tell de Schiller 65

Haber, Sigmund 206

Hanotaux, Gabriel 233

Harden, Maximilian 8I

Hardung, Victor 97, I73, 200

Hauser, Johann 7, I 5, 56

Haute-Silésie I I 8, I75

Haydn, Joseph 8I

Heimatstil I, 9, 35, 54, 56, 65, 73, 75, 8I, 83

Heine, Heinrich 8I

Heine, Thomas, Theodor I I, 65

Helvetia 22, 32, 39, 49, 54, 60, 67, 69, 76, 78, 84, 99, I 03, I I 2, I I 5, I 2 I, I 23 , I 25, I 27, I 29, I 3 I, I 33, I 34, I 49, I 59, I 8 I, I 87, I 98, 2 I 7, 223, 240

Helveticus 84

Henneberg, Rudolf 46, 2 I 3

Henrik, H. I 2, I6, I7, I I9, I 52, I65, I73

Herr Feufi 32, I 34

Herstensein, Wilhelm $22 \mathrm{I}$

Herzog, Hans 35, 93, I 3 I, 22 I

Herzog, J. (imprimeur) 23

Hess, Hieronymus X

Heyn, August I 89, 208

Hildegard Stoobkübel 206

Hindenburg (von), Paul I I 8

Hintermeister, Hermann I I, I 2, I 6, 97

Hirschler, Alfred I2, I6, I7, 95, I66, I67, I74, 2 I 3

Hoffmann, Arthur I03, I 54

Hoffmann, Karl I 29

Hohenlohe-Schillingsfürst (zu), Chlodwig 46

Holbein, Hans (le Jeune) 46, I67, 2 I 3, 217

Hollande 78, I i 8

Hongrie 39, 78, I 2 I

Huart, Louis 209

Huber, Emil I 2, I6, 83, 89, 97, 208

Huber, Eugen 78, I 27

Huber, Hermann 194

Huber, Rudolf I, 2, 7, I 5, 75, 81, 86, 89, 223

Hugo, Victor 32

Ibsen, Henrik 69, I37, 2 I 3

Identité nationale 2, 35, 76, I 33, I 54, I 8 I, 242

Illustrierte Zeitung 229

Inde 39, I I 2

Italia 5 I, I 33

Italia ride 209

Italie 25, 30, 39, 5 I , 60, 63, 8 I, 95, I09, I I 2, I I 8, I23, I 33, I 34, I 75, 230, 233 Iwan 159

Japon 39, 46, 63, 78, 95, I I 2, II 5

Japonisme 73, I92, 200

Jenni, Friedrich IX, X

Jenny, Hans I75

Jenny, Heinrich 9, I I, I 4, I6, I 7, 33, 46, 47, 49, I 24, I83, I 84, I92, I98, 20I, 228, 229, 230, 236

Jocko ou le Révélateur XI 
John Bull 159

Jonathan (oncle) II 8

Jossot, Gustave Henri 65, 83, 97, 208

Journal amusant 209

Jugend XI, I I , 25, 26, 49, 54, 73, 86, 97, I 40, I4I, I 89, I92, 200, 206, 208, 209, 2 II, 217

Jugendstil I, 9, I0, I2, I 3, I4, 33, 35, 46, 47, 49, 5 I, 54, 58, 65, 67, 69, 73, 75, $78,83,84,86,97,99$, I I 2, I 2 I, I 25 , I 27, I I I I I 37, I 40, I 45, I 54, I 57, I 70, I 87, 200, 206, 209, 223, 239

Kälin Küpfer, Josef I 2, I6, I7, 65, 67, 83

Kalnoky, Gusztav 109, I I 2

Keller, Gottfried 5, 8I, 86, I 89, 221, 235

Kirschinew (pogrom de) 60

Kissling, Richard 37, 209, 221, 235, 236, 237

Kitchener, Horatio 58,63

Kladderadatsch 192

Kling, M. I6

Knobel, Bruno 35

Knüsli, C. 9, I6, 23

Kocher, Emil Theodor 78

Koller, Rudolf I4, I 82, I 86, 235

Kotze (affaire) 46

Kranich I6

Krüger, Paul 63, 75

Kulturkampf 22, 26, 28, 30, I 25

Kunstgesellschaft го, 198

Kunsthaus I3, 29, 60, I89, I97, I98, 200, 229

Künstlerhaus I3, I86, I87, I89, I92, I93, I98, 229

Künstlervereinigung I0, 192

Künzli, Arnold I29, I3 I

L'Arbalète I 52, I 54

L'Assiette au beurre II, 208

L'Aurore 43

L'émotion de Hodler 219

L'Enfer de Dante par Gustave Doré I65, 217

L'Érasme de Holbein 213

Lile des morts de Böcklin 166, I67, 217

L'unanimité de Hodler I 57, 219

La bataille de Näfels de Hodler 192, 2 I 9

\section{La Caricature X}

La chasse au bonheur de Rudolf Henneberg 46, 56, 213

La colline jaune de Cuno Amiet 192

La dame au cochon-Pornokrates de Rops 2I 3

La danse macabre de Holbein (Totentanz) 46

La dernière sommation de Franz Deffregger 217

La Guêpe XI

La guerre de Böcklin 167, 219

La liberté guidant le peuple de Delacroix I 57, I67, 213

La libre-parole 39

La peste de Böcklin I89, 219

La Retraite de Marignan de Hodler I95, 219

La Suisse 159

Ladislaus et Stanislaus 32, 223

Landboten 5

Langen, Albert 208
Langie, André I 52

Laocoon 26, 213

Laur, Ernst 178

Lauterburg, Emil I 6

Lauterburg, Otto 208

Le Bûcheron (billet de 50 francs) de Hodler 219

Le Carillon de Saint-Gervais XI

Le Charivari X, 203, 206, 208

Le faucheur de Hodler 219

Le Figaro 43, I 57, 219, 228, 229, 230, 23 I, 232

Le Frou Frou 205, 206, 213

Le Grand hiver de Cuno Amiet 192

Le Papillon XI, II

Le Printemps de Hodler 192, 219

Le Rire (revue) 209

Le Sapajou II I 92

Le Semeur de Millet $2 \mathrm{I} 3$

Lehmann-Schramm, Willy 9, I I, I 2, I 3, I6, 33, 34, 38, 46, 47, 48, 49, 50, 5 I, $54,55,58,65,67,68,69,73,75,78,8 \mathrm{I}, 83, \mathrm{I} 87$, I89, I94, I95, I96, 200, 204, 206, 207, 219, 223, 224

Les Âmes déçues de Hodler 219

Les Las de vivre de Hodler 219

Les quatre cavaliers de l'Apocalypse de Dürer I37, 2 I 3

Les revenants d'Ibsen 213

Les Trois Grâces 213

Les victimes du travail de Vincenzo Vela I 8 I

Lex Heinze 63, 213, 217

Liberty 209

Libre-échange 63, I34

Liermann, Frieda I6, 97

Ligue suisse des beaux-arts (Schweizerische Kunstliga) 232

Lilie, Walter I I, I2, I6, 97, I65, I68, 200

Lindegger, Albert 240

Lloyd George, David I 2 I

Löfftz (von), Ludwig Io

Loi sur les faillites 123

Löpfe-Benz, Ernst 213, 223, 239, 240, 24I

Loubet, Émile 63

Luitpolde von Seeflange 206

Lüstige Blätter 192, 206, 209

Maasen, Paul 16

Mackart, Hans 14

Maehly, Otto I2, I6, I7, 33, 46, 65

Marrug, L. I2, I6, I92, 194

May (de) I6

Mayer (ou Meyer) I6

Meggendorfer Blätter I I

Messmer, Charles I6

Métraux, Peter 5, 7, 24I

Meyer, Conrad Ferdinand 35, 56

Mohr, S. I2, I6, I7, 97, 99, I62, I63, I64, I71, 219

Moos, Karl I6

Mooser, Josef 240

Morgenthaler, Ernst I6, 240

Muyden (van), Alfred 237

Muyden (van), Evert 9, I I, I 2, I6, I7, 46, 47, 49, 209, 228, 235, 236, 237 
Muyden (van), Henri 9, I I, I 2, I 5, I6, I 7, 33, 47, 49, I 29, I 86, I 87, 209, 22 I, $228,235,236,237,238$

\section{National-Zeitung 209}

Naturalisation 84, I 23

Nebelspalter (personnage) 7, 9, I 9, 22, 23, 25, 29, 31, 32, 33, 35, 49, 51, 54, 65, $67,73,84,86,94,99$, I03, I 2 I, I 23, I 25, I 27, I 29, I 3 I, I 33, I 34, I 37, I 49, I 87, I $90,200,203,206,208,209,22 I, 223,232,237,239,240$

Nef, Jakob 240

Neue Freie Presse 209, 229

Neue Zürcher Zeitung 6, I6, I 47, I 57, 209, 221, 229

Neutralité XI, 2, 30, 3 I, 37, 39, 95, I03, I 23, I 47, I 49, I 52, I 54, I 57, I 75, I 77 Nicolas Ier de Monténégro ${ }_{1} 63$

Nicolas II 39, 60, 63, 69, I I 2, I I 5, I 59, I 63

Norvège 63, I I 8 , I 49

Nötzli, Jean XI, I, 5, 6, 7, 9, I I, I 2, I 3, I4, I 5, I9, 22, 32, 33, 5 I, 54, 56, 58 , 69, 73, 75, 9I, I23, I 8 I, I 82, I 83, I87, 203, 209

Nunne 206

Orient (question d') 30, 39, 8 I

Pacte fédéral 54

Pan jouant de la Syrinx de Böcklin 2 I 7

Panama (scandale de) 39

Paula Erbswurst 206

Paysage d'été de Hodler 219

Peary, Robert 76

Perrier, Casimir 43

Pestalozzi, Johann 37, 67, 78, 84

Philippon, Charles 209

Picasso, Pablo 94

Pie X 60, 65

Pierre Ier de Serbie ${ }_{1} 63$

Piguet, Raoul I 6

Pogroms 39, 60, 223

Poincaré, Raymond I 97

Pologne 39, I75

Popolo I 47

Port-Arthur (massacre) 225

Première bataille de la Marne 167

Première conférence de La Haye 37, 39

Première Guerre mondiale IX, 2, 46, 75, 89, 93, I07, I09, I I 5, I 3 I, I 33, I 45, I65, I70, I92, 208, 217, 223, 240, 24I

Préraphaélisme 200, 209

Prince carnaval 86, 94, I03, 221, 223, 233, 240

Proportionnelle 37, 60, 78, 93, 95, 99, IOI, I25, I29, I3 I

Punch 203

Python, Georges 35, 49

Question ferroviaire 63

Rabinovitch, Gregor 240

Ramp, James I6

Ranstegg, t. A.I I 6

Raphaël 2 I 3

Raquette, M. I2, I6

Ratschiller, Marco 240
Régénération IX, X

République helvétique I27, I3 I, I98

Révolution française 39

Révolution russe (1905) 67

Révolution russe (I9I7) 95

Révolution tessinoise I 29

Revue des deux mondes IX

Rickli, Herbert I6

Ripa, Cesare 32, 240

Ropaz I6

Röpe, F. I 6

Rops, Félicien 2 I 3

Rorschach I0, 86, 213, 223, 239, 24I

Rosegger, Peter 69

Rossi, Luigi 29

Roth, Arnold 69

Rothschild (de), Edmond 43

Roumanie I I 8, I34, I 59

Rubens, Pierre 2 I 3

Ruchonnet, Antoine 22I

Ruchonnet, Louis I 29

Rüegg, Ernst I 6

Ruskin, John 209

Russ, Willy I97

Russie 30, 39, 5 I, 60, 63, 78, 95, I09, I I 2, I 34, I 54, I 75, 233

S. Galler Tagblatt 209

Salander, Martin 89

Salis, T.S. I 2, I6, 89

Salon caricatural 49, 60, I86, I87, I89, I92, I94, I95, I98, 208, 209, 2 I9

Salon de Berlin 2 I 7

Sartoris, Spyridon I 6

Saverne (incident de) 95

Scapino 206

Schaffhauser Zeitung I47, I49

Schalcher, Traugott 16

Schapiro, Meyer 239

Schenk, Karl I82, I83, I98

Schiller (von), Friedrich 65, 59

Schlegel, Karl I6, I7, 97

Schmid, Fritz I6

Schmidhammer, Arpad 208, 209, 2 I I

Schmidt Cäsar 22 I, 229, 230, 231, 232

Schneider, Prof. Dr. I 3 I

Schobinger, Josef Anton 223

Schulthess, Edmund I 54

Schützenfest 3 I, I 28, I8 I

Schweizer, Wilfried I 2, I6, 83, 90, 91, 97

Schweizerische Hauszeitung 229

Schweizerische Rundschau 228, 229

Schweizerischer Bilderkalender X

Schweizerisches Künstler-Lexikon 6, I6, 237

Sécession de Lucerne I8 I, I 86

Sechseläuten 6, 7, I0, 31, 37, 46, 58, 60, 78, 95

Secolo 219, 229, 231

Seconde conférence de La Haye i i 8, I 47, I 65 
Seconde guerre des Boers 39, 58, 63, I 49, 223

Segantini, Giovanni I 4, 86

Seidel, Robert I 50

Selig, Hans ou Jakob I6, 92

Seligmann, Adalbert Franz 209

Serbie 63, 78, I I 8, I 34

Silvestrelli (affaire) 63

Simmel, Georg 137

Simplicissimus II , 25, 49, 65, 208, 209, 21 3

Simplon 37

Société des Amis des Arts de Francfort 197

Société des Nations I I 8, I70, I75, I77

Société des peintres et artistes suisses I 82, I 86

Société suisse de surveillance économique I 59

Société suisse des femmes peintres, sculpteurs et décoratrices I 8 I, I 86

Soulèvement des Macédoniens 223

Spiller, Else I 50

Spitteler, Carl 78, I 50

Sprecher, Théophile I 52, I 57

Staehle, A. I2, I6, I7

Steffen \& Coccini 228

Steinlen, Théophile 65

Stock 17, 83, I45

Straus, Victor I6, I7, 97, I 20, I75

Strübin, J. I6

Stückelberg, Ernst I 82, I 86

Stückelberger, Wilhelm I I, I6

Suchard 32, 197

Sudermann, Hermann 81

Suède 63 , II 8 , I 49

Suez (canal de) 30, 31, 225

Sulzberger, Adolf I I, I6, 5 I

Symbolisme I4, 49, 73, 86, 97, 200

Tages-Anzeiger 37, 22 I

Tessin 29, 37, 76, I33, I 54

The Studio 206

The Times I57, I59, 163

Thesing, Paul II, I 2, I6, 95, 97, I00, I48, I75

Thomas, Albert I 54

Tiens peuple, tiens bon peuple, en veux-tu, en voilà de Daumier 206

Tolstoï, Léon $8 \mathrm{I}$

Tonhalle 35, 37, 56

Töppfer, Rodolphe IX

Traité de Versailles 173,225

Transvaal 39, 58, 63, 67, 73, 75, I I 5, 223

Treichler, Arthur I I, I 2, I 6, I7, 97, 99, I69, I70

Tribune de Lausanne $\mathrm{I} 52$

Triplice 30, 39, 60, II 5

Turica 51, 198, 200

Turnus (exposition suisse des beaux-arts) 29, 37, I 8 I , I 82, I 86, I 89, I92, 208

Turquie 39, 95, I75
Tyrol 175

Ulk II, I92, I95, 206

Ulrich, Johann Jakob IX

Ulrich, Paul 198

Un bar aux Folies Bergère de Manet I 40

Vallotton, Félix I65

Vatican 149

Vela, Vincenzo I 8 I

Venizélos, Elefthérios I 59

Vénus de Médicis 213

Vénus de Milo 8I, 2 I 3

Ver Sacrum 198, 217

Visual Studies 240

Vogel, Georg Ludwig I4

Vögelin, Salomon 228, 229

Volksrecht 22I

Vorticisme 200

Wackernagel (procès) 2 I3

Wagner, Alexander Sandor 6

Wagner, Richard 8I

Waldmann, Hans 67

Wanger, Franz 16

Wattenwyl (von), Friedrich I 52

Wedekind, Franz 78

Welti, Emil 32, I3 I, 229

Wettstein, Heinrich $22 \mathrm{I}$

Wettstein, Oskar I 50

White, Harrison 229

Wille, Ulrich 37, 93, I 50, I 52, I97, 22 I, 228

Wilson, Woodrow I 50, I 59, I67, I73, I75

Winkler, Johann I 86

Wirz, Hans I 4, I6, 46, 47, 5 I, 53

Witte, Serge 213

Wochenzeitung XI

Zasche, Theodor 206

Zemp, Joseph 223

Zentralbibliothek de Zurich 5, 227

Zeus I I 2

Zola, Émile 43, 49, 63

Zone franche 177

Zorilla, Ruiz I I 5

Zürcher Kunstverein I 86, I 89

Zürcher Presse 5

Zurich IX, XI, I, 2, 5, 6, 7, I0, I4, I9, 22, 29, 35, 46, 5I, 54, 60, 67, 69, 78, 9I, 93, 94, I I 2, I I 5, I 2 I, I 25, I 29, I 3 I I I33, I 34, I 36, I 37, I 40, I 44, I 45, I 50, I 52, I 8I, I86, I 89, I94, I97, I98, 200, 206, 207, 209, 2I9, 223, 227, 228, 229, 23I, 235, 236, 237, 238, 24I

Züricher Post I 47, I 57, 209, 22 I

Zwingli, Ulrich 31, 58, 67, I 37 


\section{TABLE DES ILLUSTRATIONS}

Fig. I. Nebelspalter I 899/52, couverture en couleur de Boscovits senior...............

Fig. 2. Nebelspalter I9I 2/48, dessin pleine page en couleur de Boscovits senior intitulé «Adieu » (Abschied)..

Fig. 3. Nebelspalter I $894 / 9$, double-page en couleur de Boscovits senior intitulée "À l'occasion du numéro Iooo du Nebelspalter " (Nebelspalter bei Nro. I00o).

Fig. 4. Nebelspalter 1908/30, dessin en couleur de Boscovits junior intitulé « Mal dessiné » (Verzeichnet).

Fig. 5. Nebelspalter I 875/I, couverture.

Fig. 6. Nebelspalter I 875/I, dessin en noir et blanc non signé intitulé «Santé Maman!» (Prosit Mamma!).

Fig. 7. Nebelspalter $\mathrm{I} 88 \mathrm{o} / 2$, couverture

Fig. 8. Nebelspalter $1876 / 53$, encart.

Fig. 9. Nebelspalter I 877/I I , dessin pleine page en noir et blanc signé Boscovits senior intitulé «L'origine de la crise » (Die Ursache der Krisis). 27

Fig. Io. Nebelspalter I 875/3 I, dessin pleine page en noir et blanc non signé intitulé «Le grand combattant du Kulturkampf » (Der grosse Kulturkämpfer).

Fig. I I. Nebelspalter I 875/8, dessin anonyme en noir et blanc et sans titre (dernière page).

Fig. I 2. Nebelspalter I 875/40, couverture en noir et blanc non signée intitulée "Une image de notre pays » (Ein Bild unsers Vaterlandes).............31

Fig. I 3. Nebelspalter I 897/52, couverture en couleur de Willy LehmannSchramm.

Fig. I4. Nebelspalter I 897/32, dessin pleine page en noir et blanc de Boscovits senior intitulé "À votre bon cœur " (Die Herzen auf).

Fig. I 5 . Nebelspalter I 895/38, dessin pleine page en noir et blanc de Willy Lehmann-Schramm intitulé "Ballade dominicale de végétariens " (Vegetarianers Sonntag-Nachmittag-Spaziergang).

Fig. I6. Nebelspalter I 894/17, double-page en couleur de Boscovits senior intitulée "Les gladiateurs modernes " (Die modernen Gladiatoren).......... 40

Fig. 17. Nebelspalter I 895/19, dessin pleine page en noir et blanc de Boscovits senior intitulé « Ennemis héréditaires " (Erblich belastet)............41

Fig. I 8. Nebelspalter I 894/27, double-page en couleur de Boscovits senior intitulée " Deux victimes " (Zwei Opfer).

Fig. 19. Nebelspalter I 898/33, dessin pleine page en noir et blanc de Boscovits senior intitulé « En France " (In Frankreich).

Fig. 20. Nebelspalter I 898/I, dessin pleine page en couleur de Boscovits senior intitulé «Affaire Dreyfus ».

ig. 2 I. Nebelspalter I 899/32, dessin pleine page en noir et blanc de Boscovits senior intitulé « Le procès Dreyfus »(Dreyfus-Prozess)............... 44

Fig. 22. Nebelspalter I 897/I3, dessin en noir et blanc non signé intitulé «Il provoque» (Provozirt).

Fig. 23. Nebelspalter I 892/53, dessin en noir et blanc de Henri van Muyden. 47
Fig. 24. Nebelspalter $894 / 40$, dessin pleine page en couleur de Willy Lehmann-Schramm intitulé «Automne » (Herbst). 48

Fig. 25. Nebelspalter I 899/27, dessin pleine page en noir et blanc de Willy Lehmann-Schramm intitulé « Ô, cette jeunesse !» $(O$, diese Jugend)........ 50

Fig. 26. Nebelspalter I 894/4I, dessin pleine page en noir et blanc et sans titre de Boscovits senior.

Fig. 27. Nebelspalter I 893/29, dessin pleine page en noir et blanc de Hans Wirz intitulé «Justice locale » (Heimliche Gerechtigkeit).

Fig. 28. Nebelspalter I 899/39, couverture en couleur de Boscovits junior intitulée "À la nouvelle année I888! " (Prosit Neujahr I888!).

Fig. 29. Nebelspalter I 897/3 I, couverture en couleur de Willy LehmannSchramm.

Fig. 30. Nebelspalter I 898/ I 5 , couverture en couleur de Willy LehmannSchramm.

Fig. 3 I. Nebelspalter I 887/49, double-page en couleur de Boscovits senior intitulée « S'ils ont de la chance... » (Ob sie Wohl glück vorüber kommen).

Fig. 32. Nebelspalter I 888/23, double-page en couleur de Boscovits senior intitulée « La course à la fortune " (Die Jagd nach dem Glück). . $.1 X$

Fig. 33. Nebelspalter I 894/9, dessin pleine page en couleur de Willy Lehmann-Schramm intitulé " Comment "il" agit » (Wie « er » wirkt)..... 55

Fig. 34. Nebelspalter 1901/24, dessin pleine page en noir et blanc de Boscovits junior intitulé « Une question de temps » (Eine Zeitfrage)......... 57

Fig. 35. Nebelspalter 1904/25, dessin pleine page en noir et blanc non signé intitulé « Le curriculum vitae de la saucisse " (Der Lebenslauf der Wurst).59

Fig. 36. Nebelspalter 1903/22, dessin pleine page en couleur de Boscovits junior intitulé « Les joies de la Pentecôte » (Pfingst-Freunden). 61

Fig. 37. Nebelspalter 1900/42, dessin pleine page en noir et blanc de Boscovits senior intitulé «Un drôle de passionné " (Ein sonderbarer Schwärmer).

Fig. 38. Nebelspalter 1903/22, dessin pleine page en noir et blanc de Boscovits senior intitulé «Il est sérieux » (Er macht ernst). 64

Fig. 39. Nebelspalter 1902/37, dessin pleine page en couleur de Boscovits junior intitulé « Un homme seul» (Ein einsamer Mann).

Fig. 40. Nebelspalter 1900/9, couverture en couleur de Boscovits junior............ X

Fig. 4I. Nebelspalter 1904/9, dessin pleine page en noir et blanc de Boscovits junior intitulé "Ambiance gueule de bois » (Katerstimmung). 66

Fig. 42. Nebelspalter $\mathrm{I}_{900 / \mathrm{I} 3}$, dessin pleine page en couleur de Willy Lehmann-Schramm intitulé "On continue de civiliser » (Es wird fort civilisiert).

Fig. 43. Nebelspalter 1903/5, double-page en couleur de Boscovits senior sans titre.

Fig. 44. Nebelspalter I90 I/I, couverture en couleur de Willy LehmannSchramm. 
Fig. 45. Nebelspalter I901/43, dessin en noir et blanc de Boscovits junior intitulé « I923, Le train de la Jungfrau est achevé » (Jungfraubahn I923 beendet).

Fig. 46. Nebelspalter 1906/40, dessin pleine page en noir et blanc de Willy Lehamm-Schramm intitulé "La fuite à l'étranger de Niki » (Niki's Flucht ins Ausland).....

Fig. 47. Nebelspalter I 904/52, dessin en noir et blanc de Boscovits junior intitulé «Vive l'auto! » (Aut Heil!).

Fig. 48. Nebelspalter I 904/I3, couverture en couleur non signée .. 74

Fig. 49. Nebelspalter 1902/28, couverture en couleur de Boscovits junior.......XIV

Fig. 50. Nebelspalter I90 I/27, couverture en couleur de Willy LehmannSchramm.

Fig. 51. Nebelspalter I909/38, dessin pleine page en couleur de Boscovits junior intitulé «Opinion suisse » (Schweizermeinung).

Fig. 52. Nebelspalter 1909/28, dessin pleine page en couleur d'Emil Huber intitulé "Sic transit gloria mundi ».

Fig. 53. Nebelspalter I 909/I7, dessin pleine page en couleur de Boscovits senior intitulé "Si ce n'est pas pour aujourd'hui, c'est pour demain " (Komm'ich heute nicht so komm' ich morgen)

Fig. 54. Nebelspalter I9 I I/ 4, dessin en couleur signé « H M » intitulé "Au café littéraire " (Im Literaten-Café).....

Fig. 55. Nebelspalter I91 I/33, dessin pleine page en couleur de Boscovits junior intitulé «En provenance de l'école militaire de Herisau " (Aus der Rekrutenschule in Herisau).

Fig. 56. Nebelspalter I 908/29, dessin peine page en couleur signé « G. St. » intitulé "Théâtre berlinois » (Berliner-Theater).

Fig. 57. Nebelspalter I 909/2, dessin pleine page en couleur de Boscovits senior intitulé «Au-delà du Gothard »(Jenseits des Gotthard).......

Fig. 58. Nebelspalter I908/2 I, dessin pleine page en couleur de Boscovits junior intitulé «Dans le cadre de la conférence germano-suisse sur les questions douanières" (In der deutsch-schweizer. Zollfragen-Konferenz). . 85

Fig. 59. Nebelspalter 1907/I3, couverture en couleur de Boscovits junior........ 87

Fig. 60. Nebelspalter I 907/I 4, texte d'Alfred Beetschen intitulé « Le Nebelspalter métamorphosé à ses fidèles " (Der metamorphosierte Nebelspalter an seine Getreuen) et dessin en couleur de Boscovits junior intitulé «Une autre manière de voir les choses » (Auch eine Ansicht)........ 88

Fig. 6I. Nebelspalter I9 I I/45, dessin pleine page en couleur signé «Stock» intitulé « Le record de hauteur» (Der Höhenrekord) $\mathrm{XIX}$

Fig. 62. Nebelspalter I913/3, couverture en couleur de Wilfried Schweizer intitulée "Aviation militaire» (Mitäraviatik). .90

Fig. 63. Nebelspalter I913/28, couverture en couleur intitulée «Concours de tir " (Schützenfeste), dessin de Wilfried Schweizer et texte de Martin Salander.

Fig. 64. Nebelspalter I913/8, encart photographique. .91

Fig. 65. Nebelspalter I913/26, composition pleine page de Jakob Selig (image en couleur) et Paul Altheer (texte) intitulée " Gustave, le lieutenant protecteur » (Gustav, der Protektionsleutnant)....

Fig. 66. Nebelspalter I913/44, dessin en couleur de Karl Czerpien intitulé "Chômage " (Arbeitslosigkeit).

Fig. 67. Nebelspalter I9I4/Io, dessin pleine page en couleur de Karl Czerpien intitulé « La garantie de la paix » (Die Garantie des Friedens).... 96

Fig. 68. Nebelspalter I920/34, dessin pleine page en couleur de Alfred Hirschler intitulé « Le bolchevisme menace chacun d'entre nous » (Der Bolchevismus bedroht jeden!).

Fig. 69. Nebelspalter i9 I 4/Io, couverture en couleur de Karl Czerpien intitulée " Exportation» (Export) 98

Fig. 70. Nebelspalter I9 I 4/23, dessin pleine page en couleur de Paul Thesing intitulé "Dans la ménagerie des suffragettes " (In der Suffragetten-Menagerie).
Fig. 7I. Nebelspalter I9I 4/26, dessin pleine page en couleur de Boscovits senior intitulé «La proportionnelle au Conseil national » (Der Proporz im Nationalrat)

Fig. 72. Nebelspalter I9 I 5/24, dessin pleine page en couleur de Karl Czerpien intitulé « L'art du funambule» (Seiltänzerkünste).

Fig. 73. Nebelspalter I9I7/49, dessin en couleur, en quatre tableaux de Boscovits junior intitulé « Métamorphose " (Metamorphose).

Fig. 74. Nebelspalter I 879/52, dessin pleine page en noir et blanc non signé, intitulé «La lune est régente de l'année I 880 » (Der Mond ist Jahresregent für I 880 )

Fig. 75. Nebelspalter I 886/45, double-page en noir et blanc de Boscovits senior intitulée " L'Europe actuelle" (Das heutige Europa). 110

Fig. 76. Nebelspalter I 892/ I 5, double-page en couleur de Boscovits senior intitulée "L'Europe actuelle» (Das heutige Europa).

Fig. 77. Nebelspalter I 897/39, double-page en couleur de Boscovits senior intitulée "L'Europe actuelle » (Das heutige Europa)....................................XXII

Fig. 78. Nebelspalter I9 I3/I 8, dessin pleine page en couleur de Boscovits junior intitulé " Le rapt d'Europe » (Raub an Europa).

Fig. 79. Nebelspalter I 900/4, couverture en couleur de Willy LehmmanSchramm.

Fig. 80. Nebelspalter I905/4, double-page en couleur de Boscovits senior intitulée "À chacun le sien " (Jedem das Seine).

Fig. 8 I. Nebelspalter 1907/20, dessin pleine page en couleur de Boscovits junior intitulé « Le nouveau truc dans le cirque Europe » (Der neueste Trik im Zirkus Europa)

Fig. 82. Nebelspalter I 9 I 4/3 I, couverture en couleur de Boscovits junior intitulée "Le premier août » (Der erste August)..... XXIII

Fig. 83. Nebelspalter 1917/3, couverture en couleur de Henrik intitulée "L'Europe mourante" (Die sterbende Europe).

Fig. 84. Nebelspalter 1920/38, dessin pleine page en couleur de Victor Straus intitulé « Le joug " (Das Joch).

Fig. 85. Nebelspalter I 920/I 8, dessin pleine page en couleur de Boscovits junior intitulé «L'Europe a besoin de calme » (Europa braucht Ruhe).....122

Fig. 86. Nebelspalter I 891/52, dessin pleine page en noir et blanc de Heinrich Jenny intitulé « Sur la guerre douanière » (Zum Zollkrieg).......124

Fig. 87. Nebelspalter I9Io/42, couverture en couleur signée d'un monogramme intitulée « La belle alliance ».................................................126

Fig. 88. Nebelspalter I 88 I/30, dessin pleine page en noir et blanc non signé intitulé "La tâche des tireurs lors de la fête fédérale de tir " (Die Aufgabe der Schützen am Eidgenössischen Schützenfest).

Fig. 89. Nebelspalter I 88I/5, dessin pleine page en noir et blanc non signé intitulé « Une nouvelle apparition » (Eine neue Naturerscheinung). .........130

Fig. 90. Nebelspalter I 876/23, dessin pleine page en noir et blanc non signé intitulé "Sur la loi de l'impôt militaire » (Zum Militärsteuergesetz).........132

Fig. 9I. Nebelspalter I 893/I, double-page en couleur sans titre de Boscovits senior.

Fig. 92. Nebelspalter I 892/38, double-page en couleur de Boscovits junior intitulée "Réunion de Zurich et de ses communes extérieures" (Vereinigung von Zürich und Ausgemeinden)....

Fig. 93. Nebelspalter I 890/I 5, dessin pleine page en noir et blanc sans titre de Boscovits senior

Fig. 94. Nebelspalter I 898/16, dessin pleine page en noir et blanc de Boscovits junior intitulé "Les cinq sens d'un zurichois » (Die fünf Sinne eines Zürchers). 139

Fig. 95. Jugend I 898/49, couverture en couleur de Oskar Graf. ......................... 141

Fig. 96. Nebelspalter I900/2, dessin pleine page en noir et blanc de Boscovits junior intitulé « Mode d'hiver I900 " (Wintermode I900).......142

Fig. 97. Nebelspalter I 905/6, dessin pleine page en noir et blanc de Boscovits junior intitulé « Drôles de races humaines " (Merkwürdige Menschenrassen) 
Fig. 98. Nebelspalter I 91 5/9, dessin pleine page en couleur de Boscovits senior intitulé "Zurich, tes œuvres de bienveillance te distraient " (Zürich, deine Wohltaten unterhalten dich). 144

Fig. 99. Nebelspalter I9I 4/32, couverture en noir et blanc non signée intitulée "Veillez! » (Wacht!). .146

Fig I00. Nebelspalter I9 I 4/ I , dessin pleine page en couleur de Paul Thesing intitulé « Rapprochement franco-allemand " (Deutschfranzösische Annäherung)... $\ldots 148$

Fig. Io I. Nebelspalter I9 I 5/34, dessin pleine page en couleur de Karl Czerpien intitulé " La cour faite aux neutres " (Das Werben um die Neutralen).......

Fig. I02. Nebelspalter I9I 4/33, dessin pleine page en couleur de Boscovits junior intitulé « Le combat pour la culture européenne » (Der Kampf um die Europäische Kultur).

Fig. I03. Nebelspalter I9 I6/9, couverture en couleur de Boscovits junior intitulée "Il parle d'expérience " (Er spricht aus Erfahrung).

Fig. I04. Nebelspalter I9I7/45, dessin pleine page en couleur de Boscovits senior intitulé "La Suisse - Une représentation symbolique » (Die Schweiz. Eine symbolische Darstellung)......

Fig. I05. Nebelspalter I91 8/45, couverture en couleur de Boscovits senior intitulée "Ante Portas». . .156

Fig. I06. Nebelspalter I9I 4/36, dessin pleine page en couleur de Boscovits junior intitulé « La journée d'un neutre strict » (Tagesordnung eines streng Neutralen).

Fig. I07. Nebelspalter I9 I6/8, couverture en couleur de Karl Czerpien intitulée "La nouvelle entreprise ou Beaucoup de bruit pour rien " (Die neue Firma oder Viel Lärm um nichts). .160

Fig. I08. Nebelspalter I9 14/34, dessin pleine page en couleur de Boscovits senior intitulé "Réflexions cannibales " (Kannibalistische Bedenken).

Fig. I09. Nebelspalter I9 I 8/35, dessin pleine page en couleur de S. Mohr intitulé « Mercure modernisé » (Der Modernisierte Merkur). .......................162

Fig. I I O. Nebelspalter I918/3 I dessin pleine page en couleur de S. Mohr intitulé «Les rois" (Die Könige).

Fig. I I I. Nebelspalter I9 I 4/40, dessin pleine page en couleur de Walter Lilie intitulé " Guerre et culture » (Krieg und Kultur).....

Fig. I I 2. Nebelspalter I9 I 8/33, dessin pleine page en couleur de Alfred Hirschler intitulé « L'ile des morts » (Die Toteninsel). ...................................166

Fig. I I 3. Nebelspalter I9I4/35, dessin pleine page en couleur de Walter Lilie intitulé « Jour de récolte" (Erntetag).

Fig. I I 4. Nebelspalter I91 8/24, dessin pleine page en couleur de Alfred Hirschler intitulé « Mort » $(T o d)$.

Fig. I I 5. Nebelspalter 1918/19, dessin pleine page en couleur de Arthur Treichler intitulé " Printemps de guerre I9I 8 » (Kriegsfrühling I9I8).....169

Fig. I I6. Nebelspalter I9I 7/43, couverture en couleur de S.Mohr intitulée "Fata Morgana ».

Fig. I I 7. Nebelspalter I9 I 8/44, dessin pleine page en couleur de Boscovits junior intitulé « L'Europe reconnaissante » (Das dankbare Europa).

Fig. I I 8. Nebelspalter I919/43, couverture en noir et blanc de Alfred Hirschler intitulée « Liquidation à Vienne » (Ausverkauf im Wien).........174

Fig. I I9. Nebelspalter I919/I, dessin pleine page en couleur de P. Bachmann intitulé « Remords» (Gewissenbisse)...

Fig. I 20. Nebelspalter I919/22, couverture en couleur de Fr. Röpe intitulée « La gloire qui chante ». $X X V I I$

Fig. I 2 I. Nebelspalter I 888/I4, dessin pleine page en noir et blanc de Heinrich Jenny intitulé « Art suisse » (Schweizerische Kunst).....................184

Fig. I 22. Nebelspalter I9I I/44, dessin pleine page en couleur de Boscovits junior intitulé « Justice artistique " (Kunstjustiz).
Fig. I 23. Nebelspalter I900/ Io, dessin pleine page en noir et blanc de Boscovits senior intitulé «Exposition de bétail à Paris » (Viehausstellung in Paris)..

Fig. I 24. Nebelspalter I 877/27, dessin pleine page en noir et blanc non signé intitulé " Dans l'exposition d'art suisse " (In der Schweizerischen Kunstaustellung)......

Fig. I 25. Nebelspalter I901/2 I, dessin pleine page en noir et blanc non signé intitulé «Une lettre " (Ein Brief).

Fig. I 26. Nebelspalter I904/ I 5, dessin pleine page en noir et blanc de Boscovits junior intitulé " $3{ }^{\text {ème }}$ Série au Künstlerhaus » (3. Serie im Künstlerhaus).

Fig. I 27. Nebelspalter 1913/37, dessin en couleur de L. Marrug intitulé "Art moderne » (Moderne Kunst).

Fig. I 28. Nebelspalter I901/I9, dessin pleine page en noir et blanc de Willy Lehmann-Schramm intitulé " Hodler et ses - amis !» (Hodler und seine - Freunde!). .196

Fig. I 29. Nebelspalter I9I0/I 8, dessin pleine page en couleur de Boscovits junior intitulé « Feuille commémorative » (Gedenkblatt). .199

Fig. I30. Nebelspalter I 891/2, dessin pleine page en noir et blanc de Heinrich Jenny intitulé « Musée national » (Landesmuseum). .

Fig. I 3 I. Nebelspalter 1904/44, couverture en couleur de Boscovits junior...XXVIII

Fig. I 32. Nebelspalter I 895/39, dessin pleine page en noir et blanc de Willy Lehmann-Schramm, sans titre. 204

Fig. I 33. Le Frou Frou, 29 mars I 902, n 76, couverture de Poulbot............... 205

Fig. I 34. Nebelspalter I901/3, dessin pleine page en noir et blanc de Willy Lehmann-Schramm intitulé "Zurich sous le signe de la danse » (Zurich im Zeichen des Tanzes).

Fig. I 35. Nebelspalter I 892/3, dessin pleine page en noir et blanc de Boscovits junior intitulé "Gravement malade » (Schwer Krank).... 210

Fig. I 36. Jugend I 900/40, dessin en noir et blanc d'Arpad Schmidhammer intitulé « Dans le boudoir de Germania » (Im Boudoir Germania).......... 211

Fig. I 37. Carton d'invitation de Boscovits junior pour un concert donné dans le cadre du Congrès suisse de la presse de I908. 212

Fig. I 38. Nebelspalter 1918/35, dessin pleine page en couleur de Boscovits junior intitulé « Compagnie précieuse » (Feine Gesellschaft).

Fig. I 39. Nebelspalter I9I I/33, dessin pleine page en couleur signé "AR » intitulé « Par cette chaleur» (Bei dieser Hitze).

Fig. I 40. Nebelspalter I9I 5/2, couverture en couleur de Boscovits senior intitulée "Le combat des peuples " (Der Ring der Völker).

Fig. I4I. Nebelspalter I 899/34, dessin pleine page en couleur de Boscovits junior intitulé "Images de chaleur " (Hitz-Bilder). .218

Fig. I 42. Nebelspalter I 897/42, double-page en couleur de Boscovits junior intitulée « Retour sur l'œuvre de Böcklin »(Ein Rückblick Böcklin’s).....XXIX

Fig. I 43. Nebelspalter $1908 / 15$, dessin pleine page en couleur de Boscovits junior intitulé "Comment ça peut venir » (Wie’s kommen kann)............. 220

Fig. I44. Nebelspalter I916/23, couverture en couleur de Karl Czerpien intitulée "Le but de guerre " (Das Kriegsziel).

Fig. I45. Nebelspalter I922/I, couverture en couleur de Ernst Morgenthaler intitulée "La robe " (Das Kleid).

Fig. I 46. Nebelspalter I 90 I/44, couverture en couleur de Boscovits junior...XXXI

Fig. I47. Nebelspalter 1905/32, dessin pleine page en noir et blanc de Willy Lehmann-Schramm intitulé "C' est fait " (Es ist erreicht !)

Fig. I 48. Nebelspalter I 887/ I 5, dessin pleine page en noir et blanc de Boscovits senior intitulé « Ô, comme c'est charmant! (Un instantané) »( $O$, wie lieblich ist's [Eine Augenblicks-Aufnahme]). 234

Fig. I 49. Dessin de la lettre du 24 novembre I 887 de Evert van Muyden à Richard Kissling (Cote I. I 4 de la succession Nötzli)...... 236

Fig. I 50. Nebelspalter I 890/I, double-page en couleur de Boscovits senior....XXXII 


\section{CRÉDITS PHOTOGRAPHIQUES}

Tous les clichés à l’exception de ceux mentionnés ci-dessous : Crédits Bibliothèque nationale suisse

Fig. 95. Crédits L. Danguy

Fig. I33. Crédits L. Bihl

Fig. I36. Crédits L. Danguy

Fig. I37. Crédits L. Danguy

Fig. I 49. Crédits Zentralbibliothek de Zurich 


\section{TABLE DES MATIÈRES}

Remerciements......................... VII

Avant-propos de Philippe Kaenel : la presse satirique en Suisse ............................IX

Introduction

Première partie

IDENTITÉ ET CHRONIQUE D’UNE REVUE SATIRIQUE ZURICHOISE

I. Genèse et figures

$\ldots .5$

I. I. Décryptage de la fondation et de la vie éditoriale:

focus sur Boscovits senior......

I.2. La domination Boscovits.

I.3. La configuration artistique et sociétale des dessinateurs ................................ 11

I.4. Ambitions voilées et assumées: de la délimitation avec les champs de

l'art et de la presse

I. 5. Liste et période d'activité des éditeurs et rédacteurs en chef .....................15

I.6. Liste et période d'activité des dessinateurs .....................................................16

2. Cycles de vie d'un organe bourgeois à l'identité complexe.

2.I. I 875, un premier numéro fixant les choses: maquette, tendance, identité visuelle et commerciale .......19

2.2. I 875-I 886: les années noir et blanc de l'ère Nötzli ou quand la Suisse prime sur le monde.

2.2.1. Identité, maquette et technique - On affine ..................................................... 22 2.2.2. Distribution, politique commerciale et lectorat - Essor ................................... 23 2.2.3. Déclinaisons thématiques d'une tendance stable ......................................... 25 2.2.4. Un langage visuel et rhétorique très typé .................................................... 30

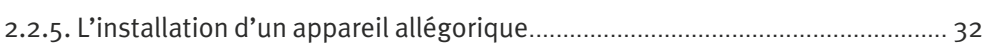

2.3 - I 887-I 899: ouverture, couleur et premier Jugendstil sous l'ère Nötzli .. 33 2.3.1. Identité, maquette et technique - Changements techniques et oscillations

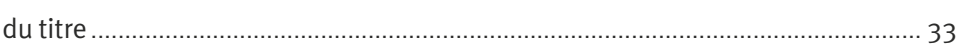

2.3.2. Distribution, politique commerciale et lectorat - En avant toute .................... 33

2.3.3. Thèmes et tendance - Ouverture et modernité ........................................... 35

2.3.4. Rhétorique - Continuité et variations ............................................................. 46

2.3.5. Langage visuel - Jugendstil, Belle Époque et caricature ................................ 46

2.3.6. La constellation allégorique du Nebelspalter-Allégorie, femme et un monde à soi........

2.3.8. Envoir de toutes les couleurs

2.4. I900-I 906: Jugendstil versus Heimatstil-Retour aux fondamentaux .... 56

2.4.1. Identité, maquette et technique - Menace sur le cadre au trait...................... 58

2.4.2. Distribution, politique commerciale et lectorat - Statu quo ........................... 58

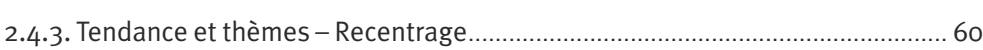

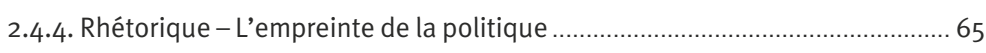

2.4.5. Langage visuel - Acculturation du Jugendstil et recyclage de formules anciennes...

2.4.6. La femme, le nu et l'allégorie
2.4.7. Du Heimatstil en couverture - Le Jugendstil helvétique ................................. 73

2.4.8. Les aléas de la couleur ............................................................................. 75

2.5. I907-I9I 2: remous, hésitations et révisions .............................................. 75

2.5.1. Identité, maquette et technique - Le temps de la refonte .............................. 75

2.5.2. Distribution, politique commerciale et lectorat - Recadrage ........................... 76

2.5.3. Durcissement de tendance et primauté à la politique .................................... 76

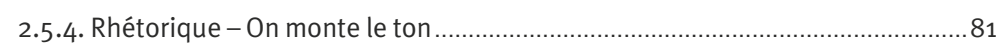

2.5.5. Victoire du Heimatstil et confinement de l'image à l'illustration satirique.......81

2.5.6. Recul de la représentation féminine et désinvestissement de l'allégorie ...... 84

2.5.7. La valse des couvertures ......................................................................... 86

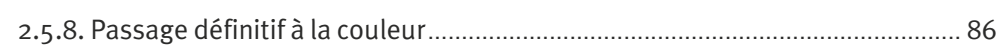

2.6. I9I 3-I92 I : l'image en perte et la Première Guerre mondiale ................. 89

2.6.1. Identité, maquette et technique - Recul ........................................................ 89

2.6.2. Distribution, politique commerciale et lectorat - Sursauts et fuite en avant.. 91

2.6.3. Tendance et thèmes - Repli et ambigüité..................................................... 93

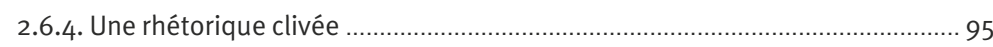

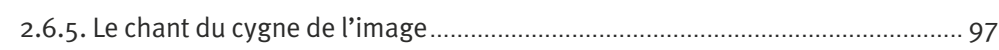

2.6.6. Divorce de la femme et de l'allégorie...................................................... 99

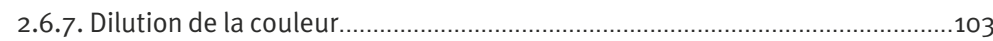

\section{Deuxième partie}

\section{UN CERTAIN REGARD SUR LE MONDE}

3. Regard sur un monde aux déclinaisons plurielles ............................................107

3.r. Une iconographie du monde ................................................................107

3.1.1. 1875-1886 : figures et motifs d'une ouverture a minima ..................................107

3.1.2. 1887-1914: déclinaisons d'un univers en expansion et d'une Europe

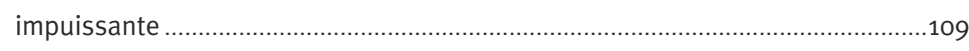

3.1.3. 1914-1921: embrasement et no man's land d'un univers en perdition ............ 115

3.2. La Suisse versus Zurich : critique et iconographie.......................................... 121

3.2.1. Le face-à-face (helvétique) du Nebelspalter avec Helvetia............................. 121

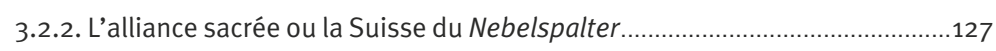

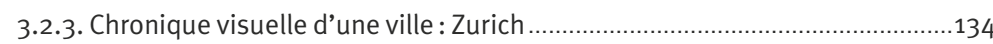

3.3. La Première Guerre mondiale: la " drôle » de guerre d'une revue............145

3.3.1. Se situer vis-à-vis d'un conflit étranger.......................................................147

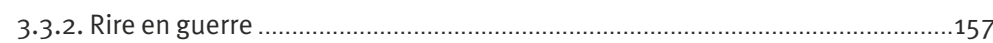

3.3.3. Montrer la guerre et renoncer au rire ..............................................................163

3.3.4. L'après-guerre : ressassements en images .....................................................170

TROISIÈME PARTIE

CULTURE, ART ET POLITIQUE:

DISCOURIR ET PRENDRE SA PLACE

4. Discours sur l'art .181

4. I. La question de l'art suisse... 181

4.2. Rendre compte des expositions et régler ses comptes via les expositions. .

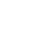
(n) . (n) . 
4.3. Le salon caricatural du Nebelspalter ou la critique de la modernité .......189 4.4. Le couple Arnold Böcklin et Ferdinand Hodler

4.5. Plaider et batailler pour la pierre à Zurich : le Kunsthaus et le Musée national suisse

4.6. La maigre réception des mouvements contemporains

200

5. Emprunts, transferts et autoréférentialité ..................................................... 203

5. I. Le Nebelspalter, la caricature et les revues illustrées européennes ........... 203

5.2. S'enrichir du " grand art»

5.3. Le statut très particulier de Arnold Böcklin et Ferdinand Hodler..........217

5.4. Transpositions médiales

.219

5.5. Se citer soi-même plus que de mesure

.221

6. Des affaires de réseaux..

227

6.I. La leçon des archives Nötzli : un éditeur et ses réseaux...

227

6.2. Intrigues suisses et influences françaises dans le monde éditorial: Jean Nötzli, John Grand-Carteret et Cäsar Schmidt

... 230

6.2.1. Acte un : correspondance entre Jean Nötzli et John Grand-Carteret de 1880 à 1891
6.2.2. Acte deux: 1897 , querelle autour de l'«Europe actuelle » .231

6.3. Quand politique, art et satire se mêlent: Numa Droz et Jean Nötzli ... 232 6.4. Passions d'artistes: Richard Kissling, Evert van Muyden, Henri van Muyden et Jean Nötzli... .235

Conclusion 239

Bibliographie sélective . .243

Travaux académiques sur le Nebelspalter. 243

Travaux académiques s'appuyant sur le Nebelspalter de manière significative.. 243

Publications de vulgarisation sur le Nebelspalter en provenance des éditions du Nebelspalter

Publications de vulgarisation sur le Nebelspalter en provenance d'autres maisons d'édition 244

Index

Table des illustrations. .251

Crédits photographiques .255 
